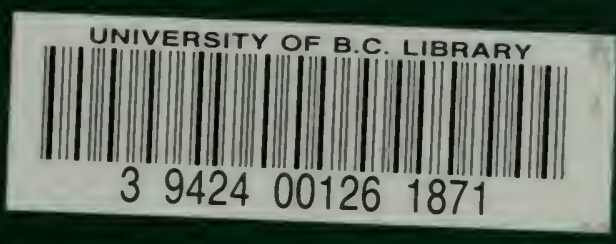

Dr. H. MAVR

Dic

Waldungen von Nordamerika

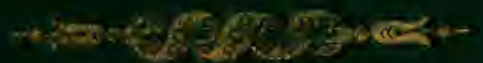

STORAGE ITEN

FROCESSING-CNE

LF 1-F 19 E

U.B.C. LIBRARY 


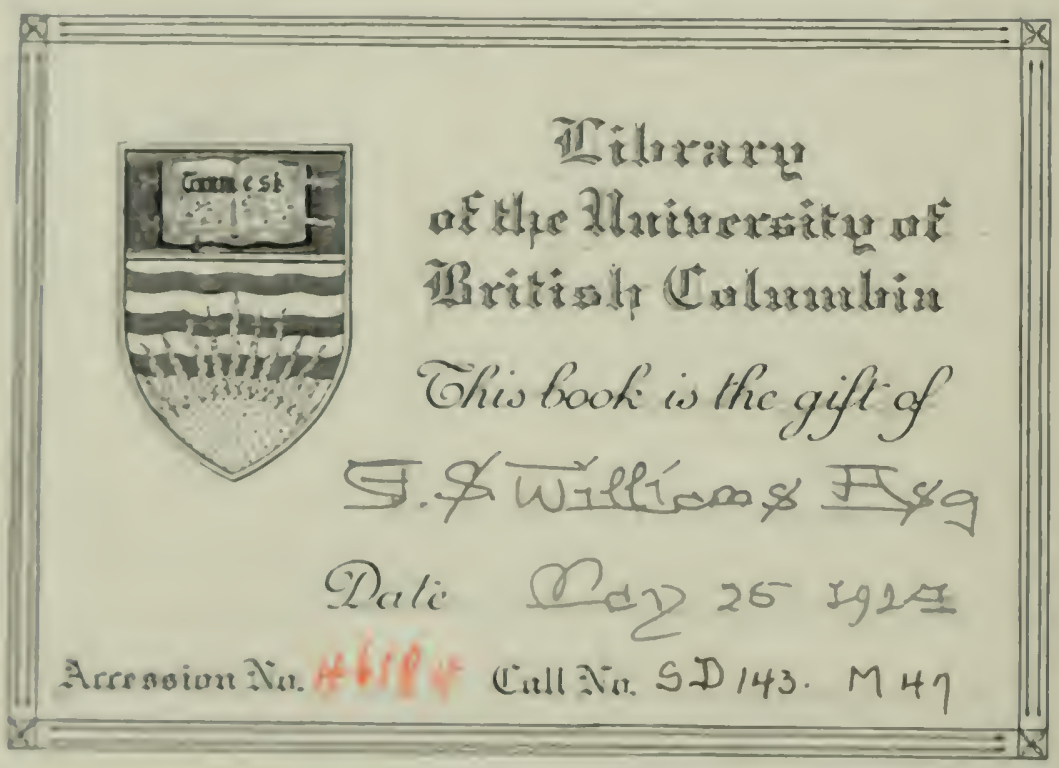






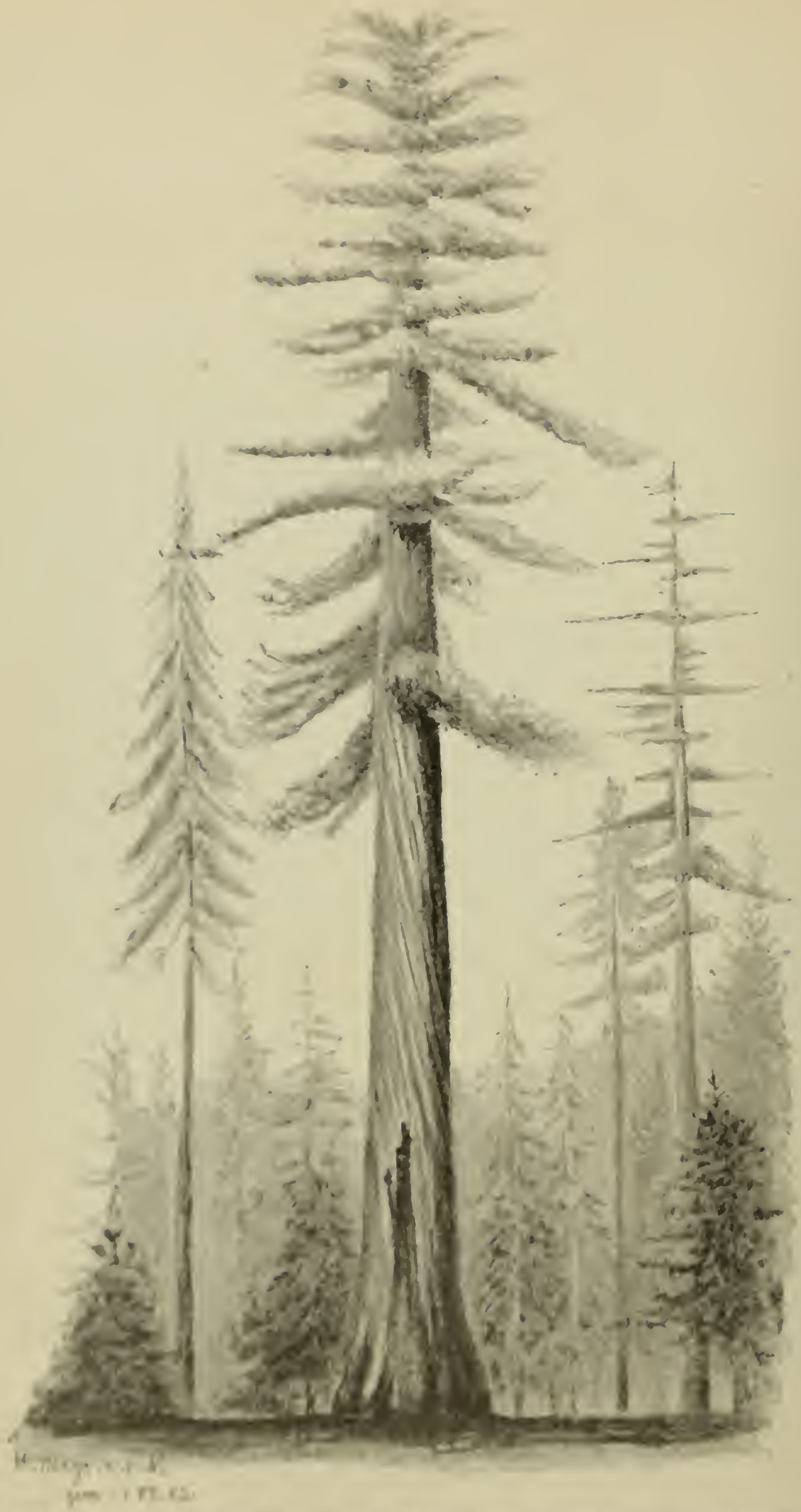

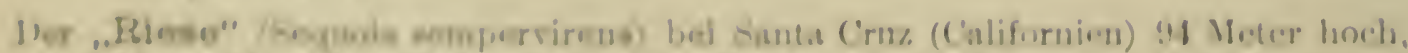

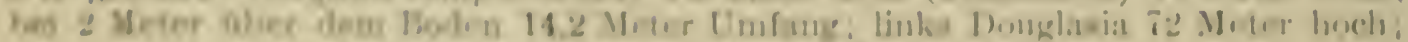

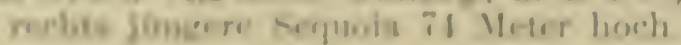


Die

\section{WALDUNGEN YoN NORDAMERIKA}

\section{ihre Holzarten,}

deren Anbaufähigkeit und forstlicher Werth

für Europa im Allgemeinen

und Deutschland insbesonders.

Nach im Auftrage des kgl. bayerischen Staatsministeriums der Finanzen unternommenen Reisen und Studien

bearbeitet von

Dr. Phil. ET OEC. PUBL. HEINRICH MAYR

Privatdozent der Universität München.

Mit 24 Abbildungen im Text, 10 Tafeln und 2 Karten.

M. R I E G E R'sche

Universitäts-

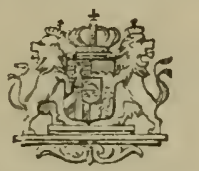

Buchhandlung.

Gustav Himmer

k. b. Hoflieferant

München 1590. 
Digitized by the Internet Archive in 2010 with funding from University of British Columbia Library 


\section{Vor w o r t.}

Der Geleitbrief, mit dem mich meine Regierung zur Einführung bei der kaiserl. deutschen Gesandtschaft und den kaiserl. Consulaten in Norlamerika ausrüstete, bezeichnet als den Zweck der Reise: „Dortselbst im Norden und Westen hinsichtlich des Verhaltens einer grösseren Anzahl exotischer Holzarten, mit welchen ron allen deutschen Forstrerwaltungen Anbaurersuche in ziemlicher Ausdehnung beabsichtigt und theilweise schon eingeleitet sind, in der Heimat der einzelnen Arten auf rerschiedenen Standorten und in verschiedenen Altersstufen eingehende Studien zu pflegen. Da hiebei voraussichtlich nicht nur rom rein wissenschaftlichen Standpunkte interessante, sondern auch für die praktische Anwendung schr nützliche Beobachtungen zu machen und insbesondere auch gute und rerlässige Samenbezugsquellen, welche zur Zeit völlig fehlen, zu ermitteln sein werden, so dürfte die von ...... beabsichtigte Reise in mehrfacher Hinsicht der gesammten Forstwissenschaft nützlich werden können."

$\mathrm{Ob}$ ich nicht allzuweit unter dem hohen Ziele, das mir in obigen Worten vorgesteckt war, verblieben bin, möge eine hohe königliche Regierung und mögen Jene beurtheilen, die dieser Schrift einige Aufmerksamkeit widmen wollen.

An die genannte Reise schlossen sich Wanderungen und Studien in den Waldungen Japans, Java's, Ceylons und Nordindiens, wodurch sich die Verarbeitung des über Nordamerika gesammelten Materiales um fast zwei Jahre verzögerte.

Kaum zu Hause angelangt, bot sich mir die entzückende Gelegenheit dar, die so lieb gewonnene, neue Welt mit ihren unvergleichlich ausgedehnten und massenreichon Wäldern ein zweites Mal betreten zu 
kümnen, en rulte nach Japan. wo ich eine vim der dortigen Regrierung mir angebutene Lehntelle an der Akadrmie fül Land- und Fonstwirthschaft zu Tokio annahm.

Die Ergebnisse diesor zweiten, cbenfalls mehrere Jlonate umfassenden Tour durfte ich mit Erlaubniss meiner Regrerung mit dem Berichte ïher die erste Rejse rereingen. Mein neuer Wirkungskeis in Japan beamspruchte anfänglich meine sanze Zcit für Vorlesungen und organisatorisebe Abeiten im katserliehen Acherbatuministerium, sn dass ich rest jetzt. nach rollen vier Jahren, in stande bin, den fälligen Rapport hei höchnter Stedle vorzulegen.

Was die samenbe\%ursquellen betriflt, auf die mit Recht grosser Werth gelent wurle. a muss idh gestehen: gut sind sie, was entsprechende Auswahl der Oertlichkeiten betrifft, aber zurerliissig sind sie nicht: daran sind die Leute schuld, mit denen ich über diesen Punt rerhandelte; keiner ron disen, oft cntlegen in den Bergen verachiedenen Berufsarten ubliegenden Leuten, wollte um eines su greringen Umsatzes willen ein Geschaift direkt mit Europa ïbernehmen; wohl aber wird es grelingen, durch Vermittelung eines grosicn nordamerikanischen Samenhandlungshauses die Quellen in Fluss zu bringen: ¿n dienem Zwecke wurlen im Anhange (6) einige Firmen angegeben.

E: war kein erfreuliches Thema, üher die Beniitzumar der Forste in Nordamerika zu schreiben: nothwendiger Weise mussten alle fohlow dies gerenwärtigen Raubsystemes, alle Folgen dieser tief beklagenswerthen Waldrerwiistung rïcksidhtslus offen gelegt werden; oine bramdige Wunde muss man mit dem Secirmesser anssehnededen, nidht mit einem wohlthuenden Pflanter verklehen: die Verureudung des Walles und des Waldberloll ist eine solche um sich fressende Wunde, die

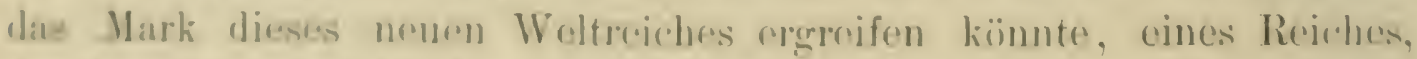
das bromfen scheint, dass seine Bewohner durch scincon Ramm, sein Lilina, seine sohatze einmal ,the landing nation" werden; froilich wemn anf anderen Gebicten der Lrpmoluktion ebenson rerschwonderisch mit

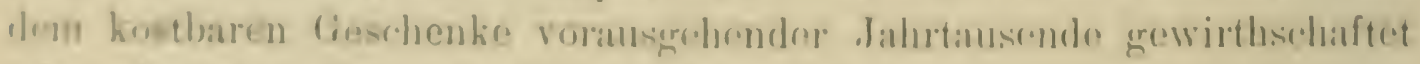
wirnl, dann hat lournpa wohl nichts zu fürchten.

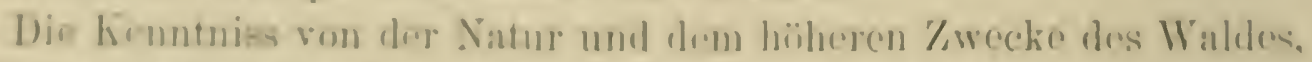

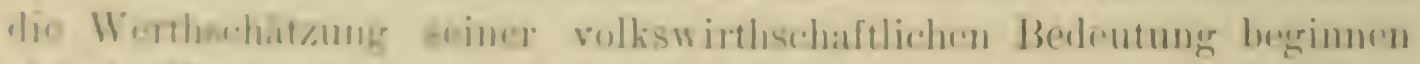

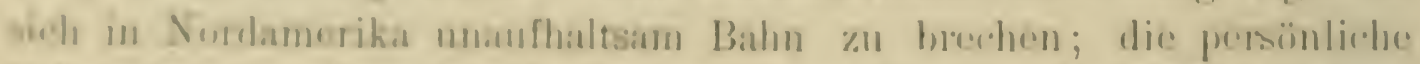

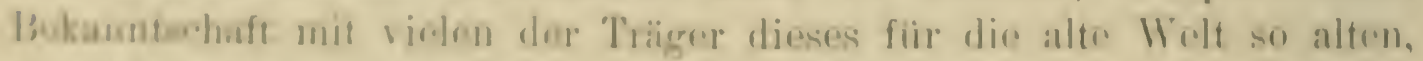

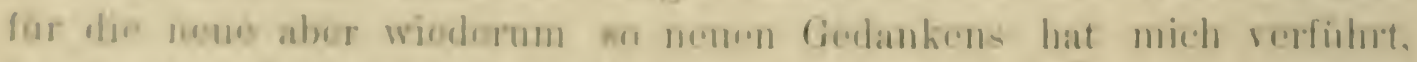

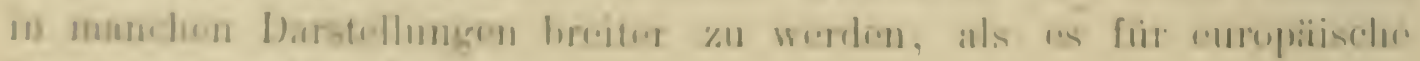
lomer erwlinscht wiln mat. 
Unter dem gegenwärtigen, forstlich geschulten und thatkräftigen Chef der Forstabtheilung des landwirthschaftlichen Ninisteriums, B. E. Fernow, wurde die Lösung einer für die Forstwirthschaft äusserst wichtigen Vorfrage, das Studium der waldbaulichen Eigenschaften der nordamerikanischen Waldbäume begonnen; manche Beschreibung einer Holzart, die für uns kaum Werth hat, ist gewachsen unter dem Gedanken, wenn auch unberufen, einen kleinen Baustein zu dem begonnenen grossen Werke beizubringen.

Eine zweimalige Durchquerung des Continentes von Ost nach West, eine Durchwanderung des Landes ron Canada bis Florida, von Vancouver bis Mexico in nicht ganz sieben Monaten hat mir Gelegenheit geboten, eine grosse Menge Herbariummaterials zu sammeln; im Westen hatte ich öfters, um eine einzige Holzart zu sehen und von ihr Zapfen und Samen zu erhalten, eine Woche Hin- und Rückreise verwenden müssen ; ich glaube, dass die Beschreibung der Holzarten nach wild erwachsenen Exemplaren, unabhängig ron unseren Florenwerken, zuverlässig sein wird; mit diesem Bestreben wurden auch die Kiefernsamentafeln gefertigt, in dem die Sämereien. zux Zeit und zum 'Zwecke des Zeichnens den grösstentheils selbstgesammelten Zapfen entnommen wurden. Die Samentafeln begleitet eine Beschreibung, welche die Controle des ron Amerika bezogenen Samens erleichtern dürfte.

Eine Bemerkung in den amtlichen Erhebungen über das Vorkommen ausländischer Holzarten in Deutschland veranlasste mich entgegen' dem Titel dieser Schrift - auch eine Tafel und Beschreibung herzustellen zur Bestimmung der in Deutschland am meisten verbreiteten Cupressineen nach Zapfen und Seitenzweigen; auch hiefür wurden Zapfen und Zweige (mit Ausnahme von Cham. nutkaensis) wild erwachsenen Exemplaren entnommen.

Die Forstwirthe Deutschlands haben längst der Frage des Anbaues von Exoten in unserem Walde gegenüber Stellung genommen; sie theilen sich in zwei sehr ungleiche Lager; eine kleine Schaar, die von den Exoten Gutes erwartet, und eine grosse Majorität, die den Fremdländern jeden Werth absprechen; für Erstere habe ich wohl zu viel, für Letztere wohl zu wenig Holzarten von meinen Arbeitsplänen ausgeschlossen; vielleicht habe ich einen betretbaren Mittelweg eingehalten, wenigstens war mein Bestreben gewesen, nur das Allerbeste aus dem nordamerikanischen Walde, das bei uns mit Sicherheit gedeiht, für den Anbau im Grossen zu empfehlen, so dass dasselbe auch an Standorte gebracht werden sollte, an denen mit gleicher Sicherhcit eine einheimische Holzart erwachsen würde. Die grösste Schaar 
meiner Pflegempfohlenen sind aber solehe, die für Oertlichkeiten bestimmt sind, in denen antweder nur greringwerthige, einheimische Arten anf\%uwachan rermügen, oder wo die inlïndischen Holzarten im Wuchse \%urückbleiben orler selhst gran\% fehlen.

Dic srüsste Gefalır für die Exoten - und das ist, wals die meisten von Versuchen absurathen bestimmt - bleibt immer die Mriglichkeit, das ein abnorm strenger Winter mit einem Schlage wieder Alles rernichten künne. Um nach dieser Richtung hin einerseits zn beruhigen, andrerseits \%u warnen. habe ich die klimatischen Zonen, soweit als mürlich. in grenaue Parallele mit den wichtigsten europäischen Landichaften gestrollt; durch diese langwierige Arbeit ist es auch mörlich, die Lare des klimatischen Optimums und Trerbreitungserehietes Jer nordamerikanischen Holzarten, dieselben nach Europa rersetzt crodicht. in Europa selbst anzuggeben. Da mir für mehrere curopaiische I.inder nicht weit genug zurückgreifende meteurologisclıe Beobaclitungen \%ugiinglich waren, so sind wohl manche ,tiefste Temperaturen" nuch etwas zu hoch angereben; für. Dentichland habe ich den Winter 1879/80 \%u Grunde exelegt, der wohl der extremste innerdalb einer mittleren Vmtricbscoit war.

Die nordamerikanischen Waldungen sind einzig in ihrer dit innerhalh der gemaissierten Region der nördlichen Hemisphäre; drer

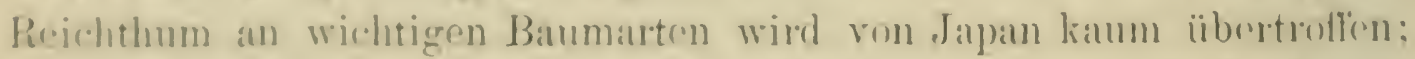
nirenends hrejten sirh soleh gewaltige Waldmassen über ein Land alls; nirgends thürmen sich gan\%e. Wïlder nicht bloss einzolne Bïume \%u (8) fathelhaftron Höhen anf; sie sind in der That merschöpflich für den; der mit Mesoband. Lupe und Botanisirbiichse sie betritt, nicht aber fur den. der mit Axt und Sigere oder gar dem Feuerbrande kommt.

Die nordamerikanischen Waldbilder, oft in tiefster Einsamlieit in menzchenlecen Bergen geximmelt, groüren zu dens schünsten, die mir

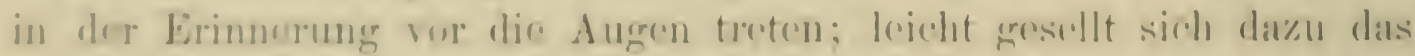

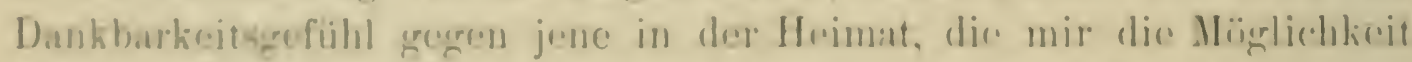
beten, in dir. Fremele zu groden und jene in dor Fremde, die mir ihre

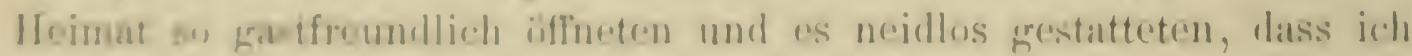

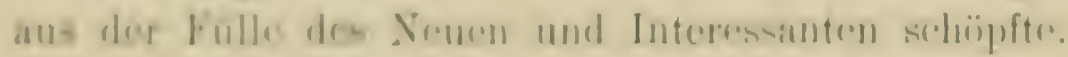

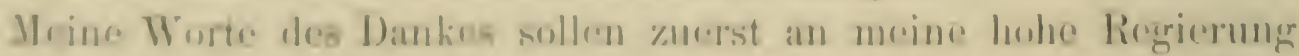
und persinlich an Excellen\% Herro Statsminister dor

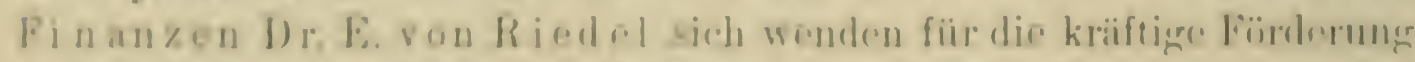

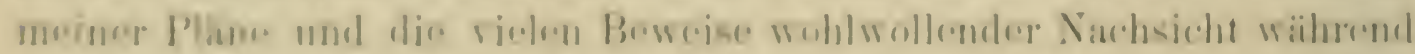

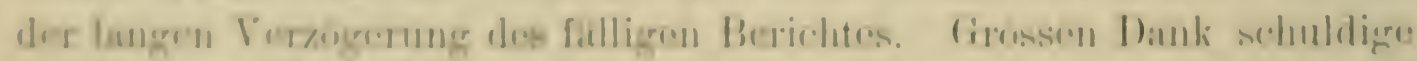

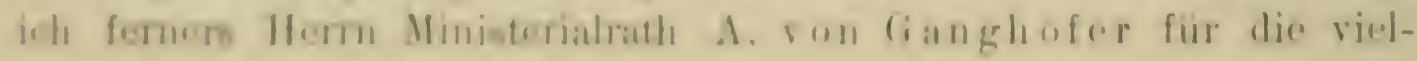


fachen Rathschläge, Herrn Universitätsprofessor Dr. R. Hartig für die reichlichen wissenschaftlichen Anregungen, Herrn Universitätsprofessor Dr. R. Weber und Herm Privatdocenten Dr. Solereder, welche die grosse Freundlichkeit hatten, die Unannehmlichkeiten der Korrektur und die Anfertigung des beigegebenen Registers zu übernehmen.

Gerne gebe ich hiemit die Namen Jener bekannt, die mir in Amerika so bereitwillig die Hand boten: Herr C. Lamar, damals Minister des Innern, gab mir einen Empfehlungsbrief an alle im Lande zerstreuten, untergebenen Behörden; Herrn Prof. C. S. Sargent in Brookline bin ich ganz besonders zu Dank verpflichtet; durch seine persönliche Bekanntschaft mit dem Walde in Folge eigener grosser Reisen war mir ein kostspieliges, zeitraubendes Kreuz- und Querfahren, um in die richtigen Oertlichkeiten zu gelangen, erspart; aus unseren gemeinsamen Gängen im Arboretum, unserer gemeinsamen Arbeit im reichhaltigen, musterhaften Herbarium, in den vielen Tagen stetigen Verkehres habe ich eine Fülle von Belehrung und Rathschlägen gewonnen, deren Werth mir je länger ich reiste, um so deutlicher zum Bewusstsein kam.

All der im Lande zerstreut lebenden Herren zu gedenken, ist mir kaum möglich; ich erwähne einige derselben in der Reihenfolge, in der ich die Freude hatte, ihre Bekanntschaft zu schliessen.

Herr Dr. G. Vas ey ron Smithsonian Institution in Washington (D. C.) führte mich selbst in den Wald; Herr L. B oehmer, ebendort, stattete mich mit Fachliteratur aus; die Herren Thos. Meehan in Germantown und Robert Douglas in Waukegan liessen mich ron dem grossen Vorrathe ihrer praktischen Erfahrungen gewinnen; die Herren J. Brucker und $K$. Ludloff in Medford haben nicht Zeit und Mühe gescheut, ihrem Landsmanne möglichst Vorschub zu leisten; neben der Unterstützung der Herren G. W. Letterman in Allenton, P. Schulze in Portland, A. H. Curtiss in Jacksonville, unseres auch in der alten Welt wohlbekannten Karl Mohr in Mobile erfreute ich mich auch der Begünstigung durch Eisenbahngesellschaften wie der Central Wisconsin R. R., der Northeru Pacific R. R., der Oregon \& California R. R., die mir damals (1885) freien Verkehr auf ihren ausgedehnten Bahnstrecken gestatteten.

Die Betrachtung der nordamerikanischen Waldungen bot so vielfache Gelegenheit, die Waldungen anderer Länder, wie Japans, Java's und Indiens zum Tergleiche herbeizuziehen.

In Japan schuldige ich den Dank für die Erlaubniss der Bereisung des ganzen Landes und für die Mitwirkung aller äusseren Behörden 
denn kaiserl. Ackerbauministerium und meinem Fremde Dr. Y. Nakamura: der Bericht ïher die. .Waldumgen ron Japan" wird wohl noch auf cinige Zoit hinaus in Folge ausgedehnter Controlreisen in petto bleiben mïsen. In Java bot Herr Direktor Dr. Treub hereitwilligst die Hand: in Indien war os Herr Dr. G. King. Dircktor des botanischen Gartens zu Calcutta, der mir Hans und Garten und den reichen Sichaty seines II issens cinige Wodien lang üfhnete; Herr Direktor Dr. W. Sehlich in Conpershill bei London und Horr Generalforstinspektor B. Ribbentrop in Cakcutta hatten die grosse Freundlichkeit, mich bei dem english-indischen Forstpersonale cinzuführen; die Herren A. Home und E. (i. Chester (damals) in Darjeeling. Herr W. R. Fischer, damals flit. Direktor der Forstschule in Dehra Dun, die Herren A. smythies und Hoarle, wetteiferten in dem Bestreben, mir miriglichst vicl son ihrem schünen Walde \%u erzählen und zu zoigen: ich gredenke stets der herrlichen Touren mit grösster Freude und nieht geringerer Diunkbarkeit.

Mit anerkennenswerther Opferwilligkeit hat mein Verleger eine schüne Austattung in Aussicht grestellt; zu dem Wunselie, den jeder Verfasser einer Sohrift hegrt, dass dieselbe gaitigre Aufnalmme beim Eintritt in dic Oeffentlichkeit finden mö̈ge, eresellt sich für mich der nicht minder innige Wunsch. dass Manuseript mud Zeidhmungen natch sechswöchentlicher Reise vorerst rinmal sliucklich in die Hände des Verligrers gerlangern möchtrun.

Tukiu im Mär\% 1889.

Der Verfasser. 


\section{I n h a $1 \mathrm{t}$.}

Allgemeine Gesichtspunkte über die Existenzbedingungen der Wälder

Seite

Allgemeine Betrachtung der Waldfloren ............. 7

Die Waldungen von Nordamerika . . . . . . . . . . 12

I. Allgemeiner Zustand des nordamerikanischen Waldes 18

II. Grösse und Vertheilung der Waldungen ........ 28

III. Walderzeugnisse, deren Gewinnung und Austausch . . 31

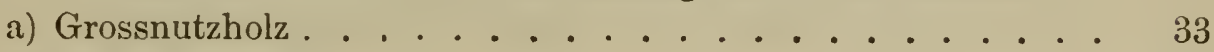

b) Eisenbahnhölzer . . . . . . . . . . . . . 38

c) Möbel-, feinere Tischler- und Wagnerhölzer . . . . . . . . 40

d) Kleinnutzhölzer . . . . . . . . . . . . . . . 4 41

e) Brenn- und Kohlholz ................. . . 43

f) Viehweide .................... . . . . 44

g) Urbarmachung . . . . . . . . . . . . . . . . 49

h) Nebenprodukte ................ . . . 53

(є) Harz . . . . . . . . . . . . . . . . . 53

ґ) Gerbstoff . . . . . . . . . . . . . . 55

y) Syrup und Zucker ............... . . . 57

d) Holzstoff . . . . . . . . . . . . . . . 58

६) Früchte und Beeren . . . . . . . . . . . . 58

६) Sonstige Nebenprodukte . . . . . . . . . . 59

IV. Zuwachs und Qualität der nordam. Waldbäume . . . 61

V. Veränderungen in der Waldvegetation durch die Ein. griffe des Menschen ............ 80

VI. Forstliche Bestrebungen in Nordamerika . . . . . . 9 90

VII. Spezielle Betrachtung der nordamerikanischen Waldflora nach Gebieten und Holzarten ........ 98

A. Die Waldflora der atlantischen Region ............ 98

a) Tropischer Wald . . . . . . . . . . . . . . 99

b) Subtropischer Wald. . . . . . . . . . . . 100

Südlicher Kieferngürtel . . . . . . . . . . 10

c) Winterkahler Laubwald der gemässigt-warmen Region . . . 122

Nördlicher Kieferngürtel . . . . . . . . . . 197

d) Nadelwald der gemässigt-kühlen Region . . . . . . . . 216

B. Die I'rärie . . . . . . . . . . . . . . 222

C. Nordmexicanische Waldflora . . . . . . . . . 231

a) Subtropischer Wald . . . . . . . . . . . . 231

b) Gemässigt-warme Region .... . . . . . . . . . 235

D. Der pacifische Wald .. . . . . . . . . . . . . 242

a) Subtropischer Wald . . . . . . . . . . . . . 261

b) Wald der gemässigt-warmen Region . . . . . . . . 280

c) Der Nadelwald der gemässigt-kühlen Region . . . . . . 345

d) Die kühle Region der alpinen Nadelhölzer . . . . . . . 353

VIII. Verhalten der exotischen Holzarten in Nordamerika . . 356 
IX. Die nordamerikanischen Holmarten rom Standpunkte ihrer Anbaufahigkeit in Europa im Allgemeinen und in Deutschland insbesonders . . . . . . . . . . 363

a) Tropische Waldzone................ . . 384

b) Subtropische Waldzone der immergrünen Laubhölzer . . . . 384

c) Der winterkahle Laubwald der gemaissigt-warmen Region . . 356

d) Der Iadelwald der gemaissigt-kühlen Region . . . . . . 391

e) Recrion der alpinen Nadelhölzer . . . . . . . . . 395

f) Baum- und Strauchgrenzen . . . . . . . . . . 356

I. Iie nordamerikanischen Holzarten hinsichtlich ihres forstlichen Werthes für den deutsehen Wald . . . . . 397

I1. Anbauplitne und Behandlung der nordamerikanischen Holzarten als Bume des deutschen Waldes......

III In liang.

1. Anatomische Merkmale der Hölzer der nordam. Coniferen .

2. Eintheilung der Kiefern (incl. der nichtamerikanischen) nach natürlichen Sectionen . . . . . . . . . . . .

3. Tabelle zur Bestimmung der wichtigeren Cupressineen nach Seitenzweigen und Zapfen . . . . . . . . . . . .

4. Tabelle zur Bestimmung der nordamerikanischen Kiefern nach iliren Simereien

i. Verucichniss der an den nordamerikanischen Waldbiumen im Spatherlste $185 j$ und 1857 beobachteten, pflamzlichen Parasiten

(i) Angabe ciniger Firmen zum Bezug nordam. Waldsamereien .

†. Corrigendar

\section{rarel n*).}

1 Vichenbluttformen.

II. I:ichenfruchtformen.

111. Blaltormen allantisclier Laubhïlzer.

11. Frucheformen ron Laubhülzern.

V. Blattermen parifisctier Laubhïlzer.

i. I. Furhl- und Sudelformen rerschiedener Comiferen.

VII. Riefornanumen I.

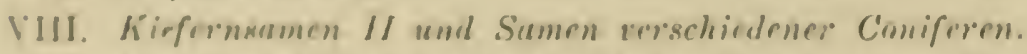

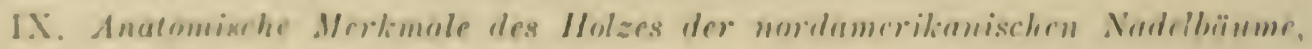

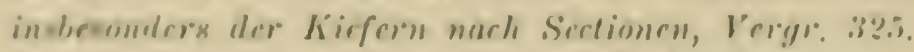

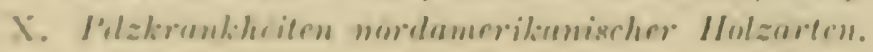

\section{IK a r t $\mathrm{t}$.}

XI Querpurufile dureh rerachiedene Comlinenle.

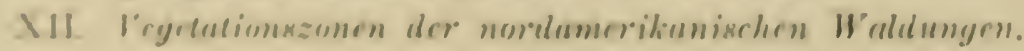

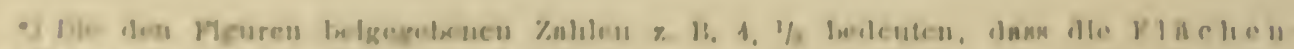
d

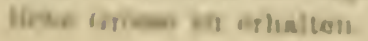




\section{Allgemeine Gesichtspunkte über die Existenz- bedingungen der Wälder.}

Tiele der Baumgattungen, die wir heutzutage herrorragend an dem Aufban der Waldungen Nordamerika's und Ostasiens betheiligt finden, wie Magnolia, Juglans, Aesculus, Catalpa, Liquidambar, Liriodendron, zahlreiche Papilionaceen und Laurineen, Schwarzeichen, Tsuga, Thuja Chamaecyparis und Sequoia sind in Europa gar nicht mehr oder nur untergeordnet vertreten; aber in den fossilen Pflanzenresten der älteren Tertiärschichten Europa's begegnen wir ihnen wieder, die damals, nach den jetzigen Fundstätten zu schliessen, Wälder von enormer Ausdehnung um den Pol herum gebildet haben müissen.

Wir schreiben das Verschwinden der zum Theil an wärmeres Klima gebundenen Gattungen im Norden der Erdtheile und in ganz Europa insbesonders einer allgemeinen Erkältung der nördlichen Hemisphäre während der sogenannten Eiszeit zu; die ron Norden kommende kalte Welle trieb die Pflanzen schrittweise nach Süden zurïck. Mit der späteren Wiedererwärmung wanderte auch die verdrängte Vegetation wieder nach Norden zurück; dass die Rückwanderung ungleichweit und unvollständig oder stellenweise gar nicht stattfand, dass viele Gattungen ganz rerschwanden und andere an ihre Stelle traten, dürfte vor Allem der unvollständigen Erwärmung zuzuschreiben sein, die nicht mehr bis zum status quo vor der Eiszeit erfolgte. Ausserdem kommen als entscheidende Faktoren die Configuration eines Landes, Höhe und Lage seiner Gebirge, die vorherrschenden Windrichtungen, welche Fenchtigkeit bedingen und die Wärme modifiziren, endlich die Temperatur und Beschaffenheit des Bodens selbst in Betracht.

Ostasien (östlich von Indien gerechnet) und Nordamerika einerseits, Europa andererseits bilden hinsichtlich ihrer Configuration Gegensïtze. Die beiden ersten Gebiete haben ror Allem keine quer 
durhe den Continent laufenden (iebirge. welche die Wanderung der

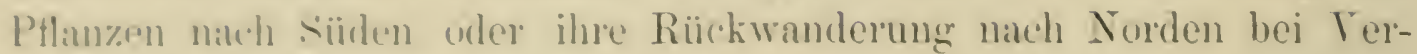
shwindon der rebeisenden Lisarhen hemmten: die Gebirge laufen dort parallel dem \%ure der Pflanze von siuden nade Nonden. Anders verhailt sich linropa. Wo nicht nur die P’yenäen, die Alpen, der Kaukasus

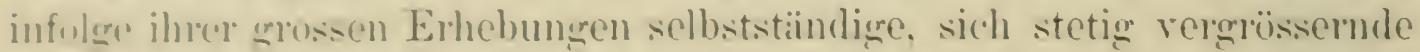
Gletwher bei Begimn dor Eiszeit bildeten, welche die von Sorlen herab-

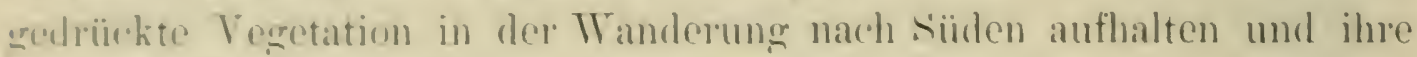
theidwrise Vornichtungr begiunstigen mussten. sondern wo noch überdiess die Vereisung bis hart an ein das mittelländische Meer mit dem laspischen See rorbindendrs Binnenmeer reichte: endlich ist Europa mit seiner

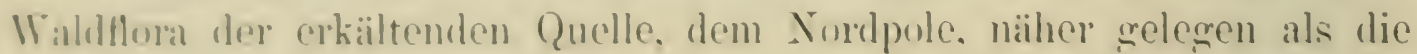
Floren von Noldamerikil und Ostasien, sumit war die Velessumg in

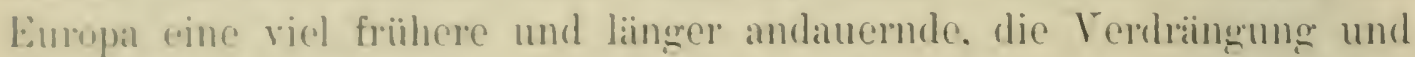

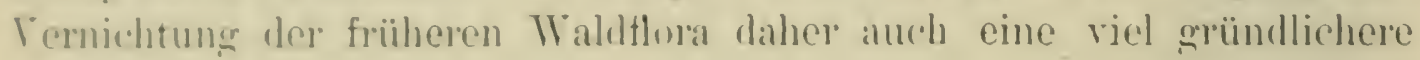
erowesell.

I)ass bei diesen eigenatigen Verhibltnissen anch die jetzigen Maldfloren Surdamerikial und Ostasiens trot\% der ungehemen Entfermung \%u

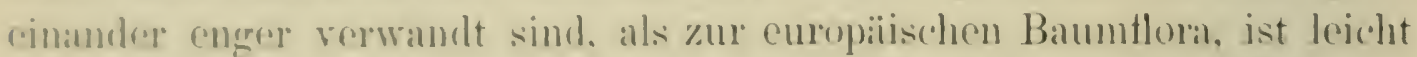
ertiälich. zumal wenn wir auf den weiteren Parallelismus der Mecresstrïmuneron arhten. dis mit ibrem erwïmenden oder erkïltenden Einfluss anf die getroffenen Festlande neben der lixistenz des

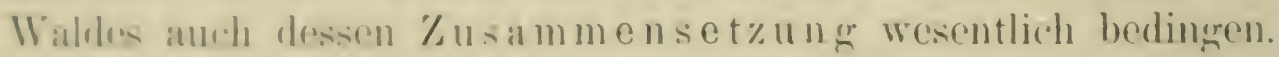

\%wri mäblitiere, in sibllicheren Breiten crwiimte Wasserströmo.

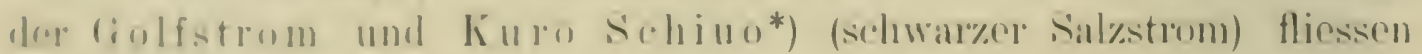
an dron Ostkiisten Amorikis's und Asiens entang bis etwa \%um $36^{0}$

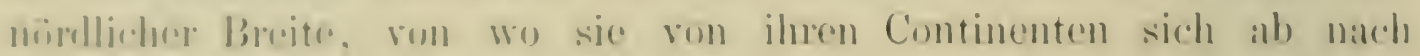

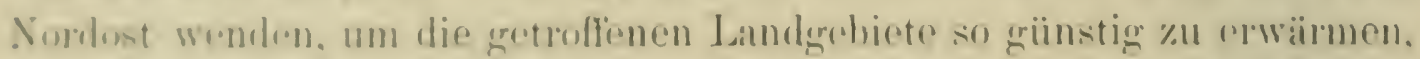

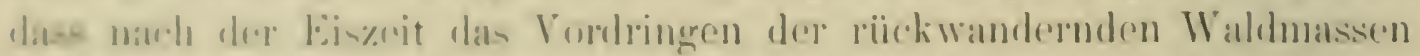

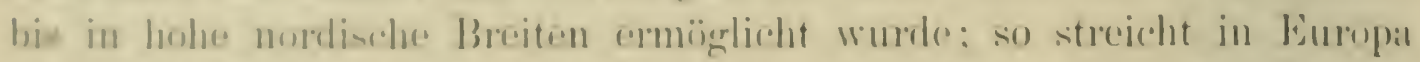

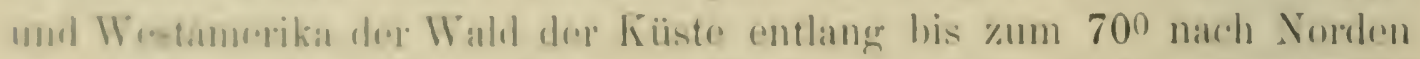

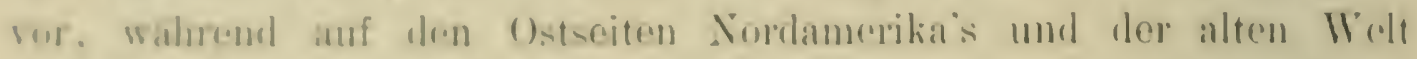

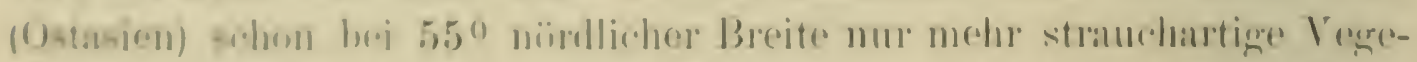

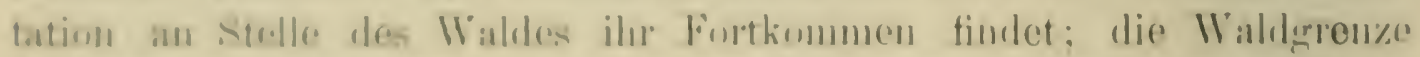

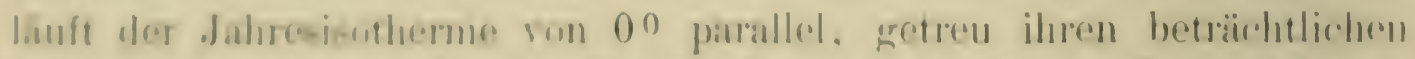

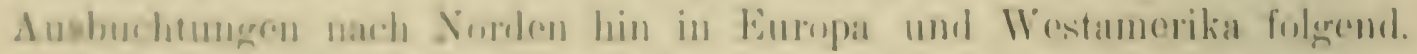

Von grumonn leinfluss anf die lixistent des Waldes sind formor

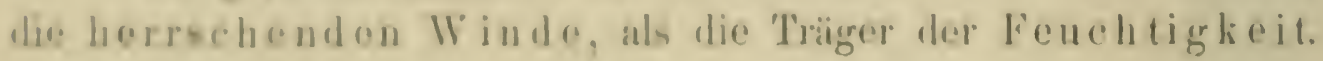

\footnotetext{
Dies Sehreibweise kommt der richtigen Aussprache des japanischen Wortes an naclieten.
} 
Die Thopen, erwärmt durch die kräftige Somnenwirkung, aspiriren kältere Luft von den Polen her; modificirt wird dieser continuirliche Strom durch die Polhöhe und andere Faktoren, insbesonders aber durch die stärkere Erwärmung des Festlandes dem Meere gegenüber; wesshalb ersteres die kühlere und feuchtere Meeresluft mit grosser Begierde einsaugt. Wo dieser wasserreiche Luftstrom ungehindert in's Land eintreten kann, ist sein Einfluss auf grosse Strecken hin bemerkbar in den dichten Waldmassen, denen er den Ursprung gibt. Auf dem Wege über den Continent hin verliert der Seewind mehr und mehr seiner befruchtenden Feuchtigkeit; endlich sinken Niederschlagsmenge und Feuchtigkeit der Luft bis zu einer Grenze, bei der Waldregetation nicht mehr bestehen kann; es tritt an deren Stelle eine niedere, kurzlebige, weniger Feuchtigkeit fordernde Vegetation ron Sträuchern und endlich das Gras, die typische Pflanze der Prärie (Steppe, Llanos. Pampas u. s. w.). Ein schönes Beispiel hievon bietet sich in Nordamerika dar, wo ein rom Golf ron Mexico aufsteigender feuchter und warmer Luftstrom in einer Breite ron fast 30 Längegraden bis in hohe geographische Breiten hinauffliesst, auf seinem Wege einer ungehenern Waldregion das Dasein gebend; erst die Polhöhe im Norden, oder die Abnalıme der Feuchtigkeit nach dem Innern des Festlandes zu, im Westen, setzen hier der Baumregetation eine Grenze.

Anders gestalten sich die Verhältnisse, wenn die rom Meere in's Land wehende feuchte Seehft an ein Gebirge anstösst, wie diess bei Continenten mit der Küste parallel streichenden Gebirgen der Fall ist; dort wird sie beim Aufstieg zur Passhöhe des Gebirges stetig abgekïhlt, ihre Feuchtigkeit wird zu Nebel und Regen condensirt; sobald die Passhöhe erreicht ist, senkt sich der Luftstrom, erwärmt sich, wird relatir trockener, die Nebel lösen sich auf. Dieses Gesetz ist ron grösster Wichtigkeit für die Existenz der Gebirgswaldungen und zeigt seine Wirkung darin, dass, beim Fehlen anderer Feuchtigkeitsquellen, Wald auf der Seeseite der Berge da beginnt, wo die Nebelbildung in der Regel ror sich geht und auf der andern Seite (Landseite) da endet, wo die Nebel sich wieder auflösen. So trägt zum Beispiel das Coast Range-Gebirge Nordamerika's auf seinem Westabhange üppige Waldvegetation, die auf der Ostseite des Gebirges nahe der Passhöhe wieder der Graslandschaft, der Prärie, das Terrain überlässt. Wie das Coast Range-Gebirge rerhalten sich auch die Anden in Südamerika, der Himalaya in Indien; natürlich fehlt in Folge der grossen Erhebung dieser letzteren Berge über dem Meeresspiegel der Wald in der Höhe der Pässe röllig. 


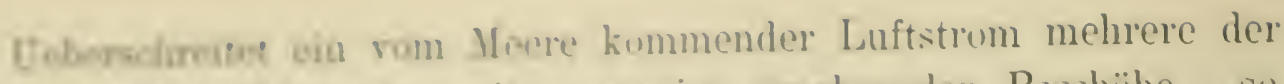

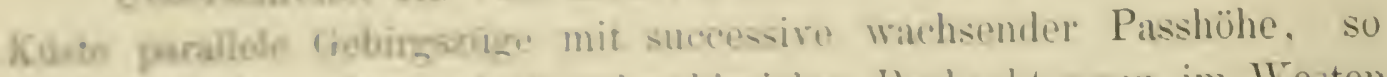

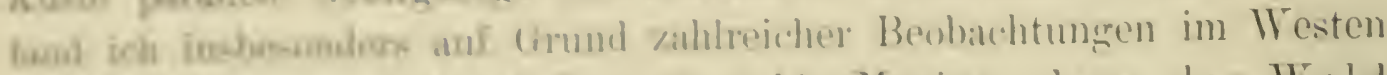

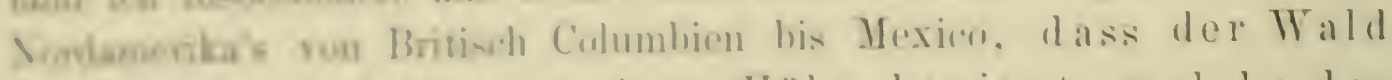

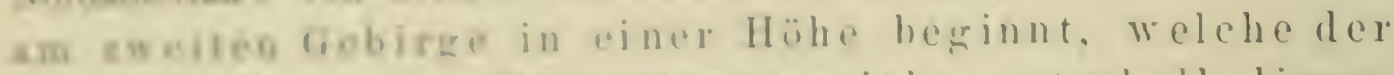

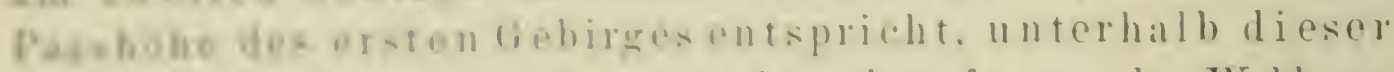

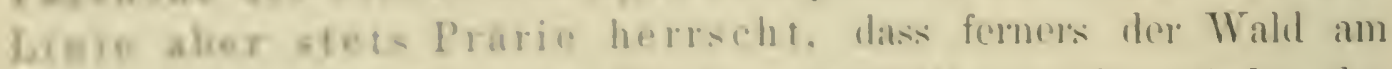

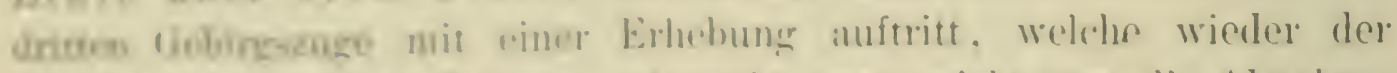

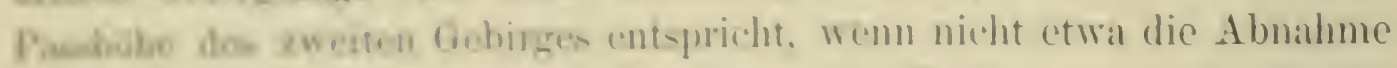

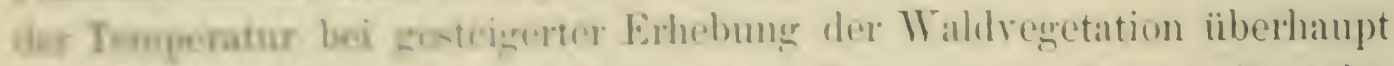

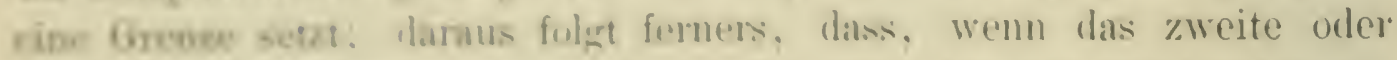

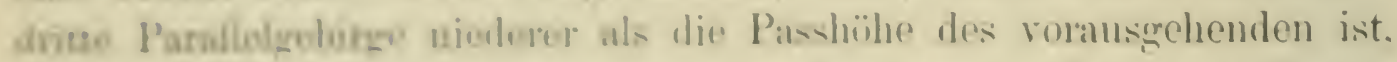

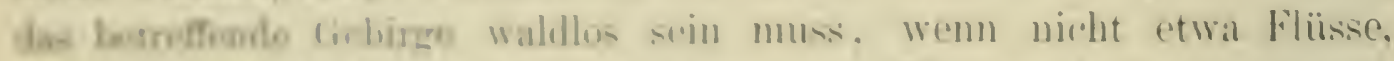

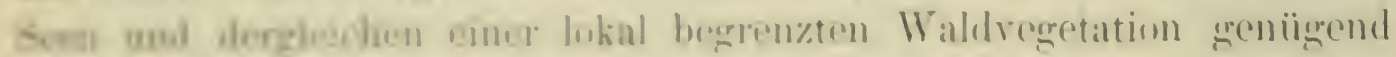
Pow libekojt liveform.

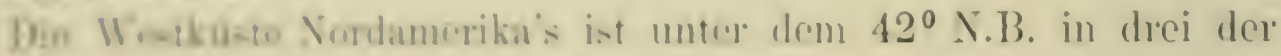

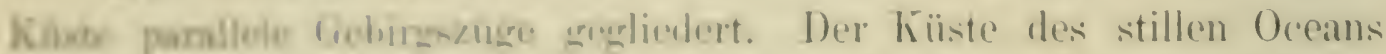

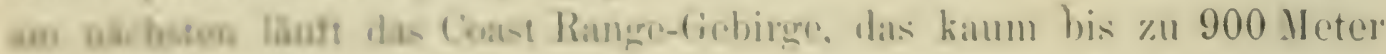

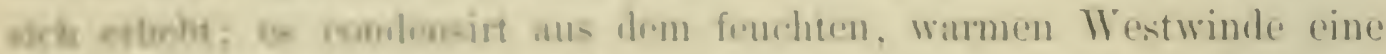

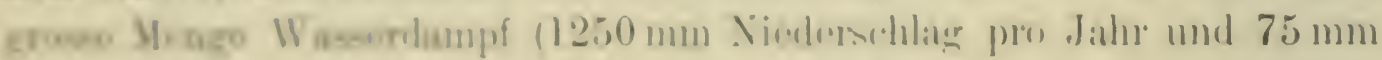

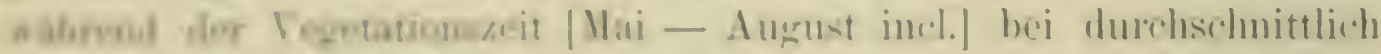

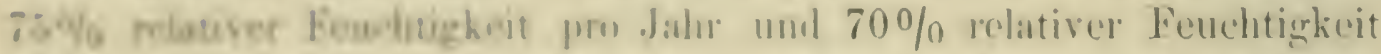

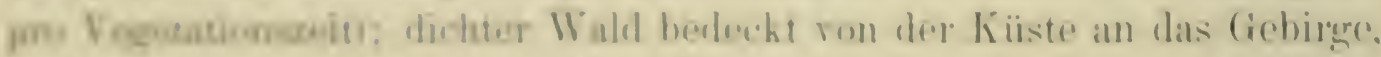

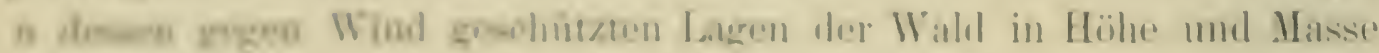

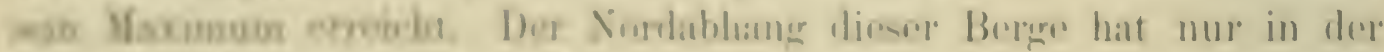

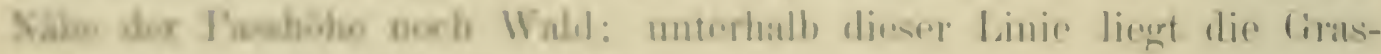

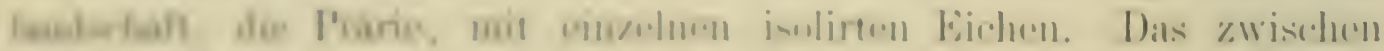

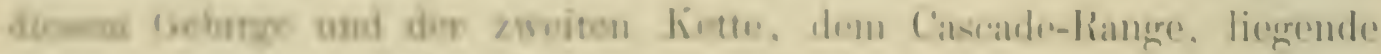

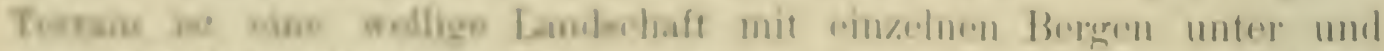

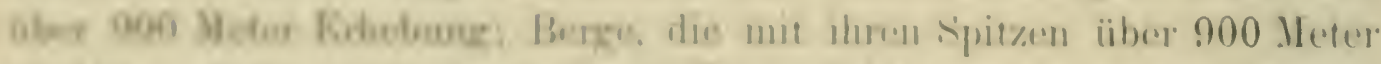

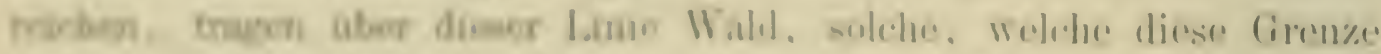

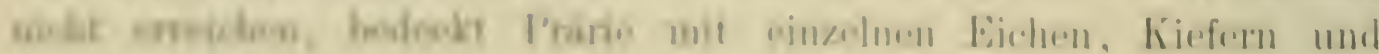
Nrour Ireces)

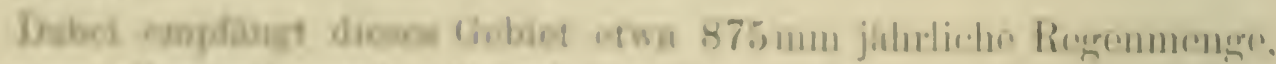

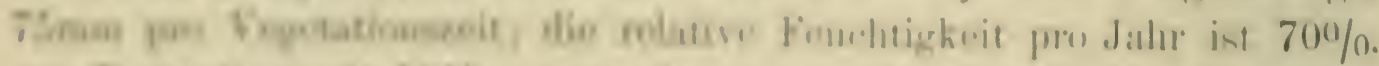

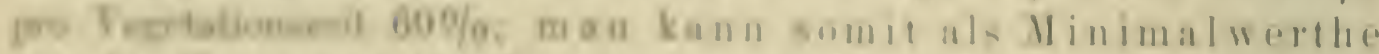

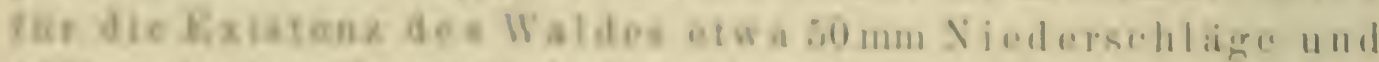

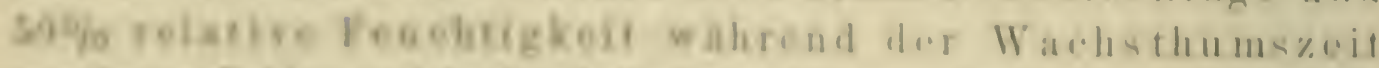

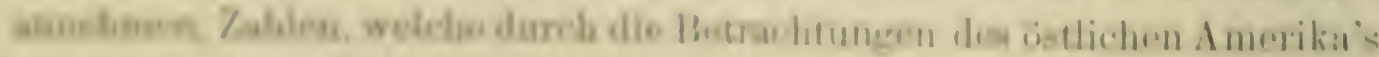
sestere keouon tindas 
Am Cascadengebirge steigt die Prärie bis etwa 900 Meter in die Höhe, wo mit einem Male nit dieser Horizontalkurve wieder Wald in seiner ganzen Fülle sich entfaltet. Der Wald überschreitet kaum die Passhöhe dieses Gebirges bei 1200 Meter, so tritt Prärie wieder an seine Stelle. Um Angaben über Regenmenge und Feuchtigkeit im Waldgebiete zu geben, fehlt es leider im Westen Amerika's noch an geeigneten Stationen, die dort, da Prärie und Wald so hart aneinander grenzen, für die Wissenschaft und Praxis wichtige Resultate liefern müssten; der Osten ist hiezu weniger geeignet, da an der Berührungslinie ron Prärie und Wald dort sich entweder ein ziemlich breiter Gürtel strauchartiger Tegetation einschiebt, oder die Grenze überhaupt eine küustliche ist. Zwischen dem Cascadengebirge und den Rocky Mountains liegt wieder Prärie, die pro Jahr nur mehr $375 \mathrm{~mm}$ Wassermenge, pro Vegetationszeit etwa $70 \mathrm{~mm}$ Regen empfängt, deren Luft 60\% relative Feuchtigkeit pro Jahr und nur $43 \%$ pro Vegetationszeit enthält; in dieser Prärie erheben sich wieder Gebirgszüge, die, soweit sie 1200 Meter überragen, wieder Wald tragen. In dem Felsengebirge beginnt der Wald bei etwa 1200 Meter Erhebung, einer Linie, die wieder der Passhöhe der Cascadenkette entspricht. Bei etwa 2700 Meter Höhe findet der Wald unter dieser Breite, in Folge der Temperaturabnahme, überhaupt seine Grenze. Oestlich von den Rocky Momtains dehnt sich eine ungeheure, nach Osten geneigte Ebene aus, die grosse Prärie, die, hart an die Berge sich anschliessend, $250 \mathrm{~mm}$ Wassermenge im Jahre und $130 \mathrm{~mm}$ während des Wachsthums empfängt. Die relative Feuchtigkeit pro Jahr beträgt $50 \%$, pro Vegetationszeit etwa 45\%. Nach Osten hin herrscht die Prärie soweit, bis der vom Süden, rom Golf ron Mexico, oder rom Osten, rom atlantischen Ocean, kommende Luftstrom wieder genügende Feuchtigkeit für Boden und Luft bringt, um die Existenz einer Waldflora zu ermöglichen. Dass diese Grenze jetzt viel weiter östlich liegt, als ursprünglich die natürliche liegen musste, dass also die Prärie durch menschliche Thätigkeit sehr'bedeutend nach Osten zu vergrössert wurde, davon später bei Betrachtung der Prärie selbst. Die beigegebene schematische Figur, welche einen Schnitt durch Westamerika unter dem $42^{\circ}$ N.B. darstellt, mag obige Betrachtung versinnbilden (Tafel XI).

Parallele Verhältnisse bestehen in Indien; der vom Golf von Bengalen aufsteigende feuchte Luftstrom verliert grosse Mengen Feuchtigkeit an die indische Ebene, die zweifelsohne in ihren höheren Theilen mit einem dichten, der südlichen Lage entsprechenden, immergrünen Walde bedeckt war. Die Kultur hat diesen bis an den Fuss des Himalaya zurückgedrängt. Am Südabhange des Gebirges erhebt sich der Wald 


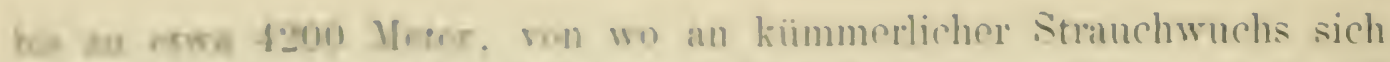

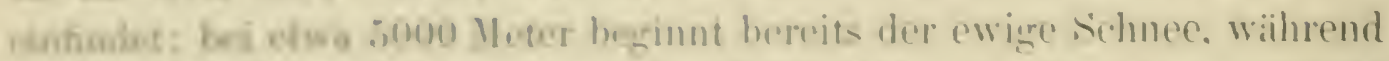

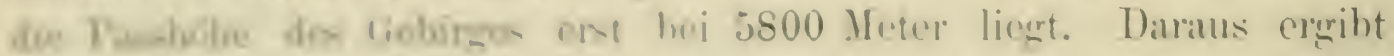

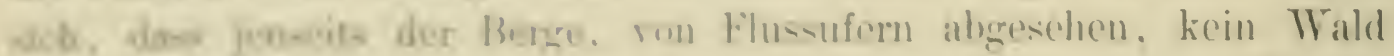

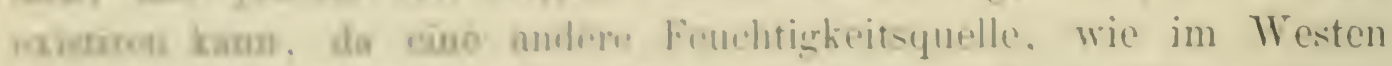

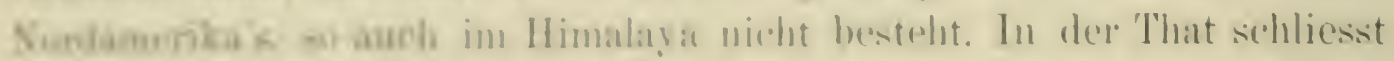

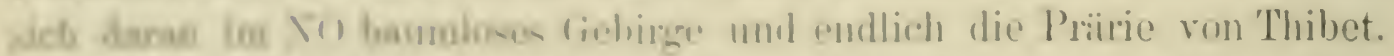

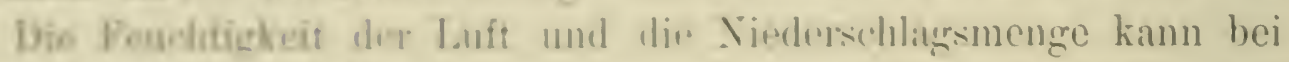

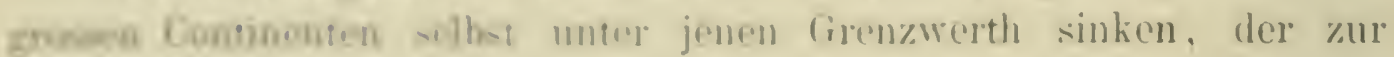

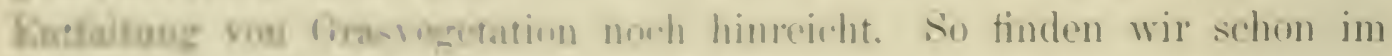

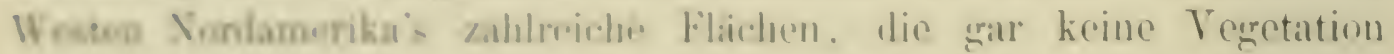

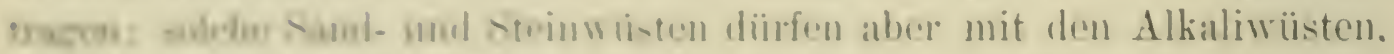
mos denou spater die hede seill soll. nicht verwedsolt werden.

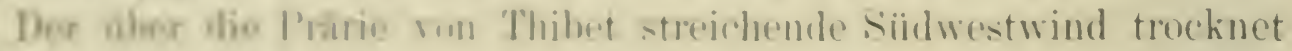

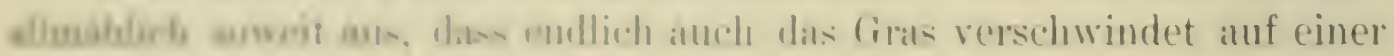

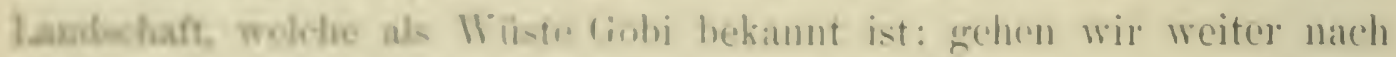

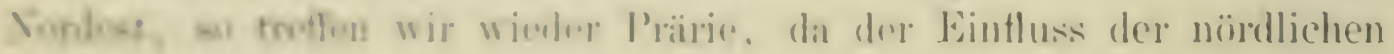

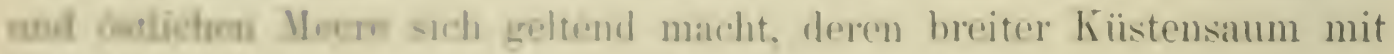

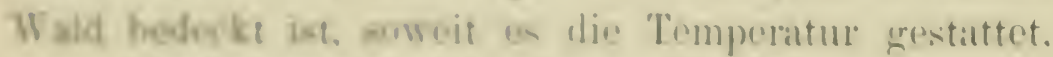

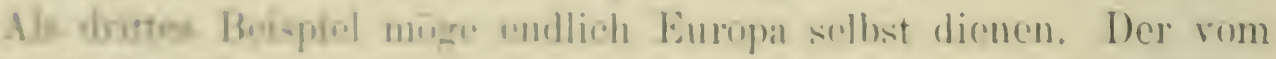

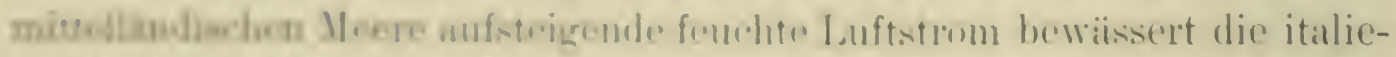

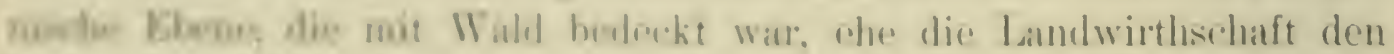

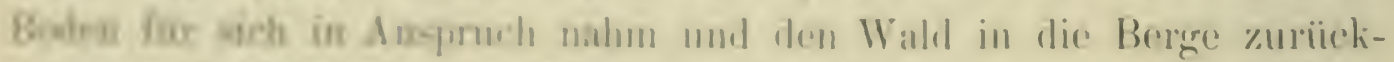

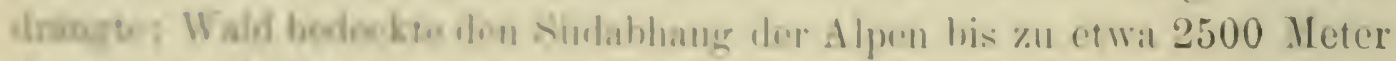

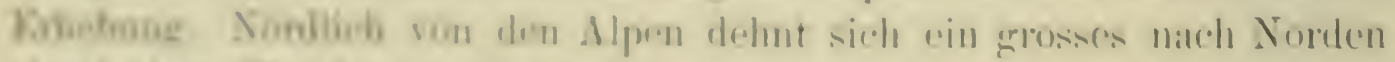

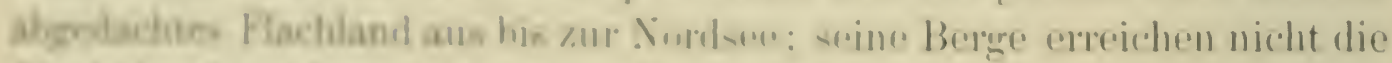

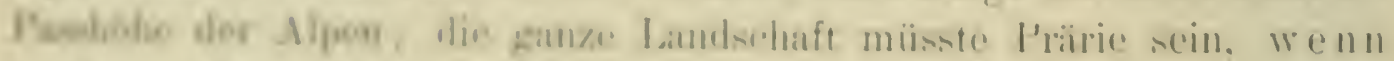

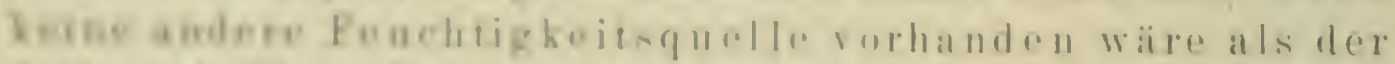

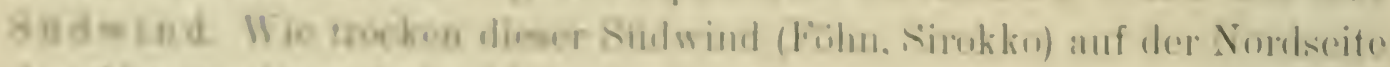

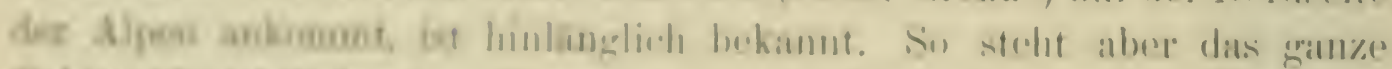

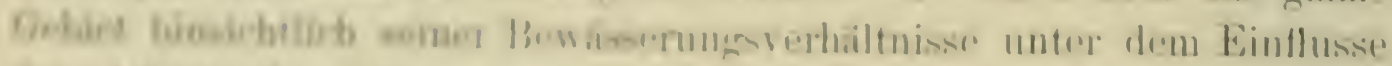

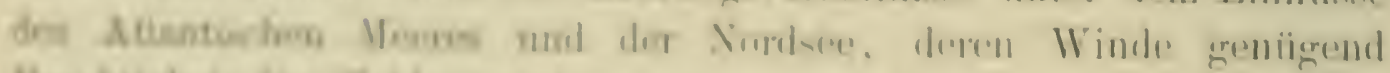

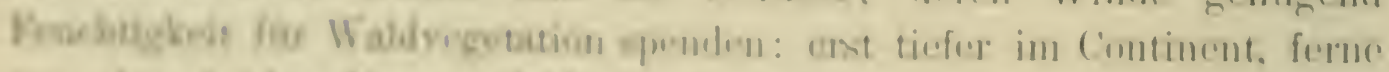

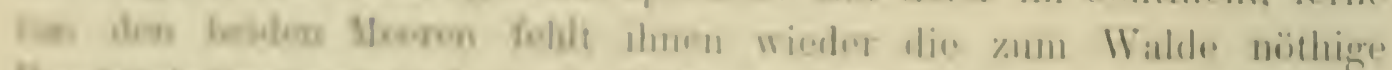

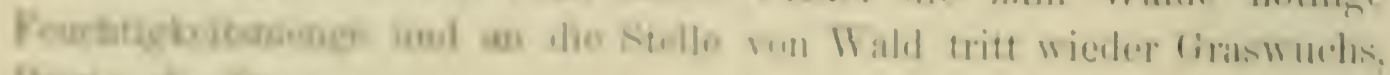

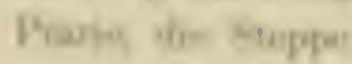

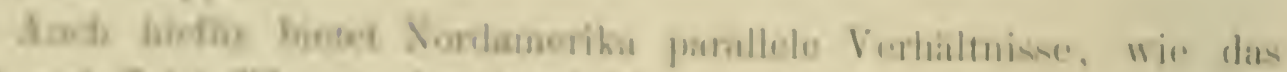

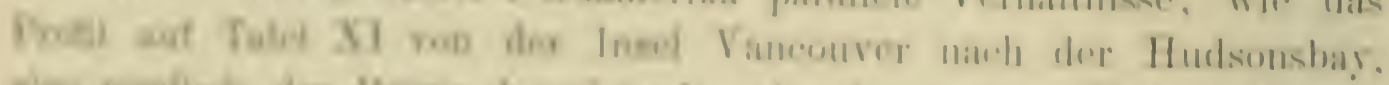

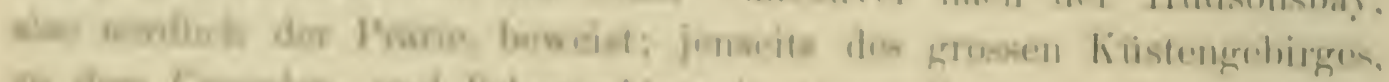

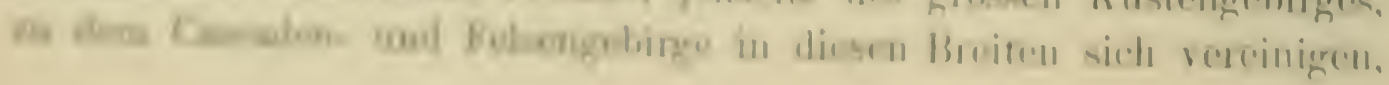


liegt keine Graslandschaft, sondern Wald, soweit die Temperatur es gestattet, da die nahen nordöstlichen Meere die nöthige Fenchtigkeit spenden.

Hinsichtlich der dem Walde zur Existenz nöthigen Wärme ist bekannt, dass bei genügender Feuchtigkeit (relativer und Regenmenge) eine obere Grenze für den Wald nicht besteht, das beweist der tropische Wald, während die untere Grenze etwa da liegt, wo in jedem I onate des Jahres Frost auftritt, ein Gebiet, das sich mit der Jahresisotherme ron $0^{0} \mathrm{C}$ decken dürfte. Der immergrüne Laubwald bedarf zu seiner Existenz einer grösseren Wärmemenge als der sommergrüne und vollends der Nadelwald; hinsichtlich des letzteren will ich bemerken, dass es keine Pinuswaldungen in der tropischen Vegetation gibt; wo Pinus in diesen Zonen auftritt, herrscht sie rermöge der Elevation ihres Standortes in subtropischer Region. Picea- und Abieswaldungen erscheinen da, wo der Winter für mehrere (2-3) Monate durch Schnee und Frost ausgezeichnet ist, mag diese Region erst bei 3000 Meter über dem Meere liegen, wie in Himalaya, oder bei 1800 Meter, wie in den Alleghanybergen, oder bei 900 Meter, wie im Durchschnitt in den Alpen, oder endlich nahe dem Meeresspiegel, wie in Sibirien, Kanada, Sachalin und Norwegen. Pinuswaldungen reichen oft in den inmergrünen Laubwald hinein, also bis zu einem Waldgebiete, das nur wenig oder gar nicht ron Frost und Schnee im Winter berührt wird, das heisst bis in die subtropische Waldzone.

Von geringerem Einfluss als die Temperatur hat sich die Bodenbeschaffenheit, insbesonders die chemische Zusammensetzung desselben, auf die Existenz des Waldes erwiesen; Wald ist, wemn die übrigen Faktoren gegeben sind, fast auf jeder Bodenart möglich; wo die Natur Jahrhunderte lang ungehindert wirken konnte, findet sich auf Hunderten ron Quadratmeilen trotz der grössten Bodenverschiedenheiten keine Blösse im Walde; erst die Verschiedenheiten in der Zusammensetzung und der Entwicklung des Waldes selbst verrathen Verschiedenheiten auch in der Zusammensetzung des Bodens, auf dem der Wald fusst. Mir sind nur wenige Böden bekannt, auf denen die Natur, sich selbst iiberlassen, keinen Wald gepflanzt hat, nämlich beweglicher Sandboden, reiner Fels und mit stagnirendem Wasser oder mit mineralischen Stoffen, Alkalien, gesättigter Boden, in dessen weisser Salzkruste keine Pflanze Wurzel fassen kann.

Eine kurze allgemeine Betrachtung der Waldflora überhaupt möge hier gestattet sein. Der Wald der Tropen ist nie so dicht geschlossen, dass jeder phanerogame Unterwuchs, wie rielfach im Laub- 


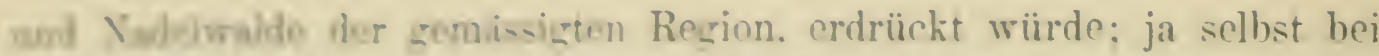

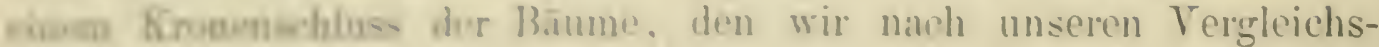

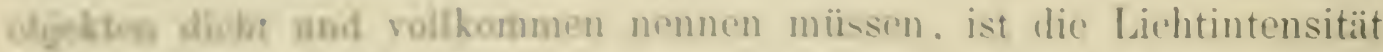

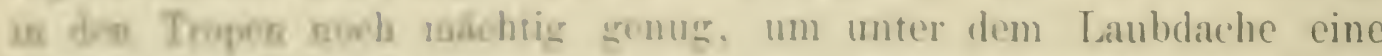

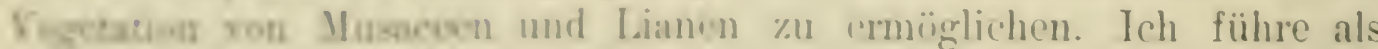

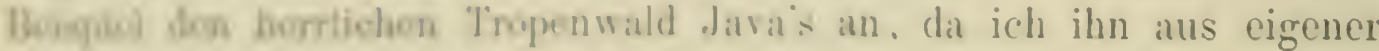
Ansclawese knomen golernt habe.

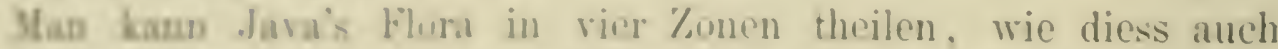
Jonakwha $)$ guchan hat, desen Wrete die Temperaturangaben cntvomenes sibul.

L. Dientropish-hoisse\%unc der Küste bis zu 700 Meter Brbchatig: wis bode nfeuches und luftenchtes, aber relativ regrenarmes

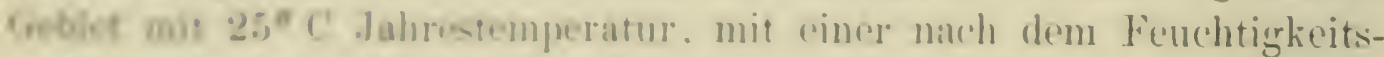

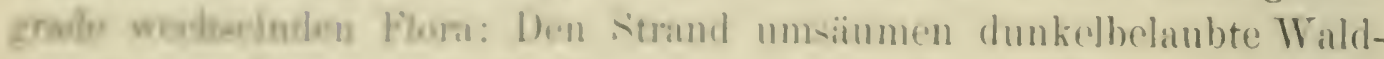

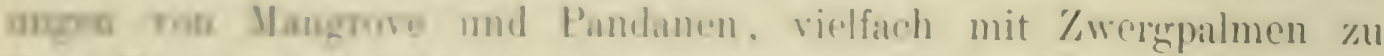

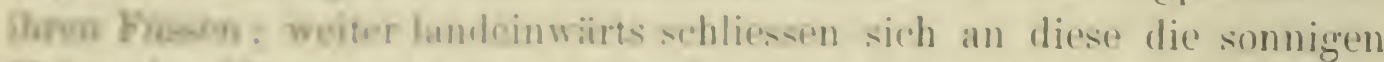
Hawe der Mmosen. Aracien. Uer 'Teakballm: Wo Misswirthschaft den Wabl wornin bret hut. ist Alang-Alangerras (Pripie) an die Stelle ge-

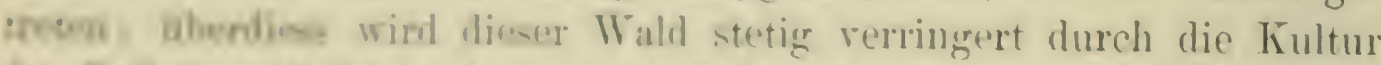
dest Bodrons mit landwinhmohaftiohen firwiolsen ron Seite der Jin-

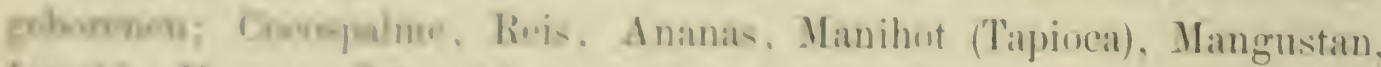

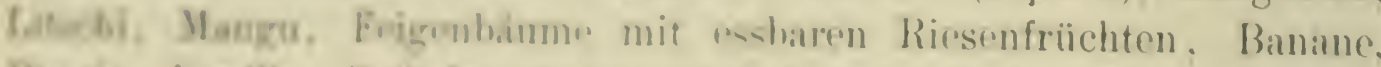

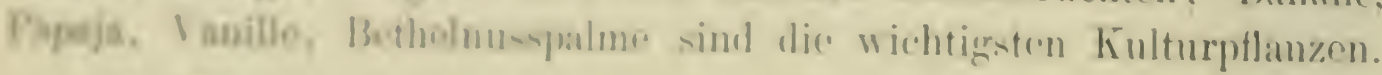

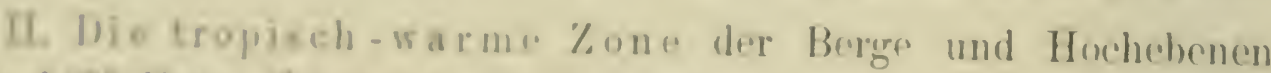

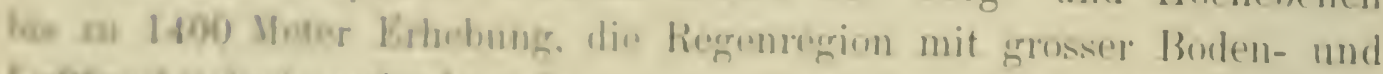

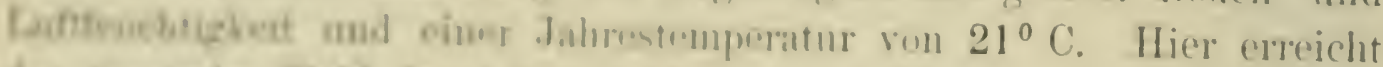

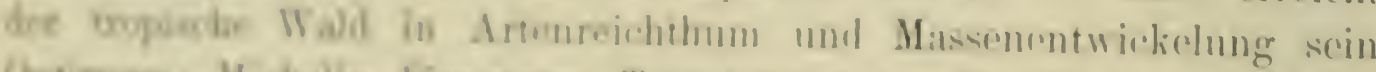

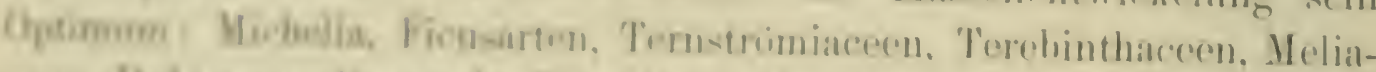

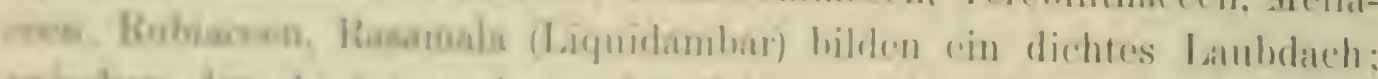

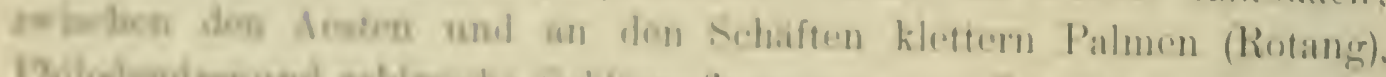

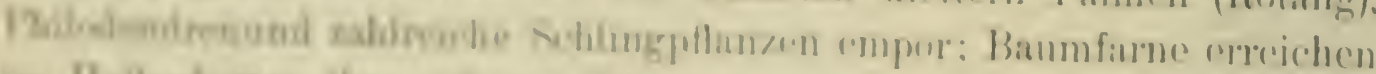

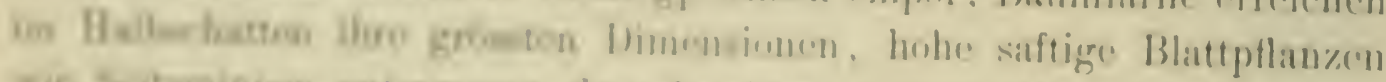

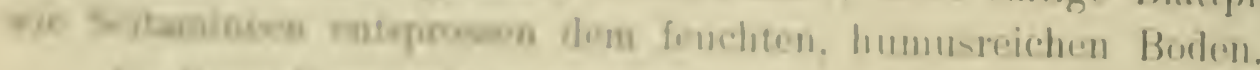

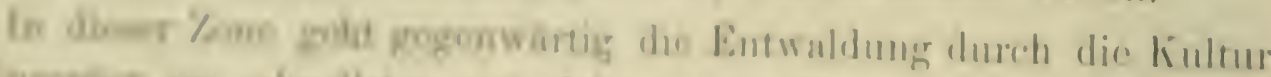

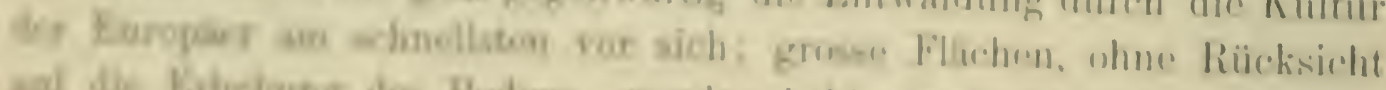

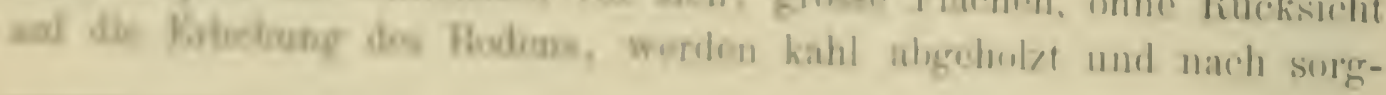

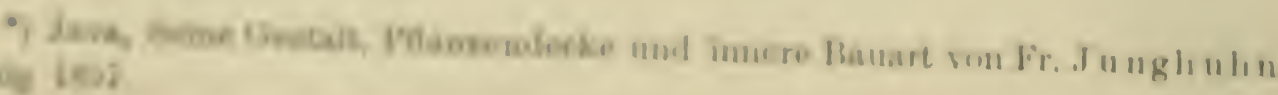


fältiger Bearbeitung mit Kaffee- oder Theestauden oder der Chinin liefernden Cinchona bepflanzt.

III. Die warme Zone der subtropischen Flora steigt bis zu 2300 Meter empor; diese Region ist die Heimat der Nebel- und Wolkenbildung, grosse Luftfeuchtigkeit, geringere Bodenfeuchtigkeit bei einer mittleren Jahrestemperatur von $16^{\circ} \mathrm{C}$. Hier erreichen die immergrünnen Eichen, Laurineen, Ternströmiaceen, Celtideen, Casuarinen ihre Vollendung; dazwischen treten Coniferen, wie Podocarpeen; an den Aesten haften zwischen dem Moose zahlreiche Orchideen und kletternde Farne (Gleichenia); Farne bedecken auch den Boden; Epheu überkleidet die Baumschäfte, europäische Gemüse und Getreidearten sind in dieser Zone und der folgenden nur spärlich angebaut.

IV. Die kühle Zone der subtropischen Flora ist in Boden und Luft wieder trockener als die vorausgehende, sie liegt eben über der Nebelregion. Ihr Klima zeigt grosse tägliche Schwankungen, dagegen grosse gleichmässige Kühle das ganze Jahr hindurch bei nur 110 C.; das ist die mittlere Jahrestemperatur des Rheinthales! Es ergibt sich daraus, wie unbrauchbar die Jahrestemperatur zur Beurtheilung des Klimas eines Landes ist. In Java liegt diese Zone auf den höchsten Bergen, die aber noch eine subtropische, immergrüne Flora ron den vorhin genamnten Familien mit geringer Höhenentwicklung sowie anderen immergrünen Arten, Angehörige der Tiliaceen, Caprifoliaceen, Leguminosen, Ericaceen kennzeichnet; Moospolster und niedere Farne liegen zu ihren Füssen. Nur Gartengemüse, die jährlich aus Samen gezogen werden, könmen dort gedeihen; man hat in diese Region europäische Ostbäume verpflanzt, das Klima war zu kühl, das Wachsthum olme Stillstand; die Obstbäume haben nicht geblüht und keine Früchte getragen.

Eine winterkahle Vegetation fehlt in der eigentlich tropischen Region stets, da es keinen Wechsel der Jahreszeiten gibt; in den tieferen Lagen ist es heiss, in den höheren warm, kühl oder kalt je nach der Eleration das ganze Jahr hindurch mit geringen Schwankungen; das Resultat ist stets immergrüner Laubwald mit entsprechend hoher, höchster und niederer Entwicklung; dann immergrüne Sträucher, Gras, Bambus, endlich kahle regetationslose Felsen. Schon bei einer nittleren Jahrestemperatur von $5^{0} \mathrm{C}$ hört unter den Tropen aus dem erwähnten Grunde jeder Baumwuchs auf, während ausserhalb der Tropen die Baumvegetation erst in Regionen mit der Isotherme ron 00 erlischt, da mit der Entfernung von den Tropen nach dem Binnenlande hin bis zu einer gewissen Polhöhe die Unterschiede zwischen Sommer und Winter 
markan Fis is daher vollig un richtig. wenn man behauptet. dow man antur den lropen mit ler Erhohnng über dem

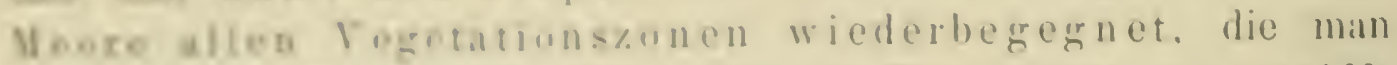

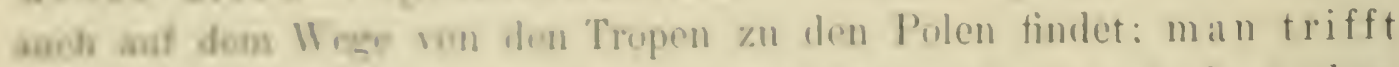
unger Aes Trapon nur den immergrinen. das heisst den

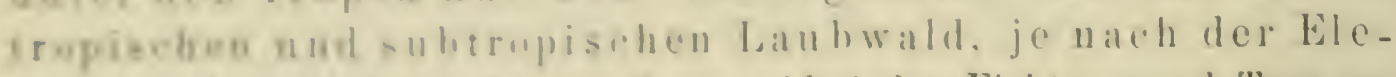
rapigh, aber jeder wimterkahle lambwald, jeder Fichten- mul 'Tamnen-

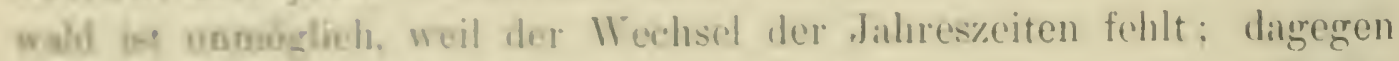

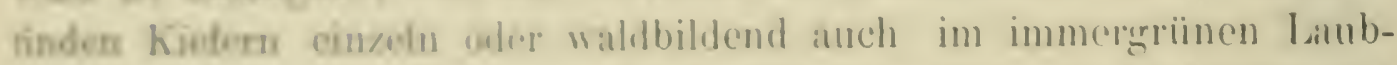

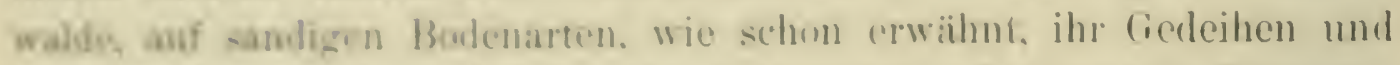

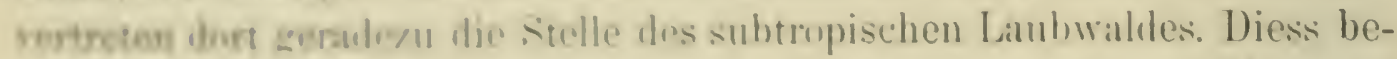

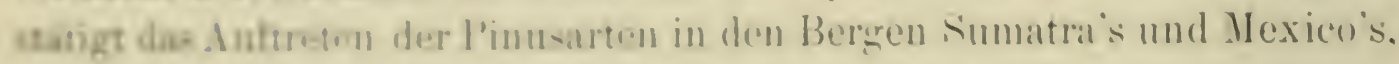

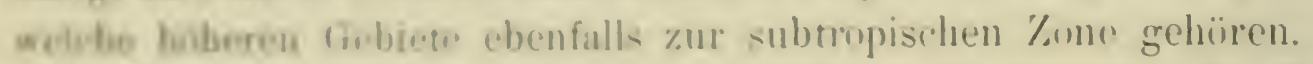

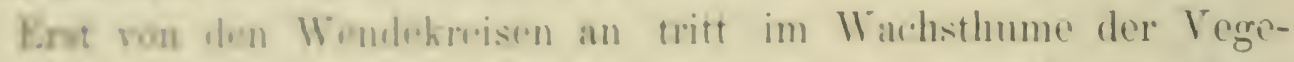

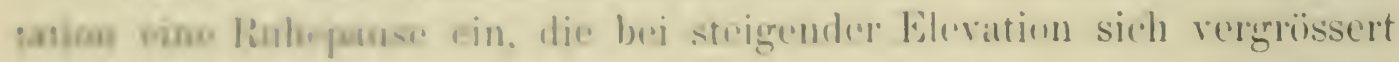

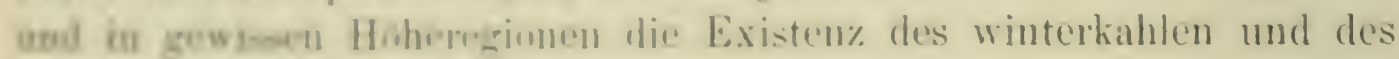
Sodelwaldes emmughoht.

Die Bonge dos intlichen Himalaya zum Boispiel unter dem Wende-

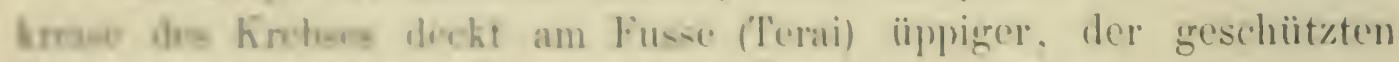

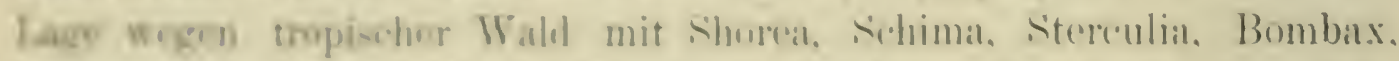
Lagertemonin, Foms. Dillenia. Trominalia. Trath (geptlangt) als den wirh-

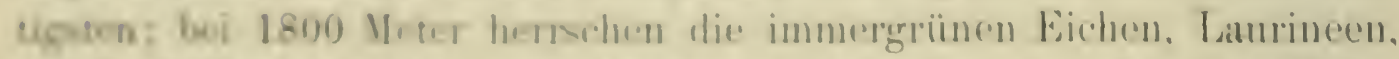

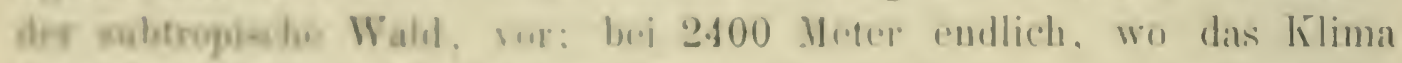

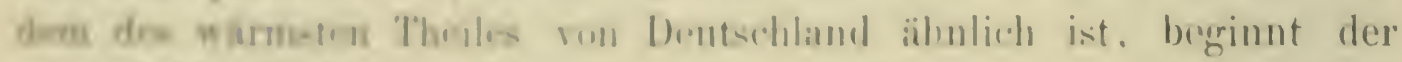

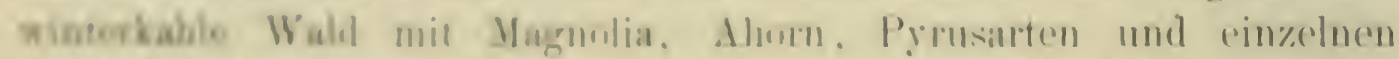

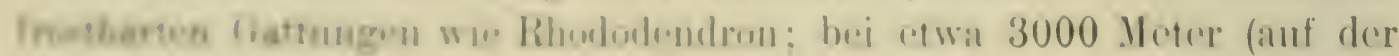

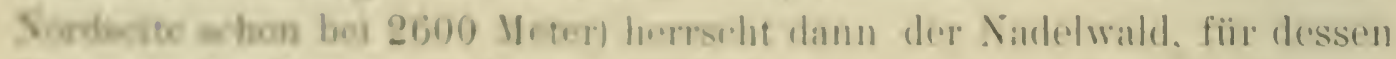

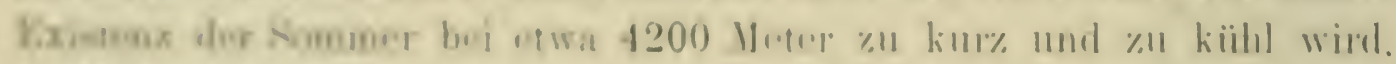

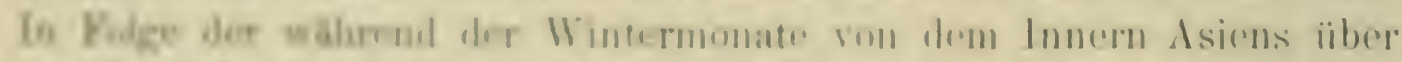

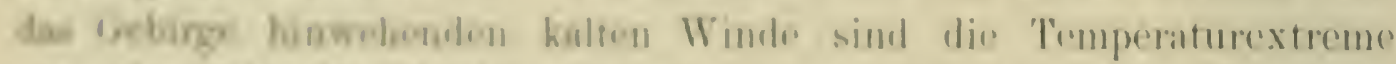

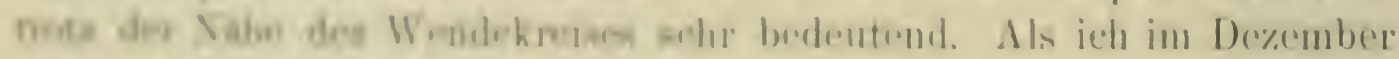

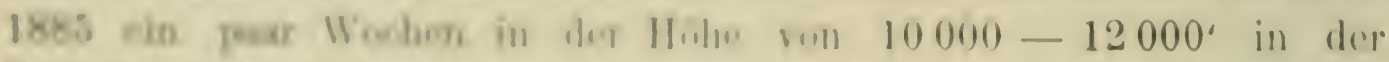

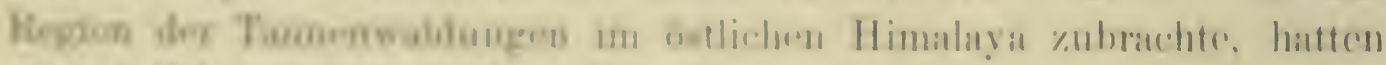

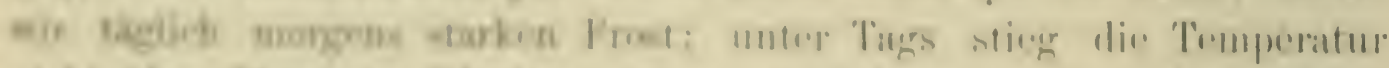

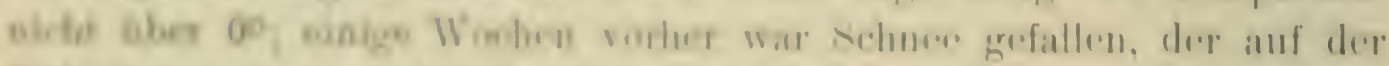

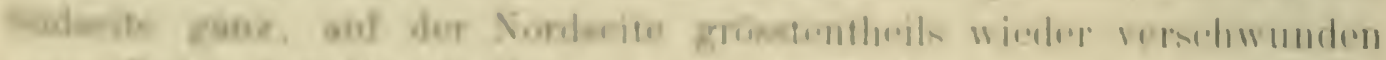

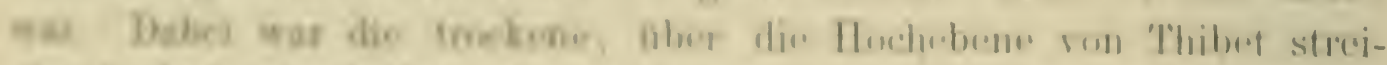

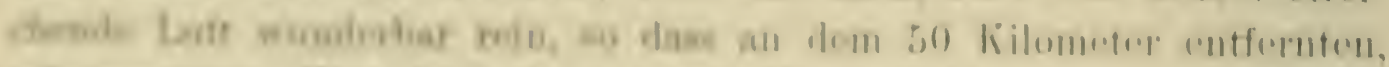

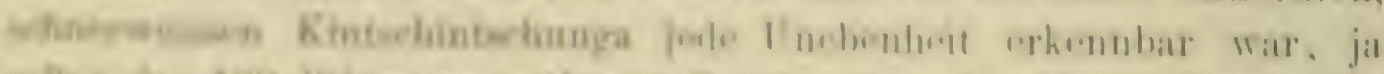

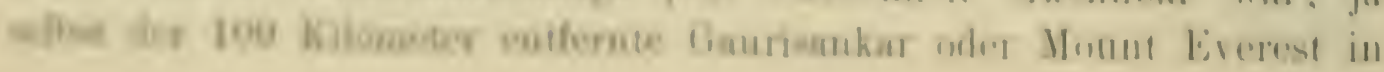


rollster Klarheit erschien. - Wie ganz anders zeigten sich dagegen die Berge Samoa's, als wir im Dezember 1887 nach langer Wasserfahrt diese Inselgruppe besuchten. Sobald unser Schiff in die Nähe der Inseln kam, änderte sich das schöne Wetter mit einem Male; es wurde windig und regnerisch, und als wir die Insel Oahu selbst betraten, schoss der Regen in Strömen zu Boden; die zackigen Berge und ihre grasgrünen Thäler verhüllte dichter Nebel; schmutzige Bäche stürzten in das tiefblaue Meer; dabei war die Luft feucht und warm. Das ist der Winter dieser, ferne ron jedem Continente im stillen Weltmeere, ebenfalls in der Nähe des Wendekreises gelegenen Inselgruppe. Die Schwankungen in der Temperatur sind während des Jahres fast Null; denn die Insel ist ron einem Meere umströmt, das im Winter eine Temperatur ron 260 C. und im Sommer ron 290 C. besitzt Trotzdem dass die Berge Hawaii's bis $13000^{\prime}$ sich erheben, begegnen wir auf ihnen nur immergrünem Laubwalde; kein winterkahler Baum, keine Tamne oder Fichte ist auf ihnen möglich, denn da wo es warm, kühl oder kalt ist, ist es warm, kühl oder kalt gleichmässig das ganze Jahr hindurch; denn trotz der geographischen Lage gehört die Inselgruppe, dank den Meeresströmungen, ins tropische Gebiet.

Die subtropische Waldregion, ron dem Wendekreise des Krebses bis etwa bis zum $35^{0}$ N.B., ist nirgends sehr mächtig entwickelt wegen der Einschnürung der Continente; sie ist gekennzeichnet durch immergrüne Eichen, Laurineen, Ternströmiaceen, Ilicineen, sowie die bei den Bergen Jara's und Indiens erwähnten Gattungen und Familien; auf sandigen Böden können auch Kiefernwaldungen fussen. Man kann die obere Grenze für den subtropischen Wald etwa dahin legen, wo zuweilen einzelne Fröste und Schneefälle im Winter sich einstellen. Einige Palmgattungen (Sabal, Livistona, Chamaerops), die leichten Winterfrost ertragen können, sowie rereinzelte winterkahle Bäume kennzeichuen diesen Wald. Hier gedeihen Orangen, Feigen, Zuckerrohr, Baumwolle u. s. w.

Innerhalb der gemässigt warmen Region, zu der ich alle Waldgegenden mit rorwiegend winterkahlen Laubbäumen rechne, trägt der Fuss des Berges, z. B. in Deutschland, den Laubwald mit den Gattungen: Quercus, Fagus, Fraxinus, Ulmus, Tilia, Acer, Carpinus, Betula u. s. w. oder bei sandigen Bodenverhältnissen Pinus; in etwa 600 Meter Höhe (Schwarzwald, Brocken) beginnen Tannen- und Fichtenwaldungen, über welchen sich kein Wald mehr erhebt. Im Bereiche dieser Region werden Mais, Tabak, Wein, Weizen, die feineren Kernund Steinobstsorten u. s. w. kultivirt. 
Endlich in der gomassigt kibhlen. in der Nadelwaldregrion

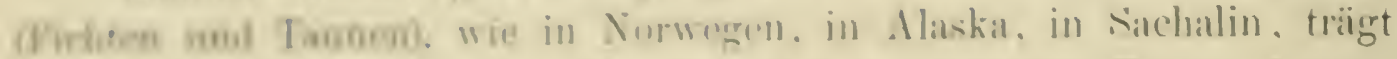

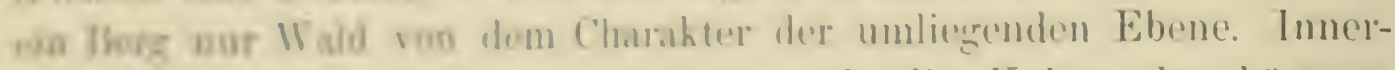

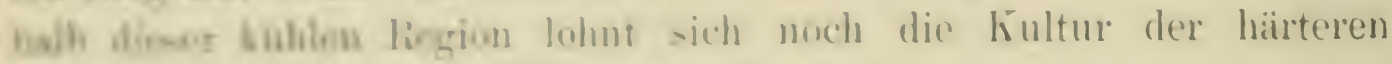

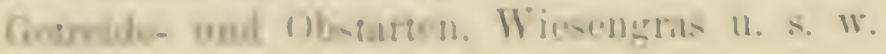

\section{Die Waldungen von Nordamerika}

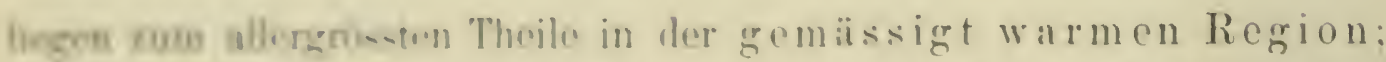

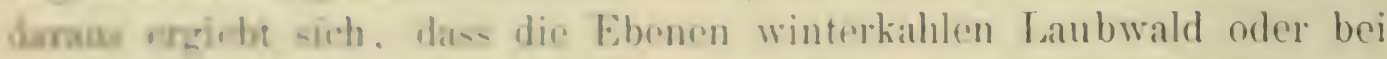
somber Bostonberdathenheit Kiefermwald trateren: beide Waldformen

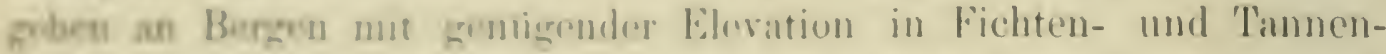

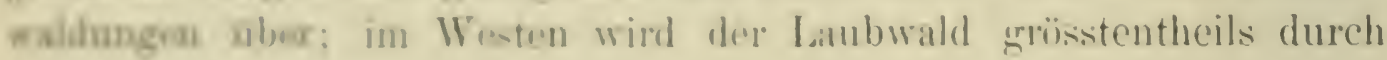
Cusifeen rertrition.

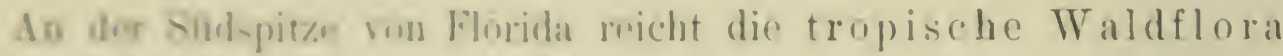

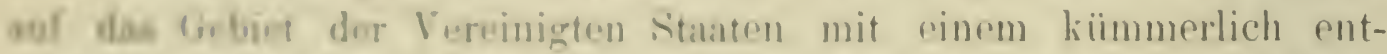

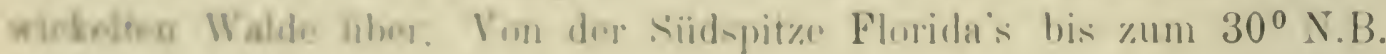

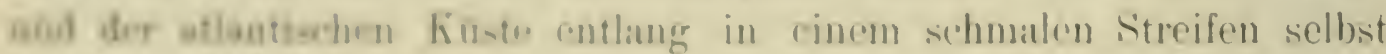
ber sum 36" S.B. herrseht dor subtropische Baumwald, vor-

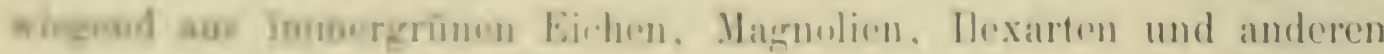

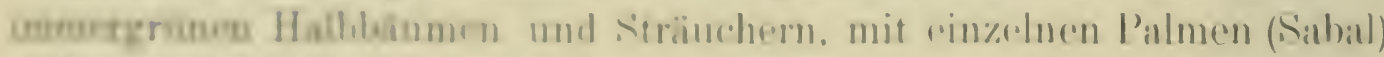

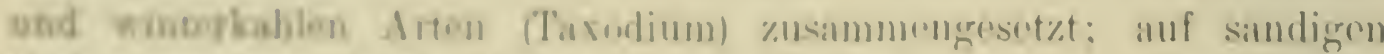

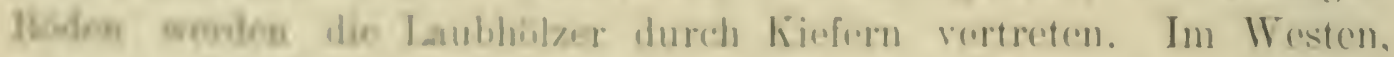

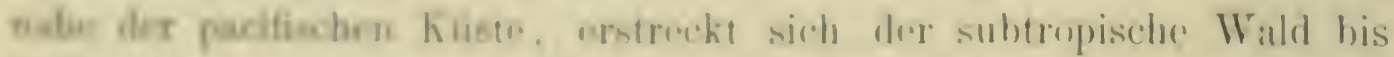

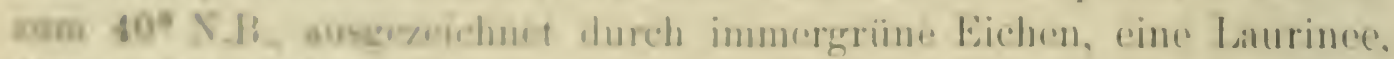

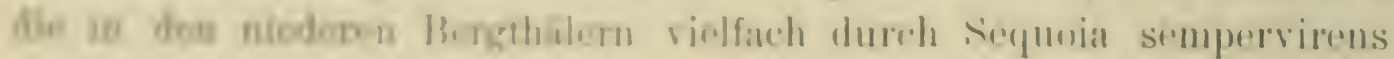

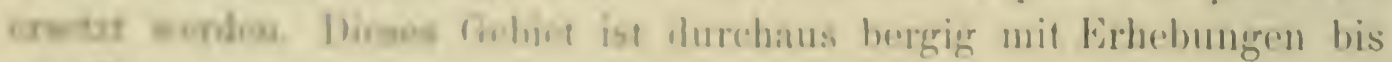
xar Tanueverive.

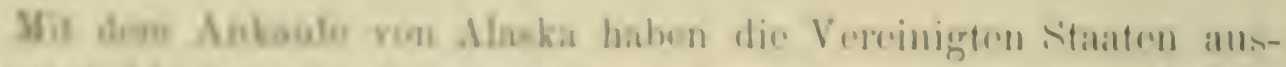

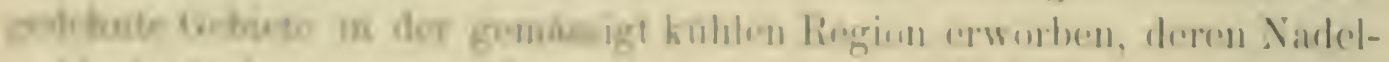

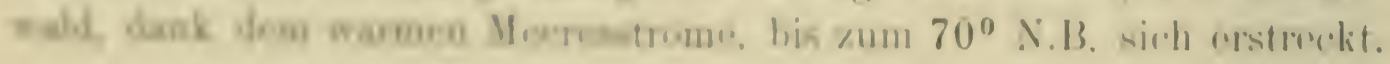

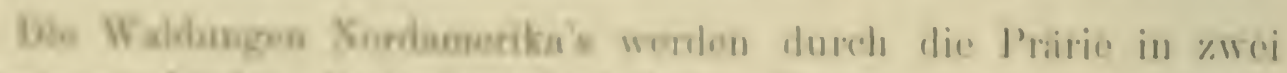

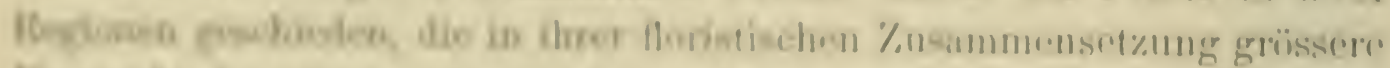

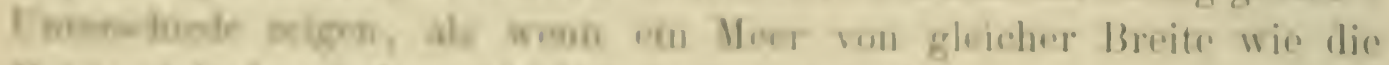

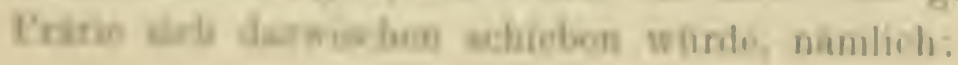




\section{Die atlantische Waldregion.}

Unter dem Einflusse der feuchten Winde rom Golf ron Mexico und dem atlantischen Ocean entstanden, dehnt sich der atlantische Wald rom Golf ron Mexico bis zur Hudsonsbay und zur Küste von Labrador; die Breite dieses gewaltigen Waldbandes reicht etwa bis zum $90^{\circ}$ W.L., wo gegenwärtig die Prärie beginnt. In der schematischen Skizze auf Tafel XI ist diese Grenze (die natürliche Grenze) an den Fluss Missouri, unter den $100^{\circ}$ W.L. verlegt, was bei Betrachtung der Prärie näher ausgeführt werden soll. Nördlich vom $40^{\circ}$ erweitert sich dieses Land nach Westen hin und erreicht unter dem $52^{\circ}$ W.B. die Basis der Rocky Mountains*); unter diesen Breiten ist daher die Prärie verschwunden, weil die nahe Küste der Hudsonsbay die nöthige Feuchtigkeit liefert, ähnlich wie in Europa bei gleicher Polhöhe der atlantische Ocean mit Nord- und Ostsee seine Wirkung bis zum Fuss der Alpen ausdehnt. Ein schematischer Querschnitt von der Insel Vancourer durch den Continent nach der Hudsonsbay, Tafel IV, zeigt in der That die gleichen Verhältnisse wie die Linie durch Europa; im nördlichen Britisch Nordamerika erstreckt sich der Wald ron der atlantischen bis zur pacifischen Küste, wie in Europa Wald ron der Tordsee bis zum Mittelländischen Meere besteht.

\section{Die pacifische Waldregion.}

Wie schon erwähnt, bildet der Wald dieser Küste kein ununterbrochenes, ron der Küste bis zu den Rocky Mountains und ron Mexcio bis Alaska reichendes Land; rom $32^{\circ}$ bis etwa $50^{\circ}$ N.B. kann man drei ron Süd nach Nord einander parallel laufende Waldbünder unterscheiden:

a) der Wald der Coast Range-Berge,

b) der Wald der Cascade Range-Kette,

c) der Wald der Rocky Mountains.

Zwischen ihnen liegen Präriestreifen reichlich ron Bergen durchzogen, mit Waldpartien auf ihren Gipfeln bei genügender Erhebung: dieser, wie schon früher erwähnt.

Vom $50^{\circ}$ an sind Coast Range und Cascade Range zu einer Gebirgskette rereinigt; es rerschwindet in diesen Breiten auch die Prärie zwischen den genannten Bergen und den Rocky Mountains, so dass in der höheren Breite atlantische und pacifische Flora sich berühren:

*) C. S. Sargent's Report, Seite 4 und 5. 


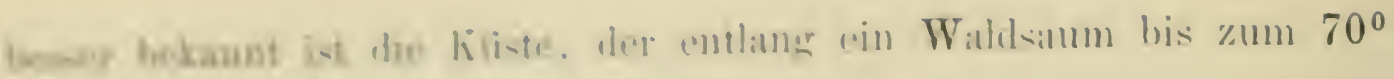
X.IS wivb erstiakt.

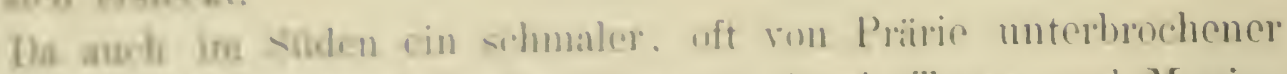

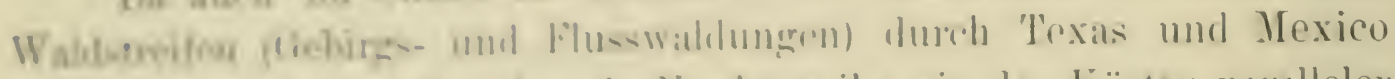

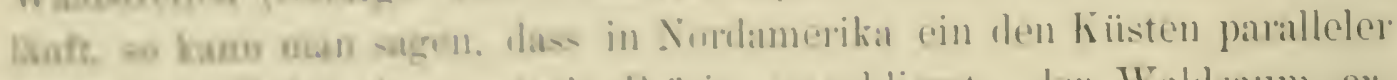

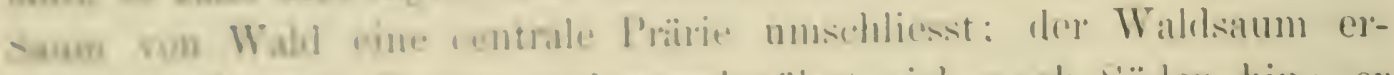

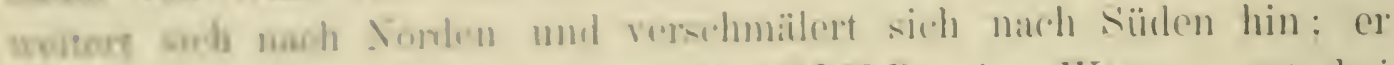

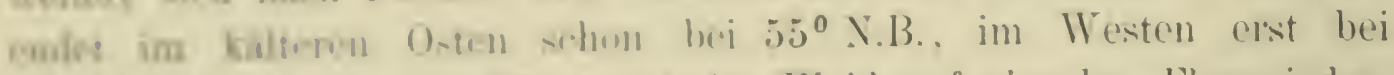

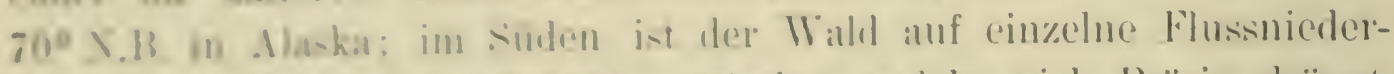

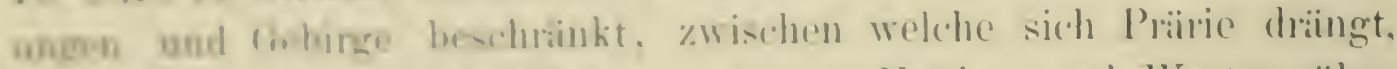

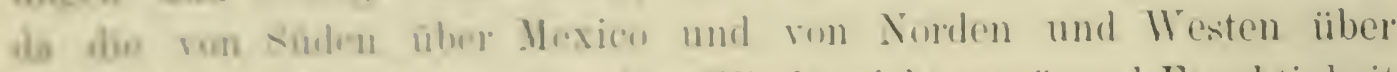

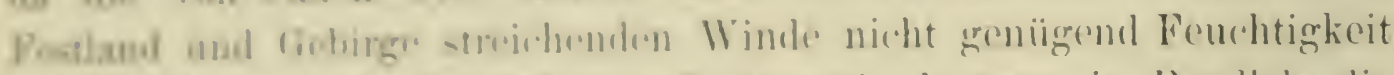

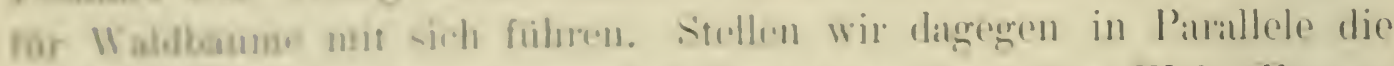

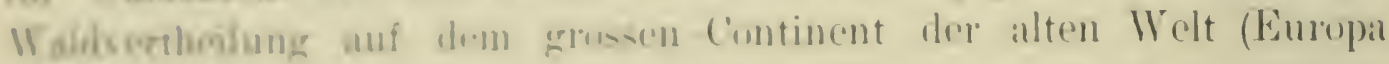

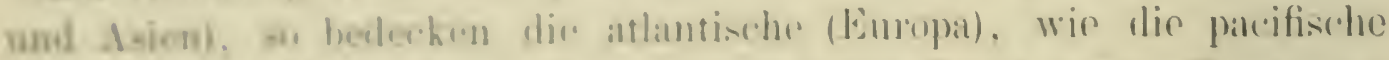

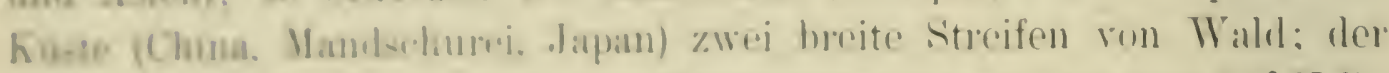

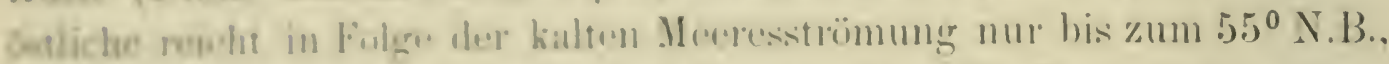

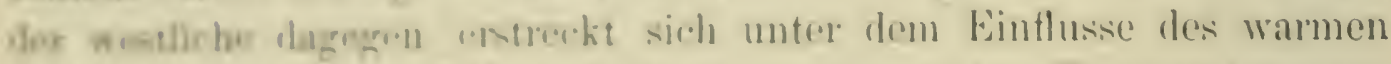

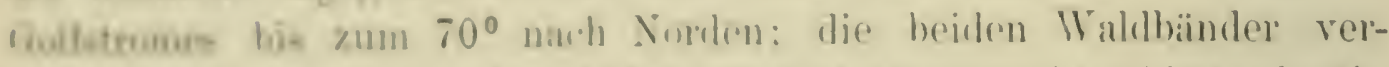

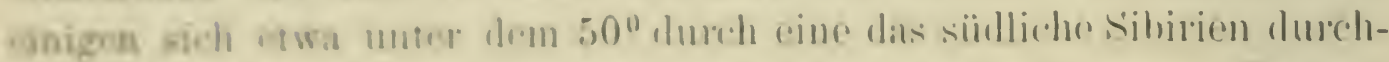

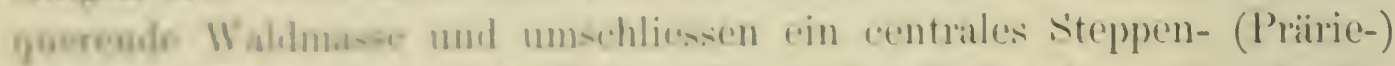

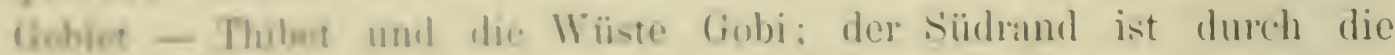
Iuburowaldungon von Birma, Indien, Afghanistan, l'erien und Kélein-

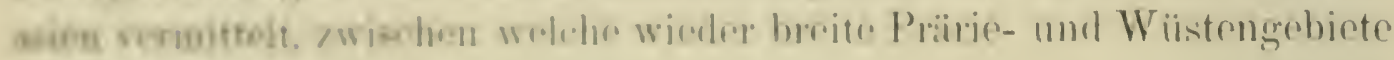
wich vine liebun.

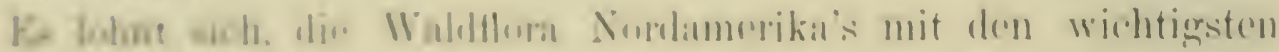

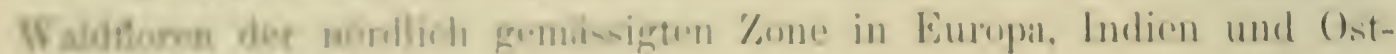

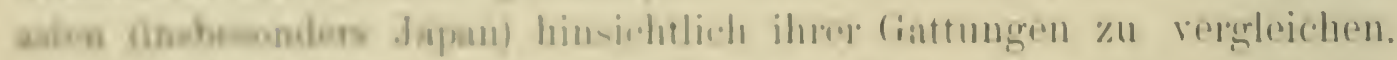

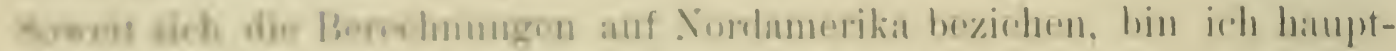

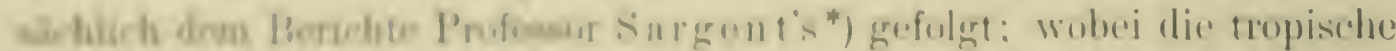

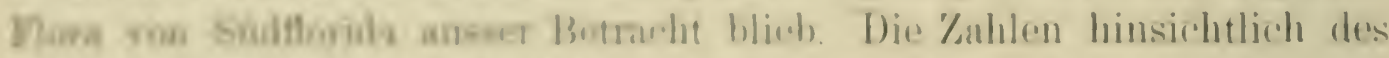

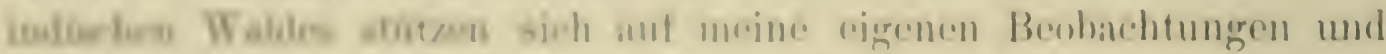

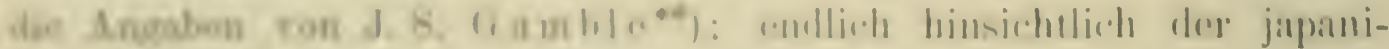

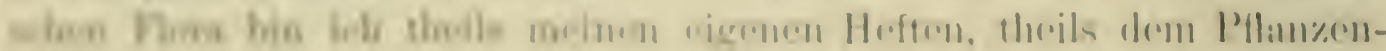

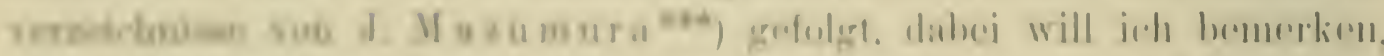

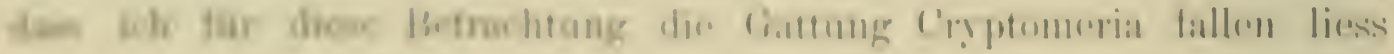


und dafür Sequoia setzte. Gattungsnamen von Sträuchern haben nu dann Berücksichtigung gefunden, wenn in Amerika ein Repräsentant derselben als Baum rorkommt.

Nehmen wir die gesammte nordamerikanische Waldflora (excl. Mexico), so sind ron den $96 \mathrm{Gatt} u \mathrm{ngen}$ derselben $40 \%$ in Europa, 50\% in Indien und 55\% in Ostasien (China, Japan, Mandschurei) rertreten; unter den 96 Waldbaumgattungen gehören 81 dem Laubholze an; ron diesen sind $60 \%$ in Ostasien, 50\% in Indien und $40 \%$ in Europa repräsentirt; ron den 15 Nadelholzgattungen Nordamerika's besitzt Ostasien volle $75 \%$, Indien 55\% und Europa $40 \%$.

Interessante Aufschlüsse erhält man, wenn man die nordamerikanische Waldflora gesondert nach den beiden natürlichen Regionen in Vergleich bringt, indem ron der atlantischen Waldregion Nordamerika's mit 85 Gattungen $65 \%$ in Ostasien, 60\% in Indien und $40 \%$ in Europa, von der pacifischen Waldregion mit 48 Gattungen dagegen 85\% in Ostasien, $60 \%$ in Indien und 60\% in Europa repräsentirt sind.

Trennt man innerhalb der beiden Regionen Laub- und Nadelwald, so umfasst der Laubwald der atlantischen Region 74 Gattungen, von denen $65 \%$ in Ostasien, $60 \%$ in Indien und 45\% in Europa sich rorfinden; der Laubwald der pacifischen Region mit 34 Gattungen ist mit circa $55 \%$ in Ostasien, Indien und Europa vertreten.

Der Nadelwald der ersteren Region in Nordamerika mit 11 Gattungen ist fast ganz (90\%) in Ostasien, mit $65 \%$ in Indien und mit $55 \%$ in Europa rertreten, während ron den 14 Nadelholzgattungen der pacifischen Region 80\% Ostasien, 60\% Indien und 45\% Europa angehören.

Aus obigen Angaben erhellt der Reichthum der atlantischen Flora in Nordamerika gegenüiber der dortigen pacifischen, während letztere ganz besonders durch ihren Reichthum an Nadelhölzern sich auszeichnet. Ostamerika und Ostasien sind floristisch am nächsten verwandt und als die glücklichen Erben der reichen, vorglacialen Laubholzflora zu betrachten; die Waldflora Europas, räumlich der ostamerikanischen am nächsten, steht hinsichtlich ihrer Terwandtschaft dieser am fernsten ; selbst Indien umfasst mehr nordamerikanische Waldgenera als Europa. Sämmtliche Gattungen der europäischen Waldflora finden sich in Nordamerika und Ostasien wieder, sind also circumpolar; 5 der nordamerikanischen Laubgattungen haben Vertretung in Indien, nicht aber sind sie in Ostasien bekannt: auch die Gattung Cupressus 


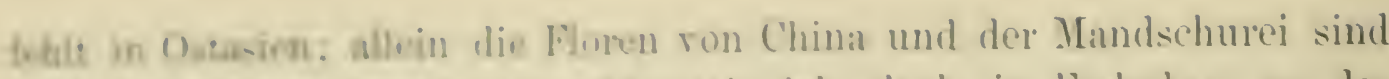
nook sche unzenazend erfurecht, sals ich doch in lindschatu an der Kasere China's in Ifirten hleine Cupresincen- (Thujopsis-) Pflanzen, die was dem Inown des lieiches stammten und mit bekinnten Arten nicht an inestificin w waren.

Fur dien nondamerikanische Flora ist es bemerkenswerth, dass es nitht mine cuzigr Bahmut gibt, welche der atlantischen und pacifischen

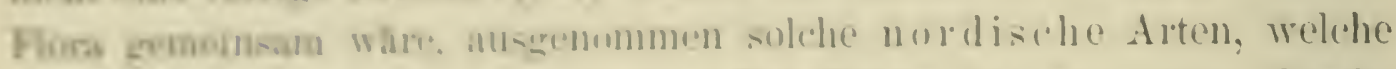
die Pranie zu ume-hron veruägen. Die Prärie hat nur eine durchebminthe Berite ron 500 lijlunneter: es beweist diess, wie schwierig Ser Austamsolı der timerejien durch Wind oder Vügrel auf grössere

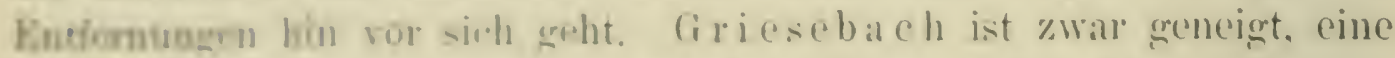

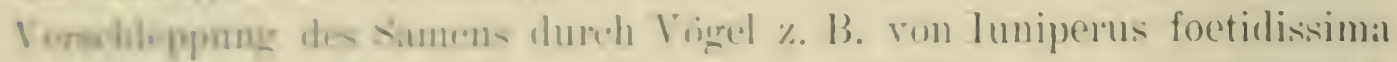

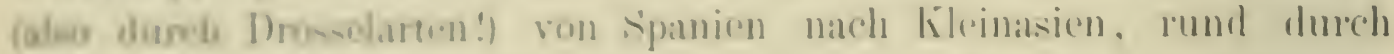
soou hiloneter, fur miglich zu halten und graubt, dass der ziemlich showe sainen son l'inus excelsit rom Winde (!) pretragen vom Himat-

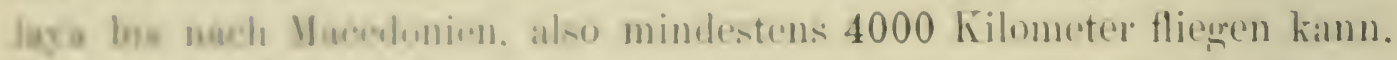
Kho man to kohus Hypothesen infstrilt, scheint e's mir näher zu liegen, zwei sieh in Bluthen und lirichton vieldeicht nahe stehende, aber räum-

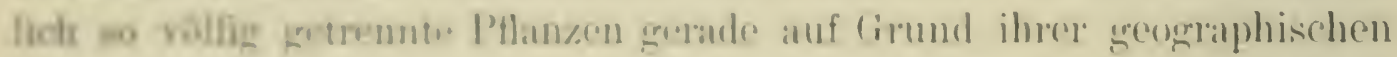

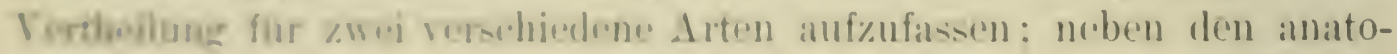
miscban Jerkmalon. die man mit Glürk in die nenere systematik ein-

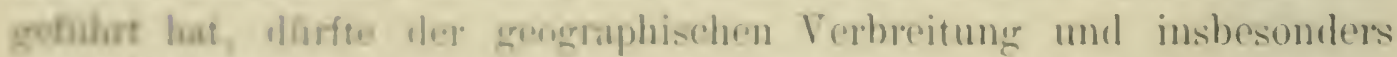
der Biolege der Pflan\% ubenfalls rine entecheidende Rolle zugespoodion wondent.

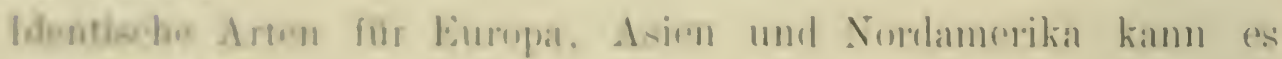

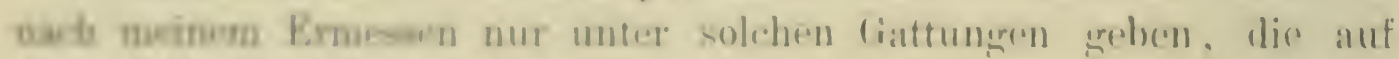

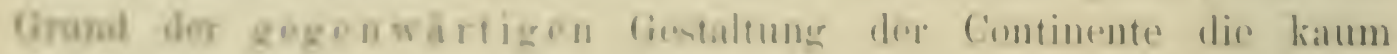

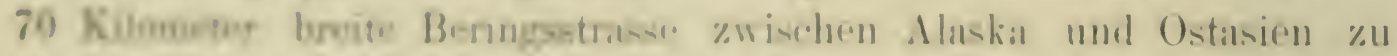
obenedumoto in stames sind. D) dort eine mittlere Jahrestemperatur

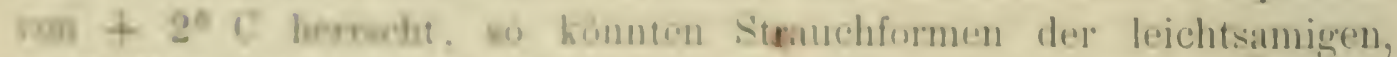

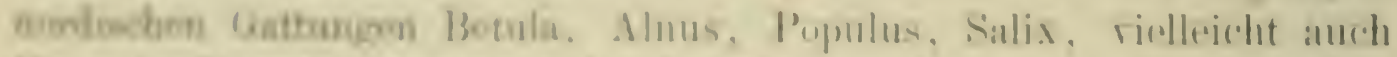

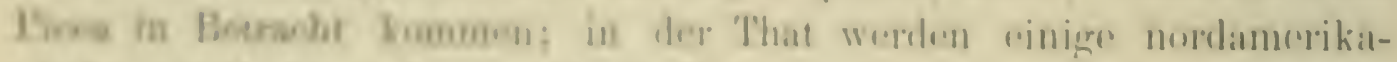

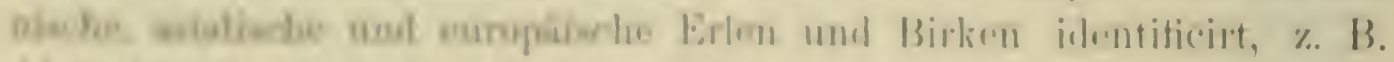

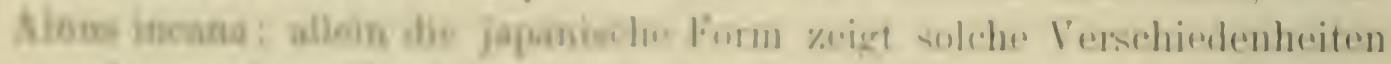

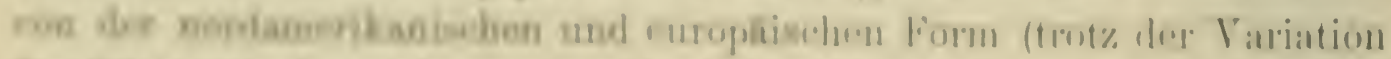

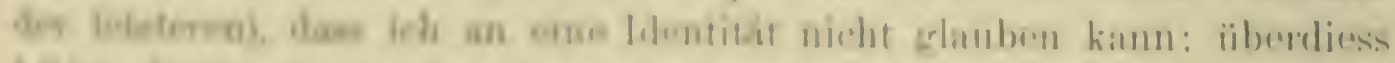

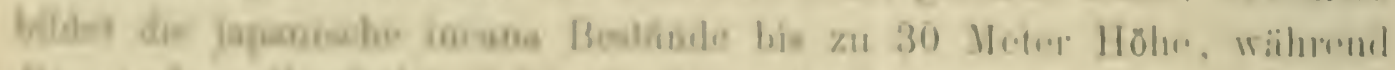

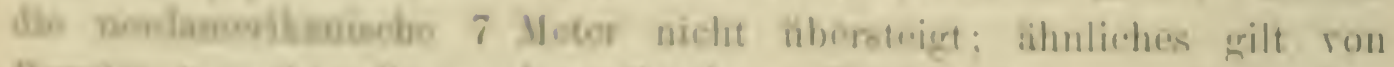

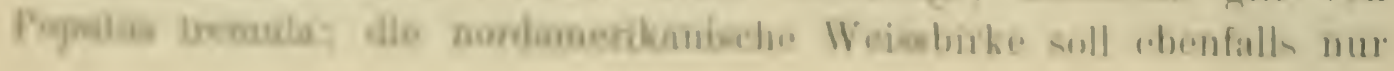


eine Varietät der europäischen Betula rerrucosa sein; da aber diesè Tarietät seit der letzten geologischen Umwälzumg von der guten Mutterart getrennt ist - denn diese selbst findet sich nicht in Nordamerika - so dürften die Merkmale der Varietät genügend lange fixirt worden sein, um jetzt als constant gelten zu können; lässt man endlich neben der geographischen Verbreitung auch die Biologie gelten, so hat diese nordamerikanische Birke mit der europäischen nichts gemein; denn erstere wird nur ein Strauch bis zu 9 Meter Höhe, und wenn sie nur die Varietät eines Baumes ist, warum geht diese leichtsamige Abart nicht südlicher und wird dann ein Baum?

Die nordamerikanischen Florenwerke berichten ferner, dass ron Neuschottland bis in den hohen Norden der westlichen Küste Juniperus communis heimisch ist; auch in Nordasien ist dieser Strauch oder Halbbaum bekannt; vermöge seiner Biologie wäre dieser vielleicht im Stande, über die Beringstrasse hinweg ron Continent zu Continent zu wandern; aber unmöglich ist es nach meiner Ansicht, an eine Identität von an wärmeres Klima gebundenen, continentalen Arten wie Eichen oder Edelkastanie oder anderen schwerfrüchtigen Bäumen zu denken; dass bei der grossen Zahl ron japanischen und nordamerikanischen Eichen (38 sind auf Tafel II abgebildet) keine einzige mit den europäischen identisch ist, ist nicht im geringsten auffällig; aber auffallend ist es, dass die plumpfrüichtigen Edelkastanien Europa's, Asiens und Nordamerika's identisch oder nur Varietäten sein sollen; eingetrocknete Herbariumsexemplare mögen vielleicht hiezu verführcn; allein die lebenden Pflanzen, die frischen Früchte und Blüthen sind so verschieden, dass bei der Unmöglichkeit eines Zusammenhanges nach der Eiszeit wenigstens die amerikanische Edelkastanie eine "gute Art" auch im botanischen Sinne sein wird.

Auffallend ist die Armuth der Westküsten der beiden Continente an Laubholzarten; es dürfte diess seinen Grund darin haben, dass die weniger frostharten Laubhölzer durch die längere und stärkere Abkühlung dieser Gebiete während der Eiszeit - infolge der hohen und ausgedehnten Gebirge - schneller und gründlicher vernichtet wurden als diess in den Osthälften der beiden Continente der Fall war; diesen gleichen Ursachen dürfte neben dem Reichthum an Naclelhölzern auch die grössere Uebereinstimmung der beiden westlichen Waldfloren überhaupt und an Laubhölzern insbesonders zuzuschreiben sein. 


\section{Allgemeiner Zustand des nordamerikanischen Waldes.}

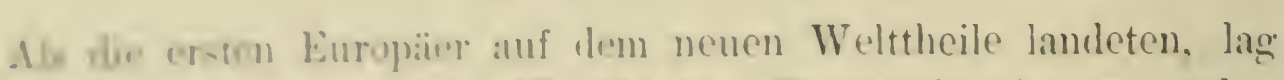

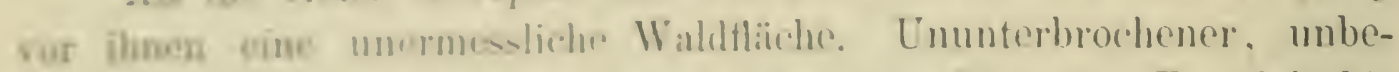

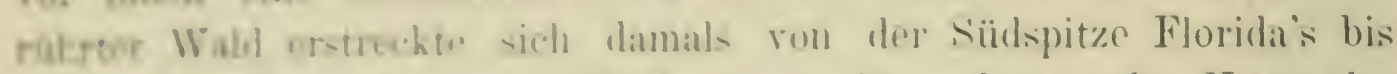

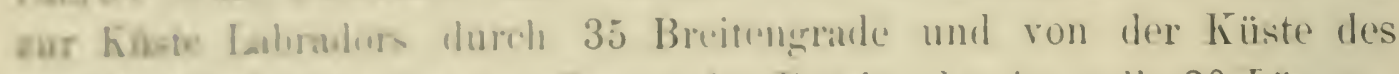

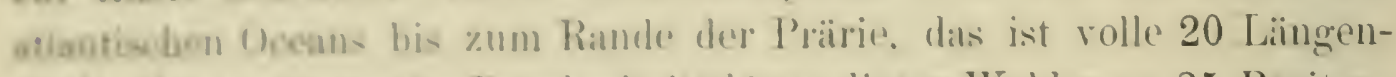

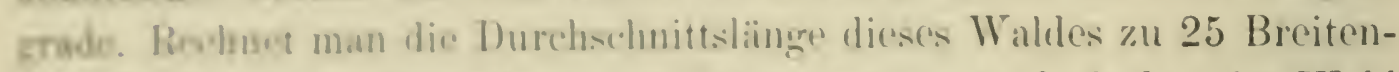

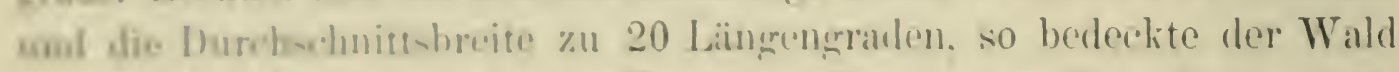

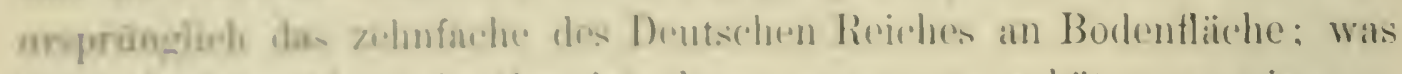

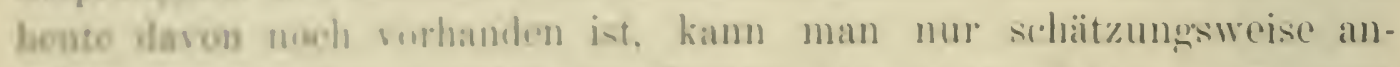

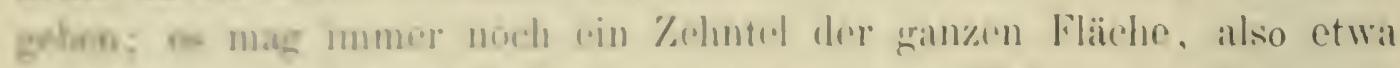

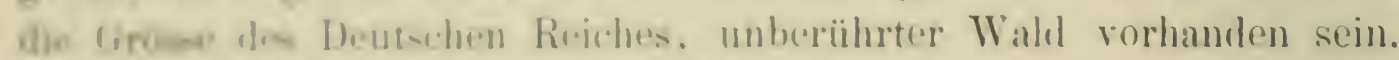

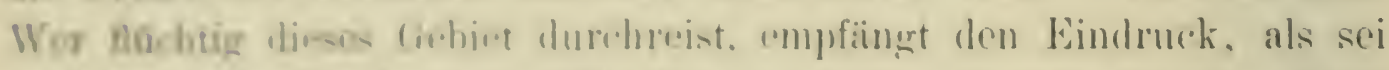

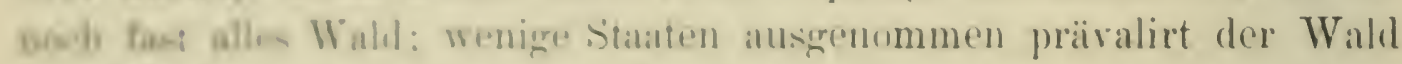

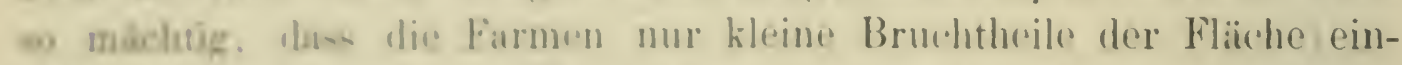

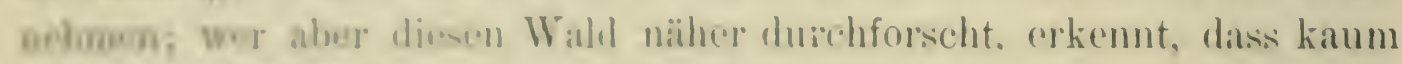

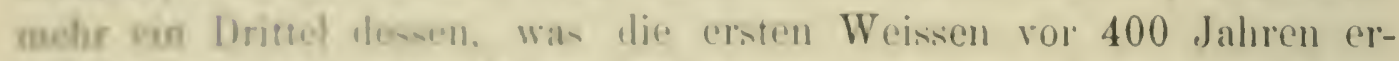
Mbken, wirktreh don Sammen Wald repdient: zwei Drittel sind nur

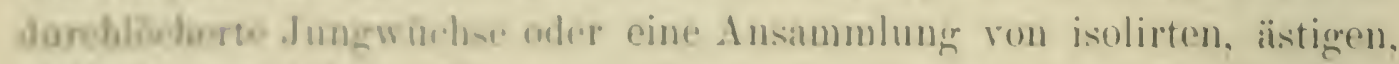

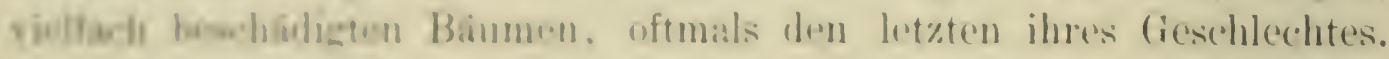

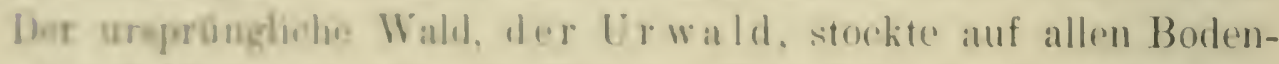

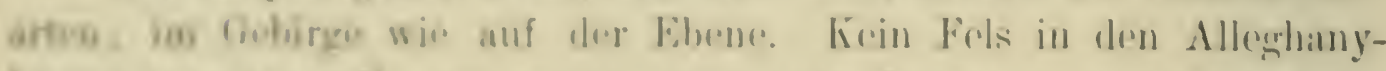

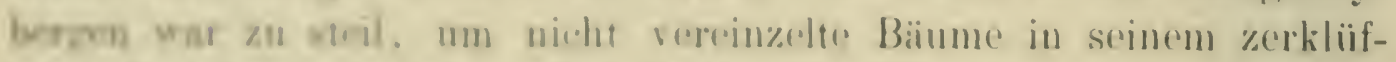

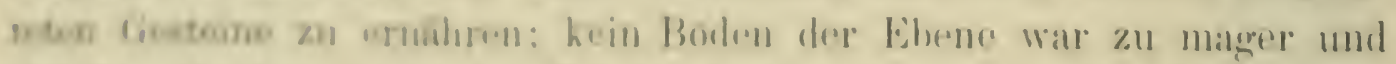

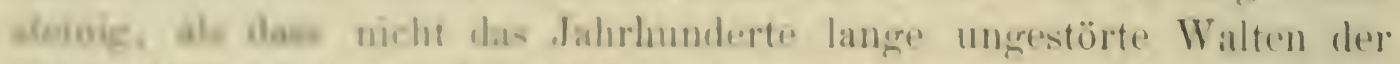

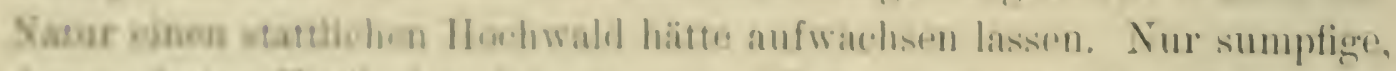

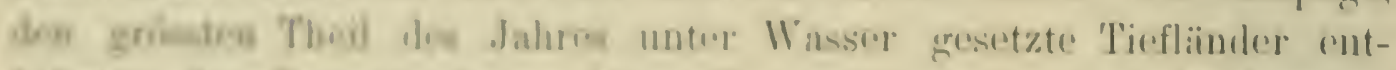

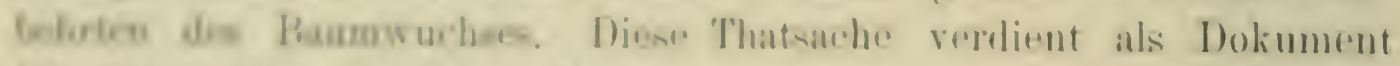

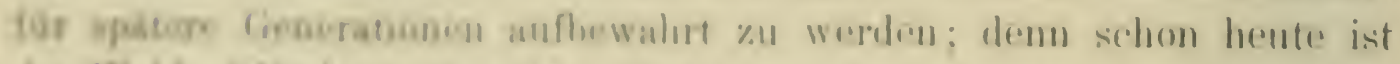

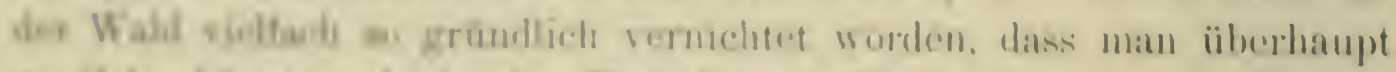

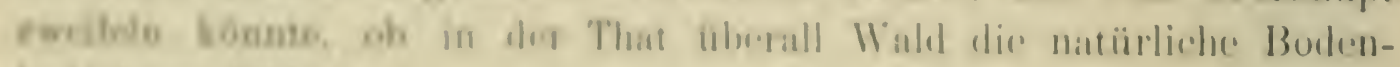
bolnokone hilitere

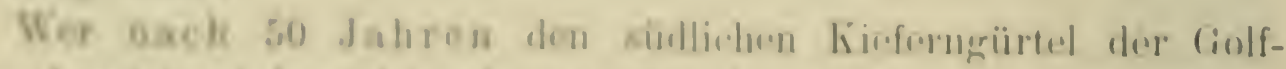

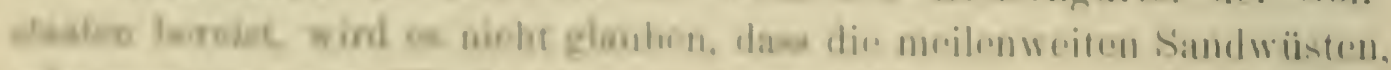

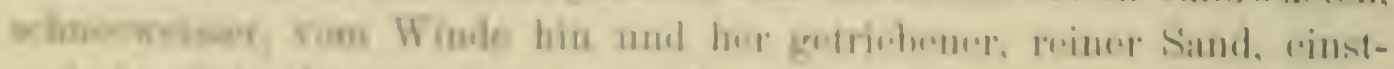

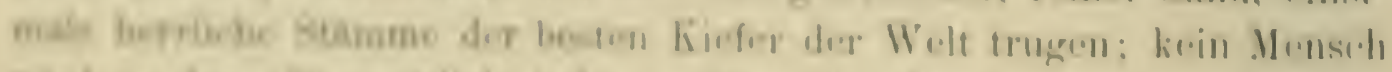

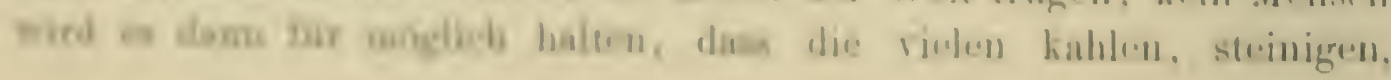


steilen Hänge der Alleghanies einstens einen Laubwald beherbergtei, Bamun der in seinem Artenreichthum, seiner Massenentwicklung einzig war. mount In 50 Jahren wird es unfasslich klingen, dass die weit ausgedehnten Sümpfe des nördlichen Wisconsin und Michigan einstens mit einem dichten Baumwuchse bedeckt und anstatt der armen Baum- und Strauchreste ron mehrhundertjährigen White pine eingefasst waren. Wenden wir uns etwas westlich und überschlagen wir wiederum 50 Jahre; welch' wohlthätiger Wald prosperirt dort, der Hand des Menschen sein Dasein verdankend, auf einer Fläche, die man einstens als desert für fast nutzlos erklärte. Man pflanzte den Wald, weil man die Unentbehrlichkeit desselben einsah. Wie herrlich blühen jetzt nach 50 Jahren die Ansiedelungen unter seinem Schutze empor, während die Stammbrüder im Osten mit Feuer und Axt darauf losstürmen, möglichst rasch an Stelle des Segen bringenden, herrlichen Waldes eine Steppe zu setzen. Es ist nur schade, dass man den Wald im Westen so viel mit fast werthlosen Holzarten gemischt hat. Wie schlecht haben sich dabei die europäischen Holzarten verhalten, von denen man nach ihrem Jugendwachsthume so viel sich versprach. Schade, dass man auf Erziehung von Brennholz statt ron Nutzholz hingewirthschaftet hat durch die weiträumige Pflanzmethode. Im Nothfalle ist ja doch Nutzholz stets das beste Bremnholz. Gehen wir noch weiter nach Westen. In 50 Jahren wird es unfassbar sein, dass das paradiesisch schöne, blühende Californien, die Fruchtkammer der Union, einstmals Prärie war; ja man wird momentan im Zweifel sein, ob man wirklich in Amerika sich befinde, denn prächtige Wälder der australischen Eucalyptus und Acacien sind dem Boden entsprungen; die von der Sonne durchglühte dürre Prärie hat man in eine subtropische Gartenlandschaft umgewandelt mit all' den Segnungen dieses herrlichen Klima's.

Aber viel, viel Geld musste darauf rerwendet werden, um die zur Regenzeit zügellos mit graubraunem Wasser von den Bergen herabschiessenden Ströme einzudämmen und von den fruchtbaren Gefilden abzulenken; viel Geld hat man der künstlichen Bewässerung des Landes geopfert, nachdem man die fast kostenlose Berieselung des Landes durch die natürlichen Quellbäche der Gebirge unmöglich gemacht durch die Verwüstung der Bergwälder in derselben rücksichtslosen Weise wie überall in den Vereinigten Staaten: einzelne wurden dadurch reich auf Kosten der Gesammtheit.

Der Weg liegt klar, auf dem die Union diesen Zukunftsbilde entgegengeht. Bei der Schilderung der einzelnen Landschaften selbst wird sich Gelegenheit geben, die theils freudigen, theils trïben Zukunfts- 
Inalder nabes zu becrimden. Hier nur noch einigre Thatsachen, die dem andmerkamen Wanderer in Ameritia anf sednitt und Tritt begegnen. Fan Bargbang. baumbas. nur zurichen den grossen steinen hat sich

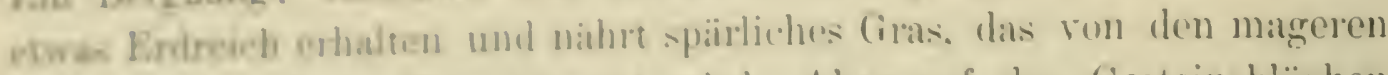

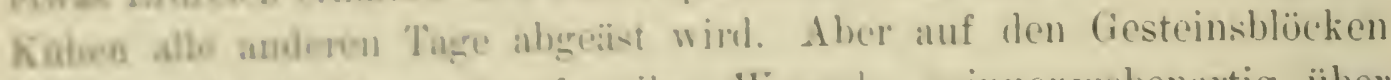

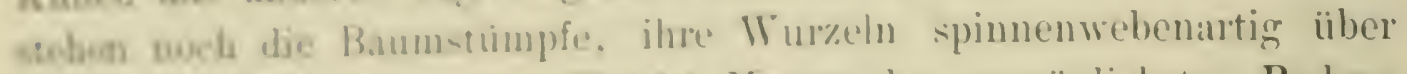
des bahten Fol hangend. Welche Menge des rorzüglichsten Bodens hat bus der Regen nach dem sinnlosen Niederschlagen oder Abbrennen Ales Waldes herunterkewaschen! Ein Jahr hat hier vernichtet, was Jahr-

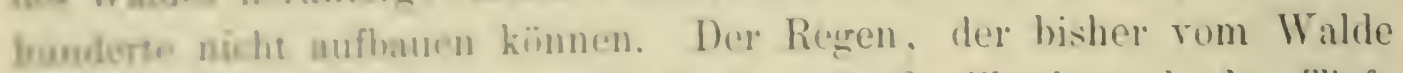

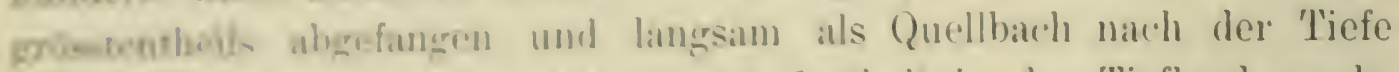
ahergebea wurle. strimt jetzt uhne Aufenthalt in das Tiefland, mehr

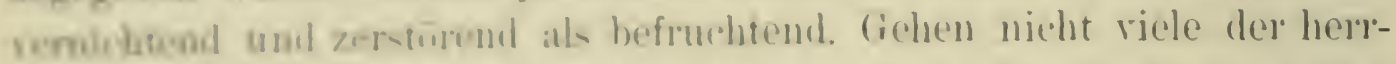
lichen Beren und Thailer der Alleghtanies, der Adirondacks und der

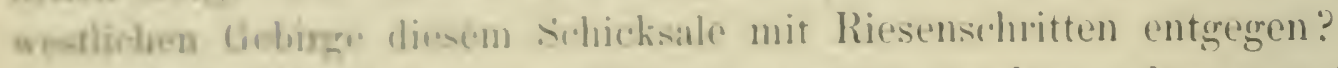

when Vidr. haben ihre stimme warnend erhoben, aber man hat sie ah Trauner erklart und sich und Anderen den sand in die Augen

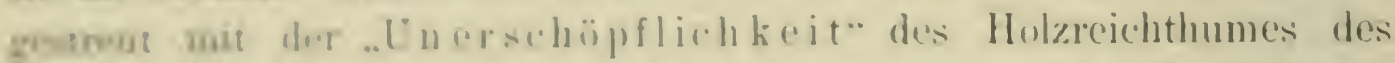
Landes. An butestun schrojen dibei dirjenigen. Welche den meisten

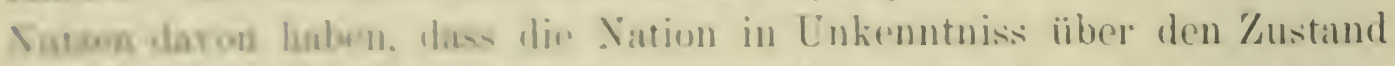
des Walias una die \%ukunft derselhen heibe. Die Nation kennt nicht

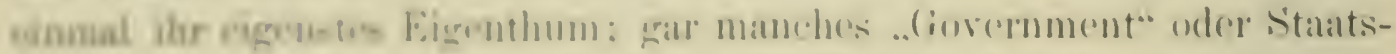
laoul hover man am Bureaturioder ...nit Wald bederekt". und doch ist

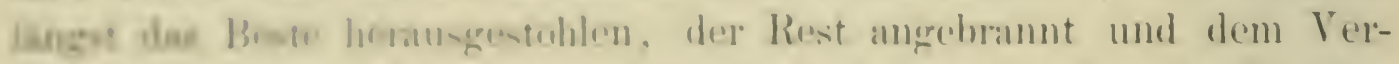

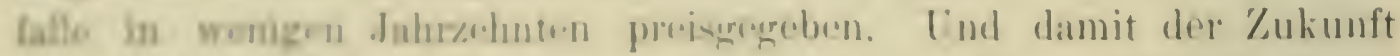

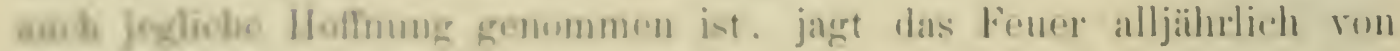

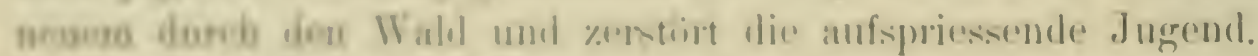

loor staat liw-lork\%, um ein Beispiel an\%ufïlıren, besit\%,

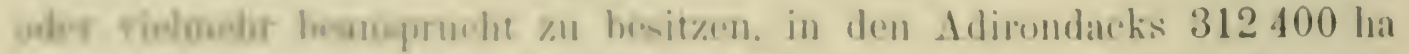

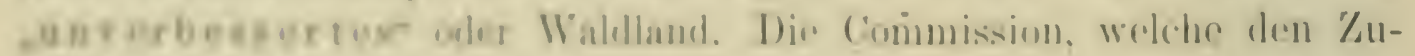
ciand dor Wablungen dieer Berge z.11 untersurhen hatte, musste, da die

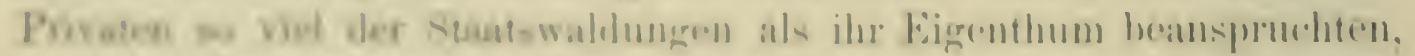

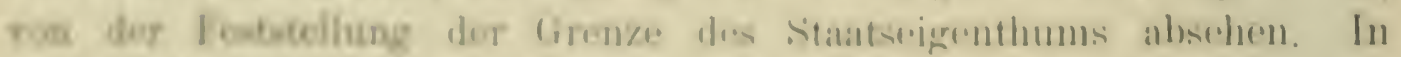

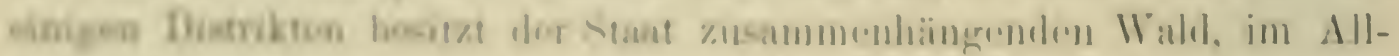

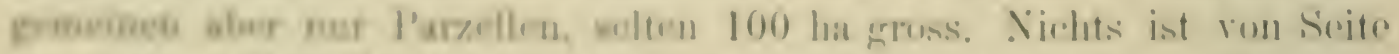

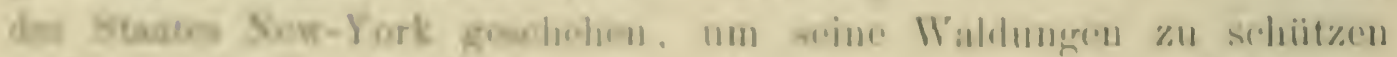

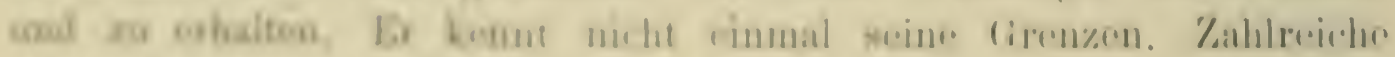

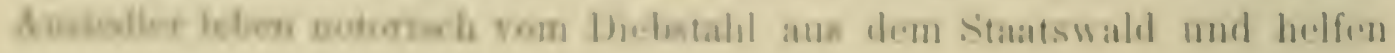

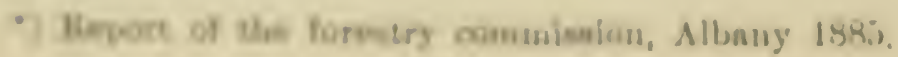


mit Feuer und Axt dem Staate, das ihm rom Volke anvertraute Waldland zu ,rerbessern", das heisst den Wald und Waldboden zu vernichten. Natürlich ist es so schlimm mit dem Schutze des Nationaleigenthumes ron Seite des Staates oder der Regierung bestellt, weil die Nation selbst sich gar nicht kümmert; ja man spricht rom Staatseigenthume, als gehöre es irgend einer Privatperson oder vielmehr gar niemand, und als hätte nicht jeder Bürger einen Rechtsantheil an dem Gute.

Mit der Entfernung ron der Hauptstadt nehmen in Amerika nach Westen hin die Rechtsbegriffe zuweilen bedenklich ab. Nach dem Regierungsberichte rom Jahre 1883 hatte die Unionsregierung vor einiger Zeit den armen Ansiedlern und Bergleuten in Colorado erlanbt, das Holz für den Hausgebrauch den Staatswaldungen zu entnehmen. Das Gesetz war ein freigebiges, die Interpretation der Ansiedler war es aber noch mehr. Regierungsbeamte, die nach wenigen Jahren dorthin kamen, fanden in einem Bergflusse eine halbe Million Schwellen liegen, die zum „Hausgebrauch" für eine breitspurige Eisenbahn bestimmt waren. Uebrigens lese ich in dem Berichte von Ferrow, dass die Regierung zum Schutze des Waldes alljährlich Millionen von Mark ausgibt, aber was nützen diese, wenn sie irgendwo verschwinden, ohne dass der Wald auch nur den geringsten Nutzen davon hat.

Zur Ehre und zum Lobe des gegenwärtigen Regimes will ich noch anfügen, dass es das Interesse an den öffentlichen Ländereien geweckt hat und sich rühmen kann, volle 40 Millionen Hektare Landfläche, die von Privaten und Gesellschaften unrechtmässig besessen und ausgebeutet wurden, der Nation zurückgegeben zu haben.

In allen Gebirgen und auf allen mageren Böden, die keine dauernde landwirthschaftliche Benutzung ertragen, an allen Flussufern, so lange nicht eine künstliche Regelung derselben eingetreten ist, ist die Erhaltung des Waldes ein Gebot der Natur zum Schutze des Tieflandes. Ich bin nicht der Ansicht, dass es für den Staat nothwendig ist, landwirthschaftlich benützbaren Boden für sich zu behalten und als Wald zu bewirthschaften. Um so mehr kann der Staat alle Mittel und Kräfte dahin concentriren, wo seine Hilfe allein einen dem Volkswohl erspriesslichen Zustand erhalten kann.

In Folge des ungeheuern Reichthumes des Landes und der Arbeitskraft des unternehmenden Volkes hat der Staat stets grosse Ueberschüsse in seinem Hanshalte. So lächerlich es vielleicht in Amerika klingen mag, nach meiner Meinung gäbe es keine passendere Rückgabe eines Theiles des Geldes an die Nation, als die Waldungen in den Bergen und auf absolutem Waldboden, mit einem Worte die Schutz- 
maldecturen. Wie for den Handen der Privaten mit dem abhïngigen

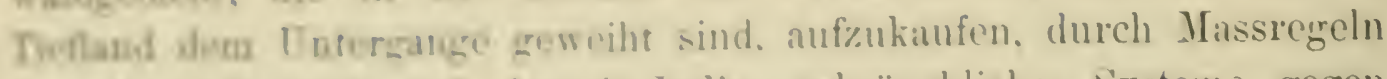

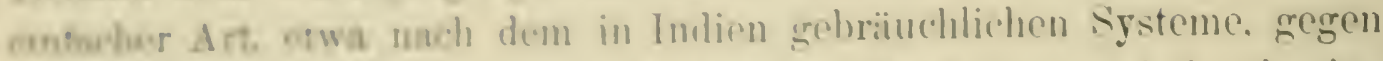

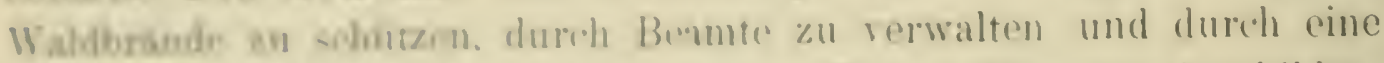

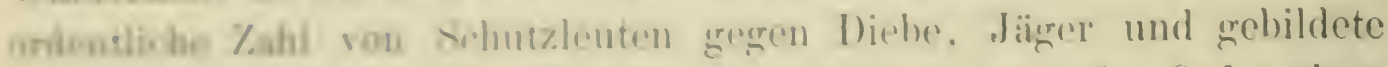

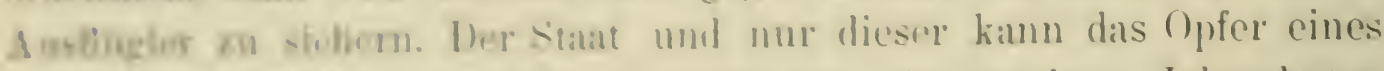

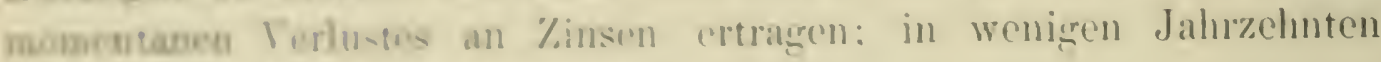
werien sin xohnfach wiederhiliren.

Die Eusmyluenzen. Welche die Fintwaldung der Berge mit sich bonget, sind wohl bokannt. Man liat die schünsten Beispicle davon in der alren $1 H_{\text {olt }}$ Mun lawe die Illusion. dass in Amerika alles anders

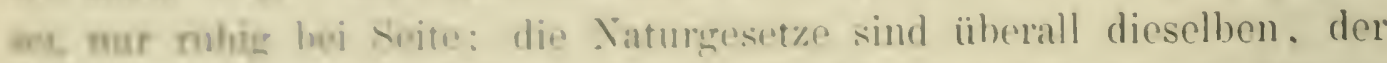

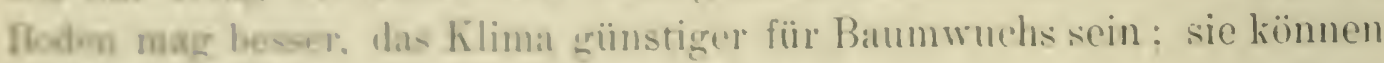

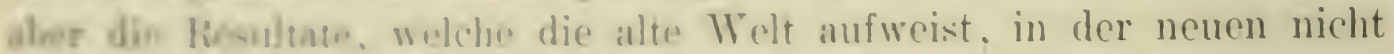
andern, nur brrizron. Cieht die Misswirthschaft, das senengen und

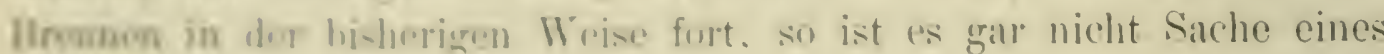

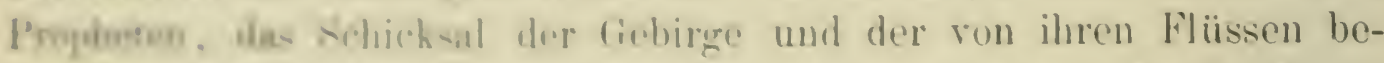

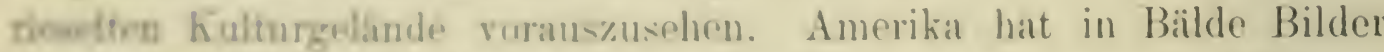
aufarmeien. dio an firusartigheit der Verwistung ron den Bergen

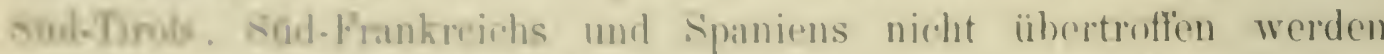

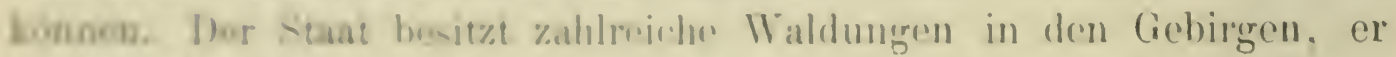

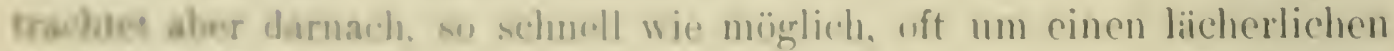
Preit woti der last erlost zu werden. Dio Wegrgible des Waldes ist

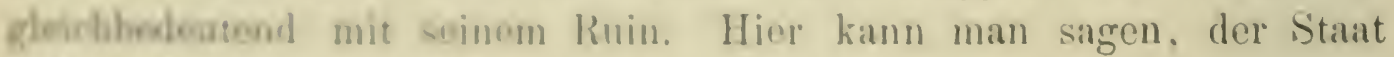

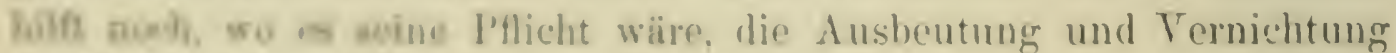

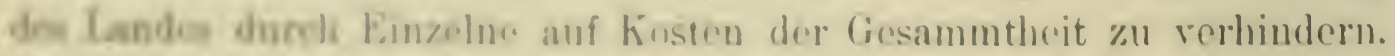

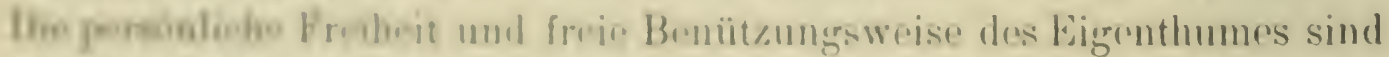

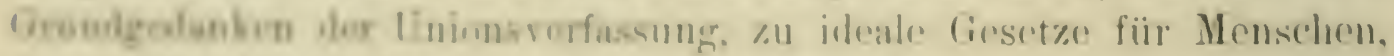

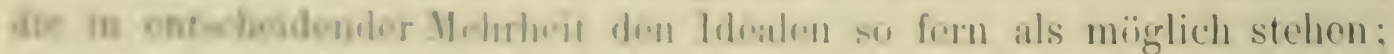

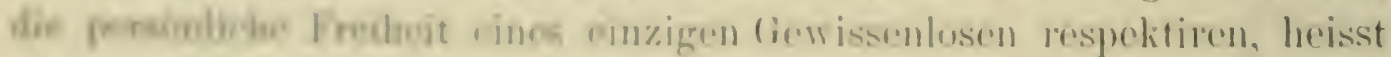

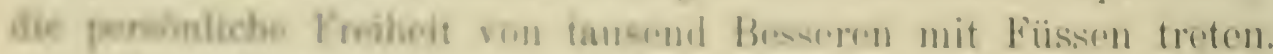

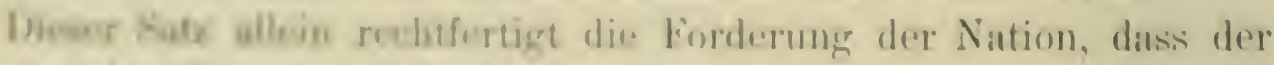

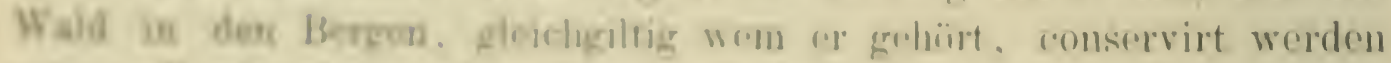

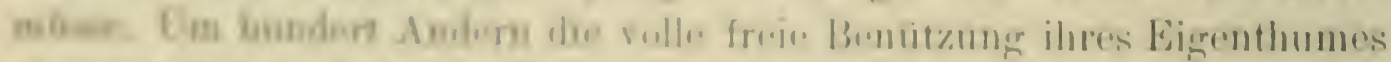

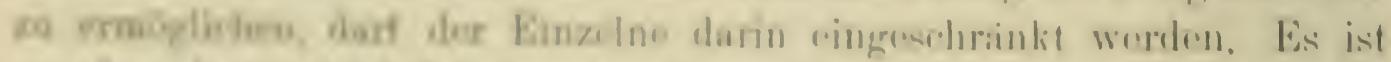

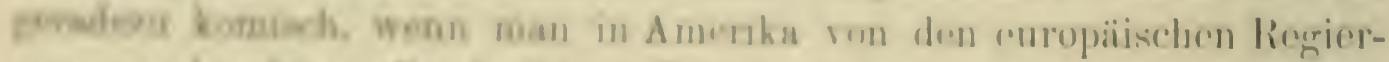

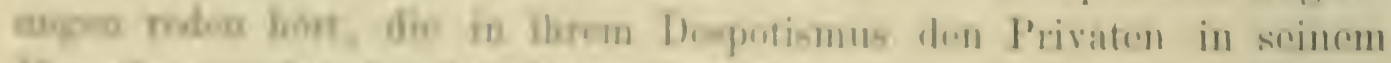

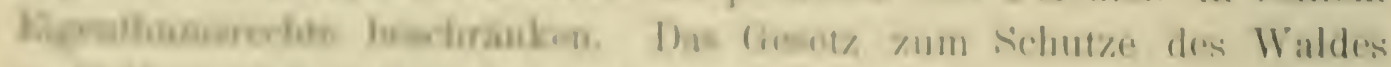

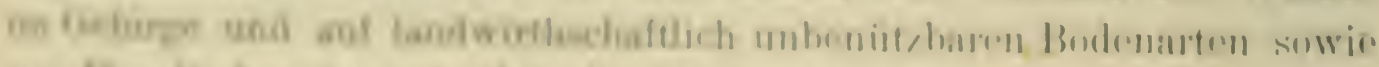

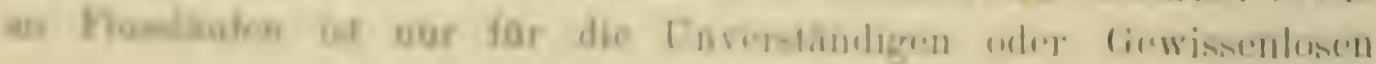


geschaffen; die ungeheuere Mehrzahl der Bergwaldbesitzer braucht das Gesetz gar nicht, da sie selbst so klug sind, sich mit dem Walde anch den Werth ihres Eigenthumes zu conserviren. Wo die Staatsverfassung es unmöglich macht, den Einzelnen zur Erhaltung des Waldes, wo es nothwendig ist, zu zwingen, da muss der Staat das Recht haben, das Besitzthum eines Widerspenstigen zum Wohle des Ganzen gegen eine billige Ablösungssumme an sich zu ziehen und selbst zu verwalten. Was in der gegenwärtigen Zeit in Amerika an Wald in den Bergen, auf den mageren Sandflächen rerschenkt oder rerkauft wird, das wird die Regierung des nächsten Jahrhunderts wieder sich aneignen müssen mit schweren Geldopfern, denn der Private rerschenkt nichts, wie es die Regierung gethan, und was es kostet, verw üstete Gebirgslandschaften wieder aufzuforsten, dazu mögen die Zahlen, welche die französische Regierung der Sache widmet, Anhaltspunkte liefern. Hoffentlich ist bis dahin nicht aller fruchtbare Boden heruntergewaschen!

Wie schon erwähnt, muss auf allen Bodenarten, insbesonders auf magerem Sandboden und zur Versumpfung geneigtem Boden, die nur forstliche Bewirthschaftung zulassen, der Wald erhalten bleiben. Solche Flächen sind in Amerika ungemein zahlreich, insbesonders im Süden, wo sie der Küste des Golfes ron Mexico und des atlantischen Oceans entlang tausende ron Quadratmeilen einnehmen. Der herrliche Wald der besten Kiefer der Welt wird dort hinweg gefegt, die Jugend wird durch Feuer vernichtet; das Zukunftsbild, das ich oben angedeutet, der blanke Sand, schimmert in seiner Nacktheit bereits ïberall durch das magere Gras hindurch. Mit dem letzten Baume und seinem Schatten stirbt auch das Gras. Die grosse Menge befruchtenden Regens, welche dieses Gebiet empfängt, kann es nicht rerhindern, dass bei dieser Misshandlung alle Tegetation verschwindet und der weisse Flugsand zurückbleibt. Auch hier ist nichts geschehen, um dem Uebel Einhalt zu thun und die Landschaft zu retten. Vielleicht bestehen schon Gesetze wie für die Erhaltung des Waldes in den Gebirgen, aber Gesetze, über die Jedermann lachend sich hinwegsetzen darf, sind schlechter als keine Gesetze.

Wisconsin, Michigan und Minnesota beherbergen ausgedehnte Laub- und Nadelholzwaldungen auf flachem oder schwach welligem Terrain. Viele hundert Quadratmeilen sind mit Lärche, mit white cedar (Thuja occidentalis) oder „spruce“ und balsam (Fichte und Tanne) bedeckt, die sogenannten Sümpfe oder swamps; zu den Füssen der niederen Bäume liegen dichte, mit Feuchtigkeit durchtränkte Polster ron Sphagnum-Moos, in dem auch Vaccinium macrocarpum, Andromeda und 
atrolere siran her ilir forthommen finden. Dom Dascin dieses Sphagnum

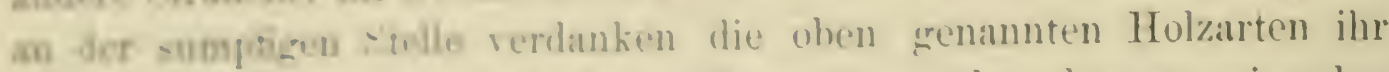
Dawno. indem sio in dem funlenden Moospolster. iiber dem starnirenden

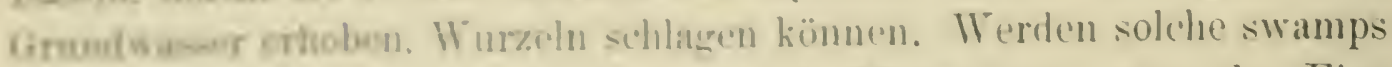

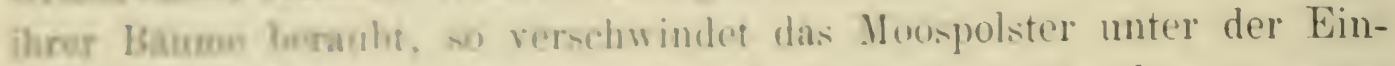

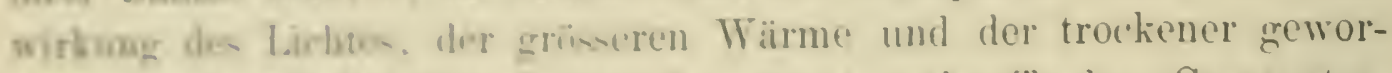
desew Iaft: liveliebonde sumpfptlanzen. Alundo, Typha. Carexarten,

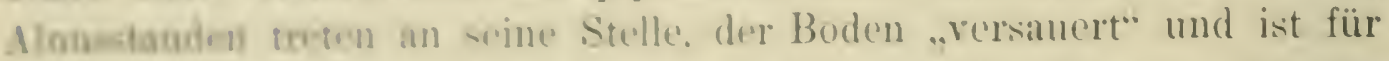
weurere Bromizung wordorhand untauglich gremacht. Schon jetzt weiss gar mavoler Burger in dies'n jungen staaten zu erzilhlen, dass dieser ader jenor jetze unpasirhar zewordene Sohilf- und Crassumpf einstens wot If abl, wom aurh geringwerthigem. hederelit war. Derartige Beob-

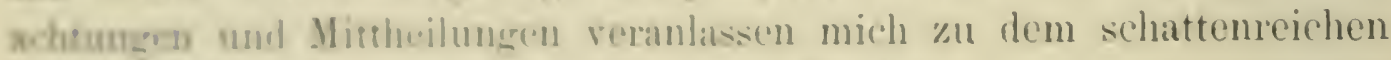
Takunftabilde diener raseh aufblülenden Staaten.

IVer woll liuropa kommt. wirl hesonders überrascht durch die

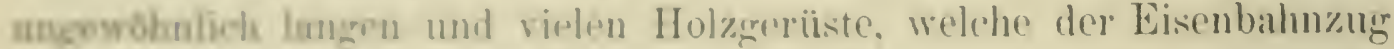

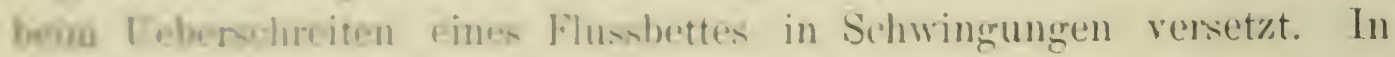

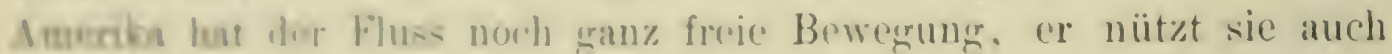
mandlinh aus: cin Jahr hieg. ein Jahr dort. Von hohen Bergen ans

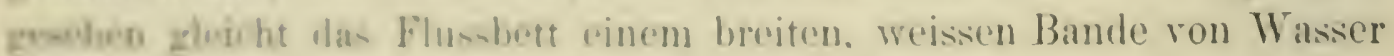

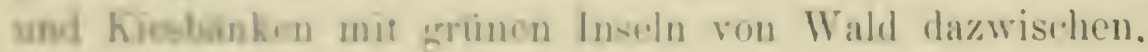

Lin Plowew sind ein zutes Mittel zur Beurtheilumg des Kulturzumeaboles dies Hinterlandes.

Hawes, die Jahr aus Jahr ein mit klarem Wasser in s Meer

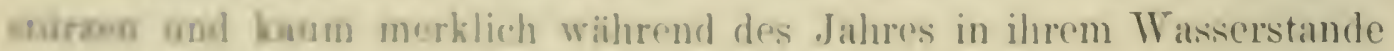
whwoblon, hommen uns ciner umberibrten Waldlandschaft, ihre Ufer

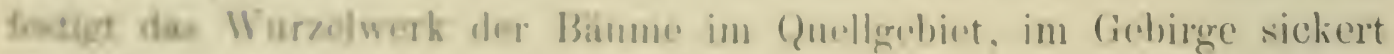

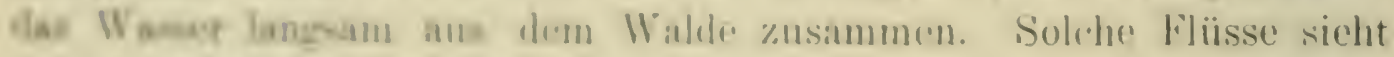

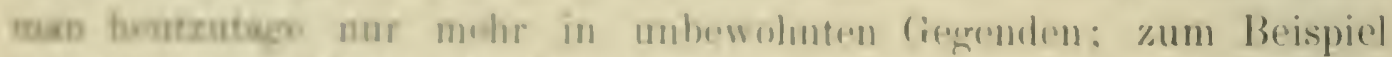

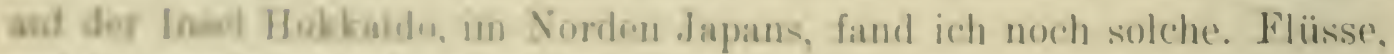

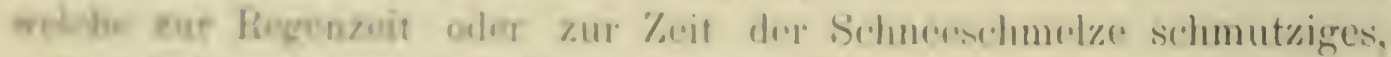

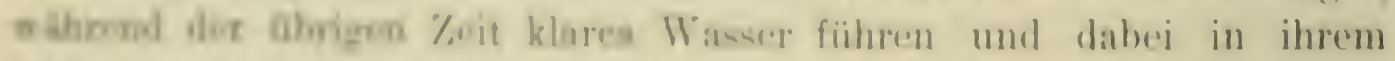

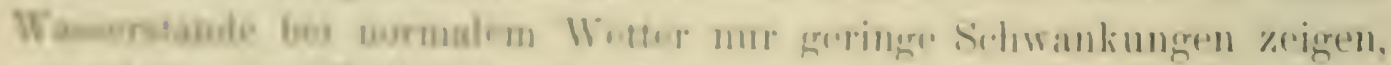

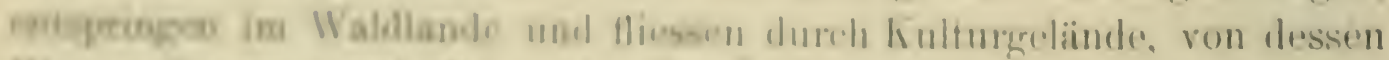

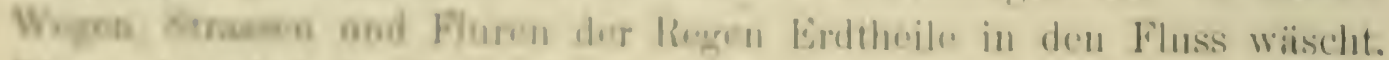

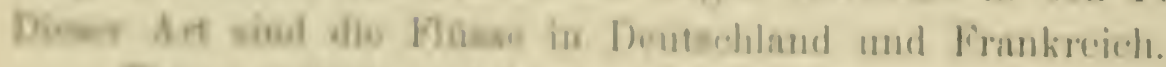

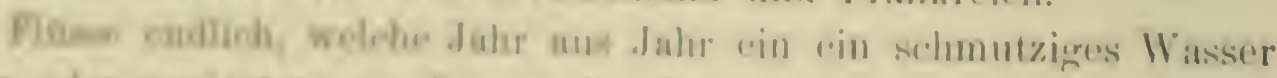

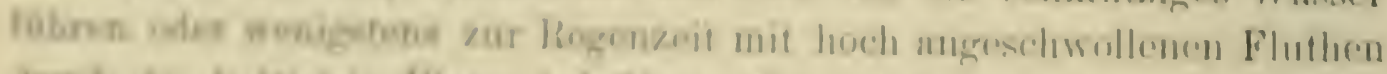

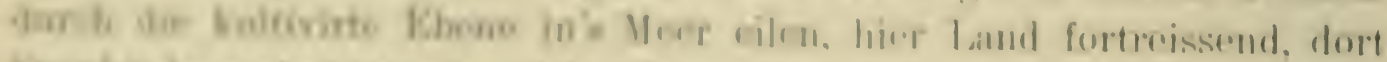

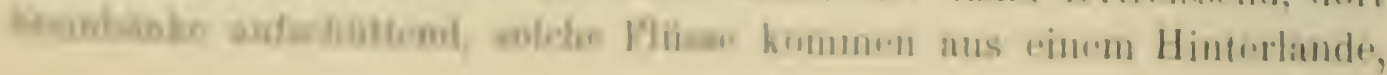


in dem Wald iiberhaupt fehlt oder die Entwaldung im vollsten Gange ist. Solche Flüsse sieht man z. B. in Ceylon, wo die Engländer mit ihren Thee-, Kaffee- und Cinchonapflanzungen die Vernichtung des Waldes und des Waldbodens in den Bergen begonnen haben; solche Flüsse sind zahlreich in Japan, Spanien, Nord-Italien; man fürchtet dort die Flüsse, sobald es einige Tage lang mehr als gewöhnlich regnet; die amerikanischen Flüsse nähern sich diesem Stadium. In ihrer Zügellosigkeit und Zerstörung des Ufergeländes, das in der Regel den vorzüglichsten Boden trägt, wetteifern sie unter sich. Es ist doch ein untrïgliches Zeichen, dass mit dem Flusse eine Veränderung stattgefunden haben muss, wenn er Ufer, die mit hundertjährigen Bäumen bedeckt sind, zur Regenzeit unterwühlt und allmählig mit den Stämmen in seine Fluthen reisst? Solche Beispiele sind in Amerika zahlreich und sprechen für jeden, der sehen kann und will, besser als alle Bücher über Einfluss der Entwaldung im Gebirge und der Ebene auf den Wasserstand der Flüsse.

Die Entwaldung in den Adirondacks durch Feuer und die nutzlosen Versuche, die Berge in landwirthschaftliche Kultur zu nehmen, rerursacht eine fühlbare Veränderung in dem Wasserstande des Hudson, der von der Bodenfeuchtigkeit der Adirondacks während der regenlosen Zeit gespeist wird. Früher war Peekskill am Hudson eine Wasserstation der New-York Central and Hudson R. R. R. Diese Station hat jetzt verlassen werden müssen, da die Salzfluth des Oceans während der trockenen Zeit weiter im Fluss aufwärts bis Tivoli dringt und Salzwasser zur Speisung der Lokomotiren unverwendbar ist.

Die amerikanischen Ingenieure kemnen offenbar die vor sich gehende Veränderung im Wasserspiegel der Flüsse genau, man sieht wenigstens in Amerika nur wenig Flusskorrektionen, die in der That nutzlose Geldvergeudung bleiben müssten, so lange die durchschnittliche Niveauhöhe der Hochwasser eine alljährlich steigende Grösse ist. Manche sehen der Entwaldung in den Bergen übrigens gleichgiltig zu, da sie den Wald in seiner wohlthätigen Wirkung durch einen grossartigen Plan ersetzen zu können glauben. Thre Idee ist, enorme Reservoirs während der Regenzeit mit Wasser füllen und den Inhalt derselben dann allmählig auf das Kulturgelände abfliessen zu lassen; nun zur Füllung eines solchen Reservoirs ist doch eine sehr beträchtliche Oberfläche nöthig, welche den Regen auffangen soll. Hoffentlich ist der Regen so gnädig, immer recht rücksichtsvoll zu Boden zu fallen, denn vesu ein Durchbruch des Reservoirs möchte schlimmere Folgen haben als ein Wolkenbruch. Mir scheint es etwas sicherer, wenn man mit dem 


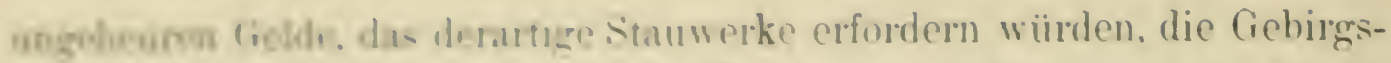
Landadiaton sufkanten und ihron $\mathbb{M a l d}$ als soldhen erhalten würde,

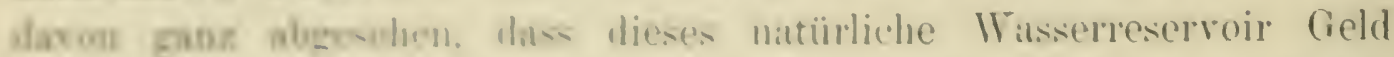

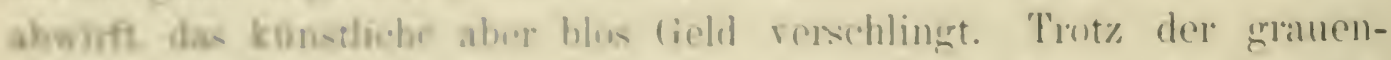

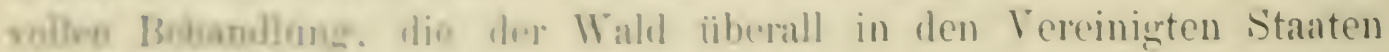

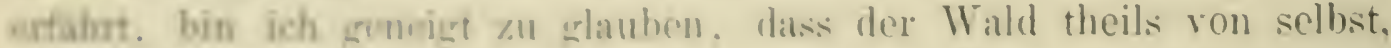

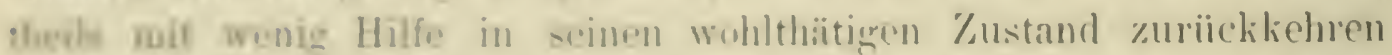

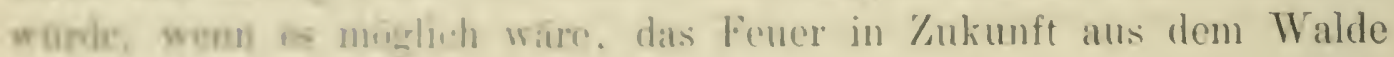
fers an halten.

The Foumbralir int in dem resitteten Theile Europats im Walde cinn selenteir grworden. zum mundesten eilt dann Alles zu Hilfe (der Sease kam zur Hilfolei-funer zwingen. Wie Norelamerilia!) um so rasch

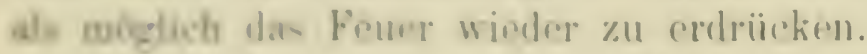

In Indion serringert sich. Dank der energischen Massmegreln der

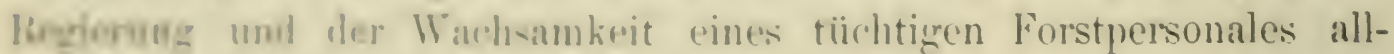

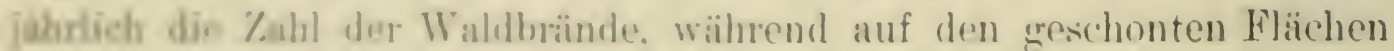
allerorts dir her: Jugond imporymiteist.

In Jepan. dom kloineren laude. haben Fenel und Axt ihren waldremirdinden Rundeang shon fast rollendet. Dic wackere Nation

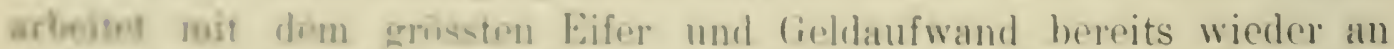

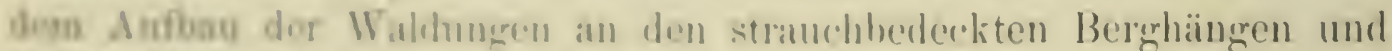
der Krhairoug do nod, Bestrolenden.

Io Sordamerika spockt dis Niederbrennen der Wäilder. anch das

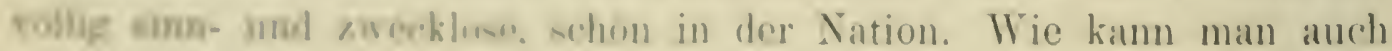
von dou Sachkumen riner Siltion, dio selbst keinen Wald hat und

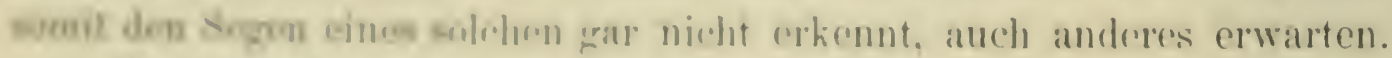

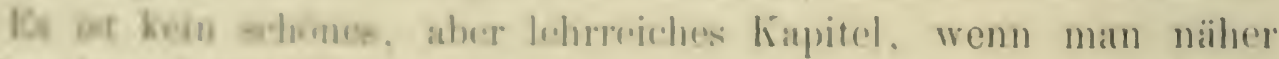

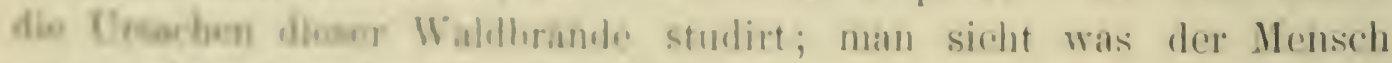
xuerger bringt m dom lamble mit dem lekannten weiten Ellenbogren-

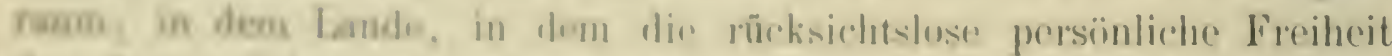

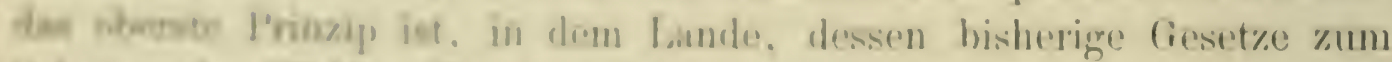
Whaser ares Waldre Hombug sind. da sie den Unverstindigen und

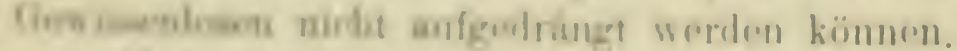

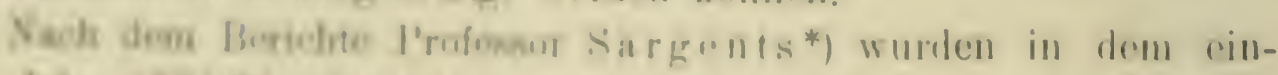

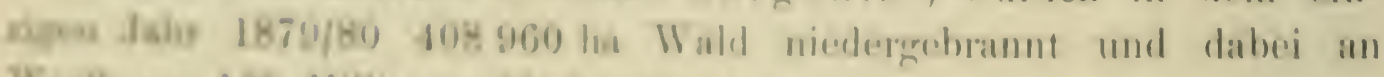

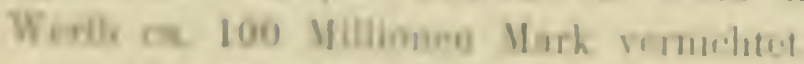

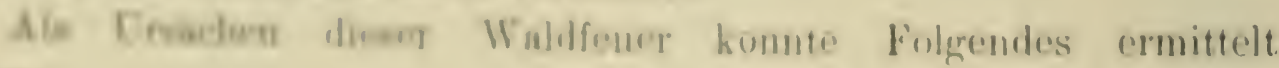
avritn 
Bei Verbesserung der Viehweide wurden 197 mal Waldfeuer verschuldet.

In 1152 Fällen lief das Feuer von der Rodung weg in den Wald über; die Funken der Lokomotive riefen 508 Fener hervor; Jäger inscenirten 628, im Walde Lagernde 72, Tabak-Rauchende 35 Waldfeuer; böser Wille zündete 262 mal an; 12 Präriefeuer griffen in den Wald über; 9 Feuer entstanden beim Kohlenbrennen, 32 mal zündete der Blitz, 56 mal steckten die Indianer, 10 mal die Holzagenten, 2 mal Reisende den Wald in Brand. In 2 Fällen soll der Wald sich selbst entzündet haben, 3 mal haben die Holzarbeiter und 3 mal unbekannte Sorglosigkeit Feuer angelegt; dieses macht die nette Summe von 2983 Fällen.

Allen voran will ich ein wenig bei der Gruppe Lokomotive, Jäger, Lagernde und Bosheit verweilen, die in 1470 Fällen Waldbrände verursacht haben.

Der Schaden, den die Eisenbahn dem Wald-Kapital zufügt, ist ganz bedeutend; wer heutzutage im amerikanischen Continent reist, muss sich an die Kohlensäulen zu beiden Seiten der Bahn gewöhnen, wenn er von der Schönheit der Landschaft einen Genuss haben will; von der Bahn aus haben die Fener unzähligemale meilenweit in den Wald eingegriffen. Auf den älteren Bahnen verringert sich die Feuer gefahr alljährlich durch das ständige Niederbrennen der Bäume auf den Lichtungen zu beiden Seiten der Bahn. Auf solchen holzleeren Lichtungen wäre es ein Leichtes, das Feuer durch einen Schutzgraben gegen den Wald hin zu isoliren. Ein anderes Mittel, als so bald wie möglich eine baumlose Lichtung herbeizuführen, scheint mir nicht zu bestehen; jedenfalls hilft es mehr als die Funkenfänger, die ein Gesetz vorschreibt; denn trotz aller Gesetze fahren die Lokomotiven ohne Fänger.

Ein schönes Product der schrankenlosen Freiheit des Einzelnen auf Kosten der Gesammtheit sind jene Fälle, in denen Jäger und im Wald lagernde Ausflügler oder Reisende Waldbrände verursachen. Im Jahre 1880 haben sie 700 Waldfeuer inscenirt.

So weit meine Erfahrungen im Westen Amerika's reichen, pflegen die Herren Jäger das sogenannte Underbrush, das Unterholz, das ist doch im Urwald die zukünftige Wald-Generation, niederzubrennen, um im Zielen weniger behindert zu sein. Anderswo werden die Wälder in Brand gesteckt, um das Wild nach bestimmten Regionen zusammenzutreiben - ein Commentar hiezu ist ganz unnöthig.

Bei den böswilligen Brandstiftungen will ich nicht länger verweilen; bezeichnend ist, dass Holzdiebe, besonders im Staatswalde, 
Fover an den Wald legen, um die spuren ihres Diebstahls zu rerwiechrus.

Mrit Beagg auf den Yollowntonne l'ark. dem zum Eigenthum der goven Sation erklartinn Wunderlande. sigert H. Winser*) in seinem Fuhrer for Reisende:

- bis ist sief zu beklagen, dass durch die surghlosigkeit der

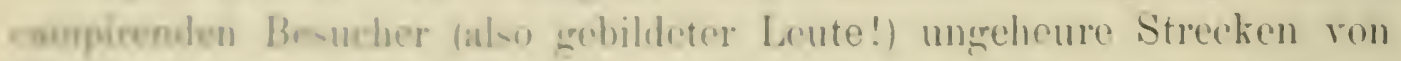
If addanal rerbrannt murlen. Dieses Fener entstand dadurch, dass man

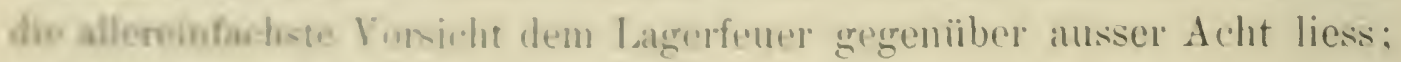
an Fulgu dmo'n ist es gar nicht selten, dass man im Parke Meilen und Ieaten woit zwinhen shwar\%n Baumstumpfen statt im erfrischenden Sifhatem do grimon Waldw roiten muss. Diesen sinnlosen Vernichtungen der Waldungen silte Wurrh strengre Bestrafung der Anstifter Einhalt esthat "wolen."

Es wrlangt ein (ieset\% dis Derjenigre. welcher ein Feuer verur-

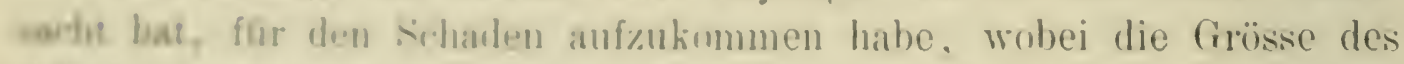

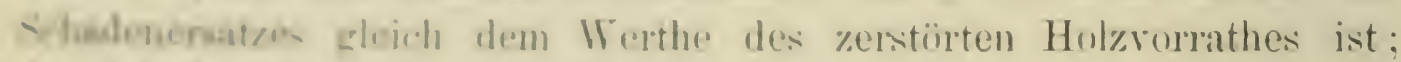
der Xchaden aber, der lem Wallı \%ugefügt wird, indem der öffentliche Glauke an fis subherheit des Waldeigenthums remichtet und von der

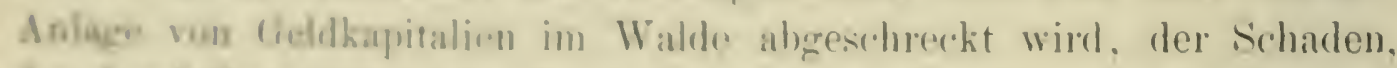

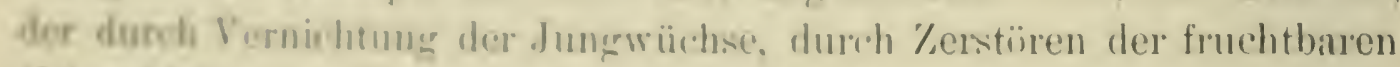

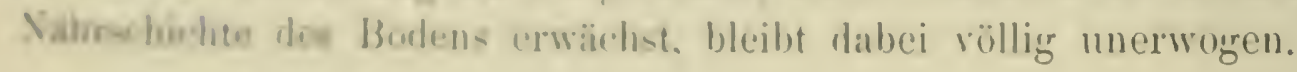

\section{Grösse und Vertheilung des Waldes.}

Ifan schamet die ge-ammente Waldfliache**) (das heisst alles Land,

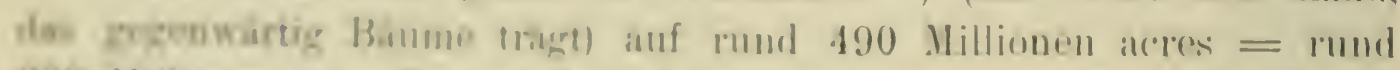

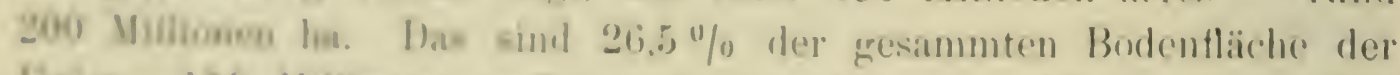
Chame; 160) Iftlionen treflion anf dire attantische Waldregrion. Fïr Surbamarika niat simen gronien klimatischen Versdiedenheiten hat

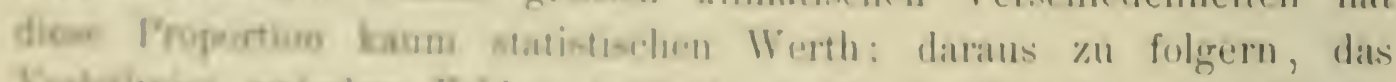

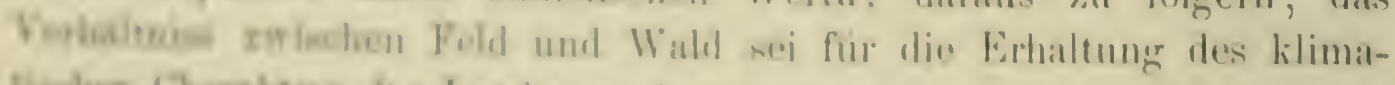

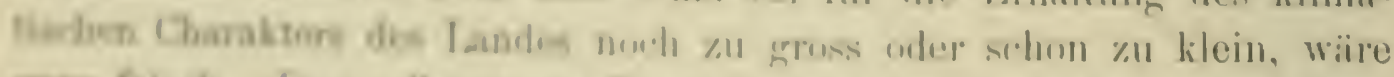

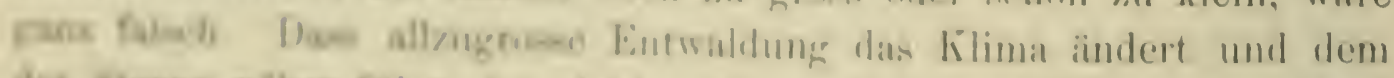

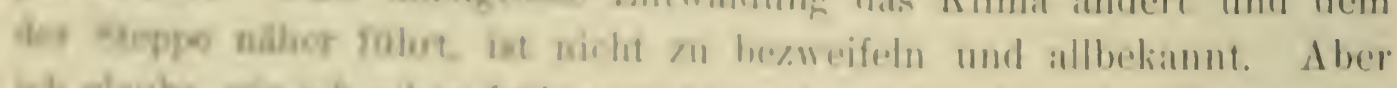

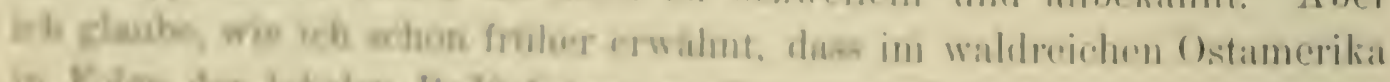

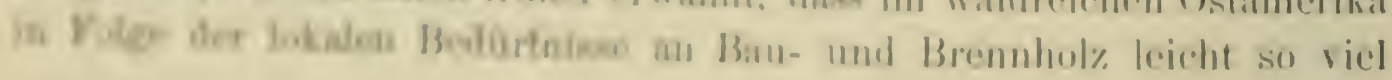

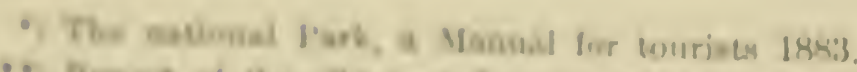

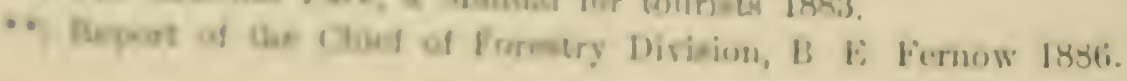


Wald und in solcher Vertheilung, theils neu angepflanzt, theils konservirt wird, als es zur Erhaltung des Klima's nöthig ist. Auf landwirthschaftlich dauernd benützbaren Böden braucht daher die Regierung: nicht zu einer Beschränkung der Benutzung des Waldeigenthums zu schreiten und es kann dort die Nation von dem so gefürchteten Gespenste befreit bleiben: in der Ebene, auf landwirthschaftlich benuitzbarem Terrain, mag es dem Einzelnen überlassen sein, die für ihn rortheilhafteste Benützungsweise zu wählen.

Von der obengenannten gesammiten Waldfläche sind 185,8 Millionen acres $=75$ Millionen ha, das heisst $38 \%$ in den Händen von Farmern, ein für die Zukunft des Landes höchst werthvolles Besitzthum, auch wenn dasselbe noch einige Jahrzehnte alle erdenklichen Misshandlungen durchzumachen hat.

Die Waldfläche, welche jetzt noch in den Händen der UnionsRegierung sich befindet, also gemeinsames Eigenthum des gesammiten Volkes ist, wird auf 73 Millionen acres $=29,5$ Millionen ha geschätzt. Sie liegen vorzugsweise im Westen und im Gebirge, und bringen der Regierung nicht einen Pfennig ein. Zum Ruin des Waldes und Waldbodens hat die Regierung zahlreiche Privilegien bewilligt, hat Servituten zum Besten ron Eisenbahnen, Corporationen, für den Bergbau, für Kohlenbrennerei, für den Hausgebrauch gegründet und alles dieses Angesichts der fieberhaften Anstrengungen der europäischen Staaten mit ihrer geordneten Waldwirthschaft, wie Deutschland, Frankreich, Italien, Oesterreich, die zur Rettung des Waldes mit schweren Geldopfern darnach trachten, die in früherer Zeit (eben auch zu Anfang der Entwickelung des Eigenthums) bestellten Servituten zurüickzukaufen. Wie es mit dem Walde der Regierung und der einzelnen Staaten bestellt ist, habe ich schon früher angedeutet; die Regierung will kein festes Eigenthum in den Händen behalten und so wird der Grundbesitz auch so schnell wie möglich zu Geld gemacht. Die Regierung will nur Land zu Vertheidigungszwecken behalten. Nun, ich denke die Erhaltung des Waldes im Gebirge ist auch eine Forderung zur Sicherheit und Wohlfahrt der Bürger und es ist auch eine Pflicht der Regierung, das Nationaleigenthum gegen innere Feinde zu vertheidigen und die Nation gegen den Unverstand und die Habsucht Einzelner zu schützen.

Der Rest von obiger Gesammtwaldfläche ist im Besitze von Holzhändlern und Sägmühlbesitzern und von Spekulanten. Diese Letztern sind nicht immer die Schlimmsten, wie man erwarten sollte. Ich habe mit Freude manchen Wald durchritten, den die Herren Speku- 
lanten als Crwalh ingretich hewachen, da sie die Zeit für die gewimnmidare Aunuzane nxeh nicht für gekommen erachten. Lommt diese

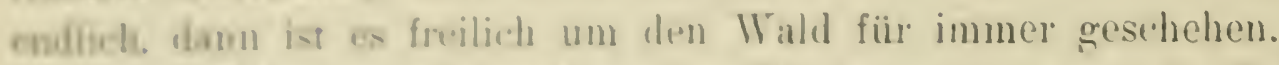

Der hwin zur Vernichtung des Waldes, auch wenn die Behand-

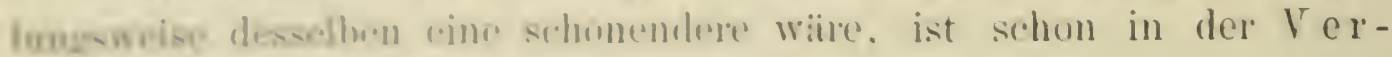
theiluag des Eigenthames gelegen.

Auf Gruml einer vortrefflidhen Vermessung ist das ganze Land in biner Qualnate grethrilt. diren kleinste Fläche, unter welcher kein Lami verkauft wiml $=40$ amerikanische acres $=16$ ha beträgt. 16 solnher Qundrato geben dann eine Sektion zu 640 acres; diese sind mummint und wrolen rom stante rerkatuft. Wobei ohne weitere Erwagung nach gradion oder ungeraten Kahlen rorgegangen wird; so glaubt die hegierung rinus Lindes zum Beispiel, alle Quadrate mit

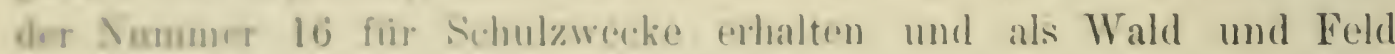
hesirelechufren zu künnon. Es ist winig Aussicht vorhanden, dass

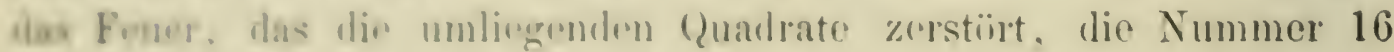
renortion wiml. Hier gilt der Satz: es kam der Frömmste nicht im Friedral beben. weon es dem büsen Nachbill nicht grefällt.

Diese An der Vertheilung des Waldeigenthumes in den Bergen sad auf nhaslumem Waldborten muss zur Vernichtung des Waldes faturn.

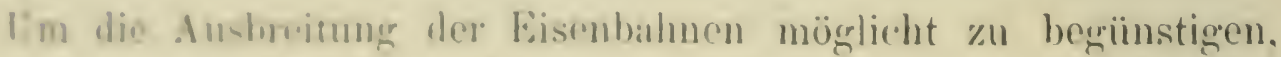

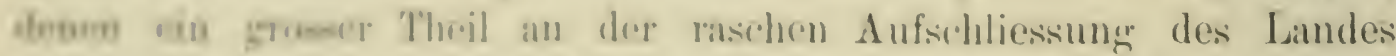
makoumt, bat det Cimpress, dis ist das loulk solbst, Ländereien an die

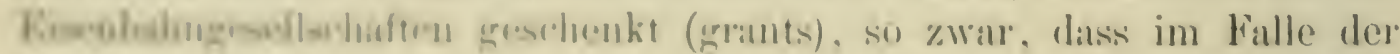
Erataung dor Babn bis zu ciner bestimmten Zeit der Eisenbahngesell-

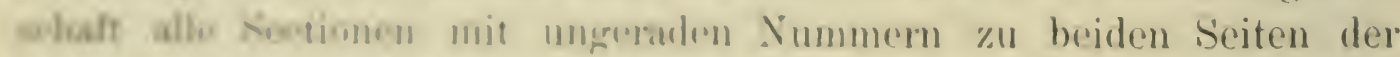
Hades, oft has zu 30 Mrilen lintfernmeg von deselben, zufallen. Nach

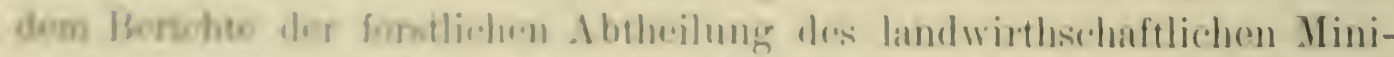

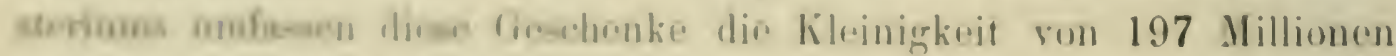
exes $=$ rand so dilliomen ha. Von dies'n sind rund 50 Millionen

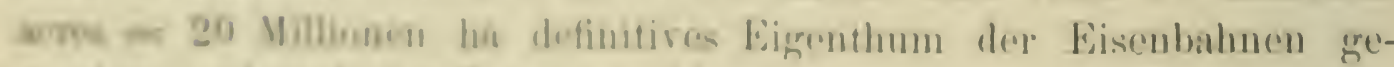

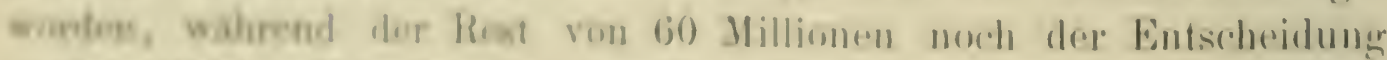

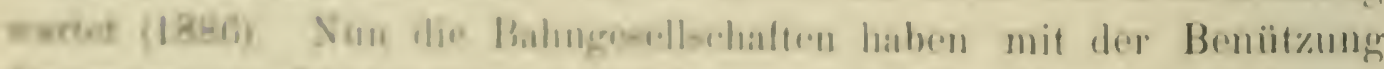

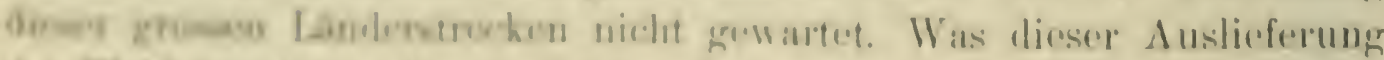

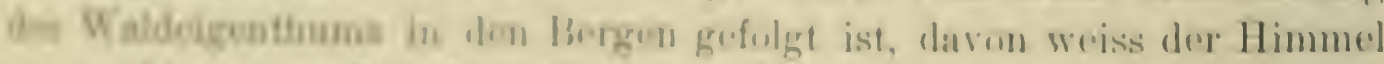

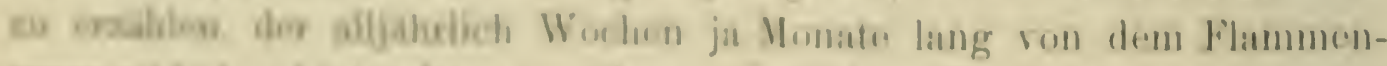

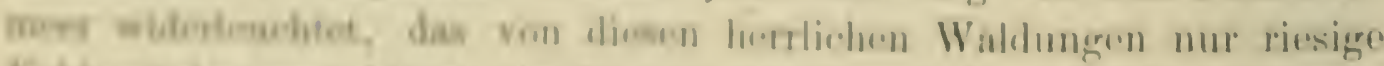

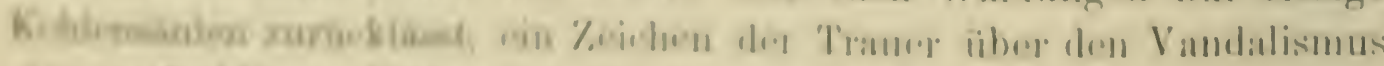

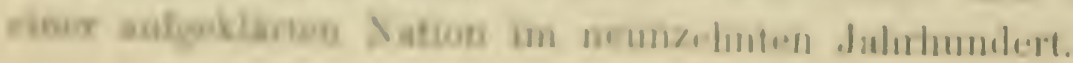


Ich sehe kein anderes Mittel, um den Wald da, wo es Noth thut, zu erhalten, als dass der Staat auf dem Wege des Tausches oder Rückkaufes die nöthigen Ländereien sich aneignet und sie so arrondirt, dass eine geregelte Wirthschaft in denselben möglich ist und die Aufstellung von Schutz- und Verwaltungsbeamten sich lohnt.

Dazu scheint mir ist die Regierung der einzelnen Staaten, die dem Arbeitsobjecte näher liegt, besser geeignet, als die Regierung des gesammten Landes, zumal wenn mehrere Grenzstaaten zu gemeinsamer Arbeit sich vereinigen.

Die Unionsregierung ist das äusserste Kleid des Volkes, das mehr dekorirt als erwärmt; näher steht dem Herzen des Volkes und seinen Leiden die Regierung des einzelnen Staates selbst; die Unionsregierung. mag die oberste Controle über die Handlungsweise der einzelnen Staatsregierungen in den Hünden behalten und die Gebiete bestimmen, deren Verwaltung durch den Staat wünschenswerth erscheint. Die Verwaltung selbst aber mag den einzelnen Regierungen überlassen bleiben. Natürlich würden in diesem Falle aụch die Ländereien der Unionsregierung, soweit sie zum obigen Zwecke nothwendig sind, den einzelnen Regierungen zufallen.

\section{Walderzeugnisse, deren Gewinnung und Austausch.}

Un den Holzhandel in den Vereinigten Staaten richtig beurtheilen zu können, muss man diese auf die gleiche Stufe mit Gesammteuropa stellen. Die Union der Staaten umfasst eine so gewaltige Landmasse, Klima, Boden und Waldregionen zeigen so grosse Verschiedenheiten, wie sie in Europa kaum rorhanden sind; hier unabsehbare Waldflächen, dort endlose Steppen, hier ewiger Frühling, dort sibirische Kälte oder tropische Hitze, hier Laubholzwaldungen ron den gewaltigsten Dimensionen der nützlichsten Bäume, ron grösster Artverschiedenheit, dort pfeilgerade, mehrhundertfüssige Nadelhölzer, eine Fülle Holzrorrath vollendetster. Qualität, die in dem Laien freilich den Eindruck der Unerschöpflichkeit hervorrufen muss. Die gesammte Union schützt sich gegen fremde Waaren überhaupt und so auch gegen das Eindringen von fremdländischen Hölzern durch Eingangszölle, deren Effect in Bezug auf Holz bis jetzt allerdings noch nicht recht sichtbar geworden ist; so besteht ein Eingangszoll für kanadische Holzwaaren ron 2 M 73 if per cbm, trotzdem gehen alljährlich circa 2 Jillionen cbm Nutz- 


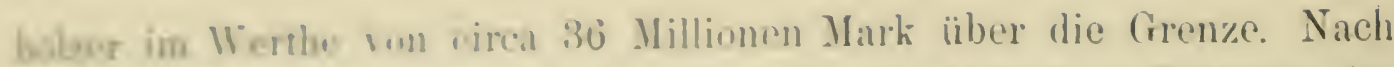
Inmen hermetht swiolien den ron cinander unabhängigen staaten, die

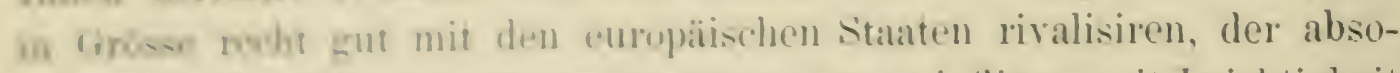
Jumete Iredhandis : ron der waldreichen Giegend tliesst mit Leichtigkeit

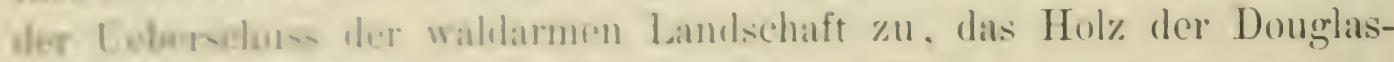
Tume, der wetlishn lielb-Kiefer, die im Washington-Territorry gevachecen stul. werden in groserer Menge im südlichen Californien vertaar: das Lồch wertholle Hol\% der südlichen Kiefer (fïlschlich in

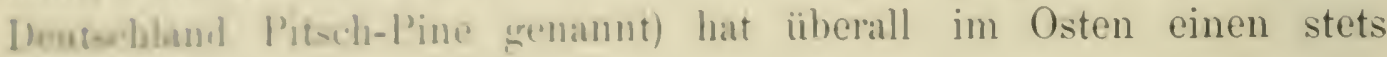
offenem Markt.

Warem die Fionbahnen in den Hinden der Gesammt-Union, so

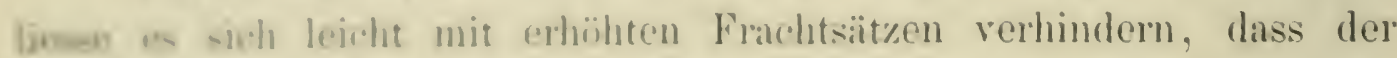
Bopern aus dem Waldlande, insbesonders ans Gebirgstertain, eine den

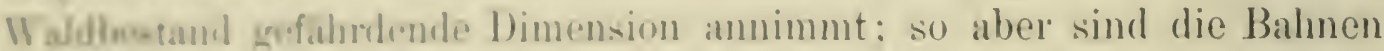
sâmmatich Privaruntronchunugren, die allein an möglichst grosse Rente deoken - pereat silvat. Umigrekehrt hahen die Bahmesesellschaften durch

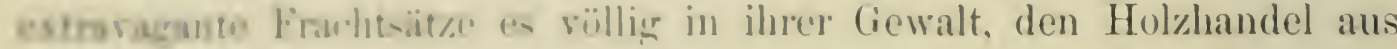
piner thnen unbequemenn Gegend, in der sie \%. B. kein Land besitzen, gais 24 untenlrivken, und diesen in ilı (iebiet cinzuleiten. Man kann

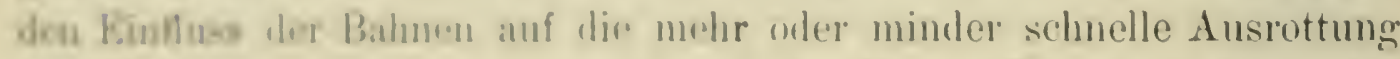
der Walduneron volstehen, wemn man die Menge [Lo]\% betrachtet, die

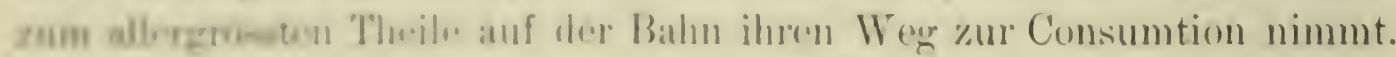

Jor sulwefpunki der gesimmten Holzindustrie liegrt gregrenwïrtig

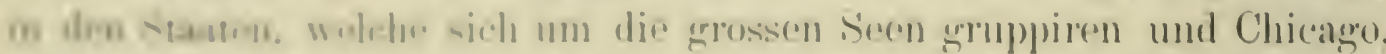

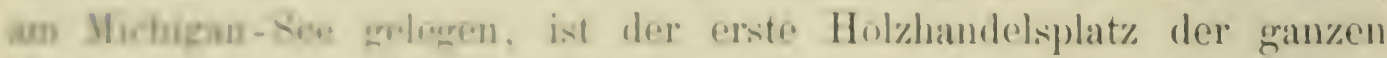

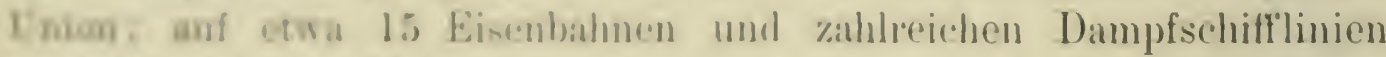

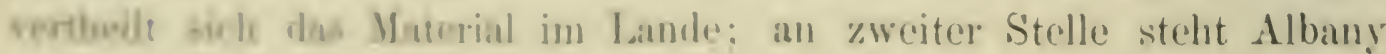
im thate Now-Yiorh, wroniger durch die Menge des Holzes, welches

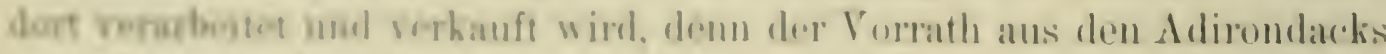

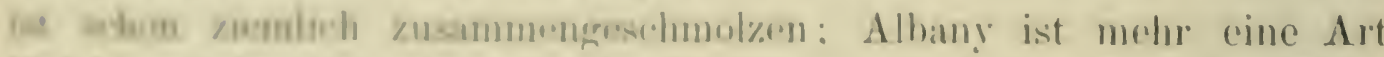

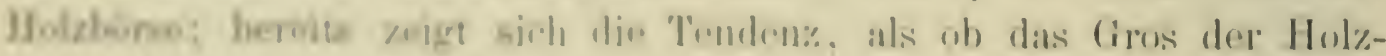

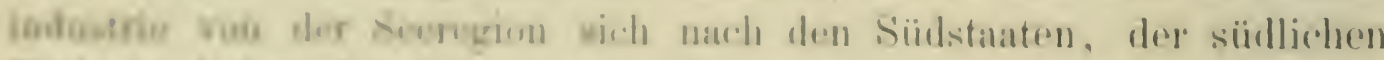

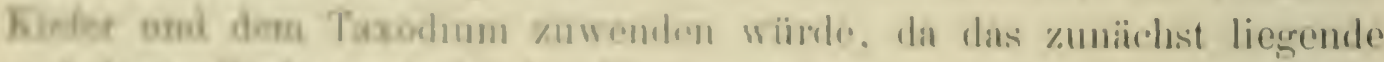

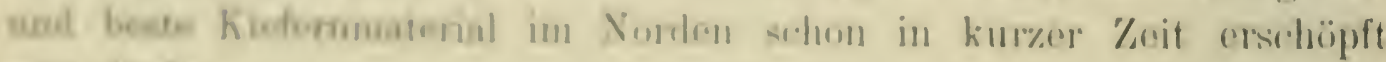
nii thedos

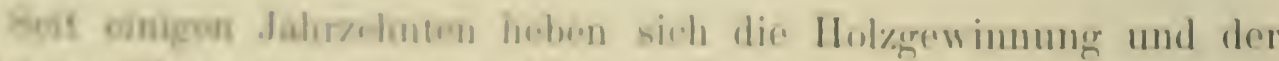

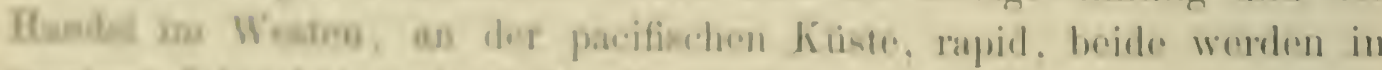

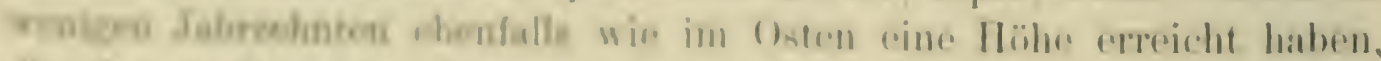

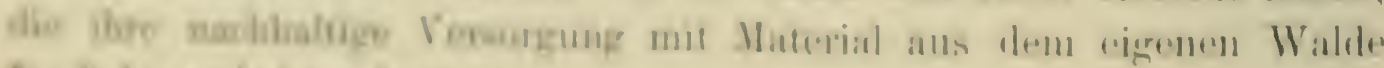
freclich stedieinem laser o. 


\section{a) Grossnutzholz.}

Nach dem schon öfters erwähnten Governments-Reporte pro 1886 beziffert sich der Terbrauch an Nutzhol\% in der östlichen Hälfte der Vereinigten Staaten auf rund 50,8 Millionen cbm, welche ron 430 Millionen acres $=175$ Millionen ha geerntet wurden, das sind $0.3 \mathrm{cbm}$ Holz pro ha; in Westen darf man die Nutzholzausbente in diesem Jahre auf etwa 50 Millionen cbm schätzen, welche ron etwa 60 Millionen acres $=25$ Millionen ha, das ist nur $0,2 \mathrm{cbm}$ pro ha genommen wurden. Dieses Material wird fast ausschliesslich auf Sägmühlen verarbeitet und zwar grösstentheils durch Kreissägen in Balken, Bretter, Latten und dergleichen zerschnitten. Im Censusjahre 1879-1880 waren nach Sargent*) 25708 Sägmühlen thätig; sie lieferten für den Markt $42 \frac{1}{2}$ Millionen cbm in Brettern und 1760 Millionen Strick Latten; der Werth der Nutzstämme, loco Sägmühle, betrug r'und 140 Millionen $\mathbf{S}$, der Werth des ron den Sägmühlen abgelieferten Materials war 182 Millionen $\mathbf{\$}$; der Werth pro cbm Schnittwaare belief sich somit auf $4,33 \mathrm{~S}=18,19 \mathcal{M}$.

Das Geld-Kapital, das bei der Schnittnutzholzerzeugung damals angelegt war, betrug rund 181,2 Millionen S, an Lohn wurden rund 31,8 Millionen ausbezahlt, bleibt bei einem Brutto-Einkommen ron 42 Millionen $\$$ eine Verzinsung des Anlagekapitals ron nur 5\%, womit kaum die jährliche Abnutzungsquote gedeckt werden kann.

Die Sägmühlenbesitzer sind aber in der Regel auch die Besitzer ausgezeichneter Waldflächen, in denen sie ihre Mühlen etabliren und die sie theils rom Staate, theils ron Privaten und Gesellschaften auf Spekulation hin um einen Spottpreis kauften oder im Wege anderweitiger oft sehr eigenthümlicher Manipulationen in ihre Hände bekamen. Der Kaufpreis ist in der Regel nur ein verschwindender Bruchtheil rom Werthe des Holzes; im Westen ïberlässt Mancher dem Sägmühlenunternelmer die Nutzung des Waldes um 2-3 S den acre, rund um $20 \mathcal{M}$ das ha: man kann somit von dem Werth obiger Sägblöcher: mit 140 Millionen $\$$ getrost 70 Millionen $\mathbf{S}$ dem Einkommen der Sägmïhlbesitzer hinzuzählen; dadurch erhöht sich ihre jührliche Bruttorente auf 80,2 Millionen und ihr Anlagekapital rerzinst sich mit circa 44\%. Trotz aller gegentheiligen Tersicherung der Betheiligten dürfte diese Berechnung hinter der Wahrheit nicht sonderlich weit zurückbleiben. So kann man sich nicht wundern, wenn der lumber-man wie der Eisen-

*) 1. c. Seite 486 . 
tahnkoniz in dir Rezed Millimen „worth" ist. Nun, wer bezahlt diesen

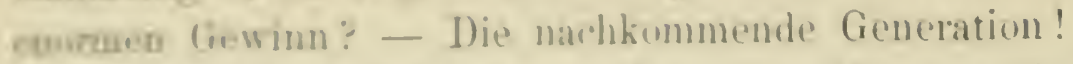

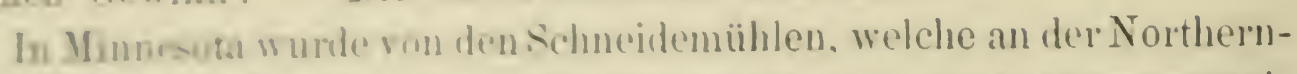

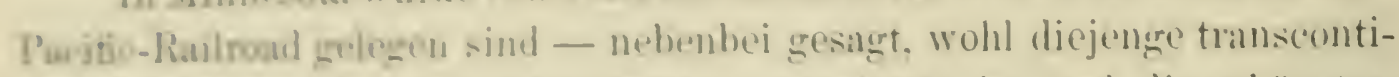
ucutal Balen. Welche am ologantesten ansegestattet ist und die selönsten

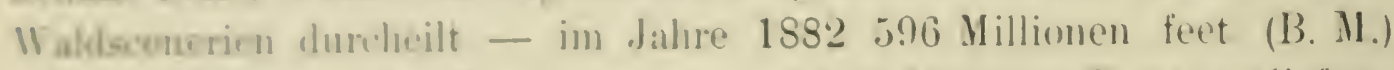
wher 1.4 Mallionen don Bretrematren und 105 Jillimen Latten gediefort.

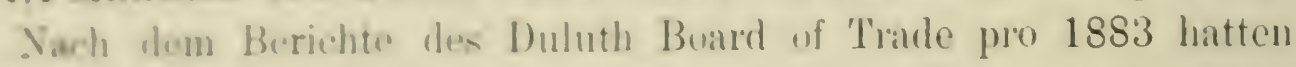

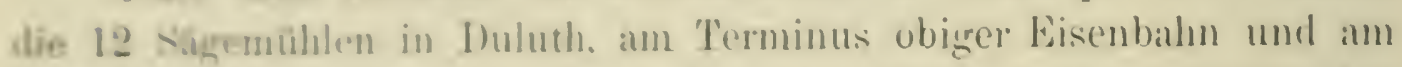

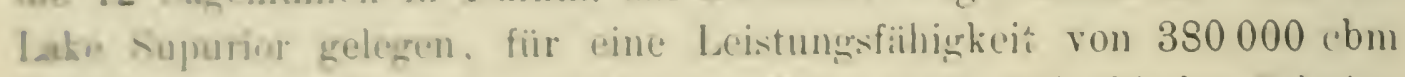

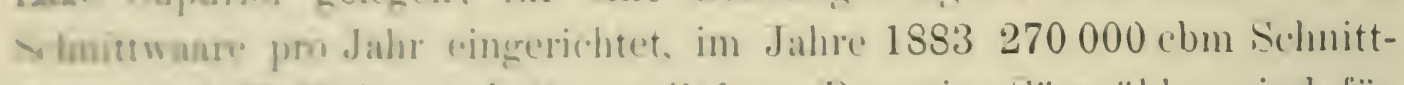

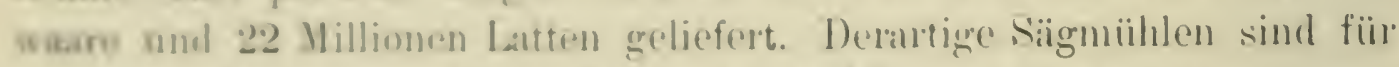

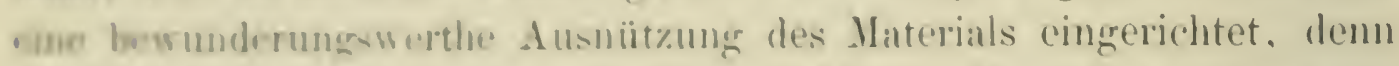
das Mnerial wirl sofort wertholl, sobald dro Mrosch an ilm cine Arbeit \& B. Fallume serrichtet hat.

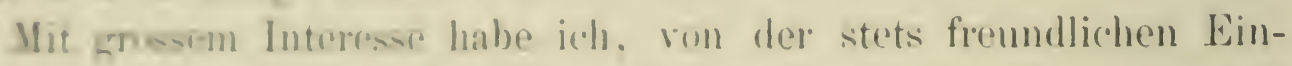

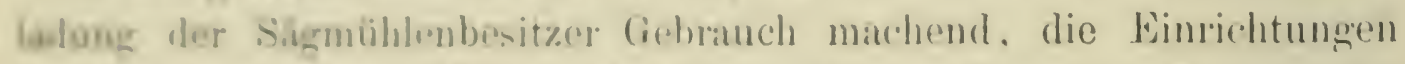
ear manchur grosson Miilhe hetrachtet: ich owithme zum Beispice dir sarworko dor lomber and Boom Co. ron C'hippewa-Fall. Besintes

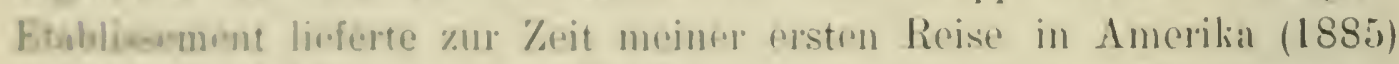

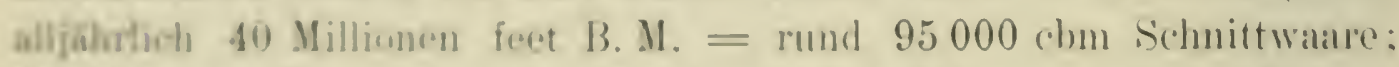

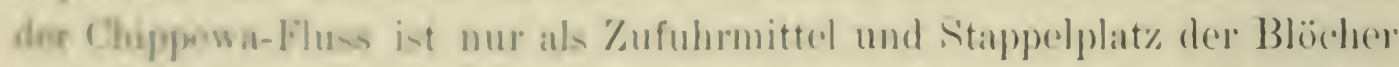
benatze dir son dem waldreichen nërdlichen Wisconsin herabkommen.

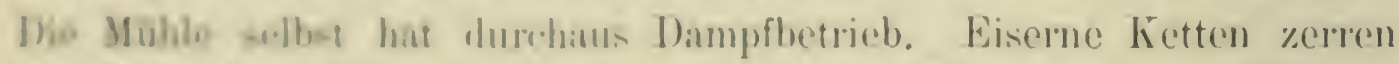

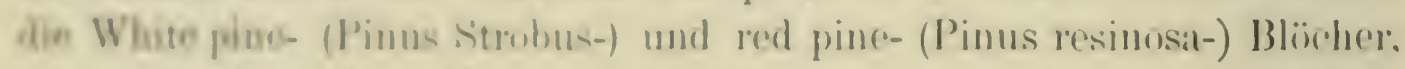

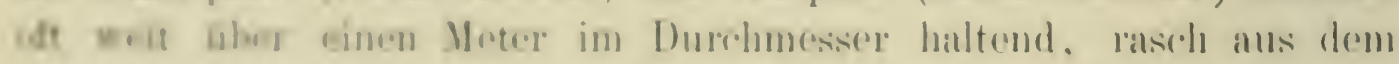
Wower; kinu in dor Mbilile angrolangt, beginnt so ein Monstrum \%u

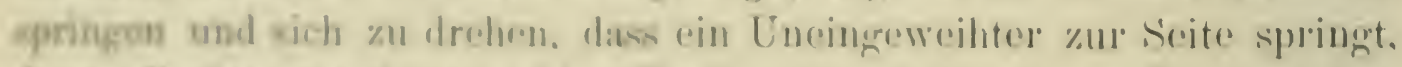

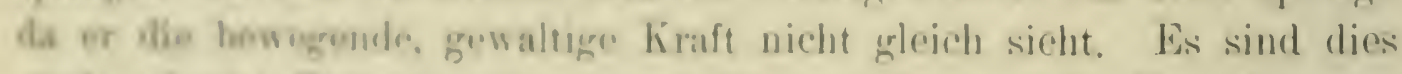

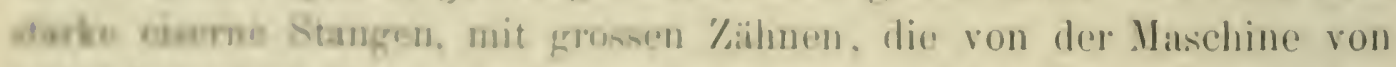

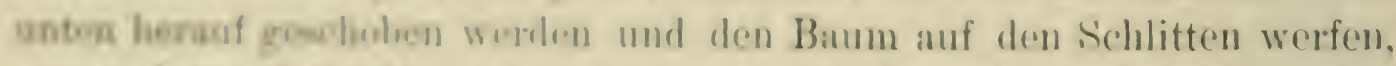

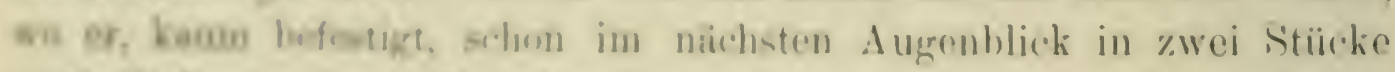

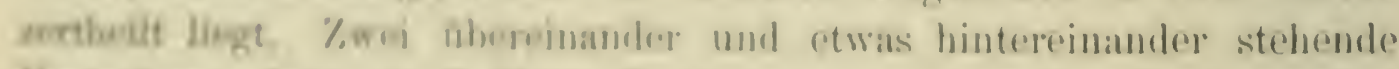

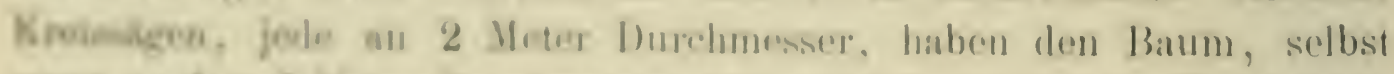

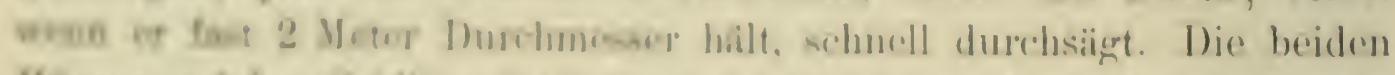

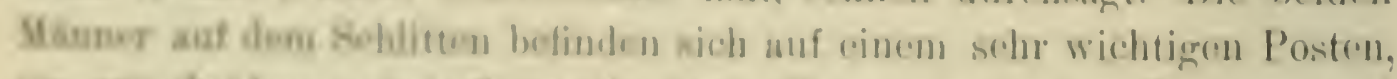

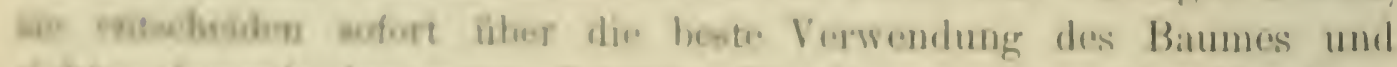

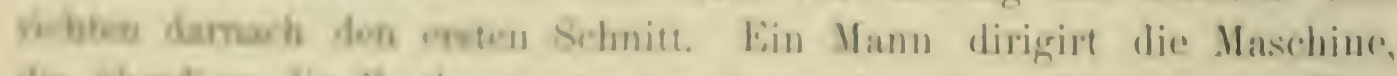

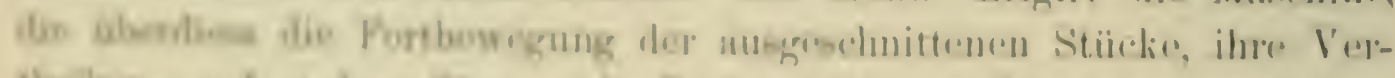

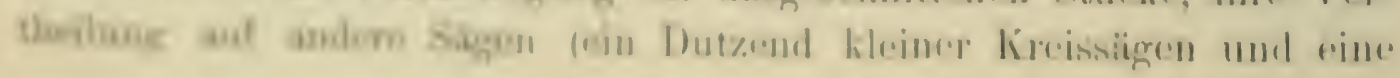


Anzahl Vollgattersägen) zur weiteren Verarbeitung besorgt. Die fertige Waare wird auf Rollen auf Wagen geschoben, welche eine kleine Lokomotive weiter zur Station schafft; Abfälle von guten Stücken wandern nach unten zu einer Maschine, welche Excelsior, Holzfäden als Packmaterial, bereitet; Abfallstücke, aus denen gar nichts mehr gefertigt werden kann, gehen in kleinen Rollwägen von der Mühle nach einem ansteigenden Gerüste, ïber das hinaus die Schienen noch verlängert sind: dort fällt das Material dann in die Tiefe, auf einen Tag und Nacht hoch auflodernden Scheiterhaufen; in der Nähe entstehen ganz respektable Berge aus Sägmehl.

Kaum umfasst eine neue Ansiedlung ein paar Häuser und ist Zuzug ron neuen Einwanderern, der Bau mehrerer Kirchen, eines Schulhauses, eines Theaters zu erwarten, so etablirt sich sofort eine Dampfsägmiüle einfachster Construktion, die den nöthigen Nutzholzbedarf zurecht schneidet.

Als wir Oktober 1887 den Gipfel des 6500' hohen Roan Mountain in den Alleghanies erklommen hatten, waren wir nicht wenig überrascht, oben ein grosses Hotel, ganz aus Tannenholz erbaut, zu finden. Zur Construktion dieses Hotels allein hatte es sich gelohnt in unmittelbarer Nähe des Berggipfels, mitten unter den Tannenbeständen (Abies Fraseri), eine Sägmühle zu errichten; jetzt ist das Hotel ausgebaut, die Mühle verlassen, die wichtigeren Eisentheile hat man wieder den Berg hinabgetragen, alles Uebrige aber ist dem Verfalle preisgegeben.

Die älteren Sägmühlen im Osten erhalten ihren alljährlichen Bedarf meist auf den Flüssen zugebracht, auf denen die Blöcher aus dem Hinterlande ungebunden heranschwimmen. Die Umgebung auf vielen Meilen im Umkreise ist in der Regel schon lange Zeit des rentablen Nutzholzes entblösst, nur wenige krüppelige, knorrige, angebrannte Zeugen der ursprünglichen Vegetation haben sich erhalten. Die aufspriessende Jugend in dem ausgenützten Gebiete ist nie geschlossen, sondern die Bäume weit isolirt und astreich, und zuweilen sieht man schöne Gruppen dichter Jungwïchse; Fener und Axt bearbeiten sie alljährlich, so dass es Wunder nimmt, wie überhaupt noch etwas Brennbares sich erhalten kann. Man braucht selten nach dem Wege zur Sägmühle zu fragen, Kohlensäulen leiten einen sicher zur Stelle hin, Kohlensäulen und schwarz gebrannte Erde umgeben das Etablissement; die Axt, die das Material fällt, lenkt kein anderer Gedanke als der des Gewinnes; was sie dabei rerschmäht, rerzehrt das Feuer: zuweilen sieht man rothe Plakate, die das Anlegen ron Feuer so und so schwer bestrafen, einen Erfolg daron habe ich aber nirgends entdecken können. 


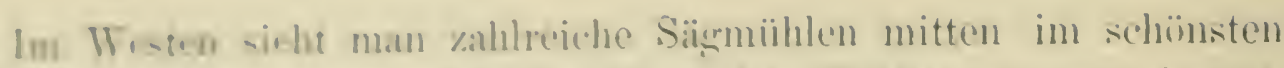
Sursuable tablint. Was immer den Ruin des Waldes mit sich bringt,

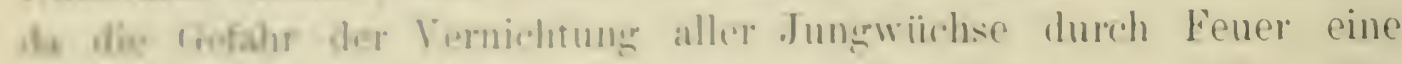
teerig demberade und leviler anch stets sich erfüllende ist. Nichts hat when we betrubendon lindruck in mir hintertasien als die Arbeit einer

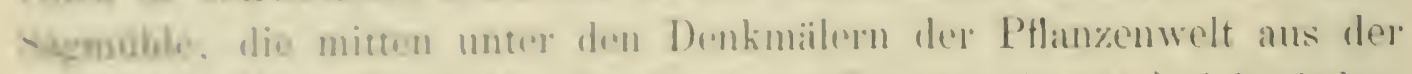

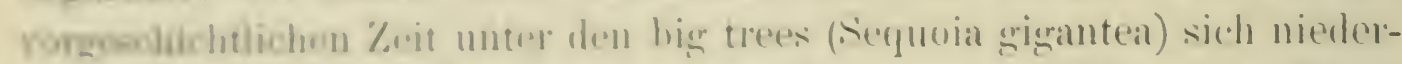

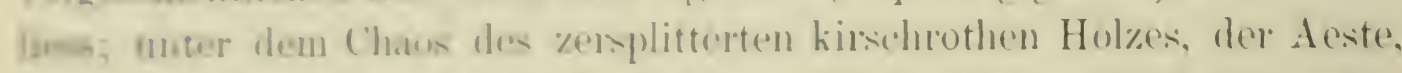

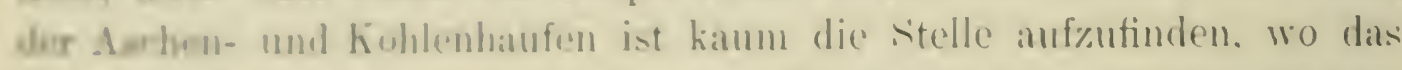

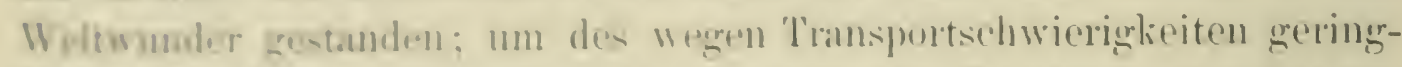

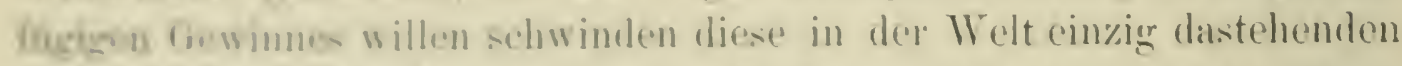
Hame dukin; jedor County in der siertal sollte sich ein palar Haine

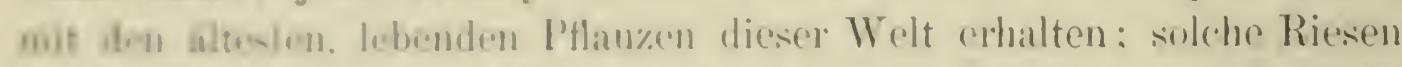
an der lirouse und im Alter werden wohl nie wieder erwaldsen, da laean ein \%eiraum ron mindestens 2000 Jahren erforderlich ist.

Die Holzmasse dieser Riesen erseheint seradezn unghanblirh:

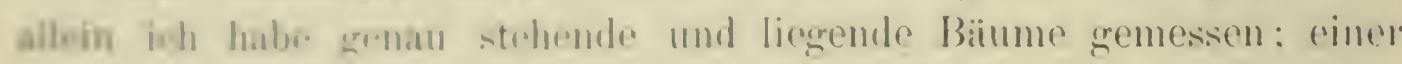

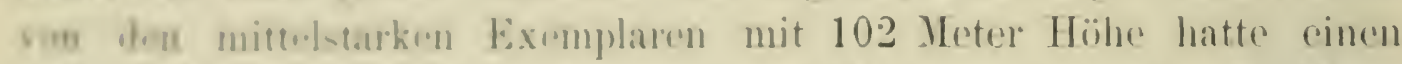

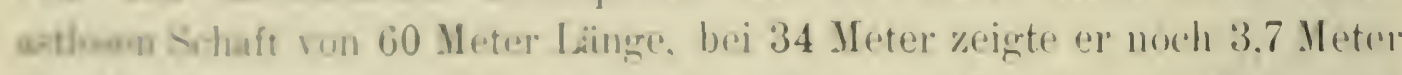
Jumburser mut der Rinde; dies giht einen Inhalt ron Hol\% und Kinde rou 822, bm. das ist so riel Hol\% in oinem Banm, als

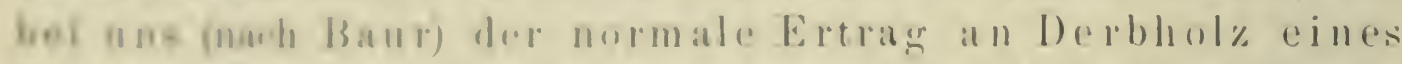
Piedatenbestandes mit 95 Jahren anf 1 ha I. Budenbonitiit beträgt.

Bei vinet wohlberochtigten Innahme von einem durchselunittliden

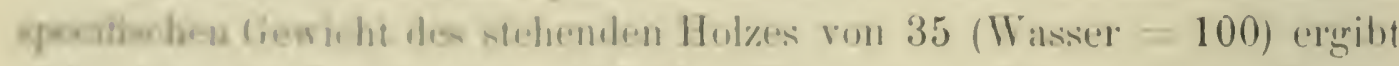

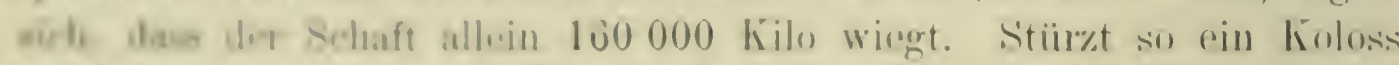

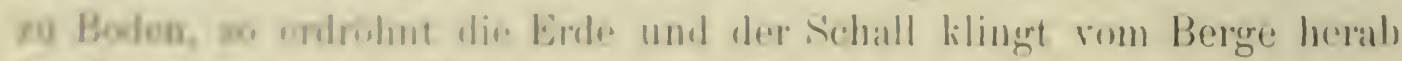

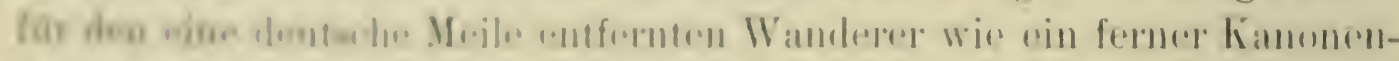

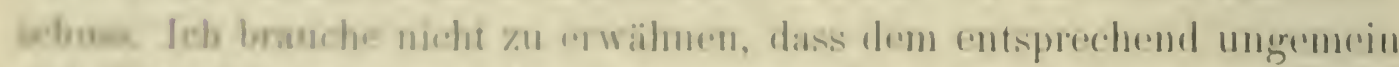

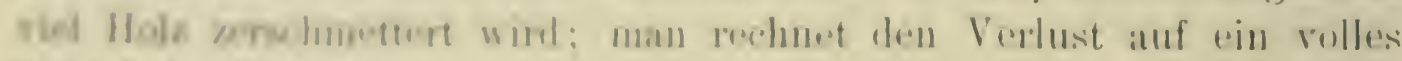
Dinited des Bfoume.

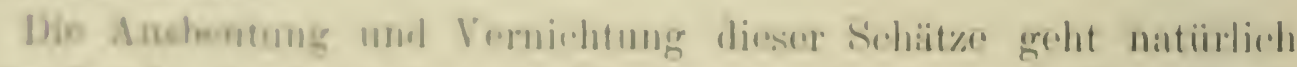

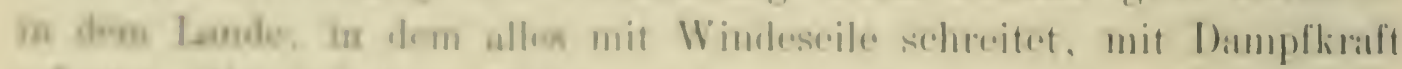

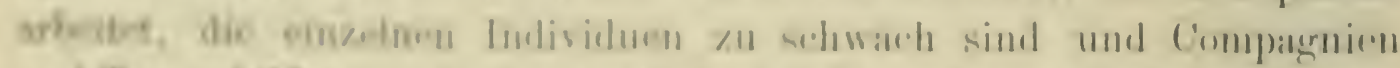

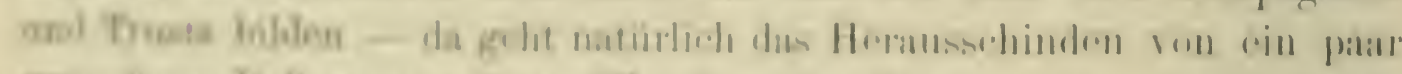

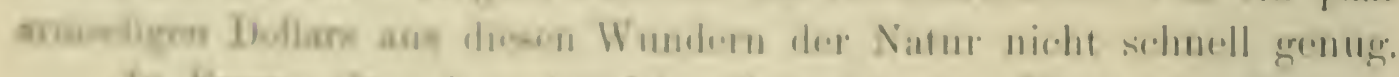

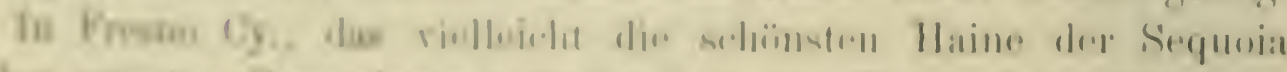

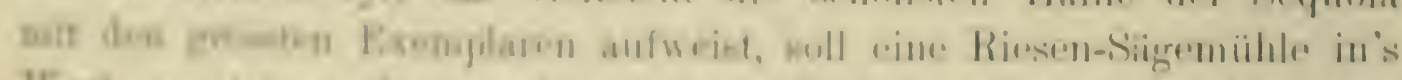

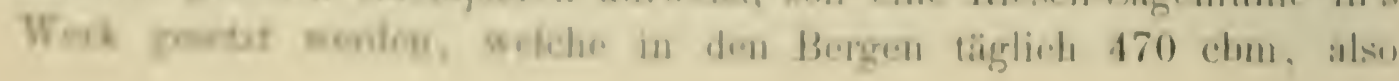


jährlich etwa $170000 \mathrm{cbm}$ Bretterware aussägen wird; diese sollen mit Hilfe einer Wasserriese in das Thal geschafft werden; die Länge dieser Riese würde $; 0$ englische Meilen betragen und zu ihrer Construction die Kleinigkeit ron 33000 cbm Holz erfordern. Ton dem Ende der Wasserriese bis zur Stadt Fresno wird eine Eisenbahn das Holz bringen. Das grob zerschnittene Material endlich wird durch zahlreiche Hobel- und Lattenschneide-Mühlen zerkleinert werden, wie es eben für den Bau der Holzhäuser in Amerika nothwendig ist. Das Project grüundet sich auf folgende Schätzungen.

In den Bergen, in denen die Sägemühle errichtet werden soll, stchen 1 Billion 200 Millionen! B. M. = 2350 Millionen cbm Nutzholz, ron denen 2 Millionen cbm der Sequoia gigantea angehören.

Fresno County hat die grössten Seyuoia-Haine, die zusammen 3600 acres umfassen, rund 1460 ha, das heisst auf einem ha stehen 1440 cbm Holzmasse, was gewiss viel zu niedrig ist, denn auf einem ha stehen durchschnittlich 10 solcher Riesen à $500 \mathrm{cbm}=5000 \mathrm{cbm}$; dazu muss man noch 1000 cbm Tannen und Kiefern zählen, gibt einen Ertrag ron 6000 cbm pro ha im Durchschnitt.

Die Flächenschätzung mit 3600 acre erscheint dagegen zu hoch. Das Anlagekapital für dieses Unternehmen ist auf 9 Millionen M. reranschlagt. Dass dies den Ruin des Waldes bedeutet, ist für den, der die amerikanische Methode kennt, absolut sicher und dieser ganze Wald. dessen Billionenbetrag wohl um einige Nullen verringert werden muss. un von dem Vorrathe eine der Wahrheit näher kommende Vorstellung zu gewinnen, steckt im Gebirge auf absolutem Waldboden, ist das Wasserreservoir für den betreffenden County. Hier sollte der Staat mit einem energischen hands off dazwischen treten, um Ebene und Gebirg der Vernichtung durch gewissenlose Spekulanten zu entreissen. Wie leicht und billig wäre es für den Staat, diese Schutzwaldungen sich anzueignen und schonend zu erhalten durch Ablösung - um den Selbstkostenpreis der Eigenthümer; nur so wird auch der der kommenden Generation gebührende Antheil an der kostbaren und kostenlosen Gabe der Natur gesichert.

Nun, mir war das Glück beschieden, noch vor Inscenirung dieser Schlächterei den herrlichen Wald zu bewundern, die frische, kühle, reine Luft dieser Gebirge zu athmen, an den wasserreichen, klaren Bächen mich zu laben; der Eindruck für mich war überwältigend und erfüllt mich noch heute durch das Grosse, das die Natur dort in mehrtausendjähriger Ruhe aufgebaut hat; wie bald wird alles das auf ewig verdorben sein! 


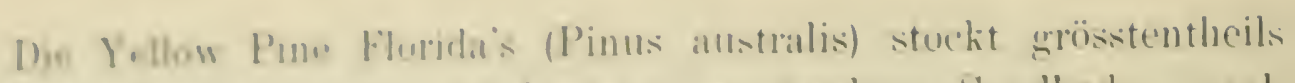

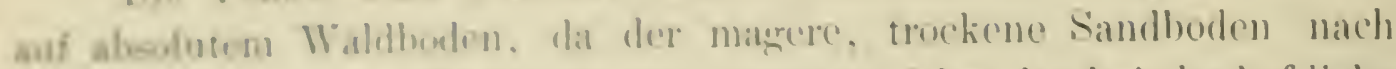
der Vomirhtung des Walde's kaum ein patar Jahre landwirthschaftliche firnten ahwirft. Die istliche Riesen-Ceder (Thaxodium distichum) tindet thre wahro Heimat in dem sumptigen, mehrmals im Jahre ïbersdismmpen Turrain immerhalb des Verbreitungsigebietes obiger Kiefer and hat sieh dadurch gegen die grössten Feinde des Waldes. Fener woul Jenwh, noch zu shiitzen rermocht: jetzt hat unter andern amarikaniwhen fiechlochaften anch cinc englische ungehemre Strecken Landion aufgrkauft. epablirt Riesen-S̈̈gemühlen und Kiefer und Ceder merden reschwinden in kïrmester \%eit; und die Amerikaner bieten

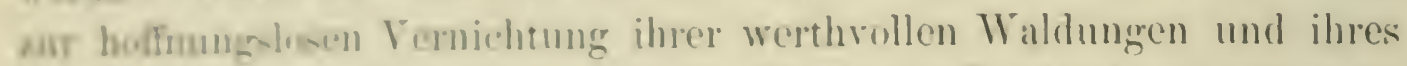
Landis um einen Judistohn noch die Hand: die Engländer haben ganz moht: was himmert os sir. wenn ihr jetziges Eigenthum in Amerika spaser eimmal nur Flugsand und Wasscepfützen produzirt!

\section{b) Eisenbahnhölzer.}

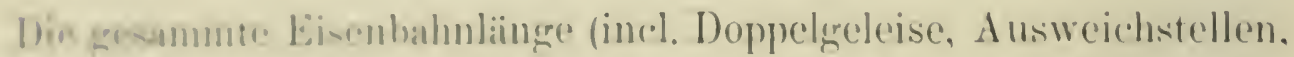

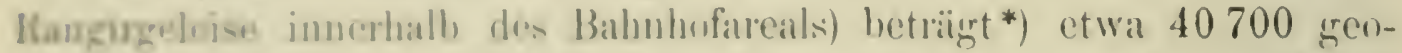
zrophumbe Meilen: boi 12140 schwellen anf eine geographische Meile fdie Sehwoflon in den Vorunigten Stanten sind viel kleiner als bei uns wad nar 1/2 Jieter ron einander entfernt, mojstens ganz schwach im Boden nugobetter) argiht sich. ditas 495 Millionen sohwellen a 0.085 (bun a 42.07 Millions dim Hal\% verwondet sind.

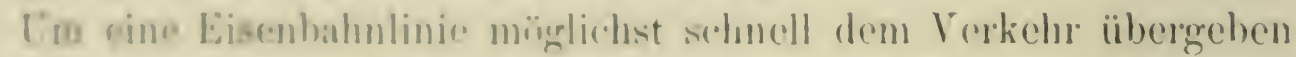
zu bonnen. werden vorliutig alle Hochbauten, wie Brürken, Viadukte,

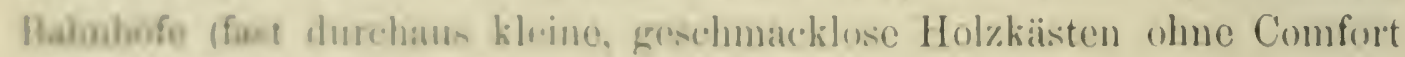
aned Rerislichkent!) ans Huls, hergestellt.

Dazil kommen in rumpfigen Gegenden, besinders im sïden des Landes, weslonlango Holyorerïste; Fachleute schitzen den Holzbedarf lar dieen Batuten auf 260 chm pro geographische Meile: dies gribt für die greanomere Buhngelojelanger noch rund 10,5 Millionen chm, womit

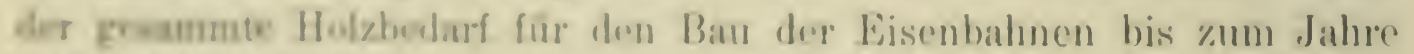

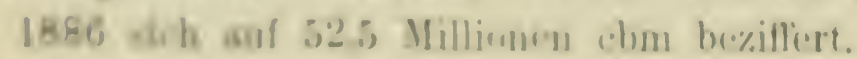

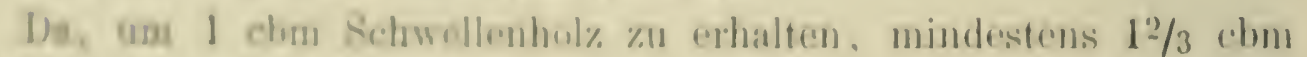
Bundhofr novelig wiml, on fulgr weiter, dass das im Jahre 1886 in der

- The relesion of Railrmale tos forret supplion and forestry, hy. M. G. K ern,

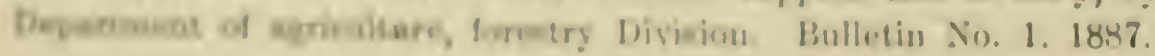


Erde liegende sowie zu Brücken und so weiter verwendete Holz aus 89,2 Millionen cbm Rundholz hergestellt wurde.

Die gesammite Zahl der Telegraphenpfosten, welche die Geleise auf eine Länge von 30000 geographische Meilen begleiten, betrug 1886 rund 5 Millionen, à $0,28 \mathrm{cbm}=1,4 \mathrm{cbm}$ Holz.

Der jährliche Neubau ron Eisenbahnen, rund 1000 Meilen, erfordert etwa 12 Millionen Schwellen = 1 Million cbm, $280000 \mathrm{cbm}$ Bauholz und 1,5 Millionen Telegraphenstangen.

Man nimmt num auf Grund langjähriger Erfahrungen an, dass eine harte Holzschwelle durchschnittlich 7 Jahre, eine weiche Holzschwelle durchschnittlich 4 Jahre lang brauchbar ist; für Brückenund Gerüstholz werden 10 Jahre Dauer angesetzt; daraus ergibt sich, dass alljährlich etwa der 7. Theil der vorhandenen Schwellen erneuert werden muss; es sind also nothwendig:

zur Erhaltung der bestehenden Bahnen:

an Schwellen . . . . . 6 Millionen cbm zubereitetes Holz,

an Brücken, Sprengwerken etc. 1

an Telegraphenstangen . . 0,14

hiezu Neubauten:

Schwellen

Baubölzer

Telegraphenstangen

gibt pro Jahr 8,28 Mill. cbm zubereitetes Holz und 0,56 Millionen cbm für Telegraphenstangen, welcher Bedarf etwa 14 Millionen cbm stehendes Holz pro Jahr absorbirt.

Mit Ausnahme der transcontinentalen Bahnen ist selbstverständlich das Holz immer in der Nähe der Bahn, auf den von der Regierung geschenkten Ländereien gefällt worden. Kern nimmt im Walde einen Ertrag von 300 Schwellen pro acre an, das sind 700 Schwellen $=59,5 \mathrm{cbm}$ Holzmasse $=100 \mathrm{cbm}$ Rundholz pro ha. Bau- und Nutzholz sollen durchschnittlich $210 \mathrm{cbm}$ auf 1 ha, gewöhnlich $350 \mathrm{cbm}$ Rundholz auf 1 ha stehen.

Zum Aufwuchse von 1335 Stück Telegraphenstangen ist 1 ha Waldfläche erforderlich; demnach wären zur Unterhaltung der bestehenden Bahnen rund . . . 100000 ha, zu Bahn-Neubauten rund 19300 ha,

zusammen rund 120000 ha Waldfläche nothwendig.

Einstweilen ist die Berechnung dieser Flächengrösse freilich noch reine Spekulation; die Art der Gewinnung des Mraterials ist eine ganz 


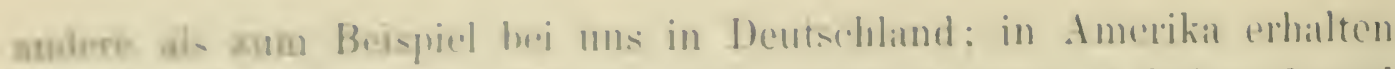

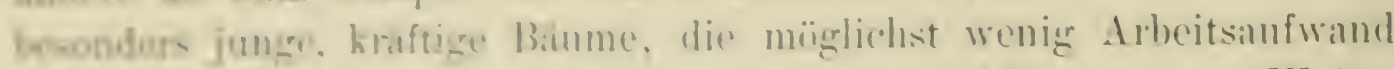
ertomirus. den Vorzug: su werden zum Beispied Millionen ron Weisisentun in disom Alter greschlagen, in welchem ans einem Banme nur

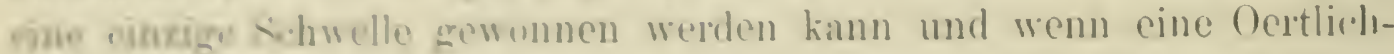
hege enshinft ish, angt Kern, so wird die siene der Sulhlichterei dieser warthoullston Nutahiume an einen indern Ort verlegt. In den, sürllimen, latubholareichen Sthaten nimmt man mit Vorliebe schwar\%e

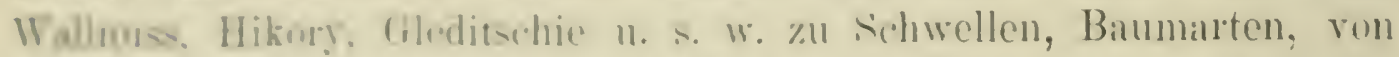
denan worthwolle Exemplare in Alt-kinglind selbst selten werden.

In Amerika wie in Europa werden bereits weren der Kustspieligrkoif dor Hulzachwollen zahlreiche Anligren mit eisernen Schwellen ansefhhrt; in wieweit diwe nit Erfolg die hülzernen Schwellen rerdnimzen wrolen, ist nuch gar nicht ahzusehen.

Aut Bahnen, dir durch waldroiche Gehicte führen, werden die

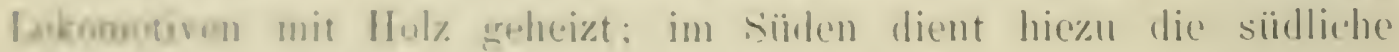

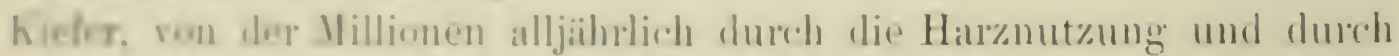
Thodenfener wertreknen: in den latubholagebieten, besonders in den dian bewalkortun stataten westlich der Alleghan! sicht maln stunden-

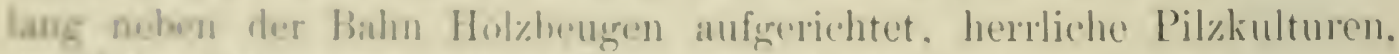
die. mit sablesen Frichten der Polyporus-Arten hedecht, die Zerstörung.

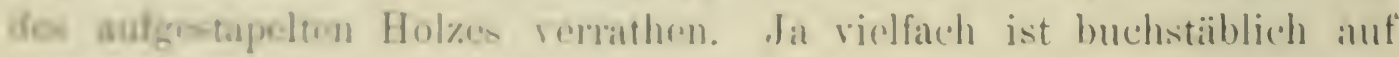

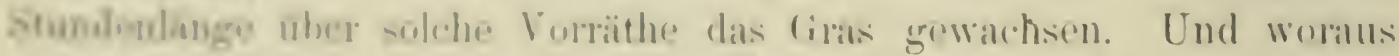

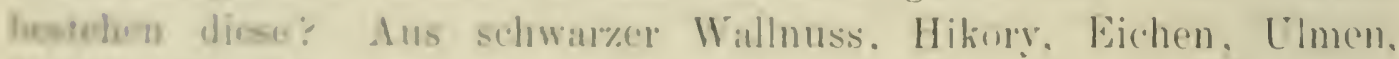

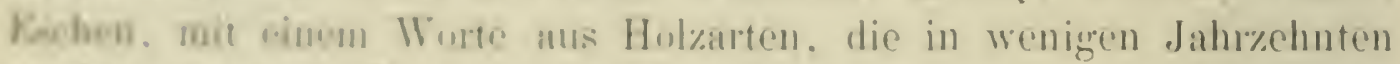

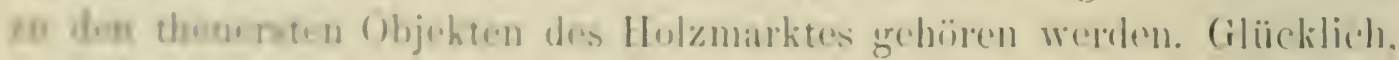

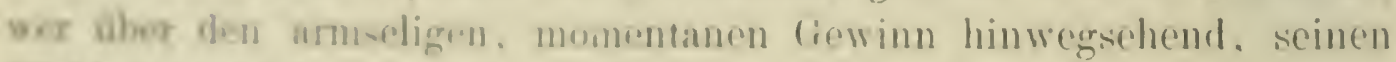
Wald robarsirt und sich anf die \%ukunft rerlisisen hat.

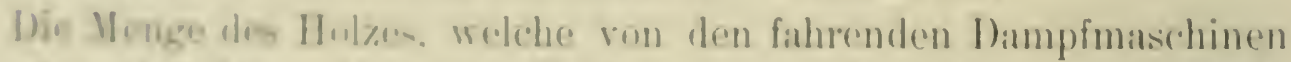

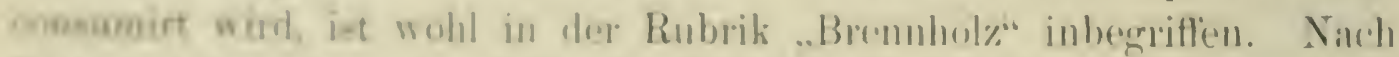
Kargent branrtuen im Jilur $1879 / 80$ die Lokomotiven für mehr als

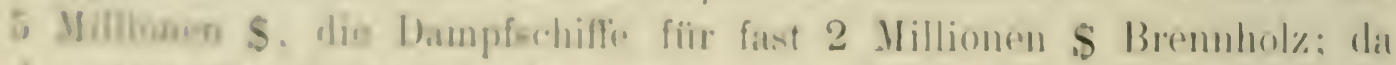

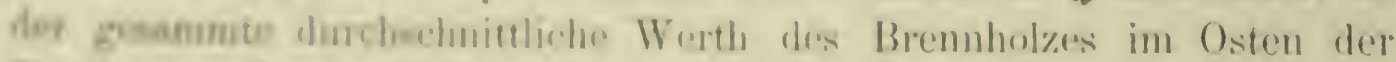
Yerrimigten stastu $26 \mathrm{~s}=10$ th pro ster betrïgrt, so wiirde obiger

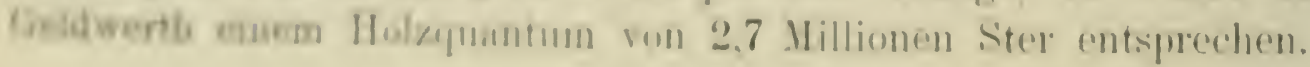

\section{c) Mobel-, feinere Tischler. und Wagner-Holzer.}

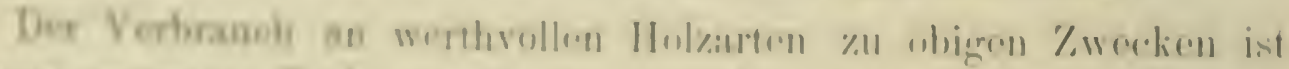

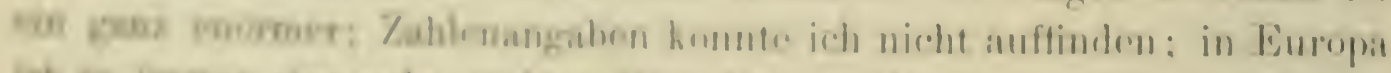

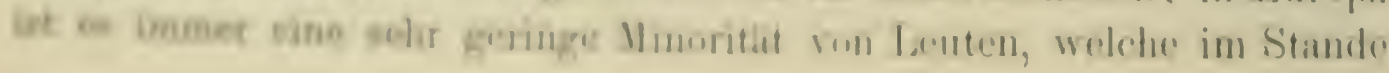


sind, sich feine Möbel oder den Luxus von Pferden und Wagen zu gestatten. Dis parlor und der sitting loom ron sogenannten Klein'bürgern sind in Amerika mit Möbeln ron Wallnuss- oder Kirschholz ausgestattet, die bei uns nur Beante höheren Ranges oder gutsituirte Geschäftslente erschwingen können. Im Lande hat fast jeder Grundbesitzer, su kilein seine Farm (nach unseren Begriffen immer noch ein grösserer Baucrnhof!) auch sein mag, auch Wagen und Pferde, welche die ,ladies" ebenso gewandt wie die Männer zu lenken verstehen. Unter 100 Europäern wäre kaum einer im Stande eine Hauseinrichtung zu kaufen, die man in Amerika die gemeinste Sorte heissen würde. Oben genannte Holzarten sind am meisten begehrt; aber angesichts der rasch steigenden Preise für Wallnussholz kommen Esche und geringere Holzarten immer mehr in Gebrauch. Die Pullman-cars, diese prächtigen Salons auf Rädern. sind mit rerschwenderischer Menge ron gemaserten Eschen und /uckerahorn ausgelegt; die Dampfschiffe, die Pferdebahnwagen sind Mustersammlungen von werthrollen Holzarten. Dass der amerikanischə Laubwald im Stande sein werde, für die Daner den Bedarf an derartigen Holzarten zu decken, glaubt kaum meln jemand in Amerika selbst. Wie selten diese Hölzer bereits geworden sind, zeigt ihre durch den Transport rerursachte rapide Preissteigerung. Bezeichnend ist, dass in letzter Zeit der Import aus Europa an seltenen, gemaserten Stiicken wieder rasch zu steigen beginnt.

\section{d) Kleinnutzholz.}

Der Bedarf der Vereinigten Staaten an Kleinnutzholz ist kaum annähernd festzustellen; der Regierungsbericht ron 1879/80 gibt 1760 Millionen Stück Latten, 5555 Millionen Stïck Schindeln, 1500 Millionen Stück Stïbe, Fassdauben und dergleichen, circa 100 Millionen Fassreife an.

Interessant ist die Art der Gewinnung dieses Materials, insbesonders der Schindeln im Westen Amerika's und der Fassreife: selbstverständlich geschieht dieses mit möglichster Vergeudung des Materials. Die nach Schindeln suchenden Leute waren vielfach die ersten Weissen. die den majestätischen Gebirgswald in Westen Amerikas betraten. Das Ziel ihrer unheilvollen Besuche war die Zuckerkiefer, die dort wegen Spaltbarkeit und ihres beispiellos cylinderisch-geraden Schaftes als die beste Holzart gilt; aber nicht jeder Baum ist brauchbar; es sind gewisse Standorte, die offenbar die Geradfaserigkeit eines Holzes bəeinflussen. Um diese aufzufinden, hat diesen so riel gepriesenen Pionieren nicht das Herz geblutet, als sie Stamm für Stamm Millionen ron Stämmen 


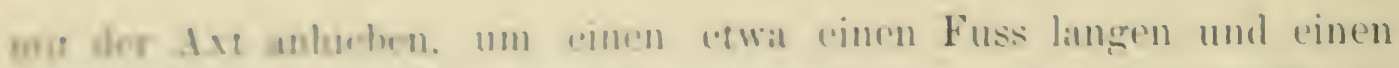

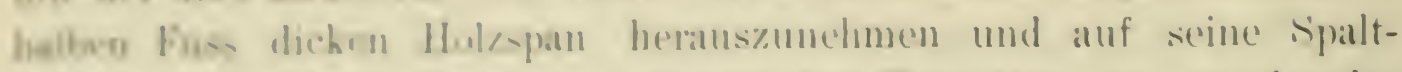
barkent zu prufen. Franhen sich giunstige hesultate. su wurde der

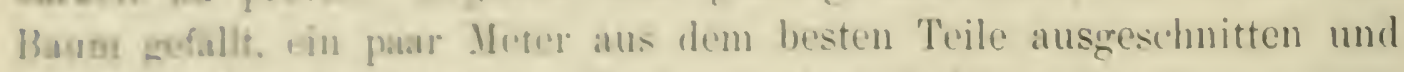

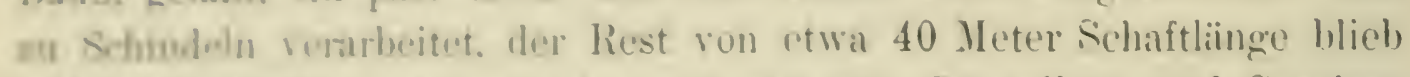

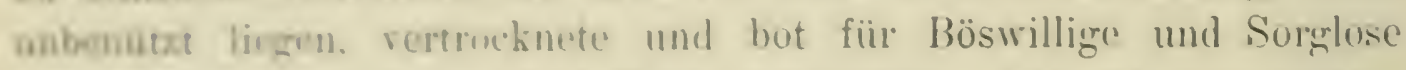

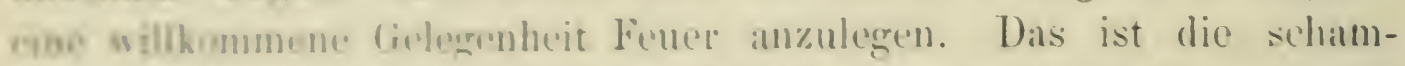

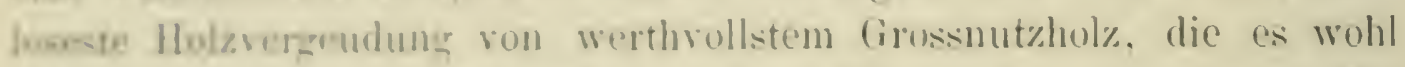

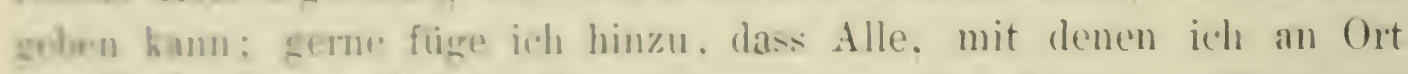

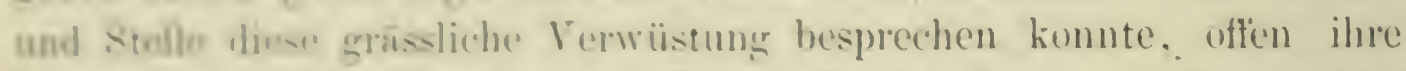

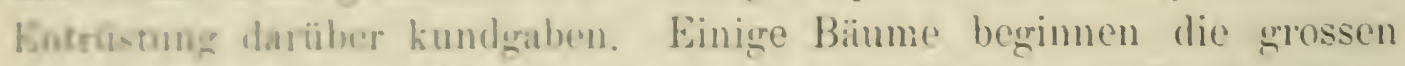

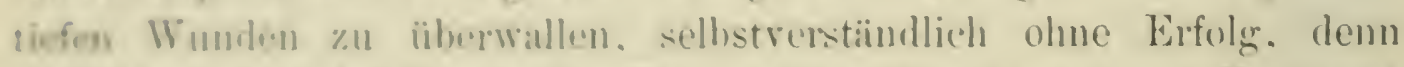
Jahre lang war das Innure des Banmes der Einwirkung ron Luft und

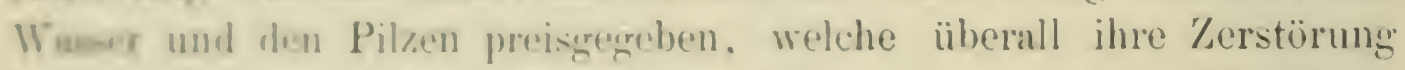
lmmis bogrmen haben. Die Melumalil der Bäume fiillt dem Fener zana (l)per. welchen an der vou Hare triefenden Wunde reichliche Safirumg tindet. um das Innere des Baumes anzugreifen und den Baum

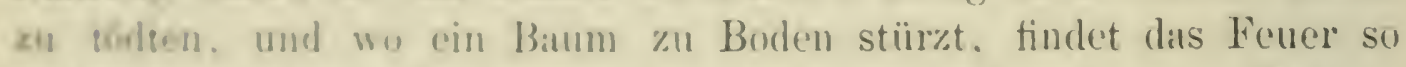
xisl Subrung. dass es, peripherisch weiter schreitend, immer neue Bäume

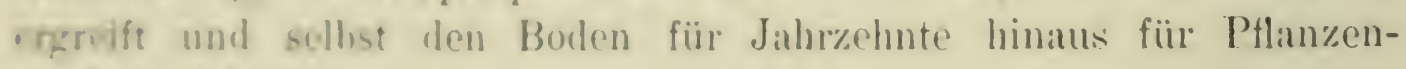
woblis ruinit.

Ge-hon herem ist das Hul\% der \%ucker-Kiefer so kostbar, dass die

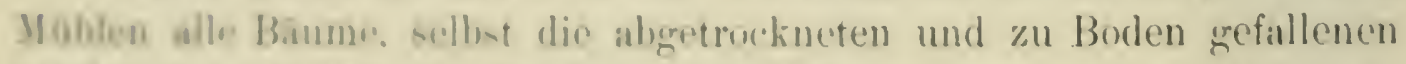
wiodir auf die siare sthleppen und zu Brettern verabeiten. Num, wic wird an erst der hummonden Generation ergehen, die doch so grut wie

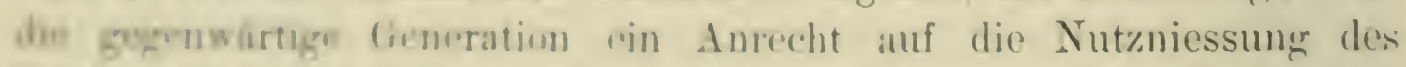

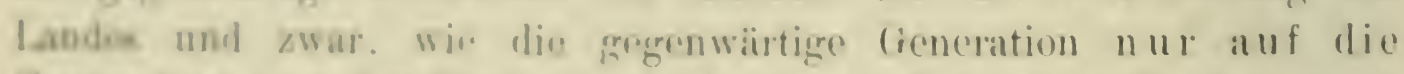
Surathesung des landen hat! Die jetzt so ribcksichtslos zerstörten

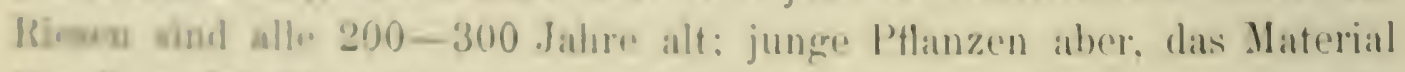

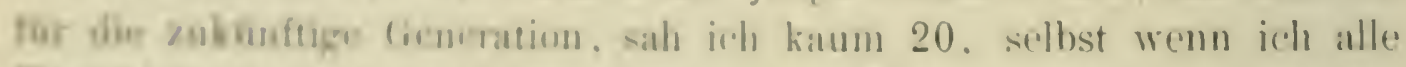

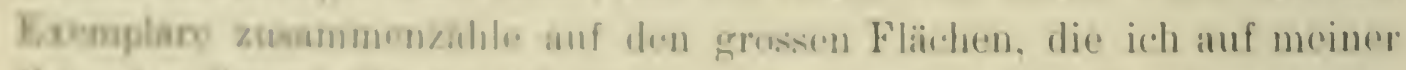

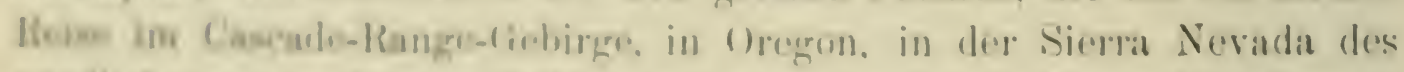

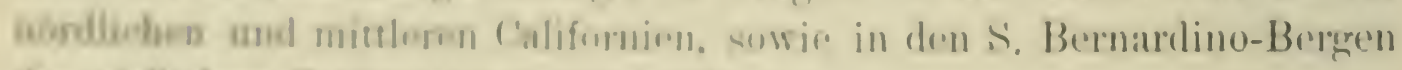

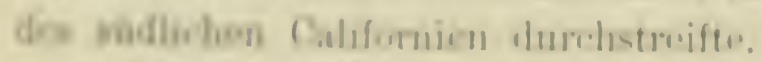

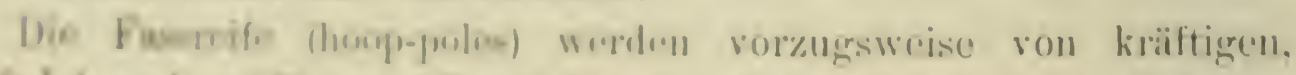
5- 10 Jafro alen Hekors - (Carga) Baumelsen grewomnen, die sich weren

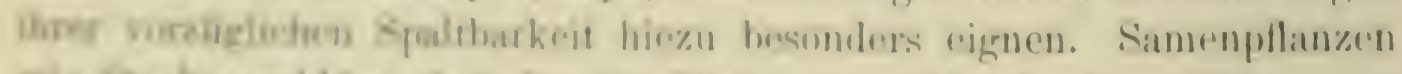

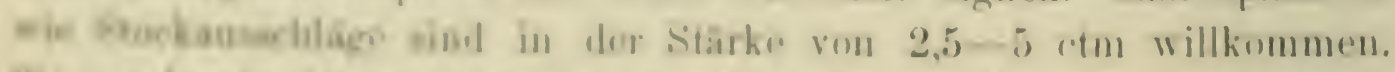

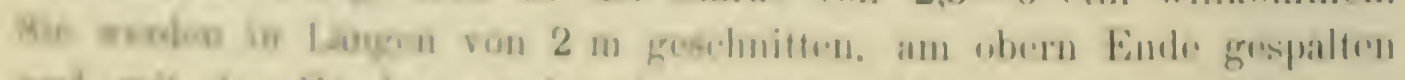

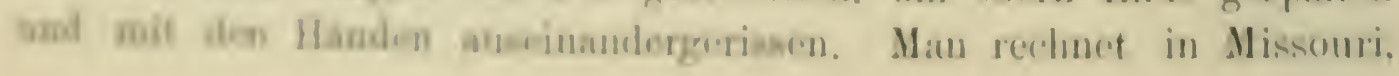


bei Allenton, auf sogenanntem guten Grunde etwa 500 Stück pro ha und die eben genannte kleine Eisenbahnstation allein sendet ca. 50000 Bündel à 500 Stïck $=25$ Millionen Stiick ab, welche einen Werth von 500000 Mark repräsentiren.

Es ist gegen die Benutzung der Pflanzen zu derartigen einträglichen Zwecken gar nichts zu sagen; aber die regellose Herausnahme derselben führt natürlich zu ihrem Verschwinden, da die stehenbleibenden iibrigen Holzarten, in deren Mischung die Hikory sich findet, sich sofort ausbreiten und einen Neuaufwuchs der Hikory aus Samen oder Stöcken verhindern. Wie leicht wäre es, in einem Niederwald-Betriebe das ganze Geschäft zu concentriren und zu einer Quelle grossen und dauernden Gewinnes zu gestalten; ron der Erhaltung der werthvollen jungen Pflanzen in anderen Gegenden zu Nutzholzzwecken ganz abgesehen.

\section{e) Brenn- und Kohlholz.}

Nach dem Censusreporte pro 1879/80 wurden in den Tereinigten Staaten über 7 Millionen cbm Holzkohle und rund 495 Millionen cbm Brennholz verbraucht, das heisst volle $70 \mathrm{cbm}$ pro Kopf im Jahre. Wenn man noch bedenkt, wie viel Steinkohle, besonders in den Städten benützt wird, so ist das Quantum Brennholz geradezu unverständlich. Einigermassen verständlich wird es, wenn man bedenkt, dass die Amerikaner trotz ihres eisigen Winters das System der Kaminfeuerung. aus der alten Welt adoptirt haben. Diese Methode der Feuerung verbraucht, gleich strenge und gleich lange Winter vorausgesetzt, mindestens das fünffache Holzquantum als die Ofenfenerung, die wegen der Unschönheit der Oefen nicht beliebt ist, was angesichts der geschmacklosen, schwarzen Eisenfässer, die man vielfach sieht, ja ganz richtig ist. Das Kaminfeuer, so traulich es auch den am Kamin in Schaukelstiihlen sich wiegenden, gesprächigen Familienkreis beleuchten mag, erwärmt durch Strahlung die zugewendete Seite zu gut, die abgewendete zu schlecht, so dass die Conversation dahinfliesst unter stetigem Frontwechseln, Hin- und Wegrücken, Fenerschüren und Abfangen der auf den Teppich herausgeschleuderten Funken und Holzstïcke; wenn man nicht durch ständige Fenerung den Kamin mit hellrother Gluth erfüllt, bleibt das Zimmer schon wenige Meter vom Ofen entfernt kalt und unfreundlich; damn aber ist die Kaminumgebung wieder unerträglich durch die Hitze.

Die Dimensionen der Kamine sind stets gross, meistens sogar ausser aller Proportion zur Kleinheit des Zimmers; ausserhalb der 
garmon stulu, hewnders in len Burgen, wo Hol\% noch im Ueberflusse vortanates and billiz ine kann sich im kamin bequem ein Mann

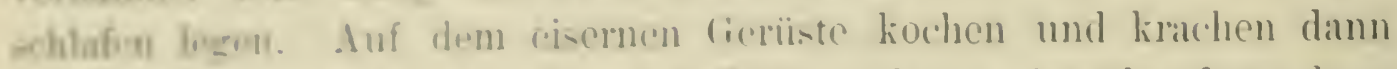
sma frah Jlergem his Abends wahre Blöcher, kamm einmal auforespalten.

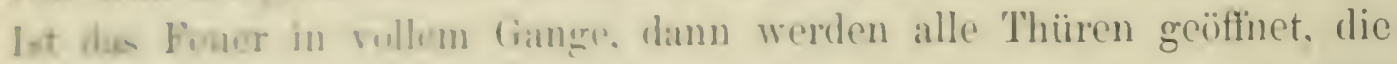
stahle on weit som hanine wergeriuckt. dass man ihn kaum mohr

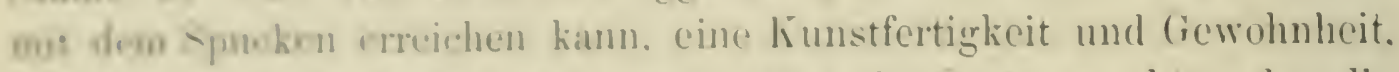

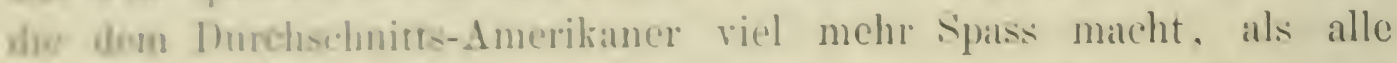
Konse and Romantik, die man dem liaminfener anhängt. Wron ich suemo im Iande mich im (iasthause (natiurlich Hötel) zu durchwärmen

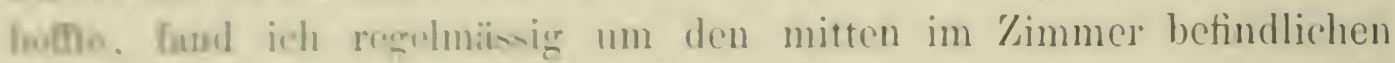
gromen Cylinderofon eine rauduende, stïndigr spuckende Gesellschaft.

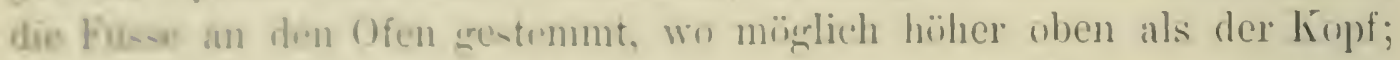
da, mus inh grotehnn. habe ich mir wirklich an stelle des stïndig

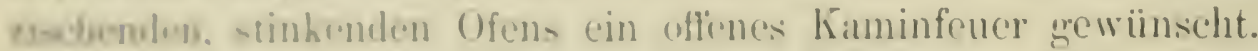

Ielo gebe zu, dass in Ländern mit mildem Winter. \%. B. Italien,

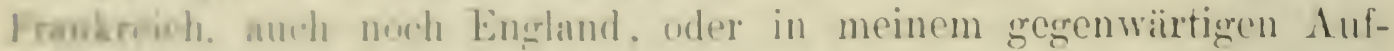
enthabte, in Japan, die Kaminfourung vor dem Ofensystem den Vor-

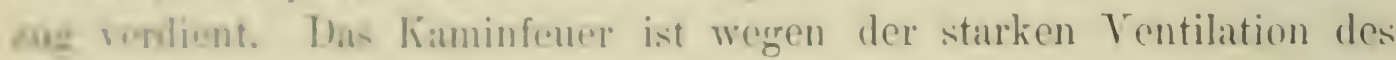

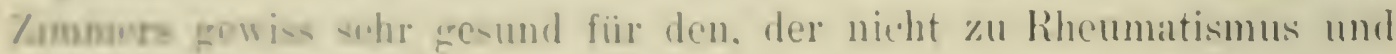
dergfointen genejert ist. Wir haben hier in T'okio einen Winter, der vinem vermonatliden deutsden ()ktober gleicht, in dem ein paarmal

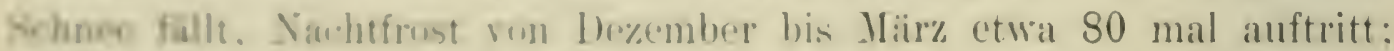
unter Tags in as bei klarem Wetter recht warm. wonn aber der Himmel bolerk in und einen Tag Nordwind woht, so jist kein Zimmer meine's

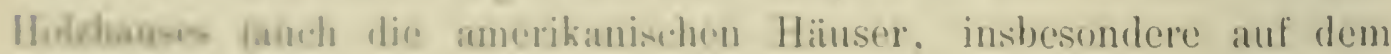
latede sind fose allo aus Hol\%) (retrieglich warm \%ul halten, trotz der helinthen stoinkwhlengluth in lianin.

Der Winter Nordamerikas, östlich ron der Prörie. ist kïlter als

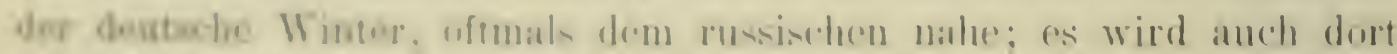
teolar hadel den \%oit kommon. in der man din Firfahrungen der alten

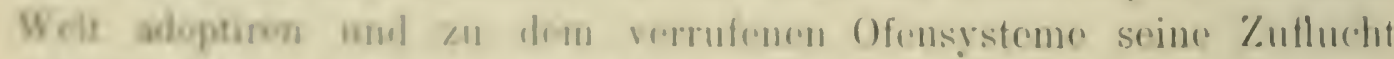

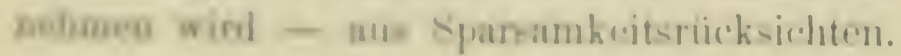

\section{f) Vichweide (Stock-raising).}

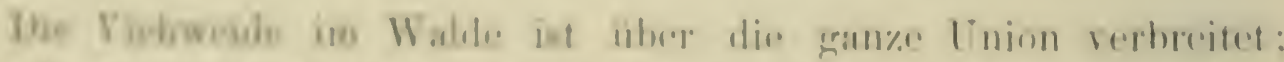

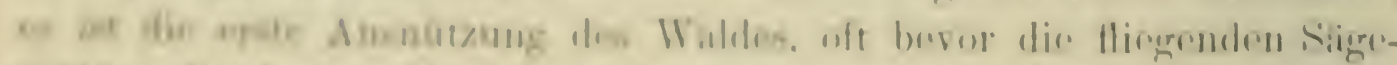

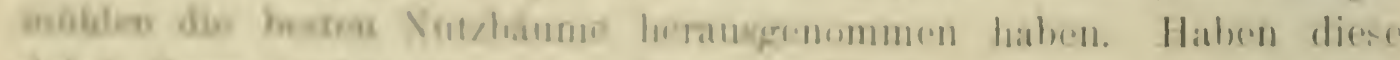

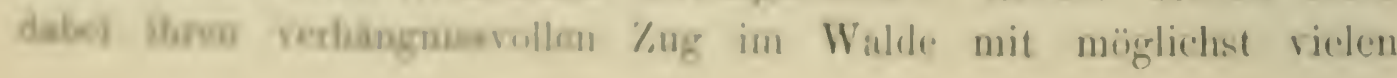


Kohlensäulen geschmïckt, um so mehr Gras entspriesst dem Boden, um so besser ist es für die Viehzucht. Wo das nicht genügt, sucht man den Graswuchs zu fördern, indem man das Dach des Waldes möglichst durchlöchert. Zu diesem Zwecke werden die Bäume geringelt, indem Rinde und Splint in einem Ringe um den Baum herum losgetrennt werden, ein Verfahren, das auch bei der Rodung, bei der Umwandlung von Wald in Feld in Gebrauch ist. Die Erfahrungen, die man auf diesem Gebiete gesammelt hat, will ich nicht vorenthalten: geringelte Hikory- und Schwarzwalhnussbäume ron einem halben bis einem Meter Durchmesser brauchen etwa sieben Jahre, bis sie durch Feuer und Pilze soweit zerstört sind, dass sie ein mässiger Wind zu Boden werfen kann. Andere Bäume sind schon in fünf Jahren mürbe.

Der waldbesitzende Farmer sucht in seinem Walde den Aufwuchs des Grases möglichst zu fördern, was der europäische Waldbesitzer möglichst zu verhindern strebt; um das alte Gras zu entfermen und reines, frisches Gras im Frühjahr zu erhalten, besteht insbesonders im Siirlen die Sitte, alljährlich Feuer über die Fläche hinlaufen zu lassen. Im Süden stockt auf einem breiten, sandigen Küstengürtel die beste aller Kiefern, die Pinus australis, zusammen mit Pinus cubensis und anderen Kiefern. Neben unübertrefflichem Nutzholze liefert dieser Baum für die Union das nöthige Harz, dessen Gewinnungsweise später besprochen werden soll. Es genügt hier die Bemerkung, dass das rom Baume herabfliessende Harz selbstverständlich bei dem kleinsten Bodenfeuer sich entzündet, wodurch der Baum an der versengten Stelle zu abermaligem Harzergusse gezwungen wird. So steigert sich alljährlich das Uebel, bis der Baum abstirbt.

Auch die nicht geharzten Kiefern gehen unter dieser Misswirthschaft zu Grunde. Wer aufmerksam die Bäume der südlichen Kiefernzone mustert, findet fast an jedem, hart am Boden eine dreieckige Brandwunde ron etwa 1' Länge und $1 / 2^{\prime}$ Basis, welche alle Bäume an derselben Seite, der Windrichtung entsprechend, in der das Fener getrieben wurde, tragen. Das erste Feuer, das den Baum berührt, kümmerlich durch Gras ernährt, ergreift

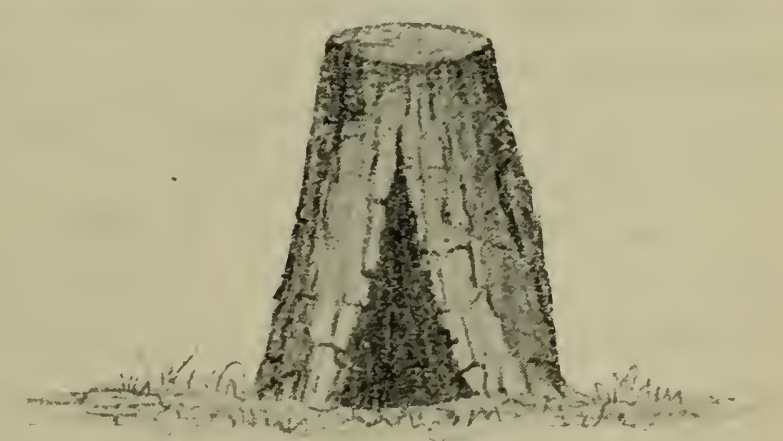

Fig. 1. Wirkung des Bodenfeners an der südl. Kiefer. nur die äusserste Borkenschichte, welche verkohlt, ohne dass der Baum irgend rerletzt wird; die nächsten Feuer greifen tiefer; endlich wird 


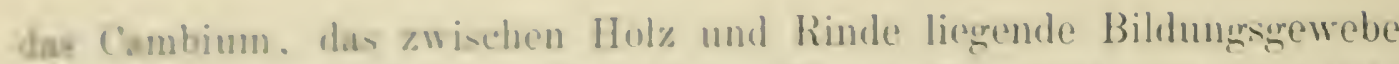

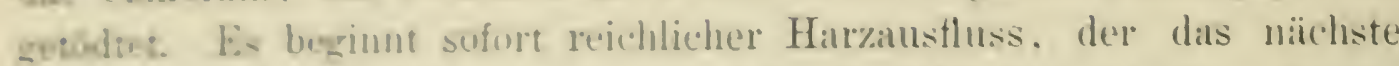
Foum reichlicher nahre. wodurch sich die Wunde vertieft und rer-

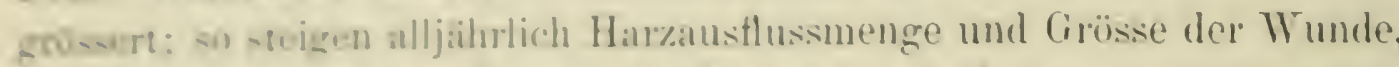

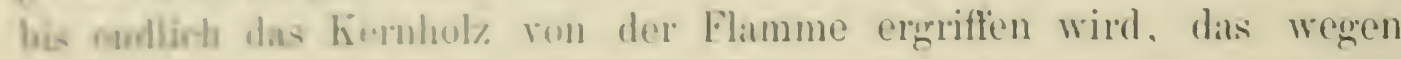
scimes Harzeichehumes und seiner Treckenheit längere \%eit hindureh

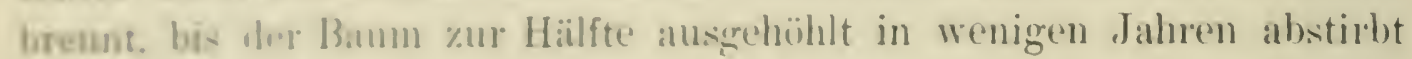

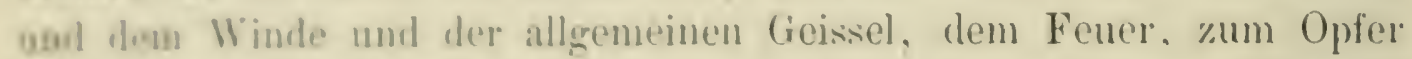

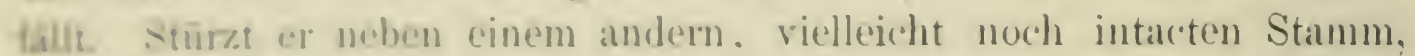
wa veleet dienen das alls dom alten Stamme mehrere Tage anflodernde Four angleide. Das ist die Wirkmor dere alljährlichen, an sich kleinen

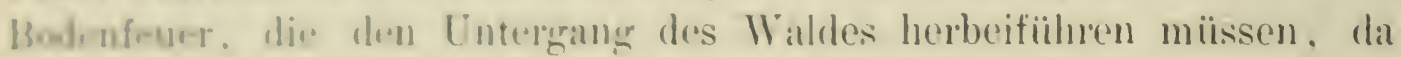
unth allo jungron l'blan\%en, jusbesonders der in den criten Jahren sehr medrig hombenden siallichen hiefer ressengt werden.

Al- dir exsons Ansiedler dort hinkamen, fanden sie unter dem

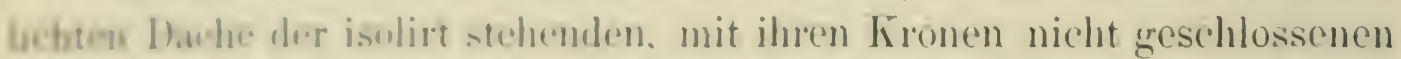

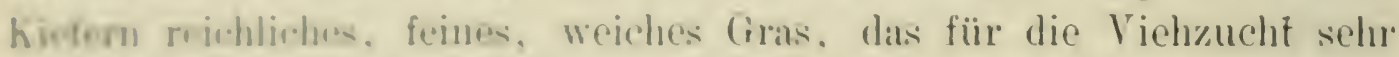
hraurhar war. Dir alljahrlichen fener haben das Kronendach so ge-

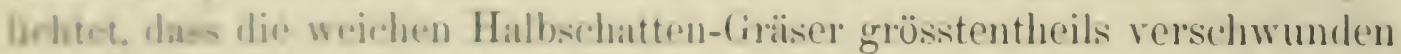
want: an ihre stelle tratten allf besseren Böden hate, hohe Ciräser, die

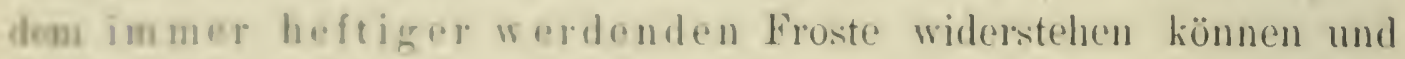

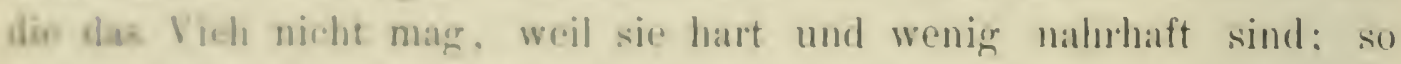
vormush ieh weniestens nach dron herumirenden, jammervollen Gerippen, tio den Wanderelo mit hörlon. matten Augen anstieren und um derent-

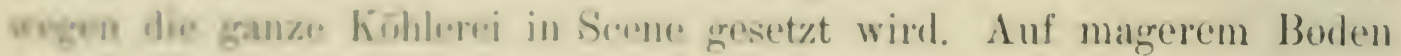

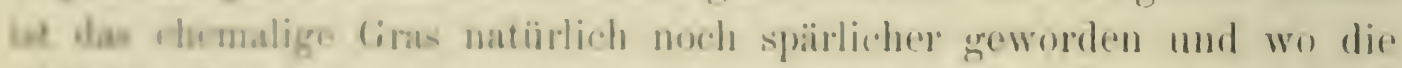

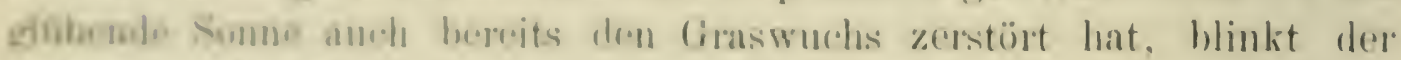

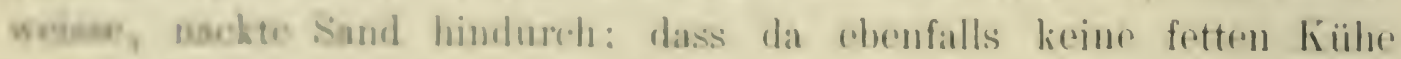

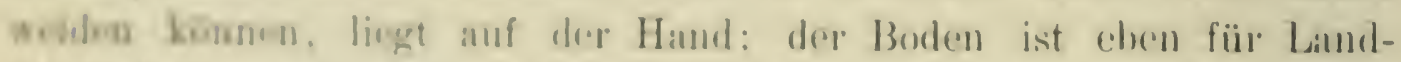

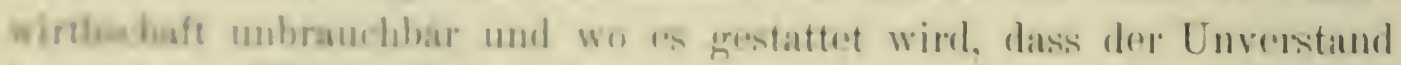

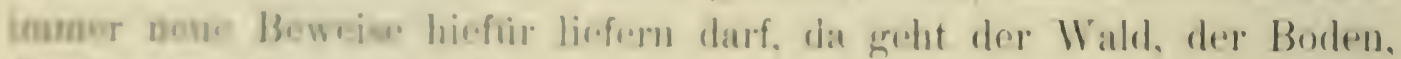
die Landatuft z.11 (irumlı.

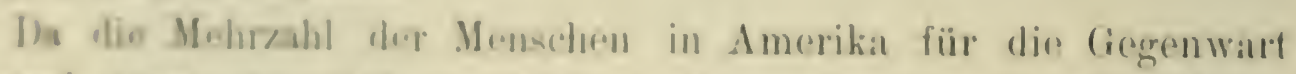

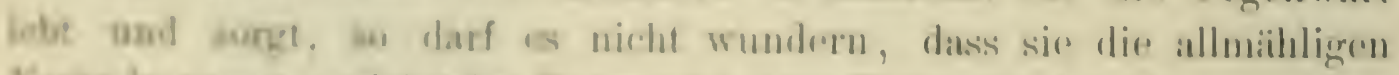

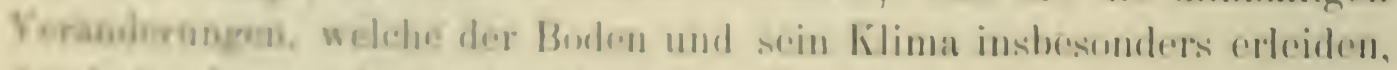

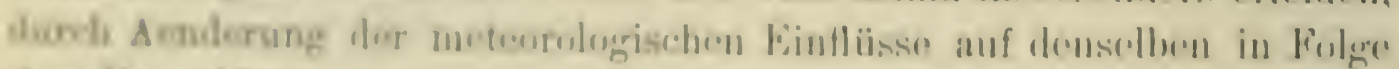

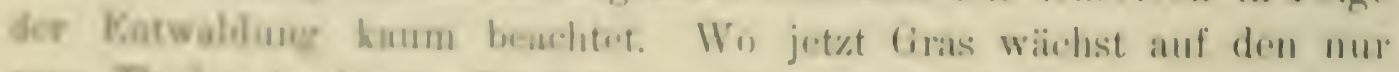

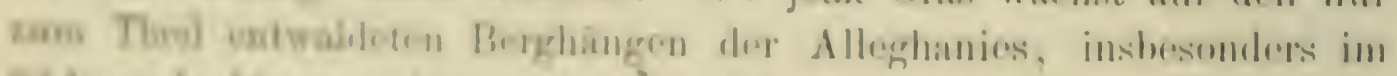

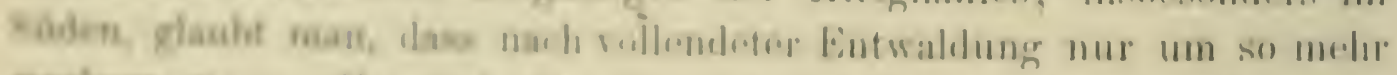

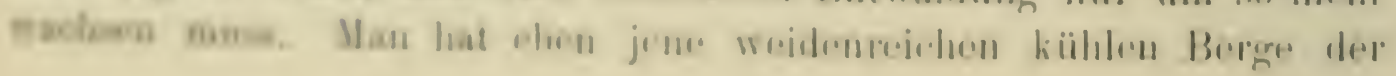


Alpen, die schottischen Berge vor Augen und bedenkt nicht, dass in diesen Gebirgen die versengende, tropische Hitze des mehrmonatlichen regenarmen Sommers fehlt.

Ich übergehe alle andern Uebel, welche die Weide im Walde in Amerika so gut wie auch bei uns zur Folge hat, wie insbesonders auf den Bergen die Lockerung des Bodens und Förderung des Abschwemmens, Vernichtung der jungen werthrollen Holzarten und Zurücklassung derer, die eben nicht nach dem Geschmacke des Viehes sind, das Beschädigen stehender Bäume an Stamm und Wurzel und dergleichen.

Interessant ist $\mathrm{im}$ unberührten amerikanischen Laubwalde das Absterben grosser Baumgruppen, ja ganzer Flächen, wo das Weidevieh seinen Fuss hinsetzt. Der Boden im Laubholzurwalde ist so locker, humusreich, die Wurzeln liegen ganz oberflächlich, dort hinreichend Nahrung findend. Wird nun eine Heerde Vieh auf solchen unberührten Wald losgelassen, so tritt sie den Boden zwischen den Wurzeln nieder, sprengt die feinen Wurzeln ab, legt die grösseren frei; der Boden trocknet aus und ungezählte Bäume und Waldflächen gehen auf diese Weise, zum Beispiel in Wisconsin, zu Grunde.

Un zu verhindern, dass das Weidevieh des Einen auf 'das Grundstïck des Nachbarn übertritt, werden Holzzäune (fence) aufgerichtet, wozu insbesonders die gut spaltenden Eichen, Hikory, im Norden und Nordwesten besonders dauerhafte Holzarten wie Juniperus virginiana (das Bleistiftholz) und white Cedar (Thuja occidentalis), in Westen Douglastanne, red fir, red wood (Sequoia sempervirens) verwendet werden.

Oft werden ungespaltene Blöcher übereinandergelegt, oft die gespaltenen Stiicke in Zickzack gelegt, wodurch eingerammte Pfosten erspart werden können; oft werden die Wurzelstöcke mit ihren. Wurzeln nach den Seiten hin nebeneinander gereiht. Zur Erhaltung dieser Zäune, die mit buntgemalten marktschreierischen Ankündigungen von Kantabak, Quacksalbereien und dergleichen bedeckt sind und die gewiss kein Mensch als eine besondere Zierde der amerikanischen Landschaften bezeichnen wird, sind nach den Angaben des mehrfach erwähnten Regierungsberichtes rom Jahre 1886 nicht weniger als 14 Millionen cbm Holz nothwendig. Wo Holz werthvoll ist, tritt jetzt schon vielfach Stacheldrahtzaun an die Stelle. Im Schutze dieser unschönen Holzzäune weidet nun das Vieh neben dem Grase selbstverständlich auch die jungen Holzpflanzen ab; was etwa nicht schmeckt, darf aufwachsen. Leider sind es gerade nicht die besten Holzarten, die das liebe Vieh so rücksichtsvoll ist zur Holzproduktion für die kommende Menschengeneration emporkommen zu lassen. 


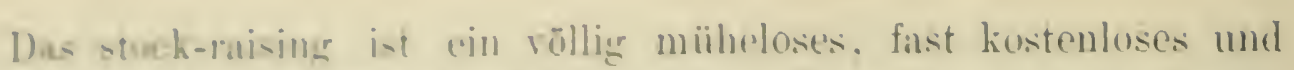

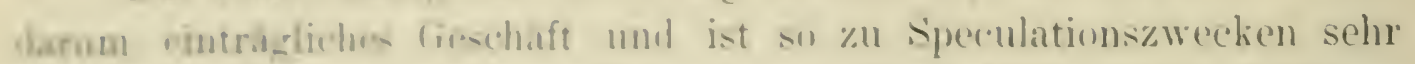

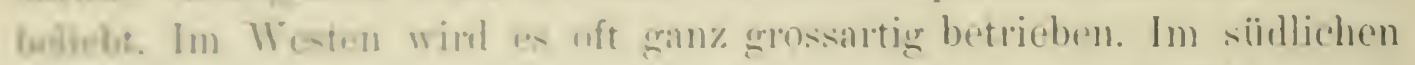

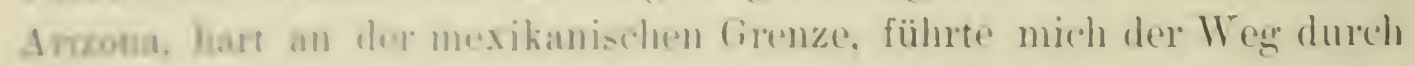

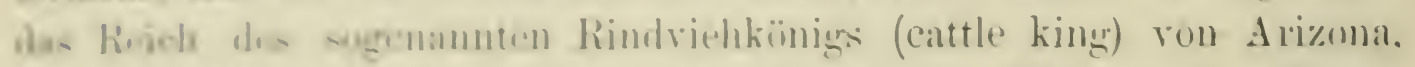

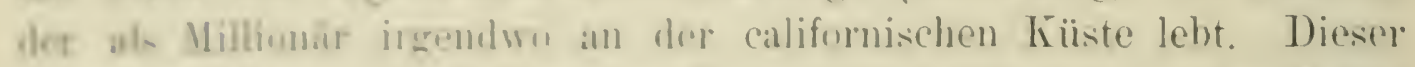

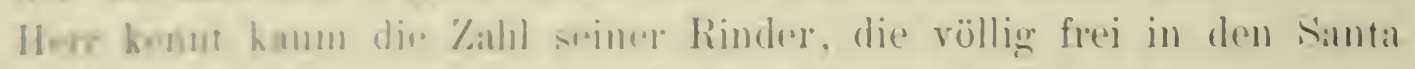

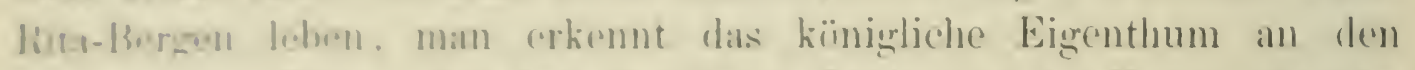

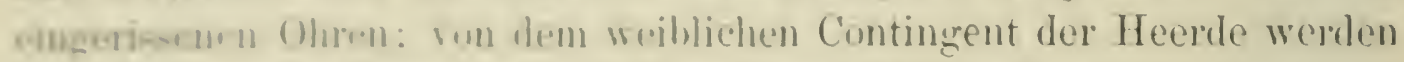
Ares Kentuge alle 'lage etwa 20 Junge \%ur Welt gebracht.

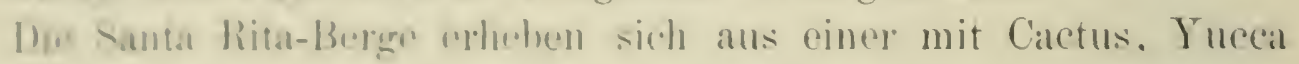
ami Agaren roinh hewathenen Pribie: in etwal $3500^{\prime}$ beginnt eine

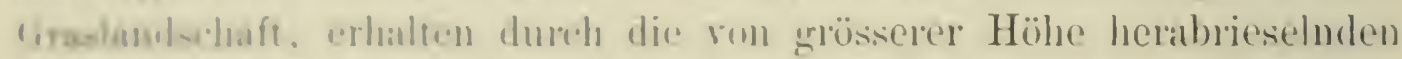

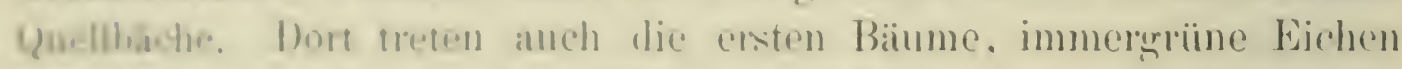

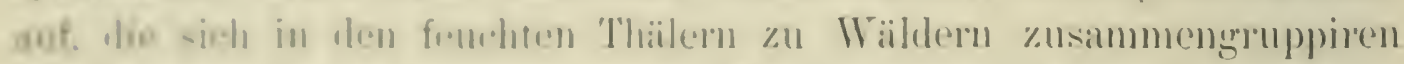

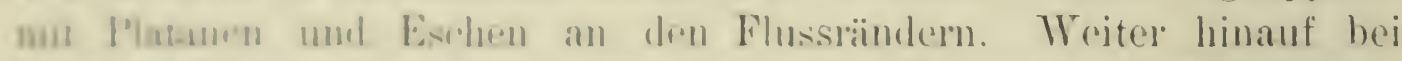

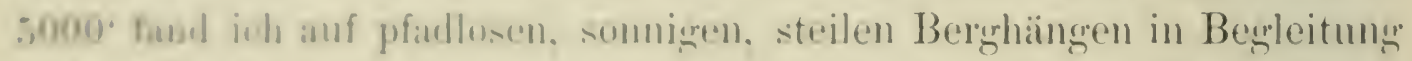

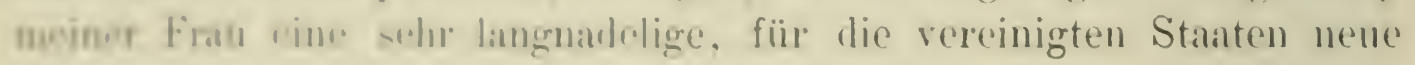

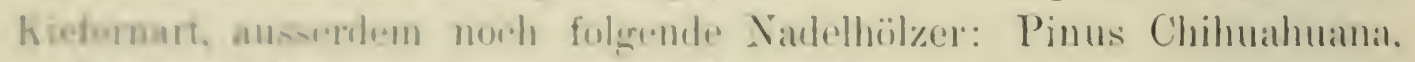

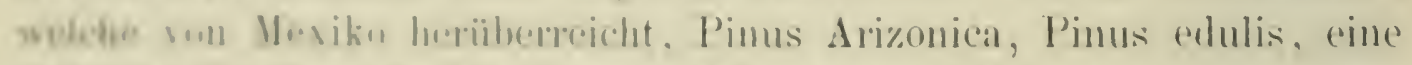

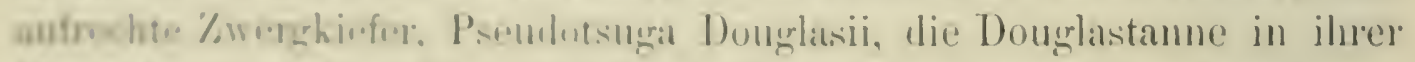

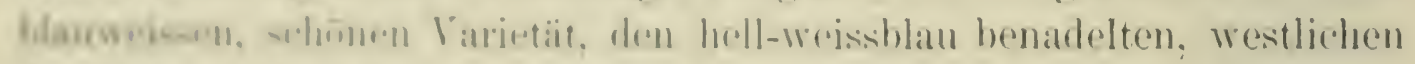
dusiperus ind sudere.

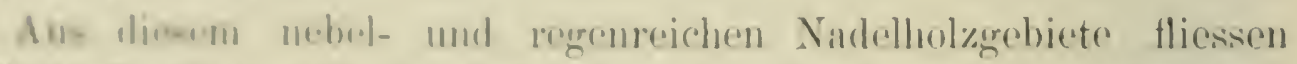

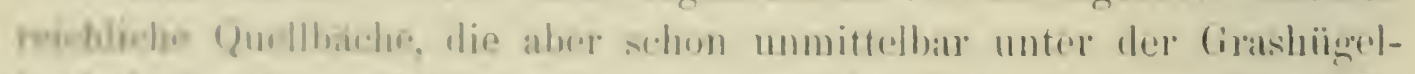

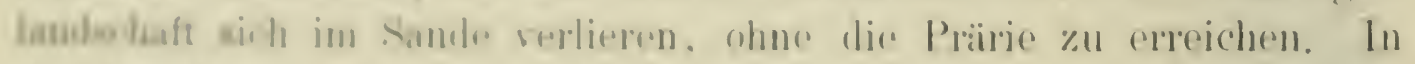

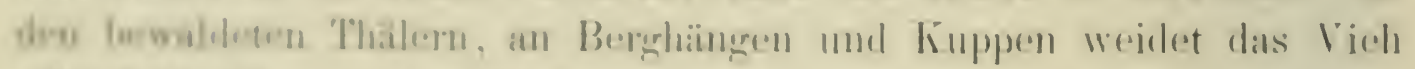

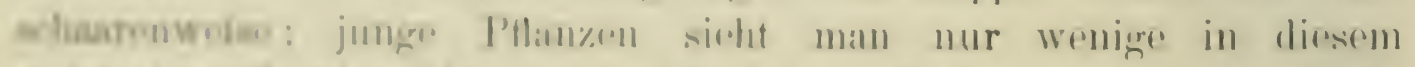

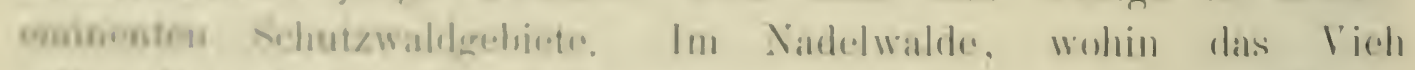

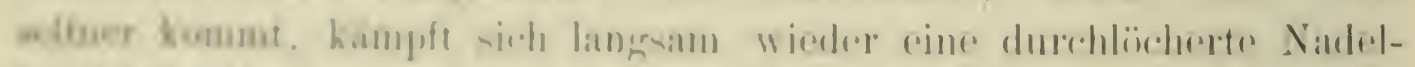

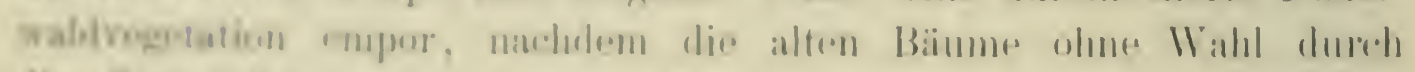

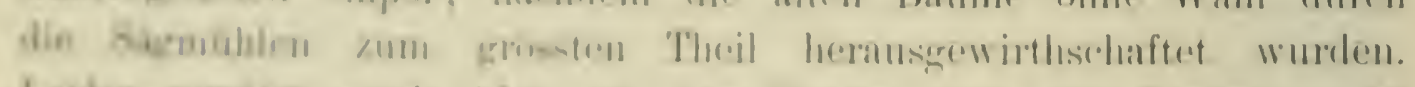

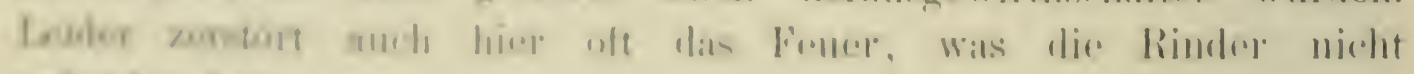
wefustern biben.

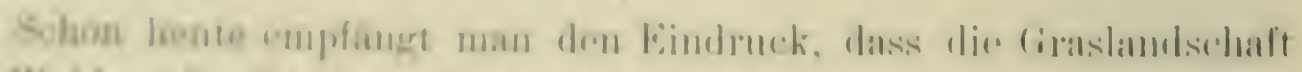

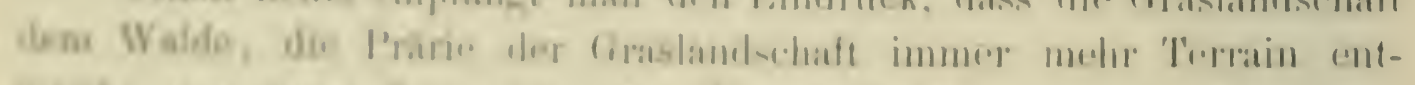

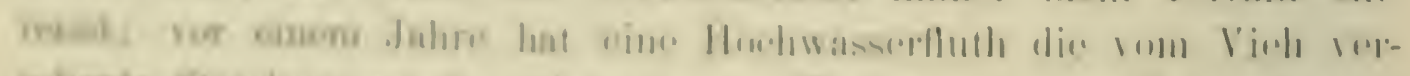

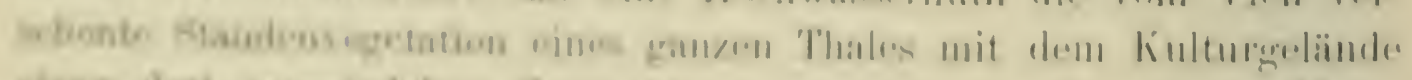

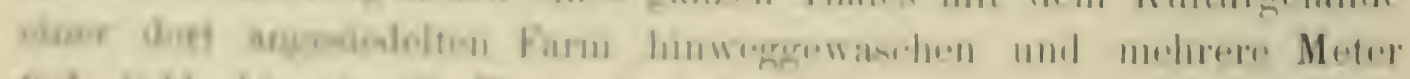

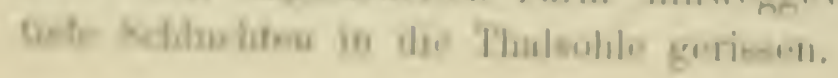


Das ist auch das Schicksal vieler Landstriche Californiens, wenn der Staat mit selbstmörderischer Ruhe noch länger zusieht, wie die Heerden von Kühen und Schafen alljährlich zu Beginn der trockenen Zeit die Gebirgswaldungen anfallen, die künftige Baumgeneration im Keime vernichten, den Boden lockern und sein Abschwemmen ins Tiefland und ins Meer einleiten.

\section{g) Zum Zweck der Urbarmachung oder Rodung, der Umwandlung in Feld}

werden alljährlich ganz beträchtliche Mengen von Waldungen vom Boden entfernt.

Mit grosser Eitelkeit haben die Pioniere es verstanden, eine Art poetischen Nimbus um sich zu verbreiten, wie sie im Kampfe mit der .,wilden Natur", mit dem Urwalde liegen, dem sie ein Stuick Land nach dem andern abringen; die Reisebeschreibungen sind voll von dergleichen geistreichen Redensarten, besonders natiurlich was jene Gegenden betrifft, die selten besucht und von den meisten Menschen daher ungekannt sind; da blühen solche Blumen am schönsten. Die wilde Natur der Sierra Nevada mit den Baumriesen, der heissen Berge Arizona's, im tiefsten Walde am Vulkan Tacoma, in Wisconsin und den Alleghanny's ist überall sehr zahm und weicht vor den Waffen der Pioniere, Axt und Feuer, überall schleunigst zurïck.

Wenn sie verdorbene, misshandelte Böden später wieder mit Wald überkleidet und in nutzbringende Verfassung zurückführt, dann ist man doch wieder recht froh um die "wilde Natur."

Wenn der Wald in der Ebene oder im schwach welligen Hügellande von den Flächen verschwindet, die dauernd der landwirthschaftlichen Benützung fähig sind, damn ist ja die Umwandlung in der Ordnung; auf solchen Geländen wird der Wald immer nur so lange geduldet sein, bis die Noth an landwirthschaftlichem Boden ihn hinweg fegt. Wer bei diesem allgemeinen Kampfe gegen die Natur die Vorsicht hatte, eine Partie des Waldes in geschlossenem Zustande, nicht in einzelnen Bäumen über die ganze Fläche vertheilt, sich zu seinem Hausgebrauche zu reserviren, wird den Werth recht bald zu schätzen wissen.

Ich erspare mir die Beschreibung des bei der Rodung üblichen Verfahrens; man kann sich leicht vorstellen, wie grundverschieden dieses ron allen europäischen Begriffen sein muss, da das Holz gegenwärtig noch fast keinen Werth hat. Unwillkürlich drängt sich einem der Gedanke auf; dass es doch nicht absolut nothwendig ist, den Kampf 


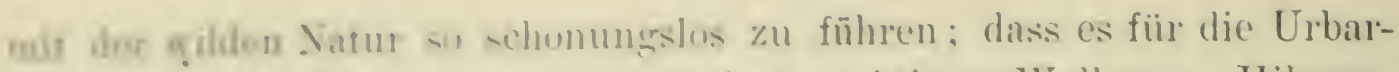

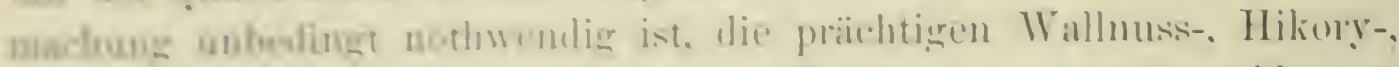

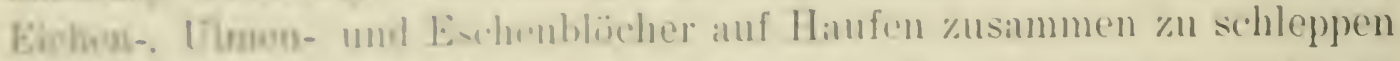

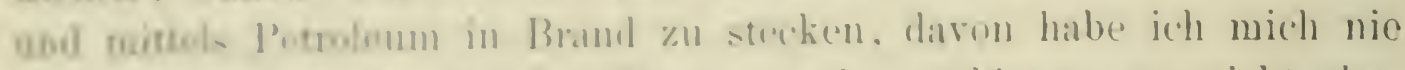

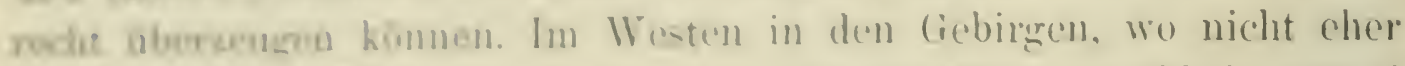
Jor Extwaldung Embale grothan wiml, bis die Natur wirklich eimmal

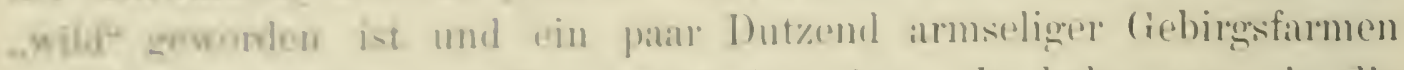
mis den lowohnern ind Thal sawaschen hat, da bolnt man in die gefalben \%uckerkitern zum Brospiel Löcher, griesst Petroleum hinein atud nach 8 Tazen in der Rirsu zu einem 60 Meter langen Aschenbiegel reducir.

Cher die Lintwaldume der Gebirge. im (Quedlgebiete der Flüsse

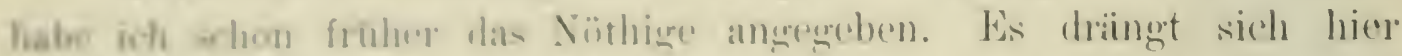

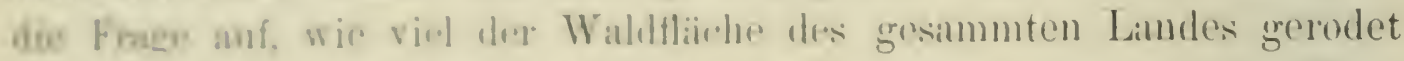

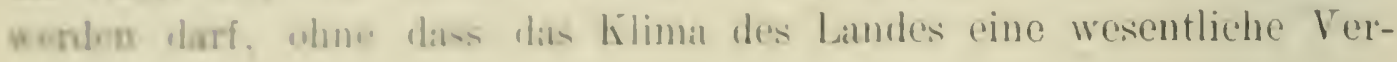
anterung erleidet.

Jumb do kintwaldung rerändert sich das Kilima, indem dassclbe

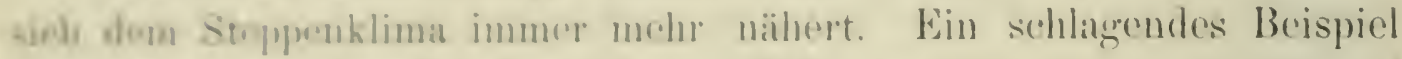
com Temperafurserumderung durch Waldvernichtung lernte ich auf

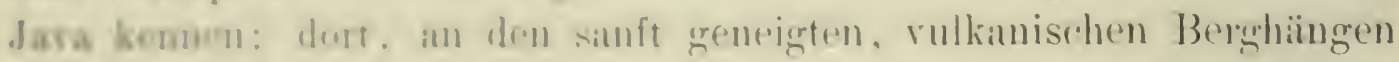

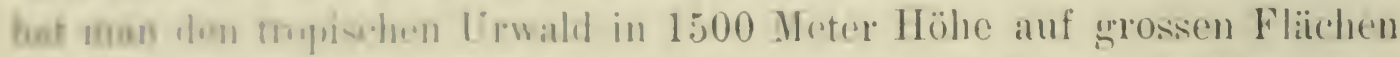

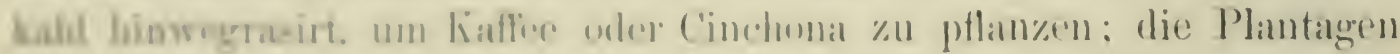
darfon aber eine zousiss. An-tehmumer. etwa 50 ha, nicht ïherschreiten,

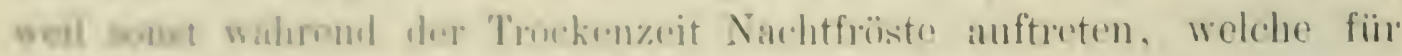

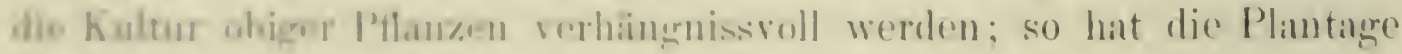

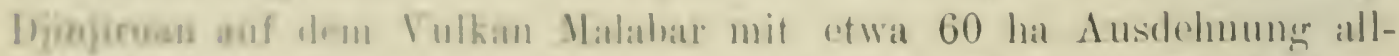

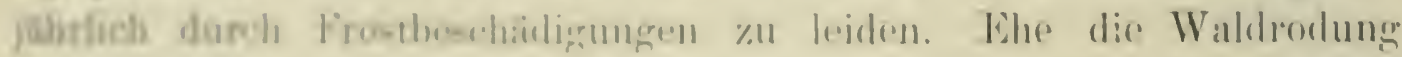

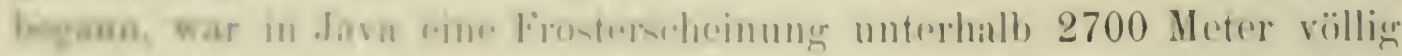

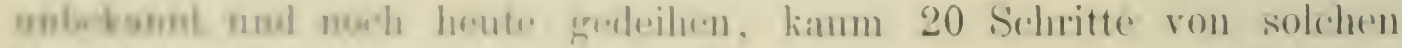

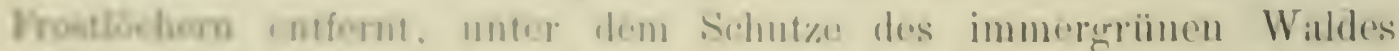

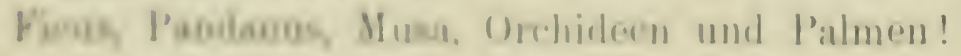

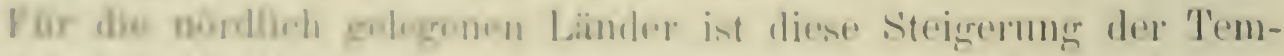

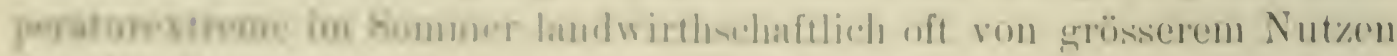

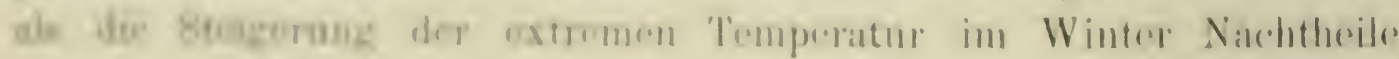

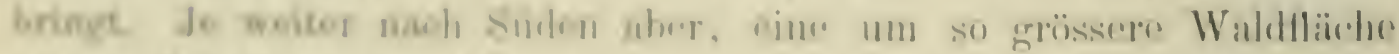

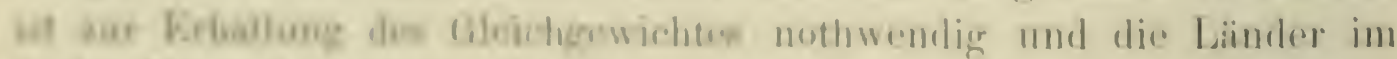

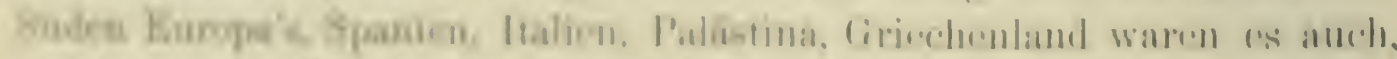

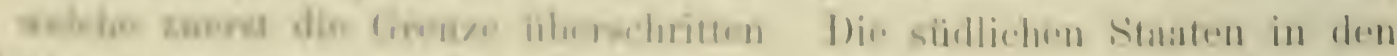

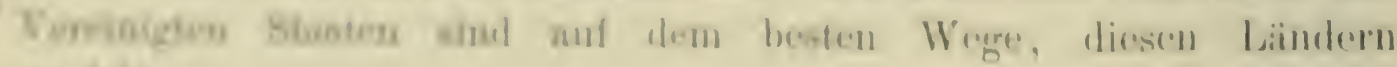
in folmon 
Von den europäischen Staaten gilt allgemein Deutschland und ron diesem wiederum Bayern als am gleichmässigsten mit Wald bedeckt. und überdiess mit einer für die Bedürfnisse des Volkes und für die Erhaltung des Klima's des Landes nothwendigen Menge. Die Richtigkeit angenonmen, so hat Bayern $34 \%$ seiner Fläche mit Wald bedeckt; Preussen hat 23\% ; da die Ebene rorwiegt, hat es ebenso himreichend oder vielleicht soviel Wald wie Bayern; das bergige Oesterreich hat 21\%, Frankreich 17\%, Italien 15\%, Norwegen, das Land mit der grössten Waldbedeckung, nämlich $60 \%$, hat an der Westküste viel zu wenig, da dort alles kahl heruntergeschlagen wurde, im Innern des Landes dagegen noch zu viel Wald; das gebirgige Japan hat mit 25\% Wald die Hälfte seiner Berge entwaldet; auch für Nordamerika hat man eine Zahl gefunden, nämlich $26 \%$.

Ich halte es für sehr bedenklich, aus diesen Zahlen irgend welche Schlüsse zu ziehen; zum mindesten, was Amerika betrifft, ist die Zahl gan\% werthlos, so lange nicht das Minimum an Wald bekannt ist, das das grosse Land in Folge seiner Configuration, seiner Bodenverhältnisse besitzen muss.

Das Minimum an Waldfläche aber ergibt sich aus dem Verhältnisse der Schutzwaldgebiete zur gesammten Fläche einer Gegend, wobei nur Landstriche von annähernd gleichem Klima und gleicher Vegetation als ein Ganzes genommen und zur Schutzwaldfläche in Proportion gesetzt werden könmen.

Als Schutzwaldungen sind in erster Linie alle Waldungen auf Berghängen und Kuppen, \%ur Erhaltung und Regelung der Wassermenge der Flüsse, damn die Waldungen auf mageren, einer landwirthschaftlichen Benützung nicht oder nur vorübergehend fähigen Böden zu rerstehen. Die Fläche dieser Waldungen drückt die wahre Menge, das Minimum aus, welches als Wald bestehen bleiben muss. Auf allen andern Flächen kann der Wald zu Gunsten der landwirthschaftlichen Zwecke weichen und hat sogar auf diese Flächen so wenig ein Recht, wie die Landwirthschaft ein solches auf den absoluten Boden der Schutzwaldungen besitzt.

Der Staat sollte aus national-ökonomischen Gesichtspunkten seinen Bürgern die Berghänge und Bergkuppen, die mageren Büden abnehmen, um sie vor den unaufhörlichen landwirthschaftlichen Misserfolgen und ihrer endlichen Verödung zu bewahren, könnte ihnen aber dafür das landwirthschaftlich brauchbare Terrain überlassen, das er gegenwärtig nuch vielfach mit Wald bedeckt in Besitz hat. 
hodunet mon mach whigen (iesichtspunkten das Procentrerhälniss

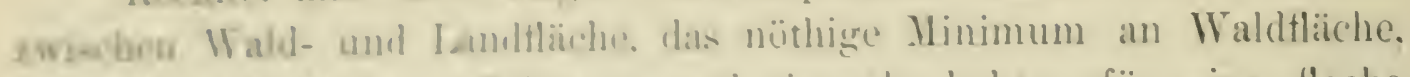

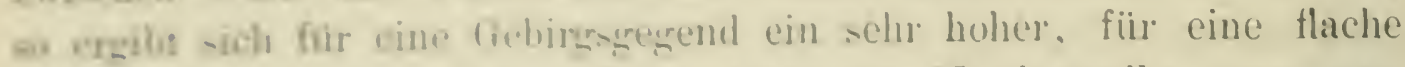
Landsobal wh selur niendriger l'rocentsit\%; für Nordamerika muss man das Waldrerhalmios nahe den drei grossen (iebicten, die atlantische liegion. be Lrario und die pacifische Region betrachten: das erste

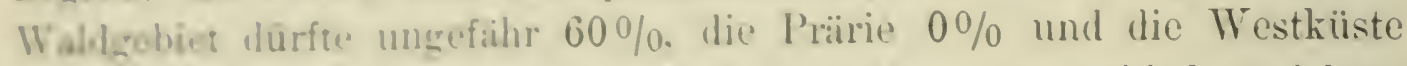
ctwa 30\% Wald aufweism: im Osten stocht noch entschieden viel zu riel Wabd in ler Ehenc auf landwirthschaftlich benutzbarem Boden; in den boheren (ieligren aber, auf den mageren Bodenarten ist schon

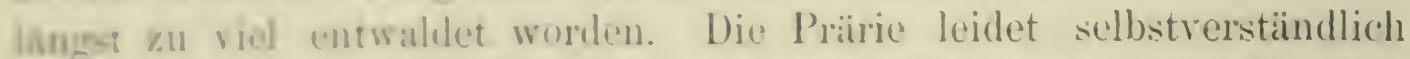
Aureh den Mangel an Wald an grausamen Extremen ihres Klima's: an dor parifi-chen Kisste ist in Norden centschieden noch zu viel Wald: im snden, in Cillifurmien, in Nevada, in Arizuna. New Mexico, Colonado fialuen sehon die eranen l'ionioge das Minimum an Wald, das zur nach-

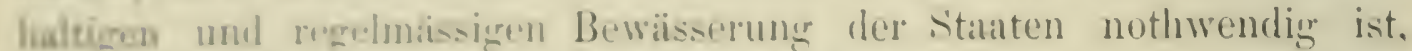

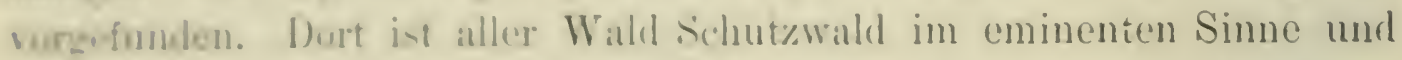
war w ron Infung an ein grusier lichler. den Wald theils rëeksichtslus zu mishanduln. Uheils zu Landwirthsohaftlichen Experimenten \%u roden;

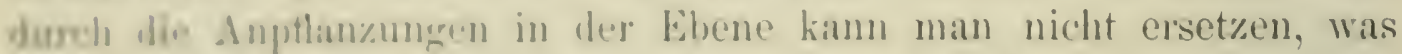

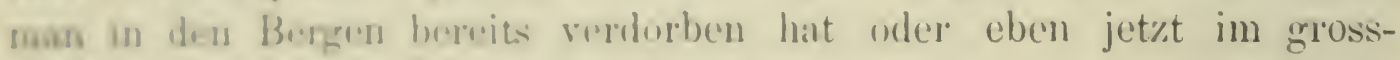

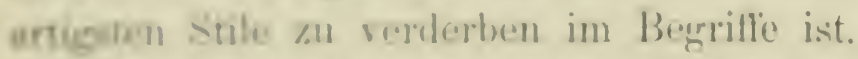

Lander mis insularem Klima ohne Gebirge branchen \% Brloultang dos Klimats und des Budens keinen Wald. England

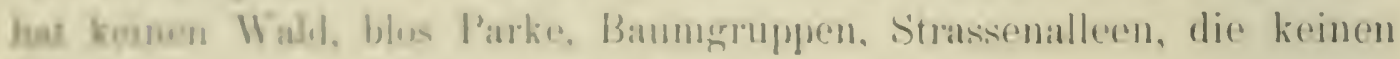
hesaleron metoorologirchen Eintluss ansiiben kïmnen.

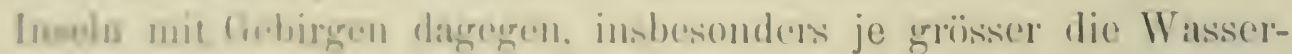

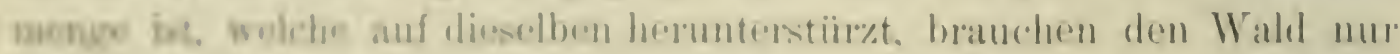

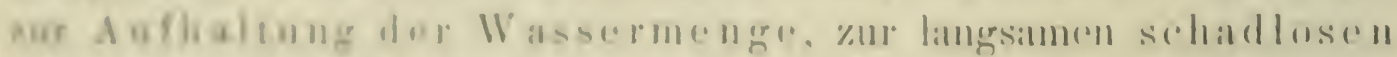

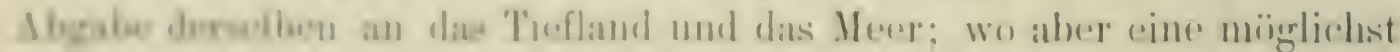

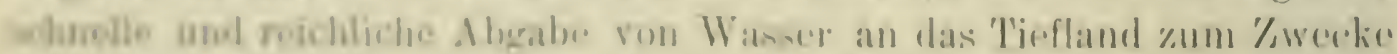

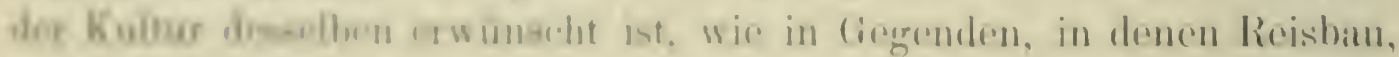

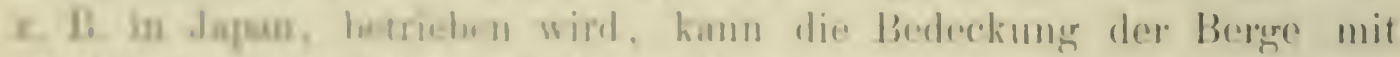

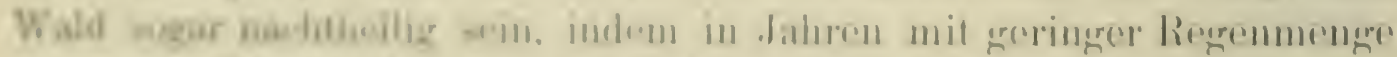

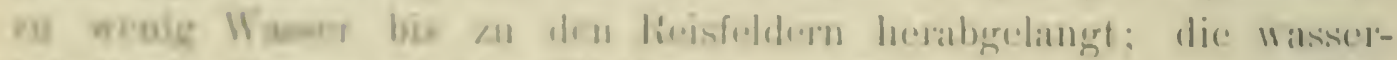

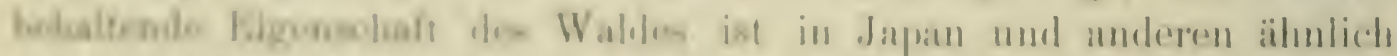

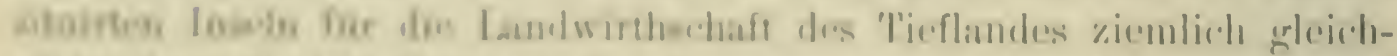

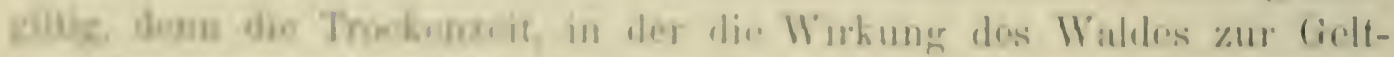

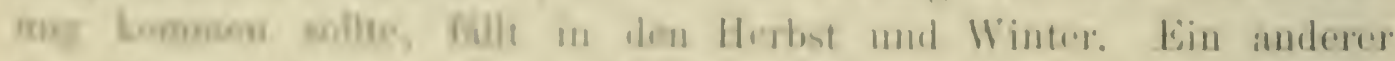

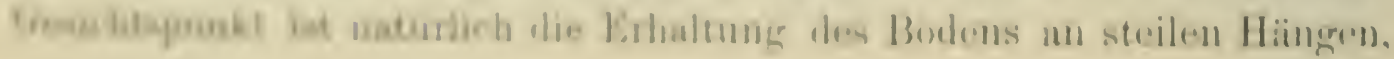


sowie einer möglichst reichlichen und gleichmässigen Wassermenge in schiff'baren Flüssen u. dgl.; für solche Gegenden und Zwecke ist Wald auch hier unentbehrlich.

Länder mit continentalem Klima bedürfen des Waldes vorzugsweise zur Z u r ü ckhaltung der Wassermenge während der Regenzeit und zur langsamen, fruchtbringenden Abgabe derselben an das Tiefland während der trockenen Zeit. Die Waldungen der Küstengebirge nähern sich in ihrer Rolle denen der gebirgigen Inseln, während den Gebirgswaldungen im Innern der Continente, wo die Regenmenge und Abschwemmungsgefahr bedeutend geringer sind, vorzugsweise die Aufgabe der Conservirung der Feuchtigkeit obliegt.

Nach diesen Gesichtspunkten wird in einem so grossen, klimatisch so rerschiedenen Lande wie die Vereinigten Staaten repräsentiren, die atich dort über kurz oder lang sich aufzwingende, regelrechte Forstwirthschaft die überlassenen Waldungen in Pflege nehmen müssen; die dabei zu wählenden Systeme werden nach dem Werthe der Waldungen für Klima, Boden, Bevölkerung und den Besitzer selbst unter sich und wohl anch ron den bestehenden europäischen Systemen verschieden sein müssen.

\section{h) Nebenprodukte.}

a. Die Harz- und Terpentingewinnung (naval stores) in den Vereinigten Staaten ist schon sehr alt und beschränkt sich auf die Region der Pinus australis, der südlichen Kiefer, welche fast ausschliesslich die Union mit Harz und seinen Produkten, Terpentinöl und Holytheer versieht; untergeordnet kommen gegenwärtig Pinus eubensis und Pinus Taeda in Betracht. Für die Zukunft werden sie, wie Karl Mohr bemerkt, eine Rolle spielen, da bei den Raubsystemen, mit denen alle Urproduktionen in Nordamerika betrieben werden, die südliche Kiefer dem Untergange geweiht ist. Schon zur Zeit der Kolonialregierung betrug die Harzmenge jährlich 88000 Fass; insbesonders als während der vierziger Jahre in den Hafenstälten das destillirte Terpentinöl beliebt wurde, schwangen sich die Industrien bedentend auf; gegenwärtig sind violfach etwas schonendere Gewinnungsmethoden, ähnlich den bei der österreichischen Kiefer in Gebrauch befindlichen, empfohlen. Die herrschende Wethode beschreibt Mohr, der mitten in dem Harznutzungsgebiete seine Studien gemacht hat, folgendermassen: „Während des Winters werden an dem Stamme etwa 1 Fuss ïber dem Boden wagrecht quer iiber den Stamm verlaufend und schief nach dem Innern desselben gerichtet, Behälter (boxes) eingehauen; die Lünge des Einhaues beträgt 


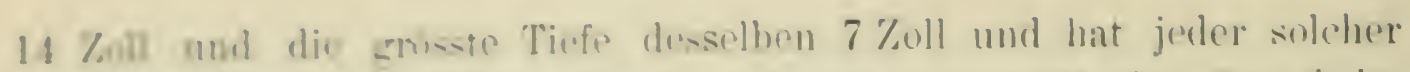

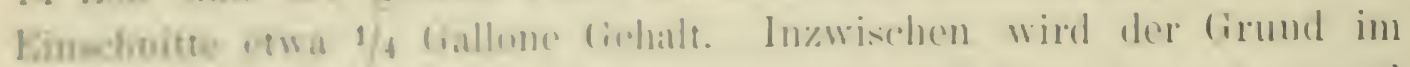

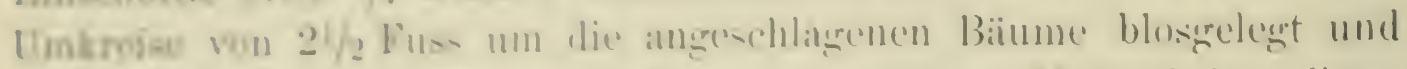

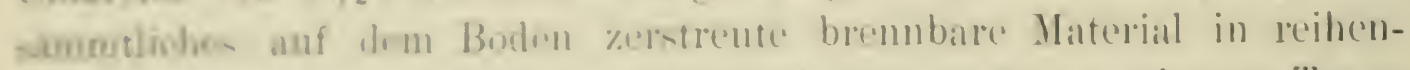

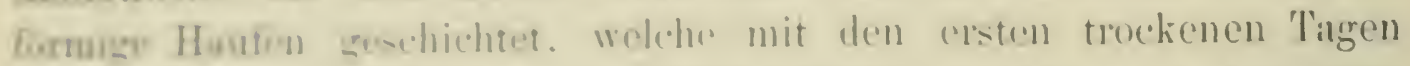

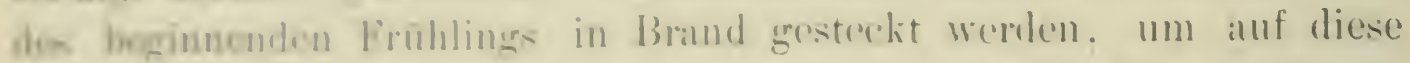

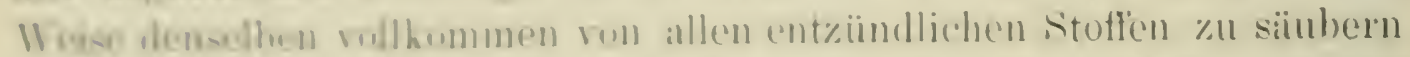

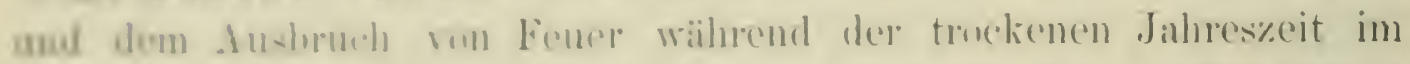

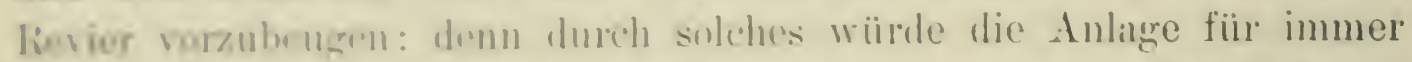

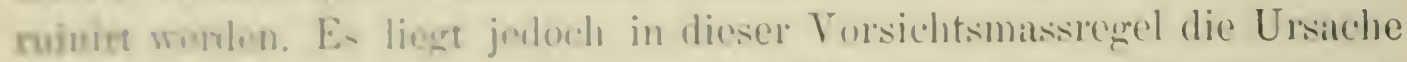

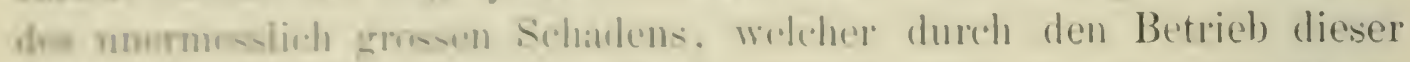

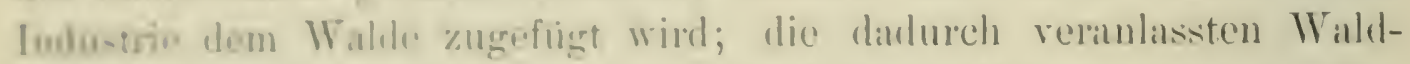

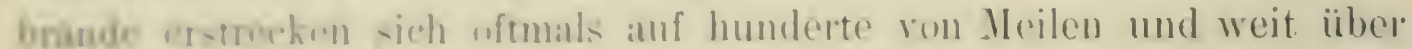

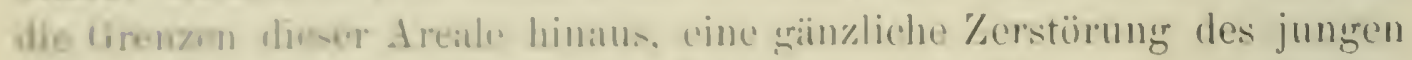

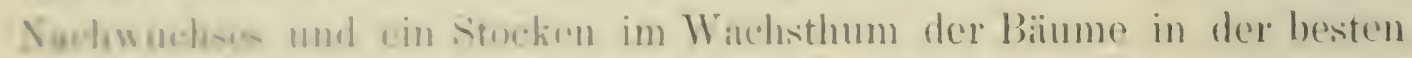
f'onote ihrer Entwicklung herbeiführend. Nich wenigen Jahren bieten

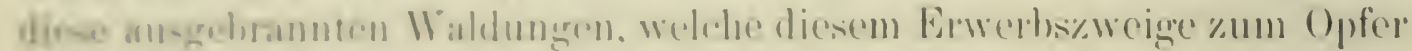
fielen. don Buden buderkend mit den durch die Stärme niedergestreckten

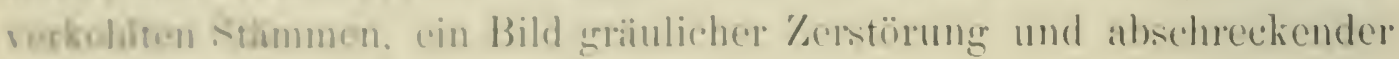
Vervidung lar.

Ilis den exton Tagen des frühlings, in denen der saft in den Bumon an strimen beginnt, wird mit dem Anrity'n derselben der

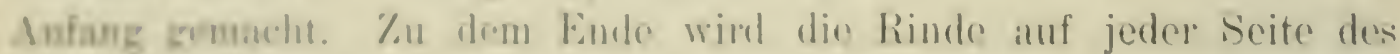

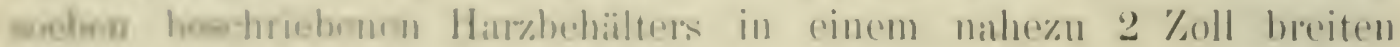
stroben hie zur Hohe ron $8 \%$ oll ïbee dem Einschnitt mittekst der

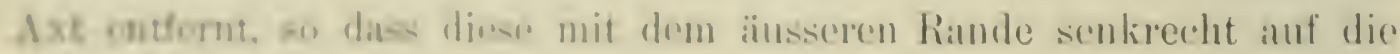

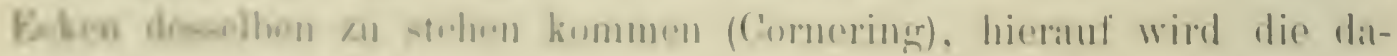

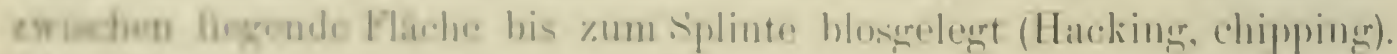

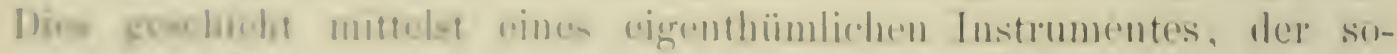

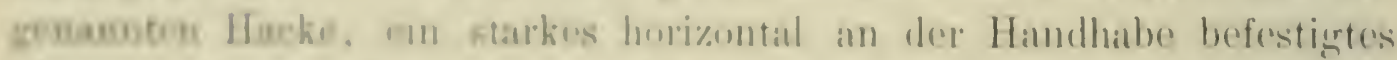

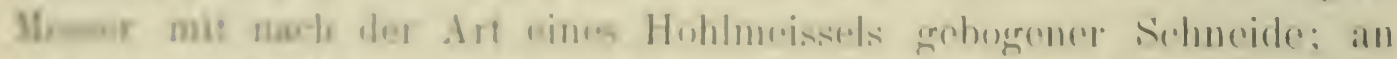

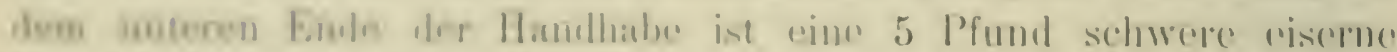

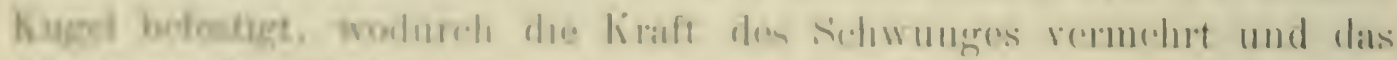

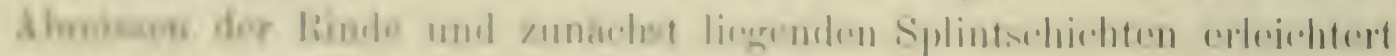

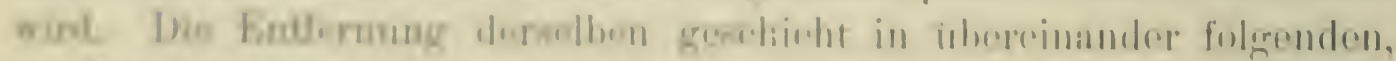

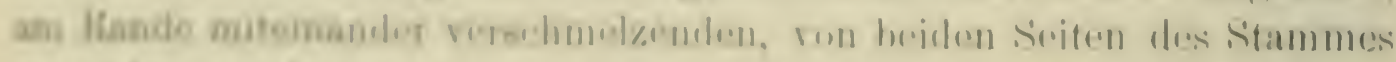

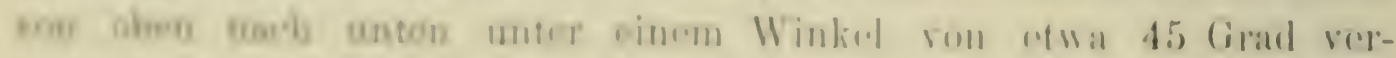

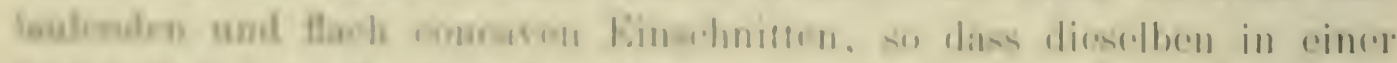

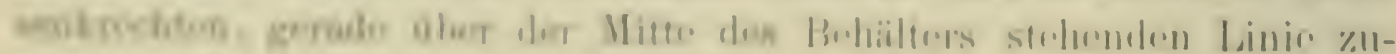

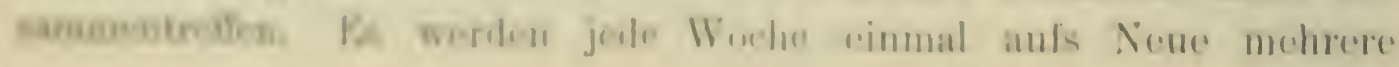


soleher Einschnitte gemacht, so dass die blosgelegte Oberfläche über dem Behälter im Laufe des Monats um 11/2 - 2 \%oll erhöht wird. Diese Operation (chipping) beginnt in der Mitte des $\Lambda$ pril und wird bis Mitte Olitober, und bei ausnahmsweise günstigem, anhaltend warmem Wetter bis zum Norember fortgesetzt; die Besorgung derselben während dieser Zeit ist die Aufgabe eines Arbeiters. Die Behälter füllon sich während des ersten und zweiten Jahres durchschnittlich alle vier Wochen und werden mittelst einer flachen Kelle entleert (dipping). Die Ausbente von 10000 Behältern beträgt bei aufmerksamer Besorgung bei jedesmaligem Ausschöpfen 40-50 Füisser von je 280 Pfund Rohharz (Terpentine). Die Behälter werden daher während der Betriebssaison sechsmal ausgeschöpft. Kommt mit dem Anbruche der kühleren Jahreszeit die Harzabsouderung zum Stillstande, so wird die harzabsondernde Fläche, sowie der Behälter sorgfültig ron dem anhängendem Harze (Scrape) befreit; dieses durch Abscharren erhaltene Harz ist von geringer Qualität, missfarbig, durch Holztheile verunreinigt und von einem um die Hälfte geringeren Gehalt an flüchtigen Bestandtheilen."

Die gegenwärtig gewonnene Masse wird verschieden hoch, im Jahre 1S79/80 zu 171/2 Millionen Gallons (794500 hl) Terpentin und 11/2 Million Fïsser Hartharz geschätyt, welche am Orte des Verbrauches rund die Summe ron 331/2 Millionen Mark Werth hatten.

Der Profit, den diese Nutzung abwirft, ist trotz der ausserordentlichen Billigkeit der Kiefernwaldungen doch ein sehr kleiner und nur bei ganz geschickten Arbeitern erreichbar; ausserdem lohnt der Betrieb in der Regel nur in den ersten Jahren, wenn jungfräuliche Bestände zur Nutzung herangezogen werden; die Folge ist, dass schon nach ein paar Jahren das Feld der Thätigkeit wieder in eine neue Waldpartie verlegt wird, zuriick bleibt - le déluge.

Der Schaden durch die Harznutzung im Holze selbst ist weniger durch den Entzug des Harzes als dadurch bedingt, dass einmal von dem werthrollsten Stücke ein Theil unbranchbar gemacht ist, dass ferner Pilze und Fäulnissprocesse aller Art in der Wunde zum Ausbruche kommen, die rasch im Baume sich verbreiten und diese werthvollsten Kiefern zerstören oder besser zerstören würden, wenn nicht das Feuer, die Geissel der nordamerikanischen Kultur, zuvorkommen und alle Vorsichtsmassregeln, mit welchen man zuweilon solche Pine orchards schützt, zu Schanden machen würde.

$\boldsymbol{\beta}$. Gerbstoff. Die Vereinigten Staaten haben einen stattlichen Reichthum ron Bäumen, welche in ihrer Rinde so viel Tamnin enthalten, dass die Nutzung sich lohnt. Ordnet man die Holzarten nach ihrem 
Gerh-totgechaire. der fur den Census-Repurt 1879/80 ron Shalples

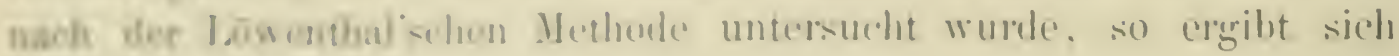
Inlgonde siala:

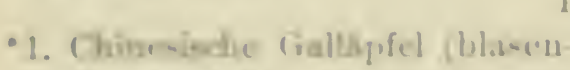

Pruccill fromigan lois $10 \mathrm{cim}$ langen Arecbwolunzen for Blatter and Blaclotiete son kilus so. miabula der im warmeren J: pon heimistren Aphis chi. Bexa-1

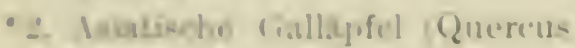
Infictoria)

x. Cacectsa, atis demin hernholze nu Acacia Colerdu

- 1. Valunes. Frudibectier von Delomsinti-cluen und prienll forlasu Raiturn

6. Rnoppern (von (thercan jeedun. ailases

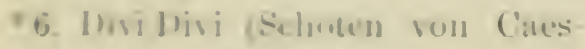
alpina coriaria)

i. Jihoopher 1langle . . . 311

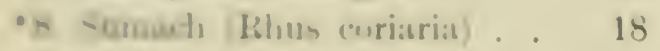

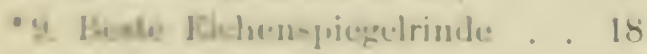

10. queress ilenwiflora . . . 16,5)

11 Piros Ënglmanui . . . 16,4

12. Tmiga I'atconimas, . . 15,7

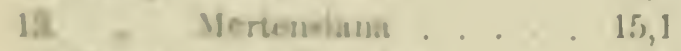

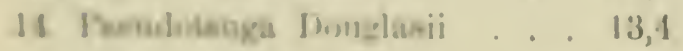

l'rocent

15. 'Tsugat canalensis . . . 13,1

16. Ounereus virens . . . . 10,5

17. .. prinoides . . . 10

*18. Alnus glutinosil . . . 10

* 19. Junge Wejiclenrimle . . . 10

20. Quercus linoryi . . . . 9,8

*21. Alte Eichenrinde (erelut $\%$ t) . 9

*22. Junger Fichterrinde . . .99

23. (quereus filleata . . . . 8,6

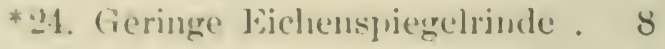

25). Piceal nighra . . . . . 7,2

*.26. Alte Fichtenrinde . . . 7

*27. Litrchenrinle . . . . . 7

*2s. Ilte Eichenrinde (ungeput\%t) 7

29. (zuercus kelloggii . . . . 6,5

30. . l'rinus . . . . 6,2

31. Castaneat ancricana . . . 6,2

*32. Europ. T'annesurinde . . . 6

33. (2uercus allia ...... 6

34. , tinctorial . . . 5,9

35. . macroc:arpal . . 4,6

36. " rubra. . . . . 1,6

:37. " nigra . . . . . 1,4

38. Prosinfis juliflora . . . . 1

"39. Lirkenriude. . . . . . 1

*10. Iiusikistintuic . . . . 3

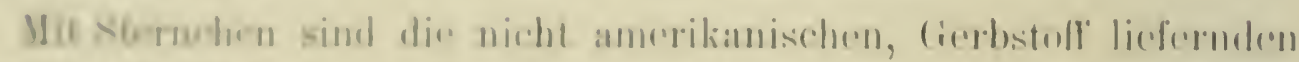

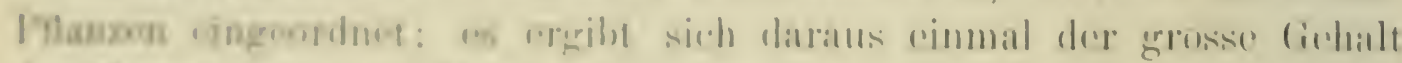

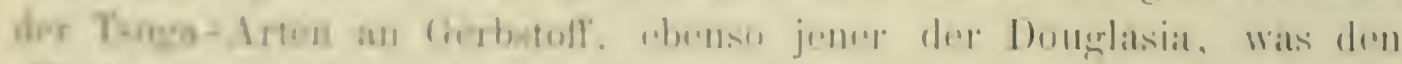

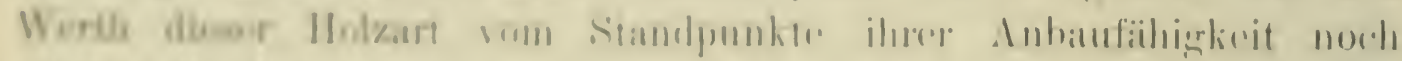

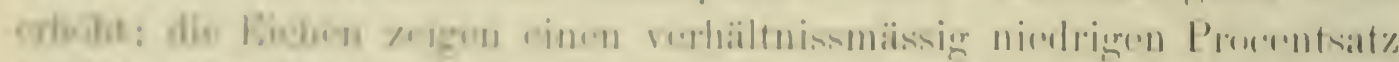

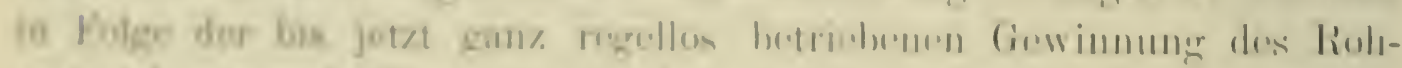

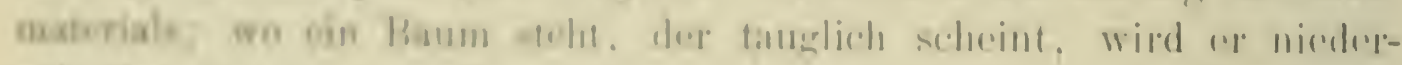

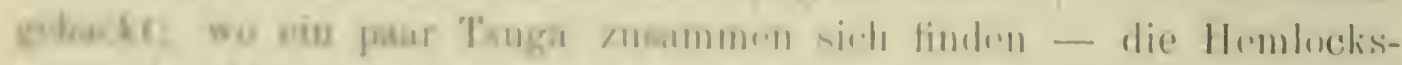

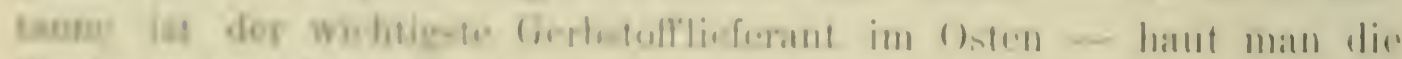

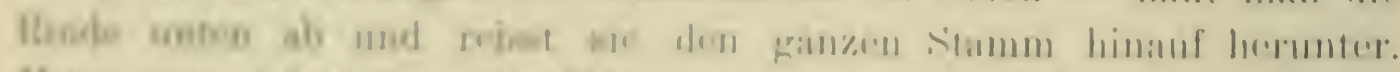

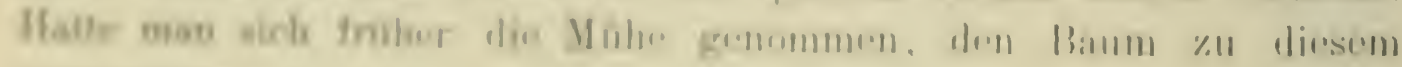

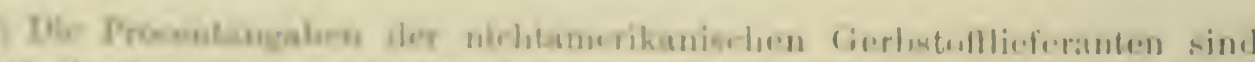

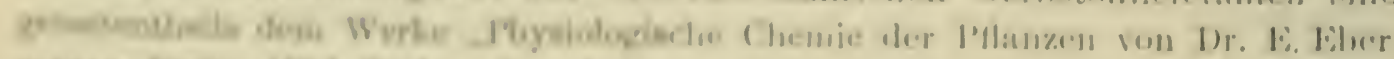

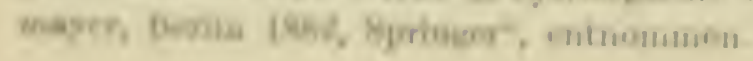


Zwecke zu fällen, so blieb er, so lange man White Pine (Pinus Strobus) hatte, als werthlos liegen, verfaulte oder verbrannte mit allem dem, was in seiner Nähe lag. Jetzt ist in vielen Staaten die White Pine bereits ausgenutzt und die Sägemühlen fangen an, die verschmähte 'Tsuga zu verarbeiten, deren Holz stetig in Preise steigt.

Zweifellos wird der Gehalt an Gerbstoff' bei den Eichen durch eine regelrechte Niederwaldkultur, die in den Vereinigten Staaten hoch lohmend sein muss und welche auch bald kommen wird, sich bedentend steigern lassen; da eine Niederwaldkultur der Tsuga nicht möglich ist, wegen ungenügender Fähigkeit aus dem Stocke auszuschlagen, so dürfte sich bei dieser Holzart die Gerbstofinutzung mit der Zeit auf die alten technisch verwendbaren Exemplare erstrecken - eine magere Ernte in der Zukunft, denn wo Feuer in die Hemlocks-Waldungen einfällt, vernichtet es junge und alte Bäume gleich gründlich.

In der Zahlemreihe liegt ein dentlicher Fingerzeig, welche Holzarten und welche Oertlichkeiten für die Niederwaldkultur am lohnendsten sein werden; man kann im Allgemeinen (bei dem unvollkommenen Untersuchungsmaterial nach dieser Richtung hin) eine Zunahme des Gerbstoffgehaltes in den Eichenarten nach Süden hin wahrnehmen; im Osten steht Querus virens, die Eiche, welche im wärmsten Gebiet wächst, oben an, im Süden verspricht ihre Kultur und jene der Quercus Prinos, in den wärmeren Orten die besten Erträge; im Norden wird Quercus prinoides in den wärmeren Lagen mit Vortheil auf Gerbstoff im Niederwalde ben ützt werden kömnen; der werthvollste Gerbstoff baum des Westens ist Quereus densiflora, aus welchen die Kultur einen Nutzbaum ersten Ranges schaffen könnte.

$\gamma$. Syrup und Zucker werden aus dem Zuckerahorn gewonnen; der sehr wohlschmeckende Syrup ist ein vortreffliches Surogat für Honig und wird in Amerika in sehr grosser Menge konsumirt. Nach dem Census-Berichte pro 1879/80 wurden in den Vereinigten Staaten $361 / 2$ Millionen Pfund Zucker und $81500 \mathrm{hl}$ Syrup aus dem Zuckerahorne gewomnen; in Folge der nördlichen Verbreitung des Baumes steht oben an Termont; das kleine New-Hampshire liefert allein 732000 Pfund, wobei die Bäume der Bergwaldungen wegen ihrer Abgelegenheit ron den bewohnten Orten meist noch gar nicht genüitzt sind. Bezüglich der Gewinnungsmethode besteht im Allgeneinen folgendes Verfahren: in den Bergen auf trockenem Boden im Spätwinter, wenn der Boden noch mit Schnee bedeckt, aber Luft und Sommenschein bereits warm geworden sind, werden die Bäume etwa 2-3، über dem Boden angebohrt bis auf eine Tiefe ron $5-15 \mathrm{ctm}$ je nach der Baumstärke. 


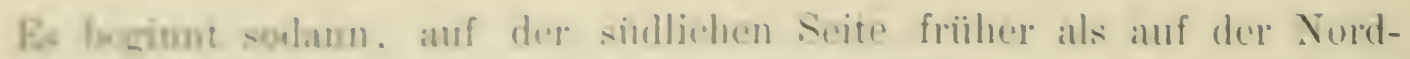

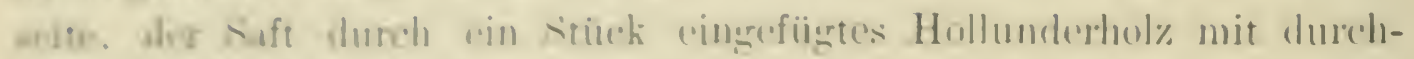

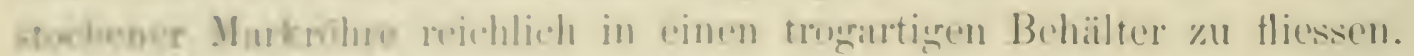

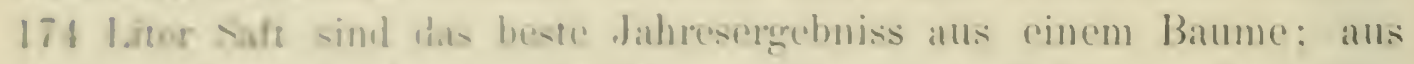

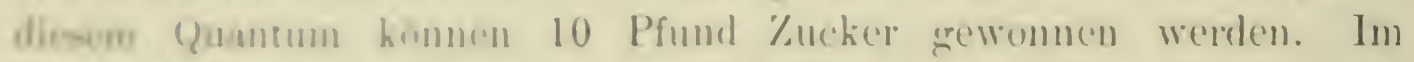

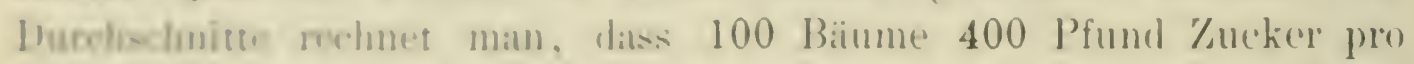
Jaht lieforn. Wor saft wird jeden Muren gresimmelt, in grosisen, flachen

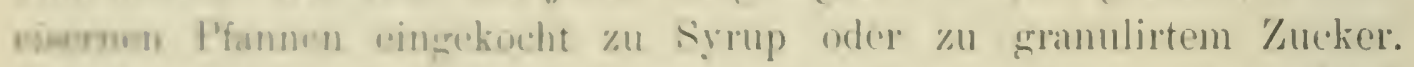
Vor dem 30. Jilnre sull kein Batum ingerebohrt werden, kiann aber dimn

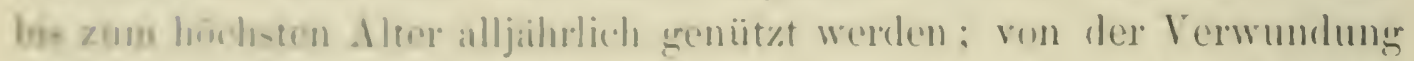

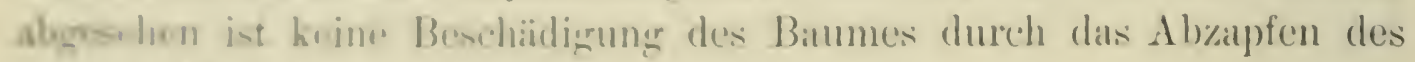

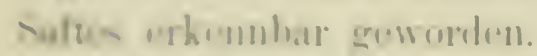

d. Hulzanff \%ul l'apror- mud Colluluse-fabribation. Wie bej

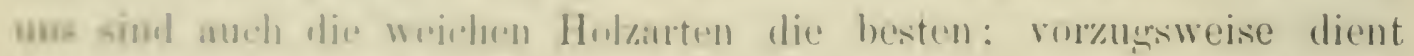

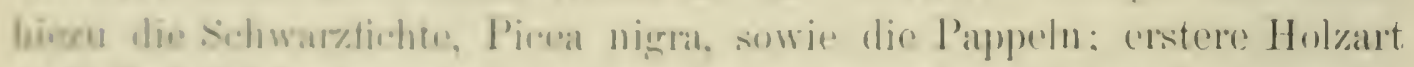

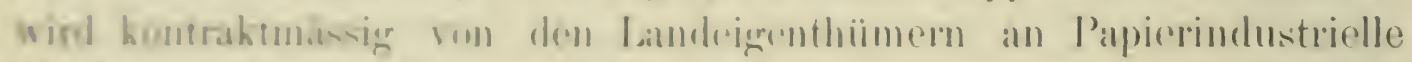

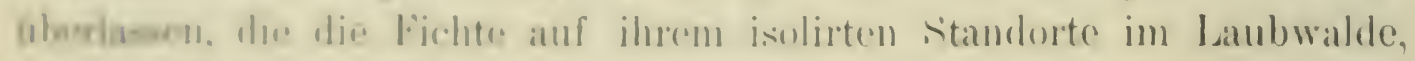

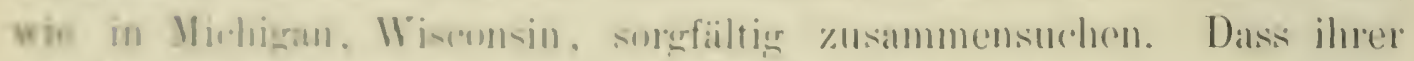

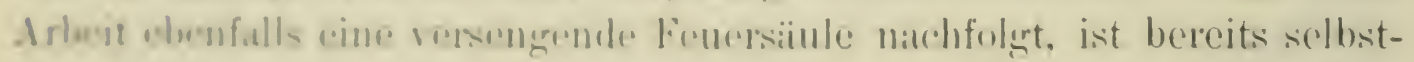

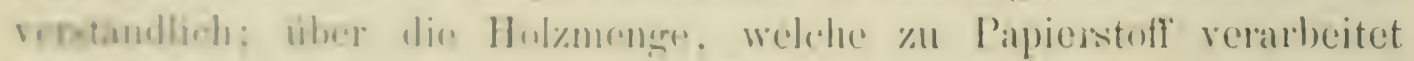

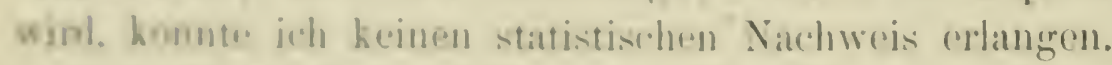

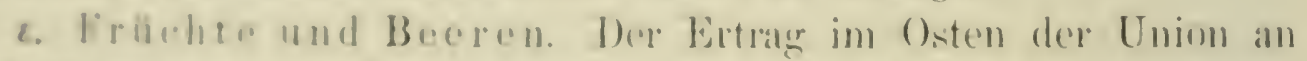

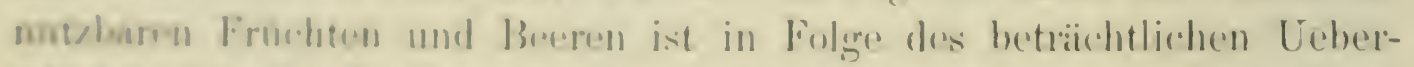

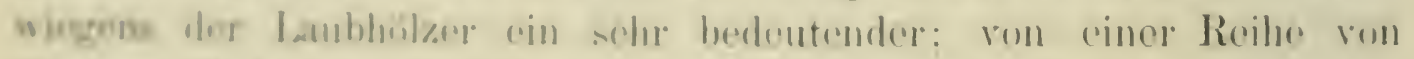

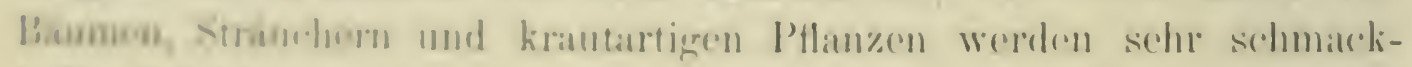

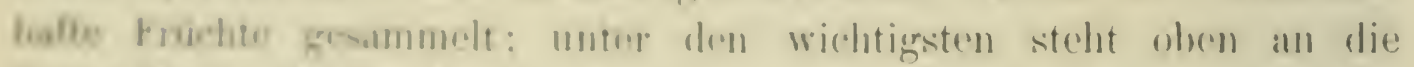

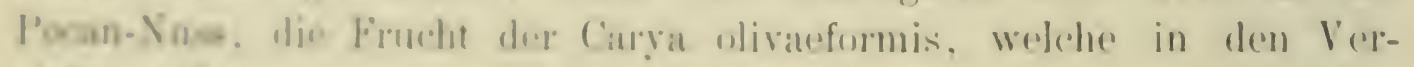

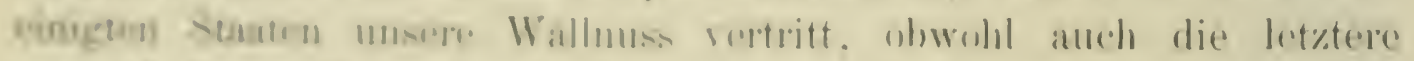

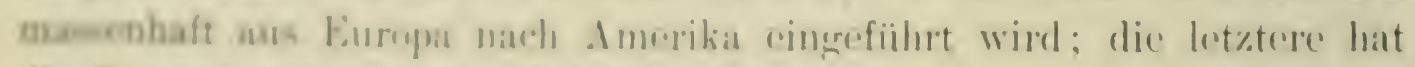

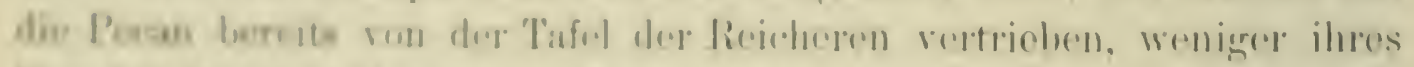

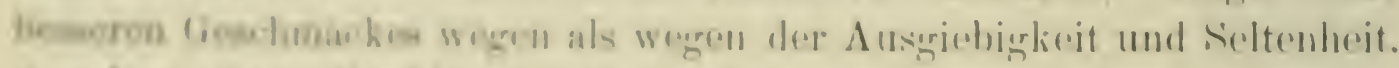

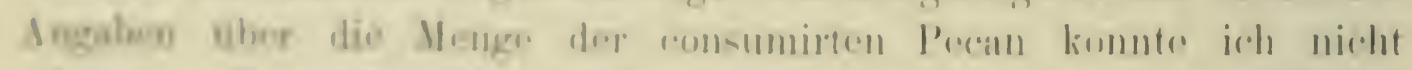

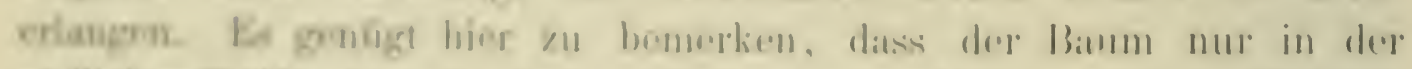

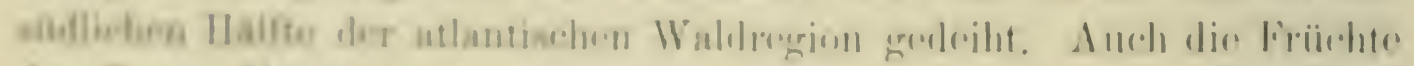

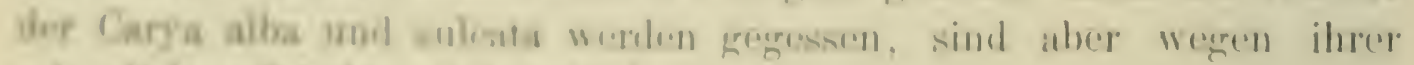

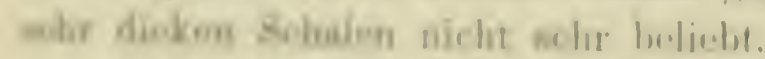

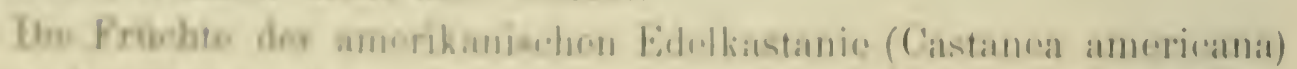

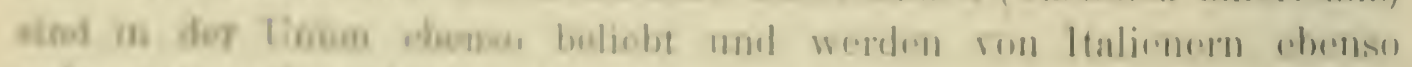

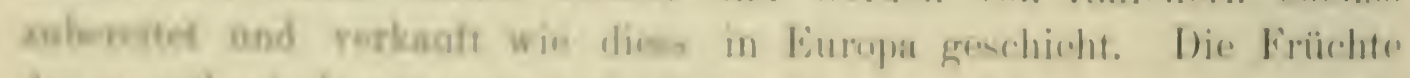

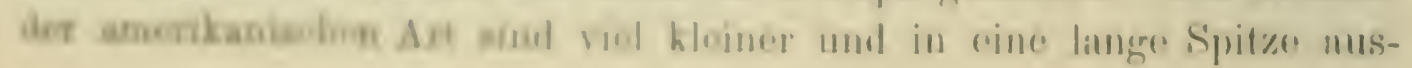


gezogen; wegen ihrer Grösse kommt auch die europäische Edelkastanie nach Amerika. Der Baum trägt in Amerika die Früchte zu seinem Unglïcke. Steht er in der Nähe ron menschlichen Wohnungen, so ist er zerfetyt von der lieben Jugend, natürlich lange, bevor die Früichte reif sind; steht er im Walde, so entgeht er seinem Schicksale doch nicht, mit Aexten und Säcken ziehen die Männer hinaus und hauen die mit Früchten beladenen Aeste herunter.

Die Persimon, die Frucht von Diospyros virginiana wird in grosser Menge verspeist, so bald der erste Frost den Bitterstoff in den Früchten in einen suissen, angenehm herben umgewandelt hat; im Westen sind eine Reihe von Pinus-Arten als Nusslieferanten bekannt, die insbesonders für die Indianer ein wichtiger Nahrungstheil sind; auch ron den Weissen werden viele der schmackhaften Samen verzehrt und in den Städten im Westen überall zum Verkaufe ausgeboten: besonders bemerkenswerth sind hier Pinus Parryana im südlichen Californien, Pinus osteosperma edulis, monophylla und Sabiniana.

Zahlenmässig lässt sich ferner kaum ermitteln die grosse Menge von Früchten, die alljührlich vom Rindvieh, insbesonders von den Schweinen, aufgelesen wird. Die grosse Zahl von Eichen östlich und westlich von der Prärie, die Buchen, die Kastanien, Hikory-Arten, die Umbellularia und andere liefern in ihren grossen stärkmehlreichen Früchten eine ausserordentlich werthvolle Mast.

Unter den zahlreichen Becren erwähne ich hier vor allem die amerikanische Preisselbeere, Vaccinium macrocarpum, die im kalten Sumpflande der nördlichen Staaten gedeiht. In Wisconsin wurden 1884 2 Millionen Liter Beeren gesammelt, welche einen Werth von 1 Million Mark auf dem Markite in Chicago repräsentirten. Ich werde später auf diese auch für Deutschland, wie ich glaube, wichtige Kulturpflanze zurückkommen.

E. Sonstige Nebenprodukte. Dass der Wald Streu, Steine, Humus, Erde und dergleichen abgeben muss, so viel man eben nöthig hat, ist kilar; ich übergehe ferner Alles, was ron Blättern, Zweigen, Rinden etc. Verwendung findet. Eine eigenartige Nutzung gewährt der Wald im Südosten der Union, insbesonders in Florida und an der Küste der Südstaaten; in Folge des luftfenchten Klima's entwickelt sich an den Baumästen eine mehrere Meter lang herabhängende, einer Bartflechte ähmelnde Pflanze, die Tillandsia usneoides. Das sogenannte „Moos" wird in den tiefen Lagen und Sumpfpartien, insbesonders zu Hochwasserzeiten, in Kähnen gesammelt, auf Haufen geworfen und etwa 10-12 Monate lang dem natïrlichen Fäulnissprocesse, der Maceration, 


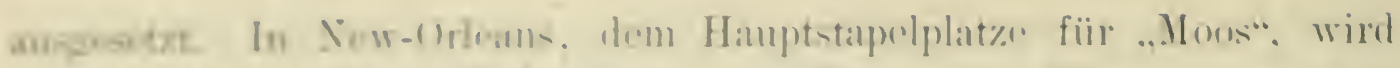

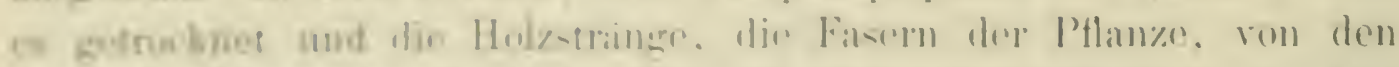

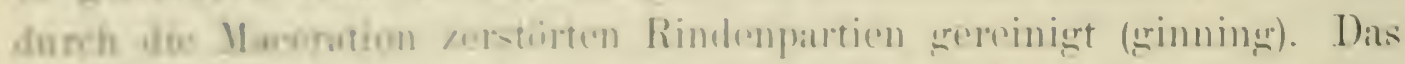

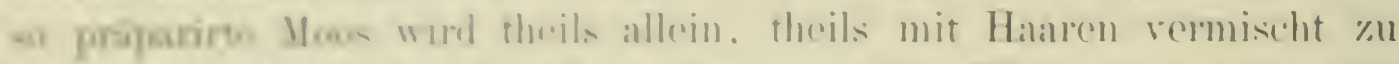

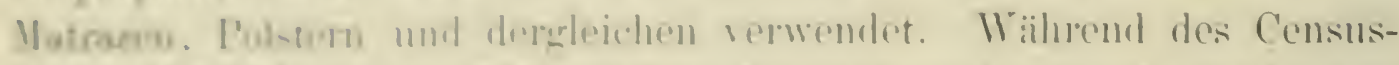
iahms 187:1/80 kamen 3500 billen Rohmons mit dem Gewichte ron

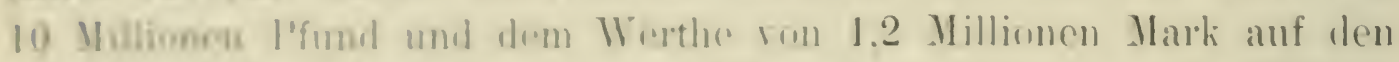

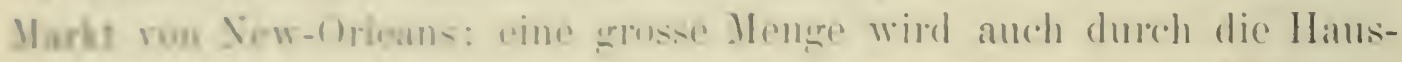

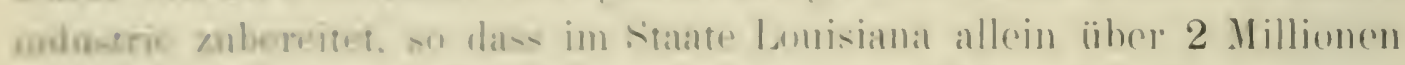

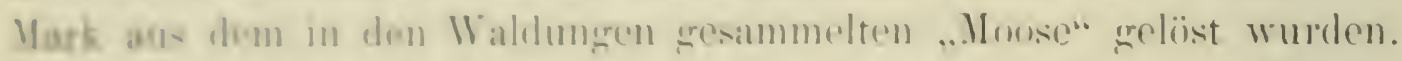

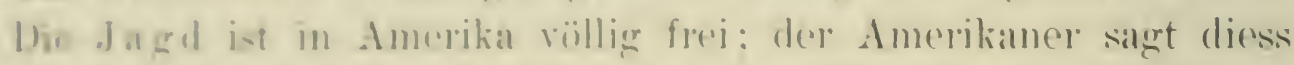

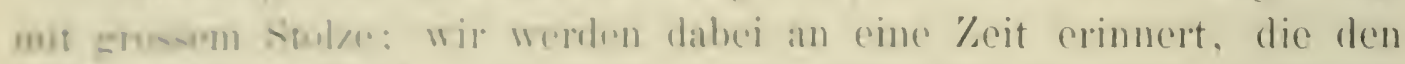

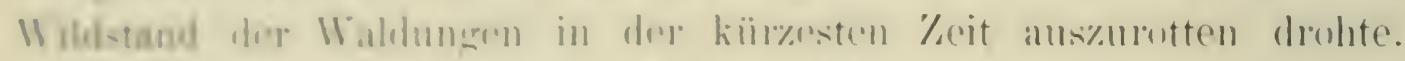

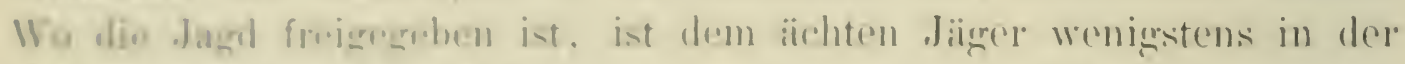

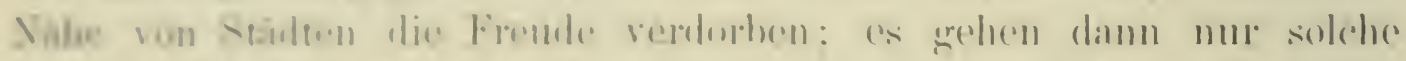

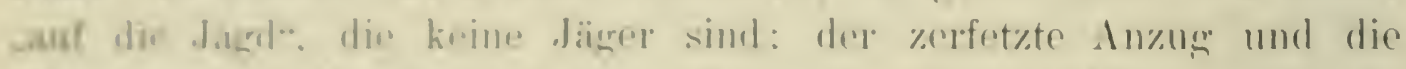

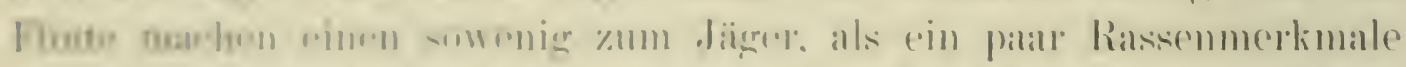

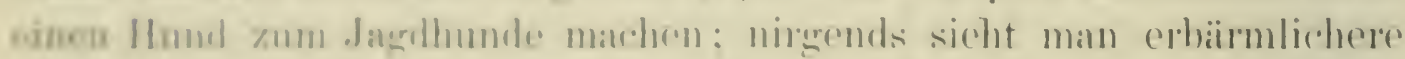

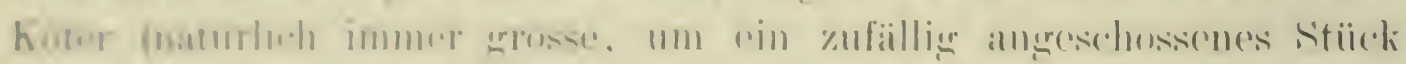

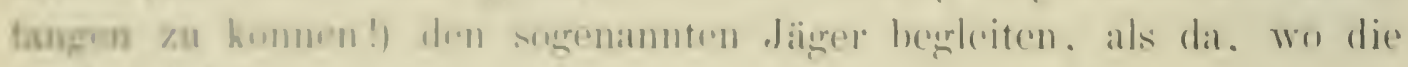
fact fret in:

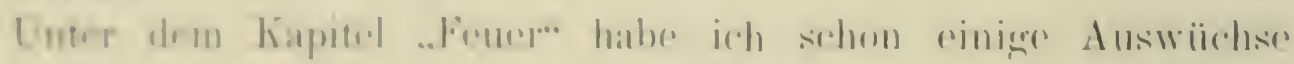

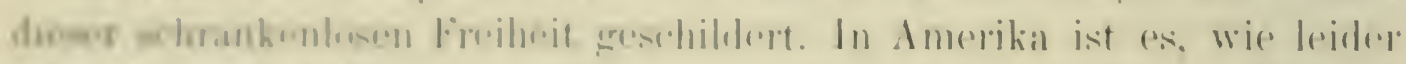

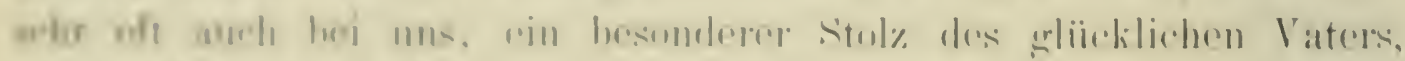

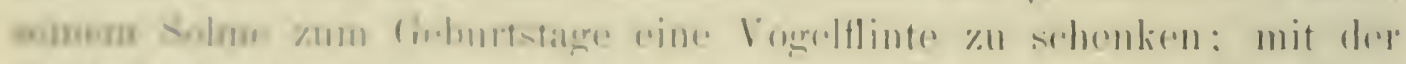

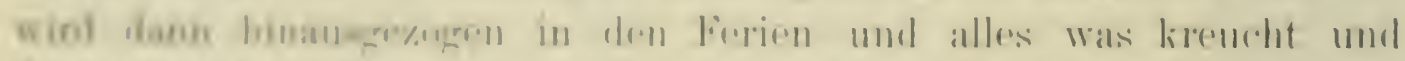

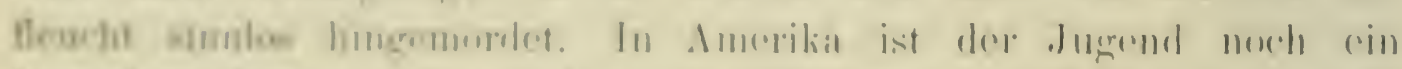

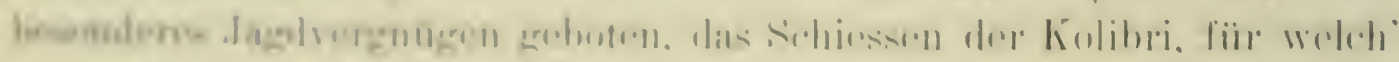

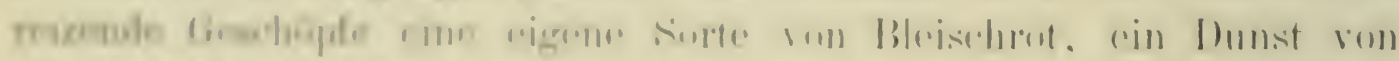

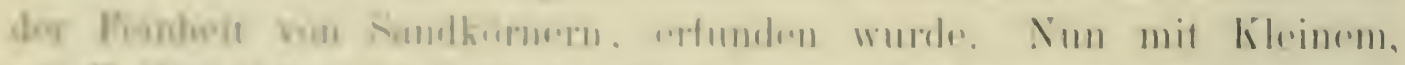

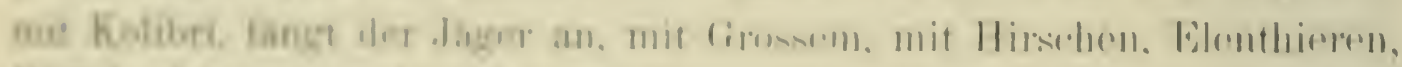

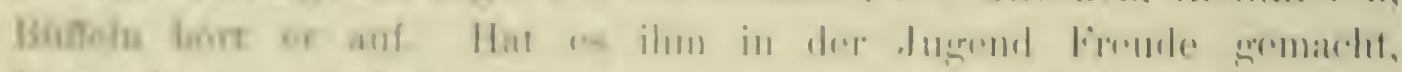

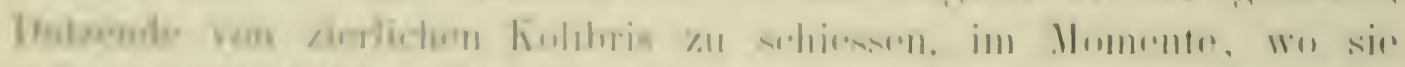

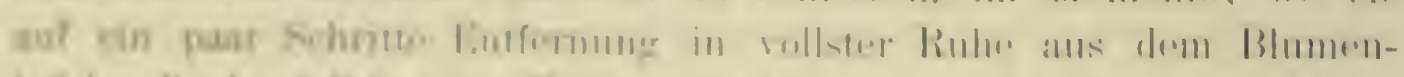

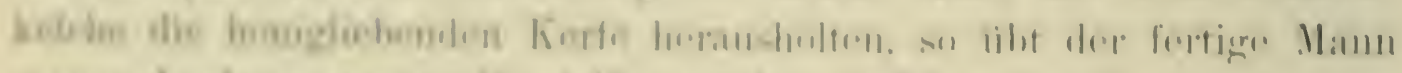

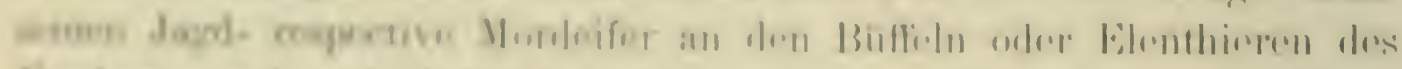

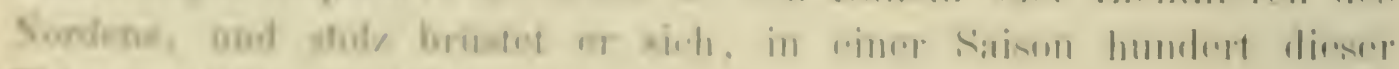

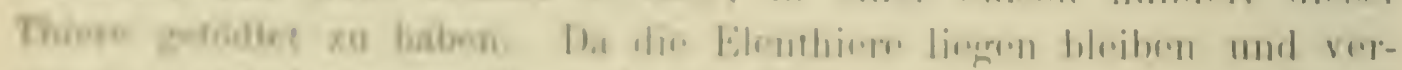

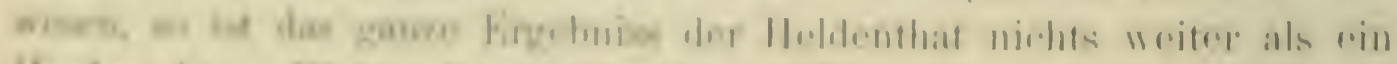

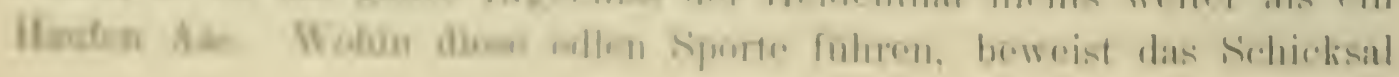


der Büffel in den Präriestaaten des Westens; noch vor zehn Jahren hörte man ron ungeheuern Heerden ron Büffeln, die in endlosen, schwarzen Linien über die baumlose Landschaft dahinzogen: jetzt kamn man ein par Dutzendmal die Prärie durchkreuzen und sieht nicht ein einziges Stiick.

Bis zu solcher Höhe steigen nur wenige "Jäger"; die meisten, oft kaum selbst so lang wie ihre Flinten, knallen und puffen, an den Somntagen natürlich, in allen Aeckern, Sümpfen und Feldern umher, weniger gefährlich für das Wild, als für den sorglosen Wanderer, der im Walde seine Ruhe sucht.

Solche, welche die Jagd gewerbsmässig treiben und nomadisirend in Hütten, mitten im Walde, leben, werden glücklicher Weise immer seltener: nicht nur haben diese Tausende ron Quadratmeilen niedergebrannter Wälder auf dem Gewissen, sie sind es auch, welche den Wildstand in den Bergen und unzugänglicheren Waldpartien gründlich ruiniren, da sie Alles schiessen, was läuft; zudem betreiben sie die Jagd mit zahlreichen grossen Hunden, die auf eigene Faust jagen und was sie fangen, zerreissen. Das Fleisch der erlegten Stücke sieht man vor den Hütten in Streifen geschnitten aufgehängt zum Trocknen, in welchem Zustande es dann in die Städte und Dörfer gebracht wird, eine Nahrung für ärmere Leute; die von den Stïcken, wie rom Kantabak, herunternagen; besser lohnen Felle und Gehörne.

Selbstrerständlich können weder diese noch die kommende Generation den Wildstand in den Vereinigten Staaten ausrotten; in den grossen Urwaldbeständen lebt noch reichlich Wild, das bei einer schonenderen Ausübung der Jagd sich rasch in den verlassenen Distrikten wieder einfinden würde. Aber da wo Menschen in der Nähe leben, habe ich die Waldungen gründlich ausgeschunden gefunden und die so beliebten Eisenbahnempfehlungen: game abounds, riversteam with fish gleichen den Plakaten ror den Dimemuseen, die immer das illustriren, was nicht darin ist.

\section{Zuwachs und Qualität der Hölzer der nord- aimerikanischen Waldbäume.}

Ueber diesen Punkt etwas Zuverlïssiges zu bringen, scheint fast gewagt; denn die Qualität ist bisher fast ausschliesslich durch die Praxis festgestellt worden, die \%. B. das Weymouthkiefernholz als das „beste“" Holz erklärt; Zuwachsbeobachtungen fehlen fast ganz und die 


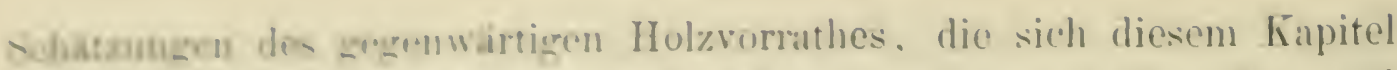

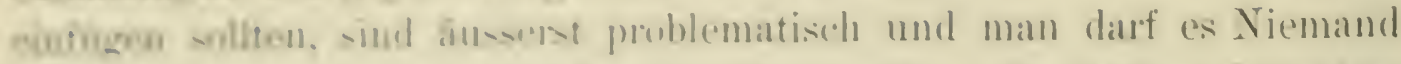

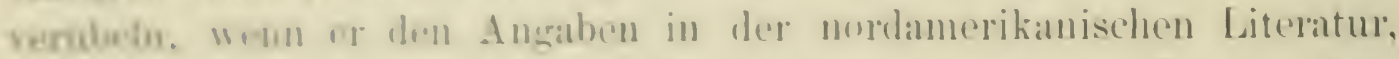

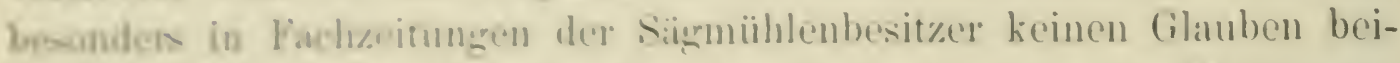

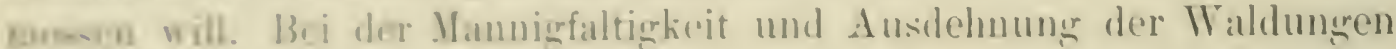

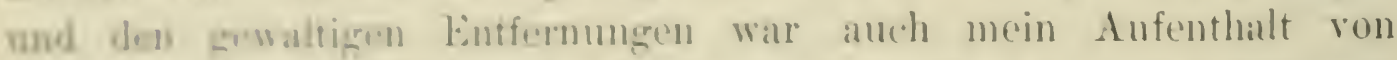

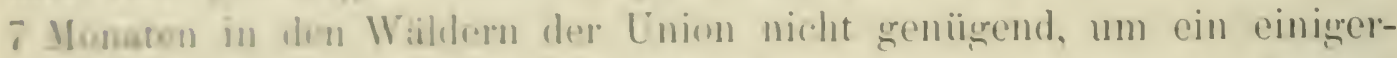

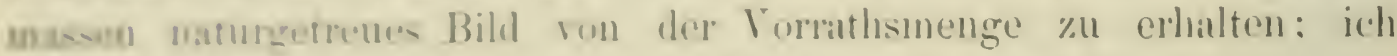

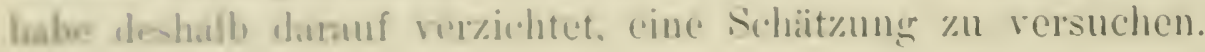

Eober die () ualitait der mordannerikindschen Holzarten haben die

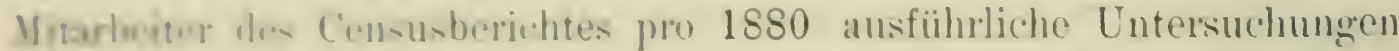

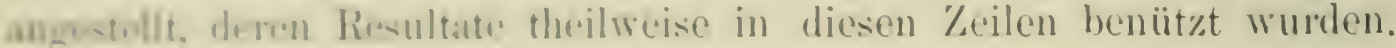

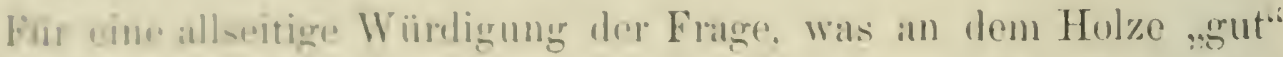

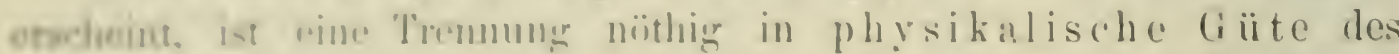

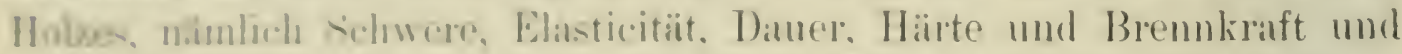

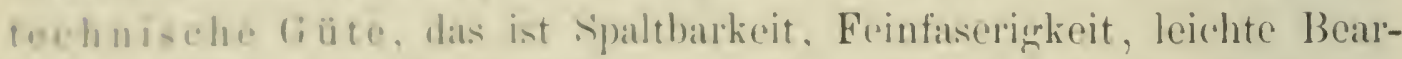

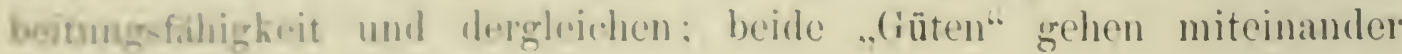
molit isn geringenten patrallel.

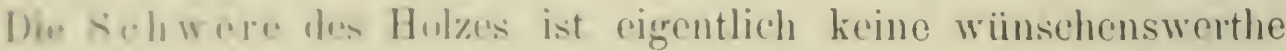

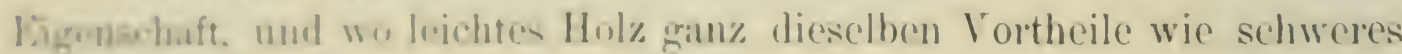

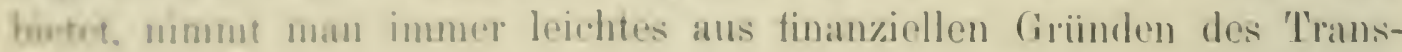

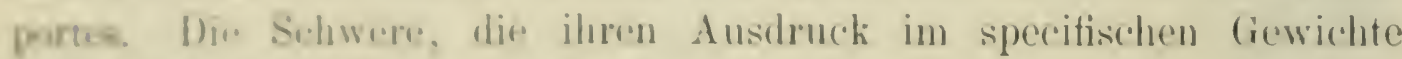

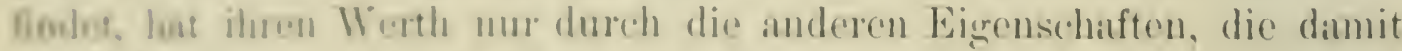

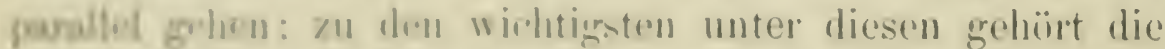

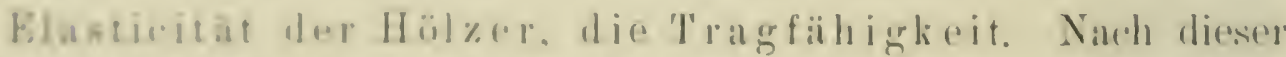

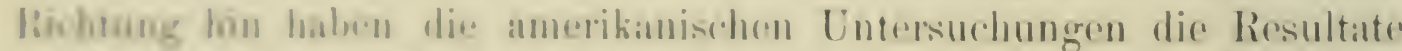

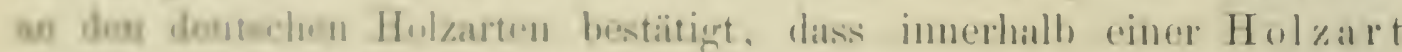

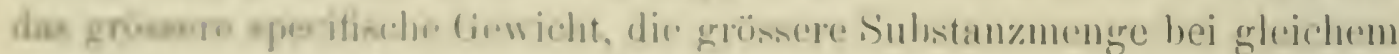

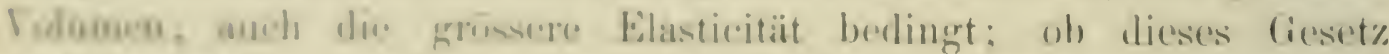

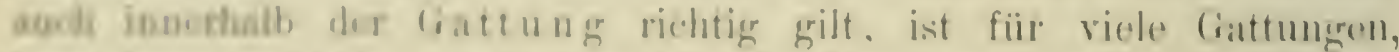

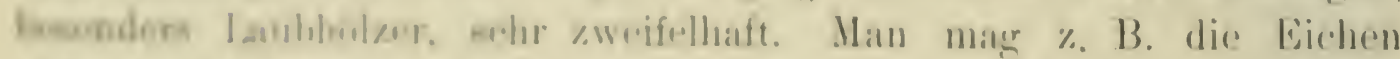

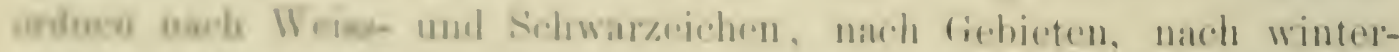

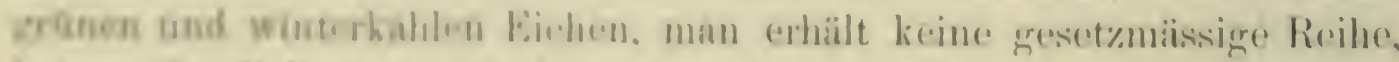

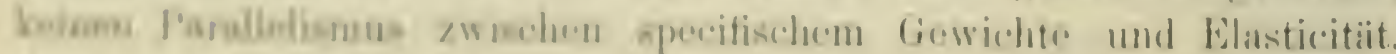

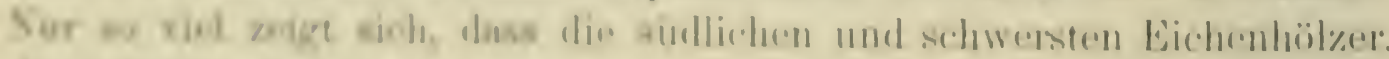

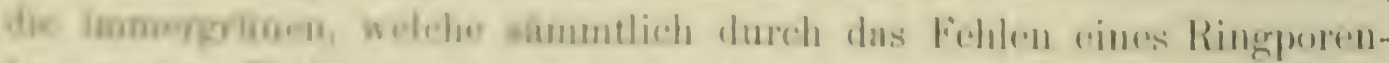

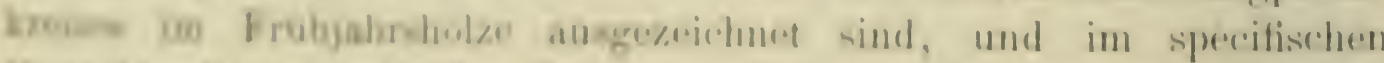

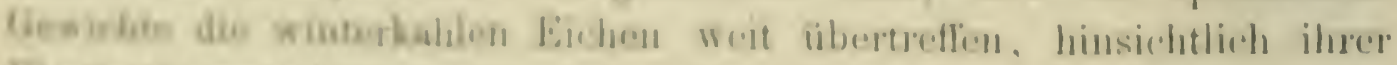

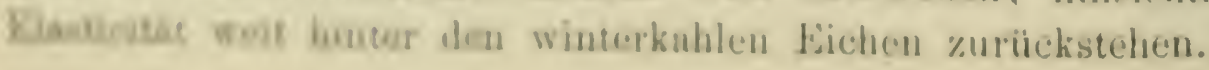


Ordnet man dagegen die Carya-Arten nach ihrer Tragfestigkeit, so ergibt sich ein gewisser Parallelismus mit dem beigefügten specifischen Gewichte auch innerhalb der Gattung: Carya myisticaeformis 80, alba 84, tomentosa 82, sulcata 81, porcina 82 (nach Censusbericht), amara 76, aquatica 74, olivaeformis 72 . Es mag diess Zufall sein, denn die meisten anderen Laubholzgattungen lassen kein Gesetz erkennen.

Anders verhalten sich die Nadelhölzer; ordnet man die wichtigsten Gattungen und Arten nach ihrer Tragfestigkeit (für die Gattungen durch Zahlen, für die Arten durch die Anordnung rom Tragfestesten an absteigend markirt), so erhält man unter Beifügung des specifischen Gewichtes folgende Reihe:

1. Larix occidentalis

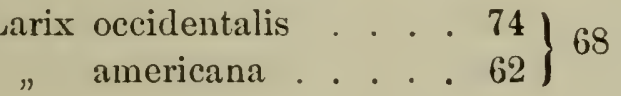

2. Pseudotsuga Douglasii . . 52$\} 49$ macrocarpa . 46$\}$

3. Abies nobilis..... . 46

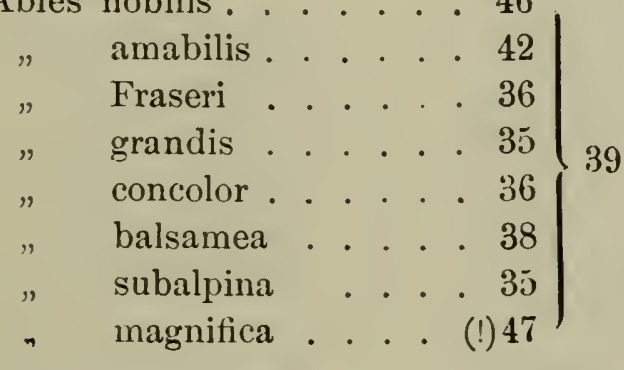

4. Tsuga Mertensiana . . . 53

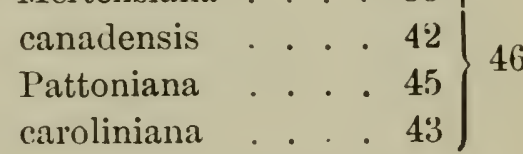

5. Picea nigra ..... 46 alba ..... 41 sitkaensis ... 42$\} 40$ Engelmannii ... . 34 pungens ..... . . 37

6. Thuja gigantea.... 38$\} 35$ occidentalis ... 32$\}^{35}$

7. Pinus ....... 50

8. Sequoia sempervirens... 42$\} 35$ gigantea . . . . 29

Es besteht ein auffallender Parallelismus zwischen Tragfestigkeit und specifischem Gewichte innerhalb der Arten einer Gattung, während innerhalb der Gattungen selbst kaum ein solcher bemerkt wird. Lärche und Douglasia stehen zwar als die schwersten Gattungen an der Spitze, dagegen geräth die Gattung Pinus mit einem specifischen Gewichte von 50 fast an das Ende aller Nadelhölzer. Es lohnt sich, die letztere grosse Gattung ausführlich zu betrachten, da der Durchschnitt aus allen Kiefer'n eine ganz falsche Torstellung ron der Tragkraft und dem specifischen Gewichte der einzelnen Sectionen und insbesonders der einzelnen Arten gibt.

Ordnet man die Angehörigen der Gattung Pinus (Kiefer) nach ihrer Tragfestigkeit, so ergibt sich unter Beifügung des specifischen Gewichtes folgende Reihe:

Pinus contorta ...58|Pinus mitis . . . $61 \mid$ Pinus Coulteri . . . 41

" cubensis .. 75 " muricata .. . 49 " resinosa . . 49

" australis .. . 70 " serotina... 79 " Taeda ... 54 


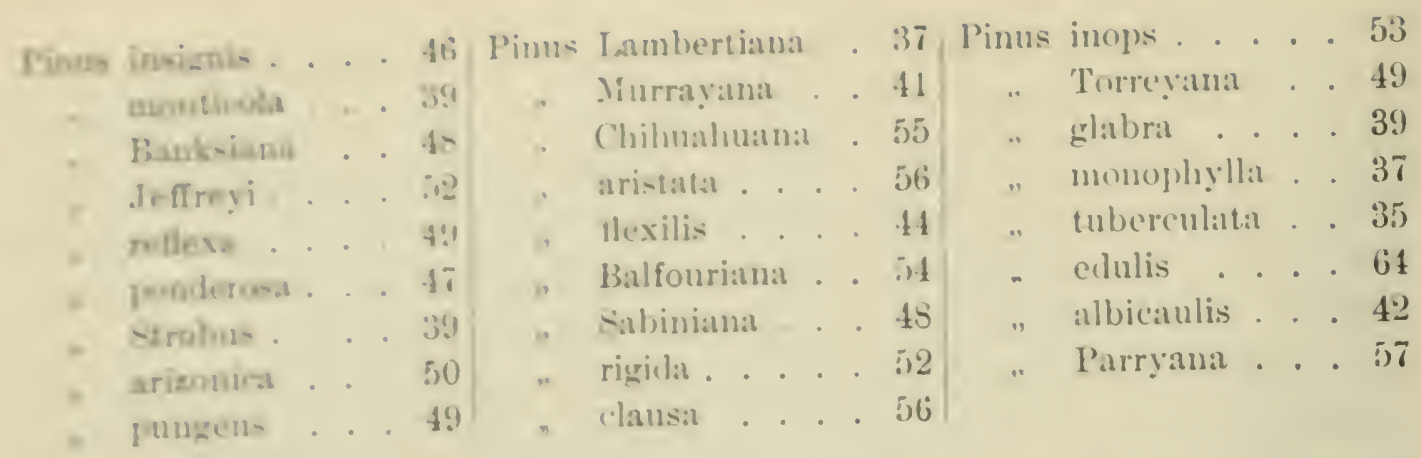

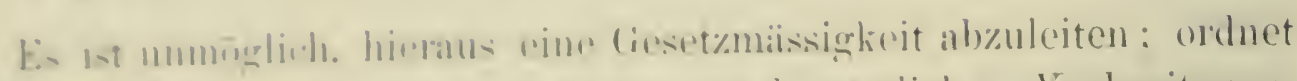

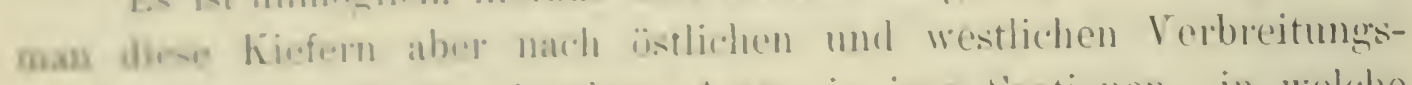

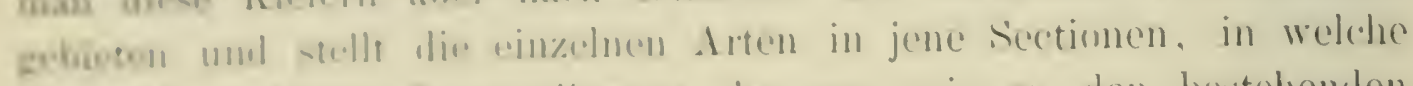

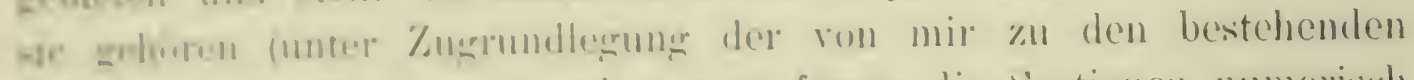

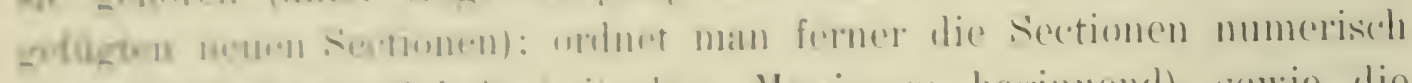

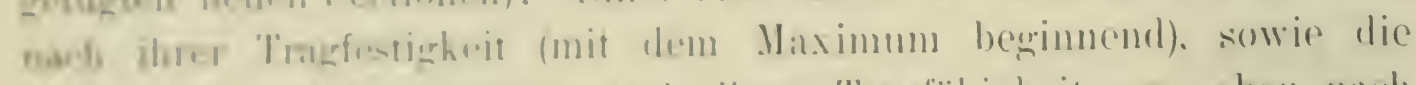

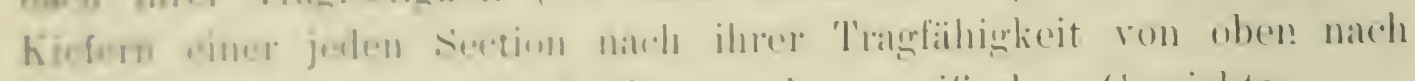

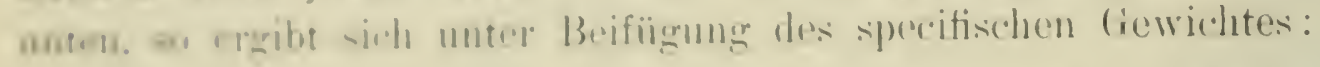

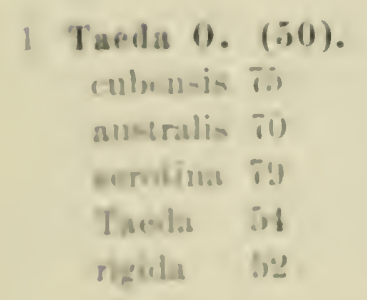

\section{Strobus W. (34).}

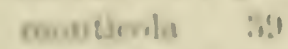
Lasibertama
Q Ermlira (1i). rethes bil Acoile 14

\author{
2. Piuaster (49). \\ resinosa 49 \\ 3. Bankisia W. (4ti). \\ conturta 58 \\ muricatil $4 !$ \\ Murray:una 41 \\ (ub)roulita :3!)
}
6. Strobus 0. (3!)). sirubus 3!!

?. Balfouria (a) arimtalla bli lastfunrians 51 albiculir 4 .'
1. Tueda W. (47).

Coulteri $\$ 1$ insignis 46 Jefrreyi 52 ponderosa 47 Sabiniana 48

7. Bankia 0. (50). mitis lil Banksiana is indes $5 \%$ mplabra $\quad 31$

10. Paryon (1i1). momoplyylla 57 mbulis li. Parryana 57

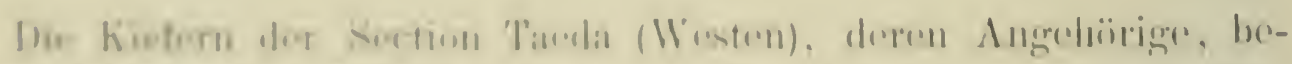

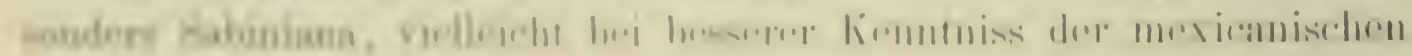

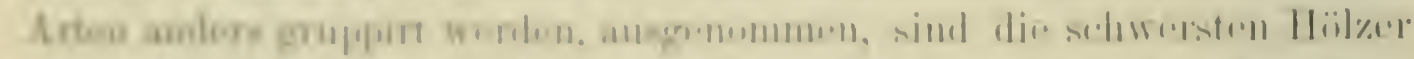

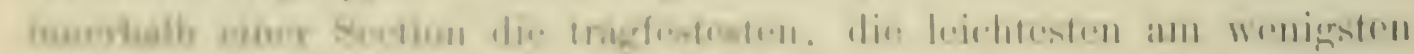

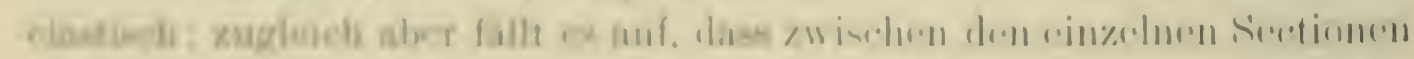

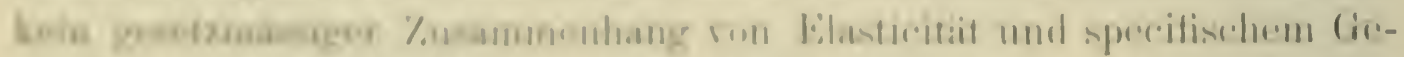

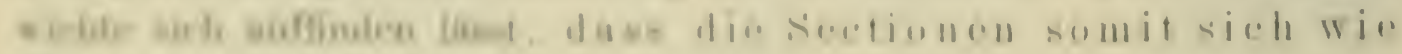
Hattuhrom yoxkalieu. 
Nach Rumford verhalten sich die Brennwerthe der Hölzer, gleiche Tolumina vorausgesetzt, wie ihre Gewichte; nach dieser Ammahme, die Fehler bis zu 11 Procent enthält, ordnen sich die amerikanischen Hölzer hinsichtlich ihrer Brenngüte sowohl innerhalb einer Art als auch nach Gattungen wie deren specifischen Gewichte; dabei muss jedoch Trennung der Hölzer nach Laub- und Nadelhölzern vorgenommen werden. Es hat sich nümlich nach Sharple's Untersuchungen gezeigt, dass die Bäume ohne Harz, die Laubhölzer durch Verbrennen von $1 \mathrm{Kilo} \mathrm{Holz}$ 4000 Wärmeeinheiten (Würmeeinheit ist die Wärmemenge, die erforderlich ist, um 1 Kilo Wasser um $1^{0}$ C. zu erwärmen) liefern, während harzführende Hölzer 4500 Wärmeeinheiten geben. Dass in Praxi zum Beispiel die Kiefernhölzer weniger Wärme geben als Eichen- und Caryaholz hat seinen Grund in der Eigenthümlichkeit, dass grosse Mengen Kohlenund Wasserstoff unbenütyt in der Form von Rauch entweichen, während die Laubhölzer mit rauchloser Flanme verbrennen.

An der Spitze der schwersten, bremnfähigsten Laubhölzer stehen die Hölzer der tropischen Bäume, dann jene der subtropischen, die immergrünen Eichen, woran sich die Carya, die winterkahlen Eichen und übrigen Laubhölzer reihen an deren unterster Stufe die nördlichen Weiden und Pappeln stehen.

Die einzelnen Sectionen der Kiefern als Bremuholzproducenten ordnen sich folgendermassen: Parrya specifisches Gewicht 61), Balfouria (51), Taeda Osten (50), Banksia Osten (50), Taeda Westen (47), Cembra (47), Banksia Westen (46), Strobus Osten (39), Strobus Westen (38).

Unter den östlichen Kiefern ist eine Abnahme des specifischen Gewichtes ron Süden nach Norden hin nicht nur innerhalb der Arten, sondern anch innerhalb der Sectionen bemerkbar. Die Section Taeda umfasst vorwiegend auf den Süden beschränkte Arten, Banksia gehört der Mehrheit ihrer Vertreter nach den mittleren atlantischen Staaten an, während Strobus auf den Norden beschränkt ist; innerhalb einer Section wachsen wiederum die schwersten Kiefern wie cubensis, australis, serotina im Süden, während Pinus rigida, die leichteste der Section Taeda im Osten, dem Norden angehört.

Unter den westlichen Kiefern, die in weitaus grösster Zahl Gebirgskiefern sind, umfasst die südlichste Section "Parrya" die schwersten Hölzer; an diese schliessen sich die alpinen Kiefern, während die leichtesten wieder Angehörige der Section Strobus sind.

Auch bei den Laubhölzern lässt sich, wie später bei den einzelnen Holzarten ausführlicher gezeigt werden soll, eine Abnahme des specifischen Gewichtes ron Süden nach Norden hin erkennen, wenn 


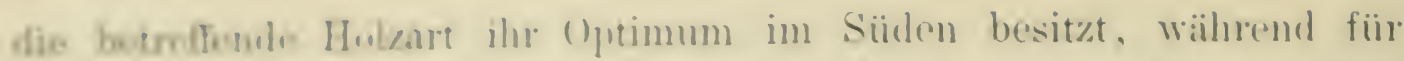

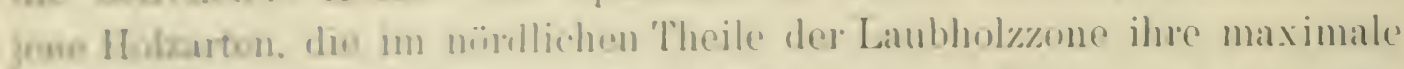

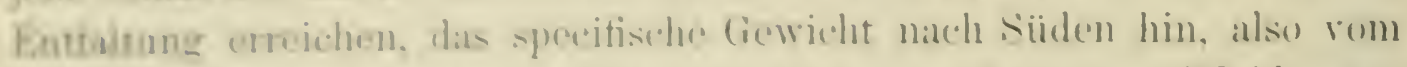

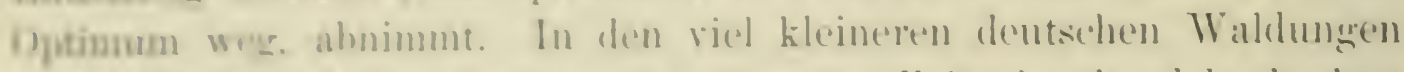

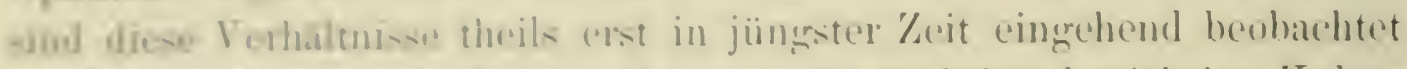

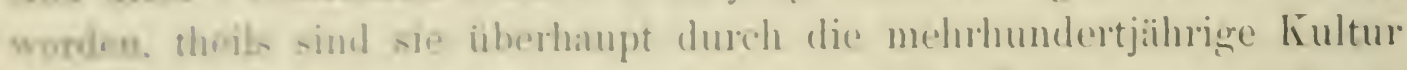

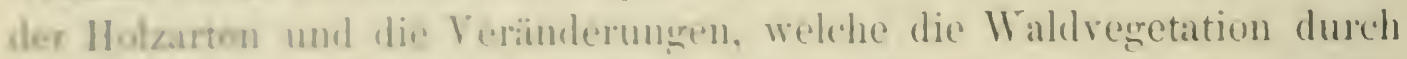

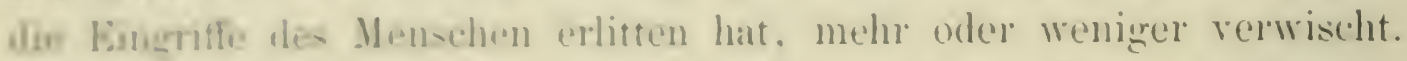

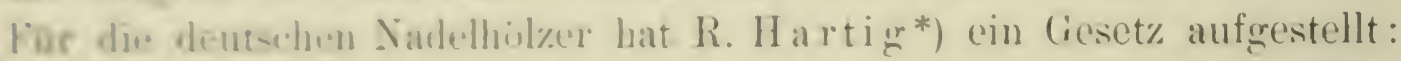
Dhe Howgebornhloma mindert die Quantitat und steigert die Qualität:

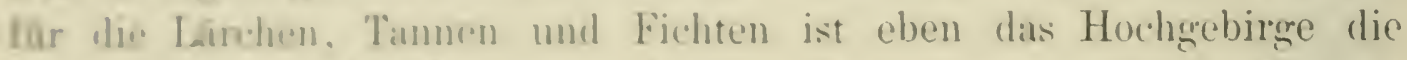
wahre Heimath. dis Optimum: für dic Laubhölzer, \%. B. die Fichen,

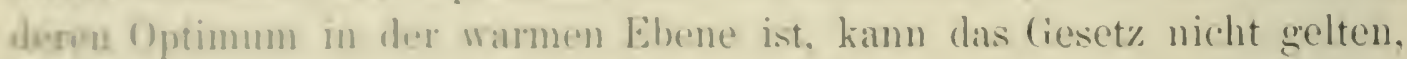
dena das How hrohirnklima, diss kïhlere Klima überhaupt, rermindert bei dem Eirhen (Quantitit mul (Qualitait (Schwere).

In Allgrmejurn kam man silgen, dass die schwersten Laubhölzer, w7. Vichen, Karanjun, Hickury. Wallnuss, schmetterlingsblithige Bämme 4. - w. Ihr (1)ptmmm in dre siidlichen Hailfte des Lambwaldes, die

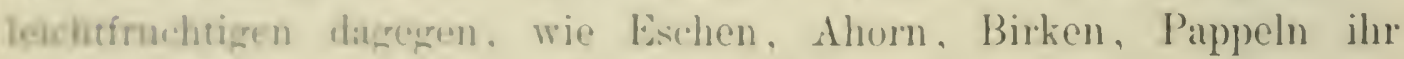

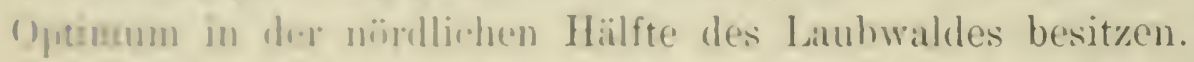

Der bere Jawab zur Beurthoilung des specifischen (iewichtes vinis Holas is nichi die Jahrringshoreite. sondern das Verhailtniss der

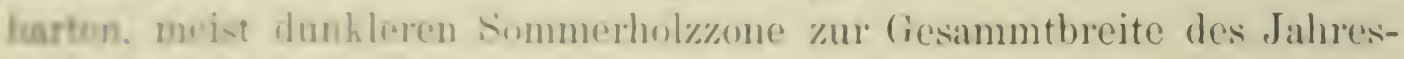

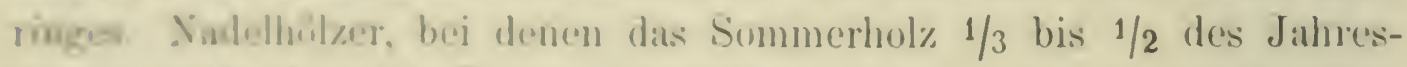

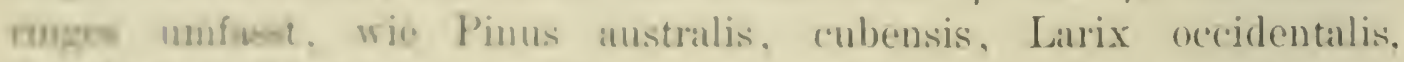
l'modownga longlavii, sind als die schwersten bekannt, es sind anch

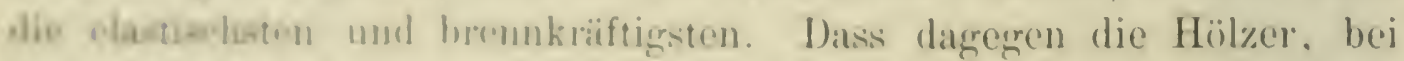

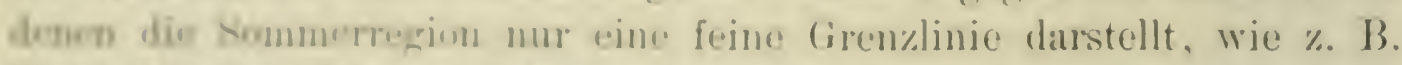

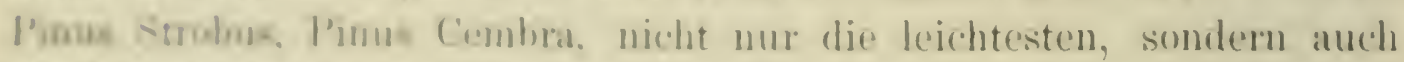

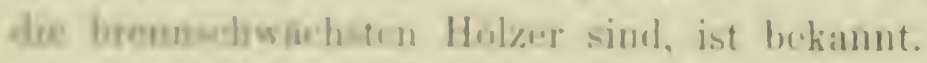

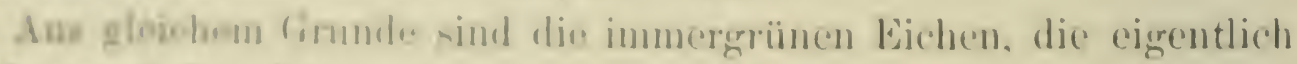

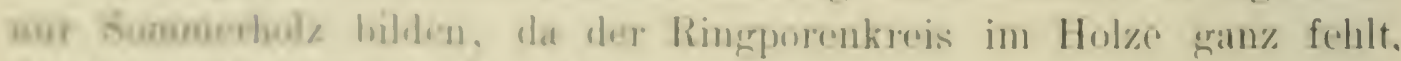

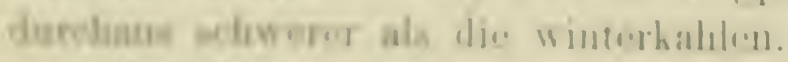

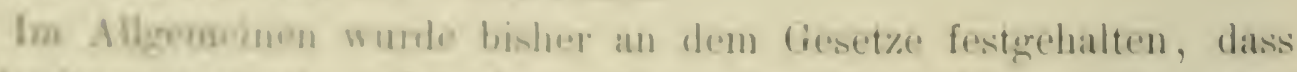

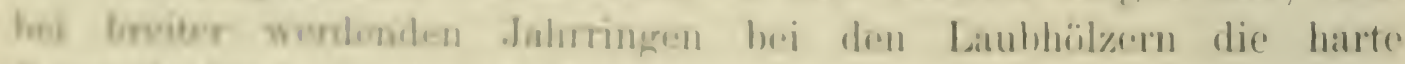

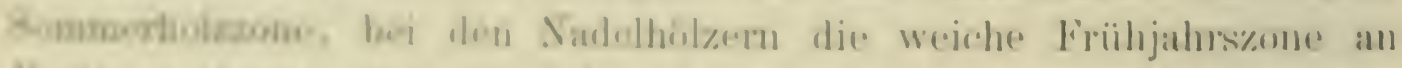

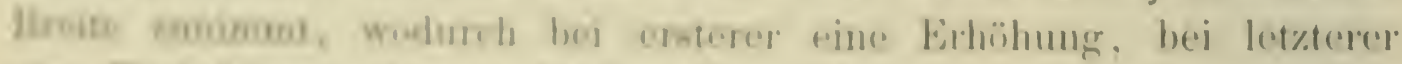

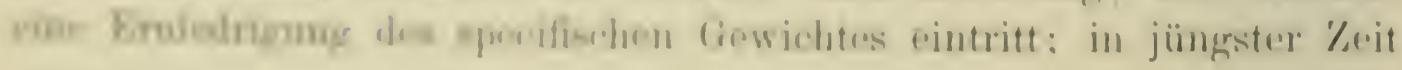

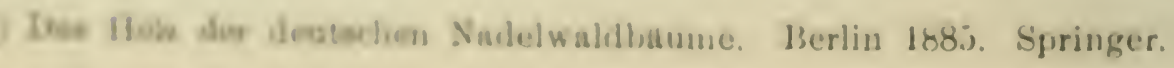


hat Professor Hartig nachgewiesen, dass auch bei den Nadelhölzern trotz zunehmender Ringbreite das specifische Gewicht so lange steigen kann, als der Massenzuwachs des Baumes überhaupt eine steigende Grösse ist. Das Untersuchungsmaterial aus dem nordamerikanischen Walde ist nach dieser Richtung hin zu mangelhaft, um das Gesetz auch für diesen constatiren zu können.

Es mag hier der Versuch erlaubt sein, das Hartig'sche Gesetz mit der so lange geglaubten -und gewiss in Wirklichkeit bestehenden Erscheinung der Abnahme der Schwere mit dem Breiterwerden der Jahrringe bei den Nadelhölzern in Einklang zu bringen. Die Laubhölzer, die zumeist innerhalb ihres Optimum gepflanzt und bewirthschaftet werden, zeigen bei der Zunahme der günstigen Nahrungsbedingungen einen gesteigerten Zuwachs, mit dem auch eine Steigerung der Substanzmenge pro Volumen, der Schwere Hand in Hand geht. Die Nadelhölzer (Fichten, Tamnen, Lürchen) folgen in ihrem Optimum, Gebirgsklima, in ihrer wahren Heimath demselben Gesetze; werden die Laubhölzer ausserhalb ihres Optimums gebaut, z. B. in kühlerem Gebirgsklima, damn rermindert sich mit der Jahrringbreite Qualitait und Schwere; werden die Nadelhölzer ausserhalb ihres Optimum's gebaut, z. B. warmen Ebenen gezogen, dann steigert sich die Quantität, aber es vermindert sich die Schwere.

Die Kiefern, die als Vertreter anderer Holzarten auf specifischem Boden aufzufassen sind, verhalten sich ebenso; da das Optimum z. B. der deutschen Kiefer im Laubholzgebiete liegt, verhält sich die Kiefer in dieser Hinsicht wie die Laubhölzer: das kühlere Gebirgsklima mindert Quantität und Schwere. Ausführlicheres soll im weiteren Verlaufe dieses Kapitels gegeben werden.

Ton entscheidender Wichtigkeit ist das specifische Gewicht als Ausdruck der Härte bei Hölzern, die der mechanischen Abnützung, wie Zerfaserung, besonders ausgesetzt sind; man bezeichnet die widerstandsfähigsten Hölzer in der Praxis auch als die dauerhaftesten, welcher Ausdruck jedoch besser den Widerstand eines Holzes bei Verwendung. desselben im Boden wiedergibt. Die Zerfaserung wirkt besonders bei oberirdischen Bauten, wie Brücken, Stiegen, Fussböden und dergleichen; wie sehr die Schwere eines Holzes bei der Wahl des geeigneten Materials entscheidet, ist bekannt; Zuckerahorn, Eichenparkett-Böden sind am beliebtesten, da beide Holzarten bei der nöthigen Härte auch in entsprechender Menge rorhanden sind; das Holz der südlichen Kiefer, Pinus australis (fälschlich Pitch-Pine-Holz genannt) zieht man dem Eichenholze rielfach ror, da es bei der nöthigen Härte in seinem Harze 


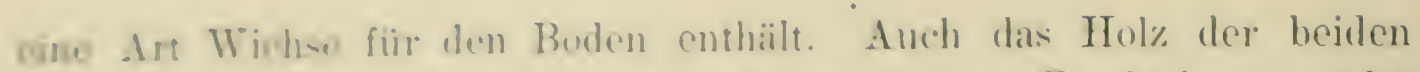

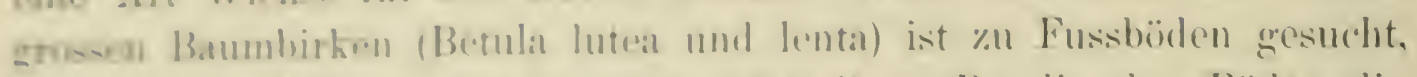

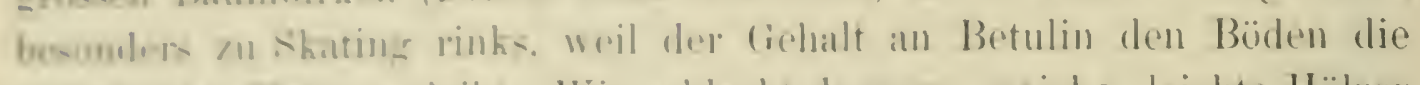

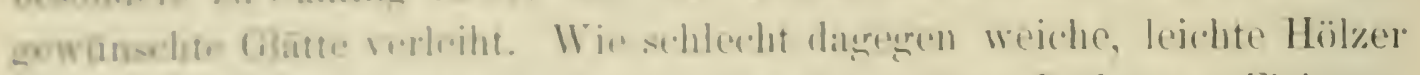

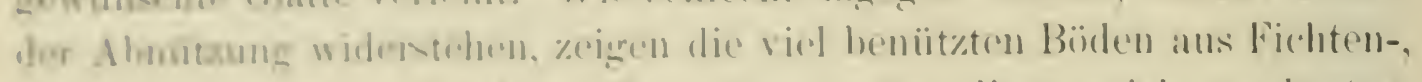

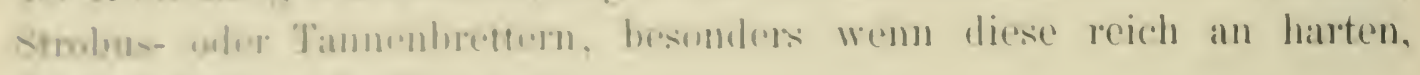
nimperachoonen derens sind.

Him-iodelich der Dauer des Holzes bee Verwendung im Boden

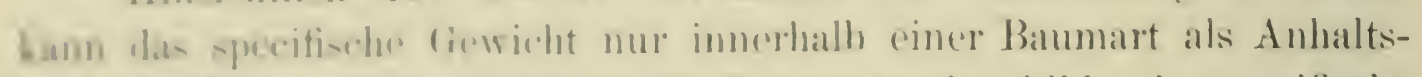

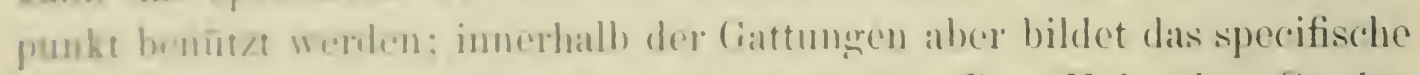

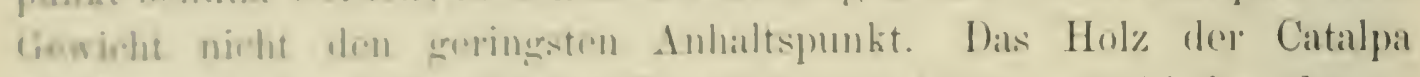

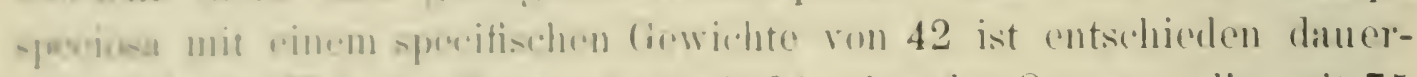

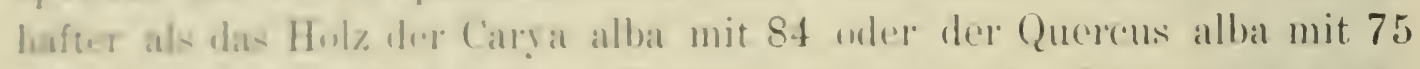

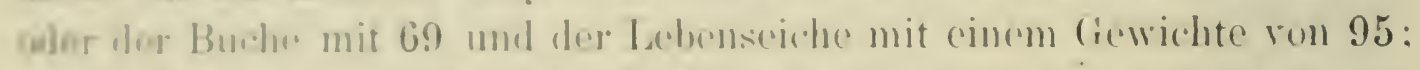

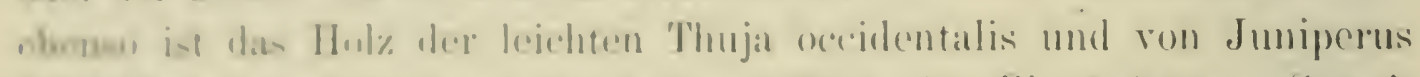

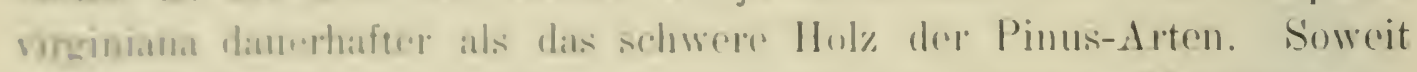

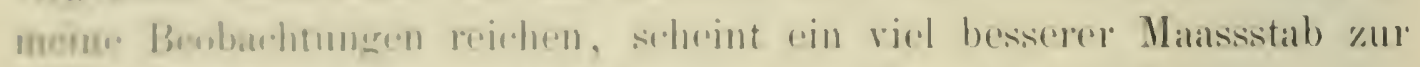

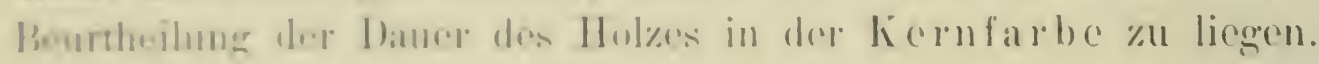

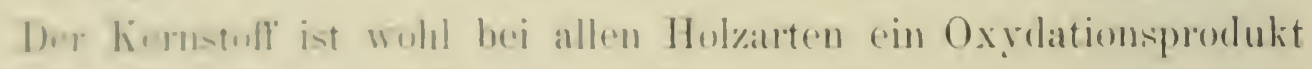

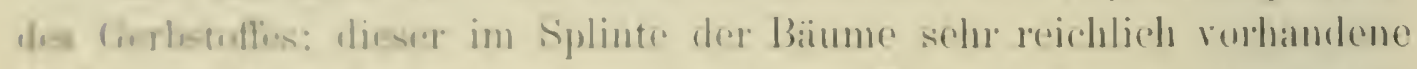

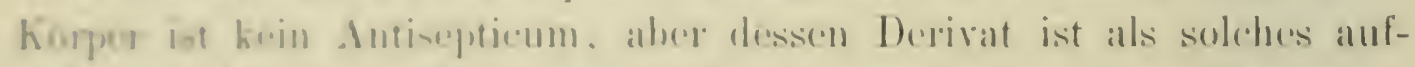

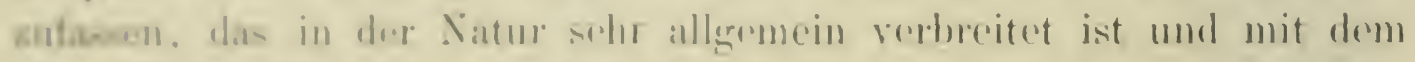
A6. Holeer, hurl dhe ans den Zollen (Parenchym\%ellen) alles Leben

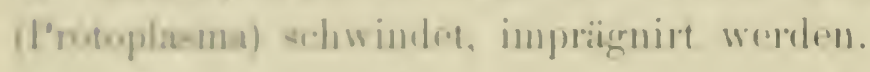

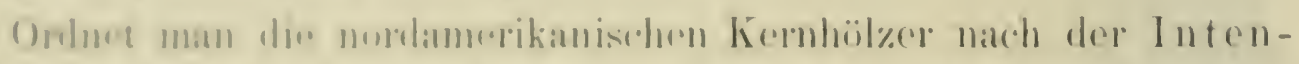

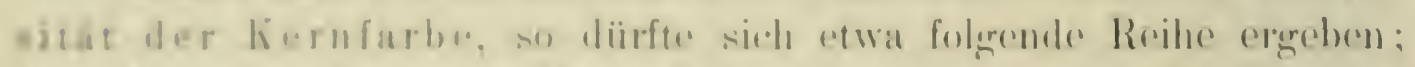

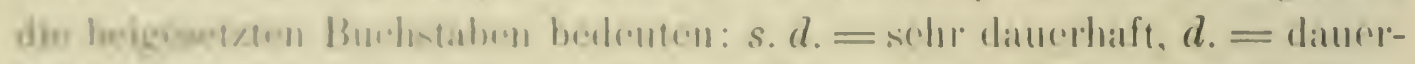

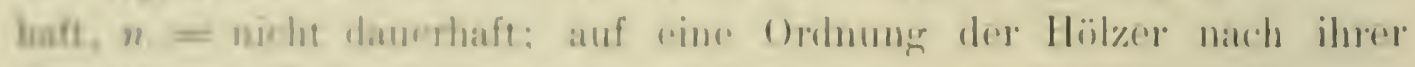

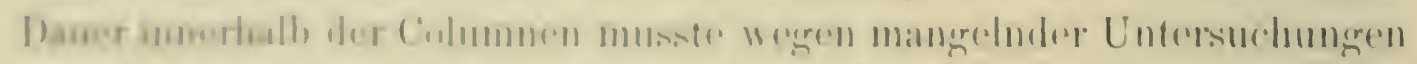

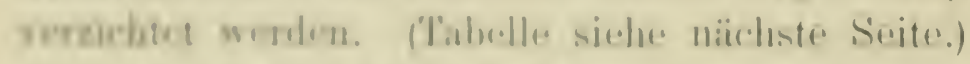

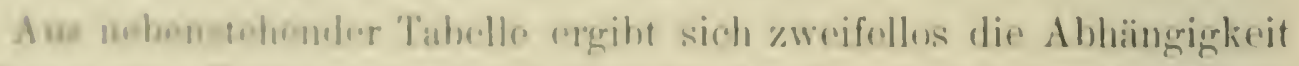

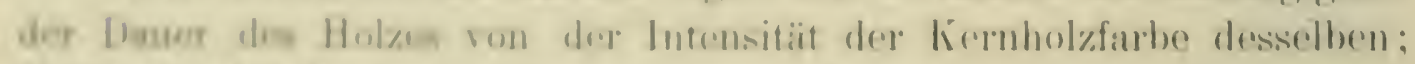

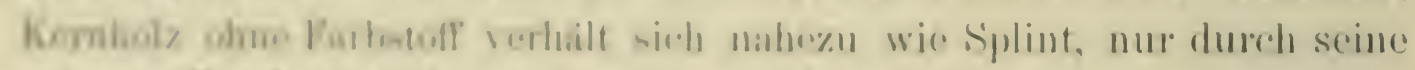

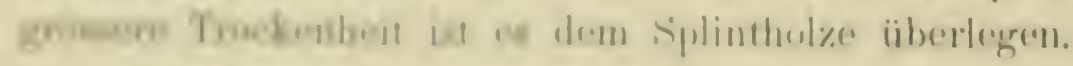

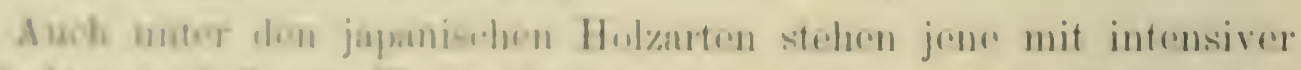

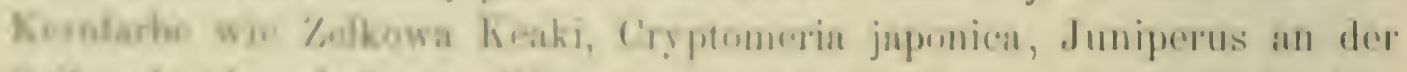

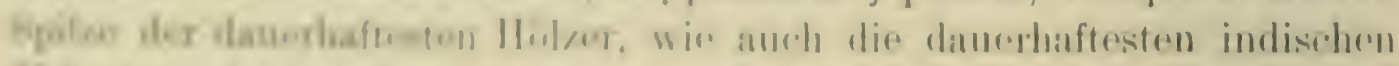

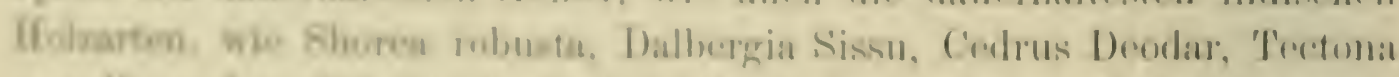

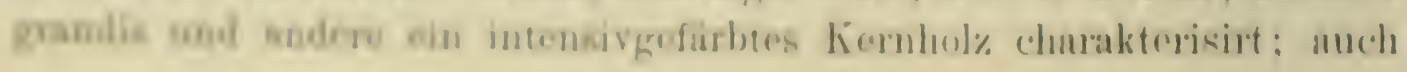




\begin{tabular}{|c|c|c|}
\hline $\begin{array}{l}\text { Intensiv schwarz, braun } \\
\text { oder roth }\end{array}$ & $\begin{array}{l}\text { Grau, hellbraun, hell- } \\
\text { roth, gelb }\end{array}$ & $\begin{array}{c}\text { Weiss, schwachgelb, } \\
\text { schwachröthlich, schwach- } \\
\text { brïunlich }\end{array}$ \\
\hline $\begin{array}{l}\text { Prosopis } s . d . \\
\text { Rhizophora } s . d \text {. } \\
\text { Catalpa } s . d . \\
\text { Maclura } s . d \text {. } \\
\text { Morus } s . d . \\
\text { Juglans } s . d . \\
\text { Libocedrus } s . d \text {. } \\
\text { Juniperus } s . d \text {. } \\
\text { Taxodium } s . d \text {. } \\
\text { Sequoia } s . d . \\
\text { Taxus } s . d . \\
\text { Larix } s . d \cdot \\
\text { Pseudotsuga } d .\end{array}$ & $\begin{array}{l}\text { Magnolia } d . \\
\text { Liriodendron } s . d . \\
\text { Robinia } s . d . \\
\text { Gymnocladus } d . \\
\text { Gleditschia } d \text {. } \\
\text { Sassafras } d \text {. } \\
\text { Ulmus } d \text {. } \\
\text { Quercus } d \text {. } \\
\text { Salix } n . \\
\text { Pinus } d . \\
\text { Chamaec. sphaeroidea } s . d \text {. } \\
\text { Thuja s. } d . \\
\text { Cupressus } s . d .\end{array}$ & $\begin{array}{l}\text { Negundo } n . \\
\text { Fagus } n . \\
\text { Betula } n . \\
\text { Aesculus } n . \\
\text { Nyssa } n . \\
\text { Acer } n . \\
\text { Tilia } n . \\
\text { Tsuga } n . \\
\text { Picea } n . \\
\text { Abies } n . \\
\text { Torreya } s . \text { d. } \\
\text { Chamaec. Lawsoniana } s . d \text {. } \\
\underbrace{\quad " \quad \text { nutkaensis } s . ~} d .\end{array}$ \\
\hline 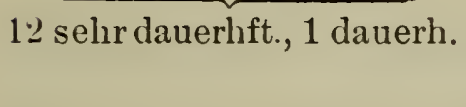 & $\begin{array}{c}5 \text { sehr dauerhft., } 7 \text { dauerh., } \\
1 \text { nicht dauerhaft }\end{array}$ & 10 nicht dauer \\
\hline
\end{tabular}

die Palmhölzer mit den schwarzgefärbten Holzsträngen sind als ausserordentlich damerhaft bekannt.

Die borkige Rinde der Bäume erhält ihre rothe oder braune Färbung ebenfalls durch einen dem Kernholze sehr nahestehenden Körper, der ein Derivat des Gerbstoffes ist; die Imprägnirung mit diesem Farbstoffe ist eine sehr intensive und alle Borken sind als ausserordentlich dauerhaft bekannt. Man kam die Dauer um so weniger auf die Anwesenheit ron Kork in der Borke zurückfülıren als bei vielen Holzarten die Korkmasse in der Borke geradezn rerschwindend klein ist, wie z. B. bei den Cupressineen und Taxodineen; eine Ausnahme scheint nur die Borke der Birke zu machen, die schneeweiss gefärbt und doch ausserordentlich dauerhaft ist; doch bei dieser ist nur die Farbe des Imprägnirungsstoffes (Betulin) eine ausnahmsweise, nämlich weiss.

Aus obiger Tabelle lässt sich weiter entnehmen, dass die danerhaftesten Laubhölzer der südlichen, wärmeren Hälfte des Laubwaldes angehören; die Hölzer mit der intensivsten Kernfärbung wie Guajacum, Sideroxylon, Diospyros, Swietenia und viele andere, sowie die Palmen gehören den Tropen an; es ist deshalb wahrscheinlich - leider fehlen darüber Versuche - dàss grössere Menge an Licht und Wärne den Gehalt an Gerbstoff im Baum erhöhen werden, wodurch wieder eine grössere Menge des antiseptischen Kernstoffes gebildet werden könnte. 
Demenach ware der froje stand am besten. der dichte Bestand-

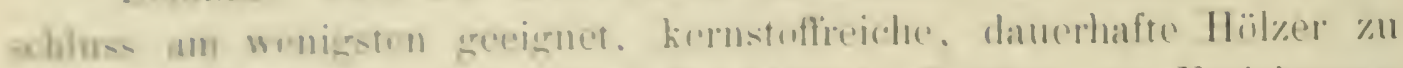

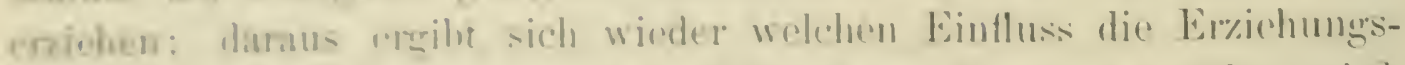

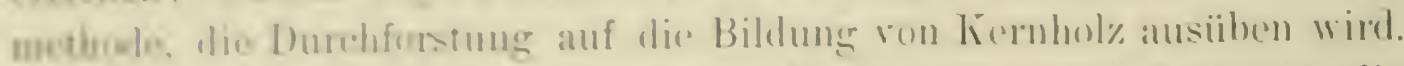

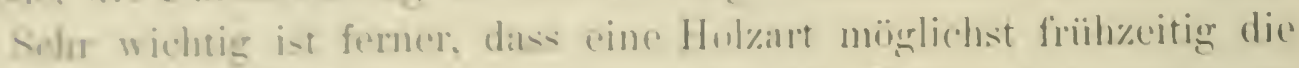

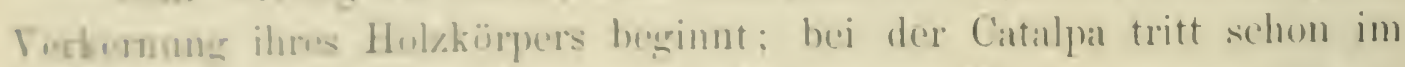
aweitrn Jahre uath dor Bildung des Holves die Verkermunge auf, wes-

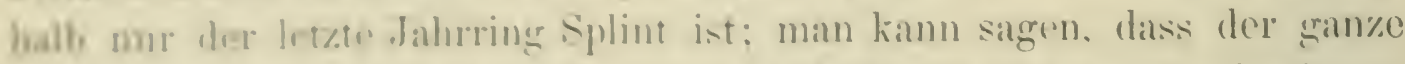

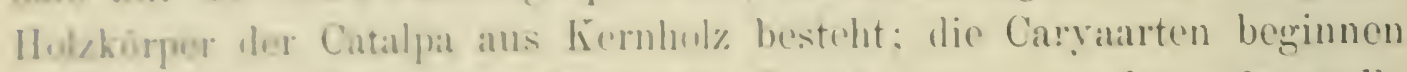
ont mit dem funfrienten Jihre die Kermbildunge. so dass also volle funfzig Jahoringe der Ausaensedichte des Holzes Splint sind: endlich bei zahlreichen Holyarten unterhleibt die Verkermung gan\%: um die muzelnen Hulzarten nach diesom Gesichtspunkte abwïgen zu kïmmen. habe wh hei der -pecifischen Betrachtung der Holzarten die Splintbreite, wo maglich. beigefügt.

Cutwe den when anerefühten Holzarten sind Torreya. Chamaceyparis nutsarnsis und Lawsoniana mit kium reförbtem Kernholze als sebr

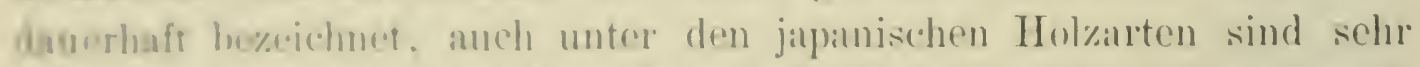
daserhafe mit kamm grofarhtem Lierne wie Campherhol\%, Chamaecyparis ubuma. pinfera. Torrega, Thujopsis dolabrata.

All. genanntwn Hïl\%er kemn\%eichet ein ganz intensiver specifischer

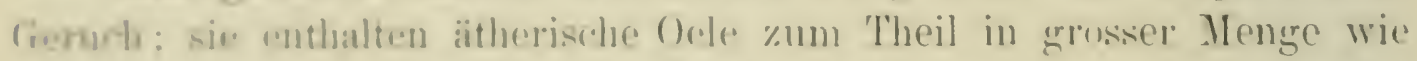
Compherholz und das Hol\% der Ialwsoniana; es ist mindestens wahlwheintteh. dass diese Hïdhtigen Ocle die Rolle des Kernstoffies überfordinen und den Hoblem die bekannte grosse Danuer verleihen.

Jasur nud Abnöt\%ungswiderstand sind combinit bei

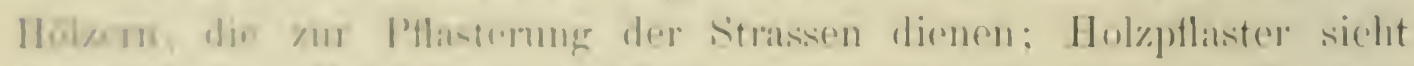

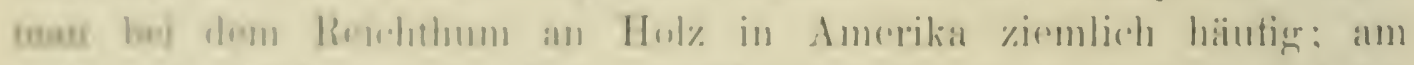

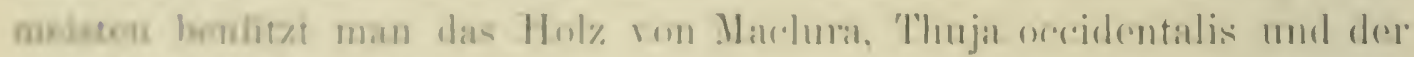

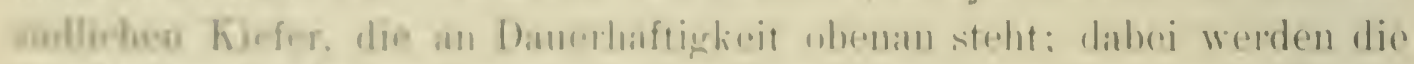

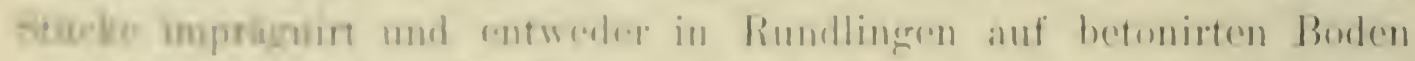

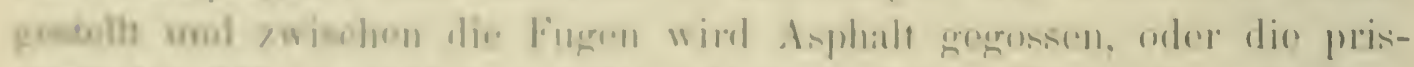

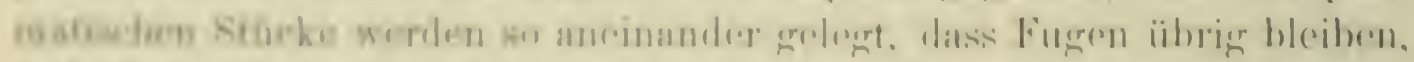

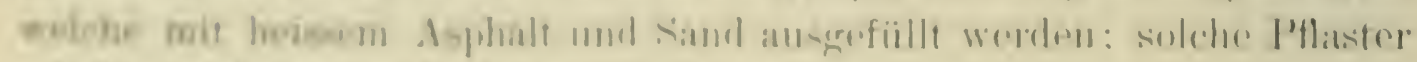

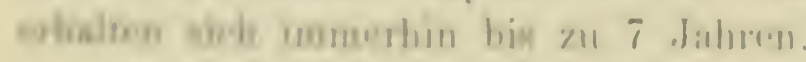

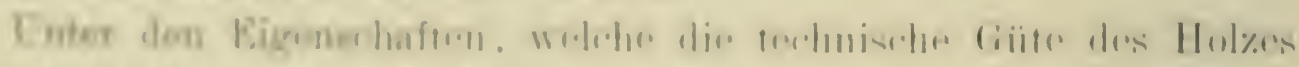

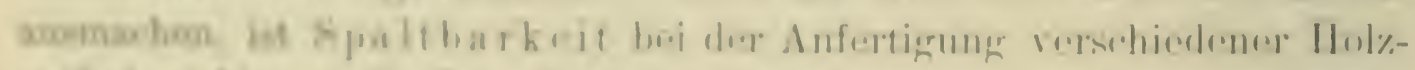

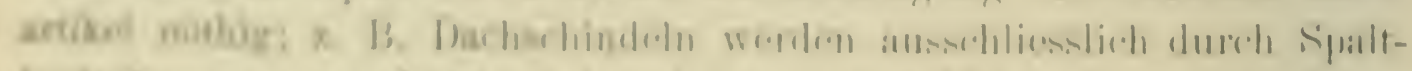

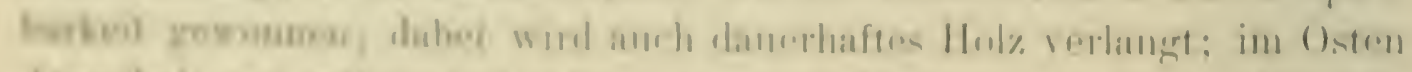

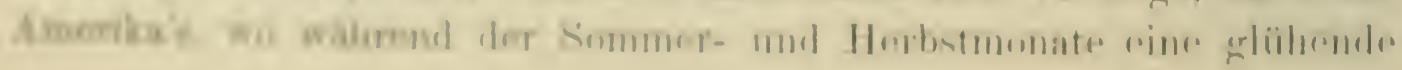


Sonne die Dächer abtrocknet, wo der Winter andauernd frostreich ist, erhalten sich die Dachschindeln viel länger als in Klima mit mässiger Kälte und Wärme und rasch wechselnder Fenchtigkeit. Man kann eine entschiedene Zunahme der Dauer oberirdisch verwendeter Hölzer überhaupt von der Küste nach der Prärie hin constatiren; am Prärierande sind \%. B. Dachschindeln von Pinus Strobus so dauerhaft wie solche aus Taxodium oder der Kugelcypresse an der Küste. Dass Nadelhölzer vorzugsweise zu Schindeln beniitzt werden, ist selbstverständlich; die Kugelcypresse ist im Osten, die Küstensequoia, die Zuckerkiefer, die Thuja gigantea sind im Westen die wichtigsten Lieferanten.

Bei einer weiteren Verwendungsweise des Holzes, die in ganz Amerika häufig ist, kommt ebenfalls die Spaltbarkeit eines Holzes in Frage: nämlich zu den schon früher erwähnten Zäunen (fence) nimmt man von den eben zur Verfügung stehenden Hölzern die spaltbarsten und dabei dauerhaftesten, als da sind Eichen, Hickory, Wallnuss, Bleistiftwachholder und andere; man benützt dabei nur die Schaftheile dieser Bäume die der Länge nach ein paar Mal aufgespalten werden.

Bei den erwähnten Terbrauchsweisen ist Spaltbarkeit nach der natïrlichen, radialen Richtung wünschenswerth; einige wenige Holzarten zeichnen sich dagegen durch Spaltbarkeit nach der tangentialen Richtung aus; so lässt sich das astlose Schaftholz der hollunderblätterigen Esche (Fraxinus sambucifolia) und jenes ron Quercus Michauxii in lange, schmale.Tangentalstücke zerreissen, eine Eigenthümlichkeit, die ihre Hölzer zur Anfertigung ron Flechtarbeiten, Körben und dergleichen verwendbar macht.

Endlich sei noch der Wermouthskiefer gedacht, ron der behauptet wird, dass sie nach allen Richtungen hin gleich gut spalte, ein Vorzug, der mit manchen unlieben Eigenschaften ihres Holzes wieder aussöhnen dürfte.

Grosses Gewicht wird ferner bei der Werthschätzung des Holzes auf die leichte, schöne Bearbeitungsfähigkeit desselben gelegt; in dieser Hinsicht entscheidet neben dem Holze auch das gebranchte, ortsübliche Instrument. Die Säge reisst Zellgruppen aus ihrem Zusammenhange heraus und zertheilt so den Stamm ohne zu schneiden; bei dieser Operation gibt das specifische Gewicht einige Anhaltspunkte; die harten Hölzer sind in Allgemeinen schwieriger zu bearbeiten als die weichen; wenigstens rerlangen erstere bessere Sägen und feinere Schränkung. Doch kommt auch eine Zähigkeit der Zellwand selbst in Frage, so bieten die spröden Zellwände des Weymouthskiefernholzes weniger Widerstand als das zähe Zellgefüge der Pappeln und Rosskastanie. Der Hobel, 
das Vr..er sohnuiden die Fascrn nach verschiedenen Richtungen: für

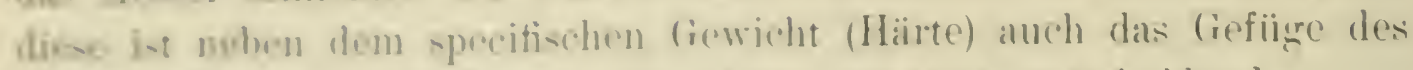

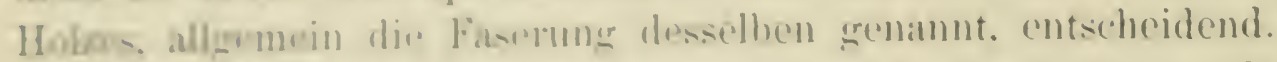

Fur alle Arten der Beabrojung ist eine möghichste Gleich-

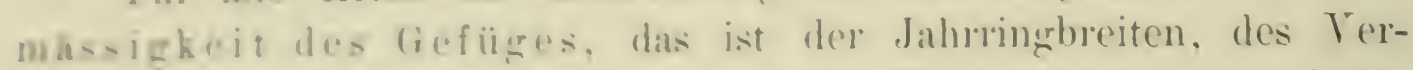

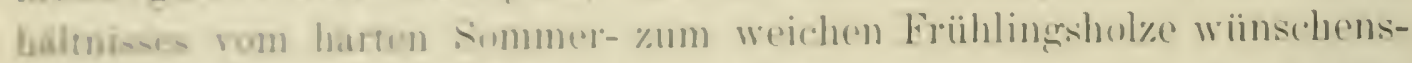
worls. Whs diesen P'unkt betrifft, so verbraucht gregenwiirtig

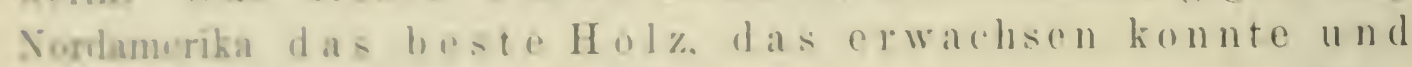
orwa.h-en wild, auf. Ein Blick auf den \%uwaldsugang der Hol\%-

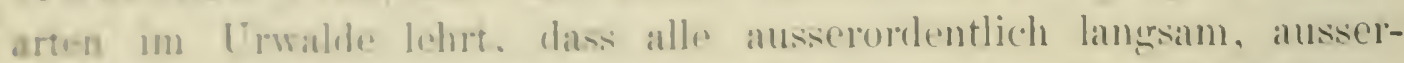

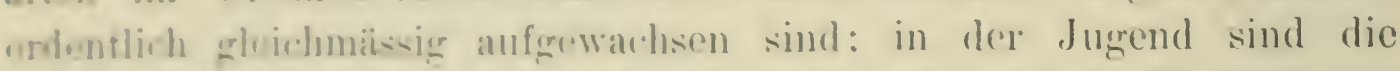

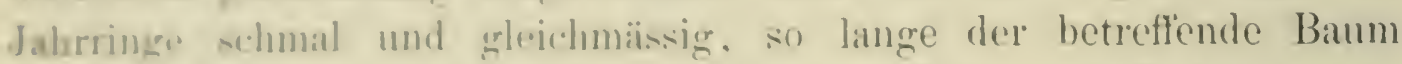
im lorange mit andorn im Volleromsse von Licht und Boden beein-

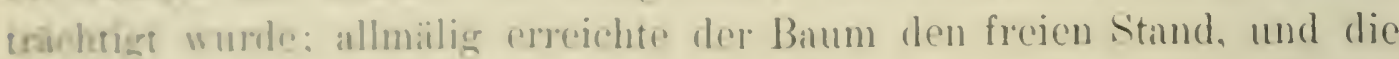

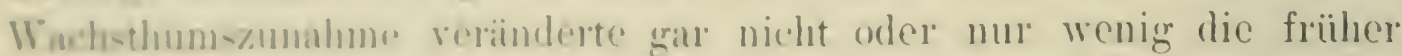

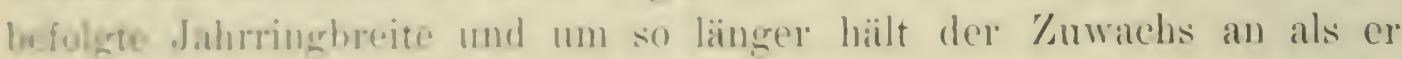
in d.r erefen \% \% an der vollen Entfaltumer behindert wurde: so

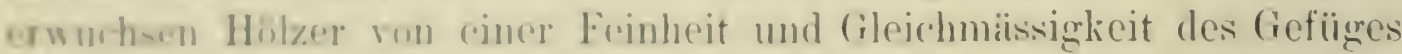

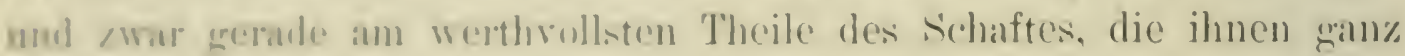
bosonders hohon Wouth rerleihron. Bei der Betrachtung der einzelnen

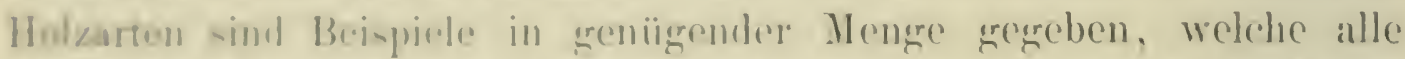

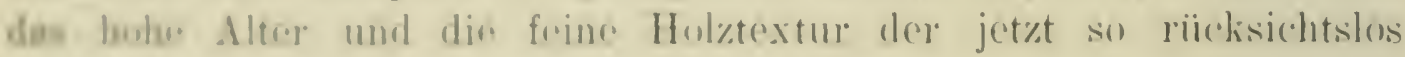

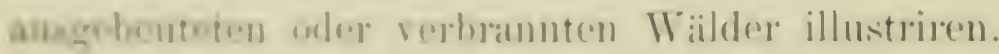

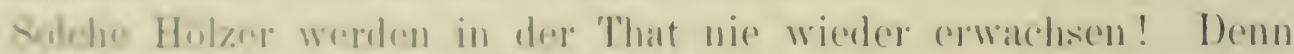

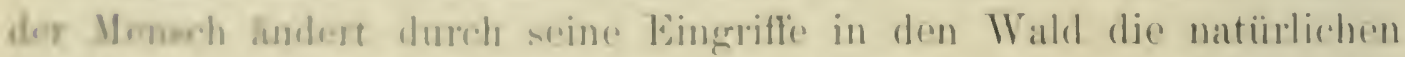

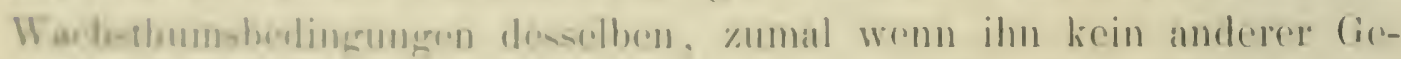

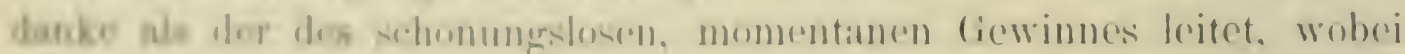

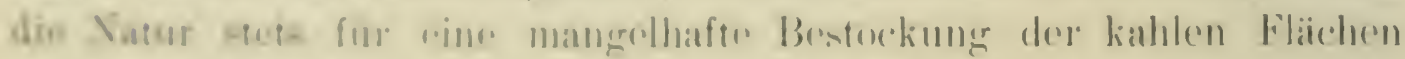

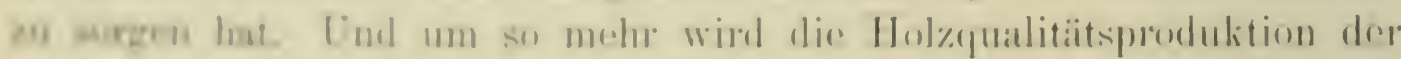

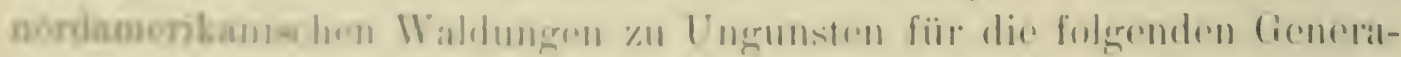

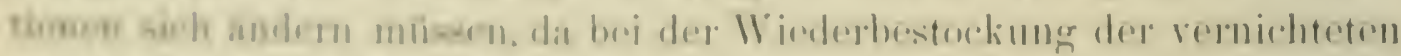

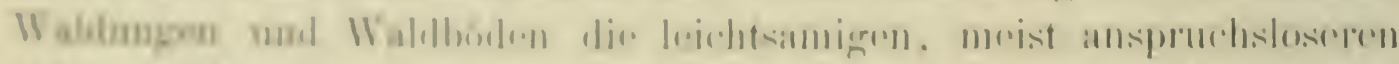

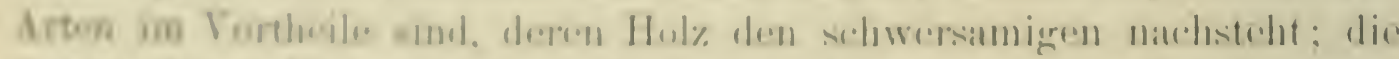

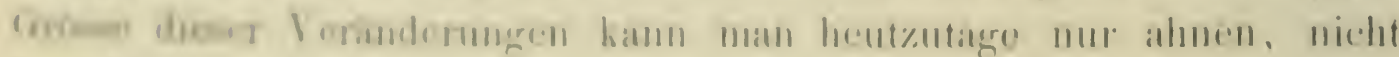
Incroclanus.

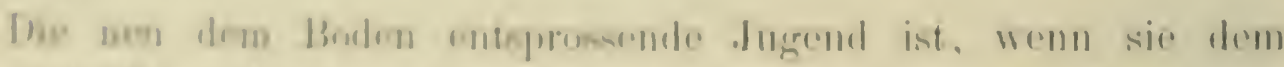

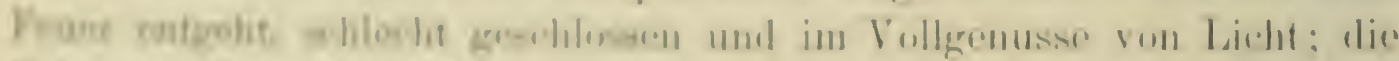

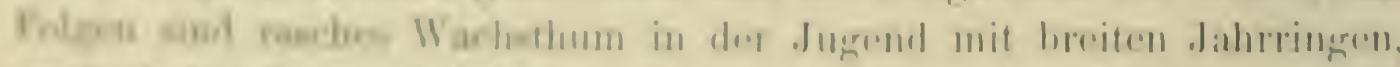

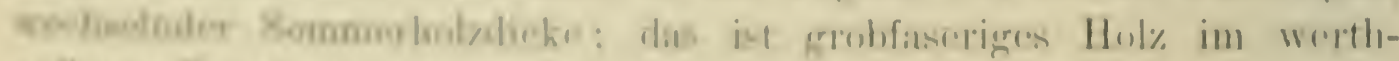

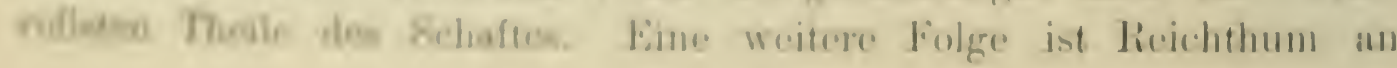


Aesten, langsames Absterben derselben, da sie bereits bis zum Eintritte des Schlusses eine beträchtliche Dicke erreicht haben; die Aststummeln werden rom späteren Holze überwachsen, wodurch jede Nutzwaare ganz beträchtlich geschädigt wird. Es ist kein Zweifel, man erzeugt am einzelnen Stamme in kürzerer Zeit grössere Massen von Holz, aber auf Kosten der technischen Güte; sicher werden durch den freien Stand die physikalischen Eigenschaften, als Härte, Brennkraft, Elasticität und wahrscheinlich auch Dauer gesteigert; da die grössere Elasticität durch das viel gröbere, ästige Material reichlich wieder aufgewogen wird, so gewimnen dabei nur die Eigenschaften, die bei dem Holze als Brenn material erwünscht sind.

Man glaube ja nicht, dass man durch Aufästung den Schaden eines schlechten Schlusses einer weiträumigen Pflanzung wieder gut machen kann; wie da sich in Amerika bei mindestens 4 Mark Taglohn das Nutzungsprocent aus dem Walde stellen wird, überlasse ich den im Business gewandteren Amerikanern; so riel sei hier gesagt, dass die Aestung durch Arbeiter, das Oeffnen des gesunden Leibes eines Baumes an mehreren Stellen trotz aller Torsicht stets die grösste Gefahr einer Infection des Holzes in sich schliesst; der Schaden, den diese im Geheimen wirkenden Pilze im Holze anrichten, dürfte ausser aller Proportion zum Gewinne stehen. Diese Künstlichkeiten sind im Walde nur in besonderen Fällen bei misslungenen Pflanzungen, bei werthrollen Ueberhältern anwendbar; auch in Amerika wird man diese Operation der Natur überlassen müssen, der man ja durch Füllpflanzungen mit kurzlebigen Holzarten bei der Bestandbegründung zu Hilfe kommen kann.

Dabei haben alle diese Erwägungen zur Toraussetzung, dass die Holzarten innerhalb ihres Optimums angebaut werden; als Optimum gilt innerhalb des natürlichen Verbreitungsbezirkes einer Holzart jenes Gebiet, in dem sie in der gesammten biologischen Entwicklung am vollkommensten gedeiht; dort bildet sie die beste physikalische Qualität ihres Holzes als das Produkt des Standortes und des Klima's und erreicht ihr Maximum an Massenentwicklung (Höhe und Stärke) als das Resultat der Standortfaktoren, des Klima's und der Zeit, als welche die natiurliche Lebensdauer erscheint. Es hat sich als ein Geset\% herausgestellt, dass, gleiche Bodengüte rorausgesetzt. mit der Entfernung rom Optimum Qualität und Quantität des erzeugten Holzes bei jeder Holzart abnehmen.

Diess scheint im Widerspruche mit früher Gesagtem und mit vielen bisherigen Erfahrungen zu stehen. So z. B. ist bekannt, dass Fichten, Lürchen und Tannen aus dem kühleren Gebirgsklima (ihrem 


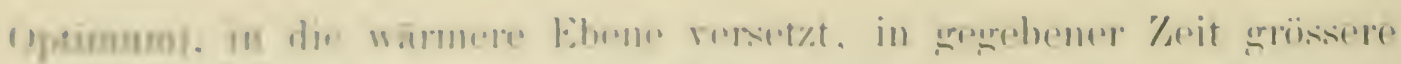

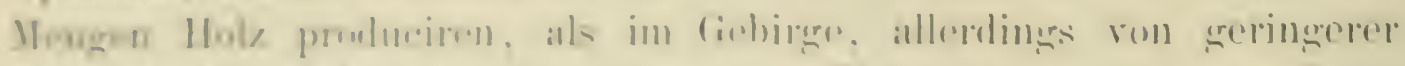

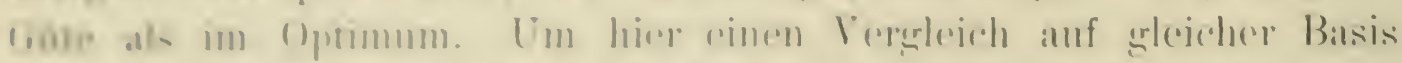

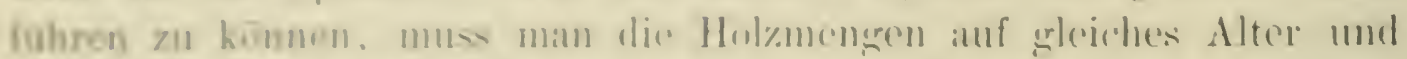

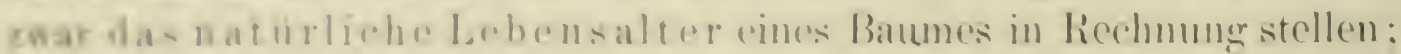

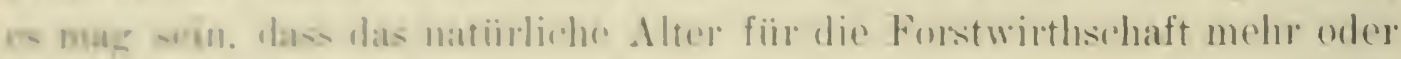

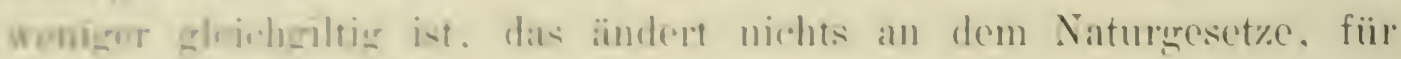

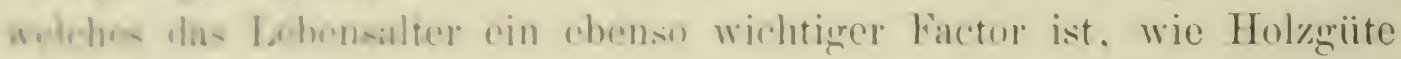
and Jlan $n$ mtwirklungr.

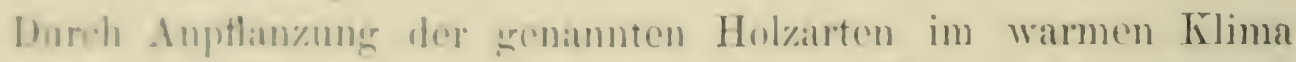

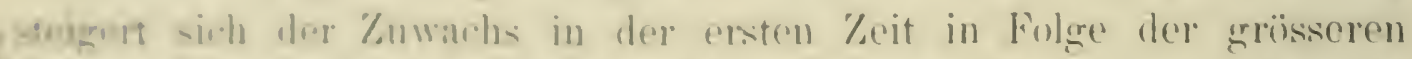

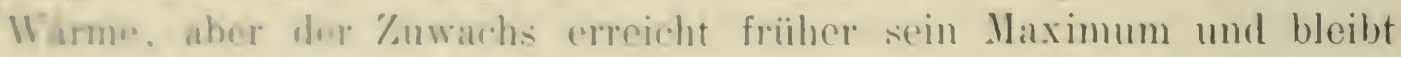

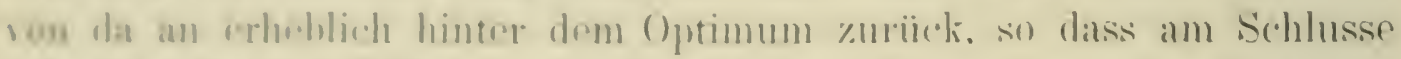

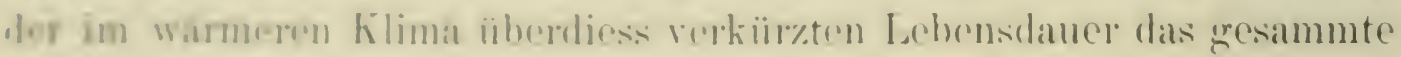

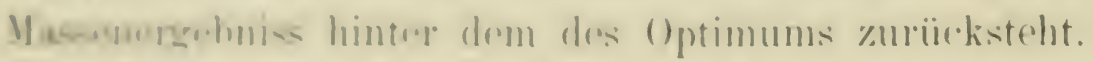

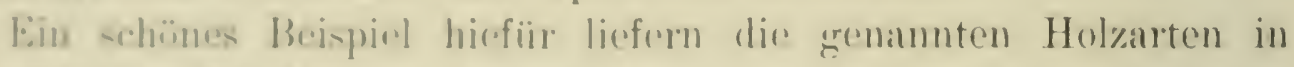

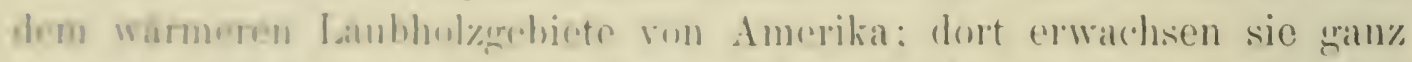

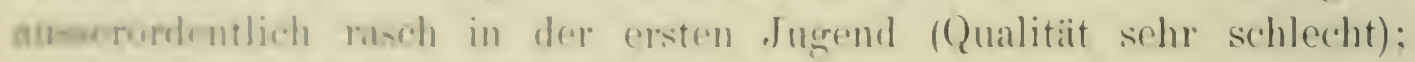

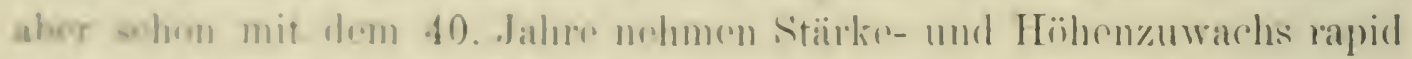
uh amel die Banmo kïmmom bis zu ihrem Ende. Dass die wämere

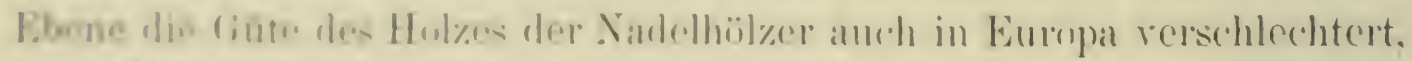

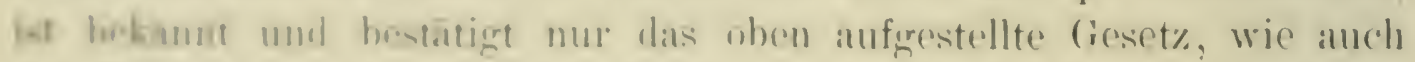

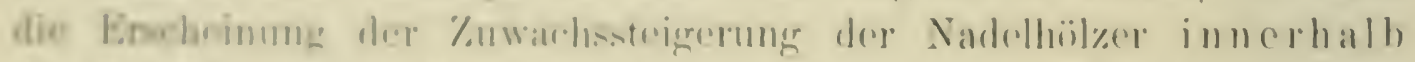

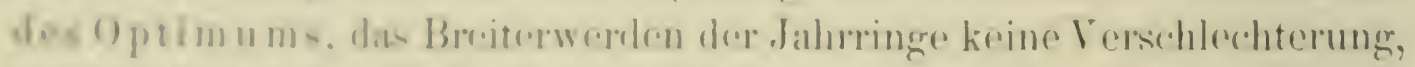

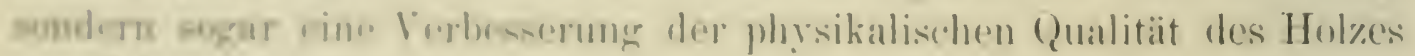
max Phleo hat.

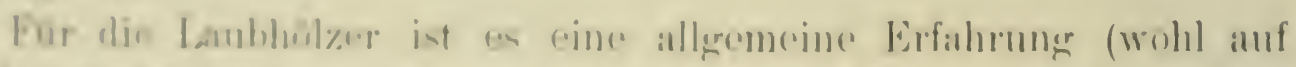

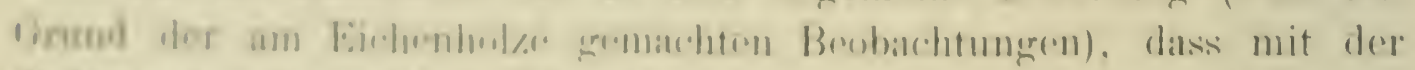

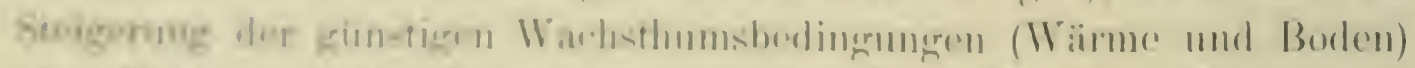

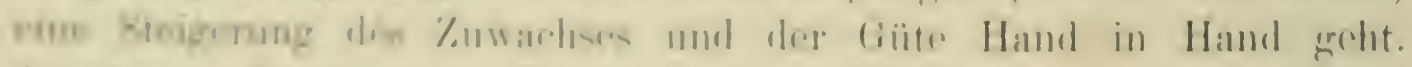

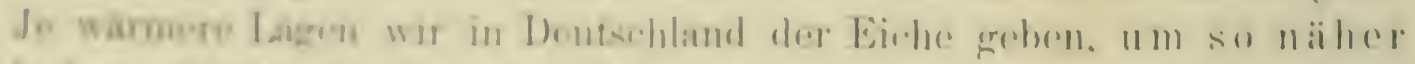

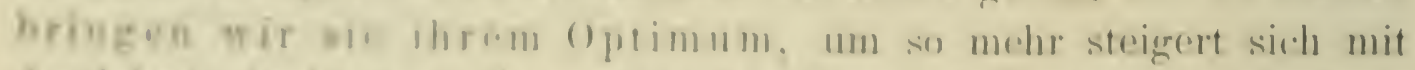

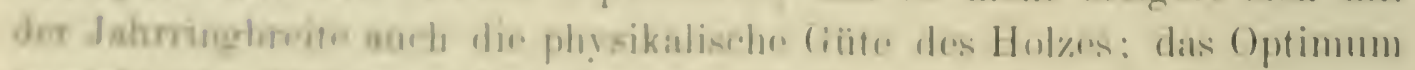

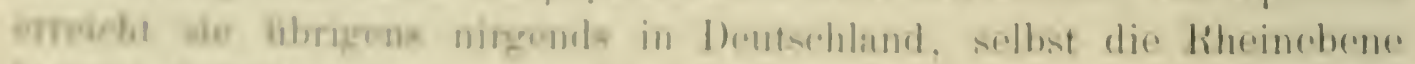

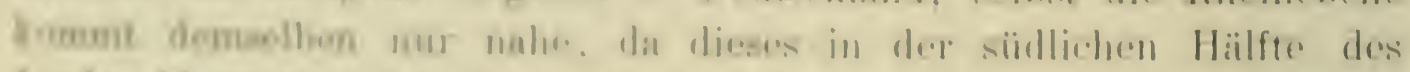

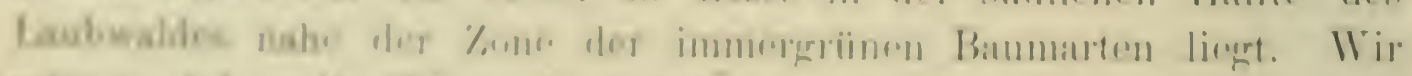

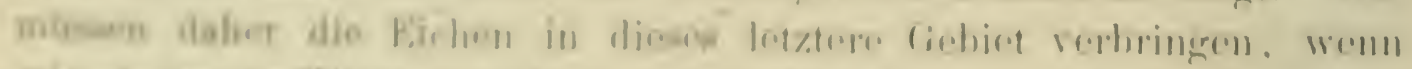

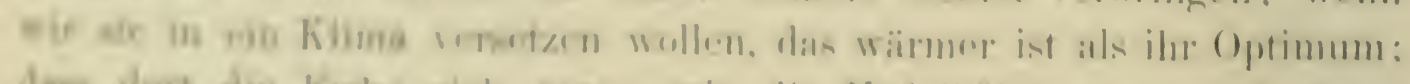

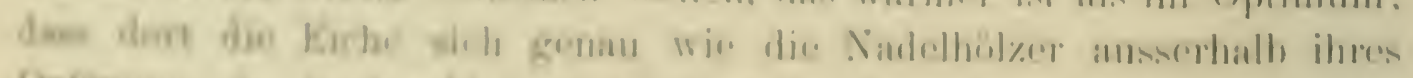

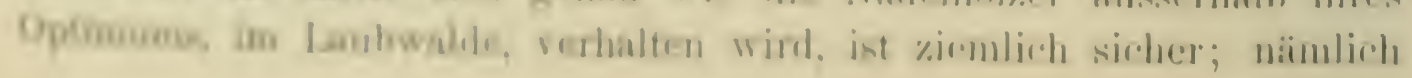


rascheres Wachsthum in der Jugend mit entsprechend abnehmender Qualitiit, langsameres Wachsthum im hohen Alter, das überdies kürzer sein wird als im Optimum. Die Buche hat ihr Optimum da, wo die Eiche zurücktritt; man rersetze die Buche in das Optimum der Eiche und sie wird das gleiche Verhalten wie diese und wie die Nadelhölzer befolgen; von dieser Regel dürfte es keine Ausnahmen geben.

Es bleibt noch zu beweisen, dass auch ein kühlerer Standort, als das Optimum, die gleichen Wirkungen auf die Pflanzen übt, wie der wïrmere Standort: für Laubhölzer dürfte das Gesetz keinem Widerspruche begegnen; dass der Zuwachs der Nadelhölzer zurüickbleibt, ist ebenfalls sicher; dass auch die physikalische Qualität im kïhleren Klima gemindert wird, das beweisen die leichten norwegischen Fichten- und Kiefernhölzer. Man kann somit sagen: die Qualitätssteigerung der Laubhölzer bei breiter werdenden Jahresringen und die Qualitätsabnahme der Nadehhölzer bei breiter werdenden Jahresringen sind keine Erscheinungen, welche Laub- und Nadelhölzer in Gegensatz bringen; sie sind vielmehr - cum grano salis - nur Bestätigungen ein- und derselben Regel.

Zahlreich sind die Beweise für das Gesagte im nordamerikanischen Walde, wo die Kultur die Erkennung des Gesetzes noch nicht erschwert hat; bei den einzelnen Holzarten habe ich womöglich das Optimum angegeben, bei vielen sind auch die phrsilkalischen Qualitäten für das Optimum, für das kïhlere und wärmere Klima ausserhalb desselben beigefügt.

Daraus lässt sich entnehmen, welche Veränderungen in Güteproduction und in der Zuwachsleistung vor sich gehen werden, wenn in Amerika. wie diess in Deutschland so oft geschieht. Holzarten ausserhalb ihres Optinums kultivirt und bewirthschaftet werden. Durch die Verkürzung der Lebensdauer, die Zusammendrängung des Zuwachses auf die erste Zeit der Entwicklung ändert sich nicht das Gesetz, das somit in Verbindung mit der Forstwirthschaft folgendermassen formulirt werden mag:

1. Innerhalb und 2. ausserhalb des Optimums einer Holzart ist der Urwald die typisehe Wirthschaft zur Bereicherung des Bodens und zur Erhaltung der Nachhaltigkeit, sowie zur Erziehung der vollkommensten Formen, der höchsten technischen Güte; dagegen liefert diese Methode in gegebener Zeit (Untrieb) die kleinste Holzmasse am einzelnen Stamme, sowie die geringste phỵsikalische Güte des Produetes.

3. Innerhalb des Optimums einer Holzart ist der Kulturiald (im extremen Sinne als Raubwirthscháft) die typische Wirthsehaft zur 
Brochügunf in Budus. zur Erzirhung der schlechtesten Form. der

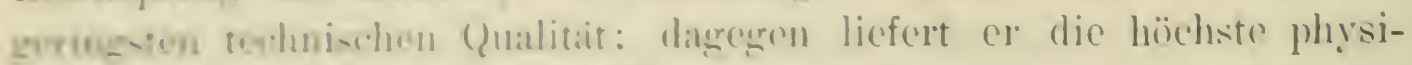
Saliseler Qualithit und grüste Holzmenge in gregrebener Zeit (Untrieb) am cinzelnen stamme.

4. An-erhalb des Optimums ciner Holzant ist der Kulturwald die typische Wirth-chafe zur Erschöpfung des Bodens. zur Er\%ichung der -bbliebtesen form, der geringsten technischen und physikilischen Gïte

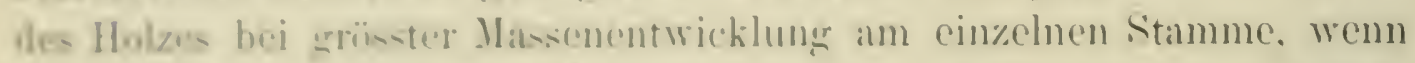
at the Wirthechaft in einem (iebiete betriehen wirl. das wämer ist als das (1primum der berreffenden Holzart: bej kleinster Massenentwicklung aber am rinzolnen stamme, wonn b) die Wirthschaft in cinem Gebiete betrieben wird, das kühler als das Optimum ist.

lis ordnen sich demnach diese beiden extremen Wirthschaftsmothoton in abateigender Reihenfolge:

Nach dor Holzmenge, die sio in gregrebener Zeit produziren: 4a. 3. 1. 4 h. 2.

Nach dre physikalischon Hol \%giite des in dieser Zeit grebildeten Holzes: 3. 1. 4 ia. 4b. 2.

Sinch der technisehen Holyrite (Gefürese) in derselben Zeit: 1. 2. 4h. 3. 4 a.

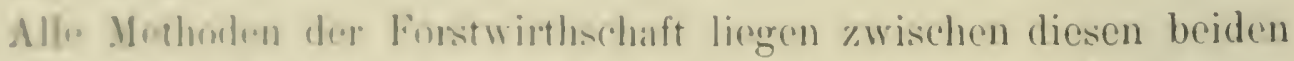

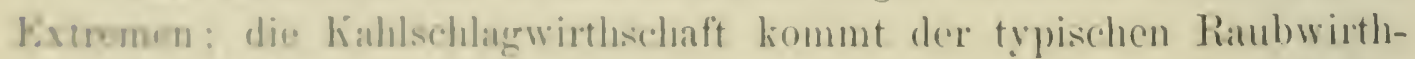
shaft am nlichsen: ub die Aufschliessuner nener Nihrstofie im Boden tum die Entnahme von Nihrstoflen in Form ron Hol\% grleichen Sohritt

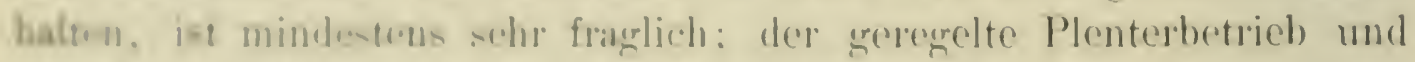
des Fehmelbetrieb hommen der Urwaldwirthschaft am nädssten: bei

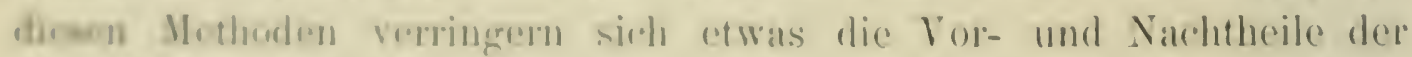

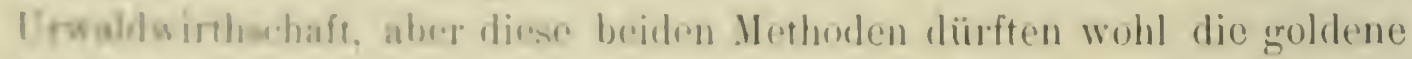

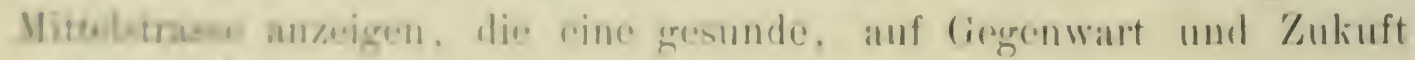
bedaction Purstirinlischaft betreten matg.

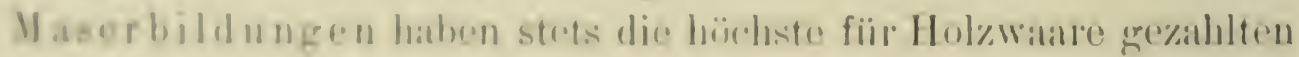

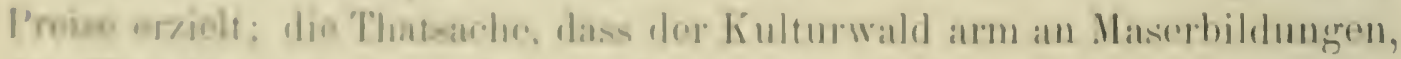

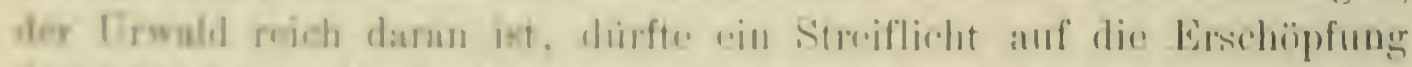

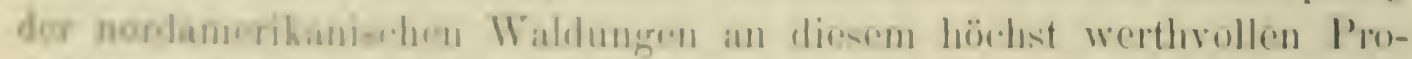
doke worfoll: auf joden labll rermögren die Waldumgren dem gregent-

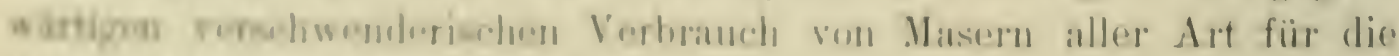
Daas oichn ziterhe zu werlen.

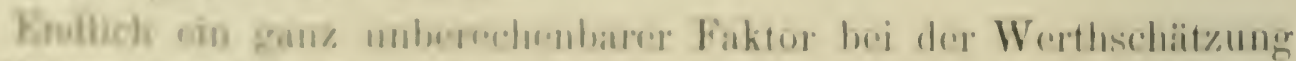

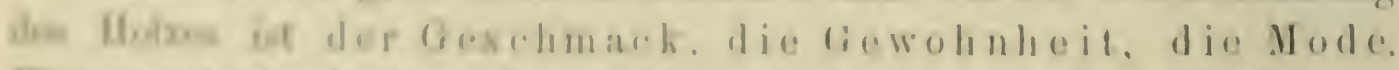

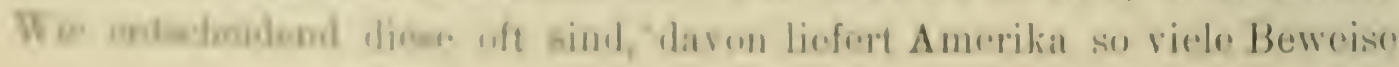


wie Europa; die feinsten Möbel sind aus Mahagoni- oder Nussbaumholz, auch Kirschholz ist noch ziemlich ,stylish"; zu Flintenschäften liebt man ebenfalls Nussbaumholz und so weiter; hierin kann kein Land Japan übertreffen, wo das Haus eines Vornehmen eine Sammlung von ein paar Dutzend Holzarten darstellt und das Haus ist dabei um so werthvoller und schöner, je feinere Hölzer es enthält, die man nicht wie bei uns mit Oelanstrichen oder Tapeten verkleidet. Was die Gewohnheit und das Vorurtheil für oder gegen ein Holz betrifft, so werden die Exoten in deutschen Walde noch manchen harten Kampf, auch wenn sie mit unserem Klima glücklich fertig geworden sind, zu bestehen haben.

Es würde den Raum dieser Schrift überschreiten, alle Verwendungsweisen der Hölzer, die sich auf viele von der Technik gewünschte Eigenschaften des Holzes gründen, hier zu erwähnen; die Praxis ist hierin der Wissenschaft weit vorangeeilt, einige Beispiele mögen genügen. An feineren Luxusbooten sind gefertigt dic Planken aus 'Thuja occidentalis-Hol\% (es wirft sich nicht, selbst wenn es in grünem Zustande verwendet wird, es schwindet nicht beim T'rocknen), Schiffsböden und Schiffsrippen sind aus Quercus alba-Holz, Schiffskiel aus schwarzer Wallnuss; zu Rudern aus einem Stïcke ist am besten das Holz der Picea alba und der Fraxinus americana; an Luxuswagen werden die Naben aus Eschenholz, die zierlichen Radspeichen aus Hickoryholz gefertigt; Regenschirmstiele sind aus Zuckerahorn, Zündhölzer aus Pinus Strobus und dergleichen.

Die Schnellwïchsigkeit der westlichen Holzarten Amerika's verrïth, dass diese iu ihren Wachsthumsleistungen ïberhaupt nicht blos die europäischen, sondern auch die ostamerikanischen Holzarten ïbertreffeu werden; dagegen kann man nicht behaupten, dass die östlichen Holzarten - ceteris paribus - in gegebener Zeit eine grössere Holzmenge prodnziren werden als die europäischen Arten; bei einer Reihe von werthvollen Holzarten wurden die Stärkezuwachsberechnungen beigefügt. Nach diesen würde sich sogar ein sehr viel geringerer Zuwachs als der der europäischen Holzarten ergeben; allein beide sind miteinander gar nicht zu vergleichen, denn die amerikanischen Holzarten sind im Urwalde bei mässigem Lichte erwachsen, die europäischen Holzarten dagegen sind im Kulturwalde bei freiem Oberlichte emporgekommen.

Gegenwärtig dürften wohl auch die ostamerikanischen Holzarten auf nordamerikanischem Boden in gegebencr Zeit grössere Mengen erzeugen als die europäischen Arten in Europa. Die seit Jahrtausenden 


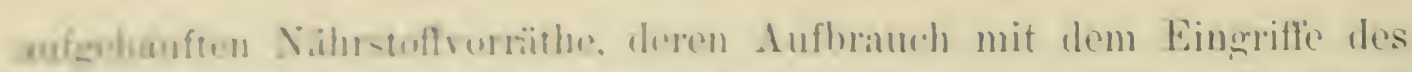

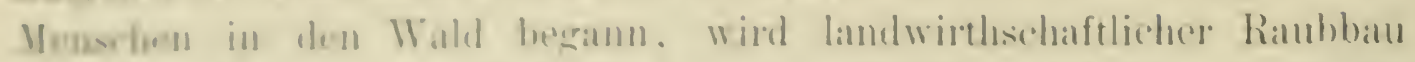

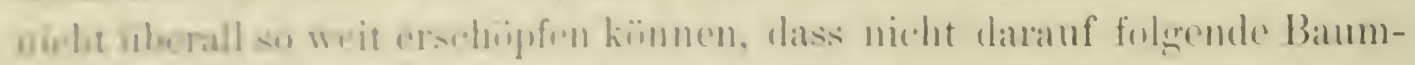

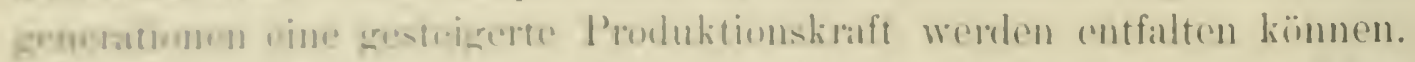

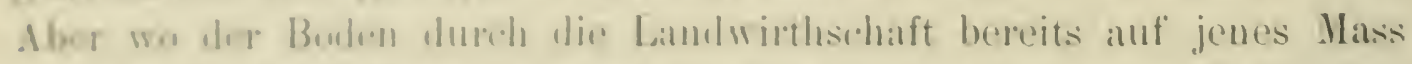
wa . Innuth herabgehratht wurde, wie or unsere greringen Waldbörlen

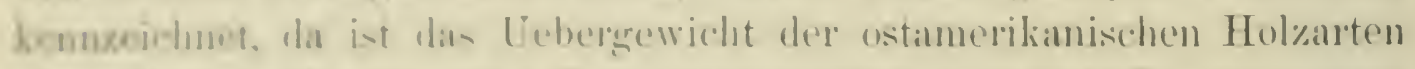

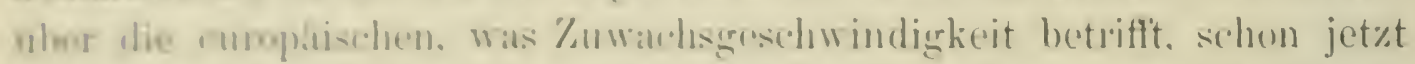

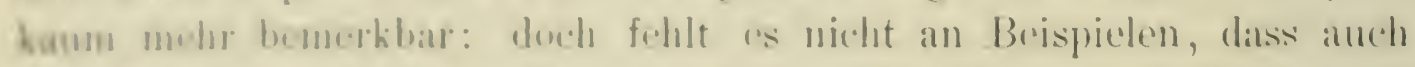

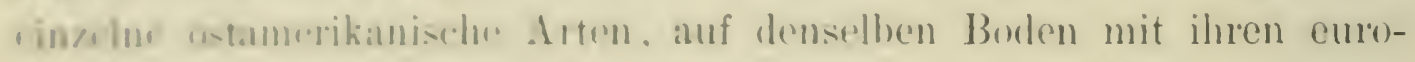

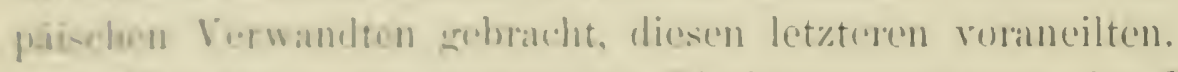

Jan kann dir \%ukïnftige Wachsthumsleistungr der Holzanton in Conlameriha nicht nach den eregenwärigen dortigen Vormithen beur-

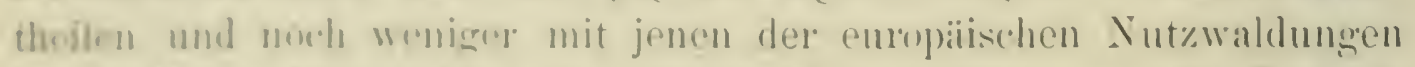
in Veroteich stedlen: denn dir jetzigen Holzorraithe sind alle Urwaldprodukte. Die \%uwadisuntersudungen und die sich daranf grö̈ndenden Yanmberechnumeren werden nur oin historisches Interesse haben, da,

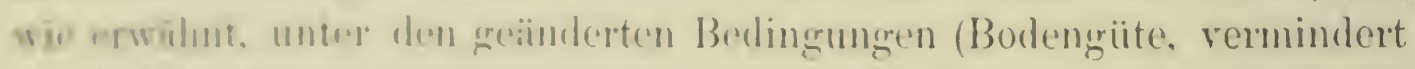
dust Fintuahme des Holzes, Waldbauliche Verhailtnisse) die Hol\%arten andwe zuwatsen und andere Vorrithe aufspeichern werden.

Din fromwitig in Nordamerika berechneten Massenertrïre pro Handseneinheit sind mit den Angaben ans den hulturaildern schon debalh nicht revgleidhatr, weil sich solche Berechnungen nur auf eine

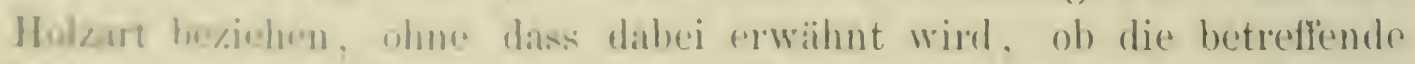
Holkan in reinen Bomtïnden oder in Mischumer mit anderen rorkommt,

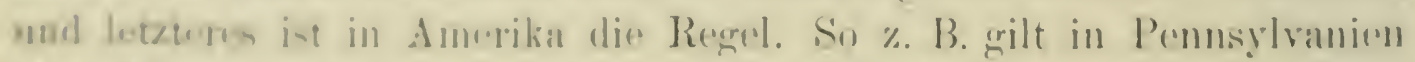

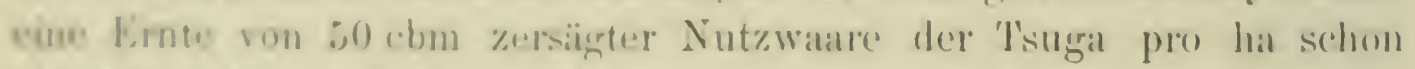

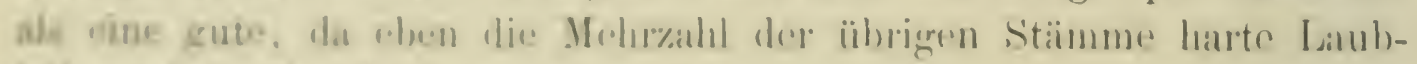
hisilzor smi, die nicht geniitzt werden.

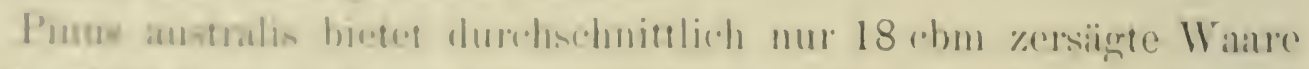

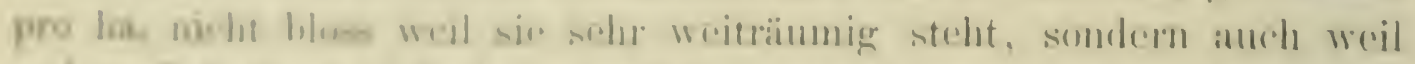

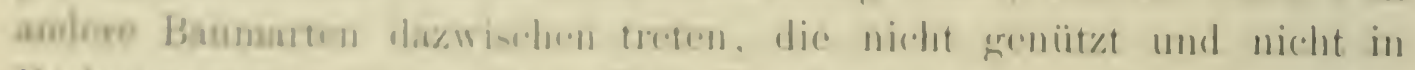

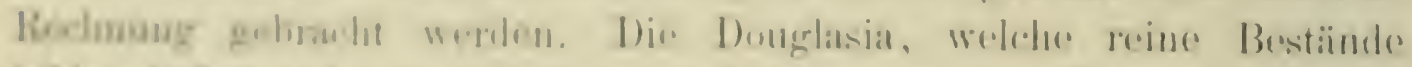

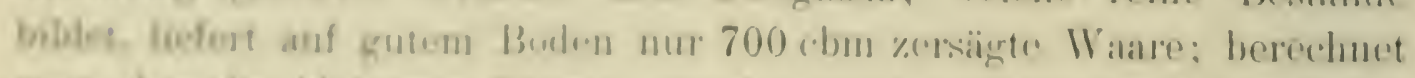

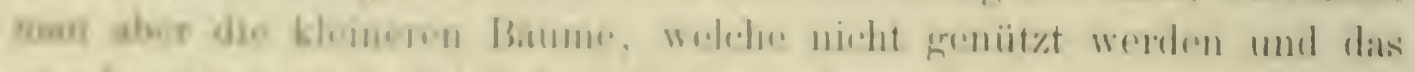

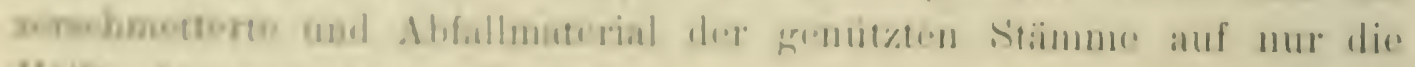

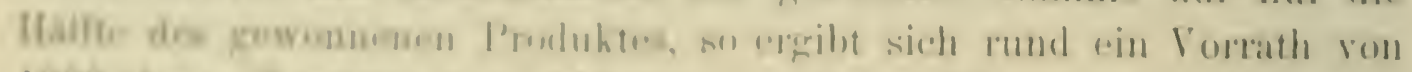

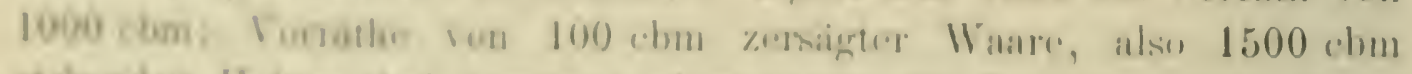

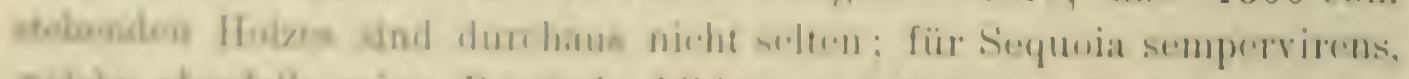

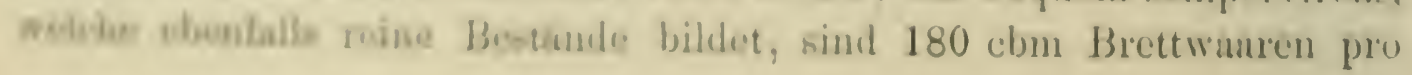


Baum und volle $12500 \mathrm{cbm}$ pro ha keine Seltenheit; meine eigenen Berechnungen ergaben $13300 \mathrm{cbm}$ pro ha für dieselbe Holzart; endlich die Sequoia gigantea baut Stämme auf, die volle 800 cbm Holzmasse führen; den Durchschnitt auf $500 \mathrm{cbm}$ berechnet, gibt pro ha bei 10 Stämmen 5000 cbm Sequoia-Holz und 1000 cbm Tannen- und Kiefernhol\%, das wären nur 6000 cbm pro ha; da es aber Haine gibt mit 25 Stämmen und darïber pro ha, so dürften $12000-13000$ cbm pro ha auch in der Sierra Nevada häufig zu finden sein.

Diess führt mich zu Vorrathsberechnungen, die ich aus den erwïhnten Grüuden vermeiden wollte. Eher liesse sich die Grösse des gegenwärtigen Holzverbrauches feststellen; doch sind auch diese Zahlen nicht zurerlässig.

Nach dem Directory of the North-western Lumberman pro 1887 sind alle Sägmühllen der atlantischen Region auf eine höchste tägliche Leistungsfähigkeit von 200 Millionen feet, das ist $500000 \mathrm{cbm}$ zersägte Waare eingerichtet; alle arbeiten wenigstens mit der halben Menge, gibt bei 300 Arbeitstagen mindestens 75 Millionen cbm zerschnittenes Holz, hiezu 1/3 für Verlust bei der Gewinnung, sind 100 Millionen cbm stehendes Holz.

Nach dem früher gesagten beträgt der jährliche Bedarf

für Eiscnbahnen . . . 8 Millionen cbm stehendes Holz, Holz zu Züunen •. . . 14 " $14 \quad$ " " " "

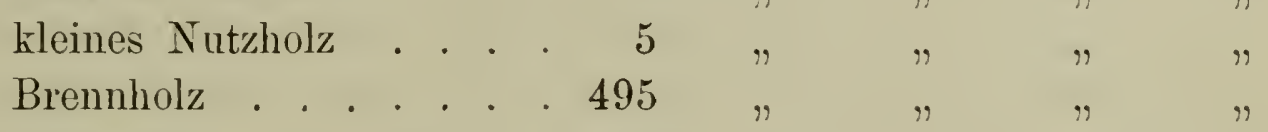
Holzkohle . . . . . 7 " " " "

zusammen 529 Millionen cbm stehendes Holz.

Der atlantische Wald umfasst etwa 150 Millionen ha; es müssen demnach, un das Quantum ohne weitere Steigerung desselben nachhaltig attam zu nützen, alljährlich 3,5 cbm Holz zuwachsen, eine Grösse, die der can p Wald gewiss zu leisten in Stande ist. Doch dazu kommt einmal eine $60 \mathrm{cu}$ stetige Steigerung des Bedarfes, dann eine rapide Verminderung der acre Waldfläche durch Rodung, die Verheerung des Waldes durch Feuer, die weniger auf eimmal verzehren als durch ihr wiederholtes Auftreten langsam ungehenere Vorräthe ron Holz verschlingen; die Schätzung ist, was den Verbrauch betrifft, gewiss noch riel zu niedrig; denn für eine Menge Holz ist statistisch der Verbrauch gar nicht nachzuweisen; so z. B. existiren allein im Osten 5500 Möbelfabriken, alljährlich werden 8 Millionen Regenschirmgriffe (aus Zuckerahornholz) gefertigt, die 3 Zahnstocherfabriken des Osten verarbeiten alljährlich 600000 cbm zersägtes 


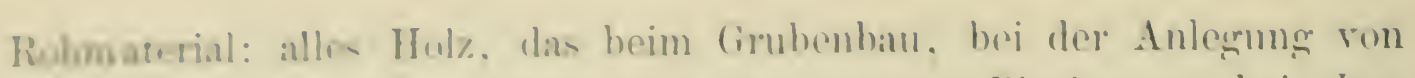

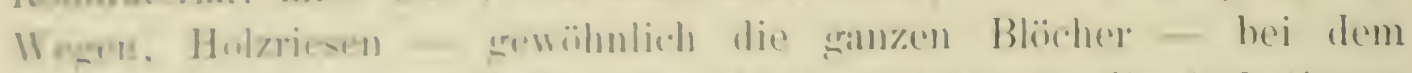

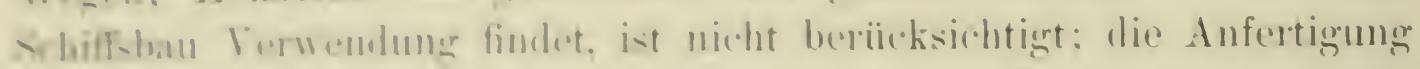

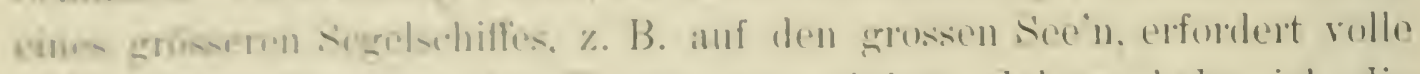

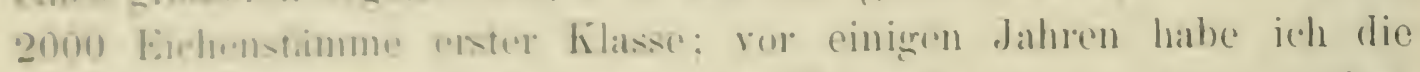

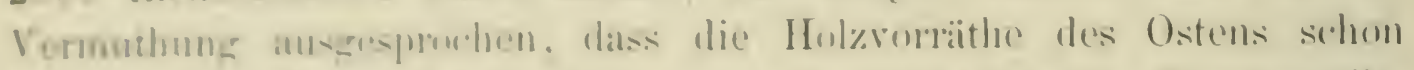

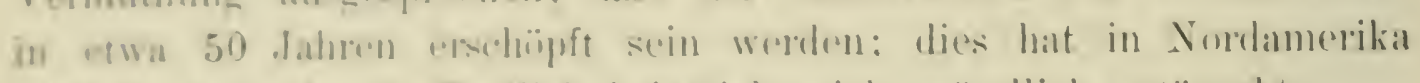

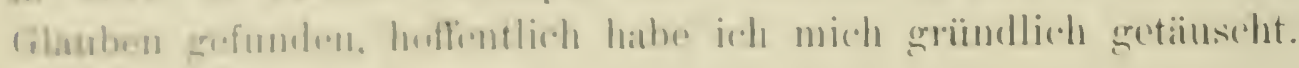

\section{$\nabla$ Veränderungen in der Waldvegetation durch die Eingriffe des Menschen.}

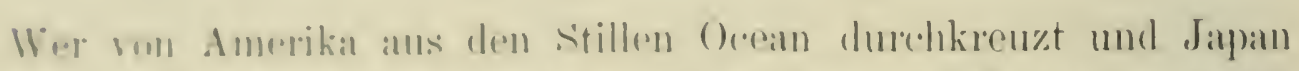

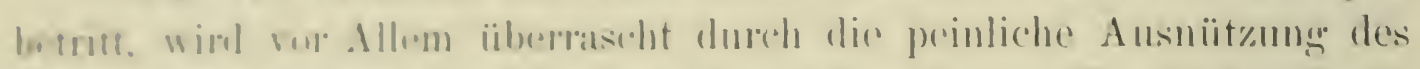

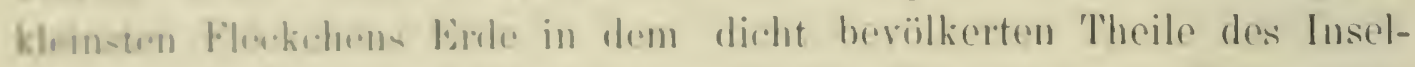

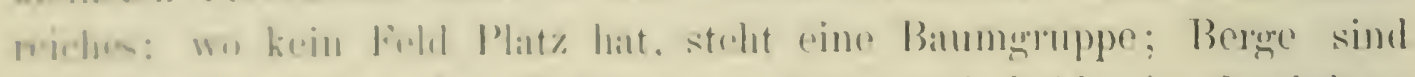

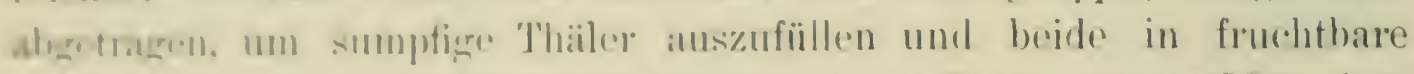

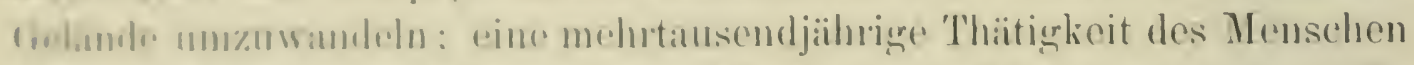

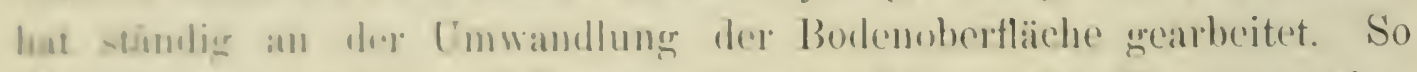

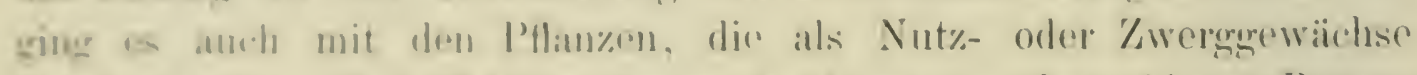

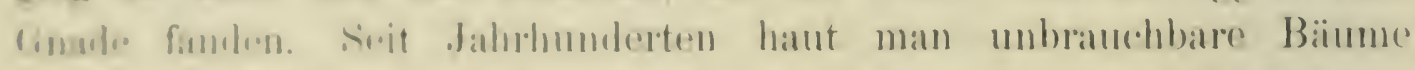

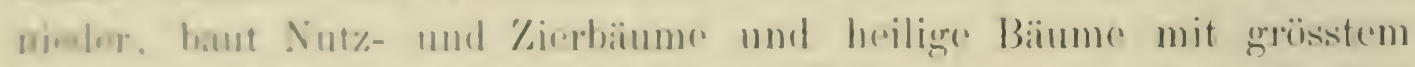

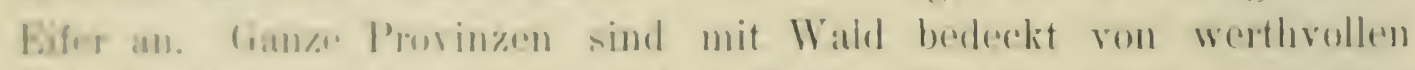

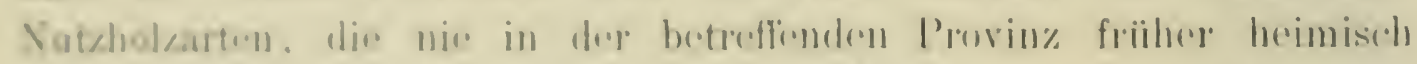

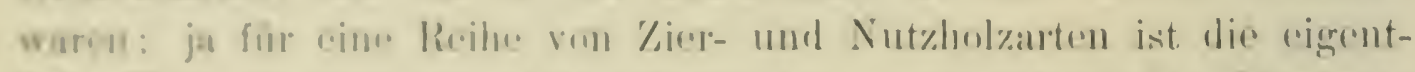

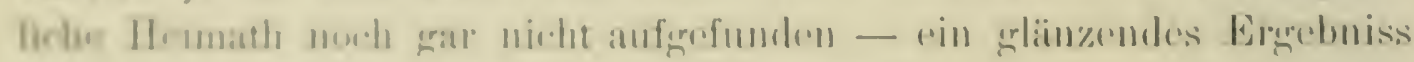

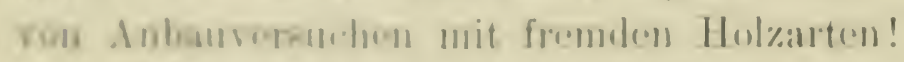

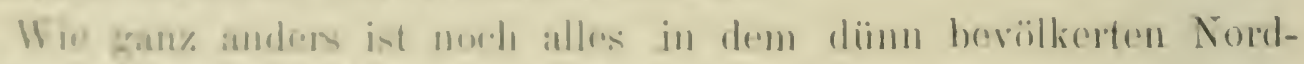

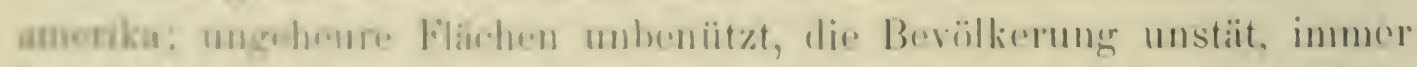

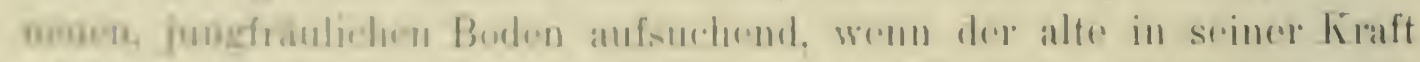

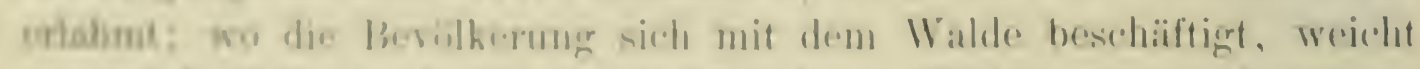

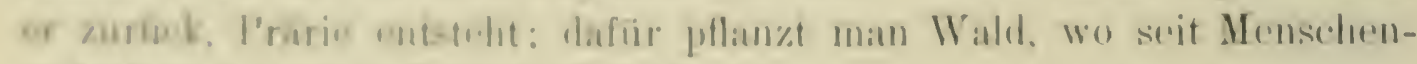

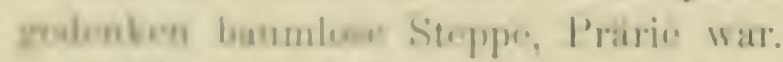

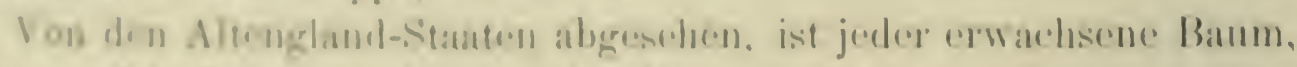

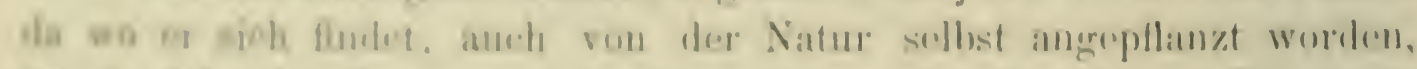

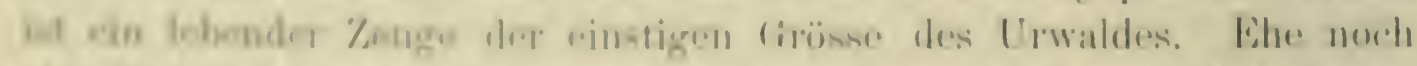

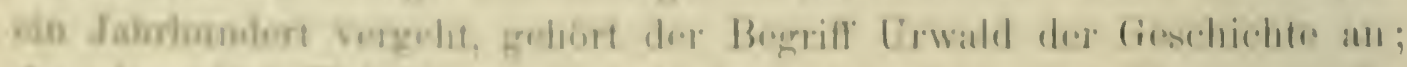
Aas elowadgen Wabbils wird rerindert sein nach den Gesctzen, die 
für alle Länder; alle Völker Geltung haben und deren Wirkungen schon jetzt auffallend sind für den, der die Waldungen der nördlichen Halbkugel so oft durchforschen kann, wie es mir vergönnt war.

Im Urwalde ist die Produktionskraft eine steigende, im Wirthschaftswalde, dem Walde, mit dem der Mensch sich beschäftigt, im allerbesten Falle eine gleichbleibende Grösse; in der Regel verringert sich dieselbe, mag der Boden noch so rorzüglich sein. Im Urwalde siegen beim Kampf um's Dasein, wenn eine Mischung von schattenertragenden und schattenfliehenden Holzarten entsteht, in der Regel die schattenertragenden Holzarten. Die wintergrünen Eichen Japans zum Beispiel, dringen vermöge dieses Naturgesetzes so weit nördlich am ror, als es das Klima erlaubt. Zwischen jenen kommen keine winter-fow kahlen, schattentliehenden Eichen empor.

Der Mensch ändert die Bedingungen; die winterkahlen Bäume, nicht mehr erdrückt durch die dicht belaubten Konkurrenten, fassen Fuss unter dem Einflusse des günstigen Klima's, welches sie selbst für einen geringerwerthigen Boden entschädigt.

Der Mensch entnimmt selbstrerständlich dem Walde die besten Vudu Holzarten, die aber in der Regel auch die schwersten Samen tragen agen und am schwierigsten sich verbreiten. Ueberall, in Europa, Japan, suche Amerika ist desshalb ein Tordringen der geringerwerthigen, leichtsamigen Holzarten, ein Zurückweichen der werthrollen, schwersamigen zu constatiren: ja es sind geradezu dieselben Genera, wie Pinus, Populus, Salix, Betula, die durch die menschliche Thätigkeit begünstigt, ständig an Terrain gewimnen. Auf der ganzen Linie ist ferner ein Vorrücken der work Bäume der kühleren Regionen nach Süden hin bemerkbar; die Nadelhölzer der kühleren Region treten in das Gebiet des Laubholzes, die winterkahlen Laubhölzer in die Zone der wintergrünen über und drängen diese wieder weiter nach Süden; das Ende, so ferne es noch liegen mag, ist in der Ebene kümmerlicher, durchlöcherter Baumwuchs auf heruntergebrachtem Boden, im Gebirge kahle Berge. -

Nach diesem al!gemeinen Gesetze wird sich wohl anch die Waldflora Nordamerika's verändern müssen, freilich viel schneller und gründlicher, als irgendwo in der Welt; denn so gewaltige Waldmassen ron so mannigfaltigster Art hat noch keine Nation besessen und noch keine Nation hat auf solche Weise gegen ihre Waldungen gewiithet.

Was Europa darin geleistet hat, ist freilich nur kleinlich, für Europa aber gross genug und wohl bekannt; für die amerikanischen Leser dieser Zeilen erwähne ich zum Beispiel das Land, in dem einst Milch und Honig floss; was ist aus demselben geworden, nachden die 
hreucfuher das Laund glïcklich erobert und die Bergwaldungen herunter-

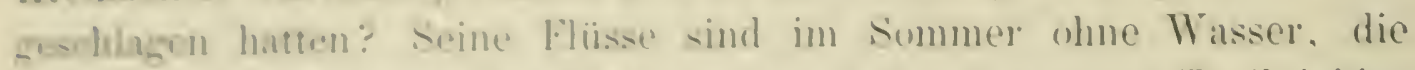
Furen sind vertrocknet. die Bewduner his auf den sechsten Theil dahinkesi.hwunden.

Spanien war ein grosoel Garten zur Zeit der Herrschaft der

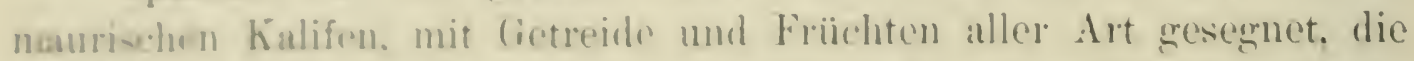
Bowblkerung war thatigr, kraftigr. mächtigr und hoch grebildet, so lamge die versediedenen sierrats mit wasserspendendem Walde hedeckt waren. Whe nawholgenden Fënige haben dir Waldungen vernichtet, ans demselben Iotise wis die Daimios in Japan thaten, nämlich um Geld zom Krimfuhren zu erhalien. Jetzt ziehen Heerden von Ziegen und Schafen

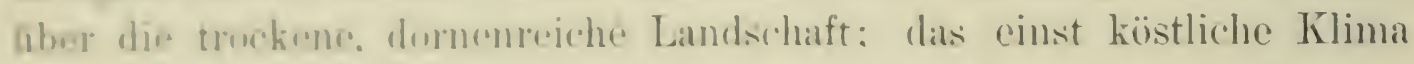
Lis unertraglich froworden, wenn der gribhende salano oder der eisige

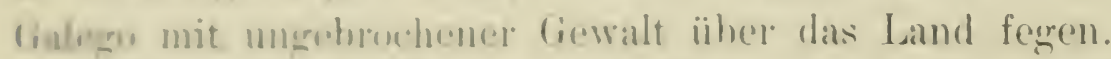

[routsdhland, Oesterreidh, Italien und Frankreich haben kahle

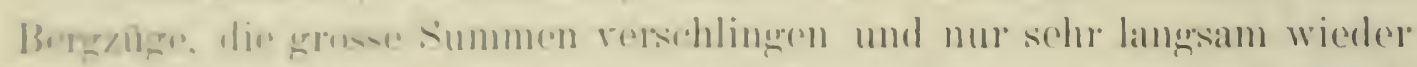

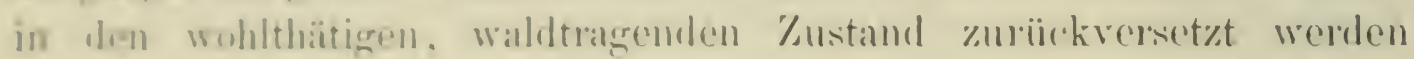

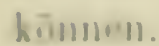

Ciehen wir weitor naw Osten, nach Ceylon, wo die Bestrebungren,

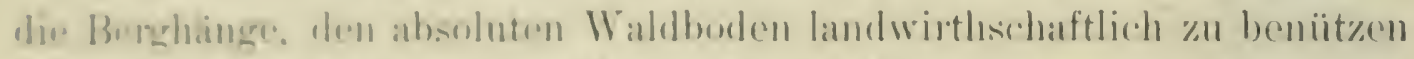

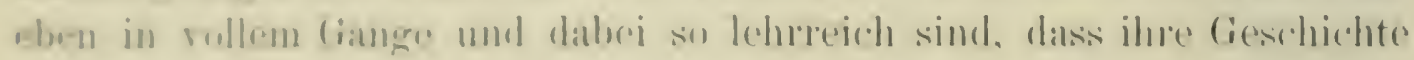

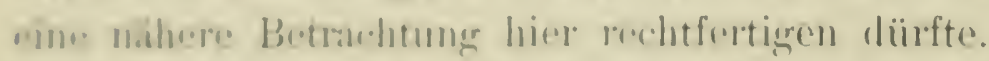

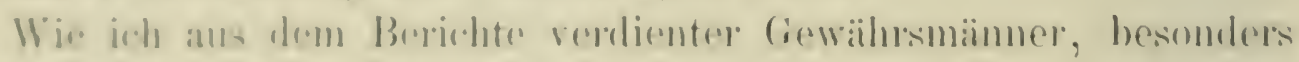

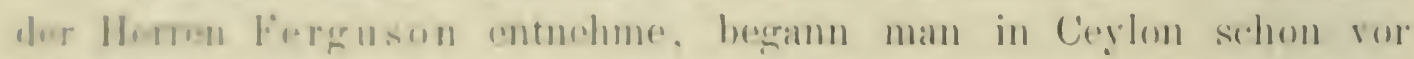

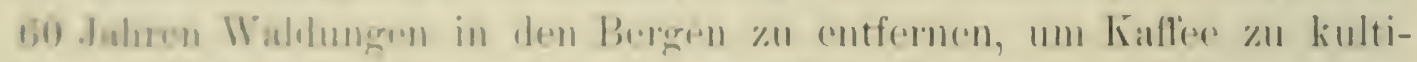
virn: allem da in lingland zu limsten West-Indions anf hatfere amderer

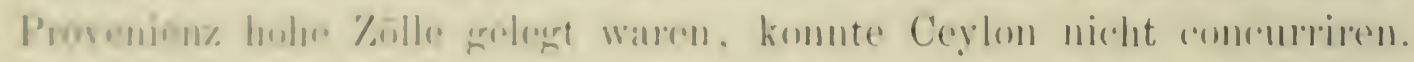

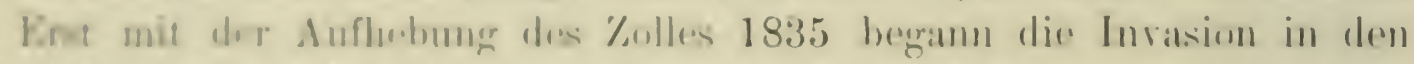

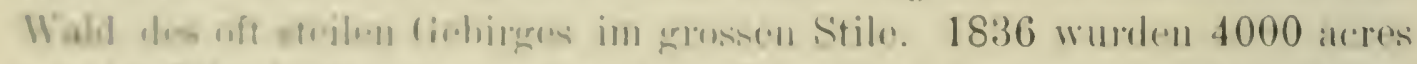
vat der Colonialer ginnmg verkinuft, im Jilne 1941 bereits über 78000 alcres

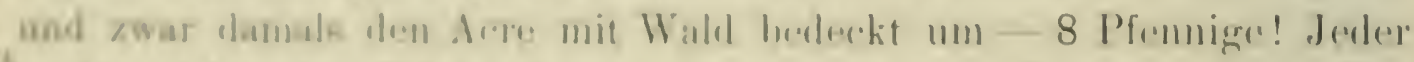

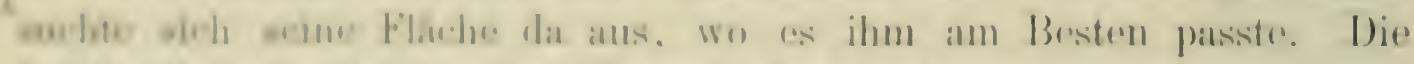

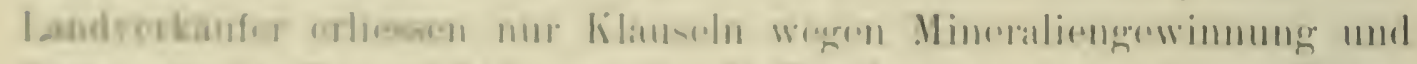

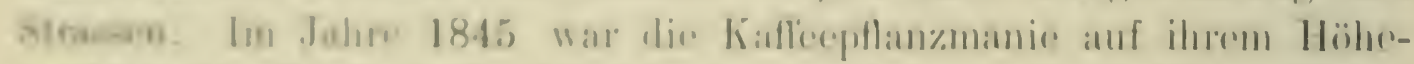

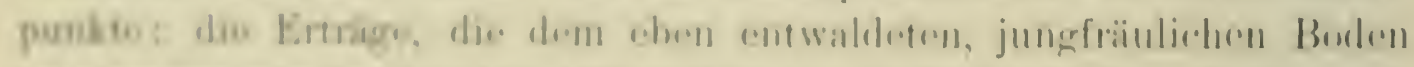

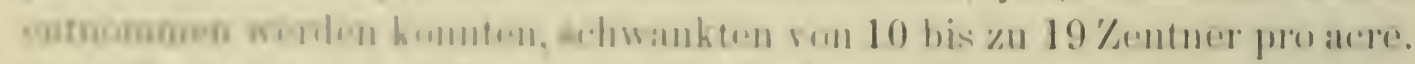

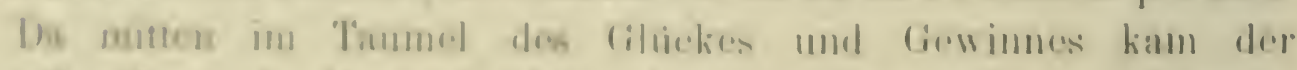

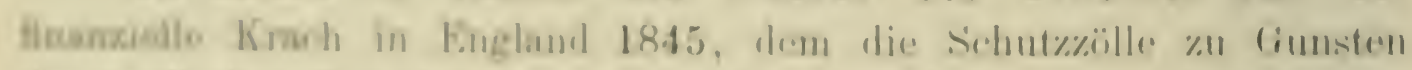

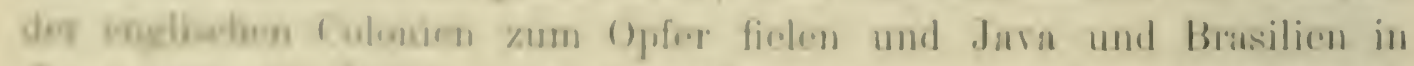

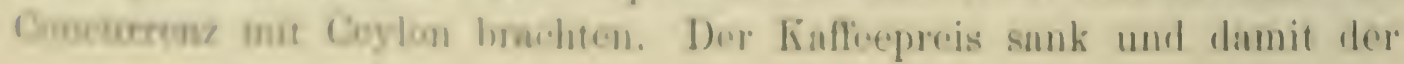


Werth der Anlagen. welche vielfach theils um ein Spottgeld rerkauft wurden, theils sich wieder mit Wald bedecken durften. Die Krisis hatte ihre gute Wirkung; frïher rodete man den Boden, pflanzte die Kaffeestauden und glaubte, von da an brauche es nur immer zu ernten und liess Gras und Kräuter wachsen; nach der Krisis begann eine gartenmässige Reinhaltung und Pflege der Plantagen, was die Erträge zwar steigerte, aber auch die Erschöpfung des Bodens beschleunigte.

Die nächsten 10 Jahre 1845 - 55 wurden etwas über 47000 acres, ron 1861-65 fast 157000 acres, von 1866-72 227000 acres rerkauft. Dabei reichten die Entwaldungen an den Bergen bis $6000^{\prime}$ hinauf. Viele Quadratmeilen ron Berghängen sind ihres Waldes beraubt und mit dem dichten, 1-2 Meter hohen Bestande ein und derselben Pflanze bedeckt worden; da kam die Reaction gegen diese unnatïrliche Verbreitung einer einzigen Pflanze, eine Reaction, die um so schlimmer werden musste, als Millionen ron Pflanzen derselben Art und desselben Alters den gleichen Bedingungen des Gedeihens oder Erkrankens ausgesetzt waren. 1869 erschien eine schwarze Schildlaus, in welchem Jahre auch zum erstenmale die Blatt-Krankheit, verursacht durch Hemileia vastatrix, beobachtet wurde. Viele behaupteten, den Pilz schon vielfach früher gesehen zu haben, derselbe habe nie irgend einen Schaden der Pflanzung zugefügt. Noch in demselben Jahre begann die Krankheit ihren vernichtenden Zug durch fast alle Pflanzungen, ein Schauspiel, das sich bei andern Kulturgewächsen in ähnlichen ungünstigen Anhäufungen, wie bei Weinreben, Kartoffelpflanzen, Kiefern und Buchenkeimlingen, ebenfalls wiederholt.

Es ist kein Zweifel, dass junge Pflanzen, insbesonders Keimlinge, in der Regel ron solchen epidemischen Krankheiten hinweggerafft werden; ältere Pflanzen tödtet oder schädigt der Pilz aber oft erst dann, wenn ihre Lebensenergie, das ist ihre Kraft durch Wundkork, Ueberwallung oder Reproduktion den Schmarotzer abzustossen oder ihm vorauszueilen, geschwächt wurde, sei diess durch das Alter der Pflanze selbst oder durch ungenügende Ernährung in Folge unpassender oder abgemagerter Standorte bedingt. Dieser letztere Factor spielt bei der Pflanzenkrankheit in Ceylon entschieden eine mächtige Rolle.

Die Pflanzen auf kräftigen Böden verloren durch die Krankheit im August zwar ihre Blätter, entwickelten abcr neue Blätter und Früchte; die Pflanzen auf herabgekommenen Böden entwickelten zwar wieder Blätter aber keine Früchte und waren dadurch werthlos geworden. Ceylons granitischer Boden ist locker und im Durchschnitte nicht tiefgründig; die Plantagen haben auf den Bergen, selbst auf steilen Hängen 


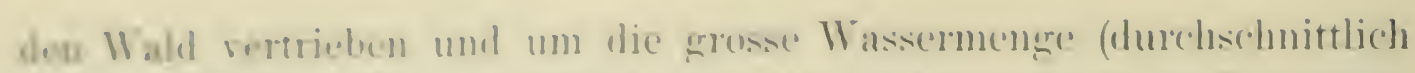

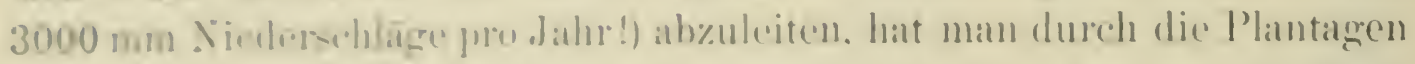

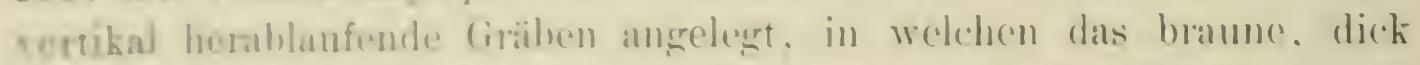

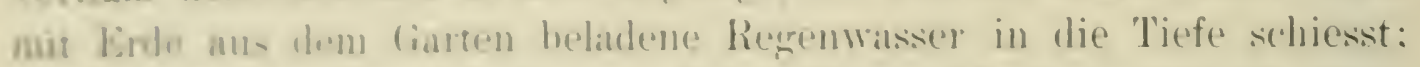
as den anfungliden Grahen sind in älteren Plantagen bereits tiefe

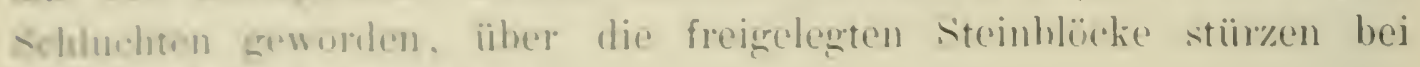
Regen marditige (ijesabiichn!

Wir whuell die Xatur in den Beregen auf die Misshandlungen der Monalyen retarirt. datron rin kleines Beispiel.

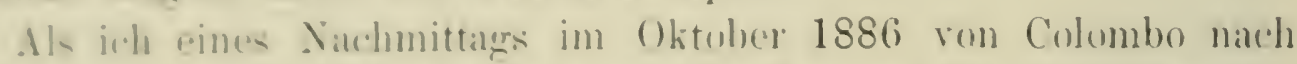
Kandr fuln, hateh win Gewitter aus, wie das bereits alltiiglich geworden

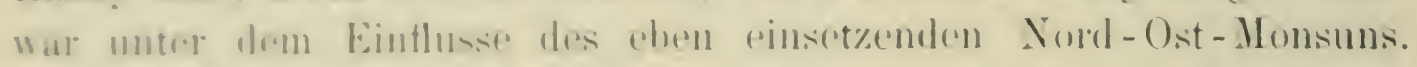

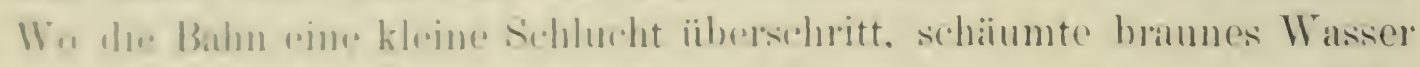
in der Tirfo. Als wir aber den Halagala (Bergre passirten. kamen einzelne

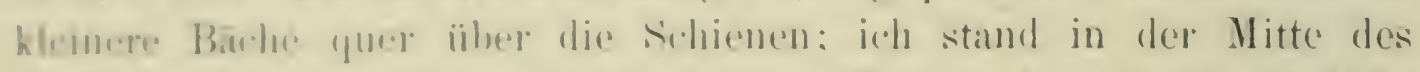

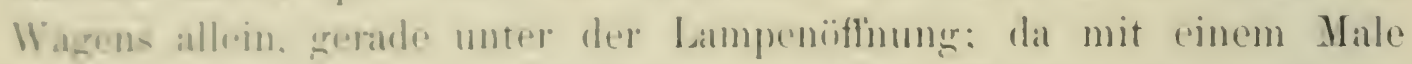
kan win dirker, branner. mit steinm beladener. Wasserstrahl dureh die

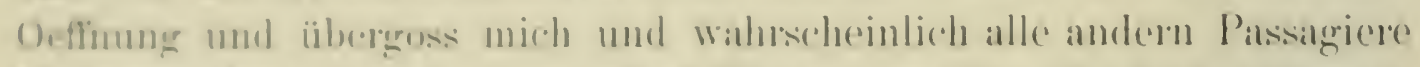
in \% \%ure ubenfalls. Als jeh cin paar Worehen narhhere die stelle abermals

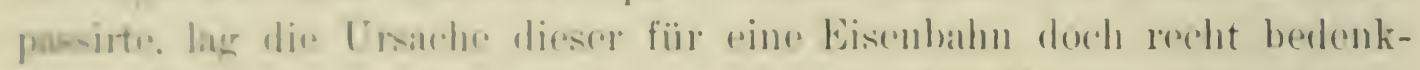

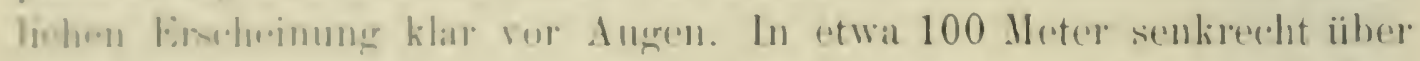

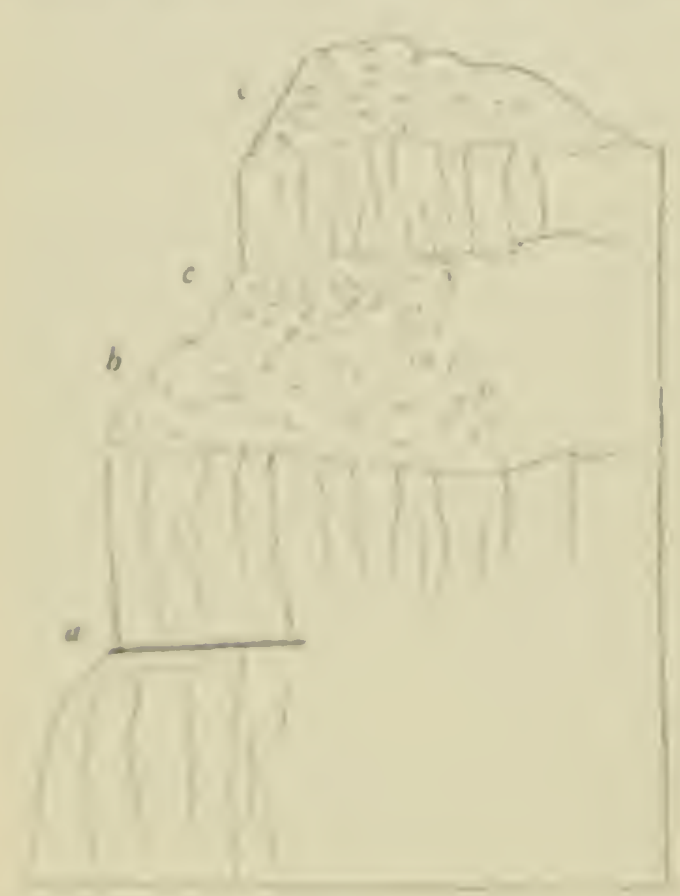

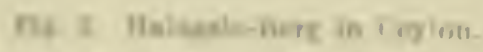

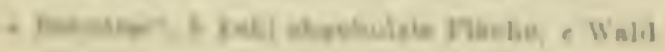
dem Bahmkürper war eine mit grossen steinen und fielsst iicken bedeckte, stark ger neigrte Fliade wenige Worden zuror kahl abgeloulzt worden, am These oner kaffee amzuptlanzen. Da diese simulase Waldvernidhtumg an einer so eminent schutohodürftigen stelle

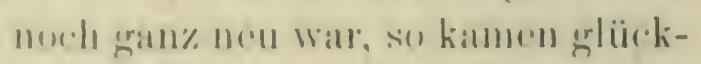
lideer Weise mit dem Regen nur Humus und klejuere steine heab); mit der \%eit werden wohl sedwerer " ineremde Beweise voul dem begrallgenen lidhler anf die bisenbalungïgr hrimbiollon.

II die Auswaschumer des fruchto hatroll. humosen Borlens sidenn län-

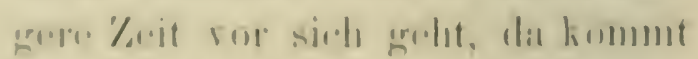
bereits der helle Granitsand 2.11 
Tage. Man sieht genug Plantagen, besonders ältere Anlagen, in denen die oberen Wurzeh der Kaffeepflanzen in der Sonne bleichen; oft bis zu 1 Fuss Höhe ragen die Wurzeln aus dem Erdreich empor; so viel des besten, unersetzlichen Bodens hat das Wasser bereits in die Tiefe gewaschen; solchen Boden heisst man worn out, als hätte die Pflanze den Boden erschöpft und nicht der Mensch, mit seinem nur auf den raschen Gelderwerb eingerichteten Raubsysteme. Dem entsprechend liefern die Plantagen, die im Jahre 1856 noch 20 Zentner Kaffee abwarfen, im Jahre 1882 nur mehr 1 Zentner pro acre! Selbstrerständlich fällt auch ein Theil der Schuld dem Pilze zu, der besonders schädlich da war, wo er schwächliche Pflanzen fand; in Java, auf dem tiefen, rulkanischen Boden ist die Kaffeepflanze viel kräftiger und darum widerstandsfähiger gegen den Pilz. Sie wurde geschädigt aber nur für kurze Zeit und das Erträgniss hat sich kaum oder gar nicht vermindert.

Zahlreiche Plantagen in Ceylon wurden rerlassen, Gras und Sträucher occupirten den Boden, der somit für einige Jahrzehnte lang vor neuen Misshandlungen bewahrt blieb; insbesonders ist es eine Lantana, welche derartiges, so reichlich vorhandenes Terrain in den Tropen in Besitz nimmt, den Boden allmählig wieder verbessert, so dass später wieder Wald Fuss fassen kann. Die Lantana gilt als der Fluch der Pflanzer, mag sein, aber sie ist der Segen der Insel.

Da fand sich mit einem Male eine Pflanze, dic, weil kleiner, auch genügsamer in ihren Ansprüchen an den Boden ist - der Thee. Mit Thee wurden num die Plantagen oft zwischen den todten Stöcken hinein bepflanzt; Thee ist das neue goldene Kalb, um dessentwillen auf der Insel der Wald der Berge geopfert, die Kultur der Eingeborenen im Tieflande bedroht und wenn nicht ein nener Pilz gebieterisch die Rechte der Natur rehabilitirt, die Berge der Insel der Vernichtung, die Insel selbst dem wirthschaftlichen Ruin entgegengebracht wird.

Die Kultur der Strauchgewächse Kaffee und Thee, überhaupt jeglicher Pflanze, welche eine Blosslegung und Lockerung des Bodens rerlangt, ist, wenn man auf Erhaltung des Bodens rechnet und mit einer etwas geringeren aber dauernden Einnahme sich begnïgt, in den Bergen der Tropen und Subtropen, der grossen Regenmenge wegen nu in steingesicherten Terassen möglich, wie die Weingelände an den Bergen Italiens oder die Orangengärten Japans.

Im südlichen Indien und östlichen Himalaya wächst der Thee ebenfalls auf den Bergen; ersteres Gebiet habe ich nicht genïgend gesehen, im letzteren sind die Folgen der Kahllegung des Gebirgsbodens kaum geringer, wenn auch langsamer sich vollziehend als in Ceylon. 
Fur einen rogolma-igen forstichen Betrich des Laubwaldes im iistlichen

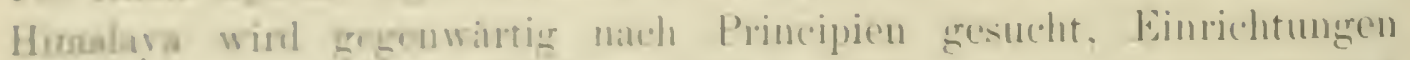

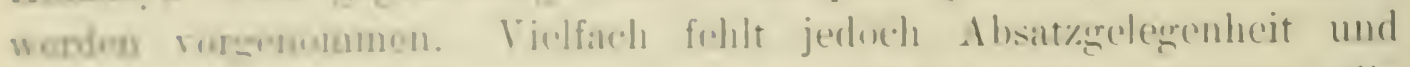

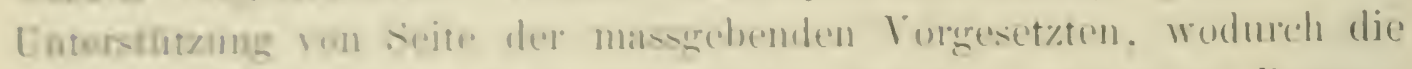

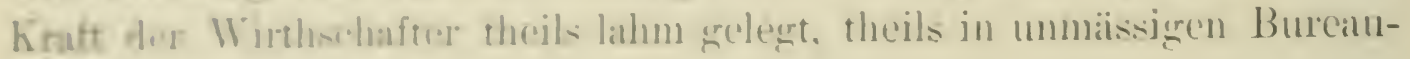
arbeiten rengevilet wird.

In der dortizn Tammonregion nimmt der Bambus überhand, weil is nicht mogrlinh int, ein Wreideverbut gegen die alle jungen Tannen-

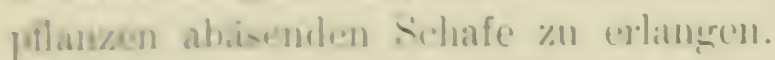

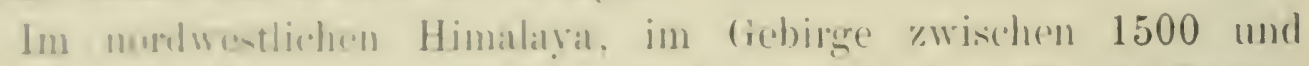

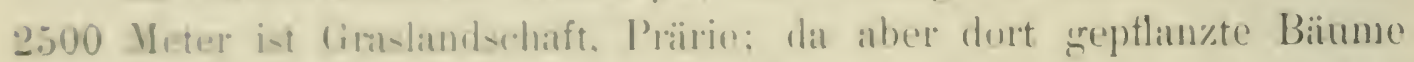

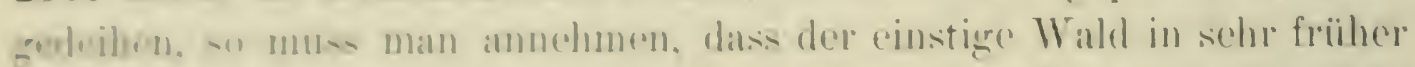

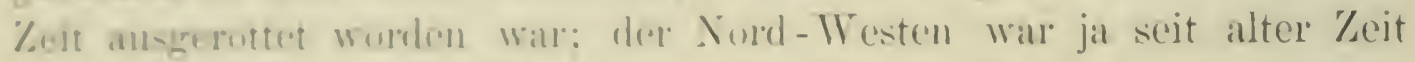
der sedauplats blutiger hïmpfe um die Hegemonie Indiens.

Besonders lehreeinh sind die offenbar erst seit der Entwaldung

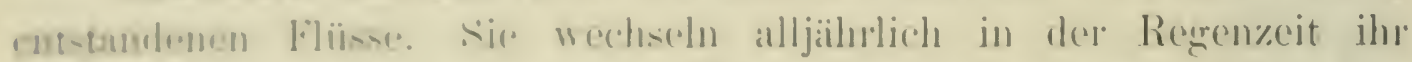

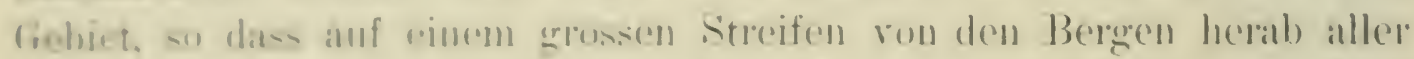
Baumwurh- sornichtet int: Wilhend del Regrenzeit mit Hochwisserfluth beladon, in ihr Brott \%ur truckenen \%eit nur Steingeröll. Dank der

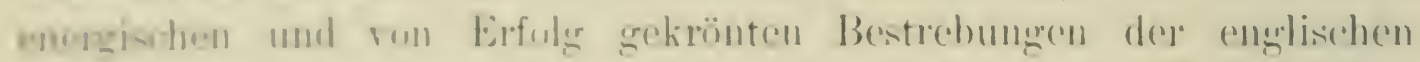

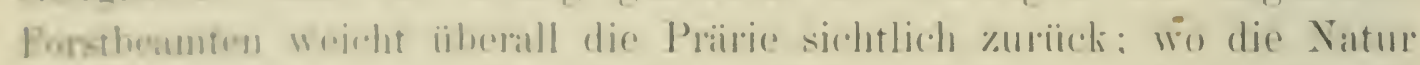

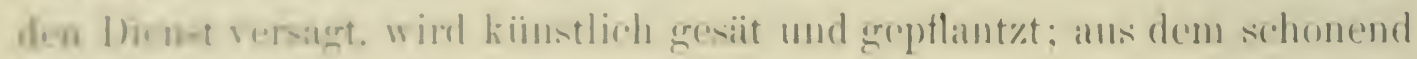

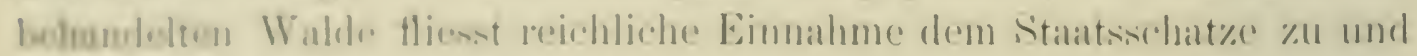

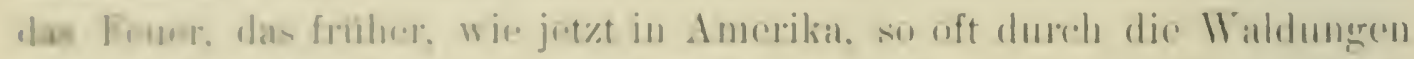

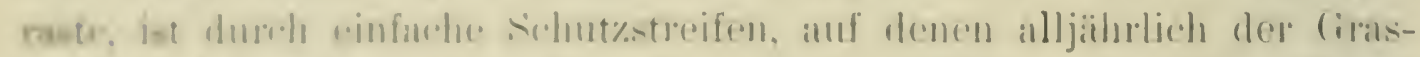

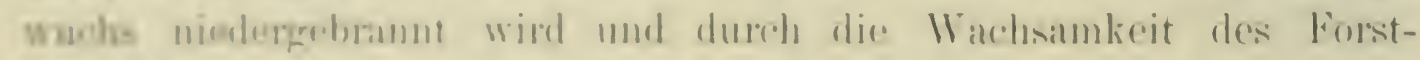

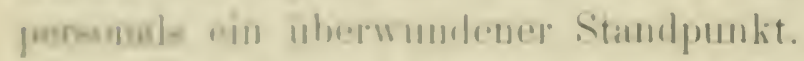

Jura ist im Vepoldeflu mit Ceylon ron der Natur günstiged

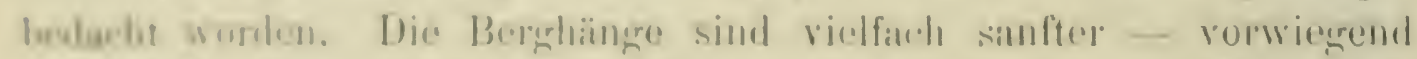

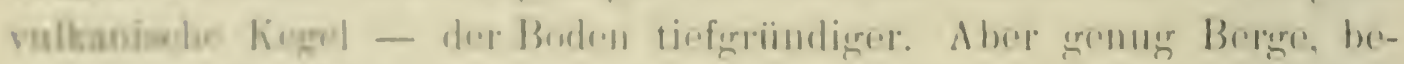

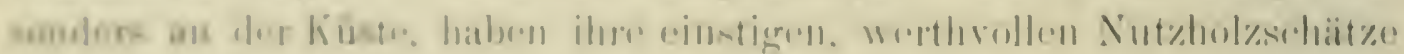

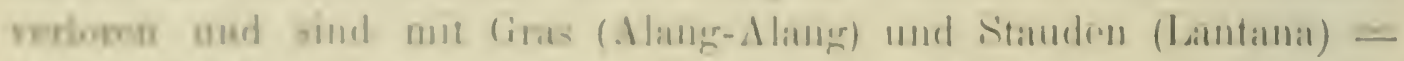

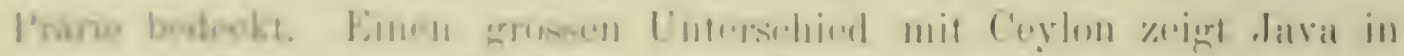

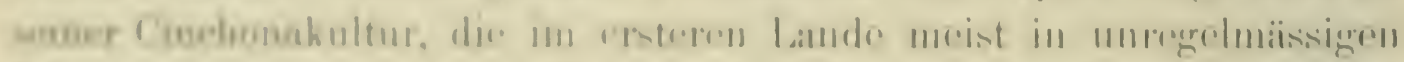

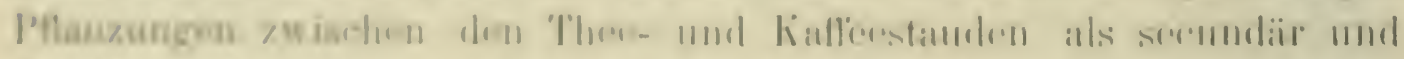

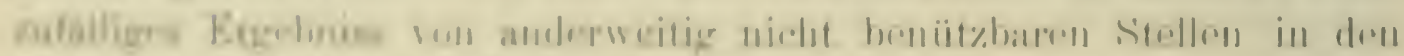

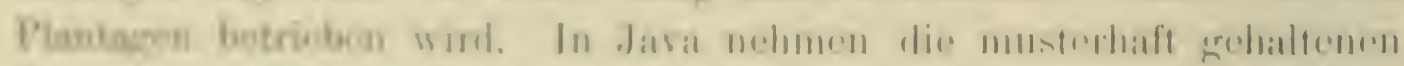

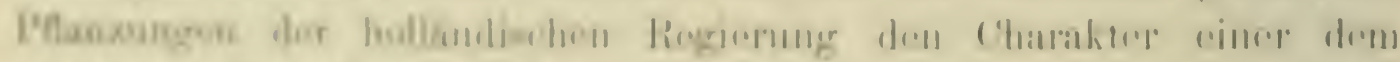

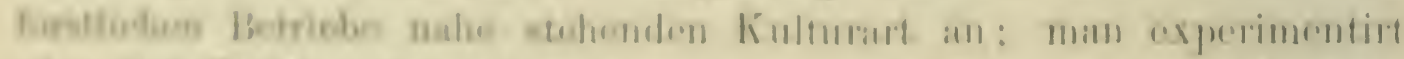

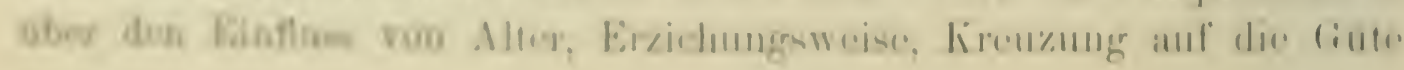


des Produktes und den Gehalt an Chinin; man beschattet möglichst den Boden und verhindert fast ganz die Abschwemmung desselben. Die englische Cinchonakultur und Gewinnungsweise der Rinde in Ceylon hat keine Zukunft, da sie nur auf den momentanen Geldgewinn eineingerichtet ist.

Japan hat schwer gebüsst für die Entwaldungen, die alle erst jüngeren Datums nach unseren Begriffen sind; was vor 30 Jahren geschah, klingt in Japan jetzt wie. mittelalterlich. Die vielen fast unabhängigen Fürsten, Hans, Kokoke und Futai-Daimios waren sehr kriegslustige Herren und brauchten viel Geld; das lieferte stets der Wald. Andere dagegen geboten ihren Unterthanen die Erhaltung des Waldes, weil sie ihre Jagdrergnügung darin hatten oder erlaubten bloss die Fällung von geringwerthigen Bäumen; zuweilen hatten die Unterthanen den Tribut in Holz, besonders Dachschindeln zu bezahlen, wodureh sie zur Erhaltung des Waldes gezwungen waren. Diese Waldungen der kleineren Fürsten sind das Gros der schönen Staatswaldungen, die Japan hente besitzt.

Viele Berge (ungefähr die Hälfte aller Berge des Landes) sind entwaldet und mit Bambus oder anderem Gestrüppe überzogen, das alljährlich zur Düngung der Reisfelder abgesichelt wird. Vor 30 Jahren kannte man kaum Ueberschwemnungen, die jetzt bereits zur Kalamität geworden sind. Als ich im Jahre 1885 Japan in seiner ganzen Länge durchreiste, hatte ich wohl ein dutzendmal mich über Bäche und Flüsse tragen oder in Kähnen überfahren zu lassen, da das Hochwasser die Brïcken und leider oft auch das angrenzende Kulturland ins Meer gewaschen hatte. Ich erimnere mich eines solchen, ganz respectablen Gebirgsflusses, der sein Bett zu einem, ron den Bergen quer durch die Landschaft laufenden, 30 Fuss hohen, pfeilgeraden Sand- und Gerölldamm aufgefüllt hatte.

Zur Schliessung des circulus vitiosus der Waldrernichtung rings um den Pol herum wird Nordamerika wohl das grösste Glied einfügen, trotz der Erfahrungen in den seit tausend Jahren bewohnten Ländern; dass es schon bald, vielleicht schon im nächsten Jahrzehnte zu einer șrstematischen Bewirthschaftung seiner herrlichen Waldschätze schreiten wird, ist leider nicht wahrscheinlich.

Es lohnt sich hier die langsamen aber stetigen Veränderumgen, die jeder Eingriff des Menschen in das Schaffen des Urwaldes in Nordamerika mit sich bringt, etwas näher zu betrachten.

Für jede Pflanze kann man innerhalb ihres Verbreitungsgebietes eine mittlere Zone unterscheiden, in weleher dieselbe in optimo gedeiht. 
E. hat sich nun gezcigrt. ditss innerhalh dieses Optimalgehiotes ar meisen Holzargon anf allen standurten ihr Fortiommen finden,

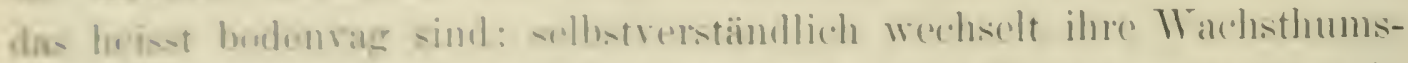

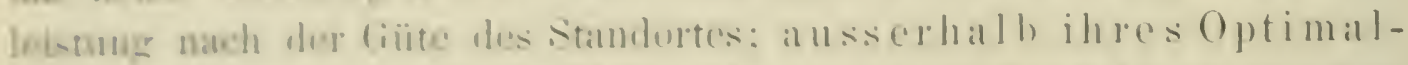

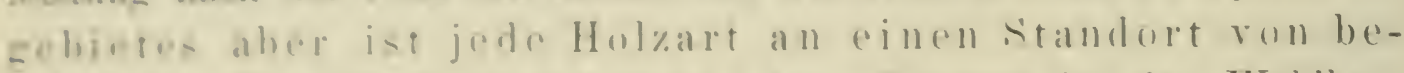

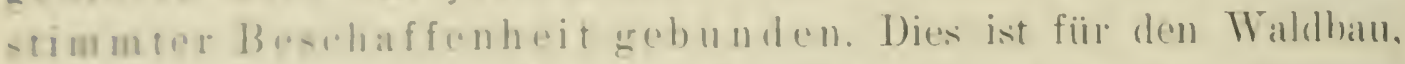
fur Anhauserache mit nicht heimischen Arten, wir mir scheint, sehr wichere und liist sich aiberall beweisen.

Die Wermmuth-kiofore hat ihe Optimalgebiet \%wischen dem 43 und

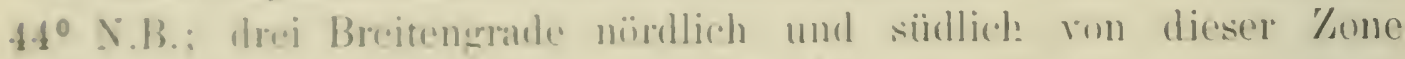
in sio auserohalb des Optimums. Im Optimum finder sie sich auf

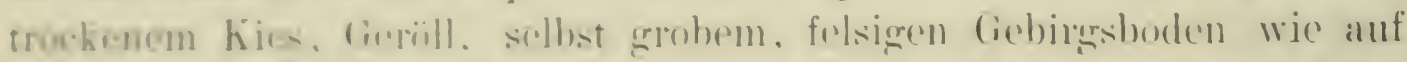

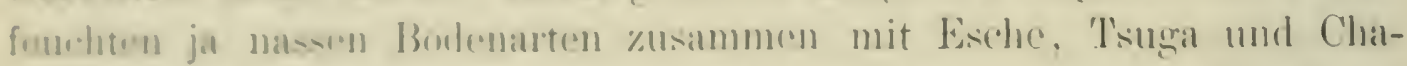

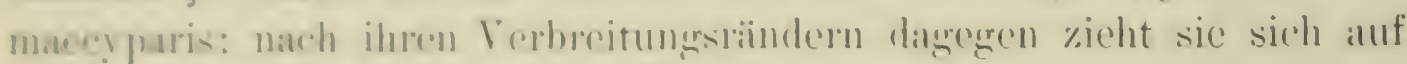

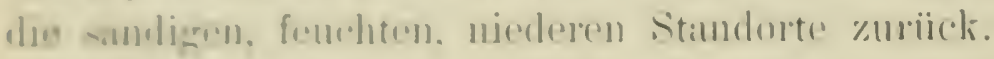

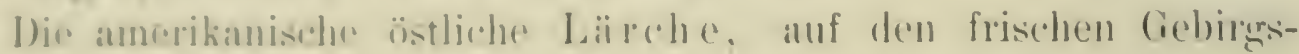
Imaten Canalas ein Baum erster Cirösse, beschräinlit sich auf ihrer sürl-

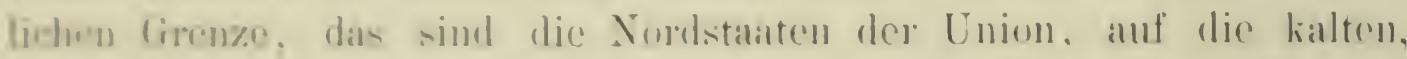

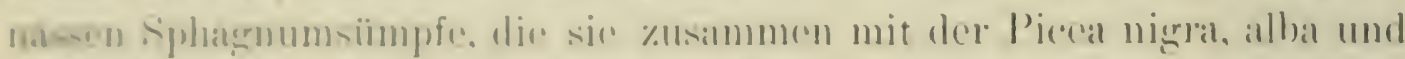

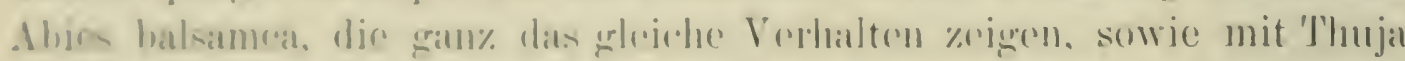
necidentalis als cine niedere Banmorengetation äber\%jelit.

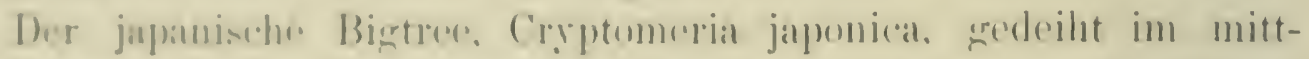

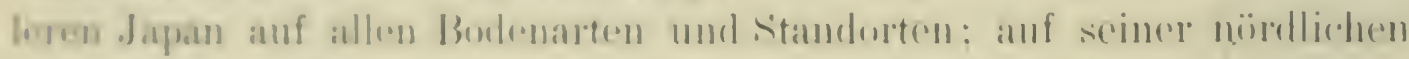

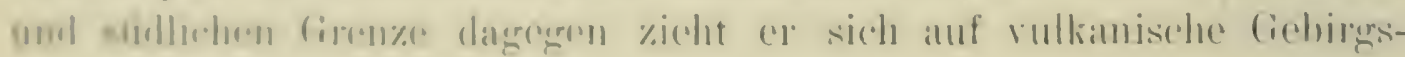
bulion zurilu.k.

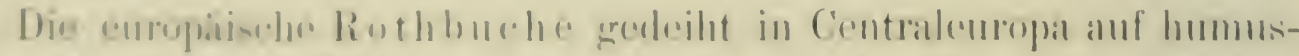

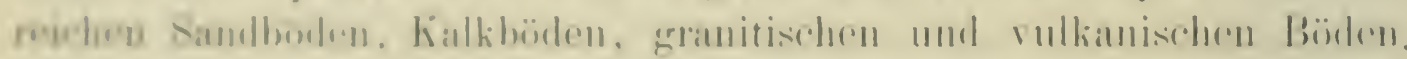

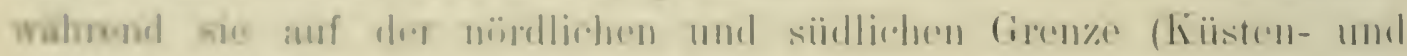

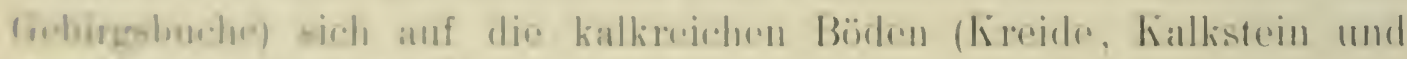
Comgemerat) bestiriukt.

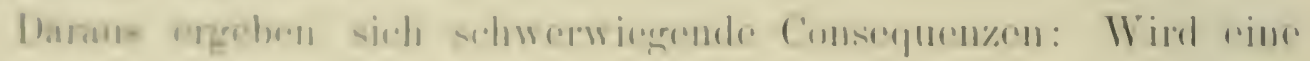

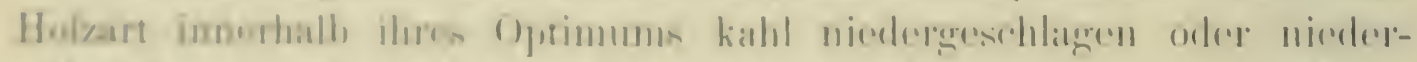

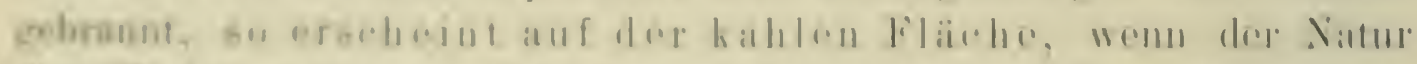

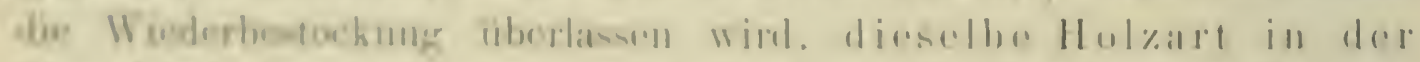

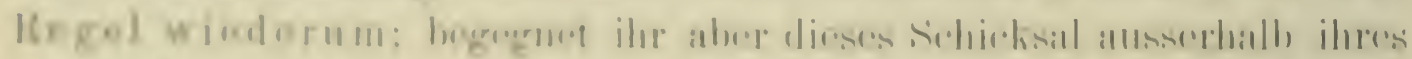

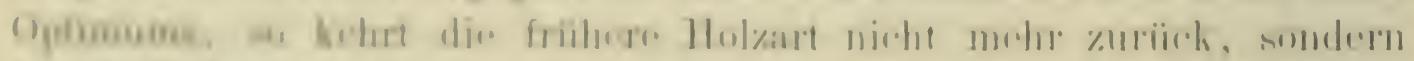

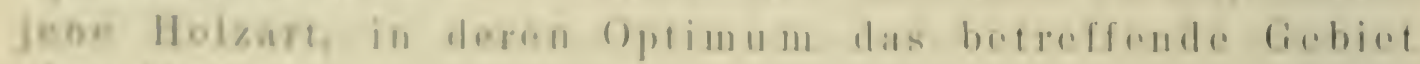
ehea linge

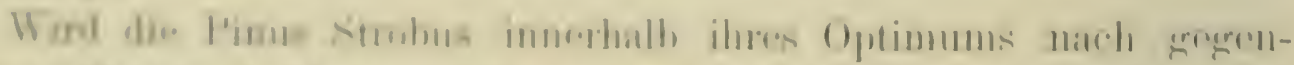

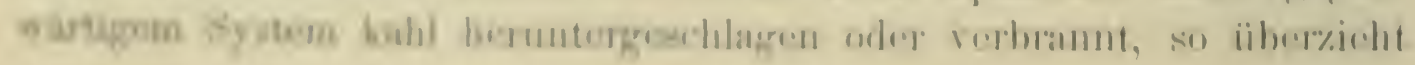


sie allmälig wieder die kahle Fläche; wird dieselbe Holzart ausserhalb ihres Optimums, zum Beispiel in Wisconsin, entfernt, wo sie die feuchten Sandinsch im Laubholzgebiete einnimmt, so kommt sie nicht wieder, sondern die Laubhölzer oder andere Kiefern, wie die anspruchlose P. Banksiana, nelmen ihre Stelle ein.

Gleiche Teränderungen erleiden die Waldungen der südlichen Kiefer, Pinus australis; ihr Optimum, in dem sie fast ausschliesslich herrscht, ist das schwach wellige, lehmig-sandige Hügelland der südlichen Küstenregion; dort erscheint sie, nachdem Mensch und Fener darüiber hinweg gegangen sind, in der Regel in schönen Jungwüchsen wiederum, die freilich über kurz oder lang dem Feuer abermals zum Opfer fallen; dagegen verschwindet sie in der Nähe der Küste, im flachen Tieflande, wo sie der Pinus eubensis einzeln beigemischt ist, weil die letztere Holzart, da in Optimo befindlich, die Stelle der Pinus australis einnimmt.

Einen harten Kampf haben natürlich die Holzarten auch in ihrem Optimum mit den leichtsamigen, anspruchsloseren Arten zu bestehen, die durch die Eingriffe des Menschen im Vortheile sind; überall ist ein Ueberhandnehmen der werthloseren, anspruchloseren, leichtsamigen Arten constatirbar; im Gebiete der Laubholzregion gewinnen in Folge der regellosen Behandlung des Waldes die Birken, Pappeln, Weiden und insbesonders Kiefern immer mehr an Terrain; im Westen, im Gebirge breitet sich die geringerwerthige Libocedrus decurrens auf Kosten der werthrollen Pinus Lambertiana, P. Jeffreyi und Pseudotsuga Douglasii aus. Wäre es möglich, den Wald vor weiteren Anfällen zu schützen, so würden zweifelsohne die früher vernichteten Holzarten wieder allmälig sich einstellen. Ein schönes Beispiel hievon gibt der japanische Wald.

In Japan reicht die Zone des immergrünen, das ist des subtropischen Laubwaldes im Binnenlande bis $35^{\circ}$, an der Ostküste, den Kuro Schiuo entlang, bis zum $36^{\circ} \mathrm{N}$.B. In der nördlichen Hälfte dieser 'Zone ișt der immergrüne Wald fast vollständig durch die Kultur des Menschen verdrängt worden; wo nicht Landwirthschaft, insbesonder's Reisbau möglich war, hat der Mensch Quereus serrata und glandulifera und Castanea japonica, Bäume des kühleren winterkahlen Laubwaldes, zur Bremnholz- und Kohlgewinnumg, Pinus densiflora und Thunbergii zu Brennholz- und Cryptomeria japonica und Bambus zu Bau- und Nutzholzzwecken angepflanzt.

Wird der noch vorhandene immergrüne Laubwald dieser Region kahl heruntergeschlagen oder niedergebranut (was in Japan anch 


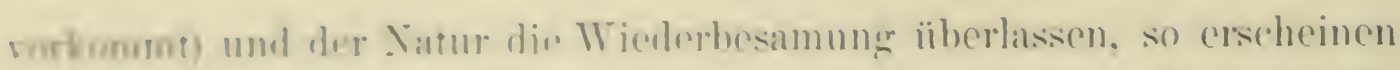
diredoun immergrimen Hobarten nur mehr vereinzelt, zahlreich aber

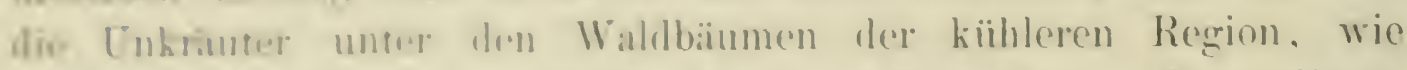
Ribus smmialata, Ruttera japunica, Alnus-, Araliat-Arten. Unter diesen

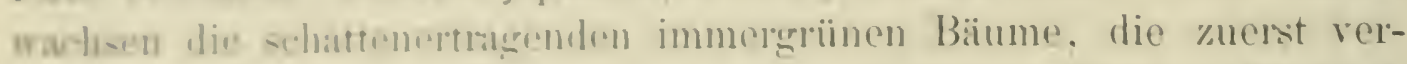
aìben wurlen. wieder lantrsam fmpor zum früheren Walde. Nördlich

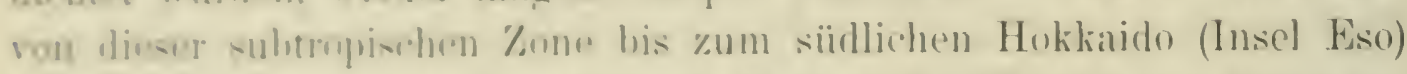

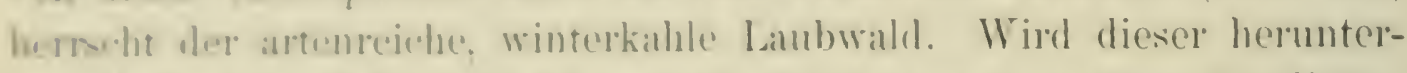

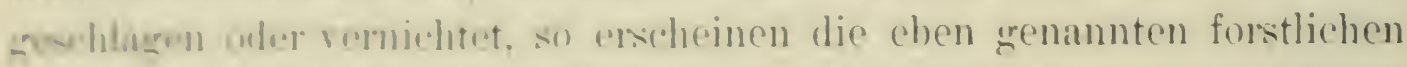

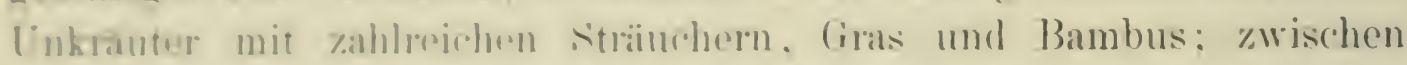
dimer kloinen Veuration siedeln sich Birken. Pappeln, greringwerthige Eiehen und Kingforn an: unter deren sichnt\% endlich arbeiten sich wieter die usprïnglich rernichteten gruten Eichen, Ahorn, Eschen,

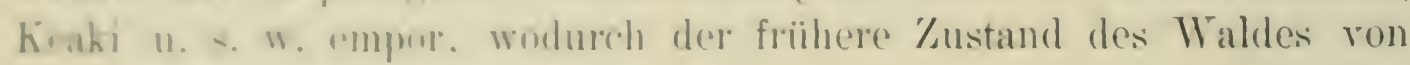
der Natnr wieder herestellt ist.

Werden aber inzwishen Bïume und Striumcher niedergeschlagen,

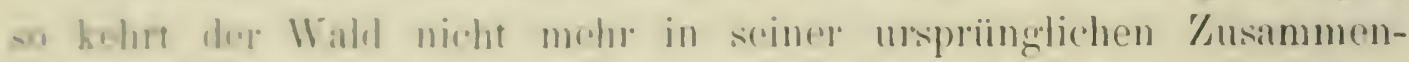

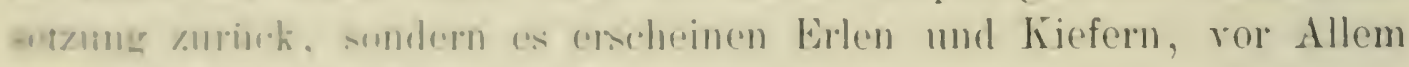
aber endriackeniles Gira und Bambus.

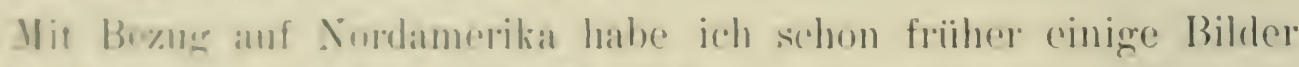

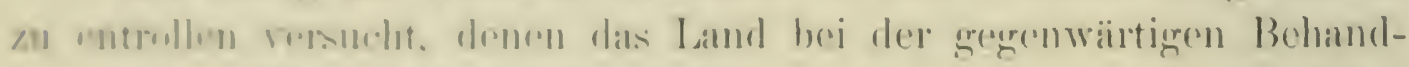

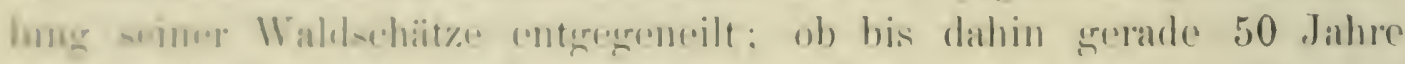

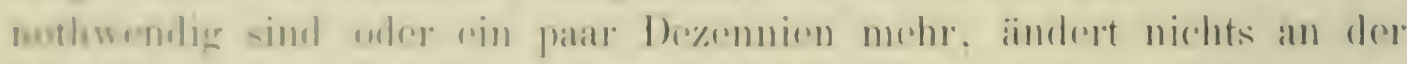

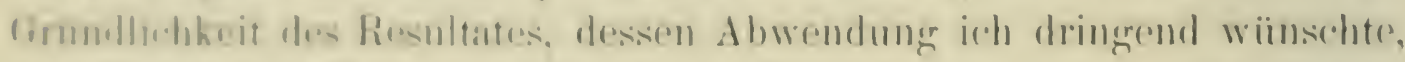

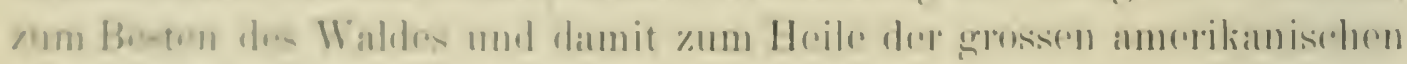
Natuan: an Trast, win hittorer freilich. bleibt den Amerikanern angesichts

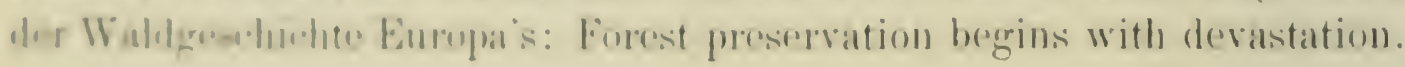

\section{Forstliche Bestrebungen in den Vereinigten Staaten.}

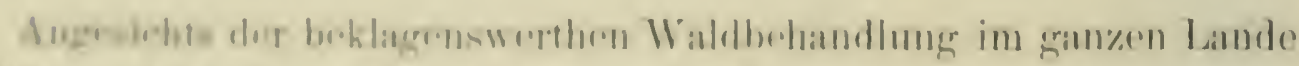

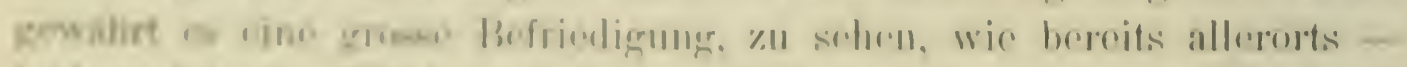

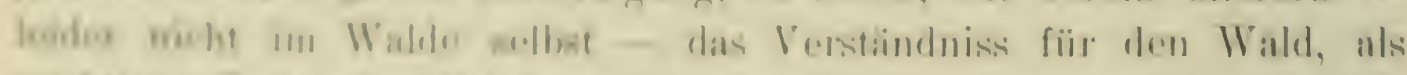

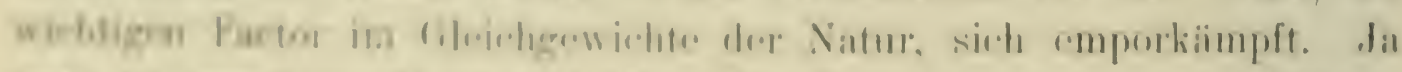

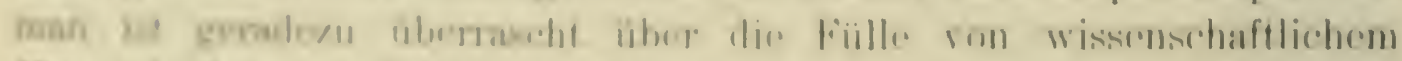

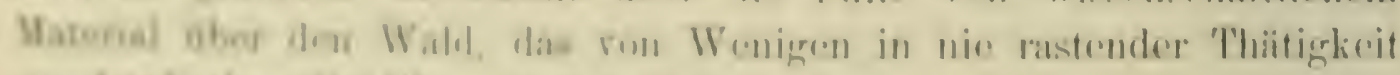
enchaute dorn l'ublikum zuganglich gemacht ist. 
Wo die Noth am grössten, beginnt man langsam mit grosser Mühe und grossem Geldaufwande Wald aufzubauen; die ersten Ansiedler in den Präriestaaten, welche den Wald ron Anfang an entbehrten, ahnten den Segen, den derselbe für ein Land mit sich bringt, besser als dic, welche im Vollgenusse des Segens alles daran setzen, desselben möglichst schnell los zu werden. In den Präriestaaten pflanzt man allerorts Wald, um durch ihn das neue Heim, den Garten, die Fluren zu schützen, mit einem Worte, die Prärie für menschliche Existenz fähig und nutzbringend zu gestalten; diese Thatsache allein spricht für den Werth des Waldes und seinen Einfluss auf Klima und Bevölkerung deutlicher als alle Reden und Bücher und wissenschaftlichen Experimente, und sollte den östlichen Waldrerderbern ein lehrreiches Beispiel sein; sie sind im besten Zuge, ihr herrliches, vom Walde geschaffenes, rom Walde geschütztes Kulturland in Prärie umzuwandeln.

Um die Anpflanzung von Bäumen in den Präriestaaten zu fördern, hat der Congress eine Bill genehmigt, die Timber-culture act, nach welcher öffentliche Ländereien (1 Section $=64$ acres) an Farmer gratis abgegeben werden unter der Bedingung, dass $1 / 4$ der Section mit Bäumen bepflanzt werde, so dass rom achten Jahre der Pflanzung an, dem Jahre der Nachweisung, 675 lebende Bäume pro acre sich fänden. Gehingt der Nachweis, so ist die ganze Section ohne weitere Auslage Eigenthum des Farmers. Der Effect scheint jedoch sehr zweifelhaft zu sein, da Fernow berichtet, dass, als der Nachweis geliefert werden sollte, $90 \%$ sich als unvollständig erwiesen. Dazu kommt noch etwas: man pflanzt sehlechte Holzarten, insbesonders die europäische Pappel, Sorbus, Kiefer und andere, ron denen, Larix ausgenommen, kaum eine einzige im Stande ist, dort einen halbwegs brauchbaren Nutzstamm zu produciren. Aber der Same ist billig, die Anzucht einfach, das Wachsthum rasch, der Schutz ist sehnell hergestellt und dem Gesetze Genüge geleistet. Wie Private haben auch mehrere Eisenbahngesellschaften, zum Beispiel in Kansas, Anpflanzungen im grossen Stile unternommen, sie sachrerständigen Männer’n anvertraut und schöne Resultate zu verzeichnen auf Gebieten, die noch vor Kurzem für völlig werthlos galten.

Ein mächtiger Factor, die Pflanzungen zu fördern, sind Pflan\%gärten, Baumschulen (nurseries), deren eine zicmliche Zahl entstanden ist; an ihrer Spitze dürften die grossen Gärten von Robert Douglas and Son in Waulegan Jll. und ron Thomas Meehan in Germantown bei Philadelphia stehen. Letztere Anstalt kultivirt die grösste Verschiedenheit, erstere den grössten Vorrath an forstlichen Gewächsen. R. Douglas hat selbst sehr lehrreiche Anbauversuche mit einheimischen 
and tremdan Hularten anf Jen Sinduferen des Lake Michigan unter-

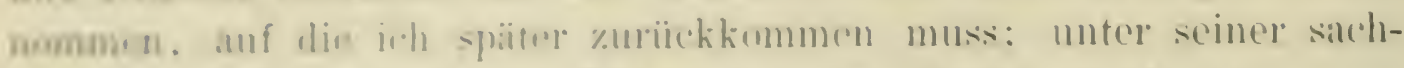
hemigen Leitumg sind vicke Pflanzungen im Westen entstanden.

Im Jalıe 1871 surde in statate Nebraska ein Tagr im Monate April as Fiertag proklamirt, der ansishliesslich der Pflanzung ron Bimm u gawilmet werlen sollte (Arbor day): an diesem Thage unter-

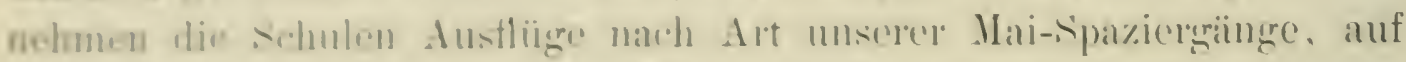

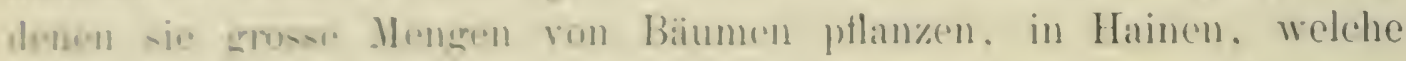

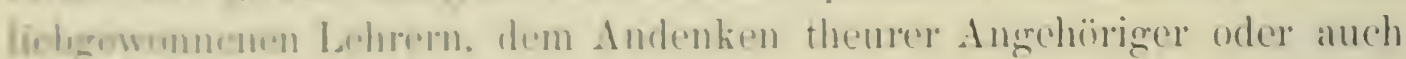

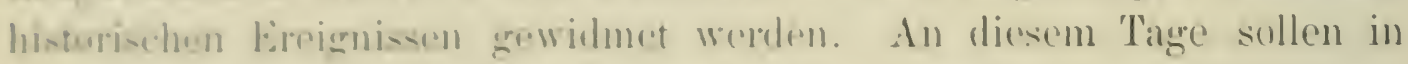
Debrasha allein oine Million Bämme areptlant werden.

Anf don exten Augenblick mörhte man diese drt der Wald-

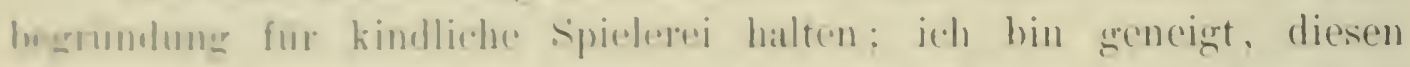

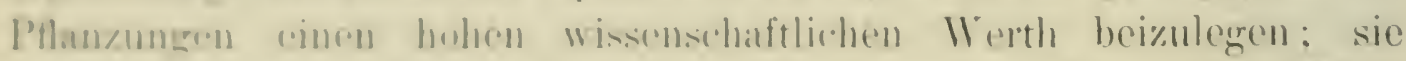

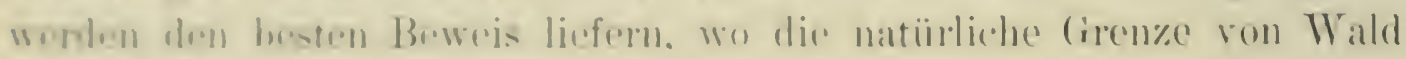

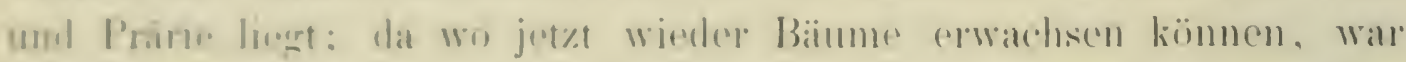
ants fruber Wabl: wo die Bäume sträucher bleiben, wall die ursprüng-

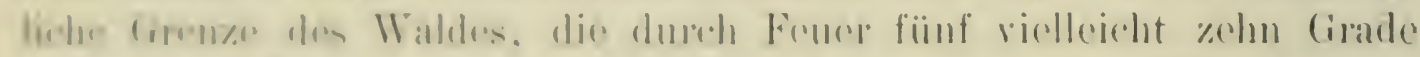

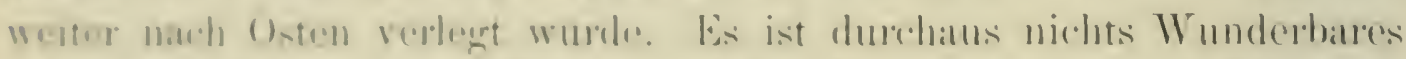

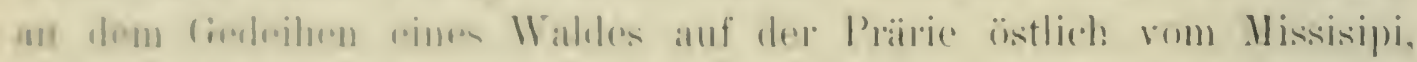
das Wumberbare ist vindmedre, datss der Wald aluf diesem (iebiete su

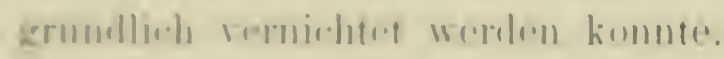

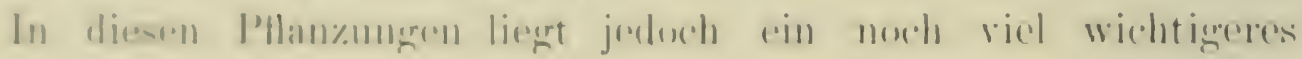

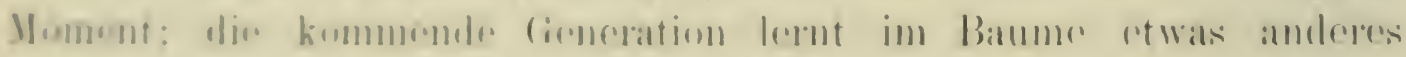
kromen als an lastiges Hinderniss der kultur: in Nordamerika muss

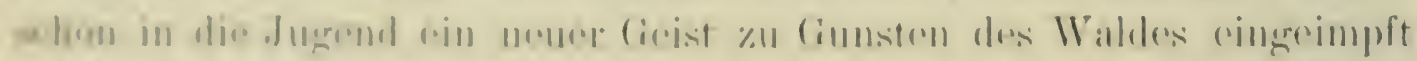

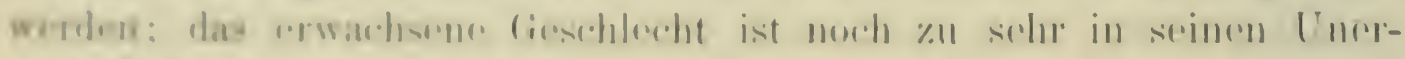

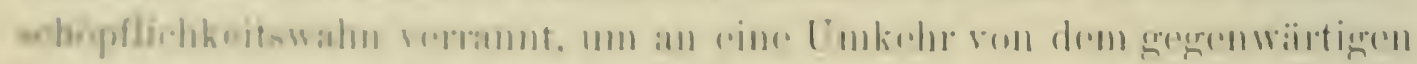

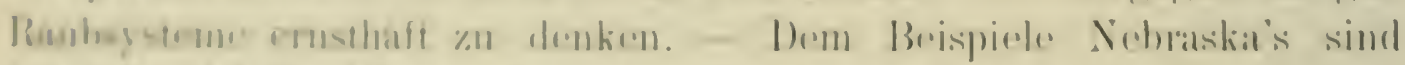

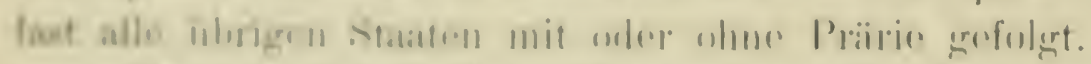

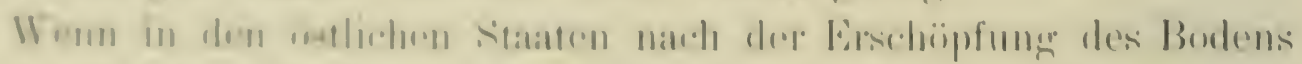

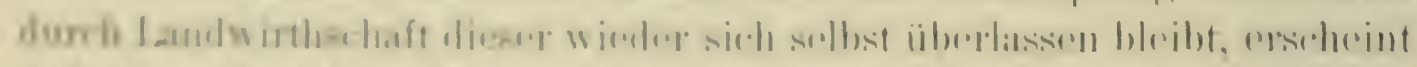

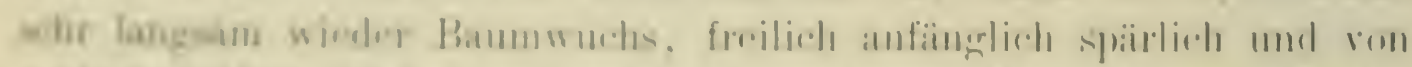

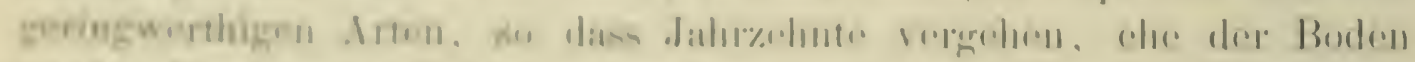

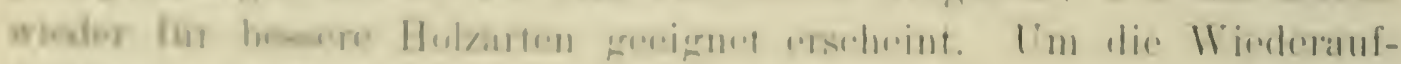

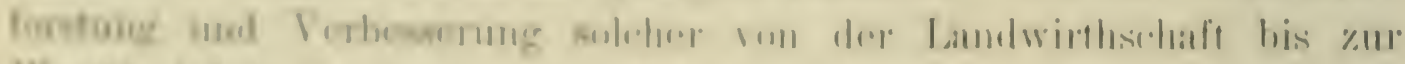

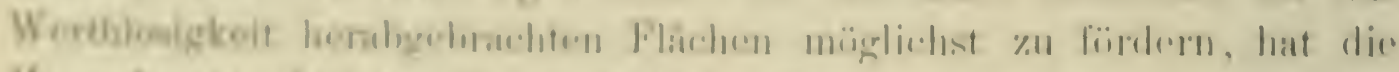

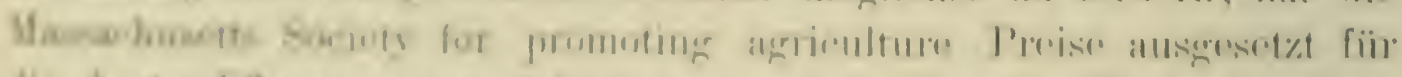

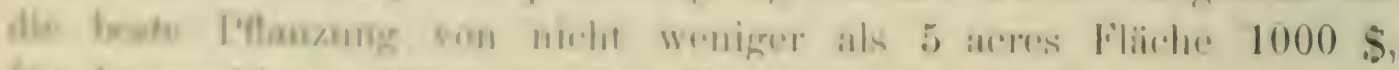

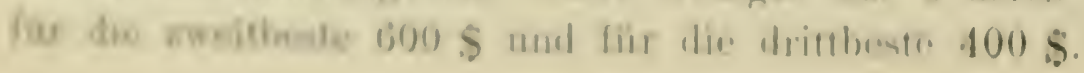


Zur Preisgewinnung*) ist es nothwendig, dass die Pflanzungen mit europäischen Lärchen ausgeführt werden; nur auf den sandigen Küstengebieten soll europäische oder korsische Kiefer oder beide zusammen verwendet werden. Bei dem Nachweis nach sieben Jahren dürfen auf dem acre nicht weniger als 2700 Bäume stehen; der Boden muss arm, erschöpft und unbrauchbar für landwirthschaftliche Producte sein; ebenso wurden Preise für die besten Pflanzungen von Fraxinus americana ausgesetzt, wobei 5000 Bäume pro acre als Minimum angesetzt wurden.

Das Unternehmen ist ein höchst lobenswerthes; aber wäre es nicht ebenso gut, neben Gesellschaften zur Wiederaufforstung auch solche kapitalfeste zu begründen, welche die Erhaltung der noch bestehenden Forste im Ange haben? Wenn man den Staat für ungeeignet hält, seinen Pflichttheil zur Erhaltung der Fruchtbarkeit und Wohlfahrt des Landes beizusteuern, wäre es nicht rielleicht besser auch die Erhaltung und Bewirthschaftung der Gebirgsforste, der armen sandigen Gebiete und so weiter, durch Gesellschaften, Vereine, Actienunternehmungen bethätigt zu sehen? Solche Gesellschaften kömnten Prämien aussetzen für alle, welche Feucranstifter, ohne Rücksicht auf den Stand des Urhebers, zur Anzeige gebracht, bei der Erstickung ron Feuer thätige Hilfe geleistet oder welche in irgend einer Weise um die Erhaltung und successire Ausnützung der Forste sich verdient gemacht haben. Für Erhaltung der Waldungen, für eine regelmässige Bewirthschaftung derselben ist bis jetzt noch nichts geschehen und ron der einfachen, schablonennässigen Baumpflanzung bis zur wirklichen Forstwirthschaft ist noch ein weiter Schritt.

Nach Fernow's geschichtlichem Ueberblick des Forstwesens in Nordamerika (1886) bestand schon im Jahre 1873 eine Forestry association in Minnesota ron Männern, die dem Walde oder besser der Waldpflanzung geneigt waren; denn die ersten Vereinigungen hatten mit ihrer Zeitschrift: Forest-Tree Planters Manual den Zweck, die Baumpflanzungen in den Präriestaaten zu fördern.

Im Jahre 1882 trat an die Stelle obigen Vereines der American Forestry Congress der alljährlich zusammenkommt. Hoffentlich sind die

*) Nach „Garden and Forest“ Nr. 45, in dem die Resultate der Preisvertheilung bekannt gegeben werden, erhielt nur eine Lärchenpflanzung den festgesetzten Preis; die Lärchen hatten in 10 Jahren 7-9 Meter Höhe erlangt; die Eschenpflanzungen waren theilweise gelungen, aber nicht genügend in Ausdehnung oder Pflanzenzahl; die Saaten hatten, wie auf der freien, unbeschütaten Fläche zu erwarten war, durchaus negative Resultate ergeben; bezeichnend ist, lass der Weymoutskiefernsame, da billiger, aus Europa bezogen wurde, was theilweise an dem Misslingen der Saaten Schuld sein soll. 
folgumen Cougrwas orwa- muthigrer und auf positivere Aufgaben bedacht.

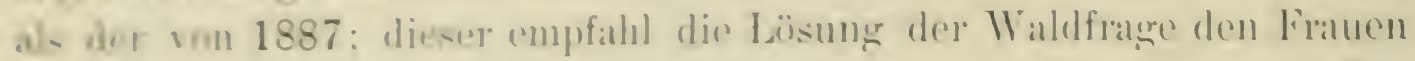

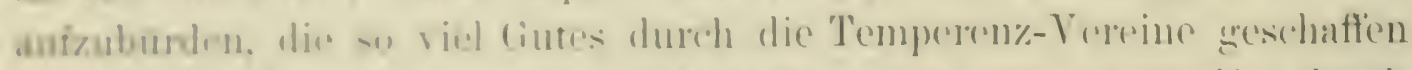

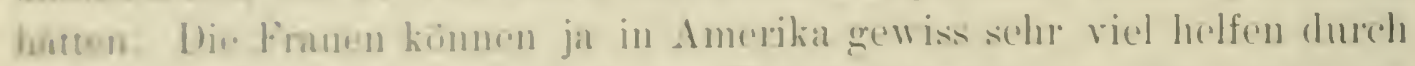

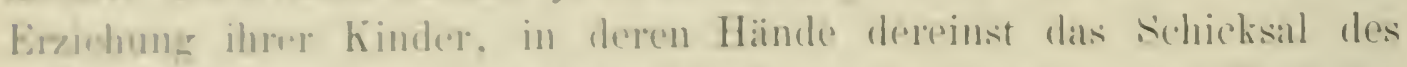

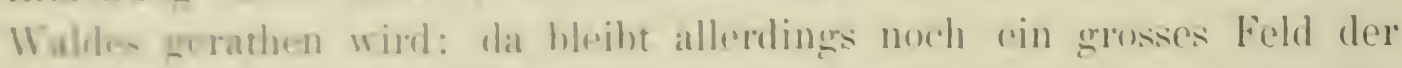

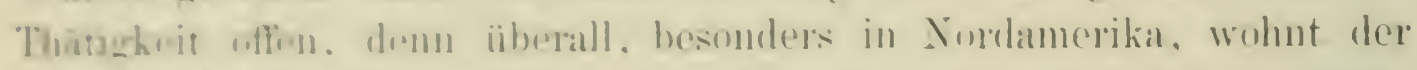
Juptul oin \%orturungtrobe inne, den man nicht aufkommen lassen

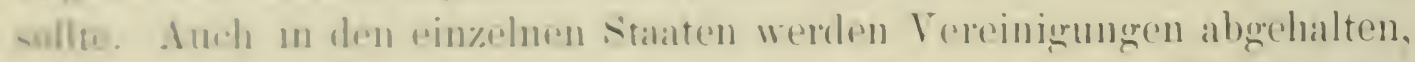

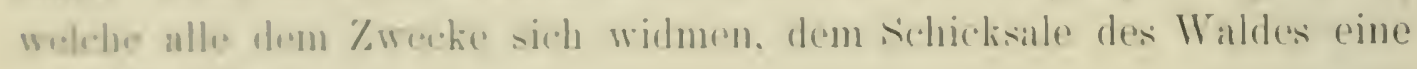

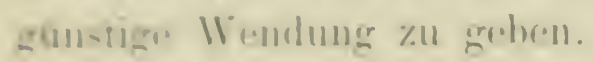

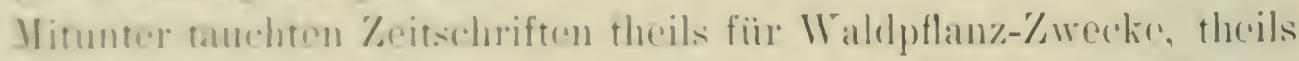

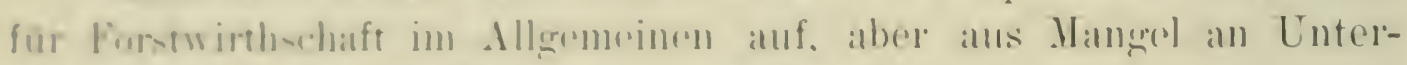

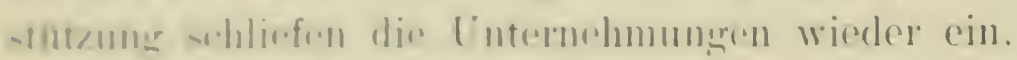

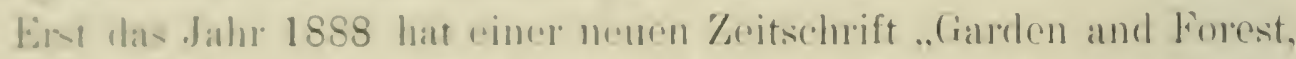

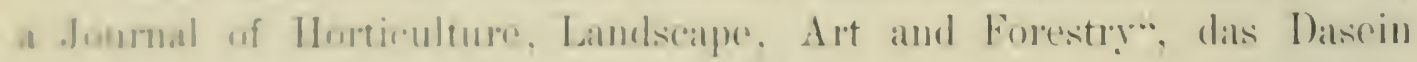

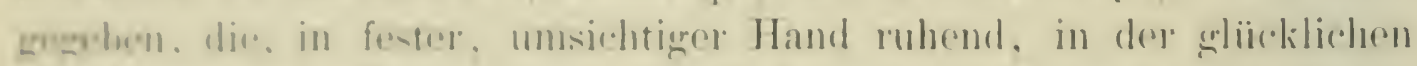

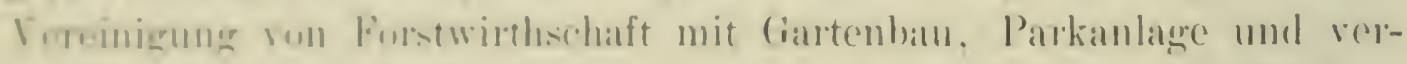

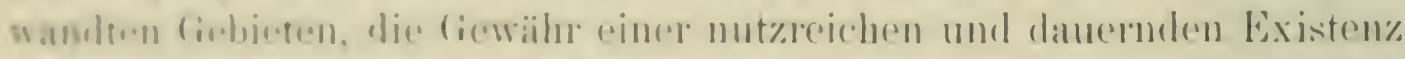

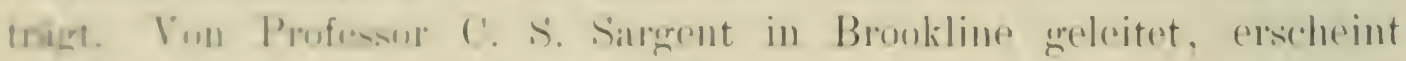

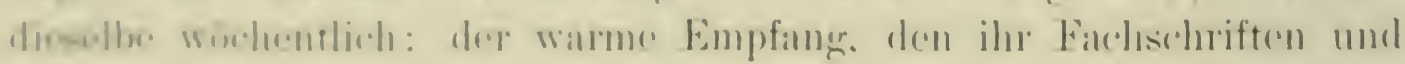

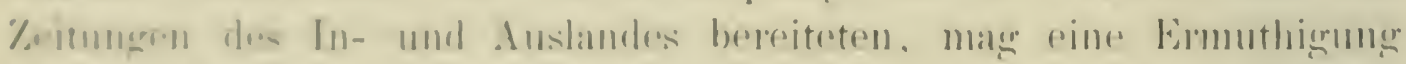

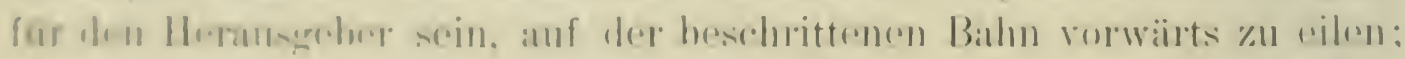

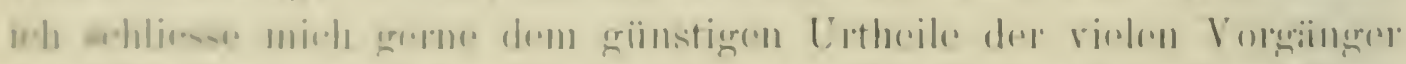

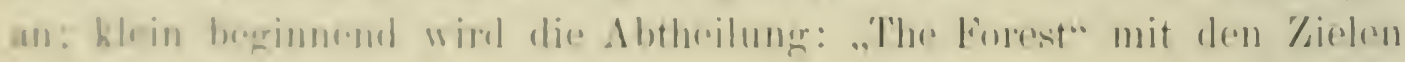

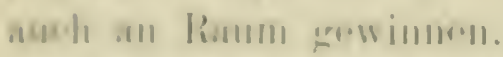

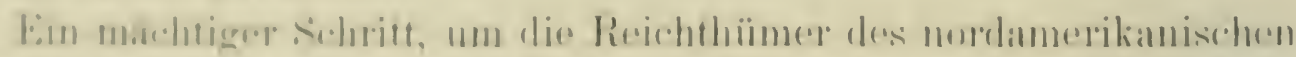

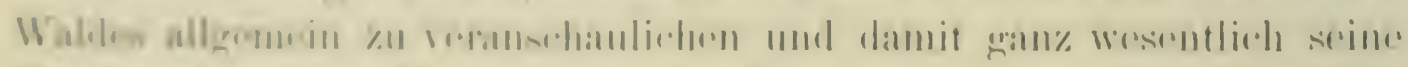

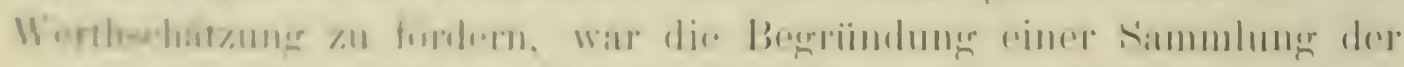

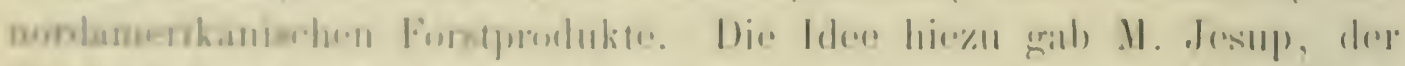

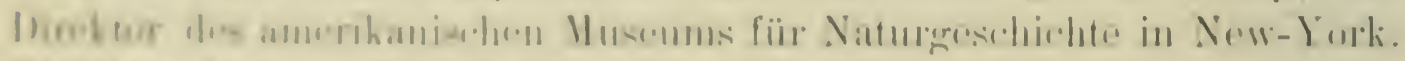

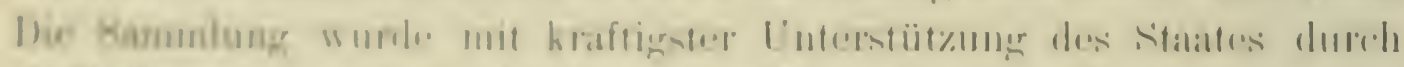

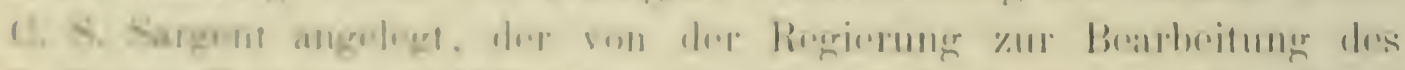

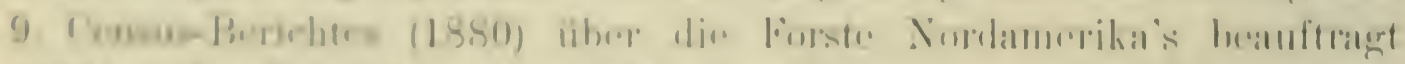

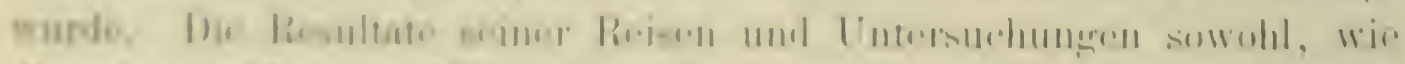

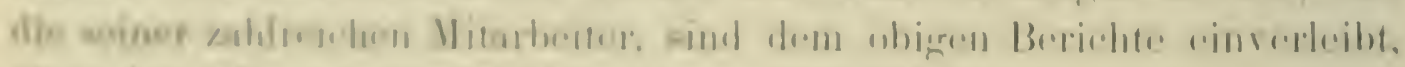

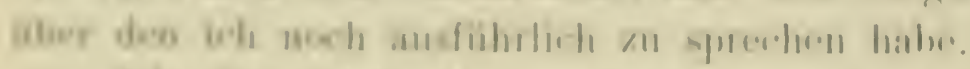

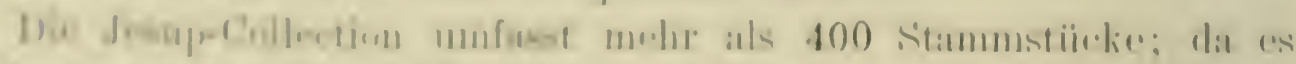

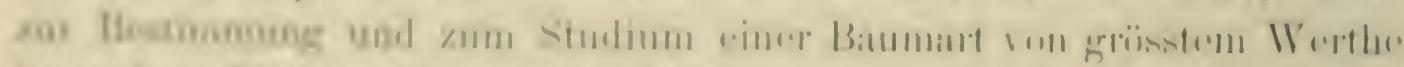

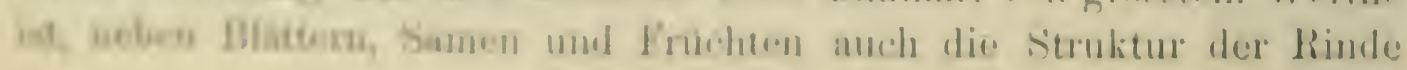


und des Holzes zu kemnen, so kann eine forstlich-botanische Sammlung nur gewinnen, je grösser die Exemplare sind, welche zur Schau gestellt werden. Nach dieser Richtung hin wurde gewiss nichts rersäumt; solche kolossale Stiicke hat keine Sammlung in der Welt aufzuweisen; die in Glaskästen mit grossen Fenstern untergebrachten Exemplare haben eine Höhe ron nahezu 1,5 Meter, die Stücke sind so ausgeschnitten, dass Quer-, Radial- und schiefer Schnitt zur Anschaumng gelangen; die eine Hälfte ist polirt, die andere roh. Jedem Objekt ist eine Etiquette angefïgt, welche Nummer, Namen, specifisches Gewicht, Aschengehalt etc. enthält, sowie eine kleine Karte der Vereinigten Staaten, auf welcher durch Farbentöne die Verbreitung der Holzart gekennzeichnet ist. Bei Anlage dieser Holzsammlung wurde neben dem wissenschaftlichen Zwecke der praktische nicht aus dem Auge gelassen; von den wichtigsten Nutzholzarten sind Bretter und Maserstücke beigegeben von gewaltigen Dimensionen; die Sequoia, die Riesin unter den Nadelhölzern, ist zum Beispiel mit einem Brette ron 2,3 Neter Breite, die Douglasia mit einem solchen ron über 1 Meter Breite repräsentirt. Eine Zierde und eine sehr werthrolle Zugabe zugleich soll die Sammlung später erhalten, durch grosse Aquarelle, welche die blühenden und früchtetragenden Stadien der einzelnen Holzarten illustriren werden. Diese Gemälde, von Frau C. S. Sargent angefertigt, lassen an künstlerischer Darstellung wie wissenschaftlicher Exactheit nichts zu wünschen übrig.

Die nöthige botanische Ergänzung findet diese Sammlung in dem Herbarium der Universität Cambridge, Mass., dessen dendrologischer Theil wieder nach Brookline Mass. rerlegt und unter die Leitung ron C. S. Sargent gestellt ist. Mit dem dortigen Herbarium der Bäume und Sträucher steht ein Arboretum (Arnold Arboretum) in Verbindung; das wellige Terrain in der Umgebung von Boston ist zu diesem Zwecke ausgewählt worden; das Terrain bietet für Laub- und Nadelhölzer geeignete Standorte; alle Holzarten, Bäume und Sträucher, welche ihre Widerstandsfähigkeit gegen das trocken-heisse Ḱlima des Sommers und die starken Fröste des Winters erprobt haben, sollen Aufnahme finden und in Gruppen systematisch und mit möglichster Berücksichtigung ilner specifischen Standorte ausgepflanzt werden. Trotz der Jugend zeigt die Anlage neben landschaftlicher Schönheit schon jetzt einen viel versprechenden Erfolg und eine reichliche Ausbeute für forstliche und forst-botanische Zwecke; ich werde mir die Gelegenheit, die Resultate dieser Anbauversuche mit eigenen und fremdländischen Holzarten eingehender zu betrachten, in einem späteren Abschnitte nicht entgehen iassen. 


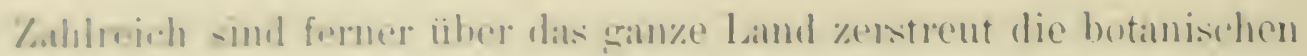
samuluneron an den sielen Unisersititon und Instituten, ron denen

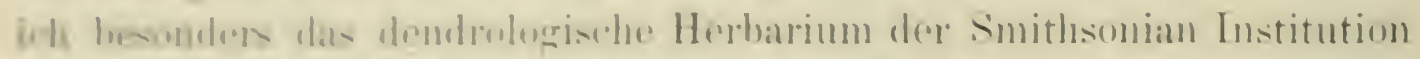
in Wa-hingtun untor beitung des bewihrten Botanikers Dr. G. Vasey,

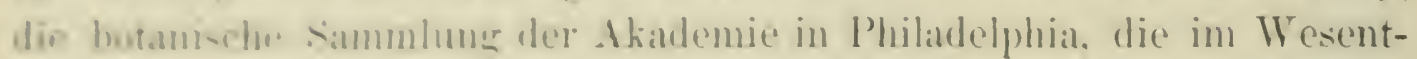
hehen dunth Britriege bun Professor Meehan entstanden ist, hervorheben will. da inh cielegenheit hatte. sie eingehender \%u studiren. Lalst not

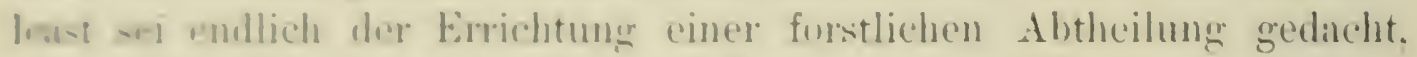

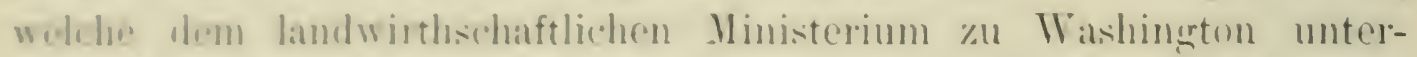
-ralle ine. Lhre Thätigkeit hat his jetzt modh geringen Einfluss anf

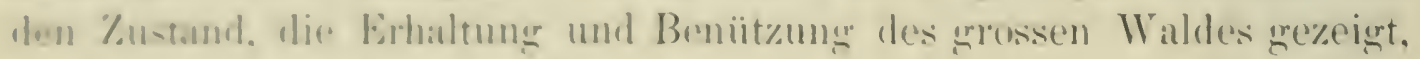

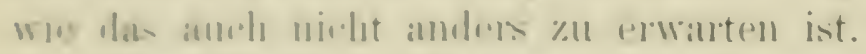

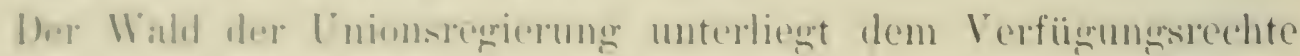

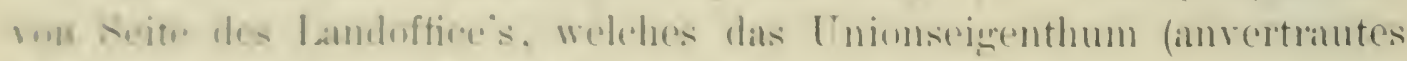
Valkstigruthum!) an P'rivate rerkinft um cinen Preis, ganz grleich-

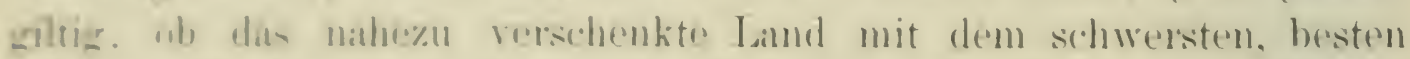

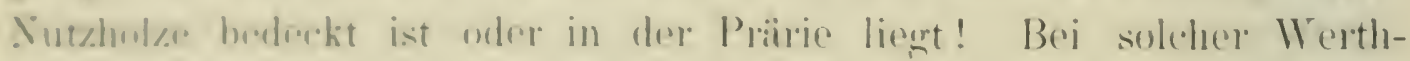
scharsung des Wables darf es cinen nicht wundernehmen, wenn dis Emkummen aus den fast 30 Millionen ha statswaldunge erecenwiirtig iull is.

Br.i der Burriandung des finstinstitutes im Jahre 1876 wat dem-

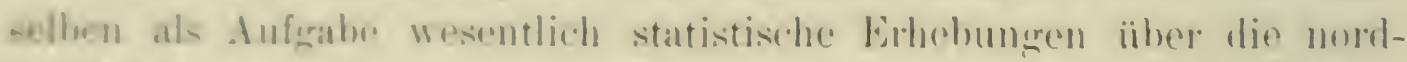
anorikaniwdwn Holzarten und Waldungen zugewiesen, anf (irind deren

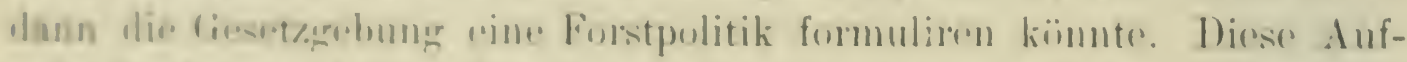

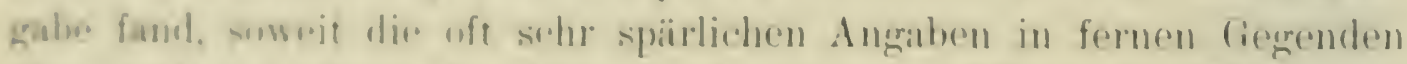

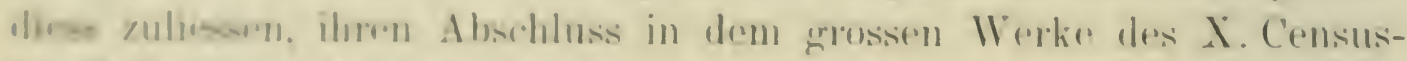

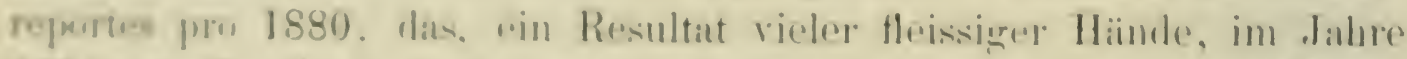

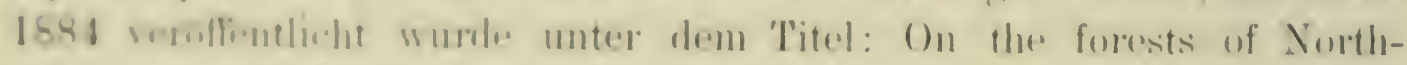

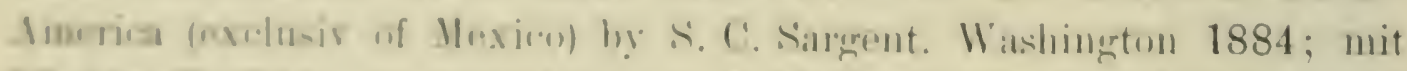

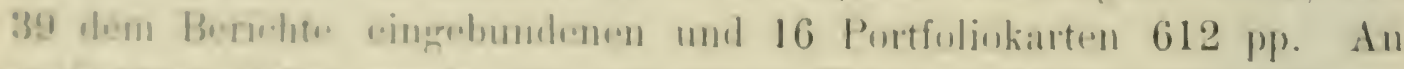

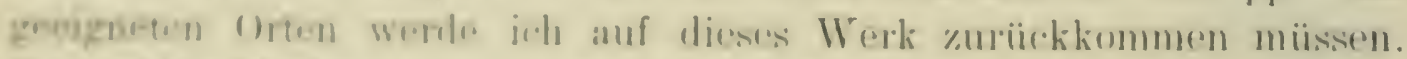

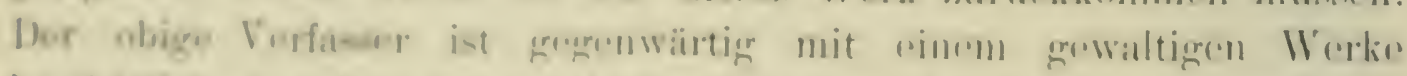

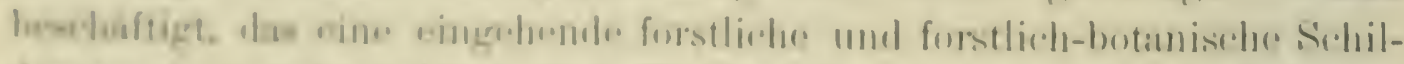

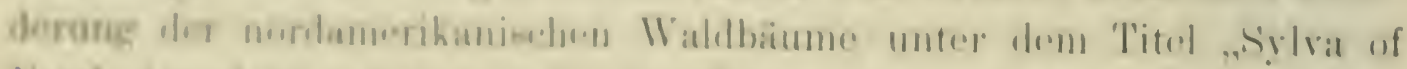

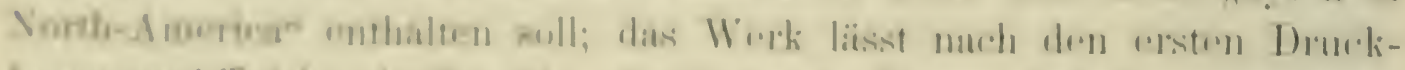

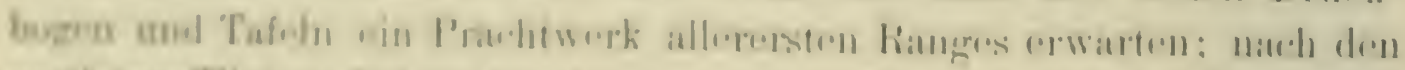

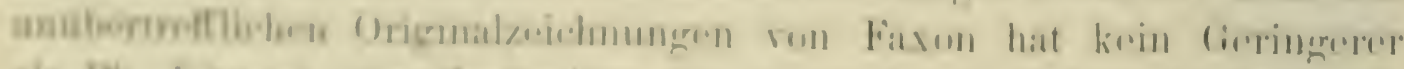

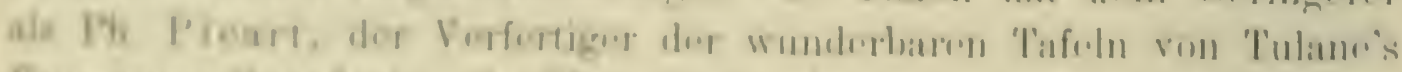

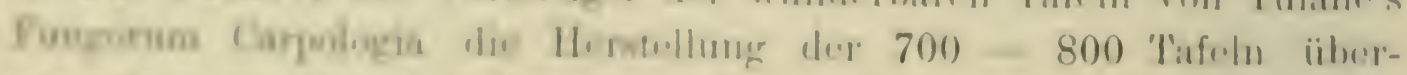

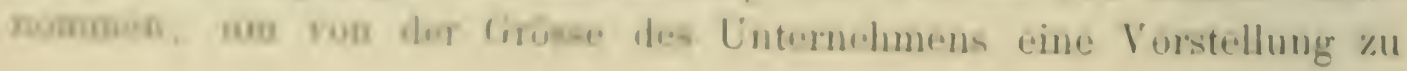


geben, erwähne ich, dass die Herstellungskosten auf etwa 360000 Mark veranschlagt sind.

Voran gehen diesen Werke zahlreiche Florenwerke und kritische Abhandlungen über nordamerikanische Baumarten von Männern, deren Namen auch in Europa einen guten Klang besitzen wie Nuttall, die beiden Michaux, A. Gray, G. Engelmann, Parry, Torrey, S. Watson, G. Vasey, Emerson und andere.

Unter dem energischen, gegenwärtigen Chef der Forstabtheilung, B. E. Fernow, wurde die für eine geregelte Forstwirthschaft nicht minder wichtige Arbeit begonnen, biologische Fakta in Bezug auf die wichtigsten forstlichen Bäume zu sammeln, zu welchem Ende die einzelnen Holzarten bewährten, in der Heimath der betreffenden Holzart lebenden Mämmern zugetheilt wurden; vielleicht ist es mir rergönnt, wenn auch unberufen, zu dem grossen Werke durch meine siebenmonatlichen Reisen in den Waldungen von 26 Staaten der Union einen kleinen Beitrag zu liefern.

Ehe die Arbeit über die Entwickelungsbedingungen der nordamerikanischen Holzarten beendet ist, müssen alle Systeme einer Forstwirthschaft, auf gut Glück unternommen, Experimente bleiben. Denn die europäischen Systeme, die für ein paar Holzarten zugeschnitten sind, können nur als Modelle dienen. Je mehr in Nordamerika von dem bunten Gemisch der Holzarten erhalten werden soll, um so mehr müssen die zu wählenden Systeme dem Fehmelbetriebe des Urwaldes sich nähern. Umgekehrt wird ein System um so mehr Holzarten aus dem Walde verdrängen, je mehr es Kahlschlag, Saat und Pflanzungen in den Vordergrund drängt.

Es darf nicht wundermehmen, wenn die grosse Majorität der Waldbesitzer rom Waldeigenthum eine geringe Meinung hat; es steht ihnen kein Beispiel ror Augen, dass eine geordnete Forstwirthschaft auch ein rentables Unternehmen sein kann; heute noch wäre das Einkommen aus einem, dem geregelten Betriebe unterstellten Walde sehr gering und würde vielleicht nicht einmal die Verwaltungskosten decken. Gerade weil der Anfang ein Opfer verlangt, erscheint der Staat als in erster Linie geeignet den Anfang zu machen; die Zeit wird rasch kommen, in der das mit Wald bedeckte Land eine ähnliche Preissteigerung erfährt wie die ehemals für werthlos gehaltene Prärie.

In der Conservirung des Waldes, nicht in der Verschleuderung: desselben, sollte der Staat rorangehen; jedes Gesetz, das der Congress zur Erhaltung des Waldes (nicht zur Anpflanzung - dazu zwingt die Noth besser als ein Gesetz-) passirt, trifft zuerst den Staat 
selbes. Whrolo or fremblligr den richtigen Weng betreten, sein Beispiel

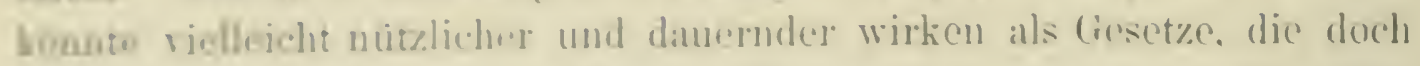
wodor durch irgend eine juristische lntervention umgangen oder lahm gelegr würden.

\section{Spezielle Betrachtung der nordamerikanischen Waldflora nach Gebieten und Holzarten.}

\section{A. Die Waldflora der atlantischen Region.}

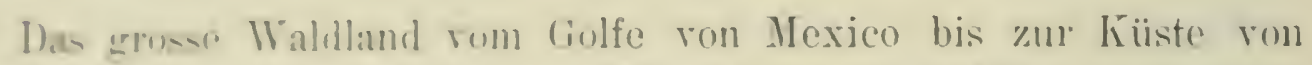
Lahmdor und wn der attintisdede Küste his zum $95^{\circ}$ W. L. ist seinen

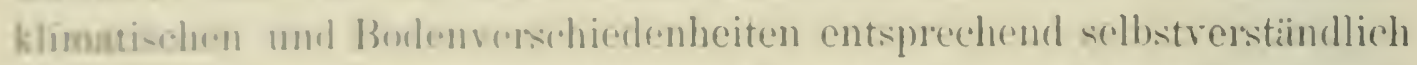
webr roich an den verschiedensten Baumarten und Walelformen. In grwe.'n \%üren lissen sich die Waldlandschaften etwa folgendermassen Alizimen.

Dow Waldflura der Südspitze Florida's und der vorliegenden Inschn irabeine durch ihre Zusammensetzung und die gengraphische lage dimer Regrion als die Nordgrenze der tropischen Regrion.

Inas fibrige Florida, suwie ein sehr schmaler Strejfen parallel dem warmen Cinlfstrom bis etwa zum $36^{\circ}$ N.B., bedeckt der Wald der subtropischen Region. cin wintergrüner Laubwald, an dessen Stolle auf sandigrol. geringen Böden Kieforn (inshesonders Pinus entemsis) reton kumen.

Sorsllich son diesem rehmalen Bande durch die ganze östliche Foion heorahe dep Wald der gemässigt warmen Region, der *ineorkahl. Lauliwald, dessen Norlerenze alusserhalb der Vereinigum Staaten in Canada lieurt.

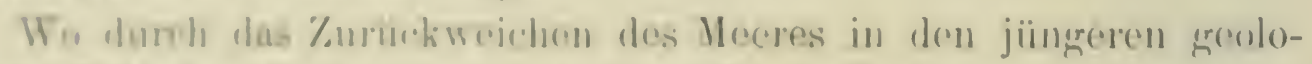

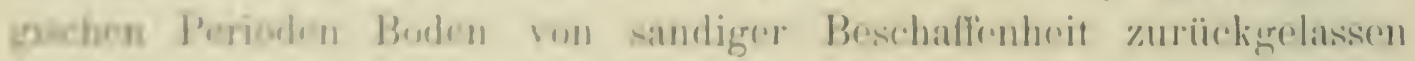

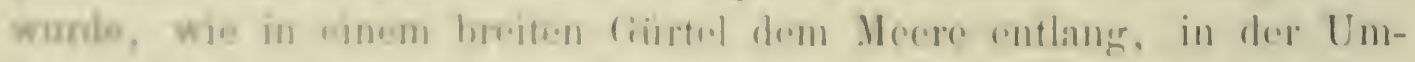
gebuge der gromen sicen und auf deren einstmaligen Vorbindungren

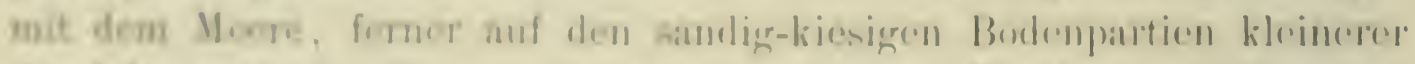

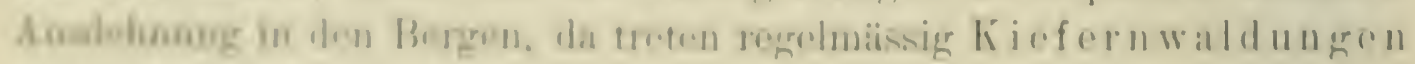

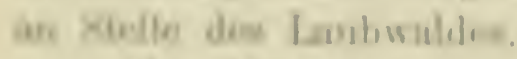

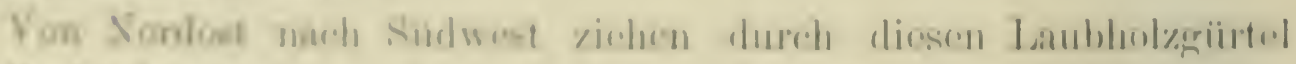

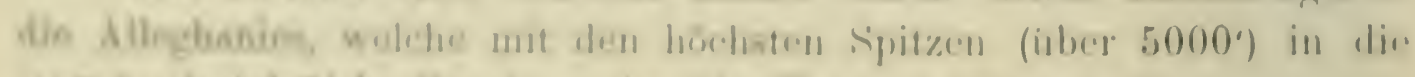

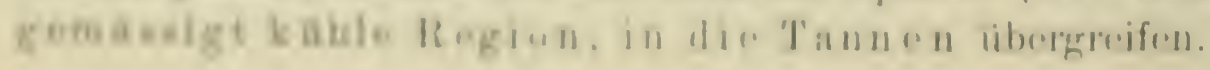




\section{a) Der tropische Wald.}

In einem Walde reich an Arten, aber klein an individueller Entfaltung, forstwirthschaftlich fast werthlos, greift der tropische Wald West-Indiens an der Südspitze von Florida und den vorliegenden Inseln auf das Gebiet der Union über. Die Florenwerke der Union bezeichnen diesen Wald als subtropisch; ich kann dieser Auffassung nicht beistimmen. Mir scheint es richtiger anzunehmen, dass die Grenze der tropischen Flora West-Indiens durch den hier gerade am wärmsten und mächtigsten Golfstrom etwas weiter nach Norden vorgedrängt wurde, als es der geographischen Lage dieser Gegend (24-26 $6^{\circ}$ N.B.) entsprechen würde. Es liegen hier dieselben Verhältnisse vor, welche auch die Existenz einer tropischen Flora, der sundanesisch-malaischen, auf den Bonin- und Riukiu-Inseln, unter gleichen Breitengraden siidlich von Japans Hauptinseln, sodann auf den Hawai'schen Inseln ermöglichen.

In diesem Gebiete sind Frost und Schnee ganz unbekannt, die Luft ist ausserordentlich feucht und warm $\left(26^{\circ}\right.$ C. $)$ das ganze Jahr hindurch; während der Hauptvegetationszeit (Mai, Juni, Juli, August) enthält sie im Durchschnitte $74 \%$, während der Monate November, Dezember, Januar und Februar $79 \%$ relative Feuchtigkeit; die Temperatur der Sommermonate ist nur um $6^{\circ}$ C. höher $\left(28^{\circ}\right.$ C. $)$ als die des sogenannten Winters; die Regenmenge ist sehr beträchtlich; während des Sommers allein fallen $433 \mathrm{~mm}$, das ist so viel als in der KiefernRegion der norddeutschen Ebene während des ganzen Jahres; die jährliche Regenmenge summirt sich auf $1000 \mathrm{~mm}$.

Dieses Gebiet ist reich an Arten, denn die Bäume der subtropischen Region erreichen hier ihre Süd- und jene der tropischen ihre Nordgrenze.

Der tropische Wald prävalirt in Key-West, der grösseren der Inseln vor der Südspitze Florida's; auf dem Festlande occupirt er einen schmalen Küstensaum nördlich bis zum Cap Malabar und zur Bay ron Tampa, die Niederungen am Rande der zahlreichen, schmalen, tief einschneidenden Meerbuchten bewohnend.

Der Wald beherbergt viele Arten, die in West-Indien wichtige Nutzhölzer liefern, wie Guaiacum sanctum, ein Baum, der hier nur nieder und gekrümmt bleibt, Swietenia Mahagoni, der wichtigste Nutzbaum von West-Indien, wird hier kaum 15 Meter hoch; zahlreich sind Gattungen und Arten, die durch Central-Amerika bis Brasilien sich erstrecken, dort ihr Optimum erreichend, wie Simaruba, Ximenia, Anona, Clusia, Capparis, Rhizophora, Combretaceae, Myrtaceae, insbesonder's der Gattung Eugenia angehörige Bäume, Rubiaceae, Myrsineae, Sapotaceae, 


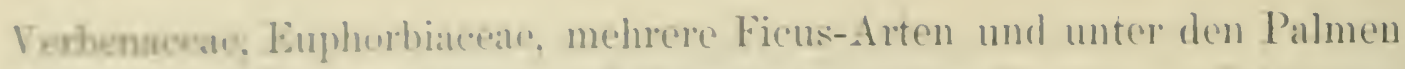
ia-benmers Thrindx-Arten und Oreodoxa regia, Familien, Ciattungen

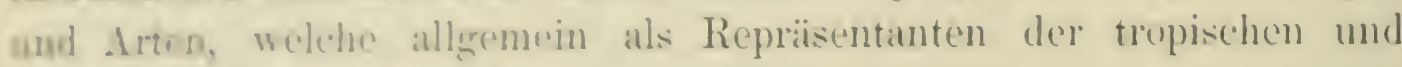
nicht ler subtropischen Flural gelten.

\section{b) Der subtropische Wald.}

Vördlich ron der trupisohen Region streicht der wintergriune L.aubald der subtropisehen Region durch Florida made links dor hise des mexionnischen Golfes entlang. nach rechts dem atlantischen () oun entlang his zum $36^{\circ}$ N.B. Das Band ist cin schmales, kiam

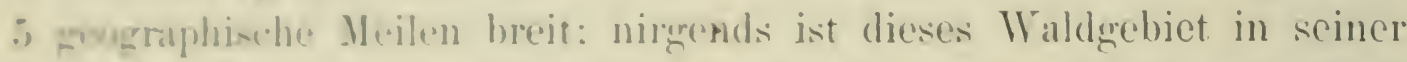
typischen Form. dem wintrogrünen Laubwalde, schr mächtig entwickelt in fintere der ungïnstigen Budenheschaffenheit; magerer Sandboden überwioge, auf dom der Latubwald dureh hiefernwaldungen vertreten wird. Din in den feuchten Mulden (hummocks) oder den Flïssen entlang komme doe artenrejele Lambwald zu seiner Entfaltung.

Furstwirth-chaftlich licert der Schwerpunkt in den Kiefernsaldungen. Wolche auch die sandiren, unmittelbar im Norden angremzenden Gehiote minnehmen, so dass im sü den der Vereinighen Stuatren, der hïste contlang ein etwa 250 Kilometer breiter Giurtel von hieforn lirgt. der in seinem südlichsten Theile der subtropischen, in sinen ubrigen 'Theilon der gromassigt warmen Region angehört.

1) is (iphirt der subtropischen \%one diisfte sich mit dem Verbreiturnergabiete dor beiden P'almen, Sabal Palmetto und Sabal serrulate leoken.

Wir anch in limopla. ist dieso Regrion in Nord-Amerika der

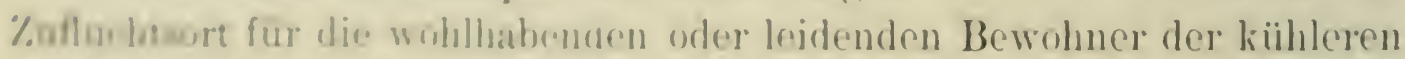

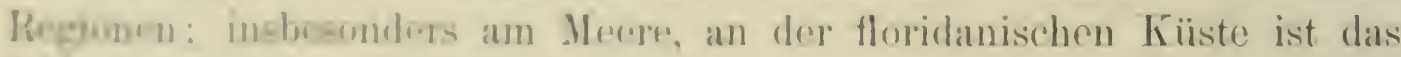
Klima mild: hier liegen dir. Winterhotels der reichen Bewohner der Serd-staate - Villon nach unserem Sinno gribt es nicht - walue

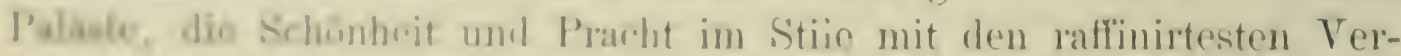

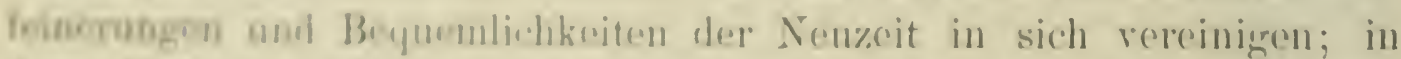

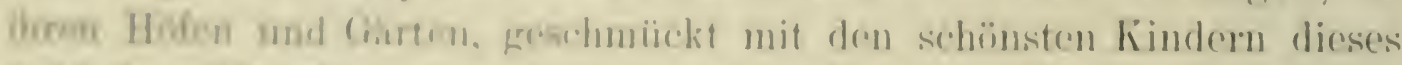

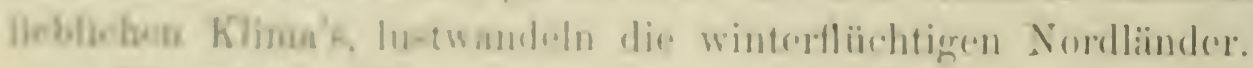

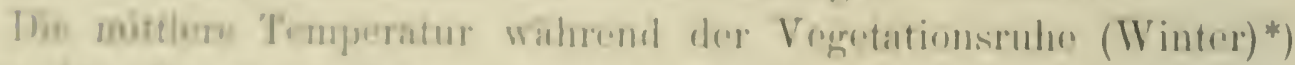

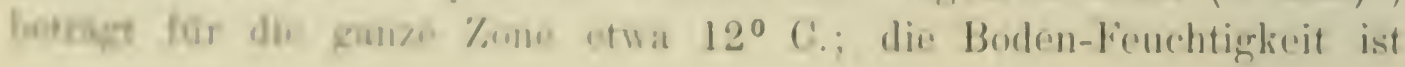

- Ala Vrovtatomsruha oder Winter sind steta dio Monate November,

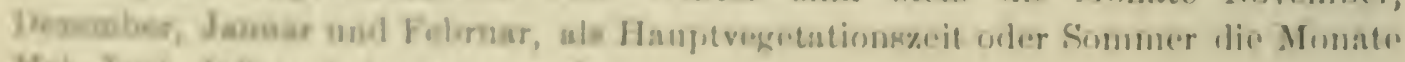

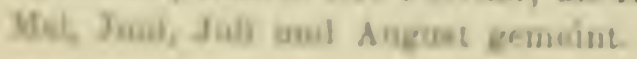


ziemlich beträchtlich, während des Winters allein fallen $589 \mathrm{~mm}$ Regen; die Luft enthält $75 \%$ rel. Feuchtigkeit, letztere schwankt während des ganzen Jahres nur unbedeutend. Wo diese dunstreiche Atmosphäre noch Zuschuss erhält aus stagnirenden Gewässern, Flüssen, in Bodeneinsenkungen und dergleichen, da flattert von den Bäumen herab die mehrere Meter lange hellgraue, flechtenartige Tillandsia usneoides; oft sammelt sie sich so mächtig an, dass die Aeste unter ihrer Last herabbrechen; die ganze Landschaft erhält durch sie ein eigenartiges Gepräge. Betrachtet man den Laubwald während des Winters, in dem Frost und Schnee nicht alljährliche Ercheinungen sind, so erfreut sich das Auge an dem dunklen, prächtig glänzenden Grïn der Magnolia grandiflora, an dem hellen Grün der Eichen, des floridanischen Lorbeer (Persea); der Raum zwischen Baumkrone und Boden ist dicht erfüllt mit immergrünen Sträuchern und Halbbäumen wie Ilex, Aralia, Illicium, Syımplocos, Cliftonia-Arten, zahlreiche Smilax und winterkahle Vitis klettern ron Baum zu Baum und vervollständigen ein Gesammtbild, das durch baumhohe Palmen, bambusartiges Schilf und fleischige Scitamineen einen fast tropischen Eindruck herrorruft. Hier gedeiht die Dattelpalme, die Cactus-Feige, wenn sie auch nicht reife Früchte zeigen; der PfirsichBaum blüht im Norember, die Orange reift im Dezember. Yucca und eine zu Boden liegende kleine Opuntie wachsen wild und die Mangrove, die typische Pflanze der tropischen Küsten, erreicht hier als niederer Strauch ihre nördlichste Grenze. Im Winter 1886 fiel das Thermometer bis auf $-8^{\circ} \mathrm{C}$. Diese ausnehmend kalte Luftwelle kam von Norden, tödtete zahllose Orangenbäume, das Hauptprodukt dieser Region und reichte nach Süden bis zur tropischen Baumgrenze, alle MangroveBüsche tödtend.

Von den beiden Palmen lebt die Sabal Palmetto als prächtiger, kleiner Baum in den feuchten Laubwald-hummocks, geschützt gegen Uebermass von Frost und Hitze und die alljährlichen Bodenfeuer; die kleinere Sabal serrulata dagegen wächst am Boden dahingestreckt (Dwarf-palmetto) ein Unkraut zwar, das aber zum Segen der Landschaft immer an Ausdehnung gewinnt. Wo der Wald der Pinus australis Swa f und cubensis niedergebrannt oder niedergeschlagen wird, und das spärliche Gras mit der Glut der Sommersonne allmählig verschwindet, da nimmt den mageren Sandboden, ehe er anfängt flüchtig zu werden, vielfach diese Palme ein, schon jetzt unter den spärlichen Kiefernresten auf viele Quadratmeilen die einzige Bodenbedeckung. bildend. Jagt Fener über die Fläche, so werden zwar ihre fächerförmigen Blätter versengt, aber der im Boden eingesenkte Stamm schlägt wieder ron 
Veuem ans: mit ihrer Hilfe wïre es, wenn man einmal energisch daran zuten wollie. dem Fenerunfugr zu steuern, ein ledehtes, dise mageren Bodenthelen wirder der natiolichen und cinzig möglichen Kütur, dem Kichromalde zurickzugeben. 1)as Bild, das solehe Kiefermwaldungen mit \%wemalmen als Bodenschut\% bieten, ist selbstverstïndlich fuir siunn Forsmann ïuserst auffillend: unter den Kiefern ist die werthwall-te die Pinus australis in Minoritiat. Pinus cubensis präralirt. Verginzolt -ioht man junge l'inus australis, hart am Boden, einem frasmache mit langen, rierlich überhängenden Halmen vergleichbar, später 2-4 Mfor hoch oft noch röllig astlos erscheint sie wie eine schmalbluterige lueca run New-Mexico: zallyeich sind junge Pflanzen der l'nns anben-is mit kürmeren Nadeln; wo der Boden trocken ist, treten besonders an der nördlichen Grenze Pinus Taeda, melir in der Mitte dir Region Pinus clutusat auf, letztere eine astige nicht hohe aber sehr node wudicige hiefor: wo der Buden grössere Feuchtiglieit besitzt, da uborzichen ihn mehrere Stratucheichen und Pinus serotina, eine langr-

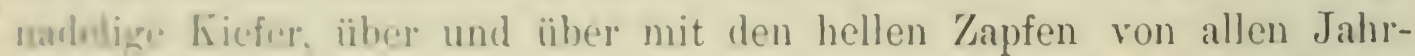

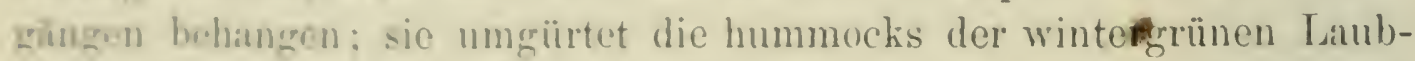
hinlzer. insbesunders der (Zureous virens, der fast wintergriunen Quereus furrifolia und aquatioa; endlich die tiefer liegenden, mehrmals im Jalure

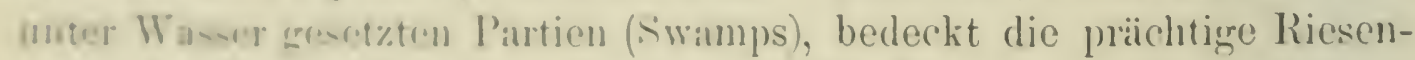
coder des ()stern. 'l'axudium distichum. Zur Zeit als ich diese ,Cedernswamp" hendefte (Anfang Norember 1887), waren trot\% der vorlser-

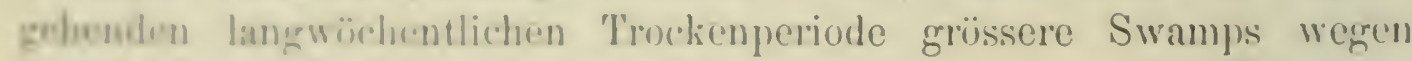

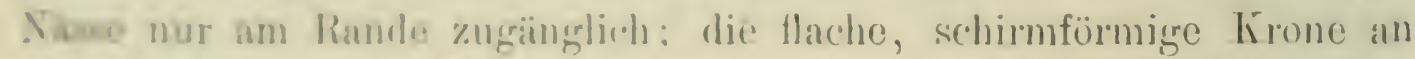

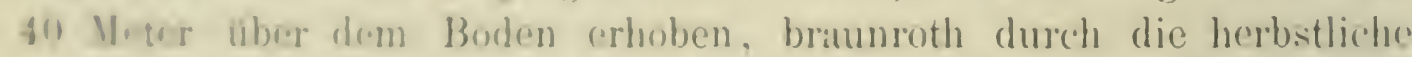

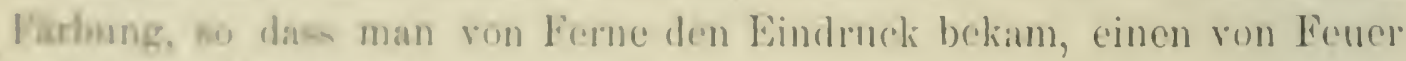

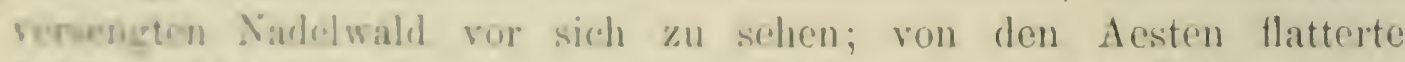

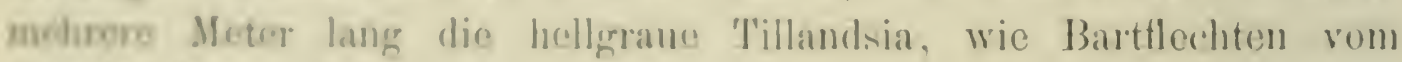
Whan hin- und horbewergt. Da erloben sich die Riesen aus dem eumptipera Gebiequ, je narh dor Ausformung dessolben bald in wenigen

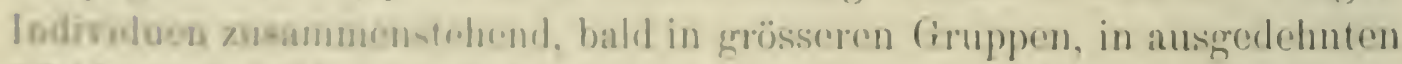
Wablungon, bald in zonsanmenhingenden, langen, schmalen Sitreifon an

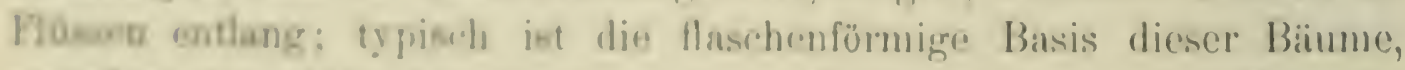

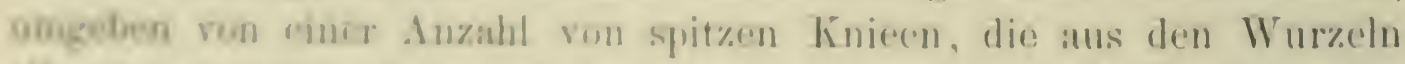

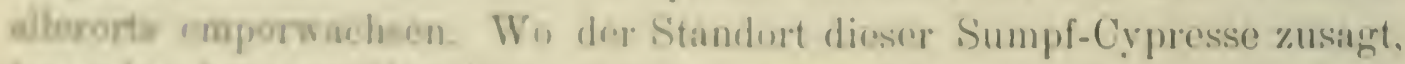

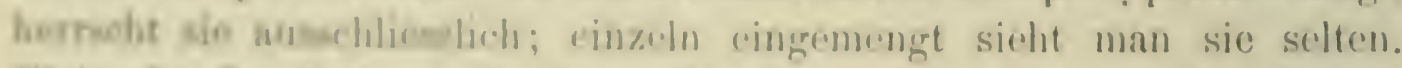
Vhele der Lantholzer, dire ihren standort mohe odve minder theilon.

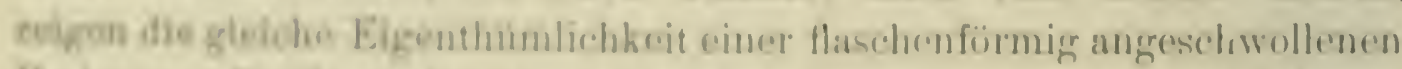

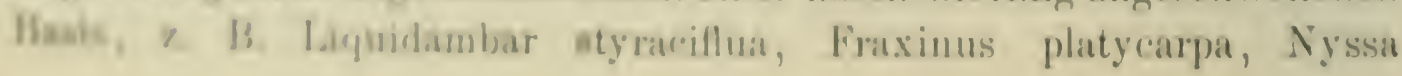


aquatica u. A.; ja selbst einzelne der zufällig am Rande eines solchen $R_{s}$ t Swamps angeflogenen südlichen Kiefern zeigen in geringem Masse diese on th Erscheinung; bekannt ist, dass auch die Mangrove in dem tropischen ewam Theile Florida's, wo sie Jahr aus Jahr ein an überschwemmten Ufern am Meere wächst, eine solche keulenförmige Basis entwickelt; dabei ist die Anschwellung um so mächtiger je nasser der Standort. Umsäumt sind solche sumpfige Niederungen von Laubhölzern, unter welche sich Juniperus virginiana, Chamaecyparis sphaeroidea drängen; erstere erreicht hier und jenseits des Mississippi ihre Vollendung.

Die zahlreichen winterkahlen Laubhölzer, welche aus der nördlichen Region übergreifen und, unter die wintergrünen Laubhölzer sich eindrängend, hier ihre südliche Grenze finden, behalten die Blätter ungewöhnlich lange, verlieren ihre schöne bunte Färbung, mit der sie in ilner nördlichen Heimath dem herbstlichen Bilde eines nordamerikanischen Laubwaldes ein besonders auffallendes Gepräge verleihen. Die ganze Entwicklung der Pflanzen ist durch die länger wirkende Wärme und Luftfenchtigkeit in die Länge gezogen; die Früchte reifen hier am spätesten und hier konnte ich noch reife Früchte pflücken von Bäumen, die weiter nördlich lüngst blätterlos waren und ihre Früchte längst als willkommene Speise für Eichhörnchen, Mäuse und Schweine zu Boden geworfen hatten. Das feuchtwarme Klima belebt die Sümpfe mit zahllosen Musquitos; das gelbe Fieber das von Cuba aus zuweilen als unheimlicher Gast die nordamerikanische Küste besucht, erhält sich hier bis spät in den Winter, hatten wir doch Mitte November uns auf ansern Touren in Florida noch auszuweisen, dass wir nicht aus dem nahen Tampa kamen, wo die Seuche besonders hartnäckig Stand hielt. Die Klapperschlange, diese unheimliche Bestie in dem raschelnden Palmgestrüppe, erreicht hier mit 8' Länge ihr Maximum; in den Bächen und Sümpfen kriechen die faulen Alligatoren, deren hoffnungsvolle Jugend in den Pfützen herumwühlt, wie Salamander in den Teichen.

Das der Landwirthschaft danernd nutzbare Terrain ist in diesem ('ebiete von rerhältnissmässig geringer Ausdelnung; die einen Oertlichkeiten sind zu trocken und in der Regel auch ohne energische Düngung vicl zu mager; die andern sind wieder zu feucht und ihre Entwässerung, wenn sie möglich wäre, würde nur die völlige Verödung der höheren Standorte zur Folge haben.

Im grossen Haushalte der Union sollte dem Staate Florida als Hauptprodukt des Landes die Erzeugung von Nutzholz und Harz zufallen; der landwirthschaftliche Aufschwung, den Florida in den letzten Jahrzehnten genommen, ist, wie in vielen andern Staaten, in allererster 
Lanio dom jungfriulichen Boden, dem Jahrhunderte angehäuften Kapitale xuzuschreiben. ren deon jetzt noeh fast ïberall in der Union ge\%ehrt wiml: uherdiess grlaube ich nicht, dass die Orangen und Trauben Florida's vinstmals mit denen aus der Fruchthammer der Union, aus Californien, verdon concurriren können; Orangen und Trauben und alle Frïchte ubromaupt sind um so schmachlafter, um so reicher an Aroma, je trockener und wämer - bis zu einem gewissen Grade natiirlich des Klima ist; in Japan, Ceylon, Honolulu und Java wachsen Orangen und Tranben ebenso gut wie in Florida: sie sind auch süss, aber ihr speciti-ches Aroma bleibt gregenüuber dem, welches das trocken-warme cuntmentale Klima der Mittelmeer-Länder, ron Afghanistan, China und Cahfornion in den Früchten zeitign, an Feinheit, für meine Zunge wenigrtens, weit zurïck.

Yon den wintergrünen Bäumen dieser Region will ich nur einzelne hervorliebon.

Unter den Eichen ist Quereus virens Ait., Live Oak, FloridaLebenseiche, der Hauptrertreter der subtropischen Zone, auch im Winter trin: ihre Früchte sind kleiner als jene der europäischen Stinleiche, cbenfalls gesticlt, von älnlicher Gestalt, aussen dunkelviolett, das Eiweiss gelblich grefirbt; die Bliitter sind ganzrandig, klein, hart, untererits weis-lich behaart, mit gewölbter Flïche, Blattränder etwas oingerollt. I) as Hul\% dieser südlichsten Eiche mit einem specifischen frewidate ron $101^{\circ}$ ) steht in Sidwere an der Sipitze aller ostamerikanischen Kielien: sie zoigt anf dem (Querschnitte die radiale Anordnung der Gonkse (Purn), einc Eigenthümlichkeit, die ich anch bei den wintergronen Eirben Japans und der grossen indisch-malaischen Eichen-Flora comatiren konnte. während bekanntlich das Hol\% der im Winter kahlen Bichen durch einen Kreis ron weiträumigen, peripherisch grestellten

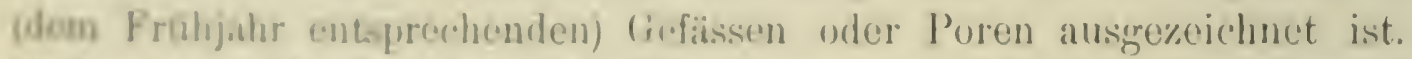
Pruler wurde das Holz zum Sichiffhau benuitzt und bildete eine Reserve fur die Regierung.

Pondiris wotur bemorkenswerth ist ferner die Sabal Palmetto B. at s. Gabbage l'almetto, ron der kriechenden Art dureh die zahnkeen Bhatetiole und die etwas \%urickgekrïmmte. Mittelrippe des Blattes

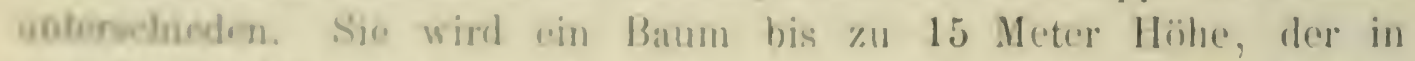

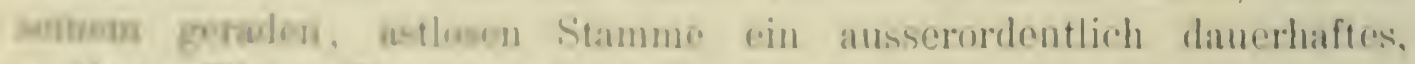
unaberenfliche Baumatorial fur Schiffswerften, kleinere Brïclenpfeiler,

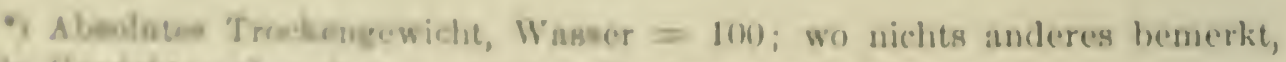

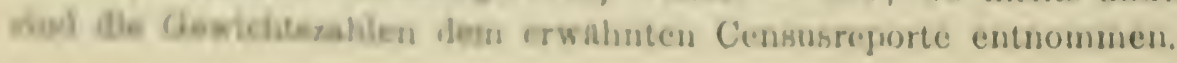


Badeanstalten, Dammbauten und so weiter abgibt, da das Holz von der Bohrmuschel nicht angegriffen wird.

Die darnieder liegende Art Sabal serrulata (Serenaea serrulata Hook.), Dwarf Palmetto, wird als Wegeinlage in sumpfigem Terrain rer'wendet.

Die übrigen wintergrünen Laubbäume haben, bis jetzt wenigstens, noch geringen forstlichen Werth; sie werden nur gelegentlich benützt, wie Persea Carolinensis Nees, Red Bay, ein lorbeerartiger Baum; ein sehr werthrolles Brennholz mit heller, ruhiger Flamme liefert die Cliftonia ligustrina Banks, Titi oder Ironwood, ein Halbbaum, nach dem eifrigst in den Waldungen gesucht wird.

Magnolia grandiflora, stets grün, ist ein Zierbaum allerersten Ranges, der es in der That rerdient wegen seiner dunkelgrünen, glänzenden Blätter, die im Lichte auf der Unterseite dunkelbraunroth sich färben, wegen seiner herrlichen Blüthen überall in den Gärten der wärmeren Region eine Ehrenstelle einzunehmen; überall in Siideuropa, selbst in Japan, ist er gepflegt und durch seine eigenartige, kräftige Belaubung unter allen Bäumen ausgezeichnet; wer schöne Bäume ron Ficus elastica in den Tropen gesehen, kann nur mit diesen die Belaubung vergleichen. Im Heimathgebiete erwächst der Baum zu einer Höhe von 30 Meter; seine Rinde ist hellgrau und glatt wie die der Buche.

Die Nadelhölzer dieser Region lassen sich besser als ein ganzes Waldgebiet, „der südliche Kieferngürtel“', beschreiben, der in Folge but of der sandigen Ausbildung des Bodens die Grenzgebiete der subtropischen sil und gemässigt-warmen Region unschliesst. Dieser Kieferngürtel stellt ein etwa 250 Kilometer breites, der Küste des mexicanischen Golfes und des atlantischen Oceans bis zum $36^{\circ}$ N.B. parallel laufendes Land dar. In der Halbinsel Florida reichen die Kiefern selbst bis hart an die Nordgrenze der tropischen Region heran. Dabei nehmen die Kiefern, wie schon erwähnt, die schwachen Erhebungen dieses Gebietes ein, während tiefer gelegene, frischere Bodenpartien die Laubhölzer der betreffenden Zone und endlich die nassen, oftmals überschwemmten Gebiete den Bigtree des Ostens, Taxodium distichum, tragen. Dimension und Holzgüte sind es, welche diesem Gebiete wirthschaftlich einen so hohen Werth verleihen; von Natur aus - wegen des mageren, sandigen Bodens - zum Walde bestimmt, kann eine landwirthschaftliche Kultur mit wenig Ausnahmen nur in der Vernichtung des Waldes und des Bodens zugleich enden, wie ich schon früher des Oefteren darauf hingewiesen habe. 


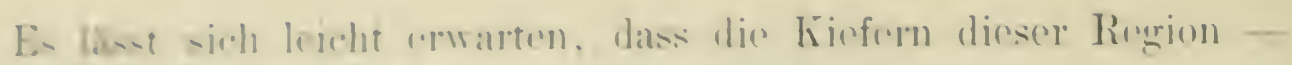

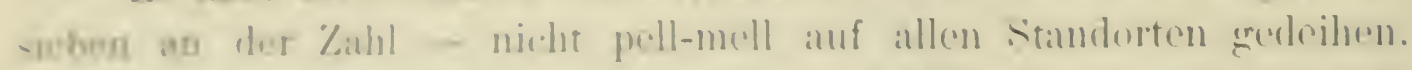

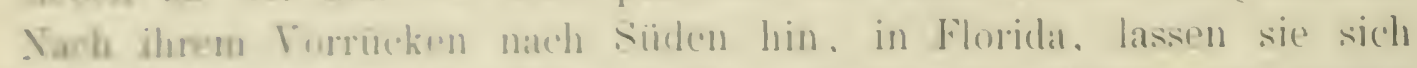

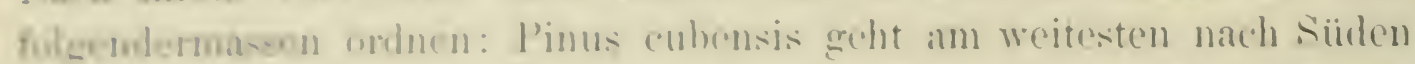

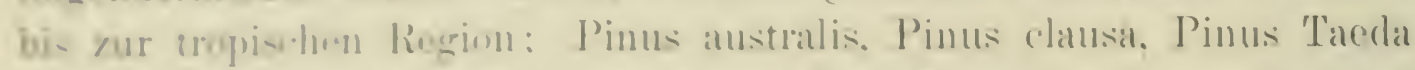

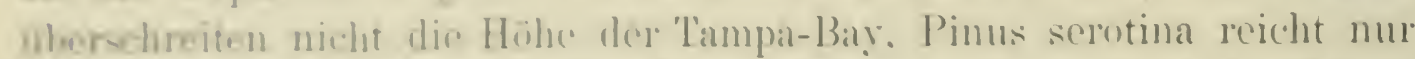

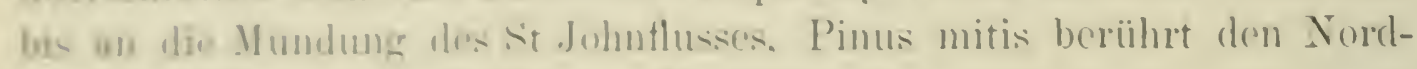
mand der hieforn an fiolfe von Mexiko entlangr.

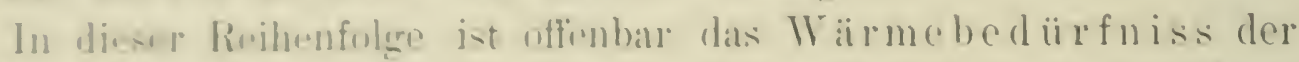

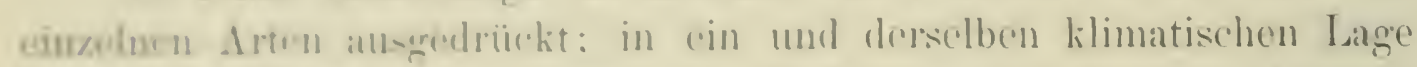

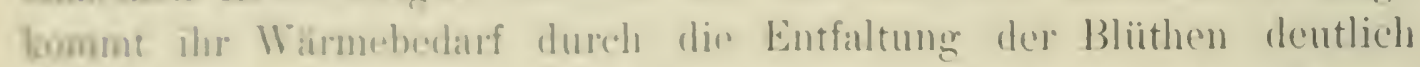
nutu Vindorin: am st. Juhntusse in östlohen Florida blüht Pinus

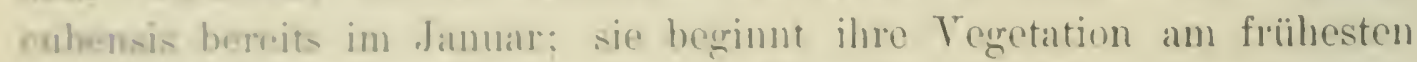
vou allen Kiefern. woil sic zur vollen Entwicklung offenbar am meisten Wh mue bredaff: Jinus anstralis blïht im Februar, Pinus Taeda im Mär\% mml l'inn- serutina im April.

Dimunt man alle Kinforn der atlantischen Region zusammen, so

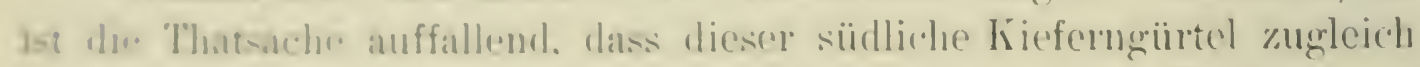

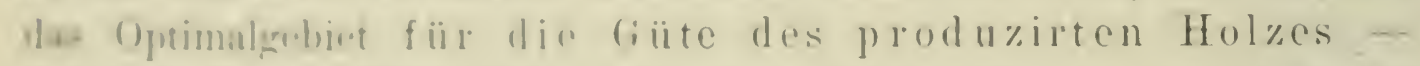

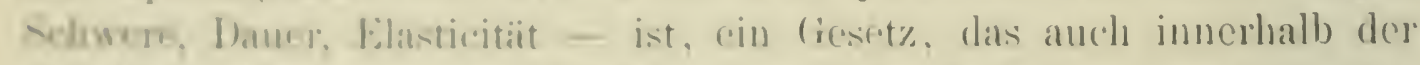

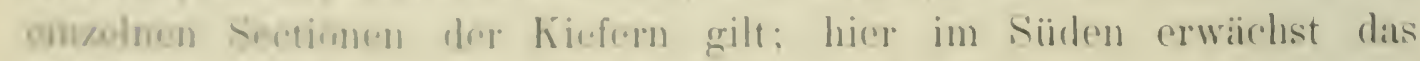

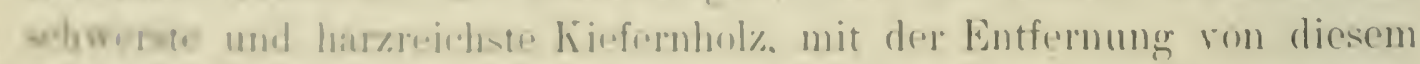
1) ptimsum dor Hulgeriete. st weit sice dureh die Schwere bedingrt wird,

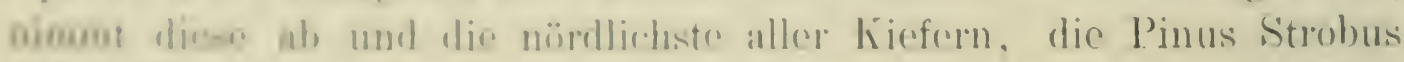

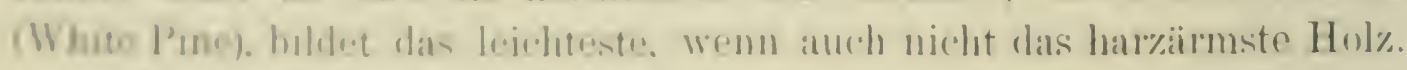

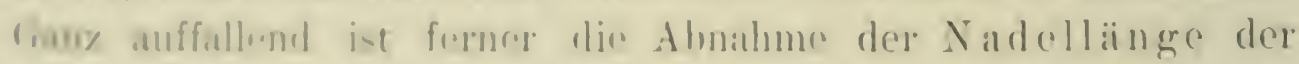

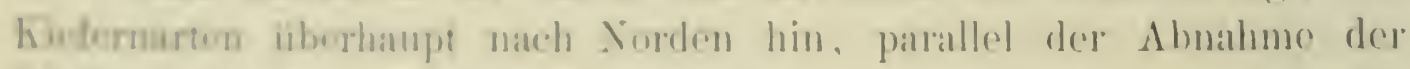

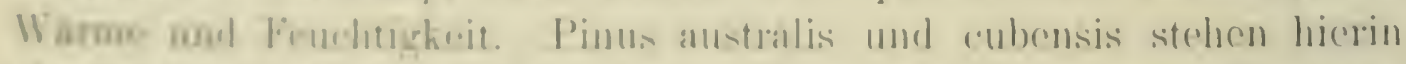

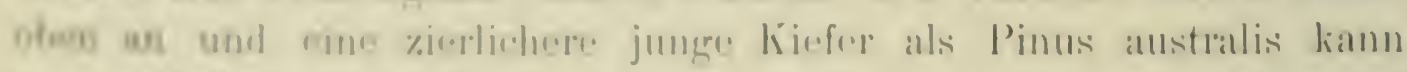

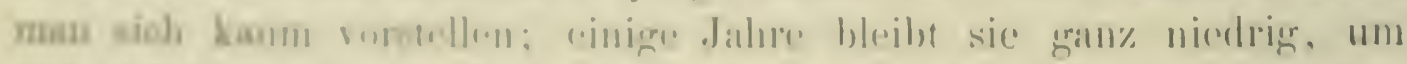

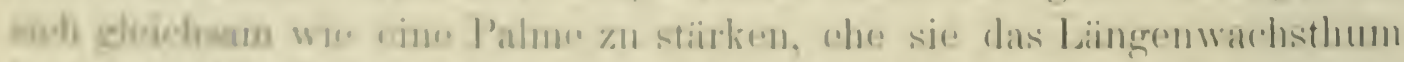

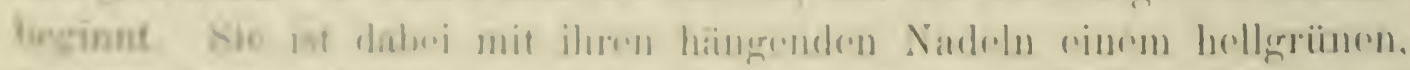

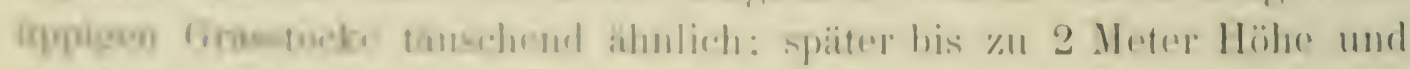

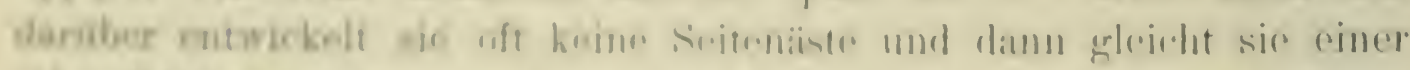

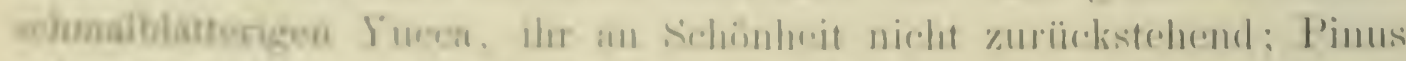

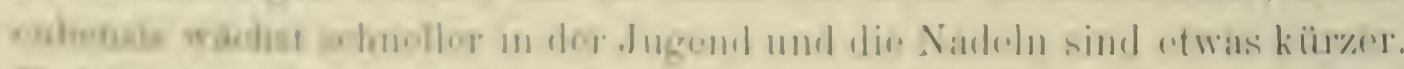

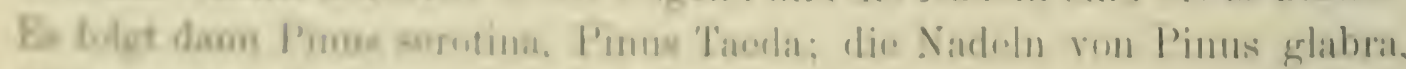

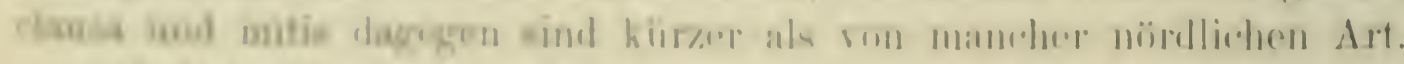

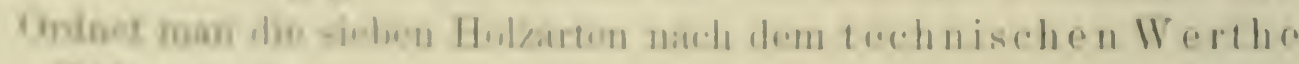

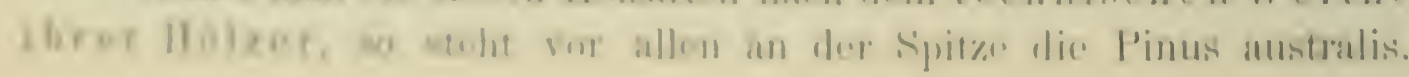


Pinus cubensis kommt der vorigen an Holzgüte und Harzgehalt sehr nahe, wird oft sogar wie australis genützt; Pinus Taeda liefert grobes Nutz- und Bremnholz; die übrigen werden nu gelegentlich verwendet.

Bei allen Kiefem ist auffallend die mächtig entwickelte, dunkle Sommerholzregion, die oft zwei Drittheile des Jahrringẹs umfasst und das hohe specifische Gewicht dieser Kiefernhölzer bedingt; alle sieben Arten zeigen ferner eine Gleichheit in der anatomischen Struktur ihrer Hölzer, insbesonders im Bau der Markstrahlzellen und der Tüpfelbildung der anliegenden Längstracheiden (Tafel VI).

Für die dreinadeligen Holzarten war die Gleichheit hierin zu erwarten, aber dass auch die zweinadelige Pinus glabra und clausa und die vorwiegend zweinadelige Pinus mitis diesem Typus folgen, ist auffallend. Es beweist diess für mich, dass Pinus mitis, glabra, clausa wie die nördlicher wachsende Pinus inops trotzdem, dass sie fast durchweg zwei Nadeln im kurztriebigen Quirl besitzen, nicht zur Gruppe „Pinaster" gerechnet werden können, zumal da auch der Aufbau der ganzen Pflanze, Seitenäste und Zapfen von den zweinadeligen völlig abweicht; es dürfte sich cmpfehlen, diese Kiefern als eine fünfte Section, vielleicht unter dem Namen „Banksia“ anzufügen. Sollte einmal die Zeit kommen, dass auf Grund der anatomisch-morphologischen Verschiedenheiten der Kiefern diese Sectionen selbst zu Gattungen erhoben würden, so mag ein passenderer Name für diese Uebergangskiefern gewählt werden.

Dass alle diese südlichen Kiefern ein grosses Maass ron Luft-soil, feuchtigkeit verlangen, beweist ihr Torkommen an der Küste; hinsichtlich ihrer Ansprüche an die Bodenfenchtigkeit zeigen sie aber beträchtliche Unterschiede und man kann sie nach folgender Reihe gruppiren. Pinus serotina nimmt die Einsenkungen, Sumpfränder an der Küste serotom entlang ein, wo in einem breiten Gürtel über dem Fluthwasserspiegel Pinus cubensis vorherischt; auf den trocken-sandigen, schwachen Erhebungen in diesem Gebiete prävalirt die ästige Pinus clausa, vereinzelnt sieht man dort Pinus Taeda; an dieses unmittelbare Küstengebiet schliesst sich eine wellig-hügelige Landschaft mit vorwiegend kiesig-sandigem Boden, das ist die Heimath der Pinus australis und Taeda; eine wald- Laeda baulich sehr merkwürdige Art ist Pinus glabra, welche besonders den frischen, wenn auch sandigen Waldboden mitten im winterkahlen Laub- Netw walde liebt; Pinus mitis rückt ron ihrem heimathlichen, kiesigen, berg- monm igen Standorte mit grosser Schnelligkeit in den Gürtel der südlichen Kiefern, zuerst die Pinus australis verdrängend, ror. 
Viwh dien kurzen Iobensshize lisst sich rermuthen, welche Hobarton der Fingrifi des Menschen in das Walten des Urwaldes begun-igt. Welche Hulzarten der Ausrottunge oder doch einer an Bedeutuma-lonigkeit srenzenden Verminderung entegegengeführt werden. llew werthullste hiefer. Pinus australis wird am meisten gesucht, mehr Hofz wiml durels Harzuntzung und durch Feuer zerstört, als zu Nutzwaure verarteitu wird. Sie tritt rom röllig hïgeligen Lande in zahlroichen aber inolirt stohonden Individuen auf das Gebiet der cubensis uher. Dout gefillt, werolon die anflicgenden jungen Pflanzen, wenn sie

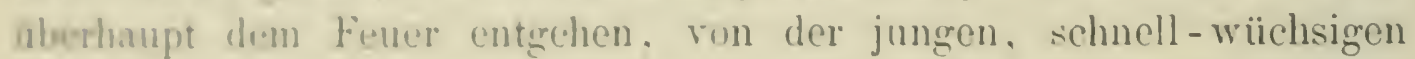
Puns cubensis liberwachsen: dic Taxodium-Sïmpfe betritt sic nie,

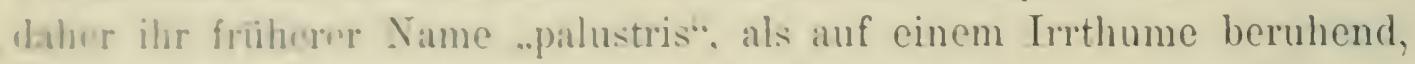
von den Botanikern einer weniger perantischen Richtung mit Recht fallen Golawin wird. Dasi sie zufïllig eimmal dont anfliegen und langoun und kiimmerlich anfwachson kamn, ist nicht auffallend, bei allen Hobarten sibt es bei der rejehlichen Samenproduktion solche Findlunge.

Anf ihrem heimatichen Sitandorte hat die Pinus australis einen

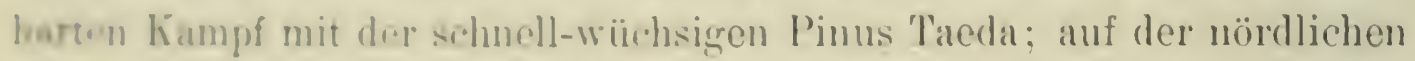
lirome in Higellande weducelt die Pinus australis bei besserer Bodenart wais Ciruppen ron Eirhen, oft einzeln unter diese gemengt. Wird sie dort enternt, si) fiillen die Iaubliöl\%er, insbesonders Quercus faleata,

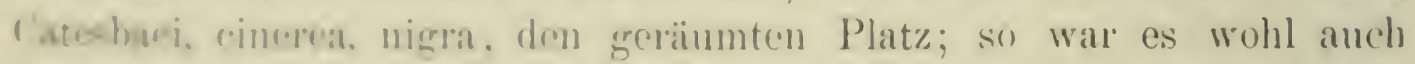
um unburibrten Drwalde und die anereflogenen Kiofern arbejteten sich langesu zwi-uhren don Lauhdiilzern ompor, da insbesonders auf warmen, wangen stundaron wohl jerle Kiefer die Beschattuugr durch die blaitter-

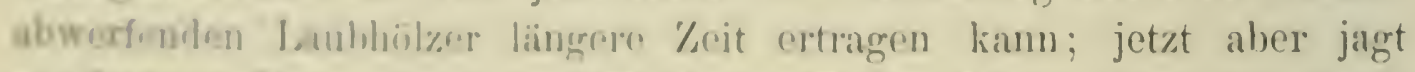

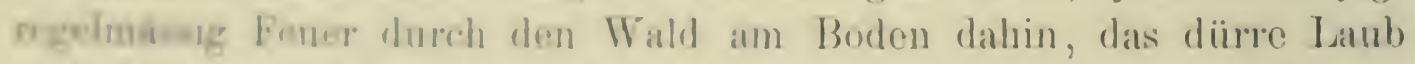

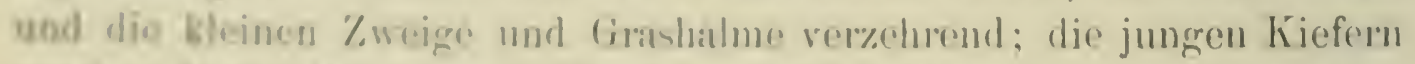

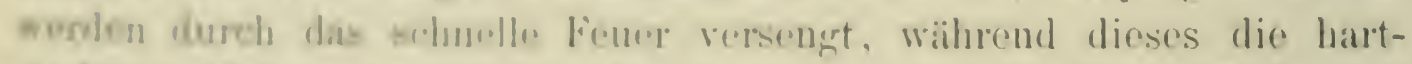

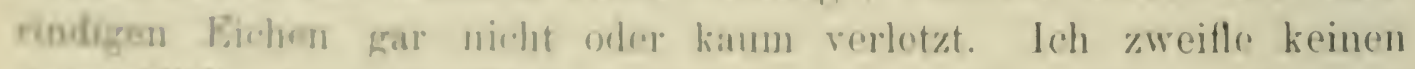

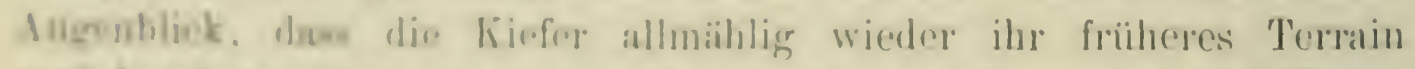

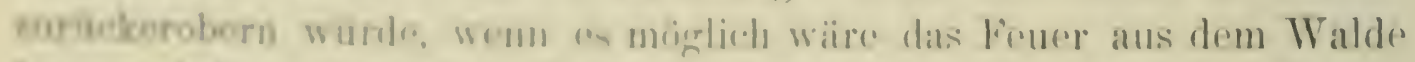

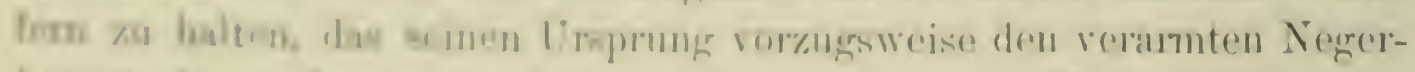

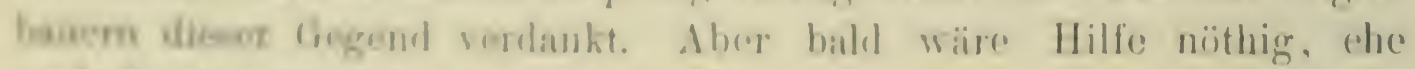

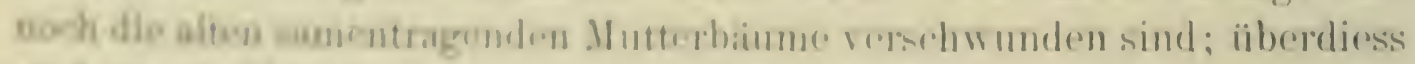

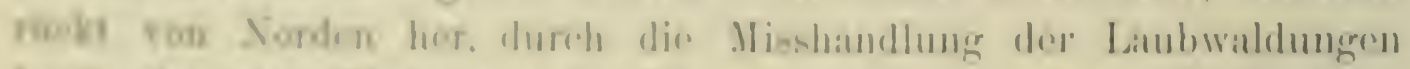

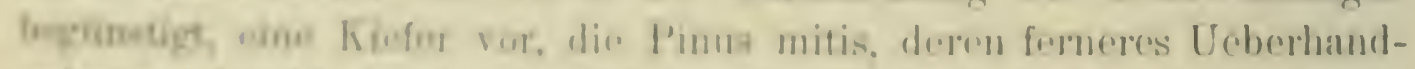

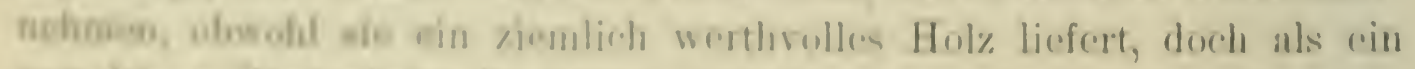

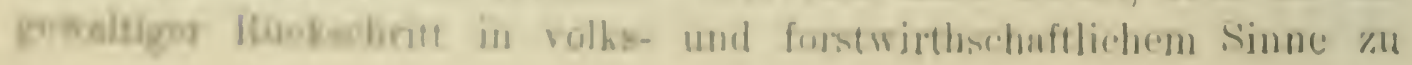


bezeichnen wäre. Ch. Mohr*) sagt von ihr wörtlich: „Unter den P. m am meisten zu fürchtenden Feinden (der südlichen Kiefer) steht oben an die Pinus mitis; zahllose Keimlinge dieses Baumes entsprossen jedes Frühjahr dem Boden, durch ihr rasches Wachsthum unterdrücken sie leicht die jungen Pflanzen der südlichen Kiefer, dringen in den Laubholzwaldungen auf dem besseren Boden dieses Hügellandes vor und nehmen sofort die ihres Holzes beraubten Partieen im Walde sowohl als die von der Landwirthschaft wieder verlassenen Oedungen in Besitz. Ausgedehnte Gebiete, ror einem halben Jahrzehnte noch mit prächtigen Bäumen der weissen, spauischen, schwarzen Eiche bestockt, wurden zur Nutzung gezogen, constant niedergehauen und endlich erschöpft; dort hat man jetzt herrliche Gelegenheit, die Natur in der Arbeit der Wiederbewaldung zu beobachten. Die jungen Pflanzen der mitis bilden zuerst ein völlig undurchdringliches Dickicht ...."

Pinus clausa und glabra warten nur auf günstige Gelegenheit, um in dem Gebiete, in dem sie sich finden, zu Alleinherrschern zu werden, da sie darin nicht blos von der Natur durch Schnellwüichsigkeit und leichten Samen, sondern auch vom Menschen begünstigt werden, der sie ihres werthlosen Holzes wegen nicht fällen mag.

Ich gebe in Folgendem noch eine specielle Betrachtung der einzelnen Holzarten; der botanische Theil ist nach den Objekten meiner Sammlung sowie nach meinen Aufzeichnungen im Walde selbst gefertigt; die etwas eingehendere Schilderung hat den Zweck, die Bestimmung der jungen Pflanzen und der Zapfen zu ermöglichen. Insbesonders mit Bezug auf die Samen verweise ich auf die beigegebenen Tafeln VII und VIII, auf deren genaue Herstellung der Verleger und ich besonders bedacht waren. Die Samen mit den Flügeln sind fast ausschliesslich zum Zwecke der Zeichnung erst den Zapfen entnommen worden, welche ich selbst wiederum in der Heimath der betreffenden Holzart sammelte; ich glaube dadurch für die Richtigkeit derselben einstehen zu können.

Pinus australis Mich., synony m „Pinus palustris", welch' letztere Bezeichnung, da auf einem Irrthume beruhend, keinen Anspruch auf Pietät oder Priorität erheben kann; longleaved Pine, Southern Pine, südliche Kiefer, Gelbkiefer. Knospe mit weissen, grossen am Rande ausgefransten Schuppen bedeckt, am Grunde etwas zurückgerollt; drei Nadeln bilden einen Quirl am Kurztriebe mit durchschnittlich

*) The future of the forests of the lower South States and their probable timber-supply, by Ch. Mohr of Mobile, Ala $188 \bar{j}$. 
34 cm Lange an Zapfon trigenden \%weigen: Ceinjähriger Zapfen $3 \mathrm{~cm}$ lam:. I cm breit. mit grerababselsenden Dornen an den Apophysen:

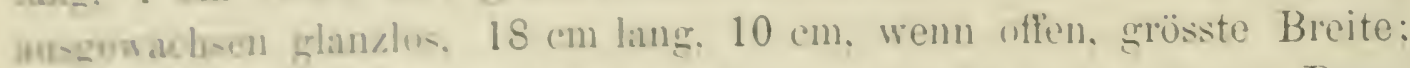
Apophyee mit erlaben sitzenden, kamm abwäts gekrümmten Dorn-piven: die Zapfon lüsen sich leicht vom Zweige ab: in Bezug auf

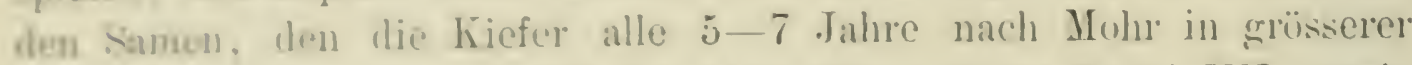
Menge trigt. redweise ich auf llo beigegebene Figur (Tafel VII) sowic die Bascluejhung desselhen. Der same keint mit neun grossen CotyJeronn. In orsen Jahre cntwickeln sich Büschel langer, cinfacher Voudn. whlnend zahlreiche Achsclknospen \%u dreinadeligen liurztrieben all-ireihen, uhne dass die stammalchse cine messbare Verlängrelung iffurt. Ciluiches findet im \%weiten und dritten Jahre, an geringen semblerten siollejcht his \%um fünften Jalhre und länger statt: erst wenn siv den Buden auf einen Umkreis um sich herum beschattet, crlsebt

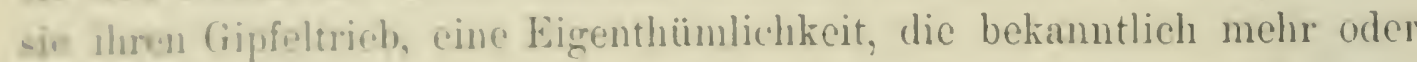
minder alle Holzarten anf unpassenden oder sehr mageren, heissen,

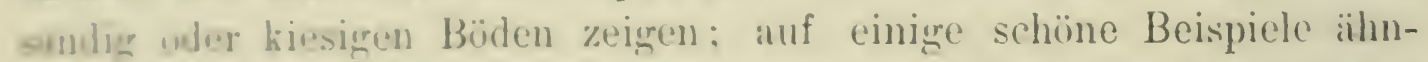
liohen Verhalerns run Pinus Strobus, der europäischen Lärche, der Citalpm will inh spitor \%urï(thiommen.

Holz und Har\% sind ron diesem Baume sehr gresucht; sein Hol\% int wohl das beste Kicfornhol\%, das es überhaupt gribt; wenigstens die bishoragn Eofuhrumeren und die Höhe des specifischen Gewichtes desmethen berwelitigen \%u diesrm Schlusse.

Dauls den Untersuchungren des Censusreportes betrïgt das specifische liewiche 70. (\%. Mohr liofert dazu vier Stamm-Abschnitte von Kivferm, the langere \% \% it anf Har\% gronutzt waren; diese zeigen zusammen das

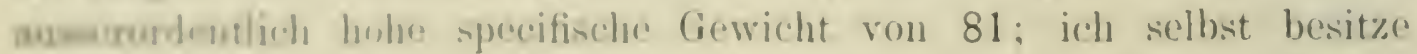

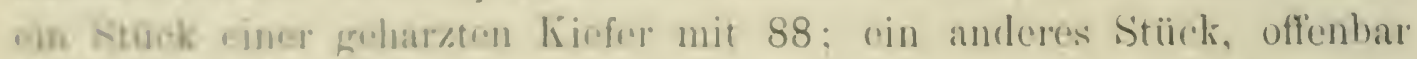

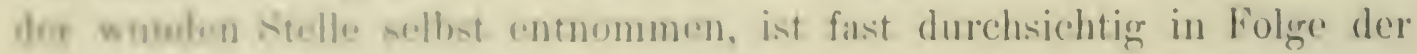
Maralunchtrankung und \%oigt rin (irwicht ron 92. D)as durchschnitt-

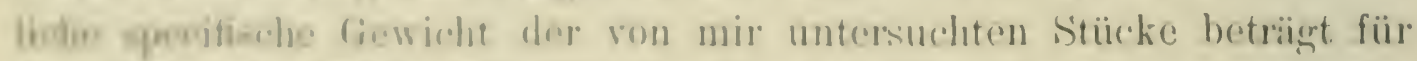

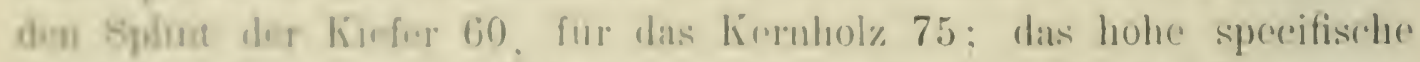
Cimwiobt, wie nelom orwhlme, ist ror Allom der 1/2-2/3 des Jaluringes

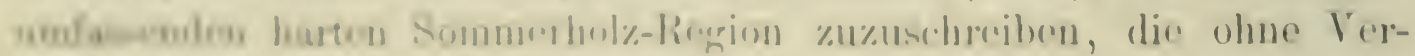

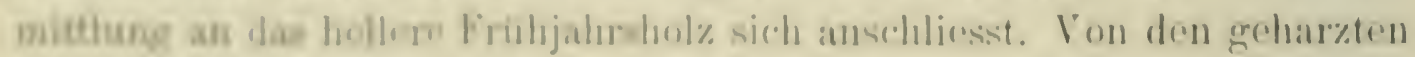

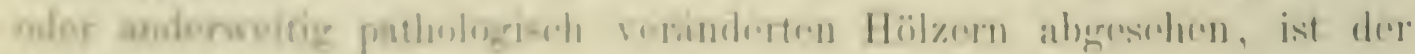

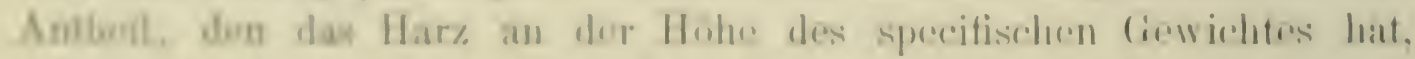

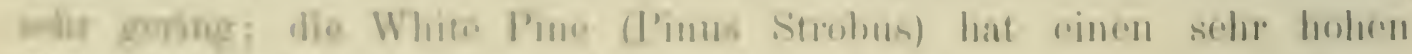

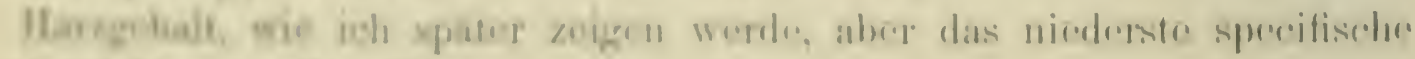
coveintit ron allon kinfori. 
Ich erhielt den Gehalt an festem Harze (Colophonium) durch mehrmaliges Auskochen sehr fein gehobelter und zerkleinerter Späne in absolutem Alkohol und Destillation desselben. Der terpentinölreiche Splint der Kiefer enthält nach dem Durchschnitte von vier, verschiedenen Bäumen entnommenen Stücken: 2,65 gr feste Harzmasse in $100 \mathrm{gr}$ absolut trockenem Holze; der terpentinölarme Kern zeigte 11,09 gr feste Harzmasse in $100 \mathrm{gr}$ absolut trockenem Holze.

P. H. Dudley in dem früher erwähnten Bulletin I der Forstabtheilung (1882) sagt, dass gewöhnliche Proben der Yellow Pine 18-20\% Harzbestandtheile enthalten (wahrscheinlich festes und flüssiges Harz zusammen). Dass der Harzgehalt das Holz so dauerhaft mache, erscheint auch mir zweifelhaft.

Trametes Pini ist an Bäumen und verwendeten Hölzern nicht selten; besonders aber wird das Schwellenholz dieser Kiefer nach Dudley durch das weisse Mycel des Lentinus lepideus zerstört; warme Feuchtigkeit begünstigt das Wachsthum des Pilzes; Schwellenhölzer dieser Kiefer, welche an der Panama-Eisenbahn verwendet waren, verfaulten in zwei Jahren, während in den Südstaaten die Dauer der Schwellen im Mittel 5-8 Jahre beträgt. Da früher die Schwellen auf den NewYork-Eisenbahnen 10-14jährige Dauer besassen, so schreibt Dudley diese auffallende Abnahme ror Allem dem Umstande zu, dass die neuen Schwellen in Boden gelegt werden, der ron dem Pilzmycel der alten Schwellen durchdrungen ist. In Schlacken soll die Zerstörung. schneller als in Kieseinbettung ror sich gehen, was bekanntlich Professor Hartig in München auch für den Hausschwamm nachgewiesen hat.

Dem entgegen wird ron allen übrigen Autoren das $\mathrm{Holz}$ dieser Kiefer als das dauerhafteste unter den Kiefernhölzern bezeichnet.

In jüngster Zeit hat man begonnen, die zu Eisenbahnschwellen, zu Werften, Brücken, Badeanstalten, Strassenpflasterung, also in sehr ungünstigen Verhältnissen verwendeten Hölzer zu imprägniren; unter anderen Stoffen hiezu hat sich das aus dem Holze der suidlichen Kiefer dargestellte Creosotöl besonders bewährt; nebenbei ist es billiger als andere Imprägnirungsstoffe. Nach W. H. Bixby (in dem früher erwähnten Bulletin I) wird diese Industrie gegenwärtig in New-Carolina betrieben. 32 Ster Holz geben 161/4 hl Oel. Bixby prophezeit der Kiefer durch Lieferung dieses Produktes eine noch "brillantere Carriere" als sie schon bisher durch ihre Terpentin-, Harz- und Holzprodukte zurückgelegt hat - arme Kiefer! Um den Einfluss der Harznutzung auf den Baum selbst zu verstehen, muss man neben der Menge auch die Tertheilung und die physiologische Rolle des Harzes im Baume kennen. Alle diese 
Vorlutenime sind nueh sehe wenig behannt: im Alleremeinen nimmt

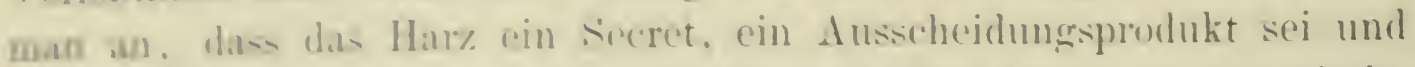

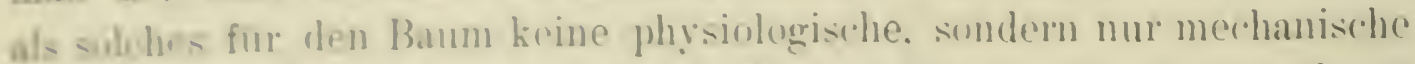

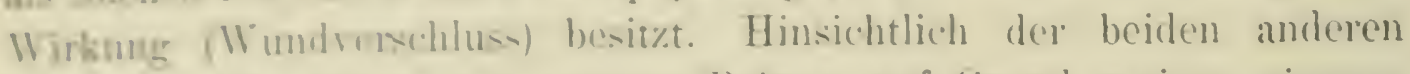

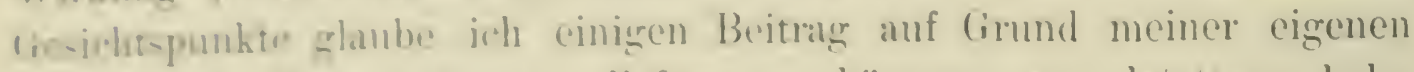

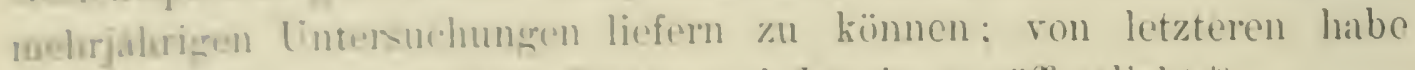
Jeh hi- jout num jene über Fichte und läiche veröffentlicht.*)

Im Bamme findet sidh das Har\% suwohl in nerhalh der \%ellen

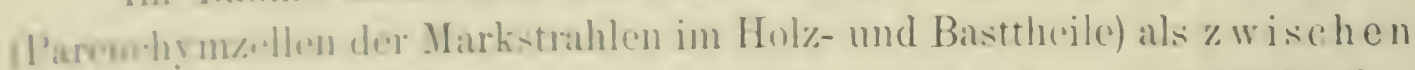

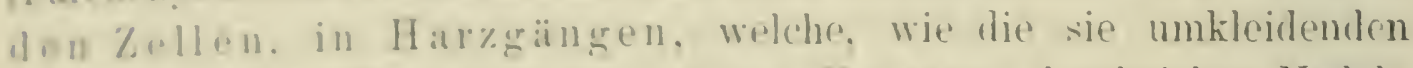

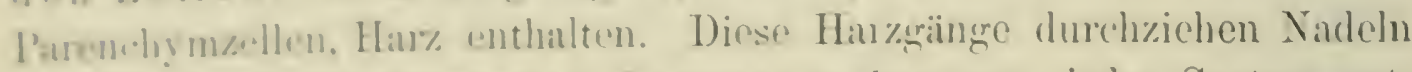

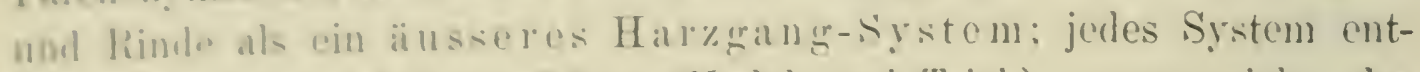

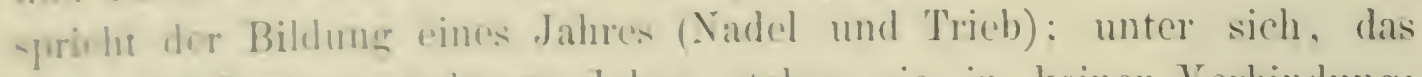

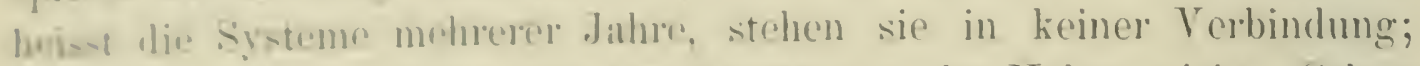

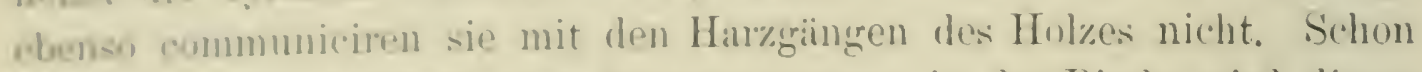
hei drm enten Auftreten von Borkensidnupen in der Rinde wird dieses Asamm rielfach durehbrothen und schom nateh etwa $15-20$ Jahren wallig mit den trockenen Burkenschuppen abgewerfen. Das innele

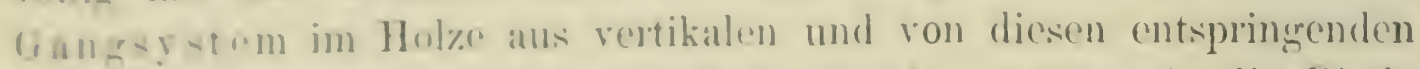

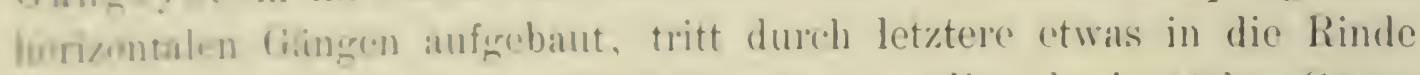

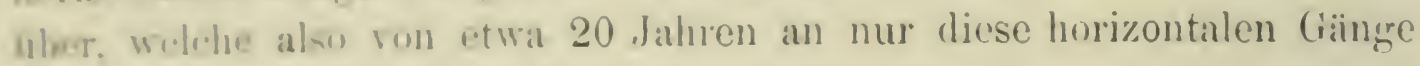
methlte die mit den Hulzgiingers communiciren.

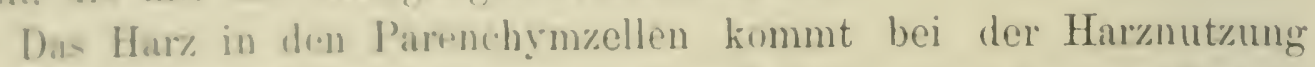
niche in B-tracht: as vorhleibt strots in der Zelle, in der es ausgeschieden word.. Wenigntens so lange als die Wandung noch $12 \%$ Wasser cuthalt, das ie die Menge, die im normalen Zustande das frisehe hermbol\%

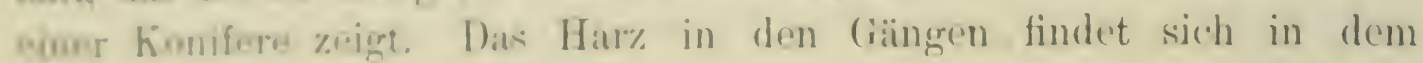

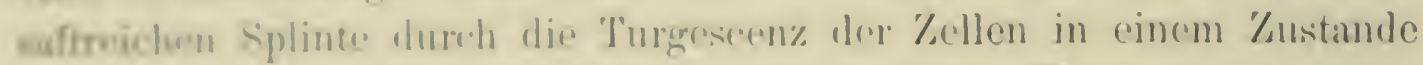

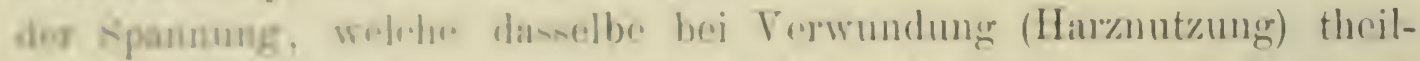

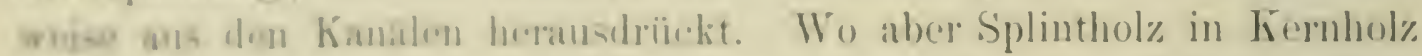

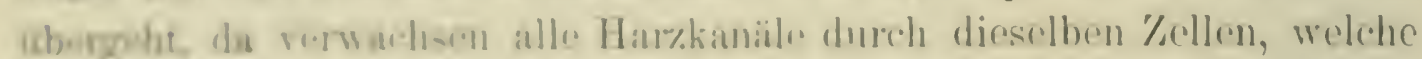

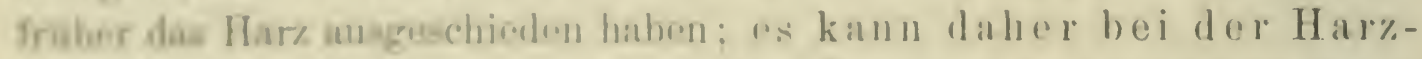

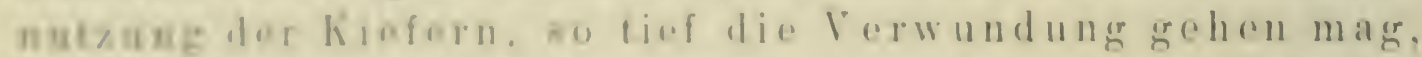

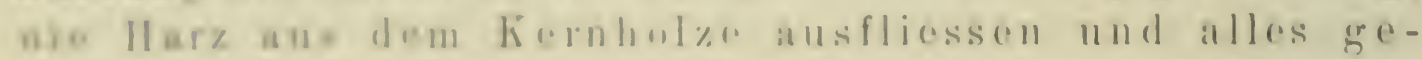

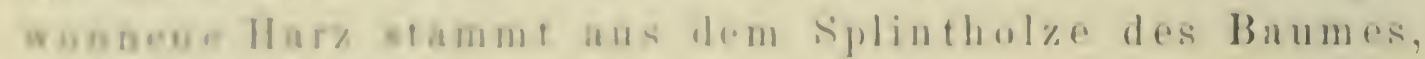

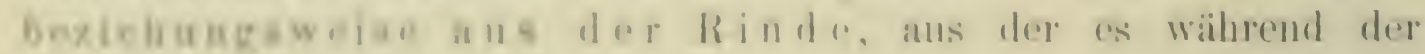

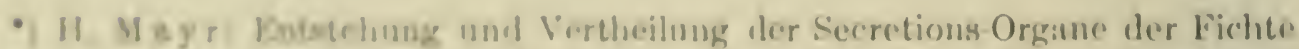

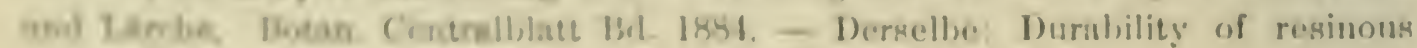

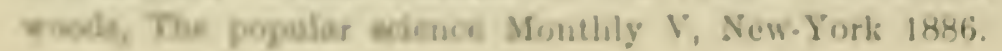


Vegetationszeit in das Holz zurückfliessen kann. Daraus erklärt sich rollständig, warum der Harzgehalt des Kernes durch die Harznutzung keine Abnahme, das specifische Gewicht und die Güte des Holzes keine Verminderung erleiden kann, von der Verwundung und ihren Folgen wie Zerstörung von Aussen und ron Insekten selbstrerständlich abgesehen. An der wunden Stelle trocknet das Holz bis in grössere Tiefen aus, die Zellwand verliert ihr Wasser, an dessen Stelle Harz tritt, das nun die Kanäle und Parenchymzellen verlässt, die Zellwandungen durchtränkt, die Zelllumina erfüllt und so das Holz „verkient." Vielfach wird die südliche Kiefer einfach angehauen, damit sie das Holz verharze und somit zu Spähnen zum Feueranzünden tauglich mache. Solches Holz zeigt in der That eine beträchtliche Zunahme des specifischen Gewichtes, eine Verharzung des ganzen Holzes, welche demselben eine ausserordentliche Schwere und Brennkraft verleiht. Wie aber das längere Zeit auf Harz genutzte Splintholz sich verhält, darüber bestehen keine Untersuchungen; bekannt ist nur, dass es auffallend schnell schwarz (durch ein Pilzmycel) und zersetzt wird.

Um zu erklären, warum gerade diese Kiefer sich so vorzüglich zur Harznutzung eignet, gibt die Menge an festem Harze, das sich im Holze nach der Trocknung findet, keinen genügenden Anhalt, denn der Harzgehalt des Splintes mit 2,65 gr fester Harzsubstanz in $100 \mathrm{gr}$ absolut trockenem Holze ist kaum grösser als der des Splintes der Douglasia (Pseudotsuga Douglasii) nämlich 2,45 gr und vollends als der Splint der White-Pine (Pinus Strobus) zeigt: nämlich 5,20 gr.

Ich rermuthe, dass das Harz der südlichen Kiefer etwas mehr Terpentinöl beigemischt enthält, wodurch es schon an sich dünnflüssiger ist als die Harze in den nördlichen Kiefern; dazu kommt jedenfalls, dass das Harz in Folge der grösseren Wärme des südlichen Standortes mit höherer Spannung im Baume zusammengedrückt und herausgepresst wird.

Von dieser Kiefer sagt Ch. Mohr, dass sie 150-200 Jahre bedarf, um zu einem nutzbaren Baume heranzuwachsen. Bei dem reichlich gebotenen Wärme-, Licht- und Feuchtigkeitsgenusse eine auffallende Erscheinung, aber glaubwïrdig, wenigstens nach der Engringigkeit des gebildeten Holzes, woran der fast durchweg magere Standort neben individueller Anlage zur Langsamwüchsigkeit mit Schuld sein mag.

Ihr langsames Wachsthum in der ersten Jugend habe ich schon beschrieben, auch später in der Vollkraft ihrer Entfaltung erreichen ihre Längstriebe nicht über $50 \mathrm{~cm}$ Länge. 
Im Urwalde arwathsen die jungen Kiefern in kleineren, ziemlich dicht govlrangten Gruppen wher anch pinzeln im lichten Halbschatten der Ifuterbanme: lange Zeit kimpfen sie um ihr Leben, dabei ein gheichnosiges. sehmalringiges. hartes Holz anlegend. Es dürfte kaum einem \% woifid unterliegen, dass das Hulz der freistehenden Exemplare fols ongenamnten 11. growth) zwar das Produkt einer viel liürzeren Zeit durselli, aber anch an Giite. insbesonders an Feinheit und Gleichmasigkeit dus Gofiuges dem des Urwaldes wesentlich nachsteht.

Anamminch repräsentirt das Hulz den Typus der dreinadeligen Section Theda. nümlich es trïgt zallhreiche T'üpfel an der Lïngstracheidenwandung. wo dime an parnchymatiche Markstrahlzellen anliegt: dadurch kann das Holz mit ziemlicher sicherheit ron dem einer andern section unturchiedion werden: ein mikroskopischer Unterschied aber innerhalb der dreinadeligen liefern selbst scheint nicht zu bestehen; der Splint umachlient in vine. Breite ron etwa $3 \mathrm{~cm}$ das dunliel-röthliche Kirnlıulz.

ber ansgrewachsene Baum reigt nicht die Dimensionen, die man dou gunstigen Klima eutsprechend crwarten sollte; der Standort ist. freilich ein geringwerthiger, denn eine magere Humusschichte, die der lange, heise sommer anstrucknet, lagert auf dem greringen, sandigen Bodin, ler oft rein weiss, oft stark eisenschiissigr erscheint. Dieses bedingt, das die Waldungen dieser Kiefer von den Kiefernwaldungen der kuhleren \%ome wesentlich verschieden sind; selbst in grutem Urwalda, ans dem nur 17 chm Brettwatre pro ha grenommen werden, sthen die libume vielfach isolirt, mageres Gras und hräuter, oder \%workpalmon uld suäucher, selbst Halbbäume ron lïchen stehen zwiethen ihnen. jo mach dor ciïte des standortes.

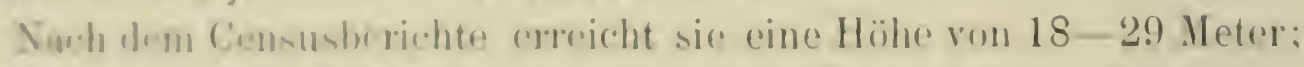
iolt whint mase mit Gh. Mohr \%usimmen ein Exemplar, das bei $80 \mathrm{~cm}$ Durchmener mille 33 Meter Hïlse anfwies.

Jus Halz diderr kirfor geht von Amerika aus in grosser Menge nach Europa und auch nach Deutschland, leider unter einem neuen, vechangniesvoll frowordenen Namin. Wïhrend Niemand in Amerika das Hola pliteh l'une hejest, homme us in Deutschland unter diesem

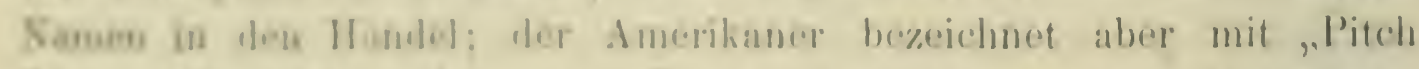
Tone eins ganz undere, sur Brounholagewinnung gaus braudhbare Kiefor, nambie of lio l'inu* ngida. lis wird wohl noch lingere \%eit

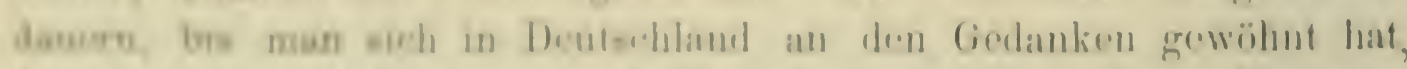

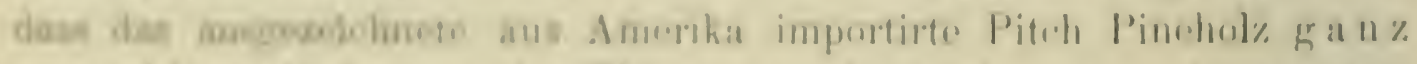

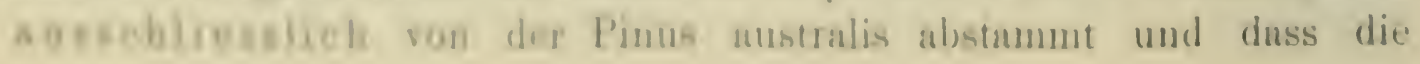


eigentliche Pitch Pine (Pinus rigida) eine für unser deutsches Binnenland wenigstens ganz werthlose Holzart ist.

Pinus cubensis Grieseb. (Pinus Elliottii vor der Feststellung ihrer Identität mit der Kiefer von Cuba), Slash-Pine, Cuba Pine, Cubakiefer, eine westindische Kiefer, die durch Florida und der Küste entlang bis New-Carolina, dem Golf entlang in einem schmalen Bande bis Louisiana nach Westen streicht.

Thre junge Pflanze steht an Schönheit der vorigen weit nach; die Nadeln sind durchschnittlich $23 \mathrm{~cm}$ an fruchttragenden Zweigen; der Quirl eines Kurztriebes besteht aus 3 Nadeln, seltener 2; der Zapfen auf einem $2 \mathrm{~cm}$ langen, gekrümmten Stiele, braun glänzend; Apophyse flach mit ganz kurzen, etwas erhaben sitzenden, geraden Spitzchen, 7-8 cm lang; grösste Breite, wenn offen, $6 \mathrm{~cm}$. Bezüglich des Samens gilt Tafel VII. Knospenschuppen braun, anliegend, stark mit Harz verklebt. Der Keimling trägt $6-7$ Cotyledonen. Die Raschwüchsigkeit dieser Kiefer ist in der That auffallend im Vergleiche zu der südlichen Kiefer. Ch. Mohr führte mich zu Gruppen von 28jährigen Bäumen, die bereits $30 \mathrm{~cm}$ Durchmesser und 16 Meter Höhe besassen. Der Splint umfasste volle $8 \mathrm{~cm}$ in Breite; das Holz, anatomisch der Section Taeda angehörig, ist dem der vorigen Kiefer gleich und ebenfalls durch das Ueberwiegen des harten Sommerholzes im Jahrringe ausgezeichnet; dem entsprechend ist das specifische Gewicht $=75^{*}$ ). Wo die Cuba-Kiefer mit der südlichen gemengt vorkommt, wie im nördlichen Florida, da werden beide von der: Sägemülle promiscue verarbeitet, ja oft rerwechselt. Diese und die rorige können in Europa wohl nur im Süden ihr Fortkommen finden. Junge Pflanzen, besonders bei dem frühen Erwachen ihrer Vegetation, werden leicht rom Froste getödtet, erwachsene Exemplare können ziemlich kräftigen Frost ertragen.

Pinus serotina Mich., Pond Pine steht bezüglich der Nadellänge mit $18 \mathrm{~cm}$ an erwachsenen Exemplaren an dritter Stelle; Knospenschuppen hellbraun, fest anliegend und mit Harz verklebt. Zapfen durchschnittlich $5,5 \mathrm{~cm}$ lang und geschlossen $4 \mathrm{~cm}$ breit. Der erwachsene Baum ist dicht beladen mit Zapfen der rorhergehenden Jahre, von denen die frischen durch ilıre fahl-gelbe Färbung hervortreten. Die an Rändern feuchter Partien, aber nirgends häufig auftretende Art erwächst

*) Wo nicht ausdrücklich anders bemerkt ist, sind alle Zahlen über specifisches Gewicht, Höhe, Durchmesser etc. dem erwähnten Reporte von Ch. Sargent entnommen. 
bis zu 24 Wetry Hëhe: ihr Hol\% das den Typus aller Kiefern der südlieben Rezion be-izt. hat bei sehr breiten sommotolzschichten das -precitioche diendeht wo 79 . Lis findet wohl nur eine gelegentliche Verwendung.

Pinus Taeda 1... L,ublolly-Pine, Old-field-Pine, Tata. Das Optimalgebiet diener livere liegt in dem suidlichen Theile des wintakahlen Laubwaldes; in die Region der Wintergriunen greift sie cbenfalls uber; sie zeigt grossis Anpissungsrermügen an heterogene Standortit; sie liobt das trocliene, sandigne Gebiet, Hoch-Platean, die Hügulnegion, welche gegenwärtig nuch vielfach die südliche Kiefer in Braitz hält: dort, wie schon erwähnt, breitet sich die Taeda immer muehtiger ans: se rewähst zu don stärliston Exemplaren auf feuchtem, sandigun Lehmbeden.

Sie bildet Bestiande und da die \%erstörung der südlichen Kiefer wohl whe Aufenthalt fortgehen wird, bis sie zum Nutzbaume untergoordneten Ranges horab gesunken scin wird, so dürften diese Kiefer und di Pinus nutis nehon der P'inus cubensis zu den wichtigsten Nuthhüumm der süllichen Kiefernzone heranwachsen. Einstweilen ist ihr Nuthulz, da besoces zu haben ist, als ,geringe Qualität" bezeichnet.

Horen Samen Old-fiedd-Pine verdient sie mit Recht; sie über\%icht nach rerunkrautete, verlassene Folder mit einer dicht anfsprosisenden, machw üchsigen .Jureiend. I)ie Kinuspen (ler Taeda mit anliegenden Schuppen sind mit Harz verklebt; der junge Trieb glatt, hellbraun, Nadeln an uften Exomplaren duredschnittlich $20 \mathrm{~cm}$ lang, drei in einem Kurztriebquirl. Die Zapfen sitzen in der Mitte des Tricbes $2-5$ zusammen, suellos, so dass sie fast scukrecht rom Tricbe abstehen. Der reife \%afen int hell wekcrfarbig, $9 \mathrm{~cm}$ lang und, wenn offen, bis $5 \frac{1}{2} \mathrm{~cm}$ hreit. Apophyse mit scharfer Spitze, welche mit dicker Basis aufsityt und etwa nuch uben gerichtet ist. Samen sieho Tafel VII. Die Rinde, aufums kJeinschuppig, grau bis zum Gipfeltrieb, später in breiten, denatn Borkenplutten; das breitringige Holz zeigt einen $4 \mathrm{~cm}$ breiten

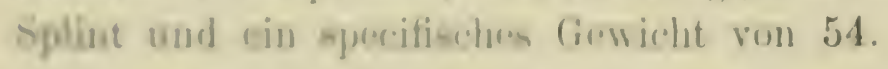

The folgedon drei kireforn hidden nach ihrem anatomischen and moxplonlogierh"n Anflom in. (iruppe.

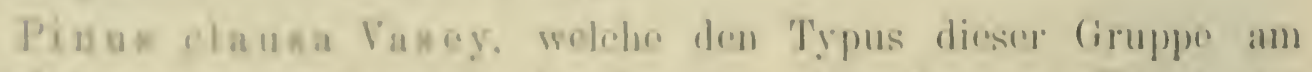

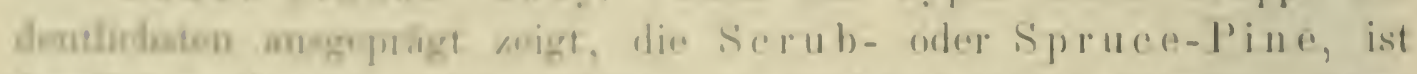

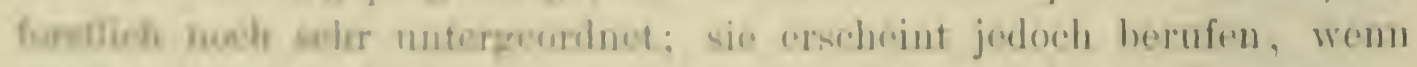

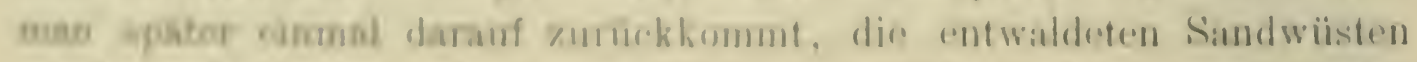

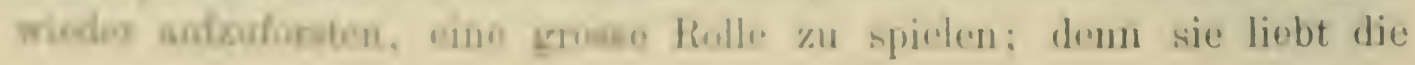


trockenen, sandigen Lagen, die Dünenzüge, wo sie sich durch Raschwüchsigkeit besonders auszeichnet. Aufbau der einjährigen Triebe und Stellung der Seitenäste und Zapfen sind wie bei den dreinadeligen Kiefern; ebenso folgt das Holz dem Typus dieser Kiefern, dagegen stehen im Kurztriebe nur zwei zarte, $7 \mathrm{~cm}$ lange Nadeln. Die junge Rinde ist glatt wie ron der Pinus Strobus, später mit kleinen quadratischen Schuppen bedeckt. Der sparrig gewachsene astreiche Stamm erhebt sich zuweilen bis zu 24 Meter Höhe. Der Zapfen ist $6 \mathrm{~cm}$ lang, fast $3 \mathrm{~cm}$ dick, wemn geschlossen. Sie verdient den ihr von G. Vasey in Washington gegebenen Namen clausa mit Recht, denn der Zapfen bleibt am Stamme mehrere Jahre völlig geschlossen, stiellos; Apophyse endigt in ein kurzes, auf einem Kissen sitzendes, gerades Spitzchen. Same Tafel VIII. Der Keimling trägt 7 Cotyledonen, die jüngsten Triebe sind zart, weisslich bereift wie bei P. inops und mitis. Männliche Blüthenknospe hellbraun glänzend, den Winter über auf einer nadellosen Stelle des Triebes sitzend, so dass sie "gestielt" erscheint. Das Holz mit einem specifischen Gewichte ron 56 findet bis jetzt noch keine Terwendung.

Pinus glabra Walt., Spruce Pine. Zur Ergänzung der über diese Holzart schon früher gemachten Angaben bemerke ich, dass ihr Optimum am Nordrande der subtropischen Zone, in den aus winterkahlen und wintergrünen Bäumen gemischten Waldungen des Mississippi-Beckens auf feuchten, sandigen Standorten liegt, da wo das Terrain sich etwas über dem Taxodium-Sumpf erhebt. Sie bildet nie reine Wälder; stets erscheint sie einzeln in den Laubwaldungen, bereit, sobald jene gefällt werden, ihren Platz einzunehmen. Erwachsen ist ibre Rinde eine kleinschuppige Borke, etwas der Eiche ähnlich, der Stamm wird gerade, mit zahlreichen, rechtwinkelig abstehenden Aesten. Ihre Nadeln, zwei in einem Kurztriebe, sind zart, durchschnittlich $7 \mathrm{~cm}$ lang und ebenfalls in einem rechten Winkel rom Triebe abstehend. Knospen schmal (1,5 mm), aber lang, Knospenschuppen anliegend, mit braun glänzender Spitze; junge Triebe an ihrem zartesten Theile weisslich. Zapfen $4 \mathrm{~cm}$ lang und $3 \mathrm{~cm}$ breit, wenn offen; Apophyse mit sehr kleinen, geraden Spitzchen. Same Tafel VIII. Der Baum erreicht in seinem Optimum nach meinen Messungen 35 Meter Höhe bei einem Meter Durchmesser; die junge Pflanze hat lange Zeit im Halbschatten der Laubhölzer zu kämpfen, bis sie deren Krone durchwächst. Das bis jetzt noch werthlose Holz hat einen sehr breiten Splint von einem specifischen Gewichte ron 39, das Kernholz wurde noch niclıt untersucht. 
Die letzte. dem südlichen Kieferngürtel beizuzählende KKiefer ist Pinus mitis Michx., Short-leared Pine, Spruce Pine. Sie geht an weitesten nach Norden. Unter den Lauhholzwaldungen in der Nahe ron Washington. die alljährlich immer woiter von der Stadt zurupgedrangt wodron. fand ioh sie noch in srö̈sseren Exemplaren mit Pinus rigida und inns zusimmen anf trockener. kiesiger, hoher Lage, mitten unter den Eichen und Hickorys. wiblend sic anf dem mugren. fas reinen simblbuden ron New-dersey mit Pinus rigida zuammen lichte Briände bildet. Woheri Pinus rigida rorherrscht. Ceberall wo siudiger oder hiesiger Boden im Gebirge wie in der Ebene auftritt. stellt sich dieser Baum ein ron Now-York südlich und westlich dureh das Corbiet des crossen Laubwaldes: sie ist in erster Linie der Baum. der den Buten der Laubhölzer nach ihrer Misshandlung an sich reist. Man kann nicht sagen, dass diese Kiefer ein schlechter Baum nei: ihr Holz ist immer noch besser als das der Pitch Pine (Pinus rigida). mit der sie iibrigens grosse Achnlichkeit in Habitus und Biolngie heitat. Im Sïden nimmt sio den Platz der misshandelten südlichen Kiefor in Bexit\%. C. Mohr bezeichnet sie als die wichtigste Kiefer in den Waldungen. welche für die kommenden Geschlechter anfwachsen werden - rin magerer Bissen im Vergleiche zu dem leckeren Mahle, son dom die Voreltern ein Fünftel verzehrten und vier Fünftel vergendeten.

Das Optimum diesêr Kiefer liegt in den westlichen Stanten Arkansas, Kansas und Missouri, wo sie in grossen Waldungen bis \%u niner Hohe ron 30 Meter sich erhebt. Ihr Standort ist der kiesigrsandige Boden dea Hügellaudes. den auch die Halbbäume unter den

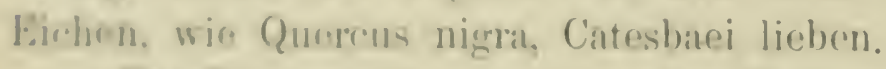

Die l'inus mitis vermittelt den Uebregang von den zwei- \%u den demandeligun Kivefern, ihe Aufbau und Mabitus ist der einer dreinadeligen,

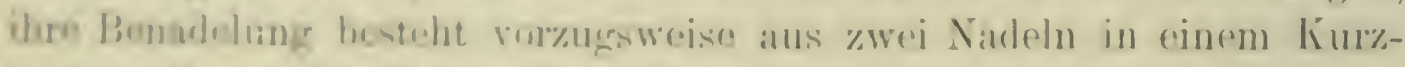

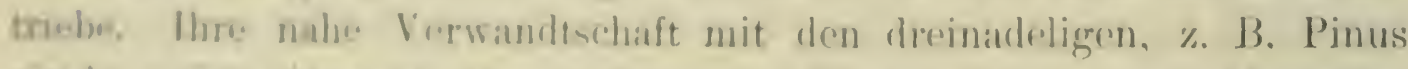

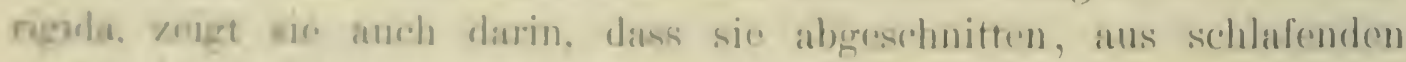
Augen on wer Nahe der Sidmittstolle Ausschlägre zu entwickeln vermag;

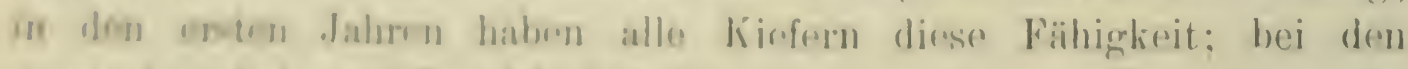

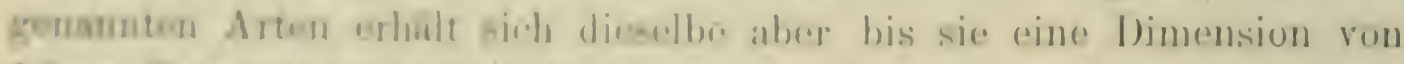

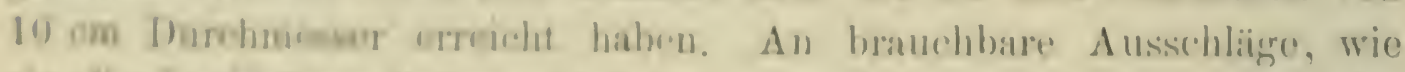
the die lanbholzer lirforn, darf man aber dabei nicht denken and die

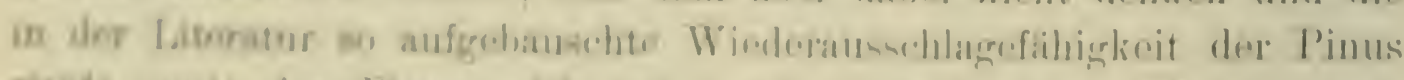

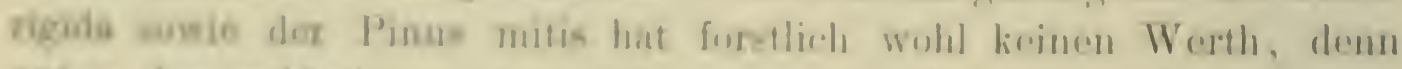

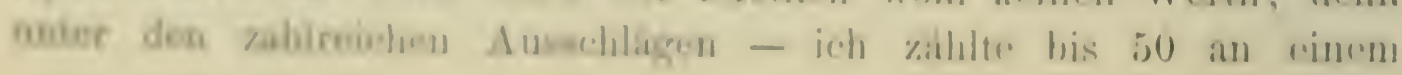


Stocke der mitis - übernehmen schon im nächsten Jahre ein oder zwei die Führung, welche zu Gipfeln heranwachsen, während die übrigen rasch zu Grunde gehen. Den erwachsenen Baum charakterisirt eine breitborkige Rinde, die zahlreiche Harzbeulen in sich schliesst, ein Merkmal, an dem dieser Baum von der Pinus rigida jeder Zeit leicht unterschieden werden kann; der Stamm erwächst gerade, astrein; bei späterer Freistellung oder auf schlechterem Boden mit geringem Wachsthume sieht man zahlreiche Kurztriebe (Klebäste) an den Ansatzstellen der Aeste.

Die junge mitis-Pflanze ist von der ihr ähnlichen rigida leicht zu unterscheiden durch den weisslichen Reif an den neuen Trieben, durch die etwas am Triebe anliegenden, kürzeren Nadeln (durchweg $8 \mathrm{~cm}$ lang), sie stehen zu zwei am unteren, zu drei am oberen Theile des Triebes; Zweige älterer Bäıme tragen immer zwei Nadeln zusammen. Das Holz zeigt den Typus der dreinadeligen Kiefern. Der Baum gehört zur Section „Banksia.“ Der Zapfen der Pinus mitis hat dieselbe Grösse wie jener der Pinus glabra, $4 \mathrm{~cm}$ lang, $3 \mathrm{~cm}$ breit, wenn offen mit etwas längerem auf einem Kissen sitzenden Spitzchen an der Apophyse. Bezüglich des Samens gilt Tafel VIII. Das Holz dieser Kiefer ist mit einem durchschnittlichen specifischen Gewichte von 61 in den oben genannten Staaten sehr werthvoll, vorzugsweise, weil wohl keine anderen Kiefernhölzer dort vorhanden sind.

An den Zweigen ron Pinus mitis fand ich besonders bei Marion bis faustgrosse Beulen, die lebhaft an die sehr häufigen Beulen an japanischen Kiefern erinnerten. Eine Untersuchung ergab, dass diese Beulen durch die Wucherung eines Mycels rerursacht werden; dieses Pilzmycel erwies sich einem Aecidium angehörig, welches, bis der Zusammenhang mit der zugehörigen Winterform gefunden, den Namen Aecidium deformans n. n. tragen mag. Die Aehnlichkeit der Anschwellungen mit jenen an den japanischen Kiefern ist bemerkenswerth; aber während der Pilz an der Pinus mitis selten zu sein scheint, sind Anschwellungen an den japanischen Kiefern ïberaus häufig, fast kein Baum ist frei davon.

Im April 1885 fand ich auf meinen Reisen im Innern des Reiches den Pilz in vollster Blüthe an zahlreichen jungen Rothkiefern (Pinus densiflora), die Beulen ron der Grösse einer Haselnuss bis zu der eines Kopfes; ja bis $1 / 2$ Meter im Durchmesser messende Kröpfe an den Stämmen der Rothkiefer und der Schwarzkiefer (Pinus Thumbergii) waren ïbersäet mit den goldgelben Blasen des fructificirenden Pilzes. Die biologischen Unterschiede berechtigen, da die Sporen ron denen 
anderer Aecidium-Arten mikroskopisch kaum verschieden sind, anch dusen einstweilen \%u henennen, zu welchem Zweeke der Name Aceidium giganteum n. n. gelten mar.

Taxodium distichum Rich. Bald Cypless. Sumpfcypresse. Je rascher die Vorrithe ron werthollen Kiefernhölzern im silden und Norden dahinschwinden, desto mohr greift der Nutzholzkonsum zu jenen gewaltigen Reserven, die ein Uebermass von Feuchtigkeit bisher ror Fonce mul Axt bewahrt hat; allerdings stürzt man

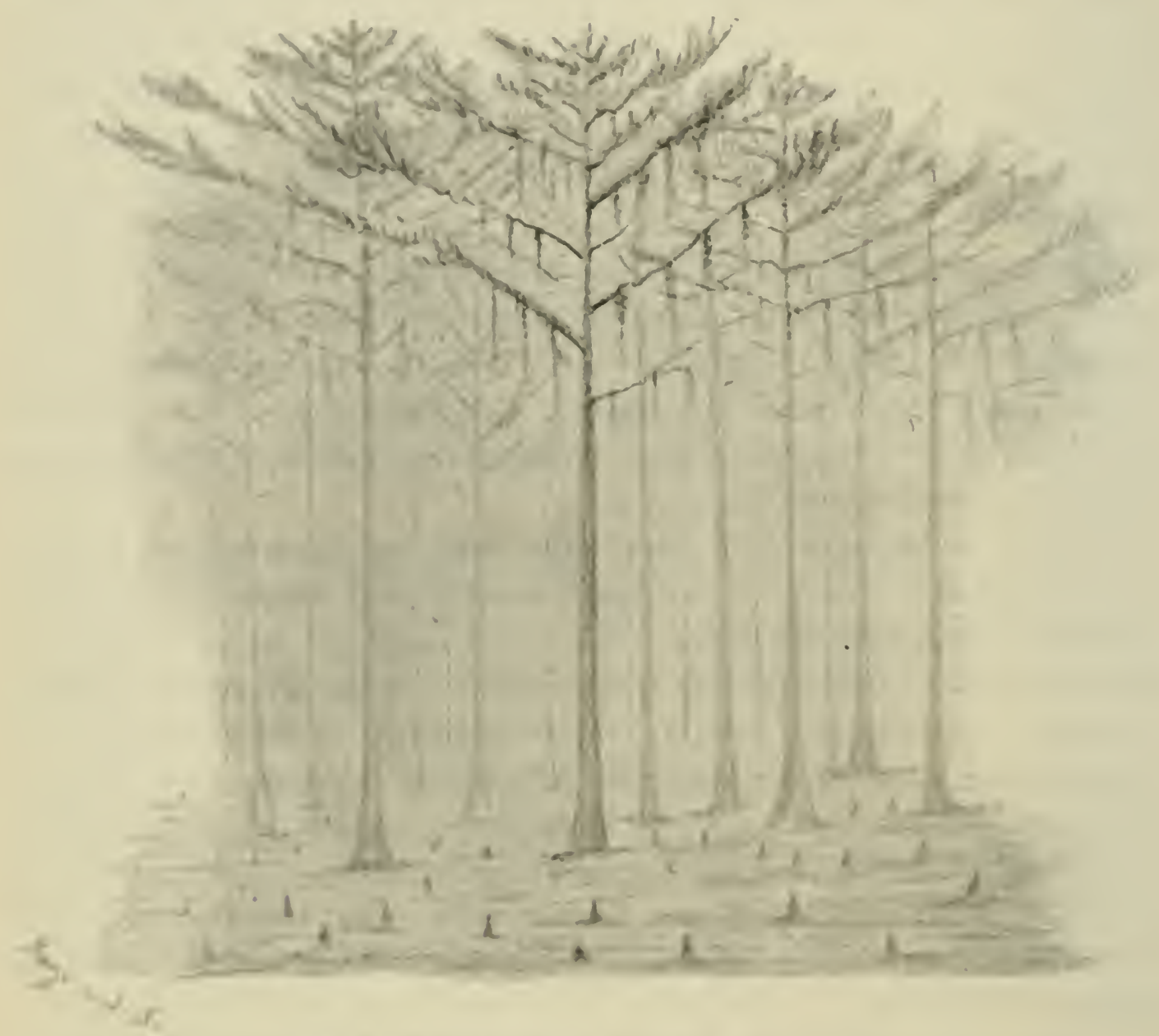

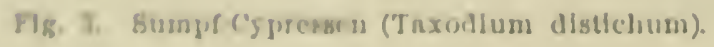

sind ant die Waldungen dor Sumplefypresse: ju an riolen Orten ist

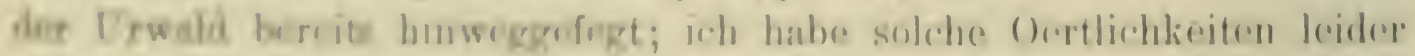

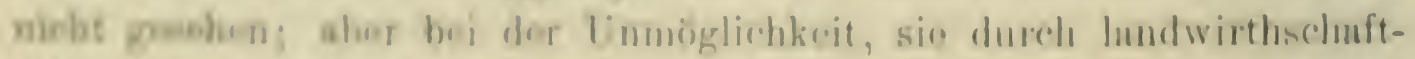

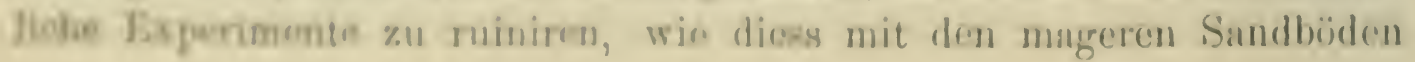


geschieht, scheint es mir wahrscheinlich, dass auf solchen kahlen Sümpfen rasch wieder die Sumpf-Cypresse nachwachsen wird.

Ein unberührter Hain voll uralten Sumpf-Cypressen überwältigt durch seine Eigenartigkeit und Grösse; die Bäume passen nicht zu der Umgebung, zu den gegenwärtigen Holzarten, am wenigsten zu den Laubhölzern über die sie hoch emporragen; man empfängt denselben Eindruck, den man empfindet, wenn man plötzlich den 60-70 Meter hohen Tammen und Kiefern, den 100 Meter hohen Kolossen der Sequoia gigantea in der Sierra Nevada gegenüber steht. Ihr ganzer Habitus harmonirt nicht mit der gegenwärtigen Flora, in Vergleich zu der sie in der That als Ueberrest einer in früheren Erdperioden allein herrschenden Nadelholzflora erscheint. Sie verräth wie Sequoia, Cryptomeria, Glyptostrobus, Gingkyo, Cunninghamia ihren vorweltlichen Charakter auch dadurch, dass sie als Baum abgeschnitten, zahlreiche Stockausschläge entwickelt; Gingkyo treibt sogar echte Wurzelausschläge und Cryptomeria wird in Japan zuweilen als Niederwald mit 25 jährigem Turnus behandelt.

Viele dieser Taxodium-Sümpfe sind nur mit Kähnen zugänglich, andere können nach längerer Trockenzeit mit Gefahr mehrmaligen Einsinkens in den morastigen Boden betreten werden. Die Eigenartigkeit des Urwaldbildes erhält ihr besonderes Gepräge durch die dicke flaschenförmig angeschwollene Basis der jüngeren Stämme, umgeben ron zahllosen, den Wurzeln entspringenden spitzen Auswüchsen (Wurzelknieen) durch die Geradschaftigkeit und Astreinheit der Stämme, ihre lange seicht-rissige, etwas röthlich-braune Borke, ihre flache, schirmförmige, im Herbste braunrothe Krone, von der in vielen Gegenden die graue Tillandsia herabhängt. Die Cypresse ist im Winter kahl durch den Abfall der Seitentriebe (Kurztriebe) mit kammförmig gestellten Nadeln, während die Längstriebe mit wechselständigen Nadeln nur die letzteren abstossen.

Auf den erwähnten Standorten herrscht die Cypresse nicht nur innerhalb des Kieferngürtels, so wie südlich bis zur tropischen Zone, sondern sie umfasst auch die ganze südliche Hälfte des winterkahlen Laubholzes; westlich rom Mississippi, wo bereits Präriepartion zwischen die Kiefern und Laubholzwaldungen sich drängen, da taucht oft mitten in der Prärie eine prächtige Gruppe oder ein ganzer Wald ron SumpfCypressen auf, je nach der Ausdehnung der Sümpfe oder Flussränder. Erst bei Ueberschreitung des $95^{\circ}$ W.L. begegnet man ihr nicht mehr.

Blüthe, Zapfen und Same sind genügend bekannt; in der Schale des flügellosen Samen fand ich eine kleine Cynips-Art(?), welche hirse- 
Lorngrowe (iallen arzugte. wodureh die samenbildung unterblicb): ron

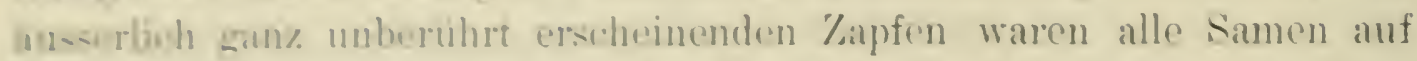

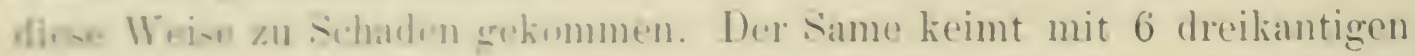

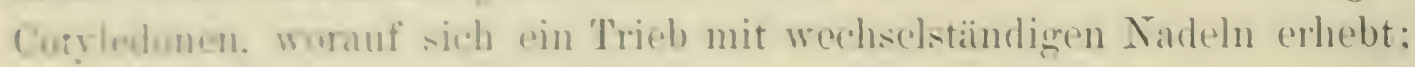
in den Winkeln der uberen Xiuleln entspriessen Seitenaiste (Kurytriebe) nui den Sadran in zwei \%oilen, welche kumen Triebe im Herbste abfallon. Dat Wandhothum ist whon im crsten Jahre sehr rasch.

Lie l'thanze ist in der ersten Jugend empfindlich gegen Frost, sputer abeg ist sie härtel als man ihrem siullichen Standorte nach erwarten sollte. Auf ihrer nördlichen (irenze in Virginia hatte sie im Jahre 1884 volle - $19^{\circ}$ C. $\%$ bestehen, ein Umstand, der es erklärt, warum sie allerorts in warmm Lagen in Deutschland \%. B. noch in Hambure selur sut im freien aushailt und $\%$ cinem stattlichen Baume heranwathot.

Lie weiche Borke bedeckt einen $4 \mathrm{~cm}$ breiten Splint und ein schmutzig-hranne liemhol\% ron grosiser Gïite: mit einem specifischen Ciewiche son tj ist das Holz ausserordentlich dauerhaft, selbst unter den ungunstirsten Verhiiltnissen rerwendet. Dieser Lmstand sowie die germaltigr. Jimension die der Baum erreicht, bis 46 Meter Höhe, erheben die sumpif-Cypresse zu einem Nutzbaume ersten Ranges.

\section{c) Der winterkahle Laubwald der gemässigt-warmen Region.}

IFohl an Artenreichthum nicht aber an Ausdehnung und Vollkommenhrit hat dieser latubwald seines diloichen in der gemaissigten Reginn der mordlichen Homisphäre. Wo dio Burlenbeschaffenheit einigermusen ginstip ist, treten (iruppen oder auch \%usammenliangende

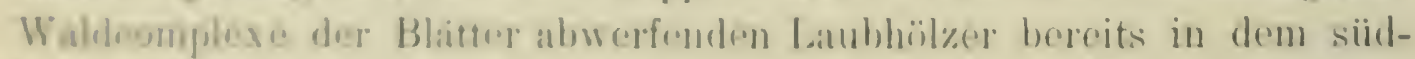
lirben hivforngiertel auf; ron da an erstreckt sich der laubwald durch

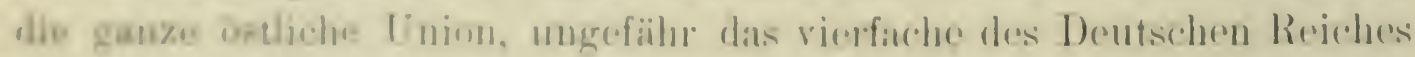

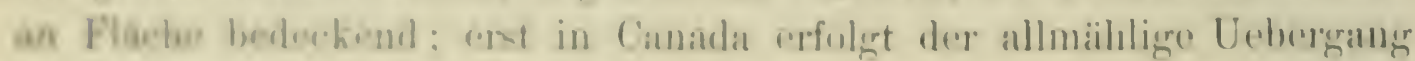

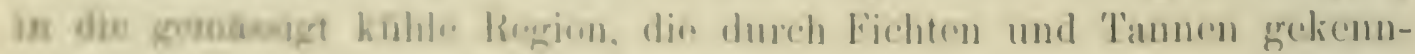

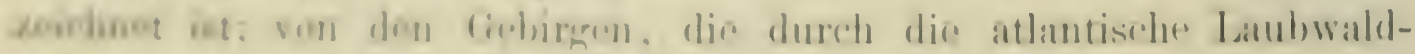

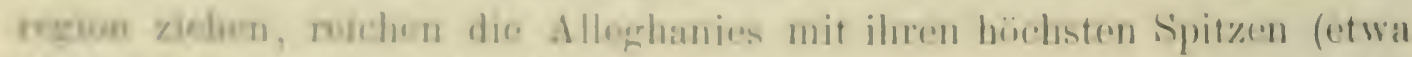

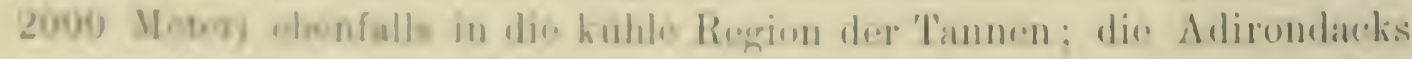
on ater Senderenze der Unon tragen den Laubwald his zu riner Er-

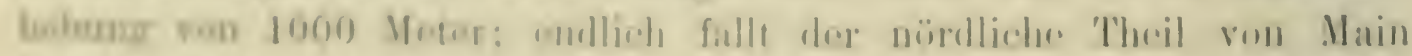

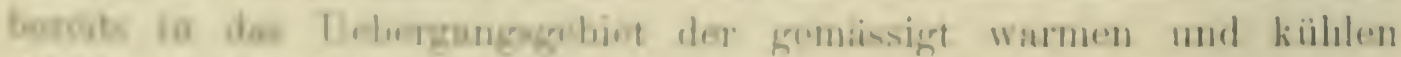

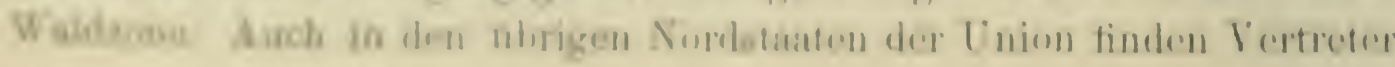


der Tannen-Region bereits Standorte, die für das Wachsthum der nördlichen Nadelhölzer geeignet erscheinen; so z. B. vermögen die nordischen Fichten, die Lärche, die Balsamtanne, die in Canada zu Bäumen erster Grösse werden, in den nördlichen Staaten im Laubholzgebiete noch auf den nasskalten Sümpfen zu leidlichen Nutzhölzern heranzuwachsen.

Bemerkenswerth ist, dass im Norden, auf der Grenze des Laubund Tannenwaldes, wie im Süden zwischen der gemässigt warmen und. subtropischen Zone sich ebenfalls ein breiter Gürtel von Kiefern einschiebt, der auf sandreichen Böden wurzelt. Mit seiner südlichen Hälfte zum Laubwalde, mit seiner nördlichen zum Tannenwalde gehörend, fusst er besonders in der Umgebung der grossen See'n sowie auf deren ehemaligẹ Verbindung mit dem Meere, dem LaurentiusFlusse entlang.

An der Küste des atlantischen Oceans herrscht ebenfalls vielfach sandiger Boden vor, dort finden sich wiederum Kiefern wie in den Bergen auf den trockenen, kiesig-sandigen Bodenausformungen. Dort sind sie einzeln oder gruppenweise dem Laubwalde beigemischt, stets bereit bei Misshandlung desselben seinen Platz einzunehmen.

Ton dieser einst lückenlosen Waldmasse ist heute schon das Meiste und bald auch das Beste dahingeschwunden; einige Staaten haben nur mehr $1 / 5$ ihres Gebietes mit Wald bedeckt, in anderen ist das Procentverhältniss in Folge der Parcellirung des Waldes kaum möglich oder die Angaben sind so bedenklichen Ursprunges, dass man ihnen keinen Werth beilegen darf; und das, was in früh besiedelten Staaten noch rom Walde übrig geblieben ist, macht wohl von Ferne den Eindruck eines Waldes, aber bei der Annäherung erkennt man eine durchlöcherte Ansammlung ron theils gering werthigen, weichen, theils ïbrig gebliebenen, ästigen, verstümmelten, harten Laubhölzern; Hunderte von Quadratmeilen, einstmals mit Wald bedeckt, sind zu verunkrauteten Viehweiden herabgemagert. Die Ebene, das Hügelland, ja selbst der hohe und steile Berg stehen der Ansiedelung, der Ausrodung offen. Die meisten Emigranten sind arm; für Viele, welche Farmer werden wollen, reicht ihr Schärflein gerade hin zum Ankaufe des billigsten Landes, nämlich einer „unverbesserten“, das ist bewaldeten Section in den Bergen; dort beginnen sie ihre Arbeit, sengen und brennen ohne Verständniss des Landes, des Klima's; alles wird kahl abgerodet, der Boden mit Getreide besät; ein paar Ernten gelingen, ein paar misslingen, da verliert man den Muth, verlässt Alles, Haus und Farm und sucht eine neue „neue Heimat." So hat man es glücklich 
ferrig gebracht, dase in den Adirondacks ganze Züge von Bergen und Huchplatesuis verbesiert, das hejsst verödet wurden: Kohlensäulen

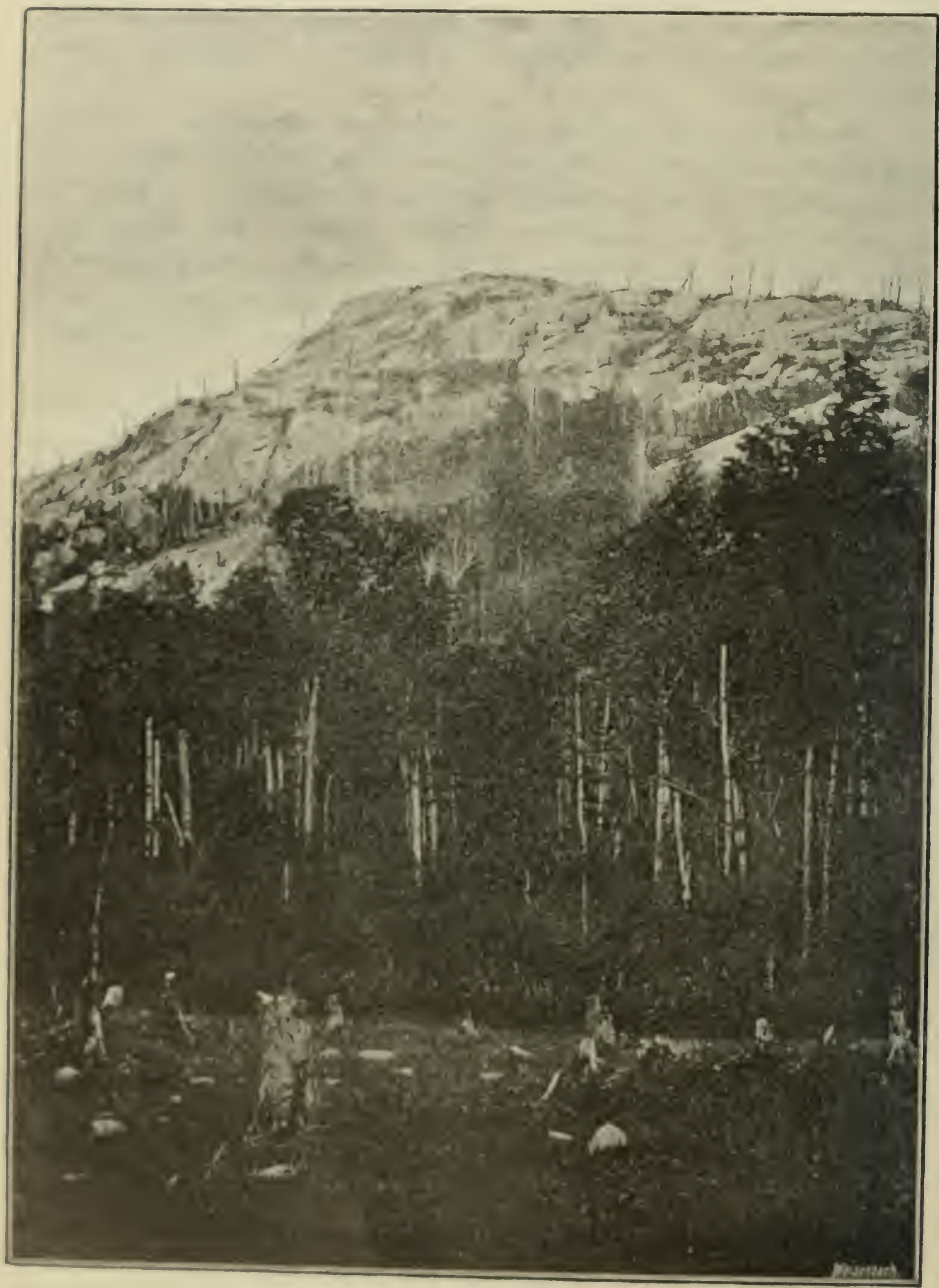


erinnern an den einstigen Laubwald, mageres Gras zwischen den nackten Steinen an die einstige Bodenkrume.

In den Alleghanies ist der Boden besser und die Natur energischer; über missglückten landwirthschaftlichen Experimenten wächst recht bald das Gras oder Staudenwerk, der Vorläufer des Waldes, wenn keine Feuer dazwischentreten. Leider hat auch hier die Regierung nicht von Anfang

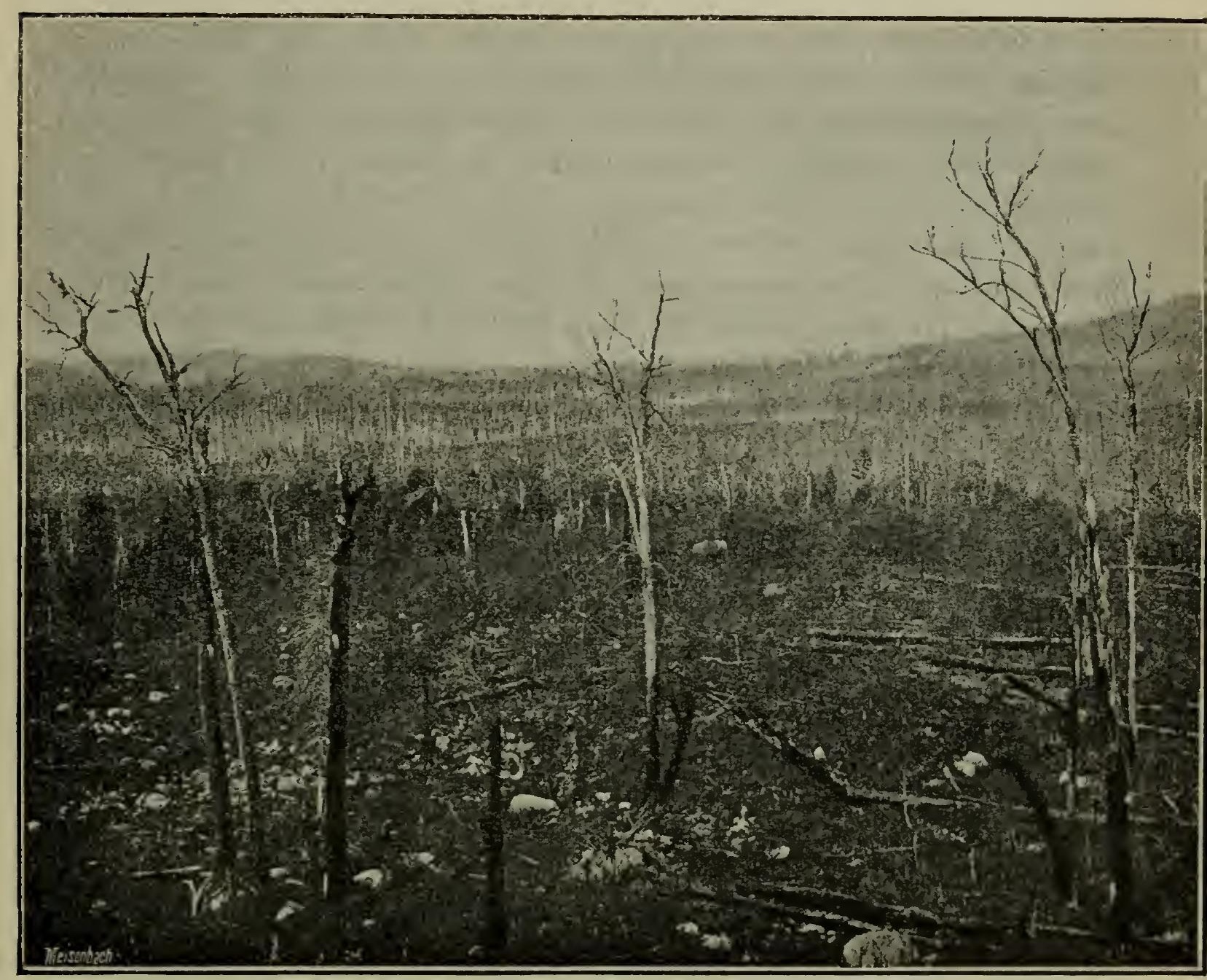

Durch Feuer verwüstete Waldungen in den Adirondacks. - (Nach Sargent.)

an die Berghänge von einer gewissen Neigung an von der landwirth-stey schaftlichen Benutzung und der Besiedelung überhaupt ausgeschlossen; shome zahlreiche Landabrutschungen und recente Auswaschungen wären verhindert, manche ron den fürchterlichen Ueberschwemmungen des Ohio, Mississippi, des Savannha, Chattahoochee wenigstens gemildert 
and dis fruchtbaren Thiler frïher und dauernd in Kultur genommen worlen.

Win der Mensh und mit ihm Ant und feuce noch gar nicht nder nur wenig hingremomen sind. entfaltet sich der buntgemischte

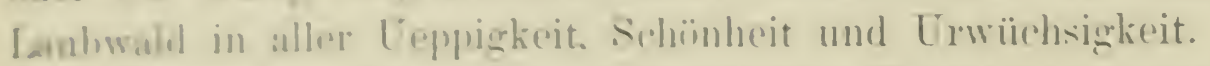

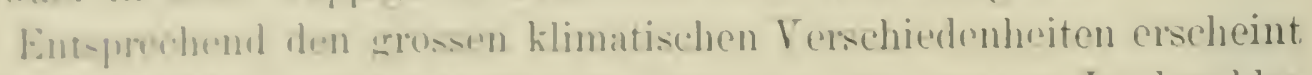
for dir Betrantumer eine abmermalige 'Tremmung des ganzen Laubwaldes nurh klinen (iebieten wiun-henswerth. Dieso Versehiedenheiten beruhen rut Allem darin, dasi vin sïden, ron dem Golfe ron Mexico, ein warmer. feuchter Luftotrum in das Land tritt, der ein Klima bedingt, dem gersentiber jumes der atlantischen Küiste wegren des kalten fregenstrom kuhler ersheint: äberliess grengt der Westen an die baumlose, trockene strppe, dir Prïrie, während der Norden wiederum feucht und talt i-t: jedus dimer liobirte ist das Optimum für gewisse Holzarten. Thailt man don atlumtisehen Linubwald dem anteprechend in eine sï dfi.he Halfte (s.). Welche his zum $39^{\circ} \mathrm{N}$. B. reicht, und in eine norllirhe (X.), sowio jeden Quergürtel wiederum in drei MeridionalYonen, nämlich eine atlantische im engeren Sinne (a.), eine contincutale (c.) und eine priiriale \%one (p.), so erhält

dice continontale \%one der siidliohen Hälfte (S. e.), das Jasimum an Wirme und Fenchtigkeit, welche der warme, feuchte sindwind in rinm hroiten Strome ungehindert durch das Thal des Mismimpi in die Gebiete der 'lributiorlliisse desselben bringt. Inshesondar andlich und westlich der Allechanies, bei scinem Aufstioge an den la recon lagert ar grosise Mengen von Fenchtigkeit ab: während

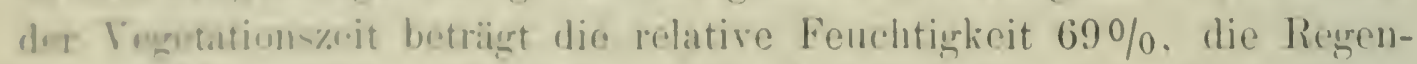
menge $800 \mathrm{~mm}$, die mittler. Tremperatur $24^{\circ} \mathrm{C}$; wihhrend dee VecetationsThler in the Temprematur $7^{0} \mathrm{C}$. : sie fällt bis $-15^{\circ} \mathrm{C}$. fast jeden Winter; die enstrn lirime exchoinm im Normber, die letzten im Mäi\%.

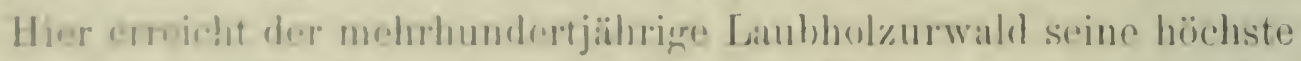
Voldkonmenlu it: fur die meisten und beston Holzarten liegrt hior das

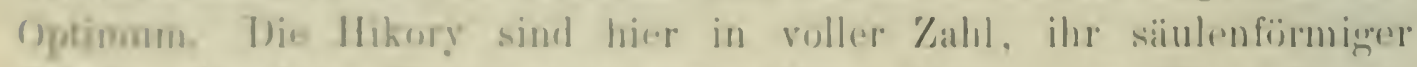

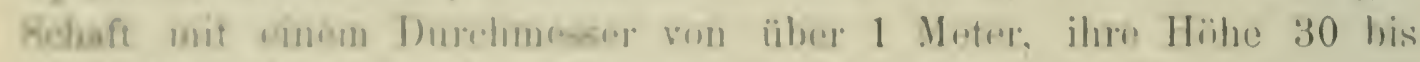

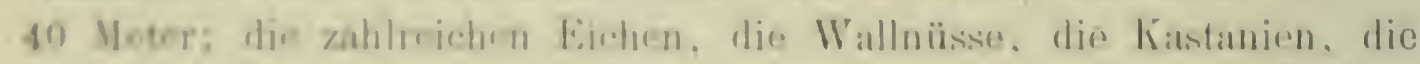

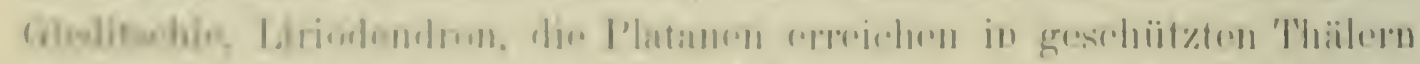
Demeneionem, die man, win jon. dur Ifammuthbïume der Sierra Nerada,

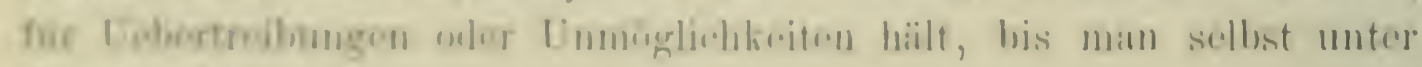
tousu weehs.

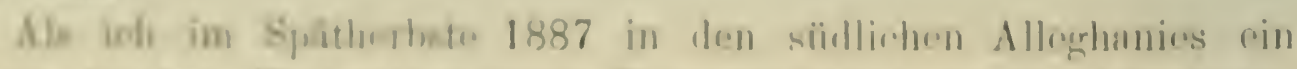

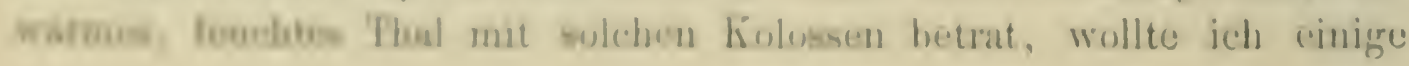


Aufnahmen ïber Holzvorrath und dergleichen anstellen; allein ich musste davon abstehen; in solchem Urwalde ist ohne vielköpfige Arbeitermannschaft nichts zu erreichen. Der Boden, uneben durch die gefallenen Bäume, durch Baumstümpfe und Wurzeln, mit Stauden und Halbbäumen aller Art bedeckt, hemmt jeden Versuch, mit dem Nessbande vorwärts zu kommen; man kann nur staunen und allenfalls noch schätzen, welcher Vorrath auf einem ha wohl beisammen stehen könnte; aber messen oder gar Probestämme fällen, sind fast ein Ding der Unmöglichkeit.

Die Tegetationszeit beginnt hier znerst und schliesst am spätesten ab; wenn im Norden die Früchte und Blätter längst zu Boden gefallen sind, kann man hier beide noch von den Bäumen pflücken; an Liriodendron, den wir auf unseren Touren durch die Alleghanies nach Süden hin in Virginia mit leeren Kapseln fanden, kounten wir in Nord-Carolina noch einige Samen den Kapseln entnehmen, welche in Süd-Carolina endlich noch ganz geschlossen und eben reif waren; dazu kommen noch einige Wochen Zeitdifferenz in der Beobachtung.

Stirbt in diesem Urwalde so ein Riese ab, nachdem Jahrzehnte lang die Pilze sein Inneres durchbohrt und endlich in eine mürbe Masse umgewandelt haben, so bröckeln zuerst die dürren Aeste ab, dem auf Licht wartenden Nachwuchse allmählig Gelegenheit zur Erstarkung gebend; endlich brechen auch die starken Aeste, der Gipfel und nachdem der Baum Jahre lang dem Wetter getrotzt, bedeckt mit den Pilz-Früchten rerschiedener Polyporeen, stürzt er zu Boden, mit seiner vermoderten Substanz das Nähr-Kapital des Bodens bereichernd; bald ist die Lücke von der aufwachsenden Jugend wieder geschlossen. Unter die guten Holzarten, die sich so langsam emporkämpfen, mischen sich zahlreiche Sträucher und Halbbäume der Gattungen Crataegus, Prunus, Rhus, Evonymus, Corylus, Hamamelis und viele andere; anch stets grüne, wie Andromeda, Kalmia, Vaccinium, Rhododendron bedecken schützend den Boden; sie nehmen nach Norden hin an Zahl und Grösse allmählig ab. Vitis rankt sich guirlandenförmig an den Aesten und Sträuchern empor; an den Baumrinden festgeklammert steigt der giftige Sumach, der im Herbste so prächtige wilde Wein (Ampelopsis) oder der Epheu in die Höhe, dem Lichte entgegen.

Dieser Wald, die Perle aller blätterabwerfenden Waldungen, verschwindet natürlich zuerst entlang den grossen schiffbaren Flüssen; die Ufer des Mississippi sind auf Meilen in das Land hinein baumlos; was von der Ferne wie Wald erscheint ist ziemlich werthloses Gestrüppe von Pappeln und Weiden; nur vereinzelnt haben sich ein paar Ulmen, Hickory, Platanen oder Gleditschien erhalten; mächtig aber haben sich 
hohe Gröiser und Schilfe ausgebreitet. Zur Zeit dor Schneeschmel\%e oder nach heftigem Regen im Bimenlande ist der Strom für Sichiffe geradez gefïhrlich, eine solche Menge ron Baumstimmen treiben in dem dicken gelbbramen Wasser. Wo der Fluss sich staut oder rasch \%ur Seite biegrt. hïufen sich die Staimme und thürmen sich ïbereinander, cin unentwirbares, greradezu werthloses Chass, an dem die Pilze ihre Freude haben. Unter ihnen fand ich einen alten Bekmuten wieder, den Coprinus Mayri Allesch.*), desisen Mycel aus dem zersetzten Holze durch die Rinde hervorwiachst und dieselbe mit cincm rost-grelhen, dickwolligen Polster über\%icht. In diesem Gebiete unter dem $33-36^{\circ} \mathrm{N}$. B. findet man ron den 23 baumartigen Eiehen des Laubwaldes fast die volle Zahl, vertheilt nach ihren specifischen Standorten und in bestimmten Elevationen: 13 ron diesen haben hier zugleich ihr Optimum: alle 8 Hickory, die beiden Wallnüsse, die Kastanien, mit einem Worte, die schwersamigen Laublübzer erreichen in der südlichen Hailfte ihre Vollendung. Hier wïchst das sehwerste Hol\%, das blatterabworfende Laubbiume produciren, im allgemeinen sowic für die einzonen Gattungen, ja selbst Arten; ron hier nach Nord hin nimmt für die schwerfiüchtigen Holzarten form und Güte, insbesonders Schwere des Holzes ständig ab. Zur Beurtheilung der klimatisehen Ansprüche der untlirhen Laublü̈zer ist der Aufstieg anf cinen hohen Berer, \%. B. dro Buan Mountain, cinen der hächsten Berge der Alleghanies, sehr lelureich.

Bis etwa 1000 Meter strigt in den warmen, fenchten Thälern die bureits orwahutr. Laubholzflorat empor: nur die Bewohner der Niederungen,

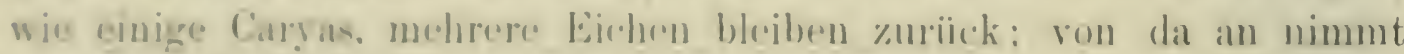
dor \%ahl und bimension der Holzarten merklich ab, bis zon ciner Höhe von ctwa 1500 Mreter: man kann dieses Gebiet klimatisch mit den warmsen Jogen in Deutechland repgleichen, mit seinen filussniederungen

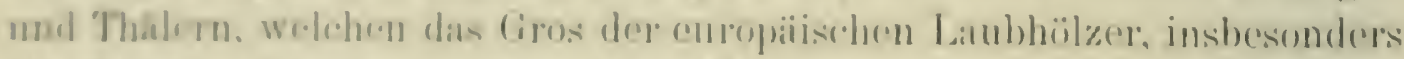

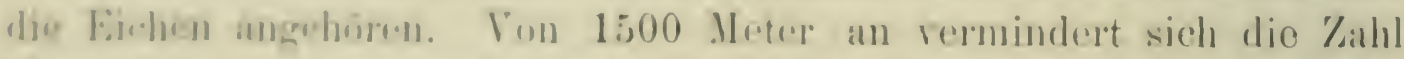
nbermale. die nordamorikanische Edelkastanio verschwindet, der Wald

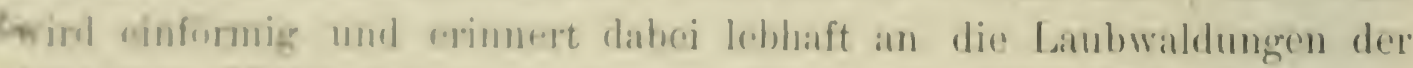

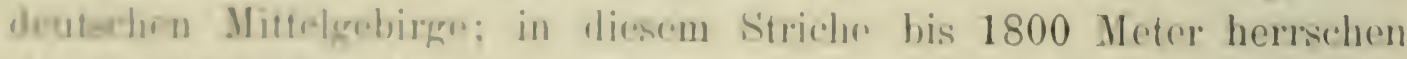

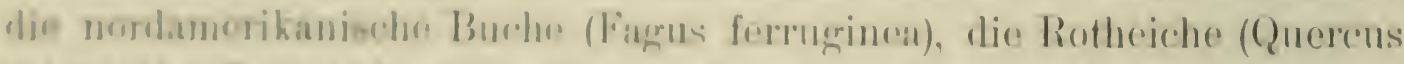

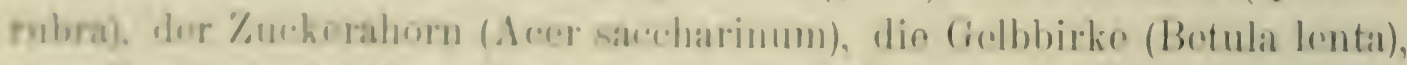

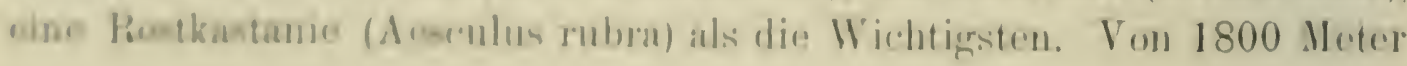

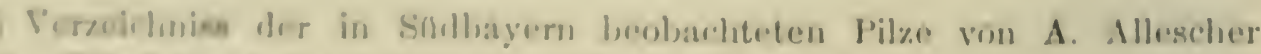
kep. Abed IX. Lericht dis botanischen Vereins in landshut. 
an dominiren die Buchen, ganz entsprechend den hohen Partien des deutschen Laubwaldes, insbesonders im Mittelgebirge und am Fusse der Alpen, Betula folgt mit; auf der oberen Grenze mischen sich einzelne Tannen und Fichten (Picea nigra, Abies Fraseri) bei; endlich von 2000 Meter an deckt die Berge der dunkle Wald der beiden Nadel-Comp hölzer, umsäumt von dem über mannshohen, dunkelblätterigen Rhodo- zouc dendron maximum und der Zwergerle (Alnus viridis).

Die östlich gelegene Zone, der's ü dlich-atlantische Laubwald im engeren Sinne (S. a.) umfasst die Küstengebiete und die östliche Abdachung der Alleghanies. Dieser Wald ist klimatisch und insbesonders in seinem Standorte verhältnissmässig weniger begünstigt. Die Temperaturunterschiede sind unbedeutend, durchschnittlich $2^{\circ} \mathrm{kälter}$; die Regenmenge coact ist mit $290 \mathrm{~mm}$ im Sommer und $364 \mathrm{~mm}$ im Winter geringer gegenüber dem vorigen Gebiete; die relative Feuchtigkeit beträgt 64 und $70 \%$ beziehungsweise. Vor Allem dürfte in der Bodenausformung die Erklärung für den sehr bemerkbaren Unterschied in der Entwickelung des Laubwaldes dieser Zone zu der vorhin genannten zu suchen sein. Die granitisch-sandigen Abdachungen der Alleghany-Berge tragen noch dichten Laubwald, der aber artenärmer ist; nur 8-10 Eichen begegnet 7 man in ihm; auf den sandig-kiesigen Erhebungen mischen sich Kiefern dazwischen oder sie ersetzen ihn vollständig wie an der Küste; dort in den feuchten, sumpfigen Niederungen vertritt den Laubwald eine Cypresse, Chamaecyparis sphaeroidea. Zu den schon früher erwähnten Pinus mitis und Pinus Taeda gesellt sich Pinus inops, eine Bergbewohnerin und Pinus rigida, einzeln in den Bergen, vorherrschend aber an der Küste, meist zusammen mit mitis.

Das Waldbild der westlichen Meridianzone der südlichen Hälfte, die präriale Zone im Süden (S. p.) vom $92^{\circ}$ W. L. bis etwa $102^{n}$ W.L. entspricht nicht den Erwartungen, die man nach den meteorologischen Beobachtungen hegen möchte; die Temperaturdifferenzen zwischen Vegetationszeit und -Ruhe sind wohl beträchtlicher, die relative Feuchtigkeit ist aber kaum geringer als jene der mittleren Zone; diess und die Regenmenge mit $456 \mathrm{~mm}$ im Sommer und $1080 \mathrm{~mm}$ im ganzen Jahre ist für Baumwuchs durchweg günstig. Dass dennoch nicht ununterbrochen dichter Laubwald durch die ganze Zone streift, dass Graslandschaft, Prärie, so viele Meilen weit in den Wald vordrängt, vom $90^{\circ}$ an oft schon beträchtlich überwiegt, muss anderen als klimatischen Einflüssen zugeschrieben werden. Schuld daran dürfte die Nähe der Prärie sein, über die alljährlich grosse Feuer dahinrasen, wo sie zuerst auf den Wald stiessen, jedenfalls war es verkümmerter, 
staudenfürmiger Wald, rersengten sie anfangs nur den Rand; das nächste Feuer fand bereits revihliche Nahrung an dem todten Waldsaum; aus dem Bodenfener wurde cin Waldbrand, der mit seiner Gluth wieder grössere Massen ron Bäumen tödtete und rerkohlte. Jeder folgende Traldbrand fand reichlichere Nahrung, bis der Wald verschwunden und Gras an seine Stelle getreten war. Prärie, deren Ursprung auf solche Urachen zurückgeführt werden muss, kamn wiederum in Wald umgewandelt werden, und in der That entspriesst und gedeiht auch dort überall Wald, wie die grossen Anpflanzungen in den Weststaaten überall beweison. Dass der Mensch, der wohl jedes Fenei im Wald und auf der Prärie am Gewissen hat, diese Prärie küustlich geschaffen, beweisen auch die einzelnen vom Feuer verschonten alten Bäume und Baumgruppen (oak openings); dieses beweist auch das Vorhandensein von Wald auf den üstlichen Ufern der Flüsse, während die westlichen, gremen dic Präric gelegenen, ihres Waldes durch Feuer beraubt wurden; endlich sicht man überall auch heute noch die Bildung vou Prärien durch Sorglosigkeit und Unverstand vor sich gehen.

So entstanden und entstehen der grösste Theil der Prärien, der Hara der japanisdden Inseln; durt fanden sich Prärieflïchen vielfach ron Uraufang an, am Fusse der V'ulkane, da der äusserst poröse, sandige Boden nicht genügrend Feuchtigkeit in der Tiefe für Bäume besitzt; son dort aus haben sich die Prïrien über grosse Flächen bergauf und -abwarts verbreitut und wachsen dieselben noch heute; ïberall aber eind [nsc.ln, Zeugen der urspringlichen Waldvegetation, erhalten geblieben. Gan\% ebanso (ntotanden und entstehen die Alang-Alang-Wildnisse anf den Bergen der fenchten, regenreichen Insel Java; auch die kahlen mit (iras bedeckten Vorbege des nordwestlichen Himalaya's zwischen 1500-2500 Metwe Erbebung dürften zum grössten Theile dem Feuer, wenu nicht ihren Uraprung, so doch ihre Ausdehnung verdanken. Eindlich sind die grossen, recenten Grasflichen innerhalb des Laubgebletes solbet in Pennsylvanien, Ohis und anderen Staaten allein durch die Thatigheit des Menschen möglich geworden - ein vielvernprechonder Anfang reiner Prïrie.

In der P'ririalzone habon ron den Laubhölzern wohl nur wenige

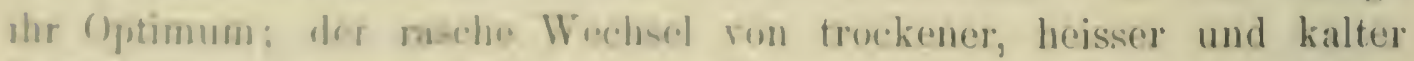
Lafe is nur wenigen Holyarten willkummen; immerhin aber finden

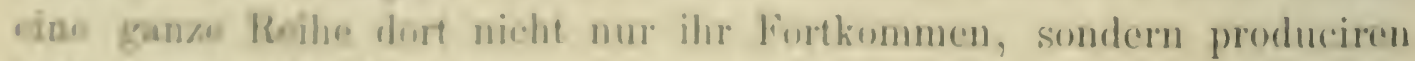

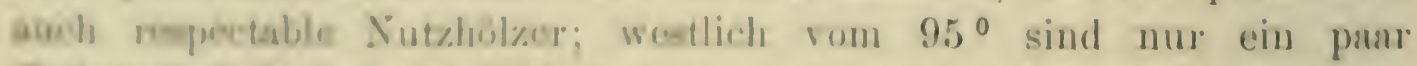

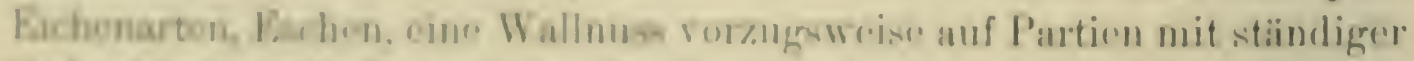

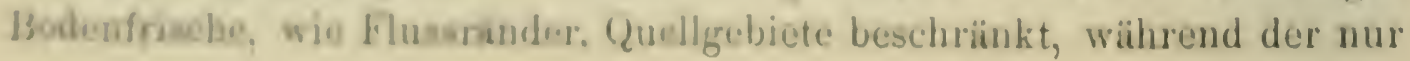


wenige Meter darüber erhobene Boden schon den typischen Pflanzen der südlichen, grasarmen Steppe, den Pflanzen des trocken-heissen mexicanischen Klima's, den Yuccas und Opuntien, dem Mesquit zusagt.

Wie weit dieser Laubwald nach Westen vordringt oder einstens vorgedrungen ist, ist schwer zu bestimmen. Es scheint, als ob die eben erwähnte Grasvegetation, Laubwald mit Steppenpflanzen wechselnd, bis zum $102^{\circ}$ sich ausdehnte, von wo der östliche Laubwald verschwindet und an den Flussrändern Pflanzen von ganz verschiedencm Typus auftreten; der Norden der Prärie verhält sich, wie wir sehen werden, ganz anders.

Die kühlere, nördliche Hälfte der Laubwaldregion (N.) vom $39^{\circ}$ an nördlich, die ich im Herbste 1885 der Länge und Quere nach durchreiste, beherbergt eine Reihe von ihr typischen Laubbäumen, insbesonders erscheint sie als die Heimat der leichtsamigen Laubhölzer, die hier nicht blos in grösster Zahl, sondern auch in grösster Vollkommenheit aufwachsen. Unter dem $42^{\circ}$ N.B. begegnet man sechs Ahornarten, unter dem $35^{\circ}$ nur vier, fünf Birken endlich im Norden und nur eine im Süden. An geeigneten, sandigen Oertlichkeiten substituiren dem Laubwald Kiefern, die von den Arten im Süden grundverschieden sind; in ständig feuchten Niederungen stehen Chamaecyparis, auch Tsuga, virginischer Wachholder und ausnahmsweise auch die Weymouthskiefer; selbst die Vertreter der Tannenregion, die Weissund Schwarzfichte, die Balsamtanne finden im nördlichen Theile dieses Laubwaldes bereits günstige Verhältnisse in den kalten, sumpfigen Niederungen.

Die ganze nördliche Hälfte ist im Verhältnisse zu ihrer geographischen Lage durch auffallend kalte Winter ausgezeichnet; von Anfangs November bis Anfangs März beträgt die durchschnittliche Temperatur $-5^{\circ} \mathrm{C}$; dem stehen wiederum auffallend heisse Sommer gegenüber; der Einfluss des grossen Continentes, des kalten Wasserstromes an der Küste, die Entfernung vom wärmespendenden Golfstrome, sowie die Nähe des eisigen Nordens, von dem ungehindert durch Gebirge die kalten Winde in das Laubholzgebiet herabsteigen können, machen sich bereits geltend in den beträchtlichen Extremen und dem schnellen Wechsel derselben. Gefährliche Frühfröste erscheinen schon Ende September, und Mitte Mai sind, wenn auch selten, noch Spätfröste zu gewärtigen.

Der östliche Theil dieser Laubholzregion, die nordatlantische Zone im engeren Sinne (N. a.) ist am wenigsten noch dem schroffen Wechsel der Witterung unterworfen; $20^{\circ} \mathrm{C}$. durchschnittliche Wärme 
waluend der Vertatims\%eit stehen $+1^{0} \mathrm{C}$. durchschnittliche Temperatur

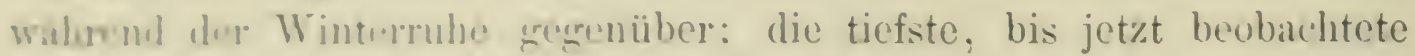
Tempentur betriigt - $27^{\circ} \mathrm{C}$. Die Bodonfeuchtigkeit ist in Folge der brrzigen Erhebungen in der Nïhe der Küiste eine ziemlich betrïchtlichn: Im summer fallon $367 \mathrm{~mm}$, im Winter $297 \mathrm{~mm}$ Niederschliage; die relative Fenchtigheit ist wibrend der Hauptregetation $67 \%$.

Wer ron Europa kommt, betritt zuerst diese Zone, welche die Adirondack- und Cat-kill-Gebirge und die White-Mountains und ihre Abdachungen unfasst. Der Urwald ist fast ganz verdrängt, denn dieser Theil. die Altrngland-Staaten, wurde znerst besiedelt; an Stelle des rielartigen. nutzholzreichen Waldes ist grösstentheils ein artenarmer, vielfach niedriger, greringwerthiger Laubbestand von vorwiegend weichen Hül\%rn oder der des Samens wegren begünstigten Kastanie getreten. Unregramiisigr durchlöchert wird dieser Wald in kurem Umtriebe abgrachlagren, für den Nachwuchs sorgt die Natur mit einer Fülle ron forstichen Unkräntern, mit Pappehn, Birken und Weiden; doch ist üherall noch so riel rom alten Walde vorhanden, so viel Produktionskraft im Boden, dass es nur greringer Nachlilfe bediurfen würde, um die greringwerthigen Bremblolz-Waldungen wieder in Nut\%holz producirende Hochwailder umzuwandeln.

Hior burinnt anch bercits die Morgenröthe für eine neue, dem Walde und dem Volke gleich nut\%bringende Acra aufzudïmmern.

Wrandet man sich westlich zur continentalen zone des nódlichen Lanbwaldes (N. c.), wolche die grossen Seen mit ihren angrenzenden Gohinton unfasst, so ist der Einfluss derselben durch rino Erhohung der Nirdenschlagsmonge ein unverkennbarer; im Sommer fallou $465 \mathrm{~mm}$; die relative Feuchtigkeit ist trot\% der Entfernung dieaelbe wie sum Mecre selbst; die durchschnittliche Sommertemperatur wird auf $18,9^{\circ}$ C. herabgemissigrt, der Winter ist nur um $2^{\circ}$ kïlter als im ()=tun. Abur cinzelne Luftwellen von Nordwesten bringen im Winter ampindlichen frost, selbst ausnahmsweise bis $201-41,7^{\circ} \mathrm{C}$. (Central-Wisconsin 1873.)

Mit Berug auf das Klima sperioll ron Wisconsin sagt R. Ludloff*) enhr richtig:

Krin Jand rom allen Staten der grossen Union besityt ein Klima,

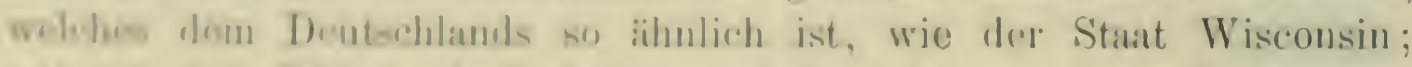
walsond der Winter dem norddentechen ihnlich ist, doch somnigrer,

-) Amerikeniecle Reivebileter; Skizen atus den Stuaten Wisconsin, Mil. wavere lois. 
trockener und weniger von Thauwettern unterbrochen, bringt der Sommer eine an Steiermark und Ungarn erinnernde Wärme. Der Uebergang rom Winter zum Sommer ist ziemlich unvermittelt, oftmals schroff und die rom Norden kommenden kalten Winde bringen in dieser Jahreszeit häufig regnerisches, trübes, kaltes Wetter. Die durch diese Ursachen zurückgehaltene Vegetation kommt dann auf einmal und in unglaublich kurzer Zeit zn nenem Leben. Desto schöner ist der Herbst, der bei sonnigem, klarem, warmem Wetter oft bis in den Monat Dezember währt und das Laub in allen Farben prangen lässt." Zur Ergänzung füge ich noch meine Erfahrungen aus den ersten Tagen des Oktobers 1885 im mittleren Wisconsin an; die Laubbäume hatten ihren Blätterschmuck bereits abgeworfen, auf dem Boden lag stellenweise noch Schnee von dem kurzen Schneegestöber der vorausgegangenen Tage, den die kräftige Mittagssone des klaren, warmen Wetters (Indian summer) rasch hinwegschmolz.

Die klaren Nächte, in denen allerorts die Feuer von den zusammengeschleppten Baumstämmen auf den „clearings" aufloderten, waren kalt und morgens überzog kräftiger Reif die Häuser und Gefilde. Je weiter nach Norden aber, dem Lake Superior entgegen, um so milder wurde wiederum das Klima; die Eichen, Wallnüsse, Ulmen, Birken, die im Central-Wisconsin schon völlig kahl dastanden, fand ich am Seeufer noch in Herbstfärbung. Vorwiegend graugrüne Farbentöne säumten die Höhenzüge - die unendliche Schaar der Weymouths-Kiefern und Hemlocks-Tannen; gegen den Abhang herab gelbe Streifen von Pappeln und Birken oder orange- und blutrothe Flächen von Zuckerahorn und Rotheiche.

Ich gebe Ludloff noch weiter das Wort und lasse ihn vom Urwalde erzählen, den er mir freundlichst selbst gezeigt und besser beschrieben hat, als ich es vermag: „Num beginnt der eigentliche Urwald, den der Mensch erst vor Kurzem in Beschlag genommen und - dem Untergange geweiht hat. Man hat über den Begriff "Urwald" in der alten Welt keine richtige Vorstellung, wenigstens bezeichnet diese Vorstellung, fabelhaften Reiseberichten entnommen, nicht Das, was man im Norden der Vereinigten Staaten sieht.. Der Wald besteht hier aus wenigstens zwanzigerlei Arten verschiedener Bäume, die in jedem Vegetationsalter stehend, ein buntes Gemisch bilden. Zwischen Sträuchern von Tischbis Manneshöhe aufwachsende junge Bäumchen, abgestorbene Stämme von höchstem Alter und kraftstrotzende, in den besten Jahren stehende Exemplare - das Alles wächst im wirren Durcheinander im herrlichsten Grün, und der Halbschatten, den diese dichte Vegetation auf den morschen Stämmen, auf den in die Höhe gerichtetẹn Wurzelstöcken, 
die der fallende Ripse beim Sturz aus dem Boden gerissen, verbreitet, macht einen tiefen, langanhaltenden, niederdrückenden Eindruck auf den Menachen, der dis erste Mal diese eigenthümliche und unberührte Workstatte der Intter Natur betritt.

Nichts rührt sich, eine tiefe stille lagert über dem fast ïngstlichen Halbdunkel, in dem Mücken und Fliegen, sowic ein par Schmetterlinge thr Wesen treiben, nur dann und wann hörst du den heiseren Ruf eines spechtes, desien Ḱlopfen du cin paar Sekunden früher vernahmst, oder das Knacken der Büsche, welches ein davoneilendes Wild verursachte, dringt an dein Ohr. Dort liegt ein umgebrochener Stamm, dessen Aeste schon längst den Humus vermehrthaben, dessen Wurzelstock in sich selbst verfaulte und der nun aussieht wie ein vernachlissigter Grabhügel; indem du dich anschicktest, den Stamm zu übershreiten, sinkst du bis ans Knie durch Moos und Rinde in das faule Holz. Nur der Mantel ron Rinde und Flechten hält die Form des Stammes \%u-ammen, er selbst ist lïngst vermodert. Man kann mit dem fichstocke den dreifüssigen Riesen durchstechen! Und wo du auch gehat und stehst, überall liegren solche Büume in allen Stadien der Fiulniss und die jüngere Generation fusst nun auf der humusbildenden Masme. Und ist eben dieser Humus das fruchttreibende Element, woldes dem Ansiedler so schnell und trefflich zu Statten kommt, so bilden die den Humus durchkreuzenden starken Wurzeln kein besonderes Hinderniss. denn sio lassen sich leicht aus der schwammartigen Masse entfremen. Im dichten Urwald, auf kräftigem, frischen Boden, wo viel Unterhol\% stcht, sicht man kaum 30-40 Schritte weit. Auf magerem Bodrn ist das anders und in solchen Gegenden existirt kein wesentlicher Unterschied zwirchen den amerikanischen und den deutschen Waldern. Wir finden in diesen Waildern, wie bemerkt, ein Gemisch dor verecdiedensten Holzarten und das Erscheinen der einzelnen (inttungrn gibt worthrolle Finger\%eige für die Qualitiit des Bodens. Wo Ahom, Lindr, Esche, Ifomlocktanne und Butternuss wachsen, kamn man mit Bustimmtheit auf gutrun Boden rechnen. Wo die Nadelhälzer vorhersechend anfrreten, int ler Boden ärmer und der in Hinsicht auf Hulaverwerthung wiohtigsto Baum, die Pine (Pinus strobus), zeigt gowohnlich sandboden an. Dice Aluornarten, in Verbindung mit amerikanimohn Birke. Buttrernuas, Fichn, Clme, wilder Kirsche, Linde, HemJockame asd Eeche hilden fust ausschliesclich den Bestand wo wir faliren and die Ferotution ist oft so michtigr, dass man nicht zehn Bobitte weit in don Wald blicken kann. Und sonderbar ist der Umstand,

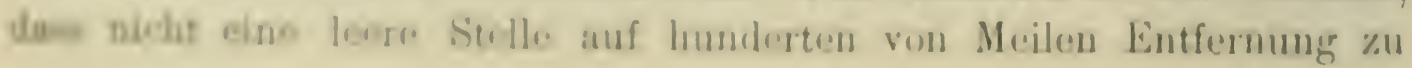


finden ist, - sie müsste denn anders von Menschenhand geschaffen sein: es ist Alles und Jedes Wald und nichts als Wald."

Dieses fast unermessliche Waldgebiet ist zum allergrössten Theil bereits in Händen von Privaten und Gesellschaften, um zu Ansiedelungszwecken parcellirt und gerodet zu werden. So weit die Ebene und Boden in Betracht kommt, der nach der Entwaldung nicht versumpft, ist die Rodung ganz am Platze; aber die steilen Seeufer, die mageren Sandpartien sollte man verschonen.

Die kahle, heisse Felswand, die zum Beispiel hinter Duluth sich aufthürmt, bleibt ewig eine Gefahr für die Stadt, wie sie auch ein ewiger Vorwurf für dieselbe ist. Der Staat hat nur mehr wenig Wald und man kann ihn von demselben durch Entrichtung der Einschreibegebühren, wie Ludloff berichtet, erhalten.

In diesem und den benachbarten Staaten liegt das Eldorado der White Pine (Pinus Strobus). Man berechnet die Vorräthe an diesem wichtigen, leichten Nutzholze noch auf Millionen von cbm und prophezeit trotzdem von allen Seiten eine baldige Erschöpfung desselben. Der Boden, wo sie wächst, rings um die Seen bis weit nach Canada hinein, enthält sandige Beimischungen und je nach der Feuchtigkeit besiedeln ihn verschiedene Kiefernarten, von denen Strobus den feuchtesten, Pinus Banksiana den trockensten Platz liebt; Pinus resinosa, als Nutzbaum ebenfalls sehr hervorragend, steht in der Mitte. Diese Kiefern bilden die Zone der nördlichen Kiefern, welche den Laubwald im Norden der Vereinigten Staaten und im Süden von Canada theilweise vertreten.

Im prärialen Theile des nördlichen Laubwaldes (N. p.) erlahmt die Ueppigkeit und Kraft des Urwaldes immer mehr. Durch grössere Boden- und Luftfeuchtigkeit begünstigt, entfaltet sich im Thale des oberen Mississippi nochmals die alte Schönheit und das bunte Gemisch der Baumarten; aber schon ehe man diese Oase betritt hat man von Osten her mehrere trockene Hügelreihen mit niederen, strauchförmigen Eichen - scrub-oaks - zu durchwandern; hier liegt thatsächlich für diese trockene Höhenlage bereits die natürliche Grenze des Hochwaldes; überschreitet man den Mississippi, so wechseln solche Straucheichen mit Kiefern, wo sandiger Boden auftritt; immer grösser werden die Flächen, die Gras überzieht, sie fliessen allmählig zusammen und endlich ist alles Graslandschaft so weit das Auge reicht; hier im Norden ist die Präriegrenze durch Feuer kaum merklich verschoben worden; dagegen gehört die südlich gelegene gegenwärtige Grenzzone der Oak-openings entschieden noch zum Laub- 
walle. Das natiirliche Uehereangserlied rom Hochwalde zur Prïric die stranhsuretation. fehlt durt: und gerade diess scheint mir zu bewhisn. ines die gregenwärtige Grenze derselben nicht die ursprüngliche, die naturliche sein kann.

Die metrombarinchen Beobachtungen lassen uns leider im Stiche dives Grengrehiet \%u fixiren: die stationen sind \%um grössten Theile in stadten, die wieder in Flussthïlern mit Banmwuchs liegen: kein Wunder, dass wir in Bezug allf Regenmenge und insbesonders relative Fouchtigkit selbst \%. B. unter lem $100^{\circ}$ Resultate erhalten, welche wohl die Existenz des Baumwuchses, aher nicht der anstossenden Prärie erklären. Allew. was sich aus den Beobachtungen erkennen lïsst, ist nach Westen hin einc bedentende Abnahme der Temperatur im Winter (Durehshuit - $7^{\circ}$ C.), eine \%unahme derselben im Sommer; im Hochsommer zittert dis Luft über den versengten Prärieflïchen auf $40,6^{\circ} \mathrm{C}$. erhitzt; im Winter stïren Nordwestwinde mit der grimmigen Kälte von $34^{\circ}$ C. und moln. den schnee wie staubwolken ror sich hertreibend (Mlizard). über das Land. Weht ein paar Wochen Südwind, dann leerrocht tropische Hitze, weht ein paar Wochen Nordwind, arktische hilte.

Wie weit nach Westen hin die ursprüngliche Grenzvegetation zwischen Prärie und Wald zu rerlegen ist, lïsst sich nur durch passend situirte meteorologische Stationen oder durch Anpflanzungsversuche in \%urammonhăngruden Walderuppen ermitteln. Das Vorkommen der Strauchregetation rerraith die Niblhe der Prärie; doch scheint es mir wahrehentich, das die obenen und tieferen Lagen im Norden noch bis zum $90^{\circ} \mathrm{W}$ ald $\%$ ernälıren vermögen. Die natürliche Grenze awivechen Wald und Praire kann nie eine plötzliche sein und der Weg aus dem reinen Waldgebiete in die reine Präre kimn sich recht wohl wher funf und modir laingengrade erstrocken.

Ich will him einige lieinde dies Laubwaldes anfügen, so weit ieh dieselfen bellet kronnen lernte; der. Schaden, den sieverursachen ist froiluch, im Versleiche \%u dem, don der Mensch dem Walde zufïgt, ein ganz. geringer.

Als ich im Auguat 1885, \%um arstenmale durch das Laubholggebiet fular, fled cehon son writem die eigenthïmliche, gelbbramne Fïrbung des leobsobles auf; bei weitrere Anniherung liess sich erkennen, dass

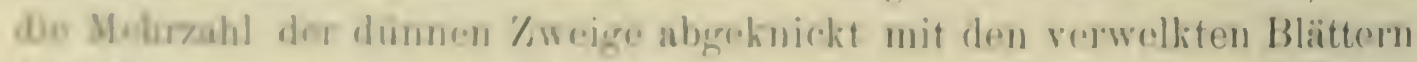

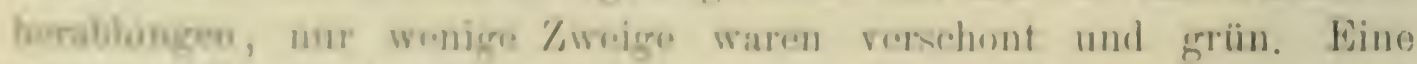

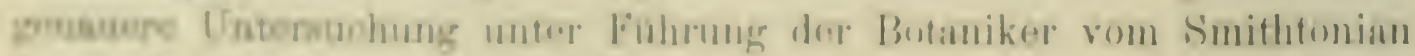
Imatation 1), Vas6y und F. L. Scribuer (agah eine liuro aber tiefo 
Längsspalte an den Zweigen, die an dieser Stelle vom Winde gebrochen waren. Diese Beschädigung rührte von einer Cicade her, welche nur alle 17 Jahre ihre Flugzeit hat; während der langen Zeit ruht sie als Larve in der Erde, so dass dieselbe Brut an gleicher Stelle erst wieder im Jahre 1902 beobachtet werden kann. Dagegen wird es möglich sein, schon 1894 einer anderen Brut zu begegnen, welche bereits 1877 ihre Schwärmzeit hatte. Bei der Eierlage sägt dieses Insekt, die Cicada septendecin eine Längsspalte in die Zweige der Eichen, Hickory und zahlreicher anderer Laubbäume, besonders auch Obstarten, an welcher Stelle der Zweig in der Regel abbricht und vertrocknet.

Eine gleich eigenthümliche Biologie hat eine weitere Art, die Cicada tredecim, wie sie von ihrem Beobachter Ch. Riley*) benannt wurde; sie ruht 13 Jahre unter der Erde, worauf sie schwärmt und gleiche Beschädigungen, wie ihre 17jährige Schwester, verursacht; am empfindlichsten aber ist der Schaden, wenn diese Leiden für eine gewisse Oertlichkeit zu gleicher Zeit auftreten, wie dies für Washington und Umgebung im Jahre 1868 der Fall war; so weit die betheiligten Bruten in Betracht kommen, treffen ihre Schwärmzeiten erst wieder im Jahre 2089 zusammen.

Die Patricier der Neu-Englandstaaten sind mit Recht stolz auf ihre prächtigen Ulmen, mit denen sie öffentliche Parke und Gärten schmückten; im Frúhherbste 1885 konnte man sie aber doch nicht einen Schmuck der Landschaft nennen, denn ihre Blätter waren an fast allen Exemplaren völlig skeletirt; Aeste und Stämme der Bäume, Zäune und Wege in der Nähe waren bedeckt mit den lebhaft kriechenden Larven eines Käfers, der aus Europa nach Amerika eingewandert ist, der Galleruca xanthomelaena; man hat vielfach Mittel dagegen versucht, von denen offenbar das beste die "Theerringe" sind wie sie bei uns in Kiefernbeständen gegen die Schmetterlingsraupen angebracht werden; die sämmtlichen Exemplare der City of Elms (New Haven), die mit Theerringen versehen waren, hatten völlig intakte Belaubung. Damals entging auf eine Länge von 4 Breitegraden keine unbeschützte Ulme den Millionen dieser gefrässigen Insekten, und alljährlich kehren sie in verstärkter Zahl wieder.

In Staate Jllinois scheint der Weissahorn, Acer dasycarpum, durch eine Wolllaus dem Untergange geweiht; diese bedeckt mit ihren weissen

*) The periodical Cicada. U. S. Dep. of Agric. Div. of Entomology Bull. 8. 1885 . 
Auschwitzungen in wahren Klumpen die Unterseite der Zweige und spritze -timble die zucherhaltigen Excremente auf alle tiefer liegenden Blatter und Zweige, auf Wege und Zaimue, an denen Strassen- und Kuhlenstanb, an dem in Amerika kein Mangel ist, sich dick ankleben. so dass der Baum mit seiner Ungebung einen widerlichen Findruck macht: überall sieht man die Zweige abgestorben und die Zahl der gretödteten Bäume wächst tïglich. Erst seit dem Jahre 1882 hat man das Insekt wahrgenommen; sein Verbreitungsgebiet umfasst den ganzen Staat Illinois.

Die Samenkonsumenten kann man zu Feinden oder Freunden des Waldes rechen; was die Eichhömchen, Eichelhüher und Andere vertilgen, wird reichlich aufgewogen durch ihr Verschleppen der Friichte, insbomders der schwersamigen, wichtigsten Holzarten, wie Eichen, Wallnus, Hickory, die ohne menschliches Zuthun nur durch ihre Mithilfe auf rorlassencm, landwirthschaftlichem Gelände, auf Rodungen, im Waldr wieder eingebracht werden hönnen; in dieser Hinsicht spielen diese Thiere eine ganz hervorragend nützliche Rolle im Haushalte der Natur. Wer aber von scinen Bätumen Nüsse ernten will, hat viel Verdruss, demn des hnackens und Herabfallens leerer Schaalen ist zur Zoit der Reife kein Ende.

ber Schaden, den Pilze anstiften, ist überall bemerklieh; besonders sind es eino Reihe ron Polyporus-Arten, viele davon auch in Europa heiminch, die das Holz äusserlich intakt erscheinender Bäume langsam zornturen; gerade die schönsten, ältesten, stälisten Exemplare sind es, in denc.n sio, da am längsten darin regetirend, am meisten schädlich werden: das: cin präichtiger Nutzstamm so oft bei der Durchsiigung sich als hohl oder mïrbe oder missfurbig und fleckigr und unbrauchbar crweist, int moist die Wirkung eines Polyporus; unter diesen sind herromagrmal: Polyporms applanatus, besonders an Zneker- und WeissAhorn; Polyporus sulphurens antwiclelt in den Höhlungen der Eichen und Wallnumarton monströse Friichte, Polyporus marginatus an Buchenstrmmen. Pulyporas igniarius zerstiolt und tödtet in Nordamerika ebense

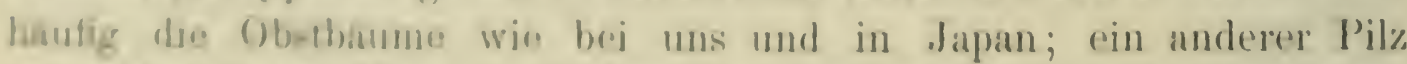
Wr Birke, deseen Jfyced in dicken, branmen, an der Oberfliche schwar\%

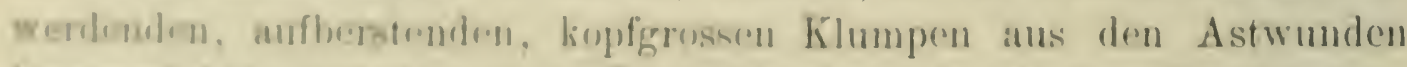
bervorsichet, Inbt uherall in Dentachland an der Birke; Fruchtträger

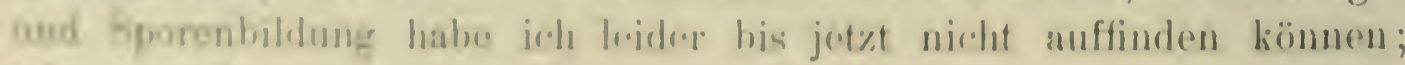

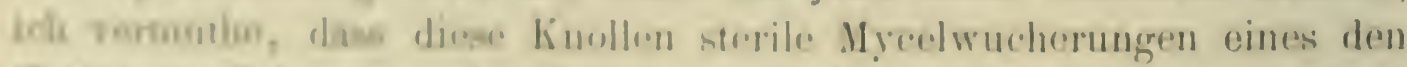

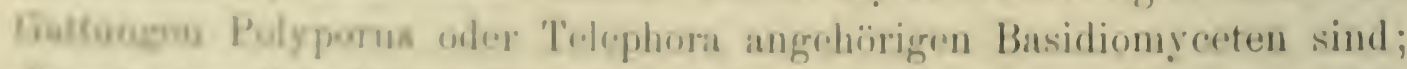

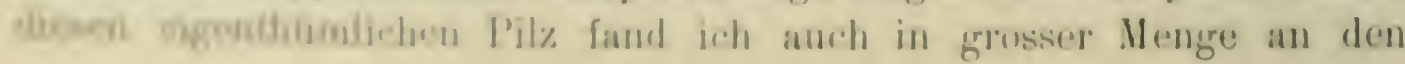


Birken Nordamerika's und, seltsam genug, auch an den japanischen Birken ist er so gemein wie Polyporus betulinus.

Ein anderer Polyporus (Sp.?) von schmutzig-weisser Farbe tödtet die halberwachsenen Eichen; das Holz der Quercus falcata und wahrscheinlich noch vieler anderer Eichenarten zerstört Telephora Perdix mit denselben charakteristischen weissen Höhlungen in der braunen Holzmasse, die der Pilz auch in den europäischen Eichen bewirkt.*)

Roestelia lacerata und aurantiaca verursachen Anschwellungen und Krümmungen der Triebe und Blattstiele an Crataegus- und Pyrusarten; ihre Winterformen leben als Gymnosporangien an Juniperus virginiana; Melampsora an Weiden sind zahlreich; an verschiedenen Eschenarten verursacht ein Aecidium (Sp.?) Krümmungen der Triebe und Blattstiele. Mehlthaukrankheiten, veranlasst durch Erysiphe, Hexenbesen, durch Exoascus-Arten hervorgerufen, fehlen ebenfalls nicht, aber merklich schädlich unter den Ascomyceten hat sich nur Sphäria morbosa an Prunus-Arten, sowohl wild wachsenden als kultivirten Arten, gezeigt. Der Pilz krümmt die Aeste und tödtet die darüberstehenden Pflanzentheile; solche Krümmungen überzieht die Fruchtschichte des Pilzes als eine grossblasige, schwarze Kruste, in deren Oberfläche die Perithecien versenkt liegen; Rhytisma acerinum bildet schwarze Flecken auf den Blättern der nordamerikanischen Ahormarten, wie auch auf den Blättern aller Ahorne Japans und Indiens.

Reich ist der Laubholzurwald an Missbildungen, Kröpfen, Masern, welch' letztere an Zuckerahorn, Birken, Eschen, Wallnussbäumen besonders werthvoll sind. Die Ursache der Maserung ist noch nicht genügend bekannt; an einigen japanischen Bäumen konnte ich in den Kurztrieben einer Kropfmaser einen Exoascus finden, der wohl im Holz- und Rindengewebe perennirend alljährlich in den Kurztrieben fruktifizirte und die Knospenstämme derselben, "die Maserfasern“, zu abermaliger Verzweigung reizte. Wie weit und ob bei Masern ohne Kurztriebe Pilze im Spiele sind, ist noch eine offene Frage.

Nicht unerwähnt soll endlich eine Art Mimicri unter den Bäumen bleiben, welche diese gegen Angriffe durch Thiere in gewissem Sinne sicherstellt; so siedelt sich bekanntlich auf den Schlägen unserer einheimischen Fichte massenhaft eine kleine Wolfsmilchart an, welche täuschend einer jungen Fichtenpflanze ähnlich ist. Auch im amerikanischen Walde lässt sich Derartiges beobachten; Desmodium nudi-

*) R. Hartig, Die Zersetzungserscheinung des Holzes der Nadelholzbäume und Eiche. Berlin 1878. 
finrum. tauschend im Blattbau einer jungen Hickory ähnlich, ist ein Laufige = Unkraut im Laubwalde: nur ein gecibtes Auge vermag dio junzen Hickorgptlanzen unter den Desmodien herauszufinden, wodurch sie geren Thine rinigen schutz finden.

Din Eichen, Quoreus, sind in Amerikil eine der widhtigsten (iattungern dos Latulswaldes, weil sie äberall und in den nöthigen Dimmsinnm \%ur Hand sind und dabei ein werthrolles, dauerhaftes Nutzhul\% (r\%eugen. Dureh das Privaliren der Eichen erhält der Laubwald sein specielles Gepräge; schöner stellt sich dem Auge die Verschindenheit und der Reichthum an Eichen in dem amerikanischen Walde nicht dar, als wemn derselbe in herbstlicher Fürbung ergliiht. (iilt die brennruthe Farbe als die schönste, so streiten sich Weisseiche, Rotheiche und scharlacheiche $u m$ den Preis. Nach Norden hin steigert sich die Farbenpracht, nach süden hin verblasst sie mehr und mehr.

Dic so oft und so poetisch beschriebene Farbenwandlung wird verschiedench Einflïssen zugeschrieben; die Einen sagen, die grossen Seè sind daran Schuld; wir wisen aber, dass alle Pflanzen, welche in Amerika dic röthliche Färbung der Blïtter anlegen, diese auch bei uns beibehaltun, wie \%. B. die Eichen, Ahom, der wilde Wein, der

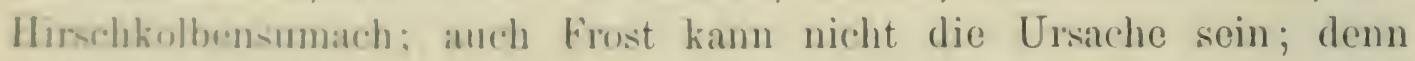

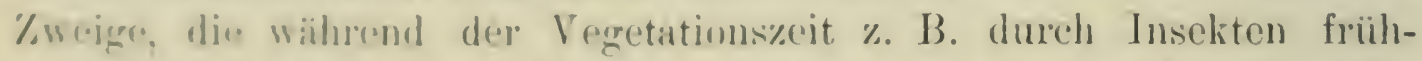
\%atig und langsam \%um Absterben grebracht werden, erhalten ebenfalls div rothe Fartwe der Bläter. Ich muss Anderen die Entscheidung äberlassen; auffallond ist jedenfalls die Abnahme der Pracht in der Herbstfarbung narh sijden hin, sowir die Figrenthümlichkeit, dass jeder Baum koinen speciollen firbentun besitzt, der alljährlich wiederkehrt.

D1. Eirdurn der atlantischen Küstes werden nach dem Vorgange des alteron Michaux in zwei Sectionen zerlegt, von denen die erste jene nemin Firhonarten umfisist, welche nur gekerbte oder gelappte

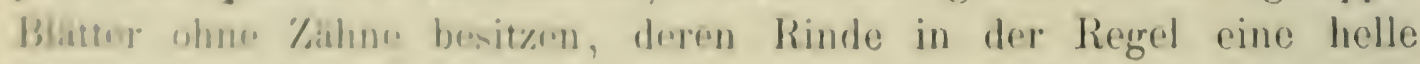
Fubung zaigt und dron sime in demselben Jahre, in dem die Blathe effulgt, reift; mit Ausnahme von Quercus alba ist ihre herbstficho Firlung groll, his lmaun; sio worden als White oaks, weisso Buben, des zoreton Section, den kichen mit Blättern, deren Lappen

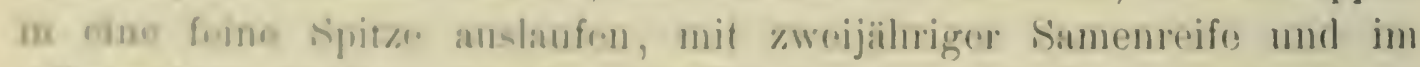

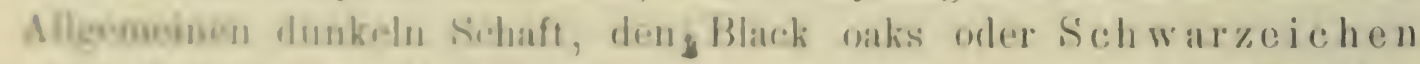

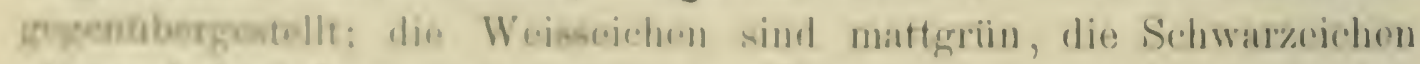

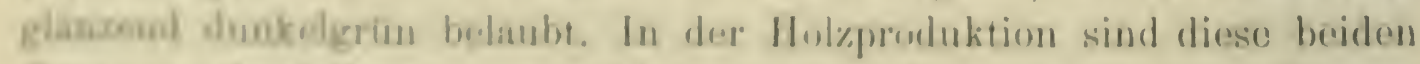

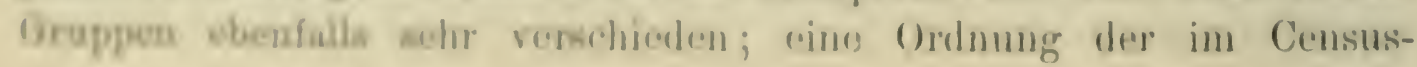


reporte veröffentlichten specifischen Gewichte von zahlreichen auf verschiedenen Standorten gewachsenen Eichen, wobei die Stücke ca. 2 Meter iiber Boden entnommen wurden, lässt erkennen, dass die weissen Eichen durch das ganze Laubgebiet ein schwereres und besseres Holz produciren als die Schwarzeichen. Dies hat die Praxis längst herausgefunden und gegenüber der Gebrauchsvielseitigkeit der ersteren ist der Werth der letzteren geradezu verschwindend.

Die Weisseichen, welche nur in Süden sich finden, haben zusammen ein durchschnittliches specifisches Gewicht von 89; diesen stehen die Schwarzeichen, die nur im Süden sich finden, mit einem specifischen Gewicht von 73 gegenüber; jene Weisseichen, die durch Süden und Norden vorkommen, zeigen ein specifisches Gewicht von 77, jene auf gleichem Gebiete rorkommenden Schwarzeichen von 70. Diese Zahlen zeigen ausserdem eine deutliche Abnahme der Holzgüte von Süden nach Norden hin, hinweg von dem heimatlichen Boden der Eichen.

$\mathrm{Zu}$ den Weisseichen gehören:

$\begin{aligned} & \text { Quercus alba L. } \\ & \text { " } \text { bicolor Willd. } \\ & \text { " } \text { obtusiloba Michx. } \\ & \text { " } \text { macrocarpa Michx. } \\ & \text { " } \text { Prinos L. } \\ & \text { " } \text { prinoides Willd. }\end{aligned}$

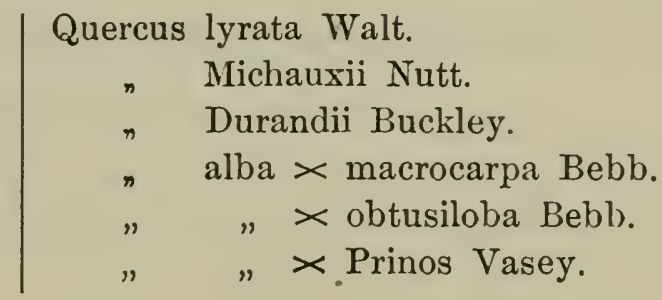

Die Section der Schwarzeichen umfasst folgende Arten:

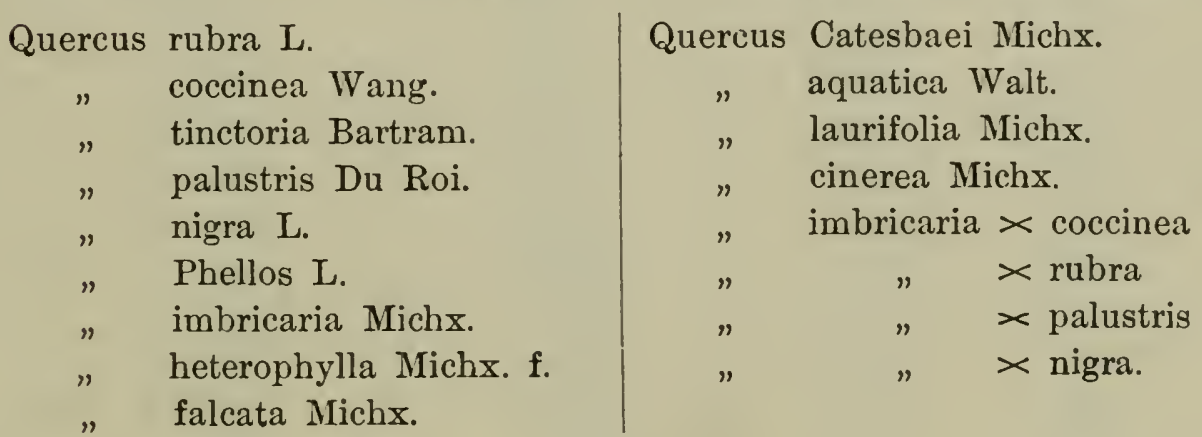

Quercus alba L., White oak, weisse Eiche, durch das ganze Gebiet verbreitet; ihr Optimum liegt in S. c. auf frischem Boden des Hügellandes und der Flussränder; sie theilt mit den nahverwandten mitteleuropäischen Eichen viele Eigenthümlichkeiten; so ihre Ansprüche an den Boden (lehmreiche Böden am besten), ihre grosse Neigung zur Astbildung im freien Stande. Ihre Rinde ist eine gross- aber dünnschuppige Borke von weisslicher Farbe, die Schuppen an den Rändern etwas abstehend; ihre Aeste bekleiden sich mit zahlreichen Kurztrieben; 
fhe Blatter sind unterseits weisslich: Blattform anf Tafel I. Wie bei atlen uhrigen lichen sind die im behatten erwachsenen Bliitter, auch innerhalb de hirone eines Bammes weit weniger tief grelappt und grüsser als die in vollen Lichte erwachsenen, ein Umstand, der bei den Schwar\%richen die Diannusis nath den Blättern erschwert. Die alba-Blätter firben sich purpurroth im Herbste. Wie die Tiefe der Buchten der Blättor sind auch ihre Früchte sehr variabel; die beigegebene Figur (Tafel II) ist die natürliche Grösse für kleine Früchte und die halbe Grüse (Flähenbild) für durchschnittliche Fruchtgrösse.

Die jetzt noch rorhandenen alten Exemplare, die so vortreffliches Nutzholz liefern, sind im unberührten Urwalde sehr langsam aufgewachsen und haben ein äusierst gleichmiissiges, engringiges Holz (rebildet.

Der Zuwachsigang des New-Yorker Sammlungsstückes, das in 2-3 Meter Hühe aus einem Baume auf gutem Boden entnommen wurde, betrug:

\begin{tabular}{|c|c|c|c|}
\hline Alter & $\begin{array}{l}\text { Durchmesser } \\
\mathrm{cm}\end{array}$ & $\begin{array}{c}\text { Kreisflichensumme } \\
\square \mathrm{cm}\end{array}$ & $\begin{array}{c}\text { Zuwachs pro Jahr } \\
\text { der Periode } \\
\square \mathrm{cm}\end{array}$ \\
\hline 10 & 2,2 & 3,8 & 0,38 \\
\hline 20 & 3,2 & 8,0 & 0,42 \\
\hline 40 & 6,4 & 30,5 & 1,1 \\
\hline 60 & 10,6 & 88,1 & 2,3 \\
\hline 80$)$ & 22,4 & 399,9 & 10,3 \\
\hline 190 & 34,4 & 929,1 & 31,7 \\
\hline 120 & 45,4 & 1617,3 & 34,4 \\
\hline 140 & .76 & 2462.9 & 42 \\
\hline 160 & $6 ;, 5$ & $: 3715,7$ & 69,7 \\
\hline 140 & 78,4 & 4840 & 56,2 \\
\hline $2(x)$ & $86 i, 8$ & 5.945 & $5 \%), 2$ \\
\hline 220 & 93,8 & 69910 & $4 ! 1,2$ \\
\hline 234 & $y \propto, 0$ & 75.13 & 33,5 \\
\hline
\end{tabular}

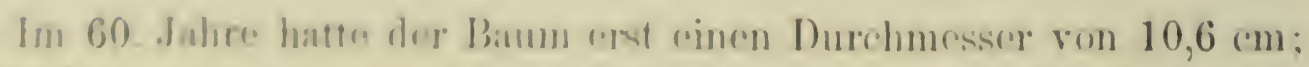
det Starksuwarts hulminirte im 160. Jature; die splintbreite betrug

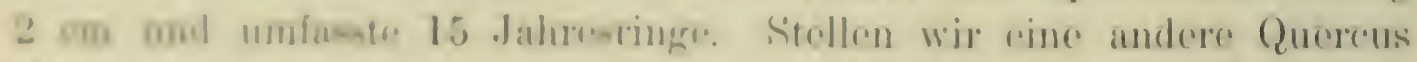
allob, sogruames socond growth, also fast free crwachsen, in Vergleich,

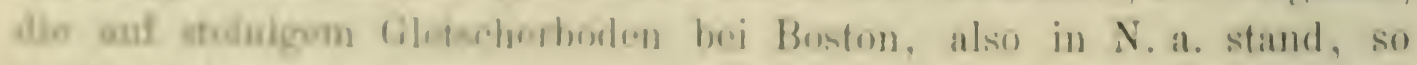
styolt siok: 


\begin{tabular}{c|c|c|c}
\hline Alter & $\begin{array}{c}\text { Durchmesser } \\
\mathrm{cm}\end{array}$ & $\begin{array}{c}\text { Kreisfliche } \\
\square \mathrm{cm}\end{array}$ & $\begin{array}{c}\text { Zuwachs pro Jahr } \\
\square \mathrm{cm}\end{array}$ \\
\hline 10 & 5 & 20 & 2 \\
20 & 10 & 79 & 5,9 \\
40 & 17 & 227 & 7,4 \\
50 & 19 & 284 & 5,7 \\
70 & 23 & 415 & 5,2 \\
80 & 26,5 & 552 & 13,7
\end{tabular}

Trotz der ungünstigeren klimatischen und Bodenverhältnisse besass der frei erwachsene Baum in 20 Jahren schon den Durchmesser, den der Baum des Urwaldes erst in 60 Jahren erreichte.

Ordnet man die Versuchsstïcke des Censusberichtes nach gleichen Ringbreiten, so ergibt sich eine Abnahme des specifischen Gewichtes von Süden nach Norden hin ron 79 auf 74; diese Abnahme kann aber durch einen besseren Standort ausgeglichen werden, indem Eichenholz, auf lehmreichem Alluvialboden im Norden gewachsen, schwerer ist als solches anf sandigem oder kiesigem Boden im Süden.

Die Weisseiche nimmt in Amerika dieselbe Stufe in der Werthschätzung ein, wie die beiden Eichen bei uns; sie übertrifft an Nutzwerth und Vielseitigkeit der Verwendung ihres Holzes alle übrigen amerikanischen Eichen beträchtlich; da sie für fast alle Bedürfnisse, für welche Eichenholz erwünscht ist, zuerst gesucht wird, so beginnt bereits der Mangel an entsprechenden Sortimenten sich fühlbar zu machen. Das Holz dieser Eiche ist anatomisch dem der winterkahlen Eichen mit peripherischem Gefässringe zu Beginn des Frühjahrs gleich, zeigt ein durchschnittliches specifisches Gewicht von 75, eine Splintbreite ron $2 \mathrm{~cm}$; in ihrem Optimalgebiete (S. c.) sind Exemplare mit 45 IIeter Höhe keine Seltenheit. Irgend welche Vorzüge vor unseren Eichen hat sie bis jetzt nicht gezeigt; sie hält bei uns überall aus, wächst aber langsamer als die einheimischen Eichen. An der raschen Zerstörung des Schwellenholzes betheiligen sich besonders Daedalia quercina, Polyporus versicolor und P. applanatus.

Quercus macrocarpa Michx., Overcup-oak, Bur oak, Grossfruchteiche. Bei grosser Verbreitung im Laubwalde meidet sie S. a.; sie ist leicht zu erkennen an den grossen Früchten, welche in einer borstigen Cupula stecken (Tafel II), an den unterseits behaarten Blättern, welche auch in der nordwestlichen Form (Tafel I) ihre typischen Einbuchtungen beibehalten; die Rinde ist der unserer Eichen am ähn- 
flchow: dir jungen Trinhe zeigen regelmässig starke Konkleisten. Auf allur iabm. reichem. fricihom Boden stockend, schafft sie ein sehr festes aher ans grubringiges Holz (Missurri): anf den höheren Lagen am Pniringande in N. p. Wachat sie in feuchteren Mulden in Gruppen (Oak openingat und langsam, gibt aber ein foinringrges Hol\% (Jllinois); in Mimuenta endlich verkümmert sie in der Nähe der Prärie zur Strauchform, wetche die hügelige Landsehaft mit einem gleichmïssigen Gestrüpe ulwerzicht (sicrub vak).

1)as Hal\% mit einem specifischen Gewichte ron 74 steht in Güte dem alba-Holze kaum nach; es gilt als sehr dauerhaft bei Verwendung im Boulcu; nur $1.5 \mathrm{~cm}$ beträgt der Splint. Der Baum äbertrifft unsere ainheimischen Eichen wohl nur in der Höhe; denn in geschuitzten, wamen Lagru erheht er sich bis zu 50 Meter und zihlt dann zu den hüchaten Iaubbiummen des Ostens.

Quereus bicolor Willd., Swamp white oak, Sumpfweissoiche. Sie liebt die frischeren, muldenförmigen, kühleren Einsankungen und geht deshalb nicht so weit nach Süden als alba. Die Blatter sind unterseits kurz behaart, weisslich; die Früchte lang gestielt (Thefel I und II); sie steht dadurch der Quercus pedunculata ann nürhsten: ihre Rinde löst sich frühzeitig in breiten Fetzen ab, wie die der weisson Hickury (Shell-bark hickory), spaiter hat sie eine liinglich riseige, weis-arche Borke; die Verwendungr des Holzes, sein specifisches Gerwicht wir bei allat der Splint umfasst $2,5 \mathrm{~cm}$. Bei lokalem Vorkmom bildut sie je nach Beschaffenheit des Standortes kleinere Gruppen, alleinherrachend, ein Bild, das der nordamerikanische Wald nicht of darbirctet.

Quercus whtusiloba Michx. (syn.: stellata Wangh.), Post oak. Hortand-Eiche, ist so allgemein verhreitet wie alba, findet wich aher meist auf einem ganz specificchen Standorte, nämlich trocken,

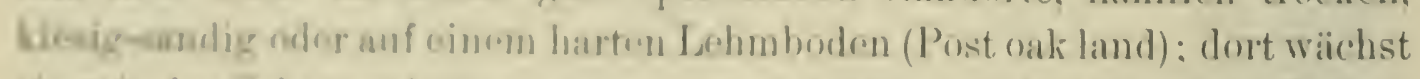

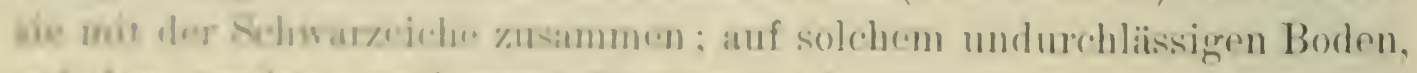
anf den tropkine mul nasse l'articen rasch wechseln, der arm an Gras

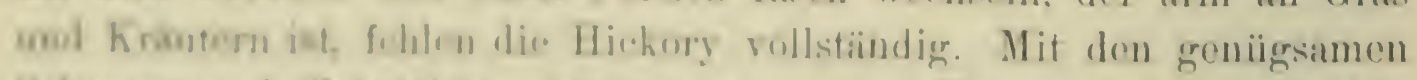

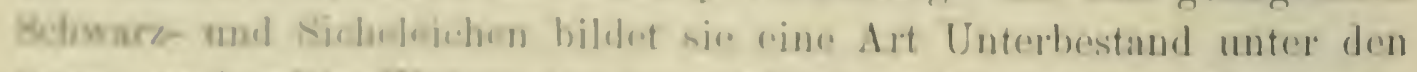

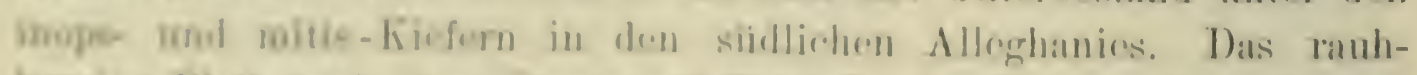

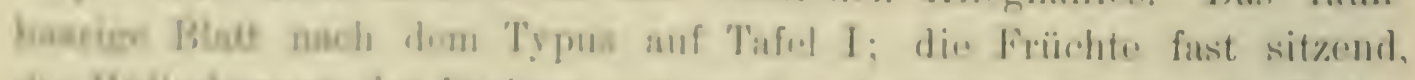

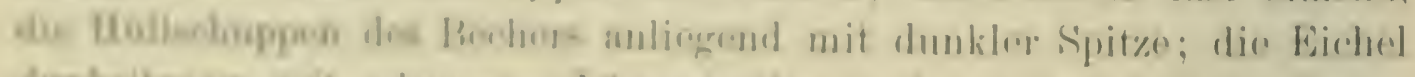

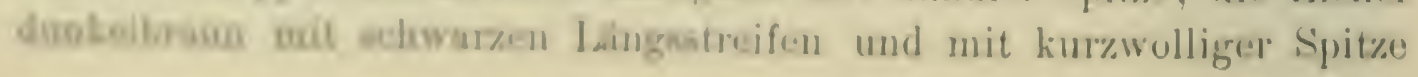


(Tafel II); das Innere des frischen Samens safrangelb. Der Baum erreicht kaum 20 Meter Höhe; sein Holz mit $3 \mathrm{~cm}$ Splint wird nur gelegentlich benützt.

Quercus Prinos L., Chesnut oak, Gerbereiche; der Name „Kastanieneiche" gebülhrt nur der Q. serrata in Japan. Der Bergregion angehörend, erreicht diese Eiche in den südlichen Alleghanies ihr Maxinum; als der wichtigste Gerbstofflieferant unter den Eichen im Osten, wird der Baum allseitig angefallen; „Millionen Fuss (b. m) dieses Baumes verfaulen im Walde, nachdem man ihnen die Rinde abgezogen, weil der Werth dieses Baumes (für Schwellenholz) in vielen Gegenden unbekannt ist oder unterschätzt wird", sagt ein Circular der forstlichen Abtheilung des landwirthschaftlichen Ministeriums. Das specifische Gewicht des dunkelbraunen Kernholzes ist gleich dem der Weisseiche; dagegen soll es elastischer sein als diese; Splint $1,5 \mathrm{~cm}$ breit, Rinde dunkel rothbraun; die Blätter sind nicht kastanienartig, wie der einheimische Namen sagt, sondern wie die Figur auf Tafel I zeigt, unterseits kurz behaart und hell; die grossen Früchte in einer dünnen, rauhen, am Rande schneidigen Cupula. (Tafel II.)

Quercus prinoides Willd, Chinquapin oak, Chinquapin-Eiche; eine Straucheiche in Massachusetts sowie in den westlichen Staaten, wird sie im Mississippidelta (die Identität beider Formen vorausgesetzt) ein Baum erster Grösse; ich gebe die Abbildung der bei der Baumform auftretenden Blätter (Tafel I) nach einem von Dr. Mo hr in Mobile mir gütigst geschenkten Exemplare; die Blätter unterseits durch kurze Behaarung heller als die Oberseite; junge Blätter und Triebe sind gelb behaart; die Früchte (Tafel II) sind nach der Zwergform abgebildet. Diese Eiche hat auffallende Aehnlichkeit mit der japanesischen Q. glandulifera, während Prinos sehr an die japanischen Q. crispula oder grossiserrata erinnert.

Quercus Michauxii Nutt., Basket oak, Cow-oak, Korbeiche. Sie erreicht in S.c. auf alluvialem Boden ihre Vollendung; ihre Blätter halten die Mitte zwischen Prinos prinoides, doch sind die Blätter (Tafel I) unterseits durch eine filzige Behaarung gekennzeichnet; die Früchte sind sehr gross (Tafel II); das Holz ist durch seine Spaltbarkeit sehr bemerkenswerth, die es ermöglicht, dasselbe zu Körben zu benützen.

Quercus Durandii Buckley, Durand's Eiche, die "weisse Eiche" des südlichen und westlichen Texas; auf trockenen Hügeln 
-traubfirmiz, im Alluvium der Flässe cin hoher Baum, in Alabama solten (Mhir).

Quercus Iyrata Walt.. Leiereiche; in S. c. zahlreich: die

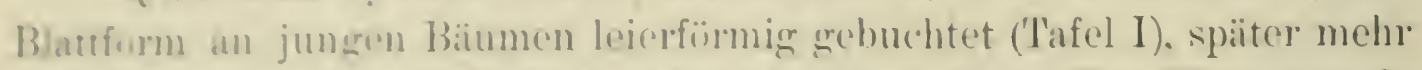

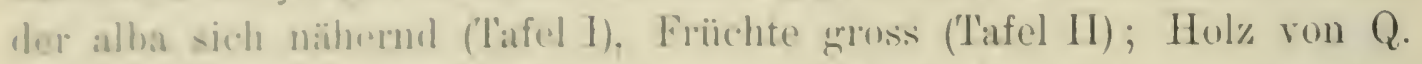
alha haum resschioden. Diese und die Konbeiche nehmen ron den sullandischen Fibhen dic feuchtesten Standorte ein, die zuerst bei Regen unter Wasieg gerathen.

Butanisch mohr als forstlich interessant sind die Bastarde der Weisedichen, won denen ich mur Q. alba und obtusiloba abgebildet labu. Herr Ci. Lotterman in Allenton (Mo) zeigte mir einen solchen Batum, den einzigren, der dem eifrigen Forscher bekannt geworden war; draselbe hatte vine Rindenbildung. wie sie der alba angehört, während dio Cupula dor Eicheln für die obtusiloba bezeichnend war; die Eichel selbut war der albal rleich. Abbildung des Blattes vide Tafel I. Bei spartanburg in sürl-Carulina war ich so glücklich ein zweites Exemplar zu entulecken, einen hohen Baum, den man vielleicht seiner ungewhhnlichen Erstheinung wegen gepflanzt hatte; die Rinde war der alba greich, die Blitter, unterseits behiart, hielten die Mitte zwisehen alba und obtusiloha; die Früchte waren völlig mit den obtusiloba-Früchten mit den dumkeln Lïngsstreifen identisch; von den übrigen Bastarden shit jeh nur gropflim\%te, kleinere Exemplare.

Die schwarycichen sind von jeher die Lieblinge der emoparahen Banmzüchfor und Parlibesitzor und zum Theil anch der Forst-

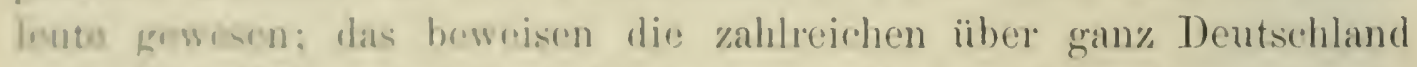

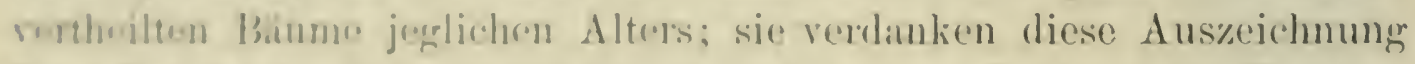

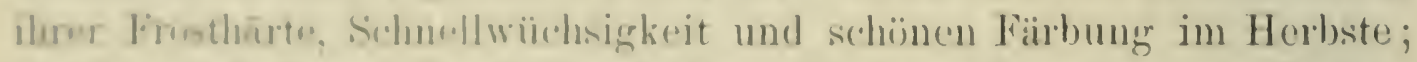

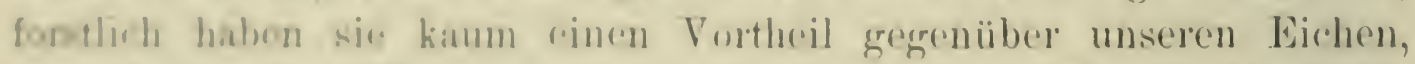

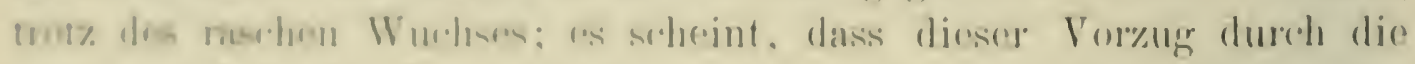

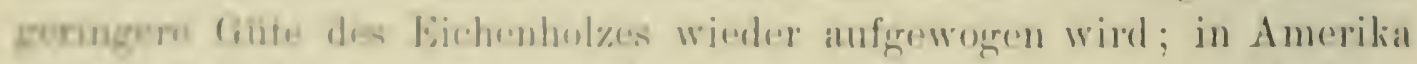

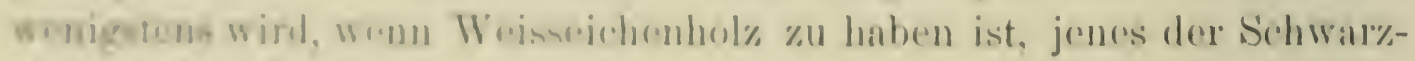
rebein nelit benütat.

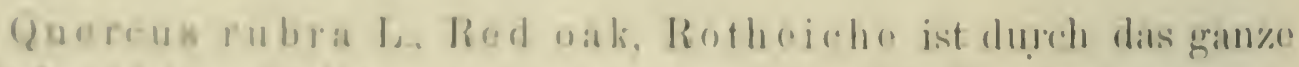

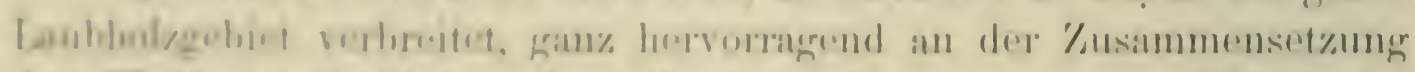

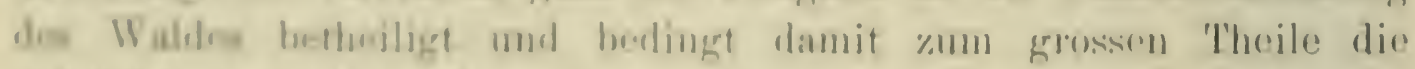

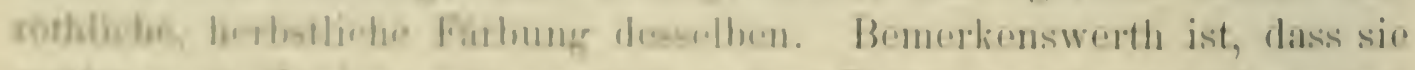

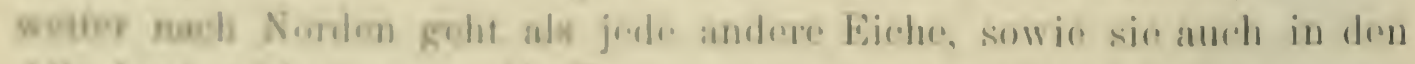

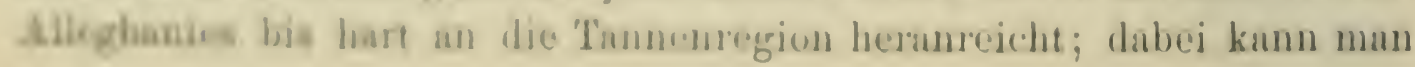


sie als stattlichen Baum auf allen guten Bodenarten und Expositionen sehen. Ihr Holz nimmt an Schwere nach Süden, also mit der Vêgetationsdauer und -Intensität dem Optimum entgegen zu; gleiches findet von sandigen Böden nach reichen, feuchten und lehmigen Böden hin statt. Das specifische Gewicht des Holzes beträgt 65 nach den Censusangaben, 64 nach meinen weniger umfangreichen Bestimmungen. Die Wachsthumsgeschwindigkeit ist, wenigstens in den ersten 50 Jahren, bedentend rascher als von unserer Eiche. Das im New-Yorker Museum befindliche, auf freier Fläche erwachsene Stück (second growth) hatte mit 20 Jahren einen Durchmesser von $15,8 \mathrm{~cm}$, mit 40 von $28,8 \mathrm{~cm}$ und mit 57 von $46,6 \mathrm{~cm}$ erreicht. Es scheint, dass die rubra ihre Schnellwüchsigkeit auch bei uns beibehält. Eine in Kleinflottbeck bei Hamburg erwachsene Eiche, die ich von Herrn J. Booth gütigst erhielt, zeigte mit 40 Jahren selbst $30,6 \mathrm{~cm}$ Durchmesser, mit 52 Jahren aber nur $37,8 \mathrm{~cm}$. So schlecht wie Em ers on das Holz darstellt, scheint es doch nicht zu sein; wenigstens wird es zu Fassdauben gerne genommen. Unbestritten bleibt ihr dekorativer Vorzug, eine Eigenschaft die sie mit anderen Eichen ihrer Heimat den unserigen gegenüber theilt. Das Holz deckt eine Borke, die in schmalen, dünnen Platten sich ablöst; ihr Kern ist röthlichbraun, der Splint weisslich $2 \mathrm{~cm}$ breit.

Das Blatt ist nur etwa zur Hälfte eingeschnitten, Schattenblätter oft nur bis $1 / 4$ der Blattspreite (Tafel I); die Früchte (Tafel II) gross mit flacher Endfläche, entsprechend der seichten Cupula; die Früchte deckt leicht abwischbarer, ockerfarbiger Flaum; die Eichelschale ist braunroth glänzend.

Quercus coccinea Wangh., Scarlet oak, Scharlacheiche. Die botanischen i. Ierkmale sind denen. der folgenden Rotheiche gegenüber gestellt (Tafel I und II); durch Süden und Norden verbreitet, erreicht diese Eiche 30 Meter, ausnahmsweise selbst 54 Meter (Sargent); im specifischen Gewichte übertrifft sie mit 74 die Rotheichen, ohne dass aber desshalb der Gebrauchswerth des Holzes bis jetzt ein grösserer wäre als jener der übrigen Rotheichen. Dekorativ ist sie ausserordentlich wirkungsvoll durch die rothe Färbung, die etwas hellere Töne als alba und rubra zeigt.

Die technisch wichtigste unter den Rotheichen ist

Quercus tinctoria Bartr., Black oak, Färbereiche, deren Rinde einen gelben Farbstoff für die Färberei gibt. Durch das ganze 
Gebiet verbreitut, int sie auf trockenen, oft steinigen, kiesigens.Höhentasun zahlecich. Die Blitter ('Tafel I) stehen zwischen rubra und coccinea in der Tiefe der Ausbuchtung. ron beiden durch die lange 7.jit sich erhaltende Bedeckung der Unterscite mit Stemhaaren unterschieden: die Blithen entfalten sich spiiter als bei coceinea und die jumen Blatter und Triche sind weiss behaart; die Schuppen der Cupula sind bei tinctoria am oberen Rande abstehend, bei coceinea fest anliegend (Tafel 1I): beide Fichen wechseln in Gestalt und Grösse der Früchte, die mit abwischbarem Flaum bedeckt sind. Die junge Rinde der tinctoria sowie das sameneiweiss sind gelb, bei coccinea weiss; die Borke der Firberviche längs- und tiefrissig mit spïrlichen Querrissen, bei der Scharlacheiche mit zahlreichen Querrissen; vom dekorativen Standpunkte rerdient sie weniger Beachtung, da die herbstliche Färbung am wenigsten unter den Rotheichen hervorsticht.

Quercus palustris Du Roi, Pin oak, Nadeleiche, spiessciche. Von allen Verwandten ist der erwachsene Baum durch den aumwprochen greraden Schaft unterschieden, der sich wie bei cinem Nadelhol\% bis in die Spitze verfolgen lässt. Da die Belaubung wogen der tief eingeschnittenen Blätter, etwa zwei Drittel der Blattfluche, aine lockere ist. fällt die Durchsichtigkeit der Krone auf; die A setw sind selır dünn, etwas herabhängend und erhalten sich, abgestorben. lange \%.jt spianformig vom Baume abstehend, wesshalb sie den Namen Pin oak. Nideleiche, orhalten hat; die Blätter sind die kleinsten von allen Rothrichen. und offtor als bei coceinea stehen bei ihnen die gregrensitigan Jappen auf ungleichor Höho; die Früchte klein mit seichtem Becher. (Thafel II.)

Auf kraftierm Boden am Filussrande und den anliegrenden Niederungen in S. c. Gwarchst sie, die Nadeleiche, mit einem walzenförmigren Sthafen ron grumer Vullkummenheit, his zu 30 Meter Höhe und darabor. Ihr Hol\% hat dem anderer Rotheichen gegenüber keine Vorzüge.

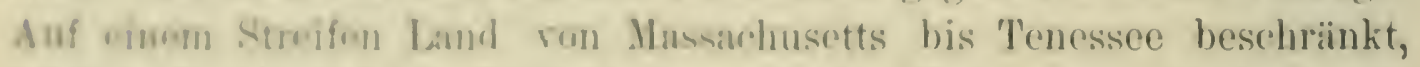
wache sin nurgend im Sumpflunde, wie ihr Name sagt, sondern nur am Rando som foulherem Termin und in Niederungen, in denen bach

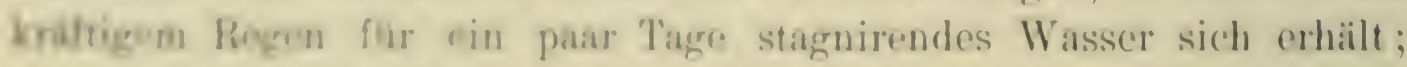
movit wragewna reichen mein. Beobachtungen. Diese Eiche wächst

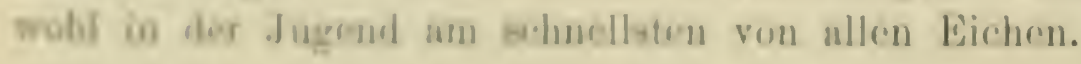

Querons faleath Michs., Spanish oak, Sicheleiche. In 8. a. aod e leimbech, bildet sie im Higgelland der Golfstanten mit 
Q. Catesbaei und nigra ein zweites Wachsthum nach Ausnützung des Urwaldes, das reichlich mit Kiefern durchsetzt die südlichen, sandigkiesigen Ausläufern der Alleghanies bedeckt; mit Catesbaei nimmt sie von den mageren Böden der südlichen Kiefer Besitz, bleibt aber ein niedriger Baum. Auf gutem Boden ist die Sicheleiche ein stattlicher Baum mit eigenartiger Belaubung, welche den Namen "Sicheleiche" rechtfertigen mag (Tafel II); an jungen Bäumen oder an im Schatten erwachsenen Blättern sieht man oft blos dreilappe Formen, oft sind die Lappen so reducirt, dass das Blatt dem der Schwarzeiche nahe kommt; die Blätter sind unterseits kurz behaart und dadurch hell; die Eichel an der Schale mit feinen Vertiefungen (Tafel II). Das Holz der Sicheleiche scheint sich zu dem der übrigen nordamerikanischen Eichen so ungünstig zu verhalten, wie das der ungarischen Zerreiche zu dem der mitteleuropäischen Eichen, es ist nämlich fast ausschliesslich Brennholz.

Quercus Catesbaei Michx., Turkey oak, Gabeleiche, ein Halbbaum, der besonders mit Q. nigra zusammen den sandig-kiesigen, ausgewaschenen Boden im südlichen Laubholzgebiete, besonders innerhalb der Kiefern einnimmt. Durch das rasche Bodenfeuer wenig verletzt, gelangt sie mit nigra in derartigen Standorten allmählig zur Vorherrschaft; sie liefert auf solchen Plätzen ein gutes Brennholz und Kleinnutzholz. Leider ist sie wie nigra bei uns, die wir so viele herabgemagerte Kiefernböden besitzen, wegen der Frostgefahr kaum brauchbar. Ihre Blattform mag den deutschen Namen rechtfertigen, den sie auch in Amerika führt; das Blatt (Tafel I) ist unterseits kahl und verfärbt unter den Eichen des Südens am besten roth; die Früchte kommen denen der Scharlacheiche am nächsten, sind aber deutlich dadurch unterschieden, dass die Hüllschuppen am oberen Rande der Cupula umgebogen sind und die Innenseite derselben bis zur halben Tiefe auskleiden (Tafel II).

Quercus nigra L., Black Jack, Schwarzeiche. Von NewYork an durch den ganzen Süden, ein Baum bis 18 Meter Höhe; mit falcata und Catesbaei auf trockenem, kiesig-sandigen oder mit obtusiloba auf lehmigem Boden lichte Bestände von geringer Höhe bildend; Blätter vorwiegend dreilappig (Tafel I), Früchte (Tafel II) der Scharlacheichel sehr ähnlich, aber durch die blauschwarzen Längsstreifen unterschieden; im Norden (Jersey) bildet sie mit Vaccinieen den Bodenschutz in den Kieferwaldungen. Die Rinde des Baumes ist eine dunkelgraue, kleinaber tiefschuppige, harte Borke. 
Quercus imbricaria Michx.. Laurel oak. Glanzeiche. en selur istiger Baum. dor besseren Boden als die beiden vorigen verlangt: die dunkrlgrïinen, glïn\%enden Blitter rechtfertigen den Namen; Rinde klein, dichochuppig. Blitter sranzandigr ('Taffel I), unterseits kurz und weichbatrie; die kleinen Frïchte (Tafel II) der Nadcleichel ahnlich.

Quereus laurifolia Michx., Laurel wak. Lorbeereiche, oftur als Variotit von Phellos genommen, ist ganz auf den Süden der Lambholzzone buschränkt, besunders mächtig im Gebiete des Immergrūnen am st. Johnflusse in Florida und dort fast immergrün. Blïter von sehr hriftig wachsenden Exemplaren an Gestalt und Grösse der vurigen sehr ihnlich (Tafel I), aher unterseits völlig kahl; gewöhnlich jedoch sind dir Blitter kleiner; Früchte ganz grlatt, glïnzend mit dunkeln Latugnotreifen (Tafel II): Sumeneiweiss ron grelber Farbe.

Quercusaquatica Walt. Walter oak, Sumpfeiche, Wasserciche; Blätter der Kurztriebe kleinen Blättern der Schwarzeiche ähnlich (Tafol I), an Langstriben und jungen Pflanzen aber wie die Abbildung auf Tafol I; dir Erüchte (Thufel II) stehen zwischen Plellos- und Laurj-

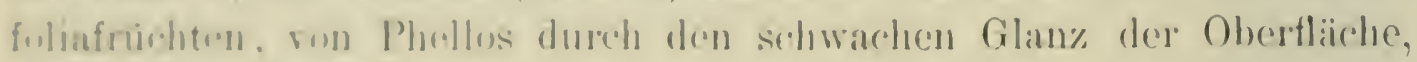
durch sparliche Hatre und durch die seichte, an Rotheiche erinnernde Cupula rersehieden. Rinde des erwachsenen Baunes grlatt. Diese Eiche wachst unter den verwandten Südlïndern in der Union am selnellsten; mit $40-50$ cm Brusthöhendurchmesser, in 30 Jahren übertriftt sie selbet rirens.

(Quercus hoterophylla Michx. f., Bartrams oak, Bartrame-liche. Diese Eiche labe ich im wilden \%ostande nicht

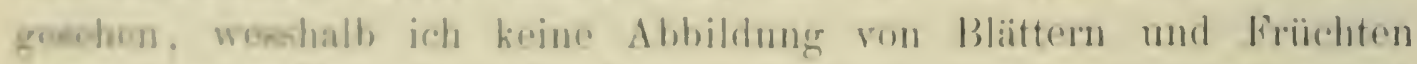
goken kann. Sin int in Norramerika selten in den Golfstaten und wird ron Vielon als Bastard betrachtet.

Quaraus Phollos L., Willow oals, Woidenejehe. Früchte

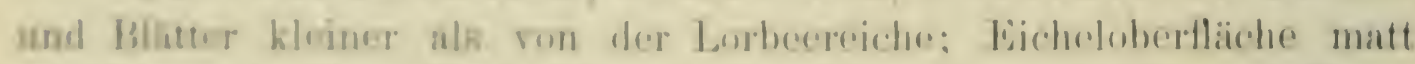

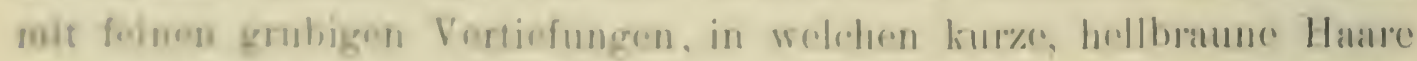
etrom. die daher nuche abwischbar sind; dir Weideneiche hat wohl die

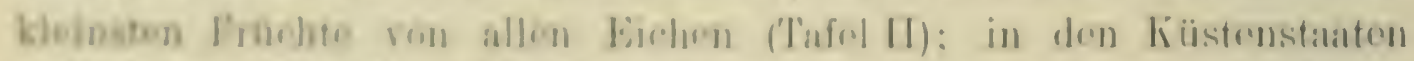

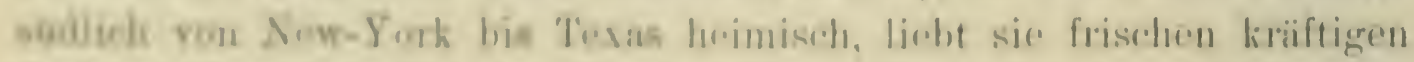

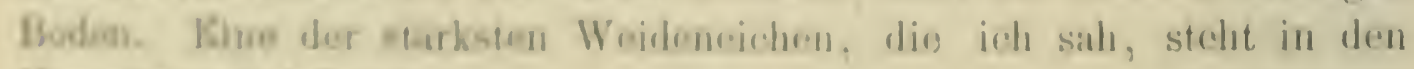
Kewgarten lei Lamdon 
Mehrere Schwarzeichen, wie Q. cinerea Michx., sind kaum Halbbäume, immerhin jedoch später ron Werth, da sie auf schechten Böden noch eine ganz beachtenswerthe Holzproduktion bieten.

Die Gattung Juglans liefert überall, wo sie wächst, werthvolles, besonders für Möbelstïcke, Büchsenschäfte sehr gesuchtes Holz; das der europäischen Wallnuss war ror Auffindung des Mahagoniholzes in Westindien fast ausschliesslich zu obigen Zwecken in Europa in Gebrauch und wurde in ziemlicher Menge, trotz der schwarzen Wallnuss, nach Amerika exportirt; heut zu Tage, da die alten, starken Wallnussbäume der Ausrottung nahe stehen, steigt wieder die Einfuhr von in Europa gewachsenem, oft mit werthvollen Masern versehenem Nutzholze. Dass es aber immer noch herrliche Exemplare der beiden nordamerikanischen Nussarten gibt, dafür konnten die schönen, polirten Riesenbretter und Maserfournire der Staatsausstellung von Missouri in St. Louis 1885 als Belege dienen. Die Menge der Nussbäume, die dem Eisenbahnbau zum Opfer fallen und auf deren Schäften die Schienen ruhen, ist enorm; man versicherte mir, dass zu Stossschwellen von 4,25 Meter Länge neben Weisseiche und Gleditschie das Holz des Nussbaumes vorzüglich sei; in manchen Staaten ist die Vernichtung der Nutzbäume geradezu schon vollendet, sie helfen anderen Staaten ihre Vorräthe aufzehren.

Juglans nigra L., Black Wallnut, Schwarze Wallnuss. Durch das ganze Gebiet rerbreitet, erreicht sie ihre grösste Entfaltung in S.c.; dort erhebt sie sich auf dem angeschwemmten, kräftigen Boden bis zu 45 Meter Höhe. Die Frucht hat die Form eines Apfels, ist mit dicker, unbehaarter, anfangs grüner, abgefallen schwarz werdender Schale umgeben; die Steinschale schwarz, tief grubig-warzig (Tafel IV); am grössten sind die Früchte im Optimum, in S. c.; nach Nord und West nimmt die Grösse beträchtlich ab. Die Nüsse von Texas sind kaum halb so gross als jene von Missouri und seicht runzelig an der Oberfläche. Den Namen „Schwarze Wallnuss“ verdankt sie der anfünglich kleinschuppigen, dunkelgrauen Borke, welche später tief rissig wird. Wo der Baum isolirt aufwächst, zertheilt sich der Stamm schon frülzeitig in sehr kräftige Seitenäste und nähert sich dadurch im Habitus unserer Wallnuss ; im Waldesschlusse dagegen, auf dem fruchtbaren Boden der Flussniederungen, an tiefgründigen Berghängen entwickelt er einen vollendeten, astreinen Schaft. Kostbarer aber als so tadellose Nutzstücke sind die Maserbildungen. Das Holz nimmt eine vorzügliche Politur 
an. furbt sich mit der Zcit dunkler, bis fast schwar\% und ist in allen reinen gutru Eigensohaften dem Holze der grauen Wallnuss überlegen; fa-t der ganze Holzhörper eines stammes besteht aus dunkelbraunrioletem hernhol\%e. denn der splint ist nur $1 \mathrm{~cm}$ breit. Der Zuwachsgang der Wallnuss im Urwalde ist selur langsam: ein 192 jähriger Baum hatte 1.5 Meter über Buden in 20 Jahren erst einen Durchmener ron 4,4 cm, im 60. von $13,0 \mathrm{~cm}$, im 100. ron $32,8 \mathrm{~cm}$, im 192. Jahre von 67 cm crreicht, wobei die bezïglichen Jalnringsbreiten sich auf $1,1 \mathrm{~mm}, 1,2 \mathrm{~mm}, 1.6 \mathrm{~mm}$ und 1,7 mm berechnen; man hann sieh denken, welch hohen Werth sulches feines, gleichmässig gewachsenes Nutgholz besitzen muss; sulches Hulz erwächst heutzutage in Amerika nirgends mehr, wo der Urwald rernichtet wurde; solches Holz wird auch schwerlich in Europa erwachsen, wenigstens nicht in Deutschland. weil bej uns die Wallmuss sich auch in der Jugend als sehr emptindlich gegen Beschattung erweisen dürfte. In Hohenheim erreichte ein astrobhes, freierwalchenes Exemplar in 100 Jahren 1 Meter Stammdurchmener, ein anderes, in der Beengung durch andere Bäume aufgewachen, ontwickelte einen vollendeten Schaft.

Juglans cinerea L., Butter nut, Butternuss, Graue Wallnuss. Hor Verbreitungserebiet ist beschüukter, die Farbe des hernhulges kaum blasser und unschöner als jene der schwarzen Nuss; aber im sperifiochen Gewiolnte steht die Butternuss mit 41 weit hinter Jer wchwargen Nuss (bi) zuriuck, obgleich dieser Fator bei dem specifischen Nutzwerthe der Nussarten ron geringer Bedeutung ist; aurh si. rerlangt tiefgrïndigen Boden, warme geschützte Lagre, wemn sie zu einrm Nutzhaumo erwadesen soll, steht aber damn an Wachsthumssohrollighoit sichor hinter der schwargen Wallnuss nicht zuriek. Die

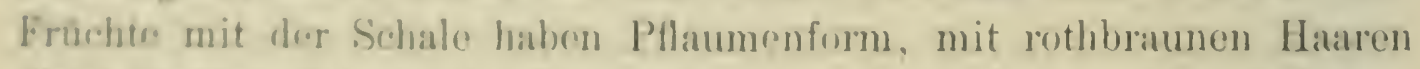
divht heeet\%t; dio streinige Innenschale mit dentlich erkemnbaren Längs-

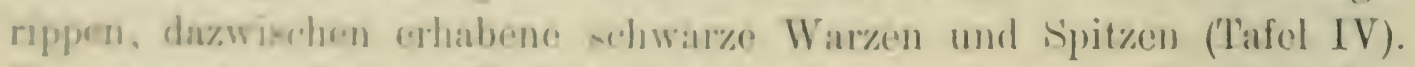
Dow umparrig gofioderto Blatt ist dem der vorigen Art solu iilulich, aber beidemoats weich behaurt.

Div zur Pamilio der Juglandineen gehörige Gattung Carya ist wise banz specifiuch nordamerikanische Gathumg und dort durch ancht

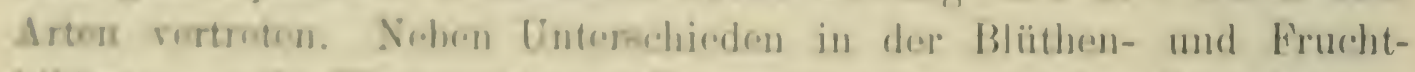

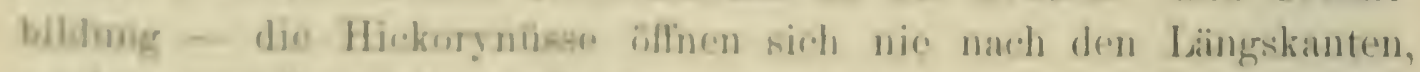

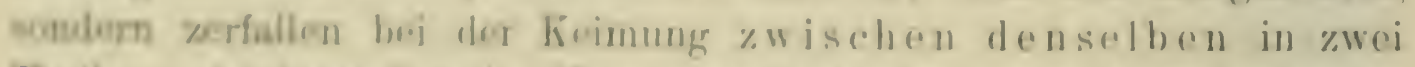

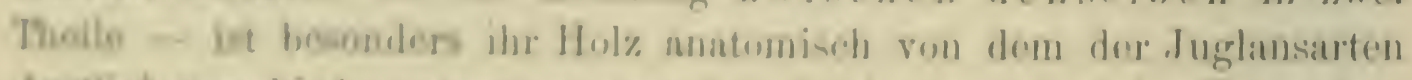

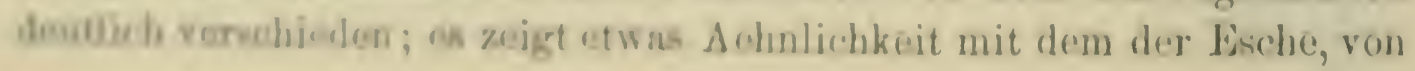


dem es leicht zu unterscheiden ist durch die zarten, dem Jahresringe parallelen Parenchymstreifen, die an feinen Querschnitten dunkel, bei beliebigem Hirnschnitte aber wie helle Linien in der dunkeln Kernholzmasse erscheinen (Fig. 4). Das Holz der Carya's ist unter dem Namen Hickory-wood bekannt und gehört zu den werthvollsten Hölzern, welche die nördliche, gemässigte Erdhälfte producirt. Der Preis für bestes Nutzholz betrug in Boston 1876400 Mark pro 2,5 cbm zugeschnittene Waare; dem hohen specifischen Gewichte entsprechend ist auch der Brennwerth des Holzes ein sehr hoher; er wird gewöhnlich gleich 100 genommen und die übrigen Hölzer dazu in Proportion gesetzt. Der Preis für 3,5 Ster Hickorybrennholz betrug in der Stadt Boston 1885 64 Mark, in dem Lande (Massachusetts) 32-40 Mark.

Anatomische Verschiedenheiten im Bau des Holzes der einzelnen Arten scheinen nicht $\mathrm{zu}$ bestehen; ihre Trennung in der Praxis ist desshalb eine mangelhafte und der Name Hickory ist ein Sammelname für Holz von mehreren Arten; bei Handelswaare ist immer das Holz einer der am weitesten nach Norden reichenden Carya gemeint; diese, Carya alba, porcina, sulcata, tomentosa und amara umfassend, stehen sich nämlich in ihrem Gebrauchswerthe sehr nahe; in erster Linie dienen sie zu Handgriffen von Geräthen aller Art, beim Wagenbau insbesonders zu zierlichen Speichen (dünnster Querschnitt an Luxuswagen $3,75 \square \mathrm{cm}$, dickster $4,5 \square \mathrm{cm}$, Radspeichenlänge $54 \mathrm{~cm}$ ), zu Reifen, Körben und zwar wird hiezu jene Art verwendet, die am nächsten zur Hand ist. Die südlichen Arten dagegen, C. olivaeformis, myristicaeformis, aquatica stehen in ihrem Holzwerthe weit zurück und werden fast ausschliesslich als Feuerungsmaterial benützt.

Diess scheint mit dem früher erwähnten Satze, dass vom Optimum hinweg die Holzgüte (Schwere) abnimmt innerhalb der Gattung sowohl, als für die einzelne Art, in Widerspruch zu stehen. Ordnet man die für den Censusbericht untersuchten Splintstücke der weissen Hickory nach ihrer Herkunft aus Nord und Süd, so zeigen die Splintstiicke mit gleicher Ringbreite in N. a. und c. ein specifisches Gewicht von 83 , in S. a. c. dagegen von 96 ; die Kernstïcke sind in geringerer Zahl vorhanden und verhalten sich N.: S. wie 80:85. Auch bei den Eichen kann man die Eigenthümlichkeit beobachten, dass die Arten mit weiterem Spielraume ein schwereres Holz bilden als die allein auf das Optimum der Gattung beschränkten Arten; die Gewichte der Hickory's, nach diesem Gesichtspunkte geordnet, verhalten sich wie 81 zu 75.

Die Hickory's erreichen alle 30 Meter, einige in ihrem Optimum selbst 40 Meter und darüber. Lange im Halbschatten um ihr Dasein 
khmpfend. kennen sie im Urwalde keine Spät- und Frïhfrïste. wachsen aber auch in Folere dresen sher langsam. Der Wachsthumgang des Sin-lurker sammlungstïche's war, dem im Urwalde geübten langsamen Verjungungsverfalmen entsprechend ein äusserst verzögerter. Die Carya alba hatte etwa 2 Meter über Boden:

\begin{tabular}{|c|c|c|c|}
\hline $\begin{array}{l}\text { Alter } \\
\text { (Jahre) }\end{array}$ & $\begin{array}{c}\text { Durchmesser } \\
\text { cm }\end{array}$ & $\begin{array}{c}\text { Kreistliche } \\
\square \mathrm{cm}\end{array}$ & $\begin{array}{c}\text { Zuwachs pro Jahr } \\
\text { der Periode } \\
\square \mathrm{cm}\end{array}$ \\
\hline 10 & 1,6 & 2,0 & 0,2 \\
\hline$\because 11$ & 2,6 & 5,3 & 0,3 \\
\hline 10 & 5), 4 & $2: 2,9$ & 0,9 \\
\hline 60 & 8,4 & $\therefore, 4$ & 1,6 \\
\hline 80 & 11,4 & $109,1)$ & 2,6 \\
\hline 100 & 15,0 & $17(i, 6)$ & 3,4 \\
\hline $1: 0$ & 19,6 & 222,9 & 2,4 \\
\hline 160 & 34,1 & $(107, \overline{1})$ & $1, \pi$ \\
\hline$\because(x)$ & 42,6 & $1: 06,1$ & 1,5 \\
\hline 233 & $49,1)$ & 1581,8 & 1,1 \\
\hline
\end{tabular}

Die Splintbreite des Stiicles hetrug 4,6 cm und umfisste 47 Jahrearinge.

Eine alte Carya porcina zeigte folgenden Zuwachscrang:

\begin{tabular}{|c|c|c|c|}
\hline $\begin{array}{l}\text { Alter } \\
\text { Jahrie) }\end{array}$ & $\begin{array}{l}\text { Durchmesser } \\
\text { ('11 }\end{array}$ & $\begin{array}{l}\text { Kreisfliche } \\
\square \mathrm{cm}\end{array}$ & $\begin{array}{c}\text { Zuwachs pro Jalir } \\
\square \mathrm{cm}\end{array}$ \\
\hline 10 & 1,4 & 2,5 & 0,2 \\
\hline 20 & 2,6 & 5,3 & 0,3 \\
\hline 40) & 4,6 & 16,6 & 0,6 \\
\hline (6) & $8,1)$ & 50,2 & 1,7 \\
\hline 8) & 10,3 & 83,3 & 1,7 \\
\hline$I(x)$ & $1: 3,1$ & 141,0 & 3,4 \\
\hline 121 & 20 & 314,0 & 8,6 \\
\hline 181 & $2 !, 8$ & $1 ; 97,1$ & 19,2 \\
\hline $1(2)$ & 84,5 & $1 \mid \leq 1,4$ & 24,2 \\
\hline$|x|$ & 45,4 & $16: 17,9$ & 21,8 \\
\hline $2\left(x_{1}\right.$ & 51,1 & 20733,9 & 22,8 \\
\hline 220 &, $1 ;, x$ & 2502,4 & 21,4 \\
\hline 2111 & 60,65 & 2840,1 & 19,0 \\
\hline 204 & $(i 2,1)$ & $301 \div 1,0$ & 8,5 \\
\hline
\end{tabular}


Auffallend ist der langsame Wachsthumgang in den ersten hundert Jahren, dann die plötzliche Steigerung und lange Dauer des kräftigen Zuwachses; der Splint betrug 4,1 $\mathrm{cm}$ und umfasste 44 Jahresbildungen. Carya tomentosa hatte:

\begin{tabular}{r|r|r|r}
\hline $\begin{array}{c}\text { Alter } \\
\text { Jahre) }\end{array}$ & $\begin{array}{c}\text { Durchmesser } \\
\mathrm{cm}\end{array}$ & $\begin{array}{c}\text { Kreisfläche } \\
\square \mathrm{cm}\end{array}$ & $\begin{array}{c}\text { Zuwachs pro Jahr } \\
\text { der Periode } \\
\square \mathrm{cm}\end{array}$ \\
\hline 10 & 1,4 & $\mathbf{1 , 5}$ & 0,2 \\
20 & 2,4 & $\mathbf{4 , 5}$ & 0,3 \\
40 & 4,4 & 15,2 & 0,5 \\
60 & 8,4 & 55,4 & 2,0 \\
80 & 10,8 & 91,5 & 1,8 \\
100 & 14,1 & 156,2 & 3,2 \\
120 & 17,4 & 237,8 & 4,1 \\
140 & 21,0 & 346,2 & 5,4 \\
160 & 28,6 & 642,1 & 14,8 \\
$\mathbf{1 5 0}$ & $\mathbf{3 5 , 0}$ & $\mathbf{9 6 2 , 0}$ & $\mathbf{1 6 , 0}$ \\
200 & 40,0 & 1257,0 & 14,7 \\
210 & 42,2 & 1389,4 & $\mathbf{1 3 , 2}$ \\
& & &
\end{tabular}

Der Splint betrug $7,1 \mathrm{~cm}$ und umfasste 51 Jahre.

Eine ausgewachsene Carya sulcata hatte:

\begin{tabular}{c|c|c|c}
\hline $\begin{array}{c}\text { Alter } \\
\text { (Jahre) }\end{array}$ & $\begin{array}{c}\text { Durchmesser } \\
\mathrm{cm}\end{array}$ & $\begin{array}{c}\text { Kreisfläche } \\
\square \mathrm{cm}\end{array}$ & $\begin{array}{c}\text { Zuwachs } \\
\square \mathrm{cm}\end{array}$ \\
\hline 10 & 1,8 & 2,54 & 0,3 \\
20 & 3,2 & 8,0 & 0,5 \\
40 & 5,4 & 22,9 & 0,7 \\
60 & 9,0 & 63,6 & 2,0 \\
80 & 13,2 & 136,6 & 3,5 \\
100 & 18,6 & 271,6 & 6,7 \\
120 & 26,2 & 538,5 & 13,3 \\
140 & 35,4 & 984,6 & 22,3 \\
160 & 42,8 & 1438,1 & 22,7 \\
180 & 48,4 & 1839,4 & 19,7 \\
200 & 54,2 & 2306,3 & 23,7 \\
220 & 60,0 & 2827,0 & 26,0 \\
240 & 65,0 & 3318,0 & 24,5 \\
260 & 70,0 & 3848,0 & 26,5 \\
280 & 74,0 & 4301,0 & 22,7 \\
300 & 77,6 & 4726,0 & 21,3 \\
340 & 84,8 & 5644,0 & 22,4 \\
& & &
\end{tabular}


Dieser Baum, der zur Zeit Kaiser Karl V. aus dem Simen keimte, stand zur Zeit der Fiillung 1879 noch in vollster Wachsthums- nergie: die splintbreite betrug $4,1 \mathrm{~cm}$ und umfasste 46 Jahre.

Endlich Curya olivaeformis zeigte in:

\begin{tabular}{c|c|c|c}
\hline $\begin{array}{c}\text { Niter } \\
\text { Juhre) }\end{array}$ & $\begin{array}{c}\text { Durchmesser } \\
\mathrm{cm}\end{array}$ & $\begin{array}{c}\text { Kreisfluche } \\
\square \mathrm{cm}\end{array}$ & $\begin{array}{c}\text { Zuwachs } \\
\square \mathrm{cm}\end{array}$ \\
\hline 10 & 4 & 12,8 & 1,3 \\
20 & 5,2 & 52,8 & 4,0 \\
40 & 15,2 & 173,5 & 6,0 \\
60 & 25,6 & 514,9 & 17,1 \\
80 & 37,0 & 1075,0 & 28,0 \\
100 & 45,5 & 1646,0 & 28,6 \\
120 & 56,0 & $\mathbf{2 1 6 3 , 0}$ & $\mathbf{4 0 , 5}$ \\
123 & 60,0 & 2827,0 & 40,4
\end{tabular}

Dic splintbreite betrug $5,4 \mathrm{~cm}$ und umfasste 20 Jahre.

Carya aqquatica im Urwalde erwachsen:

\begin{tabular}{|c|c|c|c|}
\hline $\begin{array}{c}\text { Alter } \\
\text { (Jahre) }\end{array}$ & $\begin{array}{l}\text { Durchmesser } \\
\text { cm }\end{array}$ & $\begin{array}{c}\text { Kreistliche } \\
\square \mathrm{cm}\end{array}$ & $\begin{array}{c}\text { Zuwachs } \\
\square \mathrm{cm}\end{array}$ \\
\hline 111 & 2,8 & 6,2 & 0,6 \\
\hline 20 & כ),0 & 19,6 & 1,3 \\
\hline 10 & 11,6 & 305,7 & 4,3 \\
\hline (i) & 20,4 & 326,6 & 11,0 \\
\hline 89) & 26,8 & 514,2 & 10,9 \\
\hline $1(x)$ & 32,8 & 814,7 & 15,0 \\
\hline 122 & 39,6 & 1228,9 & 17,4 \\
\hline
\end{tabular}

Splinthroite 5.2 con und 33 Jahue umfassend.

Carya aquation, II. Wachsthum (second growth):

\begin{tabular}{c|c|c|c}
\hline $\begin{array}{c}\text { Aluer } \\
\text { Jahre) }\end{array}$ & $\begin{array}{c}\text { Durchmesser } \\
\text { ('m }\end{array}$ & $\begin{array}{c}\text { Kreisfliche } \\
\square \text { (rm }\end{array}$ & $\begin{array}{c}\text { /uwachs } \\
\square \mathrm{cm}\end{array}$ \\
\hline 10 & 4,6 & 16,$6 ;$ & 1,7 \\
20 & 16,0 & 201,0 & 5,2 \\
31 & 30,0 & 707,0 & 46,0
\end{tabular}

Splinthreite $9,1 \mathrm{~cm} 16$ Jahre umfassend.

Chargh pum ima (II. Wardsthmm), anf geringem, steinigrm aber

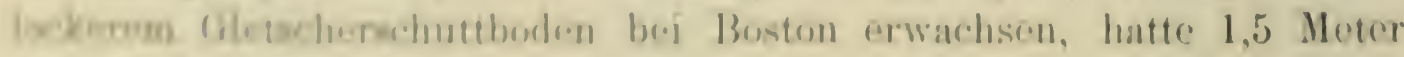
aher Boden fnlgenden Zuwarlisgang: 


\begin{tabular}{c|c|c|c}
\hline $\begin{array}{c}\text { Alter } \\
\text { (Jahre) }\end{array}$ & $\begin{array}{c}\text { Durchmesser } \\
\mathrm{cm}\end{array}$ & $\begin{array}{c}\text { Kreisflache } \\
\square \mathrm{cm}\end{array}$ & $\begin{array}{c}\text { Zuwachs } \\
\text { in einem Jahre } \\
\square \mathrm{cm}\end{array}$ \\
\hline 10 & 4,0 & 12,6 & 1,3 \\
20 & 9,0 & 63,6 & 5,1 \\
$\mathbf{3 0}$ & $\mathbf{1 4 , 0}$ & $\mathbf{1 5 3 , 9}$ & $\mathbf{9 , 0}$ \\
40 & 17,0 & 226,9 & 7,3 \\
50 & 19,4 & 293,4 & 6,7 \\
60 & 20,0 & 314 & 2,6 \\
80 & 21,0 & 346,2 & 1,61 \\
95 & 22,4 & 393,8 & 3,8
\end{tabular}

Auf diesem geringwerthigen Boden war der Stärkezuwachs anfangs verhältnissmässig rasch, erreichte schon mit 30 Jahren sein Maximum, nahm aber dann fast bis zur Unmöglichkeit die Jahresringe zu zählen $\mathrm{ab}$; erst während der letzten 10 Jahre hatte durch die starke Lichtung des Bestandes zu Anbauversuchen eine Steigerung des Zuwachses stattgefunden. - Eine in Deutschland auf sandigem Lehmboden in Kleinflottbeck bei Hamburg gewachsene Carya alba, die wie die folgenden Herr J. Booth die Güte hatte, mir zu überlassen, hatte mit 40 Jahren einen Durchmesser von $17,6 \mathrm{~cm}$, also dieselbe Stärke wie die amerikanische aus zweiten Wachsthum; vom 40.-56. Jahre der Stärkezuwachs $8,95 \square \mathrm{cm}$ pro Jahr. Eine Carya porcina erreichte mit 40 Jahren 22,3 cm Durchmesser und hatte zwischen 40 und 50 Jahren einen Zuwachs von $6,6 \square \mathrm{cm}$ pro Jahr; eine Carya amara zeigte bei 40 Jahren $14,5 \mathrm{~cm}$ Durchmesser und von da bis zum 56. Jahre einen Zuwachs von $6,9 \square \mathrm{cm}$.

Bei allen Stücken umfasste der Kern erst wenige Jahreslagen. Hickory's in der wärmsten Lage Deutschlands, wo die Wallnuss kaum ron Frost leidet, die Eiche für Deutschland am besten gedeiht, dort auf lockerem und besten Boden gepflanzt, den noch der Wald besitzt - und die Hickory's verdienen den besten Boden - wird ihr Zuwachs gewiss den einheimischen edlen Laubhölzern nicht zurückstehen.

Die Hickoryarten nehmen an dem Aufbau des östlichen Laubwaldes gleichwie die Eichen einen grossen Antheil, wenn sie auch nie bestandbildend auftreten und meist nur isolirt, insbesonders ron Eichhörnchen ausgesät und verbreitet, vorkommen. Gelangt die verschleppte Nuss in ein günstiges Keimbett, so entwickelt sie eine lange Pfahlwurzel mit spärlichen, dünnen Seitenwurzeln, so dass die Hickory's zur Erziehung in Pflanzgärten sich wenig eignen. Alle Arten lieben tiefgründigen, 
Joheron Buden und auf dem kräftigen Schwemmboden der Flussniederuneren, uher dem Hochwaserniveau erhaben, erwadsen sie zu den stantichsum Dimensionen. Allen Hickory's ist ferner gemeinsam die -jute Perkernung ihres Holzes - etwa mit dem 50. Jilhe berinnt

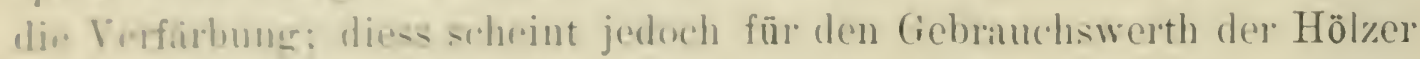
belanglus zu sein: weniestens wird bei der Verwendung darauf keine Kurck-icht genommen : ja Splinthol\% schätzt man vielfach höher als Kernhol\%.

Carya alba Nutt. Shell-bark Hickory, blatterborkige od or wroisse Hidkory: der amerikanische Name rührt von der Eigenthumbichkejt der Borke her schon im mittleren Alter in langen, etwa

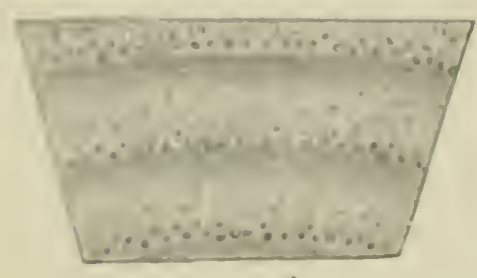

a)

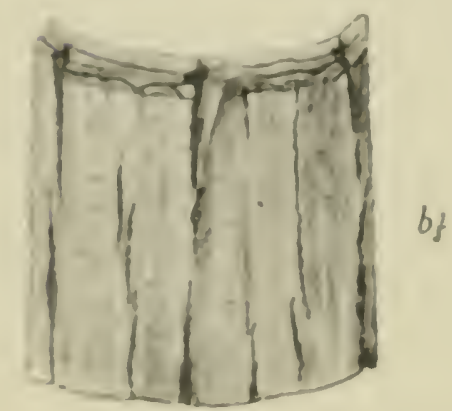

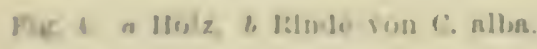
$\dot{j}$ cm breiten, dïnnen Fetzen sich abzulïsen und lose am Baume hïngen \%u bleiben: die fest sitzende Burke ist in der Regrel $1 / 2$ am dick und aus drei barten Schicliten bestehend, die sich dann spaiter in rechteckigen Figuren abtrennen. (Fig. 4). Das Splinthol\% ist $4 \mathrm{~cm}$ breit, umfasit 40 bis 50 Jahresbildungren und geht in ein hellröthlich bis braunes Kernhol\% iiber.

Die junge Pflanze ist leicht an folgrenden Eigenthümlichkeiten zu erliennen: das unpalarig grefiederte Blatt besteht aus fünf Blaittchen; unter tausend Bïumen sind fünf mit sieben Blïttchen (möglich, dass diess bastarde von alba und poreina sind). Die drei obersten Blittchen sind die grössten, oher- und unterseits glatt, mur an den starken Rippen finden sich unterseits Hatre: Blattrand

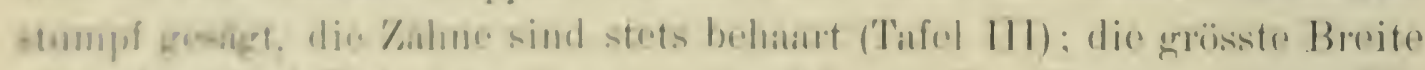

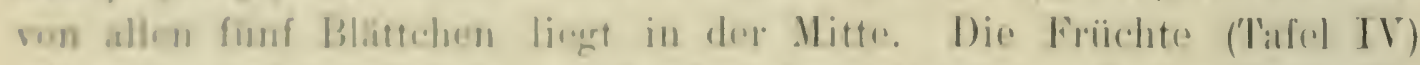

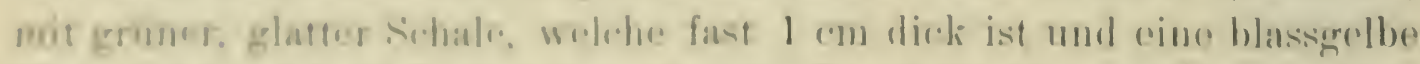

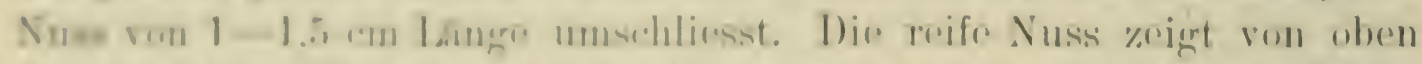

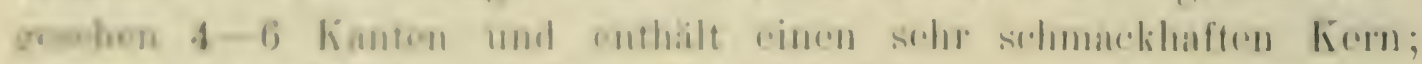

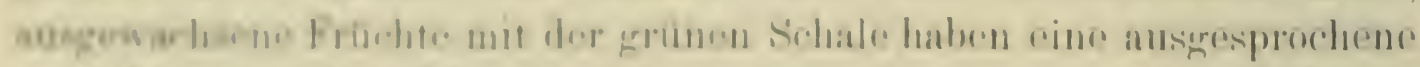
Aptedform mit a Langnsortirfungen, nach denen bei der Reife die Subate is 4 Theile zerfallt.

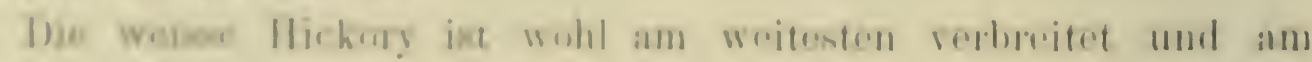
gemphatro unter den Verwanden; rom Laturentiustlusse bis Florida, 
rom atlantischen Ocean bis an die Prärie findet sie ihr Optimum in S. c. An frischen sanften Berghängen mit lockerem, fruchtbaren Boden ist sie häufig; auf sandigem oder kiesigem, mit Lehmbestandtheilen durchmengtem Boden ist sie nicht selten; auf geringen, sandreichen Böden vertritt sie C. porcina, die selbst in die wenig frischeren Partien im südlichen Kieferngürtel sich eindrängt.

Die weisse Hickory ist in der Jugend frostempfindlich bei uns wie in der Heimat, wo sie im Halbschatten anderer Bäume aufwächst und auf freier Fläche in ungünstigen Jahren oder Oertlichkeiten ebenso erfriert wie bei uns. Erwachsen nimmt sie früher als die meisten übrigen Laubbäume eine gelbe Färbung der Blätter an. Sie wächst in den ersten Jahren langsam, damit Hand in Hand geht die Möglichkeit etwas Beschattung in dieser Zeit ertragen zu kömnen - das beste Schutzmittel gegen Frost. Viele Büume geben gerade durch ihre Langsamwüchsigkeit in der Jugend einen Fingerzeig für ihre Schutzbedürftigkeit. Der Schutz des Laubholzurwaldes ist zuerst eine mässige Ueberschirmung, dann eine über hundert Jahre lange seitliche Bedrängung, aus der allmählig die Pflanzen sich zur Herrschaft durchkämpfen.

Auf freier Fläche gesät oder als einjährige Pflanze versetzt, hebt im 4. bis 6. Jahre ein sehr kräftiger Lüngswuchs an.

Carya porcina Nutt., Pignut Hickory, SchweinsmussHickory. Sie geht am weitesten nach Süden und sie allein von allen Hickory's sieht man in Nordamerika auch mit einem weniger guten, steinigen, selbst sandreichen Boden vorlieb nehmen; da ihr Holz in seinen Eigenschaften jedenfalls dem der weissen Hickory nicht nachsteht, erscheint sie für uns werthvoller als jene. Die erwachsenen porcinaund alba-Stämme sind durch ihre Borke deutlich unterschieden, die bei der porcina nicht in losen Stücken am Baume hängen bleibt, sondern eine feste, harte, kurzrissige, bis $3 \mathrm{~cm}$ dicke Borke ist. Junge Pflanzen tragen unparige Fiederblätter mit $5-7$ Blättchen; die drei obersten haben ihre grösste Breite im oberen Drittel der Blattlänge, die vier beziehungsweise zwei untersten dagegen in der Mitte. Die Zühnne der Blätter sind nach vorwärts gekrümmt, Blatt und Zähne sind kahl (Tafel III), behaarte Formen sind sehr selten und nach Engelmann Bastarde zwischen tomentosa und porcina.

Die typische Gestalt der Friichte mit Schale ist die Birnform mit vier von der Spitze bis zur halben Länge herablaufenden Leisten (Tafel IV). Die äussere, grüne Schale ist nur $1-2 \mathrm{~mm}$ dick; die ent- 
hiblow Yur ist der albat-Nuss sehr ähnlich, meist etwas kleiner und die nhabenen Rippen schwither, meist das untere Ende der Nuss nicht erreichend. Kunospen kur\%, eifürmig, kahl, Knospenschuppen mit kahlem Rand.

Das Holz der porina berechnet sich nach Sargent auf ein specifische Grwidht ron 84: meine bei Hamburg gewachsenen Stücke hatten 87 im hern und $79 \mathrm{ims}$ splinte; das Holz der albal ist nach Surgent fleich schwer, nämlich 84 ; meine mit porcina zusammen aufgowach-ene althat \%ejgrte 75 für den Splint und 82 für den Kerm, stand alow der porcina in schwere ziemlich nach.

Die Schwoinsnuss-Hirkory, deren Fruchtrerwendung der Name rerrith, rerhält sich in der Jugend der weissen Hickory parallel.

Carya amara Nutt.. Bitter nut, Bitternuss; zwar von

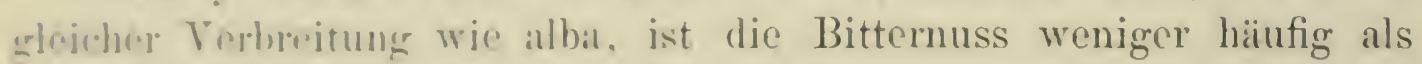
jen im Walde zu troftion: die Früchte bedeckt eine $1 / 2-1 \mathrm{~mm}$ dicke Erume Sidale, an der von der Spitze 4-6 düme, flügelartige Wülste his zur Halfer der Nuss herablaufen (Tafel IV). Exemplare mit Früchten Whr diee Hautfalm sind sehr selten; Mr. G. Setterman in Allenton (Wa) \%oigte mir cin soldhes bei einer Exkursion in das Eldorada der Hiokory, an Meramec, dinem kleinen Seitonflusse des Mississippi. Die

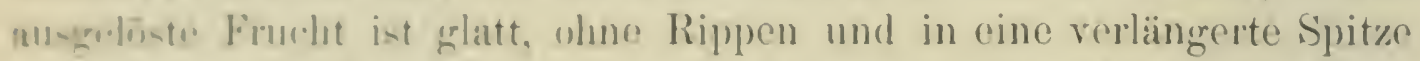
aungezoren; die harte Sichale ist rbenfalls sehr diinn. der bittere Kern ungenienhar: mojet stehen zwej früblte zusammen auf einem $1,5 \mathrm{~cm}$ langen stiel: vorherrsehend ist dic Apfolform.

Di. Blatt.p mit 7-11 Piederblittchen, auf den Blattrippen und siblon untersits Batre; charakteristisch sind die gelhegrumen, vierkuntigen, rom T'ricbe woggekrümmten Kussen.

D) Holy stoht mit einem sperifischon Gewirhte von 76 ziemlich कxit honter den bejlen vorigen Arten zuriek; anch dio Praxis kennt dies Virschiedenlurit zu Ungunsten der Bittermuss, obwohl sie oft dises Art mit anderen rerwerholt. Meine Stücke greben 73 für den Splint, 80 fïr dou Kirm. Dio Ansprüche dieser Art an den Boden sind remlich gruas: anf trockenen Höhrnlagen ist sie selten, liebt

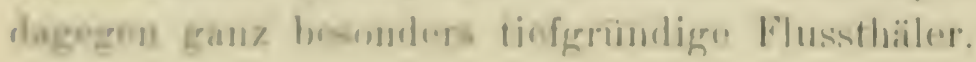

Oarya tomontuba Nutt. Nockernut-Hicliory, Spott-

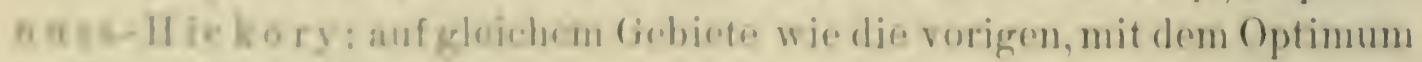

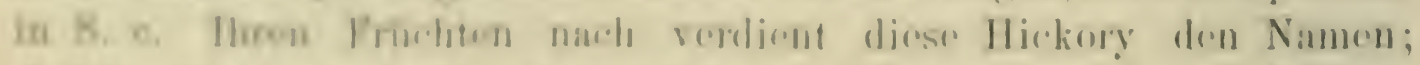
Apfole, Bions and Pflaumengentult sind hatufig, so dass ihre Früchte 
denen der alba, porcina, selbst der sulcata ähnlich sind; die grünè Aussenschale ist nicht so dick wie von alba. Bei Allenton in Missouri ist überdiess eine auffallend langfrüchtige Form häufig.

Das Blatt ist aus 7 lanzettlichen Blättchen zusammengesetzt; Blätter, Blattstiele und Rippen unterseits weichwollig behaart, ebenso wie die jungen Triebe und die Ränder der Knospenschuppen.

Die Borke gleicht der unserer Eiche und erreicht eine Dicke von $1 \mathrm{~cm}$; das braune Kernholz ist ron den übrigen kaum besseren Arten im Querschnitt durch weisse Punkte, die Ausfüllungen der Gefässe zu unterscheiden; specifisches Gewicht des Holzes gleich 82. Das beim Stärkewachsthum erwähnte tomentosa-Stück war auf kräftigem Boden des Hügellandes am Meramec erwachsen.

Carya sulcata Nutt., Big Shellbark Hickory, Grossfrüchtige Hickory. Ihr amerikanischer Name sagt: grosse, blätterborkige Hickory, weil ihre Rindenbildung der der weissen Hickory sehr ähnlich ist; die am Stamme lose hängenden Borkenstücke sind lang, rechteckig $4 \mathrm{~cm}$ breit. Die junge und etwas auch die ausgewachsene Frucht sammtartig, die reife Frucht mit Schale $5 \mathrm{~cm}$ lang (Tafel IV); die Schale ist dick, der helle Kern etwas flach gedrückt mit 4 Längsrippen; das zusammengesetzte Blatt bilden 7-9 Fiederblättchen; die 3 obersten sind die grössten (Tafel VI); das ganze Blatt ist bis zu einem halben Meter lang.

Die Spottnusshickory erwächst zu dem stattlichsten Baum unter den bis jetzt erwähnten Carya's, ist aber in ihrer Verbreitung auf einen Streifen von Pennsylvanien nach dem Indian Territory und dort auf den besten, kräftigsten Boden der Flussniederungen beschränkt. Das Holz dieser Art soll zu Axtgriffen, Wagenutensilien von allen Hickory's das beste sein (Letterman). Das specifische Gewicht beträgt 81 .

An diese schliesst sich eine Art, deren Holz nur Brennwerth besitzt, deren Früchte aber als die schmackhaftesten unter den Juglandineen gelten und in den Vereinigten Staaten neben den importirten europäischen Nüssen in grosser Menge consumirt werden. Es ist dies

Carya olivaeformis Nutt., Pecan, Pekannuss; im Thale des Mississippi südlich von St. Louis, insbesonders auf alluvialem Boden sehr raschwüchsig und bis zu 50 Meter sich erhebend. Mitte September reifen bereits in der Umgebung der rauchverhüllten Capitale von St. Louis die Früchte; diese zeigen eine längliche, olivenförmige Gestalt, die Aussenschale mit vier Längsfalten, die harte Schale mit schwarzen 
Strichen und l'upfen beretzt, die sieh mit der Zeit rerwischen ('Tafel IV): Rinde wahselnd, oft der poreina, oft mehr der alba ähnlich, doch sind die abgelüsten Burkenschuppen stets viel kleiner und nur $1-2$ ('m breit.

Das Blatt setzen $1 \dot{3}$ Fiederblättehen zusammen, jedes etwas sichelfurmig gekrümmt, was auch C. amara etwas zeigt; die seichte Bezahnung fehlt in der Regel auf der Innenseite (Schneide) der Sichel ganz (Tafel III).

Ihre Raschwüchsigkeit verräth die Pekamnuss schon im ersten Jahre; fast alle samen keimen im Jahre der Aussant, wahrend jene der vorerwähnten Arten erst im folgenden Jahre hervorkommen; noch im ersten Jahre erwiichst die Pflanze bis zu einem halben Meter Höhe.

Die beiden letzten Hickory's, in demselben südlichen Theile beheimathet, sind weder durch ihr Hol\% noch durch ihre Frïchte bemerkenswerth. Der Vollständigkeit halber seien sie kurz erwähnt.

Carra aquatica Nutt., Swamp Hickory, Sumpfhickory, in den Alluviunen der Flüsse, besonders des unteren Mississippi. Die grüne Frucht (Tafel IV) hat vier kräftige Längsfalten an der Aussenshale, die ausuguchiilte ist seitlich glattgedruickt auf ein Drittel des Durchmessers der rundgedachten Frucht, rauh durch Spitzen und Warzen. Die Blätter zuweilen mit paariger Fiederung und 12 Blittchen; das Holz hat ein specifisches Gewicht ron 74. Borke in schmäleren und klcineren Stiucken abstehend als die ron alba.

Caryamyisticaeformis Nutt., Nutmegr Hickory, Muskatnusshickory auf luft- und bodenfenchte Standorte wie vorige Art boschrinkt. Die Frïchte dieser Art (Tafel IV) mit dünner, grïner, schwach berippter Anssenschale; die harte Schale glatt und dunkelmarmorirt von der Gestalt und Grösse einer Muskatnnss. Ihr Maximum liggt in Aransas. wo sie Flnss- und Sumpfufer bewolunt; Hol\% mit sperifiachom Gowicht 80 , wohl besser als die beiden vorangehenden Artin; bis jetzt noch wenig beniatzt.

Nicht der geringste Antheil an dem Werthe und dem Reize des untichen Taubliwaldes falle den Acerineen zo; das Gros der Ahorn-

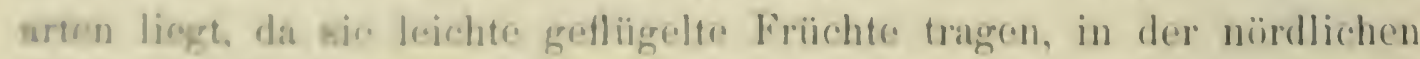
Hilfte des Jamhisolagebietes; os gribt kejne nur dem Süden, wohl aber twei bur dom Korden angrehörige Arten; dort liegt auch ihr Optimum der Botwicklang; in den höheren Bergen der Alleghany der südlichen Staase fondron sire ahnlichre klimatische Verhältnisse wir im Norden toud deshalb eine z.weite Heimat. 
Die Ahornarten nützen nach vielen Richtungen hin, nicht blos durch ihr zum Theil sehr werthvolles Holz, sondern theils auch dadurch, dass sie in ihrem Safte Zucker liefern, theils dass sie als die schönsten Baumzierden bezeichnet werden müssen, welche aus dem Walde in die Nähe der menschlichen Wohnungen, an die Strassenränder, in die Parke gewandert sind; sie sind die ersten, welche das purpurrothe Herbstkleid anlegen. Die wichtigste Art dieser Gattung ist

Acer saccharinum Wangh., Sugar maple, Zuckerahorn; ein Baum, um den wir allen Grund haben, die Amerikaner zu beneiden, so vielseitig nutzbringend, so freudig grün und Schatten spendend im Sommer, so herrlich bunt im Herbste, so hart und widerstandsfähig gegen Frost, Strassenstaub und Kohlendampf ist dieser Baum. Das Blatt dieses Ahorns habe ich auf Tafel IV abgebildet; stets ist die Rundung in den Buchten auch bei unterdrüickten, auf drei Lappen reducirten Blättern ein gutes Kennzeichen; dem Spitzahorn steht das Blatt sehr nahe, eine Verwechslung ist aber unmöglich, da beim Abbrechen der Blattstiele und Triebe des Spitzahorns Milchsaft ausfliesst, der dem Zuckerahorn fehlt; der Blattrand ist wollig, die Unterseite behaart, besonders bei Exemplaren im Süden; die Blätter färben sich schon vor Eintritt des Frostes orangepurpurroth; jeder Baum hat seine typische Färbung, die er alljährlich wieder annimmt, mag die Witterung noch so verschieden sein, wie Emerson beobachtet hat.

Die Früchte reifen im Herbste; die auf Tafel IV abgebildete Figur a wurde nach Früchten gezeichnet, die ich von alten Bäumen in Canada pflückte; die kleinere Frucht (b) stammte aus dem Staate Missouri, war also ferne vom Optimum erwachsen; es scheint, als ob in der Fruchtgrösse ein guter Fingerzeig für die Herkunft des Samens liege, indem der Same um so grösser ist, je näher dem Optimum er gebildet wurde. Der Same, den ich in 1500 Meter Höhe in den südlichen Alleghanies sammelte, war von gleicher Grösse wie der canadische.

Die Rinde ișt eine schmalrissige Borke, die im hohen Alter sich in lose hängenden Fetzen vom Baume löst (shell-bark). Das sehr werthvolle Holz hat ein specifisches Gewicht von 65, auf kräftigem Boden im Hügellande bis 75. Wegen seines schönen Seidenglanzes wird es zu Möbeln und im Drechslergewerbe sehr begehrt; zu Schuhleisten, Sattelbäumen, Hausfluren benützt man es oft, der Schiffbau liebt es zu Kielen, und vollends die ziemlich häufigen Maserbildungen, der berühmte "Birds eye maple", mit dem in so verschwenderischer Dicke die Palastwagen (Pullman cars) ausgelegt sind, erzielen die höchsten Preise, die für Holzwaaren überhaupt gezahlt werden. 
Obwohl bis zur Küste ron Florida sich erstreckend, liegt die Heimat dieses Ahorn im Norden: in einer Region, die klinatisch unseren Buchenrevieren nahe kommt, am südlichen Ufer des Lake Superior bildet sie grosse Waldungen. in denen die ïbrigen Holzarten (rorzugweise Birken und Ulmen) nur 25\% ausmachen. Dort auf Jehmreidem, ciscuschïsigen, rothem Sandstein mit starker Humusdecke ist ihre mittlere Entfaltung 0,67 Meter Durchmesser; 27 Meter Höhe mit einem astlosen Schafte ron 14 Meter; im dortigen Urwalde bedarf er zu solehen Grössendimensionen 150-200 Jahre; das durch die gofallenen stimme unebene T'erain bedeckte ein dickes Polster Laubstreu und niederes Balsamtannengestrüpp. Das ebenfalls im Norden gewachsene Newyorker simmlungsstück hatte folgenden Stärkezuwachs:

\begin{tabular}{c|c|c|c}
\hline $\begin{array}{c}\text { Alter } \\
\text { (Jahre) }\end{array}$ & $\begin{array}{c}\text { Durchmesser } \\
\mathrm{cm}\end{array}$ & $\begin{array}{c}\text { Freisfliche } \\
\square \mathrm{cm}\end{array}$ & $\begin{array}{c}\text { Zuwachs pro Jahr } \\
\text { der Periode } \\
\square \mathrm{cm}\end{array}$ \\
\hline 10 & 1 & 0,78 & 0,08 \\
20 & 2,4 & 4,5 & 0,4 \\
40 & 4,2 & 13,8 & 0,4 \\
60 & 6,6 & 34,1 & 1,0 \\
80 & 8,2 & 52,7 & 0,9 \\
100 & 14,2 & 185,6 & 6,6 \\
120 & 33,8 & $8,6,5$ & 35,5 \\
140 & 45,0 & 1586,7 & 34,5 \\
160 & 50,6 & 2224,7 & 31,9
\end{tabular}

Gesanmtalter 162 Jahre; im 100. Jahre erfulgte oflenbar plötzliche Freistellung des schwädhlichen, muterdrïcliten Exemplares.

Fin auderer, angenscheinlich unter günstigeren Verhälnissen crwacherener \%uckerahorn zeigte

$$
\begin{aligned}
& \text { mit } 10 \text { Jahren 3,6 ('m Durchmesser, }
\end{aligned}
$$

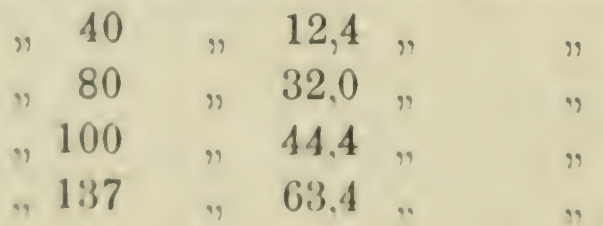

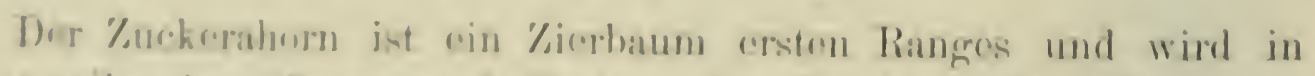
Sorblam rika in Cilirten and Parkon des Landes und der Stidte,

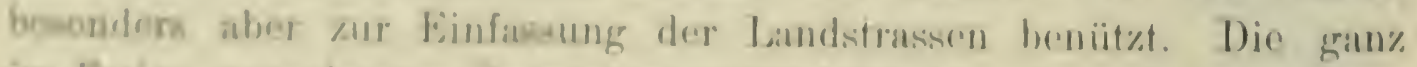

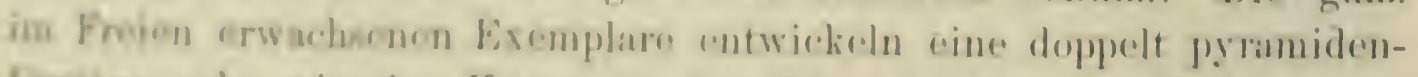
formages vehr enhattige krune; in de'n Stadten gehört der Zuckernhorn 
noch zu jenen Bäumen, die am ehesten dem oft grässlichen Steinkohlenrauch widerstehen können; wegen seiner tiefgehenden Wurzeln ist er widerstandskräftig gegen Wind und liefert in seinem Safte einen Syrup von eigenartig angenehmem Geschmack.

Dieser Ahorn ist mit Recht zum Anbau in den deutschen Waldungen im Grossen empfohlen worden und scheint auf sonnigen Lagen im Laubholzgebiete den Erwartungen zu entsprechen.

Acer rubrum L., Red maple, Rother Ahorn. Ist an dem rorwiegend dreilappigen Blatte zu erkennen, dessen Lappen in scharfen Winkeln wie $\bigvee$ zusammenstossen (Tafel III); die Früchte sind etwas kleiner als jene des Zuckerahorns und platt gedrückt (Tafel IV). Der rothe Ahorn steht in Grössenentwicklung, Güte des Holzes (specifisches Gewicht 62) und dessen Verwendung weit hinter dem Zuckerahorn zurück, übertrifft ihn an Grelligkeit der herbstlichen Verfärbung; man sieht oft mitten im Sommer die Blätter eines Zweiges in brennendes Roth übergehen, während die übrigen Zweige noch völlig grün sind; solche Zweige erweisen sich als krank, ron einem Insekte oder Pilze bewohnt, oder rom Winde geknickt.

Dieser Ahorn liebt feuchteren Boden als die vorige Art und beschränkt sich vorzugsweise auf die Flussränder und Alluvionen vom Laurentius- bis St. Johns-Flusse in Florida. Sein hartes Holz findet geringen Absatz für Drechslerarbeiten und zu billigen Hauseinrichtungsgegenständen.

Acer dasycarpum Ehr., Soft maple, White maple, Weisser Ahorn; erkenntlich an der lappigen Blattform; die Lappen berühren sich wie zwei sich schneidende Kreisbogen (Tafel IV). Unterseite des Blattes weisslich, die kahlen, faltenreichen Früchte sind die grössten unter denen des Ostens (Tafel III); sie reifen schon Ende des Frühjahrs - im Mai; sogleich ausgesät entwickeln sie sich noch in demselben Jahre zu Pflanzen von 50-70 cm Drrehmesser. Der Baum ist überdiess sehr raschwüchsig, sein Holz aber gilt als schlecht (specifisches Gewicht von 52); ist nicht elastisch und gibt dem Baume keine Widerstandskraft gegen Wind, der die Aeste leicht vom Baume bricht. Das Holz zersetzt sich rasch bei Verwendung im Boden.

Acer Negundo L. (syn. Negundo aceroides Moench), Box Elder, östlicher Eschenahorn; ist ein in Europa wohlbekannter Baum mit gefiederten, der Esche ähnlichen Blättern, der seine Heimat vom Laurentiusflusse bis zum Mississippidelta und westlich bis in die 
Rocky Mountains hat; er wiichst sehr rasch: besonders die blauweise bereifte Varietät (viulaceum) schiesst, aus Absenkern in der Regel erzugen, auscerordentlich rasch empor. In der Heimat aber entwickelt dieser Ahurn nur in tiefem. krïftigem Boden in Fhssniederungen einen nutzharen schaft, dessen Gebrauchswerth jedoch gering ist: zuweilen werden billige Hausgeräthe oder Papiermasse darans hergestellt; Früchte Tafel IV.

Acer californicum Diet. ist cine in Californien heimische eigene Art, cin Halbbaum ron durchschnittlich 9 Meter Höhe; Acer Necrundo californicum ist eine ungenaue und unnüthige Bezeichnung. Zwei dem Norden angehürige Arten mügen noch hier erwähnt werden:

Acer striatum Du Roi (syn. pennsylvanicum L.), Striped shaple. Gestreifter Ahorn. Blätter vorwiegend dreilappig, fein duppelt gesiigt, wenn jung, schwach filzig behairt. Kinospen violett, mit Wimpern versehen: das zweite Blattpaar, das an dem Triebe sich entwickelt, ist nicht gelappt: Früchte in Grösse und Gestalt dem Zuckerahorn ähnlich; zwei- und mehrjährige Triebe mit weissen I ängsstreifen, die Zwischenstiicke dunkelgrün; ein Halbbaum bis zu 10 Meter Hohe; meistens Zierstrauch.

Acer spicatum Lam. (syn. pennsylvanicum Du Roi), Mountain maple. Achrenblüthiger Ahorn. Blitter dreilappig, grob einfach gesignt, unterseits behaart; Früchte kleiner als von voriger Art; Rinde ohne weison Struifen; bis 10 Meter hoch ist dieser Ahorn als Zierstrauch öfters gepflanzt.

Dic Eschenarten sind ebenfalls leichtsamige Bäumo, deren gröate Enffaltung in die Nordhälfte des Laubholygebietes fält. Sie herrechen zwar durch Nord und Süd in gleicher Artenzahl; allein die beiden nur im Siblen heimischen, mexicanischen Arten sind strïucher his Halbbame, ebenso wie die Sumpfbewohnerin, die breitfrüchtige Evolde Florida's, deren Hol\% durchschnittlich ein specifisches Gewicht ron 60 besitzt gugenüber 68 der nordischen Arten.

Vom der Weinsesche wurden nicht weniger als 26 Bäume aus allon Thailon der ostlichen Haifte der Vereinigten Staten untersucht; ordnet man dienes reichliche Untersuchungsmaterial nach gleichen Ringhreiton, so argiht sich cine Abnalume dor Härte, des specifischen Gesichtes vom Noril nach Siid, nämlich ron 66 aluf 62 ; trot\% der groberm Fouchtigkeif und Whame rerschlechtert sich das Hol\% dieser

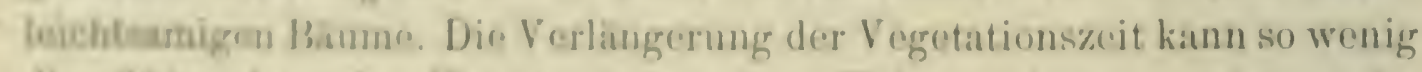
die Gave einer im Nordon hromischen Holzart stoigern, als es dio 
Verkürzung der Vegetationszeit bei einer im Süden heimischen Holzart vermag; wie Nord und Süd verhalten sich in dieser Frage auch Ebene und Gebirg. Dass vielfach in der forstlichen Finanzrechnung dem Gelderlöse nach durch die Masse ausgeglichen werden kann, was an Güte verloren geht, bedarf kaum der Erwähnung; ist doch die Massenproduktion die Tendenz der gegenwärtigen Forstwirthschaft; im extremsten Falle führt sie zu der bereits empfohlenen Anpflanzung von Pappeln zur Papierfabrikation.

Als Holzproducenten spielen die nordischen Eschen eine Rolle un ähṇlich der europäischen Art, mit der sie überdiess in ihrer Biologie grösstentheils übereinstimmen.

Fraxinus americana L., White ash, Weisse Esche. Sie ist von der europäischen Esche zu unterscheiden durch die rostfarbigen Knospen, die hell ockerfarbigen Triebe; der Rand der sieben Fiederblättchen ist schwach gekerbt; Blättchen unterseits heller, das unpaarige Endblättchen ist das grösste unter den sieben; Früchte Tafel IV. Die Borke des erwachsenen Baumes ist der unserer Esche sehr ähnlich. Besonders in N. a. und S. a. verbreitet wird sie in N. c. vielfach durch die Grünesche (Fr. viridis) vertreten.

Die Weissesche erwächst zu einem stattlichen Baume von 30 selbst 40 Meter Höhe und entsprechendem Durchmesser; sie erreicht diese Dimensionen im geschlossenen Walde, in den Niederungen des Ohioflusses und zwar auf kräftigem, feuchtem Boden.

Ihr Holz steht in Güte jedenfalls dem unserer Esche nicht nach; das specifische Gewicht des Splintes ist 72, jenes des Kernes 65; man beniützt das Holz vielfach, besonders zu landwirthschaftlichen Geräthen (insbesonders wo Hickory spärlich geworden), beim Wagenbau, zu Werkzeugstielen, Rudern, Hauseinrichtungsgegenständen u. dgl. Holz aus dem kälteren Maine (engringig) wird wegen grösserer Zähigkeit besonders geschätzt.

Der Zuwachs an Stärke ist ein sehr bedeutender, wenn der Baum der Bedrückung im Urwalde entwachsen ist, wie das Newyorker Sammlungsstück zeigt. - Dieser Baum erreichte

\begin{tabular}{c|c|c|c}
\hline $\begin{array}{c}\text { Alter } \\
\text { (Jahre) }\end{array}$ & $\begin{array}{c}\text { Durchmesser } \\
\mathrm{cm}\end{array}$ & $\begin{array}{c}\text { Kreisfläche } \\
\square \mathrm{cm}\end{array}$ & $\begin{array}{c}\text { Zuwachs pro Jahr } \\
\square \mathrm{cm}\end{array}$ \\
\hline 10 & 2,4 & 4,5 & 0,4 \\
20 & 7,6 & 45,4 & 4,1 \\
40 & 22,0 & 380 & 16,7
\end{tabular}




\begin{tabular}{c|c|c|c}
\hline $\begin{array}{c}\text { Alter } \\
\text { (Jahre) }\end{array}$ & $\begin{array}{c}\text { Durchmesser } \\
\mathrm{cm}\end{array}$ & $\begin{array}{c}\text { Kreisfiiche } \\
\square \mathrm{cm}\end{array}$ & $\begin{array}{c}\text { Zuwachs pro Jahr } \\
\square \mathrm{cm}\end{array}$ \\
\hline 60 & 35,5 & 1046 & 32,8 \\
80 & 50,5 & 2003 & 47,8 \\
100 & 67,5 & 3309 & 50,3 \\
1240 & 79,0 & 4902 & 64,7 \\
140 & 57,5 & 60.12 & 57,5 \\
160 & 96,5 & 7314 & 63,1 \\
180 & 193,5 & 8413 & 54,9
\end{tabular}

Die Finführung dieser Esche in Deutschland ist ein grosser Gewinn: denn sie ertrïgt unser Klima besser als die cinheimische Art, welche auf freier Fliche empfindlich ron Spätfrösten leidet; da die amerikanische Art spïter ihre Blätter entfaltet, entgeht sie den Frösten. Pflanzungen, dio ich im Thale der Salzach mit meinem Bruder auf gan\% recenten, durch die Flusskorrektion gewomenen Alluvionen anlugte, erwachsen priichtig, trotzdem sie völlig ungeschützt liegen und alljihrlich ein parmal vom Hochwasser überfluthet werden.

Fraxinus sambucifolia, Black ash, Schwarzesche. Korbesche kam ron der. Weissesche dadureh unterschieden werden, dass sammeliche Blittchen gleich gross sind und am gemeinsamen Blattstiele direkt sitzen, während sie bei der Weissesche mit einem dentlichen stiele befestigt sind; die Blättchen sind scharf gesägt. Früchte auf Tafol IV. Knospen dunkelgrau; Rinde frühzeitig eine kleinschuppige, wejche Burke. Die Schwarzesche lirbt noch feuchtere Standorte als die vorige Art, din wir bereits als Erlenbruchboden bezeichnen müssen. In N. a. und e. errejcht die Sidhwaresche etwa dieselhen Dimensionen wio dir Wrissesche. Das Hol\% mit einem specifischen Gewicht ron 63

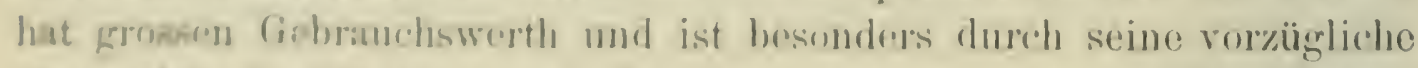

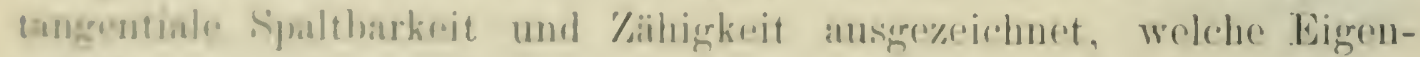

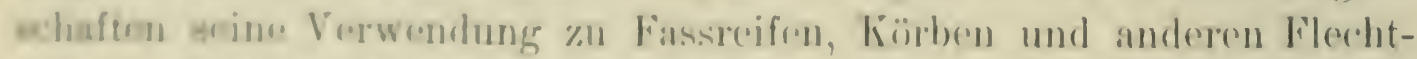
wasro zuldost. Die Korbesche scheint dieselben fiir den Anbau in

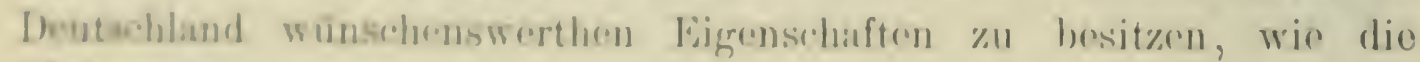
Weisearlie.

Dow ubrigen lischenaten stohen diesen briden an Werth bedeutond nach.

Praxinuteriridis, Grome ash, Günosche. Durch N. und 8. besondors for a und p. alen im Westen serhoreitet, bleibt sie meist 
ein kleiner Baum von höchstens 18 Meter Höhe; Blättchen beiderseits gleich grün, in den beiden oberen Dritteln der Blattfläche gesägt; Knospen braun filzig. Da die Grünesche stets ein kleiner Baum bleibt, so kann schon a priori gefolgert werden, dass sie nicht so hohe Ansprüche an den Boden, wie die vorausgegangenen Arten, erhebt. Die Grünesche findet man sehr oft in trockenen, sandigen Lagen, ja selbst unter die Kiefern (P. resinosa) drängt sie sich als niedriger, astreicher Baum; Früchte Tafel IV.

Fraxinus pubescens Lam., Red ash, Rothesche. Durch das ganze Laubgebiet rerbreitet, von der vorigen Art durch die Behaarung der jungen Triebe, der Blattstiele und Blattunterseite unterschieden; Fiederblättchen gestielt, junge Blätter wollig, Knospen braun, etwas behaart; Früchte Tafel IV. Die Rothesche bleibt auch auf dem guten Boden der Flussniederungen, auf den Erlenbruchböden ein kleiner Baum ron 12-15 Meter Höhe. Das Holz wird, da es mit dem der Weissesche verwechselt wird, zuweilen benützt.

Fraxinus quadrangulata Michx., Blue ash, Blauesche. Blättchen in eine lange Spitze ausgezogen und unterseits wollig; junge, kräftige Triebe mit korkigen Längskanten ähnlich wie Evonymus europaeus; Knospen hell weisslich, filzig; Früchte auf Tafel IV. Auf die Hänge im Hügellande der centralen Staaten beschränkt, wächst sie zu einem stattlichen Baume heran, dessen Holz in Wagenbau, zu Brettwaaren sehr geschätzt wird.

Fraxinus platycarpa Michx., Water ash, Wasseresche, ein niederer Baum, der den Namen vollauf verdient, betritt er doch sogar die nassen Taxodiumsümpfe; das Holz ist aber werthlos und ist mit einem specifischen Gewicht ron 35 leichter als Pappelholy; Früchte Tafel IV.

Die Birken sind ebenfalls eine nordische Gattung; ihre Arten leben in der kühleren Hälfte des Laubwaldes, einige reichen in die warme Hälfte, andere in die kühleren Regionen der Tannen, oder bilden sogar, nach den Polen zu, die Baumgrenze. Der leichte Same wird rom Winde überall hingeführt; das Resultat dieser mehrtausendjährigen Anbauversuche der Natur ist, dass wir heute die Birken und andere leichtsamige Holzarten wie Erlen und Pappeln auf den heterogensten Standorten, in trockenen, kiesigen Höhenlagen sowohl wie in feuchten, selbst sumpfigen Partien oder an Flussrändern wieder finden. Im nördlichen Theile des Laubwaldes, wo ihr Optimum liegt, sind die 
Birkon wahre Unkriuture unter den forstlichen Gewissen, die sich auf jeder froigelegten Flïche zuerst einstellen; selbst wo es für Fichten und Tannen zu kalt wirl, da rermign noch die weissschaftige Birke anf Quadrameilen hin alleinherschend aufzutreten und bouchtenswerthe Halzbestande zn bilden; hierin rerhalten sich die Birken Europa's, Asiens und Nordamerikats gant gleich.

Betula lenta L., Red Birch, Blackbirch, Hainbirke, mag ein passender Name sein. da die Bliitter denen der Hainbuche almlich sind. Diese Art wurde und wird noch vielfach mit der folgenden rerwechselt: sie wurde run Aiton als B. excelsa, ron Du Roi als B. nigra beschrieben, wïhrend die folgende Art (B. lutea Michx. f.) von Pursh als B. excelsa und ron Regel als B. lenta aufgefasst wurde.

Die Hainbirke hat, wie gesagt, ein Blatt, das in Gestalt an die Hainhuche rrinnert und ist fein gesïgt, wihrend das Blatt der Gelblirk" mohr dem einer Llme nahe kommt und grobe, ungleiche Säge\%ahne besitzt ('lafel 1II); die jungen Triebe sind kahl; Willkomms*) grusse . Furstlicho Flora" führt diess Seite 301 auf; allein auf Seite 325 heist es ron deralben Hulzart: junge Triebe dicht beharrt; diess passt fur lutea, nicht für lenta; auch den Emerson schen Abbildungen scheint aine Verwechselung der beiden Arten zu Grunde zu liegen; der aufrechte, zapfenförmigo Fruditstand sitzt anf 1 cm langem Sticle, Stiel hahl, simmschuppe und Same wie Tafol IV. Flügel des Samens ganzrandig.

Dir Hainbirke erreicht ihre Vollendung auf dem kräftigen Boden der Flus-niedrrungen und Berghäinge, mit durchschnittlich 25 Meter Hohe: ihe Haly mit dem hohen sperifischen Gewichte von 76 mit deutlichem bramen Kern; dasselbe ist gute's Nutzholz für Möbel und Cieratherhaften, sowis ein ausgezeichnotes Bremuholz, das mit ruhiger Flammo und kriftiger Gilnth, wie hestes Buchenhol\% verbrennt.

Brotula luton Michx. f., Yellow birch, Gelbbirke. Fruchtzupfon stzond. Biw is behatrt; der Same greflïgelt mit einem oder zwei bigntzetion am oberen Rande ('Tafol IV); diese Birke ist ebenfalls im nônlichen Laubsaldo sowie auf den hohen Kïmmen der Alleghanies beomath und theile die standorte der vorigen $A$ rt. $\Lambda$ m Südufer des Lake Buprenior. auf kriftigem Boden zusammon mit Zurkerahorn ansgestelente Wablumgen bildend. erreicht sio eine mittlere Höhe ron

- f forellidise Hera mo Deutachland und Oesterreich. Leipzig 1887. 
27 Meter, einen mittleren Durchmesser von $50 \mathrm{~cm}$ und eine astreine Schaftlänge von 13 Meter. Auf diesem frischen, kräftigen Waldboden bleibt sie in ihren Stärkedimensionen hinter dem Zuckerahorn zurück; vom Wind ist sie vielfach auf felsige Höhenlagen und kiesige Standorte gebracht; auch da gedeiht sie noch, selbstverständlich bleibt sie in ihren Dimensionen entsprechend zurïck.

Die Rinde des Baumes ist nie weiss; anfangs röthlich wird sie im höheren Alter röthlich grau und löst sich in dünnen horizontalen Fetzen ab, welche den Stamm dicht bekleiden; der Jugend und den Jägern soll es ein besonderes Vergnügen sein, die Rinde anzuzünden und fast momentan in eine leuchtende Feuersäule zu verwandeln.

Das Holz mit deutlich röthlich gefärbtem Kern und $3 \mathrm{~cm}$ Splint ist als Bauholz gesucht; wegen seines Oelgehaltes gibt es die besten Bretter für Skating Rinks; und da wegen der Abnahme des Wallnussholzes die hellen Möbel mehr in Mode kommen, wächst der: Werth des Birkenholzes zu solchen Zwecken ständig. Die grösste Holzmenge ist bis jetzt Brennholz, das die guten Eigenschaften des besten Buchenholzes besitzt.

Als Schatten fliehende Holzart strebt sie, rasch wachsend, nach Kronenfreiheit, die sie im Urwalde mit 13 Meter Höhe nach 40 Jahren erreicht.

Der Zuwachs nach Stärke des in New-York befindlichen Stückes ist folgender :

\begin{tabular}{c|c|c|c}
\hline $\begin{array}{c}\text { Alter } \\
\text { (Jahre) }\end{array}$ & $\begin{array}{c}\text { Durchmesser } \\
\mathrm{cm}\end{array}$ & $\begin{array}{c}\text { Kreisfläche } \\
\square \mathrm{cm}\end{array}$ & $\begin{array}{c}\text { Zuwachs } \\
\square \mathrm{cm}\end{array}$ \\
\hline 10 & 3,2 & 8,0 & 0,8 \\
20 & 7,8 & 47,8 & 4,0 \\
40 & 21,0 & 346,0 & 14,9 \\
$\mathbf{6 0}$ & $\mathbf{3 6 , 0}$ & $\mathbf{1 0 1 8 , 0}$ & $\mathbf{3 3 , 6}$ \\
80 & 45,0 & 1590,0 & 28,6 \\
100 & 48,8 & 1859,1 & 13,45 \\
120 & 50,0 & 1963,0 & 5,2 \\
140 & 52,2 & 2129,1 & 8,3 \\
160 & 54,0 & 2290,0 & 8,0
\end{tabular}

Splint $4 \mathrm{~cm}$ breit, 76 Jahre umfassend.

Die Verwechselung dieser und der vorigen Art hat praktisch glücklicher Weise keine Consequenzen; beide Holzarten haben gleich gutes Holz und theilen dieselbe Biologie. 
Betulanigra I., (syn. rubra Michx.). Red Birch. Schwarzhirke. Das Blatt dieser Birke ist nach Tafel III doppelt gestigt; untereits mit weissen Secretpunliten: die Brakteen des Fruchtstandes sind hehart: ibensis junge Triebe und Blattstiele. Die Rinde, anfangs schwarmoth. blittert sich schon frïhzeitig in losen, diinnen, horizontalen Stukeken ah, dio dem stamme oine hellroth-graue Fürbung geben.

Die Schwarhirke liebt ror Allem die Flussufer, also frischen, kriftigen Bodlen, wo sie mit Platane und Catalpa zusammentrifft. Sie ist die am meisten Wärme liebende Art unter den Birken und erreicht ihre grissten Dimensionen in den südlichen Staaten. Ihr Holz mit einem sperifischen Gewicht ron 58 steht dem der übrigen Birken weit nach.

zwei nordische Birken wären noch hervorzuheben die in der Rindenbildung unserer eurupaiischen sehr nahe kummen.

Betula paproifera Marsh., Canoe-Birch, Nachenbirke; durch die Form der beharten Brakteen des Fruchtstandes ('Tafel IV)

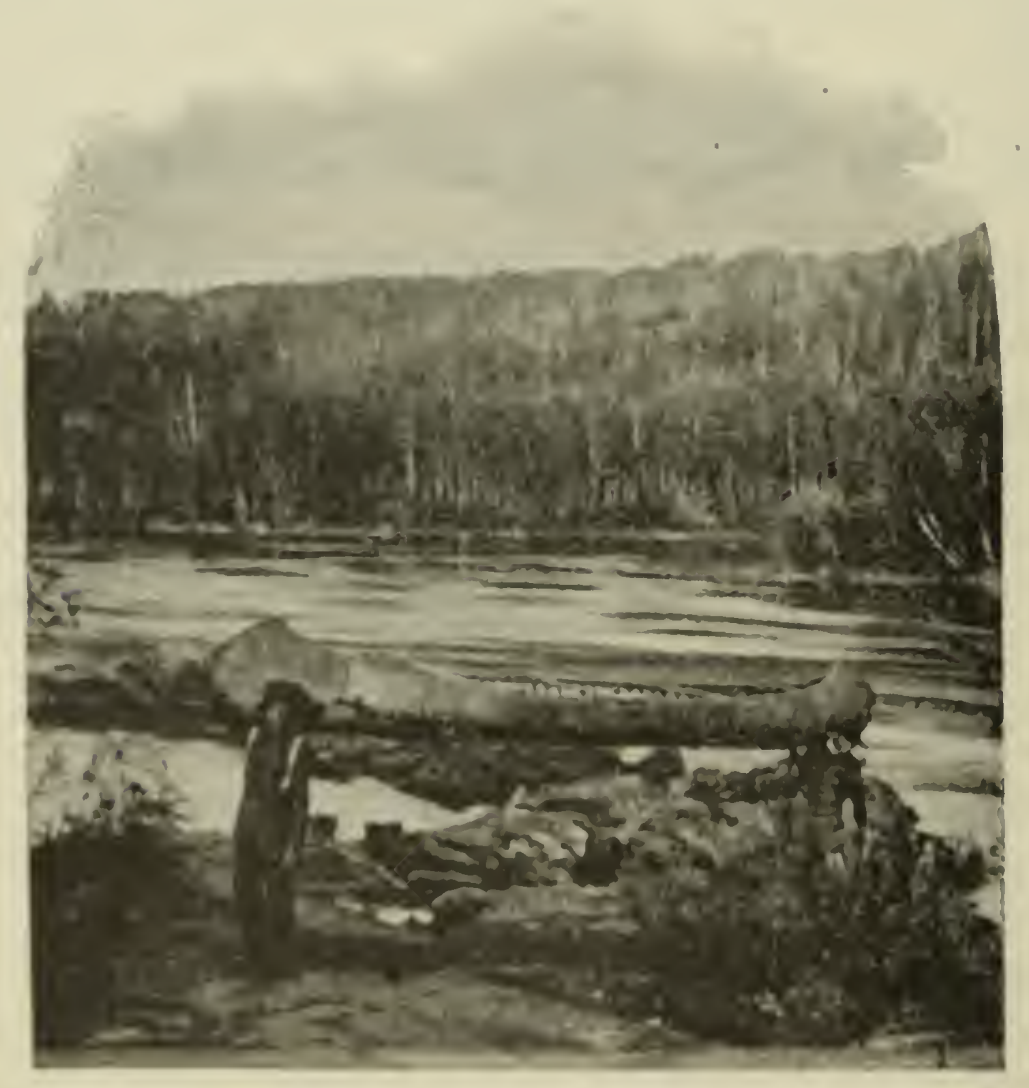

Wahluuk der Socloeshblrke In Coundu.

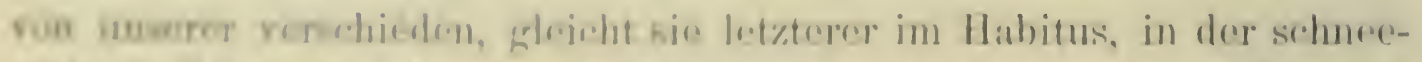
moimen kinde and in iture Biologie. An wreitesten ron allen Latub- 
bäumen des Ostens nach Norden vordringend überschreitet sie nördlich to tha vom $52^{\circ} \mathrm{N}$. B. den Continent und erscheint in der westlichen Flora wiederum. Sie liebt Flussufer, frische, selbst nasse Bodenarten, z. B. im nördlichen Wisconsin die kalten Lärchensümpfe, wächst aber auch eu sehr rasch auf magerem Sandboden.

Das Holz der Nachenbirke wird zu Spinnspuhlen, Schuhnägeln, Papiermasse und Brennholz benützt. Die weisse Rinde dient in Canada zu so mannigfachen Zwecken wie die Birkenrinde in Russland; man fertigt Schachteln, Körbe, deckt damit die Hausdächer oder näht die Rindenstïcke mit Wurzeln der Weissfichte zu Kähnen zusammen, welche die Indianer und französichen Canadier auf ihren Wanderschaften mit sich führen, um über die zahllosen Flüsse und -See'n überzusetzen; davon hat die Birke ihren Namen bekommen.

Betula populifolia Ait., White Birch, Pappelbirke; ein im hohen Norden lebender Halbbaum, der im besten Falle 9 Meter hoch wird; er wird vielfach als Abart unserer verrucosa aufgefasst; im sumpfig-kalten Boden und auf trockenen kiesigen Standorten heimisch.

Die Ulmen sind insoferne eine nordische Gattung, als sie allein im Norden zu werthvollen Nutzhölzern heranwachsen; die nur im Süden heimischen Arten sind Halbbäume. Vermöge ihrer Leichtsamigkeit sind sie wohl in jedem Walde des Ostens keine seltene Erscheinung. Der nordamerikanische Wald ist zu reich an Eichen und vielen anderen Nutzhölzern als dass die Ulme den Werth haben könnte wie die unsere; immerhin hat Ulmenholz den Vorzug bei Anfertigung von Radnaben, beim Schäfflergewerbe, auch beim Boot- und Schiffsbau spielt es eine Rolle.

Die wichtigste von allen ist Ulmus americana $\mathrm{L}$, White or American Elm, Amerikanische Ulme, weisse Ulme. Im Ulmenparadies, im Thale des Connecticut erreicht dieser stattliche Baum eine Höhe bis zu 35 Meter und 1 Meter Durchmesser. Die Ulmen wurden von jeher von der Axt verschont, da sie ein Lieblingsbaum der Leute ron Neuengland sind. In den weiträumigen Niederlassungen vor hundert und mehr Jahren angebaut, erwuchsen die majestätischen Ulmen von New-Haven (City of Elms); ob aber die Ulme, mit der Verdichtung der Bevölkerung und der Zunahme der Schornsteine, auch noch zu einer so hervorragenden Zierde der Städte aufwachsen kånn, darf man nach Analogien anzweifeln.

Botanisch ist die Art von der europäischen nicht gut unterschieden; junge Pflanzen sind unseren Ulmen sehr ähnlich. Ein gutes Kenn- 
zodicken. Wir ich glaube, habe ioh anf 'lafel IIIb abgobildet; jede Rippe ribt val dom Fintritt in die Zahnspit\%e einen hervorragenden, rechembolier abstehenden Ast nach der Zahnbasis ab; ausserdem ist die spitzo des Blattes lang ausgezogen (Tafel III a). Dic auf $1 \mathrm{~cm}$

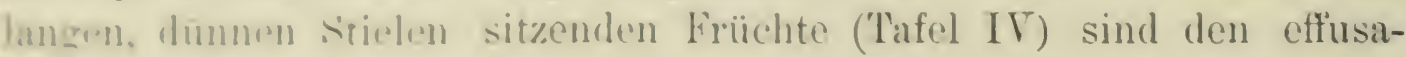
Frurhen schr ahnlich, an Rande bewimpert. Rindenbildung der montana ähulich.

Dureh das ganze Laubrebiet wurgelt die amerikanische Ulme auf krafrigem, frischem Boden der Flussufer und Tieflinder; auf trockenen Buden bleihe sie niudrier: ihr Hol\% zoirt ein specifisches Gewicht von 6j. ist schwerspaltig und ron hellbramer Farbe.

D) junge Ulme wiichst selır rasch; auf guten Böden erreichen rinjahrige l'flanzen eine Höhe ron $30 \mathrm{~cm}$ und zeigen die Eigenthümlivder.it. dass dic Blitter opponirt stehen: erst im folgenden Jahro nehmen sie zweizeilige Neflung an; ob alle Ulmenkeimptlanzen sich so verlablen. vermar ich nicht \%u entscheiden.

Ulmus fulva Michx., Red Elm, Slippery Elm, Rothulme ist seltencre als die vorige Art, mit der sie die Heimat gemein hat: sio bloibt in Hühnn- und Stärkewnchs gegren die americana zurück; ihr Oprimum liegt in den westlich gelegenen Staaten. Die Blätter sind duck. in uine lange spit\%o ausgezogen, mit unsymmetrischer Basis, fast witzend; junge Triche und Kunspen braunfilyig behaurt; die Früchte sud der U. muntana an Grïsse grleich, der den Samen umschliessende Theil die filigels behatart (Tafel IV). Das Holz wird zu Eisenbahnund Thursdiwellon, zu Radnaben ete, benützt.

I)1. um im Norden hermische Ulmus racemosa Thomas, losek Elm. Felnenulmu, kommt nicht, wie ihr Name sagt, mit Forlube auf feligam Terrain vor, sondern uur getegentlich, erroicht

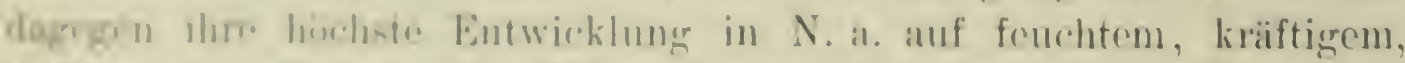

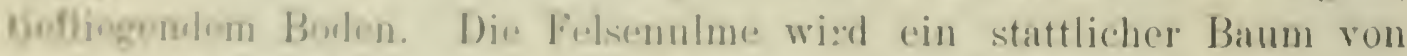
20 - 80 Mreer Huhe mit tief- und breitrissiger Borke, die in diumnen,

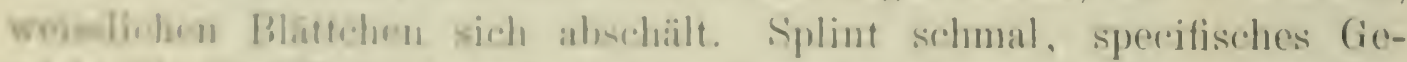

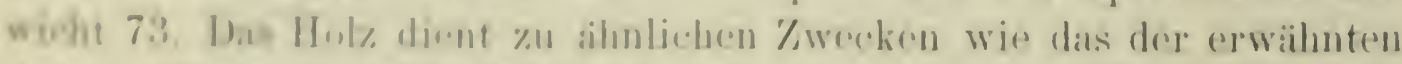

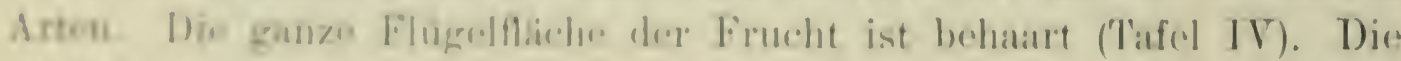

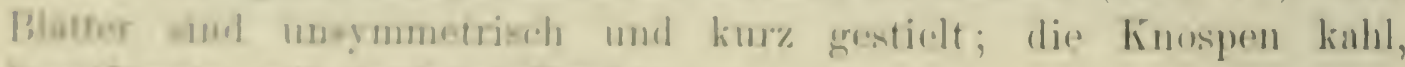
bopulformige, mit dunkelm Rands.

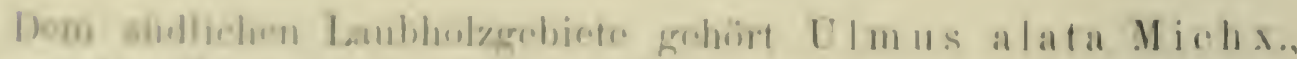
Wabon, the flagelnlme, an, ein Habbatum ron höchstens 12 Meter 
Höhe; sie bildet, wie zumeist die Korkulme, Korkflügel an den jungen Zweigen; ihre Früchte sind die kleinsten von allen Ulmen, länglich, am Rande bewimpert (Tafel IV).

Ulmus crassifolia Nutt., Cedar Elm, Dickblätterige Ulme. Vertritt in Texas die Stelle der amerikanischen Ulme, ihr Blatt ist klein, derb, unsymmetrisch, die Früchte am Rande kurz bewimpert (Tafel IV); Rinde tief schmalrissig. Der Baum erreicht auf dem besten Boden der Flussauen nur 20 Meter Höhe, ist aber westlich rom Trinity-Flusse viel kleiner und dort wegen des Mangels besserer Holzarten die beste.

Die Leguminosen-Bäume fehlen in Europa so gut wie ganz. Die Robinie, ron Amerika eingeführt, hat selbst in den wärmeren Partien Deutschlands diese Lücke ausgefüllt; sie ist dort, wie insbesonders im südlichen Europa, rerwildert. Auch in Nordamerika gehören die Leguminosen als schwersamige Bäume dem Süden an; keine Art erreicht als Baum die nördlichen Staaten.

Im Urwalde sind diese Bäume stets lokal und rereinzelt demselben beigemischt.

Robinia Pseudacacia L., Locust, Akazie, Robinie, Schotendorn. Dieser Baum ist auch in Amerika erst durch den Menschen aus seiner engen Heimat in den siidlichen Alleghany-Bergen durch die ganze östliche Union verbreitet worden; von Ostamerika aus rerpflanzte man denselben nach Europa, nach der pacifischen Küste; in Japan ist er als Zierbaum der Gärten und Strassen so häufig wie in Italien.

In Nordamerika fällt das Optimum in S. c., an somnigen Berghängen, wo er eine Höhe von 27 Meter erreicht. Sein Holz ist wohlbekannt und in Nordamerika zu ähnlichen Zwecken verwendet wie in Europa. Die Anpflanzung des Baumes an Rändern von Weidegründen ist, nach Sargent, grösstentheils aufgegeben worden, da die meisten Bäume den Angriffen des Akazienbohrers, Cyllene picta, erlagen.

Robinia viscosa Vent., Clammy Locust, Drüsige Robinie. Ist nur botanisch und pflanzengeographisch bemerkenswerth. Der Standort, auf dem sie zuerst gefunden wurde (südliche Alleghanies), ist zwar bekannt, aber der niedere Baum selbst komnte nicht wieder gefunden werden. Die Kultur hat jedoch reichlich für seine Ausbreitung gesorgt. 
Gleditsehia triacanthos L. Honey-Loeust, Gleditschiè, Christusdorn. Die Gleditschie ist durch den langjährigen Anbau bei un in Deutschland so bekannt ereworden, dass ich eine botanische Shize werlasen kimn; in der Heimat in S. e. erreicht sie auf kräftigem Boden dor Flussniphlerungen 30, selbst 40 Meter Höhe; seltener und sich niedrigur ist sie anf trockenen, herahgemagerten Hügeln; das rusurothe Kurnhuly ist im Batue dem srü̈ngelben Kernhol\%e der Robinie ahnlich: im specifischen (iewichte verhalten sie sich wie 67:73.

Eine durch die Kultur entstandene dornenlose Varietät ist insoferne bemerkenswerth, als Gleiches anch bei der japanischen Gleditschie bewbachtet wird.

Gymnocladns canadensis Lam., Kentucky Coffeetree, schusserbat um nach Willkomm. Im mittleren Theile der Union mit dum Optimum in S. c., nicht in Canada: auf gutem Buden der Fhaniroderungen erreicht der Baum eine Höhe ron 33 Meter und livefre rin hellbraunes Kornhol\%, das ein sehr schmaler Splint bedeckt; dio Rincle ist eine $2-3 \mathrm{~cm}$ breite rissige Borke, die wieder $1 \mathrm{~cm}$ dick ist. Der Batum ist in Amerika nicht laüufigr genugr, um seinem Holze rine ansgodelunte Verwendungr zu geben.

Die Samen sind platt, von der Grösse eines Zweimarkstückes und wurlen früher als ein Surrogat für Kaffee benuitzt; was die Grisse der Simen dieser drei bei uns ziemlich häufigen Bämme betrifft, su hat Gymnocladus den grössten, Robinie den kleinsten Samen, Gleditarhie steht in der Mittc.

Cladrastis tinctoria Raf., Yellow Ash, ist auf die südlichen Staten beschränkt; die Rindo dieses Halbbaumes grleicht äusserlich sollig der Buchenrinde; das Hol\% liefert einen grelben Farbstuft.

Fagut forruginca Ait., American Beech, die amerikanische. Buche ist durch das ganze Gebict rerbreitet, nördlich von Iake Superior his \%um Golf ron Merico; ihr Optimum liegt im nôndlichen Iaubwalde, wo sie ein stattlicher Batum, \%. B. am Lake

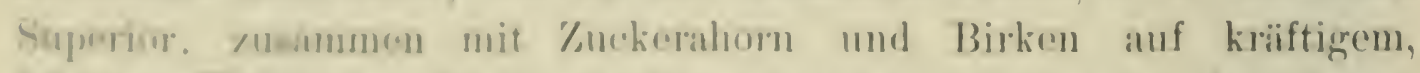

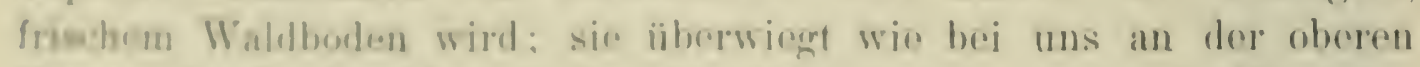

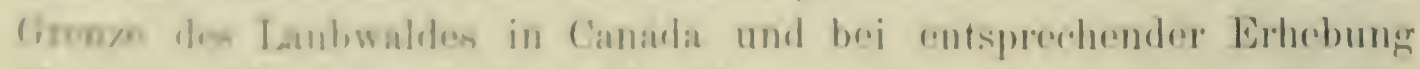

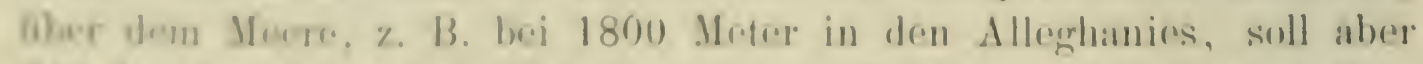
ther hö hese indisiduelle lintfaltung anf den Hïgrellïpfen des unteren

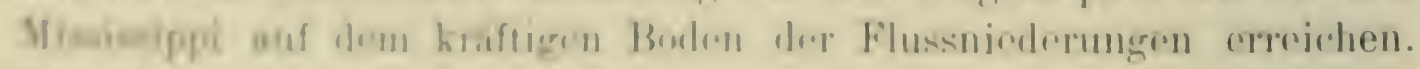

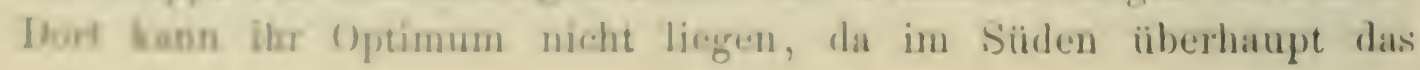


Holz der Buche nur ein specifisches Gewicht von 66 zeigt, während Holz ron Buchen der nördlichen Hälfte des Laubwaldes ein specifisches Gewicht von 74 erreicht. Die Blätter der nordamerikanischen Buche sind länger zugespitzt und gezähnt; schon mit 50 Jahren geht die glatte Rinde in eine seicht längsrissige Borke über.

Die amerikanische Buche steht in forstlicher Bedeutung hinter der europäischen noch weit zurück; reine Waldungen fehlen in den Vereinigten Staaten ganz; ihr Holz ist in Qualität von dem europäischen kaum verschieden.

Die amerikanische Edelkastanie, Castanea americana Rafin. auch Koch und Nuttal, Chestnut. Die Früchte sind klein und in eine lange Spitze ausgezogen. Sie erreicht ihr Optimum auf den kräftigen Gebirgsböden im Süden; nach Norden hin geht sie so weit als Eichen wachsen und zeigt sich dadurch als merklich härter unserer Edelkastanie gegenüber. Ihr Holz ist gut spaltbar, zu Schwellen und in der Kunsttischlerei brauchbar; die Früchte, alljährlich sehr reichlich, geben dem Baume seinen gegenwärtigen Werth und veranlassen seine stetig wachsende Verbreitung. Ein nahe verwandter Halbbaum, Castanea pumila Mill, Chinquapin, Zwergedelkastanie, überzieht im Süden die trockenen, steinigen Berghänge und wird der essbaren Früchte wegen wie der grosse Kastanienbaum alljährlich zerfetzt und verstümmelt. Früchte von der Grösse und Gestalt einer spitzen Eichel; Blätter unterseits hell, etwas behaart.

Carpinus americana Lam. (syn. Carolineana), Hornbeam, Am. Hornbaum; ein kleiner Baum in Nord und Süd. Die junge Pflanze hat grosse Aehnlichkeit mit Betula lenta, ist aber unterschieden dadurch, dass die Kurztriebe drei bis vier Blätter tragen. Standort, Habitus, Bau der Rinde und des Holzes, sowie Verwendung des letzteren, hat die amerikanische Hainbuche mit der europäischen gemein.

Ostrya virginica Willd., Hop Hornbeam, Virginische $\mathrm{Hopfenbuche.} \mathrm{Halbbaum} \mathrm{in} \mathrm{Nord} \mathrm{und} \mathrm{Süd} \mathrm{mit} \mathrm{dem} \mathrm{Optimum} \mathrm{im}$ Süden; gewöhnlich an trocken-steinigen Berghängen.

Platan us occidentalis L., Sycamore, Plane-tree, Buttonwood, Westliche Platane. Seit länger als 250 Jahren wird dieser schöne Baum als Schattenspender in Europa gepflegt, selbst da, wo ihn frühe Winter beschädigen. In der Union findet sich die Platane in grössten Exemplaren auf den frischen, tiefgründigen Flussufern in 
Süden: durch Nord und Süd erwïchst sie ferner auch auf recenten Kies- und Sundablagerungen der noch nicht stabilen Flussliufe in den Bergen, ebenso wio die beiden Verwandten im Westen; dadurch trägt sie zur Festigung der Flussufer bei: überdiess liefert sie ein gut brauchbares Nutzholz.

Die Dimensionen, welche die Platane erreicht, 40 Meter Höhe und 4,2 Meter Durchmesser, erheben dieselbe zu einem der grössten und stärksten Latubbaitume des Ostens; an Exemplaren von 2 Meter Durchmesser, die ich unweit des Mississippi mass, war die Rinde eine kleine und dickschuppige Borke, die sich nicht aus dem Stamme horausschälte.

Unter den Prunus-Arten sind fünf Halbbäume; eine Art ist cin werthroller Nutzbaum; auch die Gattung Prunus gehört dem Süden an; eine Art ist nur im Norden zu finden, drei sind nur im Süden zwei erstrecken sich durch Nord und Süd. Die nördlichen Arten liefern ein $\mathrm{Hol} \%$ ron dem durelssehnittlichen specifischen Gewichte von 52, jene im Süden dagegen ron 87. Sie nehmen an Verbreitung täglich \%u, da sie auf den misshandelten Waldböden, durch Vögel eingebracht, vor den werthrolleren Holzarten erscheinen.

Die wichtigste Art ist Prunus serotina, Wild black eherry, Spate Traubenkirsohe: sie gehört zu den in Trauben blühenden Paduskirschen: von der europaiischen Art durch die nierenförmige Grostalt der Friichto ('Tafel IV) rersehichlen. Den erwachsenen Baum umgiht eine kleinschuppige Borlin: im hohen Alter entwickelt sich eine Borke mit breiten I'lattron. ähulich wir bei d(1 Kirfor. Dureh das ganze Lanbholggebiet solbreitet, bleibt die Trauhenkirsche auf der nördlichen

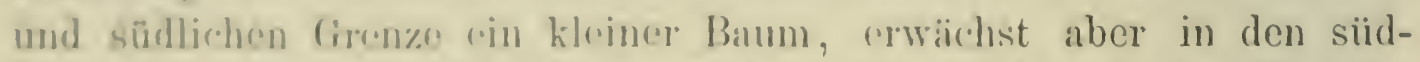
lichon Allowhanies auf kräftigem Boden, einzeln dem Laubwalde eingesprengt, zu cinem stattlichen Bamme von 20 bis 30 Meter Höhe und liefort dann minen selar werthvollen Sihaft.

Das schine rothe Nut\%hol\% widel \%u Mbihcln aller Art, besonders

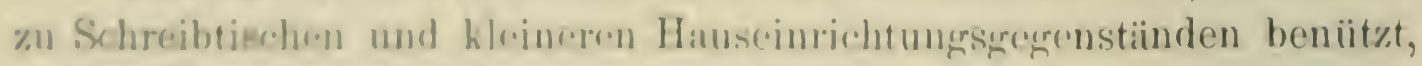
sturke Exemplare sind bereits eine Seltenheit.

Dor Baum Eothert \%u don am schnollsten wachsenden, werthollen Hurtholzarten dres Nordens; er wächst leicht auf frockenem Boden, auch wenu inowelbe fur landwirthschaftliche Zweede bereits za arm ist, junge Pflanzen ertrigen gut das Umpllan\%en.

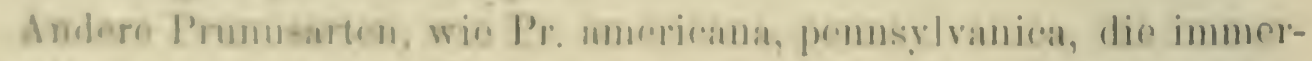
govae (der subtropischen Region ungchürige) P'r. Caroliniana, spielen 
im Laubwalde eine untergeordnete Rolle; sie betheiligen sich, ebenso wie die Angehörigen der Gattungen Pyrus und Crataegus reichlich als strauchförmiges Unterholz am Aufbau des nordamerikanischen Waldes; viele sind in Europa als Ziersträucher geschätzt.

Die Magnolien fehlen den Westküsten der alten und neuen Welt ganz; der atlantische Laubwald Nordamerika's beherbergt sieben Arten, ron denen keine hervorragenden, forstlichen Werth besitzt; Japan hat neun Arten, inclusive einer forstlich sehr beachtenswerthen Art, Indien besitzt sechs auf den Himalaya beschränkte Magnolien, von denen vier baumartig und forstlich benützbar sind.

Die schwerfrüchtigen Magnolien sind südliche Pflanzen mit grossen Blättern und Blüthen; nur zwei Arten von den sieben der atlantischen Flora erstrecken sich auch nordwärts bis etwa Massachusetts; diese beiden sind:

Magnolia glauca, Sweet Bay, mit unterseits weisslichen Blättern und kleinschuppiger, aschfarbiger Borke; sie erreicht ihre grössten Dimensionen im nördlichen Florida, an der Südgrenze des Laubwaldes, ist aber an der nördlichen Grenze ihrer Verbreitung nur Strauch.

Magnolia acuminata, Cucumber tree, mit einer langrissigen, sich abblätternden Borke erreicht im Süden ebenfalls eine Höhe von 30 Meter.

Magnolia macrophylla mit einem Blatte von 1 Meter Länge eine südländische Pflanze, welche die Parkkultur bis in die Breiten von New-York verpflanzt hat.

Forstlich beachtenswerth ist der den Magnolien verwandte Liriodendron tulipifera, Tulip tree, Tulpenbaum, mit leichtem, geflügeltem Samen in aufrechten Kapseln; der Baum geht am weitesten nach Norden, ist in Europa lange in Parken kultivirt, wo er sogar auf der kalten bayerischen Hochebene noch baumartige Dimensionen erlangt. In seinem Optimalgebiet, in den geschützten Thälern der südlichen Alleghanies erwächst der Tulpenbaum nicht selten zu 60 Meter Höhe und 4 Meter Durchmesser; rasch erwachsend ist der pfeilgerade Schaft bis in die Spitze zu erkennen. Das leichte und weiche Holz wird sehr geschätzt als Construktionsholz, zu Thür- und Fensterstöcken, Schindeln, beim Schiffbau und besonders zu Pumpröhren, für welch letzteren Zweck es unübertrefflich sein soll (Douglas in Waukegan Jll.); zu letzterem Zwecke dient allein das grünlich gelbe bis grünbraune Kernholz. 
Der nordamerikanische Laubwald ist verhältnissmässig arm an Linden; man unterscheidet nur zwei einander sehr nahe stehende Arten, sowie eine Varietiit.

Tilia americana. Lime tree, Lindentree, Amerikanische Linde, ist die wichtigste; ron der europäischen Art durch die tiefer gesiigten Blätter, deren hellere Unterseite, sowie das längere Vorblatt de's Blüthenstandes unterschieden. Durch das ganze Gebiet rerbreitet, ist sie roichlich den Laubwaldungen an den grossen Seen und in den Alleghany-Bergen beigemengt und erwächst auf kräftigem Boden bis zu 30 Meter Höhe.

Das leichte Holz zu kleineren Waaren und zu billigen Möbeln gesucht: aus dem Baste wird Bindmaterial gewonnen.

Die im Süden heimische Linde gilt als Varietït - pubescens der rorigen Art.

Tilia heterophylla ist eine anf die Central- und Südstaaten beschrinnkte Art, die in der Praxis von der Vorigen nicht getrennt wird.

Ein Baum, auf den man in Amerika als besonders werthvoll zu Anpflanzungen im Westen, am Prïrierande, hingewiesen hat, ist die

Catal paspeciosa Warder, Westliche Catalpa; nach ihrem Benemer ist die Western Catalpa von Catalpa bignonioides rerschicelen durch die grössere Blüthe, grüsseren Samen und breiteren Samenhüilsen; die Blätter sind gross, heryförmig und, wenn zerrieben, ohme den unangenehmen Geruch, der die Blïtter der bignonioides auszeichnet.

1) Gm Genzgebiete ron N. und S. in (c. angehörend, ist diese Catalpa bosonders nach S.W. hin rerbreitet, wo sie auf kriftigrem Bodon der Flussniedroungen ausnahmsweise bis za 45 Meter Höhe sich erherbe. Ohwohl schr rakch wachsend, liefert sie ein gutes, besonders danerhaftes Nutzhol\%; in Amerika hält man 20-35 Jahre zur Nutzholzeryinhung für gentïgend, wobei aber ein riemlich enger Stand der Pflanzung, wegren der Neigung des Batumes zur Astbildung, erforderlich ist. R. Douglas in Waukegan hat anf armon Sandboden des Lake Michigan dio Catalpa in grosser Menge und mit Vortheil angebaut;

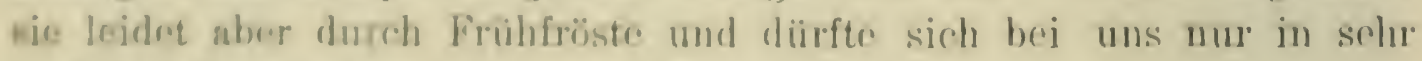
gesedityten Tagen in der ersten Jugend erhalten.

Wow dunkelvinlatte Rermhol\% ist leicht (42 specifisches Gewicht), abor sogen seinos groseren Gehaltes an Kromfarbo sehr damerhaft bei Vorwoulung im Bodon: dabei umfasst der Splint nur den letaten Jahrering. 
Warder berichtet, dass in New-Madrid (Ky) ein Stück Waldes durch ein Erdbeben im Jahre 1811 so tief gesenkt wurde, dass über dein Boden 3--10' Wasser standen und alle Bäume zu Grunde gingen; im Laufe der Zeit sind die Stämme alle verfault mit Ausnahme jener der Catalpa, welche noch fest im Grunde hafteten; Eisenbahnschwellen wurden nach 12 jährigem Gebrauch umgedreht, da die Schienen in das leichte $\mathrm{Holz}$ sich eingedrückt hatten, das Holz aber zeigte noch keine Spur von Zersetzung.

Die Catalpa bignonioides Walt. Catalpa steht wenigstens in der Schaftbildung der Vorigen beträchtlich nach; auf den Flussufern, zusammen mit Schwarzbirke und Platane bildet sie in S.a. einen sparrigen Baum, der gegen die alljährlich steigenden Fluthen ankämpft, vielfach zur Seite gebogen und unterwaschen. Ihr Holz ist der vorigen Art gleich; sie erreicht aber nur 15 Meter Höhe.

Bemerkenswerth für die östliche Baumflora ist weiters eine bis zur Nordgrenze des Laubwaldes vordringende, winterkahle Laurinee, die überall sich findet und durch ihre zahlreiche Jugend, ihre variablen Blattformen (ganzrandig, zwei- und dreilappig) auffällt, es ist diess

Sassafras officinale Nees, Sassafras, mit schwarzen, auf dicker, rother Basis sitzenden, gestielten Früchten. Das leichte Holz gilt als sehr damerhaft bei Verwendung im Boden, die Rinde ist medizinisch.

Die Weiden und Pappeln sind sehr leichtsamige Bäume und Sträucher von grösster Verbreitung; die nordamerikanischen Weiden hat $\mathrm{Bebb}$ in Rockford (Jll.) geordnet und mit vielen Varietätennamen versehen, sie scheinen ein so schwieriges Studium zu sein, wie die europäischen Arten und Varietäten. Bemerkenswerth ist, dass keine der nordamerikanischen Weidenarten zu technischen Zwecken verwendbar erscheint.

Salix nigra, amygdaloides und longifolia sind Weiden, welche die Prärie umgehen und in der pacifischen Flora sich wieder finden; ausser diesen besitzt die atlantische Region noch zwei Arten, S. cordata und discolor, während die pacifische Flora ausser obigen Arten noch sieben beherbergt. Von den Pappeln überschreiten zwei Arten

Populus tremuloides Michx., Aspen, amerikanische Zitterpappel und

Populus balsamifera L., Balsam, Balsampappel den Continent im Norden der Prärie. 
Die Zitterpappel kennzeichnet sich nach jeder Richtung als eine nahe Verwandte der europäischen: sie ist ein forstliches Unkraut, das auf den zahlreichen ron Holz entblüssten Partien ihres nördlichen standortes in grosser Menge sich einfindet und bessere Holzarten verdrïngt; doch ist sie. wie die übrigen Pappeln, keineswegs werthlos; sie bedeckt den Boden und conservirt ihn und liefert iiberdiess in ihrem sehr leichten, weissen, weichen Holze ein vortreffliches Material zur Papiermasse und Packspinen.

Die Balsampappel betritt das Gebiet der Tereinigten Staaten nur in einer schmalen nördlichen Zone, sowohl im Osten wie im Westen; südlich von ihr tritt im Osten

Populus monilifera Ait., Cottonwood, Wollbaum, im Westen P. trichocarpa an seine Stelle. Der Wollbaum erreicht zuweilen 50 Jeter Höhe und ist üstlich ron den Rocky Mountains, wie am Yellowstoneflusse vielfach der einzige Baum in der Prärie, wo er unmittelbar an den Flüssen die nöthige Feuchtigkeit in Luft und Boden findet; er wird wegen seiner Schnellwüchsigkeit in grösster Menge der Billigkeit wegen bei den Pflanzungen im Westen als Füllmaterial zwischen besseren Holzarten und zugloich zur Erfüllung der Gesetzesvorchriften der 'limber-culture-act benuityt; in neuerer Zeit dringt man darauf, bessere Holzarten zu obigrem Zwecke zu verwenden.

Zwei andere Pappeln, P. grandidentata Michx. und P. heterophylla, haben nur granz untergeordneten Werth.

Die merkwürdigen Hamamelideen, die Hexenbäume und -Strïucher besit\%en im Laubwalde zwei Vertreter, die Hexennuss, Hamamolis virginica L., Witch-hazel, die in Blittern und Früchten täuschend dio Hasclnuss nachahmt: sie ist ein Striuch zu Füssen des Laubhol\%ed, besonders in den Bergen so hïufig wie die Haselnussstrancher enlbst; wie hei diesen lockt ein warmer Herbst die gelben Blithen hervor.

Andre Hosenbäume, wic \%. B. in Indien, geben im Aussehen cinen Kirschbaum oder eine Pappel wicder; cin inderer, nordamerikuniseher Hexenbaum, der Liguidamber oder Sweot Gum (Liquidambur styraciflua L.) erinnert wenigstens in den Blättern an

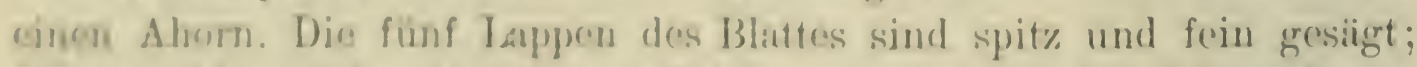
jongen. on- und molurjührigen Trieben entspringen bis $1,5 \mathrm{~cm}$ breite kiorkleisten.

Dor Baum urrojcht woino grôssten Dimensionen im Süden, unmiteolber an dis Sumpf-Oypresse in seinen Ausprüchen an die Boden- 
feuchtigkeit sich anschliessend; dort entwickelt der Baum eine dicke, flaschenförmige Basis, wie Taxodium selbst und einen pfeilgeraden Schaft, der dem der Cypressen nicht nachsteht; selbst auf freier Fläche erwachsene Bäume behalten diese letztere Eigenschaft bei.

Das Holz des raschwüchsigen Baumes ist dem des Apfelbaumes in Farbe ähnlich und als Ersatz für schwarzes Wallnussholz von grossem Werthe.

Drei Urticaceen mögen hier angeschlossen werden: Der westliche Zürgelbaum, Celtis occidentalis L., Sugar Berry, ein hoher Baum mit ziemlich geringwerthigem Holze, wie der südeuropäische Zürgelbaum, der im Nordwesthimalaya als Futterbaum dient, von dem alljährlich die Seitenzweige herabgeschnitten werden. Die nordamerikanische Art wird ein hoher Baum in dem feuchten Flussgebiete des Mississippi und erstreckt sich, auf die Flussufer und Quellgebiete beschränkt, weit nach Westen hin, nach Texas, wo er von der Mistel besonders gerne bewohnt wird.

Der amerikanische oder rothe Maulbeerbaum, Moruș rubra L., Red Mulberry, mit schön rothen, essbaren Früchten; das dunkelbraune Kernholz dem der M. alba nahestehend und viel benützt; als „Füllholz" ist der rothe Maulbeer zu den Pflanzungen am Prärierande neuerdings vielfach empfohlen:

Maclura aurantiaca Nutt., Osage Orange, ist ein ausserordentlich raschwüchsiger Baum mit grossen, orangefarbigen Früchten; in den westlichen Staaten wird er zur Anlage von Hecken verwendet; sein Holz ist dem des Maulbeer ähnlich und dient zur Strassenpflasterung, zu Eisenbahnschwellen und Radnaben.

Aesculus glabra Willd., Ohio Buckeye (syn. Pavia glabra Spach), Ohio-Rosskastanie, ein Baum bis zu 20 Meter in den Thälern der südlichen Alleghany-Berge; Fruchtschale grobhöckerig, Rinde eine $6 \mathrm{~cm}$ breite und lang-rissige Borke von hellgrauer Farbe; das Holz zu Holzwaaren, Papiermasse, künstlichen Gliedern, Hüten etc. wie das der folgenden Art verwendet.

Aesculus flava Ait. (syn. Pavia flava Moench), Sweet Buckey, Gelbe Rosskastanie, wird in ähnlichen Oertlichkeiten wie die glabra ein hoher Baum, dessen Borkenschuppen in breiten Stücken, ähnlich wie bei der Palme, sich ablösen. Fruchtschale ganz glatt. Zusammen mit einer rothblühenden Varietät als Schattenbaum vielfach kultivirt. 
Die zu den Cormaceen gehörige Gattung Nyssa gehört mit ihren schwerfrüchtigen Arten dem Süden an: Nrssa sylratica Marsh, Tupelo reicht am weitesten nach Norden und übertrifft im specifischen Gewichte ihres Holzes die Arten mit beschränkter räumlicher Terbreitung beträchtlich (64:48); der Baum bewohnt im Süden die Taxodiumsümpfe, und die bisher als N. aquatica L. aufgeführte Art ist mit $\mathrm{N}$. srlvatica identisch.

Blätter ganzrandig, kahl (Tafel III), Früchte $1 \mathrm{~cm} \mathrm{lang,} \mathrm{1/2} \mathrm{cm}$ breit, glänzend schwarz, auf $4-6 \mathrm{~cm}$ langem Stiele. Im Hügellande der südlichen Kiefer nimmt der Tupelo mit der Carya tomentosa den besseren und feuchteren Boden in schwachen Einsenkungen und Mulden ein. Die Rinde gleicht der unserer Eiche; das gedrehtfaserige Holz ist zu Pfeilern an Werften, zu Wasserleitungsröhren brauchbar.

Nissa capitata Walt., Sour Tupelo, Sauertupelo. Früchte $2.5 \mathrm{~cm}$ lang: $1 \mathrm{~cm}$ breit; Blätter, Blattstiele und Triebe behaart; ist wie Nyssa uniflora Wangh. auf den Süden beschränkt; letzterer Baum erreicht eine Höhe ron 30 Meter; sein Holz ist sehr leicht, aber zäh und nicht spaltbar und empfiehlt sich zu Drechslerwaaren aller Art.

Die Erlen im östlichen Laubwalde der Union spielen nicht die Rolle wie die Erlen im kühleren Theile Europa`s; es fehlt dazu durchaus nicht an Standorten; ich glaube, der Grund liegt darin, dass die atlantische Flora eine ganze Reihe ron Nadelholzpflanzen besitzt, welche den gleichen Standort wie die Erlen aufsuchen und dabei durch ihr Schattenerträgniss den lichtliebenden Erlen mit Erfolg das Terrain streitig machen.

Die Erlen der atlantischen Region sind theils nur Sträucher, dann aber massenhaft zusammenstehend und die nassen Vertiefungen in Laubwalde mit einem kurzen, gleichmässigen Gestrüppe überziehend, wie z. B. in Wisconsin, theils Halbbäume, die kaum noch forstliche Beachtung verdienen.

Alnus serrulata, Black Alder, Amerikanische Schwarzerle. Von Massachusetts bis Florida, aber nirgends über 12 Meter hoch, regelmässig ein Dickicht bildender Strauch; das helle Holz wird, der Luft ausgesetzt, schnell roth; der Blätter grösste Breite im oberen Drittel.

Alnus glauca Michx. f. (syn. A. incana Willd.), Speckled Alder, Amerikanische Weisserle. Wird nur 6 bis 7 Meter 
hoch; an gleichen Oertlichkeiten wie die vorige; ihr Holz wie das der vorigen Art zu Schiesspulverkohle verwendet. Diese Art zeigt Verschiedenheitcn von der europäischen und japanischen Art, freilich nur solche, die nur bei einer vergleichenden Betrachtung aller drei Formen nach lebenden Exemplaren deutlich werden, die aber im Zusammenhalt mit der geographischen Verbreitung zur Annahme getrennter Arten solange zwingen, bis nicht durch Uebergänge und für die japanisch-chinesischen und europäischen Formen auch räumlich der Zusammenhang und die Identitüt festgestellt ist. Gleiches gilt für die Birke und Zitterpappel.

Alnus maritima Muhl, Seaside Alder, See-Erle. Kommt ron Delaware an südlich, im westlichen Amerika aber gar nicht ror; auch diese Art soll mit der japanischen Art identisch sein; diese letztere Art verdient den Namen maritima gewiss nicht, da sie eine Bergbewohnerin ist. Die amerikanische Art erreicht nur 6-7 Meter Höhe.

Es eruibrigt noch, eine Reihe ron Sträuchern und Halbbäumen zu erwähnen, die, mit der Jugend der Nutzhölzer kämpfend, als Füllmaterial im Walde dienen, die aber technisch nur untergeordneten Werth repräsentiren; eine regelrechte Forstwirthschaft wird sie sowenig verdrängen, wie diess in Deutschland der Fall ist; immerhin aber dürfte sich ihre Menge, zu der sie bei der herrschenden Raubmethode im Walde unverdienter Weise herangewachsen sind, wieder allmählig beträchtlich rermindern.

Dass die einzelnen Gattungen in Amerika viel reicher an Arten sind als die europäischen, lässt sich a priori erwarten; volle 12 Crataegusarten erwähnt der Censusbericht, darunter die allbekannten C. Crus galli, coccinea, tomentosa; viele Gattungen, die bei uns nur niedere Strauchformen erreichen, besitzen neben diesen auch Halbbaumarten wie Taccinium arboreum, eine Heidelbeer, die in den Pinus rigida- und australis-Waldungen bis 9 Meter Höhe erreicht; Andromeda ferruginea in feuchten Oertlichkeiten, Oxydendron arboreum DC.; ein Baum bis 18 Meter Höhe fehlt wohl nirgends den trockenkiesigen Höhenzügen der südlichen Landschaften; Kalmia latifolia L., eine immergrüne Ericacea, bildet undurchdringliche Dickichte in sonnigen Lagen der südlichen Alleghanies; Rhododendron maximum L. wird am Fusse der Alleghany-Berge im Süden ein Baum bis zu 12 Meter Höhe, steigt als astreicher Strauch an den Bergen in die Höhe bis in die kühle Tannenregion; auch dort noch erreicht er an 3 Meter Höhe und $10 \mathrm{~cm}$ Durchmesser, bedarf aber zur Erreichung solcher Dimensionen 
volle 100 Jahre; solches langsam erwachsenes, hartes $\mathrm{Holz}_{\mathrm{z}}$ ist als Ersatz für Buxbaumholz verwendet.

Diospyros virginiana L., Persimmon, Virginische Dattelfeige, gehört zu jenen wohlthätigen Pflanzen, die im südlichen Hügelund Tieflande das durch die Landwirthschaft verödete Terrain occupiren und seine Wiederbewaldung einleiten. Die orangefarbigen Früchte sind, nachdem einige Fröste darüber gegangen, geniessbar; das Holz mit dunkeln Streifen ist selten ganz schwarz wie das verwandte Ebenholz.

Die mexicanische Persimmon, im westlichen Texas und anstossenden Mexico heimisch, Diospyros texana Scheele, hat schwarze Früchte; das Holz dieses Baumes gilt als das beste, um das in Amerika fehlende Buxholz zu ersetzen.

Halesia diptera L. und tetraptera L. bewohnen guten Flussuferboden im Süden; Planera aquatica Gmel. ist im westlichen Süden des Laubholzes in kalten, tiefen, von Flüssen genährten Sümpfen häufig; die Genannten bilden Halbbäume bis zu 12 Meter Höhe.

Chionanthus, Osmanthus, Forestiera sind durch Arten vertreten, welche, wie die übrigen Oleaceen, feuchten bis nassen. Boden lieben.

Viburnum Lentago L. und prunifolium L. vertreten die spärlich bedachte Familie der Caprifoliaceae.

Cornus florida L. fehlt nirgends; er ist durch die klein- und weisslich-schuppige Borke leicht zu erkennen und durch seine zusammengesetzten Blüthen besonders auffallend im Norden und Süden. C. alternifolia L. f., wird im Nordwesten auf gutem Boden bis 8 Meter hoch.

Pyrus sambucifolia Cham. et Schlecht. ist ein kleiner nordischer Baum (Sorbus) der kühlen Fichtenregion, der mit Birken, Pappeln und Anderen den Continent überschreitet, ja selbst wie es scheint bis auf das asiatische Festland übergreift; von den übrigen Pyrus-Arten erreicht keine 12 Meter Höhe, die Dimension der vorgenannten Vogelbeere.

Keinem atlantischen Walde fehlen die Rhus-Arten, von denen besonders Rhus 'Toxicodendron, Poison iry, kletternder Giftsumach auffällt, da er an allen Bäumen, oft tief in der Borke derselben liegend, hinaufwächst; Zäune und Strassenhecken sind seine Lieblingsplätze; er ist sehr giftig und vielen Menschen gefährlich, während Andere seine Blätter berühren oder zerreiben könnon ohne beschädigt zu worden.

Rhus typhina L., Staghorn Sumach, Hirschhorn-Sumach, fehlt bei uns wohl keinem Garten und verräth sich schon durch seine prächtige, rothe Fïrbung der Blätter im Herbste als ein Amerikaner, ebenso wie der bei uns längst zum Bürger gewordene "wilde Wein", Ampelopsis 
quinquefolia, der in seiner Heimat an den Bäumen emporklettert oder morsche Baumstïmpfe mit dichtem Laubwerk ïberzieht, so dass sie bei herbstlicher Färbung wie glühende Säulen erscheinen Die meisten Sumacharten, auch Rh. cotinoides, venenata, copallina, liefern in Blättern und Rinden theils Farb-, theils Gerbstoffe.

Der amerikanische Kreuzdorn mit essbaren Früchten, Rhamnus caroliniana Walt., bewohnt den besten Boden im Flusstieflande zusammen mit Evonymus atropurpureus und mehreren Jlex-Arten, von denen nur Jlex opaca Holly, auch die nördliche Hälfte der atlantischen Laubholzflora betritt.

Asimina triloba Dunal, Papaw oder Custard-apple, mit grossen, essbaren Früchten, rerdient Erwähnung, ebenso einige als grosse Ziersträucher bekannte Rutaceen wie Xanthoxylum americanum Mill. und Clava Herculis L., Prickly Ash; ersterer Strauch ist dem Norden, letzterer dem Süden angehörig; beide sind an ihren Stämmen durch kegelförmige lokale Korkbildung ausgezeichnet, die ihnen den amerikanischen Namen Stachelesche eingetragen haben; Ptelea trifoliata, Hop tree ist desshalb bemerkenswerth, weil er im Süden der Prärie den atlantischen Laubwald mit jenem von Mexico verbindet.

Dass es zahlreiche Standorte in dem Laubwaldgebiete gibt, auf denen die Laubhölzer im Kampfe um die Existenz durch andere Holzarten verdrängt wurden und werden, ist bei dem grossen Wechsel der Configuration, der geologischen Abstammung, der physikalischen und chemischen Verschiedenheiten des Bodens selbstverständlich. Wo der Boden zu mager wird, in Folge übergrosser Beimengung von Kieselsäure, z. B. also auf kiesigem Boden im Gebirge, auf sandigem Boden an der Küste, da treten die Laubhölzer, unter denen es keine ausgesprochenen Sandpflanzen - vielleicht einige kleine Eichen ausgenommen - gibt, zurück und überlassen Kiefern den Sandort; wo der Borlen zwar kräftig genug, dagegen die Feuchtigkeit zu gross ist, da betheiligen sich am Kampfe um den Raum mit grösserem Vortheil c ypressenartige Bäume oder bei genügender Kühle, also in nördlichen Lagen, auch Vertreter der Tannenregion, Fichten, Lärchen und Tannen.

Die Kiefern, so vertheilt, dass sie bei einer allenfallsigen Misshandlung des Laubwaldes und einer Vermagerung des Bodens sofort und überall mit der neu aufstrebenden Vegetation in Konkurrenz treten können, finden natürlich, da bescheidener, bei der gegenwärtigen Forst- und Landwirthschaft eine herrliche Gelegenheit, auf Kosten der besseren Arten sich auszubreiten. 
Unter den drei Kiefern mit grösster Verbreitung durch N. a. c, und S. a. c. nenne ich Pinus rigida, mitis und inops. Am erwachsenen Baume hat rigida die längsten Nadeln, fast rechtwinkelig abstehend, die grössten Zapfen, die Rinde ohne Harzbeulen; mitis folgt dann in Länge der Nadeln, die etwas am Zweige anliegen, Harzbeulen in der Rinde; inops hat die kürzesten Nadelı, steht in Zapfengrösse zwischen mitis und rigida; mitis liefert werthvolles Nutzholz in den westlichen Staaten; inops herrscht im centralen Theile und wird dort zu Wasserleitungsröhren, zu Brenn- und Kohlholz gesucht; rigida ist auf die atlantische Längszone beschränkt und besonders auf dem Sandboden der nördlichen Küste entwickelt; sie gibt Brenn- und Kohlholz, zu Nutzholz war sie früher benützt; mitis bildet den besten Schaft und erreicht 30 Meter Höhe; der Schaft von rigida ist astreicher und der Baum wird selten über 24 Meter hoch; inops ist in den östlichen Staaten sehr astreich und steht an Grösse den beiden anderen nach; in ihrem Optimum in den Centralstaaten aber erwächst sie mit glattem Schaft und bis zu 36 Meter Höhe; demnach möchte es fast scheinen, als wäre rigida die geringste von den genannten Arten; doch hat sie auch Vorzüge, die eine nähere Betrachtung des Baumes rechtfertigen mögen; sie geht überdiess am weitesten nach Norden bis Neubraunschweig.

Pinus rigida Mill., Pitch-Pine, Pechkiefer. Die junge Pflanze wächst ziemlich schnell und ist gekennzeichnet durch drei Nadeln von $9 \mathrm{~cm}$ I änge in einer Scheide und die hellbraune glänzende Rinde der jungen Triebe. Bei kräftigen Pflanzen lässt sich folgender Aufbau beobachten:

Unter der ersten nadellosen Stelle, von der Basis an gerechnet, sitzen Kurztriebe mit vier Nadeln in einem Quirle; unter der zweiten sind die Zapfen, mehrere in der Zahl, befestigt; unter der dritten stehen Seitenäste, unter der vierten bilden sich Knospen aus; an weniger krïftigen Exemplaren sind weniger Abschnitte entwickelt. Ende August ist der Stiel des neuen Zapfens $2 \mathrm{~cm}$ lang nach abwärts gekrümmt; die jungen Zapfen sind grün bis violett mit hellbraunen Stacheln; die im zweiten Jahre stehenden Zapfen sind $5 \mathrm{~cm}$ lang, grün, nach abwärts gewendet mit vertrockneter Apophysenspitze; wenn reif ist der Zapfen hell-ockerfarbig, bleibt längere Zeit am Zweige hängen und wird von dem wachsenden Holze so umschlossen, dass der Zapfen später in die Höhe gedrückt wird, rechtwinkelig, vom Stamme abgekehrt, stiellos demselben aufsitzt; Zapfenlänge $5 \mathrm{~cm}$, Breite $5 \mathrm{~cm}$. Die Pechkiefer macht gern Johannitriebe und behält eine Benadelung von 3 Jahren 
bei; ihre Rinde ist eine grauschuppige Borke, die wie bei der österreichischen Kiefer bis in die Baumspitze reicht.

Der Nutzholzwerth dieser Kiefer ist heutzutage in Nordamerika geradezu Null; ihr Holz mit dem durchschnittlichen specifischen Gewichte von 51 ist grobfaserig und durch keine hervorragend vortheilhafte Eigenschaft ausgezeichnet; als Brenn- und Kohlholzproducent ist der Baum dagegen bemerkenswerth.

Eine auf kiesigem Geschiebe bei Boston erwachsene Pechkiefer hatte 1,5 Meter über Boden

\begin{tabular}{c|c|c|c}
\hline \hline Alter & $\begin{array}{c}\text { Durchmesser } \\
\mathrm{cm}\end{array}$ & $\begin{array}{c}\text { Kreisfläche } \\
\square \mathrm{cm}\end{array}$ & $\begin{array}{c}\text { Zuwachs pro Jahr } \\
\square \mathrm{cm}\end{array}$ \\
\hline 10 & 7,2 & 40,7 & 4,07 \\
20 & 16,2 & 205,7 & $\mathbf{1 5 , 4 9}$ \\
$\mathbf{4 0}$ & $\mathbf{3 0 , 2}$ & $\mathbf{7 1 8 , 9}$ & $\mathbf{2 5 , 7}$ \\
60 & 36,6 & 1051,9 & $\mathbf{1 6 , 6}$
\end{tabular}

Sargent*) berichtet von einem reinen Kiefernbestande, der in New-Yersey auf verlassenem, landwirthschaftlich ausgeraubtem Boden aufgewachsen war; der dicht geschlossene Wald, dessen Bodendecke aus Moos besteht, liegt 20 Kilometer vom Meere und zeigt mit 50 Jahren eine mittlere Höhe von 15 Meter und einen mittleren Durchmesser von $25 \mathrm{~cm}$.

In New-Jersey sind die Kiefernbestände in der Nähe der Küste mit P. mitis gemengt, aber rigida prälarirt; Vaccinium-Arten, Clethra alnifolia, Smilax, Quercus nigra und ilicifolia, Pteris aquilina bilden den staudenförmigen Bodenschutz.

Anfangs von der Wichtigkeit der Pechkiefer für den deutschen Wald nach den Anpreisungen in der forstlichen Literatur überzengt, habe ich viel Zeit mit ihr vergeudet. So besuchte ich einen ausgedehnten Kiefernkomplex in New-Jersey, lauter Bestïnde rom jüngsten bis zum 30. Jahre; mitten unter ihnen war eine Klenganstalt etablirt, die alle europäischen Baumzüchter mit dem Pitch-Pine-Samen versorgte.

In diesen nur wenige Meilen von der See entfernten Waldungen brütet während der Sommermonate eine erdrückend feuchte, heisse und schwïle Luft; die Musquito in ungewohnter 'Lahl und Grösse sind so lästig, dass man die Hände nicht aus den Taschen ziehen darf, das Gesicht mit einem Tuche schïtzen muss; ja selbst Thüren und Fenster

*) Garden and Forest Vol. I. Nr. 14. 1888. 
der Wohnhäuser erhalten einen eigenartigen Gazevorhangverschluss, um die zahllosen Musquito's abzuhalten; das ist das Klima, in dem die rigida in Optimo gedeiht. Dort waren einst starke, hohe Exemplare vorhanden, jetzt sind nur wenige, ästige, verkrümmte Ueberreste aus der Urwaldzeit auf unzugänglichen Sumpfinseln erhalten geblieben.

Auf solchem mageren Sandboden erreicht die Pechkiefer in 30 Jahren 1,5 Meter über Boden, 12,5 cm Durchmesser ohne Rinde und eine Höhe von 7,5 Meter; nach den Versicherungen verlässiger Gewährsmänner hatte der Urwald im Durchschnitt 22 Meter Höhe; das Holz diente zur Kohlenbereitung.

Mehrere erfolgreiche Anpflanzungen mit der Pechkiefer sind nach Berichten Anderer in Amerika unmittelbar an der Küste ausgeführt worden; die oben erwähnten grossen Kiefernwüchse sind aus Naturbesamung durch Mutterbäume, zum kleineren Theile aus Pflanzung entstanden.

Weitere-Pflanzungen sah ich bei Professor Me ehan in Germantown bei Philadelphia; dort steht die rigida weit hinter der europäischen sylvestris zurück.

Rob. Douglas in Waukegan hat sehr lehrreiche Anbauversuche mit amerikanischen und europäischen Holzarten auf dem armen Dünensandboden des Lake Michigan ausgeführt; dort sind 12 Jahre alte Pechkiefern erst 1 Meter hoch, die Mehrzahl ist längst abgestorben; nur Pinus pungens kann ihr in Kümmerlichkeit gleichkommen; die Pechkiefer hat nicht die Fähigkeit den Boden mit nadelreichen, tiefstehenden Seitenästen zu schützen, eine für den Anbau auf kahlen, heissen Sandflächen unbedingt nothwendige Eigenschaft; unsere europäische sylvestris ist hiezu viel besser; selbst die Weymouthskiefer hat bei dem erwähnten Versuche noch die doppelte Höhe der P. rigida in 12 Jahren erreicht.

Eine weitere Pflanzung ist mir auf besserem Sandboden, auf dem Versuchsfelde der ehemaligen Forstakademic zu Odschi bei Tokio in Japan, also in der Nähe der Meeresküste, bekannt; die anfangs sehr rasch erwachsenen Pechkiefern kümmern und sterben jetzt ab, ohne äusserlich erkennbare Ursache, während die benachbarten P. Thunbergii, die japanischen Küstenkiefern, kräftig weiter gedeihen ; die japanischen Binnenlandskiefern, P. densiflora und P. sylvestris, übertreffén zwar die rigida beträchtlich, stehen aber der japanischen Küstenkiefer nach.

Hinsichtlich der Fähigkeit der Pechkiefer, wenn abgeschnitten, Ausschlïge aus dem Stocke entwickeln zu können, verweise ich auf die P. mitis, welche die gleiche Eigenschaft zeigt. 
Es war mir nicht möglich, eine alte Pechkiefer zu erlangen, um sie auf ihren Harzgehalt hin zu prüfen; bei der geringen Bedeutung, die diese Kiefer für Deutschland und Nordamerika hat, scheint mir die Unterlassung der zeitraubenden Untersuchung ein nicht gar zu schwerer Fehler; der Name „Pechkiefer" rührt offenbar von dem empirischen Vergleiche des rigida-Holzes mit dem der Weymouthskiefer her; über solche populäre Bezeichmungen entscheiden oft ganz geringfügige Umstände, z. B. der Ausfluss von Harz aus dem frisch abgeschnittenen Stocke; ich zweifle nicht im Geringsten, dass eine genaue Harzprüfung keinen Grund wird entdecken können, warum gerade diese Kiefer unter allen amerikanischen Verwandten die "Pechkiefer" par excellence heissen soll; die Praxis nennt in der That noch eine Reihe von Kiefernhölzern „Pitch-Pine“, so das Holz der mitis, der resinosa; auch im Westen gibt es diese Bezeichnung; nie aber heisst das vortreffliche Holz der Pinus australis, das einzige Kiefernholz, das auf den europäischen Markt kommt, in Nordameri.ka Pitch-Pine.

Ich muss hier meinen verehrten Freund C. Mohr in Mobile (Alabama) in Schutz nehmen gegen Verdächtigungen mehrerer forstlicher Zeitschriften, als wäre er an der unheilvollen Verwechslung des in Deutschland importirten Kiefernholzes mit dem der Pitch-Pine (Pinus rigida) schuld.

Niemand in Nordamerika kennt das Holz der Pinus australis und die Pflanze selbst besser, als der seit Jahrzehnten unter ihrem Schatten lebende Mohr; und Keiner weiss besser als er, dass das Holz der Pinus rigida (Pitch-Pine) nur Brennholz, kein Nutzholz ist. Ob es nur Unwissenheit oder Oberflächlichkeit ist, welche das nach Deutschland gebrachte sogenannte Pitch-Pine-Holz von der Pitch-Pine-Pflanze (Pinus rigida) abstammen lässt (man vergleiche z. B. M. Sering, die landwirthschaftliche Concurrenz Nordamerika's in Gegenwart und Zukunft 1887 in Danckelmann's Zeitschrift für Forst- und Jagdwissenschaft. 1888. 2. Heft), will ich hier nicht entscheiden. Es genügt mir, den wahren Sachverhalt hier und an vielen Orten deutlich genug klar gelegt zu haben.

Pinus inops Ait., Jersey Pine, Jerseykiefer, die etwa nur die geographische Breite ron New-York erreicht; zwei Nadeln mit $5 \mathrm{~cm}$ Länge stehen in einer Scheide; Zapfen in der Mitte des Längstriebes, im ersten Jahre aufrecht auf $1,5 \mathrm{~cm}$ langem Stiele, wenn reif etwas hängend und 2 bis 4 zusammen in einem Quirl; Zapfen 
durchschnittlich $5 \mathrm{~cm}$ lang, wenn reif rothblau, wenn offen $2,5 \mathrm{~cm}$ breit; Nabeldorn fein, etwas nach vorne gekehrt und sehr leicht wie bei Taeda abbrechend. Der Same (Tafel VIII) ist auffallend durch den Uebergang zum Typus des Fichtensamens; derselbe liegt nämlich in der löffelförmigen Basis des Flügels; eine schmale Spalte in dem Löffel erinnert an die Zangenform der übrigen Kiefern; junge Triebe weissblau bereift wie bei mitis; Rinde kleinschuppig, etwas unserer Fichte ähnlich.

Die anatomische Structur zeigt den Typus der dreinadeligen Section Taeda, so dass die zweinadelige inops zur Section Banksia gezählt werden muss.

Auf den geringwerthigen, trockenen Höhenlagen, wo die Axt die Laubhölzer immer mehr und mehr lichtet, gewinnt die Jerseykiefer zusehends an Ausdehnung.

Pinus pungens Michx. f., Table-mountain Pine, Stechkiefer; eine interessante Kiefer, für welche die westliche Pinus Coulteri ein Analogon bietet. Sie nimmt die trockenen, kiesigen Höhenlagen in den Alleghanies, die Hügelköpfe und Plateau's ein, während inops und mitis nach der Tiefe zu sich anschliessen.

Zapfen stets 3 bis 5 in einem Quirle sitzend, Apophyse erhaben, Nabeldorn dick, am geschlossenen Zapfen nach oben gekrümmt. Unter den östiichen Kiefern trägt die Stechkiefer, von jenen der P. australis abgesehen, die grössten Zapfen; die Länge schwankt zwischen 8-10 cm, die Breite des offenen Zapfen zeigt die gleichen Dimensionen; wie bei P. tuberculata stehen oft zwei Zapfenquirle übereinander an einem Jahrestriebe.

Nadehn steif, dick, stechend, an kräftigen Exemplaren $9 \mathrm{~cm}$ lang, dunkelgrün; an zapfentragenden Zweigen sind die Nadeln oft bioss $5 \mathrm{~cm}$ lang; junge Triebe braun glänzend, die Rinde eine kleinschuppige graue Borke.

Die Stechkiefer auf Sandboden anzubauen hat man mehrfach versucht; aber jedesmal war der Erfolg zweifelhaft; auf kräftigem Boden in Hügellande wächst sie schr rasch, doch ist dort der Boden für die Stechkiefer verschwendet; auf Sandboden ist sie schlechter als rigida, weil sie ebenfalls den Boden nicht mit Zweigen zu beschatten vermag; am Lake Michigan sind zwölfjährige Pflanzen nur 1 Meter hoch und dicht mit 'zapfen beladen.

In ihrer Hcimat, in den Bergen, ist die Stechkiefer ein sehr astreicher Baum, die Aeste weit ausgreifend, gabelig getheilt, voll von 
Zapfen von allen Jahrgängen am Hauptstammie und an den Seitenästen, so dass man nicht ungestraft die Zapfen herabholen kann und der Name „Stechkiefer" sehr am Platze ist. Sie ist ein niederer Baum, der kaum 18 Meter Höhe erreicht und liefert nur Kohlholz. Nach der anatomischen Structur des Holzes, nach dem Aufbau der Triebe, Zapfen und Nadeln gehört die P. pungens zur Section Banksia.

Eine andere Vertreterin des Laubwaldes ist die

Chamaecyparis sphaeroidea Spach, White Cedar, Kugelcypresse. Ihr Optimum liegt in S. a.; ihr Standort muss als Erlenbruchboden bezeichnet werden; dort mischt sie sich in Norden den Eschen, Erlen und anderen Sumpfbewohnern, sowie einzelnen Hemlockstannen, Weymouthskiefern und rirginischen Wachholdern bei; bei grösserer Feuchtigkeit oder bei ärmerem Boden treten ihre Begleiter zurück, die Kugelcypresse wird alleinherrschend und bildet in dichtem Stande, anfänglich langsam wachsend, ein leichtes Holz -(specifisches Gewicht 33), das jedoch grosse Dauer besitzt und zu Dachschindeln, Thürschwellen, Zaunpfosten Verwendung findet; die stärkeren Exemplare dienen zu Wassereimern.

Im Optimum, im Süden, durchziehen den morastigen Boden die Wurzeln von immergrünen Sträuchern und Rubus-Arten; Farne, Sphagnum, zahlreiche annuelle Blattpflanzen leben in der dicken Humusschichte, die z. B. in Alabama oft auf weissem Sandboden direct auflagert. Dort erreicht die Kugelcypresse, ron kletternden Smilax- und Vitis-Arten bewachsen, nach meinen Messungen eine durchschnittliche Höhe ron 26 Meter und einen Durchmesser von $60 \mathrm{~cm}$; wird solches Terrain der Landwirthschaft zugewendet, so ist schon nach wenigen Ernten der Humus rerschwunden und weisser Sand bleibt zurück, der während der Trockenzeit zerfällt und beweglich wird, während der Regenzeit aber unter Wasser steht.

Der Splint des Kugeleypressen-Holzes ist cirea 2,0 cm breit und bedeckt ein schmutzig graubraunes Kernholz. Das Längsparenchym des Holzes in peripherischen Linien im Querschnitt; Borke weich, lang-schmalrissig; die peripherisch gestellten Harzlücken mit weissem Harz erfüllt; der weiss-bereifte Zapfen klein (Tafel VII, Same Tafel VIII); junge Pflanzen von kräftigem Wuchse zeigen grosse Aelnlichkeit mit virginischem Wachholder.

Der Stärkezuwachs des New-Yorker Sammlungsstiickes, ferne rom Optimum, in N. a. erwachsen und etwa in zwei Meter Höhe dem Baume entuommen, war folgender: 


\begin{tabular}{r|c|c|c}
\hline Alter & $\begin{array}{c}\text { Durchmesser } \\
\mathrm{cm}\end{array}$ & $\begin{array}{c}\text { Kreisfläche } \\
\square \mathrm{cm}\end{array}$ & $\begin{array}{c}\text { Zuwachs } \\
\square \mathrm{cm}\end{array}$ \\
\hline 20 & 2,4 & 4,5 & 0,2 \\
40 & 6,0 & 28,3 & 1,1 \\
60 & 13,6 & 145,2 & 6,4 \\
80 & 30,0 & $\mathbf{7 0 7 , 0}$ & 28,0 \\
100 & $\mathbf{4 2 , 0}$ & $\mathbf{1 3 8 5 , 0}$ & $\mathbf{3 3 , 9}$ \\
128 & 48,0 & 1810,0 & $\mathbf{1 5 , 0 0}$
\end{tabular}

\section{Splintbreite 1,4 cm.}

Wie jede Holzart, die von Natur aus in der ersten Jugend langsamwüchsig ist, auch während dieser Schatten zu ertragen vermag, kommt diese Eigenschaft besonders der Kugelcypresse zu, die Jahrzehnte lang, wie die meisten ihrer Verwandten, unter dem Halbdunkel des Laubwaldes sich erhält, bis sie endlich das Licht erreicht und in kurzer Zeit das Versäumte wieder nachholt.

Juniperus virginiana L., Red Cedar, Virginischer Wachholder, ist dem japanischen Wachholder J. chinensis, botanisch nahe verwandt. Es dürfte wenige Holzarten geben, die so klimavag sind wie dieser Wachholder. Von den kalten Küsten Neu-Braunschweigs bis in das heisse, winterlose Florida, bis zur tropischen Waldzone, von der feuchten atlantischen Küste bis zur Prärie unter dem $100^{\circ}$ W.L., so extrem in Temperatur und Feuchtigkeit, ist er heimisch; ein ständiger Begleiter des Nadelwaldes überschreitet er nördlich vom $54^{\circ}$ N.B. den Continent nach Westen hin, erscheint in den hohen, schneereichen Rocky Mountains und erreicht im britischen Columbien wiederum die feuchte Seeküste.

Seiner Anpassung an das Klima geht jene an die Bodenverhältnisse parallel; auf felsigem, trockenem und kiesigem Gebirgsboden, auf heissem, magerem Sandboden, auf verangerten Viehweiden, auf feuchtem, sumpfigem Boden, zusammen mit Eschen, auf frischem AueBoden in den Flussthälern, gemeinschaftlich mit Eichen, Hickory und Magnolien trifft man diesen Baum, allerdings mit je nach der Bodengüte wechselndem Gedeihen. Bemerkenswerth ist aber, das sein Optimum im Süden liegt; nach Norden hin nimmt er nicht an Zahl der Individuen, wohl aber in der Grössenentwicklung ab, und innerhalb der Tannenregion, auf die warmen, sonnigen Parthien beschrünkt, ist er in seinen Dimensionen unserem einheimischen Wachholder kaum mehr überlegen. 
Sein Holz ist trotz des geringen specifischen Gewichtes von 33 ausserordentlich dauerhaft, ein Zeichen, welch' grosse Rolle bei der Dauer neben dem Harzgehalte und dem specifischen Gewichte die Verkernung spielt. Frisch gefällt ist das Holz des virginischen Wachholders prächtig roth, bekommt aber später einen gelbbraunen Ton; Geruch und Verwendung zu Bleistiftfassung sind bekannt.

Im nördlichen Theile der Vereinigten Staaten werden die geringeren Individuen nicht zu Bleistiftholz zerschnitten, da es sich nicht lohnt; sie dienen zu Schindeln, Telegraphen- und Zaunpfosten, zu Thür- und Eisenbahnschwellen u. dgl.; im Süden dagegen, im östlichen Texas und nördlichen Florida insbesonders, wo der Baum bis zu 30 Meter emporwächst, liegen die Sägmühlen, die den europäischen Bedarf zerschneiden.

Er ist in der Jugend auch im Norden raschwüchsig, lässt aber dort bald im Wachsthume nach; ein auf lockerem, tiefgründigem, geringwerthigem Boden zusammen mit Hickory's und Eichen jedoch frei bei Boston erwachsener Baum erreichte mit 62 Jahren erst 11,2 Meter Höhe und hatte 1 Meter über Boden nur $22 \mathrm{~cm}$ Durchmesser, 6,2 Meter über Boden nur 9,5 cm Durchmesser; dabei betrug die Breite des zu Bleistiftholz untauglichen Splintes $4 \mathrm{~cm}$.

Ausser Gymnosporangium macrosporum, das einen Hexenbesen verursacht, scheint der Baum keine Feinde zu haben, dagegen lieben seine Beeren viele Vögel, die damit zu seiner Verbreitung wesentlich beitragen.

Tsuga canadensis Carr., Hemlock, Schierlingstanne, Tsuga. Die Heimat der Tsuga ist das Grenzgebiet der Laub- und Tamnenwald-Region, wo sie die kühlen Lagen des Laubwaldes und die warmen des Nadelwaldes bevorzugt, mehr darauf bedacht als auf die Beschaffenheit des Bodens; dem entsprechend sucht sie die Nordseiten der Berge, wo sie trotz des mageren, felsigen Bodens oft allein herrscht; sie liebt feuchte, enge Thalschluchten und betritt selbst die nassen, kalten Sümpfe, wo sie mit Erlen, Eschen, selbst der Kugelcypresse zusammenlebt; in solchen Oertlichkeiten, in der Nähe der grossen See'n erreicht sie noch 25 Meter Höhe bei $75 \mathrm{~cm}$ Durchmesser, so weit meine Messungen reichen; in den Alleghany-Bergen dringt sie weit nach Süden vor, erreicht in den engen Flussthälern 31 Meter Höhe, steigt aber nicht bis zum Tannenwalde auf, dem sie im Norden der Union, in Canada bis Neuschottland beigemengt ist.

Die kleinen, hängenden Zäpfchen der Schierlingstanne enthalten einen dem Lärchensamen sehr ähnlichen Samen; der Flügel fest mit 
dem Korn verwachsen; die Rinde ist anfangs glatt, grau mit zahlreichen Harzbeulen, später kleinschuppig; Zapfenschuppen und Nadeln gibt Tafel VII wieder. Wie bei allen Tsuga-Arten hängt der Leittrieb über; sie neigt zur Astbildung und Zertheilung des Hauptstammes, den eine breite, parabolische Krone umschliesst; in dichtem Schlusse aber erwächst ihr Schaft tadellos.

Das Holz zeigt den Typus des Fichtenholzes, doch fehlen ihm die Harzgänge, wie dem Tannenholze, dem es an Gewicht und Güte nahekommt.

Früher allgemein verschmäht oder zum Zwecke der Gerbstoffgewinnung auf barbarische Weise verstümmelt, steigt jetzt das Holz der Tsuga in der Gunst der Sägmüller, wo diese den Vorrath an Weymouthskiefern bereits aufgebraucht.

Das Holz wird in grosser Menge zu Schwellen verarbeitet und hält sich stark imprägnirt so gut wie jedes andere so behandelte Holz; ohne Antiseptika zerstören die Schwellen der Tsuga schon in wenigen Jahren verschiedene Pilze, unter denen Agaricus melleus, Polyporus pinicola, abietinus und borealis bemerkenswerth sind.

Tsuga Caroliniana Engelm., Hemlock. Diese zweite Tsuga des Ostens ist eine ziemlich seltene auf die südlichen Ausläufer der Alleghanies zwischen 1200 und 1500 Meter Erhebung beschränkt; dort an trockenen Felsrüicken erwächst sie bis zu 15 Meter Höhe; ihre botanischen Unterschiede gegenüber der canadischen Hemlock in Zapfen und Nadel ergeben sich aus der Tafel VII; forstlich ist sie bedeutungslos.

Thuja occidentalis L., White cedar, Arbor vitae, Lebensbaum. Dieser Baum hat bei uns als Zierpflanze seit langer Zeit sich eingebürgert; in Parken und auf Gottesäckern, in der Stadt und am Lande ist er beliebt wegen seiner völligen Unempfindlichkeit gegen Frost und seines dekorativen Werthes; unter den Cupressineen hält er noch am besten in den raucherfüllten Städten während des Winters aus.

Die Thuja liebt in ihrer Heimat Kühle und grosse Bodenfeuchtigkeit; so bildet sie \%. B. die kleinen Waldbestände auf den Fclseninseln des Niagara-Falles; in den Alleghanies finden wir sio in höheren Lagen hart an den Gebirgsbïchen wieder. Dort erreicht sie offenbar ihro maximale Entfaltung.

Berühmt sind die grossen Lebensbäume bei Natural Bridge, die leirler der Vandalismus der 'Touristen angebrannt und dem Untergange geweiht hat; einer der Riesenbäume liegt bereits zu Boden, ein anderer, 
der nach meinen Messungen 1,40 Meter Durchmesser und volle 31,5 Meter Höhe besitzt, trägt einen dürren Gipfel, der bald herunterbrechen wird; der virginische Wachholder nimmt dort das beschränkte Terrain der Thuja ein.

In den nördlichen Staaten der Union und in Canada bis Neubraunschweig okkupirt die Thuja, oft in reinen Beständen, oft zusammen mit der Lärche die kalten, sumpfigen Standorte, eingefasst von der Weissfichte und der Balsamtanne oder den Laubhölzern der Erlenbrüche.

Ein Thujasumpf ist kaum zu passiren; durch die wasserdurchtränkten Polster der Sphagnum- und Mnium-Arten sinkt man fusstief ein; ein dichtes Geflecht abgestorbener aber nicht abgestossener Aeste der Thuja versperrt den Weg; selbst die zu Boden gefallenen Aeste und Stämme, mit nassem Moos bedeckt, verwesen nur äusserst langsam, so ausserordentlich widerstandsfähig ist dieses Holz gegen Fäulniss; dabei ist das Holz weich und leicht, der Kern dunkelgelb gefärbt; seine grosse Dauer bestimmt das Holz der Thuja zu Zaunpfosten, Eisenbahnschwellen und Dachschindeln.

Die Thuja ist langsamwüchsig durch ihr ganzes Leben und erträgt kräftige Beschattung.

Forstlich unbedeutend, aber pflanzengeographisch beachtenswerth, sind zwei Halbbäume in den südlichen Ausläufern der Alleghanies, eine Eibe - Taxus floridana Nutt. - und eine Nusseibe Torreya taxifolia Arn.; beide seltene Bäume sind auf die Flussufer des Apalachicola in Westflorida beschränkt.

Der nördliche Kieferngürtel. Ein Blick auf die Landkarte Nordamerika's lässt schon vermuthen, dass im Norden der Vereinigten Staaten ein breiter Streifen sandiger Bodenausformung liegen muss, der die Süsswassermeere Nordamerika's, die grossen und zahllosen kleinen See'n umsäumt; als ein nur wenig von altvulkanischen Erhebungen durchbrochenes Sediment der einstens noch gewaltigeren Wasserflächen erstreckt sich dieser Streifen dem Laurentiusflusse entlang bis zum Meere, in seiner ganzen Ausdehnung durch das Prävaliren von Kiefern gekennzeichnet.

Es mögen an dieser Stelle einige Notizen über die geographische Vertheilung der Kiefern überhaupt gestattet sein.

Auffallend ist, dass alle Kiefern auf die nördliche Halbkugel beschränkt sind, eine einzige Art, Pinus Merkusii, überschreitet in den Bergen Sumatra's den Aequator. Die Kiefern lieben oder ertragen den s andigen Boden, ja die Mehrzahl derselben ist geradezu an die Gegen- 
wart von Sand gebunden; nur die Kultur hat die Kiefer vielfach auf Standorte gebracht, wo sie theils ihrer leichten Erziehungsweise, theils ihrer bescheidenen Ansprüche oder anderer Vorzïge wegen wünschenswerth erschien.

Viele der Kiefern sind in ihrer natürlichen Verbreitung auf den Sandboden der Meeresküsten angewiesen - die Strandkiefern. In der schwachsalzigen Seebrise muss neben der constanten Feuchtigkeit ein unbekanntes Etwas liegen, das diesen Kiefern behagt und dessen Fehlen ihre Aufzucht im Binnenlande auf gleichbeschaffenen Böden vereitelt.

Hieher gehören in Europa Pinus maritima, halepensis, weniger Pinea, in China P. sinensis, in Japan P. Thunbergii, in Westamerika P. insignis, contorta, Parryana, weniger ausgesprochen P. muricata, Sabiniana, in Ostamerika P. cubensis, serotina, clausa, weniger ausgesprochen P. rigida (obwohl sie am Sandufer des grossen Lake Michigan nicht gedeiht!), P. australis, glabra, Taeda, mitis und inops. Andere Kiefern leben auf dem sandigen oder kiesigen Boden des Binnenlandes, sei dieser in der Ebene oder in den Bergen - Binnenland-Kiefern.

Hieher zählen in Europa P. silvestris, Laricio, pyrenaica, in Indien P. longifolia, Khasia, Gerardiana, anf Malakka und Sumatra P. Merkusii, in China P. Bungeana, in Japan P. densiflora, in Westamerika P. ponderosa, Jeffreyi, Coulteri, tuberculata, Murrayana, edulis, osteosperma, monophylla, Chihuahuana und zahlreiche mexicanische Arten, in Ostamerika P. resinosa, Banksiana, pungens.

Den weitesten Spielraum hinsichtlich ihrer Ansprïche an den Boden scheinen die fünfnadeligen Kiefern zu besitzen, in soferne sie wenigstens im Gebirge mit Standorten verschiedenster geologischer Abstammung verlieb nehmen, in der Ebene dagegen zumeist sandige Böden okkupiren; darum findet man die fünfnadeligen Kiefern in grössten Exemplaren anderen Holzarten, Laub- oder Nadelhölzern, einzeln beigemengt. So gedeiht in Europa P. Cembra in den Alpeñ auf Kalk-, Granit- und altvulkanischem Boden zusammen mit Fichten oder selbst als Grenzbaum der Waldzone; in der Ebene (Russland) liebt sie vorwiegend feuchten Sandboden; Pinus Peuce in Griechenland verhält sich in kleinerem Massstabe ähnlich; Pinus excelsa in Nordwestindien lebt in 2000 bis 3000 Meter Höhe zusammen mit Fichte (P. Smithiana) und Tanne (Abies Pindran, nicht Webbiana), in der Ebene in Belutschistan und Afghanistan ist sie auf den Sandboden angewiesen; gleiches gilt für P.parviflora und Koraiensis in Japan und Corea, für P. Lambertiana, monticola und verwandte mexicanische Arten und für P. Strobus in Ostamerika. 
P. arizonica, flexilis und reflexa in Westamerika sind nur Gebirgspflanzen, P. Torreyana nur Strandkiefer.

Endlich gibt es noch einzelne Kiefern, die die obere, kalte Grenzzone des Waldes bewohnen - alpine Kiefern. Hieher zählt in Europa P. montana (zweinadelig), in Westamerika P. Balfouriana aristata und albicaulis (fünfnadelig), in Japan Pinus ? (fünfnadelig).

Der nördliche Kieferngürtel in Ostamerika fällt zum grössten Theil jenseits der Vereinigten Staaten auf canadisches Terrain; seine Vertreter erscheinen aber im Laubwalde der Union, der sandigen Bodenausformung entsprechend, inselweise und streichen in den Alleghanybergen in kleineren Gruppen selbst weit nach Süden vor (P. Strobus).

Nach Westen hin wechseln Gruppen von Kiefern mit Prärie oder Laubholzbuschwerk als Uebergang zur eigentlichen Prärie; nördlich von dieser überschreitet eine Angehörige dieses Gürtels (Banks' Kiefer) den Continent und nähert sich den Abhängen der Rocky Mountains und dem Mackenzieflusse unter dem $67^{\circ}$ N.B.; an der vom kalten Strome abgekühlten Ostküste bildet der 50. Breitegrad, entfernt von der Küste etwa der $54^{\circ}$, die nördliche Grenze der Kiefern.

In diesem Streifen finden sich drei heterogene Kiefern zusammen, die Weymouthskiefer als Vertreterin der Section "Strobus", die Rothkiefer als Vertreterin der Section "Pinaster" und Banks' Kiefer der Section „Banksia" angehörig. Hinsichtlich ihres Werthes wird in Amerika die Weymouthskiefer weitaus am höchsten geschätzt, dann kommt die Rothkiefer, weit zurück steht Banks' Kiefer. Bei uns, die wir andere Ansprüche an ein Kiefernholz stellen, würde die Rothkiefer die erste, die Weymouthskiefer die zweite Stelle einnehmen. Das Haupterforderniss für amerikanisches Bauholz ist Leichtigkeit, Elasticität, leichte Bearbeitungsfähigkeit und grosse Dimension; diese Forderung befriedigt am besten von allen östlichen Holzarten die Weymouthskiefer; Dauer ist nicht verlangt und wo Dauer in Frage kommt, nimmt man andere Holzarten.

Hinsichtlich des Standortes sei benerkt, dass im Allgemeinen die Weymouthskiefer den feuchsten Boden erträgt, während Banks' Kiefer den trockensten besiedelt; die Rothkiefer steht in der Mitte; dagegen verlangt letztere Art den besseren Sandboden, Banks Kiefer begnügt sich mit dem geringeren, und die Weymouthskiefer steht in dieser Hinsicht zwischen Beiden.

Pinus Strobus L., White Pine, Weymouthskiefer, Strobe. Wenn man nach der Holzquantität, welche genützt wird, urtheilt, so ist dieser Baum der werthvollste und wichtigste der ganzen Union; 
denn kein Baum wird in solcher Menge zersägt als dieser. Bei der rapid fortschreitenden Erschöpfung der Kiefernzone an diesem werthvollen Baume kann sich dieses Verhältniss nicht mehr lange aufrecht erhalten; die Douglasia wird in kürzester Zeit die Weymouthskiefer hinsichtlich der genutzten Holzmenge übertreffen.

Keine Kiefer ist in Europa so lange bekannt, so lange angebaut, wie diese und was besonders bemerkenswerth ist, sie ist der einzige fremdländische Nadelbaum, der auch im grossen Forstkulturbetriebe Gnade gefunden hat und mit einem Eifer gepflanzt wird, den eine bessere Holzart verdienen würde.

Die in Bezug auf Anbauversuche mit fremden Kulturgewächsen der Landwirthschaft gegeniiber viel schwerfälligere Forstwirthschaft hat an die Strobe von jeher grosse Hoffnungen geknüpft, hat aber bis jetzt nur Enttäuschungen erlebt und mag die Weymouthskiefer noch so alt werden und noch so vorzüglich sich entwickeln, die Enttäuschungen werden fortbestehen so lange, bis man aufgehört hat von ihr etwas zu verlangen, was sie auch in ihrer eigenen Heimat nicht leistet; die Weymouthskiefer ist eben eine fünfnadelige Holzart und schon darum wird ihr Holz unter allen Verhältnissen leichter, weicher sein müssen als das von zwei- oder dreinadeligen Verwandten; wir dürfen uns desshalb nicht wundern, wenn sich die Hoffnungen bezüglich der Brennkraft, Festigkeit und Schwere des Holzes nicht erfüllen. Diesen Eigenschaften verdankt das Weymouthskieferholz seinen hohen Ruf in Nordamerika auch nicht und die Bezeichnung "vorzügliches Holz" bezieht sich nur auf seine Leichtigkeit und leichte Bearbeitungsfähigkeit, die seinen Gebrauchswerth für zersägtes Holz, Bauholz, Bretter, Latten und ganz besonders Kisten bedingen. Dass zu letzterem Zwecke möglichst leichtes $\mathrm{Holz}$ das beste ist, liegt auf der Hand; dazu kommt, dass dieser Baum in Ostamerika die stattlichsten Dimensionen erreicht und in grösster Menge einstens vorhanden war; möglich, dass auch etwas von Vorurtheil bei der Werthschätzung unterläuft; wenigstens spielt bei uns Vorurtheil eine grosse Rolle. Wo Kiefern herrschen, gelten die Kiefern, wo Tanne prävalirt, die Tannen, wo Fichte herrscht, diese als die besten Nutzbäume hinsichtlich der Güte ihres Holzes; wo zwei oder drei der Genannten zusammen vorkommen, benutzt, man sie oft ohne Unterschied.

Wir beklagen uns mit Recht, dass das Holz der Weymouthskiefer, insbesonders das junge Splintholz, keine Dawer und Schwere besitzt, dass es nicht harzreich sei, und hoffen, dass das höhere Alter die gewünschten Eigenschaften bringen werde. 
Durch die Güte des kgl. bayer. Forstamtes Ansbach erhielt ich im Jahre 1884 eine im dortigen Bezirke gewachsene 87jährige Weymouthskiefer zur Untersuchung nach München geschickt; Forstmeister Sau er begleitete die Stücke mit folgender Bestands- und Standortsbeschreibung: „440 Meter über dem Meere, rings von 80-90 jährigen gutwüchsigen Fichten und Föhren umgeben, geschützt, fast eben in einer ron Ost nach West ziehenden Mulde; sandiger Lehmboden, mitteltief, mild, frisch mit Moos und Nadeln bedeckt. Die reinen Weymouthskiefernbestände, welche auf einer Fläche von 8,74 ha im Reviere Ansbach vorkommen, sind zwar wüchsig und geschlossen, zeigen jedoch einen geringeren Zuwachs und Massenertrag als die vereinzelnt unter anderen Holzarten eingesprengten Weymouthskiefern; bis zum 40. Jahre ist der Zuwachs und Massenertrag sehr gut, dann kommen aber alljährlich einzelne Dürrhölzer vor ..... Als Brenn- und Baunutzholz ist das Weymouthskiefernholz nicht beliebt."

Zum Vergleiche mit dieser liess ich im September 1885 in Wisconsin auf sandigem Lehmboden, auf einem Standorte, wie er später ausführlicher beschrieben werden soll, eine Weymouthsliefer fällen und zerlegte sie in Sectionen, wie diess mit der Ansbacher Kiefer geschehen war; aus jedem Baume wurden etwa 50 Stïcke einer genauen Bestimmung des specifischen Gewichtes und des Gehaltes an fester Harzmasse unterworfen. Die Untersuchungsergebnisse habe ich bis jetzt nur zum Theile veröffentlicht.*)

Die bayerische Weymouthskiefer hatte ein durchschnittliches specifisches Gewicht von 38,3, der amerikanische Baum von 38,9; der Censusbericht gibt 38,5 als specifisches Gewicht aus einer grösseren Zahl von Stämmen. In beiden Stämmen zeigte sich eine geringe Zunahme des specifischen Gewichtes von der Basis nach der Spitze hin.

Auffallend war die Verschiedenheit in der Splintbreite der beiden Stämme; der bayerische Stamm hatte an der Basis eine Splintbreite von $2,7 \mathrm{~cm}$, in der Mitte ron 2,4 cm, in der Krone von $2,3 \mathrm{~cm}$; der amerikanische Baum hatte entsprechend $9 \mathrm{~cm}, 6 \mathrm{~cm}$ und $4 \mathrm{~cm}$. Ich bin geneigt zu glauben, dass der heissere, trockenere Sommer in Amerika eine grössere Menge wasserleitenden Splintes bedarf, um das Gleichgewicht zwischen Wasserabdunstung durch die Nadeln und Wasseraufnahme durch die Wurzeln zu erhalten; bemerkt sei, dass die Wisconsin-Kiefer 138 Jahre alt war.

*) H. Mayr, The White Pine in Europe. Garden \& Forest Vol 1 No. 1 and 10. New York 1888. 


\section{$-202$}

"Im höheren Alter bekommt die Weymouthskiefer harzreiches Kernholz", hört man bei uns Viele sich rertrö

Was die Farbe anbelangt, so ist in dem frisch gefä Splint und Kern kaum zu unterscheiden; das Austretes markirt die Grenze zwischen beiden besser als die Far erscheint im Lichte, unter Einwirkung der Luft, eine Ke ron der unserer Kiefer im Tone kaum rerschieden ist; die gelagerten Stücke der bayerischen und amerikanischen $K$ keinen Unterschied in der Farbe.

Hinsichtlich des Gehaltes an fester Harzmasse beider den ich nach der schon kurz geschilderten Methode für und die wichtigsten europäischen Nadelhölzer ermittelte, folgendes Resultat:

Der durchschnittliche Gehalt an festem Harz in absolut trockener Holzmasse betrug

bei der bayerischen Wermouthskiefer für a st ü cke

auf der Nordseite des Baumes $3,752 \mathrm{gr}$, durchschn. spec

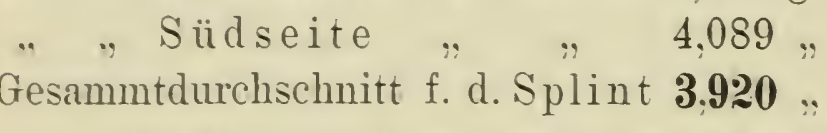

Der Harzgehalt steigerte sich nach der Mitte zu und den Gipfel zu ab.

Die Teymouthskiefer ron Wisconsin zeigte für den Splint auf der Nordseite 4,978 gr festes Harz u. 37 ,

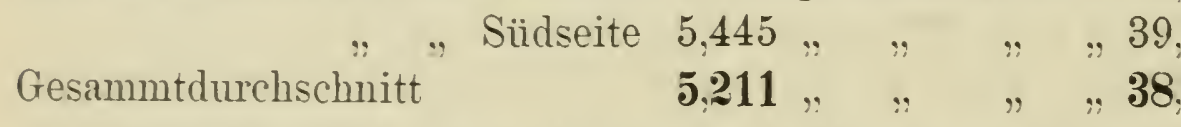

Das specifische Gewicht blieb sich bis auf die lichten gleich; der Harzgehalt zeigte eine Steigerung ron der Basis b

Die Kernstücke aller Sectionen der bayerisch hatten

auf der Nordseite des Baumes 6.224 or Harz und 384 


\section{$-203$}

Specifisches Gewicht und Harzgehalt waren nur gering ungen unterworfen.

Dabei bemerke ich, dass die Kernstiicke der einzeln noch weiter in zwei bis drei Theile, ron innen nach aus der Untersuchung zerlegt wurden, so dass die Durchschn ganzen Bäume aus 18 bezw. 24 Stücken genommen w unterste Theil des Baumes bis 2 Meter iiber dem Bod am harzreichsten und die Harzmenge geht bis auf das I Durchschnittsgehaltes.

Diess fand ich auch an einer Weymouthskiefer, die auf lehmigem Boden in Kleinflottbeck bei J. Booth erw: sie hatte am Fusse $5 \mathrm{~mm}$ Ringbreite im Kernholze, 33 Gewicht und einen Harzgehalt ron 13,6 gr.

Gleiches zeigte eine ron Dr. Wilhelm aus Oesterreic: Weymouthskiefer; der innerste Kern (10 Jahresringe ron lich $6,4 \mathrm{~mm}$ Breite umfassend) hatte $5,65 \mathrm{gr}$ feste Har äussere Kern mit 1,4 mm Ringbreite zeigte $14,46 \mathrm{gr}$ Harz mit $1 \mathrm{~mm}$ Ringbreite $3,32 \mathrm{gr}$ Harz.

Die Weymouthskiefer steht unter den in Deutschland Nadelhölzern hinsichtlich ihres Harzgehaltes an erster Stell die Durchschnitte aus den Kernstücken der wichtigste Nadelhölzer berechne - eine Berechnung, die sich auf Analysen gründet, die ich vor Jahren in München ausfü sie mit den Durchschnitten einiger amerikanischer Nade gleiche, so hat in $100 \mathrm{gr}$ absolut trockenem Holze:

die südliche Kiefer (P. australis) . 11,1 gr festes Harz, 7

"Weymouthskiefer ron Wisconsin $7,4, "$ " " 3

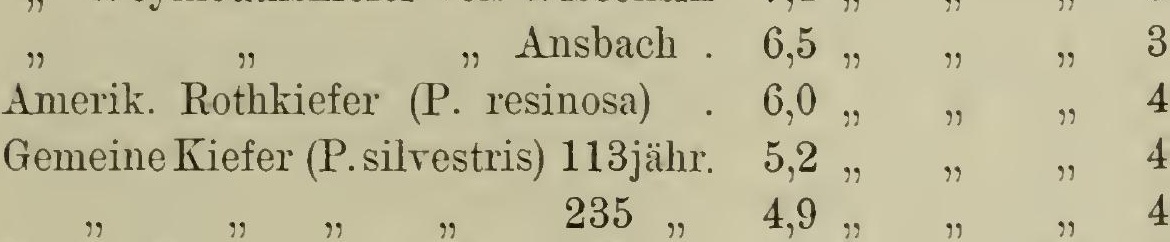


irgend etwas gewonnen ist, möchte ich bezweifeln; dass die Schwere und die Dauer des Nadelholzes durch den Harzgehalt wesentlich bedingt wird, kann man nach obiger Zusammenstellung nicht gut behaupten, demn das sehr dauerhafte und schwere Lärchenholz des Hochgebirges enthält nicht halb so viel Harz als das leichte und schnell im Boden zersetzte Holz der Weymouthskiefer.

Bei der Extraction des Harzes aus der Weymouthskiefer geht mit dem Harze ein Bitterstoff ron äusserst scharfem, unangenehmen Geschmack in die Vorlage über, der durch Auswaschen in warmem Wasser entfernt werden kann.

Das frische Splint- und Rindenharz enthält in $100 \mathrm{gr}$ $61,702 \mathrm{gr}$ feste Harzsubstanz; in dem frischen Splintharz der einheimischen Kiefer (P. sylvestris) fand ich 69,478 $\mathrm{gr}$ festes Harz; in der Fichte 74,868 gr, in der Tanne 62,845 gr.

Das frische Harz des Kernholzes ist viel reicher an festem Colophonium; die Gewinnung ist jedoch sehr schwierig und nur möglich bei lokaler Ansammlung in pathologischen Gewebspartien des Holzkörpers oder in Spalten wie bei den Lärchen und Douglasias, die radiale Risse des Kernholzes nahe dem Boden zeigen. Das Lärchenkernholz enthält im frischen Harze 79,327 gr feste Substanz, die Fichte $80,900 \mathrm{gx}$; dass das Kernholz im Baume ständig seinen Gehalt an festem Harz durch Oxydirung der flüchtigen Substanzen vergrössert, ist gewiss; die schnellste Bereicherung an festem Harze erfolgt aber erst nach der Fällung, wenn das Wasser aus den Zellen und Zellwänden schwindet, die flüchtigen Harze in diese eindringen und dort festes Harz deponiren. Während im stehenden Baume bei der Fichte die Bereicherung an festem Harz beim Uebergange von Splint in Kernholz etwa $6 \%$ beträgt, steigt die Harzmenge nach der Fällung und Trocknung von $80,900 \mathrm{gr}$ allmählig bis zu $92,857 \mathrm{gr}$ in $100 \mathrm{gr}$ des dem trockenen Holze entnommenen Harzes; diese Bereicherung ist nur zum geringsten Theile eine relative durch Verflüchtigung von Terpentinöl.

Da allein das feste Harz, das Colophonium, im Stande ist, die Dauer eines Nadelholzes zu erhöhen, so ergibt sich hicraus, dass sowohl uraltes Kernholz im Baume wie auch lange Zeit luftig aufgespeichertes Nutzholz eine grössere Dauer besitzen müssen als verhältnissmässig junges Holz oder bald nach der Fällung unter Verhältnissen verbautes Holz, welche den Luftzutritt mehr oder minder hemmen. Bekanntlich zeigt sich viele Jahre nach der Verwendung des Nadelholzes immer noch weicher Harzfluss, ein Beweis, wie langsam die Verhärtung vor sich geht. 
Das Harz wird in der Weymouthskiefer ganz ebenso gebildet und ist auf gleiche Weise vertheilt wie bei der südlichen Kiefer; die Harzgänge schliessen sich ebenfalls bei Uebergang des nassen Splintes in trockeneres Kernholz.

Im Winter sind wie bei anderen Kiefern die horizontalen, $\mathrm{Holz}$ und Rinde durchsetzenden Harzgänge innerhalb des Cambiums geschlossen, so dass, wenn man die Rinde im Winter abtrennt, kein Harz oder nur spärliches (wenn das Cambium mit der Rinde abgelöst wird) aus dem Holze fliessen kann. Die Harzlücken der Rinde sind die angeschwollenen und isolirten Endigungen der Horizontalgänge des Bastes; ihre Auskleidungszellen (Epithel) sind kräftig und schliessen so fest aneinander, dass man solche Lücken als Kugeln herauspräpariren und auf der Glasplatte mit merklichem Widerstande zerdrücken kann. Bei der Borkebildung wachsen die Harzgangzellen zu einem Füllgewebe aus, das Harz entweicht zum Theil in die benachbarten Gewebe und verhärtet. Die Borkebildung wird durch Schichten von Sklerenchymund Korkzellen eingeleitet; liegt die Harzlücke in der ersten Schicht, so sklerosiren sämmtliche Epithelzellen; wenn in der letzten, werden sie alle zu Korkzellen; liegt die Harzlücke im Phelloderm, werden ihre Zellen zu Phellodermzellen.

Gegenüber der gemeinen Kiefer ist die Grösse der Harzgänge im Holze der Weymouthskiefer auffallend; die Grösse der Vertikalgänge nimmt rom Gipfel des Baumes nach der Basis hin zu:

bei der gemeinen Kiefer v. 0,0043 $\square \mathrm{mm}$ (incl. Epithel) auf 0,0064 $\square \mathrm{mm}$, " "Weymouthskiefer $, 0,0900 \square \quad$ " " " $, 0,1100 \square$,

Die Horizontalgänge sind oben wie unten gleichweit:

bei der gemeinen Kiefer $0,0031 \square \mathrm{mm}$ und 45 auf $1 \square \mathrm{cm}$ Fläche,

" "Weymouthskiefer $0,0400 \square$ " "40 "1 " "

Schon aus der Grösse der Harzgänge erklärt sich der grössere Harzgehalt der Weymouthskiefer der einheimischen gegenüber. Dass erstere stets nur geringe Dauer besitzt, dürfte neben den dümnen Wänden des Zellgefüges und der schmalen Entwicklung dickwandigen Sommerholzes der schwachen Kernfarbe und der Verwendung von Splintholz zuzuschreiben sein.

Insoferne bei der Werthschätzung des Holzes das gleichmässige Gefüge und dadurch die Bearbeitungsfähigkeit in Erage kommt (bedingt durch gleichmässig weite und feine Jahresringe), so dürfte es keinem Zweifel unterliegen, dass in Amerika, mach Vernichtung der Urwald- 
vorräthe, schlechteres Holz aufwachsen wird. Die unter geänderten Bedingungen im freien Stande wachsenden Weymouthskiefern (second growth), dem Wechsel von Licht, Feuchtigkeit und Wärme weit mehr unterworfen als im nivellirenden Urwalde, werden auch ein $\mathrm{Holz}$ von wechselnder Ringbreite und grobfaseriger Struktur produciren, ein Holz, das in Güte dem bei uns unter ähnlichen Bedingungen heranwachsenden kaum mehr überlegen sein dürfte.

Das Verbreitungsgebiet der Weymouthskiefer in Nordamerika erstreckt sich rom nördlichen Ufer des Laurentius- bis zum südlichen Ufer des Michigan-See's und entlang den Alleghanies bis Northern Georgia; Pennsylvania besass im oberen Laufe der zum Ohio gehörigen Flüsse einstens grosse Vorräthe an starken Strobusstänmen, die alle bereits genützt sind; überhaupt dürfte es kaum mehr in der Union einen grösseren Complex von Strobus geben, der nicht schon in Angriff genommen wäre. Die Angabe vieler Bücher, dass die Weymouthskiefer auch im Westen der Prärie sich wiederfindet, dürfte auf einer Verwechselung derselben mit der ihr nahestehenden P. monticola beruhen.

Die Nordstaaten der Union umfassen die südlichen Grenzbezirke der Strobe; gerade diese Standorte ausserhalb ihres Optimums sind für uns besonders lehrreich, denn dort ist die Kiefer das Resultat der von der Natur selbst gemachten Anbauversuche; solche Standorte lehren die Verhältnisse, unter denen sie mit Erfolg mit anderen Holzarten in Concurrenz treten kann; sie zeigen mit einem Worte den specifischen Standort. Demmach wäre der specifische Standort der Weymouthskiefer hinsichtlich des Bodens: der schwach sandige Lehmboden mit geringer Erhebung über dem Grundwasserspiegel. Sich selbst überlassen okkupirt sie, mit Erfolg die eindringenden Laubhölzer bekïmpfend, denselben Standort immer wieder; es bedarf jedoch nur eines einmaligen Eingriffes durch das Fener oder die rücksichtslos geschwungene Axt, um sie zu verdrängen und den Standort den Laubhölzern auszuliefern.

Der Staat Maine liegt im Optimum der Weymouthskiefer; dort ist sie in grosser Menge vorhanden und erscheint, misshandelt, immer wieder auf demselben Standorte und nähert sich solbst der Küsten, um die ärmeren, sandigen Böden zu überziehen. Klimatisch dürfte der Strobe am besten das Grenzgebiet zwischen Eichen- und Tannenwald entsprechen; das wäre bei uns in Deutschland jene Zone, welche Eichen- und Buchenmischwald, reinen Buchen- und Buchen- und Tannenmischwald umfasst. 
Zur besseren Orientirung hinsichtlich der Ansprüche der Strobe an Feuchtigkeit und Boden gebe ich beifolgendes Profil durch eine Kieferninsel im Laubwalde des nördlichen Wisconsin:

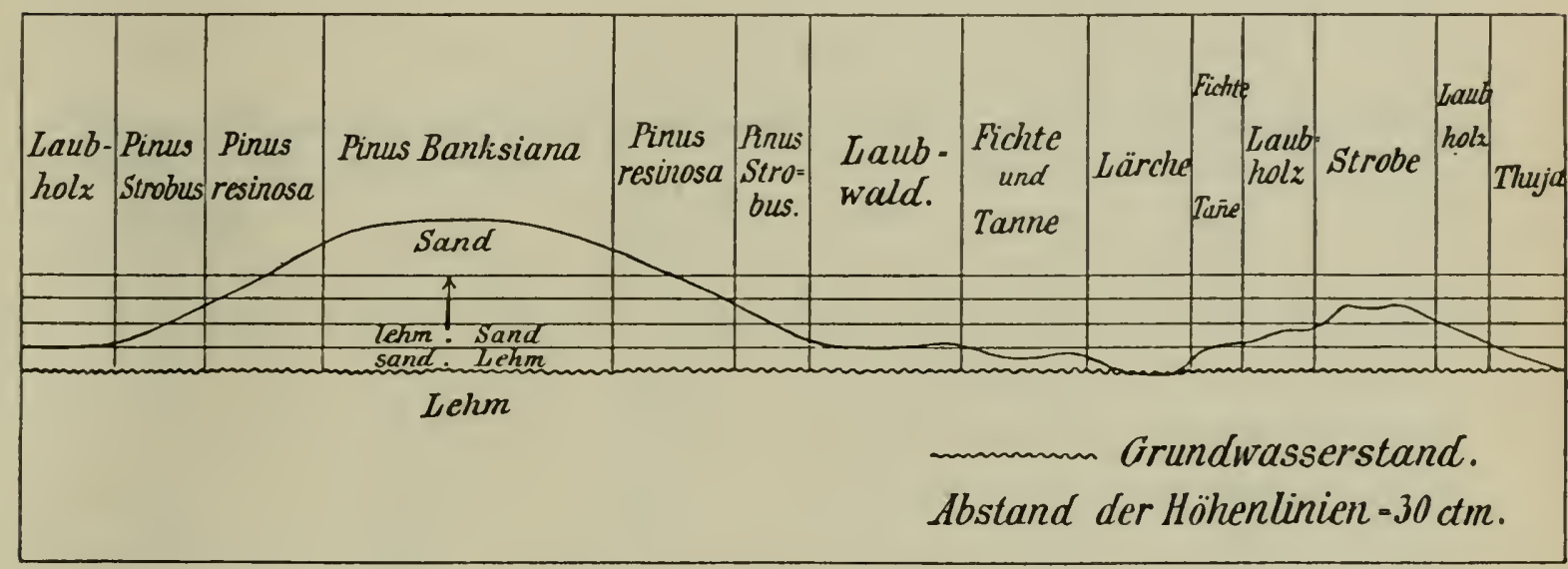

Fig. 5. Profil aus dem Waldgebiete von Nord-Wisconsin.

Auf dem undurchlässigen lehmreichen Boden lagern 1-2' Humus - das Produkt einer Jahrtausende ungestörten Thätigkeit des Waldes; in diesem Humus liegt das ganze Wurzelwerk der Laubhölzer. Sobald das Terrain um mehr als $1-2^{\prime}$ sich über das Grundwasserniveau erhöht, erscheint die Weymouthskiefer; wo dasselbe um 1' sich vertieft, sammelt sich stagnirendes Wasser mit Typha und Carex; Depressionen von grösserer Ausdehnung stellen die schon erwähnten Lärchen-, Tannen- und Thujensümpfe dar; erheben sich schwache Hügel, so bildet die Krone der magerste Sandboden, nach unten nimmt die Beimengung an Lehm zu; dementsprechend ist auch die Vertheilung der Kiefern; den feuchteren Boden beansprucht die Weymouthskiefer, den trockensten erträgt noch Bank's Kiefer; der Boden der Weymouthskiefer gibt die besten Wiesen, jener der Rothkiefer geringen Getreideboden, jener der Bank's Kiefer lohnt nicht die Rodung.

Je nach dem gebotenen Raume steht die Strobe einzeln oder in Gruppen ron mehreren Stämmen; reine Waldungen dieser Holzart gibt es hier nicht; ihre sehr flach über die lehmreiche Schichte hinstreichenden Wurzeln berühren das Niveau des Grundwassers.

A uf diesen Standorten ist ihre mittlere Entwickelung nach meinen Messungen etwa 38 Meter Höhe und 1 Meter Durchmesser mit einem astlosen Schafte ron 20 Meter; solche Exemplare besitzen ein Alter von 200-250 Jahren und erheben sich mit ihrer spärlichen, durch 
fehlende Aeste oft unterbrochene Krone 8-10 Meter über dem Dache des Laubwaldes; die Borke solcher Bäume ist kleinschuppig, aschgrau.

Von den beiden früher hinsichtlich ihres Harzgehaltes betrachteten Weymouthskiefern gebe ich im Folgenden eine vergleichende Uebersicht ihres Zuwachsganges.

a) Bayerische Weymouthskiefer.

\begin{tabular}{c|c|c|c|c|c|c}
\hline Section & $\begin{array}{c}\text { Meter } \\
\text { über } \\
\text { Boden }\end{array}$ & $\begin{array}{c}\text { Durch- } \\
\text { messer } \\
\mathrm{cm}\end{array}$ & Jahre & $\begin{array}{c}\text { Kreisfläche } \\
\square \mathrm{cm}\end{array}$ & $\begin{array}{c}\text { Periodischer } \\
\text { Zuwachs } \\
\square \mathrm{cm}\end{array}$ & $\begin{array}{c}\text { Periodischer } \\
\text { Längen- } \\
\text { zuwachs } \\
\mathrm{cm}\end{array}$ \\
\hline I & 1 & 55,2 & 76 & 2391,9 & 31,47 & 12 \\
II & 7,2 & 47,0 & 66 & 1735,0 & 26,29 & 62 \\
III & 13,4 & 42 & 53 & 1404,4 & 26,57 & 48 \\
IV & 20 & 30 & 36 & 707,0 & 19,64 & 39 \\
V & 27 & 12 & 14 & 113,0 & 8,07 & 32
\end{tabular}

Gesammtfläche 31 Meter, Alter 84 Jahre, Inhalt des ganzen Schaftes 3,310 cbm, Formzahl des Schaftes 44, Jahrringsbreite der untersten (I.) Section $3,6 \mathrm{~mm}$.

b) Weymouthskiefer von Wisconsin.

\begin{tabular}{c|c|c|c|c|c|c}
\hline \hline Section & $\begin{array}{c}\text { Meter } \\
\text { über } \\
\text { Boden }\end{array}$ & $\begin{array}{c}\text { Durch- } \\
\text { messer } \\
\mathrm{cm}\end{array}$ & Jahre & $\begin{array}{c}\text { Kreisfläche } \\
\square \mathrm{cm}\end{array}$ & $\begin{array}{c}\text { Periodischer } \\
\text { Zuwachs } \\
\square \mathrm{cm}\end{array}$ & $\begin{array}{c}\text { Periodischer } \\
\text { Längen- } \\
\text { zuwachs } \\
\mathrm{cm}\end{array}$ \\
\hline \multirow{2}{*}{ I } & 1. & 58,8 & 130 & 2678,6 & 20,60 & 12 \\
II & 7,2 & 45 & 90 & 1590 & 17,67 & 15 \\
III & 13,4 & 37 & 47 & 1075 & 22,90 & 15 \\
IV & 20,0 & 20 & 30 & 314 & 10,47 & 20 \\
V & 27,0 & 5 & 4 & 19,6 & 4,9 & 27
\end{tabular}

Gesammthöhe 28 Meter, Alter 138 Jahre, Inhalt des ganzen Schaftes 2,679 cbm, Formzahl 35, durchschnittliche Jahrringbreite der I. Section $2,3 \mathrm{~mm}$.

Eine andere 240 Jahre alte Kicfer hatte (ebenfalls in "Wisconsin) eine Höhc von 37,7 Meter und 1 Meter über Boden 1,1 Meter Durchmesser. Diess gibt nach Abzug von $4 \mathrm{~cm}$ für die Rinde eine Ringhreite von $2,2 \mathrm{~mm}$ und bei Annahme einer Formzahl von 30 einen Cubikinhalt des Holzes im Schafte von 4,748 cbm. 
Hieraus erhellt das anfängliche langsame Wachsthum der Weymouthskiefer im Urwalde gegenüber der ständig mit freiem Gipfel aufgewachsenen bayerischen Kiefer; die Freistellung im Urwalde erfolgt allmählig, der Zuwachs steigt langsam an; die einzelnen Bäume stellen sich lichter, eine Abnahme der Formzahl ist die Folge, welche bei der im danernden Schlusse erwachsenen bayerischen Kiefer günstiger sich stellt. Trotz der Langsamwüchsigkeit ist das nordamerikanische Holz, soweit specifisches Gewicht in Frage kommt, nicht besser als das rasch gewachsene europäische; dagegen steht die europäische Kiefer der amerikanischen an Feinheit ihres Holzgefüges weit nach.

Solches gröberes Holz bilden sicher alle White Pine in Nordamerika, die von Jugend an mit freier Krone aufwachsen können; nach meinen Messungen erreichen völlig frei und fast ohne seitliche Beengung erwachsene Strobus (so wachsen mehr oder minder alle second growth auf!) in einem Alter von 80 Jahren auf gutem Boden eine durchschnittliche Höhe von 25 Meter und $60 \mathrm{~cm}$ Durchmesser; zieht man rom Durchmesser $3 \mathrm{~cm}$ doppelte Rindendicke ab, so bleiben $57 \mathrm{~cm}$ Durchmesser mit 3,7 mm durchschnittlicher Jahrringsbreite 1,3 Meter über Boden, also nahezu die gleichen Dimensionen in Stärke und Jahrringsbreite wie die bayerische Strobe. Emerson erwähnt, dass die Weymouthskiefer bei Boston im 30. Lebensjahre alljährlich um $60 \mathrm{~cm}$ in die Höhe und um $2 \mathrm{~cm}$ in die Dicke wachse.

Die Kieferninseln im nördlichen Michigan sind bedeutend grösser als jene von Wisconsin; in der Nähe der Seen fliessen sie zu grösseren Flächen von einigen 100 Aren zusammen; am unteren Laufe des Laurentiusflusses, also ebenfalls in ziemlich feuchtem Gebiete, bildet die Strobus nach Sïden hin ausgedehnte, zusammenhängende Waldungen auf kiesig-sandigem, angesschwemmten Boden.

Am sandig-hügeligen Ufer des Lake Superior lebt die Strobe auf den Nord- und Osthängen mit der Balsamtanne, auf den Süd- und Westhängen mit der Rothkiefer (resinosa) zusammen; sie erreicht dort ebenfalls etwa 37 Meter Höhe, ist aber weit herab mit Aesten besetzt. Die Kämme der Berge bestockt sie mit Tsuga canadensis. Bei Spooner breitet sich sehr schwach welliger, magerer Sandboden aus; dort liebt sie die feuchteren Einsenkungen, der resinosa zwar an Höhe und Stïrke überlegen, aber an Reinheit des Schaftes weit zurückstehend. Wo dagegen die Strobus in die Erlenbrüche selbst geräth, da erwächst sie sehr rasch, bleibt aber kurz, astreich und gibt ein sehr schlechtes Hol\%. 
Nach den Angaben des Censusberichtes kann die Strobus eine Höhe von 52 Meter und einen Durchmesser von 3,5 Meter in seltenen Fällen erreichen.

Aus dem Vorausgehenden ergibt sich, dass die Weymouthskiefer frischen bis feuchten, mit Sand gemengten Boden liebt, wie ihm Niederungen und Ränder sumpfiger Vertiefungen bieten; reichlicher Humusgehalt ist zu ihrem Gedeihen erforderlich. Dass auch der felsigkiesige Boden ihr in Deutschland wie auch in Amerika noch genügt, lässt sich mit ziemlicher Sicherheit erwarten; der trocken-heisse nordamerikanische Sommer schadet ihr an solchen Oertlichkeiten durchaus nicht.

Schöne Erfahrungen über den Anbau der Weymouthskiefer auf humusreichem, besserem Sandboden hat R. Douglas in Waukegan während einer 30 jährigen Thätigkeit gesammelt. Bringt man P. sylvestris und P. Strobus auf solchen Böden zusammen, so ist im vierten Jahre nach der Pflanzung die gemeine Kiefer noch einmal so gross als die Strobus, im achten Jahre sind beide gleich, im 10. Jahre kommt die Strobus voraus und im 15. Jahre wird die gemeine Kiefer überschattet und erdrückt.

Bei den Anpflanzungen auf reinerem Sandboden an den Ufern des Lake Michigan hat sich die Strobus besser bewährt als die gemeine Kiefer und P. austriaca, welch' letztere Holzart auf diesem Boden wieder der sylvestris nachsteht; durch zwei aufeinander folgende nasse Sommer leidet die Weymouthskiefer mehr als die P. sylvestris; hart am See aber, auf ganz kahlen Sandboden gebaut, braucht die Weymouthskiefer vicle Jahre, bis sic den Boden durch Scitentriebe überschattet; erst dann erhebt sich ein Gipfeltrieb. Dasselbe geschieht mit der gemeinen Kiefer, mit der Lärche, ja selbst mit Laubhölzern wie Catalpa; auf solchen exponirten, für Waldbäume völlig unnatürlichen Standortsverhältnissen beschreibt der Wind mit der Pflanzenspitze einen Kreis im Sande.

P. Strobus wird am leichtesten durch Feuer getödtet wegen der glatten, dümnen Rinde - ein Feind, der bei uns glücklicher Weise wegrfällt; das Altholz zerstört in zicmlichem Masse Trametes Pini. Bei uns leidet die juncre Pflanze sehr wenig durch Schüttepilze wie Lophodermium und Pestalozzia*), dagegen werden ihre Pflanzungen durch

*) Diesen Pilz fand ich im Jahre 1884 in J. Booth's Garten in Kleinflottbeck auf den Nadeln der Weymouthskiefer und der japanischen Sciadopitys, welche schon im August ihre Nadeln fast ganz verloren. Meine damals gefer- 
Wurzelparasiten wie Agaricus melleus, Trametes radiciperda dezimirt. Schnellwüchsigkeit, Schattenerträgniss und völlige Frosthärte (eine bei dem herrschenden Kahlschlagbetriebe hochwillkommene Eigenschaft!) sichern der Weymouthskiefer für lange Zeit hinaus das Bürgerrecht im Walde, das sie als Füllpflanze auch vollauf verdient.

Für die Weymonthskiefer gilt Winterfällung bei weitem Transporte zur Säge als Regel, damit die Rinde am Stamme erhalten bleibt; wird diese entfernt, wie diess bei der Sommerfällung zu leicht geschieht, so befällt das saftige Splintholz sehr bald ein Pilz (Ceratostoma), der es blauschwarz färbt und dadurch in seiner Qualität schädigt.

Pinus resinosa Ait., Red Pine, Amerikanische Rothkiefer. Diese zweinadelige Kiefer gehört nach dem anatomischen Baue ihres Holzes zur Section Pinaster, von der sie zugleich die einzige Vertreterin in Nordamerika ist; der Laricio ähnlich ist jedoch die Rinde des alten Baumes eine dünne, breitschuppige Borke von hellgraugelber Färbung; ebenso sind die Nadeln feiner, durchschnittlich $15 \mathrm{~cm}$ lang; die reifen Zapfen braun bis hellgelb und wenn offen $4,5 \mathrm{~cm}$ lang und 3,5 breit, ohne Spitze an der Apophyse; Knospen braun mit zurückgerollten Schuppen; junge Triebe hellroth; Same Tafel VIII.

Das Verbreitungsgebiet der Rothkiefer deckt sich zwar mit jenem der Weymouthskiefer, doch tritt sie im Osten nur ganz vereinzelt auf, ihr Optimum liegt auf der canadischen Seite. Hinsichtlich der Ansprüche dieser Art an Boden und Klima bot sich vielfach Gelegenheit bei der Weymouthskiefer derselben zu gedenken; auf ärmstem Boden kann sie wie jede andere Kiefer oder Holzart überhaupt ein paar Jahre recht gut wachsen, ein werthvoller Nutzbaum kann sie aber in derlei Verhältnissen so wenig werden als irgend ein anderer Baum.

Hinsichtlich der Geradheit und Reinheit des Schaftes ist sie der Weymouthskiefer und vollends der Pechkiefer und der folgenden Art überlegen; in der Höhenentwicklung dagegen bleibt die Rothkiefer hinter der Weymouthskiefer zurück; ich habe in den reinen Beständen Minnesota's keine über 30 Meter Höhe und 0,60 Meter Durchmesser gemessen; der Censusbericht gibt als Maximalgrössen 46 Meter Höhe und über 1 Meter Durchmesser.

tigten Abbildungen stimmen ganz mit der von v. Tubeuf (Beitrïge zur Kenntniss der Baumkrankheiten, Berlin 1888) publizirten Pestalozzia Hartigii überein; ob somit der Pilz eine nadel- und eine stammbewohnende Form besitzt (letztere an europaischen Abietineen und japanischen Cupressineen), müssen weitere Beobachtungen entscheiden. 
Um hinsichtlich ihres Wachsthums und der Güte ihres Holzes einige Andeutungen geben zu können, liess ich Ende September 1885 in Brainerd (Dakota) auf geringem, lehmigem Sandboden eine resinosa fällen; ihr Alter betrug 141 Jahre, ihre Höhe 25 Meter, ihr Durchmesser 1,5 Neter über Boden, $37 \mathrm{~cm}$ ohne Rinde; der Kubikinhalt des Schaftes $0,93 \mathrm{~cm}$, die Formzahl desselben 34. Zum Vergleiche des Zuwachses und der Qualität des Holzes einer auf lehmigem Sandboden des Revier Geisenfeld (Hopfenbaubezirk) in Bayern gewachsenen gemeinen Kiefer führe ich an:

Alter 113 Jahre, Gesammthöhe 23,6 Meter.

I. 1,5 Meter über Boden hatte die gemeine Kiefer:

\begin{tabular}{r|c|c|c}
\hline \hline Jahre & $\begin{array}{c}\text { Durchmesser } \\
\mathrm{cm}\end{array}$ & $\begin{array}{c}\text { Kreisfläche } \\
\square \mathrm{cm}\end{array}$ & $\begin{array}{c}\text { Zuwachs } \\
\square \mathrm{cm}\end{array}$ \\
\hline 30 & 19,4 & 295,2 & 9,8 \\
40 & 24,0 & 471 & 17,6 \\
105 & 31,4 & 774 & 5,0
\end{tabular}

Splint spec. Gewicht 48,7, Harzgehalt 4,317 gr feste Masse. Kern " " $\quad 53,2, \quad$ " 6,856 " "

II. 5,5 Meter über Boden:

\begin{tabular}{c|c|c|c}
\hline Jahre & $\begin{array}{c}\text { Durchmesser } \\
\mathrm{cm}\end{array}$ & $\begin{array}{c}\text { Kreisfläche } \\
\square \mathrm{cm}\end{array}$ & $\begin{array}{c}\text { Zuwachs } \\
\square \mathrm{cm}\end{array}$ \\
\hline 20 & 10,4 & 84,9 & 4,2 \\
40 & 14,4 & 162,9 & 3,9 \\
90 & 22,5 & 398 & 4,3 \\
92 & 23 & 415 & 8,5
\end{tabular}

Splint spec. Gew. 47,9, Harzgehalt 3,573 gr feste Masse. Kern " " $49,8, \quad$ " 4,500 " " " III. 11,7 Motor über Boden:

\begin{tabular}{c|c|c|c}
\hline Jahre & $\begin{array}{c}\text { Durchmesser } \\
\mathrm{cm}\end{array}$ & $\begin{array}{c}\text { Kreisfläche } \\
\square \mathrm{cm}\end{array}$ & $\begin{array}{c}\text { Zuwachs } \\
\square \mathrm{cm}\end{array}$ \\
\hline 20 & 14 & 154 & 7,7 \\
40 & 16 & 201 & 2,3 \\
75 & 20 & 314 & 3,2
\end{tabular}

Splint spee. Gew. 43,8, Harygehalt 3,771 gr feste Masse. Kern

" $\quad 47,2, \quad$ "


IV. 22,1 Meter über Boden:

\begin{tabular}{c|c|c|c}
\hline Jahre & $\begin{array}{c}\text { Durchmesser } \\
\mathrm{cm}\end{array}$ & $\begin{array}{c}\text { Kreisfläche } \\
\square \mathrm{cm}\end{array}$ & $\begin{array}{c}\text { Zuwachs } \\
\square \mathrm{cm}\end{array}$ \\
\hline 10 & 3,4 & 9,08 & 0,9 \\
20 & 6,5 & 33,18 & 2,4 \\
30 & 9,2 & 66,48 & 3,3
\end{tabular}

Splint spec. Gew. 45,4, Harzgehalt 3,876 gr feste Masse. Inhalt des ganzen Stammes: 0,74 cbm, Formzahl 43.

Pinus resinosa.

I. 1,5 Meter über Boden:

\begin{tabular}{r|c|c|c}
\hline Jahre & $\begin{array}{c}\text { Durchmesser } \\
\mathrm{cm}\end{array}$ & $\begin{array}{c}\text { Kreisfläche } \\
\square \mathrm{cm}\end{array}$ & $\begin{array}{c}\text { Zuwachs } \\
\square \mathrm{cm}\end{array}$ \\
\hline 30 & 13,2 & 136,6 & 4,6 \\
40 & 16,6 & 216,7 & 8,0 \\
100 & 32,8 & 844,7 & 10,5 \\
130 & 37,0 & 1075 & 7,7
\end{tabular}

Splint spec. Gew. 44,4, Harzgehalt 2,573 gr feste Masse. Kern " " $45,2, \quad$ " 5,654 " "

II. 5,5 Meter über Boden.

\begin{tabular}{r|c|c|c}
\hline Jahre & $\begin{array}{c}\text { Durchmesser } \\
\mathrm{cm}\end{array}$ & $\begin{array}{c}\text { Kreisfläche } \\
\square \mathrm{cm}\end{array}$ & $\begin{array}{c}\text { Zuwachs } \\
\square \mathrm{cm}\end{array}$ \\
\hline 20 & 10 & 79 & 3,9 \\
40 & 16 & 201 & 6,1 \\
100 & 32 & 804 & 10,1 \\
125 & 35 & 962 & 6,3
\end{tabular}

Splint spec. Gew. 37,1, Harzgehalt 2,421 gr feste Masse. Kern " " $38,9, \quad$, $5,746 \quad$ " " "

III. 11,7 Meter über Boden.

\begin{tabular}{c|c|c|c}
\hline Jahre & $\begin{array}{c}\text { Durchmesser } \\
\mathrm{cm}\end{array}$ & $\begin{array}{c}\text { Kreisfiäche } \\
\square \mathrm{cm}\end{array}$ & $\begin{array}{c}\text { Zuwachs } \\
\square \mathrm{cm}\end{array}$ \\
\hline 20 & 8 & 50 & 2,5 \\
40 & 14 & 154 & 5,2 \\
90 & 26 & 531 & 7,5 \\
99 & 28 & 616 & 9,4
\end{tabular}

Splint spec. Gew. 35,4, Harzgehalt 3,093 gr feste Masse. Kern " " 36,4 , " 6,575 " " " 
IV. 22,1 Meter über Boden:

\begin{tabular}{c|c|c|c}
\hline Jahre & $\begin{array}{c}\text { Durchmesser } \\
\mathrm{cm}\end{array}$ & $\begin{array}{c}\text { Kreisfläche } \\
\square \mathrm{cm}\end{array}$ & $\begin{array}{c}\text { Zuwachs } \\
\square \mathrm{cm}\end{array}$ \\
\hline 10 & 2,9 & 6,6 & 0,7 \\
20 & 6,1 & 29,2 & 2,3 \\
24 & 7,6 & 45,4 & 4,0
\end{tabular}

Splint spec. Gew. 34,9, Harzgehalt 3,932 gr feste Masse. Inhalt des Stammes 1,54 cbm, Formzahl 50.

Berechnet man den Durchschnitt aller Sectionen (auch Nord- und Südseite wurden getrennt gerechnet) so zeigen:

durchschnittl. Harzgehalt spec. Gew. $\mathrm{gr}$

Alle Splintstücke der Geisenfelder Rothkiefer .

" Kernstücke "

"Splintstücke der Minnesota Rothkiefer

" Kernstücke "
46 3,916

. 48 . 38

. 41
5,239 3,005 5,992

Es ergibt sich daraus, dass einmal die bayerische Kiefer (in Bayern gewachsen) der amerikanischen (in Amerika gewachsen) an Wachsgeschwindigkeit anfangs voraneilte, dagegen früher ihr Maximum erreichte; dass ferner die bayerische Kiefer ein beträchtlich schwereres, aber (im ganzen Durchschnitte) harzärmeres Holz lieferte als die amerikanische; beide lassen eine Abnahme des specifischen Gewichtes nach der Spitze des Baumes hin erkennen.

Die Splintbreite des amerikanischen Baumes beträgt $6,5 \mathrm{~cm}$, jene des bayerischen $4 \mathrm{~cm}$, so dass bei gleichen Volumina die gemeine Kiefer mehr Kernholz enthält als die amerikanische.

Da diese Kiefer kaum mit geringerem Sandboden vorlieb nimmt als die gemeine Kiefer, so hat sie wohl keine Aussicht bei uns im Walde im Grossen angebaut zu werden; sie verdient geprüft zu werden; jedenfalls übertrifft sie die europäische Kiefer vom dekorativen Standpunkte.

Pinus Banksiana Lamb., Check Pine, Gray Pine, Bank's Kicfer nimmt, wie die früher erwähnte Skizze zeigt, den trockensten und magersten Sandboden im Binnenlande ein, wo sie selbstverständlich auch nur geringe Dimensionen erreicht, da überdiess regelmässige Durchfeuchtung von Luft und Boden fehlt. Wo sie zusammen mit resinosa wächst (resinosa auf den besseren Mulden von oft nur einigen Quadratmetern Ausdchnung), da ist das Bild, das solche geschlossene Waldungen bieten, täuschend einem mittelalterigen Fichtenbestande mit 
Kiefernüberhältern ähnlich. Dabei repräsentiren die ausgewachsenen Bank's Kiefern mit ihren spitzkegeligen Kronen die Fichten; die Benadelung ist jedoch heller grïn als ron der Fichte.

Die dunkelgraue Borke ist aus kleinen prismatischen Schuppen gebildet und reicht bis zum Gipfel mit gleicher Färbung empor. Da sie mit dem magersten Boden vorlieb nimmt, ist ihr Wurzelsystem weit verzweigt. Gegenwärtig geht diese Kiefer massenhaft in Amerika zu Grunde; da sie die Gipfel der schwachen, sandigen Erhebungen einnimmt, wird ihr durch die Rodung und die daraus folgende Drainirung des tiefer liegenden Bodens immer mehr Sickerwasser entzogen und die nicht mehr genügend während der sehr langen Trockenzeit befeuchteten, höher gelegenen Waldpartien trocknen ab.

Die Höhenentwicklung dieser Kiefer spricht für die Bescheidenheit in ihren Ansprüchen an den Boden; denn selbst auf gutem Boden bleibt sie ein Baum zweiter Klasse von höchstens 22 Meter Höhe und $30 \mathrm{~cm}$ Durchmesser, während ihre durchschnittliche Höhe zwischen 10 und 15 Meter Höhe liegt.

Sie erwächst mit dem Habitus einer Fichte, reinigt sich schwer von den Aesten; ihre Nadeln sind 4-6 cm lang; die Zapfen, aus Quirlknospen hervorgegangen, $5 \mathrm{~cm}$ lang und $2 \mathrm{~cm}$ breit, sind etwas gekrümmt, nach aufwärts gerichtet, dem Haupttriebe angedrückt; der geflügelte Same (Tafel VIII) gleicht völlig dem der Fichte, in dem das Samenkorn in einer löffelartigen Vertiefung des Flügels liegt.

Hinsichtlich ihrer Wuchsgeschwindigkeit in der Stärke mögen folgende Angaben dienen:

1,5 Meter über Boden, auf demselben Boden wie die vorhin erwähnte resinosa, hatte die Bank's Kiefer:

\begin{tabular}{c|c|c|c}
\hline \hline Jahre & $\begin{array}{c}\text { Durchmesser } \\
\mathrm{cm}\end{array}$ & $\begin{array}{c}\text { Kreisfläche } \\
\square \mathrm{cm}\end{array}$ & $\begin{array}{c}\text { Zuwachs } \\
\square \mathrm{cm}\end{array}$ \\
\hline 10 & 7,0 & 38,48 & 3,85 \\
20 & 10,6 & 88,25 & 4,98 \\
30 & 13,4 & 141,03 & 5,28 \\
40 & 15,0 & 176,71 & 3,57 \\
50 & 17,2 & 232,36 & 5,56 \\
60 & 20,4 & 326,56 & 9,42 \\
65 & 21,2 & 352,46 & 5,18
\end{tabular}

Splintbreite $3 \mathrm{~cm}$, durchschnittliches specifisches Gewicht 48; das braun gefärbte Kernholz dürfte dem der gemeinen Kiefer an Güte kaum nachstehen. 


\section{d) Der Nadelwald der gemässigt-kühlen Region.}

Je weiter nach Norden man im amerikanisch-canadischen Walde vordringt, um so ähnlicher werden Klima und Waldbilder denen von Deutschland; mit dem Eintritt in die Tannen- und Fichtenregion glaubt man sich in den Nadelwald der Alpen, in den Schwarzwald oder nach Thüringen versetzt; die Einförmigkeit in der Entwickelung, die dunkelgrüne Färbung der Baumkronen, die Bedeckung des Bodens mit Moos oder beerenfrüchtigen, niederen Stauden, die ätherischen, harzigen Düfte, das Rauschen des Windes in den Zweigen, die Vögel, die den Wald beleben, alles erinnert an den kühlen Nadelwald der heimatlichen Berge und des Nordens.

Auf den Berggipfeln der Alleghanies finden sich die Schwarzfichte und Fraser's Tanne als Vertreterinen dieser Waldzone; erst einzeln den Buchen beigemengt, herrschen sie über 1800 Meter allein; Moospolster der europäischen Hypnumarten bekleiden den Boden zu den Füssen der dicht geschlossenen, ästigen Nadelhölzer; umsäumt und unterstellt sind letztere von dem immergrünen Rhododendron maximum, der noch in 1900 Metern über dem Meere trotz des strengen und langen Winters bis zu über armesdicken Stämmen von 2-3 Meter Höhe sich erhebt.

Die kühle Tannenregion Canada's, an der Küste von dem antarktischen Meeresstrome mit einer Temperatur von $15^{\circ} \mathrm{C}$. im Sommer und $0^{0} \mathrm{C}$. im Winter bespült, ist zugleich auch feuchter als die südlich gelegenen Gebiete; von zahllosen See'n und Sümpfen durchsetzt, delınt sich nördlich vom $54^{\circ}$ N.B. der Nadelwald in einem breiten Bande quer von der Küste dureh den Continent, erreicht die Fortsetzung der Rocky Mountains und berührt, dem Flussthale des Makenzie entlang, selbst den Polarkreis. Die Weissfichte und an geeigneten Oertlichkeiten Bank's Kiefer sowie einige Laubhölzer wie Birken, Erlen, Pappeln, Weiden erstrecken sich selbst bis an die östliche Abdachung der Coastrangeberge, wo sie mit nahe verwandten pacifischen Arten in Berührung treten.

Die wichtigste Holzart der kühleren, nördlichen Lagen ist die Weissfichte; sie dringt am weitesten von allen östlichen Nadelhölzern nach Norden vor, stockt dort in reinen Waldungen von ungeheurer Ausdehnung selbst auf Boden, der schichtenförmig ewiges Eis enthält; gelangen dort - nördlich vom $57^{\circ}$ Breite - die Wurzeln dieser Fichte auf eine gefrorene Erdschichte, so weichen sie darüber hinkriechend ihr aus wie einer Felsenplatte; wo Flussthälor mit etwas wärmeren 
Verhältnissen dieses hügelige Binnenland durchfurchen, tritt die Weissfichte zurück; die Balsamtanne, Weiden, Erlen, Balsam- und Zitterpappel, die blendend weissrindige Kahn- oder Nachenbirke erfüllen das Thal, die Schwarzfichte bekleidet die Hänge.

Im fernen Nordwesten unter dem $160^{\circ}$ W.L. steigt der Wald bis zu etwa 1000 Meter empor, wo darniederliegende Tamnen (Ab. subalpina) die Baumgrenze bezeichnen.

Nach Süden hin treten zu ihnen andere Nadelholzarten, die dort ihre Nordgrenze finden, wie Thuja, Tsuga, Juniperus; in warmen, geschützten Lagen gesellen sich, wie diess auch z. B. in der bayerischen Hochebene der Fall ist, einzelne Rotheichen, Zuckerahorn, Ulmen und Eschen zu einem Laubwalde zusammen, der nach Süden hin an Ausdehnung zunimmt, und schon innerhalb der nördlichen Kiefernzone die Vertreter der kühlen Region zu inselartigen Beständen auf kalten, nassen Böden zusammendrängt.

In forsttechnischer Hinsicht stehen die nordischen Waldungen an Güte ihres Produktes, nicht aber an Masse gegen die Laubwaldungen der wärmeren Zone zurück; ihr Werth ist fortwährend noch eine steigende Grösse, dank der fortschreitenden Erschöpfung der südlich gelegenen Vorräthe.

Bis jetzt haben die Canadier vorzugsweise in den wärmeren Strichen ihres Landes gewirthschaftet und zwar ganz nach amerikanischem Muster; die enormen Vorräthe und die billigen Arbeitskräfte gestatten es, Holz in grosser Menge trotz des Eingangszolles über Land nach den Vereinigten Staaten zu exportiren; in neuester Zeit wurden wiederholt Versuche gemacht, Riesenholzflösse der Küste entlang nach Süden zu bugsiren. Im Norden und Westen liegen noch gewaltige Vorräthe unerschlossen für spätere Generationen, die, solange Ueberfluss vorhanden ist, geradeso unwirthschaftlich wie ihre Vorfahren handeln werden.

Abies Fraseri Lindl., Balsam, Frasers Balsamtanne, ist ein auf die Berggipfel der Alleghanies beschränkter Baum zweiter Grösse, der sich bis zu höchstens 25 Meter erhebt; der astreiche Schaft wird nur gelegentlich zu Nutzholzzwecken verarbeitet.

Die Nadeln an Seitentrieben sind bis $2,5 \mathrm{~cm}$ lang, an Lüngstrieben oft nur $1 \mathrm{~cm}$; die Seitentriebe mit kurzen braunen Haaren, Haupttrieb kahl; Zapfen 3-5 cm lang, $2 \mathrm{~cm}$ dick, Blïthen- (Deck-) Schuppe weit hervorstehend und zurückgerollt, so dass wie bei einem Abies nobilis-Zapfen überhaupt nur Deckschuppen sichtbar sind; das $\mathrm{Hol}_{\text {z }}$ rom Typus der Tannen, ohne Harzgänge, weich, leicht (spec. Gew. 36). 
Dass in der feuchten, kïhlen Luft eine Anzahl von Pilzen auf Kosten der Tanne leben, lässt sich erwarten; besonders interessant war mir aber das Auftreten von Trichosphaeria parasitica Hrtg., dessen Mycel die Nadeln der jungen Triebbasis bräunt und Nadeln und Triebe mit einem weissen Gespinnste überzieht, ganz so wie der Pilz in Dickichten der europäischen Tanne wuchert; andere Pilze, FusicladiumArten, tödten Nadeln und Triebe in auffallender, aber bei dem geringen Werthe der Tanne überhaupt belangloser Weise.

Die Gesellschafterin ron Fraser's Tanne ist

Picea nigra Link (syn. rubra), Black Spruce, Schwarzfichte. Ton den Hochkämmen der Alleghanies in Nordkarolina bis zur Küste von Labrador unter dem $55-60^{\circ}$ N.B. und von dort in einem breiten Bande durch Canada bis zur Mündung des Mackenzieflusses unter dem $70^{\circ}$ N.B. und dem $135^{\circ}$ W.L. dehnt sich das Verbreitungsgebiet dieser Art; überall aber steht sie hinsichtlich ihrer Entwickelung und ihres Nutzwerthes hinter der Weissfichte zurück; dagegen erwächst sie auf der südlichen Grenze der letzteren, in den Nordstaaten der Union, in isolirten Individuen durch die Laubholzwaldungen vertheilt zu einem stattlichen Baume, dessen Holz zur Papierfabrikation dient. Die Fäller der Schwarzfichten sind vielfach noch heute die ersten Weissen, welche den Laubwald betreten; sie sind es auch, welche den ersten Feuerbrand in den unberührten Wald geworfen haben; die Weissfichte in den benachbarten, kalten Sümpfen bleibt dagegen nieder und vereinigt sich mit der Balsamtanne, der östlichen Lürche, der Nachenbirke und der Thuja zu einstweilen noch geringwerthigen ausgedehnten Beständen.

Der Zapfen der Schwarzfichte ist etwas kürzer als jener der Weissfichte, dunkel violett wenn unreif, die Schuppen am Rande etwas zackig; Deckschuppe kleiner als bei alba; die Zapfen gehen aus Seitenknospen dex vorjährigen Triebe hervor und stehen aufrecht, bei der alba gehen die Zapfen vorzugsweise aus Endknospen der vorjährigen Triebe hervor, wesshalb sie sich durch ihre Schwere mehr oder weniger abwärts drehen.

Das Holz der Schwarzfichte zeigt den Typus der Gattung Picea in seinem anatomischen Bau; das Kernholz ist durch Wasserarmuth, nicht durch dunklere Farbe vom Splinte verschieden; specifisches Gowicht 46; das Hol\% ist durch keine besonderen Vorzüge ausge\%eichnet; um ein Nut\%baum von hervorragendem Werthe zu sein, dazu sind die durchschnittlichen Dimensionen des Baumes - 20 Meter - 
nicht gross genug. Wo Ueberfluss an diesem Fichtenholze ist, wird es zu Bauholz, Schwellen und dergleichen verwendet; im Allgemeinen wird das Holz der nigra höher geschätzt als das der alba, wiewohl beide Holzarten ron der Praxis nicht immer auseinander gehalten werden.

Die Unterscheidung der jungen Schwarzfichte von den nahe verwandten Weissfichten und den westlichen Fichten wie P. Engelmanni, P. pungens, welche Pflanzen in europäischen Gärten nicht immer richtig bestimmt werden, dürfte vielleicht mit Hilfe folgender Notizen möglich werden.

P. nigra hinterlässt beim Zerreiben der zarteren Zweige in der Hand keinen Geruch, der bei der alba stets sich deutlich zeigt; die Nadeln der alba sind kürzer als jene der Engelmanns Fichte, welche jedoch beim Zerquetschen der Zweige keinen Geruch zeigt; die Nadeln der Stechfichte (P. pungens) sind länger als bei der Engelmanns Fichte, stechender; die gelben Knospenschuppen $z$ ur ückgerollt, welche wieder bei der Engelmann's Fichte fest an liegen.

Picea alba Link, White Spruce, Weissfichte, ist Nutzbaum erster Klasse im Norden der Vereinigten Staaten; südlich, auf den Gipfeln der Alleghany-Berge fehlt die Weissfichte, sie erreicht als niedriger Baum schon in den kalten Sümpfen Wisconsins, Michigans und Minnesotahs ihre Südgrenze; ihr Optimum liegt viel nördlicher ron dem Optimum der Schwarzfichte. In den kalten Sümpfen der Südgrenze endigt ihre Kronenentwicklung in eine lang ausgezogene Spitze, womit sie ihren Längenwuchs beschliesst; auch die Balsamtanne auf gleichem Standorte und die Schirmtanne in Japan zeigen ähnliches; ja selbst die Douglastanne im Westen endigt ihren Höhenwuchs durch Aufsetzen

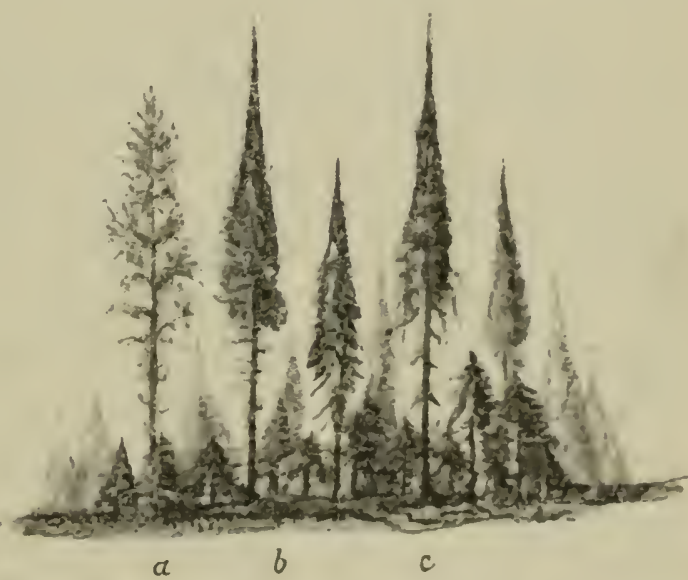

Fig. 6. Nadelhölzer in:den Sümpfen des nördlichen Laubwaldes: $a$ Lärche, $b$ liehte, $c$ Tanne. einer kleinen spitzkegeligen Krone, gleichsam eines Bäumchens, von der Kronenform des jugendlichen Alters.

In solchen Sümpfen ist die Lärche meist nur vereinzelnt; wo aber Sphagnum als dickschichtige Bodenbedeckung prïvalirt und wie ein Badeschwamm die Feuchtigkeit in sich hält, da treten Fichte und 
Tanne zurück, Lärche oder Thuja, beide in oft ausgedehnten reinen Beständen, überziehen die Fläche. Die spitzkronigen, niederen Fichten in diesen Sümpfen werden vielfach als Picea nigra aufgefasst; Andere betrachten sie als eine Varietät von nigra; ich halte sie für das, als was ich sie beschrieben, für Weissfichten, die von anderen Weissfichten nur wenig, von Höhe und Habitus abgesehen, verschieden sind.

Von vielen dieser Fichten hängen die Zweige ausserordentlich verlängert und dicht verflochten herab, Hypertrophien, die von einer in den Zweigen perennirenden kleinen Mistel verursacht werden, die wohl mit dem Arcenthobium pusillum Peck der Schwarzfichte identisch sein dürfte; einen eigenthümlichen Gegensatz zu diesen, besonders in den Nadelwaldungen der pacifischen Küste sehr auffallenden Hexenbesen, bilden die aufrecht wachsenden Hypertrophien an den Balsamtannen, welche einem Accidium angehören; da die Zeit der Sporenreife vorïber war, kann ich die Identität mit Aec. elatinum nur vermuthen; das reichliche Vorkommen von Vaccinium macrocarpum in diesen Oertlichkeiten unterstützt die Vermuthung, dass die Winterform des Pilzes auf den Blättern der Pflanze sich findet. Die Weissfichte soll nach den Angaben des Censusberichtes an den östlichen Abdachungen der Rocky Mountains bis zu 50 Meter Höhe erreichen und ist dort wie auch in Canada der wichtigste Nutzbaum. Das Holz mit einem specifischen Gewichte von kaum 41 steht hinter der Schwarzfichte an Dauerhaftigkeit zurück.

A bies balsamea Mill., Balsam Fir, Balsamtanne; Nadeln unterseits weniger weiss als von Frasers Tanne. Haupt- und Seitentriebe kahl; ein Baum zweiter Grösse, der 25 Meter nur in seltenen Fällen übersteigt; sie ist eine ständige Begleiterin der Weissfichte in den Bergen und in den sumpfigen Partien der Nordstaaten der Union; dort wird sie wie die hellweissliche Fichte ein Baum bis zu 15 Meter Höhe und schliesst ebenfalls, wie die früher gegebene Skizze zeigt, ihre Krone und ihr Längenwachsthum mit einer feinen Spitze ab; die dunkelgrïnen Kegel der Tanne geben zusammen mit den hellen der Firhte und der im Herbste fast schwefelgelben Krone der Lärche ein eigenartiges Bild en miniature \% den Lärchen, Tannen und Fichten Liuropa's und vollends jenen der pacifischen Küste.

Der Zapfen der Balsamtanne ist durchschnittlich $10 \mathrm{~cm}$ lang, $2,5 \mathrm{~cm}$ breit; die Deckschuppe ist von der Zapfenschuppe völlig überleckt, also erstere nicht sichtbar; das Holz ist schlecht (specifisches Gewicht 38), wenig dauerhaft, astreich und kaum benüt»t; werthvoll aber ist der Balsam (flüssiges Harz), der in den Beulen der Rinde 
(wie auch in geringerem Masse bei der Tsuga und Douglasia) sich anhäuft; umbestreitbar ist ihr dekorativer Werth, zumal wenn sie die elegante Kronenform auch bei uns beibehalten sollte; in höheren Lagen bleibt sie ein Strauch, eine Varietät, die als Abies Hudsonica bei den Coniferenzüchtern bekannt ist.

Bemerkenswerth in biologischer Hinsicht insbesonder's ist

Larix americana Michx., Larch, Tamarack, Oestliche Lärche, indem sie auf ihrer südlichen Grenze auf kaltem sumpfigen Boden mit Balsamtanne und Fichte, oder Thuja und Nachenbirke (B. papyracea) Mischbestände, oder selbst reine Waldungen mit Ausschluss jeder anderen Holzart bildet; zu ihren Füssen liegen mächtige Polster von Sphagnum, so dass man beim Betreten eines solchen Lärchenbestandes bis zu den Knie'n im nassen Moose einsinkt; unter dem gutgeschlossenen Kronendache vermögen nur Vaccinium macrocarpum und Ledumarten aufzukommen. In solchen Oertlichkeiten ist die Lärche als Nutzba um von geringem Werthe; sie bleibt niedrig (etwa 15 Meter hoch), ästig, ihr Holz ist weich, leicht und wenig dauerhaft. Dagegen hat sie dort grossen Werth als Schutzbaum. Wird nämlich auf solchen sumpfigen Standorten die Lärche kahl entfernt, durch die Axt oder durch Feuer während der trockenen Zeit, so geht die Oertlichkeit in einen völligen Carex- und Typhasumpf über, in dem sich nur isolirte, krüppelhafte Reste der ursprünglichen Vegetation erhalten kömnen; derartige Flächen nehmen an Zahl und Grösse in Wisconsin und Michigan alljährlich beträchtlich zu.

Nördlich von den Vereinigten Staaten, in den kühlen und bergigen Landschaften insbesonders, ist ihr Vorkommen, ihre Stamm- und Holzerzeugung von unserer Lärche nicht mehr wesentlich verschieden; ihr Holz ist hart, specifisches Gewicht 62, während Holz von sumpfigen, südlichen Standorten 55 kaum erreichen dürfte.

Botanisch ist die Lärche durch sehr kleine Zapfen von $1,5 \mathrm{~cm}$ Länge und $1 \mathrm{~cm}$ Breite ausgezeichnet; die Zapfen sind von denen der Tsuga stets dadurch unterschieden, dass sie aufgerichtet sitzen und dass der Uebergang aus den Nadeln in die breitere Deckschuppe an der Basis des (Lürchen) Zapfens sehr deutlich ist. Die westliche Lärche (L. occidentalis) und Griffiths Tü̈rche im östlichen Himalaya tragen auf der ganzen Länge des Zapfens nadelförmige, weit aus den Zapfenschuppen hervorstehende Deckschuppen. Häufig ist an der Lürche in ihrem südlichen Standort ein aufrechter Hexenbesen, ähnlich der an der Balsamtanne durch ein Aecidium hervorgerufenen, hypertrophischen Missbildung. 


\section{B. Prärie.}

Den Westrand des eben betrachteten grossen atlantischen Waldgebietes begrenzt eine Graslandschaft von der halben Ausdehnung wie das östliche Waldgebiet und wenn man die gras- und regetationslosen Partien zwischen den Rocky Mountains und der Sierra Nevada hinzurechnet, ron etwa gleich grosser Erstreckung. Die Frage, wo die natiurliche Grenze zwischen Wald und Prärie, was die Ursache ist, dass thatsächlich da sich Prärie findet, wo die Feuchtigkeitsmenge so gross ist wie in dem benachbarten Waldgebiete, ist schon oft in Amerika und Europa bearbeitet worden. Die Einen nehmen an, es war alles Wald und durch die nomadisirende Lebensweise der Ureinwohner Amerika's, der Indianer, sei der Wald vernichtet worden, indem diese den Wald niederbrannten, um Gras für die Büffel zu gewinnen. Diese Ansicht hat sehr viel für sich und ist zweifellos richtig für die Frage der Ausbreitung der Prärie auf Kosten des Waldes.

Dass es thatsächlich auf der Erdoberfläche Oertlichkeiten gibt, die von Uranfang an mit Gras bedeckt waren, habe ich schon bei der allgemeinen Betrachtung über die Existenzbedingungen des Waldes hervorgehoben; wo die relative Feuchtigkeit der Luft während der Vegetationszeit unter ein gewisses Minimum - etwa 50\% - sinkt, da ist kein Wald möglich, denn die Luft in den höheren Schichten ist zu trocken, als dass eine zarte Pflanze - der junge, neue Längstrieb eines Baumes ist stets eine einjährige zarte Pflanze - in ihr enıor wachsen könnte; die Verdunstung des Wassers aus den Blättern und Trieben ist rascher, als durch die Wurzeln Ersatz zugeführt werden kann; nur eine unmittelbar über dem Boden, im Thaubereiche desselben liegende Vegetation - Gras, Kräuter oder niederes Strauchwerk - sind existenzfähig. Auch der umgekehrte Fall kam eintreten; die Luft mag genügend Feuchtigkeit enthalten, aber trotzdem nichts oder zu wenig (etwa $40 \mathrm{~mm}$ ) an den Boden abgeben, dessen Vegetation alljährlich die heisse Glut des Sommers versengt; solchen Wechsel in 'Temperatur und Feuchtigkeit ist ebenfalls nur das Gras mit seinem unterirdischen Stocke gewachsen; wo beide Faktoren zusammenhelfen, Luftfeuchtigkeit und Bodenfeuchtigkeit fehlen, da fohlt in der Regrel auch jeder Pflanzenwuchs; das ist die Wüste, die wahre desert.

Man hat immer die absolute Niederschlagsmenge während des Jahres angezogen und versucht, mit ihr allein das Fehlen des Waldes zu erklären; ich glaube, die relative Feuchtigkeit spielt dabei 
eine ebenso grosse Rolle wie jene; der östliche Theil der Prärie erhält über $600 \mathrm{~mm}$ jährliche Niederschläge, über $200 \mathrm{~mm}$ mehr als die mit Kiefern bedeckte norddeutsche Tiefebene; auch die californische Prärie zwischen Coast Range und Sierra erhält im Jahre etwa 5-600 mm, aber fast die ganze Regenmenge fällt in den Monaten November und Dezember; je gleichmässiger Regenmenge und Luftfeuchtigkeit während des ganzen Jahres vertheilt sind, um so günstiger sind die Bedingungen für den Wald; je grösser dabei die relative Feuchtigkeit, um so höher wächst der Wald, insbesonders der Coniferenwald empor; so gewaltig beeinflusst die constante Luftfenchtigkeit den Höhenwuchs, dass die übrigen Faktoren eines Standortes, welche seine Gütequalität bedingen, geradezu untergeordnet erscheinen. Es ist sehr wahrscheinlich, dass in jenen Theilen der Prärie (östlicher Theil der Prärie, californische Prärie), in denen relative oder absolute Feuchtigkeit gross genug sind, nach der künstlichen Begründung des Waldes dieser durch seine conservirende Eigenschaft nach beiden Richtungen hin sich erhalten und auf natürlichem Wege sich wieder verjüngen kann. Dass durch die Begründung von Wald die relative Feuchtigkeit auf eine gewisse Entfernung hin eine Steigerung erleidet, ist anzunehmen; dass aber auch eine Steigerung der Niederschlagsmenge durch Anpflanzung. und Besiedelung der Prärie damit Hand in Hand gehe, wie man sie schon rielfach jetzt ausgerechnet hat, scheint mir sehr zweifelhaft. Wo beide Faktoren schon jetzt gross genug sind, ist es nicht zweifelhaft, dass schon früher Wald bestanden hat und solcher auch heute wieder möglich ist.

Ich pflichte der Ansicht Jener bei, die an die Ursprünglichkeit der Prärie auf einem kleineren Unfange glauben, die aber eine ganz beträchtliche Ausdehnung derselben durch Fener nach Osten hin annehmen; diese Ausdehnung wird um so wahrscheinlicher, als gerade zur grössten Trockniss, zur Zeit der grossen Präriebrände - September und Oktober - die Westwinde rorherrschend sind.

Dem Auge erscheint die Prärie nicht als ungeheure Ebene, in der die Sehweite wie am Meere erst durch die Krümmung der Erde abgeschnitten wird; sie ist stets schwach wellig, theilweise selbst hügelig, im Norden nur mit hohem Gras bedeckt, dessen Wachsen und Verwesen allmählig die Hunusschichte bis zu 6' Tiefe angehäuft hat, reiner Humus, der, wie Dr. Fle ischman n von Washington sagt, alle organischen und unorganischen Stoffe enthält, welche die Kunturpflanzen, Getreide, zur vollendeten Entfaltung bediirfen. Im trockenen Zustande hat der Prärieboden keinen Zusammenhang; sondern zerfällt zu 
Staub; er absorbirt Wasser sehr rasch und verliert es ebenso schnell; wemn nass, ist seine Farbe schwarz, wenn trocken, grau; die oberen halb verwesten Schichten verbrennen wie schlechter Torf, eine Menge Asche zurücklassend. Wenn geschmolzen, frittert er zusammen wie Schlacke wegen seines grossen Gehaltes an Kieselsäıre; wie alle zersetzten vegetabilischen Stoffe enthält er eine grosse Menge Ammoniak. Schon die Gleichmässigkeit des Bodens spricht, nach Fle ischmann, dagegen, dass er je eine Waldvegetation getragen hat und selbst wenn dieselbe auch vor 1000 Jahren schon durch Feuer vernichtet worden wäre. Nach Fleischmann ist es viel wahrscheinlicher, dass ein grosser Theil der Prärie einstmals ein Binnensee war; mit der fortschreitenden Vertiefung der Flüsse trocknete das gewaltige Wasserbecken aus; in der Mitte desselben konnten zuerst Wasserpflanzen sich ansiedeln, grosse Mengen vegetabilischer Stoffe wurden angehäuft; später dann änderte sich die Vegetation, grasartige Pflanzen traten auf und jede der folgenden Generationen lebte von den organischen Stoffen der vorausgehenden, da sie den Urboden nicht mehr erreichen konnten. Fleischmann schätzt die Grösse der landwirthschaftlich benutzbaren Präriefläche auf 100 Millionen acres und sagt, dass die Vereinigten. Staaten an der Prärie einen der grössten der existirenden Schätze besitzen, einen Schatz, der nicht übertroffen wird an Werth und Wichtigkeit von allen werthvollen Metallen im Innern der Erde. Nur da wo die Alkalien in solcher Menge sich finden, wie z. B. im Sïdwesten, wo sie als weisse Salzkruste aus dem Boden herausblühen, ist kein Pflanzenwuchs möglich. Wer im Herbste die nördliche Prärie durchreist, dem erscheint die gewaltige Fläche schmutzig gelbbraun; aber stundenlang fährt der Zug. ïher schwarzen Boden hinweg, denn die Präriefeuer, meist aus Muthwillen oder durch die Lokomotiven angefacht, rasen alljährlich auf Hunderten von Quadratmeilen dahin, empfindlich schadend, wo sie auf in Kultur genommenes Terrain übergreifen. Nicht selten fährt der Zug durch den erstickenden Rauch, zu beiden Seiten prasselt das Feuer in seincm raschen Laufe hoch empor.

Bricht in der Präric dic Nacht an, so fällt das Thermometer sche lasch und bis zu l'iefen, die jenen in Sibirien gleichkommen; I'emperaturen von $-25^{\circ} \mathrm{C}$. hat jerler Winter, solche von $-40^{\circ} \mathrm{C}$. sind nicht solten. Griesebach hat ausser dem Regenmangel (der ijstlich der Rocky Mountains gar nicht besteht) auch der niederen 'Temperatur das Fehlen von Baumvegretation zugeschrieben; es ist diess cin hysteron proteron; während der Vegetationszeit ist die Wärmemonge gross genug für Baumwuchs, und die Kälte während der 
Vegetationsruhe, so tief sie auch sein mag, kann das Aufwachsen von Laub- und Nadelwald nicht verhindern; überdiess findet sich thatsächlich im Norden der Prärie bis hina u zum Polarkreise wi ed er Ba umw uchs.

Die nördliche Prärie ist zum weitaus grössten Theile eine Grassteppe, dessen Flora insbesonders das Buffalo-Gras, Buchloë dactỵloides, Munroa squarrosa, Vaseya comata und riele andere Gattungen und Arten zusammensetzen.

Die Prärie westlich von den Rocky Mountains ist viel trockener und die breiten, steppenartigen Erweiterungen inmerhalb der Berge erhalten oft kaum $40 \mathrm{~mm}$ während des Sommers und $100 \mathrm{~mm}$ Niederschläge während des ganzen Jahres, und die relative Fenchtigkeit während der Vegetationsmonate sinkt auf 50 selbst $40 \%$.

Die Prärie steigt von Osten nach Westen allmählig zu einem Hochplateau an, das in Minnesota mit etwa 400 Metern beginnt, bis zu 600 Meter in Dakota ansteigt und mit etwa 900 Meter in Montana sich an die Rocky Mountains anlehnt.

Die Prärie scheidet die atlantische Flora von der pacifischen, besser, durchgreifender, als wenn an Stelle der Prärie ein Meer von gleicher Breite sich dazwischenschöbe.

Kaum hat man die Ausläufer der Rocky Mountains betreten, so beginnt am Rande der Flüsse wieder Baumwuchs; in den Felsspalten nesteln sparrige Stauden, krüppelige Kiefern, die allmählig an Grösse und Menge zumehmen; in engen Schluchten, wo die Verdunstung vermindert und Bodenfenchtigkeit genügend ist, drängt sich eine dunkelgrüne Tannenwaldflora zusammen; dringt man weiter in das Gebirge vor, so bedecken sich die Nordhänge der Berge mit Wald, die Südhänge sind noeh Prärie; immer höher werden die Berge, denen man entgegeneilt, die hüchsten bedeckt bereits Wald wie eine Kappe, auch nach Süden ïbergreifend; je tiefer man in das Innere des Gebirges eintritt, um so weiter zieht sich das Waldkleid auch auf der Südseite der Berge herab, bis zu einer gewissen Grenze, wo stets die Baumvegetation rasch an Höhe abnimmt und in Prärie übergeht. Wo ein Thal sich erweitert, tritt der Wald zuruick, Prärie an seine Stelle; aber dieser Wald hat nichts an sich, was die Waldbilder des Ostens in das Gedïchtniss zurückrufen würde; er gehört eben der westlichen pacifischen Flora an.

Die südliche Prärie ist von der nördlichen grundverschieden, wenigstens der an das mexicanische Gehiet sich anlehnende 'Theil: das üstliche Texas und Louisiana zum Theile zeigen (irasprärie, aber 
Gruppen ron Bäumen haben sich erhalten, isolirte alte Bäume stehen scheinbar mitten auf der Prärie; ihre astlos gewachsenen Schäfte verrathen, dass sie nicht isolirt, sonder'n in Gesellschaft mit anderen aufgewachsen sein müssen. Diese Prärie ist wohl zum grössten Theile künstlich geschaffen, wobei der Laubwald allmählig bis zu den Resten auf feuchteren Partien reducirt wurde, wo er allein Möglichkeit fand, dem Feuer zu entgehen. Wie feucht auf dieser Präirie die Luft noch ist, beweist das Torkommen der Tillandsia . des Florida-Mooses", selbst auf den isolirten Bäumen. Aber längst bevor man St. Antonio unter dem $98^{\circ} \mathrm{W}$. L. erreicht, trifft man Laubwald nur in Flussniederungen und in quelligenGebieten: die überwicgenden schwachwelligen Partien aber, die dazwischon liegen, tragen eine Buschvegetation, welche einer ganz anderen Flora, der mexicanischen, angehört, die hier ihre Nordgrenze findet.

Diese Strauch präri e beherbergt niedriges, dornreiches Gestrüpp, besonders von schmetterlingsblüthigen Holzpflanzen, von denen viele nach Westen und Süclen zu Halbbäumen aufwachsen; kleine Opuntien liegen am Boden, die prächitige Yucca canaliculata breitet ihr dunkles Haupt hoch über die Umgebung; andere Yuceas mit graziösen, schmalen Blättern geben der Landschaft einen eigenthümlichen Reiz. Da bei Sibinal, also fast unter dem $100^{\circ}$ W.L. erhebt sich aus dem Sumpfe noch einmal eine majestätische Gruppe von Taxodien, aber an Stelle der lang ron den Aesten flatternden Tillandsia ist cine andere Tillandsia mit kurem, dicken Tegetationsstock, geeigneter für ein trockeneres Kilima, getreten. In den kleineren Flussbetten, wasserlos zur trockenen \%rit, sirkert in der 'Tiofe noch so viel Fenchtigkeit - einem unterirdischen Strome rergleidehbar - dass niederer Laubwald Wurzel fassen kann: ïberall tritt der nackte, mineralische Boden in der hïgeligen Landschllaft zol Tage.

I) ir: nürdliche P'räire war einst heriihmt dureh ungeheure Heerden ron Büffehn, die man noch vor 20 Jahren nach Quadratmeilen Büffelstandlaum schä̈tyte und auf die die Reisenden von den Bahnzügen aus cino larmlose lïsilarle cröffheten; jetzt kann man zu jeder Jahres-

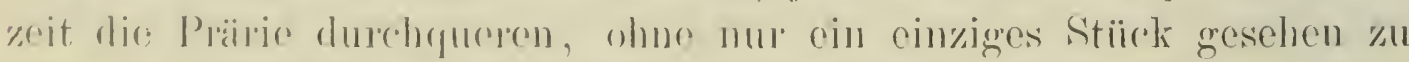

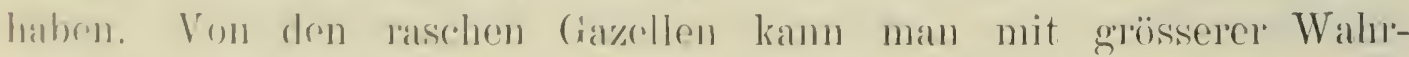
sreheinlichkeit moch comen kur\%en Blick erhaschen. Nicht so monoton monl lobles scheint mir die sürlliche Prärie zu sein. Wer ein Auge

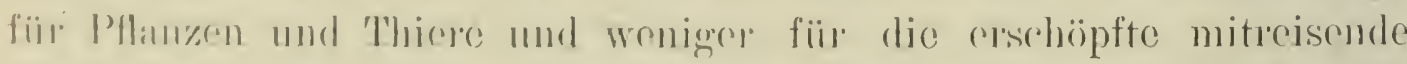
Ciesollschaft hat, findet die mohrtignige 'Tour werler ermïdend noch langweilig. Der Prärie-dogn, unter weldem Namen man im Norden 
einen Hamster, im Süden ein Eichhörnchen bezeichnet, baut allerorts in der lockeren Erde seine Hügel, richtet sich beim Herannahen des Zuges auf und verschwindet dann plötzlich in der 'T'iefe; cinige Gazellen rasen roriiber und langohrige Hasen eilen in ein paar Tinkelsprüngen zur Seite. Langweilig sind nur die ausgehungerten Rinder, die in dem Gestrüppe nach Futter und Wasser lechzend herumirren.

Die Phantasie eilt roran und malt sich die Ufer des Rio grande in den reizendsten Farben; endlich ist El Paso erreicht, die Enttäuschung ist vollständig - ein schmutziger, gelber, kleiner Fluss, unwürdig des volltönenden Namens, kaum einzelne verkiüppelte Bäume an den Ufern; die Landschaft ist bergig geworden, aber so wie die Prärie nicht zu Ende ist, wenn man im Norden die Rocky Mountains erreicht hat, so wenig ist sie im Süden mit dem Eintritt in die bergige Landschaft abgeschlossen.

Anch die südliche Prärie steigt plateauartig an, aber nie zwängt sich die Bahn durch enge Thäler, die mit frischem Tannengrün den crsten Gruss vom neuen Walde brächten; die Gebirgsstöcke, welche eine Fortsetzung der Rocky Mountains darstellen, stehen isolirt, breite Plateau's treten dazwischen, immer seltsamer wird das Bild, um so fremdländischer für den, der zum erstenmale die Heimat der Baumcacteen, jener merkwïrdigen Vertreter des trocken-heissen Klima's betritt. In einer hellen lautlosen Nacht, die dem Untergange der glühenden Sonne rasch folgt und Abkühlung bringt, fern ron jeder menschlichen Wohnung dieses Gebiet zu durchwandern, hat seinen cigenen Reiz, auch seine eigenen Beschwerden, weniger von Seite der gefürchteten Indianer und wilden Thiere, als ron den Vertretern der Flora selbst. Einzelne schwarze Säulen, oft armleuchterartig vertheilt, ragen gespensterhaft aus dem lockeren Buschwalde empor die Schüfte des Cereus giganteus, des mexicanischen Riesencactus, der im südlichen Arizona bis zu 18 Meter Höhe sich erhebt und die niederen Berge bedeckt, so dass diese ron Ferne wie mit Nadeln gespickt erscheinen. Andere Cacteen bilden kurze, reich veräistelte Stämme mit weisslichen Stachehn übersät oder liegen zu einem Dickicht verflochten am Buden. Viele von diesen gelten bei den Einwolnern als giftig; das weiss ich nicht, aber so riel weiss ich, dass bei der geringsten Berührung die stacheln mit den zahllosen, unsichtharen Tiderhaken in den Keleidern und in der Haut festsitzen, und, dass ihre Lostremnung schwierig und äusserst emptindlich ist: Opuntion mit rothen orler gelben Stacheln cheben sich den Weg cntlange. stets zerfetzt, aber wo ein Stück an der Erde liegt, schlägt es Wrurzoln und 
crwächst zu einem neuen Stocke; grosse Büsche von peitschenförmigen Euphorbiaceen, ebenfalls dicht bewehrt, sind typische Gestalten der Landschaft. Nicht fehlen die hohen, vertrockneten Blüthenstände der Agaren und Yuceas; spärliches, tief wurzelndes Gras vermag die monatelange, regenlose Zeit zu überdauern, mit den Früchten des Mesquit eine Nahrung für die zahlreichen, auffallend langohrigen Hasen, für die Gazellen, deren Frieden weniger der Mensch als der Präriewolf und der Silberlöwe stören.

Man muss an den Bergen noch ein paar tausend Fuss hinansteigen, wie wir diess auf der Ost- und Südseite der Santa Rita-Berge, hart an der mexicanischen Grenze thaten, ehe die letzten Vertreter dieser trocken-heissen Region zurïckbleiben und in den kühleren Höhen jene Grasprärie auftritt, die dem ganzen Norden charakteristisch ist.

Diese Grasprärie wird auf den Hochplateau's und den sanften Abdachungen der Berge durch niederes Gras gebildet, das weniger der Berieselung durch Flüsse von den Bergen herab als den Regen und Thamiederschlägen dieser Höhenregion seine Existenz verdankt.

Dort bietet sich mehrmals ein hübsches Bild, wie allmählig die Erde sich durch die Einwirkung des Menschen verändert und wie schnell sic darauf reagirt.

Der Boden ist ein humusreiches Zersetzungsprodukt des Porphyr, aus dem die Santa Rita-Berge bestehen, oft mehrere Meter in den sanften Mulden tief. Unter der Decke des Wurzelgeflechtes gegen Regen geschüt\%t, hat sich diese werthvolle Erde bilden und erhalten können. Die Strassen sind natürlich in diesem Winkel der Erde Meilen weit entfernt von jeder Ansiedelung, sehr primitiv; durch Fahren in einem Geleise bilden sich die Strassen, die dann etwas geebnet werden. Diese Entblüssung vom Graswuchse genügt, um die humose Erde in Bewegung zu bringen. Das Wasser, das bei den häufigen Regengüssen ron der Strasse zur Seite fliesst, frisst nach der tiefen Stelle hin anfangs gan\% kleine Rinnen; in der. Thalsohle begegnen und verstäken sich die Wasserläufe; der nächste Regenguss setzt das begonnene Werk fort; in ein par. Jahren muss die Strasse verlegt werden, da die nach rïrkwärts answaschenden Wasserrimen almählig die Strasse mit tiefen (quergräben durehfurehen; die Thalsohle hat inzwischen ein viele Meter hreites und tiefes Flussbeet crhalten, in das die steilen Ufer bei Regen und Sonnenschein abbröickeln wie lösliche Salze. Inmer leichter wird lic Albeit der Fluthen, denn das festigende Gras zu beiden Seiten an den Uferu stirbt ab, da das Wasser sich nicht mehr anstauen und alhmählig in den Boden versickern kann; manche Strasse hat man dort 
verlegt auf die andere Seite der Thalsohle und jeder Schritt zeigt, dass sie binnen weniger Jahre abermals nach den Bergen hin verlegt werden muss; 100 Jahre dïrften genügen, um den Anblick dieser sanften, wiesenreichen Thäler gründlich zu veründern; steile cañons dürften sich dort bilden, die durch ihre Grösse den Gedanken an ganz recente Auswaschungen kaum aufkommen lassen.

Die Bergflüsse berühren mit einem spärlichen Wasserfaden den Rand dieser Graslandschaft; in der Vegetation markirt diese Punkte das Auftreten ron isolirten, immergrünen Eichen oder Cypressen je nach der Süd- oder Nordseite eines Hanges, die Eichen scharen sich weiter hinauf zu Gruppen, in den Thälern zu continuirlichem, wenn anch lockerem Walde zusanmen; winterkahler Laubwald tritt dazwisehen, Kiefern gesellen sich bei; über 2000 Meter, wo auch die Douglasia hinzukommt, dürfte das Klima der kïhlen Laubwaldregion nahe kommen.

In Yuma überschreitet man den Colorado-Fluss, nur 15 geographische Meilen oberhalb seiner Mündung in den Meerbusen ron Californien; 30 Meilen westlich liegt der ungeheure Ocean, der Feuchtigkeitsspender; aber nichts in der Pflanzenwelt verrüth die Meeresnähe; die feuchte Luft vom Meere schneiden vorliegende Berge ab, die trockenheisse Luft rom N.W., rom Colorado-desert streicht über thier- und pflanzenlose Wüsteneien, über Sümpfe, deren Ufer schneeweisse Alkalien ausblühen, über niedere Strauchgruppen der erwähnten Prärieflora.

Bei dem Fleeken Cabazon auf californischem Gebiete treten die hohen Berge im Süden zurück, im Verlaufe einer Eisenbahnstunde ist auch die Strauch-Prärie verschwunden, alles ringsum ist Graslandschaft, die, anfangs Dezember, im freudigsten Grün, im Frühlingskleide prangt; die feuchte, nebehreiche Atmosphäre, die der grosse Ocean bis hieher sendet, hat mit ihren Niederschlägen die ganze Landschaft umgezaubert; aber nur Gras, kein Baum bedeckt, ron den Flusslïufen abgesehen, die Ebene. Erst bei grösserer Elevation beginnt der Wald.

Diese Prärie, die sich zwischen dem Coast Range-Gebirge und der Sierra Nevada durch ganz Californien zieht, scheint bestimmt zu sein, die Fruchtkammer der Union zu werden; nur wenig Hilfe ist nöthig zur Unterstützung der Bewässerung, zur zweckmässigen Vertheilung der von den Bergen herabkommenden Wasserläufe; je nach dem Grade der Bewässerung, den man gibt, kann man in diesem herrlichen Klima alles ziehen; die an die feuchte, salyige Brise des Meeres gewohnte, grossfrüchtige Cypresse (C. macrocarpa) wïchst so rasch empor wie die im dürren, heissen Mexico heimische schinns; die australische Eucalyptus treibt das ganze Jahr hindurdr, in cinem Jahre 
bis zu 5 Meter Höhe emporschiessend, die australisehen gerbstoffreichen Akazien, die Palmen, Yucea, Pandanen gedeihen mit einer Kraft und Wachsgeschwindigkeit, die in der Heimat dieser Pflanzen nicht grösser sein kann; Kern- und Steinobst mit feinem Aroma, Trauben und Orangen beladen die Gärten der rasch heranblühenden Farmen; die Atmosphäre ist genügend mit Feuchtigkeit gesättigt für Baumwuchs jeder Art, aber die Niederschlagsmenge ist besonders zur Zeit des hö̈hsten Sonnenstandes so spärlich, die Somnenstrahlen selbst so heiss, dass selbst die Präriegräser bis auf den Wurzelstock absterben.

Kaum aber hat der Regen einige Tage herabzuströmen begonnen (November), so bricht der Frühling an; die Berge und Thäler überkleiden sich mit prächtigen Grün; die Gärten füllen sich mit Blumen und Wohlgeriichen, selbst Bäume mit Ruheknospen beginnen sich zu regen.

Das saftige Grün erinnert an den Frühling, der Blüthenflor an den Sommer, die kühle Abendluft an den Herbst und das Pelzwerk der Damen an den Winter.

Wer frisch ron Europa kommt, erkennt nur Sommer und Frïhling im Wechsel der Jahreszeiten, während der länger Ansässige auch von eincm Winter spricht, in welchem alles grünt und blüht. Die kälteste \%eit in San Francisco (nur $8^{\circ} \mathrm{C}$. kälter als die heisseste Zeit) fällt sogar in den Juli, wenn durch das Golden Gate dichte Nebelmassen cindringen und sich tagelang in die Thäler legen, so dass in den Wohnungen Kaminfener in Stand gesetzt wird.

In den Thälem von Californien vertritt die Prärie den subtropischen Laubwald; an der Küste treten Kiefern, Cypressen und Sequoien an seine Stolle.

Blickt man zurück auf die ungeheuern, baumlosen Flächen der Union und fräigt man sich nach den Ursachen derselben und der klimatischen und floristischon Verschiedenheiten, so kann man vielleicht alle prärialen fiächen in drei Jä̈ngsonen theilen, und zwar

1. dic Prärie ästlich von den Rocky-Mountains, entstanden durch Mangel an relativer Fenchtigkeit während der Vegetationszeit, während die Niederschlagsmenge für Baumwuchs genïgen würde; sehr heträchtich nardh Osten hin vergrössert durch Fener; für Landwirth-

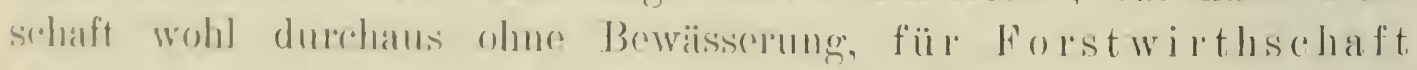
$1111 \mathrm{r}$ so weit beniityar, alses sich um kïnstlich geschaffene Priariefliatehen hatudelt.

2. Jie Prärie zwischon Rocky-Monntains und sierra Novada, boziohungewoise Cascarle Range, contstanden durch 
Mangel an relativer Feuchtigkeit und Niederschlagsmenge; landwirthschaftlich nur bei künstlicher Bewässerung, forstlich ka $u \mathrm{~m}$ ben ützbar.

3. Die Prärie zwischen Coast Range und Cascade Range, bezichungsweise Sierra Nerada, entstanden durch ungenïgende Yiederschlagsmenge während der Hauptregetationszeit bei gen ïgender relativer Feuchtigkeit; land- und forstwirthschaftlich bei künstlicher Bewässerung benutzbar.

Ich gebe diese, wie mir scheint, natiirliche Eintheilung der Präric sowie die beigefügte Erklärung über die Entstehung, bei dem Mangel an geeignet situirten meteorologischen Beobachtungsstationen mit aller Reserve.

\section{Die nordmexicanische Waldflora,}

soweit sie auf Unionsgebict ïbergreift, gehört insoferne zur pacifischen Flora als sic in Mexico die pacifische Küste erreicht; sic ist aber von der pacifischen Flora der Union grundverschieden. A uf die höchsten Perge Nen-Mexico's und Arizona's beschränkt, ist dieser Wald, verglichen mit den beiden anderen Gebieten, verschwindend klein und nur für die unmittelbarsten Nachbarn ron Wichtigkeit; diese haben auch bereits das Beste davon herausgeholt.

Schon hier, besonders aber bei der pacifischen Flora, fällt die Erscheinung auf, dass der winterkahle Laubwak ausserordentlich spairlich zur Entwicklung kommt und grösstentheils durch Kriefernarten vertreten ist, während die subtropische Zone mit immergrünen Hol\%arten an den heissen Süidhängen der Berge höher emporsteigt als man erwarten sollte. Im südlichen Arizona liegt die Grenze der immergrïnen Laubwäilder und der Kiefern. die auch in die subtropische Zone herabsteigen, etwa bei 1800 Meter.

Die gemäissigt-warme Region nimmt den Rest der Erhebung bis 2500 Meter ein, vielleicht dass die obersten 300 Meter in die 'Tannenregion fallen und die dort noch wachsende Douglasiatanne als Vertreterin dieser '/one erscheint.

a) Die subtropische \%onc.

Die trocken-heissen Ehenen, charakterisirt dureh die erwïhnte präriale Vegetation von Cacteen und Yucas, trïgt rinen Baum, den schon erwihnten Mescuit, Prosopis juliflora DC.. den typischen 
mit Tiscum reich bedeckten Strauch der Prärie in Texas und NeuMexico; der Mesquit erreicht im südlichen Arizona, seinem Optimum, Baumdimensionen, indem er bis zu 15 Meter Höhe und einem Meter Durchmesser heranwächst; er ist dort in der baumlosen Ebene als Brennholzlieferant von allergrösstem Werthe. In der angrenzenden mexicanischen Provinz Sonora bleibt er niedriger und wird dort stets seiner Zweige zu Brennmaterial beraubt. Dadurch entwickelt sich allmählig ein dicker, unterirdischer Stock mit starken Wurzeln, welche als ,unterirdischer Wald" bezeichnet werden, in welchem man nach Holz gräbt.

Das Kernholz des Baumes ist dunkelroth, der Splint sehr schmal; Rinde kleinschuppig mit locker hängenden Schuppen, später tief- und grobschuppig. Selbst auf Boden, der sich mit weissen alkalischen Ausblühungen bedeckt und der Landschaft das Ansehen gibt, als hätte cin leichter Schneefall stattgefunden, selbst auf solchem Boden vermag der Mesquit noch zu wachsen. Die Früchte, eine lange Schote mit zahıreichen Bohnen, sind eine Hauptnahrung der Pflanzenfresser der Prärie.

Einen anderen „Baum“ dieser Landschaft, den Cereus giganteus Engelm., den Riesen-Cactus, habe ich schon erwähnt; 18 Meter Höhe und $60 \mathrm{~cm}$ Durchmesser sind wohl die stärksten Dimensionen, die diese merkwürdige Pflanze erreicht; zahlreiche Löcher führen von aussen in das weiche Innere des Stammes, von Vögclu, besonders Spechten, verfertigt, deren Jugend durch ihr ununterbrochenes Cieschrei schon von weitem sich verräth; die junge Pflanze bleibt lange \%eit nicdrigg und wächst nur in die Dicke, wie eine Palme und schicbt dam erst in die Höhe; aber schon junge, noch kugelige Pflanzen sind mit Blïthen und Früchten reich besetzt.

Die Tertreter dieser Zone in den Bergen sind immergrüne Eichen und Cypressen; letztere bilden oft reine Bestände auf der Nordseite, erstere vereinigen sich in den feuchten Thälern, an Bachläufen entlang \%u Giruppen und lichten Waldungen mit weitkronigen und kurschaftigon Individuen. Das Klima ist dort milde, Schnee erreicht selten diesen Laundstrich, leichte Fröste wïhrend der klaren Nächte des Winters sind häufigr an trockenen, sonnigen Lagen erscheinen wierler Agaven, Yurea und Cactern; weiter westlich, am Coloradoflusse und den benachharten Bergen lobt auch cins typische Vertreterin der subtropischen \%onse, eine Palme, die abere in Mrexice nicht vorkommt und besser zur

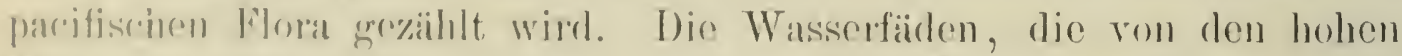
Bergen herabriasoln verlieren sich nnter den Fichen im Kiese. 


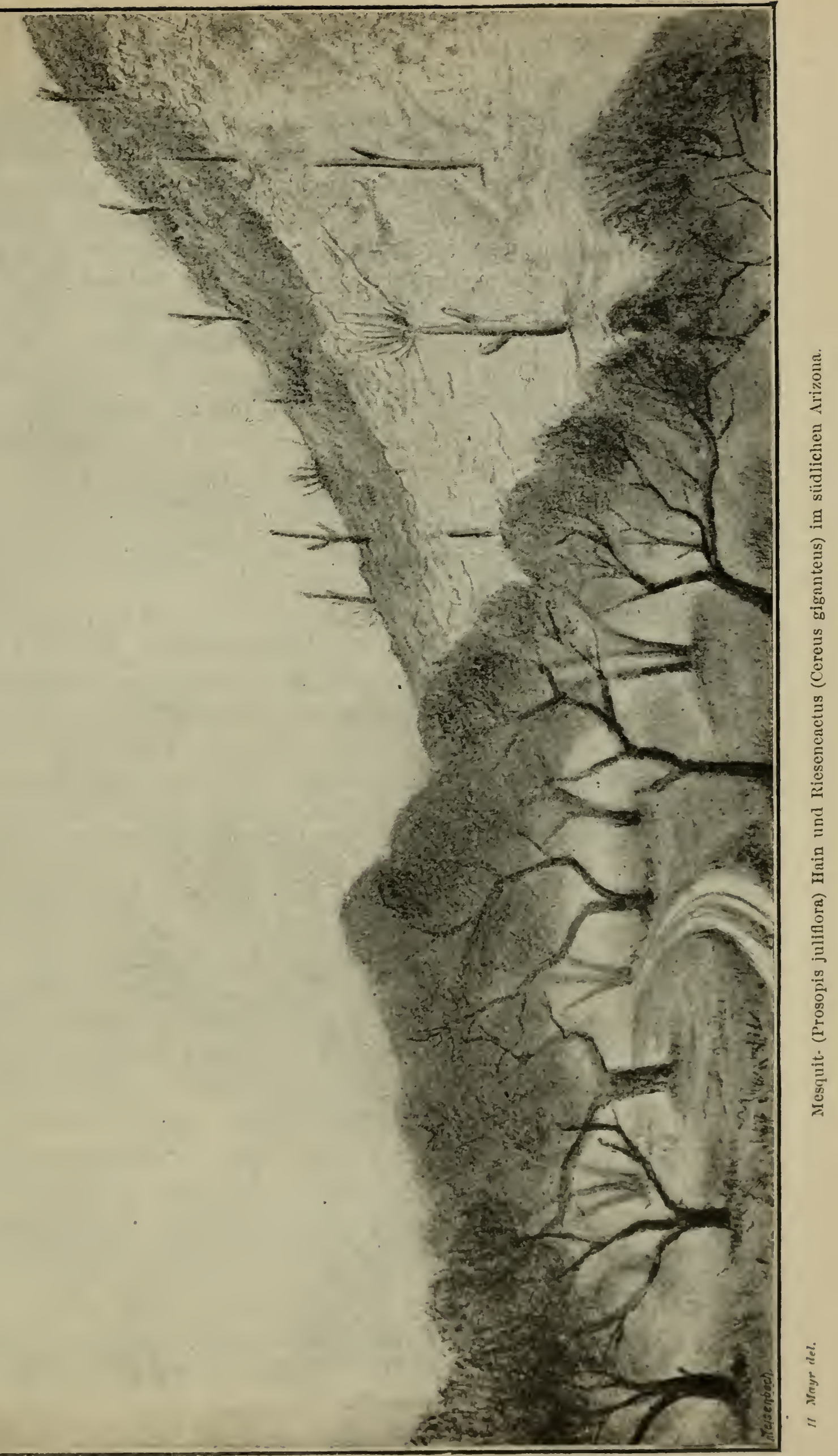


Unter den Holzarten sind besonders bemerkenswerth die Eich en, die mit einer Ausnahme den Weisseichen mit einjähriger Samenreife \%ugezïhlt werden künnen; sie sind wohl alle völlig immergrün, wenigstens zeigte sich noch keine Spur von Herbstfärbung als wir Ende Norember die Südhänge der Santa Rita-Berge bestiegen; die Früchte, zum Theile schon gefallen, näherten sich bei den meisten Eichen erst ihrer Reife. Die Zahl der Eichen ist nicht ganz sicher, etwa acht mögen dort und in den benachbarten Sant Catalina-Bergen ihr Fortkommen finden. Dass sie immergrün und Angehörige der subtropischen Zone sind, beweist ihr Holzgefüge und ihr ausserordentlich hohes specifisches Gewicht; die drei wichtigsten Arten haben zusammen ein specifisches Gewicht von 96, Quercus hypoleuca, die sich erst an der oberen Crenze dieses Eichenwaldes findet, hat 80; alle sind in sehr lichtem Stande erwachsen, mit dicker Basis, kurzen Schäften und breiter Krone. 'Technisch ist ihr Werth gering. Die Häufigste ron allen ist

Quercus Emoryi Torr., Black oak, Mexicanische Schwar\%eiche, wie sie wegen der dunkeln Früchte und der dunkelbreitrissigen Borke genannt werden mag. In Mexico ebenso läufig in höheren Elevationen wie in Arizona und im südlichen Neu-Mexico. Das Holz hat ein specifisches Gewicht ron 93; die Früchte werden von den eingeborenen Indianern sowie von den Mexicanern roh gegessen. Ias Blatt, wemn jung mit groben Stachelzähnen, später weniger scharf ge\%ilhnt (Tafel III). Eicheln mit dunkel-violetter Schale ('lafel II).

Quercus grisea Liebm., White oak, Mexicanische Weisseiche. Immergrün, Blïtter und Früchte sind auf Tafel III Ind 'Tafel II abgebildet. Weder hier noch südlicher in Mexico hat diese Eiche rine hervoragende Berleutung. Ihre Früchte werden von den Indianem gegressen, nadudem sie dieselben zerstossen und mit Sand zur Vertreibumg des Bitterstoffes vermengt haben. Sie variut

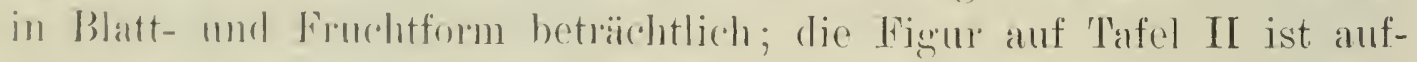
fallend dureh das schmale und grezillonte Blatt.

(2ucreus hypolonca Engelm. Ihre Blatform erinnert an

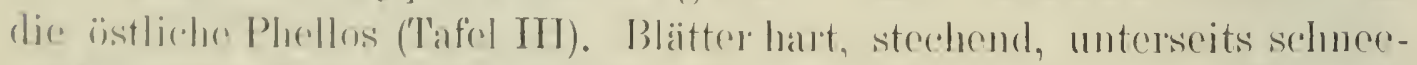

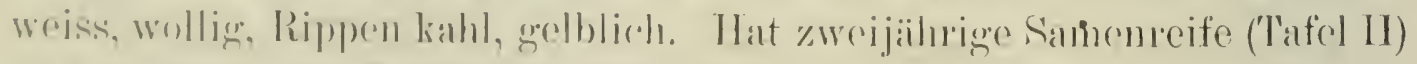

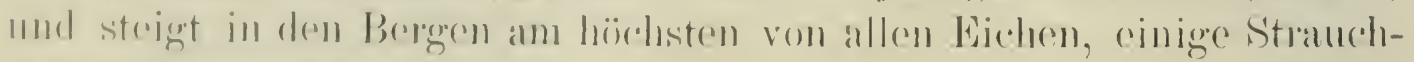
richroll als:gemmmmen.

Arbutus xalapensis. H. B. K. Madrona, die Mexicanisehe Madrona (spr. Mardronja) erhebt sirh bis 15 Meter Höhe, liebt die 
trockenen, sonnigen Hänge und entfaltet sich dort zu einem sehr schönen, immergrünen, sparrig gewachsenen Baume mit rother, glatter, im hohen Alter kleinschuppiger Rinde; das Blatt lancettlich, gestielt ('Tafel III); dic Früchte rothe, warzige Beeren (Tafel IV).

Arctostaphylos pungens, die Manzanita, ein Strauch mit schönen, glatten, rothen Zweigen überzieht die trockenen, kiesigen, der Sonne exponirten Berghänge, erreicht aber seine stärkste Entwicklung in der Sicrra, in der pacifischen Flora, wo er abermals crwähnt werden soll (Blatt auf Tafel TI).

Die felsigen, steilen Ufer der Flüsse, die Cañons, sowie die kïhlere Nordseite der Berge liebt eine Cypresse

Cupressus Guadalupensis Wats., die bis nach Mexico sich crstreclit. Sie tritt, wenn man von der Prärie an aufsteigt, zu gleicher Zeit mit den Eichen auf, erst als kleiner Busch, später baumartig; crhebt sich bis zu 20 Meter Höhe; Zapfen klein, Nadeln kur\% schuppenförmig mit einer Längsvertiefung an der Oberseite. Das Holz mit sehr breitem Splint ist noch ron geringem Werthe. Höher im Gebirge aber noch im Gebiete der Immergrünen rertritt diesen Baum ein baumartiger Wachholder.

Juniperus pachyphloea Torr., dessen schön rothes Kernhol\% man nicht genügend schätzt. Dieser grossfrüchtige Wachholder wird ein Baum ron 15 Meter Höhe und über ein Meter Durchmesser; die junge Pflanze schön weisslich; an älteren Stämmen ist nur der letztjährige Trieb weisslich. eine Erscheinung, die auch bei der weisslichen Varietät der Donglasia sich zeigt. Die Rinde des Wachholders ist cine kleinschuppige Borke, mit quadratisch weissen Stïcken an alten Bäumen. Die Früchte von der Grösse gresser Erbsen mit weissblauem Reif überzogen und zahlreichen Samen, die zuweilen aus der Fruchthülle hervorsehen; Nadelschuppen der vorigen Cypresse sehr ähnlich. aber Tertiefung rund mit weissem Secret.

Mit den Kiefern, die bei weiterer Erhebung folgen, betritt man wohl das Gebiet der

b) gemässigt warmen Region.

zu der blattabwerfende Bämme dieser eigenthïmlichen Flora gechören.

Die warmen Hänge der in der Prïlic grelegenen Gebirgsstëclie emö̈glichen offenbar das Anfsteigen der harten und kleinbliatterigen. immergrä̈nen Bäume bis zu den Höhen, in denen unter anderen kimatischen Bedingungen die gemaissigt warme Florat alleinherrschend ist; 
die an luft- und bodenfeuchtes Klima gebundenen blattabwerfenden Laubhölzer, die Tertreter der gemässigt warmen Region, konnten sich nur an den Flussufern entlang erhalten, an welchen Standorten sie auch bergab bis fast in die Prärie wandern. Es entsteht dadurch cine Nischung ron zwei verschiedenen Floren, deren Trennung wohl nach Individuen, kaum aber Jäumlich möglich ist; Gleiches sehen wir auch an der pacifischen Küste; die hoch emporsteigenden immergrünen und die weit herabreichenden, stellvertretenden Kiefern engen die winterkahle Flora auf einen kleinen Raum ein oder zertheilen sie zu isolirten Individuen.

Von forstlich untergeordneten Bäumen mag erwähnt sein

die westliche Walluuss, Juglans rupestris Engelm., die jedoch der mexicanischen Flora nicht angehört, wohl aber die californische Küste erreicht. Sie ist der schwarzen Wallnuss nahe verwandt, doch deutlich durch die kleineren Früchte mit gefurchter Steinschaale, ohne spitzig-waryige Erhebungen, unterschieden. Triebe behaart. Sie jst ein Baum hart an den Wasserläufen der Thalschluchten, unter günstigen Verhältnissen wächst sie ausserordentlich rasch; das New-Yorker Sammlungsstück zeigt $4 \mathrm{~cm}$ breite Jahresringe und einen Durchmesser des Baumes ron $40 \mathrm{~cm}$ in neun Jahren! Sie lebt zusammen mit der mexicanischen Esche, Platane und Pappel; erstere

die Fraxinus pistaciacfolia ist ein zierlich beblätterter Baum 1I. Grösse, der in Mexico bis zu 20 Meter Höhe sich erhebt; scine Früchte sind klein ('Tafel IV); das Holz wird nur gelegentlich verwendet; die Qualitït des Holzes dieser südlichen Art ist viel geringer als jene der nordischen Eschen.

Platanus Wrightii Wats., Sycomore, mexicanische Platane. Die jungen J'rebe filzig behart, später lange Zeit graugrïn; Bunke klein aber tief schuppig; wie die Platane des Ostens und jene Californiens lebt der Baum vor\%ugsweise in den kiesigen Flussläufrom und sicelelt sich dort auf den recenten Anschüttungen an, wie bri uns Pappentu und Erlen; in den engen Thälern, Cañons, erreicht er bedentende Dimensionen und steht dann an Schönheit der Blätter ('Tafol III) den in Emopat kultivirten Arten sicher nicht nach; als S'rhattenbaum magr er vielleicht wegen der tiefer eingeschnittenen Blïter wrniger vortheilhaft sein.

Gibcichen Standont theilt cine Balsam-Pappel, Populus Fremontii var. Wisliceni Wats. ('Tafel III), wie alloh zwee Weiden, 
ron denen eine Salix nigra ist, die auch in einer Varietät die pacifische Küste erreichen soll und eine andere Art, die aber ohne Frïchte bei der grossen Variabilität der Blätter der nordamerikanischen Weiden mir nicht bestimmbar war.

Chilopsis saligna D. Don, eine Bignoniaceae mit weidenartigen Blättern (Desert willow) ist ein gemeiner Strauch bis Halbbaum dieser Berge. An Stelle der winterkahlen Laubhölzer und der immergrünen zum Theile treten vielfach Kiefer'n, welche ron 1800 Meter an dem Walde reichlich sich beimischen und nach oben hin an Zahl und theilweise an Grösse zumehmen. Einige dieser Kiefern sind reine Mexicaner, die hier ihre Nordgrenze, andere sind Angehörige der Union, die hier ihre Südgrenze finden.

Pinus Chihuahuana Engelm., Kiefer von Chihuahua. Auf dem Unionsgebiete ziemlich selten, ist diese Kiefer die wichtigste Nutzholzlieferantin der anstossenden mexicanischen Provinzen; sie findet sich dort erst in höheren Regionen, bildet lichte mit Gras und Buschwerk durchstellte Bestände, oder mischt sich, wie auf den Santa Rita-Bergen zwischen 1500 und 2000 Meter den eben betrachteten Laubhölzern in den feuchteren Partieen der Thalsohlen bei. Diese Kiefer hat drei dünne, gelb-grüne Nadeln von 10-12 cm Länge in einem Kurztriebe; junge Triebe sind glatt, gelblich bis ockerfarbig glänzend; Knospen-Schuppen braun mit hellen Wimpern, anliegend olme Harz. Junge Zapfen am oberen Drittel des T'riebes und an der Spitze; einjährige Zapfen eiförmig von der Grösse einer grossen Erbse. Spitzchen scharf, gerade abstehend, Stiel aufrecht, 1,5 cm lang, wenn reif haben die Zapfen eine Länge ron $5 \mathrm{~cm}$ und eine Breite ron $4 \mathrm{~cm}$ wenn offen (ausnahmsweise kräftige Zapfen sind $6.5 \mathrm{~cm}$ lang), blauviolett mit hellockerfarbiger Apophyse. Wenn trocken, ist der Zapfen meist gelblich mit weisslicher Apophyse, wobei die Spitzchen grösstentheils abgebrochen sind. Zweige, oft knieförmig gebogen, Schaft ästig, Rinde eine grobe, dunkelgrane Borke, deren Schuppen in höherem Alter bis handgross werden, aber stets dunkelgrau bleiben. Bei einem Meter Durchmesser hatte der höchste Baum, den ich sah, 25 Meter Hühe. Das Holz, mit einem specifischen Gewichte von 55, zeigt den 'Yypus der dreinadeligen Kiefern, wobei die parenchymatischen T'ïpfel der Markstrahlen zahlreiche schmale, mandelfürmige Wandrerdünnmgen dasstellen. Die Kiefer gehört nach dem Bau ihres Holzes der Section der westlichen Titeda an. Sime nach dem Fichtensamentypus gehant, Tafel VIII. 
Pinus Engelmanni Carr. (syn. macrophylla Engelm.), Santa Rita Kiefer. Auf unserem Ausfluge in die Sühlhänge der santa Rita-Berge. an der Südgrenze Arizona's fanden wir in 2000 Meter Erhebung anf somigen, kiesigen Freilagen eine grossnadelige Kiefer, reichlich mit Zapfen behangen, die mir in der completen Sammlung nordamerikanischer Kiefern zu Brookline nicht begegnet waren. Der Baum war wenigstens für die Tereinigte Staaten-Flora neu; ich zweifle jecloch, ob es sich überhaupt um eine neue Species handelt. Nach den Exemplaren in Kew bei London ist eine Bestimmung nicht möglich; ein Zapfen, der als P. macrophylla bezeichnet jst, stimmt in der Grösse. aber keine Nadeln sind beigegeben; ein anderes Exemplar als macrophylla bezeichnet, hat zu grosse Zapfen und zu kleine Nadeln.

Im botanischen Garten zu Buitenzorg auf Jara stehen als P. macrophylla zwei Exemplare, die ron den meinigen grundrerschieden sind; die Nadeln sind nicht bloss länger $(40 \mathrm{~cm})$, sondern überdiess fünf in einem Kurztrieb; der Zapfen ist gekrümmt, Apophyse nur wenig rerdickt, $26 \mathrm{~cm}$ lang und an der Basis $6 \mathrm{~cm}$ dick; nach der Kew' Sammlung sind die Buitenzorger Kiefern wahrscheinlich .Pinus Cirewillea aus Mexico.

Dass die Santa Rita-Kiefer die ächte P. macrophylla ist, deren Torkommen, so weit nördlich, bis jetzt nicht beobachtet wurde, ist wahrscheinlich, da die Engehmanni in Nordmexico*) läufig ist.

Um die Identitï meiner Kiefer mit der mexicanischen feststellen zu kïnncu, s(dnich) i(h an C. G. Pringle und erhielt freundlichst Zapfenschuppen und Nadelii zugesandt. Die Sendung war begleitet ron folgenden \%eilen: "Pinus Engelmanni Carr. extends along the eastern base of the Cordilleras of North Hexico, on their foothills and coen on the plains at their base, for several hundreds of miles. It yickls bumber of goorl fuality not so soft and free from knots, prohably, as the white pine, because the forests of our Southwest are always more open than those of the North and the trees branch lower and more frealy. I will concloso herewith a cluster of nocolles of this spereies and scales of the rone."

I) ir heigegehenen Nadeln hatten eine lü̈nge ron 30,5 cm, die

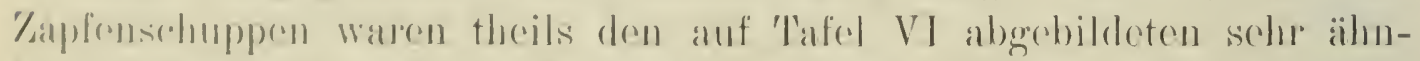
lich, theils entheb sich der mittlere Theril dor $\Lambda$ pophyse mit dem Nabel

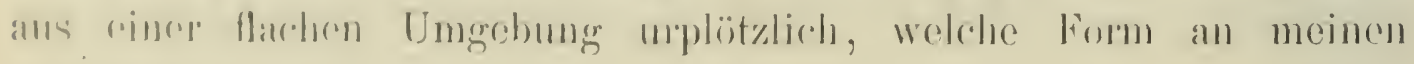

*) ('. (i. l'ringle, The forest vecretation of North Mexico. Garden and foreet Vinl. I, Nr. 2(1). 
Exemplaren ganz fehlt; der Same war dem auf Tafel VIII abgebildeten ähnlich; die ron C. G. Pringle beigeschlossene Skizze eines offenen Zapfens mass $11 \mathrm{~cm}$ Lünge und nur $5,5 \mathrm{~cm}$ Breite.

Auf Grund dieser Angaben kann ich die Identitït nicht mit Sicherheit feststellen: die Entscheidung mag umsomehr den amerikanischen Botanikern überlassen sein, als es sich um einen ihrer Angehörigen handelt.

Die Kiefer, die ich auf den Südhängen der Santa Rita-Berge fand, liennzeichnet folgende Diagnose: Die durchschnittliche Lünge der Nadeln, ron denen drei in einer Scheide sich finden, beträgt an erwachsenen Bäumen $27 \mathrm{~cm}$; Nadeln kräftig, fast $2 \mathrm{~mm}$ breit, sehr dekorativ: Zapfen an alten Bäumen $8 \mathrm{~cm}$ lang, $6 \mathrm{~cm}$ grösste Breite, wemn offen; Apophyse nach den Figuren auf Tafel VI; am trockenen Zapfen dunkle Lüngsrisse an den Apophrsen; an jüngeren (etwa 20 bis 30 Jahre alten) Bäumen sind die Zapfen beträchtlich grösser, $11 \mathrm{~cm}$ lang, $8 \mathrm{~cm}$ breit, wenn offen. Same nach Tafel VIII. Zweige dick, knieförmig gebogen, kur: Ḱnospenschuppen breit, ausgefranst und zurückgerollt. Rinde tief rissig, Furche der Risse hell-rothbraun, Rücken der Risse dunkelgrau.

Das Holz zeigt den Typus der Section Taeda. In Mexico ein werthroller Nutzbaum, ist diese Kiefer im Gebiete der Tereinigten Staaten ron untergeordneter Bedeutung; in lockeren Gruppen, spärlich dem Laubwalde beigemengt, erwächst sie in dem fast freien Stande zu einem kurschaftigen (25 Meter Höhe), astreichen Baume.

Pinus arizonica Engelm., Arizona-Kiefer, eine nach vielen Gesichtspunliten hin sehr auffallende Kiefer, die sich auf die Berge des südlichen Arizona's und des nördlichen Mexico beschü̈nlff.

Diese schöne Kiefer hat fünf zierliche Nadehn von 10-17 ('m Lä̈nge und fast $1 \mathrm{~mm}$ Breite in einem Kurtriebe; der einjährige und etwa auch noch der zweijährige Trieb sind hell blanweiss bereift wie bei Pinus Jeffreyi; Knospenschuppen schmal, hellbraum, anliegend, nicht durch Har\% verklebt; der erwachsene Baum mit dunkelgrauen Borkenschuppen und hellen Innenrindern derselben: der Zapfen ist dem der vorigen Art ähnlich, aber viel kleiner und rundlicher, durchschnittlich $6 \mathrm{~cm}$ lang und $5 \mathrm{~cm}$ breit, wenn offen, dunkelviolett wenn reif, später bram, Apophrse wie bei der vorigen Art: ebenfalls mit Langrisschen: Zalpfen sitzend.

Das Holz mit schënem, röithlichen lierne und cinem spereifischen Gewichte von 50 zeight den 'typus der Taedat-isection; as kam daher 
diese fünfnadelige Kiefer in keine der bestehenden Sectionen eingereiht werden.

Diese Kiefer ist angenscheinlich die nördlichste Vertreterin einer in Mexico ron zahlreichen Arten gebildeten Section; einstweilen, bis die mexicanischen Kiefern besser studirt sind, wird auch Pinus Torreyana in diese Section aufzumehmen sein, wiewohl sie in Habitus und Anatomie des Holzes der P. Sabiniana näher steht als der arizonica.

Da auch P. Pseudostrobus in diese Section gehört, erscheint „P sendostrobus" als geeignéter Name der nenen Section, die folgendermassen charakterisirt ist: fünfnadelig, Zapfen Pinaster-artig, Holz nach dem Typus der Section Taeda gebaut; hieher gehören, ausser P. arizonica, Pseudostrobus und Torreyana (provisorisch) noch P. Montezumae, tenuifolia, leiophylla, oocarpa, occidentalis auf Cuba und wahrscheinlich noch einige andere Mexicaner.

In Arizona erreicht diese Kiefer eine Höhe bis zu 30 Meter und steigt im Gebirge nicht unter 1800 Meter Erhebung herab.

Pinus edulis Engelm., Piñon, die, wie ich glaube, für Arizona noch nicht beobachtct wurde, und daher wahıscheinlich anch in das benachbarte Mexico übergreift; ihre Heimat liegt südlich von Pike's Peak in Colorado an trockenen, kiesigen Bodenpartien, in Colorado bis 2500 Meter emporsteigend.

Die drei (zuweilen zwei) Nadeln, die in einer Scheide sich finden, sind 2,5 cm lang, an den Berührungstlächen der Nadeln weisslich, wie bei fünfnadeligen Kiefern. Zapfen, wenn offen, $2 \mathrm{~cm}$ lang und $3 \mathrm{~cm}$ breit, auf $1 / 2 \mathrm{~cm}$ langen Stielen. Same im Verhältniss zum Zapfen schr gross, ohne Flügel, in einer Vertiefung der Zapfenschuppe liegend; ein wulstiger Rand der Kapfenschuppe umfasst den Samen; in der Regel kommt nur ein Same zur Ansbildung. Die Samen ('Tafel VTI) werden unter dem Namen Piñon von Indianern und Weissen gregressen.

Die in Colorado gesammelten Exemplare tragen Zapfen mit $4 \mathrm{~cm}$ Länge, 3 ('m Brcite; Same ('Jafel VII) ebenfalls gross, gleichmässig hellbram orler etwas gefleckt.

Rinde anfangs glatt, später kleinschuppig, dunkelgrau, das Hol\% ist grageniaber allen anderen Kiefern besonder's ausgezeichnet durch lie stark verdirkten Panenchymzellen der Markstrahlen, welche einen schmalon. spaltfirmigen J'üpfel tragen; die Wand der MarkstrahlT'racheriden gelatt: sio bildet zusammen mit den folgenden Kiefern, welehe chenfalls fliggenlose Samen, kleine Zalpfon tragen und gleiche anatomische 
Structur des Holzes zeigen eine neue Section, welcher der Name "P arrya" nach der zu dieser Section gehörigen Pinus Parryana gregeben werden mag; es ist bezeichnend, dass unter dem Tolke alle zu dieser Gruppe gehörigen Kiefern (4 an der Zahl) als Piñon bekannt sind; ihre Samen, nicht aber die ron anderen nordamerikanischen Kiefern, sind wohlschmeckend.

Die edulis lebt an trockenen, heissen Berghängen, auf geringem, kiesig-sandigem Boden, erreicht dem entsprechend auch nur 9 Meter Höhe; wie bei allen Kiefern der höheren Region erhält sich auch bei ihr eine drei- bis fünfjährige Benadelung.

Noch drei andere Kiefern theilen die eigenthümliche Biologie der edulis, nämlich

Pinus osteosperma Engelm. (syn. cembroides Gordon not Zncc.) Piñon, ein ron der japanischen Pflanze, welche hier in Japan den Namen P. cembroides Zuce. führt, grundverschiedener Baum; auch der Name Llareana ist nicht brauchbar, da auch Pinus Purryana früher als Llaveana bezcichnet wurde, wesshalb ich glaube, alle Missverstiindnisse sind durch Engelmanns Namen osteosperma ausgeschlossen; und das ist doch wohl der Zweck der botanischen Systematik, der trotz Priorität und Autor obenan steht.

Diese Kiefer "Steinkiefer" hat zwei Nadeln in einer Scheide (dic japanische hat fünf); an der Berührungsfläche sind dieselben weisslich: Zapfen $4 \mathrm{~cm}$ lang und fast eben so breit, Apophyse rorstehend; Same der Zirbelkiefer ähnlich. Er fehlt der Samentafel.

An den trocken-heissen, kiesigen Hängen der Santa Catalina in Arizona und in Nordmexico bei 1000 Meter Erhebung erwïchst die Kiefer zu einem Halbbaume (die japanische, am Boden liegende Kiefer bezeichnet das obere Ende der Baumregetation bei etwa 3000 Meter). Das Holz gehört zum Typus der Section "Parrya"; die japanische Kiefer gehört zur Section „Cembra."

Pinus manophylla Torr. und Frem. (syn. Fremontiana), Piñon, einnadelige Kiefer. Eine gefurchte Nadel in ciner Scheide, aus Verwachsung ron zwei herrorgegangen; Nadelscheide in drei Theilen zurückgerollt, Nadeln nach dem 'Typus der fünfnadeligen Kiefern gebaut, wie bei allen Angehörigen der Section Parrya, Fïrbung der ein- und mehrjährigen Pflanzen schon blauweiss: Nadellänge an jungen Exemplaren $5 \mathrm{~cm}$; Zapfen $7 \mathrm{~cm}$ lang, aufrecht sit\%end; Apophyse sehr kräftig nach abwärts gebogen; Samen nach Tafel VII, mit beigegebener Beschreibung. 
Von Utha an den östlichen Vorbergen der Sierra Nevada bis in das östliche Arizona, bis jetzt nicht in Mexico beobachtet. Sie occupirt ähnliche Standorte wie die vorige Art; Holz nach dem Typus der Section Parrya, Rinde Anfangs glatt, grau, später kleinschuppig.

Die vierte Piñon, Pinus Parryana Engelm. im südlichen Californien, hat als Vertreterin des pacifischen Laubwaldes der subtropischen Zone dort Erwähnung zu finden.

Pinus reflexa Engelm., White Pine, Hackenzürbel. Im südlichen Nen-Mexico, in Arizona und wahrscheinlich auch im benachbarten Mexico bewohnt dieser Baum die kühlen, feuchten, fast unzugänglichen Schluchten zwischen 2000 und 2700 Meter Erhebung; dort erreicht er 30 Meter Höhe.

Im Bau seines Holzes und den übrigen botanischen Merkmalen (5 Nadeln in einer Scheide) erweist sich diese Kiefer als Angehörige der Section „Cembra."

Der Zapfen 11 bis $20 \mathrm{~cm}$ lang, 4,5-8 $\mathrm{cm}$ dick wenn offen, etwas gekrümmt; Apophyse hellockerfarbig mit Längsrunzeln, breit, dünn, hakenförmig nach rückwärts geborgen; Zapfen auf $1 \mathrm{~cm}$ langen Stiele; Same flügellos nach Tafel VII.

\section{Der pacifische Wald.}

Schon früher habe ich versucht, eine Erklärung für die überraschend eigenartige Vertheilung von Wald und Präric zu geben; ich zeigte damals, dass nach meiner Ansicht ein Berg von Natur aus dort Graslandschaft tragen muss, wenn seine Spitze nicht über die Passhöhe des vorliegenden, den feuchten Meereswind abhaltenden Gebirges reicht und andere Feuchtigheitsquellen nicht geboten sind; dass aber die Spitze eines Berges Wald trägt, wenn diese über die Passhöhe der in der herrschenden Windrichtung vorliegenden Berge hinausreicht; dass Nordhänge, enge Thäler, Flussufer, mit einem Wort Verhältnisse, welche entweder die Luftbewegung hemmen und die Entführung der stagnirenden, fouchteren Luft verhindern oder welche Ersaty für die gesteigerte Verdunstung durch reichliche Bewässerung von unten bieten können, die Existen\% von Wald ermöglichen, während hart nebenbei Prärie sich anschliesst.

Nachrlem man die erste Kette der Rocky Mountains durchquert hat, die nur in den höchsten, gegen ïbergrosse Somnenhitze geschützten Lagen Wald zeigt, begegnet man Wald auch auf der Süidscite der 
Berge und zwar in Montana zuerst bei etwa 1200 Meter, während auf der kühleren und feuchteren Nordseite der Wald bis etwa 900 Meter herabsteigt; und 1200 Meter dürfte die Passhöhe des vorliegenden Cascaden-Gebirges sein.

Dass in Idaho und Montana, in diesen zum pacifischen Waldgebiete gehörenden Landschaften, der kühle Nadelwald allein herrscht, ist bei der geographischen Lage $42-48^{\circ}$ N.B. und der Elevation nicht auffallend.

In Oregon und Washington ist aber der Nadelwald auch im Thale, in der Ebene, so mächtig entwickelt, dass der Laubwald fast ganz rerschwindet; trotzdem müssen in diesen Staaten alle Gebiete bis zu 1000 Meter Erhebung der warm-gemässigten Regr ion zugez:ihlt werden, deren Laubhölzer durch anpassungsfühigere Nadelhölzer (besonder's Douglasia und Kiefern) unterdrückt wurden. Dort begimnt in den Bergen erst bei 1000 Meter der Nadelwald der kühleren Region, Tannen, Fichten und Läirchen. In Idaho und Montana dagegen, im Bereiche des Felsengebirges, ist unter 1000 Meter Erhebung die relative Feuchtigkeit und Regenmenge so gering, dass an Stelle des Laubwaldes Prärie tritt.

Besser prägt sich das Uebergewicht der Nadelhölzer im Westen nicht aus als in der beachtenswerthen Erscheinung, dass dort ein- und derselben Art entweder ein grosser Spielram in ihren Ansprüchen an Klima und Boden zukommt, so dass sie im Gebiete des Laubwaldes diesen vertritt und innerhalb der 'Tannenregion noch herrscht, oder indem eine Gattung mehrere Arten besityt, ron denen eine ausschliesslich im wärmeren Klima eine Vertreterin des Laubwaldes, eine andere eine typische Pflanze der Tannenregion ist, eine dritte selbst auf der Grenzzone beider sich hält.

Die Douglastanne vertritt den winterkahlen Laubwald und reicht bis in die Tannenregion; eine zweite Spezies, die grossfrüchtige ist dem warmen Grenzgebiete der subtropischen und gemässigten Region heimisch; Abies grandis ist in der Ebene und in niederen Bergen der gemïssigt-warmen Region, Abies nobilis, amabilis und magnifica sind typische Vertreter der kühlen Region, A. subalpina gehört der kalten Region an, in der aller Baumwald seine Grenze findet; A. concolor und bracteata sind im Grenzgebiete der warmen und kühlen Region. Picea sitkansis ist die getreue Begleiterin der Ab. grandis, P. Engelmanni und pungens sind ausschliessliche Bewohner der höheren Berge: P. Breweriana ist an der Baumgrenze, 'T'suga Mertensiana findet ihr Optimum in der Ehene, im Laubwaldgebiete, Tsuga Pattoniana nur 
ïber der Tannregion der höheren Berge; Sequoia sempervirens vertritt den subtropischen Wald, Sequoia gigantea liebt den kühleren Theil der gemässigt-warmen Gebiete zusammen mit Ab. concolor und Pinus Lambertiana; auch Chamaecyparis Lawsoniana, nutkaensis und Thuja mit dem Optimum in der Ebene gegenüber Libocedrus decurrens in den Bergen, Juniperus californica einerseits und Juniperus occidentalis andererseits mögen sich hier anreihen.

Auch in dem nadelholzreichen Japan zeigen sich ähnliche Verhältnisse; Abies Mfomi z. B. muss dem Laubholzgebiete zugezählt werden, während $\mathrm{Ab}$. Veitchii die typische Vertreterin der Tannenregion ist. Dass die Kiefern keine Ausnahme machen, habe ich schon theilweise erwähnt; als Nachtrag gebe ich hier die Gruppirung der Kiefern nach Waldzonen, nach ihren Ansprüchen an die Wärme geordnet; zu bemerken ist, dass alle Kiefern als Stellvertreter anderer Baumarten bezeichnet werđen können, da sie vorzugsweise auf Boden stocken, der für die anspruchsvolleren Holzarten zu geringwerthig, zu porös und trocken ist.

Demnach kann man die nordamerikanischen Kiefern bezeichnen als Vertreter der Laubholzflora in der subtropischen Region; hieher gehören: Pinus, cubensis clausa, scrotina, insignis, muricata, Sabiniana, Torreyana, Parryana, auch Chihuahuana, tuberculata und macrophylla (kühllere Theile); in der gemässigt-w armen Region und zwar deren süd l i ch c n Hälfte: P. glabra, australis, Taeda, arizonica, edulis, monophylla, osteosperma, reflexa, mitis, inops; nördliche (oder höher golegene) Hälfte P. rigida, contorta, pungens, resinosa, ponderosa, Jeffireyi, Coulteri, Strobus, monticola und Lambertiana; in der gemässigtkühlen Region: Pinus Murrayana und Banksiana und in der alpinen Region: P. Balfouriana, albicaulis, aristata und flexilis. Von den Cupressineen erreicht nur Libocedrus und Thuja zun Theil die Tannenregion; ihrem Optimum nach gehört erstere dem Grenzgebiete zwischen Laub- und Nadelholz, letztere entschieden dem Laubholzgebicte an.

Tritt man ron Osten her, nach langer Fahrt durch die von der Sonne versengte und vom Feuer verkohlte Prärie, in das Gebirge ein, so erscheint Anfangs der Wald auf die Nordlıänge allein beschränkt, cin Wald, der in seinem allgemeinen Bilde die Erinnerung an den Wald der Vorberge unserer Alpen wachruft. Die Lärchen einzeln und ihre Umgehung überragend, leuchten in goldgelber herbstlicher Färbung aus dem dunklen (irün der Douglasia hervor; die wärmeren und extremeren Sürlhänge überzicht die glaugrüne, mächtige Gelbkiefer (Pinus prinderosa). 
Man nähert sich dem Meere um eine halbe Tagereise, da tritt ron der Nordseite herüber der Tannenwald über die Gipfel der Berge nach der Südseite über; die Kiefer ist auf den schmalen Streifen zwischen Tannenwald und Prärie zusammengedrängt; wird das Thal enger, dann ist alles überfüllt ron Douglasias und Lürchen, zu denen sich die westliche Weymouthskiefer (Pinus monticola) gesellt; an den felsigen Ufern der Gebirgsbäche erscheinen zwei neue Holzarten, eine Thuja und Tsuga, niedere Bäume hoch oben im Gebirge, aber rasch mit dem Abstieg an Grösse wachsend; erweitert sich das Thal, dann zichen die genamnten Luftfeuchtigkeit verlangenden Arten sich wieder zurück, die Gelbkiefer oder selbst die Prärie tritt wieder an ihre Stelle.

Da mit einem Male öffnet sich eines der lieblichsten landschaftlichen Bilder, die mein ziemlich verwöhntes Auge je erblickte; die Bahn betritt die Ufer des himmelblanen See's Pend d'Oreille, ron dicht bewaldeten Bergen eingefasst, reich an grünen Inseln, nicht breit und ständig die landschaftlichen Bilder wechselnd, ist diese 100 Kilometer lange blaue Wasserfläche vielleicht der entzückendste See, den die Union besitzt; diese Perle wurde leider den Indianern als Reservation zugewiesen, die, in ihre rothen Tücher gehüllt, ihr Leben mit Fischfang und Nichtsthum verbringen.

Der Einfluss dieser gewaltigen Wassermenge auf eine Verzögerung. des Herbstes und jedenfalls auch des Frühjahrs ist unverkennbar. Hier an den Uferhängen waren die Lärchen noch grün, die unmittelbar nach dem Verlassen des Seebeckens wieder in goldgelber Farbe glänzten; die Thuja ist dort in der feuchten Atmosphäre und dem feuchten Grunde besonders mächtig; sie liefert vortreffliches Nutzholz, das man zur Erbauung einer langen Brücke über einen Seitenarm des See’s benutzt hat.

Eilt man weiter nach Westen, so ändert sich mit einem Male die ganze Landschaft, Berge tauchen auf mit sanften Wölbungen, die Thäler weniger eingeengt, der Boden von vorwiegend sandiger Beschaffenheit - Douglasia, Lärche, Thuja und Tsuga sind verschwunden, die Gelbki efer tritt auf und eine zweite kurznadelige Kiefer (Pinus Murrayana), die mit der östlichen Banksiana nahe verwandt ist und dieser in allen Stiicken so parallel geht, wie in diesen Oertlichkeiten die Gelbkiefer (ponderosa) der Rothkiefer (resinosa).

Das Terrain senkt sich, die Kiefernwaldungen öffnen sich mehr und mehr, lösen sich in Gruppen und endlich in einzelne auf der angrenzenden Prärie zerstreute Individuen auf; die Grenzlinie 1200 Meter 
ist uibcrschritten, der herrliche Wald ist zurückgeblieben und alles ist wieder gelbbraune Prärie soweit das Auge reicht.

In dieser trostlosen, welligen Graslandschaft erhebt sich ein rulkanisches Mittelgebirge, die Blue Mountains; reichliche Wasserläufe aus der Nebelregion der Berge durchrieseln die Thäler und erfüllen sie mit üppigem Baumwchse; mit 1200 Meter betritt man augenscheinlich die eigentliche Waldzone, einen Wald, der dem in Montana entschieden an Höhenentwickling überlegen ist, die westliche Lärche auf den nördlichen, tiefgründigen Berghängen erscheint als der höchste Baum mit 45 Meter Höhe; die gelbe Kiefer auf den sandigen und sonnigen Plateau's erhebt sich bis zu 40 Meter Höhe; die Douglasia reiht sich mit 35 Meter durchschnittlicher Höhe an; zu ihr gesellen sich noch eine Fichte (Picea Engelmannii) und eine Tamne (Abies grandis), die ich in unmittelbarer Nähe nicht in erwachsenen Exemplaren finden konnte. Eigenthümlich ist das Verhalten der Pinus Murrayana, die Identität mit der früher erwähnten vorausgesetzt. Diese Kiefer überzieht in vielen reinen Beständen die feuchten, kalten Einsenkungen mit nördlicher Exposition; mit den zahlreichen Aesten ineinandergreifend erheben sich diese Kiefern zu einer durchschnittlichen Höhe von 28 Metern.

An die Stämme der Bäume in den Rocky Mountains besonders der rauhborkigen Douglasia heftet sich eine hellgelbgrüne, auffallende Strauchflechte, von etwa $5 \mathrm{~cm}$ Länge; hier in den blauen Bergen nähır der Feuchtigkeitsquelle, dem Stillen Ocean, flattert eine lange, braune Bartflechte von den Aesten der Bäume; leider ist die Regenmenge und Feuchtigkeit der Luft nicht konstatirbar, aber die Leute, die mitten im Walde auf der Höhe der Berge wohnen, versichern, dass in den Mrnaten April, Mai und Juni heftige Regen herabstürzen.

Zur Zeit, als ich diese Berge bestieg (Mitte Oktober), war Wochen lang wolkenloses Wetter vorausgegangen; der heftige Nachtfrost verschwand da, wo die Sonne auftraf; im Schatten aber blieb die Bodenflïche fest gefroren.

Bei Dalles ist das Cascarlen-Gebirge überschritten, die feuchte Juft des Meeres streicht ungehindert im Thale res hellblauen Columbiaflusses aufrecht, einen Wald aus dem Boden hervorlockend, der überrascht durch soine Frische, seinen Artenreichthum und vor allem seine Höhonentwicklung. Laublü̈lzor mischen sich dem Walde bei, Ahorn, Fschen, Eilon, an denen eben die ersten Spuren einer herbstlichen Färbung erkonntlich sind; 'T'suga und 'Thuja erscheinen wieder unter' ihnen, grünes Gras, ein seit Wochen ungewohnter Anblick, äberzieht 
die baumlosen Stellen und baumlos ist es nur da, wo das Feuer, diese Landplage, gew ïthet hat.

Regierungsberichte und Versicherungen der Reisenden stimmen darin überein und eigene Anschaumng kam es bestätigen, dass viele Quadratmeilen dieser herrlichen Bergwälder verkohlt sind und man darf sich glücklich schätzen, während der trockenen Zeit (Herbst) ron der ganzen Landschaft überhaupt etwas zu sehen, denn es gehört zu den alljährlichen Erscheinungen, dass über die Staaten MIontana, Washington und Oregon Wochen lang dichter Rauch sich legt, der wie Nebel jeden Ausblick rerschliesst; so wird in den dortigen Waldungen gewirthschaftet!

Hand in Hand mit dem eben geschilderten Wechsel in der Waldregetation, ging, als ich im Oktober diese Fahrt unternahm, auch eine Teränderung des Witterungscharakters; östlich von den Bergen und in den Bergen war wolkenloser, klarer Himmel mit kräftigen Nachtfrösten; kaum bog man in die Thäler des Cascaden-Gebirges ein, so zeigten sich kleine Wölkchen, die weiter nach Westen hin zusammenflossen und endlich den ganzen Himmel mit bleigranen Wolkenmassen ïberzogen; unter Tags löste sich das Gewölke wieder auf, hatte somit nur während der Nacht die Abkühlung, die Nachtfröste verhindert, das Klima gemildert.

Nun beginnt auch die menschliche Thätigkeit in anderen Zeichen, als in Kohlensäulen sich zu äussern; einzelne Farmer haben bereits im Thale den Wald hinweggefegt, mit Holzz:̈unen ihr Eigenthum umgeben wie im Osten.

Im Unterlauf des Columbia, wo das 'Thal sich verbreitert, sowie an den Tributärflïssen desselben auf dem reichen, aus vulkanischem Gestein hervorgegangenen Boden gesellen sich zu den riesenhaften Douglasia's Eichen, Thujen, 'Tsuga und Tamien, endlich Pappeln, Laubbäume, die mit 60 Meter Höhe den berïhmten Rasamala's (Liquidambar Altingiana) von Java an Grösse gleichkommen.

Nur ein paar Breitengrade nördlich, am Puget Sound, wo das Meer in vielen Armen tiefer in das schwach hügelige Land eingreift, da liegt in dem feuchten, gemässigt-warmen Ḱlima das Optimum der Douglasia und der Thuja.

Diesen Wald übertrifft kein Nadelwald der nördlichen und sïdlichen Halbkugel an Flächenausdehnung und nur die Waldungen der Sequoia's kommen ihm in der Höhenentwicklung gleich.

Ich habe nicht nach Riesen-Donglasia's gesucht, lionnte aber gelegentlich mehrmals 80 Meter, selbst 90 Meter konstatiren; die Tsugia, 
die Grosstanne, die Sitka-Fichte reihen sich mit 60 Meter und darüber an, und die kleinste Baumriesin, die Thuja erreicht noch 55 Meter Höhe.

Hier liegt das Gros der westlichen Nutzholzproduktion und Verarbeitung; das Material liefert in erster Linie die Douglasia. Bei uns ist es ein Segen für den Wald, wenn eine Bahn ihn erschliesst; in Amerika ist es in der Regel sein Untergang. Viel schlimmer als die gründliche Abschlachtung alles Brauchbaren und vor allem der Samen liefernden Mutterbäume ist selbstverständlich das Fener, das nie fehlt, wo der Mensch auftritt und nur zur Ruhe kommt, wenn es an Erschöpfung der brennbaren Vorräthe von selbst stirbt oder durch langen Regen niedergeschlagen wird. Die beigegebenen Abbildungen: „F äll u n $g$ der Douglasia, ihre Verbringung durch Zugthiere und Eisenbahn" mögen ein Bild geben von der Energie und Schonungslosigkeit, mit der alle derartigen Unternehmungen in Amerika in Scene gesetzt werden. Auf den möglichst schnellen und grossen Profit von einigen Wenigen zugeschnitten, rentiren solche Unternehmungen nur wegen der seit Jahrhunderten angehäuften kolossalen Holzvorräthe; sie riicken dem Holzvorrathe nach, wenn ein Platz erschöpft ist; solche ephemere Unternehmungen gehen von selbst zu Grunde wie das Fener, nachdem alles Brauchbare aufgezehrt und der Rest verwüstet ist; ein (ilück, wenn nicht auch das Nährkapital des Bodens dabei ruinirt wirl, wie das so oft in den White-Pine-Waldungen des Ostens der Fall ist. Möglich, dass in den entfernten, bergigen Gebieten sich noch eine tüchtige, unberührte Reserve erhalten kann; die Vertreibung dor Chinesen im Westen, der billigen Arbeitskräfte, die damit Hand in Hand gehende Erhöhung der Arbeitslöhne dürfte vielleicht manches drrartige Unternehmen, das auf diese Honigtöpfe in den Bergen gemünzt ist, vereiteln, bis zu einer '/cit, in der man, beschämt über die Vergangenheit, gewissenhafter und klüger mit dem Geschenke Gottes ım\%ugehen verstehen wird.

IItten in dem mächtigen Forste erglänzt das schneebedeckte Haupt des 4400 Meter hohen Vulkanes Tacoma, ein Gebilgsstock für sich in der Cascaden-Reihe, stark zerklüftet, reich an unzugänglichen Thalschluchten, in denen Bäche von den gewaltigen Gletscherfeldern des Berges \%ur Tiofe eilen. Nichts sonst unterbricht die Stille des Sarlelwaldes; dicke Klumpen von wasserdurchtrankten Moospolstern lagern auf den Aesten, ein Z/cichen von ständiger und grosser Feuchtigkroit der Luft; in den Schluchten, hart äber den Gebirgsbächen hänght dio Thuja, fosterewureelt in den Felsspalten; wo die Ufer sich verbreitcrn und reichlich unterirdisch vom Bache durchträint werden, 


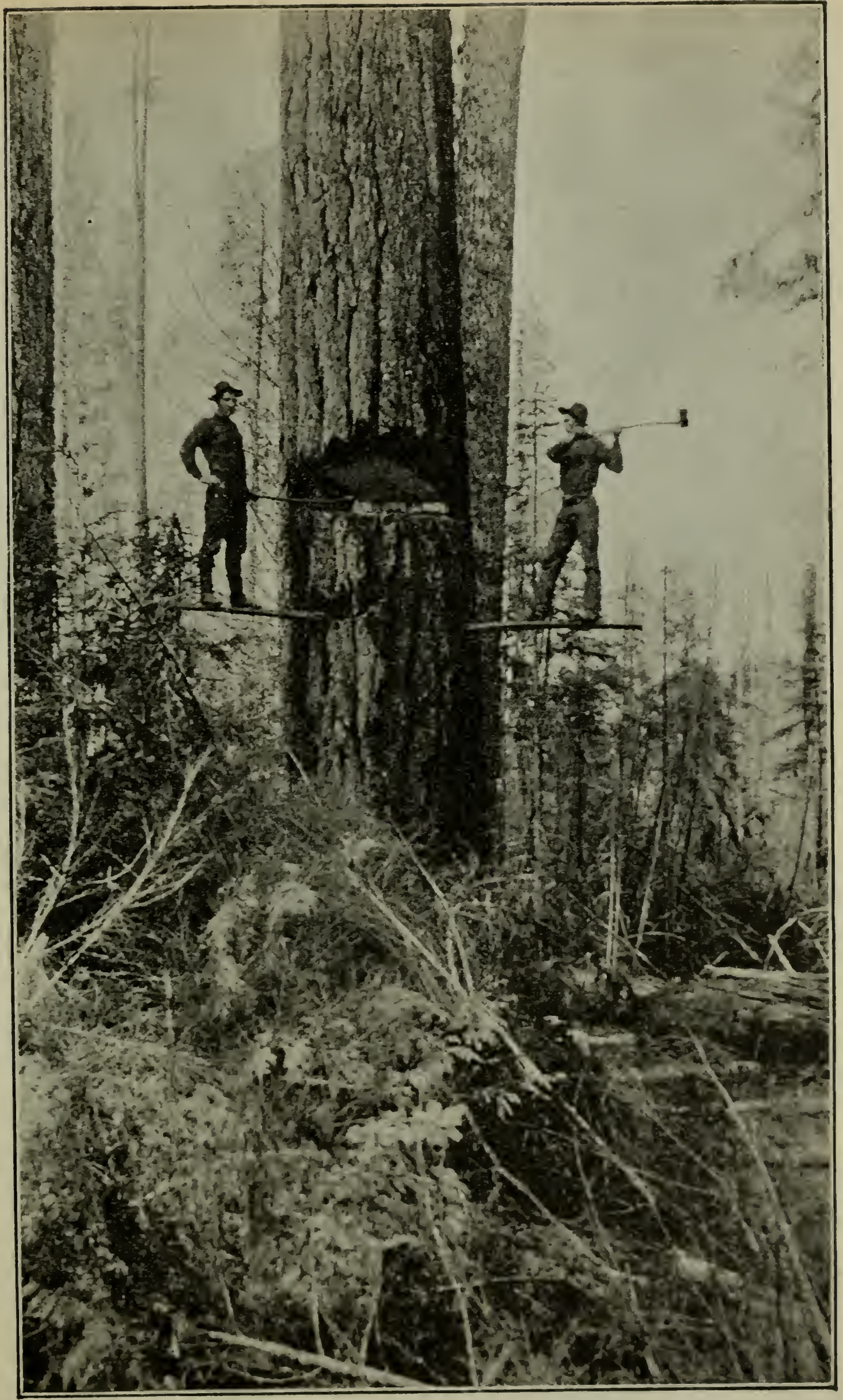

Fällung der Douglasia in Washington Territory. 


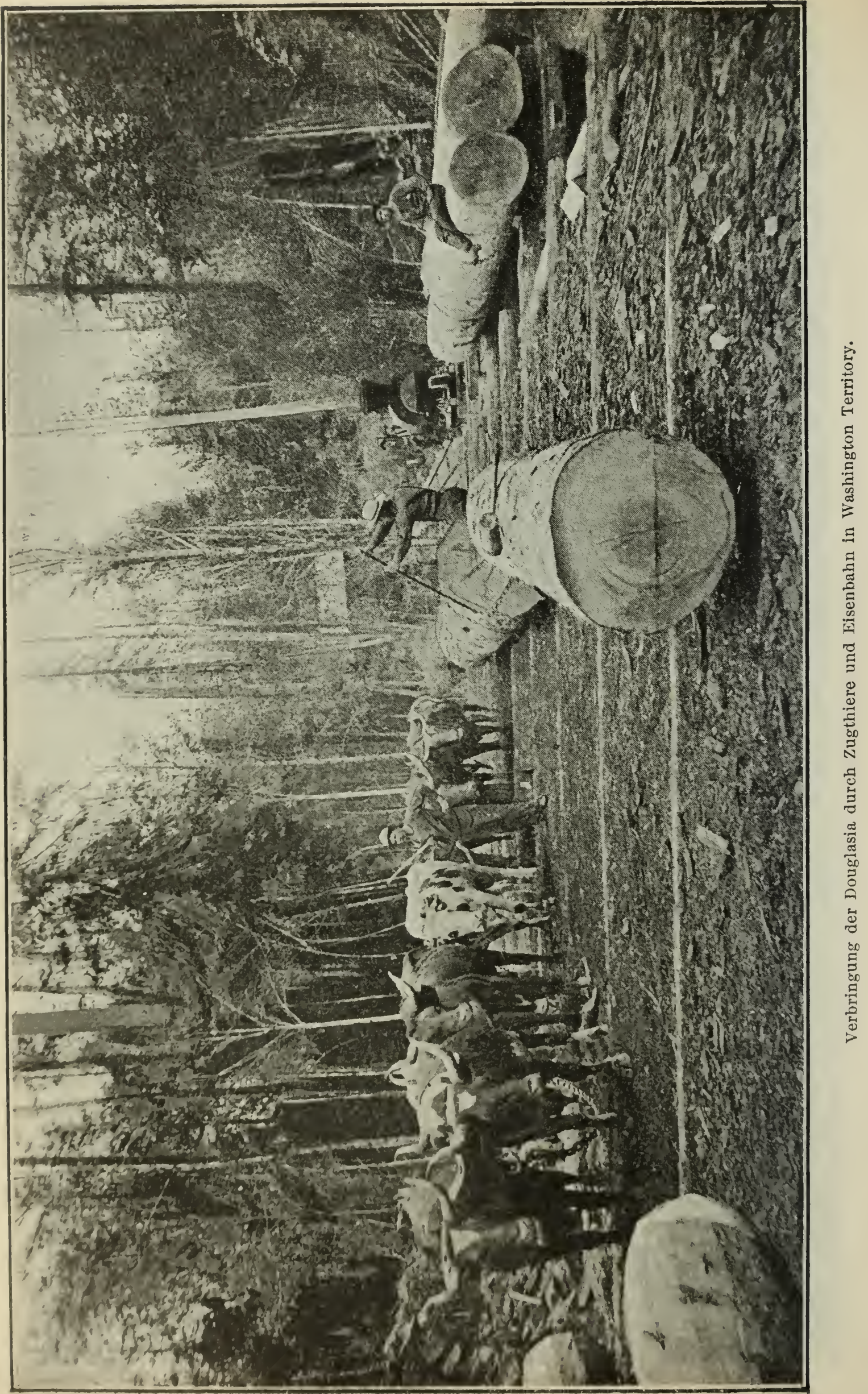




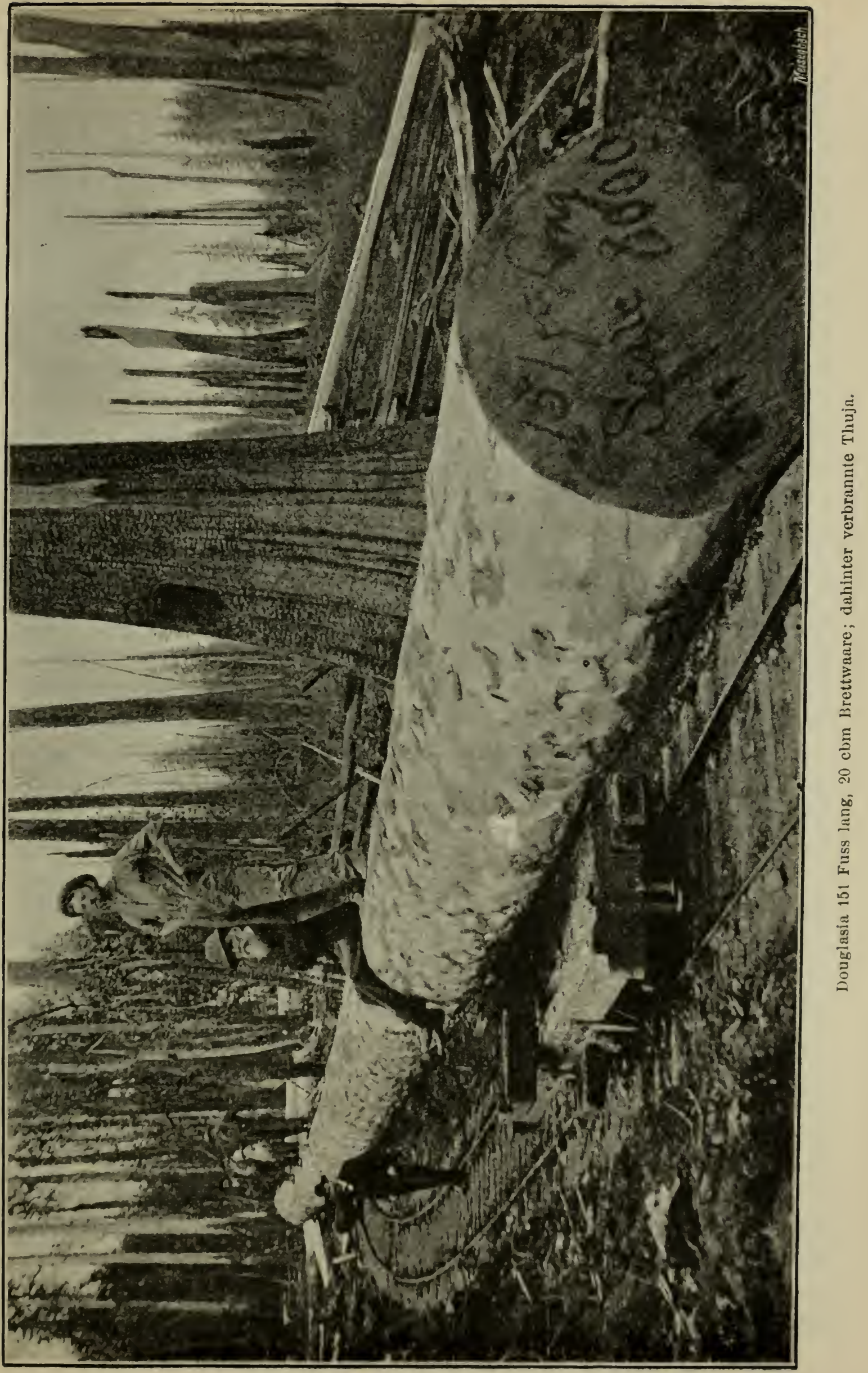


entsprosst ein Dickicht ron grasgrünen Halbbäumen, dem Acer circinatum, kaum Raum für saftige, grossblätterige Liliaceen oder mannshohes Schilf, oder für ein Brombeer- und Sambucus-Gestrüppe lassend; und mitten unter diesen erhebt sich mit mächtigem Stamme die SitkaFichte, ihre Krone weissschimmernd wie die der Silbertame des Himalaya; mit ihr wetteifert die Thuja, die mit ausserordentlich breiter Basis beginnend (ich mass oft in 1,5 Meter Höhe noch über 3 Meter Durchmesser) rasch in eine feine Spitze ausläuft. Wo weniger Befeuchtung des Bodens gegeben ist, überziehen mannshohe Farnkräuter oder Moose den Boden, der uneben ist durch die zahllosen Dämme aus humoser Erde - den Ueberresten der vergangenen Baumgeschlechter. Dass da Douglasia's stocken konnten, die bis zu 100 Meter Höhe emporwuchsen und nach den Versicherungen von Sägmühlenbesitzern mit 4 Meter Durchmesser eine Bretterwaarenausbeute von 28 cbm lieferten (da überdiess ein Drittel des Schaftes dabei verloren geht, so berechnet sich der ganze Inhalt solcher Holzriesen auf volle $42 \mathrm{cbm!),} \mathrm{darf} \mathrm{man}$ füglich nicht in Frage stellen. Jeder Schritt in diesen Bergen verräth die Kraft des vulkanischen Bodens, die Güte des Klima's, das alle Vorzüge für Nadelholzregetation — schneereiche, lange Winter, warme Sommer, gleichmässige Vertheilung der Niederschläge und grosse relative Feuchtigkeit der Luft während des ganzen Jahres - in sich schliesst.

Blickt man über eine steile Wand in die Tiefe, Wald stockt auf allen Bergen und Thälern, Wald überzieht die ferne Ebene bis zur Küste, und nach Osten hin ist wiederum alles Wald, so weit die Sehkraft reicht.

Einstweilen sind Farmen, ja ganze Dörfer und Städte mit- dem fïr Hunderttausende von Einwohnern ausgelegten Strassennetze immer noch unscheinbare Löcher in dem dunkelgrïnen Teppiche. Dort ist zweifellos noch viel zu riel Wald, dessen Produkte die ganze Küste entlang verfrachtet werden. Viel Boden ist vortrefflich für Landwirthschaft geeignet, der Wald wird dort weichen müssen und mit Recht; so blïht zum Beispiel im Puyalhup-Thale der Hopfenbau; aber mancher Hügel ist bereits kahl oder es überzieht ihn nur noch ein niederes, krïppelhaftes Wachsthum der Douglasia; man rasirt eben den Wald des Holzes oder auch der Viehzucht wegen überall kahl hinweg und wenn man dann daran geht \%u untersuchen, ob auch landwirthschaftlich aus dom Borlen etwas zu machen wäre, so ergibt sich nur zu oft ein negatives Resultat.

Wor ans dem Osten kommt, der beginnt im Westen wierlerum, als hätte or in dem jahrelangen Ringen im Osten nichts gelernt. Der 
Westen steht den im Osten lebenden Amerikanern so fern, wic uns Europäern Amerika; dort heisst es wiederum, ist alles anders als in der Heimat, eines ausgenommen - die geträumte Unerschöpflichkeit der Holzrorräthe. Am schlimmsten freilich für den Wald und für vieles andere sind die Neu-Eingewanderten; wer frisch aus Europa kommt, den Grimm auf die sklavische und dumm-ideale alte Welt im Herzen und auf der Zunge, oft zur Entschuldigung des eigenen misslungenen Ich's, findet hier im Westen, wo Gesetze und Sitten noch ziemlich locker sind, ein freies Feld für die Entfaltung sciner unterdriickten Geistesgaben. Nur Wenige finden Ruhe und Zufriedenheit und werden zu brauchbaren Mitgliedern des grossen Staatswesens; die Meisten aber irren, trotzdem sie Bürger geworden, heimatlos umher und verderben mehr als sie erwerben und dem gesammten Wohle nützen.

Im Optimum der Douglasia gesellen sich zu den schon früher genannten Laubhölzern noch eine Weisseiche, Cornus, Pyrus, PrunusArten, mehr Halbbäume und Sträucher als werthvolle Nutzstämme.

Das Klima dort gleicht den wärmeren Länderstrichen Deutschlands, dem Klima der Flussniederungen mit rorwiegend Eichen, Ulmen, Eschen als Baumvegetation, wo Weizen und Hopfen, selbst Mais und Wein gedeihen. Als ich dic Gegend besuchte - Ende Oktober fiel eben das Laub von den Bäumen; in den Blumenbecten blühten noch Dahlien unberührt von frostigen Nächten. Der Winter ist schneereich und mild (durchschnittlich $4^{0} \mathrm{C}$.); die tiefste in diesem Landstriche bis jetzt (Winter 1884) beobachtete Temperatur war $-17^{\circ} \mathrm{C}$., während der Hauptregetationszeit fällt ca. $130 \mathrm{~mm}$ Regen, während des ganzen Jahres $1375 \mathrm{~mm}$; auffallend gross und gleichnässig durch das ganze Jahr ist die relative Fenchtigkeit mit $75-80 \%$.

An der Küste entlang nordwärts dürfte diese gemässigt-warme Region auf der Höhe ron Sitka almählig in die gemässigt-kühle Region übergehen; nach Süden hin fällt die Grenze der gemässigrtwarmen und der subtropischen Zone mit der Staatsgrenze zwischen Oregon und Californien zusammen, genau genommen sind es die SiskyouBerge und der vulkanische Gebirgsstock MIt. Shasta, welche die Grenze markiren.

Die Insel Vancouver muss noch der warmen Region zugezaihlt werden, denn ihre Eichen, Eschen, Pappeln und äbrigen Laubhölzer stehen in ihren Dimensionen kaum hinter dencn von Oregon zurück. Wo das Meer an seichte, flache Kü̈sten schlägt, spielt es mit den grossen Baumstämmen, die ron den Flüssen der Insel und des benach- 
barten Continentes in's Meer getragen werden; es fällt auf, dass die Mehrzahl dieser Stämme, besonder's astlose Schäfte, nachdem sie Jahre lang ron den Wellen an's Ufer geworfen wurden und wieder in's Meer zurückrollten, schliesslich eine Gestalt annehmen, die unverkennbar der eines Seehundes, also einem in gleichen Oertlichkeiten lebenden Thiere, ähnlich ist.

Wendet man sich vom Puget Sound wieder nach Süden, rasch bleibt der schöne Wald zurück, die wollige Landschaft ändert ihren ganzen Charakter; wo der Boden sandig wird, treten wieder Pinus auf, Prärie drïngt sich dazwischen; der Grund liegt klar vor Augen. Im Westen gegen die Feuchtigkeitsquelle, das Meer, zu hat sich ein Gebirge, das Coast Range vorgeschoben. Da mit einem Male erscheint wieder der nördliche Wald in voller Ueppigkeit, Eichen, Pappeln, Eschen und Ahorn sind ihm reichlich beigemengt, soweit eben dureh das breite Thal des Columbia-Fhusses die feuchte Seeluft in das Land treten kann. Wenige Meilen südlich ist der Wald der Douglasia wieder auf die höheren Berge oder die Ufer kleinerer Flüsse beschrïnkt, eingefasst von dem kaum 50' hohen Wachsthum von Eichen mit flachen Kronen, von Ferne einen aufgespannten Schirme vergleichbar; an den Aesten derselben, an den ungepflegten Obstbäumen der primitiven Farnen, ja selbst an den Telegraphenstangen und Züunen haftet cine lang herabhängende, weisse Bartflechte. Sie ïberzieht die West- und Südwestseite und verräth eine grosse Menge von Feuchtigkeit, freilich zu einer Zeit (Oktober bis Februar), in der nur sie den Nutzen davon hat.

Wie es dem flüchtigen Blicke olme genaue Messung scheint, steigt die Waldzone im südlichen Oregon zwischen Coast Range und Cascaden-Gebirge an den Bergen herab genau in demselben Verhältnisse, als das vorliegende Coast Range-Gebirge seine Passhöhe senkt.

Eine 'Tou iiber' dieses Gebirge, die letzte Barriere, die ron dem grossen Feuchtigkeitsppender, dem stillen Ocean, trennt, dürfte manches Bemerkenswerthe bicten, zumal im südlichen Oregon, wo an der Küste bereits cinzelne Vertreter der subtropischen Region anftreten.

Beim Aufstiege an den Bergen beginnt der Wald mit buschigen Eichen und Strauchwerk von Cornus, Crataegus etc. und einzolnen Kiefern; die Eichen drängen sich in den Thälern, an den Flussläufen \% (iruppen zusammen mit sparrigen, isolirt aufgewachsenen Stämmen; in dem niedoren Gesträuch erscheinen zuerst an den Nordhängen einzelne Libocedrus und Douglasias; sie nehmen immer mehr an Kahl \%" und ku\% bevor man die Passhïhe erreicht hat, gesellen sich \%u ihnen an den Bachufern die T'Tuja, damn die 'Tsuga und mehrere 
Tannen. Hat man die Passhöhe übersehritten, so erscheint ein neuer Baum, eine immergrüne Castanopsis mit goldgelben Blättern; rasch ansteigend wachsen die Grössenverhältnisse der genannten Nadelhölzer; Douglas-Tannen mit 90 Meter Höhe ragen aus den Schluchten empor; man erblickt zuerst in Augenhöhe den Gipfel und beachtet ihn kaum; einige lange Strassenserpentinen führen dann zur Basis des Kolosses. Ein neuer Strauch mit lorbeerartigen Blättern und gewürzigem Aroma tritt auf, je tiefer man steigt; dazwischen einzelne kleine, weisse Pflänzlinge der Chamaecyparis Lawsoniana; nach langem Abstiege sind sie ein erfreuliches Zeichen, dass das Ziel der beschwerlichen Reise auf bodenlos primitiven und menschenleeren Bergwegen endlich näher rückt.

Als ich Ende Oktober 1885 die Tour unternahm, hatte leider bereits der Winterregen cingesetzt; Dora, eine einsame Ansiedelung in einem fruchtbaren Thale auf der Westscite der Berge war endlich in tiefer Nacht erreicht; wie überraschte da das Bild, das sich dem neugierigen Auge am andern Morgen bot; alles war verändert, nur der bleigraue Himmel nicht; die immergrünen Umbellularia's waren inzwischen zu mächtigen Bäumen geworden, die sich an den Flussufern zu dicht geschlossenen, aromatisch duftenden Wäldern vereinigten, die lorbeerartigen Früchte fielen eben zu Boden, ein Leckerbissen für die Schweine; auf den Aesten und Stämmen lagerten dichte Moospolster, in denen auch noch eine reichliche Farnkrautflora genügend Nahrung fand; aber nahebei, auf sonnigen Hängen, standen bereits einzelne Lawsonia's mit 50 Meter Höhe.

Noch waren mehrere kleinere Bergrïcken zu übersteigen; dic immergrüne Castanopsis mengte sich zwischen die Nadelhölzer mit pfeilgeradem, mässig hohem Schafte, langsam erwachsen unter dem ziemlich dichten Dache der Kronen; Rhododendron (maximum?) so mächtig wie im Osten, Berberis Aquifolia und andere Immergrüne gesellen sich zu den Sträuchern; steigt man an den Bergen abwärts, so versehwindet die Thuya an den Bachufern, die Lawsonia tritt an ihre Stelle; endlich liegrt ror den Augen eine schwachwellige Landschaft, reichlich durchzogen von seefürmigen Erweiterungen der Flüsse. ron Brakwasserpfützen, die die Fluth anstaut, und tief in das Land schneidenden Mecresarmen, und in weiter Ferne schimmert in unvergleichlichem Blau der grusse, nie stille Ocean; das ganze Küüstengebiet, iiber das das Auge hinschweift, ist die Heimat der Lawsonia.

Nïher dem Meere gewinnt die sandigre Beimengung im Boden allmählig das Uebergewicht, die Zahl der Douglasia's und Fichten 
nehmen allmählig ab, jene der Lawsonia zu; an die Nähe des Meeres gebunden, ist das Verbreitungsgebiet der Lawsonia ein beschränktes; die Küste des südlichen Oregon, wo sie in Optimo gedeiht, kennzeichnet ein sehr gemässigt-warmes Klima; Dahlien standen noch Ende Olitober in voller Blüthe in den Gärten, die Feige (Ficus Carica) gedeiht im Freien und reift Früchte, ja selbst der Eucalyptus bleibt unberührt ron den geringen Frösten des milden Winters. Dort und im Norden Californiens wird die Lawsonia höher geschätzt als jeder andere Nutzbaum; doch auch hier musste der Besitzer einer grossen Sägmühle, die fast ausschliesslich Lawsoniaholz verarbeitet, zugestehen: „Millions of acres are burnt."

Der Gebirgsstock des Mount Shasta ist ein mächtiger Grenzpfahl zwischen der bisher kurz geschilderten Waldflora der gemässigt-warmen Region und der subtropischen, die sich von da an südlich bis tief in das Lower California ausdehnt.

Die Eigenartigkeit des californischen Klima's habe ich in allgemeinen Zügen bereits geschildert; der Küstenstrich ist feucht und warm; der klimatisch auffallendste Ort ist, wie schon erwähnt, San Franciseo, dessen mittlere Temperatur der Monate Juni, Juli und August, niedriger ist als die irgend einer anderen Stadt in den Vereinigten Staaten, selbst die nordwestlichen Präriestaaten nicht ansgenommen. Die täglichen Temperaturschwankungen, w:e jene zwischen Sommer und Winter, übersteigen nicht $8^{0} \mathrm{C}$; nördlich und südlich ron San Francisco ist der Sommer wärmer. Hoch oben in den forstlich so merkwürdigen Bergen bestehen keine meteorologischen Stationen; jene in der Ebene südwärts zwischen Coast Range und Cascade Range beweisen nur das Fehlen von Wald in Folge allzugeringer Niederschläge während der Vegetationsmonate; leichter Frost ist dort nicht selten, westlich rom Coast Range-Gebirge dagegen unbekannt.

Tom mittleren Californien aus in die hohen Berge der Sierra Nevada rorzudringen, war mir im Jahre 1885 nicht mehr möglich; die Zeit und die Wanderlust drängten mich weiter nach Westen, wo las Wunderland Japan mit all' seinen unbekannten und darum doppelt anreizenden forstlich-botanischen Schät\%en vor mir auftauchte; erst auf meiner zweiten Reise nach Japan im Jahre 1887 bot sich mir Gelegenhoit, das mit grossem Unrecht Versiumte nachzuholen.

Vom Süilen kommend und durch manche harte 'Tour in menschenJeeren Bergen ohme Reisegelegenheit und Unterkunftsstäte gestählt, wählten wir den durch seine Waldhestände im Hocharebirge berïlunten Fresnu County, dessen Berge fast nie ron Touristen besucht werden, 
die näher bei San Francisco in das scenerienreichere aber baumärmere Yosemite-Thal eilen.

Schon ehe wir die Prärie verliessen, deren Oberfläche zahllose, kleine Hügel von kaum ein paar Fuss Höhe und spärliches Gras bedeckten, betraten wir grosse Haine ron ziemlich locker stehenden Eichen, der grossfrüchtigen Quercus lobata, die der von den Bergen herabsickernden Bewässerung ilıren Ursprung verdanken. In den Bergthälern reichen diese Eichen mit Qu. oblongifolia und Douglasii bis zu 1800 Meter empor; unterwegs gesellen sich zu ilmen an den Flussläufen einzehne Eschen, Platanen (Platanus racemosa), weissrindige, strauchartige Rosskastanien, Cercis, Straucheichen; die Sabinkiefer, die sonst unter den isolirten, breitkronigen Eichen in zahlreichen Individuen mit laubholzartigem Aufbau sich einmengt, fehlt hier ganz.

Bei ca. 1800 Meter begegnet man wieder Gelbkiefern, die vorerst noch die Nordseite der sandig-kiesigen Hügel bedecken und dort eine blätterabwerfende Flora vertreten. Mit der Gelbkiefer erscheint eine weitere Eiche, Quercus Kelloggii, deren Standgebiet zweifellos zur gemäissigt-warmen Region zühlt. Ton 2000 Meter aufwärts lag zur Zeit als wir aufstiegen (Anfangs Dezember) bereits Schnee. In den trockenen, warmen, sonnigen Lagen erreichten noch die Eichen respectable Dimensionen, rorwiegend sind aber Gelbkiefern; an den Flussläufen lebt, wie die Thuja im Norden so hier die Libocedrus, die Stellvertreterin jener Holzart; auf feuchten, sandig-kiesigen Abdachungen erwächst die Pinus Jeffreyi, bis zu 70 Meter Höhe emporsteigend, einzelne Tammen (Abies concolar) von gleicher Höhe stellen sich dazwischen; wo aber das Klima nur wenig kühler wird, sei es durch nördliche Exposition oder durch klammartige Einengung, da rereinigen sich 'Tamnen und Libocedrus mit der Zuckerkiefer, Pinus Lambertiana, zu einem mässig geschlossenen Hochwalde, dem auch jüngere Geschlechter nicht fehlen; die Durchschnittshöhe der Althölzer ist sicher mit 70 Meter Höhe nicht zu hoch gegriffen. Ein paar hundert Fuss höher hinauf verschwindet die Gelbkiefer ganz, Jeffrey's Kiiefer wird seltener; 'Tamne und 'zuckerkiefer dagegen häufiger, da betritt man mit einemmale eine Mulde - ohne zu wollen hïlt man sein Pferd zurück. Bevor man Darjecling im östlichen Himalaya erreicht, biegt man plötzlich $\mathbf{m}$ eine Felsmauer, die während des Aufstieges jeden Fernblick abschnitt; da mit einemmale tudut der schneeweisse Riese unter den Bergen, der Kintchinchunga auf: solch' unerwartete Grösse und Schönheit unterdruickt jedes Wort und hemmt die Bewegung; das war auch der Eindruck, den das Waldbild in der Sierra Nevada in mir hervorrief. 
Dass man da den Massstab für Bammhöhe und Massenschätzung verliert, ist verzeihlich; der 70 Meter hohe Hochwald ist dort wieder zum Nebenbestand geworden, über den ein Hochwald von ca. 100 Meter hohen Sequoia's sich aufthürmt; in über tausendjähriger Ungestörtheit an einem enormen Schafte und einer demselben proportionalen Höhe banend, hatten sie mehrere Generationen des etwa dreihundertjährigen Bodenschutzbestandes zu Boden stürzen sehen.

Tiefer Schnee bedeckte damals den Boden, ein klarer Himmel wölbte sich über den dunklen Baumkronen, während in der Tiefe kalte Nebel wogten; frische, erquickende Luft durchwehte den majestïtischen, ron rothen Säulen getragenen Dom; kaum dass man das leise Gezwitscher der geschäftigen Meisen in den Baumkronen hören konnte.

Mit freiem Blicke nach dem fernen, regenspendenden Meere, mit dem Rücken durch hohe Berge gegen allzu kalte und trockene Winde gedeckt, crfreuen sich solche Sequoiahaine eines langen, aber nicht kalten Winters, eines warmen und fenchten Sommers; dass in dieser Region ganz kiäftige Stürme hausen, das bestätigen die abgebrochenen Baumkronen; dass aber ein Baum mit über 30 Meter Basisumfang auch manchen Stoss ertragen kanm, ist jedenfalls nicht zu bezweifeln; freilich sind die stärksten Exemplare, die man bis jetzt gemessen, mit vollen 50 Meter Umfang und 120 Meter Höhe in unzugänglichen Klammen erwachsen; hoffentlich werden sie dort, gegen Menschen und Feuer geșichert, den nachkommenden Geschlechtern erhalten bleiben.

Mit traurigem Blicke trennt man sich von der Stelle und schnell bleiben zurück Landschaft, Vegetation und Klima, all' der Zauber der entzückenden, durchaus nicht "wilden" Natur, wie die vielen-Reiseeräblıungen aus dem ,fernen Westen“ ihren leichtgläubigen Lesern auftischen; von wilder Natur kann man allenfalls damn reden, wenn man bei Nacht und heftigem Sturme einen Wald von über $100^{\prime}$ hohen, morschen Kohlensäulen zu passiren hat - aber diese Wildniss hat erst dor Mensch, nicht die Natur geschaffen.

Diesor Gedanke fühnt naturgemäiss zur Forstbenutzung in Californien.

Während im Norden wie Oregon, Washington, Montana vorwiegend harte Nádelhölzce zur Verfügrung stchen, wie die westliche Lärche, die Donglasia, die Cielhkiefer, vorsorgt Californien den Markt mit Hölzern, welche wiedor die im Osten so beliebten Eigenschaften, nämlich Leichtigkreit und leichte: Boableitmogsfähigkeit besitzen.

Hierher gehört das Redwood, das Holz der Sequoia sempervirens, woldhe anf die feuchten Westhänge del Coast Range-Berge beschränkt 
ist und Seenähe und Wärme zu ihrem Gedeihen verlangt. Dass die Vorräthe rasch der Erschöpfung entgegeneilen, kann nicht mehr bestritten werden.

Das Holz der Sequoia gigantea in der Sierra Nevada ist noch riel leichter als das Redwood; wie dieses Holz gewonnen wird, daron habe ich schon frïher gesprochen; ein paar Haine, wie der Mariposagrove und das Yosemite-Thal hat man als "National-Eigenthum" erklärt; in solchem National Property kann keine Ansiedelung, welche den Wald rodet, Fuss fassen und hoffentlich sind auch Vorkehrungen getroffen, dass Feuer, dem doch so leicht rorzubeugen wäre (durch strenge Ueberwachung der Touristen!), ummöglich ist.

Am Yellow Stone-Flusse hat man ein geologiseh äusserst merkwürdiges Gebiet vor den Zerstörungen durch Reisende, Ansiedler und Minenarbeiter gerettet durch Erklärung zum „National Property", wie es aber mit den Bäumen, der pflanzlichen Zierde der Merkwürdigkeiten bestellt ist, erwähnte ich schon früher.

Nachdem man allmählig erkannt hat, dass die Freigabe der Berge unabänderlich mit der Verwüstung derselben und des darunter liegenden Tieflandes endet, sollte man allen Wald in den Cascade Range und Rocky Mts. als "National Property" erklären, den für die Nation zu erhalten und geeignet zu nützen allein der Staat die beste Bürgschaft bietet.

Vortreffliches, leichtes Nutzholz liefert ferner die Zuckerkiefer; auch über diese möge das Wichtigste dem früher Gesagten entnommen werden; weniger ergiebig und geschätzt sind die Hölzer der JeffreyiKiefer, der Gelb-Kiefer und der Libocedrus, am wenigsten von allen das Holz der 'Tanne; der schwierige Transport in die Ebene verzehrt den grössten 'Theil des Gewinnes, obwohl das Material selbst entweder' fast nichts gekostet hatte oder überhaupt gestohlen wurde.

Das südliche Californien zwischen den Gebirgszïgen ist rorwiegend eben und tief liegend; das Coast Range-Gebirge steigt in vielen paralielen Ketten nach Süden hin immer höher an, bis es endlich in dem Gebirgsstocke der San Bernardino und San Jaeinto sich mit dem Cascaden-Gebirge zu einer Kette vereinigt.

Ein Aufstieg auf den San Bernardino im südlichen Californien mag ein Bild der Vegetationsvertheilung geben.

Von der Prärie am Fusse der Berge bis zur Passhühe bei etwa 2200 Meter hat man mehrere Hügehreihen mit sucressiver Erhebung \%u passiren; die erste Bergkette fanden wir bei unserem Aufstiege Anfangs Dezember 1887 mit etwa 1-3 Meter hohen grünen Strätchern 
bewachsen, werthroll nur durch die Bindung und Erhaltung des Bodens; die nächste Hügelreihe bedeckte abermals Gesträuch, darunter besonders Manzanita, während die kiesigen Häng'e eine Kiefer (Pinus tuberculata), einen Baum von etwa 15 Meter Höhe, trugen; meist nur zu Gruppen, seltener zu kleineren, reinen Beständen schliesst sich dieser Halbbaum zusammen. Die dritte Hügelreihe erhob sich steil von 700 Meter zu 1700 Meter. Torherrschend sind zahlreiche immergrüne Eichen, die ein undurchdringliches Dickicht auf den Südhängen dieser Bergkette bilden. In diese Zone, welche den Schluss der subtropischen Zone bezeichnet, fällt das erste Auftreten von winterkahlen Laubhölzern (Platanen) und der grossfrüchtigen Douglasia; diese, welche mir eine g'ute Species zu sein scheint, erhebt sich an den heissen Südhängen bis hart zur Passhöhe, überschreitet diese aber nicht. Der vierte Berg trägt in der Nähc der Passhöhe winterkahle Eichen und einzelne Kiefern, linter derselben senkt sich das Gebiet sehr sanft und von vielen Hügeln durchzogen.

Kaum hatten wir die Passhöhe erreicht nach einer 'Tour in glïhendheisser Sonne, so überraschte uns ein eisiger Wind, der von Nordost wchte, tiefer Schnee bedeckte den Boden; die Mittagssonne thaute zwar die Oberfläche des Schnee's auf, allein in der Nacht fror diese wieder so stark, dass man auf ihr wie auf einer Eisschichte gehen konnte olne einzubrechen; und nur 300 Meter tiefer auf der Südseite regetirt die letzte Vertreterin der subtropischen Flora, die im tiefsten Winter nur leichter Frost berührt.

Oben, bei 2000 Meter Höhe ist offenbar die Grenze des Laubwaldes rereicht, der sich mit Eichen, Erlen und Weiden auf die warmen Thälcr und Südhänge zuriickzieht; Platanen steigen nicht empor zu dem Waldgebiete, das klimatisch unserem Mittelgebirge mit Eichenund Buchen-Vegetation sehr nahe kommen dürfte.

Dort erwachisen die grössten Jeffrey-Kiefern, die man bis jetzt berbachtet hat, wenigstens übertreffen meine Messungen - volle 65 Meter - jene de; Census-Reportes noch um 30 Meter; sie ist dort nicht weit von den Flussläufen in den besser bewässerten, sandig-lelmigen Böden, über ihr in dem trockeneren Theile fusst die Ponderosa mit 75 Meter Höhe; wie auch nördlich in der Sierra Nevada theilen das kühlere Terrain in engen 'Thälern und Schluchten und an Nordseiten die Tanne mit vollon 70 Meter Höhe, die '/uckerkiefer mit etwa gleicher Erhebung; unmittelbas an den Bergbächen die Libocedrus mit nicht weniger als 50 Moter; die sonnigen Plateau's der Hügel nit kiesigem, trockenem Boden krönt eine merkwärdige Art, die P'inus Conlteri mit dicken, 
geschwungenen Aesten, an deren Enden die enorm grossen und schweren Zapfen befestigt sind. Der ästige Baum bleibt in Höhenentwickelung gegenüber den vorigen zurück, erreicht aber zuweilen 45 Meter.

Eine kaum minder grosse Merkwürdigkeit als diese prächtige Baumvegetation war, dass an einer Menge von Stämmen ein brennrothes Plakat befestigt war mit der Aufschrift, Feuer anzulegen ist rerboten; schon der Wille ist lobenswerth, geholfen hat es freilich nichts.

Die dort etablirten Sägemühlen schätzen die Zuckerkiefer aus den schon erwähnten Gründen und wegen ihres tadellosen Schaftes am höchsten; ihr zunächst stcht Jeffrey's Kiefer mit schönem etwas röthlich gefärbtem Nutzholze; daran reihen sich die Gelb-Kiefer, die Libocedrus, zuletzt kommen Tanne und Pinus Coulteri.

Der Feịnde des Waldes, insbesonders der Schmarotzerpflanzen zu gedenken, wird sich bei den einzelnen Holzarten Gelegenheit bieten; der Urwald ist ja in dieser Hinsicht viel besser gestellt, als der Kulturwald - die Altholz-bewohnenden Pilze ausgenommen.

\section{a) Der subtropische Wald.}

Von immergrünem Laubwalde kann man kaum reden; ausgedehnte Waldungen aus immergrünen Eichen, aus dem californischen Lorbeer und anderen subtropischen Pflanzen gibt es nicht. Einzelne Eichen bilden zwar grössere, sehr licht stehende Waldungen; sie werfen die Blätter ab während der heissen Zeit im Sommer und mit der Regenzeit (November bis Dezember) beginnt allmählig wieder neues Leben; die Kiefernknospen fangen langsam an sich zu strecken; Schnee ist unbekannt, Frost nur sehr gering oder ebenfalls unbekannt; solches Klima kemnzeichnet die Subtropen, auch wo ihre typischen pflanzlichen Produkte fehlen. Vorherrschend ist die Prärie zwischen den beiden ParallelGebirgen, welche im suidlichen Californien in den Vegetationsmonaten nur $10 \mathrm{~mm}$ Niederschläge empfängt, während auf der Westkïste der Coast Rangc-Berge $12 \mathrm{~mm}$ Regen während der Vegetationszcit herabfallen. Dagegen ist die relative Feuchtigkeit während dieser Zeit auf der Prärie 42\%, an der Westlüste 75\%. Da gedeihen Palmen aller Art, wemn sie auch nicht Früchte zeitigen; einige australische Büume wie Eucalyptus, Aeacien, der mexicanische Schinus haben hier ihre zweite Heimat gefunden; Orangen, Citronen, Opuntien, Süiffrïclite aller Art hat man durch kiunstliche Bewässerung dem Boden entlockt.

Die einheimische Flora ist besonders durch zahlreiche Eichen vertreten, insbesonders Straucheichen, die oft Quadratmeilen ron heissen Südhiingen an Meere und höher im Gebirge ïberkichen. 
Das nördliche Californien, die nördliche Hälfte der subtropischen Zone ist ebenfalls prärieartig zwischen den beiden Gebirgsketten; rom Sacramento durchflossen, der zur Trockenzeit wasserarm, zur Regenzeit, Norember, mit stürmischer Fluth und brannem, erdebeladenem Tasser in's Meer stürzt, hat dieses Gebiet im Sommer (Mai bis August incl.) nur 45\% relative Feuchtigkeit mit $65 \mathrm{~mm}$ Regen, bei einer durchschnittlichen Temperatur von $22^{\circ} \mathrm{C}$; jührliche Temperatur $16^{\circ} \mathrm{C}$., tiefste Temperatur, bis jetzt beobachtet $-7^{\circ} \mathrm{C}$.; höchste $43^{\circ} \mathrm{C}$.; die Westhänge und Thäler des Küstengebirges, das Optimalgebiet der Küstensequoia, erhalten im Sommer weniger Regen, nämlich $45 \mathrm{~mm}$; dagegen enthält die Luft volle $80 \%$ relative Feuchtigkeit, bei $15^{\circ} \mathrm{C}$; jährliche Temperatur $12^{\circ}$; höchste Temperatur $32^{\circ} \mathrm{C}$, tiefste $-2^{0} \mathrm{C}$.

Quercus agrifolia Née, Coast live oak, californische Lebenseiche. Eine immergrüne Eiche, die im mittleren und südlichen Californien und dem spanischen Theile an trockenen, kiesigen nach Sïden gerichteten Berghängen heimisch ist; in hohen Lagen ein Strauch, wird sie unmittelbar am Meere rom Winde zur Seite geblasen und erhebt sich, mit Flechten dicht behangen, nicht über die vorliegenden, niederen Dünen; es gibt nur wenig Eichen, die in so ausgesprochen schlechtem Sandboden immerhin vegetiren, und respectable Durchmesser erlangen können; die Quercus dentata in Hockaido oder Eso, der nördlichsten Insel Japans, zeigt die gleiche Eigenthümlichkeit. Das Blatt ist dick, dunkelgrün, die Zähne in scharfe Spitzen ausge\%ogen ('Tafel III), die Früchte sind auffallend lang zugespitzt (Tafel II), die Innenseite der Schale ist mit langen, gelbbraunen Haaren bẽsetzt. Dor Fruchtbecher mit etwas glänzenden, hellen Schuppen besetzt. In isolirtem Stande aufgewachsen, ist der forstliche Werth des malerisch schönen, tief schattigen Baumes ein geringer; die Aeste weit ausgreifend und herabhängend mit dunkelgrünem Laube bedeckt; der Schaft mit stets glatter, hellgrauer Rinde bekleidet; das Holz, das leicht von Pilzen zersetzt wird, ist nach dem Typus der immergrünen Eichen gehaut und reigt, wenn gesund, ein specifisches Gewicht von 83; es wird als Brennholz benützt.

Quereus Wisliceni A. DC. wird ebenfalls in hohen Lagen \%ı aincm Stranche reduzirt, anf den trocken somnigen Hügeln am Westahhange der Sierra Nevada erwächst die Eiche zu einem Baume zweiter Crösse. Eichel sehr spitz mit grossschuppiger Cupula. Blätter and Frühte nach Tafel II und III. Die Rinde dieses Baumes ist 
eine sehr tiefrissige Borke. Das Holz zeigt ein specifisches Gewicht von 79. Der Baum ist nicht sehr häufig.

Quercus chrysolepis Liebm., Live oak, grossfüchtige Lebenseiche. Die grösste der immergrünen Eichen, bis 50 Meter sich erhebend; besonders in geschützten, sonnigen Oertlichkeiten auf nahrungsreichen Böden der Flüsse und Wildbäche, oft dort zusammen mit Umbellularia; in höheren und trockeneren Lagen dagegen zu einem Strauche redurirt; die Unterseite der Blätter selten goldgelb, meistens nur hell weisslich; Blätter hart, ganzrandig oder mit einzelnen Zähnen. (Tafel III). Keimlinge und junge Pflanzen tragen dicht mit scharfen Zähnen besetzte Blätter. In dieser bewehrten Jugendform erwachsen eine Menge ron immergrünen Bergeichen, insbesonders auch in Asien; es scheint, als ob damit die Natur ein Schutzmittel gegen abïsende Thiere hätte schaffen wollen. Früichte, die ich mit nach Japan nahm, entwickelten in dem heissen und feuchten Sommer dieses Landes junge Pflanzen mit drei, selbst vier Trieben; der Keintrieb erschien im Mai, der zweite (Johamnitrieb) sprosste Anfangs Juli, endlich der dritte Anfangs August, und Ende September lockte das warme Wetter bei vielen Pflanzen die Endknospe zu weiterer Entfaltung. Auch andere Eichen, z. B. die nordmexicanischen, zeigten das gleiche Verhalten. Die Früchte sehr gross, es sind die ausserordentlich dicken Becher auffallend (Tafel II). C. R. Orcutt gibt eine zweijährige Samenreife an; meine Exemplare, Ende Norember gesammelt, hatten alle reife Frïchte an den Trieben der letzten Vegetationszeit.

Rinde glatt, grau, Holz mit einem specifischen Gewichte von 35 nach den Angaben des Censusberichtes wohl zu leicht, da die untersuchten Stiicke durch Pilzmycel zerstört waren.

Quercus densiflora Hook. und Arn., Tan-bark-oak, Chesnut oak, Californische Gerbereiche. Dieser Baum, mchr Kastanie als Eiche, erreicht in den Sequoia-Waldungen der californischen Küste seine Maximalentfaltung mit 24 Meter Höhe; dort in den Thälcru, an den Flussläufen ist ihm guter Boden, reichliche Bewässerung und grosse Wiirme geboten. Werth hat diese Eiche durch ihren Tamningehalt der Rinde, worin sie ron keiner einheimischen Holzart an der pacifischen Kü̈ste ïbertroffen wird. Da sie bisher ohne Rücksicht auf Nachwuchs zur Nutzung gezogen wurde, so erscheint es nur natïrlich, dass ron allen Seiten eine baldigo Erschöpfung rorhergesehen wird; ron einer rationellen Aufzucht im Niederwaldbetricbe habe ich bis jetzt nichts vernommen. 
Der männliche Blüthenstand ist aufrecht, ährenförmig und dicht mit Blüthen besetzt; der Same reift im zweiten Jahre; der Baum gehört somit zu den Schwarzeichen; Fruchtbecher mit langen Stacheln besetzt (Tafel II), Blätter gesägt nicht gelappt (Tafel V) unterseits, und wenn jung, auch oberseits, ebenso Blattstiele und Triebe wollig behaart; Samenschale sehr dick und hart, innen filzig; Rinde eine sehr tiefe und breite, längsrissige Borke.

Eine nah rerwandte Eiche, die bloss Strauchform erreicht, findet sich im nördlichen Californien, im Gebiete der concolor grosse Flächen überziehend; ihre Früchte und Blätter sind auf Tafel II abgebildet als varietas montana mihi; ich habe jedoch die Ueberzeugung, dass die meisten sogenannten Strauchformen von Baumeichen sich als eigene Arten entpuppen werden.

Quercus oblongifolia Torrey. Eine immergrüne Eiche, welche die trockenen Hänge am Fusse der Berge bewolnnt und östlich bis nach Arizona und Mexico vordringt; Blätter und Früchte von dieser Art sind auf Tafel II wiedergegeben.

Quercus lobata Née verliert während der trockenen Herbstzeit ilıre Blätter; aber nach dem Regen (November) kommen zahlreiche neue Triebe, besonders an den Wasserreisern zum Vorschein; diese Blätter aber sind kaum halb so gross als die zu Boden gefallenen der Hauptregetationszeit; diese Eiche bildet ausgedehnte, licht gestellte Waldungen mit breitkronigen Bäumen am Fusse der Sierra Nevada und in deren unteren Thälern; die Bestände dieser Eiche sind ein vorziigliches 'Terrain für Vichweide; alle Nager und Wiederiküuer, Schweine und zahlreiche Vügel stellen den sehr grossen und ergiebigen Früchten nach. Die Cupula ist warzig ('Tafel II), grau. Die Blätter sind gelappt wie Tafel $\mathrm{V}$ zeigt. Rinde hellgrau mit Schuppen ron $10-20 \mathrm{~cm}$ Länge und $5 \mathrm{~cm}$ Breite. Sie wird eine der höchsten Eichen des Westens (30 Meter), ihr Holz kommt an Schwere und Güte dem der ̈̈stlichen Woisseichen gleich. An dieser Fiche beobachtet man häufig einen Hexenbesen (Exoascus?) mit abnorm verlängerten, hängonden Ruthen, wio auch von den Aesten bis zwei Meter lange Büsche eincr Mistol ( $V$ iscom sp. ?) herabhingen.

Auch Querens Douglasii Hook. Und A rn., Blue Oak, Blauciche, diurte als eine Vertreterin der subtropischen Zone aufgefasst werden; in den Vorbergen der Sierra Nevada heimisch, erscheint ihre Krone von forme mit cinem blanen Farbentone; Blätter ganzrandig 
oder gezühnt, wahrscheinlich fast immergrün (Tafel V). Von den Früchten kann ich nur eine Skizze nach dem Herbariummateriale in Cambridge geben (Tafel II). Das Holz von tiefbrauner Fürbung mit $6 \mathrm{~cm}$ Splintbreite.

Typisch dieser Zone ist

Umbellularia californica Nutt., Myrtle tree, California Laurel, Cajiput, Californischer Lorbeer, ein Bam, der auf Standorten mit grosser Luft- und Bodenfeuchtigkeit in den warmen Thälern der Bergflüsse sein Optimum erreicht; diese Verhältnisse findet der Baum nur in den engen Flussthälern der Sierra-Gebirge und am Westabhange des Küstengebirges; dort erwächst er bis zu 30 Meter; je trockener das Klima und der Boden, desto mehr sinkt der schöne Baum zu einem Strauche herab.

Das Blatt ist breit, lorbeerartig, würzig, die grünen Früchte olivenförmig mit braunem Kerne und dicken Samenlappen wie eine Eichel - eine vorzügliche Mast für die Schweine. Die Borke ist kleinschuppig, weit hinauf an den Stämmen kriecht dichtes Moos, in dessen Polster wieder die Rhizome zahlreicher Farne wurzeln. Das rorzügliche Holz mit einem specifischen Gewichte ron 65 ersetzt an der pacifischen Küste das Wallnuss- und vielfach auch das Eichenholz; das hellbräunliche Kernholz deckt ein $4 \mathrm{~cm}$ breiter Splint.

Castanopsis chrysophylla A. DC., Chinquapin. Dieser schöne immergrüne Baum erreicht seine Maximalentfaltung in den fenchten Hüngen des Küstengebirges ron Californien, steight aber auf den Westhängen des genannten Gebirges unter dem Schutze ron anderen Holzarten, besonders Kiefern und Douglasia's gegen allzu grosse T'emperatur-Extreme gedeckt im südlichen Oregon als Baum noch bis zur Passhöhe; als Strauch erreicht diese Art im südlichen Californien selbst dic kïhlere Region.

Den Baum zeichnet ein auffallend gerader Stamm nit diumen Seitenästen aus; Blätter oberseits dunkelgrün, unterseits goldgelb, harig (Tafel V); Knospen kahl, mit bewimperten Schuppenrïndern; Firuchte in Mehrzahl an einem gemeinsamen Sticle; Fruchtschale stachelig wie bei der östlichen Zwergkastanie. Das harte Holz ist zu Werkzeuggriffen verwendbar.

Alle diese Bamarten nehmen von der Bodenflïide der subtrupischen Zone nur einen kleinen Kaum ein; den grrüssten Theil umfasst die Präire; den zweitgrïssten, die niederen Hë̈gel und Vorberge, neupirt 
immergrünes Strauchwerk, das in umpassirbaren Dickichten weit herab bis nach Nieder-Californien sich fortsetzt.

Diese immergrüme Strauchflora ist sehr reich an Compositen, Rosaceen, 'Zygophyllaceen, Leguminosen, Hydrophyllaceen, Labiaten und anderen. Einige sollen hier specielle Erwähnung finden.

A retostaphylos pungens H. B. K., Manzanita, ein immergrüner, typischer Strauch der trocken-somnigen Lagen der Vorberge, oft ausschliesslich herrschend; von Oregon durch Californien und östlich bis Arizona verbreitet, entspringen an dem Wurzelstocke der Pflanze zahlreiche, knieförmig gebogene Sprosse mit völlig glatter, schön rother, glänzender Rinde; die sehr selten geraden Sprosse sind besondlers zu Spazier- und Peitschenstöcken sehr gesucht; junge Triebe mit Borstenhaaren besetzt; Früchte rothe Beeren; an günstigen Oertlichkeiten erreicht der Wurzelstock vor der Verzweigung einen Durchmesser von ïber 1 Fuss. (Tafel V.)

Qnercus dumosa Nutt. An der südcalifornischen Küste ein niederer Strauch mit dicht verflochtenem Gezweige, wird diese Eiche in höheren Lagen ein kleiner Baum; Blatt- und Fruchtgrösse sind sehr variabel (Tafel II). Nicht wenig trägt zu der Undurchdringlichkeit solcher Dickichte bei ein immergrüner Prunus mit ilexartigen Blättern, Prunus ilicifolia Walp. (Tafel III), sowie immergrüne RhusArten, theilweise giftig. Zahlreiche Pflanzen sind eingeschleppt worden; so mit den aus Australien gebrachten Sämereien gelangte der äusserst kleine Same von Nicotian a glauca, des Tabakbaumes nach Californien, wo er keimte und mit grösster Schnelligkeit sich über ganz Californien, so weit es der subtropischen Zone angehört, sich verbreitete. Das gelb blühende Unkrant ist ganz werthlos. Die A udibertia mit weissfilzigen Blättern, die schön rothfrëichtige Heteromeles arbutifolia Roem., dazwischen an sonnigen trockenen Lagen mehrere Opuntien, Cereus oder im Grase versteckte für den Sammler äusserst unangenehme Echinocactus, zahlreiche dickstämmige Yucceas und an den Flussläufen der Wildbäche aus der höhoren Region herabgewanderte, wïhrend der kühleren Monate blattlose Platanen geben dieser ganzen Flora ein eigenthïmliches Geprägre; so rasch ist im sürllichen Californion der Wechsel von Feuchtigkeit, dass an einem Berge an der Grenze von westlicher und östlicher Exposition fouchte Küstenflora und Vertreter der trockenen Prärie ineinandergreifen. 
Die Küste beherbergt aus der Klasse der Coniferen einige Arten, welche den subtropischen, immergrüen Laubwald in gewissen Oertlichkeiten ersetzen oder sich wenigstens dem Laubwalde in reichlicher Menge beigesellen; für die meisten Arten ist die Nordgrenze Californiens auch die Grenze ihrer Verbreitung.

Zu den wichtigsten gehört:

Die Küsten-Sequoia, Sequoia sempervirens Endl., Red wood, ausschliesslich auf das Coast Range-Gebirge, also die Region mit der grössten Luft- und Bodenfeuchtigkeit beschränkt, erfüllt dieser prächtige Baum die Thäler und Schluchten in geringen Erhebungen über dem Meere, begrenzt die Ufer der Bergflüsse und steigt in manchen Cañons, die nach Südwest gegen das Meer hin geöffnet sind, vielleicht bis in die Region der gemässigt-warmen Region empor; sein Optimum liegt aber durchaus in der subtropischen Vegetationszone. Feuchtigkeit der Luft, warme Tage, kühle Nïchte ohne Frost, das ist das Klima Jahr aus Jahr ein der Gegend, wo dieser Baum lebt. So durchtränkt mit Feuchtigkeit ist das kräftige, sandig-lehmige Erdreich, in dem der Baum seine Vollendung an Stärke und Standdichtigkeit erreicht, dass die Ausbringung der schweren Nutzstämme auf Schlitten geschehen muss, die mit breiten Kufen auf dem schlammigen Boden dahingleiten.

Der Zufall führte mich in ein solches Thal mit noch unberührtem Sequoia-Bestande, der zugleich in seiner gesammten Entfaltung einen guten Durchschnitt repräsentiren dürfte; eben war man daran, dic stärksten Stämme herauszuschaffen; der Boden war sandig-lehmig mit starker Humusschichte ron der beschriebenen Frische. Der Bestand selbst war fast rein aus Sequoia zusammengesetzt, nur einzelne Douglasia's fanden sich vor; als Unterholz fristete der 'alifornische Lorbecr, einzelne Acer circinatum ein mehr strauchartigés Dasein in dem tiefen Schlusse.

Aus der Messung einer grösseren Anzahl ron Stämmen ergab sich cin mittlerer Umfang ron 6,9 Meter; ein Modellbaum ron 6,7 Meter war aufzufinden und mass 84 Meter Höhe mit seinem schün wal\%enförmigen Schafte; ein anderer Baum mit 9,3 Meter Umfang hatte 88 Meter Höhe.

Unter Zugrundelegung ron 84 Meter Höhe und der gewiss \%u niedrig gegriffenen Formzahl ron 30 berechnet sich der Cubikinhalt des Modellstammes a uf rund 95 chm. Der durehschnittliche Abstand der Stämme des Bestandes betrug 9,6 Mnter, es standen somit auf einem Hektar etwa 140 Stämme, woraus sich cin Vorrath an 
Schaftholzmasse ron vollen 13300 cbm pro ha ergibt. Diese ungeheure Zahl rerliert aber das Unwahrscheinliche, das ihr auf den ersten Blick anhaftet, wenn man die Zeit berïcksichtigt, die erforderlich war, um solche Holzmassen aufzuspeichern; ein benachbarter Stock von etwa gleicher Dimension zeigte 680 Jahringe; der centrale Theil ron etwa $28 \mathrm{~cm}$ Durchmesser war zerstört; für diesen noch 20 Jahre gerechnet, geben rolle 700 Jahre als Alter des Bestandes. Die beigemischte Dougłasia bleibt hinter der Sequoia hier ziemlich zurück, erreicht aber immerhin 75 Meter Höhe und 2 Meter im Durchmesser.

Bestände mit 1200 cbm Holzmasse sind in Deutschland schon selten; die japanische Cryptomeria gibt nach Aufnahme durch Probeflächen im Norden Japans in guten Lagen 3000 cbm Holzmasse*) bei einer durchschnittlichen Höhe von 45 Meter und einem durchschnittlichen Umfange von 2 Meter. Solche Vorräthe wie die der KüstenSequoia duirften nur noch einige Bestände der Douglasia am Puget Sound angesammelt haben; die Riesen-Sequoia in der Sierra bildet keine geschlossenen Bestände; freilich sind ihre Dimensionen noch weit enormer als jene der Küsten-Seqnoia und wie sich erwarten lässt, auch ihr Alter viel höher.

Einzelne Bäume der Küsten-Sequoia erreichen ganz respectable Dimensionen. Bei Santa Cruz füllt die Sequoia ein herrliches Thal zusammen mit der Douglasia; mit grosser Energie sprossen immer wieder von Nenem junge Bäume trotz der Misshandlung empor.

In einem geschiitzten Thale steht ein Baum, der grösste der Serfuoia's, der erhalten wurde. Nach drei Messungen, die ich von versediedenen Seiten vornahm, ergaben sich 94, 96 und 92 Meter Höhe, so dass wohl 94 Meter der Wirklichkeit am näehsten kommt; bei 70 Mcter Hühe begannen die crsten grossen, grünen Aeste, dürre Aeste waren nicht vorhanden; der Unfang in Brusthöhe betrug 15 Meter, iibor der Anschwellung in 2 Meter Höhe noch 14,2 Meter. Die als T'itelbild beigegabene Skizze des Bammes zeigt, wie die Rinde eine ticfrissige, gedrehte Borke darstellt, wahrscheinlich entspricht im Innern dieser Bonke audh cine gedrohte Anordnung der Holzfasem, doch sind Bänme mit vällig rertikalen Rissen überwiegend. In die dicke, weiche röthliche Bonko spiesst jeder Besucher seine Visitenkarte; Reclamen frhlen natürlich auch nicht und las feuer hat wohl sehon mehmals an drin Stammo hinaufgeleckt, bis jetyt aber nur die äussere Borkenschichte verkohlt.

*) Nach Mittheilung des Herm D)r. Nakaunuma zu Tokio. 
Die Gattung Sequoia theilt mit der sehr nahe verwandten Gattung Cryptomeria die Eigenthümlichkeit, dass Bäume, auch in hohem Alter abgeschnitten, zahlreiche Stockausschläge entwickeln können; aus den Stöcken des oben erwähnten Sequoia-Bestandes, die doch 700 Jahre alt waren, erfolgten noch zahlreiche Ausschläge, eine Eigenschaft, die auch der lebende Stamm an seinem Wurzelstocke zeigt.

In der Nïhe des oben erwähnten Riesen stehen mehrere Gruppen ron Sequoien, ron denen ich die als Captain Ingersolls Cathedral bekannte abgebildet habe. Der Hauptstamm in der Mitte der Gruppe entsandte im Laufe der Jahrhunderte aus seiner enorm vergrösserten

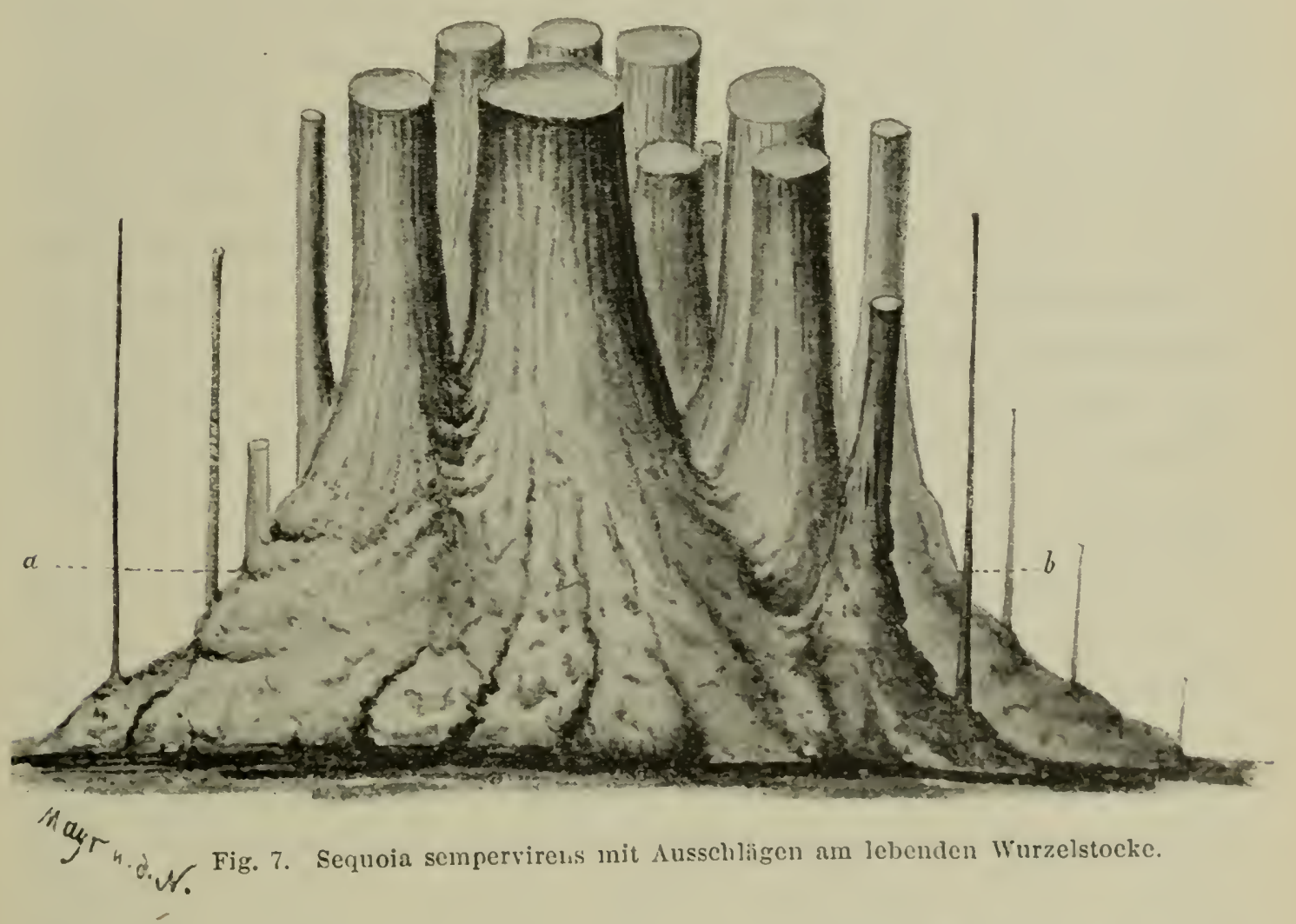

Stammbasis zahlreiche Ausschläge, von denen der stärkste bereits einen Umfang ron etwa 6 Meter in 10 Meter Höhe besass, während 7 ron seiner erwachsenen Jugend mit 3 Meter Unfung ummittelbar 1 m den alten Stamm sich gruppirten.

Fast von jedem Alter waren Stockiusschläge rorhanden, nur eine geringe Zahl haben auf der beigegebenen Skizze Plat\% gefunden; selhst solche von nur ein paar Jahren entsprossten dem Stamme und zwar nahm ihre Grösse und ihr Alter mit der Entfernung vom Hauptstamme ab; die Jüngsten sassen da, wo der Wurzelhals cben aus der Erde 
hervortrat; bei der bezeichneten Linie, etwa 2,5 Meter Höhe, mass der Wurzelhals 21,8 Meter Umfang. Die in einem Kreise stehenden ca. 80 Meter hohen Riesen, Three sister's and General Fremont sind mit grosser Wahrscheinlichkeit die Stockausschläge eines längst gefallenen. und rermoderten Hauptstammes; von den jetzt ausgebrannten und wohl bald zu Boden stürzenden Kolossen erheben sich keine Stockausschläge mehr.

So gross ist die Wiederausschlagsfähigkeit dieser Holzart, dass selbst uralte, dicke Aeste sich bei Verstïmmelung oder plötzlicher Freistellumg noch mit neuen Trieben bedecken.

Die Früchte reifen, nach den amerikanischen Florenwerken, im zweiten Jahre; die Gattung Sequoia dürfte sich hierin genau wie die nahverwandte Gruppe Cryptomeria verhalten; die jungen Zäpfchen wie auch die männlichen Blüthen sind schon im Herbste vorgebildet, die Bestäubung und Befruchtung findet aber erst im Frühjahre statt, worauf in demselben Jahre die Reife des Zapfens und Samens eintritt; ebenso rerhalten sich auch Cupressineen und im Grunde genommen die Mehrzahl aller Bäume, da in dem der Befruchtung und Samenreife vorhergehenden Jahre die Organe hiezu in der Regel bereits vorgebildet sind, ohne dass man deshalb sagt, dass die Früchte der betreffenden Pflanzen im zweiten Jahre reifen; bei Samen mit wirklich zweijähriger Samenreife, wie Schwarzeichen, Kiefern und anderen sind bekanntlich Befruchtung und Reife auf zwei Jahre vertheilt.

Die junge Pflanze beginnt mit zwei Cotyledonen, die ersten Nadeln tragen weisse Streifen auf der Unterseite; im ersten Jahre erreicht die Pflanze im Walde nur etwa $2 \mathrm{~cm}$ Höhe; im folgenden Jahre wächst sic rasch; die flachen Nadeln an den Seitentrieben mit zwei breiten weissen Streifen unterseits und zwei schmalen oberseits; am Längstriebe sind die Nadeln auf halbe Lünge am Triebe angewachsen und ohne Streifen; an den blühenden Zweigen werden die Nadeln auffallend jenon der Sequoia gigantea in Gestalt ähnlich, behalten aber zwei woisse Streifen bei. Schon frühzeitig entwickelt sich wie bei allen Riesenbäumen eine sehr breite Basis, welche genügende Standfestigkeit gribt; der Stanm spitzt sich dann sehr lasch lregelförmig zu.

I) Splint umfasst $3-5 \mathrm{~cm}$, das kirschrothe Kernholz hat dem Baume den cinheimischen Namen ,rothes Hol" gegeben.

Das Hol\% mit engen und gleichmässigen Jahrringen ist Nutzhol\% allerersten Ranges; es vereinigt in sich alle in Amerika beliebten Vorziige eines grossen Nutzholzes, nämlich Leichtigkeit (specifisches Gewicht 42), leichte Bearbeitungsfihigkeit und T'ragfestigkeit, Vorzïge, 
welche auch die Weymouths-Kiefer im Osten bietet; dazu kommt für die Sequoia auch noch grosse Dauer des im Boden rerwendeten Holzes.

Anatomisch ist das Holz Sequoia von dem der Cryptomeria nicht zu unterscheiden, ein weiterer Grund, der vielleicht die Cassirung der Gattung Cryptomeria rechtfertigen würde. Das Holz besteht vorzugsweise aus Tracheiden, vereinzelnt ist Längsparenchym mit kirschrothen harten Kugeln der Kernsubstanz erfüllt, die Markstrahlen bestehen durchaus aus Parenchymzellen, die dickwandigen Sommerholzorgane sind reichlich mit gehöften T'üpfeln an den Tangentalwänden versehen; Harzkanäle fehlen im Holze ganz.

Die Küstensequoia liefert fast ausschliesslich alles Bauholz fül Californien, ausserdem dient es zu Schindeln, Telegraphenpfosten, Eisenbahnschwellen, zu Wassereimern und Särgen; besonders werthvoll sind Maserbildungen. Von Californien aus geht das Holz zersïgt per Bahn weit in das Innere des Landes nach den holzarmen Staaten, selbst bis nach Texas; ebenso wird eine grosse Menge auf Schiffe verladen und kam einst sogar bis Japan.

Dass bei dem grossen Bedarfe an diesem werthrollen Material die Vorräthe rasch zusammenschmelzen, lässt sich denken; schon heute ist der Mangel allerorts fühlbar und die Douglasia- und Gelbkiefernhölzer von Oregon dringen mit Erfolg in das bisherige Monopolgebiet der Sequoia ein.

Cupressus macrocarpa Hort., Monterey Cypress, Monterey Cypresse. Diese merkwürdige, werthrolle Art steht an den gefestigten, granitisch-felsigen Ufern des Stillen Oceans, so dass jahraus jahrein die salzige Brise durch ihre Zweige streicht. Der heftige Wind, ständig ron einer Seite wirkend, drückt sie zur Seite und verhindert die Ausbreitung von Aesten nach dem Meere hin; viele alte Bäume liegen ganz darnieder und nur die Kŕrone mit einem Gipfel erhebt sich. Del feine Meeresgischt tropft ständig von den sparrigen, mit flatternden Bartflechten behangenen Aesten, deren Unterseite eine rothe Alge überzieht (Lecanora subfusca ?).

Diese Cypresse ist ein riemlich seltener Baum und auf wenige Punkte südwestlich ron San Francisco beschränlit; aber an der ganzen pacifischen Küste gibt es wohl jetzt lieinen Garten, der nicht diesen Baum als Schut\%- und Schattenspender enthält; seine Raschwiichsigkeit und dichte Verzweigung eignen ihn hiezu rortrefflich. Ja man laat diesen Baum, der aus einer Oertlichkeit stammt, in der Frost cine völlig unbekannte Eirscheinung ist, sogar in frostreiche Gegrenden gebracht, bis hinauf nach Oregon; er wächst dort nur langsamer, 
gedeiht aber eben so sicher; selbst bei Tokio in Japan, wo während vier MLonaten des Jahres fast alltäglich Frost auftritt und das Thermometer bis zu - $10^{\circ} \mathrm{C}$. sinkt, bleibt der Baum unverletzt und raschwüchsig - eine für Anbauversuche sehr beachtenswerthe Erscheinung.

Die junge Pflanze zeichnet ein eigenthümlicher Aufbau ihrer Acste aus, welche auffallend lang in eincm spitzen Winkel pfeilgerade rom Hauptstamme abstehen; die beigegebene Figur einer erwachsenen Crpresse lässt diess ebenfalls erkemnen. Die Rinde des erwachsenen Baumes ist eine sehr schmale mitteltiefrissige Borke; der Splint $(2,5 \mathrm{~cm}$ breit) ist hell, der Kern röthlich.

An der Küste Monterey, einem der schönsten und klimatisch berorzugtesten Seebïder; die ich kenne, hat man die Monterey-Cypresse zur Festigung des Sandes am Strande benuitzt; man hat sie mit der Monterey-Kiefer zusammen bis hart an die Brandung hingepflanzt, so dass starke Wellen oder Hochfluth das salzige Wasser bis in die Pflanzung werfen; dennoch steht sie vortrefflich, da wähırend der trockenen Zeit, obwohl ummittelbar am Neere gelegen, die Pflanzung durch ein Röhrensystem künstlich bewässert werden kamn.

Der Same keimt sehr leicht und schnell und erhält sich mehrere Jahre keimfähig; die junge Pflanze wächst sehr rasch, die Schuppenb) Butter des Haupttriebes abwechselnd gegenständig und herablaufend; Sritentriebe vicrkantig, alle Schuppen gleich geformt mit zwei Rinnen auf dem Rücken; '/apfen rundlich mit 2,5 em Durchmesser, auf einem dicken Sticle sitzend und nach abwärts gekrümmt.

Cupressus Goveniana Gord. ist eine ebenfalls sehr béschränlit vorkommende Cypresse der südlichen californischen Küste, wo sie an den Flussufern bis zu 15 Metern Höhe sich erhebt; sie überzieht als nicderer Strauch die heissen felsigen Berghünge. Im Bau der Narlelschuppe ist sie der vorigen Art sehr ähnlich, diese tragen aber an ihrer Rürckenseite keine oder nur e ine rinnenförmige Vertiefung. Zalpfen 2,5) ('m, rundlich etwas aufwiirts gerichtet; Same klein, schwarz mit holler Ansatzstello.

('upressus Macnabiana Murr. ist im südlichen Califomien heimisch, wo der Baum nur geringe Dimensionen erreicht, meist sogar Strauch bleibt, Yanfen 2 (m lang, rundlich, auf einem dimnen, kurzen Sticeso, Schilder nicht runzelig, sondern glatt, grau glänzend, Hauptund Seitcntricbe der vorigen Art ähnlich, aber Rücken der Blätterschuppen stark gokielt und am Ende des Kieles eine Oeldrüse. 


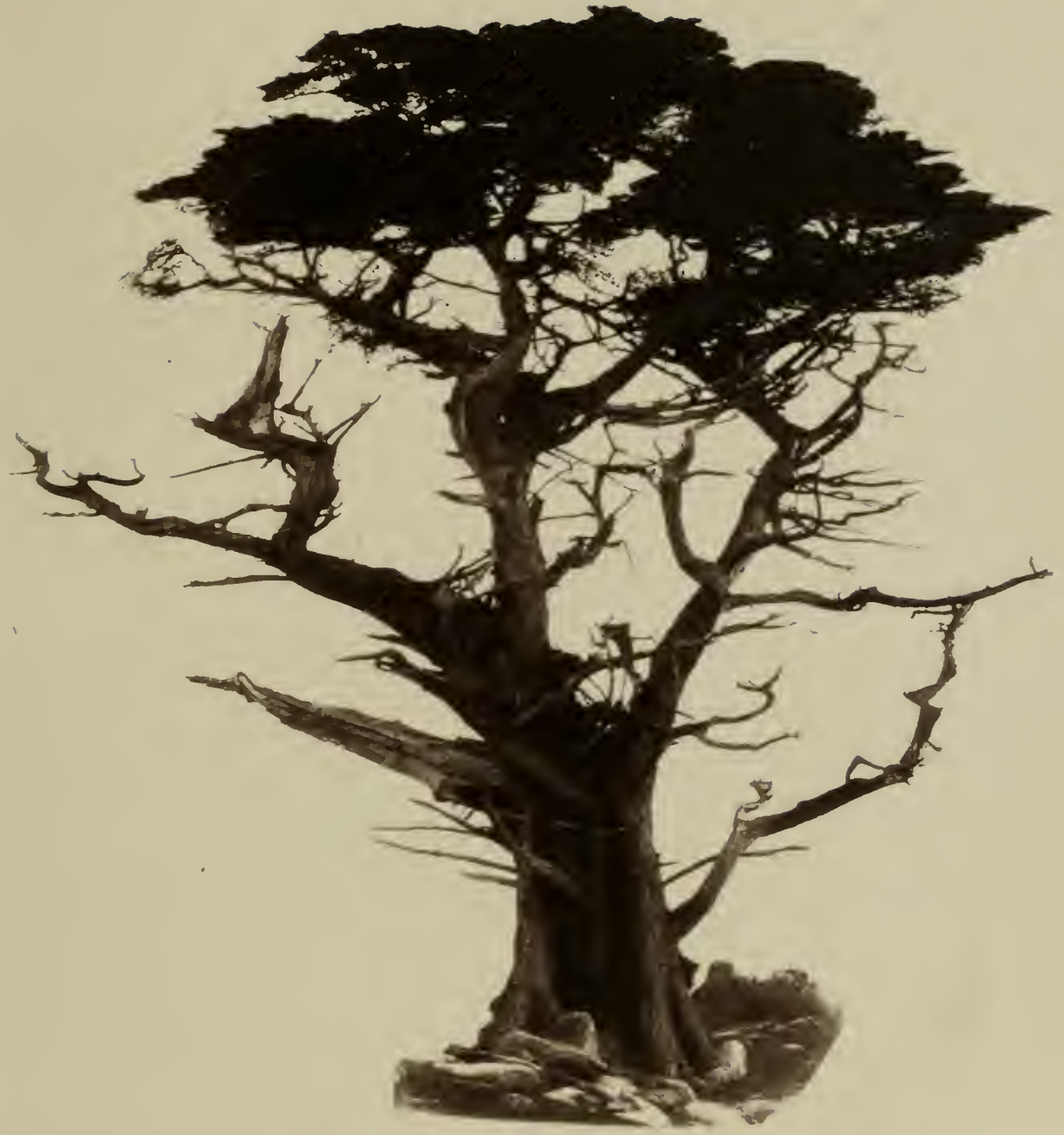

Fig. 8. Monterey-Cypresse. Cupressus macrocarpa IIort. 

Hier mag sich der Californische Wachholder Juniperus californica Carr. anschliessen, der in den trockenen, somnig-felsigen Hügehn bis zu 9 Meter Höhe erreicht; das Holz dient zu Zäunen und als Brennholz; Keimling mit 5 Cotyledonen.

Auch Torreya californica 'Torr., die an den West-Abhängen der Sierra Nevada bis zu 1500 Meter emporsteigt, muss dieser Region zugezählt werden; die Nusseibe ist auf die feuchten Standorte in der Nähe von Flüssen beschränkt und ziemlich selten. Thr Holz gilt für sehr dauerhaft.

Pinus insignis Dougl., Monterey Pine, MontereyKi efer, auf die sandigen Böden der californischen Küste beschränkt, lehnt sich bei San Francisco an dic Monterey-Cypresse nach dem Binnenlande zu an. Diese Kiefer wird jetzt in ganz Californien so häufig angebaut, wie die Cypresse, mit der sie die Raschwüchsigkeit theilt; die lange Vegetationszeit, die ilnr dort geboten ist, lässt ihr Wachsthum kaum zum Stillstande kommen; schon nach dem Regen, im Norember, streckt sie wieder ihre langen Knospen; insbesonders hat sie sich anch zur Festigung des Dünensandes an genannter Küste als sehr werthroll erwiesen; wie weit sie, von der Heimat entfernt, mit kaltem Winter und Frost sich verträgt, darïber fehlen Erfahrungen; einjährige ca. $20 \mathrm{~cm}$ hohe Pflanzen haben in Japan völlig unbedeckt Fröste bis zu $10^{\circ}$ C. unter Null ohne Schaden überstanden, freilich bei grosser Luftfeuchtigkeit.

An zapfentragenden Exemplaren beträgt die Nadellänge $10 \mathrm{~cm}$, an jungen Exemplaren bis zu 15; drei Nadeln zusammen in einem Kurztriebe; Knospenschuppen braun, nicht ausgefranst, anliegend, in der Regel mit weisslichem Harze überzogen. Junger Trieb braun und glatt; freistehende Excmplare sehr stark in die Aeste wachscnd und wie bei der Cypresse sind dieselben auffallend lang und gerade ausgestreckt; an sehr kräftigen Trieben kamn man vier nadellose Stellen erkemnen, nämlich unmittelbar an der Basis: hier fehlen stets zapfen und Triebe; etwas unter der Mitte: hier sitzen in der Regel Zapfen, oft bis zu sechs in einem Quirl beisammen, etwas oberhalb der Mitte mit Knospen und Seitentrieben und zuweilen Zalpfen; endlich in etwa Zweidrittel der Trieblänge: hier ebenfalls Zapfen, zu mehreren im Quirl. Junge Zapfen schwach nach unten gekiimmt, reife Zapfen durchschnittlich $12 \mathrm{~cm}$ lang und $8 \mathrm{~cm}$ breit und dürr, wenn offen. Grösste Länge selbst $16 \mathrm{~cm}$. Apophyse auf der Oberseite des Zapfens 
mit dicken, nach oben gekrümmten Fortsätzen und feinen Spitzchen. Dadurch erhält der Zapfen eine nach abwärts gerichtete Krümmung. Der reife Zapfen hellbraun, glänzend, Same nach Tafel VII. Borke schmal, tiefrissig, Stamm astreich. Im engen Schlusse erwachsen diese Kiefern zu schlanken Stangen, die aber in ihrer Heimat voll von Beulen sind durch ein Viscum, das auf ihnen lebt.

Nach der Anatomie des Holzes und dem Aufban der Triebe und Nadeln, gehört diese Kiefer zur Section Taeda. Das Holz ist sehr rasch erwachsen, breitringig, hat einen Splint von $18 \mathrm{~cm}$ Breite, einen röthlichen Kern; es ist nur Brennholz.

Noch einige andere Kiefern gehören, wenigstens dem Optimalgebiete ihrer Verbreitung nach, zu den Vertretern des subtropischen Laubwaldes; es ist dies vor allem

Pinus tuberculata Gord., Knob Pine, Warzenkiefer. An trockenen, kiesig-sandigen Südhängen von 300-1500 Meter Erhebung in der Sierra Nevada und dem Küstengebirge erwächst diese Kiefer in sehr günstigen Oertlichkeiten selbst bis zu 22 Meter Höhe, in der Regel bleibt sie jedoch viel niederer und oft sogar stellt sie einen aufrechten Strauch dar; die vielfach ungleich schnell sich entwickelnden Nadeln haben eine Länge ron $7-15 \mathrm{~cm}$, durchschnittlich $11 \mathrm{~cm}$; drei stehen zusammen in einem Kurztriebe. Knospen lang zugespitzt, braun glänzend, etwas mit Harz zusammengehalten. Zapfen oftmals nach derselben Anordnung wie jene der Monterey-Kiefer, in einem oder zwei Quirl an einem Jahrestriebe, zwei bis sechs in einem Quirl vereinigt an $1,5 \mathrm{~cm}$ Stielen im ersten Jahre. Im zweiten Jahre stark nach abwärts gekrümmt und durch das kräftige Dickenwachsthum des Haupttricbes, an dem die Zapfen vorzugsweise sitzen, erscheinen die Zapfen im zweiten Jahre oft stiellos. Zapfen selbst gekrümmt, auf der Oberseite mit dicken, etwas gebogenen Apophysen; Apophyse selbst nach zwei Seiten hin mit schneidigen Kanten; Nabeldorn ebenfalls breit, festsitzend, ähnlich wie bei der Coulteri ('lafel VI). Die Zapfen wechseln an Grösse von 9-12 cm Länge und etwa $5 \mathrm{~cm}$ Dicke, wenn geschlossen.

Diese Beschreibung passt für die Tuberculata, welche ich im San Bernardino-Gebirge sammelte; sie weicht ziemlich bedeutend ab von rler aus nördlichen Gegenden kommenden, insbesonders zum Beispicl im Universitätsgarten bei San Francisco kultivirten Kiefer. Die Ziapfen dieser sind auch ausgewachsen an $1 \mathrm{~cm}$ langen Stielen gefestigt, ahwärts dem Stamme angerliöckt, auffallend gross, bis 16 em lang; die 
Apophyse nicht zweischneidig, sondern kegelförmig mit rundlichem Querschnitte; der Dornfortsatz stets fein und leicht abbrechbar (Tafel VI); auf der Unterseite sind die Apophysen glatt; anch die Rinde harmonirt nicht zwischen den beiden Formen; da die Berkley'sche Kiefer ron Professor Sargent als die wahre tuberculata bestimmt wurde, so erseheint die San Beruardino-Form als Tarietät mit auffallend stechenden Zapfen und mag dieselbe deshalb als Pinus tuberculata $v$. acuta angesehen werden (Tafel VI).

Ihrem ganzen anatomischen Bau nach gehört die werthlose Kiefer zur Section Taeda.

Pinus muricata D. Don, Obispo Pine, Obispo-Kiefer. eine zweinadelige Kiefer, die bis zu 36 Meter sich erhebt; diese Dimension erreicht sie aber nur ausnahmsweise, gewöhnlich ist sie nicht höher als 15 Meter; sie lebt in nassen, dem feuchten Südwinde ausgesetzten Oertlichkeiten oder auch auf armen kiesig-sandigen Böden. an in das Meer abfallenden Hängen des Küstengebirges im südlichen Californien. Die Nadeln haben eine durchschnittliche Lünge ron $17 \mathrm{~cm}$, sind steif und hart; die Knospen kurz, braunschuppig, Schuppen anliegend und mit Harz zusammengeklebt; junge Triebe rothbraun; der Zapfen sitzt im ersten Jahre auf $1 \mathrm{~cm}$ langem Stiele, aufrecht mit senkrecht abstehenden, kräftigen, stacheligen Spitzen; die reifen Zapfen oft in zwei, selbst drei Quirlen übereinander an einem Triebe sitzend wie bei den vorhin genannten Kiefern. Der Zapfen steht in Form und Grösse dem der Pinus serotina im Osten sehr nahe, $6 \mathrm{~cm}$ lang und $4 \mathrm{~cm}$ breit, wenn geschlossen. Apophyse nicht herrortretend; Spitzchen gerade abstehend, scharf stechend. Same nach Tafel VIII. Die Rinde des erwachsenen Baumes ist eine sehr tief-rertikal und mittelbreit-rissige Borke; der raschwüchsige Baum bildet $7 \mathrm{~cm}$ Splint und einen nur schwach schmutzig, rüthlich gefürbten Kern. Niah der Anatomie des Holzes gehört diese zweinadelige Kiefer zur Section Banksia.

Die pflanzengeographisch merkwürdigste, wenn auch forstlich unwichtigste von allen westliehen Kiefern ist entschierlen

Pinus Tor Teyana Parry, 'T'orrey's Kiefer; diese Kiefer ist eine sehr seltene Art, deren Existenz anf etwa 200 Individuen beschränkt ist*): an der lehmig-sandigen, hügreligen Kü̈ste des südlichen Cali-

*) Soeben lese ich, dass diese Kiefer auch auf einigen kleinen Inseln ror der californischen hüste entdeckt wurde. 
forniens, wenige Stunden von San Diego, bewohnt diese Kiefer die gegen das Meer sich öffnenden Schluchten, die Hügelköpfe und etwa noch das landeinwärts liegende, mit niederem Buschwerk bewachsene Gelände. So lange die Kiefer existirt, hat sie in ihrer Heimat unmittelbar am Meere kein Frosthauch berührt; die Samen, die ich von dort mit mach Japan brachte, keimten rasch und entwickelten cine sehr kräftige Pflanze mit drei Nadehn in einem Kurztriebe als Abschluss für das erste Jahr; an 1. Dezember zeigte auf dem kahlen Boden, auf dem die Sämlinge völlig schutzlos standen, das Thermometer - $8^{\circ} \mathrm{C}$; es war dies der erste Frost, der die benachbarten hohen, ebenfalls im Freien verbliebenen Bananen völlig versengte; von da an wiederholten sich die Fröste fast täglich, mehrmals sank das Thermometer bis zu $-12^{\circ} \mathrm{C}$, die Pflanzen blieben völlig unberührt.

Diese Kiefer ist ein kurzlebiger, ästiger Baum, oft ganz am Boden liegend und bis jetzt noch von geringem forstlichem Werthe; die am Boden liegenden Aeste schlagen Wurzeln, ein Umstand, der vielleicht zur Nutzbarmachung des dortigen, völlig holzleeren Küstenstriches benutzt werden könnte.

Die 'Torrey'sche Kiefer hat fünf ausserordentlich starke, steife Tardeln in einem Kurytriebe, von durehsehnittlich $26 \mathrm{~cm}$ Länge und $2 \mathrm{~mm}$ Dicke; Knospen lang, Schuppen lang zugespitzt, anliegend, am Rande ausgefranst, ohne Harz; junge Triebe weissbereift; die junge Rinde glatt, lellgran, bleibt lange Zeit glatt, später wird sie kleinschuppig, bleibt aber hellgrau. Borkenschuppe $3 \mathrm{~cm}$ breit, $5-10 \mathrm{~cm}$ lang; der '/apfen sitzt am kurzen Stiele, ein wenig nach abwärts gekehrt mit durchschnittlich $13 \mathrm{~cm}$ Länge und $10 \mathrm{~cm}$ Breite, wemn geschlossen und $13 \mathrm{~cm}$ Breite, wenn offen; Apophyse vorstehend mit sehr breit aufsitzender Spitze.

Der reife frische '/apfen dunkel violettroth; wenn trocken, braun glänzend; Same schr gross, T'afel VII.

I)urch den Aufbau und die Anatomie des Holzes steht der Bamm der Pinus arizonica am nächsten, weshalb ich diese beide in die nene Section "Pseudestrobus" vereinigt habe. Der merkwürdige Baum ist durch Gesetze zwar vor der Ausrottung geschützt, zahlreiche junge Bäume kommon zwar jetzt ïberall empor, allein ein einziges Fener in den otwa cinen Meter hohen Gestrüppe kann alle Sämlinge zerstioren, die erwachsonen Exemplare versengen und mithin die Species vornichten*); wie leicht wäre es durch Ausstufen der Samen, durch

") Soeben erfahre ich, dass die 'Torrey'sche Kiefer auch auf einer der kleinen Inseln an der californischen Küste gefunden wurde. 
Kinder zum Beispiel, um ein paar Dollars die Verbreitung des Baumes an der hügeligen, schluchtenreichen Küste zu begünstigen und damit die seltenste aller Kiefern zu erhalten. Das Holz mit zweierlei Parenchymzellen, dick- und dïnnwandigen, in den Markstrahlen.

Eine, wenigstens auf Uniongebiete, ebenfalls seltene Art ist

Pinus Parryana Engelm., Piñon, Parry's Kiefer. Sie ist im südlichen Californien nur vereinzelnt anzutreffen, ist aber in Nieder-Californien, auf mexicanischem Gebiete an trockenen Höhenrücken und Hängen unweit von der Küste ziemlich zahlreich; wie alle Angehörigen der Section „Parrya" ist sie stets isolirt, nie Bestïnde bildend, ein nur bis 9 Meter hoher Baum oder besser Strauch, der mehrere Jahre seine Benadelung beibehält. Zwei Nadeln finden sich zusammen in einer Scheide, an ihrer Berührungsfläche sind sie weisslich. Nadeln 2,7 cm lang; der reife Zapfen erscheint, wenn offen, breiter als lang, nämlich $6: 5 \mathrm{~cm}$. Apophyse gelb, glänzend, schnabelförmig erhaben und nach rückwärts gebogen mit sehr kurzem Spitzchen; der Same liegt, wie bei allen Kiefern dieser Section, ohne Fliigel, tief in der Fruchtschuppe von einem häutigen Fortsatze derselben festgehalten; meist ist nur ein kräftiger Same im Winkel der Schuppen entwickelt. Same nach Tafel VII. Holz nach dem Typus dieser Section gebaut; sie erhebt sich nie zu solchen Elevationen, wie die nah verwandten, schon früher erwähnten mexicanischen Arten.

Pinus Sabiniana Dougl., Digger Pine, Sabins Kiefer. Im Gebiete der immergrünen Ejchen heimisch, auf den Hängen der dem Mecre exponirten Küstengebicte, sowie an den Vorbergen der Sierra Nevada bis zu einer Erhebung von 1000 Meter im südlichen Californien; der Baum ist sehr zahlreich den Eichen beigemengt, bildet nie zusammenhängende Wälder und fehlt strichweise in der sierra ganz. Der Zapfen dieses Baumes ist in seiner Grösse sehr variabel: kugelig, wenn offen, so dick als lang von 10-20 cm Apophlyse wie bei der Coulter'schen Art stark schmabelförmigr verlängert und in eine dicke, stachelige Spitze auslaufend, Zapfen auf $4 \mathrm{~cm}$ langem Stiele abwärts hängend, Benadelung hellgriin, so dünn und durehsichtigr, dass alle \%apfen eines Baumes ron einem Standpunkte aus sichthar sind.

Ton ferne glaubt man cher einen Oelbaum orler eine Wride. nicht aber einen Nadelholzbam ror sich zu haben, so atufiallend erinnert der Aufban des Bammes an cin Laubhol\%: schon wenige Moter äher

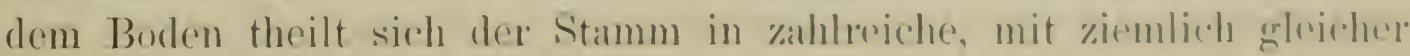


Stärke aufstrebende Aeste, die sich wierler vertheilen und verästeln; trotzdem erhebt er sich in günstiger Lage bis zu 30 Neter, aber gerade Nutzstücke sind aus dem Schafte nicht zu gewinnen, dagegen ist sein Holz als Brennmaterial sehr gesucht.

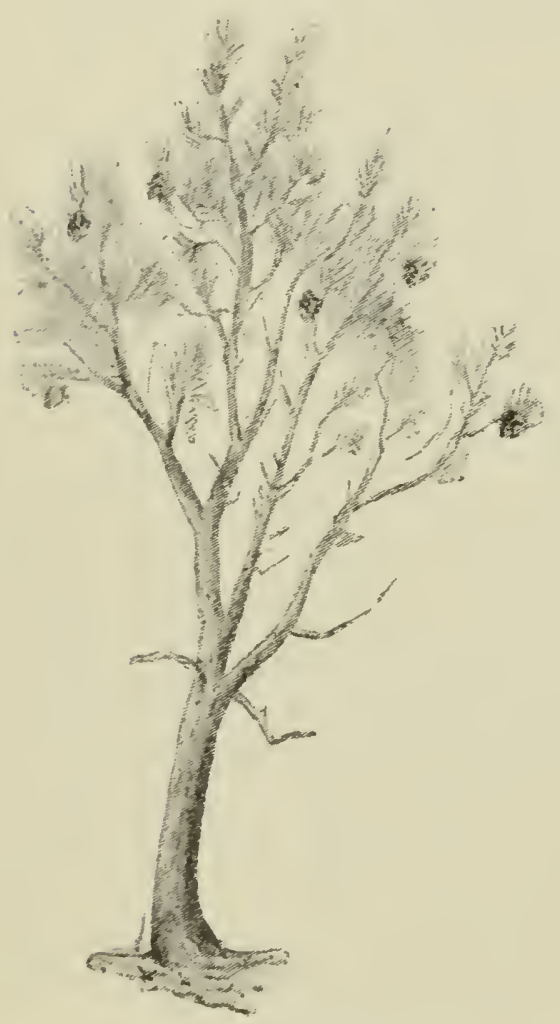

Fig. 9. Sabin's Kiefcr, l'inus Sabiniana. Alte Bänme bedeckt eine sehr breite, rothbraune, tiefrissige Borke. Der Aufbau und die Anatomie des Holzes stellen den Baum zur Section Taeda. Im San Bernardino-Gebirge trifft man oberhalb der Warzenkiefer (1000 Meter), ehe man noch die Gelbkiefer erreicht, in engen, heissen, nach Süden offenen Thalschluchten cine Douglasia, die von Engelmann als Pseudotsuga Douglasii var. macrocarpa beschrieben wurde; es gehört diese Douglasia in die Region der immergrünen Zwergeichen, dem Grenzgebiete der subtropischen und gemässigt-warmen Region an. Das Klima dort ist warm und ziemlich trocken, erst wenn man die Nordseite der Berge erreicht, erscheint mit der grösseren Feuchtigkeit und gemässigten W:ärme der spärliche winterkahle Laubwald mit der

ganzen Fülle des Nadelwaldes. Dass das Klima zur Erzeugung dieser grossen Früchtevarietät beigetragen hat, kann man nicht gut behaupten, denn die Dimension des Baumes bleibt beträchtlich hinter den nördlicher wachsenden Donglasien zurück. Ueberdiess bieten die Berge Arizona's dieselben klimatischen Bedingungen, dort aber ist nur eine ganz kleinfrüclutige Art der IJouglasia zu finden, die mit Recht als Varietait der Kiistenform gilt.

Was mich besonders reranlasst, die grossfrüchtige Form als eigene Art mit dem Namen

Pseudotsuga macrocarpa mihi einzuführen, sind nicht nur biologische Vorschiedenheiten. Jch gebe deshalb cine ausführliche Beschreibung der Vorschiedenheiten der grossfrürditigen Douglasia, der gemeinen I)ouglasia (Psendotsuga Donglasii) ron Oregon, Washington und Ilontana, sowice der Varretit glatuca ans Colorado und Arizona. 
Die Nadeln der grossfrïchtigen Art sind an Zapfen tragenden Exemplaren spitzer als die der gemeinen Douglasia und länger und zarter als die der glauca. Die Kuospe doppelt kegelförmig, mittelgross, Knospenschuppen glänzend braun, ohne Fransen am Rande; die Zapfenschuppen am Rande kahl, sehr gross, Blüthenschuppen dreitheilig, der mittlere Theil ist nur wenig länger als die Zapfenschuppe; die Unterschiede lassen sich auf der Tafel VI besser erkennen als beschreiben.

Die Zapfen sitzen auf $2 \mathrm{~cm}$ langen und $8 \mathrm{~mm}$ dicken Stielen, durchschnittliche Länge $13 \mathrm{~cm}$, durchschnittliche Breite, wenn offen, $6 \mathrm{~cm}$; die grössten Zapfen der gemeinen Douglasia aus dem Optimumgebiete im Puget Sound und Oregon erreichen nur $8 \mathrm{~cm}$ Länge und $3 \mathrm{~cm}$ Dicke; die Zapfen der glauca-Varietät, sowie der Uebergangsform ron letzterer zur gemeinen in Montana sind $5 \mathrm{~cm}$ lang und $2,5 \mathrm{~cm}$ dick. Die Grössenverhältnisse ergeben sich aus der beigegebenen Tafel VI. Es besteht keine Uebergangsform ron der grossfrïchtigen zu der gemeinen Douglasia. Parallel den Verschiedenheiten in der Zapfengrösse verhalten sich die Samen, die auf Tafel VIII abgebildet sind.

Dazu kommen noch folgende entscheidende Merkmale: die jungen Triebe der grossfrüchtigen Art sind kurz behaart, jene der beiden anderen Formen sind völlig kahl; das Holz der grossfrüchtigen Art hat zahlreiche Spiralfasern in den Tracheiden des Frühjahrs- und des harten, dickwandigen Sommerholzes. Bei breitem Sommerholze führen die drei oder fünf ersten und letzten Tracheidenzellen die Spiralbänder, die zwischenliegenden Partien sind frei daron. Das Holz der gemeinen Douglasia enthält bekanntlich selten Spiralbänder in den Sommerholztracheiden.

Die Markstrahlen der grossfrïchtigen Art sind ron Tracheiden begränzt, welche ebenfalls Spiralfasern enthalten, die dem Holze der Küsten- und der Binnenlands-Douglasia fehlen (Tafel LX).

Die Aeste stehen an erwachsenen Baume horizontal vom Stamm ab, wodureh der ganze Habitus einen, ron der Form der früher zusammen mit der Sequoia gegebenen Douglasia, abweichenden Habitus erhiilt.

Die anfangs glatte Rinde geht später in eine sehr tiefrissige Borke über, die keine Verschiedenheit ron der gemeinen Douglasia zeigt. Das Kernholz ist tief brammoth und jedenfalls sehr dauerhaft: der Baum wird jedoch wegen seines seltenen Vorkommens (er findet sich nur auf den San Bernardinn- und Cuyamaca-Bergen im siddlichen Californien) nur gelegentlich geniit\%t. 


\section{b) Die gemässigt-warme Region, die Zone der blatt- abwerfenden Laubbäume}

umfasst die Ebenen und Thäler von Oregon und Washington-Territory, die Berghänge, bis zu etwa 1000 Meter Erhebung, die Küste von British-Columbia und die Insel Vancouver, sowie die Küste bis etwa zur Höle ron Sitka.

Dieses wichtige Gebiet klimatisch erschöpfend zu fixiren, ist leider nicht möglich wegen Mangels geeignet situirter meteorologischer Stationen im Gebirge; immerhin aber können die Optimalgebiete mehrerer wichtiger Holzarten klimatisch genügend beschrieben werden. So ist z. B. das Gebiet der Lawsonia, der Westhang des Cascaden-Gebirges und dic Küste des südlichen Oregon, also des südlichen Theiles, also der gemässigt-warmen Region ausgezeichnet durch ein ausserordentlich gleichmässiges und feuchtes Klima: Temperatur der Vegetationsmonate $15^{\circ} \mathrm{C}$. und des ganzen Jahres $10^{\circ} \mathrm{C}$. Die höchste beobachtete Temperatur war $28^{\circ} \mathrm{C}$., die tiefste $-6^{\circ} \mathrm{C}$.; während der Vegetationszeit fallen durchschnittlich $91 \mathrm{~mm}$ Regen bei vollen 85\% relativer Feuchtigkeit. Die Wintermonate kennzeichnet eine geringere relative Feuchtigkeit als die Sommermonate, gerarle umgekehrt als bei unserem continentalen Klima. Nördlicher liogt am Puget Sound das Optimalgebiet von vier Holzarten: der Küstenfichte, der Douglasia, der pacifischen Thuja und der pacifischen Tsuga; um ihre höchste Vollendung, was Dimension betrifft, zи erreichen, verlangen diese Holzarten grosse Feurhtigkeit während der Vegetationsmonate, nämlich zwischen 70 und $80 \%$; ïhor $80 \%$ Feuchtigkeit unmittelbar an der Küste sagen besonders der Fichte und der Riesenpappel zn. Dieses Gebiet ist verhältnissmässig ebenfalls kühl. Nur $15^{0}$ durehschnittlich im Sonmer (4 Monate gerechnet) und $10^{\circ} \mathrm{im}$ Jahr. Die höchste beobachtete Temperatur war $33^{\circ} \mathrm{C}$., die tiefste $-16^{\circ} \mathrm{C}$; w während der Vegetationszeit fallen $137 \mathrm{~mm}$ Regen.

Bei $66 \%$ relativer Feuchtigkeit während der Vegetationszeit crlangen die genannten Holzarten noch sehr stattliche Dimensionen; bei $63 \% / 0$ kïnnen 'I'sugra und 'Thuja, wie es scheint, nicht mehr fortkronmen, die Douglasia wird ein Baum von mässigen Dimensionen; bei $60 \%$ ist anch die Grenze für die Douglasia erreicht, bei $54 \%$ relativer Feuchtigkeit und $100 \mathrm{~mm}$ Regen und $18^{\circ} \mathrm{C}$. während der Vegretationszeit kann sie nicht mehr wachsen; es tritt die Gelbkiefer an ihre Stenle; aus diesem Gebiete, in Montana, wo die Gelbkicfer bei dieson klimatischen Beedingungen die Grenzregretation zwischen Nadel- 
wald und Prärie darstellt, führt ein Weg von nur wenig geographischen Meilen in die baumlose Prärie, deren Nähe sich in den grossen Extremen der Temperatur bereits ankündigt. Die Gelbkiefer widersteht dort einer Temperatur von zuweilen $39^{\circ} \mathrm{C}$. im Sommer und $-35^{\circ} \mathrm{C}$. im Winter.

Auf wenige Baumarten beschränkt, erreicht der Laubwald nur in Oregon eine bemerkenswerthe Ausdehnung in lockeren Hainen von niederen Eichen, die als Bindeglied zwischen Prärie und Nadelwald erscheinen, oder in compacten Waldungen an den Ufern des ColumbiaFlusses und seiner Tributärflüsse, also dem wärmsten Theile des Landes; dort allerdings erreicht der Laubwald unvermuthete Dimensionen. Zu hohen Eschen und Eichen gesellen sich Pappeln, über die einzelne beigemengte T'annen und Douglasia's kaum emporragen. '/umeist aber ist der Laubwald rertreten durch Nadelhölzer, unter denen besonter's Kiefern, Donglasia, Küsten-Tsuga, die Küstentamme, die Küstenfichte, Thuja und Chamaeeyparis-Arten die bemerkenswerthesten sind; ron dem Laubwalde sind dann nur einzelne Individuen an geeigneten Lagen in diesem Nadelholzcomplexe wahıunehmen.

Die Berglandschaft über 1000 Meter, sowie nördlich ron Sitka muss wohl zur gemässigt-kühlen Region mit Gebirgstanne, Gebirersfichte und Lärche gerechnet werden; in diesen gedeiht die Douglasia ebenfalls noch überall; eine feste Grenze lïsst sich auf Grund der mangelhaften Höhenbestimmungen wohl noch kaum angeben.

Hervorragend wirthschaftlich werthvoll sind unter den Laubhölzern etwa drei Arten, eine Weisseiche, eine Esche und ein Ahorn; sie sind die wichtigsten Hartnutzholzproduzenten der nördlich-pacifischen Kïiste.

Quercus Garryana Dougl., White Oak, Westliche Weisseiche, wird in Oregon und Vincouver ein Baum bis zu 30 Jeter Höhe in den warmen Niederungen, bleibt dagegen 1 m so mehr in seiner Höhenentwickelung zurück - anch bei gebotener enrösster Wärme - je trockener das Klima wird. Auf der Girenze zwischen Nadelwald und Prärie ist die Weisseiche oft stratuchförmign oder ein niederer Baum dicht mit weissen Flechten behnugen. die bei Regen hellgriün sich färben. Oft kann sic auf der Nordseite kleiner Hügel Fuss fassen, der grösseren feuchtigkvit wegen, während die Süidseite eine sonnenverbrannte Grastliche ïberzicht. Solcho Eirchen stehen dann isolirt, die breite Krone einem greöffneten schirme oder einem Pilze rergleichbar. \%u ilmen gesellt sich now (quercus hollogrgii: cinzelne Gelbkiefern überragren sie um ein Violfahes. 
Die Weisseiche kennzeichnet ein eigenartig gelapptes Blatt, von dem eine naturgetreue Skizze auf Tafel V sich findet; Blätter oben stets mit Sternhaaren besetzt, unterseits kurz behart, ebenso Blattstiele und Triebe behaart. Die Schuppen der Cupula sind sehr zahlreich und dabei schmal, fast pfriemartig, anliegend (Tafel II). Die Früchte, ohne Stiele sitzend, reifen in einem Jahre und noch in demselben Jahre keimt die Mehrzahl derselben, da der Abfall in die Zeit der reichlichen Regengüsse fällt; bei schneearmem Winter geht dann wohl die Mehrzahl der Keimlinge wieder zu Grunde; Triebknospen gross, zugespitzt, braun glänzend, Knospenschuppen am Rande mit Wollhaaren, Endknospe stets mit langen Zotten. Die Borke des Baumes ist auffallend weisslich, sie wird hierin nur noch von der japanischen Quercus crispula übertroffen, mit einer Rinde, die ron Ferne wie die einer Weissbirke glänzt. Das Hol\% mit einem specifischen Gewichte ron 75 und einem Splinte von $4 \mathrm{~cm}$ Breite wird zu allen den Zwecken benützt, zu denen auch bei uns Eichenholz Verwendung findet.

Quercus Kelloggii Newby., Blackoak, Kellogg's Eiche vertritt die Stelle der Garryana in Californien, wo sie in der Sierra Nevada nicht unter 1300 Meter herab geht, wohl aber bis zu 2700 Meter cmporsteigt; sie fällt auf durch ihre an die Färbereiche des Ostens (Quercus tinctoria) erinnernden Blätter mit Lappen, die in Spitzen auslaufen. Unterseits ist sie, den Hauptlappen parallel, wollharig. Bezüglich der Elevation an den Bergen folgt sie genau der Gelbkiefer, innerhalb der lockeren Bestïnde dieser Holzart fusst sie auf den besseren Bodenparticen, einzoln sowohl als in grösseren Hainen, eben je nardı der Grösse der besseren, lehmreicheren Nester im Boden.

Die Rinde ist eine dunkelgraue, klein- aber tiefschuppige Borke. Eichel gross nach Tafel II; entsprechend ihrem Vorkommen in den kühleren Regionen ist auch die Höhe des Baumes (25 Meter), sowie das sperifische Gewicht (64) beträchtlich geringer als diess bei den tefer wachsenden Eichen der Fall ist. Sie ist die Gebirgseiche der pacifischen Küste, liebt die kühleren Standorte, während sie die wärmeren Flussniederumgren ausserhalb der Gebirge der Q. Garryana überlässt; sie groht desshalb auch am weitesten nach Norden und wind noch im sïdlichen Alasca ein stattlicher Banm.

Fraxinus oregana Nutt, Oregon Ash, Oregon Esche. Dis jungen Triebe, Blattstiele und Blättchen, beiderseits wollig, weisslich bchaart; Blättchen schwarch grekerbt oder ganzrandigr, wenn ausgewachsen 
oberseits kahl und griü; Knospe gelbroth, filzig; Frïchte nach Tafel IV.

Dieser Baum rertritt mit Fr. dipetala, einem kleinen Baume, die Gattung Fraxinus im Westen und berorzugt dieselben Oertlichkeiten (Auwaldungen), welche unsere einheimische Esche liebt. Wie fast alle westlichen Bäume hat sie cine ausgesprochene Tendenz zum schnellen Wachsthum; ihr Same keimt schon im ersten Jahre und die jungen Pflanzen erreichen in dem selben Jahre selbst in dem kälteren Klima Deutschlands (Grafrath bei München) eine Länge bis zu $65 \mathrm{~cm}$; auch in Japan ist die Oregonesche ron allen ausgesïten Eschenarten die längste geworden; Frost belästigt sie wohl nicht mehr als unscre europäische Esche.

Populus trichocarpa Torr. und Gray, Black Cotton wood, die pacifische Balsampappel, ist cin ausserordentlich rasch wachsender Baum, der in seinem Optimalgebiete, im unteren Columbia, an Puget Sound und in Vancouver nach dem Censusberichte 60 Meter Höhe erreicht; nach Angaben ron Holzarbeitern, die meist zurerlässig sind, gehören Exemplare mit 80 Meter Höhe durchaus nicht zu den Seltenheiten, so dass diese Pappel mit den ihr oftmals beigemengten Douglasia's, Küstentannen und -Fichten in erfolgreiche Concurrenz treten kann. Der Schaft dieses Baumes ist vollendet gerade. astrein bis zu 40 Meter Höhe; solche Stämme erwachsen aber nur auf sehr kräftigem Boden mit reichlichen Durehfeuchtungsverhältnissen, wie sie Flussufer oder die Nähe der Küiste bieten.

Oestlich rom Caseaden-Gebirge tritt an Stelle dieser Pappel eine atlantische Balsampappel, Populus balsanifera, welche, da in die kiuhle Region übergreifend, mit den östlichen Fichten die Prärie im Norrlen überschreitet und theilweise selbst innerhalb der pacifischen Flora erscheint.

Die Früchte sind dicht behaart; Blätter selı schwach grekerht (Tafel V) unterseits weisslich; die Knospe balsamisch; die Rinde alter Stämme ist eine sehr breit- und tiefrissige Borke; das sehr leichte Hol\% (specifisches Gewicht 38) wird besonders \%u Zuckerfïssern verarbeitet.

Acer macrophyllum Pursh, Broad leaved maple. Grossbläteriger Alrorn. Er theilt vielfach die fenchten standurte der Pappeln, der Esche, im südlichen Theile ron Oregon anch des californischen Lorbeers, wo er mit 30 Meter Höhe seine Maximal- 
entfaltung erreicht. In den Bergen licbt er in warmen Thälern die Ufer der Bergbäche.

Die Blattform ergibt sich aus Tafel V, Blatt zuweilen sehr gross. Friichte mit goldgelben langen Borstenhaaren bedeckt nach Tafel IV; Knospen und Triebe grün; Blüthe wohlriechend, gelb, nach dem Laubausbruch; Rinde des ausgewachsenen Baumes eine langrissige Borke mit ca. $2 \mathrm{~cm}$ breiten Stücken. Das Holz ist mit einem specifischen Gewichte von 49 für ein Ahornholz auffallend leicht, es scheint aber immerhin zu Möbeln, Handgriffen an Werkzeugen und dergleichen gut verwendbar zu sein; werthvolle Maserbildungen sind häufig. Dieser Ahorn ist ein sehr beliebter Strassenzierbaum in den Städten der pacifischen Küste.

Dort wic anch im Walde leidet der Baum durch eine Fleckenkrankheit, ein Rhytisma, das aber nicht grössere, compakte schwarze Lager bildet, wie das Rh. acerinum der östlichen und vieler japanischen und indischen Ahornarten, sondern in einzelne Punkte ohne Rücksicht auf die Nervatur des Blattes aufgelöst ist; dadurch ist dasselbe von den bekannten Formen mehr oder weniger verschieden, so dass neben Rh. punctatum an Acer opulifolium auch Rhytisma punctiforme n. sp. an Acer macrophyllum und Acer crataegifolium in Japan berechtigt sein mag. An den gesammelten Exemplaren waren die Sporen noch nicht reif (Tafel X).

An diesen Nut\%bazum mögen sich die ürigen Laubholzarten, deren forstlicher Werth war gering ist, anreihen.

Nogundo californicum Torrey und Gray (syn. Acer californieum Dietr.), Box Elder, Californischer Eschenaborn, ist ausgezeichnet durch stark wollige Behaarung der Blattunterseite, Blattstiele und jungen 'Triebe; der Baum erreicht nur mässige Dimensionen, selten 12 Meter Höhe und ist forstlich ron geringem Werthe, sein Hol\% wird nur gelegentlich zu Möbelstïcken verwendet; scin Holy ist wie das des atlantischen Negundo auflallend weich mit cinems specifischen (iewichte von nur 48. Dabei ist sein Vorkommen auf warme Gegenden beschränkt, vielfach auf Oertlichkeiten, welche ich der subtropischen Gewächszone zuzihlele, wie das untere Thal des Sacramcuto, die Westhänge der Coast Range-Berge Californiens.

Acer circinatum P'ursh, Vinemaple, Weinahorn; der Name ist durch das 7-9lappige Blatt gerechtfertigt ('lafel V); junge Blätren untrerseits späilich mit langen Hatren besetzt; Früchte horizontal 
abstehend nach Tafel IT. Meist strauchartig bildet diese Art in feuchten Standorten der warmen Küste entlang Dickichte wie die Straucherlen des Ostens; dabei erreicht die grasgrüne glatte Stange nicht über 10 Meter Höhe.

Acer glabrum Torr., Dwarf maple, Zwergahorn, bleibt so niedrig wie der vorige Ahorn; Blätter nach Tafel $V$, vorwiegend dreilappig, grob gezähnt; der Baum ist seltener an der Küuste Florida's, zahlreicher im Inneren der Rocky Mountains bis Colorado und NewMexico, während ein anderer Zwergahorn, Acer grandidentatum Nutt., die Bergstöcke zwischen dem Felsen- und Cascaden-Gebirge in engen feuchten Schluchten bewohnt. Blätter nach Tafel V.

Platanus racemosa Nutt., Sycamore, Californ ische Platane. Die Blïtter (nach Tafel III) sind unterseits behaart, besonders sind die Blattsticle dicht wollig, flaumbedeckt. Sammelfucht an einem gemeinsamen langen Stiele, einzelne Frucht lang-stachelig, den gemeinsamen Stiel etwas umfassend. Nebenblätter halbkreisförmig mit ein oder zwei Zähnen. Dieser Baum erreicht in den Thälern der Sierra und der Cascaden, am oberen Theile des Sacramento ummittelbar an den Flussläufen, besonders mit kiesig-steinigem Bette, einen Standort, wie ilm alle Platanen in ihrem wilden Zustande lieben, Dimensionen bis zu 30 Meter.

Der Baum rerdient den Namen ,ästig" in der 'That; nicht blos zertheilt sich der kurze Schaft rasch in Aeste, sondern auch diese Aeste sind wieder mannigfach getheilt und knieförmig gebogen. An Schönheit steht die californische Platane der atlantischen und der ArizonaPlatane wesentlich nach. Das rothbraune Kernholz wird katum benuityt.

Die Erlen der feuchten pacifischen Kriiste sind Baiume mit stattlichen Dimensionen und dadurch ron den niederen, strandhförmignen Erlen der atlantischen Küste auffallend unterschieden; inn Norden bewohnen sie Flussufer und feuchte Niederungen, im Sïrlen, in Californien, ziehen sie sich auf die höheren Berge zurück.

Aluus rubla Bong., Alder, Amerikanische Rutherle, mit glattem, hellgrauem Stamme, reicht vom Sitka die Kö̈ste entlangr bis in das mittlere Californien ostwärts bis Montana; sie ist die gemeine Baumerle von Washington und Oregon, wo sie 30 Meter Höhe erreicht und als Möbelhol\% geschätzt wird. Blitter nach Tafel $V$ grrob geräihnt, Fruchtzapfen 2,5 cm lang und $1 \mathrm{~cm}$ breit; das Holz hat ein specifisches Gewicht ron 48. 
Alnus rhombifolia Nutt. ist die strauch- oder halbbaumförmige Erle in gleichem Verbreitungsgebiete: das schwach gesägte Blatt gross, unterseits etwas haarig nach Tafel $V$. Fruchtzapfen $1,5 \mathrm{~cm}$ lang, 0.7 ''m breit; Rinde eine breit- und tiefrissige Borke.

In der Region der Kiefern und Quercus Kelloggii wächst in den San Bernardino-Bergen, damn im mittleren Californien und in Mexico die

Alnus oblongifolia Torr., Alder, ein höherer Baum mit doppelt gesägten Blättern (Tafel T); Fruchtzapfen wie ron der rorigen Art. Diese Erle wird ein hoher Baum, der unserer einheimischen Rotherle nicht nachsteht; die Rinde ist glatt, dunkelgrau; das gelbbrame Kernholz, in dieser Höhenlage gewachsen, ist mit einem specifischen Gewichte ron 40 auffallend leicht.

Betula occidentalis Hook., Black birch, die westliche Schwarzbirke. Ein- und zweijährige Triebe, sehr stark mit röthlichem Drüsenbeleg: mittlerer Theil der Fruchtzapfenschuppen rerkleinert und meist zurückgebogen Tafel IV, Blätter nach Tafel III. Rinde des erwachsenen Baumes dunkel grauroth mit sehr breiten hellen etwas rüthlichen Lenticellen. Diese Birke bewohnt die hohe Bergregion der Küiste, während sie in der Ebene mit geeignet kühlem KKlima, das Ist in Britisch-Columbien, durch die von der atlantischen Kü̈ste übergreifende Betula papyrifera ersetzt wird.

Einer der auffallendsten Bäume unter allen Laubhölzern ist

Arbutus Menziesii Pursh, Madroña. Dem forstlichen Werthe nach reiht sich der Baum den Eichen an; sein schweres, hartes Hol\% wirl ganz besonders zur Bereitung ron Schiesspulver verkohlt; dir Rinde enthält etwas Tannin. Dieser schöne Baum, ästig mit grossen, hreitrn Blättern, die sich bis spät in den Winter am Baume grün crhalten, ist auch als Zierbaum an der Küste sehr beliebt; in der freien Natur liebt er feuchte, geschüityte Lagen, von den Inseln von Britisch-Columbien an der Küste entlang bis nach dem mittleren Californien; jm südlichen Oregon dürfte das Optimum des Baumes liegen. In feurhten 'Thälern ein hoher Baum bis zu 25 Meter, bleibt er auf sonnigen Brrghüngen in der Höhe zurück, wird breitkronig, dagegen nimmt der kurge Schaft an Dicke beträichtlich zu.

Die lotytjührigen 'T'riebe des rasehwüchsigen Baumes sind grün, dis vorletzten rothbraun; später geht die Rinde in eine kleinschuppige, in Blättchen sich ablïsende, rïthlich-graue Borke über.

Ion Osten her überschreitet mit den Nadelhölzern den Continent 
Populus tremuloides Michx., die amerikanische Aspe, welche als kleiner Baum den oberen Rand der Laubholzzone und den wärmeren Theil der kühlen Fichten- und 'Tannenregion einnimmt; an der pacifischen Küste kann sie in Folge der hohen Gebirge weit nach süidcalifornien, bei entsprechender Erhebung bis zu 3000 Meter, rordringen; sie ist das am weitesten verbreitete forstliche Unkraut, zu dessen Gunsten die besseren Holzarten zurückweichen, wenn sie systemlos hermutergeschlagen werden.

Populus Fremontii Watson, Cottonwood, Californische Pappel rom oberen Laufe des Sacramento bis zu den Sian Bernardino-Bergen, ostwärts nach Nevada und Utah. Durch das eigenthïmlich geformte Blatt ('Tafel V) von den übrigen Pappeln gut geschieden; der südöstlichen Form Var. Wislizeni, Tafel III, wude bei Betrachtung der nordmexicanischen Flora gedacht. Sie ist wie alle Pappeln vorzugsweise auf die Flussauen beschrïnt und erreicht dort 30 Meter Höhe.

Mr. II. S. Bebb, der beste Kemner der nordamerikanischen Weiden beschreibt in der Flora of California 19 californische Weiden, während er die Zahl der nordamerikanischen Weiden überhaupt auf 60 schïtzt; fast jede Art ist ron ihm mit ein oder zwei Tarietiiten versehen; daraus ergibt sich, dass die nordamerikanischen Arten in Variation, Bastardirung und Schwierigkeit ihrer Bestimmung hinter den europäischen gewiss nicht zurückstehen. Mehrere derselben kommen ron Osten her mit dem Nadelwalde nördlich ron der Prärie in die pacifische Region wie Salix amygdaloides und Salix longifolia, wïhrend Salix nigra wohl auf dem südlichen Wege, nämlich dem Crolfe ron Mexico entlang über Texas und Arizona die pacifische Küste erreichte. Diese Art ist allein in sechs Varietïten beschrieben worden.

Bezeichnend ist, dass unter allen Weiden der pacifischen Küste noch keine gefunden wurde, die ihre Kultur zu Flechtarbeiten lohnen würde, sie sind daher einstweilen noch, bis ihr Werth geprïft ist. forstlich belanglos. Alle sind an die unmittelbare Nïhe der Flüsse und Bergbäiche gebunden.

Salix laevigata Bebb mit lanzettlichen Blättern ron $7-15$ cm Länge, drüsenlosen Blattstielen und $3-5$ staubfäden auf Californien beschränkt, wird zuweilen baumartig; das Terbreitungrgebiet dieser Weide liegrt ganz in der subtropischen Zone. Diese und Salix lasiolepis Benth., mit zwei Stamina und glatten Fruchtlitpseln, sind häufige Weiden des californischen Thales zwischen den hohen Bergen. 
Salix lasiandra Benth. rom Sacramentoflusse an nordwärts und in den Bergen östlich bis Neu-Mexico. Ein kleiner Baum mit Drüsen an den Blattstielen und 3-5 Stamina.

Salix sessilifolia Nutt. mit zwei Stamina, mit Drüsen an den Blattstielen; vom Puget Sound bis Californien.

Unter den Sträuchern erwähne ich die bekannte Salix cordata, die ron Nordosten her nach Colorado und Utah, selbst bis Califormien, aber dann nicht unter 2500 Meter Erhebung, eindringt; durch zwei Stamina und glatte Früchte und die grossen halbmondförmigen Blätter ausgezeichnet.

Salix Sitkaensis Säns. durch schöne, dunkelgrün glänzende Blätter mit weisssammtiger Unterseite ausgezeichnet. Salix Breweri Bebb ist die einzige Weide aus der Gruppe der Viminales, die bis jetzt in Nordamerika gefunden wurde.

Mehrere alpine Weiden der pacifischen Küste endlich bescheiden sich mit dem kühlen Klima im hohen Norden und auf der Baumgrenze der Hochgebirge bis nach Mexico.

Als typischer Vertreter der Strauchregetation sei Cornus Nuttallii Audub. erwähnt, dessen „Blüthe" eigentlich einen Blüthenstand mit hellfarbigen Involucralblättern darstellt. Wie im Osten Cornus florida, so fehlt der starke Strauch im Norden keiner der spärlichen Laubholzgruppen, während er im Süden, auf den höheren Bergen, im Schatten der Nadelhölzer bis zum Baume II. Grösse heranwächst; Rhamnus Purshiana DC. theilt das Gebiet und die Eigenthümlichkeit der vorigen Art hinsichtlich seines Gedeihens.

Die Rosskastanien sind durch eine Art: Aesculus californica Nutt., California Buckeye, die californische Rosskastanie verticten; diese Art ist aber mehr Strauch als Baum. Zahlreiche Tricbe zweigen von dem Hauptstamme unmittelbar über dem Boden ab), und crheben sich mehrere Meter; dabei ist die Rinde derselben atuffallend weiss gefübt. Dic cinsamigen Frïchte sind von einer dünnen, loderartigen, höckerlosen Schale bedeckt, die Samen von doppelter Grösse als dio der östlichen Rosskastanion.

Prunus cmarginata Walp. und lemissa Walp. aus der Soretion Cerasus, Pyrus rivularis Dougr. mit einer Borke, die in sehr breiten und diumen Sohuppen sich ablöst. Pyrus (Sorbus) sambucifolia Cham. Und Schlecht. gehört wie die verwandte, 
europäische Vogelbeere mehr der kühleren Region als jener der Laubhölzer an; rom polaren Nordamerika dringt sie hoch in den Bergen bis zur Grenze von Mexico vor.

Mit der Vogelbeere kommt auch Amelanchier canadensis Torr. und Gray (nach amerikanischen Florenwerken, nach deutschen C. Koch) in die pacifische Region über; vielleicht lässt sich die Terbreitung der canadischen Felsenbirne durch Alaska nach Kamtschatka nachweisen, wodurch sich das Auftreten dieser Art in Japan erklären liesse. Crataegus-Arten, Sambucus glauca Nutt. mit schönen weissbereiften Beeren und andere stellen mit den vorgenamnten ein Buschwerk dar, zu dem die früher genannten Büume an der Grenze ihres Verbreitungsbezirkes ebenfalls als Sträucher oder Halbbäume sich gesellen.

Es erübrigt noch einiger Laubhölzer zu gedenken, welche ausschliesslich auf das Gebiet zwischen der Prärie und der Sierra Nevada, beziehungsweise dem Cascade Range-Gebirge beschränkt sind; die meisten derselben reichen in das nordmexicanische Gebiet über und sind dort bereits nüher beschrieben worden; einige aber stehen isolirt da, wie zum Beispiel Acer grandidentatum Nutt. Blätter nach Tafel V, ein Zwergahorn, der vielleicht auch Mexico erreicht, an Flussrändern.

Ein eigenthümlicher Baum ist Fraxinus anomala Torr. mit ungefiederten Blättern; Triebe rierkantig mit Korkleisten; ein kleiner Baum, der auf Sandboden häufig sein soll.

Populus angustifolia James, Black Cottonwood crscheint schon in den Black Hills ron Dakota; diese Pappel reicht weit in das kühle Gebiet der 'Tannen über; sic bleibt stets ein kleiner Baum.

Ich wende mich nun zu den Nadelhölzern, die ich insofern als die Vertreter des Laubwaldes auffisse, als ihr Optimum entschieden dem Laubholzgebiete angehört. An der Westkïste Nordameriki's die von der Natur selbst so reich mit Nadelhölzern bedacht wurde, hat sich im Kampfe während der Jahrtausende jener Pruzess rollyogen, der sich gegenwärtig im Osten Amerika's, in Europa, in Japan, an der Küste China's durch das Eingreifen des Mensehen vollzicht; die werthvolleren Laubhölzer werden genütyt, die anspruchsloseren Nadelhölzer gepflanzt oder ihnen das Tertain geebnet; in Westamerika ist die Laubholzflorat ron der Natur selbst auf rin Minimum zurückgedrïngt worden. 
Unter den Nadelhölzern, welche nördlich von Californien an der pacifischen Küste wachsen, spielt zweifelsohne

die Douglas-Tanne, Douglasia, Pseudotsuga Douglasii Carr., Red fir, Douglas fir, die grösste Rolle; bei uns ist sie auch als Douglas-Fichte bekannt; daher will ich zuerst Einiges über den Namen hier anfügen. Die Douglasia, wie ich die Holzart, um allen Unrichtigkeiten auszuweichen, nennen möchte, ist keine Picea oder Fichte; die Anatomie des Holzes, der Rinde, der Nadeln und der Zapfen spricht dagegen; sie ist keine Abies oder Tanne; die Anatomie des Holzes, der Rinde, des Zapfens und der Borkenbildung spricht dagegen; sie ist auch keine Tsuga, Habitus, Anatomie des Holzes, der Rinde, der Blüthen und Nadeln sprechen dagegen; sie ist auch keine Pinus, Anatomie der Rinde, Nadeln und Zapfen sprechen dagegen; die Douglasia ist eben, wie Carrière sie richtig aufgefasst, von den genannten Gattungen, deren lateinische Namen sie alle über sich ergehen lassen musste, verschieden.

Nach bisherigem Sprachgebrauch werden zuweilen zwei einander nahe stchende Gattungen oder Arten mit dem Namen „pseudo" belegt; so sagt man Pseudolarix, weil diese Holzart der Lärche ähnlich sieht; man spricht ron Acer Psendoplatanus, weil dieser Baum der Platane ähnlich sieht; man sollte nun erwarten, dass die Pseudotsuga der Tsuga unter den Nadelhölzern am ähnlichsten sehen würde, allein sie gleicht gerade dieser unter allen oben genannten Gattungen am wenigsten; Pseudopicea oder Psendoabies hätten mehr Berechtigung gehabt; allein der Name wurde, trotz seiner mangelhaften Basis, von den amerikanischen Botanikern, die zumeist interessirt sind, adoptirt; und so wird er wohl beibehalten werden.

Von der Narlelform abgesehen, ist die Douglasia schon vom ersten Tage ihres Lubens an völlig Fichte. Sie wird schon im ersten Jahre bis zu $10 \mathrm{~cm}$ hoch, im zweiten Jahre bis zu $20 \mathrm{~cm}$ und darüber. Ihr Leittrich reigt zahlreiche, unregelmässig vertheilte, kräftige Seitenknospen, welche, wenn die Hauptknospe zu Grunde gegangen ist durch Erfrieren oder Abïsen durch Thiere, wie bei der Fichte, sofort zu neuen Gipfeltricben emporwachsen können. Von da an entwickelt sich die Douglasia rasch weiter, wohl schneller als irgend eine nordamerikanische Nadelholyart; sie behält aber den Habitus der Fichte, eine spitze Kegelform der Krone bei, bis im höheren Alter ihre Krone sparrig wird. Die Rinde, die in der Jugend und natürlich auch im (iipfel des Baumes tannenartig glatt ist, erscheint in den Rocky Mountains 
weisslich, im Caseaden-Gebirge etwas röthlich; sie geht später in eine kleinschuppige Borke mit dunkelgrauer Färbung über; endlich treten sehl breite, bis zu $20 \mathrm{~cm}$ dicke Borkenplatten mit hellbräunlichen Thälem dazwischen auf. Untersucht man diese Borke, die etwa mit dem hundertsten Jahre des Baumes am Fusse des Stammes zuerst auftritt, unter dem Mikroscope, so ergibt sich, dass sie aus kleinen, scheibenförmigen Stücken des Rindengewebes mit reichlichen sklerosirten Elementen und Krystallschläuchen besteht, dass aber neun Zehntel der gesammten Borkenmasse aus reinen Lagen eines ockerfarbigen Korkes bestehen, die wieder durch dïnn- und dickwandige Zelllagen eine Schichtung erhalten.

Im Schlusse bildet die Donglasia eine sehr spitze, kegelige Krone und schliesst im höchsten Alter, wie noch andere Nadelhölzer des Urwaldes ihn Wachsthum mit einer Krone ab, die wieder völlig der jungen Pflanze ähnlich ist, und anf der Krone des alten Stammes wie eine neue Pflanze aufsitzt; man vergleiche das Titelbild. In dichtem Schlusse erwäichst sie zu einer ausserordentlich dünnen und schlanken Stange; an Berghängen beginnt der Stamm zuweilen mit einer kur\%en, sübelförmigen Krümmung oder einer kräftigen Anschwellung, wesshalb er dort erst ein bis zwei Meter über dem Boden gefällt wird. Meist ist der Stamm überhaupt an seiner Basis so stark, dass es bei den theneren Arbeitslöhnen in Amerika einen Zeitgewinn darstellt, ein Gerüste zu bauen und den Stamm erst in grösserer Höhe etwa 3-4 Meter über dem Boden abzukappen.

Nur das allerbeste Material, das im Walde steht, hat bis jetzt einen Werth und nur dann. wenn es in grossen Massen beisammen steht; das wird damn ohne Rücksicht auf irgend etwas anderes - les déluges après - herausgeschunden; nur in grossen Vorrathsgebieten lohnt sich die Nut\%ung, welche mit Dampfmaschinen, Eisenbahnen und dergleichen in allergrïsitem Massitabe betricben werden. Ich liann mich zur Bewunderung der Kraft und Energie, die in su insecnirten Unternehmungen liegrt, nieht aufschwingen; etwas Honig bekommt

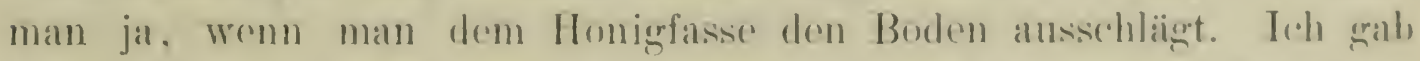
früher schon cinige Bilder, die für sich solbst reden mügren: wie sidhön liesse sich da Uutermehmungsereist mol Kapital mit einem einfachen. klaren, anf Nahhaltigkoit des Gewinnes geridhteten Systeme combiniren zum Seren des bandes und zum Nutzen der Unternohmer.

Die Douglasia passt sioh mit Leiohtigkeit dem grogebenen Boden an; sir entwickelt anf sejuhten Böden ein flarh stroichendes Wur\%olsystem. dringt in die Folsipalten, in lockere Birden mit kriftiger Pfahl- 
wurzel ein, meidet aber stets harte Thonböden und fehlt in ihrer Heimat auch auf mageren Sandböden; sie wird dort durch die Gelbkiefer vertreten; auf lehmigen Sandböden oder sandigem Lehm entwickelt sie eine centrale Partie ron zwei bis drei kräftigen Wurzeln, welche in die Tiefe gehen, während die übrigen Wurzeln seicht verlaufen; wo lehmige Bestandtheile vorwiegen, tritt zur Douglasia die Küstenfichte oder in den Bergen die concolor-Tanne, wo die sandigen Bestandtheile überwiegen, gesellt sich zu ihr in den Bergen die Gelbkiefer, die Libocedrus, an der Küste die Lawsonia.

Nicht minder leicht accomodirt sich die Douglasia an Standorten mit rerschiedenen Befeuchtungsgraden, sowohl des Bodens als der Luft an. Im mittleren Oregon und in Montana drängen sich einzelne Exemplare bis hart an die Prärie heran, mit unterständigen, niederen Eichen, freilich auch keine Riesen; im suidlichen Oregon stehen starke Stämme unmittelbar an den "Slough" an, durch brakisches Wasser gebildeten Neereseinbuchtungen, so dass die geringste Stauung das Wurzelwerk unter Wasser setzt; mit Thuja und Tsuga erfüllt sie im nördlichen Oregon und Washington und Britisch-Columbia die engen Schluchten ummittelbar an den Ufern der Bergwasser; im lufttrockenen Binnenlandklima Montana's gedeiht sie und wird ein werthvoller Nutzbaum, um endlich in der Nähe des Meeres, in der wasserdampfreichen Luft der Küste zu riesenhaften Dimensionen emporzuschiessen.

Wo die Douglasia aus natuirlicher Besamung und gleichalterig aufwächst, ein Verhältniss, das in Amerika sich auf uralten Brandstellen findet, da fällt ihr dichter Schluss, ihr gleichmässiges Wachsthum auf; dabei bleibt die durchschnittliche Lünge der Jahrestriebe sehr beträchtlich hinter jenen der freistehenden und gleich alten Exemplare zuruick.

Es wird vielfach behauptet, dass der gedrängte Schluss das Höhenwachsthum nicht begünstige und dass diese Eigenthümlichkeit das ganze Leben des Baumes im Bestande sich erhalte. In der Jugend mag diess richtig sein; allein unter allen ausgewachsenen Bäumen waren stets die in dichtestem Schlusse stehenden, also die am wenigsten von Aesten umkleideten Exemplare die höchsten; je mehr der Baum auf Ausbildung der Blätter und Zwweige, also der Krone verwendet, um so mehr \%eigt sich der Effekt dieser Lebensthätigkeit in einer Durchmesserzunahme und einer Höhenwuchsverzögerung.

Schöne Beispiele hievon kann man im westlichen Himalaya beobachten, dem Optimumgebiete der Cedrus Deodara; dort sicht man oft in geschïtyten Oertlichkeiten dichte Gruppen von etwa 20 Cedern 
zusammen stehen; untersucht man eine solche, wahrscheinlich gleichalterige Gruppe, so erhält man zum Beispiel für die Randbäume mit den stärksten Kronen eine mittlere ,Höhe ron 45 Meter mit einem Durchmesser ron 0,77 Meter; Aeste beginnen bei 25 Meter Höhe, für die im engsten Schlusse - 2 Meter Abstand von den Nachbarbäumen - 50 Meter Höhe und 1,06 Meter Durchmesser, Aeste beginnen bei 30 Meter; endlich bei fast ganz freistehenden Bäumen reichen die Aeste bis zu 3 Meter über dem Boden herab, die Höhe bleibt auf 36 Meter stehen, dagegen erreicht der Durchmesser 1,53 Meter.

Es ist gewiss auch kein Zufall, dass die grössten Riesen der Douglasia, Sequoia, Cryptomeria so oft in engen Gruppen beisammen stehen.

Wenn die Vegetation rechtzeitig, vor Eintritt der Frühfröste zum Abschluss kommt, ist die Douglasia absolut frosthart; sie wächst auf völlig freier Fläche in Nordamerika auf, in Montana in Oertlichkeiten, wo Temperaturgrade ron $-35^{\circ} \mathrm{C}$. im Winter durchaus keine Seltenheiten sind, Temperaturen von $-25^{\circ}$ aber alljührlich auftreten. In Gebiete der Rocky Mountains, in Montana, Idaho und Colorado entwickelt eben die Douglasia keinen zweiten Trieb im Nachsommer, keinen Johannitrieb, der dagegen an der warmen und feuchten Küste oft schon im ersten Jahre und nicht blos an der Douglasia, auch an Abies grandis und Pinus ponderosa sich zeigt.

Es dürfte diese Eigenthümlichkeit der Johannitriebe vielleicht ein Licht auf die Verbreitung der genannten Holzarten von den Rocky Mountains nach der Küste hin werfen, wobei die Pflanzen an das wärmere, fenchtere Klima mit längerer Vegetationszeit sich durch ein zweites Austreiben der Knospe noch in demselben Jahre durch den Johannitrieb angepasst haben. Ueberdiess fällt an der Küiste der Abschluss der Knospe, bevor diese zum neuen Triebe (Johannitrieb) sich streckt. der Zeit nach mit dem Abschlusse der Knospe und der Tegetation im Felsengebirge zusammen. Dabei entwickelt sich der Johannitrieb in der Regel aus einer Seitenknospe am Gipfel des Haupttriebes: die Endknospe dieses neuen Triebes bleibt klein und ist ron zusammengedrehten Narleln völlig umhiillt; unterbleibt der Johannitrieb, daun schliesst die P'flanze ihr Wachsthum mit einel grossen, von grünen Nadeln nicht eingehüllten, glänzend braunen, kegelförmiggen Knospe ab.

Dass frostharte Pflanzen ohne Johannitrieb anch langsamerwüchsig sind, ist eine Erscheinung, die man in Ostamerika und Europa an kultivirten Exemplaren und auch im Westen, in der Heimat der Douglasia, beobaditen kaun; in Montana, wo lieine Johannitriebe anftroten. 
und der Längstrieb im günstigsten Alter $50 \mathrm{~cm}$ nicht überschreitet, braucht die Douglasia auf gutem Boden volle 190 .Jahre, um 45 Meter Höhe und $80 \mathrm{~cm}$ Durchmesser zu erreichen; an der feuchten Küste ist sie schon mit 80 Jahren 40 Meter hoch und hat einen Durchmesser ron $80 \mathrm{~cm}$; die Montana Douglasia hat den Höhenpunkt ihres Zuwachses längst überschritten, die Küisten-Donglasia steht mit dieser Dimension in der Tollkraft ihres Wuchses.

Dass die Standfaktoren, wenn sie Jahrtausende lang durch viele Generationen auf eine Pflanze einwirken, dieser endlich eine erblich gewordene Tendenz zu schnellerem oder langsamerem Wuchse anerziehen können, dürfte die Erscheinung bestätigen, dass Pflanzen aus Samen von Colorado-Bäumen und solche aus Samen von Küstenbäumen, auf ganz das gleiche Beet gebracht und gleich behandelt, durch viele Jahre hindurch sofort an der Wachsthumsgeschwindigkeit und ihrer ererbten Johannitriebbildung zu erkennen sind; erstere sind in Deutschland und in Ostamerika völlig frosthart; letztere sind in Deutschland schwierig und in Ostamerika gar nicht aufzuziehen.

Erst von der Zeit an, in der der Holzbildungsprozess in der Pflanze grössere Dimensionen annimmt, etwa vom zehnten Lebensjahre, unterbleibt auch an der Küsten-Douglasia der Johannitrieb; an frei erwachsenden Exemplaren beginnt mit dieser Zeit oft schon die Samenproduktion, ohne dass eine Abnahme des Längenwachsthumes bemerkbar wäie.

Uebrigens übt auf das Auftreten des Johamnitriebes auch an der Küste die Güte des Bodens einen wesentlichen Einfluss aus, insofern als schlecht crnährte Pflanzen nicht genügend Material zum Aufbaue eines Johannitriebes besitzen, während umgekehrt Pflanzen, die keine ererbte Anlage zum Johannitriebe überhaupt besitzen, auch durch den besten Boden nicht zur Bildung desselben angeregt werden können.

Auf geringem, seichtem, steinigem Boden am Puget Sound zeigten einjührige Pflanzen eine Höhe von $1,6 \mathrm{~cm}$ über den Cotyledonen und waren alle ohne Johannitricb, zweijährige Pflanzen $4 \mathrm{~cm}$ ïber den Cotyledonen und hatten $60 \%$ mit Johannitrieb. Auf besserem Boden, in muldenförmigen Linsenkungen unmittelbar neben dem ersten Orte hatten einjährige Pflanzen eine Höhe von $3,5 \mathrm{~cm}$ über den Cotyledonen; alle Pflanzen mit Johammitrieben, zweijährige Pflanzen sine Höhe ron $11 \mathrm{~cm}$ iiber den Cotyledonen und alle Pflanzen mit Johinnitrieben.

Dic Wuchsgeschwindigkeit hängt somit neben ererbter Wuchsancrgic anch von der Güte des Bodens ab; wo \%. B. an Eisenbahn- 
böschungen jeglicher Humus entfernt wird und nur der nackte, fast nahrungslose Kies zu Tage liegt, da fliegt die Douglasia ebenso reichlich an wie bei uns an gleichen Oertlichkeiten die Fichte. Sie wächst ausserordentlich langsam, zuerst zu einem breiten, den Boden beschützenden Busch aus, ohne erkemnbaren Leittrieb; solche Pflanzen ron kugeliger Gestalt sind oft 15 'Jahre alt und noch nicht 1' hoch. Erst wenn die Beschattung des Bodens erzielt ist und überdiess die Verwitterung durch die abgefallenen, regetabilischen Stoffe beschleunigt wird, beginnt allmählig von den zahllosen Endknospen eine voran zu eilen und soweit es eben möglich ist, erwächst ein, wenn auch sehr niedrig bleibender Baum; ebenso verhalten sich bekanntlich die Kiefernarten, wemn sie auf nacktem Sandboden angebaut werden. Bedeckung des Bodens und Schutz der Wurzeln ist die erste Thätigkeit ihres Lebens, erst dann beginnt das Längenwachsthum der Pflanze. Ganz ebenso verhält sich auch die Douglasia, wenn sie auf den allerschlechtesten Boden kommt; dass sie ein niederer, technisch werthloser Baum dort bleiben muss, braucht kaum erwähnt zu werden; denn die Douglasia ist nie und nimmer eine Holzart, um damit auf heruntergebrachten, vermagerten Böden Versuche anzustellen.

Am rollkommensten gedeiht sie offenbar in den geringen Erhebungen der Flussniederungen, mit humusreichem, tiefgriundigem Buden; im Gebirge liebt sie den Boden, auf dem Rubus, Spiraea, Sambucus wachsen, also einen guten frischen Boden; auf Sandboden kommt sie nur in der Nähe des Meeres vor in untergeordneter Zahl, aber immerhin in sehr stattlichen Exemplaren, vorausgesetzt, dass dieser sandige Boden sehr frisch und humos ist; nur zufällig gelangt sie auf schweren Lehmborlen, bleibt aber dort auffallend kur\%.

Schon mehrmals erwähnte ich, dass nach meiner Ansicht die relative Feuchtigkeit der Luft während der Vegetationszeit des Baumes ron grösstem Einflusse auf dessen Höhenwachsthum ist; Doughlasian, die in der trockenen Luft mit rasch wechsehdem Feuchtigheitsgehalte in Montana aufwachsen, erreichen auf dem allerbesten Boiden nicht 45 Meter Höhe, während dieselbe Holzart diese Dimension im luftfeuchten und regenreichen Puget Sound auf dem schlechtesten Kiesboden zeigt, auf gutem Boden aber bis zur doppelten Höhe heranwïchst, und dass anch nicht das mildere Küstenklimat mit der längeren Vegetationszeit dabei allein den Ausschlag gibt, das beweist, dass im südlichen Oregon, im wärmeren Klima, wo aber wieder Prärie sich zwischen die Berge schiebt, die Douglasia auch anf dom besten Flussaucboden nicht über 30 Moter Höhe erlangt. 
Grisebach*) sagt, dass das Auftreten der Riesenbäume im Westen sich nicht durch grössere Feuchtigkeitsmenge erklären lasse; denn dieselben Bäume finden sich in den trockenen Rocky Mountains ebenfalls; er erwähnt freilich nicht, dass sie dort nur halb so hoch sind wie im Westen. Es ist gewiss auch kein Zufall, dass gerade im Westen, in der Strichlinie des warmen feuchten Windes rom japanischen Golfstrome her auch die grössten Früchte der Gattungen Pinus und Abies überhaupt und soweit Nordamerika in Frage kommt, auch der Gattungen Picea und Larix reifen. Selbst bei ein und derselben Holzart ist ein Unterschied hierin bemerkbar; z. B. die Zapfen der Donglasia sind in den Rocky Mountains durchschnittlich $5,5 \mathrm{~cm}$, an der Küste durchschnittlich $8 \mathrm{~cm}$ lang; parallel damit geht auch die durchschnittliche Entwickelung des Längstriebes an jungen Pflanzen von etwa zehnjährigem Alter: in Montana $30 \mathrm{~cm}$; im Cascaden-Gebirge $60 \mathrm{~cm}$, im Coast-Range volle $85 \mathrm{~cm}$, wobei allerdings auch die Steigerung durch die gebotene längere Vegetationszeit in's Gewicht fällt; im Felsengebirge fehlt der Johannitrieb ganz, der im Cascaden-Gebirge klein bleibt, an der Küste aber volle $30 \mathrm{~cm}$ Länge erreicht.

Im Felsengebirge überkleidet die Douglasia in Vereinigung mit der Gelbkiefer und der westlichen Lärche die feuchteren Nordhänge, bei grösserer Erhebung derselben ist sie auch den Gelbkiefern auf der Südseite beigemengt; auf der kühleren und feuchteren Nordseite bildet sie ziemlich gut geschlossene Wälder, sehr reichlich durchstellt mit Lärchen, die in einzelnen Hainen selbst reine Bestände bilden. Wer unsere Fichten- und Lärchenwaldungen am Nordhange der Alpen, z. B. bei 'Tegernsee, gesehen hat, hat ein völlig naturgetreues Bild von den Mischwaldungen der Douglasia und Lärchen im Felsengebirge.

Abermals tritt sodann die Dougłasia waldbildend auf an den zwischen dem Felsengebirge und dem Cascaden-Gebirge gelegenen Blue Mountains oder Blauen Berge; dort herrseht sie ebenfalls mit der Lärche, dazu kommt noch eine Fichte - Engelmann's Fichte, eine T'anne - die grosse Küstentanne - und an entsprechenden Oertlichkeiten Kiefern, eine grosse, die Gelbliefer, und eine kleinere, auf kältere, sumpfige Jagen beschränkte Kiefer - Muray's Kiefer. Zicht man hier cine Parallele mit dem Gebirgswalde der bayerisch-siiddentschen Grenze, so sind vertreten: Lärche, Fichte, Tanne, gemeine Kiefer und sparrige oder Sumpfkiefer; aber eine der Douglasia parallele Holmat besitzen wir nicht. 
Endlich im Caseaden- und Coast Range-Gebirge, an der feuchten, nebelreichen Küste von Puget Sound, auf der Insel Tancourer und südlich in den Küsten- und Cascaden-Bergen beziehungsweise der Sierra Nevada wahrscheinlich bis in das mittlere Californien entsprossen in Gesellschaft von Cupressineen, Küstentannen und -Fichten und Laubhölzern Bäume und Waldungen von durchschnittlich 60, im Puget Sound und im Küstengebirge von vollen 70-80 Meter Höhe; Maximal-Entfaltungen mit 100 Meter sind ebenfalls keine Seltenheiten.

Im Coast Range-Gebirge des südlichen Oregon, in den feuchten, engen, von Bergwassern durchnässten Westhängen fand ich die höchsten Douglasia's, die mir zufällig zu Gesicht kamen; die eine mass 1,8 Meter Durchmesser und 90 Meter Höhe, hart daneben stand eine zweite mit 2,3 Meter Durchmesser und 80 Meter Höhe.

Selbstverständlich ist das Alter solcher Baumriesen entsprechend; eine Douglasia mit einem Meter Durchmesser aus dem Urwalde ist sicher 200-300 Jahre alt; solche mit zwei Meter jedenfalls 600 und darïber; eine Douglasia bei Takoma zählte ein Meter ïber dem Boden 237 Jahre und hatte dabei einen Durchmesser des Holzes von $82 \mathrm{~cm}$; eine andere bei Limekill in den Torbergen des Vulcanes Takoma unweit des Puget Sound mass einen Meter Durchmesser und zählte 241 Jahre, ebenfallș zwei Meter ïber dem Boden.

Grösseres Interesse hat für uns, was die Douglasia in kleineren Zeiträumen und auf freier Fläche aufgewachsen zu leisten vermag. Einen Beitrag zu dieser Frage gibt ein Bestand 80 . Jahre alt auf lem besten, sandigen Lehmboden mit kräftiger Humusschichte erwachsen, im südlichen Oregon, im Optimum der Lawsoniana, nur cin par Stunden rom Meere entfernt, völlig gleichmässig, dicht geschlossen, sogenanntes zweites Wachsthum, das seinen Ursprung und seine fileichmässigkeit. offenbar einem vorhergehenden Waldbrande \%u revdanken luatte, der das erste Wachsthum fast röllig vernichtete. Es ergab eine Messung mehrerer Stämme einen mittleren MLdellstamm ron einem Durchmesser von $90 \mathrm{~cm}$ mit Rinde in Brusthöhe und einer Höhe - von 40 Meter; es betrug also der jührliche Stärkezuwachs (nach Abzug ron etwa $10 \mathrm{~cm}$ Rinde) genau $5 \mathrm{~mm}$, der jührliche Längenzuwachs $57,5 \mathrm{c}(\mathrm{m}$; ein bereits gefïllter Stamm desselben Bestandes stand leider in seinen Dimensionen hinter dem Modellstamme zurüek und mass nur $75 \mathrm{em}$ ohne Rinde, hatte bei 10 Meter über dem Boden noch 45, bei 15 Meter noch $32 \mathrm{~cm}$, bei 24 Meter noch $20 \mathrm{~cm}$ Durchmesser. Höhe 30 Meter, woraus $3,82 \mathrm{cbm}$ Inhalt des Schaftes und rime Formzahl ron 29 ergeben. Nimmt man die graphische Baumform des gemessenen Stammes als 
Basis und konstruirt die Baumform des mittleren Modellstammes nach jener des gemessenen Stammes, so erhält man ungefähı 6,49 cbm Inhalt; nimmt man das Mittel aus beiden, 1 m gewiss keine Ueberschätzung zu begehen, so ergeben sich 5,15 cbm.

Dichtere Bestände, als aus einer Vollsaat hervorgehen, und aus denen nie ein Baum durch die Axt entnommen wurde, dürfte es wohl nicht geben; solche Bestände sind gewiss normal und in seinem Sehlusse seiner Bodenbedeckung - Moos und Nadeln - in seiner Dunkelheit der Beschattung kam der erwähnte Bestand einem völlig geschlossenen schlagbaren Tammenbestande in Süddeutschland gleich. Es erseheint deshalb gerechtfertigt, eine Stammzahl von 920 pro ha anzunehmen, eine Zahl wie nach, Lorey auf Böden erster Bonität bei achtzigjährigen Tannen sich findet. Die Kreisfläche der Tannen beträgt 58,2 $\square$ Meter, die mittlere Höhe 27,3 Meter, der Inhalt 816 cbm Derbholz.

Um abermals keiner Uebertreibung geziehen werden zu können, nehme ich nur 800 Stämme pro ha an; ihre Kreisfläche war somit $50,89 \square \mathrm{m}$, der Cubikinhalt dieses Douglasiabestandes betrug somit mindestens rund $4100 \mathrm{cbm}$ Derbholz!

Stellt man eine Betrachtung iiber das Stärkenwachsthum uralter Bäume an, so ergibt sich das auffallende Resultat, dass die westlichen Holzarten alle viel raseher in der ersten Jugend erwachsen sind als die in langem Kampfe um Licht und Nahrung stehenden östlichen Holzarten. Daraus zu schliessen, dass die westlichen Holzarten Schatten nicht ertragen können oder einen grösseren Lichtzufluss überhaupt geniessen, wäre nicht richtig; eher dïrfte hier eine allgemein zu beobachtende, grösscre Wachsthumsenergie iiberhaupt, unabhängig vom Boden und Klima, in's Gewicht fallen, eine Energie, die, die Pflanzen auch in gleiches Klima und in gleichen Boden mit ihren östlichen Verwandten gebracht, den Letzteren vorantreibt.

Die Folge davon ist, dass junge Pflanzen von westliehen Arten rascher der Beschattung entwachsen können, die im Urwalde überdiess nie jene 'Tiefe wie im Culturwalde creicht.

Wie dunklo Schatten fehlen im Urwalde auch ausgerlehnte kahle Färchen, die allen Extremen von Hitye, Kälte und wechselnder Fenchtigkneit der Luft und des Bodens ausgesetzt sind; die grösste kahle Fläshe in Urwalde überschreitet nicht die Grösse der fliegenden Pflanzgärten in unseren Forsten, Verhältnisse, die allgemein als die günstigsten zar Aufzucht jungen Materials betrachtet werden.

Seitenschut\%, nicht Boschirmung ist rie natiorliche Pflege, dic allen jungen IIolzarten wohl bekommt; mit freiem Gipfel aber 
seitlich gedeckt, erwäehst auch die Douglasia am sichersten. Dass solche Exemplare auch schnell aufwachsen, zeigen folgende Beobachtungen:

Ein Stamm, im Puget Sound, also im Optimum auf kräftigem, tiefgründigem, lehmigem Boden erwachsen, zeigte 2 Meter über dem Boden mit

\begin{tabular}{r|r|r|r}
\hline Jahre & $\begin{array}{c}\text { Durchmesser } \\
\mathrm{cm}\end{array}$ & $\begin{array}{c}\text { Kreisflache } \\
\square \mathrm{cm}\end{array}$ & $\begin{array}{c}\text { Zuwachs } \\
\square \mathrm{cm}\end{array}$ \\
\hline 10 & 12 & 113,1 & 11,3 \\
20 & 22 & 380,1 & 26,7 \\
30 & 30 & 706,5 & 32,6 \\
40 & 40 & 1257 & 55,1 \\
50 & 48 & 1810 & 55,3 \\
60 & 61 & 2922 & 111,2 \\
70 & 76 & 4536 & 161,4 \\
80 & 92 & 6648 & 211,2 \\
90 & 100 & 7854 & 120,6 \\
100 & 108 & 9161 & 130,7 \\
120 & 126 & 12469 & 165,4 \\
150 & 148 & 17195 & 157,5 \\
200 & 180 & 25344 & 162,9 \\
241 & 200 & 31400 & 148,0
\end{tabular}

Der Hauptstärkezuwachs fällt zwischen 70 und 80 Jahıre und erhält sich bis in hohes Alter auf ausserordentlicher Höhe. Die durchschnittliche Jahrringbreite beträgt $4,1 \mathrm{~mm}$, die durchschnittliche, jührliehe Höhenzunahme (76 Meter gesammte Länge) $32 \mathrm{em}$.

In demselben Gebiete erreichte auf geringem, kiesigem Boden, mit kaum $20 \mathrm{em}$ Humusschichte eine Douglasia 2,4 Meter ïber dem Boden mit:

\begin{tabular}{r|c|c|c}
\hline Jahre & $\begin{array}{c}\text { Durchmesser } \\
\mathrm{cm}\end{array}$ & $\begin{array}{c}\text { Kreisfläche } \\
\square \mathrm{cm}\end{array}$ & $\begin{array}{c}\text { Zuwachs } \\
\square \mathrm{cm}\end{array}$ \\
\hline 10 & 8 & 50,2 & 5,0 \\
20 & 12 & 113 & 6,3 \\
30 & 16 & 201 & 8,8 \\
40 & 20 & 314 & 11,3 \\
50 & 24 & 452 & 13,8 \\
60 & 30 & 707 & 25,5 \\
70 & 35 & 962 & 25,5 \\
80 & 39 & 1195 & 23,3 \\
100 & 46 & 1662 & 23,3 \\
150 & 62 & 3019 & 26,9 \\
200 & 73 & 4185 & 23,3 \\
237 & 82 & 5281 & 29,6
\end{tabular}


Ton der offenbar durch Lichtung in den letzten Jahren hervorgerufenen Zuwachssteigerung abgesehen, fällt das Maximum des Stärkezuwachses etwa in das 150 . Jahr; die durchschnittliche Jahrringbreite beträgt $1,7 \mathrm{~mm}$; die durchschnittliche jährliche Höhenzunahme beträgt bei einer gesammten Höhe von 43 Meter nur 18,1 cm.

Auf demselben Boden erreichte eine völlig frei (auf einer Brandfläche) aufwachsende Jugend in 17 Jahren $40 \mathrm{~cm}$ über dem Boden $9 \mathrm{~cm}$ Durchmesser und 7 Meter Höhe.

In Montana crreicht die Douglasia auf dem besten Boden (humoser, sandiger Lehm der Flussniederungen) mit 190 Jahren einen Durchmesser von $80 \mathrm{~cm}$ und eine Höhe von 35 Meter; die durchschnittliche Jahrringbreite beträgt somit $2,1 \mathrm{~mm}$, die durchschnittliche Höhenzunahme $18,4 \mathrm{~cm}$; das heisst auf dem besten Boden im lufttrockenen Montana mit kürzerer Vegetationszeit leistet die Douglasia nicht mehr als auf dem magersten Boden ihres Optimums.

Nur wo der Douglasia ein grosses Mass von Boden und Luftfeuchtigkeit gegeben ist (wechselnde Bodenfeuchtigkeit, nicht stagnirende), da erscheint sie auch auf dem Sandboden im südlichen Oregon zusammen mit der Lawsonia; selbstverständlich sind ihre Wachsthumsleistungen beträchtlich geringer; sie erreicht völlig ausgewachsen nur 38 Meter Höhe bei 1 Meter Durchmesser, während sie auf den lehmreichen Partien in unmittelbarer Nachbarschaft wieder bis zu 76 Meter emporsteigt.

Der werthrollste Theil des Baumes, der nutzbare Schaft lässt an Vollholzigkeit und Astreinheit nichts zu wünschen übrig.

Einige Angaben aus dem Optimalgebiete mögen über die Vollholzigkeit der Douglasia erwünscht sein.

Ein Baum, der 1 Meter über Boden $72 \mathrm{~cm}$ Durchmesser zeigte, besass bei 11 Meter $54 \mathrm{~cm}$, Tnhalt des Stückes somit $3,12 \mathrm{cbm}$, Inhalt der Walze 4,07 cbm, Formzahl des Stückes 76,6, Abnahme des Durchmessers auf 1 Meter Lünge $1,8 \mathrm{~cm}$;

bei 21 Meter war der Durchmesser $47 \mathrm{~cm}$, Inhalt des Stiickes 2,01 chm, Inhalt der Walze 2,29 cbm, Formzahl des Stückes 87,8, Abnahme des Durchmessers anf 1 Meter $0,7 \mathrm{~cm}$;

bei 31 Meter betrug der Durchmesser 35 (m, Inhalt des Stiickes 1,32 (b)m, Inhalt der Walze 1,73 (b)m, Formzahl des Stïckes 76,3 und Abmalmo des Durchmessers auf 1 Meter Iänge $1,2 \mathrm{~cm}$; der Rest des Baumes war abgebrannt.

Ein anderer Stamm lag zu Boden, die untersten 6 Meter waren wrorgrabumnt; der Durchmesser 6 Heter über dem Boden betrug $60 \mathrm{~cm}$; 
bei 11 Meter war der Durchmesser $57 \mathrm{~cm}$, Inhalt des Stückes 1,34 cbm, Inhalt der Walze 1,41 cbm, Formzahl des Stückes 92, Abnahme des Durchmessers auf 1 Meter Länge $0,6 \mathrm{~cm}$;

bei 21 Meter Durchmesser $50 \mathrm{~cm}$, Inhalt des Stückes 2,26 cbm, der Walze 2,55 cbm, Formzahl des Stiuckes 88,7, Abnahme des Durchmessers auf 1 Meter Lïnge $0,7 \mathrm{~cm}$;

bei 31 Meter Höhe, Durchmesser $40 \mathrm{~cm}$, Inhalt des Stückes 1,59 cbm, der Walze 1,92 cbm, Formzahl des Stückes 82,8, Abnahme auf 1 Meter Länge um $1 \mathrm{~cm}$;

bei 37 Meter, Durchmesser $29 \mathrm{~cm}$, Inhalt des Stückes 0,57 cbm, dêr Walze 0,75 cbm, Formzahl des Stückes 76, Abnahme auf 1 Meter Länge $1,8 \mathrm{~cm}$.

Die Schaftform dürfte von den besten Tamnen haum übertroffen werden; junge Stämme sind, wie alle Riesenbäume in der Jugend, sehr abfällig gebaut; für einen 80 jährigen Baum mit $75 \mathrm{~cm}$ Basisdurchmesser ist eine Formzahl von 29 sehr niedrig; wenn anders die Douglasia bei uns ein hoher Baum wird, sind hohe Umtriebszeiten zux Er'zeugung von vollholzigen Schäften nothwendig.

Hinsichtlich der Fähigkeit, sich von Aesten zu reinigen, habe ich schon früher hervorgehoben, dass die Douglasia dichten Schluss verlangt, um feine, schlanke, astreine Stangen zu bilden, die dann auch in dieser Eigenschaft unsere einheimischen Holzarten entschieden übertreffen; ron diesem dichten Schlusse bis zu röllig freiem Stande nimmt die Beastung zu, so dass im ganz freien Stande die Krone so tief herabreicht wie bei den einheimischen Coniferen.

Vergleicht man die gesammte Höhe des Baumes mit der Kronenlänge, so erhält man einige Anhaltspunkte über diese Frage, während das unter der Krone liegende Schaftstiick eigentlich die Höhe der Ungebung wiedergibt; ans vielen Messungen, die ich anstellte, kann ich sagen, dass etwa die Hälfte der Baumlänge in die Krrone fällt, eine bei dem lockeren Schlusse des vor der Besitznahme durch den Menschen herrschenden Naturplenterbetriebes durchaus nicht auffillende und ungünstige Erscheinung.

Tom Radius des Dougrlasholzes gehen 3 cm auf den weissen Splint: der Rest ist Kernholz, das unmittelbar bei der Fiallung des Bammes nur wenig durch cinen hellbraunen Farbenton rom Splint sich abhebt: aber rasch dunkelt diese Farbe der Luft und dem Lichte ausgesetzt nach, bis sie die Fïrbung des Gebirgslinchenholyes erreicht; bei am Boden verwendeten Brettern färbt sich insbesonders die harte Summerholzschichte tief blanschwar\%. 
Was den anatomischen Bau des Holzes anlangt, so besteht es, wie das Holz aller Nadelhölzer, vorwiegend aus spindelförmigen, verholzten Zellhiillen mit gehöften Tüpfeln auf den Radialwänden und den Tangentialwänden der letzten Herbstholzzellen. Diese Tracheiden sind bei der jungen Douglasia durchschnittlich 2,38 mm lang; mit dem Alter nimmt, wie bei allen Bäumen, die Länge der einzelnen Zellen (Fasern) zu, und die Fasern der 300 jährigen Douglasia haben eine Länge ron $3,50 \mathrm{~mm}$.

Die Markstrahlen sind denen der Lärche oder Fichte ähnlich gebaut; die Grenzzellreihen eines Markstrahles bestehen aus Tracheiden mit Hoftüpfeln, die dazwischenliegenden sind Parenchymzellen mit einfachen Tüpfeln; einzelne dieser zeigen eine eigenthümliche Verdickung in Gestalt eines zarten Spiralbandes. In den Markstrahlen verlaufen Harzgänge, oft je zwei in einem, die mit den zahlreichen, vertikalen des Holzes in offener Verbindung stehen. Die horizontalen Harzgänge treten mit den sie umschliessenden Markstrahlen bis in die secundäre Rinde über; die primäre Rinde trägt, wie schon erwähnt, Harzgänge, die vertikal verlaufen und diese kömnen gelegentlich, wie bei der Tanne, \%u harzerfuillten Beulen anschwellen; die Innemrinde (secundäre Rinde) ist sehr hart, da sie von einer sehr grossen Zahl spindelförmiger, steinharter (sclerosirter) Zellen, ähnlich wie bei der Lürche, durchsetzt wird.

Die Tracheiden des Frühjahrsholzes, welche, wie im Holze der Eibe, durch eine zarte, spiralige Verdickung ausgezeichnet sind, sind bezüglich ihrer Wandungsdicke und der Weite der Zellen (von Mittellamelle zu Mittellamelle gerechnet) im jungen wie im alten, im eng- wie im weitringigen Holze ganz gleich; es beträigt die Wandungsdicke zweier benachbarter Zellen 3,3 $\mu=$ micra, $(1$ Micron $=1 / 1000 \mathrm{~mm}$ ), die ' $/$ ellweite $=24,2 \mu$.

Die 'I'racheiden des Herbstholzes dagegen haben viermal so dicke Wandungen als die des Frrïhjahrsholzes, nämlich 13,2 $\mu$ (Gesammtwandung zweier $/$ ellen); die '/ellweite im Herbstholze aber variirt mit der Ringhreite, indem die \%ellweite (von Mittel- zu Mittellamelle) im jungen, weitringigen Holze 26,4 $\mu$ beträgt, wogegen die Zellweite des engringigen alten Holzes nur 16,5 $\mu$ misst, das heisst, das Zelllumen ist nur eine schmaie linie. Dabei ist auffallend, dass die Tracheiden des Herbstholyes meistens keine spiralige Verdickung ihrer Innenwandung reigen; die letyten englumigen Zellen des Sommerholzes enthalten zuweilen Spiralverdickung ('Tafel X).

Durch die Fremdlichkeit des Herm o. Booth war ich in die Latge vorsetyt, das älteste in Deutschland existirende Exemplar der 
Douglasia auf specifisches Gewicht und Harzgehalt untersuchen zu können; Herr J. Booth begleitete die schönen Versuchsstiicke mit folgender Etiquette: „Erzogen aus dem ersten von Douglas 1827 bis 1829 aus dem nordwestlichen Amerika nach England gesandten Samen, 1830 gepflanzt auf milden Lehmboden in Kleinflottbeck bei Hamburg, ältestes Exemplar in Deutschland, gefällt Januar 1882, Alter 52 Jahre, Höhe 16,19 Meter, Durchmesser 53 cm, $30 \mathrm{~cm}$ ïber dem Boden." Diese auffallend niedrig gebliebene Douglasia stand völlig frei und hatte nur einen durehschnittlichen Längenzuwachs von $31 \mathrm{~cm}$, einen Stärkezuwachs dagegen von $5 \mathrm{~mm}$ Jahrringbreite.

Ich untersuchte diese Querscheibe auf ihr specifisches Gewicht und ihren Harggehalt gleichzeitig mit einem aus Oregon stammenden Stücke einer: dreihundertjährigen Douglasia; beide lassen sich wegen der Altersverschiedenheit nicht direkt vergleichen, aber doch dürfte sich daraus entnehmen lassen, was die Douglasia bei uns zu leisten vermag:

Das junge, kräftig in die Dicke gewachsene, deutsche Exemplar zeigte rolle $8 \mathrm{~cm}$ Splintbreite mit Jahrringen von $10-12 \mathrm{~mm}$ Breite; aber mit dieser ausserordentlichen Jahrringbreite ging nicht auch eine ausserordentliche Verschlechterung (Weichheit, Schwamnigkeit) des Holzes Hand in Hand, sondern, da die harte Sommerholzregion die Hälfte bis Zweidrittel der Jahrringbreite einnahm, fand sogar eine Steigerung des specifischen Gewichtes statt; auch der alte Baum bestïtigte diese Erscheinung.

100 Volumtheile des abs. trockenen Holzes der amerik. Douglasia hatte

bei $0,8 \mathrm{~mm}$ Jahrringbreite $46,64 \mathrm{gr}$ feste Substan\% (spec. Gew.)

\begin{tabular}{|c|c|c|c|c|c|c|}
\hline 1,0 & $"$ & $"$ & 47,29 & $"$ & $"$ & $n$ \\
\hline 1,7 & $"$ & $"$ & 48,95 & $"$ & , & $"$ \\
\hline 2,0 & $"$ & ", & 56,00, & $r$ & " & $"$ \\
\hline 3,0 & $"$ & " & 59,00 & " & " & $n$ \\
\hline
\end{tabular}

Bis $4 \mathrm{~mm}$.Jahringhreite nimmt die Substanzmenge in einem gegebenen Volumen Hol\% zn, ron da an zeigen die amerikanischen Exemplare eine Abnahme.

100 Volumtheile des absolut trockenen Holzes der in J)eutschland gewachsenen Doughlasia hatten

bei $6 \mathrm{~nm}$ Jahrringhreite 50,99 gr feste Substan\% (spece (inw.)

"Zum "rergleiche mögren einige Angaben über die deutschen Nadelhïlzer hier folgen. 
Es enthält in 100 Volumtheilen des absolut trockenen Holzes die Tanne bei 1,0 mm Ringbreite $48 \mathrm{gr}$ feste Subst. (sp. G.) bayer. Hochebene

\begin{tabular}{|c|c|c|c|c|c|c|c|c|}
\hline$"$ & $" 1,4$ & $"$ & $"$ & $41 "$ & $"$ & $"$ & $"$ & $"$ \\
\hline$"$ & $" 2,7$ & $"$ & $"$ & 39, & $"$ & $"$ & $"$ & $"$ \\
\hline$"$ & $\because 6,0$ & $"$ & 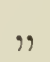 & $39 "$ & $"$ & $\eta$ & $"$ & T'oscana \\
\hline$n$ & $" 7,0$ & $"$ & $"$ & $38 "$ & $"$ & $"$ & $"$ & Hamburg \\
\hline "Ficlite & $" 1,0$ & $"$ & $"$ & 48, & $"$ & $"$ & $"$ & bayer.Hochebene \\
\hline$"$ & $" 1,0$ & $"$ & $"$ & $47 \%$ & $"$ & $"$ & $"$ & Norwegen \\
\hline$"$ & "2,9 & $"$ & $"$ & 42 & $"$ & $"$ & $"$ & Hamburg \\
\hline$"$ & $" 6,0$ & $"$ & $"$ & $36 \%$ & 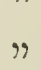 & $"$ & $"$ & bayer.Hochebene \\
\hline Lärche & $" 1,0$ & $"$ & $"$ & $66 "$ & $"$ & " & 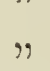 & Hochgebirg \\
\hline$"$ & $\# 2,0$ & $"$ & $"$ & $55 \%$ & $"$ & $"$ & $"$ & bayer.Hochebene \\
\hline$"$ & $" 2,2$ & $"$ & $"$ & $51 \%$ & $"$ & $"$ & $"$ & Hamburg \\
\hline$"$ & $" 6,0$ & $"$ & $"$ & $41 "$ & $"$ & $"$ & $"$ & bayer.Hochebene \\
\hline$"$ & $" 6,0$ & $"$ & $"$ & $41 \%$ & $"$ & $"$ & $"$ & Hamburg. \\
\hline
\end{tabular}

Daraus ergibt sich eine zweifellose Ueberlegenheit der Douglasia, die in ihren substanzreichsten, schwersten Holze der Lärche nahe konmt, in ihrem leichtesten Holze aber mit unseren besten (schwersten) Fichten- und Tannen- (auch Kiefern-) Hölzern auf einer Stufe steht; da mit dem specifischen Gewichte Brennwerth und zum Theil Tragkraft des Holzes parallel gehen, so dürfte das Douglasiaholz anch in diesen Eigenschaften den einheimischen Nadelhölzern (Lärche ausgenommen) überlegen sein; für die Dauer ist weniger das specifische Gewicht als die intensive Imprägnirung mit Kernstoff entscheidend; anch in dieser Hinsicht steht die Douglasia mit dem Lärchenholze auf gleicher Höhe.

Der Gehalt an Har\%, dem wenigstens im völlig ausgetrockneten Holze eine conservirende Rolle zugeschrieben werden muss, stellt sich bei der amerikanischen Douglasia folgendermassen :

Es sind in 100 Gewichtstheilen fester Substanz

$$
\begin{aligned}
& \text { bei 1,0 mm Ringhreite 2,204 } \mathrm{gr} \text { festes Harz (Kernholz), }
\end{aligned}
$$

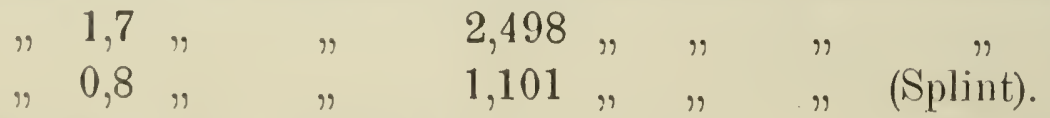

Dice deutsche Douglasia hatte

bei 8,6 mm Ringloreite 4,073 gre festes Har\% (Kernhol\%),

$$
\text { " } 5,0 \quad \text { " } \quad 2,426 " \quad " \quad "
$$

Ich glaube, dass der grosse Harygehalt in der deutschen Douglasia weniger nuf Zunahme der Jahrringbreite als auf das jugendliche Alter 
des Baumes zurückgeführt werden muss, überdiess zeigen alle Nadelhölzer unmittelbar $(30 \mathrm{~cm})$ über Boden einen erhöhten Harzgehalt.

Es zeigt die europäische

Tanne bei 1,4 mm Ringbreite 1,927 gr festes Harz (Kern) bayer. Hochebene

\begin{tabular}{|c|c|c|c|c|c|c|c|c|c|}
\hline " & . $\quad 2.7$ & ., & $"$ & 1,299 & $"$ & "y & $"$ & $"$ & $\mu$ \\
\hline . & .. 7,0 & $"$ & " & 2,283 & . & " & " & ." & Hamburg \\
\hline Fichte & $\because \quad 1,0$ & $"$ & 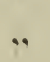 & 0,652 & ". & $"$ & $"$ & $"$ & Norwegen \\
\hline " & ., 1,0 & $"$ & $"$ & 1,260 & , & , & $"$ & $"$ & Bayern \\
\hline$\ddot{~}$ & $\because \quad 2,0$ & $\because$ & 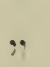 & 0,857 & 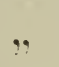 & . & $"$ & $\because$ & Tyrol \\
\hline "* & .. 3,3 &. & $"$ & 1,419 & , & $"$ & , & . & Hamburg \\
\hline Lärche & " 1.0 & " & " & 2,010 & " & $"$ & $\because$ & , & Hochgebirge \\
\hline ", & .. 1,0 . & $"$ & $"$ & 6,629 & $"$ & $"$ & $"$ & ., & Hochebene \\
\hline$"$ & $\because \quad 1,5$ & $"$ & $"$ & 7,275 & 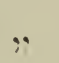 & " & $"$ & $"$ & Hamburg \\
\hline .. & , 2,0 & $"$ & " & 4,586 & $"$ & $"$ & $"$ & " & Hochebene \\
\hline " & . $\quad 2,2$ & ". & " & 4,106 & $"$ & $"$ & . & $"$ & Hamburg \\
\hline$"$ & $" \quad 6,0$ & , & $"$ & 3,702 & ", & . & $"$ & $"$ & Hamburg. \\
\hline
\end{tabular}

Daraus ergibt sich, dass der Harzgehalt nicht nur nach Baumarten verschieden ist, sondern auch innerhalb einer Art wechselt und zwar von der Baumhöhe und von individuellen geringen Schwankungen abgesehen, insbesonders mit dem Klima, indem das wärmere Klima harzreicheres Holz producirt, ausserdem, dass mit der abnehmenden Jahrringbreite, mit dem specifischen Gewichte auch die Menge an Harz abnimmt.

Eine weitere Aehnlichkeit des Holzes der Douglasia mit dem der Lärche rom specifischen Gewichte, Harzgehalt und der Kernfarbe abgesehen, besteht endlich noch darin, dass der imnere Kern am Fusse erwachsener, stehender Büume in Radialspalten aufreisst, in welchen das Harz aus den benachbarten Harkanälen sich ansammelt; da offenbar in dieser Region nicht alle Harygïnge bei dem Uebergang rom Splint in Kernhol\% sich durch die Füllzellen verschliessen; bekamntlich werden diese Spalten bei der Lürche angrebohrt und das Har\% ausgeschöpft, gleiches könnte bei der Dourglasia stattfinden.

Entscheidend für die Schwere des Holzes und die damit parallel gehenden übrigen Eigenschaften ist das Verhiltniss des harten. liernstoffreichen Sommerholzes zum leichteren, helleren, weicheren Frühjahrsholze; an einer Querscheibe durch den frei erwachsenen Stamm liegen die reitesten Jahrringe nahe dem Centrum, die engsten an der Peripherie; parallel mit der Abnahme der Jahrringbreite geht anch eine Verminderungr des Verhältnisses rom Sommer- zum Frïhjahrs- 
holze ror sich; es umfasst nämlich das Sommerholz im Innern des Stammes 0,5 der Ringbreite, im mittleren Theile 0,4, im äusseren Theile 0,3 .

Der rothbraune Farbstoff des Kernholzes, der nicht nur dic Wandungen der Zellen durchtränkt, sondern auch in den Parenchym-Markstrahlzellen und in den Harzganggeleitzellen in dickflüssigen Tropfen sich anhäuft, hat sich als ein Oxydationsprodukt des im Splinte in reichlichem Masse nachweisbaren Gerbstoffes erwiesen; dass diese intensive Imprägnirung mit Kernfarbe, insbesonders, wenn die Umwandlung durch die Aufbewahrung an warmen, luftigen Orten beschleunigt wird, die Dauer des Holzes wesentlich bedingt, wurde schon früher in der allgemeinen Betrachtung der Qualität der Hölzer hervorgehoben.

Die Feinde der Douglasia in der Heimat sind ziemlich zahlreich; am auffailligsten ist ein phanerogamer Schmarotzer, A ree u th ob i um Douglasii*), eine mit Viscum verwandte Pflanze, welche im kühleren, trockenen Montana sehr häufig, dagegen westlich von dem Felsengebirge nur selten auftritt; im südlichen Oregon und Californien sah ich sie gar nicht. Während bei den Viscum-Arten die Schmarotzerpflanzen selbst sich hexenbesenartig aufbauen, veranlasst Aceuthobium die Wirthspflanze zu einer eigenthümlichen, besenartigen Hypertrophie, welche in einer abnormen Verlingerung der befallenen Zweige besteht; wie im Osten sind diese Schmarotzer auch im Westen auf Nadelhölzer beschränkt.

Befällt eine solche Zwwergmistel einen Seitenzweig der Douglasia, so wächst dieser wieder in eine abnorme Zahl von Seitenzweigen aus, welche sich verlïngern und peitschenförmig geschwungen zu Boden hängen; der Leittrieb des Seitenzweiges stirbt ab und die Missbildung allein vegetirt weiter; solche Aeste brechen damn oft durch ihr eigenes Gewicht zu Boden. Ist die Missbildung an einem Aste hart am Hauptstamme, dann entwickelt sich die Wucherung zu ganz enormen Dimensionen; wird aber, was ebenfalls ziemlich häufig ist, der Gipfel selbst befallen, so verliert er den Leittrieb, und wird allmählig durch einen dichten Busch ersetzt, der alle in den Nadeln gebildete Nahrung selbst verbraucht, so dass der darunter liegende Stamm allmählig zu Grunde geht; beigegrebene Figur, nach der Natur gezeichnet, zeigt eine durch Arceuthobium getörltete alte Douglasia.

*) Diese und die folgenden Arceuthobien hat v. Tubeuf nach den von mir gesammelten Exemplaren ausführlich untersucht; diese Arbeit (1. c.) sowie deren schr genaue Habitushilder ïberheben mich einer ausführlichen Beschreibung. 
Von Nadelkrankheiten durch Cryptogamen (Parasiten) komnte ich trotz eifrigster Spähe weder an jungen noch alten Pflanzen etwas auffinden; ich fand auf Brandstellen junge Douglasias, gleich alt in grösster Menge, aber alle waren frisch und kräftig, unberührt von Insekten und Pilzen; so war es freilich früher auch bei uns, bevor Pilze und Insekten an der durch Kahlschlag gedeckten Tafel sich füttern und vermehren konnten. Dass die Douglasia so wie andere amerikanische Nadelhölzer von Natur aus mit grösserer Widerstandskraft gegen Jugendkrankheiten aller Art als unsere einheimischen Nadelhölzer ausgerüstet ist, lässt sich nach ihrem bisherigen Verhalten in ihrer zweiten Heimat, dem deutschen Walde, nicht gut behaupten.

An erwachsenen, starken Exemplaren findet man alte grosse Fruchtträger von 'l'rametes Pini, der durch die Zerstörung des Kernholzes im werthvollsten Schaftstücke als sehr schädlich erscheint; dabei verwandelt das Mycel des Pilzes das rothbraune Kernholz in eine weissgefleckte, durchlöcherte, brüchige Masse, wie diess die typische Zerstürung'sweise des Pilzes ist. (Tafel X.)

Häufig ist ferner am Fusse der

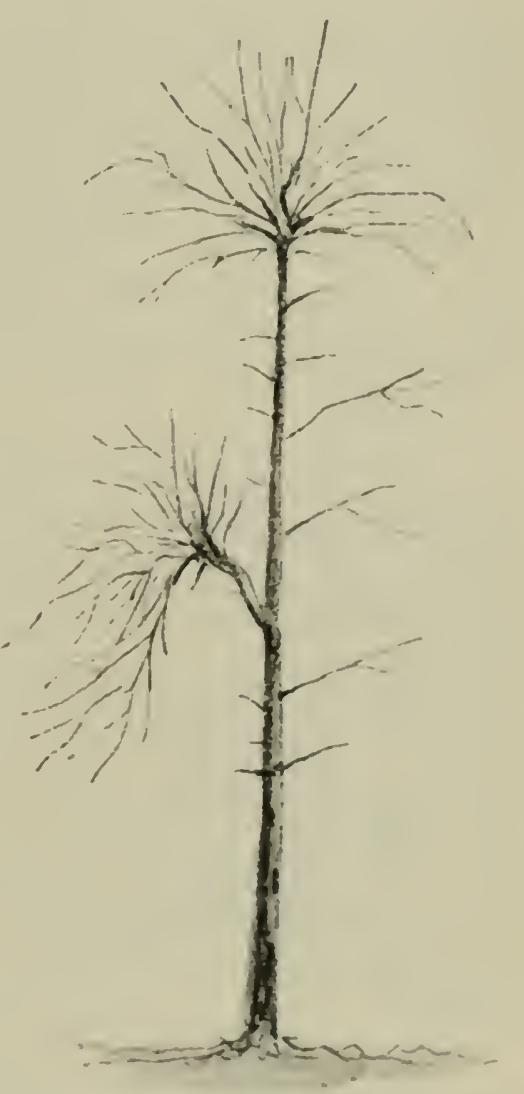

Fig. 10. Douglasia, von Areeuthobium befallen unil gelüdtet. Stämme ein Polyporus, den ich rou Polyporus hispidus an Rothbuchen nicht zu unterscheiden vermag; dieser verwandelt das Holz in eine gleichmässig dunkelbraune, brïchige Masse; das gleiche Verhalten zeigt der Pilz im Holze lebender. europïischer Rothbuchen.

Pseudotsuga Douglasii var. glauca, Colorado Douglasia ist ausgezeichnet durch eine auffillende, hellweissliche Fürbung der Nadehn; doch zeigen nur die cinjährigen Nadehn diese schü̈se Bereiftheit; an den zwej- und mehrjährigen Trieben verschwindet wiederum die weissliche Farbe, weshalb eigentlich nu jungren bxemplaren besondere Schönheit verliehen ist; anch andere soldhe glaucatVarietïten und -Arten, wie Pinns pungens, zeigen dieses Verhalten. 
Die glauca-Douglasia ist in Colorado, New-Mexico und Arizona (Santa Rita) heimisch. Auch der Zapfen zeigt einige Verschiedenheiten; er ist nämlich kleiner und ärmer an Schuppen als die westliche Form (Tafel VI); die kleinfrüchtige Douglasia von Montana bildet hierin die Verbindung zwischen der glauca und der typischen Douglasia. In trockenem und im Winter kälterem Klima erwachsen hat sich diese Varietät im Osten der Union als frosthart, das heisst wohl in den allermeisten Fällen als trockenhart, wenn man so sagen kann, erwiesen. Sie ist in ihrer Heimat wie überall, wo sie kultivirt wird (auch im deutschen Walde) langsamwüchsig (verglichen mit der typischen Form), eine unangenehme Eigenschaft, die ihre sonstigen Vorzüge wieder aufhebt; auch als Nutzholz soll sie weit hinter der Küstenform zurückstehen.

Pinus ponderosa Dougl., Yellow Pine, Gelbkiefer. Ihr Verbreitungsgebiet ist kaum kleiner als das der Douglasia, von Vancourer bis Siud-Californien und durch die Rocky Mountains bis Colorado und Montana tritt sie schon im westlichen Texas und Dacota auf; ihr Optimalgebiet, wenigstens was die Dimensionen betrifft, liegt entschieden in den Westhängen der Sierra Nevada in Californien; allein durch den beschränkten Standort ist sie dort nicht in sehr grosser Zahl; die Rocky Mountains, die östlichen Gebiete umfassen Standorte, welche diese Holzart in ausgedehnten Waldungen sowohl allein als in Mischung mit der Douglasia erfüllt und dort liegt anch das Gros der Industrie, die das Gelbkiefernholz verarbeitet.

Diese Kiefer ist botanisch von den übrigen westlichen Kiefern gut unterschieden, obwohl sie, wie bei ihrer enormen Verbreitung zu erwarten steht, in mehreren Varietäten auftritt, ihre Neigung zur Variation tritt sogar in ein- und derselben Oertlichkeit, ohne sichtbaren Grund hiezu auf.

Auf dem San Bernardino-Berge in Süd-Californien gesammelte Exemplare zcigen die /appen in Quirl bis zu sechs zusammenstehend, mit kurzen Stielen, $10 \mathrm{~cm}$ lang und $5 \mathrm{~cm}$ Durchmesser, wenn offen; die Nadeln mit 22 cm Iü̈nge, 1,5 mm Dicke; die Zapfenquirle schliessen durch ihr. Wachsthum in zweiten Jahre, im Jahre der Reife, so fest zusammen, dass der gleichzeitig sich entwickelnde, darüber stehende Trieb theilweise verkïmmert; er bleibt kurz und die Nadehn erreichen nur die halbe Dicke und die halbe Länge; die Apophyse ist vorstehend mit scharfem, gerade abstehendem Spitzchen; am offenen Zapfen stechen die Stachelspitzen an den Apophysen über die Oberfläche des Zapfens hinus, cin gruter Unterschied gegenüber dem Zapfen der Pinus Jeffreyi, 
welche Kiefer man so lange als Varietiit von Pinus ponderosa angesehen hat.

Unmittelbar neben diesen Exemplaren fanden sich andere mit $13 \mathrm{~cm}$ langen und $8 \mathrm{~cm}$ dicken Zapfen; die Apophyse derselben an der Basis kugelförmig mit nach der Spitze zugedrehter Stachelspitze, mit Nadeln von $24 \mathrm{~cm}$ Länge und $2 \mathrm{~mm}$ Dicke.

Dieselbe Kiefer im nördlichen Montana, also etwa 240 geographische Meilen nördlicher, besass Zapfen mit $7,5 \mathrm{~cm}$ Länge und $6 \mathrm{~cm}$ Dicke, wäbrend die Nadeln kaum eine Verschiedenheit $(19 \mathrm{~cm})$ aufweisen; die Apophyse mit sehr feinen, scharfen Spitzchen.

Wie bei der Douglasia erfährt auch bei dieser Kiefer das Höhenwachsthum mit Znnahme der Luftfeuchtigheit eine beträchtliche Steigerung; Exemplare, die in Montana aus Samen erwachsen waren, die der Wind aus den benachbarten Waldungenin die Prärie hinausgetragen hatte, die also an der Grenze ron Wald und Prïrie standen, erreichten be$90 \mathrm{~cm}$ Durchmesser nicht mehr als 25 Meter Höhe; die im feuchteren Waldgebiete, ebenfalls in Montana stehenden, erwachsenen Exemplare erheben sich auf bestem Kiefernboden bis $z u$ einer Höhe ron 35 Meter mit $70 \mathrm{~cm}$ Stammdurchmesser; dieselbe Holzart zeigt in den Blue Mountains, also näher der Feuchtigkeitsquelle, eine Maximalhöhenentfaltung von 45 Meter bei 1 Meter Stammdurchmesser; cndlich am Westabhange der San Bernardino-Berge sind Exemplare mit 75 Meter Höhe und 1,9 Meter Durchmesser ein gruter Durchschnitt; nach dem Censusberichte sind auf den noch feuchteren Hängen der Sierra Nevada des mittleren Californien sogar Bäume mit 90 Meter und vollen 4,5 Meter Durchmesser gefillt worden. Völlig

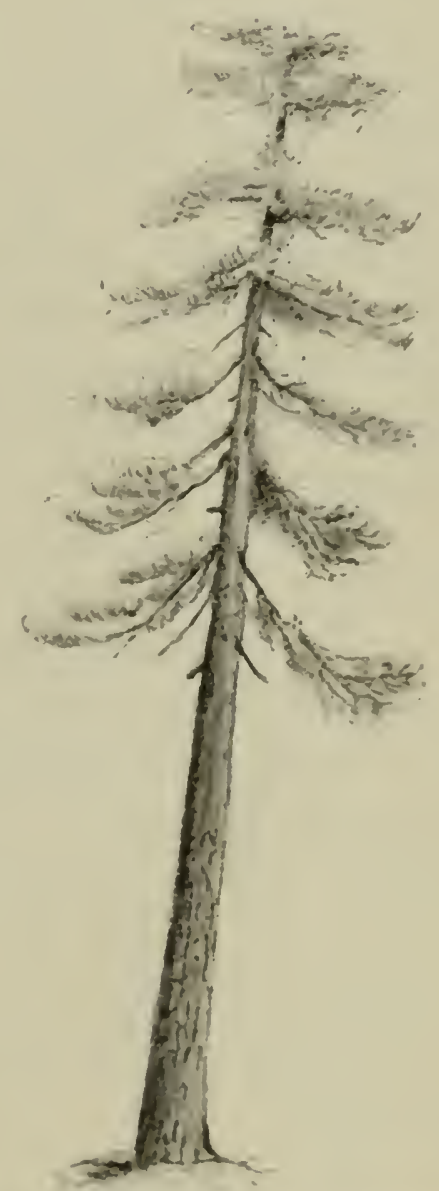

Fig. 11. Erwachsene Gelbkiefer (Pinus ponderosa);

San Bernardino, vo Neter hoch. frei erwachsene Exemplare sind tief herab beastet; die Aeste selbst vielfach knieförmigr gebogen wic ron einer malerischen Eiche; die granze Krone scheint bei den an der Prärie stehenden Bäumen compacter und mit einer zweijährigen, graugrüenn lienadelung rerdichtet, als wollte der Baum sich anf diese Art geegen 
allzu grosse Terdunstung schïtzen; dagegen fällt bei der frei erwachsenen Gelbkiefer im feuchteren Oregon ihre lockere, mit Bartflechten behangene Bekronung auf, bei der nur eine einjährige Benadelung an den Enden der mehr geschwungenen Aeste sich anhäuft.

Die Knospen des Baumes sind cylindrisch, plötzlich in eine kurze Spitze endigend; Schuppen anliegend, bräunlich mit weisslichen Spitzen; Ende des Triebes glänzend braun mit weisslichen Harzkörnchen; später wird die Rinde hellgrau, kleinschuppig, mit bramen Stellen zwischen den Schuppen; mit dem Alter wird sie dunkler; endlich treten grosse Borkenplatten auf, röthlich, durch tiefe Risse geschieden. Löst man aus der Borkenplatte kleine Schuppen ab, so ist die frische Stelle hell ockerfarbig; in der Borke kleine Höhlungen mit Harz erfüllt, die isolirten Endigungen der horizontalen Harzgänge im Basttheile; die Nadeln an der Basis kräftiger Triebe gédreht. Die jungen Pflanzen wachsen sehr rasch nach den ersten 5 Jahren, bilden oftmals Jahrtriebe ohne Seitenäste: an Pflanzen in besten Wachsthume sind einjährige Triebe mit $3,2 \mathrm{~cm}$ Durchmesser und mit einer Markröhre von 1,7 cm Dicke nicht selten; die den Trieb abschliessende Knospe hat gleiche Dimensionen; grössere Ruheknospen dürfte es, ron Monocotyledonen abgesehen, unter den phanaerogamen Pflanzen wohl nicht geben.

Die Pflanze beginnt in der Jugend mit ciner dicken Stammbasis, um für die spätere Dimension die nöthige Standfestigkeit zu erhalten.

Einige Angaben über die Wachsthumsleistungen im Urwalde mögen hier am Platze sein. Auf sehr gutem Boden in Montana, wo die Bestände mit überwiegend Douglasia und Lärehen gemengt waren, hatte cine Durchschnittskiefer in 230 Jahren 1 Meter über Boden $70 \mathrm{~cm}$ Durchmesser ohne Rinde erreicht; bei 6 Meter ïber Boden war der Durchmesser $50 \mathrm{~cm}$; bei 17,3 Meter $37 \mathrm{~cm}$, bei 25 Meter $30 \mathrm{~cm}$ und 34,6 Meter betrug die gesammte Höhe des Baumes; der Cubikinhalt beziffert sich als Durchschnitt aus mehreren Berechnungsweisen auf 4,92 cbm, wodureh sich eine Formzahl ron 37 ergibt, eine für das Alter des Stammes sehr hohe Zahl.

Der Stärke\%wachs bei 6 Meter über dem Boden war folgender:

\begin{tabular}{c|c|c|c}
\hline $\begin{array}{c}\text { Alter } \\
\text { (Jahre) }\end{array}$ & $\begin{array}{c}\text { Durchmesser } \\
\mathrm{cm}\end{array}$ & $\begin{array}{c}\text { Kreisfliche } \\
\square \mathrm{cm}\end{array}$ & $\begin{array}{c}\text { Zuwachs pro Jahr } \\
\square \mathrm{cm}\end{array}$ \\
\hline 10 & 5 & 19,6 & 2,0 \\
20 & 10 & 78,5 & 5,9 \\
30 & 14 & 154,0 & 7,8 \\
40 & 16,5 & 214,0 & 6,0
\end{tabular}




\begin{tabular}{r|c|c|c}
\hline $\begin{array}{c}\text { Alter } \\
\text { (Jahre) }\end{array}$ & $\begin{array}{c}\text { Durchmesser } \\
\mathrm{cm}\end{array}$ & $\begin{array}{c}\text { Kreisfläche } \\
\square \mathrm{cm}\end{array}$ & $\begin{array}{c}\text { Zuwachs } \\
\square \mathrm{cm}\end{array}$ \\
\hline 50 & 21,4 & 359,0 & 14,5 \\
60 & 23,6 & 429,0 & 7,0 \\
70 & 26,4 & 547,0 & 11,8 \\
80 & 28,0 & 616,0 & 6,9 \\
90 & 30,0 & 707,0 & 9,1 \\
100 & 31,6 & 784,0 & 7,7 \\
130 & 36,2 & 1018,0 & 7,8 \\
160 & 40,2 & 1170,0 & 7,6 \\
20)$. & 44,8 & 1575,0 & 6,1 \\
215 & $45,9$. & 1654,0 & 5,2 \\
& & &
\end{tabular}

Der Hauptstärkezuwachs fällt zwischen 50 und 70 Jahren, ist durchaus ein sehr geringer gewesen; während der letzten 65 Jahre betrug die Jahrringbreite nur $0,4 \mathrm{~mm}$; volle $7 \mathrm{~cm}$ ist die Breite der Splintschichte, der Uebergang in das Kernholz ist ein sehr unregelmïssiger; Dicke der Rinde an der Basis 3, in der Mitte des Stammes $2 \mathrm{~cm}$.

In den Blauen Bergen zeigte eine Gelbkiefer mit 320 Jahren bei 1 Meter über Boden einen Durchmesser ron 3,8 Meter; bei 22 Meter über Boden $63 \mathrm{~cm}$ Durchmesser.

Gesammte Höhe 44 Meter, sohin Cubikinhalt des Baumes 15,55 cbm mit einer Formzahl von 31 .

Der Stärkezuwachs 1 Meter über Boden war folgender:

\begin{tabular}{c|c|c|c}
\hline $\begin{array}{c}\text { Alter } \\
\text { (Jahre) }\end{array}$ & $\begin{array}{c}\text { Durchmesser } \\
\mathrm{cm}\end{array}$ & $\begin{array}{c}\text { Kreisfläche } \\
\square \mathrm{cm}\end{array}$ & $\begin{array}{c}\text { Zuwachs pro Jahr } \\
\square \mathrm{cm}\end{array}$ \\
\hline 10 & 3,8 & 11,3 & 1,13 \\
20 & 8,8 & 60,8 & 4,9 \\
30 & 15,6 & 190,7 & 13,0 \\
40 & 24,0 & 452,0 & 25,13 \\
80 & 59,0 & 2734,0 & 57,0 \\
100 & 68,0 & 3632,0 & 44,9 \\
150 & 94,0 & 6940,0 & 66,2 \\
200 & 112 & 9852,0 & 58,2 \\
320 & 122 & 11690,0 & 15,3
\end{tabular}

Auch der Zuwachsgang dieses Baumes beweist, dass er bei der langsimen Kulturmethode des Urwaldes lange Zeit unter dem seitlichen Drucke zu kimpfen hatte; die Jahrringe des letzten Jahrhunderts waren so ausserordentlich fein, dass sie sich kaum mit der Lupe erkennen liessen. 
Eine andere Kiefer war auffallend durch ihre Vollholzigkeit des werthvollsten Schaftstückes:

0,6 Meter über Boden betrug der Durchmesser des Holzes $100 \mathrm{~cm}$

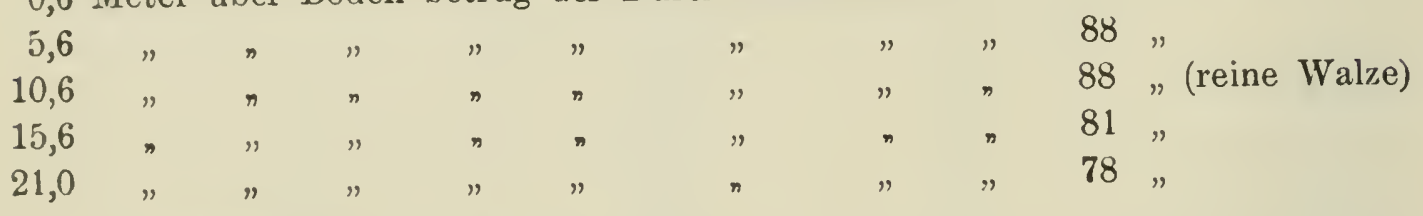

Gesammthöhe 43 Meter, Inhalt des Stammes somit 18,91 cbm, Formzahl des Schaftes 56.

Unsere einheimische Tanne, wohl der vollholzigste Baum, hat nach den bayerischen Massentafeln bei $100 \mathrm{~cm}$ Baumstärke eine Formzahl von 40 .

Der Splint betrug an diesem Exemplare durchaus $16 \mathrm{~cm}$; das New-Yorker Sammlungsstiick weist $21 \mathrm{~cm}$ Splint auf; dieser Wechsel der Splintbreite ist für den Werth, besonders die Dauer des Holzes von grösster Berleutung. Im nördlichen Californien auf vorzüglichem, vulkanisch-sandig-humosem Boden, Verhältnissen, in welchen die Pinus ponderosa ihr Maximum an Wuchskraft entfaltet, geht damit Hand in Hand auch eine auffallende Verbreiterung des Splintes; auf solchen feuchten, kräftigen Standorten bleibt auch die Borke auffallend klein, diinn, grauschuppig; der Baum heisst dort Pitch-Pine, da aus den Baumstïmpfen nach der Fällung sehr reichlich Harz ausfliesst, denn fast der ganze Holzkörper eines Baumes von 1 Meter Durchmesser besteht aus Splint.

Eng geschlossene Gruppen von gleichalterigen Stämmen, etwa 20-30 an der '/ahl, findet man öfter; sie rühren wohl von Windbriichen her; in solchen Gruppen ist die Bodenbedeckung auch in hohem Alter nur von kräftigen Nadeln hergestellt; sie geben einen Anhalt, wie gewaltig sich die Holzmassenproduktion pro Fläche durch eine dichtere Verjüngungsweise bei geregelter Bewirthschaftung wird steigern lassen, ob nachhaltig, ist freilich eine andere Frage.

Dass die Cielbkiefer in den Bergen die sandig-kiesigen Oertlichkeiten occupirt, braucht kaum erwähnt zu werden; je nach der Güte derselhen wechselt die Wachsthumsleistung und die Schwere des Holzes.

Soviel scheint aus meinen Messungen und den Zahlen des Censusborichtes hervol\%ugehen, dass das kühlere Gebirgsklima der Rocky Mountains keinen grïnstigen Einfluss auf die Güte des Holzes übt, soweit für diese das specifische Gewicht ein Coëffieient ist; denn Splinthol\% von $1 \mathrm{~mm}$ Ringrbreite hat in Montana und Colorado ein spmeifisches Gewicht von 49, während solches von Californien ein 
specifisches Gewicht ron 54 aufweist; mit der Zunahme der Jahrringbreite sinkt das specifische Gewicht; bei $7 \mathrm{~mm}$ Ringbreite hat californisches Holz nur ein specifisches Gewicht von 44 ; bei $1 \mathrm{~mm}$ Ringbreite scheint bei dieser Kiefer, wie wohl bei den meisten Nadelhölzern, das schwerste Holz gebildet zu werden. Soviel kann man wohl behaupten, dass das Gelbkiefernholz in Schwere das unserer einheimischen Kiefer nicht übertrifft und dass erstere den Namen ponderosa nicht verdient.

Die Gelbkiefer entwickelt in lockeren Boden eine in die Tiefe gehende Pfahlwurzel mit zahlreichen seicht streichenden Astwurzeln; in der Heimat bleiben junge Pflanzen im ersten Jahre sehr niedrig; kaum 1,5 cm über den Cotyledonen erreicht der Trieb. Im zweiten Jahre beträgt die Länge $6,5 \mathrm{~cm}$, wobei die einfachen Nadeln durch die mit dem weiter unten beschriebenen Lophodermium besetzt sind; im dritten Jahre ist sie erst $12 \mathrm{~cm}$ hoch; rom fünften Jahre an hebt sich ihr Höhenwachsthum rasch und ein Jahres-Trieb mit dem oben erwähnten Durchmesser hat auch eine Länge von $1 / 2-1$ Meter.

Der Baum gehört der Section Tacda an, sowohl als dreinadelige Holzart als auch nach dem Bau seines Holzes; als ron einer westlichen, dreinadeligen Kiefer stammend, kann das Holz an den Parenchymwandungen der Markstrahlen erkannt werden, welche schwach rerdickt sind und wie die darunter liegenden Tracheïden einfache Tüpfel tragen, während bei den östlichen Arten der Section die Wandungen zart und nur die darunter liegenden Tracheïden mit T'üpfel versehen sind.

In ihrer Heimat leiden die ein- und zweijährigen Kiefern ron der Schüttekrankheit, soweit diese durch einen Pilz, ein Lophod e r m i um, veranlasst werden.

In der Sporenbildung ist der Pil\% ron Lophodermium Pinastri kaum verschieden; die acht glatten Sporen von der Länge des Ascus liegen in spiraliger Anordnumg; auffallend ist jedoch die Gestalt der Paraphysen, die eine wunderliche Copie verschiedener Spazierstockformen sind (Tafel X); so schlecht lateinisch das Wort baculiferus sein mag, so gut wie ein Eigemname ist es zur Charakterisirung des Pilzes immer noch; es mag desshalb der Pilz Lophodermium baculiferum n. sp. hoissen. Die Spernogonien erscheinen an einfachen und Kurtriebnadeln schon im ersten Jahre der Infektion; im zweiten reifen die Sporen in den Asken dor langgestreckten schwarzen Perithecien. Der Pil\% war vor der Auf zucht der Gelbkiefer im Osten der Union unbekannt, ist aber mit dem Samen, wohl an Nadelbruchstiicken, dorthin eingeschleppt worden, wo er die der'Zierde wegen gepthanzte P'inus austriaca sowic die P'inus resinosa durch Missfïrbung der Nadeln verunstaltet. 
Unter den phanerogamen Schmarotzern sei Arceuthobium robustum und das zierlich gebaute Arceuthobium occidentale erwähnt, welche, in der Rinde von Seitenzweigen lebend, diese zu abnormen Terlängerungen, zur Entwickelung eines hängenden Hexenbesens amreizen.

Chamaecyparis Lawsoniana Parl. (syn. Cupressus Lawsoniana M(urr.), Port Orford Cedar, White Cedar, Lawson's Cypresse, Lawsonia. Diesen schönen Baum bezeichnet der' Berichterstatter der amerikanischen Regierung als einen Baum, der dem ikonomischen Terthe nach unter den ersten stehe; der Baum ist weiters insufern interessant, als er, soweit die bisherigen Erfahrungen reichen, auch in Deutschland rortrefflich gedeiht; es ist diess um so auffallender, da sein Optimum im wärmsten Theile ron Oregon, im Siiden und unmittelbar an der rom warmen Mecre begrenzten Küste liegt, in dem Gebiete, in dem der Feigenbaum (Ficus Carica) und Eucalyptus röllig ungeschützt gedeihen, in dem Ende Norember die frostempfindlichen Dahlien noch in voller Blïthe stehen; dort gesellen sich zur Lawsonia, wie der Baum wohl kurz genannt werden mag, noch die Douglasia, die Küstenfichte und immergrüne Sträucher wie Rhododendron, Arctostaphylos und andere, welche die Nähe der Zone der immergrünen Holzarten verrathen.

Das Verbreitungsgebiet der Holzart ist sehr beschrïnkt; in Oregon greht sie nicht nördlicher als Coos Bay, in Californien findet sie sich am oberon Flusslaufe des Sakramento; dabei entfernt sie sich nirgends mehr als 7 geographische Meilen von der Küste. In dem Küstengebirge (Coast Range) steigt die Lawsonia etwa bis 500 Meter empor, liebt dic Ufor der Bäche, die engen, feuchten, der Sonne zugekehrten, also warmen Schluchten; dort stockt sie auf mineralisch kräftigem Boden und erwärchst zu reinschaftigen greraden Stïmmen; Höhen von 50 Meter und I)urchmesser von 1,78 Meter sind wohl gute Durchschnitte.

Auf sandigem Boden wechselt die Wachsthumsleistung selbstverständlich nach der Beimengung von 'Thon und Humus.

Auf frischen, sandlig-lehmigen Böden, da, wo das früher angegebene zweite Wachsthum der Douglasia stand, erwächst in 80 Jahren die Lawsunia bis zu cinn Höhe von 35 Meter mit einem Durchmesser von 78 c'n (mit Rinde); sie bleibt auf diesem Boden hinter der Douglasia, deren Optimum otwas nördlicher liegt, in ihren Wachsthumsleistungen \%uriick. 50 Mreter Höhe bei 90 cm Durchmesser in auscrewachsenem Zastande ist aurh dert rince gute Durchschnittsleistungr; 61 Meter Höhe 
und 4 Meter Durchmesser sind Maximalleistungen. Auf Boden, der als lehmiger Sandboden angesprochen werden muss, zeigte ein Exemplar mit 1 Meter Durchmesser 48 Meter Höhe; auch auf solchem Boden kommt bei genügender Bodenfeuchtigkeit die Douglasia und die Küstentanne fort, welche beide die Lawsonia in ihrer Höhenentwickelung überragen.

Endlich auf Boden, den wir etwa als mittleren Sandboden oder Sandboden III. Bonität bezeichnen würden, erheben sich uralte Exemplare in dem luft- und bodenfenchten Klima bis zu 38 Meter Höhe und 1,28 Meter Durchmesser; die Aeste beginnen bei einer Schafthöhe von 17 Meter; eine andere ganz nahe stehende Lawsonia hatte 39 Meter Höhe und volle 1,90 Meter Durchmesser, also keine Höhenzunahme im Vergleiche zum Stärkewachsthum.

Ueberall in der Heimat, wo immer durch die Axt oder durch Fener Platz geschaffen wurde, ja selbst in Gärten und auf wenig benützten Wegen siedelt sich die Lawsonia durch natürliche Besamung an, da der leichte Same überall hin rom Winde getragen wird und junge wie alte Exemplare reichlich alljährlich Samen herrorbringen.

Im Gebirge über 500 Meter, sowie auf der ganzen Ostseite der Berge tritt der Riesen-Lebensbaum (Thuja gigantaea) an die Stelle der Lawsonia.

Der Zuwachsgang an Stärke war für das New-Yorker Sammlungsstiick folgender bei etwa 3 Meter über Boden:

\begin{tabular}{c|c|c|c}
\hline $\begin{array}{c}\text { Alter } \\
\text { Jahre) }\end{array}$ & $\begin{array}{c}\text { Durchmesser } \\
\mathrm{cm}\end{array}$ & $\begin{array}{c}\text { Kreisfläche } \\
\square \mathrm{cm}\end{array}$ & $\begin{array}{c}\text { Zuwachs pro Jahr } \\
\square \mathrm{cm}\end{array}$ \\
\hline 10 & 3,4 & 9,2 & 0,9 \\
20 & 6,4 & 32,2 & 2,3 \\
40 & 11,8 & 109,4 & 3,8 \\
60 & 16,4 & 211,2 & 5,1 \\
80 & 20,8 & 339,9 & 6,4 \\
100 & 23,0 & 415,3 & 3,7 \\
120 & 26,4 & 547,0 & 6,6 \\
140 & 30,0 & 707,0 & 8,0 \\
160 & 36,0 & 1018,0 & 15,5 \\
180 & 41,6 & 1359,0 & 17,0 \\
193 & 44,2 & 1534,0 & 13,0 \\
& & &
\end{tabular}

splintbreite beträgt $3,2 \mathrm{~cm}$.

Aus dieser 'Tabelle greht herror, dass dieser Baum lange '/eit im Urwalde beengt war und langsam erwachsen ist, wïhrend Exemplare. 
die jetzt auf demselben Gebiete, auf kahler Fläche frei aufwachsen, mit 10 Jahren bereits $10 \mathrm{~cm}$ Durchmesser und 5,5 Meter Höhe erreichen, also einen Zuwachs ron $7,8 \square \mathrm{cm}$ pro Jahr bei $0,5 \mathrm{~cm}$ Jahrringbreite und $55 \mathrm{~cm}$ Jahrestrieblänge zeigen.

Die Lawsonia fällt in ihrer Heimat durch eine besonders starke, weissliche. Färbung der Blattschuppen-Grenzen auf der Unterseite der Zweige auf, während das kräftige Längenwachsthum in dem bogenförmig überhängenden zarten, weichen Längstriebe sich verräth. Das Ueberhängen des Leittriebes ist durchaus keine zufällige Erscheinung: und hat einen ganz anderen Grund als die bei den Trauer-Varietäten verschiedener Holzarten beobachtete Erscheinung; der überhängende Leittrieb richtet sich bekanntlich in folgenden Jahre völlig gerade auf. Das Ueberhängen des Triebes ist sogar ein guter Gattungscharakter. Zum Beispiel sämmtliche Tsuga-Arten, die indische, japanische und die drei amerikanischen Arten zeigen alle in der Jugend den abwärts gebogenen Leittrieb; auch unter den Laubhölzern kann man Aehnliches beobachten; so ist es auffallend, dass alle Ulmacaeen schief gestellte Endtriebe tragen, die sich erst später gerade richten. Unter den Holzarten, die man unter der Gattung Chamaecyparis zusammenfasst, sind zwei nordamerikanische Arten, deren Triebe in der Jugend gerade in die Höhe ragen, nämlich Chamaecyparis nutkaensis und sphaeroidea, während die beiden japanischen Arten sich wieder wie die Lawsonia verhalten. Es ist schr wahrscheinlich, dass die beiden genamnten Ausnahmen keine Ausnahmen, sondern entweder eine Regel für sich, das heisst eine eigene Gattung oder dass man sie mit Unrecht ron der Gattung Cupressus selbst abgetrennt hat, die auch steife Jahrestrjebe besitzt.

Die Rinde des jungen Batumes im Bestande ist braunroth, glatt, im Lichte heller; später wird sic klcinschuppig und geht im höhcren Alter in eine Borke über mit sehr langen, tiefen, verticalen Rissen; die I)icke der Borke beträgt bis $5 \mathrm{~cm}$, die Breite der Platten $5 \mathrm{~cm}$, dabei verlaufen die Risse eine Strecke abwäits, enden plötzlich, während unweit davon andere einsetzen und weiter abwärts verlaufen. Das beigegebene Habitushild gibt eine uralte Lawsoniana, auf geringem, lehmigem Boden erwachsen, wieder.

In Stangenholzalter sind die Zweige etwas anfrecht gerichtet, während die Spitzen stets abwärts hängen; an alten Bäumen kehren sie sich otwas nach abwirts, in der Regel mit gabeliger Theilung; die Krrme, in der Jugend liegelförmign, greeft im Alter weit aus und nimmt Zuckerhutform an; lis gesammte fürbung ist blaugriun. Die Früchte sind kugrelig, $8 \mathrm{~mm}$ im I)ur(hmesser, Zapfenschilder dünn mit einer 
rinnenartigen Vertiefung an der Aussenseite (Tafel VI). Der Same (Tafel VIII) soll ziemlich rasch seine Keimfähigkeit rerlieren; meine Erfahrungen stimmen hiemit nicht ganz überein; Same, den ich im November 1885 in der Heimat der Lawsonia in Coos Bay gesammelt, erwies sich, im Frühjahı $18 \varepsilon S$ in Japan ausgesät, noch gut keimfähig; dabei hatte derselbe eine Reise über den Stillen Ocean und zwei Reisen durch die Tropen über Singapore nach Deutschland und wieder zurück nach Japan zurückgelegt. Auch durch Stecklinge kam der Baum fortgepflanzt werden, ein Verfahren, das bekanntlich auch bei den japanischen Verwandten Ch. obtusa und pisifera sowie bei der Cryptomeria gehandhabt wird. Solche Stecklinge eilen den Sämlingen in Wachsthume beträchtlich voraus.

Von den aus Stecklingen erwachsenen Bäumen soll ein grösserer Procentsat\% ,rothfanl" oder pilzkrank sein als bei den aus Samen erwachsenen Bäumen der Fall ist, eine Erscheinung, die sich durch eine Infection der Schnittfläche des Stecklings zur Zeit der Pflanzung erklären lïsst. So lange die Pflanzen im krïf-

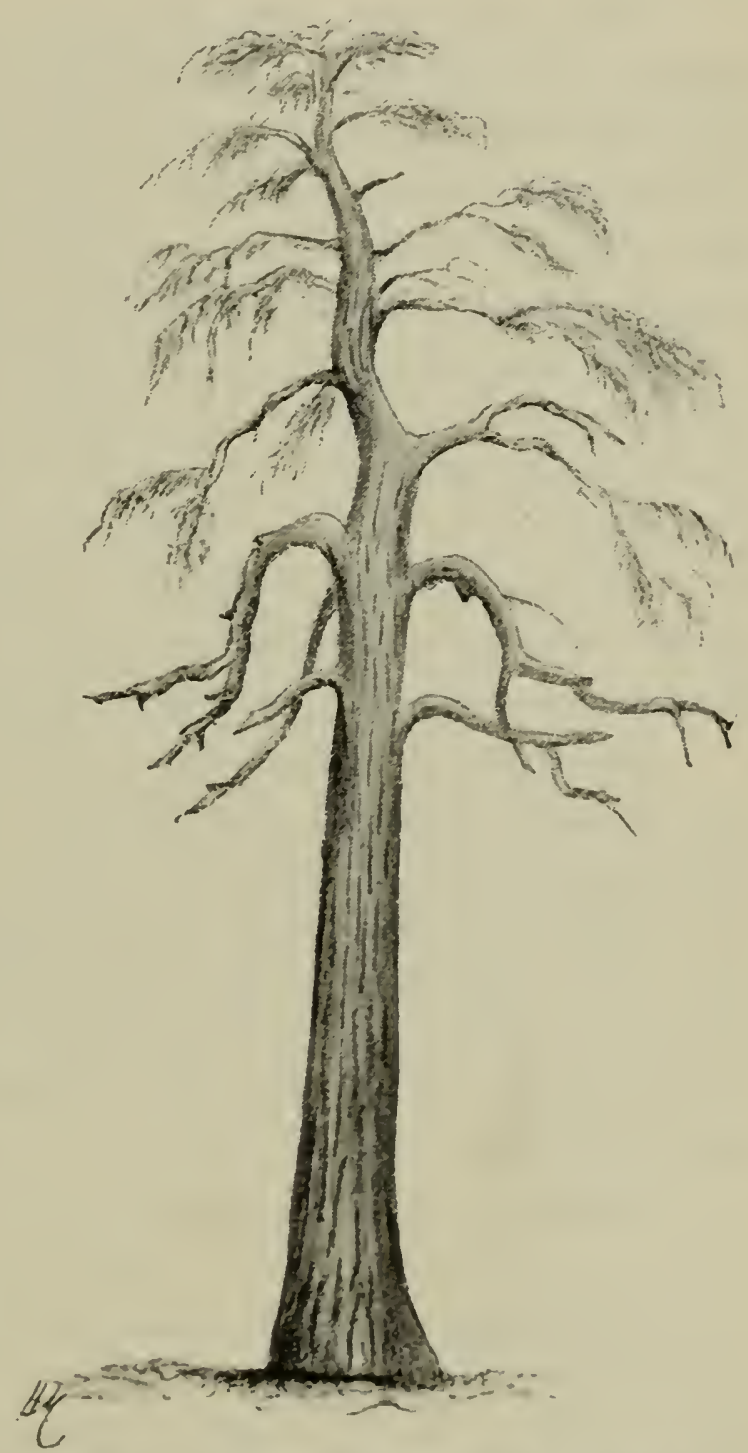

Fig. 12. rhamaccyparis Iawsonia, I.แsonia; altes Exemplar, 33 Meter hoeh, 1,23 Meter Durchmesser, Beginn der Aeste hei 17 Meter. tigen Dickenwachsthum stehen, bleibt der Pilz im Holzkörper zurück; erlahme die Wuchskraft der Pflanze, so eilt der Pilz voran und zerstört das Innere in grösserer Proportion als die nene Holzmasse hinzuwächst. Aehnliches kann man wenigstens bei den Stecklingspflanzungen in Japan beobachten.

Die Lawsonia kamn in der Jugend lange Keit Schatten ertragen, gedeiht aber im Waldgebiete auch völlig frei, wenn die Feuchtig- 
Keit der Luft stets gross ist; wo diese rasch wechselt, besonders im Winter, wie im östlichen Nordamerika, leidet ihr zarter Gipfel; es gibt diess einen Fingerzeig, durch seitlichen Schutz, durch Füllung der Pflanzung für Erhaltung der Fenchtigkeit der Luft und des Bodens \%u sorgen.

Wenn man sich einer Sägemühle nühert, die Lawsonia-Holz verarbeitet, so fällt der durchdringende, angenehme Geruch auf, den das frische $\mathrm{Holz}$ ron sich gibt. Es ist eine Eigenthümlichkeit aller Cupressineen, dass sie intensiv riechende Hölzer produciren und überdiess jede Art wieder ihren speciellen Geruch besitzt; die japanischen Cupressineen stehen den amerikanischen hierin nicht nach, Thujopsis dolabrata aber übertrifft alle Angehörigen der grossen Familie sowohl durch Stärke des Geruches als auch durch dessen Unannehmlichkeit. Manche Holzstücke der Lawsonia sind so mit dem ätherischen Oele durchtränkt, dass man sie analog der Verharzung bei den Nadelhölzern als ",erölt" bezeichnen könnte; solche Stücke sind ausserordentlich schwer, röthlich und emittiren einen Geruch, der Kopfweh verursacht. Diesem Oele rerdankt das Holz offenbar seine grosse Dauer.

Das Holz ist ausgezeichnet durch starke Zellwände des Frühjahrswie des schr schmalen Sommerholzes; darin liegt das hohe specifische Gewicht (46), die Härte des Holzes, verglichen mit der östlichen Verwandten, begründet; das Sommerholz erhält seine dunkle Färbung durch die zahlreichen, mit rothbraunem Kernstoffe erfüllten Längsparenchymzellen, die auf 'Tangentalschnitten auch mit freiem Auge sichtbar sind; die Markstrahlen enthalten nur Querparenchym; Harzgänge fehlen.

Der $4 \mathrm{~cm}$ breite Splint ist in Farbe nur ummerklich von dem helleren, gelblichen Kerne versehieden; schwach seidenartig glänzend mit feinen Jahrringgrenzen nimmt das Holz eine vorzügliche Politur an; das specifische Gewicht mit 46 ist für eine Cypressen-Art auffallend hoch; es ist leicht zu bearbeiten und dient besonders $z u$ Brettwaren für die innere Fertigstellung der Hüuser, zur Dielung, Eiscubahnschwellen, Zampfosten etc. In sumpfigem 'T'errain an der Mecresküste werden die Bäıme zu Rostbauten benützt, bei welcher Verwendung sie 4-5ma! längere Dauer besitzen als das Holz der Donglasia, das unter diesen ungünstigen Verhältnissen schon nach 4-5 Jahren zorstört ist. Bei solchen Bauten muss man aber erwähnen, dass die ganzen Stämme eingerammt werden, olne Rinde oder Splint zuvor zu cutfernen, oder missfurbige, pilzkranke Stïcke anszuschneiden, wie diess iiberhant in Amerika bei keiner Terwendungsweise des Bau- 
holzes geschieht. Desshalb sind auch alle Angaben über die Daner des rerwendeten Holzes nicht absolut zuverlässig. In dem erwähnten Falle scheint eher der Beweis geliefert, dass unter den Douglasia-Stämmen ein grösserer Procentsatz pilzkranken Materials sich findet.

Thuja gigantea Nutt., Red Cedar, pacifische Thuja, Riesen-Thuja, Riesen-Lebensbaum (sym. Thuja Menziesii Dougl., Thuja Lobii Hort., Thuja plicata Don. (zum Theil); zu dieser heillosen Menge von synonymen Namen hat wohl die Verwechslung dieser Art mit der folgenden viel beigetragen, ron der sie jedoch so grundverschieden ist; unter Thuja plicata beschreibt Willkomm in seiner forstlichen Flora eine eigene Art aus dem Nordwesten Amerika's, welche amerikanische Botaniker mit Recht als identisch mit der Thuja gigantea Nutt. auffassen; in der Flora Willkomm's ist unter "Thuja gigantea (syn. Lobii)" jener Baum beschrieben, der allgemein als Libocedrus decurrens Torr. gilt, während wieder unter dem Namen "Thuja JIenziesii" die wahre Thuja gigantea Nutt. beschrieben wird; freilich ist sie nicht ein Baum zweiter bis dritter Grösse mit einer Lünge ron 55 Meter.

Mit Hilfe der Abbildungen von Seitenzweigspitzen, Samen und Früchten der Cham. Lawsoniana, Cham. nutkaensis, Cham. sphaeroidea, Thuja occidentalis, Thuja gigantea und Libocedrus decurrens auf Tafel VI und VIII dürfte eine Bestimmung der Pflanzen in jedem Stadium ihrer Entwickelung möglich sein. Um anch die bei uns immer häufiger werdenden japanischen Verwandten daron trennen zu können, habe ich auch von Chamaecyparis obtusa, Cham. pisifera, Biota orientalis und Thujopsis dolabrata Seitenzweige und Früchte auf Tafel VI gezeichnet.

Die pacifische 'I'huja geht in vielen Stücken parallel mit der atlantischen Thuja, die im Gebirge auf unmittelbare Nähe der Bäche beschränkt ist, in der sumpfigen Ebene aber auf grosse Strecken hin selbst reine Bestände bildet. Auch die pacifische Thuja ist im Felsengebirge auf die unmittelbare Nähe der Gebirgsbäche angewiesen und erwächst, insbesonder's am Puget Sound in dem boden- und luftfeuchten Gebiete, nur wenig über dem Niveau des Meeres erhoben, zu gewaltigen Dimensionen. Der Censusbericht gibt 45 Meter Maximalhöhe an; nach meinen Messungen ist die Durchschnittshöhe der dortigen reinen Bestände oft 50 Meter und Exemplare von 54 Meter Höhe bei 1,75 Meter Durchmesser sind sehr häufig; 60 Meter dürfte wohl die Maximalentwicklung sein. 
Der Stamm baut sich auffallend spitz, kegelförmig auf, ja vielfach ist seine Form näher einem Neileïd als einem Kegel; die Basis ist enorm breit; in 2 Meter Höhe sind Durchmesser von 3 und mehr Meter häufig genug; dabei ist die Krone so schwach beastet und locker belaubt, dass der Stamm bis in die oberste Spitze erkennbar ist. Die Anfangs aufrecht stehenden Aeste senken sich bei alten Exemplaren; von ihnen hängen dann die feineren, dünnen Zweige mit der Benadelung senkrecht herab; das äusserste Ende des Triebes hebt sich in der Regel wieder etwas empor.

Der Baum erträgt lange Zeit von Jugend auf Beschattung, wächst dabei stetig, aber sehr langsam; bei eintretender Freiheit des Gipfels hebt sich das Wachsthum sehr rasch

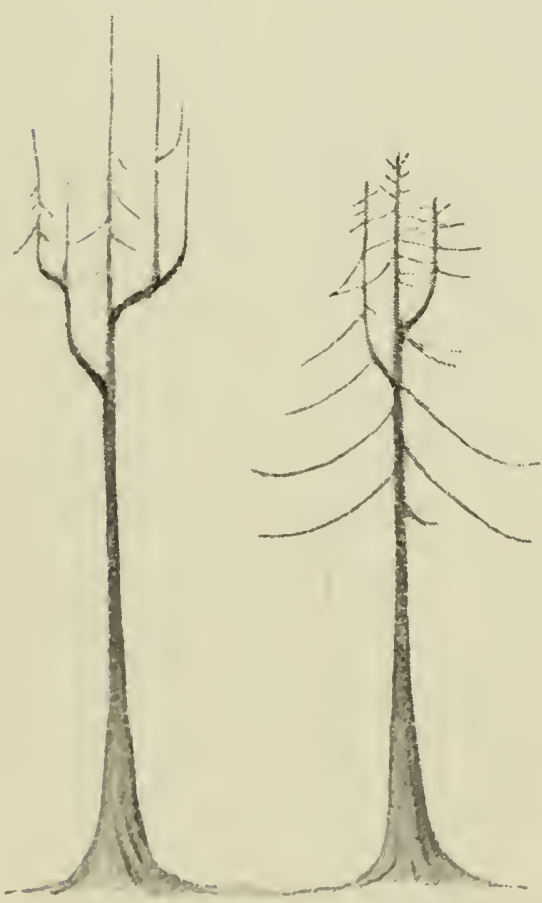

Fig. 13. Schaftormen der Thuja gigantea. und freistehende Exemplare erwachsen in der Jugend so schnell wie solche der Lawsoniana; wenn der Baum einen astreinen Nutzschaft bilden soll, muss er in engen Druck gebracht werden, denn er reinigt sich so schwierig von den langlebigen, harten Seitenästen, wie sein östlicher Verwandter; der Hauptstamn gabelt sich im hohen Alter gerne oder wird gebrochen, worauf neue Gipfeltriebe sich erheben; die beigegebene Schaftform, nach einem rom Feuer getödteten Stamme gefertigt, möge das dem Texte Fehlende ergänzen.

Den Baum deckt eine schmale, weiche und seicht-rissige Borke; die Risse zerlegen die Borke in lange $2-3 \mathrm{~cm}$ breite Stïcke; die gesammte Farbe ist grau bei freistehenden, röthlich bei im Schlusse aufgewachsenen Exemplaren; junge Pflanzen wachsen auch in der Heimat, wenn sie freistehen, kräftig; am Puget Sound erreichen einjährige Pflanzen 5,5 cm Lünge, zweijührige $13 \mathrm{~cm}$ Höhe, südlicher in Oregon erwachsen einjührige Pflanzen zu einer Höhe von $9 \mathrm{~cm}$, zweijährige bis zu $20 \mathrm{~cm}$; labei ist der Leittrieb stets gerade aufgerichtet; an den Seitentrieben fällt die hellere Unterseite auf.

Der Stärkezuwalds des New-Yorker Stüickes, das offenbar etwas freistehroml rerwadisen war, war folgender: 


\begin{tabular}{c|c|c|c}
\hline $\begin{array}{c}\text { Alter } \\
\text { (Jahre) }\end{array}$ & $\begin{array}{c}\text { Durchmesser } \\
\mathrm{cm}\end{array}$ & $\begin{array}{c}\text { Kreisfläche } \\
\square \mathrm{cm}\end{array}$ & $\begin{array}{c}\text { Zuwachs pro Jahr } \\
\square \mathrm{cm}\end{array}$ \\
\hline 10 & 7,2 & 40,7 & 4,1 \\
20 & 11,4 & 102,1 & 6,1 \\
40 & 23,8 & 444,3 & 17,1 \\
60 & 38,2 & 1145,3 & 35,0 \\
80 & 48,0 & 1810,0 & 33,2 \\
100 & 66,0 & 3421,0 & 80,5 \\
104 & 69,0 & 3739,0 & 79,5 \\
\end{tabular}

Das graubraune Kernholz bedeckt cin $3 \mathrm{~cm}$ breiter Splint; das Holz, unschön ron Farbe, von der Schwere des Weymouthskiefern-Holzes, ist schr dauerhaft bei Verwendung im Boden und wird zu Brückenbauten, Eisenbahnschwellen, Dachschindeln, Zaunpfosten, zu Füssern aller Art benützt.

Anatomisch fallen die weiten Lumina und die dümnen Wandungen der Frühjahrszellen auf, welche die Leichtigkeit des Holzes erklären; die Sommerholzschichte ist kräftig und dunkel, führt Lüngsparenchym wie die Lawsonia; auch im übrigen Baue folgt das Holz dem Typus der Cupressineen.

Libocedrus decurens Torr., White Cedar, Bastard Cedar, Heyderia. Auch dieser Baum hat rersehiedene Benemmungen erhalten, die man wenigstens im Deutschen rermeiden könnte, wenn man den Koch`schen Namen Heyderia aceptiren wollte; Carrière hat unglücklicher Weise diesen Baum als Thuja gigantea beschrieben, Koch nennt ihn Heyderia decurrens.

Wer diese und die vorigen Arten in ihren natürlichen Terbreitungsgebieten in jungen und alten Exemplaren sieht, der kann diese drei Arten unmöglich rerwechseln; rä̈mlich scharf geschieden sind sic auch botanisch in ihrem ganzen Aufban ron Rinde und Habitus. Die Thuja erreicht im südlichen Oregon jhre Südgren\%e; diess ist der Anfangspumlit der Lawsonia, an welche sich dann nach Sïden die Heyderia anschliesst, die in den Bergen zwischen 1500 und 2700 Meter an der Westscite der Sierra Nevada und des Küstengebirges mit Tamnen und Kiefern in grosser Menge auftritt. Dabei reicht sie in ihrer rertikalen Verbreitung hart an dic Grenze der gomässigt-kühlen Region heran; ob sie in dieselbe übertritt, ist cine Frage, denn die Tanne, mit der sie stets in Gesellschaft lebt, die Abies coneolor; ist keine typische Vertreterin der Fichten- und 'annenregion. 
Die Pflanze ist charakterisint durch den Aufbau der schuppenförmigen Blätter, von denen stets vier zusammen auf gleicher Höhe des Triebes sitzen ('Tafel VI); Schuppen scharf zugespitzt; 'Triebe aufrecht. An frei erwachsenen Exemplaren erscheint der Leittrieb in der Heimat der Pflanze oft iiberhängend, da solche isolinte Exemplare die Lieblings-Ruheplätze für die Tögel sind, welche durch ihr fleissiges Besitzen die elastischen Zweige während

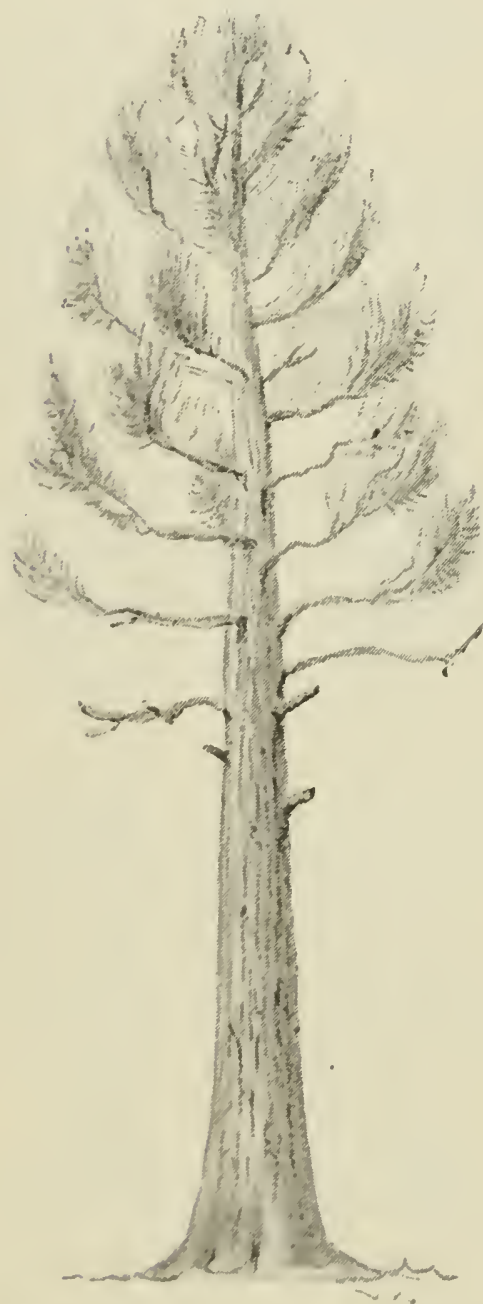

Irig 1i. Lilorentrus ilecurrens. ifi Heter locel, 1,3i, Neter Iurchmesser. der Vegetationszeit herabkrüummen.

Die ersten 10 Jahre wächst der Baum langsam, dann aber rasch in die Höhe; dabei geht die Rinde sehr bald in eine Borke mit kleinen Schuppen iiber, die sich leicht ablösen; später erscheinen damn Längsrisse. Den völlig erwachsenen Baum charakterisirt eine schr breite, tiefrissige, rothbrame, weiche Borke; Borkenplatten 8-10 cm breit, 4-6 cm dick; dabei unterscheidet sich die Borke ron der der Lawsonia dadurch, dass viele der Risse diagonal zwischen zwei Längsrissen verlaufen.

Wo ein Borkenthal verläuft, ist der imnen liegende Holzkörper ausgebaucht. so dass der Querschnitt eines Stammes einen grobwelligen Verlauf der Jahresringe freilegt; der helle Splint wechselt zwischen 7 und $16 \mathrm{~cm}$ in der Breite.

Der ansgewachsene Baum trägt eine Krone, die im Aufbau ganz wesentlich ron einer Thuja rerschieden ist; die Krone ist ein langgestreckter Zuckerhut, die Acste sind ku1\%, kräftig, sparrig und vielfarh knieförmigr gebogen und etwas aulgerefintet. Beigecrebene Figur, nach der Natur gezeichnet, stellt

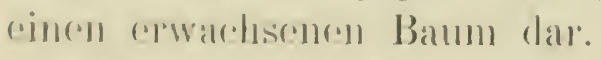

Firristelente Exemplare sind auffallend gelbgriü, während im Halfsidatten befindliche unfer junge Exemplare eine dombelgräue, enlinzende fö̈rhung tragens.

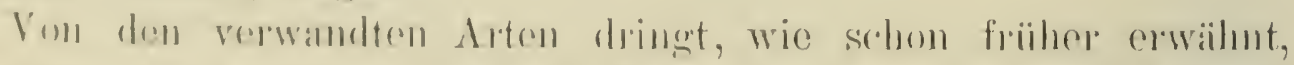

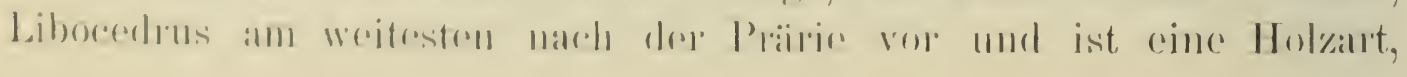


die auch Borlen mit rorwiegend sandiger Beimengung nicht verschmäht. Dorh liegt ihr Optimum auf mineralisch-kräftigem Borlen mit reichlicher Lufteuchtigkeit; im Cascaden-Gebirge in den fenchten Thälern, in der Sierra Nerada, in den San Bernardino-Bergen, hoch oben in den engen Schluchten, hart an den Ufern der Bergwasser gedeiht sie am besten.

Aus meinen Messungen ergibt sich als Maximalentwicklung 56 Veter Höhe und 1,56 Meter Durchmesser, während Höhen ron 50 Ireter einen gruten Durchschnitt darstellen. Trot\% dieser grossen Dimensionen ist sie in den genannten Bergen die Kileinste in ihrer Gesellschaft; die Tanne und die Zuckerkiefer, mit denen sie besonders gerne zusammen lebt, ïberragen sie noch ganz beträchtlich.

Bei der gegenwäitigen Misshandlung der Wülder lüsst sich anf dem sanzen Verbreitungsgebicte rler leichtsamigen Heyderia eine Ueberhanduahme dieser Holzart auf Kosten der werthrolleren Arten constatiren; der mit grossen Flügelrändern (Tafel VIII) versehene Same wird überall hin rom Winde getragen und in dichten Horsten wachsen die jungen Pflanzen empor, die langsamwïchsige Zuckerkiefer und Jeffrey's Kiefer, sowie die lichtbedüıftige Gelbkiefer erdrückend. Der rerhältnissmüissig grosse Zapfen ist aufrecht gerichtet (Tafel VI); Same der grösste unter den Verwandten.

Das schmutzig gelbbraune Kernholz des Bammes hat ein specifisches (iewicht ron 40 und einen eigenthïmlichen Geruch und Geschmack; beim Katuen des Holzes wird cin an Pfeffer erinnernder Stoff extrahirt, der schliesslich zum Auspuclen des Holzes \%wingt. Im anatomischen Bau stimmt das Holz mit dem der übrigen Verwandten ganz überein: das Längsparenchym ist anf die sommerholzregion beschränkt und sehr späirlich; für all' diese Hölzer sind Farbe und besonders der specifische Geruch, den man leider nicht beschreiben kann, die einzigen Unterscheirlung rmerkmale.

Die dunkle Farbe des Kernholzes verräth eine grosse Dauer: in der That ist das Holz zu Wasserleitungen, Schindehn und derogleichen sehr viel benützt.

Die Heyderia hat mehrere Feinde in ihrer Heimat. Ein Gymnosporangium sp.? veranlasst Beulen an den Aesten, oft hoch oben in der Krone des Baumes; ein Areuthobium lebt ebenfalls an der Heyderia und veranlasst hexenbesenartige Missbildungen dor Wirthpflanze. oft von einer Grösise, dass die hefallenen Wweige herabbrechen. Da ich jedesmal nur im Winter die westlichen Waldungen bestchen konnte. fehlen mir Bläthen tragende Exemplare; es scheint, dass Arocuthohion 


\section{- $324-$}

an Cupressineen in engeren Simne in Ancrika ziemlich selten sind; einstweilen mag die Zwrergmistel der Heyderia als Arceuthobium Libocedri n. sp. gelten. Sehx schädlich scheint ein Pilz zu sein, Daedalea vorax, der das Kernholz der stehenden Stämme zerstört; dasselbe erscheint durch denselben dunkel rothbraun gefärbt, mit grossen linsenförmigen Höhlungen; dabei wird das Holz sehr brïchig. Endlich sei noch eines Pilzes gedacht, der an den Schuppennadeln der Heyderia orangerothe Flecken verursacht: Chrysomyxa Libocedri mihi, der zur Zeit der Beobachtung (Ende November) in der Sporenbildung begriffen war (Tafel X).

Pinus Lambertiana Dougl., Sugar Pine, Zuckerkiefer, 7 uckerstrobe ist wohl die stattlichste von allen Kiefern, die sie überdiess alle an Tollholzigkeit, Geradheit und Astreinheit des Schaftes übertrifft.

Die Zuckerkiefer erreicht volle 92 Meter Länge, ist abcr langsamwüchsig durch ihr ganzes Leben hindureh; schon die einjährige Pflanze entwickelt nur einen 1,5 cm Längstrieb oberhalb der 12 Cotyledonen; in besten Falle erreicht sie in ihrer Heimat bis zu $3 \mathrm{~cm}$ im ersten Jahre. Die cinfachen Nadeln sind $3 \mathrm{~cm}$ lang; steif; im zweiten Jahre crreicht sie $51 / 2 \mathrm{~cm}$; an in voller Wuchskraft stehenden Pflanzen lassen sich keine Triebe von über $40 \mathrm{~cm}$ Länge auffinden.

Die Rinde der jungen Triebe ist spärlich mit braunen, kurzen Haaren besetzt, brïunlich grau; 5 Nadeln von $7 \mathrm{~cm}$ Länge stehen \%usammon in einem Kurztriebe; bei Regenwetter sind sie, wie bei der Sitrolus, zusammengeklebt. Das erste Drittel des Triebes ist nadellos; den 'Jrich schliesst eine Endknospe ab, die zwar kräftiger aber kürzer ist als die aufrechten Seitenknospen; dabei sind die Knospen verlıältnissmässig dïnn, völlig cylindrisch mit fingerhutförmigen Ende; die Kuospenschuppen stehen nur an dem obersten Rande etwas ab.

J)ie Riude bleibt lange Keit dunkel g'raugrün, dann elscheinen kileine, schmale, dunkelgraue Borkenstücke, spätes durch tiefe Risse

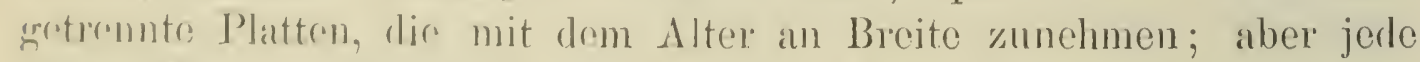
solcho Joskemplatte lässt sich wierler in zahllose kleine umregelmässig graformes Stüclir - ähnlich den Epidemismellen eines Blattes \%orthroilrn: dir frisch abgelösten Stellen sind dabei röthlich violett; stmmolt matl ein P'obestiick der Borke, so sieht man dasselbe, sobald

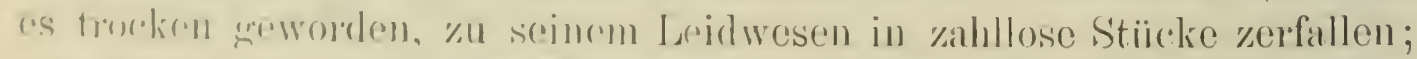

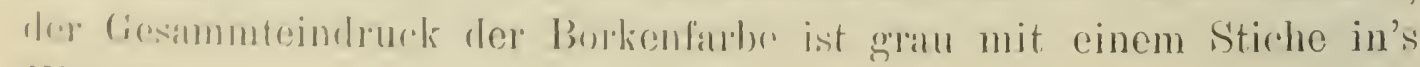
linlettre. 
Ausgezeichnet ist die Krone des Baumes, die in dem mässigen Schlusse des Urwaldes aus wenigen aber weit ausgreifenden Aesten aufgebaut ist; die Scitenäste selbst sind ziemlich dicht mit Nadeln besetzt, an ihren Enden hängren die grossen Zapfen. Wo dagegen die Krone frei ïber die Umgebung hinausragt, z. B. an den Bergkämmen, damn entwickelt sie eine Krone, welche offenbar den kleinsten Widerstand gegen Wind bietet, eine Krone, welche noch andere exponirt aufwachsende Nadelhölzer wie Pinus Pinea, die Cedrus-Arten im hohen Alter aufbauen; Fig. 16 c.

Die grossen, senkrecht herabhängenden Zapfen sind hell gelbroth und schon ron grosser Entfernung sichtbar; in den San BernardinoBergen, dem südlichsten Punkte des Vorkommens der Kiefer (soweit die gegenwärtigen Kenntnisse reichen; ihr Vorkommen auf einzelnen hohen Bergstöcken von Nieder-Californien ist sehr wahrscheinlich), ist der Stiel des Zapfens $11 \mathrm{~cm}$ lang, $2 \mathrm{~cm}$ dick. Der Zapfen selbst ist im guten Durchschnitt $42 \mathrm{~cm}$ lang; die kleinsten sind $35 \mathrm{~cm}$ auf $9 \mathrm{~cm}$ langen Stielen; Zapfen, wemn offen, $15 \mathrm{~cm}$ breit; Nadellänge am erwachsenen Baume $8 \mathrm{~cm}$. Die Zapfenschuppen sind an der Basis nach dem Sticle zurückgerollt; die Zapfenschuppe selbst verläuft in eine breite Schneide mit unscheinbarer Apophyse; Innenseite der Zapfenschuppe chocoladefarbig.

Im südlichen Oregon, im nördlichsten Torkommen der Kiefer. bleibt der Zapfen merklich in den Dimensionen zurück; die grössten Zapfen messen nur $34 \mathrm{~cm}$, die kleinsten 26 c'm ohne Stiel; der Samenflügel ist, wie der aller Kiefern der Section Strobus, am oberen Samenrande aufgewachsen, so dass der feine, braunrothe Flügel bei dem Reinigen des Samens stets abbricht.

Diese Kiefer verlangt ein kühleres, luftfenchteres Klima als die übrigen Kriefern; ilı Optimum liegt in den Bergen oberhalb der Gelbkiefer; ihre Ansprüche an die Feuchtigkeit der Luft und des Bodens decken sich mit denen, welche die Abies concolor stellt. Die Zuckerkiefor ist auf allen Bodenarten zu funden, verlangt aber für ihre tiefgehenden Wurehn einen lockeren Boden, sandig-lehmig, selbst lumoser Sand, kiesiger oder steiniger Boden mit reichlichen Verwitterungsprodukten da\%wischen und genïgender Frische; selbst Anschwemmungsbüblen der Gebirwsbäiche an deren Oberlauf trangen mächtige Exemplare der \%uckerkiefer. In den San Bernardino-Bergen nimmt

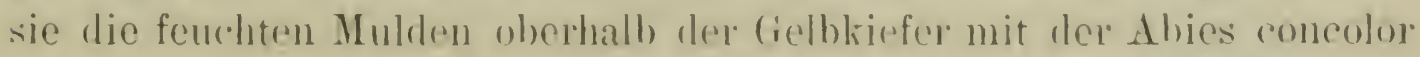
und der Legderia ein, steigt sellst höher als die Jeffrey's Kicfer. In der Sienar Nevada des mittleren Californien bildet sie mit der Tamne 
ausgedehnte Mischwaldungen und auf den nach Westen geneigten Thälern und Mulden zusammen mit der Sequoia gigantea dic schon beschriebenen merkwürdigen Haine.

Die junge Pflanze kann entschieden Ueberschirmung einige Zeit ertragen, gedeiht rortrefflich bei Jahrzehnte langer, mässiger seitlicher Beschattung und scheint wie die übrigen fünfnadeligen Kiefer'n, zum Bcispiel die östliche Schwester, die Strubus und die indische Schwester; die excelsa, auf sandreichen, der Sonne sehr exponirten Oertlichkeiten einen seitlichen Schut\% geradezu zu verlangen.

In allen Lagen und Bodenarten wächst die '/uckerkiefer ziemlich langsam und bleibt hinter den übrigen Kiefern (in gleicher klimatischer Lage) zurück; dafür aber wäichst sie gleichmässig und andauernd.

Eines der höchsten Excmplare, die ich zufüllig fand, stand auf dem san Bernardino und mass bei 2,59 Meter Durchmesser mit Rinde 64 Meter Höhe; die Aesta reichten ziemlich weit herab; unweit davon war eine Zuckerkiefer gefüllt mit einem Holzdurehmesser ron 1,61 Meter in 2 Meter Höhe; dieselbe zeigte folgenden Stïrkezuwachs:

\begin{tabular}{c|c|r|r}
\hline $\begin{array}{c}\text { Niter } \\
\text { Jahre) }\end{array}$ & $\begin{array}{c}\text { Durchmesser } \\
\text { cm }\end{array}$ & $\begin{array}{c}\text { Kreisfliche } \\
\square \mathrm{cm}\end{array}$ & $\begin{array}{c}\text { Zuwachs pro Jilır } \\
\square \mathrm{cm}\end{array}$ \\
\hline 10 & 3 & 7,1 & 0,7 \\
20 & 8 & 50,3 & 4,3 \\
30 & 14,4 & 162,9 & 11,3 \\
40 & 21,0 & 364,0 & 20,1 \\
50 & $2 \times, 0$ & 616,0 & 25,2 \\
60 & 35,4 & 982,0 & 36,5 \\
70 & 43,0 & 1432,0 & 47,1 \\
80 & 50,0 & 1963,0 & 51,1 \\
90 & 57,0 & 2597,0 & 63,4 \\
100 & 63,0 & 3117,0 & 52,0 \\
120 & 76,0 & 4536,0 & 70,9 \\
150 & 95,0 & 7085,0 & 85,0 \\
200 & 119,0 & 11122,0 & 80,7 \\
250 & 136,0 & 14527,0 & 68,1 \\
300 & 154,0 & 18714,0 & 81,9 \\
317 & 161,0 & 20331,0 & 95,1 \\
& & &
\end{tabular}

Die Rindendicke beträigt 10 ('m, die Splintbreite 12 cm.

Trotz des hohen Alters von 317 Jahren fand noch keine Abnahme

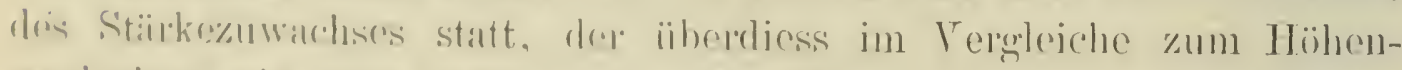

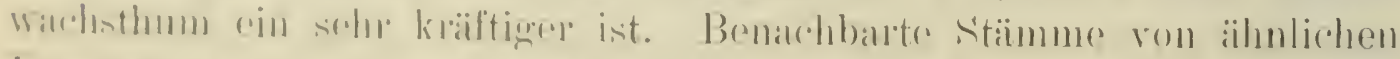

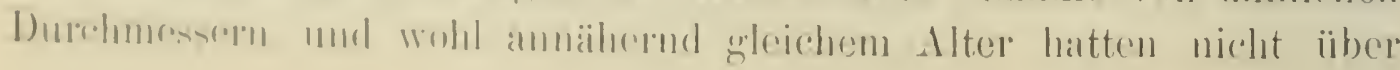


70 Meter; ja selbst Stämme mit 2,58 Meter Durchmesser mit Rinde hatten nicht über 64 Meter Höhe. Die Zuckerkfefer erreicht in diesen suidlichen Gebirgsstöcken kaum die Dimensionen der grössere Wärme liebenden Gelbkiefer, sie übertrifft kaum die Jeffrey's Kiefer; das Optimum liegt offenbar in den feuchten Thälern und hohen Bergen des mittleren Californiens; dort trifft man schon Exemplare mit nur 1,7 Meter Dürchmesser, aber 63 Meter Höhe; dort erreicht auch ihre Gescllschafterin, die Abies concolor, Dimensionen, gegen welche die Angaben der nordamerikanischen Florenwerke um volle 30 Jeter zuriickbleiben.

Das Holz spaltet in gewissen Standorten rorzüglich und war frïher allein zu Schindeln benützt; an manchen Standorten spaltet es gar nicht: was ron der damals ïberall barbarischen Benutzungsmethode übrig grelassen wude. ist jetzt in Sägremühlen ein hochwillkommenes Material, das zersägt bein Häuserbau zu Thüren, Blenden, zu Kisten, Füissern und Holzwaaren aller Art rerwendet wird.

Anatomisch gehört das Holz, wie die ganze Kiefer, zur Section Strobus; als von einer westlichen Art stammend ist das Holz durch schwach rerdickte, Tüpfel führende Markstrahl-Parenchymzellen ausgezcichnet; die darunter liegenden Tracheïdentüpfel correspondiren mit ersteren; bei weitlumigen Organen des Frühjahrholzes finden sich zwei bis drei schlitzaugenförmịge Tüpfel auf einer Tracheïdenwand, wodurch das Holz von anderen Angehörigen der Section und damit ron anderen Kiefern überhaupt unterscheidbar ist. Auffallend sind ferner am Holze die grossen Harzgänge. Obwohl im specifischen Gewichte etwas leichter als die Weymouths-Kiefer (nämlich 37), ist es doch nicht leichter zu bearbeiten; die Zellwandungen der Zuckerkiefer sind zäher, nicht so spröde als jene des Holzes der Wermouths-Kiefer.

An frischen Splintwunden tritt ein Saft aus, der eingetrocknet ein grelbweisses, bröseliges Mehl hinterlässt, das sich im Munde völlig auflöst und sïss schmeckt, und als Mittel gegen Husten gepriesen wird. Im August kommen zahlreiche Leute in den Wald, um diesen Zucker zu sammeln, daher rührt der Name Zuckerkiefer.

Pinus Jeffreyi Murr., Bull Pine, Jeffrey's Kiefer. Mit Unrecht wird diese prächtige Kiefer ron einigen Floristen als Varietät der Gelbkicfer aufgefasst; wo beide ummittelbar nebeneinander stehen, und doch eigentlich kein Grund zu einer Variation vorhanden sein kann, ist eine Verwechslung ummöglich, selbst wenn man zweihundertfüssige stämme vor sich hat, an denen man weder Zapfen noch Nadeln 
und Triebe erkennen kann, gibt der Bau und die Farbe der Borkenrinde untrüglichen Aufschluss.

Schon im zweiten Lebensjahre der Pflanze tritt ein typisches Icrkmal auf, das sie für ihr ganzes Leben auch beibehält, nämlich ein hell weissblauer Reif an den jungen Trieben; junge ponderosaTriebe sind stets glänzend braun. Die Nadeln sind etwas dem Triebe zugekehrt, bei der Gelbkiefer rechtwinkelig abstehend; sie sind nicht gebogen, von weisslich grüner Färbung, wogegen die Nadeln der Gelbkiefer dunkelgrün sind. Knospen ohne Harz, Knospenschuppen eng anliegend, hellrothbraun mit dunkler Spitze. Nadellänge im südlichen Oregon an der Nordgrenze der Verbreitung der Kiefer $23 \mathrm{~cm}$ lang, Zapfen $14 \mathrm{~cm}$ lang und $9 \mathrm{~cm}$ breit, wenn offen; Nabelspitzen der Apophyse am offenen Zapfen so weit zurückgebogen, dass keine über die Fläche des Zapfens hervorsieht; fasst man den Zapfen mit der Hand an, so fühlt man keine Dornen, welche dagegen an dem offenen Zapfen der ponderosa empfindlich stechen. Auf dem südlichsten Standorte der Jeffreyi in der Union, der zugleich ihr Optimum zu sein scheint, in den San Bernardino-Bergen - nach neuen Beobachtungen sollen die höheren Berge ron Nieder-Californien auch noch mit den Kiefern der San Bernardino-Berge bewachsen sein - erreichen die Zapfen, die in Quirlen bis zu sechs zusammen an kurzen Stielen sitzen, eine Länge von $18 \mathrm{~cm}$ und $10 \mathrm{~cm}$ Durchmesser an der Basis; der zweijälırige Tricb, welcher sechs solcher grosser /apfen tragen muss, hat einen Durchmesser von 2,5 cm; über einem solchen enggeschlossenen Quirle verkümmert im Jahre der Reife der Zapfen der entsprechende Jahrestrieb; die Nadcln erreichen nur $14 \mathrm{~cm}$ Länge und $1 \mathrm{~mm}$ Dicke, während die normale Lünge derselben im Süden $23 \mathrm{~cm}$ wie im Norden und $2 \mathrm{~mm}$ Dicke betrïgt.

Die schöne weisse Fürbung des Triebes verliert sich schon mit dreijährigem Alter desselben ganz; die äusseren Schichten springen auf und eine graue, dïnne Borke tritt an ihre Stelle; Grösse und Dicke der Schuppen nehmen mit dem Alter zu, aber auch an uralten Stämmen sind die Borkenschuppen stets viel kleiner als von der ponderosa; jede Borkenschuppe \%erfällt, ähnlich wie bei der /uckerkiefer, wieder in kleinere Jiguren mit hell weisslichem Rande; anf der Somnenseite ist der Gesammteindruck der Borke eine röthliche Farbe, auf der Nordseite dagegen weiss-violett; die frisch ausgelösten Borkenschuppen sind rosaroth gefürlot.

Das Vorhreitungsugebiet der Kiefer laisst sich dentlich abgrenzen; sio heginnt hinsichtlich der Elevation da, wo die Gelblsiefer an Kahl 
und Massenentwieklung bereits abnimmt und endet nach oben hin da, wo die Zuckerkiefer und concolor-Tanne ihr Optimum erreichen; dass natürlich einzclne Exemplare diese Grenzen überschreiten, ändert die Thatsache nicht, die sich überall im südlichen Oregon wie an der mexicanischen Grenze bestätigen lässt; sie liebt lockeren, kiesig-sandigen Boden mit reichlicher, wechselnder, nicht stagnirender Bodenfeuchtigkeit; wenn ein Thal sich sanft gegen einen Fluss abdacht, da steht auf der Krone des Thales die Gelbkicfer, etwas tiefer, näher dem Flusse Jeffrey's und unmittelbar am Wasser selbst Erlen und Weiden; wo das Terrain eine Mulde ohne stagnirende Feuchtigkeit im Centrum bildet, nimmt die Jeffreyi stets die tiefsten Punkte ein; wo dem lockeren Boden reichlich Quellen entspringen oder langsam im geneigten Boden abwärts suchen, da siedelt sich die Jeffrey's Kiefer in reinen Bestandgruppen an, wïhrend sie sonst überall nur zerstreut steht und anderen Holzarten beigemengt ist; an den Ufern des oberen Sacramento findet man auf dem lockeren, kicsigen Grunde, hart am Flusse präichtige Exemplare der Jeffreyi, während die anstossenden, trockneren Hänge nur yon der Gelbkiefer besiedelt werden; offenbar ist der Same der Jeffireyi dorthin rom Flusse aus den grösseren Hainen des Quellgebietes herabgeschwemmt worden.

Die Kiefern des erwähnten Standortes am Flussufer hatten, wenn ich das Mittel aus mehreren meiner Hessungen nehme, eine Höhe von 44 Meter und einen Durchmesser von 1 Meter; in der Sierra Nevada des mittleren Californien, in jener Höhe, in der die Riesen-Sequoien begrinnen, wo bereits keine Gelbkiefer mehr wächst, trifft man wieder die Jeffreyi in den flachen Mulden, während sic die luftfeuchten Thäler. das Eldorado der Riesen kaum betritt. Endlich im Süden erreicht sie nach meinen Messungen eine Durchschnittshöhe von vollen 61 Metern bei 1,4 Meter Durchmesser; dort ist ihr Holz höher geschïtzt als jenes iler Gelbliefer.

Ordnet man die Nutzholzarten, die sich in diesem Gebiete nahe bei einander finden, nach ihren Ansprüichen an die Bodenfeuchtigkeit, so erhiilt man folgende Reihe: Libocedrus, P'inus Jeffreyi, Abies concolor; Pinus Lambertiana, Pinus ponderosa, Pinus Coulteri.

Ordnet man dagegen dieselben Holzarten nach ihren Ansprüchen an die Feuchtiglieit der Luft, so erhält man die Reihe: Abies concolor, Pinus Lambertiana, Pinus Jeffreyi, Pinus Coulteri, Libnedrus. Pinus ponderosia.

In diesen allen Misshandlungen ausgesetzten Waldungen nimmt, wie schon erwälnt, die Heyderia am meisten von dem entblössten 
Borten in Besit\%. Auch die Tanne erscheint ziemlich zahlreich; die Gelbkiefer findet in den warmen, steinigen, felsigen Lagen eine \%ufluchtsstiitte: digegen sicht man selten junge Pinus Jeffievi, am wenigsten dic \%uckerkicfer und Coulter's Kiefer.

Die zukünftige Waldgeneration, wenn anders das Fener später abgehalten werden sollte, wird somit rusammengesetzt sein nach dem Terhiiltnisse der Schwere der Sämereien der einzelnen Holzarten, ein Geset\%, das sich, wie erwähnt, auch bei dem Laubwalde des Ostens vollzicht. Dabei wächst die

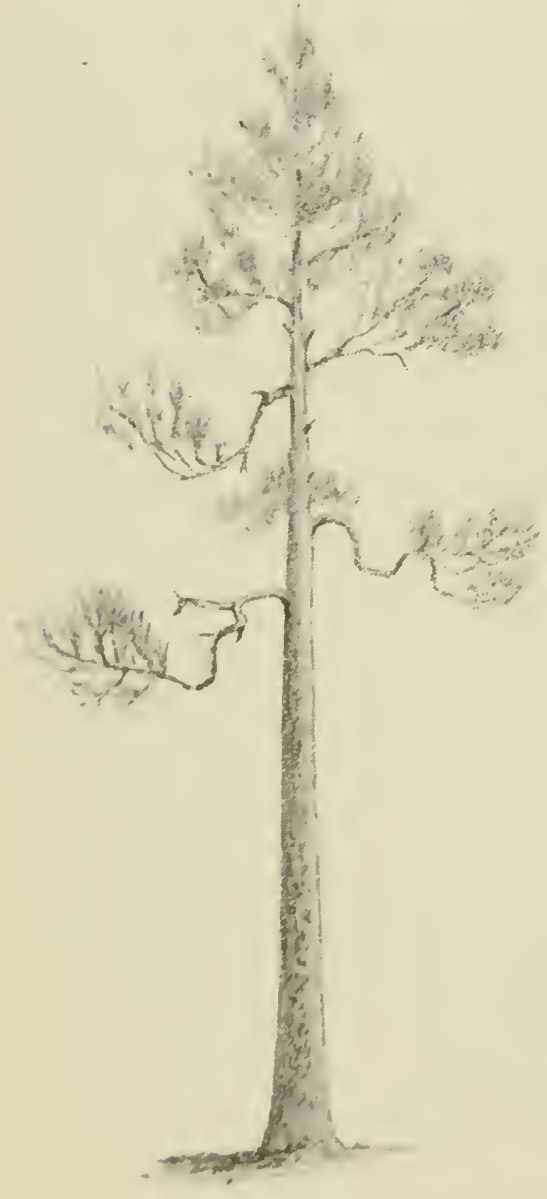

Fir. 1.i. Jeflrey's kiefor (l'ium Jeflireyi). Jugend der genannten Holzarten stets in isolirten Gruppen auf, aus denen später, wenn sie das Feuer nicht rernichtet, ein schlecht geschlossener Waldbestand mit allen seinen Nachtheilen hervorgehen muss.

Dic junge Jeffreyi bleibt im ersten Jahre nieder; einige der jungen Pflanzen schliessen - was cine Seltenheit bei einer Kiefer ist - noch in demselben Jahre mit einer durch häutige Schuppen geschützten Winterknospe ab; auch im zweiten und dritten Jahre wächst sie langsam, erst dann streckt sich der schön weissliche Längstrieb beträchtlich. In der Jugend steht sie hinsichtlich ilurer Ansprüiche an das Licht zwischen der /uckerkicfer und der Gelbkiefer; wïhrend letztere stets volles Licht rerlangt, gerleiht die Jeffreyi anch bei ciniger Ueberschattung angenseheinlich grut; doch ist es sehr wahrseheinlich, dasssice im deutschen Walde, wo Wüirme und anch Licht beträichtlich geringer sind als in dur Hoimat, bessere im vollen Oberlichte, nur seitlich etwas urechiitzt, anfwarlsen wird.

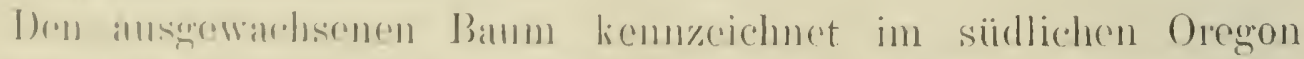

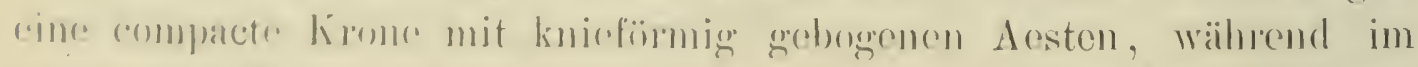

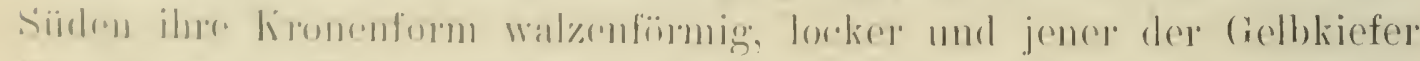

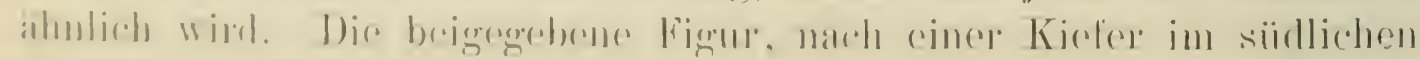

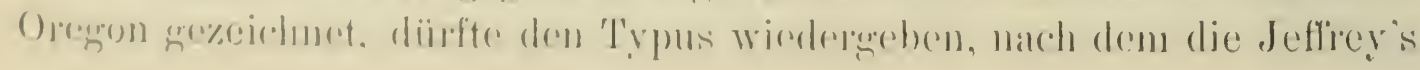


Kiefer sich bei uns, wenn anders sie ein grosser Baum wird, aufbauen wird.

Nach dem New-Yurker Sammlungsstücke war der Stärkezuwarhs 2-3 Meter über Boden

\begin{tabular}{|c|c|c|c|}
\hline $\begin{array}{c}\text { Alter } \\
\text { (Jahre) }\end{array}$ & $\begin{array}{l}\text { Durchmesser } \\
\text { cm }\end{array}$ & $\begin{array}{c}\text { Kreisfliche } \\
\square \mathrm{cm}\end{array}$ & $\begin{array}{c}\text { Zuwachs pro Jahr } \\
\text { der Periode } \\
\square \mathrm{cm}\end{array}$ \\
\hline 10 & 6 & 28,3 & 2,9 \\
\hline 20 & 11 & 95,0 & 6,7 \\
\hline 40 & 20 & 314,0 & 10,9 \\
\hline 60 & 29 & $6(; 1,0$ & 17,3 \\
\hline 80 & 37 & 1078,0 & 20,7 \\
\hline 100 & 45 & 1590,0 & 25,7 \\
\hline 107 & 47 & 1735,0 & 20,1 \\
\hline
\end{tabular}

Mit 100 Jahren scheint das Maximum an Zuwachs noch nicht überschritten zu sein, denn die letzten Jahrringe ergeben immer durch die grössere Schwindung bei der Austrocknung Zuwachsmessungen, die mit denen tiefer liegender Partien nicht genau verglichen werden liönnen; die Splintbreite betrïgt rolle $15 \mathrm{~cm}$; nach meinen Messungen umfasst der Splint zwei- bis dreihundertjähriger Exemplare $12,5 \mathrm{~cm}$ rom Radius des Holzes; immerhin wird dureh diesen breiten Splint der Werth des Schaftholzes wesentlich beeinträchtigt; das Kernhol\% hat eine schöne, rosarothe Fürbung, auffallend durch die Feinheit und Zartheit der Sommerholzregion und die grossen Harzgänge; anatomisch grehört das Hol\% zum Typus der Section Taeda, mit schwach rerdiekten Parenchymzellen.

Das Holz mit einem specifischen Gewichte ron 52 dürfte dem unserer einheimischen Kiefer an Werth kaum nachstehen, wenn es auch in Amerika, wo es zu Nutzholz in grosser Menge zersïgt wird. als coarse lumber bezcichnet wird, - eine grobe Ware im Vergleiche zur Zucker- und Weymouthskiefer.

Pinus monticola Dougl., Bergstrobe, rertritt die Section Strobus in dem Cascaden-Gebirge rom Washington und Oregon, wo die \%uckerkiefer an ihrer nördlichen und die Berg-Strobe an ihrer siidlichen Grenze incinandergreifen; sie bewohnt fermers die inneren Bergzügre ron Britisch Columbien, Ilaho und Montanal wie die z̈brigen stroben steight aluch diese an den Bergen alus ihner gembissigt-wamen

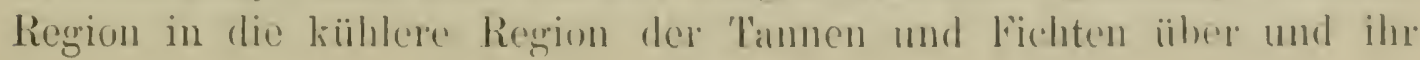


isolirtes Torkommen zwischen Tamnen, Fichten und Lürchen beweist, dass aluch sie eine Pflanze ist, der längere Zeit in der Jugend der Halbschatten zum Vortheile gereicht, und die durchaus nicht an bestimmte Standorte gebunden ist; in Einzelmischung mit Douglasia und Lärche errcicht sie eine Maximalhöhenentwicklung von 46 Meter bei cinem Durehmesser ron 1,5 Meter; die Pflanze ist botanisch in jeder Hinsicht ein Mittelding zwischen Weymouths-Strobe und ZuckerStrobe; die Nadeln sind $10 \mathrm{~cm}$ lang; junger Trieb mit braunen Haaren; der Zapfen sitzt anf $2 \mathrm{~cm}$ langem Stiele, ist 23 cm lang und wenn offen, $6 \mathrm{~cm}$ breit; Borke grau, keinschuppig, der Weymouthskiefer sehr ähnlich. Das Holz folgt im anatomischen Baue völlig dem der Section Strobus.

Pinus Coulteri D. Don, Coulter's Kiefer. Schon aus dom früher crwähnten Standorte, trocken, warm, liesig-lehmig, im Kieferngebiete der hohen San Bernardino- und Cuyamaca-Berge des südlichen Californiens kam man schliessen, dass dieser Baum in seiner Höhenentwicklung hinter seiner Umgebung zurückbleiben wird; in der That erreicht er im günstigsten Falle nur 46 Meter, 35 dürfte bereits cinen guten Durchschnitt darstellen. Der Baum ist dabei astreich und die starken Aeste, bestimmt, die grossen Zapfen an ihren Fnden zu tragen, schwingen sich zuerst nach abwärts, um damn ihr Ende wieder empor zu heben; die schweren Zapfen in Quirlen erhalten sich in reichlicher Zahl an Baume ron mehreren Jahrgïngen und zerfallen damn in der Regel schon an Baume in Schuppen.

Dic Zapfen sitzen auf 3 ('m langen, $6 \mathrm{~mm}$ dicken Stielen; Zapfen des ersten Jalnes kugelig, 4,5 cm lang und breit, Schuppen mit hackenfriminger Aprohyse aufwälts geliümmt; der reife \%alpfen zeight eine I) urchischnittslänge von $25 \mathrm{~cm}$ (30 ('n dürfte wohl das Maximum sein) und wenn geschlossen cine Dicke von 15 ('m; Kapfen etwas abwïrts hïngend. Apophyse des '/apfens in eine dicke, breite, stachelige Spitze ansiafend, die an der Spitze des Zapfens dieser, an der Basis desselben zugetiümmt ist. Fischer Zalpfen, hellockerfarbig, matt, meist mit zahlecichen hellgelben Hawtropfen; 1 Kilo und dariiber schwer; Kunspen aylindrisch mit dicht anliegenden Schuppen; junge Triebe grolberriun; Nadroln 27 am langr, zu drei in einem Kur\%tricbe; Rinde des erwachsenen Bammes eine ranhe, schmalrissige, dumkelgrame Borke.

Aus dre Aehulichkeit der Kapfen der Sibin'schen und Coulter'schen Kirfern (wregen dor Simen wolle Talfel VII vereglichen worden) hat man auch anf oine Achulidhleit der Bäume ïberhaupt geschlossen mit grossem Unrecht; demn die Sabin'sche Kiefer rerhält sich zur 
Coulterschen etwa wie eine Teide zu einer Pyramidenpappel; die Coulter'sche Kiefer hat stets einen ungetheilten geraden Schaft, reich an abwärts geschwungenen Seitenästen, so dass ihr Habitus eher mit dem einer freistehend erwachsenen Fichte zu vergleichen ist; den Habitus der Sabin schen Kiefer gibt Figur 9 wieder.

Das weiche, leichte Holz zeigt einen $13 \mathrm{~cm}$ breiten Splint; der Kern ist röthlich.

Diese Art bildet auf den Hügelköpfen Haine ron schr lichter Stellung, so dass die Jugend fast völlig frei aufwachsen kann; Beschattung scheint sic gar nicht ertragen zu können.

In der ersten Jugend ist sie ziemlich raschwüchsig; ein 111 Jahre altes Exemplar hatte

\begin{tabular}{c|c|c|c}
\hline $\begin{array}{c}\text { Alter } \\
\text { (Jahre) }\end{array}$ & $\begin{array}{c}\text { Durchmesser } \\
\text { cm }\end{array}$ & $\begin{array}{c}\text { Kreisfläche } \\
\square \mathrm{cm}\end{array}$ & $\begin{array}{c}\text { Zuwachs pro Jahr } \\
\text { der Periode } \\
\square \mathrm{cm}\end{array}$ \\
\hline 10 & 10,0 & 78,5 & 7,8 \\
20 & 14,4 & 162,9 & 8,4 \\
40 & 25,0 & 491,0 & 16,4 \\
60 & 34,0 & 908,0 & 20,8 \\
80 & 41,4 & 1345,0 & 21,8 \\
100 & 48,0 & 1810,0 & 23,2 \\
111 & 52,0 & 2124,0 & 29,0
\end{tabular}

Anatomisch und nach seinem Aufbau gehört der Baum zur Section Taeda mit den Eigenthümlichkeiten einer westlichen Holzart in den Parenchỵmzellen der Markstrahlen.

Pinus contorta Dougl., Scrub Pine, Drehkiefer. Von Alaska an südllich bis in das mittlere Californien heimisch, bleibt diese Kiefer ganz auf die Küste beschränkt, wo sie nicht über 9 Meter Höhe crreicht; auf Vancouver, wo der Baum auf sandigem Boden ebenfills häufig ist, ist die Drehkiefer astreich mehr ein Strauch als cin Baum.

Die Nadellänge (zwei Nadelı zusammen in einem Kurztriebe) beträgt $5 \mathrm{~cm}$ bei $1 \mathrm{~mm}$ Dicke; Knospenschuppen fest anliegend mit Hiu\% verklebt; Zapfen $4 \mathrm{~cm}$ lang, $3,5 \mathrm{~cm}$ breit wemn offen, glïnzend hellbraun; Apophyse wenig erhaben, Nabel schwarz, Nabeldorn nach vorn der Spitze zugewendet, oft anliegend, ebenfalls schwar\%, leicht abbrechend. Diese Farbenuntersehiede und die Stellung des Dormes scheinen typisch zu sein; Rinde kleinschuppig grau, nur wenign Millimeter dick. 
Tom ihr worde mit Recht die nach Habitus, Verbreitung und gut botanischen Merkmalen unterschiedene Murray'sche Kiefer getrennt, die, da sie ihr Optimum in der gemässigt-kühlen Region findet, dort nïhlier betrachtet werden soll. -

Unter den westlichen Tammen findet sich eine Art, dic entschicden dem Laubholygebiete angehört, wo sic ihr Optimum erreicht; sie greift jerloch anch in die gemässigt-kühle Region über. Es ist diess

Abies grandis Lindl., White fire, grosse Küstentanne, Tanne ron Vancouver. Von der Insel Vanconver, wo sie die rinzigne 'lanne ist, an der Küste entlang bis zum nördlichen Californien herrscht sic in der kïhlen Region der Blanen Berge und an den Westhängen des Felsengebirges. Thr Optimmm liegt an der Küste in Oregon und Washington, wo sie oft mit der Riesenpappel zusammen eine Höhe bis zı 92 Ureter erreicht; auf ihrem z̈stlichen trockenen Grenzgebicte dagegen crhelot sie sich in engen, feuchten Schluchten kaum bis zu 30 Meter.

Sie ist die erste 'lanne, die den von der Prärie kommenden Reisenden der Northern Pacific R. R. begrüsst.

Die junge Pflanze ist an ihrer violetten Knospe zu erkennen; dis Nadeln auf der Oberseite des Tricbes sind kürzer als jene auf der. Unterseite, sind aber in demselben Winkel wie diese rom Triebe abstehend. Die Rinde, anfangs glatt, weniger weisslich als ron unserer 'lanne. geht in höherem Alter in eine kleinschuppige, graue Borke ïber. Die '/alpfen, anfrecht an der Oberseite des Tricbes, durehshluttlich 10 cm lang, Zapfenschuppen breit, Aussenseite kul\%, filzig hrahart. Bbüthenschuppen am gesehlossenen Zapfen nicht sichtbar.

Diese T'anne berlarf eine ziemliche Menge von Bodenfenchtigkeit und stcht hierin zwischen der Douglasia und der Küustenfichle, welch' Intytere Eilenbruchboden liebt; auf Vancouver durehstellt sie mit der Firdatr Esten- Imol Pappehwaldungen; freistehende Exemplare nit 4:3 Mcter Höho oft 1,4 Mreter Durehmesser; das leichte Hol\% wird zu İrettwaren beim Iausban, insbesondere aber zu Kisten zersägt.

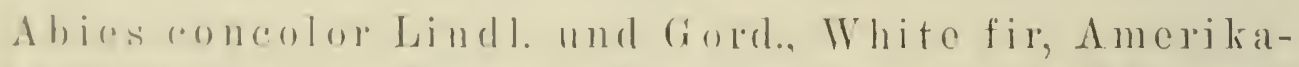

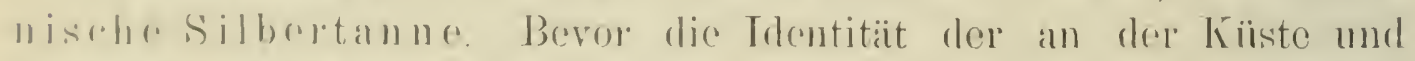

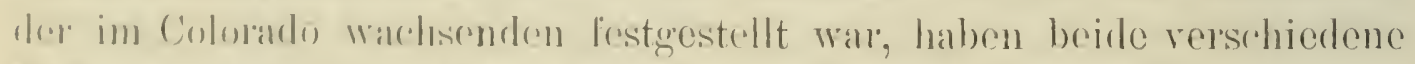
Simen erhalten; äberdiess warde sie nit grandis oft rerwechselt, von

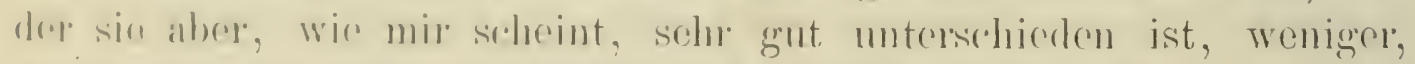

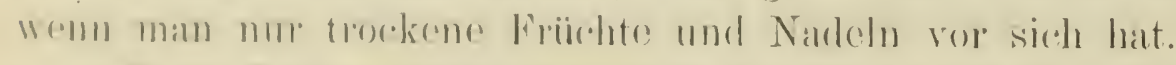

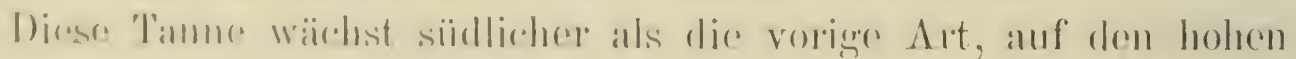

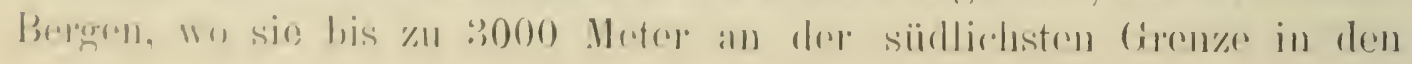


San Bernardino-Bergen emporsteigt. Von der Sierra Nerada geht sic östlich an hohen Bergen entlang bis Colorado. Ihre wichtigste biologische Eigenschaft wurle schon erwähnt; ich wiederhole, dass ihr Optimum an der Grenze der gemïssigt-warmen und der kühlen Region \%u liegen scheint: ein Habitusbild erwachsener Pflanzen gibt die Abbildung eines Haines ron Riesensequoien (Figur 16d), wo diese Tamne mit der Zuckerkiefer ren Nebenbestand bildet. Sie rerlangt ein zicmliches Mass ron Luft- und Bodenfenchtigkeit wie die Sequoia, schwarche, seitliche Beschirmung, erreicht aber dort Dimensionen, die alle bisherigen Beobachtungen weit übertreffen; die höchste Tamne, die ich fand, mass nur 1,28 Meter Durchmesser, aber voile 75 Meter Höhe; bei 32 Meter begannen die ersten Aeste. Auf den San BernardinoBergen bleibt sie kaum in der Höhenentfaltung zurüick: ein schlechtes, schr beastetes und deshalb von den Sägmühlen rerschontes Exemplar hatte bei 1,48 Meter Durchmesser 68 Meter Höhe; dort reigt sich cine Eigenthümlichkeit, die ich nicht unerwähnt lassen will: hoch oben im Gipfel zertheilt sich oft der Hauptstamm in 2-20 kleinere, aufrechte Gipfel; vielleicht wurde der Hauptgipfel durch ein Accidium getörltet, wenigstens sah ich Exemplare mit einem typischen AccidiumHexenbesen am Gipfel.

Auch an der Grenze ron Californien und Oregon, an der Basis ron Mt. Shasta erreicht sie nach meinen Messungen Dimensionen ron 62 Meter Höhe und 1,6 Mcter Durehmesser. Ḱnospen der jungen Pflanze rosa-riolett; an den Gipfeltrieben ron gedreliten Nadeln eingehïllt; Seitenknospen mit einer dieken Basis aufsitzend: junger Trieb violett, gelbgriun, Narleln der Lüngstriebe gerade, etwas abstehend, an den Seitentridben nach der Oberseite des Triebes gekrümmt; obere Nadeln etwas kiurzer und gleich gerichtet wie die unteren: an der Küste wie insbesonders in Colorado tragen die Nadeln im Lichte auf beiden Seiten weisse Streifen in gleichem Masse; im Schatten dagegen sind die Nadeln einmal flacher angeordnet, auf der Oberseite ols ne weisse Streifen oder nur an der Spitze der Nadeln: solehe Exemplare getrocknet sind in der 'That der grandis :̈lnnlich; dic Rinde anfämglich glatt, hellgrau, die hrone spitzig-kegelig; später wird die Rinde dunkler und schuppig; im hohen Alter bleiben die Sidhuppen

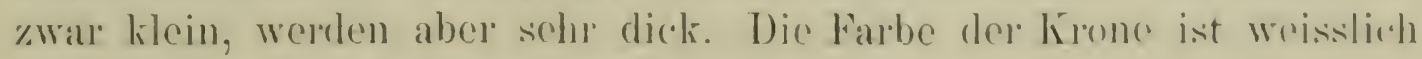
grrüu, viel heller als jene der Domglasia.

Der Zalpfen steht jenem der Kïstentamne sohr nahe, durds-

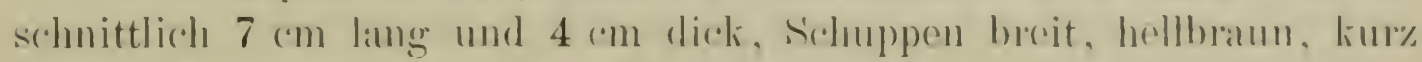
behatist. Blüthensodupuen nichts sichithatl. 
Da in der Umgebung dieser Tamne sich stets besseres Nutzholz findet, so wird sie meistens rerschmäht; ihr Holz ist aber mit einem specifischen Gewichte ron 36 gewiss nicht schlechter als das leichtere Holz der Küustentanne. Auch diese Tamne greift auf dem höchsten Punkte ihres Torkommens in die kühle Region über.

Dic amerikanische Silbertanne ernährt mehrere Parasiten, die in dem kïhlen, luftfeuchten Klima sich kräftig entwickeln; es dürfte wenige Nadelhölzer geben, die an einer Nadel zwei, verschiedenen Gattungen angehörige. Pilze zu gleicher Zeit tragen, von denen eine noch überdiess mit ihren drei Generationen rertreten ist.

Auf der Nordgrenze dieser Tanne, am Fusse des Shasta-Berges f:̈̈llt an der Tamne ein Pilz auf, ein Lophodermium, besonder's an unterdrückiten oder in Dickichten stehenden Exemplaren; dieser Pilz entwickelt auf der Unterseite der Nadel auf der Rippe entlang ein ununterbrochenes, nach den weissen Streifen hin bläulich rerlaufendes Polster ('Tafel Xa) gegenüber, auf der Rippe an der Oberseite der Nadel stehen die Spermogonien, eine oftmals unterbrochene Linie darstellend (b). Die Sporen waren zur Zeit der Einsammlung (Anfang Norember 1885) noch nicht reif, so dass es nicht möglich war, die Identität mit dem Lophodermium nervisequium auf der europäischen Tamne festzustellen. Der Pilz befällt die einjïhrigen Nadeln und reift an den zweijährigen, worauf Nadeln und Pilz zu Grunde gehen; bis zur Feststellung der Identität mag cler Pilz, der viel kräftigere Fruchtlager als die emropäische A't entwickelt Lophodermium abietis concoloris n. sp. heissen.

Terschieden ron dem genannten nach jeder Richtung ist ein Lophodermium, welches ebenso häufig wie das erstere die Nadeln der Concolor-Tanne auf ihrer Sïdgrenze, in den Sin Bernardino bewohnt. Nie so kräftig wie die der vorigen Art sind die Fruchtpolster dieses l'ilzes nur aine kin'ze Linic; selten rerläuft ein Polster ununterbrochen rom dor Basis bis zur Spitze ('Tafel Xa); ausserdem ist dasselbe nur laalh so breit als Leiphodermium abietis eoncoloris; dic Polster erscheinen

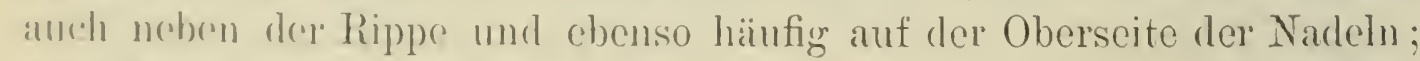
dayn krmmt nexh, dass dieses Tophodermium unter gö̈nstigen Umstinden nicht nur die neuen, sondern auch alle älteren Nadeln - bis zu sechsjührigrn Nadeln - grlcichzoitig zn infieiren vermang, so dass die Nadeln einer Pflanz: alle auf cinmal zu Boden fallon. Dieser Parasitismus charakterisint den Pil\% als merklich schaillich und als versehieden von den bisher bekannt gewordenen Arten, so dass der Name Lophoderminm infortans n. sp. angezoigt sein mag. Teislep waren an meinen linde November 1887 gesammelten Lxemplaren die Perithecien und 
Sporen noch nicht reif und die Fruchtlager der zweijährigen wie sechsjährigen Nadeln fanden sich im gleichen Stadium der Entwicklung. Auffallend ist ferner, dass die Spermogonien als schwarze Flecken unregelmässig auf beiden Seiten der Nadeln zerstreut stehen (Tafel Xb).

Im Norden, wo Lophodermium abietis concoloris heimisch ist, lebt mit diesem zusammen oftmals auf ein- und derselben Nadel ein Accidium, das kleine Becher ron $1 / 4 \mathrm{~mm}$ Durchmesser besitzt, erfüllt mit farblosen Sporen, erscheinen die Becher weisslich; die Sporen, durchschnittlich $10 \mu \mathrm{im}$ Durchmesser, mit warzigen Episporium; der Pilz inficirt die jungen Nadeln, fructificirt aber mit Aecidien und Spermogonien erst an der zweijährigen Nadel. Im Grunde der Becher oder auch seitlich ron diesen setzt damn eine kräftige, dunkle Mycelwucherung ein, die über den Becherrand hinaus wachsend ein Polster bildet, ron dem Uredosporen ron $7 \mu$ Grösse mit warzigem Episporium, dunkelbraun gefürbt, abgeschnürt werden. Später endlich treten zwischen den dünnwandigen Organen des Stroma's dickwandige, kurzzellige, fast schwarzgefürbte Organe, welche durch das Stroma hindurch wachsen, und an seiner Oberflïche die Teleutosporen abschnüren. Diese wechseln sehr. in Gestalt und Grösse, sind ein-, zwei- oder dreimal der Lünge nach getheilt; häufig sind zweizellige und vierzellige Formen, weniger häufig die drei- und einzelligen. Diese Eigenthümlichkeit mag die Aufstellung einer neuen Gattung unter dem Namen Puccinidia n. g. rechtfertigen; die Diagnose wäre: Dauersporen ein-, zwei-, drei- und vierzellig, schwarzbraun, auf isolirt stehenden Fïden eines schwarzen Stroma's gebildet; Uredosporen schwarz, Aecidiumsporen weiss; ob diese letzteren auch Gattungs- oder nur Artcharaktere sind, kann ich noch nicht entscheiden. Von dieser Gattung habe ich bis jetzt nur eine Art, nämlich die oben beschriebene, beobachtet; sie mag als P'uccinidia abietis n. sp. gelten; sic entwickelt Aecidium-, Uredo-, T'eleutosporen mit Spermogonien und Mesosporen (Teleutosporenartig mit warzigem Episporium) auf den Nadehn ron Abies concolor (Tafel X).

A bies bracteata Nutt., Santa Lucia-Tanne, auf den Santa Lucia-Bergen in den kühlen und feuchten Thälern zwischen 1000 und 2000 Meter Erhebung, auf nördlichen Expositionen. Sie wird cin Banm bis zu 60 Mreter Höhe; auscrezeichnet vor allen andern Tannen durch den Zispfen, an dem die Bracteen die ursprüngliche Nadelform beibehalten haben. Der '/apfen ist $9 \mathrm{~cm} \operatorname{lang}, 4,5 \mathrm{~cm}$ dick und dicht besetzt mit den pfriemenförmigen $4 \mathrm{~cm}$ langen Bractecn. Dabei ist die Bractee etwass nach der Zalpfenbasis za gekrümmt, steif, 1, 5cm 
breit, unterscits nit zwei weissen Streifen rersehen. Nadeln durchschnittlich $5 \mathrm{~cm}$ lang. $31 / 2 \mathrm{~mm}$ breit, unterseits mit zwei breiten, weissen Streifen, oberseits glänzend grün, in eine scharf stehende Spitze auslaufend: junge Triebe nackt, rothbraum. Diese Tanne ist weiters auffallend durch das ausserordentlich schwere Holz mit einem specifischen Gewichte ron 68. Dass daran die Krystalle schuid sind, die in den letzten Tracheiden eines Jahrringes sich reichlich finden (Tafel IX), ist wahrscheinlich.

Tsuga Mertensiana Carr., Hemlock, westliche Schierlingstanne, westliche Tsuga. An der feuchten, nebehreichen, gleichmässig kühlen Küste Süil-Alaska's, besonders auf den zahlreichen Inseln nördlich von Tancourer, von da an südlich bis in's nördliche Californien, dort auf die Berge beschränkt, erreicht diese Tsuga ihr Optimum an gleichen Oertlichkeiten mit der Thuja und Douglasia, geht dann nach Osten bis in die feuchten, hoch gelegenen Thäler des Felsengebirges, an die Nähe der Quellbäche gebunden, bleibt jerloch dort ein Baum ron nur kaum über 30 Meter Höhe, während sie in ihrem Optimum die doppelte Höhe crlangt. Sic bildet stellenweise reine Waldungen, in der Regel aber kommt sie mit der Douglasia zusammen ror, ein Grund, wesshalb die Tsuga jetzt noch als ziemlich werthlos gilt, obwohl das Holz gut und die Dimensionen stattlich sind; cinstweilen liegt iln. Werth noch in dem Tanningehalte ihrer Rinde. Die junge 'l'suga wächst sehr rasch. Nadeln olme Yä̈hne, an der Oberseite feine, kure Vertiefungen: Zapfen in Bracteen und Schuppen ron der ïstlichen Art verschieden; Näheres auf Tafel VI.

Diese T'suga iubertrifft als Nut\%holzproducentin die östliche beträchtlich: ihe Sihaft ist reiner, vollkommener; doppelte mol mehrfarhe (iipfer sicht man bej ihr viel seltener als bei der östlichen $A$ rt.

Picon Sitkachsis Carr. (syn. P. Menziesii), Tideland sprure, Sitlat Firhte. Das Adjektiv "Sitchensis" dürfte besser wrmirmlen worden, dat anch die Nutka-Cypresse nicht ,nutehensis",

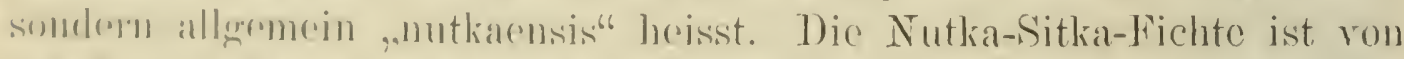
der Küste Alaskal's his nach Californien heimisch, ereicht ihr Optimum im IIrstrm ron Wishington und Oregon, wo sie in luft- mul boden-

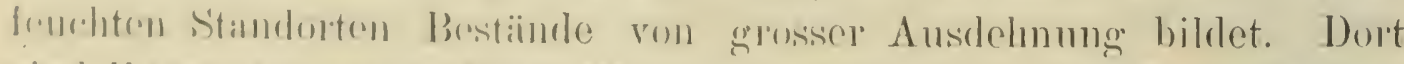

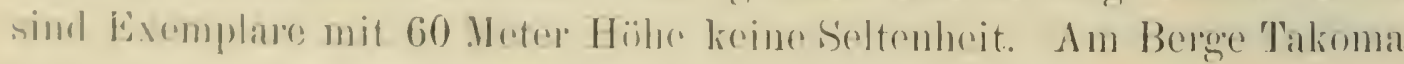

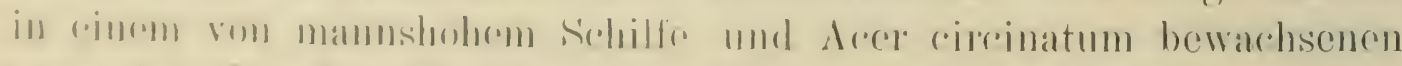

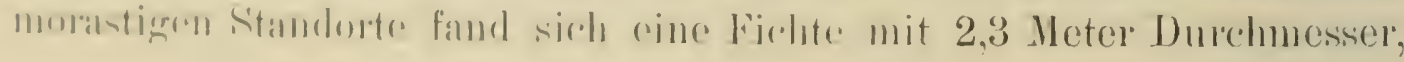


60 Neter Höhe und einem astreinen Stamme bis zu 30 Meter. Dabei schimmerte die Krone eigenthümlich weiss, während den Stamm eine kleinschuppige, unserer Fichte sehr ähnliche Borke bedeckte; der Stamm ist sehr massig und cylindrisch gebaut, auf den Aesten ruhen schwere wasserdurchtränkte Moospolster.

Die junge Pflanze ist gekennzeichnet durch ockerfarbige, glänzende Knospen, durch lange, dunkelgrüne Nadeln, welche an der Oberseite des 'Triebes an ilner Unterseite und an der Unterseite des Triebes an ihrer Oberseite zwei weisse Streifen tragen; der gesammte Farbeneindruck von oben gesehen ist dunkelgrün glänzend; die letztjährigen Seitentricbe oftmals, wie auch bei der Douglasia, etwas sichelförmig gebogen, die convexe Seite nach oben gekehrt. An zapfentragenden Exemplaren sind die Nadeln küizer, breiter und weniger scharf stechend.

In der Jugend stark in die Seitenäste wachsend, rerliert sie diese auch im hohen Alter schwer, daher reinschaftige Exemplare nur in dichtem Schlusse zu finden sind.

Junge Triebe und Blattkissen gelbgriun glänzend, Knospe an dor Basis etwas eingeengt. Sie ist gegen Kïlte viel weniger empfindlich als gegen Trockniss; in Alaska erhebt sie sich in dem fenchten Küstenklima bis in die Nähle der Gletscher; dass sie aber frostempfindlicher wirl, je trockener zugleich die Luft ist, ist bei dieser wie bei anderen Holzarten schr wahrscheinlich.

Wie mehr oder weniger alle pacifischen Holzarten ist auch diese Art auffallend raschwïchsig. Das Holz ist dunkler gefärbt als das der ül)rigen Fïhlten; specifisches Gewicht 43; sie wird in sehr grosser Ifenge für Gegenstände aller Art, zum Bootbau, zu Füssern und dergleichen verwendet; der Splint, kaum erkenubar, ist $4,5 \mathrm{~cm}$ breit. Anatomisch ist das Holz dieser und aller Fichten Nordamerika's dem Hol\%e der curopäischen Fichlte grleich, sie folgt somit grenau dem Typus der Gattung P'icea *).

*) Die Sitka-Fichte bililet mit den beiden anderen Fichten des Westens (P. pungens und Engelmannii), sowie mit der Fichte von Tezo, der nördlichsten Insel Japans, eine Gruppe von Fichten mit weissen Streifen an der Oberseite der Nadeh und mit'kleinen 'aapfen, deren Schuppen dünn, weich und längs. gefaltet sind.

Willkomm (1. c. Seite 10!) scheint geneigt, in diese Gruppe anch Picea Omorika hereinziehen zu wollen und sagt: „Dieser merkwiurdige Baum (l’icea Omorika), welcher dadırch ein hohes wissenschaftliches, beziehnngsweise pflanzen. gengraphisches Interesse gewinnt, dass er der naicliste Verwandte der im fernsten Osten Asiens (anf ller Insel Yesso) heimischen Ajan-Fichte (l'icea ajanensis Fisch) ist, wurle ....; hal,ituell zwischen fichte mul Tanne steheml, unterscheidet sich 
Viele der alten Fichtenstämme brechen zusammen, da ihr Inneres durch Trametes Pini in eine mürbe, durchlöcherte Masse umgewandelt wurde; an dem liegenden Stamm überkleiden damn die Fruchtträger in breiten Massen die Baumoberfläche, vom Innern durch Vermittlung der Aeste ernährt.

Oefters sieht man weiters die Nadeln der Fichte erkranken, wie unter dem Einflusse eines Lophoderminms (Hysterium) macrosporum; die Fürbung der kranken Nadeln ist jedoch nicht röthlich, sondern gelblich; das Lophodermiumlager offenbart sich bei genauer Untersuchung als eine Pycnide mit Spermatien-artigen Sporen; der Pilz gehört zu den unvollständig benannten Dichaenacei Fr. Perithecien einfächerig, mit einer Längsspalte sich öffnend, wie bei den Discomyceten. Die Gattung weicht von den bestehenden emropäischen, die alle Triebbewohner sind, ab. Der Pilz lebt an den Nadeln, erzengt schwarze Polster unterhalb der Epidermis, welche bei der Reife in einem Längsspalt aufreissen $=$ Hysteriopsis n. g. als einzige bis

die Omorika von beiden dadurch, dass ihre Nadeln, wie die der P. Menziesii (Sitka-Fichte) und P. ajanensis die Spaltöffnungen nur auf der oberen Fläche in den beiden mit einem Wachsüberzug bedeckten Streifen tragen, die beiden Harzgiinge derselben, wie bei $P$. ajanensis der unteren, nicht (wie bei den Tannen) ler oberen Breitflïche zunäclıst liegen, dass, wie Purkyn ̌ nachgewiesen, die Markstrahlzellen des Holzes wie bei den Cedern nur behöfte Tüpfel besitzen und die Rinde äusserlich Aelnlichkeit mit der Kiefernrinde, bezüglich ihres mikroskopischen Baues mit der Cedernrinde hat. Von P. Menziesii unterscheidet sich die Onorika nicht allein durch ihre stumpfen Nadeln, sondern auch durch lie Gestalt und die versehiedenartige Richtung ihrer Zapfen. Sie bildet mit $P$. ajanensis und $P$. Menziesii und vielleicht einigen japanischen, noch nicht niher bekannten Fichten (Picea Alockiana Lindl, Picea jezoensis Carr.) eine eigenthümliche Abietineen-Gruppe, die vielleicht richtiger eine besondere Gattung der Abietinecn als nur eine Unterabtheilung der Fichtengattung zu bilden hat."

Wenn die Omorika, sowie die Sitka-Fichte und die Ajan-Fichte mit anderen japanischen Fïchten den von Purkynĕ entdeckten merkwürdigen Bau der Markstrahlen wirklich besässen, so wïre gegen die Aufstellnng einer neuen Gattung hitum ein triftiger Grund vor\%ul,ringen; allein unglücklicher Weise zeigt das Holz der Onorika, wenigstens an meinen zapfentragenden Exemplaren, eben so wie der Sitka-Fichte, der Ajans-Fichte, sowie anderer japanischer und nordamerikanischer Jïchten ganz denselben J'an, der für die Gattung l'icea typisch ist, nimlich: Markstralılen aus Parenchym mit einfachen Tiupfeln, Grenz;ellen dersollwn Tracheiden mit gohöften Tüyfoln (Tafel IX); nicht viel besser seheint ('s nit dor Angabe Purkyně's wegen des Cedernhol\%es bestellt zu sein; die von mir selfst in Nordwest-Indien gesammelte Cedrus Deodar hat sehr dentliche Matrstrahlon, dic aus Parenchymzollen mit einfachen Tüpfeln aufgebant

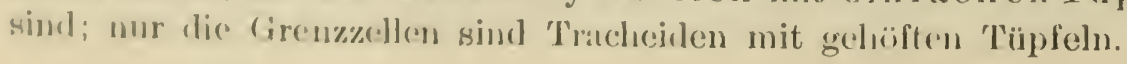


jetzt bekannte Art Hysteriopsis acicola n. sp. auf den Nadeln der Picea Sitkaensis, welche gelb schüttig werden und im zweiten Jahre nach der Infection durch den Pilz abfallen; besonders in feuchten Oertlichkeiten häufig (Tafel X).

Sequoia gigantea Decsn. (syn. Wellingtonia), Big tree, die Riesen-Sequoia. Von sehr lokaler Verbreitung steigt diese Sequoia in der Sierra Nerada des mittleren Californiens ron 1200 bis fast zu 2000 Meter empor. Ueber die Biologie dieses Wunderbaumes wurde schon früher das Wichtigste angegeben; das Auffallendste bleibt die Massentwicklung, daher zuerst einiges hierüber.

Das höchste Exemplar, das ich im Fresno Cy gemessen, ohne gerade nach den grössten Riesen gesucht zu haben, hatte 102 Meter, die grü̈nen Aeste beganmen bei 60 Meter Höhe, der Durchmesser 2 Meter über dem Boden war 7 Meter; das Exemplar stand so günstig an einem Bergahhange, dass es möglich war, bei dem klaren Sonnenschein den Durchmesser des Schatten in 34 Meter Baumhöhe zu messen; er betrug 3,7 Meter. Es berechnet somit nach der Hossfeld'schen Formel $\left(J=3 / 4 \mathrm{~g}^{-1} / 3 . \mathrm{h}\right)$ anf volle $822,4 \mathrm{cbm}$ Schaftmasse; daron muss man etwa $22 \mathrm{cbm}$ Rindenmasse abzichen (!), bleiben immer noch $800 \mathrm{cbm}$ Holzmasse, eine Menge, die unsere einheimische Fichte auf 1 ha des besten Bodens in 80-90 Jahren zu erzeugen vermag. Die Formzahl des Riesen betrug nur 21.

Ein zu Boden liegender und zersägter Stamm hatte ohne Rinde über Boden bei

2 Meter 2,60 Meter Durchmesser

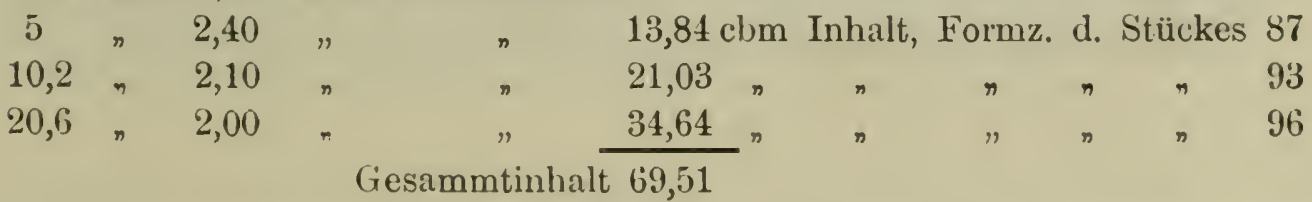

Der Rest war so zersplittert, dass es sich nicht mehr lohnte. Nutzstiicke auszuschneiden; er blieb unbenützt liegen.

Eine andere Sequoia mit

10,2 Meter Durchmesser (4 Meter über Boden) hatte 99 Meter Höhe,

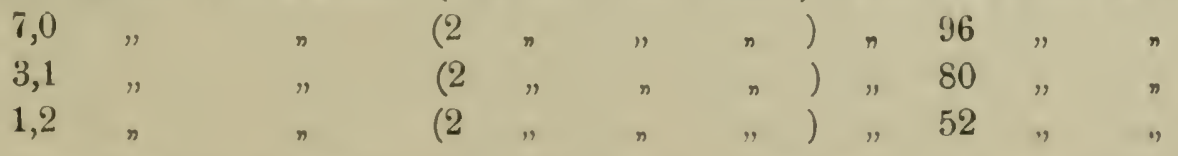

Der vorhin erwïhnte liegende Stamm diirfte eine Höhe von etwa 66 Meter bescsien haben, wonach sich der Inhalt anf 155,43 (b) berechnet mit einer Eormzahl von 44. Der Durchschnitt aller Höhen- 
messungen betrug 98 oder rund 100 Meter. Schon früher erwähnte ich, dass man in engen, geschützten Thälern Stämme mit 120 Meter Höhe und 16,1 Meter Durchmesser gemessen hat, Angaben, die mir nicht im geringsten zweifelhaft erscheinen.

Dürre Aeste an ausgewachsenen Exemplaren sind nicht rorhanden; dic Kronenform ergibt sich aus der beigegebenen Figur 16.

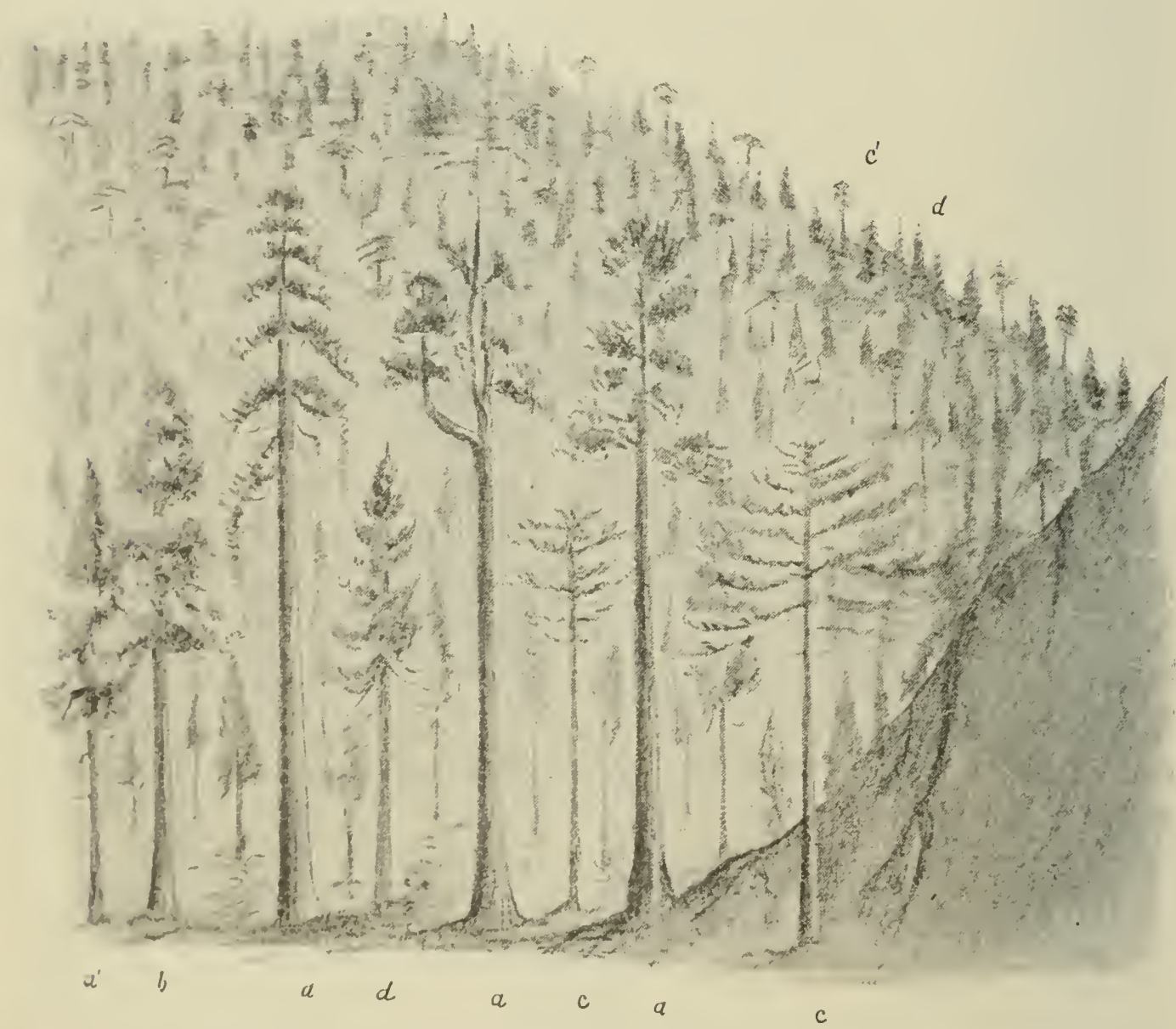

Fig. 16. a Erwachsene Sequoia gigantea, 100 Meter IIöhe; $b$ junge Sequoia; $c$ Zuckerkiefer; d Abies concolor, 70 ileter.

Die hell-rothblatune Rinde lïst sich in gan\% feinen Blättchen ab, ist aber gan\% allsserendentlich stark; von unserer 'Tour sehleppten wir cin Burkenstiick von 46 cm Durdmesser nach Hause. Die Borke ist schr weich mol in lange, dïnne Fäden zerlegbar; mein Stïck trägt auch Splint und otwas Kernhol\%. Der Splint beträgt 10 cm und umfasst 100 Jahringe, dabei so ansserendentlich gleichmaissign, dass fast genau auf ein 1 mun cin Jahrring trifft, was in dem hohen Alter noch eine

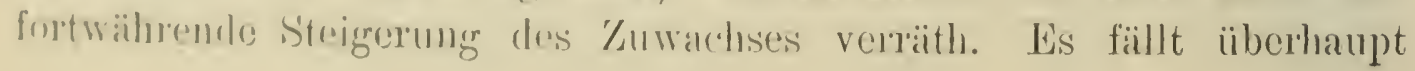


die grosse Gleichmässiglicit im Wachsthume des Baumes auf; bei der schwachen, seitlichen Beschirmung in der Jugend wird das Wachsthum verÿ̈gert, so dass kein Jahrring mit über $3,5 \mathrm{~cm}$ Breite an Querschnitten sich findet, während im höchsten Alter die Ringbreite bis auf $0,6 \mathrm{~mm}$ sinlit. Aus einem Dutzend Messungen der Jahrringe aus den unteren Schaftthcilen mehrerer Bäume ergab sich eine mittlere Jahrringbreite von 1,2 mm pro Jahr. Mit dieser Zahl in die Stadien der erwähnten obigen Stämme dividirt, ergibt für den Stamm mit 8,5 Meter Radius ein Alter ron 6500 Jahren, cine Zahl, die viel zu hoch ist, da dieser Radius jedenfalls unmittelbar über dem Boden genommen ist, wo der Stamm mit ungeheueren Wurelanläufen beginnt. Für den stärksten Stamm, den ich selbst mass mit 5,1 Meter Radius in 4 Meter Höhe berechnet sich ein Alter ron 4250 Jahren, eine Zahl, die ich für wahrscheinlich halte; der Stamm mit 3,5 Mreter Radius wäre demnach fast 3000 Jahre alt, jener mit 1,5 Meter 1 160 Jahre, endlich jener mit 0,6 Meter etwa 500 Jahre.

Das Krernholz ist frisch lirschroth und mit einem specifischen Gewichte ron 29 ausserordentlich leicht; entsprechend seiner starken Verkernung ist das Holz sehr dauerhaft, dient zu Schindeln, Eisenbahnschwellen, Zä̈unen.

Die botanischen Merkmale sind bekannt. Die Zapfen sitzen an den \%weigenden und reifen in einem Jahre; durchschnittliche Länge 5 em und Durchmessel $4 \mathrm{~cm}$; der hellgelbe Same mit dümnen, flügelartigen Rïndern (Tafel VIII); er hialt sich mehrere Jahre keimfähig; die junge Pflanze mit zwei Cotyledonen rerästelt sich schon im ersten Jahre zu cinem kicinen Busch; im vollen Lüngswachsthum und frei stehende Exemplare entwickeln eine auffallend breite Basis, gleichsam um die nüthige Standfestigkeit fü1 spätere Zeit zu gewinnen; die Rinde, klein längsschuppig, an dem in das Halbdunkel des Bestandschlusses untergetanchten Stammtheile hellröthlich, an uberen, von der Sonne getroffenen Schaftheile hell grlänzend mit schwach röthlichem Anfluge.

Von Krankheiten ist mir nichts bekannt geworden; in Deutschland. wo die sequoia in stattlichen Exemplaren bereits vorhanden ist, \%. B. in Kileinflottbeck bei Hamburg, leidet die junge Pflanze durch eine Butrytis, welehe die Spitzen der jumen Triebe tüdtet: ansserdem werden sie, wie schon erwilhnt, von einer Pestalozriat befallen, die dicke, schwar\%e Pulster, ïnsisplech wie siclerotien an den Nadeln el\%eugt.

Dem Grengyebiete der gemïssigt-wamen und der folgenden Region gehërt ferner 
Chamaecyparis Nutkaensis Spach., Sitka-Cypresse, Nutka-Cypresse an. Dieser Baum ist auf das denkbar luftfeuchteste Klima, die Inseln und das Küstengebirge von Britisch-Columbien angewiesen; in den Vereinigten Staaten bieten nur die engen Thäler der hohen Bergregion die wünschenswerthe Luftfeuchtigkeit; überdiess ist der Baum im Cascaden-Gebirge der Union ein ganz seltener Baum, der die Nordgrenze Californiens nicht erreicht. Gegen Trockniss scheint der Baum deshalb sehr enpfindlich zu sein; in Ostamerika und bei uns geht der Baum ohne seitlichen Schutz der Besonnung bei Frostwetter ausgesetzt, regelmässig zu Grunde; nach dem Vorkommen des Baumes in der Heimat (Alaska) sind derartige Verhältnisse eben für den Baum ganz unnatürlich. Ich zweifle nicht, dass der Baum an der norwegischen Küiste wachsen kann, ohne vom Froste getödtet zu werden, während er im lufttrockenen Winter des Binnenlandes ausserhalb des Waldes wohl stets zu Grunde gehen wird. Dass der Baum empfindlicher gegen Trockniss und Kälte ist, als die weit südlicher wachsende Lawsonia bleibt aber immer noch auffallend.

Der Baum wird an 40 Mcter hoch und gilt wegen seines sehr dauerhaften, leichten Holzes von angenehmem Geruche als der werthvollste Nutrbaum des südlichen Alaska; langsam von Jugend auf in einem seitlichen Drucke erwachsen, sind werthvolle Exemplare auch schr alt. Das New-Yorker Sammlungsstück hatte

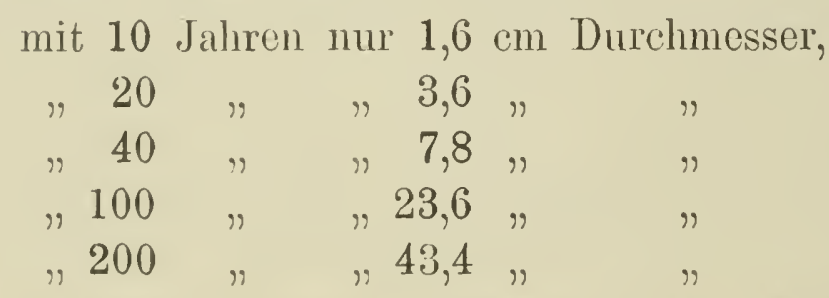

I)er Splint betrun 2,4 cm, die Jahrringe des Splintes hatten nur melse eine Breite ron $0,7 \mathrm{~mm}$.

Jic junge Pflanze ist von anderen Verwandten gout durch dic spit\%en, schuppenartigen Blïtter ansge\%cichnet (Tafel VI), die auf der Unterseite der '/weige cin wentg heller groin sind als anf der Oberseite; an Jängstrieben drei Schuppen anf gleicher Höhe; Früchte und die Samen mit einem diumen, liellen, flügelartigen Rande sind von den ïbrigen Arten grut untersehierlen.

Nach dem Optimalgebiete - westliches Oregon und Washington - gehört norh hicrher die

Pareifische Eibe, Taxus brevifolia Nutt.; sic geht an der

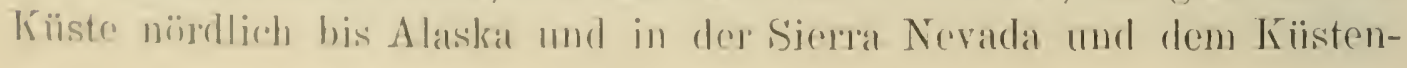


gebirge südlich bis in das mittlere Californien. Benadelung, Rinde, Bau und Fürbung des Holzes sind ganz unserer einheimischen Eibe ähnlich, ron der sie rielleicht, wie die japanische Taxus cuspidata specifisch nicht genügend unterschieden ist. Sic erwächst schr langwam, crträgt tiefen Schatten, cr\%cugt einen schlecht geformten Schaft, ist astreich wie die europäische Eibe.

Der Stanm mit nur $1 \mathrm{~cm}$ breitem gelblichem Splinte; Holz hart, sehr danerhaft mit tiefrothem Kerne; es wird ron den Indianern besonders zu Specrgriffen, Bögen, Fischangeln und dergleichen benüt»t; die Amerikancr rerwenden es zu Zaunpfosten, bis die Zeit den Werth des Holzes für feincre Schmuckarbeiten, wie Kästchen und dergleichen gelehrt haben wird.

\section{c) Der Nadelwald der gemässigt-kühlen Region.}

Das nebelreiche, luftfenchte, kühle Klima, dic Heimat der Fiehten-. Tamnen- und Tärchenwaldungen liegt im Unionsgebiete, im Cascarlenund Sierra-Gebirge, erst obcrhalb 1000 Meter im Norden und 2500 Meter im Sürlen, streicht von da an durch britisches Gebiet nördlich bei konstanter Abnahme der Elevation, bis es etwa auf der Höhe des südlichen Alaska das Mecresniveau erreicht. Von dort an erstreckt sich das kïhle Gebict, unter dem Einflusse des japanischen Mecresstromes an der Küiste entlang bis zur Behringstrasse, und im Innern des Tandes in geschüt»ten Thälern und Berghängen nordwärts bis zur Mündung des Mackenzieflusses; überall auf dem Wege nordwärts und östlich berühren sich die Vertreter der pacifischen Waldregion mit solchen des atlantischen Waldes mit gleichen klimatischen Ansprüchen.

Von allen Waldznen der Union nimmt die gemässigt-kühle den kleinsten, ron jenen Nordamerika's überhaupt wohl den grö̈sten Flïchenraum ein; für die Vereinigten Staaten kann man etwa folgende Proportion aufstollen: Von dem Waldgebie te ocenpirt: der tropische Wald $1 / 2 \%$, der subtropische $15 \%$, der winterkahle Laubwald 75\%, der Fidhten- und T'annenwald den Rest, etwa $9,5 \%$; in Britisch-Nordamerika dürten rom Waldgebiete 10\% der gemïssirt-warmen und volle $90 \%$ der gemäissigt-kühlen und alpinen Waldrecrion zu\%uzählen sein. Dass floristisch es keine scharfen Grenzen geben kann, liegt am Klima, das ebenfalls nur allmählige Uehergänge zeigt; so kommt es, dass die untere und wärmere Mälfte der gemässigntkïhlen Regrion noch vielfach Standorte in sich schliesst, die für Lauhhölzer, die leichtsamimen Erlon. Birken, Pappeln und Weiden, grecignet 
sind. Jeteorologische Angaben stehen mir nur hinsichtlich des Territoriums Alakka \%ur Terfuigung; aus diesen geht herror, dass das Klima des südlichen Alaska etwa unter dem $56^{\circ}$ N.B. dem der höheren dentschen Mittelgebirge, des bayerischen Waldes, Schwarzwaldes, der Torberge der Alpen, dem Schwedens und Norwegens nahe kommt.

Sitka, auf der Insel Sitka, lat folgende meteorologische Aufzeichnungen :

Mittlere Jahrestemperatur $6^{0} \mathrm{C}$; ; höchste beobachtete Temperatur $27^{\circ} \mathrm{C}$, ticfste $-15^{\circ} \mathrm{C}$; Regenmenge im Sommer $500 \mathrm{~mm}$, relative Furchtigkeit 78\% ; Niederschläge im Winter 1130 mm, relative Feuchtigkeit 75\% jülnrliche Regenmenge $2625 \mathrm{~mm}$.

Unter dem $64^{\circ}$ X.B. auf dem Continente, aber nahe der Küste. ist die mittlere Jahrestemperatur - $4^{0}$; die höchste Temperatur $25^{\circ} \mathrm{C}$, die tiefste $-45^{\circ} \mathrm{C}$; die Regenmenge im Sommer $152 \mathrm{~mm}$, die relative Fenchtigkeit $86 \%$; die Regenmenge im Winter nu $55 \mathrm{~mm}$ bei vollen $96 \%$ relativer Feuchtigkeit; Niederschlagsmenge pro Jahr $335 \mathrm{~mm}$.

Anders ist das Klima der Insehn des Beringmeeres, die allein heutzutage bei ciner Pflanzenwanderung ron Amerika nach Asien als Uchergangsbrürke dienen kï̈nten. Sie haben cine mittlere Jahrestemperatur von +2 bis zu $0^{0} \mathrm{C}$.; im Sommer fallen $160 \mathrm{~mm}$ Regen, im Wintre $181 \mathrm{~mm}$; die Feuchtigkeit der Luft ist 90, bezw. 85\% ; die hüdhste T'emperatur ist $18^{\circ} \mathrm{C}$., die tiefste nur - $18^{\circ} \mathrm{C}$; während des ganzen Jilhes sind $550 \mathrm{~mm}$ Nielerschlïge rer\%eichnet.

Inncelalb) dor Yereinigten Staaten, in Mrontana, herrscht ron Mitte september an Frost wïhrend der klaren Nänte; anfangs November fiillt sidusec, der die zarte Jugend der forstlichen Nutzbïmme - Dou-

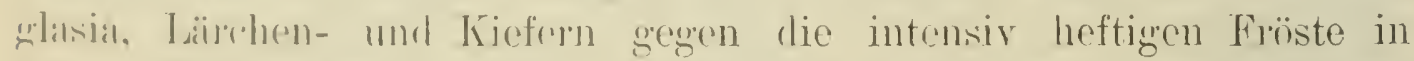

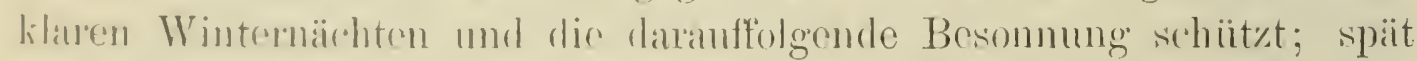
crwacht dise Vexperation und contwickett sich raseh.

IIt dieser 'zone betpitt man cin Gebiet, das mserer cinheimischen

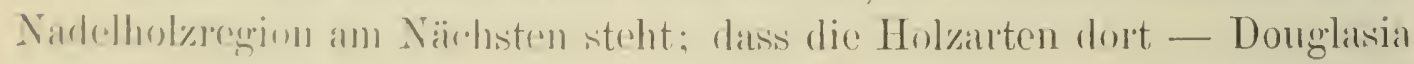
ansgenemmen - moseren cinheinnischen botanisch nahe verwandt mol

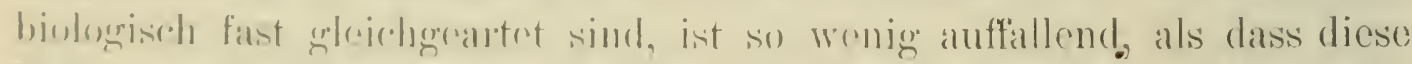

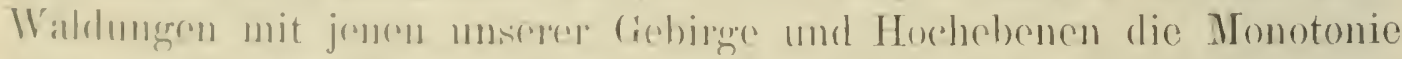

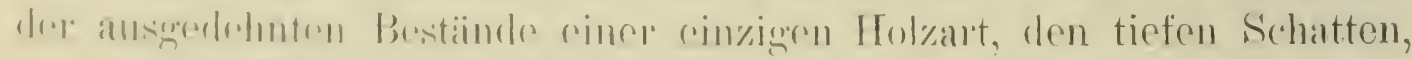

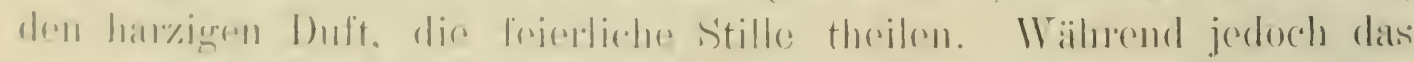

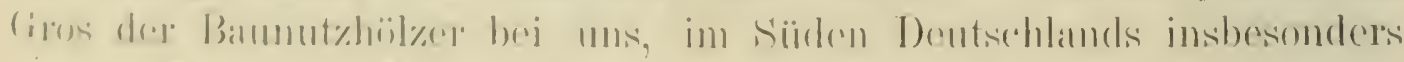

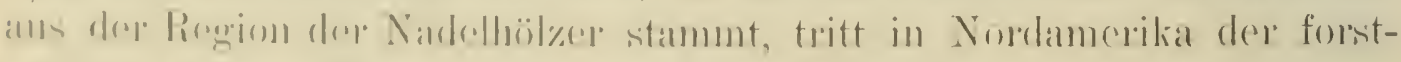

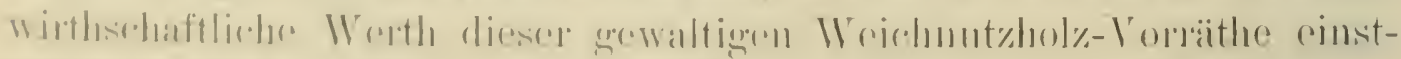

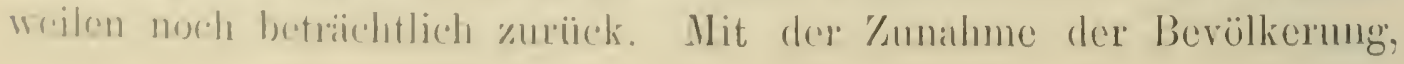


der Ausstockung der ron werthvolleren Holzarten noch occupirten, wärmeren, landwirthschaftlich benutzbaren Gelände, mit der Ausnützung und Verwïstung der zugänglicheren Waldungen, werden die nun zu betrachtenden Holzarten an Nutzwerth gewinnen. Es steht aber mit Sicherheit zu erwarten, dass durch rücksichtslose Entnahme des Holzes und eine regellos betriebene Alpenweidewirthschaft anch hier das Beste an Holz und Boden ruinirt werden wird, ehe eine pflegliche Behandlung sich von selbst aufdrïngt.

In dieser kühlen Region haben nur solche Holzarten Aufnahme gefunden, die in derselben ihr Optimum erreichen; manche steigen bis in die gemässigt-warme Zone herab, manche sind in ihrem obersten Verbreitungsbezirke ästig, forstlich nach ihrem Holzwerthe belanglos und nur als Schutzholz wichtig; dort finden sie sich an der Baumgrenze, welche in Nordamerilia einige dieser Höhenlage tỵpische Nadelhölzer cnthält, welche im folgenden Abschnitte zusammengefasst wurden.

Larix occidentalis Nutt., Tamarack, westliche Lärehe. Von den kïhlen Nordhängen des Felsengebirges in Montana nördlich bis etwa zum $53^{\circ}$ N.B. steigt dieser Baum; dabei bildet er oft ausgerlehnte reine Bestände; sein Optimum liegt da, wo die Donglasia zwar noch zu einem werthrollen Nutzbaum erwächst, gegen ihr Optimum aber um die halbe Baumlänge zurïckbleibt; so fand ich in Montani, an Fusse eines Berges in kräftigem, aus verwittertem, vulkanischem Gesteine hervorgegangenem Boden am Big Blackfoot River eine Lärche mit 43 ILeter Höhe, $86 \mathrm{~cm}$ Durchmesser: und einem Alter ron 270 Jahren; Rinde, Benadelung, Habitus sind von unserer Lürche in den Alpen kaum rerschieden; auch der rothbraune Kern, der $2 \mathrm{~cm}$ breite Splint, die rothe Borke, das harte, schwere, danerhafte Holz mit einem specifischen Gewichte ron 74 beweisen ihre nahe Terwandtschaft mit der europïischen. Verschieden ist dagegen der Kapfen, desien Schuppen an offenen Zapfen horizontal abstehen; die Bracteen über den Zalpfen hinaus pfriemenförmig verlängert; '/apfen, $3,5 \mathrm{~cm}$ lang, 2,5 breit; Zalpfenspindel dicht hellgelb fil\%ig behaart; junge Triebe kahl, glinzend, grelbbram.

In Montana rerjüngt sich die Lärche reichlich durch nattiirliche Besamung; die aufwachsenden Forste oft so dicht geschlusien, dass dazwischen stehende Dunglasia's verkïmmern; die jungen Pflanzen wachsen schr rasch; Jahrestriébe ron 1 Meter Länge sicht man häufig genugr auf mit Rosenstrïuchern, wilden Johamnisheeren hewahsenen, also guten und frischen standurten. 
In den Blanen Bergen stchen schöne Exemplare dieser werthvollen Holzart, theils mit Tamnen und Fiehten, theils mit der grösseren Bodenfenchtigkeit liebenden Pinus Murrayana, nie mit der Gelbkiefer zusammen; auch dort kann man Stämme mit 44 Meter Höhe und $90 \mathrm{~cm}$ Durchmesser finden.

Das Holz, zuweilen so hart, dass es schwierig ist, einen Nagel cinzutreiben, wird zu Bauhol\%, Zaunpfosten, Eisenbahnschwellen ete. beniitzt.

Wo die Douglasia durch Arcenthobium Douglasii befallen und verumstaltet wird, da geht dieser Schmarotzer auch auf die Lärche über; ganze Scitenäste sind durch den Reiz der sehmarotzenden Zwergmistel mit langen, herabhängenden, dïnnen Zwweigen an der Missbildung betheiligt; am Hauptstamme lebt die kileine Pflanze ebenfalls und rerursacht grosise Beulen. Tn den Blauen Bergen ist als Zerstörer des harten, massiven Kernholzes ein Pil\%, Trametes Pini, häufig, der das Hol\% in eine durchlöchert-weissfleckige Masse verwandelt, ganz so wio derschbe Pilz an der europäischen Lärehe. Solche zerstörten Stücke - meist der wertluvollste. Theil des Schaftes - bleiben dann im Walde licgen und überzichen sich in dem fenchten Moose mit prächtigen liruchttrïgern.

Pinus flexilis James, White Pine, Nevada-Cembra, Nevadazïrbel. Sie bewohnt, die sandig-kiesigen, besomuten Standorte, wo sie sehr weiträumig gestellte Waldungen bildet, oft nur in Gruppen onler zerstreut steht; in Central Nevada ist diese Zirbelkiefer der werthmollste Nutzbaum zu Schächten beim Bergbau. Fünf Nadeln stehen zusammen in einem Kurztriebe, Nadellänge durchschnittlich 5,5 cm lang, $1 \mathrm{~mm}$ dick; Kapfen $10 \mathrm{~cm}$ lang, dor Koreazüubel (P. Koraiensis) ähnlich, die Schuppen jedoch glänzend hellhraun; ziemlich dicke Apophysen; Nabel am schneidigen Sehmpenrande sitzend; die untersten Sehuppen dick und nach riorkwärts gekrümmt, Zapfen sitzend; der Same beiderseits marmorirt, whe lilügel ('lafel VII). Die Kiefer überschreitet nicht 18 Mroter Häho; ih. Hol\% mit einem specifischen Gewiehte von 44 ist srhwrere als das der enropüischen Zü̈rbel; der Baum gehört zur Section Cembra.

J'inus Murayana Balf., Black Pine, Murray's Kiefer. Friiher wurden diesse Art und P'inus contenta als identisch betrachtet sio strhen sich entschieden scher nahe, aber mit Hilfe ihrer Biologie, gengraphischen Vorhreitung, Habitus und anch der Kalpfen ist es nicht 
schwierig; sie ron einander zu tremnen; Herbariumsmaterial, an dem die Färbung der Zapfentheile verblasst ist, die Nabeldome in der Regel abgestossen sind, erschwert die Bestimmung. So dürfte es nach getrockneten Exemplaren sehr schwierig sein, Pinus resinosa, densiflora, sinensis, Thumbergii und austriaca zu trennen, welche in lebenden, erwachsenen Exemplaren nicht zu rerwechseln sind. Wührend P. contorta (nach meiner Auffassung) allein auf die Küste ron Alaska bis in's mittlere Californien beschränkt ist, somit der genässigt-warmen Region angehört, occupirt die Murray'sche Kiefer die inneren Berge von Alaska, Washington, Oregon, die Sierra Nerada, die Blauen Berge, das Felsengebirge ron MIontana und Britisch-Columbien nordwärts bis zum $64^{0}$ N.B. Die in Colorado und ron dort bis in's nördliche Arizona heimische Form zeigt nach den zapfentragenden Exemplaren solche Verschiedenheiten, dass ich sie, bis sie durch eingehenderes Studium vielleicht als eigene Art erkannt wird, einstweilen als Varietït der Murray'schen Kiefer hier vortrage unter dem Namen Pinus II urayana var. Sargentii mihi.

Die Murray'sche Kiefer ist in ihrem Optimum eine sandliebende Pflanze, die biologisch wie auch botanisch der östlichen Bank's Kiefer nahe steht; sic ibertrifft aber letztere in ihrem Optimum auf den sandig-feuchten, kühlen Einsenkungen der Blue Mountains durch ihre Höhen- und Massentwicklung; mittlere Stämme der an solchen Oertlichkeiten in reinen Beständen aufwachsenden Kiefer erreichen nach meinen Messungen 28 Meter Höhe; die Schäfte weit herab, trot\% des dichten Schlusses, mit Aesten bekleidet; Durchmesser solcher Stïmme $42 \mathrm{~cm}$; selbst auf den kïhlen, sehr feuchten, unseren Hochmooren am Fusse der Alpen ïlnnlichen Standorten gedeiht sie kiäftig.

Murray's Kiefer in den Blauen Bergen besitzt Narleln (zu zwei zusammen) von $5 \mathrm{~cm}$ Länge; Zapfen $3,5 \mathrm{~cm}$ Lünge und $3 \mathrm{~cm}$ Breite wenn offen; frische Zapfen matt hellbraun oder schwach glänzend, Apophyse auf der Oberseite des Zapfens kegelförmig erhaben und mit dem Nabel und dem Nabeldorn von gleicher Farbe wie die Zapfenschuppen; Dorn gerade oder nach dem Stiele zugekehrt. Ḱnospenschuppen fest anliegend, durch Har\% verklebt.

Nach dieser Diagnose sind die meisten, als contortil bei uns bezeichneten Exemplare zu P. Murayana \%u richen; an kultivirten

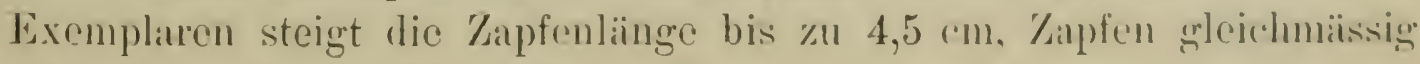
dick, 2 cm wenn geschlosien.

Wie Bank's Kiefer ïhnelt aurh diese im Mibbitus unserer Finde: die Rinde wird schon frühzeitig eine kleinsehuppige llunkelgrane Borke, 
wesshalb sie in den Blauen Bergen "Schwarzkiefer" heisst; im höheren Alter rerbreitern sich die Schuppen nicht, sondern rerdicken sich nur. Das Holz mit einem specifischen Gewichte ron 41 , hat $4 \mathrm{~cm}$ Splint und wird gelegentlich zu Nutzholz verarbeitet.

Unter den Feinden sei Arceuthobium americanum, eine Zwergmistel erwähnt, die eine peitschenförmige Missbildung der Aeste rerursacht; ausser diesem Hexenbesen ist auch jener a ufrechte, dicht verflochtene Hexenbesen an dieser und anderen amerikanischen Kiefern bekannt, den man auch reichlich an der europäischen Kiefer und ebenso an den beiden zweinadeligen, japanischen Kiefern wieder findet: die Ursache dieser Missbildung ist bis jetzt noch nicht aufgekliärt.

Das Holz erwachsener Stämme wird oft ron T'rametes Pini zerstört.

Professor Sargent und der als Autor schon öfters genannte Engelmann sammelten auf felsigen, trockenen Gebirgsböden in Colurado zapfentragende Zweige einer Kiefer, die sie als P. contorta r. Murrayana bestimmten; da Murray's Kiefer und die Drehkiefer der Kïiste als zwei gute Species anerkannt wurden, so muss auch die Colorarlokiefer entweder einer der beiden Arten zugetheilt werden, oder als Varietait von einer ron beiden oder als neue Art beschrieben werden; lat ich diesc Kiefer selbst nicht gesehen habe, getraue ich mir weder die Irlentitï mit den erwähnten Kiefern zu behaupten, noch auch eine eigene Art aufzustellen; ich !nabe desshalb den Ausweg gewählt, die [Bmeinmung Pinus Mrrayana var. Sargentii mihi für die Coloralo-Drehkiefer zu wählen.

Narleln $6 \mathrm{~cm}$ lang. oft $8 \mathrm{~cm}, 2,5 \mathrm{~mm}$ dick; Zapfen $5 \mathrm{~cm}$ lang; $4 \mathrm{~cm}$ breit, wenn offen; Nabel und Nabeldorn glänzend hellbraun; Nabeldorn sche krifftig, gararle abstehend; Apophyse nicht glänzend, legelig orhaben; die als contonta kultivirten Exemplare mit sehr dicken, kräftigen Nadeln diirften hicher zu ziehen sein (Simen 'Tafel VIII).

Die 'I'annen dieser Region kann man in Parallele mit unserer 'I'anne stelle, was Biologrie und klimatologische Ansprüche betrifit; die Bestiunde, die sie bilden, sind denen unserer T'annenwaldumgen im Mittrogehirger sche ähnlich, Fichten mischen dazwischen; da das aros

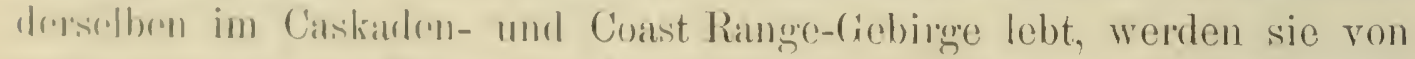
rauhen, frockenen firisten nicht belïstigt: ihr Wintre ist selmeereich, aber mild.

Ahoes nobilis Lindl., Red fir, pacifische Edeltanne.

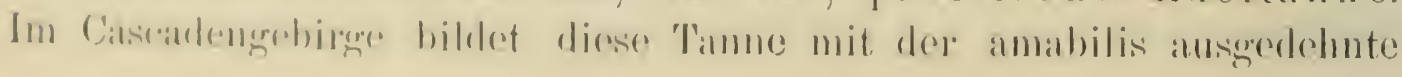


Waldungen; einzelne Individuen in günstigen Lagen des feuchteren Coast Range erreichen 92 Meter Höhe. Ohme sich Zapfen ron den Büumen $\%$ schiessen, ist es haum möglich, erwachsene 'Tamnen ron cinander zu unterscheiden; bei allen ist die Rinde dunkelgrau, glatt, nur im höchsten Alter schuppig: erst damn sind einige Unterschiede crkennbar; so ist die Borke der pacifischen Edeltame schmal aber tiefrissig, fast der Schwar\%kicfer :̈hnlich. Um so besser dagegen sind die jungen Pflanzen und die Frïchte charaliterisirt; der Zapfen der Edeltame ist ein Schmuck für jede Sammlung; die Tanne trägt bercits an viclen Orten Europa`s, besonders in Frankreich und England Früchte, die sich, wie bei allen in Kultur gepflegten Holzarten, durch besondere Frühzeitigkeit, Häufigkeit und Grösse auf Kosten der Schaft- und Nutzholzproduktion auszeichnen. Der Zapfen in der Hcimat ist durchschnittlich 12,5 cm lang, $5,5 \mathrm{~cm}$ breit; an jungen, unreifen Frïchten ist die Bractee nur wenig zwischen den Zapfenschuppen hervorstehend; an ausgewachsenen Kapfen dagegen ist die Bractee fast dreitheilig und nach rückwärts umgebogen, so dass rom ganzen Zapfen überhaupt nur Bracteen sichtbar sind. An kultivirten Exemplaren erreicht der Zapfen eine Länge ron 22,5 cm und der grösste Durchmesser an der Basis beträigt $7,5 \mathrm{~cm}$. Das Holz, das dem 'Typus der Gattung folgt, wird kaum beniitzt.

Junge Pflanzen mit rothbraunem Triebe; Nadeln an der oberen Seite der Triebe halb so lang als an der Unterseite und parallel lem l'riebe gestellt, untere Narlehn vielfach nach Oben zu gekrümmt.

Abies magnifiea Murr., Red fir, Schasta-Tanne, bildet auf den Bergen, welche die Basis des grossen Vulkanes Schasta umgiinten, zwischen 1500 und 2500 Meter atsgerlehnte Bestainde; alte Bämme mit 5 cm dieken und 7 cm breiten Borkenschuppen; an dem Zapfen sind die Blüthenschuppen (Bracteen) kïr\%er als die Zalpfenschuppen und damn ron aussen nicht sichtbar, oder sic stehen nur wenig über dem Zalpfen hervor; die grösisten Zalpfen erreichen 15 am Länge mal $8 \mathrm{em}$ Dicke; durehschnittliche (irösisen sind 13 r'm 6,5 ('m; Zapfensehuppen sehr breit, ofwas kur\%, filyig bohant.

An jungen Pflanzen sind die Nadeh der sedenzweige alle greidhgrosis und ofwas mach anfwäts gewendet.

Ahies amabilis Forb. P'urpurtanne: im C'aseaden-Gebirge fält dieser Bam ror Allem dureh die dunkelgriune Benadelungr anf:

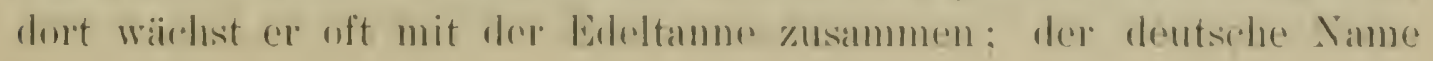


wurde wegen der dunkeln, purpurnen Farbe des reifen Zapfens gewählt wodurch der Baum mit Sicherheit von anderen Verwandten unterschieden werden kann. Die grössten Zapfen bis zu $14 \mathrm{~cm}$ Länge, 7 cm Durchmesser, meist nu $8: 5 \mathrm{~cm}$. Bractee nicht vorstehend.

An jungen Pflanzen sind die oberen Nadeln kürzer als die unteren und etwas dem Triebe parallel angedrückt; an Zapfen tragenden Zweigen sind die Nadeln so gedreht, dass die Unterseite aufwärts kommt. Dic Rinde des erwachsenen Baumes der unserer Tamne ähnlich. -

Die Fichten Nordwestamerika's in dieser Region theilen die Biologie unserer einheimischen Fichte vollständig. Vom $56^{\circ}$ N.B. an im Cascaden- und Felsengebirge südlich bildet

Picca Engelmanni Engelm., White Spruce, Engelmann's Fichte, im mittleren Theile der Felsengebirge ausgedehnte Bestände; sie crfüllt dort die tiefen, feuchten Cañons; von 3400 Meter an aufwärts bleibt sie aber nieder, strauchförmig, erreicht aber in ihrem Optimum 46 Meter und ist dort der werthvollste Nutzbaum. Der abwärts hängende Zapfen $4 \mathrm{~cm}$ lang, $3 \mathrm{~cm}$ dick, wemn offen; Zapfenschuppen dlünn, weich, längs gefaltet, am Rande ausgebissen.

Die junge Pflanze, heller als unsere einheimische Fichte gefïrbt, mit stechenden Nadeln, doch weniger scharf als die der eigentlichen S'terhfichte und kiurzer wie diese. Die Nadeln, denen der Weissfichte (alba) sehr nahe stehend, doch von diesen dureh das Fehlen des unangenchmen Cieruches beim Drücken der Zweige unterscheidbar; junge Triebe schwach rosia bereift; Knospenschuppen hell ockerfarbig, inatt, fest anliegend. Die Borkenschuppen des erwachsenen Bammes sind kloiner und seichter als von unserer Fichte, weisslich; frisch ausgelöste Śchupuen röthlich; Holz nach dom Typus unserer Fichte gebaut, gelblich, sche loicht (specifisches Gewicht 34).

Picea pungens Engelm., White or Bluc Spruce, Blauudre Siterhfichte. Diese Fichte ist ein hoher Baum des Felsengebirges von Colstarlo, wo er in den feuchten 'Thälern eingesprengt vorkmmet dar 'zapfen ist kaum von dem der Engelmann's Fichte zu unterscheiden, 6 cm langr, 2 ('m dick; Yaypfenschuppen dünn, weich, lïngsfialtige, an Rande ausgebissen; die Borke diek-kleinschuppig; das

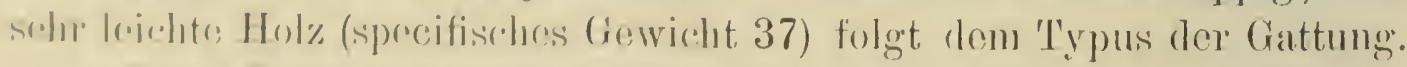

funge lixemplare mit präehtigrer, blan-weisser Firbung der Nadeln;

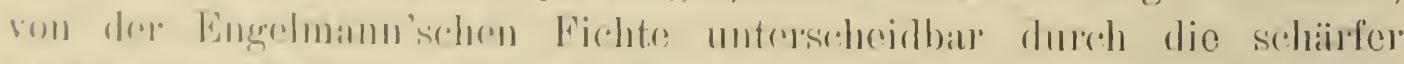

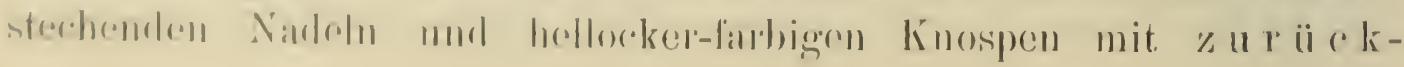


gerollten Kuospenschuppen. Beide Fichten werden bis jetzt noch kaum genützt.

Juniperus oceidentalis Hook., Juniper, Westlicher Wachholder; selten erreicht die Art Baumform, meistens ist sie nur ein Strauch, besonders am Rande der Prärie, an trockenen heissen Hüngen; ausgezeichnet und herrorragend dekoratir durch die weisslichblaue Fürbung. Von den blauen Bergen südlich durch die Sierra erstreckt sich dieser Wachholder in einer variirten Form bis nach Colorado und in's westliche Texas.

Die schuppenförmigen Blätter habe» oberseits eine schmale Rinne mit einer Drüse, aus der hellgelbes Harz austritt; Früchte ron der Grösse unseres Wachholders, weiss bereift, lünglich; alle Nadeln stellen kurze, anliegende Schuppen dar; nur am Leittrieb verlaufen sie in eine rom Triebe abstehende Spitze.

Die Rinde des erwachsenen Baumes ist eine seichte, breite, vertikalrissige Borke; das Kernholz roth, ron einem $15 \mathrm{~cm}$ breiten Splinte bedeckt; entsprechend der intensiven Färbung ist das Kemholz sehr dauerhaft, wesshalb dieser Wachholder zu Eisenbahnschwellen und Telegraphenstangen sehr gesucht ist.

\section{d) Die kühle Region der alpinen Nadelhölzer.}

Die alpine Region bezeichnet die obere Grenze des Baumwaldes; wo typische Vertreter dieser Region nicht rorhanden sind, bilden Nutzbänme ron tieferen Lagen mit niederen Individuen die Grenze; nirgends aber dürfte diese Region so sehr eine eigene Betrachtung rerdienen als in Nordwestamerika, wo fast jedes Genus der Abietineen auch so hoch oben noch Vertretung findet; freilich sind alle meist nur Halbbäume und Strüucher; 30 Meter Höhe erreichen nur wenige in den wärmsten und besten Lagen ihres Gebietes; auf die höchsten, unzıgänglichsten Gebirgsparthien beschränkt sind die alpinen Coniferen, nur durch ihren Schutz auch Nutzpflanzen; sie werden sehr werthroll werden, wenn es sich um Festigung des Terrains im Quellgebiete der Flüsse handelt.

Pinus aristata Engelm., Foxtail Pine, Fuehsschwanzkiefer. Diese Art wird noch vielfach als Varietiat der Balfour schen Kiefer aufgeführt; ihr Verbreitungserebiet ist rom Süden Californiens an ästlich bis nach Colorado zwischen 2500 Meter und 3600 Meter hïufig. liebt somit warme Gebiete, die vielfach in die gemiissigte Region 
grehören: sie stellt für die Bergwerksdistrikte Nevada's einen werthrollen Baum dar, ein Grund, der Schuld ist, dass sie dort nahezu ausgerottet wurde; nur in gïnstigen Lagen erreicht sie 30 Meter; ihren Namen hat sic erhalten regen der dünnen Zweige, die viele Jahre hindurch die buschige Benadelung beibehalten.

Nadeln durchschnittlich $3,5 \mathrm{~cm}$ lang, dünn, fünf zusammen in eincm Kurztrieb; junge Triebe rothbrann behart; der Zapfen ist $7 \mathrm{~cm}$ lang, $3 \mathrm{~cm}$ breit, $5 \mathrm{~cm}$ wenn geöffnet, blauroth; Apophyse mit einem Dornfortsatz ron 0,5 cm Lïnge; Dorn nach der Spitze des Zapfens zu, diesem angedrüickt.

Das Holz dieser Kiefer ist sehr schwer (specifisches Gewicht 57) und völlig nach dem Typus der Gattung Picea gebaut (Tafel XI); diese Eigenthümlichkeit zusammen mit jenen des Zapfens und Samens (Tafel TIII) reranlassen mich, für diese und die folgende Art eine nene Section der Gattung Pinus aufzustellen mit dem Namen Balfouria.

Pinus Balfouriana Murr., Foxtailpine, Balfours Kiefer ist in den höheren Regionen der Scotts Berge in Nordealifornien, im Quellgebiete der King- und Kernflüsse heimisch, wo sie einen breiten Kieferngürtel als oberste Waldgrenze clarstellt; sie bleibt ein niederer (bis 19 Meter erreichender) aufrechter Baum; fünf Nadeln von 2,53 cm Länge, zusammen in einem Kurztriebe; Nadeln mehrere Jahre am Triche festsitzend; Zapfen $10 \mathrm{~cm}$ lang, $6 \mathrm{~cm}$ breit wenn offen, hellpurpurn, schwach gekrümmt; Apophyse etwas erhaben mit kurzem, nach der Basis des Kapfens zugekehrtem Nabeldorn. Der Splint ist nn 1 ('m breit, der Kern schön roth; die Rinde wie die einer Eiche. Das Hol\% zoigt den Typus der Fichte, jst ebenfalls verhältnissmässig solhwor (sperifisches Gewicht 54); der Baum bildet mit dem rorausunchenden die Section Balfoncia. Same nach Tafel VII.

Pinus albicaulis Engelm., Weissstämmige Züubcl. Zapfon diesser fünfuadeligen Kiefer Cembra-artig, $4 \mathrm{~cm}$ lang, Apoplyse stark vorsteluend, gekriummt; Same olhne Fiügel (Tafel VII); Borke der

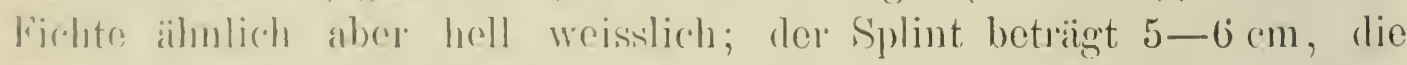

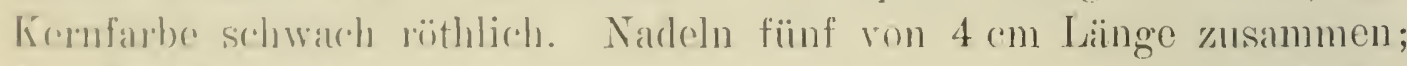
Soitentriebe behalten lange Zejt die Nadeln bei, ohne äusserlich erkennhares Dirkienwachsthum.

In den hüheren Regionen des Cascarlen-Gebirges von BritischColmmbion bis in's südliche Callifornien und Utah wolnend, ist diese Ziinbed meist mohr Stranch als Baum; sic gehört zur Section Cembra.

D) Fe Fichte dieser kïhlen Region ist die seltene 
Picea Breweriana Wats., Siskiyou Eichte, die erst ror wenigen Jahren 1884 ron Th. Howell an den alpinen Hängen der Siskiyou-Berge aufgefunden wurde; ein Baum mit lang herabhängenden, dünnen Zwweigen; Nadeln 2,6 cm lang, 2,5 mm breit, oberseits mit zwei weissen breiten Streifen; Zapfen $10 \mathrm{~cm}$ lang, $4 \mathrm{~cm}$ breit wenn offen, geschlossen Cigarren-förmig; Schuppen des Zapfens hart, abgerundet, nur wenig ausgebissen; grösste Breite der Zapfenschuppen $1,5 \mathrm{~cm}$; wie der Zapfen ist auch der Same der grösste von allen nordamerikanischen Fichten.

Weitere Angaben über diese Fichte wurden in der Fussnote bei Besprechung der Sitka-Fichte gegeben.

Als alpine Tanne dieser Region ist

Abies subalpina Engelm., Balsam, westliche Balsamtanne, aufzufassen; in den tieferen, wärmeren Lagen wird sie ein hoher Nutzbaum; sie ist dagegen niedrig, oft strauchartig an der oberen Grenze der Waldvegetation Britisch-Columbiens, im Cascaden-Gebirge, in den Blanen Bergen und von da südlich bis Colorado.

In den botanischen Merkmalen der Früchte, nicht aber in seiner Biologie steht die Balsantame der grossen Küstentanne und der amerikanischen Silbertanne sehr nahe; die Zapfen sind $6 \mathrm{~cm}$ lang, $3 \mathrm{~cm}$ dick; Blïthenschuppen nicht sichtbar; Nadehn an Früchte tragenden Zweigen 1,5-2 cm lang, an der Basis eben so breit wie in der Mitte; junge Triebe hellbram behaart; die Rinde alter Bäume mit $3 \mathrm{~cm}$ breiten Schuppen bekleidet, hell.

Die europäische und japanische Lärche erheben sich bis hart an die Baumgrenze, wo sie selbstrerstaindlich niedrig bleiben; sie sind aber in wärmeren Oertlichkeiten Nutzbäıme erster Klasse, insbesonders was die europäische Lärche betrifft; eine alpine Lürche in wahren Sinne ist dagegen

Larix Lyallii Parl., Lyall's (spr. Leiall's) Lärche. Auf den hohen Bergen Britisch-Columbiens und an der Nordgrenze der Vereinigten Staten zwischen dem 49. und 510 N.B. (nördlich daron tritt wicher die östliche Lärehe auf) bildet Lyall's Lürche mit der woissstaimmigen Ziürbelkiefer und der alpinen J'sugal den obersten Vegretationscrïrtel; selten erlangt sie 15 Meter Höhe, meist stollt sie cinen istigen, sparrigen, nickleren Baum dar, der in diesem rauhen Klima auch noch die Nordseiten bevoryurt. 
Diese merkwürdige Lärche ist gekennzeichnet durch weisswollig behaarte Triebe, dunkelviolette Bracteen des Zapfens mit nadelförmig rerlängerter Rippe; Zapfenschuppen breit, weich, am Rande bewimpert; Zapfenlïnge $4 \mathrm{~cm}$, Dicke $2 \mathrm{~cm}$.

Endlich ist die Gattung Tsuga repräsentirt durch

Tsuga Pattoniana Engelm. (syn. Hookeriana), Alpine Tsuga oder Hemlock. Sie ist im Cascaden-Gebirge und in der Sierra ein astreicher, oft viclgipfeliger Baum, der selten 30 Meter erreicht; östlich geht er bis Montana; junge Zapfen blau-purpurn, reife Zapfen $6-8 \mathrm{~cm}$ und 3-4 cm breit wenn offen, somit die grössten Zapfen ron allen Tsuga's, Bractee sich leicht von der Zapfenschuppe ablösend (Tafel VI). Narleln click, fichtenartig an zapfentragenden Zweigen, oft dreikantig, gekrümmt, Oberseite ohne Lüngsrinne; junge Triebe dicht hellbraun, filzig bchaart; Rinde des erwachsenen Baumes eine tiefrissige, dunkelgraue Borke.

\section{Verhalten der exotischen Holzarten in Nordamerika.}

Will man eine Untersuchung des Verhaltens der für Nordamerika exrotischen Holzarten anstellen, so muss man vor Allem die Anbanversuche nach den im Vorausgehenden angenommenen Waldregetationszonen trennen.

Im Osten, in der atlantischen Region, in N. a. und N. c. sind die Versuche am ïltesten, zahlieichsten und für uns auch am lelireichsten, da diese Region klimatisch unserem Laubwalde am nächsten steht. Freilich darf man dabei nicht vergessen, dass die Versuche in Nordanerika nur zum greringsten Theile im Walde selbst ausgeführt wurden, wis umgekehrt die meisten nordamerikanischen Holzanten auch bei uns his vor Kur\%m nu' \%ur Kicrle gepflanzt wurlen, wobei sie allen Unbilden dor Witterung auf ihren unnatiurlichen Standorten preisgregrebon waren.

Abgesehorn von Witterungseinflüssen hat man in Nordamerika mit norh gan\% anderen finden zu kïmpfen. R. Douglas hat äusserst Irhrectehe Vursuche am Lake Michigan angelegt; das Terrain dort ist parallal dee Strandlinio wellig; auf den höheren sandigen Partieen liegen die Anbanversucho mit Kiefern; die niederen parallelen Streifen sind mumptigr. Im Winter mit Wis berleckt. Die besseren Stinde aus 
der Umgebung belustigen sich dort mit Schlittschuhlaufen; unter dem Schutze einiger abgehanener Exemplare von Douglas' Pfleglingen wird kampirt und geluncht; che man hinwegzieht wird alles in Brand gesteckt; die Zäune zum Schutze gegen Weidevieh werden gestohlen oder verbrannt, und die Pflanzen sind dem Vieh, das zum Schutze gegen Mosquito an die Pflanzen schlägt, preisgegeben. Die Versuchsflächen sind völlig kahl, die ursprüngliche Tegetation war, nach den noch vorhandenen Weymouths-Kieferstöcken zu schliessen, ein ganz leidlicher Wald. In den sumpfigen Partieen wurden Thuja occidentalis und die europäische Fichte versucht, jedoch ohne Eifolg. Auf den höher liegenden Particen sind die schon mehrfach erwähnten Versuche mit den Nadelhölzern, die Douglas nach ihrem Verhalten in der ersten Jugendzeit folgendermassen gruppirt: Am besten ist die Weymouthskiefer, dann kommen europäische Lärche, europäische Kiefer, österreichische Kiefer; am schlechtesten sind Pinus ponderosa, rigida und pungens; die Anlagen mit resinosa sind verbrannt und Banksiana sind leider nicht versucht worden.

Vieljährige Erfahrungen hat auch Professor Me ehan in Germantown bei Philadelphia und Professor Sargent in Broockline gesammelt. Als das Resultat aller bisherigen Versuche ergibt sich folgendes:

a. Verhalten der Laubhölzer. Von den beiden mitteldeutsehen Eichen sagt Emerso n, dass sie bei Boston, also in N. a. so gut gedeihen, wie irgend eine einheimische Eiche, die rubra nicht ausgenommen und dass sie so reichlich Früchte tragen und sie cben so sicher zeitigen, wie in ihrer Heimat; die Ulmen haben sich ebenfalls zu stattlichen Bäumen entwickelt; Acer platanoides und Pseudoplatanus, Sorbus aucuparia erwachsen so schmell und zu denselben Dimensionen wie bei uns; die Rosskastanie wird ein hoher Baum; die Rotherle (Alnus glutinosa) wird in den westliehen Präriestaten, also in N. p. auf der Prärie angebaut in Oertlichkeiten, die für andere Holzarten zu feucht sind; dagegen erfriert die Edelkastanie in ihrer Jugend wie auch die Pyramiden-oder italienische Pappel, die leider wegen ihrer Raschwïchsigkeit und aus heimatlichen Erinnerumgen so massenhaft angebaut wird trot\% zahlreicher, viel schönerer und dankbarerer einheimischen /ierbäume - schon frühzeitig ihren Gipfel verliert und dann so hïsslich ist wie gegenwärtig die vielen Pyramidenpappeln in Deutschland. Dic japanische Pawlownia imperialis, die bei uns in Dentschland nur in den wärmsten Lagen bis zur Baumgrösse gebracht werden kann, gedeiht gut in den mittleren Staaten, also in s. a. und ". Anders verhalten sich b. die Nadelhöl\%er, deren Misslingen sehr Beachtung verdient. 
Unsere Fichte, Kiefer und Lärche werden in der atlantischen Zunc N. a. und insbesonders in N. p., in den Präriestaaten in grösstem Jassstabe wegen ihrer Billigkeit und Raschwüchsigkeit erzogen und gepflanzt, in den Städten und Gärten zur Zierde, in den Präriestaaten als Windbrecher für Haus und Garten. Die jungen Fichten leiden oft durch Schütte ohne Pilz, wemn die Pflanzen lange Zeit während des Wrinter's mit Schnee bedeckt waren; nach dem Abschmelzen des Schnee's von der warmen Füuhjahrssomme getroffen, vertrocknen sie durch übergrosse Verdunstung ron Seite der zart gebliebenen Nadeln, die in kiurzester Zeit braumroth werden. In den Städten und deren Umgebung. lcidct die Fichte ebenso wie bei uns in gleichen Oertlichkeiten durch Rauch und chemische Gase; ihre Nadeln färben sich im Winter braun und ist sic dann so hässlich, wie auch die dort gepflanzten einheimischen Fichtenarten wie Pieca alba und nigra.

Wo man iibrigens bisher Fichten und Kiefern angebaut hat, beurannen diese Holzarten mit dem 40.-50. Lebensjahre plötzlich in ihrem Höhenwachsthume nachzulassen; sie überladen sich dann mit Zipfen - der Anfang rom Ende - verlieren den Gipfel und werden unschïn und werthlos, ehe sie Dimensionen erreicht haben, die zu Nut\%holzzwecken nöthig sind. Auffallend ist dabei das rasche Wachsthum in den ersten Jahrzehnten; auf einer Pflanzung der Universität von Jllinois erhob sich unsere Fichte auf tiefem, lehmreichen Boden, nachilem dersolbe mehrere Jahre zu landwirthschaftlichen /wwecken heniitzt worden wal, ron $32 \mathrm{~cm}$ Läinge im Jahre 1872 bis zu $11,4 \mathrm{~m}$ Höho im Jahre 1888, also pro Jahr nahezn $70 \mathrm{~cm}$ Längenzuwachs; der Durchmesser, wahrscheinlich ïber dem Boden genommen, betrug $42,5 \mathrm{~cm}$, also bei durchschnittlich zwanzigjährigem Alter pro Jahr $1 \mathrm{~cm}$ Jahringhbreite. Man kann ahnen, was für eine Qualität Hol\% diess scin muss. Die europaiische Lärehe bleibt in ihren Wachsthumsleistungen hinter dor Fichte keineswegs zuriick und gilt allgemein als der beste Nadelholybaum, der ron Europa eingeführt wurde. Sie wächst nicht in tiefen Lagen, wohl aber im Hochlande, selbst auf Boden, der für andere Holzarton \%u arm ist, ausgenommen die Weymouthsliefer und die gremeine, ouropäische Kiefer.

l) je Lärrde soll \%u cinem Nutzhaume emporwachsen, während der Schaft als. .unsishön" bezeichnet wird. Auflallend ist das Verhalten der Läreche anf Düncnsandboden, zu welchem Zwecke sie wohl bei uns noch nicht verwendet worden sein diurfte; die Lärche bleibt dort

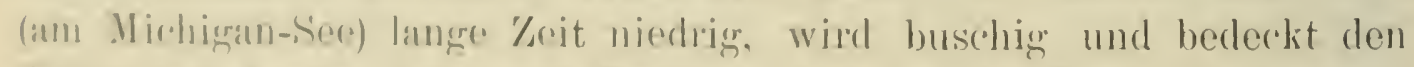
Buden mit Aesten anf cincm Unkreis, der etwa das Verbreitumgsgebiet. 
der Wurzeln markirt; dabei wird die Rinde der Pflanze auffallend dickborkig, ein Schutzorgan gegen Kälte und Hitze. Erst wenn so der Boden beschattet und in einem frischeren Zustande gehalten wird, beginnt die Lärche einen kräftigen Längstrieb; im Jahre 1885 erreichten die Längstriebe einen vollen Meter Länge; dass die Lürche dort ein Nutzbaum werden wird, erwartet Niemand. Die gemeine Kiefer steht in ihren Leistungen im Allgémeinen hinter der Lärche zurück, übertrifft aber die Fichte wenigstens in der Schnelligkeit des Wuchses, worauf es bei Anlage eines Schutzmantels gegen Wind in den Präriestaaten hauptsächlich ankommt. Auf denselben sandigen Boden am See Michigan gebracht, ist sie nicht besser als die Lärche, iibertrifft aber die Leistumgen der einheimischen Kiefern, wie Stechkiefer, Pechkiefer (Pinus rigida) ganz beträchtlich.

Die Pinus austriaca bleibt hinter der sylvestris iiberall entschieden zurück, ist dagegen als Zierpflanze in den Gärten und Parkanlagen sehr beliebt und hat mit der Weymouths-Kiefer im New-Yorker Stadtparke am besten noch der rauchigen Atmosphäre widerstanden; in Jllinois leidet sie dagegen von einem Pilze, Lophodermium baculiferum, der ron der Gelbkiefer auf die österreichische Kiefer übergewandert ist.

Pinus Pinea hat man vor 20 Jahren in Alabama, also in S. a. auf sandigem Boden anzubauen rersucht, sie ist ganz niedrig geblieben.

Cryptomeria japonica wurde mit anderen japanischen Nadelhölzern zusammen wie Chamaecyparis obtusa und pisifera vor ein paar Jahren im Central-Parke in New-York ausgepflanzt; dass die beiden letzteren Holzarten sich gut halten werden, ist zu erwarten, ebenso dass die Cryptomeria zu Grunde gehen wird, denn sie ist in dem milderen Philadelphia, in Germantown schon bei $-17^{0}$ erfroren, resp. vertrocknet.

Abies Nordmaniana wird bei Philadelphia also in N. a. nicht über 2 Meter hoch, weil sich jeden Winter ihr Gipfel bräunt. Abies cilicica rerliert dort jedes Jahr einen Theil seiner Endtriebe, wie auch Abies Pindrau und Webbiana.

Von Holzarten, welche zwar in Nordamerika heimisch sind, aber der Zone $\mathbf{N}$. a. fehlen, mögen crwähnt werden: die Magnolia macroplyylla aus den Südstaaten, die bei gutem seitlichen Schut\%e durch Nachbarbaume in der Breite ron New-York im Freien aushält; Thxodium distichum wird dort ein stattlicher Baum, während Pinus australis als Topfpflanze den Winter im Kalthause zubringt; Catalpa speciosa ist in N. a. als werthroller Nutzbaum nicht mehr auf\%uziehen.

Sehr bemerkenswerth sind ferner die Anbaurersuche mit westlichen Nadelhülzern, die in N. a. und N. e. fast sämmtlich zu Grumde 
gehen; bald wird die Ursache auf die Trockniss im Sommer zurückgreführt, bald heisst es, die Hitze im Sommer verzögert die Entwicklung und die Fröste im Winter tödten dann die Pflanzen, so bald die Sümercien aus Gegenden westlich vom Cascaden - Gebirge gesammelt wurden.

Eine Verminderung der relatiren Feuchtigkeit der Luft, sei es durch das Klima selbst oder durch die unnatürliche Stellung einer waldbildenden Pflanze ausserhalb des Waldgebietes, oder eine gesteigerte Verdunstung ron Seite der Pflanze selbst durch direkte Besonnung im Winter und Sommer steigert die Empfindlichkeit derselben gegen Frost und Hitze. Die Nadelhölzer von der Küste des Stillen Ocean's, wenn sie nicht unmittelbar an der Küste in N. a. gepflanzt werden, finden cine geringere relative Feuchtigkeit, grössere Extreme in der Temperatur in Sommer und Winter und überdiess eine unnatürliche Stellung auf freier Fläche, der direkten Besonnung und den austrocknenden Winden preisgegeben. Dass da diese Hölzer ohne Ausnahme fehlschlagen, darf nicht wundern. So ist z. B. die Douglasia von Washington Terr. und Oregon bezogen, in N. a. nicht aufzubringen; R. Douglas brachte zuerst Samen der Colorado-Douglasia (v. glauca) nach dem Osten und diese, an grössere Extreme der Temperatur und Feuchtigkeit gewölnt, vermag dem östlichen Klima zu widerstehen. Sic hat sich jedoch, wie anch bei uns in Deutschland, als langsamwïchsig crwiesen und ihr Holz gilt als nittlere Qualität, da der Baum ïberdiess nicht hoch wird. Same aus Montana, wo er z. B. bei Missoula mit grösster Leichtigkeit zu beschaffen wäre, wurde leider bis jetzt noch nicht versucht; ganz das gleiche Verhalten zeigt die Küsten- und Coluralis-Abies concolor; 'Thuja gigantea und Chamaecyparis nutkaensis ron der. Küste gehen stets zu Grunde; Pinus ponderosa am Michigan-See auf Sinnlborlen gebracht, wird im Sommer durch Trockniss getödtet, während die kräftigen Pflanzen im Saatkampe ron dem Schüttepilz (Lophordromium baculiferum) vernichtet werden.

Weniger interessant sind die Versuche im Westen, da diese sich auf lie Küste Califomicns, also die subtropische \%one, beschränken. Unsre einhesmische Eiche (Quercus pedunculata) wächst in der Jugend wenigstens hesser als alle ostamerikanischen lichen. Unerwartet günstig hathen sich hisher dio australischen Holyarten entwickelt; Eucalyptus (moistentheils (ilubulus) wird scit $1865 \mathrm{im}$ Grossen angebaut zum Schatye greren Wind und Sonne; bis zum Jahre 1882 rechnete man bereits cinc halhe Million Bämme in Californien; ihr Wachsthum gelangt während des ganzen Jahres wohl katum rum Stillstande; Blüthen und 
reife Früchte mit keimfähigen Samen finden sich zu jeder Jahreszeit; im südlichen Californien wurde der Fall bekannt, dass ein achtjähriger Baum 34'Höhe und $55 \mathrm{~cm}$ Durchmesser erreichte; ausserdem werden des Gerbstoffes wegen Acacien-Arten mit grossem Erfolge gebaut; die Lawsonia wächst in diesem winterlosen Klima vortrefflich mit Palmen und Yucea in demselben Garten.

Aus dem Gesagten mag entnommen werden, dass das Klima des nordöstlichen Amerika's N. a. und c. den europäischen Laubhölzern konvenirt, während die Coniferen zwar Anfangs sehr rasch wachsen, aber bald zu Grunde gehen, ehe ihr Holz Nutzwerth erlangt hat; dass ferner die Bäume der pacifischen Küste westlich rom Cascaden-Gebirge überhaupt nicht, östlich ron diesem nur langsam im Freien aufzuziehen sind.

Schliesst man umgekehrt auf das Verhalten der nordamerikanischen Holzarten in Europa und in Deutschland insbesonders, so dürfte zu erwarten sein, dass die nördlichen Laubhölzer sich bei uns ebenso verhalten wie unsere Laubhölzer in Nordamerika, was in der That dio bisherigen Erfahrungen bestätigen; auch die nordöstlichen Nadelhölzer wie die Weymouthskiefer, die Weissfichte bilden keine Ausnahme. Ebenso ist es sicher, dass die pacifischen Nadelhölzer bei uns sich in besseren Verhältnissen befinden als an der atlantischen Küste Nordamerika's.

Dagegen wäre es sehr traurig, wenn diese Holzarten sich bei uns ebenso verhielten, wie die europäischen Nadelhölzer in Ostamerika, das heisst nur in den ersten Jahrzehnten recht üppig wüchsen und damn verkümmerten.

Unsere Fichten und Lärchen sind durch den Anbau in N.a. und p. c. in ein Klima gebracht worden, das wärmer ist als jenes in der Heimat, nämlich aus der gemässigt-kühlen Region in die gemässigtwarme Region der blattabwerfenden Laubhölzer; das цnag nicht das Fehlschlagen der Versuche, wohl aber das ausserordentlich rasche Wachsthum in der Jugendzeit erklären. Warum unsere Nadelhölzer so geringwerthig bleiben, dürfte wohl in erster Linie der geringeren, relativen licuchtigkeit während der Vegetationsmonate zu\%uschreiben sein, die am Meere und an den grossen See'n zwischen 60 und $70 \%$, in den an die Prärie angrenzenden Staaten \%rischen 55 und $65 \%$ schwankt.

Geringere Feuchtigkeit der Luft bedingt, wie erwilhnt, grössere Empfundlichkeit der Pflanzen gegen Kïlte und Hitze, welch letztere insbesonders in den Monaten Juli und August in Nordamerika äusserst 
intensiv ist und eine Höhe erreicht, wie sie wohl nie in der Heimat der Nadelhölzer beobachtet wird.

In ähnlichen, freilich viel gïnstigeren Verhältnissen finden sich die westamerikanischen Holzarten in Europa. Aus einem Klima stammend, dessen relative Feuchtigkeit während der Vegetationszeit zwisehen $70-80 \%$ schwankt, erreichen die westamerikanischen Holzarten, wie Douglasia, Lawsonia, Thuja erst bei $80 \%$ relativer Feuchtigkeit ihr Optimum; dazu kommt, dass sie an eine längere Vegetationszeit gewölınt sind, somit von Frïhfrösten überrascht werden müssen, ehe vollständiger Stillstand in ihrer Wachsthumsthätigkeit eingetreten ist; es verdient Beachtung, dass Pflanzen, erzogen aus Samen, der aus östlicher, n icht $n$ ördlicher gelegenen Gebieten stammt, die wünschenswerthe Härte gegen Extreme ron Frost und Hitze bieten.

Es ist schr wahrseheinlich, dass in vielen Oertlichkeiten in Europa, welche sich durch eine Vergleichung der klimatischen Verhältnisse mit jenen der amerikanischen WVestkiuste ergeben (vide Karte) diurften, die westlichen Holzarten sich so verhalten, wie unsere Nadelhölzer in Tordamerika, das lleisst, dass sie 4-5 Jahwehnte lang kräftig wachsen, dam aber zum Stillstande kommen und langsam dahinsiechen; es ist auch sehr wahrscheinlich, dass es vicle Oertlichkeiten in Europa gibt, wo die Douglasia und die übrigen westamerikanischen Arten alles, was sic \% ilırer Vollendung wïnsclen, finden werden; nach den nenesten Angaben \%. B. scheint Schottland mit seinem feuchten, insularen, glcichmässigen Klima dem Optimum der paeifisehen Holzarten sehr nahe zu stch(ru**) anch die deutsche Küste düufte hierin kaum zurüekstehen; lic friilıce crwilunte Kleinflottbecker Douglasia in einem Klima mit $74 \%$ relativer Fenchtigkeit, wähend des. Vegetationsmonate erwasehsen, (Mangrte nur 16 Moter Hölıe in 52 Jahren; das spricht nicht für diese Annahme. Dass aber das Klima an dieser auffaliend ungünstigen

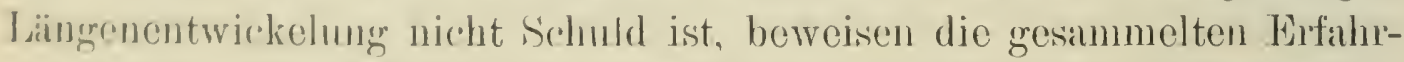
ungen übor das Vorkommen gewisser fremdlandiseher Holzarten in 1) (ntsrohand**). Dieselben erwihnen ciner dreissigjährigen Douglasia brej Harburer mit 12 Mrefer Höhe und einer vierzigjährigen in Jägerhof

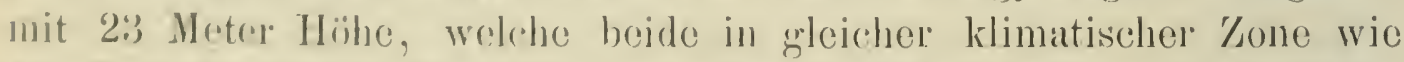
las Kleinflotthecker bxcmplar erwarehsen sind. Leider ist bei dem

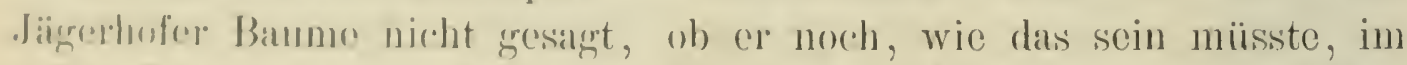

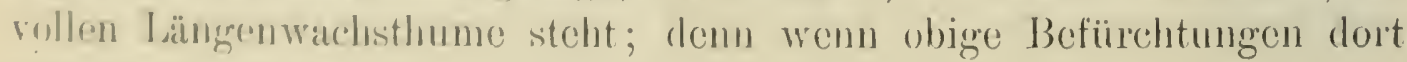

*) The Inouglas Fir in Scotland in "The Indian Forester". Roorke 1889.

**) Heransgegoben von lionstrath Weise, Berlin 1882. Sipringer. 
zur Wahrheit werden könnten, müssten sich jetzt bereits oder in Bälde Symptome davon zeigen, da das kritische Alter bereits erreicht ist.

So viel verdient noch hervorgehoben zu werden, dass von den nordamerikanischen Holzarten die meisten in Europa und sehr vicle auch in geeigneten Oertlichkeiten Deutschlands anbaufähig sind; ob diese auch rom forstlichen Standpunkte sich als a n b a u w ï rdig erweisen werden, ist eine Frage, zu deren Lösung beizutragen die Absicht der folgenden Abschnitte ist.

\section{Die nordamerikanischen Holzarten vom Stand- punkte ihrer Anbaufähigkeit in Europa im All- gemeinen und in Deutschland insbesonders.}

Die Feststellung der Thatsache, dass eine Holzart anbaufähig ist, genügt schon für eine Reihe von Zwecken, für welche die betreffenden Holzarten dann auch anbauwürdig erseheinen, zum Beispiel für wissenschaftliche Gärten und dekorative Zweeke; es ist dabei nicht rerlangt, wohl erwünscht, dass die Holzarten auch zu Bäumen erwachsen und Früchte mit keimfähigem Samen zeitigen; es genügt, dass sie überhaupt „wachsen." Die Forstwirthschaft verlangt von einer anbaufähigen Holzart fast durchweg deren Aufwachsen zum Baume; bis zur Anbanwürdigkeit ist freilich immer noch ein weiter Schritt!

Man sollte erwarten, dass die Frage der Anbaufähigkeit einer Holzart gelöst wäre, so bald es gelänge, deren heimatlichen Standort erschöpfend klimatisch und nach seiner Zusammensetzung zu fixiren, so wie die Holzarten selbst nach ihren waldbaulichen Eigenschaften zu erforsehen. Freilich muss ich gestehen, das diess mir wohl bei keiner Holzart gelungen ist; auch selbst damn, wemn ieh ein so naturgetreues Bild des Lebens einer Holzart in ihrer Heimat geben könnte, dass wir im Stande wären, ihr Boden, Klima und waldbauliche Verhältnisse so im deutschen Walde anzubieten, wie sie sich derselben in ihrer Heimat erfreut, selbst dann kamn immer noch etwas hinzu kommen. was einen Versuch unerwartet vereitehn oder auch gelingen lassen kamn.

Nach der Beschreibung, die ich ron der Lawsonia gegeben. möchte wohl niemand erwarten, dass diese an ein mildes, kaum rom froste berïhrtes, konstant feuchtes Gebiet - etwal sü̈lwestküste ron lirankreich - gewöhnte, zicrliche Baumart bej uns, in Her\%en des trockeneren Continentes 'Temperaturen von $-25^{\circ} \mathrm{C}$. und darïber selbst Wochen 
lang zu widerstehen vermag. Dagegen erliegt die volle sechs Breitegrade nördlicher heimische Nutka-Cypresse, ebenfalls eine Küstenbewohnerin, die vicl robuster gebaut ist, unserem Winter, wohl weniger durch Kälte als durch Trockniss beschädigt. Pinus rigida, die auf Kosten ciner anderen Kiefer berïhmte und ungebührlich bevorzugte Pitch-Pine oder Pechkiefer hat sich auf dem Sandboden der Küste im Yordosten der Vereinigten Staaten als sehr brauchbar zur Wiederbestockung erwiesen; aber an dem gleichen Boden an der Küste des Binnenmeeres Michigan fristet sie nur eine kümmerliche Existenz, obwohl ihr nichts fehlt als die salzige Brise, ohne welche diese Holzart auf schlechtem Sandboden nicht zu gedeihen scheint. Auch das plötzliche Fehlschlagen der mit solcher Ueppigkeit in der Jugend aufwachsenden europäischen Nadethölzer in Nordamerika hat wohl niemand geahnt; obwohl der Grund wohl leichter nachweisbar ist, als in den uben erwähnten Fällen, die glücklicherweise doch mehr vereinzelt dastehen.

Man nemnt oft eine Holzart ,acclimatisirt", wenn sie ein paar Jahrzehnte kräftigst gewachsen ist; für’s Erste muss man das Endresultat abwarten, che man die Frage schon für entschieden hinstellen kann und damn ist in vielen Fällen die Frage der Acclimatisation überhaupt gar nicht gestellt. So sagt man zum Beispiel die Weymouthskiefer, die bei uns zu einem Nutzbaume erwächst, wie in ihrer Heimat, sci hei uns völlig acclimatisirt; allein es war gar nicht nöthig, sich an irgend etwas zu aeclimatisiren, da die Weymouthskiefer aus ihrer Heimat dic Fïhigkeit mitgebracht hat, am besten auf frischem bis fenchtlehmigem Santboden oder selbst geringerem Sandboden bei 14 bis $17^{\circ}$ C. und $72 \%$ relativer Fenchtigkeit während der Vegetationsmonate zu wachsen und im Winter sogar einer Temperatur von $-37^{\circ} \mathrm{C}$. widerstchen zu kömnen; solchen Boden, solchen Sommer können wir ihr ïberall im dentschen Walde bieten, während sie so harte Frostproben wohl kaum bei uns zu bestehen hat; somit war eine Acclimatisation der Weymonthskiofer bei uns gar nicht nöthig. Aus gleichen (irinden warhsen eine Reihe ron anderen amerikanischen Holzarten bei uns so grut wie in ihrer Heimat, woraus zugleich der grosse Werth ainer mögrichst genauen S'childerung der Standortverhältnisse in Klima and Borlen fïr cine anzubaucnde Pflanze erhellt.

Die japanische Cryptomeria japenica findet man bei Darjeeling im östlichen Himalaya bei 2000 Mcter Erhebung, anf Java und Ceylon hei 1500 Meter Erhebung in Fxemplaren, die an Wuchskraft und schönheit len hestren japanischen nicht nachstehen; sie hat sich dort 
an das constant feuchte, warme Klima nicht erst adaptiren müssen: denn das ist gerade das Eldorado der Cryptomeria.

Wo dagegen der neue Standort thatsïchlich ron dem in der Heimat gebotenen variirt und zwar einmal in seinen Temperaturverhältnissen, da hat sich gezcigt, dass die meisten Holzarten, wemn sie in ein wenig wärmeres Klima versetat werden als die Heimat bietet, sich dabei sehr wohl befinden; sie wachsen kräftig und sicher, begimnen frïhzeitig die Reproduktion durch Samen, wie es aber dabei mit ihrem Holze, mit ihrer Lebensdauer, ihrer Anbauwürdigkeit bestellt ist, darüber verbreitet sich ausführlicher das IV. Kapitel.

Laubhölzer adaptiren sich leicht an ein wärmeres Klima durch Verlüngerung ihres ganzen Entwicklungsganges; unsere einheimische Eiche (Quercus pedunculata) aus ihrer gemässigt-warmen Heimat in das klimatisch unmittelbar sich anreihende Gebiet der subtropischen Zone gebracht z. B. in Californien, ist in der ersten Zeit sehr raschwüchsig, erreicht in gleicher klimatischer Zone Australiens in neun Jahren 7 Meter Höhe. Die japanischen Kohlholzeichen (Quercus glandulifera und serrata) bewirthschaftet man in grossem Massstabe in der subtropischen Zone Japans als Niederwald, wo sie schon mit 8 Jahren so stark sind wie mit 15 Jahren in ihrer eigentlichen Heimat; die Paulownia imperialis in warmen blattabwerfenden Laubwalde der Gebirge Japans in seltenen Exemplaren wild wachsend, wird des Holzes wegen in der subtropischen Zone kultivirt, wo sie bei ganz ausserordentlich raschem Wachsthum ein sehr leichtes Holz produeirt, das sich nicht wirft und das nicht schwindet. Der Baum rentirt dort seine Kultur besser als in der Heimat, aber mit 20 Jahren ist er bereits erschöpft, wird hohl und stirbt ab, während in der Heimat bis ror kurzer Zeit nor'h Bäume mit 6--7' Umfang und 48' bis zu den Aesten nicht selten waren.

Eben desshalb zeigen auch Pflanzen aus den Subtropen in die 'Tropen versetzt, eine gesteigerte Wachsthumsenergie in den ersten Jahlrzehnten. Der japanische Kampherbaum z. B. gehört der subtropischen Zone der Immergrünen an; in den 'Tropen Indiens und Java's wiihst er ausserordentlich rasch, seine Wuchskraft zertheilt den Schaft in zahllose kräftige Aeste, wodurch der Baum kaum meln seinen Ahnen gleicht. Dass durch dieses beschlemigte Wachsthum in der Jugend ein früherer Verbrauch der Vitalitït, ein früherer natürlicher 'Tod cintreten wird, ist sehr wahrscheinlich; denn alle in derantige Verhältnisse gebrachten Holzarten kennzeichnet ein aufjallend frühzeitiges und überreiches Samenerträgniss. Wird bei dem Anbaue einer Holzart 
eine Vegetationszone gainz übersprungen, so wachsen die blattabwerfenden Laubhölzer, in die 'liopen gebracht, nach den in Indien und Java gemachten Erfahrungen, so kümmerlich, dass man sie nicht anbaufähig. nennen katmn.

Nadclhölzer' scheinen sich schwieriger einem geänderten Klima ïberhaupt anzupassen; solche die ihr Leben mit später Entfaltung der Kinospe beginnen, behalten diese Eigenschaft auch im wärmeren Klima bei, z. B. die Nordmanmstanne, die Douglasia von Colorado; in wärmeres Klima rersetzt, entfalten sich diese spät und schliessen zeitig ihr Wachsthum ab. In wärmeres, aber nur unbedeutend geringer luftfeuchtes Klima rerbracht, gedeihen Fichten und Lärchen rascher als in ihrer kühleren Bergheimat, freilich ist auch ihr Holz physikalisch und technisch geringerwerthig; diese Erfahrungen hat man nicht nur in Europa gesammelt, sondern auch die betreffenden Vertreter dieser Bäiume in Nordamerika wie in Japan verhalten sich ganz ebenso; was rlagegen resultirt, wenn die genamnten Nadelhölzer in wärmeres und betrïchtlich luftrockeneres Klima verbracht werden, das bezeugen diese Holzarten durch ihr Verhalten in Nordamerika.

Dic japanischen Chamaccyparis-Arten, deren Heimat die obere, kïhlere Hälfte des Laubwaldes ist, als Vertreterimnen der Laubhölzer, nicht als eigene Gewächs\%one, wachsen ausserordentlich rasch, sobald sic in die sürlliche Hälfte oder selbst in die subtropische Küstenzone Japans verbracht werden; die japanische Tamne, Abies Momi, eine Allgchürige des tieferen, also wämmeren Theiles des blattabwerfenden Laubwaldes - die typischen 'Tannen der kïhlen Region sind Abies Veitrhii und Mariesii - gerleiht mit grosser Wuchsenergie - in der subtrupischen '/one der immergriuen Laubhölzer, wo sie mit der aus cricolur Höhonlage stammenden Cryptomeria japonica an Höhenentwirklıng wettrifert. I)agegen sind die Narlehö̈zer der kühlen Region, dio 'lammcn, Jijohten mud Jäl'chen, europäische wie japanische, in der' subtropisclen Region so kïmmerlich, vielgipfelig und in dic Aeste lahlend, dass sic dont kanm als anbaufühig gelten können.

Sehr viel schwierigne ist es offenbar fül eine Ptlanze, sich mit rinem Kilima, das k ii hlor jst als jenes der Heimat, abzutinden. Weniger

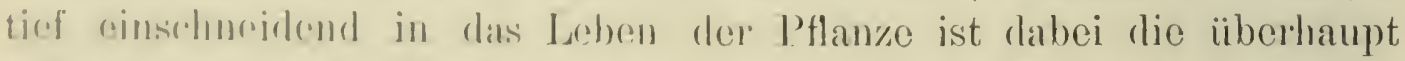

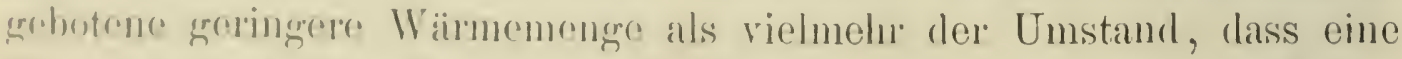
liammant dureh lonpflan\%mg in kühleres Gebiet dem kritischen Kälte-

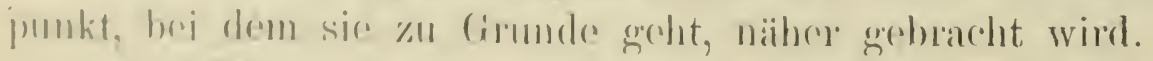

All IJulzatron verlinen, wenn sie aus ilner Heimat (Verbreitumgsgebiet) in eine kiihlere Region versetzt werden, inre Wichtigkeit als 
Kulturgewächse, wenigstens rom forstlichen Standpunkte aus wegen Beschädigungen aller Art, Mangel oder Seltenheit an reifen Früchten, geringwerthige Holzproduktion und dergleichen.

An der warmen subtropischen Küste Südcaliforniens können alle Arten von Palmen und Bäumen aus der tropischen Region kultivirt werden, aber nur zu dekorativen \%wecken, denn sie zeitigen dort keine Früchte; vicle von den immergrünen Laubbäumen aus der nördlichen Hälfte des subtropischen Waldes halten in der südlichen Hälfte des blattabwerfenden Laubwaldes dem Klima stand; Bäume des letzteren endlich, z. B. Eichen, hat man vielfach in die kühlere Grenzzone von Laub- und Nadelwald rerpflanzt; hervorragenden Nutzwerth erlangen sie dort nicht mehr.

Bei dieser Uebertragung in kühleres Klima begegnet man oft merkwürdigen Erscheinungen; Holzarten werden frostempfindlich, ron denen man es nach ihrer einheimischen Lage nicht erwarten sollte; andere erweisen sich als frosthart, die in ihrer Heimat, so lange sic existiren, keine Gelegenheit gehabt, sich gegen Frost zu feien. Des auffallenden Verhaltens der Lawsonia, der Nutka-Cypresse habe ich schon früher gedacht; andere Holzarten wie die südlicher in der subtropischen Zone erwachsende Pinus insignis, Pinus Torreyana, Cup. macrocarpa, die in ihrer Heimat keinen Frost kennen, halten im zartesten Alter als einjährige Pflanzen mit unbedeckten, offenen Knospen monatelang Temperaturen von $-5^{0}$ selbst $-10^{\circ} \mathrm{C}$. bei durchschnittlicher Lufffeuchtigkeit ron über $60 \%$ stand, während Pinus canariensis, fül die Frost auch unbekannt ist, schon bei ein par Mal $-5^{0} \mathrm{C}$. erfriert. Alle diese Holzarten haben im Frühjahre 1888 aus frischem Samen hier in Japan gekeint; alle trieben kräftig in die Höhe; da kam Anfangs Norember der erste Frost mit $-6^{\circ} \mathrm{C}$. über dem Boden. Die dimebenstehenden Bananenstämme erfroren bis auf die innersten Blattlagen, die genamnten Holzarten aber widerstanden, bis auf die canarische Kiefer, die nach drei Nïchten schon ihre Gipfel hängen liess; freilich war sie auch von etwa 30 ausgesäten Kiefernarten die lïngste geworden. Aus der Reihe der insignis und der Cypressen hatten etwa ein Viertel am Schlusse des Winters gebräinte Gipfel; die übrigen waren völlig unversehrt; ron einer Acelimatisation der gesund gebliebenen Pflanzen kann wohl nicht die Rede sein; ich bin nicht im Stande, einen Grund für das versehiedene Verhalten rüllig gleich situirter Pflanzon anzugeben; dabei muss ich hinzufügen, dass alle Pflanzen einer Art aus dem Samen ein und desselben Zapfens erzogen waren. 
Bekamntlich sind alle Pflanzen gegen Frost während der Winterruhe viel weniger empfindlich, als während der Vegetationszeit im Frühjahre und Herbste; wie schwierig es für eine Pflanze ist, sich an kühleres Klima anzupassen, geht aus dem Verhalten gegen Spät- und Frühfrost herror; den Beginn der Entwickelung hinauszuschieben oder die Beendigung derselben zu beschleunigen, mit anderen Worten frosthart zu werden, scheint für viele Arten geradezu unmöglich. Die Gleditschie und Robinie sind in den südlichen, atlantischen Staaten zu Hause, einem Gebiete, das hinsichtlich der Wärme in Sommer und Winter, der Daner der Vegetationszeit unsere wärmsten Weinlande übertrifft: beide Bäume werden weit über ihren Verbreitungsbezirk hinaus in Amerika, Europa und Asien kultivirt; aber während der langen Kultur hat sich keine „Rasse" gebildet, die durch eine Verkürzung der Vegetationszeit gegen Frühfröste gesichert werde; dabei stammt bekanntlich der Same der Robinie stets ron Exemplaren, die bercits im kühleren Klima crwachsen sind; die Sämlinge behalten die Eigenschaften der Mutter unverändert bei. Junge Exemplare der von der Küste stammenden Douglasia entwickeln ihren Johannitrieb, auch wemn der selbe jedes Jahr abfriert; erst von dem Alter an, in welchem auch in der Heimat die Bildung dieses zweiten Triebes unterbleibt (also etwa vom zehnten Lebensjahre an), fehlt er auch in der Fremde; das Unterbleiben les zweiten 'Triebes ist somit keine Adaptirung an das Klima, sondern hat cincn inneren, nicht äusserlichen Grund. Die nun frosthart gewordenen Exemplare stehen den von der Natur selbst erzogenen frostharten "Rassen“, llie in Montana 'Temperaturen von - $34^{0}$ bestehen, kaum nach.

Man staunt, weleh' tiefo 'Temperaturen eine in Ruhe befindliche IInlzart zu ertragen vermag; bei genügender Feuchtigkeit der Luft orler verminderter Figenverdunstung, wie es Waldesschluss, insulares Kilima, ruge (iehirgs- mol Flussthäler mit sich bringen; dagegen werden dic meisten l'flanzen gegen Winterfrost um so empfindlicher, je trockener die Luft ist: neun Zehntel von allen Fällen, die als Frostbeschädigmmen während des Winters bezeichnet werden, gehören in die Kategorie der Vertrocknumgserscheinungen bei dureh Frost gehinderter oder gemindrutrer Wassorbowrogumg. So lassen sich vielleicht die Widersprïiche enkliiren, dass manche Holzarten in notorisch kälterem Klima als "hart" bergedmot weralen, die in notorisch milderem Klima für ,empfindlich" Ereltru; wahrscheinlich waren die P'flanzen an ersteren Oertlichlieiten

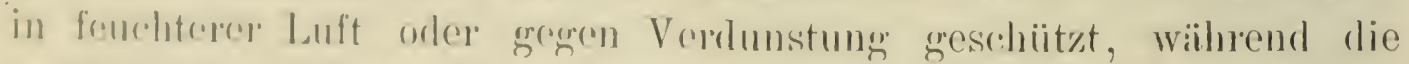

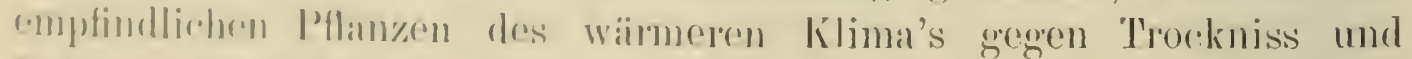
firost zal kimpfen hatten. 
Es ist zu erwarten, dass insbesonders alle Holzarten, welche von der warmen Küstenzone stammen, sumpfige Standorte lieben, zu grösseren Waldmassen vergesellschaftet leben, gegen die Vereinigung von Trockniss und Frost empfindlich sein werden; roran unter den nordamerikanischen Holzarten, die in Frage kommen, stehen die Nadelhölzer der pacifischen Küste, westlich vom Cascaden-Gebirge; um diese bei uns ohne Verlust durch Frost anbauen zu können, scheinen nur die Küste, das Innere grösserer Waldmassen, feuchte Fluss- und Gebirgsthïler oder selbst feuchtere Unterlagen, als in ihrer Heimat nöthig sind, geeignet; die Lawsonia, Douglasia, die Riesen-Thuja, die Sitka-Fichte und NutkaCypresse sind unter solchen Verhältnissen völlig frosthart; fehlen aber diese Bedingungen, dann erfriert sogar die Sitka-Fichte, die in ihrer Heimat an der Küste Alaska's bis hart an die Gletscher herantritt.

Einiges Vermögen, auch mit geänderten Feuchtigkeitsverhältnissen vorlieb zu nehmen, besitzt jede Pflanze, dabei kann die Feuchtigkeit der Luft oder des Bodens, jede für sich oder beide zusammen zu- oder abnehmen; die Pflanze reagirt entsprechend diesen Combinationen auf rerschiedene Weise. Untersuchungen über diese Frage sind mir nicht bekannt. Freilich fehlt mir auch jede Literatur, um danach umschauen zu können; so beruhen die Angaben, die ich zur Unterstützung der aufgestellten Sätze vorbringen kann, auf den wenigen eigenen Beobachtungen. Wenn eine Literatur hierüber bestehen sollte, sehr gross wird sie wohl nicht sein, da die Feuchtigkeit der Luft als ein wichtiger Falitor im Leben der Pflanze bis jetzt nicht genïgend berïcksichtigt wurde.

Ist die Feuchtigkeit der Luft am neuen Standorte geringer als jene in ihrer Heinat, so kann die Differenz bis zu einem gewissen Grade durch grössere Wasserzufulı von unten, rom Boden her ausgeglichen werden. Diess beweisen die mit Bäumen eingefassten Flussränder innerhalb der nordamerikanischen Prärieen; es dürfte hierin ein Finger\%eig liegen, dass wir eine Pflanze, die aus luftfeuchtem Klima stammt, bei uns kultiviren können, wenn wir ihr eine etwas grössere Bodenfeuchtigkeit zur Verfügung stellen, damit sie der Gefahr einer Ueberverdunstung im Sommer oder Winter trotzen kamn; ein anderes Mittel ist, dass wir die Eigenverdunstung der Pflanze selbst vermindern entweder durch Anbau derselben an nördlichen Expositionen oder durch andere, waldbauliche Massregeln. Dic Lawsonia erwïchst in ihrer lufffeuchten Heimat unter dem $30^{\circ}$ N.B. im vollen Lichte am besten; bei uns im trockeneren Klima unter dem $48-58^{\circ}$ N.B. gredeiht sie am sichersten unter seitlichem Schutze: so ist es recht 
gut möglich, dass auch andere Holzarten in ähnlichen Verhältnissen wenigstens in del ersten Jugendzeit aus schattenertragenden für gewisse Oertlichkeiten geradezu schattenfordernde Holzarten werden, um über die Klippe allzu grosser Verdunstung im Sommer und Winter hinwegzukommen.

Hinsichtlich der Empfindlichkeit gegen geringere Luftfenchtigkeit verhalten sich die Holzarten in ungleicher Weise; an der Spitze der Empfindlichen stehen ihres anatomischen Aufbanes und ihrer Verbreitung nach die Angehörigen der Familie der Cypressen. Die Gattungen Cupressus, Thuja, Chamaecyparis, Libocedrus, Thujopsis, Biota haben bekanntlich dünne, weiche Längstriebe und Endknospen, die während ler Vegetationsiuhe umbedeckt durch trockene, häutige Schuppen, dem Wechsel ron Temperatur und Verdunstung widerstehen müssen; alle Bäume mit solchen offenen Knospen sind an ein grosses Mass von Feuchtigkeit der Luft und des Bodens gebunden; je geringer die Schwankungen, desto günstiger verhalten sie sich. Dieser Generalregel folgen, um Beispiele anzuführen, die Thuja-Arten in West- und Ostamerika, wie auch die japanische Thuja, die Lawsonia und Nutkacypresse im Westen, wie die Kugeleypresse im Osten, wie die ChamaecyparisArten in Japan, die Libocedrus wie die Thujopsis: die grössten, schönsten Excmplare dieser Holzarten stehen entweder im Gebirge, in den gleichmiissig-feuchten Thälern innerhalb der Laubwaldregion oder unmittelbar am Meere, an der Küste; auch die Cupressus macrocarpa und Goveniana, die Juniperus wie z. B. der virginische Wachholder, die so grossen Spiclaum in Luft- und Bodenfeuchtigkeit besitzen, erlangen ihr Optimum in feuchten Flussthälern oder hart am Mecre.

Allen diesen Holzarten ist bis zu einem gewissen Grade die Fïhigrkeit innewohnenel, sich von ilırem feuchten Gebiete in ungüustigere zu cinfrenen, freilich auf Kosten ihrer Warchsthumsleistungen; so kann \%. B. die Cupressus macrocarpa, die in ihrer Heimat gewiss keine gergen trockmere Luft widerstandskräftige Form bilden konnte, doch in der trordeneren und heisseren Prärie Californiens nach einigen Jahron künstlichor lowäisserung hestehen, so bald sie einmal den Boden beschlattent und ihn so gregen ïbergrosse Verdunstung sehützt. Auch dir Lawsonia hat nareh dieser Richtung hin riemlichen Spielraum; wo im trockencren Klima \%. B. bei uns die Grenze ihner Anbaufähigkeit limet, ist ohme Experimente wohl kaum zu bestimmen; nach dem natürlinden Vorkommon sollto man fïr Libocedrus dio grö̈sste Fïhigkeit, greren maginstige Luft- und Bunlenfeuchtigkeit sich hart zu erweisen, erwarten. 
An die Cupressineen schliessen sich die übrigen Nadelhölzer, die robuster gebaut sind und ihre Vegetationsspitze mit einer von Schuppen eingehüllten Knospe abschliessen; man darf daraus schliessen, dass sie weniger empfindlich gegen geringere Feuchtigkeit der Luft sein werden. Fichten, Tamnen und Lärchen aus ihrer Vegetationszone in die tiefer liegende Laubholzzone verpflanzt, gelangen, von der Küste abgesehen, stets in lufttrockeneres Klima; denmoch gedeihen sie dort kräftig; dic Lärche, die schon in ihrer Heimat Kronenfreiheit und Luftbewegung liebt, nähert sich in diesem Punkte am meisten den Laubhölzern; dass diese letzteren weniger empfindlich als die Nadelhölzer sein werden, so weit Luftfeuchtigkeit in Frage kommt, geht schon daraus hervor, dass sie einen grossen Theil des Jahres nur einer ganz geringen Verdunstung durch Zweige und Knospen ausgesetzt sind. Auch die Verbreitung der Laubhölzer, da wo die Extreme von Luftfeuchtigkeit gross sind, wie in Westamerika, gibt schon Anhaltspunkte hiefür. So erklärt sich, dass Laubhölzer, Strauchwerk, niedere Eichen, die Grenzregetation zwischen Wald und Prärie bilden; erst wenn die Feuchtigkeit der Luft gross genug wird, dass die Laubhölzer zu Bäumen aufwachsen können, begimnen auch einzelne Nadelhölzer mit verhüllten Knospen dazwischen zu treten, und erst wo diese sich zur Erhaltung der Luftfeuchtigkeit, zur Verminderung der eigenen Verdunstung zu dichten Waldmassen zusammen gruppiren, erst da in den feuchten Thälern im Gebirge, an der Meeresküste erscheinen auch Cupressineen mit offenen Knospen.

Den meisten Waldbäumen ist eine gleichmässige Luftfeuchtigkeit willkommen; das Zusammenschliessen vieler Individuen zu einem Walde spricht schon dafür und bei geeigneten Bodenverhältnissen ist nirgends der Wald dichter und höher entwickelt als an der Küste, oder in hohen Elevationen, in kühlen, feuchten Gebirgsthälern, wo die relative Feuchtigkeit während des ganzen Jahres so geringen Sehwankungen wie an der Kï̈ste unterliegt. Selbst für die meisten Kiefern, die als Gewächse trockenerer Klimate bekannt sind, liegt das Optimum an der Kïiste oder im höheren Gebirge.

Klima, das lufteuchter ist als jenes in der Heimat, hat denselhen Einfluss wie jenes, das wärmer ist als die Heimat; es reranlasst die Pflanzen in den ersten Jahrzehnten zu ausserordentlied raschem Wachsthum, vorausgesetyt, dass der neue Standort nicht kühler ist als jener der Heimat. Die nordamerikanischen Laubbiume der atlantischen Region finclen sich in Europa viclfach in luftfenchterem Ḱlima, sie wachsen überall gut; da wo die Wäme genüugentl ist, sugar 
rortrefflich; die feuchte aber winterlose Küste Californiens behagt ihnen nicht. Die kühlere Küste Oregons und Washingtons scheint, nach den wenigen rorhandenen Exemplaren zu schliessen, ihnen ebenfalls vortrefflich zu bekommen; schon früher erwähnte ich, dass die aromareichsten Obstsorten nach meinem Dafürhalten in continentalem Klima mit geringer relativer Feuchtigkeit während des Hochsommers gedeihen: der Baum selbst aber erreicht seinen Lebenszweck am besten in luftfeuchtem Kilima, dort wïchst er am schnellsten, die Blätter entfalten sich zu bei uns ungewöhnlicher Grösse, die Triebe zu ungewöhnlicher Länge, die Büume blühen alljährlich und tragen reichliche Samen, freilich in einer Fıuchthuille, die den Kulturzwecken nicht entspricht.

Ob das feuchtere Klima nicht etwa wie das wärmere die Zahl und Energic der Feinde einer Holzart steigert, ist eine Frage für sich.

Welche Vortheile eine grössere und welche Nachtheile eine geringere Luftfeuchtigkeit für die Pflanzen im Kampfe gegen Temperaturextreme mit sich bringen, wurde bereits angeführt.

Was die Bodenfeuchtigkeit betrifft, so wäre herrorzuheben, dass das Optimum weitaus der grössten Zahl der nordamerikanischen Holzarten in den Flussniederungen, auf den alten, ron Flüssen nur noch durch unterirdisches Sickerwasser berieselten Geländen liegt; dort ist nicht nur der beste, nahrungsreichste, sondern anch der frischeste Borlen, dessen Fenchtigkeit sich rasch ernenert; für die Holzarten höherer Regionen sind die besten Standorte wieder die von den Gebirgsbächen berieselten Gelïnde. Daran schliessen sich die Berghänge mit mineralisch kräftigen Böden und rasch wechselnder Befeuchtung; schon innerhalb) ihrer V'erbreitungsgebiete entfernen sich die meisten Holzarten rom Optimum hinweg nach trockeneren Gebieten; einige Holzarten, wic Eischen z. B. haben nach dieser Richtung hin einen sehr engren Spirtraum, andere wie Birken, Pappeln, Erlen wiederum einen sehr weiten.

Wriche Wirkumgen geringere Bodenfeuchtigkeit bei steigender Luftfunchtigkeit (Ifereskiiste) oder geringere Bodenfenchtigkeit bei

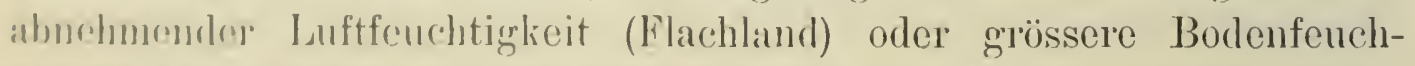
tigkrit bei grïsserer Luftfeuchtigkeit (Gebirge) auf die einzelnen Holzarten ausüben worden, dafür mögen aus den bisherigen Betrachtungen rinige Anhaltspunkte grewonnen werden.

Nach dieser Richtung lim hat man mit den Exoten die kühnsten Experimente gemarht, \%. B. die Lawsonia, Douglasia, die Thuja, die Nomemannstanne auf trockenen herabemagerten Kiefermboden gebracht, wo sio doch wohl nie zu Nutzbiamen aufwachsen werden. 
Werden dagegen Holzarten auf Böden gebracht, deren Feuchtigkeit gross und nicht oder nur langsam wechselt, z. B. Erlenbruchboden, Eschenboden, so kümmern alle Holzarten, ausgenommen die dort heimischen; es ist die Thatsache auffallend, dass die baumartigen Holzarten in solchen Standorten im östlichen Nordamerika nicht dem Geschlechte der Erlen angehören; ausser einigen wenigen Laubbäumen wie die hollunderblätterige Esche, die Papier- oder Nachenbirke im Norden, Planera aquatica, Nyssa capitata, Rhizophora, Liquidambar, Jlex Dahun und andere im Süden, sind es vorzugsweise Nadelhölzer, Thuja, Chanaecyparis, Taxodium, die in solchen Oertlicbkeiten Bestände bildend erscheinen, Holzarten, die der europäischen Waldflora ganz fehlen.

Die Zunahme der erschöpften Standorte bei uns im Walde spricht dafür, dass -wenigstens auf nahrungsarmen Böden die Stoffentnahme und Stoffzufuhr sich nicht das Gleichgewicht halten; Angesichts der wachsenden Schwierigkeiten, solche Standorte wieder zu bewalden und ihnen abermals Erträge abzuringen, hat man an die Exoten gedacht und von ihnen eine Wiederverjüngung der erlahmten Bodenkraft oder eine Aussaugung des letzten Blutstropfens, wenn man so sagen kann, erhoffit. Die Frage der Bescheidenheit einer Holzart in ihren Ansprïchen an die Bodenguite spielt eine grosse Rolle bei der Erwägung der Anbauwürdigkeit einer Holzart vom forstlichen Gesichtspunkte; doch weil dabei implicite von der betreffenden Holzart auch grosse Anforderungen hinsichtlich ihrer Widerstandskraft gegen Hitze, Frost und Ueberverdumstung gestellt werden, so ist wenig Aussicht vorhanden, dass sich unter den Exoten eine finden wird, die bei schlechter Ernährung auch noch allen Misshandlungen der Menschen und des Klima's Trotz bieten kann.

Im Urwalde lassen sich manche Gesichtspunkte zur Beurtheilung der Ansprüche einer Holzart an die Bodengüte gewinnen; in ihm stehen die Holzarten nach einem mehrhundertjährigen Kampfe um's Dasein auf ihren speciellen Standorten; der Kampf unter den erwachsenen Individuen wenigstens ist nahezu \%um Stillstande gekommen; es ist bemerkenswerth, dass auf geringen Bodenarten, mit unverwitterten kiesigen oder reichlich sandigen (kieselsäurehaltigen) Bestandtheilen von der subtropischen bis zur kïhlen Waldregetation die Kiefer fast alle ïbrigen Holzarten verdrängt hat; eine Erscheinung, die mich reranlasst hat, die Kiefer überhaupt als Vertreterin anderer Holzarten anfzufassen, da wo den letzteren der Boden zu geringwerthig ist.

Mir sind nur wenige Fälle bekannt, in denen ausgepräigt geringrwerthige Sandböden auch einem Laubholzbaume noch genügrten; so 
betreten Fraxinus viridis und Carya porcina die nur wenig feuchteren Einsenkungen in Kiefernbeständen; Qnercus nigra Catesbaei und falcata nehmen als Sträucher oder Halbbäume noch mit den trockeneren kiesigsandigen Hügelzügen vorlieb, die ein Oberholz von Kiefern wie die australis, auch inops, mitis und rigida bedeckt. Bemerkenswerth ist in diescr Richtung auch die Quercus dentata, jene japanische Eiche, welche die grössten Blätter und den knorrigsten Stamm besitzt; die Eiche überkleidet nicht nur die Sandkegel der niederen Vulkane der Tnseln Eso oder Hokkaido, sondern bewohnt selbst den Dünensand der Küiste; wo sie rom Winde zur Seite geblasen, ganz nieder bleibt und mit ihren Aesten an der Erde liegt; doch sobald vorliegende Hügel oder Felsenblöcke gegen den Wind Schutz bieten, erhebt sie sich zu ganz respektablen Dimensionen. Sandböden, wenn auch arm an Nährstoffen, aber reich an Sickerwasser und mit grosser Luftfeuchtigkeit bedachte Lagen werden in Nordamerika von Chamaecyparis-Arten, von Thuja, in Japan von Thujopsis bevorzugt, welche Holzarten, da Schatten crtragend, keine Licht liebenden, für solche Standorte passenden Laublı̈̈l\%er (Erlen) aufkommen lassen.

Selbst unter den Kiefern bestehen wieder Verschiedenheiten hinsichtlich ihrer Ansprüiche an die Bodengïte; ich erinnere an die Abbildung eines Profiles durch cine Kieferninsel in Wisconsin, wo die Woymouthskicfer, welche dic stïrksten und höchsten Dimensionen mercht, den besten, die amerikanische Rothkiefer den mittelguten und dic kleinste von den drei Kiefern, die Banksiana, die trockeneren, :irmoren, hochgelegenen Sandböden einnimmt. Analoge Verhältnisse bestrhen zum Beispiel auch an der Küste von Florida; die stattliche Cubakiefor behauptot den besseren, tiefer liegenden, frischeren Sandborlon, die kloiner bleibende clausa den trockeneren, ärmeren, oft noch bewrerglichen Sandhoden; in den Alloghanies ocenpirt die Pechkiefer (rigrida) dio mitis und inops den besseren sandig-kiesigen Boden, auf drom noch die Laubhölzer gut fortkommen, überlïsst dagegen trockenere, laubholzarmo: Hü̈rolkïpfe ler niedrigen, astreichen Stechkiefer (pungens).

Aurh der. Westen bietet Beispicle der Art, die niederen Kiefern dre Serefiun P'arrya sind alle auf trockenen, heissen, kiesig-sandigen Ocetlichkriten hoimisch, während die frischeren Thäler mit dem besseren Buden ein Kiefornwald mit stattlichen nutzbaren Schäften erfüllt; die Conlters-Kiofer goht der Stechkicfer des Ostens genau parallel; auch anf den trockencrn, kiesigen Hügelkäpfen heimisch, ist sie ästig und niredrig im Vergroiche mit den den besseren und frischeren Boden brwhncmblen 'zurkerkiefern und-Jeffrey'schen Kicfern. 
Es erhellt daraus, dass die Bäume, welche die geringsten Ansprüiche an die Bodengüte stellen, auch die geringsten Dimensionen überhaupt crreichen; man kann nicht sagen, die geringen Dimensionen sind Folgen des geringen Standortes, denn eine Banksia, eine pungens-Kiefer bleibt niedrig, auch wenn sie auf den rorzüglichsten Boden gebracht wird, so gut wie ein Strauch auch auf dem besten Boden Strauch bleibt und nicht Baum wird. Unter den Bäumen zweiter und dritter Grösse haben wir uns daher umzusehen, wenn wir Pflanzen mit geringen Ansprüichen an die Bodengüte suchen; es ist sehr wahrscheinlich, dass diesc bescheideneren Holzarten auf geringeren Böden mehr leisten werden, als z. B. unsere einheimische Kiefer, da sie dort wohl länger lebensfähig sind und somit auch längere Zeit einen beachtenswerthen Holzzuwachs beibehalten werden.

Dass auch Bäume erster Grösse in den ersten Jahrzehnten ihres Lebens bescheiden sein kömnen, eben so lange sie noch ihrer Dimension nach Sträucher oder Bäume dritter Grösse sind, ist nicht wunderbar; ob sie aber II. und I. Grössendimensionen erreichen, hängt, vom Klima abgesehen, von der Güte des Bodens ab. Dass dic riesenhaften Pinus ponderosa, Jeffreyi, die Thuja und andere in der Jugend bescheiden sind, berechtigt nicht zum Schlusse, dass sie auf den mageren Böden eine grössere Rente abwerfen als unsere einheimische Kiefer. Es dürfte hier das Gesetz sich geltend machen, dass ein Standort eine bestimmte Gewichtsmenge Holzsubstanz zu erzeugen vermag; ron einer Holzart mit schwerem Holze erhalten wir daher nur sehr geringes Volumen, von einer solchen mit sehr leichtem Holze dürfen wir ein grösseres Volumen erwarten; die Gelbkiefer, Jeffrey's Kiefer; Pinus rigida haben ein Holz, das im specifischen Gewichte dem unserer Kiefer sehr nahe steht; dass sie in gleicher Zeit zu höheren Bäumen aufwachsen werden als unsere Kiefer, dass sie in gleicher 'Zeit mehr Holz produciren werden als unsere Kiefer, erscheint mir unwahrscheinlich. Viel wahrscheinlicher ist es, dass die Weymonthskiefer mit ihrem leichten Holze auf demselben Borlen in gregebener Zeit grössere Volumina Holz produciren wird als die genannten und die europäische Kiefer.

Dass das Optimum der weitaus grössten Zahl der Holzarten auf dem besten, mineralisch kräftigsten, frischen, lockeren Boden liegrt, den allmähligr die Landwirthschaft an sich ziehen wird, geht aus der speciellen Betrachtung der Holzarten hervor; aber schon innerhalb des Verbreitungrsbezirkes entfernen sich die verschiedenen Holzarten nach geringeren Standorten hin verschieden weit; an weitesten streichen in Nordamerika unter den Laubhölzern Birken und Pappeln, Holzarten, mit denen die 
Natur seit Urzeiten rom Optimum im tiefgründigen, nahrungsreichen Boden hinweg Anbauversuche vermittels des Windes vorgenommen hat.

Es ist sumit nicht überraschend, wenn im Allgemeinen leichtsamige Holzarten eine grössere Anpassungsfähigkeit an heterogene Standorte zeigen als schwersamige, da sich bei letzteren diese Fähigkeit durch das Fallen des Samens auf den Boden der Mutterpflanze nicht vder nur schwierig durch Vermittelung von Thieren entwickeln konnte.

Dagegen sehen wir, besonders im Westen, eine Reihe von Holzarten mit leichtem Samen wie Sequoia, Chamaecyparis, die nur ganz lokale Terbreitung gefunden haben; es dürfte daran aber wesentlich die Schwierigkeit schuld tragen, die zahlreichen, breiten Präriestreifen, welche das dortige Waldgebiet zerstückeln, zu überschreiten.

Theilweise Hand in Hand mit der Schwersamigkeit geht die Vertheilung der Holzarten; auch diese gibt Anhaltspunlite für die Beurtheilung der Anspriiche einer Holzart. Holzarten, die nur in einzelnen Individuen dem Walde eingesprengt sind, werden wohl anspruchsvoller sein als solche, welche waldbildend ïber grosse Flächen hinweg, ohne Unterschied der Verschiedenheiten des Bodens in Feuchtigkeits- und geognostischen Verhältnissen sich verbreiten.

So gibt es keine reinen Waldbestände rom Wallnussbaume, von der Hickory, Gleditschie, oder einer Art von Eichen in Nordamerika; letztere bilden Gruppen ron geringer Ausdehnung oder sind wie stets dic erst Genannten nur einzeln dem Urwalde eingemengt; dagegen sind rrine Bestände in grösster Ausdehnung von Birken und Pappeln in Canada bekannt. Auch die schwer- und leichtsamigen Kiefern kann man hier anzichen, indem die in isolirten Individuen aufwachsenden Augchörigen der schwersamigen Sectionen Cembra und Parrya am wenigsten, dic leichtsamigen und waldbildenden Kicfern aus den seretionen Pinaster und Banksia am ehesten mit nahrungsarmem Sandboden vorliob nelmen.

In cinem früheren Kapitel habe ich hervorgehoben, dass eine Holzart innorhalh ilures Optimums mehr oder weniger bodenvag, ausserhalb dresselben dagregen an Boden ron specifischer Beschaffenheit gebunden ist; ass ist gut mörglich, dass Holzarten, die wir bei uns aubauen, gerade wril sio in cin Gebict gehnacht werden, das sich klimatisch nicht mit ihrem Optimum deckit, specifische Standortsanspriiche erheben werden, die fiir vicle: Holzarten noch nicht genëgend erforscht sind.

Aus der folgenden Gegenüberstellung des nordamerikanischen uncl curopaiischen Kilima's möge entnommen werden, ob eine Holzart dat, wo wir sio anbauen wollen, innerhalb oder ausserhalb ihres Optimums 
oder selbst ihres Verbreitungsbezirkes zu stehen kommt; ich glaube nicht, dass es einen Werth hat, eine Holzart auf geringerem Boden zu versuchen, wo dieser noch überdiess ausserhalb des Optimums der betreffenden Holzart liegt. Wo immer wir in Deutschland die Wallnüsse, die Hickory, die Eichen (von bicolor abgesehen), anbauen werden, gelangen diese Holzarten in ein Gebiet, das ausserhalb ihres klimatischen Optimums liegt; es dürften kaum finanziell günstige Resultate zu erwarten sein, wenn wir die Versuche auf anderen Standorten als den wärmsten, tiefgründigsten und nahrungsreichsten, die wir überhaupt noch besitzen, anstellen. Dass Hickory- und Wallnussbäume auch in der nördlichen Hälfte des atlantischen Laubwaldes, der klimatisch mit dem Verbreitungsgebiete unserer Eiche sich deckt, zu Nutzbäumen aufwachsen, lehrt ein Blick in diese Waldungen; dass sie aber dort insbesonders auf geringeren Böden ein poröses, weiches $\mathrm{Holz}$ bilden, zu dessen Erzeugung überdiess eine Zeit nöthig ist, während welcher eine andere Holzart rentabler forstlich arbeiten würde, zeigt jeder Querschnitt durch den Schaft dieser Bäume. Bei dem grossen Holzwerthe dieser Laubhölzer ist in unserem wärmsten Waldgebicte kein Boden für sie zu gut; dagegen vermeide man es, die ausländischen Kiefern auf den besten Boden des Waldes zu bringen, denn wohl keine der a usländischen Kiefern, die bei uns aufwachsen, erzeugt ein besseres Holz als die einheimische. Wenn wir ihnen guten Boden geben, werden sie wohl sehr kräftig wachsen, aber wie früher erwähnt auf Kosten der technischen Qualität ilnres Holzes; ihre vegetative Kraft äussert sich in der Zertheilung des Schaftes, in einer Verbreiterung der Ast- und Kronenbildung, welche rom forstlichen Standpunkte wohl nie willkommen sein werden.

Auf alle einzelnen Faktoren, welche die Guite des Standortes bedingen, hier einzugehen, ist nicht möglich. Es soll hier noch kur\% der geologischen Abstammung, der chemischen Zusammensetzung der Böden gedacht werden; diese gewinnt an Gewicht, für den Wald wenigstens, wo es sich um heruntergebrachte oder einseitig constituirte Böden handelt. A uf mineralisch kräftigen Böden gedeihen cet. par. alle Holzarten, auf Böden ron cinseitig chemischer Beschaffenheit nur wenige; so ertragen die Kiefern kieselsäure-reichen Boden am besten; kalkreiche Böden bevorzugen die Fraxinus quadrangulata, Magnolia macrophylla, die nordamerikanische Buche; auf Alkali überreichen Böden fehlt jede Holzart; dass einer Holzart innerhalb des Optimums die chemische Zusammensetzung mehr oder weniger grleichgültig ist, dass sic dagegen ausserhalb desselben an bestimmte, mineralische 
Zusammensetzungen gebunden sein kann, ich erimnere an unsere Buchen, an die Cryptomeria, wurde früher erwähnt.

Im heimatlichen Urwalde erwächst cine Holzart, geschützt und gepflegt gegen äussere Unbilden, aber auch zugleich bedrängt durch den Mitbewerb ron seit urdenklichen Zeiten gewöhnten Nachbarbäumen; in dic Fremde, unter fremde Holzarten und in Nitbewerb mit diesen gebracht, ïndert sich der der Pflanze gebotene Schutz wie auch der Krampf um die Existenz; dass dieses nene waldbauliche Verhältuiss das Gedeihen des neuen Ankömmlings sehr wesentlich becinflussen wird, ist voraussichtlich. Wie weit dadurch die Sicherheit des Aufwuchses, der Zuwachs, das Samenerträgniss einer Holzart berïhrt wird, kamn man heute nur vermuthen. Es lässt sich z. B. hente noch nicht bestimmen, wie die Lawsonia sich verhalten wird, wenı sie in Minorität einem Fichten-, Tamnen- oder Kiefernbestande beigremischt wird; denn einmal findet sich, was bemerkenswerth ist, die Lawsonia in ihrer Heimat nie zusammen mit Kiefern, ihre Ansprüche sind also gar nicht die glcichen, anderseits ist die Lawsonia, wo sic auftritt, entweder in Majorität, Douglasia und Tannen sind in Minorität, oder sie crscheint einzeln in Douglasia-Beständen, einer Holzart, die weder mit der Fichte noch mit der Tanne in Parallele grestellt werden kann.

Dazu kommt ferner, dass alle nordamerikanischen Holzarten aus $10-15^{0}$ südlicherer Breite stammen, somit einer intensiveren Lichtund Wärmewirkung ausgesetzt sind, als den Bäumen des deutschen Waldes wenigstens geboten ist; diese erfreuen sich zwar einer länger dancruden Belenchtung, allein diese Verlängerung gleicht die Differenz in der Intensitait nicht aus, da der deutsche Sommer zu oft durch Bowölkung gretrïbt und somit ärmer an Wärme und Licht ist; so wrren wohl Laubhölzer, die in Nordamerika eine ziemliche Beschattung crtakgen können die jungen Eichen und Hickory fallen in diesem Punkte auf - bei uns volles Licht verlangen. Was die westlichen Nidelhölycre betrifft, werden wir in Dentschland wohl auf einigen \%uwachs in der crsten Jugendzeit ver\%ichten müssen, um sic durch scitliche Beschirmung ïber die Frost- und 'Trocknissgefahr hinwegzubringen; dagegen sollen die nordamerikanischen Laubhölzer völlig free anfwadsen, um von Wärme und Licht unserer Some möglichst vicl $\% 11$ gewinnes.

Ein letyter P’unkt, der \%u erwägen bleibt, ist das voraussichtlingre Vrobalten der nordanorikanischen Holzanten in unserem Walde gremontiber den thierischen und pefanzlichen Feinden. 
Im Samen kann keine der Krankheiten in der Heimat, die auf iussere Ursachen zurückzuführen sind, in die neue Heimat mitgebracht werden, wohl aber wandern im Samen die Dispositionen für gewisse Krankheiten, wie sie in der Langsamwüehsigkeit einer Holzart, in der geringen Ueberwallungsfähigkeit, in der Zeit, in der eine Pflanze sich belaubt und dergleichen liegen können; dagegen ist es wohl möglich, dass äusserlich am Samen als Verunreinigung anhaftende Theile des Krankheitstrïgers mit in die neue Heimat verschleppt werden; so sind \%. B. auch Peronospora viticola oder die Reblaus zu uns gelangt; auf solche Weise kam auch Lophodermium baeuliferum nach OstAmerika. Lebende Exemplare, die alle Feinde des Jugendstadiums beherbergen können, kommen selten zu uns.

Dass den nordamerikanischen Holzarten eine grössere Widerstandskraft als den inländischen Holzarten gegen Feinde überhaupt innewohnt, ist möglich, aber durchaus nicht nöthig und auch nicht wahrscheinlich. In Urwalde, der aus rerschiedenen Holzarten ron verschiodenen Altersstufen gemischt ist, fehlen die verheerenden Epidemien, wie sie Pilze hervorrufen kömnen; dass dagegen die Insekten sehr empfindlich schaden können, beweisen die Cicaden, die Galleruca im atlantischen Walde.

Es fehlt nicht an Anzeichen, dass die Exoten bei uns sogar mehr Feinde, haben als in ihrer Heimat; rom Menschen abgesehen, der ohne Ueberlegung, nur durch die Neuheit der Pflanze gereizt, ron den exotischen Pflanzen gerne Zweige oder Gipfel bricht oder abschneidet, sind Exoten wahre Leckerbissen für die Thiere des Waldes, rom Reh angefangen bis herab \%u den Mäusen; Reh und Hasen lieben so sehr die seltenen, aromatischen Delieatessen, dass es eine Verschwendung von Geld und Zeit ist, Exoten erziehen zu wollen, wo man diese nicht gegen diese Thiere schützen kann oder will; dass auch Käfer sowie andere Insekten Geschmack an den Exoten finden dürften, ist mit Recht \%u befürchten.

Was die Pilze betrifft, so sind sie schon in Nordamerika in grosser Zahl an den Exoten schmarotzend; dass ich selbst nur so wenige fand, hat seinen Grund darin, dass ich jedesmal nur während einer kur\%en Zeit des Jahres (August bis Dezember) die Waldungen durchmusterte. Dass mehrere unserer einheimischen Parasiten die Exoten bei uns befallen, ist bereits mehrfach nachgewiesen.

So sind Agaricus melleus, T'rametes radiciperda, die beiden Wurmelparasiten an den Weymouth-Kiefern im Verhältnisse zu der Individuenzahl dieser häufiger als an irgend einer anderen Conifere; 
anch für die Donglasia und Lawsonia sind sie als Feinde befunden worden. Nach meinen Beobachtungen in Nordamerika steht zu befürchten, dass auch Trametes Pini an nordamerikanischen Fichten, Lärchen, an Douglasia und Strobus sich einfinden werden, so bald diese gross genug sind; in der That war der innerste Kern der mir von Ansbach zugesandten Weymouths-Kiefer von Trametes Pini zerstört; ebenso werden die nordamerikanischen Eichen von Polyporus sulphureus, Telephora Perdix und Pol. igniarius, die Ahornarten von Pol. applanatus und Rhytisma acerinum, die Birken von Pol. betulinus, die Wallnussbäume von Pol. sulphureus befallen werden, wie diese und andere Beispiele aus dem ..Anhange $5^{\text {" }}$ entnommen werden mögen.

Den Reigen der Beobachtungen und Studien über Krankheiten der Exoten bei uns in Europa hat von Tubeuf (1. c.) eröffnet mit einer Botrytis Douglasii.

Die Krankheit wurde an meines Vaters und meinen Pfleglingen in Grafrath, dic wir ungezählte Male besuchten, beobachtet. Ich darf wohl sagen, dass auch uns die Krankheit, die sich schon Anfangs August zeigte, nicht entgangen war. Allein wir hielten die Botrytis ohne sic weiter zu untersuchen, für die gemeine cinerea (Peziza sclerotiorum), die zwei Jahre früher im April 1885 in dem benachballen Pflanygarten hunderte ron nordamerikanischen und japanischen Exoten törltete, die aus Mangel genügender Erfahrung zum Schutze gregren Winterfröste allzu stark mit Tannenreisig eingedeckt worden waren. Ganze Reihen der zum Theile sehr seltenen Pflanzen waren damals dicht übersponnen von dem grauen Mycel einer Botrytis, ganz si) wie es r. 'T'ubeuf für die unter Glasglocken gehaltenen Douglasia und andere Pflanzen erwähnt; ich hielt damals die Botrytis, freilich ohne Beweise zu besitzen, für identisch mit einer Botrytis, die mir in Kloinflottherk als gefährliche Feindin der jungen Sequoien gezeigt wurde, deren Gipfel und Scitentriebe sich krïmmten und braun wurden. Da die Beschroibung der Krankheit an den Douglasia in Grafrath einen fiir mich wichtigen Punkt nicht berührt, muss ich etwas bei der Genesis der Pflanzen und der Pflanzung hier verweilen.

Der Same aus dem die Pflanzen aufgezogen wurden, war von J. Pooth im Frühahre 1883 als "frosthart" geliefert worden; das War vollstindigr richtig, keine cinzige der Pflanzen entwickelte einen Johamnitrieb. Sie wurden im ersten Jahre daranf (1884) leider etwas zu spait - im Mai versehult; die bereits gestreckten Knospen verturkurofen und dire ganme Vegetation bestand in der Anlage neuer Knospen fiir das kommende Jahr. Sic blieben aber auch in diesem 
Jahre (1885) niedrig, mehrere gingen ein und wurden mit einjährigen Douglasiapflanzen ersetzt; im folgenden Jahre 1886 starb wiederum eine Anzahl ab - ob durch die später beobachtete Botrytis hat mein Vater (ich selbst war im Herbste 1885 und $1886 \mathrm{im}$ Auslande) nicht constatirt. Die leeren Stellen wurden mit jüngeren Douglasia's ausgefüllt. Der Stand der Pflanzung im Sommer 1887 war nun der, dass die ïbriggebliebenen Frostharten vom Jahre 1883, die durch etwas Bereiftheit (v. Glauca) auffielen, etwa 20-30 cm Höhe erreicht hatten, während die ein selbst zwei Jahre jüngeren Ptlanzen, die alljährlich Johannitriebe schoben (Küsten-Douglasia), das Zwei- und Dreifache in Höhe zeigten. Das Auffallende war nun, dass die Krankheit im Spätsommer 1887 zumeist die niedrig gebliebenen glauca's befiel, leren Gipfel und Seitentricbe getödtet wurden; die Gipfel und höheren Aeste der grossen Pflanzen aber blieben völlig verschont. Es war offenbar nur unmittelbar über dem Boden die Luft feucht genug zur Infection und Entwicklung des Pilzes; der Vortheil den die glaucaVarietät gegen Frost gewährte, war reichlich wieder verloren durch den Entgang an Zuwachs und die Ver-stümmelung durch den Pilz.

Für unsere Kenntnisse der Anbaufähigkeit der nordamerikanischen Holzarten in Deutschland bilden die ron Forstrath We ise veröffentlichten amtlichen Erhebungen*) das Alpha und Omega; um den Werth derselben zu erhöhen, wäre vielleicht eine abcrmalige Enquête mit Einschluss der inzwischen im Walde reichlich gesammelten Errfahrungen geeignet; insbesonders aber wären solche Oertlichkeiten, in denen Empfindlichkeit der Exoten gegen Frost oder Hitze konstatirbar sind. eingehend nach ihren klimatischen Verhältnissen zu beschreiben, insbesonders anch das Verhalten der einheimischen Holzarten an solchen Oertlichkeiten zu berücksichitigen. Schon J. Booth**) hat darauf hingewiesen, dass die Resultate der Erhebungen „für den Wald direkt nur bedingt anwendbar" sind. In der That haben die exotischen Holzarten die gehegten Erwartungen ausserhalb des Waldes cnttäuscht, dagegen unerwartete Eigenschaften im Walde selbst gereigt. Die meisten Berichte stammen aus botanischen Gïrten oder Parkanlagen, die in oder in der Nähe von Städten gelegen sind, die bekamntlich wieder alle ein breiter Streifen ron entblüsstem Ciebiete

*) Das Vorkommen gewisser, fremdliindischer Holzarten in Dentschland, nach autlichen Erhebungen, Berlin 188:. Springer.

**) Die Naturalisation ausländischer Waldbiume in Deutschland, Berlin 185:. Springer. 
umgibt. Dem Rauch, Staub und rerschiedenen Gasen ausgesetzt, sind diess kaum die richtigen Oertlichkeiten um zurerlässige Angaben zu liefern. Wollte man z. B. im botanischen Garten in München Erhebungen pflegen über das Verhalten der Fichte (Picea excelsa) und Tamne (Abies pectinata) auf der bayerischen Hochebene, so wïrde man dic merkwürdigen Beobachtungen referiren können, dass beide Holzarten alljährlich im Winter dic Nadeln bräunen und verlieren, kümmern, kam 20' hoch werden und somit in der bayerischen Hochebene weder rom forstlichen noch rom dekorativen Standpunkte, weder anbaufäbigg noch anbauw ürdig sind! Auch Gäiten und botanische Anlagen, die mehr als 1 Kilometer vom Walde entfernt sind, geben keine zurerlässigen Resultate für den Wald selbst; wenn es sich um Aufforstung ron öden Gründen, Wiesen, kahlen Hängen und dergrleichen handelt, sind Beobachtungen ron solchen Oertlichkeiten brauchbar. Selbst Pflanzschulen im Walde, wenn ihre Grösse etwa $1 / 2$ ha übersteigt, sind nicht ganz zurerlïssig. Versuche in solchen Kïmpen verhalten sich wie Anbauversuche auf übergrossen Kahlschlïgen, in Frostlöchern; die Resultate sind daher verwendbar, wemn es sich um Fragen handelt, die in einem richtigen forstwirthschaftlichen Betriebe ïberhaupt nicht gestellt sein sollten.

Nichts beweist besser die Unnatürlichkeit der meisten Standorte, in denen bisher die Exoten kïmpfen mussten, als wenn man solche Marvdeure aus den Städten und öffentlichen Gärten wiederum in den Wald resbringt. Der Wald, ihre Heimat, wirkt wie ein heilkrïitiges Sanatorium; die Benadelung der Coniferen - und diese sind am (mpfindlichsten ron allen Waldbäumen - werden nochmal so gross, dunkelgrïn, schon im nächsten Jahre erhebt sich ein krä̈tiger Lüngstrich. Mreine Patienten aus Mïnchen habe ich nur eine Bahnstunde writ mitten in den Wald nach Grafrath geschleppt und alle haben sich wienter sholt mit Ausnahme derer, die zur Zeit der Pflanzung im Frühjahre herrits den grössten Theil der Benadelung eingebüsst hatten; froilich wurle bei ihrer Ausptlanzung im Walde anch auf den passenden Standont gerbührend Rü̈cksicht gonommen, ein weiterer Umstand, dessen Beandhtung in botanischen Gïirten und meist auch in Parkanlagen ganz werfiillt.

In dron kiluinen Pflanzgiilten meines Vaters in Grafrath, 530 Meter

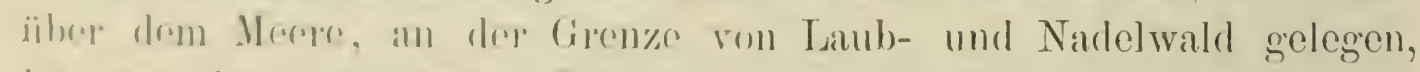
ist vin den zum Anban Empfolulenen noch lieine erfroren. Durch Jen Hoxhwald scitlich eneschiotyt, haben sich alle Kïnsteleien zur Aufzuclat der Lxoten wis Deckung und eigene Behandlungsweise 
als überflüssig erwiesen. Haben doch unter solchen Verhältnissen japanische Laub- und Nadelhölzer, darunter die empfindliche Cryptomeria japonica, Temperaturen ron $-25^{\circ}$ im Winter Widerstand geleistet*); auch die als empfindlich bekannten indischen Nadelhölzer, wie Abies Webbiana, Abies Pindrau, Cedrus Deodar und andere, die ich rom Himalaya herab als zwei- und dreijährige Exemplare mit nach Hause brachte, sind bis jetzt völlig unverletzt geblieben.

Also erst Versuche in kleinen, sogenannten fliegenden Pflanzgärten mitten im Forste an geeigneten Oertlichkeiten angelegt, in Verhältnissen die der Wiederaufzucht der Exoten in ihrer Heimat, dem Urwalde, am nächsten hommen und anerkanntermassen unseren einheimischen Holzarten am meisten zusagen, werden die Möglichkeit der Auf»ucht einer fremden Baumart endgültig zur Entscheidung bringen; alle iibrigen Experimente stellen nur die immerhin auch wissenswerthe Thatsache fest, was eine fremde Holzart überhaupt aushalten kann.

Angesichts der grossen Schwierigkeit, mit der sich eine Holzart an ein Klima, das ron dem der Heimat verschieden ist, anpasst, sowic Angesichts der immer komplizirter sich gestaltenden Reactionen ron Seite der Pflanze, der sich steigernden Unwahrscheinlichkeit eines erspriesslichen Gedeihens derselben, je grösser diese Differenzen in Klima werden, erhüht sich die Wichtigkeit, einmal möglichst genau den heimatlichen Standort klimatisch zu fixiren, andererseits nur solche Holzarten in Zukunft anzubauen, denen man annühernd gleiche Vegetationsbedingungen wie in ihrer Heimat bieten kann. Aus diesen Gründen scheint eine möglichst präcise Gegenüberstellung der klimatischen Zonen der nordamerikanischen Waldlandschaften, mit denen ron Europa und insbesonders Deutschland wïnschenswerth. Die meteorologischen Angaben stïtzen sich auf die reröffentlichten officiellen Berichte der meteorologischen Stationen. Nach diesen habe ich für fast ganz Europa die klimatisch verschiedenen Gebiete zusammengestellt.**) Ich gestehe gerne zu, dass für meine $/$ wecke die Uebersichtlichkeit und Reichhaltigkeit der nordamerikanischen Berichte (Report of the chief Signal officer) ron keiner der von den emopiischen stanten ausgehenden Publicationen erreicht wurden; so musste ich \%. B., um amnihlernd gute Durchschnitte \%u bekommen, für dic europiischen

*) Diess ist durchaus natürlich, denn da wo die schönsten Bestïnde der Cryptomeria liegen, sind - 25,0 in Winter keine allyngrosse Seltenheit!

**) Ich nuss dabei die "luvorkommenheit erwilhnen, mit der mir von Herm Direktor Arai in Tokio die Benützung der grossen meteorulogischen Bibliothek zur Verfïgung gestellt wurde. 
Landschaften die Monatsberichte ron 5-10 Jahrgängen zusammenstellen; der amerikanische Bericht eines Jahres enthält alle Abweichungen ron der normalen Witterung vollständig rerzeichnet; ein Jahrgang genügt zum rölligen Studium des nordamerikanischen Klimas.

Dass die meisten Stationen in Stälten, somit ausserhalb des Waldes situirt sind, ergibt etwas zu hohe Temperaturen und etwas zu geringe relative Feuchtigkeitsmengen gegenuiber dem Walde; wo aber, wie vielfach in Nordamerika, die Stationen ganz ausserhalb der Waldzone in Präriegegenden liegen, da musste es unterlassen werden, auf das Klima des benachbarten Waldes irgend welche Schlüsse zu ziehen.

Zur Abkürzung öfters sich wiederholender Bezeichnungen dient

A für die atlantische Waldregion,

C " "nordmexicanische Waldregion,

D " " pacifische Waldregion.

Die Angaben über Temperatur in Celsius, relative Feuchtigkeit und Regrenmenge vor der fett gedruckten Zahl der mittleren Jahrestemperatur bezichen sich auf das durchschnittliche Klima der Hauptregctationsmonate Nai, Juni, Juli und August. Die Monate, z. B. Mai, S'eptember, bedeuten letzter und erster Frost; die letzte Zahl gibt die tiefste bis jetzt beobachtete Temperatur, für Europa meistens nur fiir die letzten 5-10 Jahre.

\section{a) Die tropische Waldzone.}

\section{Nordamerika :}

Nur in $\boldsymbol{\Lambda}$ auf dem Gebiete der Vereinigten Staten entwickelt: $28^{\circ} \mathrm{C} .74^{\circ} \% .440 \mathrm{~mm} .25^{\circ} \mathrm{C}$. Ohne Frost, $+7{ }^{\circ} \mathrm{C}$.

Dor westindisch-tropische Wald beriihrt in eincr nördlichon Ausbuchtung die S'ïdkïste Florida's und die vorliegrenden Tnseln; der Wald ist niedrign, die Holyarten sind ohme hervorragend wirthschaftlivhe Bodedutung.

\section{Europa :}

In Europa olme Parallele.

\section{b) Die subtropische Waldzone der immergrünen Laubhölzer.}

A : $28^{0} .73 \% / 0.600 \mathrm{~mm} .21^{0}$. Januar odre Dezember; $-7^{n}$.

Hol\%arten: (querus virens,
I ta li en. Süditalien, Sicilien und Sardinien, Kiistengebict: $23^{\circ} .60 \%$. $140 \mathrm{~mm} .18,5^{\circ}$. Kein Frost. 
Magnolia grandiflora, Sabal Palmetto, Sabal serrulata. Persea carolinensis, Cliftonia ligustrina, Pinus cubensis, Tix xodium distichum,Pinus australis (Optimum: Grenzgebiet ron b und $\mathrm{e}(\mathrm{)})$, Juniperus virginiana, (Opt. c c), Chamaceyparis sphacroidea (Opt. c $\alpha$ ), Pinus serotina, Pinus clausa.

C. Ḱlima der Präri e. $24^{\circ} .40 \%$. 13-270 mm. 17 ${ }^{\circ}$. Höchste beobachtete Temperatur: $48^{\circ}$. Tiefste Temperatur: $-5^{0}$ bis $-22^{\circ}$ (höchste Lagen).

Holzarten: ('Tiefste Lagen) Cereus giganteus. Prosopis juliflora.

Klima der Bergwaldregion: - - ? Holzarten: Quercus Emoryi, grisea, hypoleuca, Arbutus jalapensis, Cupressus Guadalupensis, Juniperus pachỵphloea.

D. $16^{0} \cdot 76 \%, 29 \mathrm{~mm}, 1^{0}$. Januar $-2^{0}$.

Holzarten: Quercus acrifolia, chrysolepis, Umbellularia californica, Sequoia sempervirens, Cupressus macrocarpa, Goveniana und Macnabiana, Pinus insignis, muricata, Torreyana und Parryana.

Das Klima der inneren Berghkette (Sierra Nevada) ist wegen Mangels von meteorologischen Stationen nicht bestimmbar.
Spanien. Teneriffa: $22^{\circ} .79 \%$ $26 \mathrm{~mm} .21^{\circ}$. Kein Frost.

Küste von Südspanien : $22^{\circ} .64 \%$. $116 \mathrm{~mm}$. 18 . Мӓ̀\% $-1^{0}$.

Küste ron Griechenland. (Alexandria 25\% $71 \%$ Kein Regen. 20 ${ }^{\circ}$. Kein Frost.)

Bimmenland ron Unteritalien und Sicilien mit einer Temperatur wie oben und einer relativen Feuchtigkeit ron $50 \%$ und darunter.

Bimmenland ron $S$ üdspanien bis 600 Meter: $22^{\circ} .51 \%$. $115 \mathrm{~mm}$. $17^{n}$. Mä̈\%-Dezember - 50. Ton 600 bis 1000 Meter: 21 ${ }^{\circ}$. 47\% $120 \mathrm{~mm} .15^{0}$. Mäirz. Dezember. $-7^{\circ}$.

Spanien. Nordküste: $18^{n} .780 \%$. 217 mm. 130. М̈̈н. Dezember $-4^{0}$. Bei 250 Neter Erhebung: $15.5^{0}$. $72 \% .309 \mathrm{~mm} .13^{n}$. Mär.December. $-7^{\circ}$.

Spanienund Portugal. Westliiiste: $18^{\circ} .72 \%$. $132 \mathrm{~mm} . \mathbf{1 5}, 5^{0}$. M:ïr. Dezember. $-1^{0}$.

Bergregion Portugals und Siidspantens. 
Holzarten: Quercus Wisliceni, ublongifolia auch lobata und densiflori, Aretostaphylos pungens, Pinus tubereulata, Sabiniana, Pseudotsuga macrocarpa, Juniperus californica, Washingtonia filifera.

\section{c) Der winterkahle Laubwald der gemässigt-warmen Region.}

A. $\alpha$ S Südliche Hälfte bis жи $39 .{ }^{\circ}$ N.B.: $24^{\circ}$ C. $400 \mathrm{~mm}$. $69 \%$. 15 ${ }^{\circ}$. Мä1\% bis Norember. $-14^{n}$.

Holzarten : Quereus lyrata, falcata, Catesbaci, laurifolia, aquatica, heterophylla und Durandii, Carya sulcata olivacformis, aquatica und myristicaeformis, Fraxinus quadrangrulata und plattycarpa, Ulmus alata und crassifolia, Robinia Psendacacia, (ileditschia Triacanthos, Cercis canadensis, Castanea pumila, Magnolia macrophyylla, 'Tilia heterophylla, Ira(.) lura aurantiaca, Nysia uniflora und capitata, Catalpa bignonioides und speciosa, P'inus glabra, mitis, Taeda, insps, anstralis, Chamaecyparis sphacroidea, Juniperus virginiana, Taxodium distichum (Opt. b), T'axus floridama, Torreya taxifolia. Truga "amliniana.
O esterreich. Südtirol, tiefste gegen die adriatische Ebene geüfnete Thäler: $21^{\circ} .350 \mathrm{~mm}$. $68 \%$. $12,6^{\circ}$. März bis November. - $7^{n}$.

Nordadriatisches Küstenland: 20,50 . 64\% $306 \mathrm{~mm} .13,7^{0}$. Müirz. Norember. $-\delta^{0}$.

Südadriatisches Kïistenland: $22,5^{\circ} .60 \%$. $112 \mathrm{~mm}$. 16,4 ${ }^{\circ}$. Febr. $-2^{\circ}$.

Italien. Norditalien bis 400 Mtr. Erhebung: $20,5^{0} .61 \% .360 \mathrm{~mm}$. 12, $8^{\circ}$. Mӥ̈\%. November. - $11^{\circ}$.

Mittelitalien bis 500 Meter Erhebung: $21^{0} .57 \%, 206 \mathrm{~mm} .14,6^{n}$. Nür\%. Norember. - $11^{0}$.

Ton 500-700 Meter Erhebung: 18,40.53\% $267 \mathrm{~mm} .12,3^{\circ}$. Frost (?) Sardinien $17,5^{\circ}$.

I talien is e h-franz $0 \ddot{\text { s ische }}$ Riviera: $21^{\circ} .64 \% .150 \mathrm{~mm} . \mathbf{1 5}^{0}$. Nä̈\%. November. - $\dot{j}^{0}$.

Frankreich. Südküste bis 300 Meter Erhebung: $20^{\circ} .60^{\circ} / 0.207 \mathrm{~mm}$. 13,50. April. Norember. - 110.

Girechenland, nördlicher 'Theil.

spanien. Pyrenäen bis 300 Meter: 200. 39\% (!) $23 \mathrm{~mm} . \mathbf{1 3}^{0}$. April. Oktuber. $-10^{\circ}$. (Wald 
unmöglich wegen Feuchtigkeitsmangel.)

Nordöstliches Binnenland bis zu 200 Meter: $21,50.57 \% .16 \mathrm{~mm} .(!)$ 14". März. November. - $7^{\circ}$.

Mittleres Bimnenland bei 600 Meter: $21^{\circ} .49 \%$. (!) $23 \mathrm{~mm} . \mathbf{1 5} \%$ April. Norember. $-9^{\circ}$.

ß) Nördliche oder kïhlere Hälfte des Laubwaldes:

A: $19^{\circ} .67 \% .406 \mathrm{~mm} .9^{\circ}$. April. Olitober (sehr selten Mai-September) $-2 i^{\circ}$, an den grossen Seen $-41^{\circ} \mathrm{C}$.

Holzarten: Quercus bicolor, Acer striatum u. spicatum, Fraxinus sambucifolia, Betula papyrifera und populifolia, Alnus glauca, Ulmus racemosa, Tilia americana, Prunus pennsylvanica, Populus tremuloides, grandidentata und balsamifera,'Tsuga canadensis (auch d) Pinus Strobus, resinosa und Banksiana (auch d, Optimum in Grenzgebiete von c und d), Thuja occidentalis (auch d), Larix americana (Optimum d), Picea nigra (Optimum d), Picea alba (Optimum d), A bies balsamea(Optimum d).

c A. $\alpha$ und $\beta$ gemeinsame Holzarten:

$$
\begin{aligned}
\mathrm{N} & =\text { Cptimum im Norden, } \\
\mathrm{S} & =\quad " \text { "Süden, } \\
\mathrm{NS} & =\quad " \text { Trenzgebiete. }
\end{aligned}
$$

Juglans nigra (S), cinerea (S), Quercus alba (S), macrocarpa (NS), Prinos (S), prinoides (S), rubra (NS), eoccinea (NS), tinctoria (S), palustris (S), cinerea (SN), Carya alba $(\mathrm{S})$, porcina $(\mathrm{S})$, amara $(\mathrm{S})$,
Deutschland. Rhein, Untermain, Ioselthal: $17^{0} .70 \%$ 0. $250 \mathrm{~mm}$. 10 ${ }^{\circ}$. April. Oktober (selten MaiSeptember). - 16";

Bayerisches Gebiet am Rhein und Untermain: $18,5^{\circ} .65 \%$. $235 \mathrm{~mm}$. $9^{0}$. Mai. Oktober. $-22^{\circ}$;

Württemberg Neckarthal und Barlen Rheinebene: 17,50. 70 $/ 0$. $277 \mathrm{~mm}$. 9,6 $6^{\circ}$ April. September. $-25^{n}$;

Elsass bis 200 Meter Erhebung: $17^{\circ} .320 \mathrm{~mm}$. $60 \%$. 8, $8{ }^{\circ}$. Mai. Oktober. - $26^{\circ}$

Oberlauf der Orler: $16^{\circ} .72 \%$. $274 \mathrm{~mm}$. 8,5. Maii. Okitober. $-30^{0}$ (1880);

Mittellauf der Elbe und Oder: $16^{\circ} \mathrm{C} .69 \%$. $206 \mathrm{~mm}$. 8,50. Mai September. $-19^{\circ}$;

Sachsen bis zu 200 Meter: $15,6^{\circ}$. $71 \%$. $227 \mathrm{~mm} .8,1^{\circ}$. Mai. Septenber. $-28^{\circ}$;

Thüringerwald bis zu 200 Meter: $14^{0} .75^{\circ}\left[0.276 \mathrm{~mm} .14^{0}\right.$. Mai. September. - 21

Thal der W' Teser und Nebentlïsse: 15\%. 75\%. $264 \mathrm{~mm}, \mathrm{~S}^{0}$. Mai. September. $-27^{\circ}$;

Thal des mittleren Mains, der 
tomentosa (S), Acer saccharinum (N.) rubrum (SN), dasycarpum (NS), Negundo aceroides (NS), Fraxinus americana (NS), riridis $(\mathrm{N})$, pubescens (N). Ulmus americana (N), fulva (SN). Betula lutea $(\mathrm{N})$, lenta $(\mathrm{N})$, nigra (S), Grmmocladus canadensis (SN). Castanea americana (S), Carpinus americana (S), Ostria virginica (S), Platanus occidentalis (S), Magnolia glauca (S), acuminata (S), Liriodendron tulipifera (S), Aesculus grlabra (SN), flava (S), Prunus serotina (S), americana (S), Sassafras officinale (S). Liquidambar styraciflua (S), Celtis occidentalis (S), Morus rubra (SN), Salix nigra (NS), Populus heterophylla (NS), monilifera (NS), Pinus rigida (NS), pungens (SN). Chamaceyparis splaeroidea (SN), Juniperus virginiana (S).
Pegnitz, unteren Donau (Kelheim bis Passau), des Bollensee, tiefere Thäler der pfälzer Berge, des Spessart, Steigerwald, Jura und Rhön: 17,30. $300 \mathrm{~mm}$. 69\% $\mathbf{8}^{0}$. Mai. September. $-25^{\circ}$.

O es t er ei ch. Südtyrol, imnere Thäler bis 300 Meter: $20^{\circ}$. 58\% 369 mm. 11,4 . Mä̀z. Norember. $-10^{0}$

Untersteycrmark bis 400 Meter Erhebung: $18^{\circ}$. $380 \mathrm{~mm}$. 72\%. 10 ${ }^{\circ}$. April. Oktober. $-18^{\circ}$;

Krain bis 400 Meter: $17,5^{\circ}$. $76 \%$. $500 \mathrm{~mm}$. 9, $4^{0}$. April. Oktober. $-22^{\circ}$;

Niederösterreich bis 500 Meter: $17^{\circ} .70 \%$. $340 \mathrm{~mm}, 9, !^{0}$. April. Oktober. $-19^{\circ}$;

Böhmen bis 250 Meter: $16^{\circ}$. $68 \% .291$ mm. 9 ${ }^{0}$. April. Oktober. $-21^{\circ}$.

Südtyrol 300-600 Meter Erhebung: $17^{\circ} .62^{\circ}{ }_{10} . \quad 346 \mathrm{~mm} .8,9^{\circ}$. April. Oktober. - $14^{0}$;

Mïhren bis 300 Meter: $16^{\circ}$. $72 \%$. 280 mm. 8,5 . April. Oktober. $-18^{\circ}$;

Vorarlberg bis 400 Meter: $15^{\circ}$. $74 \%$. $721 \mathrm{~mm} .8,4^{\circ}$. April. Oktober. -140 ;

Salzburg bis 500 Meter: $16^{0}$. $76 \% .527 \mathrm{~mm} .8,3^{\circ}$. April. Olitober. $-25^{0}$;

Kärnten bis 500 Meter: 17 . 670\%. 459 mm. 8, ${ }^{\circ}$. April. Oktober. $-20^{\circ}$;

Oberösterreich bis 500 Meter: $16^{\circ} .74 \%$. $600 \mathrm{~mm}$. 8,1 ${ }^{\circ}$. April. Oktober. $-20^{\circ}$; 
Galizien bis 300 Meter: $16^{0}$. $75 \%$. $360 \mathrm{~mm}$. $\mathrm{s}^{0}$. April. September. $-26^{\circ}$;

Bukowina bis 300 Meter: $17^{0}$. $71 \%$. $318 \mathrm{~mm}$. $8^{0}$. April. Oktober. $-20^{\circ}$

Siidliches Ungarn bis zu 200Meter: $20^{\circ} \mathrm{C} .69 \% .289 \mathrm{~mm} . \mathbf{1 1}, 3^{\circ}$. Mä̈rz. Oktober. - $21^{\circ}$;

Mittleres Ungarn bis 500 Meter: 19. 73\%. $298 \mathrm{~mm}$. 9,7\%. April. Oktober. - $24^{0}$;

Nördliches Ungarn bis 400 Meter: 19 $.300 \mathrm{~mm}$. 67\% 9.4 . April. Oktober. $-23^{\circ}$ :

Südliches Ungarn 200-600 Mtr. : $18^{\circ} .74 \%$. $448 \mathrm{~mm}$. 8,60. April. Oktober. $-23^{\circ}$.

Norditalien ron $400-600 \mathrm{M}$. Erhebung: 18 . 60\%. $266 \mathrm{~mm}$. 11 $1^{\text {}}$. Mäı. November. $-13^{0}$;

Von 600-1000 IItr. : $17^{\circ} .60 \%$. $440 \mathrm{~mm}$. 10 ${ }^{\circ}$. März. Oktober. $-12^{\circ}(?)$.

Schwei . Südschweiz bis 300M. : 19,5 . 73\%. $707 \mathrm{~mm} . \quad \mathbf{1 1}, 8^{\circ}$.

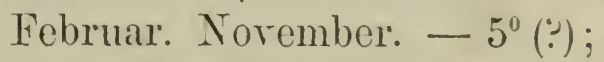

Von 300-700 Meter: $17,8^{\circ}$. $71 \%$. $558 \mathrm{~mm} .10,3^{\circ}$. April. Oktober. $-11^{0}(?)$;

Nordschweiz bis 500 MItr. : $16.6^{\circ}$. 73\% $494 \mathrm{~mm} .9^{\circ}$. Mïr\%. Okitober(\%). $-15^{\circ}(\because)$.

Frankreich. Südliches Frankreich (Binnenland): $18^{\circ}$. 72\% $266 \mathrm{~mm} . \quad 12 "$. Mai. Oktuber. $-16^{\circ}$

Mittleres Frankreich (Bimnenland): $18^{\circ} .266 \mathrm{~mm}, 75^{\circ} / 0.11^{\circ}$. Mai. Oktober. - $18^{\circ}$; 
Nördliches Frankreich (Binnenland): $16^{\circ} .74 \%, 190 \mathrm{~mm} . \quad \mathbf{1 0}^{\circ}$. Mai. September. $-13^{0}$;

Französische Pyrenäen bis 500M. : $16^{\circ} .70 \%$. $240 \mathrm{~mm} . \mathbf{1 0}^{\circ}$. Mai. September. $-18^{\circ}$.

Nordöstlicines Frankieich: $15^{0}$. 200 m. 75\%. Mai. September. $-12^{\circ}$

Französische Vogesen bis $400 \mathrm{M}$ : 16. $305 \mathrm{~mm}$. 70\%, 9,5. Mai. September. $-18^{\circ}$.

Spanien. Nordwestl. Binnenland bei 800 Meter: $16,7^{\circ}$. 58\% $/ 0$. $110 \mathrm{~mm}^{1} \mathbf{1 1}^{\circ}$. Mai. Oktober. $-13^{0}$;

Pyrenäen bei 800 Meter: $17^{\circ}$. 47\% $23 \mathrm{~mm}$. 10,5\% . April. Oktober. $-10^{\circ}$.

Mittleres Bimnenland bei 1000 M. : $15^{\circ} .46^{\circ} /$ (!). $20 \mathrm{~mm}$. Jahrestemp. (?). Mai. Olitober. $-12^{0}$.

C. a) Siurlliches Gebiet:

Klima nicht bekannt.

Holzarten: Platanus Wrightii, Juglans rupestric Fraxinus pistaciacfolia. Chilopsis valigna, Pinus Chihuahmana, Engedmanni, arizonica, isteosperma, monophyylla, edulis.

3) Nördlarlaes oder hïheres Gebiet:

Pinus reflexa. Psemdetsigat Dongrlasii rar. glanc"i.

I). a) Sïdliolas Gobiot:

15". $91 \mathrm{~mm} .85 \%$ (10 $\mathbf{1 0}^{\circ}$. Decomber. Mй\%(:). - 6".

Hol\%alrten: (Zuerous densiflora, Platams racomosa, Arbutus Men-

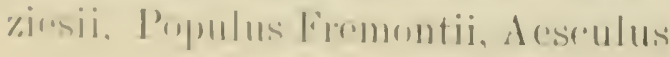

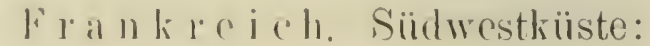
17". $76 \%$. $270 \mathrm{~mm}$. 11,3\%. Oktober. $-11^{\circ}$. 
californica, Negundo californicum, Chamaecrparis Lawsoniana;

Im Süden, aber hochgelegen: Quercus Kelloggii, Alnus oblongifolia, Abies bracteata, Abies concolor syn. lasiocarpa, Libocedrus decurrens, Pinus Lambertiana, Jeffreyi, Coulteri, Sequoia gigantea.

ß) Nördliches Gebiet:

15\%. 75\% $137 \mathrm{~mm}$. 10 . Мӓц. November. - $16^{\circ}$.

Holzarten: Quercus Garryana, Fraxinus Oregana, Populus trjchocarpa, Acer grandidentata, glabrum(?), Populus angustifolium (?), Fraxinus anomala (?), Alnus rubra, rhombifolia, Betula occidentalis (auch d), Sorbus sambucifolia (auch d), Thuuja gigantea, Pinus monticola (auch d), Chamaecyparis nutkaensis.

$\alpha)$ und $\beta$ ) gemeinsame Holzarten:

Acer macrophyllum (Optimum in S), Acer circinatum (N), Cornus Nuttallii (S), Rhamnus Purshiana (S), Pseudotsuga Douglasii (N, auch d), Picea sitkaensis ( $\mathrm{N}$, auch d), Pinus ponderosa (NS, auch d), contorta (N), Abies grandis (N), Tsuga Mertensiana $(\mathrm{N})$, Taxus brevifolia.
Eng galand. Süidengland: $14,4^{0}$. $81 \% .210 \mathrm{~mm} .10^{\circ}$. Mai. Olitober. $-16^{\circ}$.

Nordengland: $13,8^{\circ} .790 ; 0.230 \mathrm{~mm}$. $9^{0}$. April. Oktober. $-12^{\circ}$.

Irland: $14^{\circ} .79 \% .270 \mathrm{~mm} .9^{\circ}$. April. Oktober. - 12 .

Holland. Kï̈ste: $16.70 .75 \%$. $120 \mathrm{~mm}$. 9,50. April. Oktuber. $-9^{0} .(?)$

Binnenland: 17,60.72\% $163 \mathrm{~mm}$. 10,5 $5^{\circ}$. April. Oktober. $-15^{\circ}$.

Frankreich. Nordwestküste: 15\%. $86 \%$. $242 \mathrm{~mm} . \mathbf{1 0}^{\circ}$. Mäirz. November. $-18^{\circ}$.

Belgien.

Deutschland. Nordsecküste und westlicher Theil der Ostsee: 14,, $5^{\circ} .75 \%$. $280 \mathrm{~mm}$. 8 $\mathbf{8}^{\circ}$. April. Oktober (selten Mai, September). $-19^{\circ}$.

Dän emark. Südküste: $14,8^{\circ}$. $75 \%$. $188 \mathrm{~mm}$. 8 ${ }^{\circ}$. April. Okitober. $-18^{\circ}$.

Sch w e den. Südküiste: Klima?

\section{d) Der Nadelwald der gemässigt-kühlen Region.}

A. : $15^{\circ} .77 \%, 376 \mathrm{~mm}, 6^{\circ}$. Mai (selten Juni). September. - $42^{\circ}$.
De eutschla la d. Schwarzwald $400-700$ Meter: $15^{\circ}$. $75 \%$. 
Holmarten: Betula papyrifera (c. N.), Sorbus americana (c. N.), Populus tremuloides (c. N.), Larix americana. Picea nigra, alba, Abies balsamea, Fraseri. Juniperus virginiana (c. S.), Thuja occidentalis (c. X.), Tsuga canadensis (c. N.), Pints Strobus, resinosa, Banksiana (c. d.).
$400 \mathrm{~mm} . \quad 7,6^{0}$. Mai. September. $-17^{\circ}$

Oestlicher Theil der Ostseek ïste: 14,50. $74 \%$. $224 \mathrm{~mm} . \quad \boldsymbol{7}^{0}$. Mai. Septcmber. $-25^{\circ}$;

Höhere Theile des Hart- und Fichtelgebirges, der Rhön, des Spessart und bayerischen Waldes bis 500 Meter, der bayerischen Alpen bis 600 Meter: $15^{\circ}$. $70 \%$. $470 \mathrm{~mm} . \boldsymbol{\gamma}^{0}$. Mai (selten Juni). $-28^{\circ}$

Sachsen, Erzgebirge von 200 bis 1000 Meter: $13,8^{\circ} .72 \% .307 \mathrm{~mm}$. 6, $4^{0}$. Mai. (Juni.) September. $-25^{\circ}$;

Bayerische Alpen von 700 bis 1000 Meter: $14^{\circ} .72 \%$. $590 \mathrm{~mm}$. $6^{\circ}$. Juni. September. $-28^{\circ}$;

Oesterreich. Vorarlberg von 400 bis 600 Meter: $15^{\circ}$. $74 \%$. $537 \mathrm{~mm}$. 7,4 . April. Oktober. $-20^{\circ}$

Südtyrol 500 bis 1000 Meter:

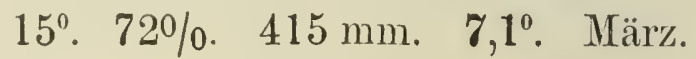
Oktober. $-12^{\circ}$;

Obersteyermark 400 bis 800 Mtr.: 14,50.70\%. $336 \mathrm{~mm}$. 7,10. April. Oktober. - $21^{0}$;

Kürnten bei 1000 Meter: $14^{0}$. $81 \%$. $545 \mathrm{~mm} .7,1^{\circ}$. April. Oktober. $-19^{\circ}$;

Böhmen von 250 bis 500 Meter Erhebung: 14\% $.72 \% .294 \mathrm{~mm}$. $\boldsymbol{7}^{\circ}$. Mai. September. $-23^{\circ}$;

Ungarm, nördliches von 400 bis 1000 Meter: $14^{\circ}$. $77 \%$. $385 \mathrm{~mm}$. 6,, $4^{0}$. Mai. September. $-29^{\circ}$;

mittleres iiber 500 Meter: $15^{\circ}$. 70\% $432 \mathrm{~mm}$. $7^{\circ}$. April. Oktober. $-17^{\circ}$; 
Salzburg ron 500 bis 900 Meter: $14^{0} .70 \% .480 \mathrm{~mm} .6,4^{\circ}$. April. September. $-21^{\circ}$;

Nordtyrol bis 800 Meter: $14^{0}$. $740_{0}^{\prime}$. $378 \mathrm{~mm}$. 6,40. Mai. Septbr. $-19^{9}$.

Schweiz. Südschweiz ron 700 bis 1000 ILeter: $14,9^{\circ} .67 \% 0.537 \mathrm{~mm}$. Mai. September. - $18^{\circ}$;

Nordschweiz ron 500 bis 700 ILeter: $15,1^{0} .76 \% .649 \mathrm{~mm} . \mathbf{7}, 7^{\circ}$. Mai. September. - $17^{\circ}$ (?);

Ton 700-1000 Meter: $13,5^{\circ}$. $77 \%$. $592 \mathrm{~mm} . \quad 6,3^{\circ}$. Mai. September. $-17^{\circ}$ (?).

It a lien. Mittelitalien 950 MItr.: $15^{\circ}$. Regen? $66 \%$. 7,8 $8^{\circ}$. Frost?

Norditalien 1000-1500 Meter: $13,7^{\circ} .65 \%$. $460 \mathrm{~mm} .6,3^{0}$. Frost?

\section{Klima (?).}

Holzarten: Pseudotsuga Douglasii v. glauca (?), Pinus flexilis.

D. Küstengebiet: $10^{\circ} .78 \%$. $500 \mathrm{~mm} .6^{\circ}$. IIonat $(?)-15^{\circ}$.

Holzarten: Chamaeevparis nutkaensis, Picea sitkaensis (Optimum e. $\beta$ ), Abies nobilis, magnifica, amabilis.

Binnenland und Küste:

Preudotsuga Douglasii (Montana) Optimum e, Abies grandis (c). Pinus ponderosa (e), Abies concolor (e d), Thuja grigantea (c), Tsuga Mertensiana (c), Juniperus occidentalis.
En $\mathrm{ng}$ a a nd. Nordengland bei 300 Meter Erhebung: $12^{\circ} .187 \mathrm{~mm}$. $63 \%$. 7, $5^{\circ}$. Mai. September. $-20^{\circ}$; Schottland bis 300 Meter: $13,5^{\circ}$. $82 \%$. $745 \mathrm{~mm}$. 7.5\%. Mai. September. $-13^{\circ}$;

Bei 330 Meter: $11,5^{\circ}$. $80 \%$. $910 \mathrm{~mm} .6^{0}$. Mai. September. $-24^{\circ}$.

Dän emark. Nordwestl. Theil (Jütland) : $13,5^{\circ} . \quad 70 \% .195 \mathrm{~mm}$. 7, $4^{0}$. Mai. September. $-16^{\circ}$.

Norwegen. Südnorwegen (Kíiste) : 12,7 $75 \%$ o. $280 \mathrm{~mm}, 6,6^{\circ}$. Mai. September. $-17^{\circ}$; 
Klima des Binnenlandes (Montana):

Wärmerer, tiefer liegender Theil, das Grenzgebiet ron Wald (Pinus ponderosa und Murrayana) und Präric: 18\%. 55\%. $100 \mathrm{~mm}$. 7.8 . Frost? $-35^{\circ}$.

Das höher und nahe liegende Waldgebict der Douglasia, Gelbkiefer, Lürche, an Flussrändern auch Thuja gigantea und Tsuga Mertensiana hat wohl grössere relative Feuchtigkeit, gering e re sommerwärme und wohl auch ctwas mildere Winter.

Binnenland allein:

P'seudotsuga Douglasii var. glauca (Colorado), Picea Engelmanni, Picea pungens, Larix occidentalis, Pinus monticola*), Pinus Murrayana var. Sargentii, Juniperus virginiana (๕. A. S.), Sorbus sambucifolia, Betula occidentalis (c. D. $\beta$ ).

Klimaron Colorado.

*) Pinus monticola wurde im Texte zur klimatischen Zone des nördlichen Laubwaldes gezogen, dïrfte aber seinem Optimmm nach cher zu d gehören.
Mittleres Norwegen (Küste): $12,6^{\circ} .74 \%$. $288 \mathrm{~mm} .6,1^{0}$. Mai. September. $-17^{\circ}$.

Kühle Sommer im Verhältniss zur mittleren Jahrestemperatur.

De uts chland. Thüringerwald bei 600 Meter: $12^{\circ} .79 \% .345 \mathrm{~mm}$. $6^{\circ}$. Mai. Oktober. $-17^{\circ}$;

Riesengebirg bei 600 Meter: $13^{\circ}$. $76 \%$. $430 \mathrm{~mm} .6^{0}$. Mai. September. $-32^{\circ}$;

Harz bei 600 Meter: $12^{\circ} .78 \%$. $600 \mathrm{~mm}$. 5,5 . Mai. September. $-18^{\circ}$

Scliwarzwald 700-1000 Meter: 13․ $77 \%$. $546 \mathrm{~mm} . \quad 6^{0}$. Mai. September. $-17^{\circ}$.

Oesterreich. Mähren 300 bis 700 Neter: 13․ 75\% $386 \mathrm{~mm}$. 5,50. Mai. September. $-18^{\circ}$;

Galizien 300-800 Meter: $13^{\circ}$. - $\%$. $600 \mathrm{~mm}$. 50. Mai. September. $-24^{0}$;

Oberösterreich ïber 500 Meter: Klima? 


\section{e) Region der alpinen Nadelhölzer.}

Durchschnittl. Jahrestemperatur: 2 bis $5^{0}$.

A. Abies balsamea v. Hudsonica, Picea alba (d), Populus tremuloides (c u. d), balsamifera (c u. d), Betula papyrifera (c u. d), Amelanchier canadensis (c u. d).

c.

D. Pinus cristata, Balfouriana, albicanlis, Picea Breweriana, Abies subalpina, Larix Lyellii, 'Tsuga Pattoniana, Sorbus sambucifolia, Populus balsamifera, Betula papyrifera, Amelanchicr canadensis.

(Beringinsel 55 N.B.: $7^{\circ}$. 90\% $160 \mathrm{~mm} . \mathbf{2}^{0}$. 1 Monat ohne Frost. $-15^{\circ}$.)
Deutschland. Riesengebirge ron 1000 bis 1300 Meter;

Har\% bei 1000 Meter ;

Bayerische Alpen ron 1300 bis 1800 Meter.

Oesterreich. Nordtyrol ron $1000-1800$ Meter: $10^{\circ}$. 77\% $776 \mathrm{~mm} .4^{0}$. Mai. September. $-19^{\circ}$ :

Steyermark bei 1260 Meter: $10^{\circ}$. $74 \%$. 3,8 $383 \mathrm{~mm}$. Mai. September. $-20^{\circ}$.

Schwei\%. Nordschweiz: 1000 bis 1700 Meter: $11,3^{\circ} .72 \%$. $3,4^{0}$. 2 IIonate olne Frost. $-21^{\circ}$;

Südschweiz 100-1800 Meter: 10,4\% $70^{\circ} / 0$. ? mm. 3,70. 2 Monate ohne Frost. $-18^{\circ}$.

Frankreich. Pyrenäen bei 1460 Neter: $9^{0} .82 \% .436 \mathrm{~mm}$. $3,6^{\circ}$. 2 Monate ohne Frost. $-16^{\circ}$.

It a $l$ i e 11 . Norditalien bei $1500 \mathrm{ML}$. $11,5^{\circ}$. ? \% $224 \mathrm{~mm} .2,4^{0} .2$ Monate ohne Frost. - ?

Norwegen, mittleres, Binnenland bei 100 Meter: $13^{\circ} .280 \mathrm{~mm}$. $70 \%$, 4, $9^{\circ}$. 2 Monate ohne Frost. $-25^{\circ}$;

nördliche Küste: $11,1^{\circ}$. $72 \%$. $164 \mathrm{~mm} .3,4^{\circ} .2$ Monate ohne Frost. $-27^{\circ}$;

mittleres bei 200 Meter: $9,1^{0}$, $76 \%$. $258 \mathrm{~mm} .0,6^{\circ} .2$ Monate ohne Frost. - 4 $3^{\circ}$.

D) ä $n$ e $\mathrm{m}$ ar k. Island: $5,6^{\circ} .82 \%$. $300 \mathrm{~mm} . \mathbf{2}, 2^{\circ}$. 2 Jonate ohne Frost. $-16^{\circ}$. 


\section{f) Baum- und Strauchgrenzen.}

(Bei 0 bis $1^{0}$ Jahrestemperatur.)

Hudsonsbay 58 . NB.: $6^{0}$. Jahrestemperatur $-9^{n}:$ tiefster $-45^{\circ}$.

Behringstrasse (Polarkreis): $8^{0} .86 \%$. $150 \mathrm{~mm}$. - $3^{0} .2$ Monate ohne Erost. $-46^{\circ}$.

In Folge der hohen Sommertemperaturen (Südwind), findet sich an der Küuste, trot\% der Jahrestemperatur unter $\mathbf{0}^{0}$ noch niedere, strauchartige Vegetation.

Lis crhrellt aus obiger Giegenüberstellung, dass die Jahrestemperatur allein nur immerhalb kleiner Gebiete als Anhaltspunkt zur Beurtheilung den. Wäme des Klima's eines Ortes benütyt werden kamn. Insulares mol kontinentales' Klima kömnen gleiche Jahrestemperaturen besitzen mol doch klimatisch sehr wesentlich verschieden sein; England z. B. hat eine höhere Jahrestemperatur als das mittlere Ungarn, das eine mittlere 'Tromproatur der Hauptveretationszeit ron $19^{\circ}$ charakterisirt, willrend lingland nur $14^{\circ}$ besityt, welche 'Temperatur im Continente cince Jahrestrmperatur von $6^{0}$ entspricht. Ebenso wenig gibt die xrmmertemperatur allein einen genügrenden Anhalt; das kontinentale 


\section{- $397-$}

Canada unter dem $55^{\circ}$ N.B. hat $\%$. B. dieselbe Sommertemperatur wie die Küste des mittleren Californien unter $38^{\circ}$ N.B. Die Jahresisotherme $0^{\circ}$ kommit zu Stande durch ticfe Sommer- und hohe Wintertemperaturen, wie auch durch hohe Sommer- und tiefe Wintertemperaturen; ersteres ist der Fall an der Baumgrenze im insularen Klima, letzteres im kontinentalen Klima; interessant ist das Zustandekommen der Jahrestemperatur ron $-3^{0}$ an der Beringstrasse, wo sich noch niederer Baumwuchs findet, eine Erscheinung, die mit der Annahme, dass die Jahresisotherme 0 die Baumgrenze fixirt, in Widerspruch steht; die Sommertemperatur gibt Aufschluss; sie betrïgt $8^{0}$, für die Monate Juli und August selbst $12^{\circ}$; während dieser beiden Monate aber weht Südwind, wogegen während des ganzen übrigen Jahres Nordwind weht.

Jahres- und Sommertemperatur zusammen geben zum Vergleiche zweier Orte hinsichtlich ihrer Wärme genügende Anhaltspunkte; die Wintertemperaturen zweier, getrennt liegender Oertlichkeiten kömmen ziemliche Differenzen zeigen; dennoch ist das Gedeihen der Holzarten der einen Oertlichkeit in der anderen sehr gut möglich; denn die tiefen Wintertempcraturen sind für die meisten Holzarten, solange sie sich im Walde, und dort auf den richtigen Standorten sich finden, nicht gefährlich.

Aus obiger Gegenüberstellung ergeben sich die Differenzen in relativer Feuchtigkeit, in den Wärme- und Regenverhältnissen, woraus die Behandlung der anbaufähigen Holzarten, ihre gegen Spät- oder Frülfrost und Trockniss gesicherte Erziehung sich ableiten lässt; soweit dieses sich auf die im deutschen Walde anbauwüirdigen Holzarten bezieht, wird im folgenden Kapitel die Rede sein.

\section{Die nordamerikanischen Holzarten vom Stand- punkte ihrer Anbauwürdigkeit in den deutschen Waldungen.}

Angesichts der glänzenden Erfolge, welche die Landwirthschaft und Gïrtnerei durch den Anbau fremdländischer Gewächse aufzuweisen hatte, regte sich sehr frühe schon das Bestreben, auch für den deutschen Wald Holzarten zu finden, welche die einheimischen entweder in Güte oder in Wachsthumsleistungen oder in anderen winschenswerthen Eigenschaften, insbesondere auf den mehr und mehr vermagernden 
Büden, übertreffen würden. Das Angemmerk richtete sich zuerst auf Nordamerika, wo nicht blos eine Fülle von Holzarten zur Auswahl rorhanden war, sondern wo noch ïberdiess die klimatischen Bedingungen nicht allzurerschieden ron den einheimischen erschienen, um von Versuchen im Toraus abzuschrecken. In Frage kamen zumeist solche Arten, für welche Park- und Ziergärtnerei bereits die Anbaufähigkeit festgestellt hatten.

.Als im vorigen Jahrhundert", sagt Grisebach, "die Bäume Nordamerika's zuerst nach Europa kamen, erwartete man von der Acclimatisirung besondere Vortheile für die Forstwirthschaft; diese Erwartungen sind nicht erfüllt worden, indem sich alsbald herausstellte, dass dieselben an Holzwerth den Einheimischen Europa's nachstehen, während sie sie häufig an Schnelligkeit des Wachsthums übertreffen, wie es bei weicheren Holzarten gewöhnlich ist; bei Paris sah man cinen Baum in 30 Jahren 80 Fuss hoch und 3 Fuss dick werlen; jene Schilderung ron den häufigen Windfällen in den Oregonforsten, wo der Boden des Waldes von den niederstürzenden Ricsenbäumen bedeckt wird, ist ebenfalls ein Beweis ron der kurzen Wachsthumsperiode (300-400 Jahre! Ref.) rerbunden mit geringer Widerstandskraft gregen Störungen von Aussen."

Nach diesem mit einem Scheine von Beweiskraft hingeworfenen Ausspruche wiire es thöricht, noch weiters Versuche mit amerikanischen Holzarten vorzunchmen. Hierauf haben die forstlichen Versuchsstationen gebiuhrend geantwortet mit Anbauversuchen nordamerikanischer Waldbïume in grö̈sserem Massstabe als früher.

Uebrigens steht $G$ rieseba ch mit seiner absprechenden Meinung nirht allein da und die wohlgereiften Urtheile eines Nördlinger und Burckhardt, die auf o $\mathrm{g}$ ene Beobachtung ihre Ueberzengung aufhauten, mahmen zur. Vorsicht bei dem neuen Unternehmen.

Nach den Ausführungen des vorhergehenden Kapitels ist es freilich eine sehr grosse Zahl von nordamerikanichen Bäumen, welche in don deutschen Waldungen anbaufühig zu sein scheinen; ihr Werth, ihre Anbawwïrdigkeit lässt sich von rerschiedenen Gesichtspunkten aus betrarhten.

Derjenige Standpunkt, der die meisten Anbaufähigen auch anbauwïrdig crschemen lässt, ist der ästhetische, der die Holzarten von ihrer dekorativen Sroite erwïgt, sie also hinsichtlich ihres Werthes für die Landschafts- nnd Parknirtnerei pröft. Dass auch dem Walde ein holurp isthetischer Werth innowohnt, bestreitet wohl niemand, wenn dirsen auch zumeist nur denen zum Bewusstsein kommt, die im 
schattigen Walde Erholung und Ruhe suchen und nur selten das Glück haben, in seiner frischen würzigen Luft geistig und körperlich sich zu stärken. Wen der Beruf in den Wald fülnt, der achtet dergleichen kaum; aber sein verwöhntes Auge wird sich an forstlichen Pflanzen anderer Art als die Einheimischen sind, erfreuen, für welche überdies so viele Punkte im Walde gegeben sind, die einer Verkleidung, einer Verschönerung fähig sind, ohne dass dabei ein fühlbarer Verlust an Bodenfläche entstände. Die Monotonie unserer Kulturwaldungen, z. B. der am wenigsten ästhetischen Werth besitzenden Kiefernwaldungen, fordert heraus zur Durchbrechung durch einzelne verschieden gefärbte, verschieden geformte Individuen; Kreuzungen von Waldschneusen, die Ränder der Strassen und Waldwege, die Pflanzgärten, die Umgebung forstlicher Behausungen sind herrliche Plätze, wo etwas Seltenes Platz finden mag. Wer überhaupt Sinn und Interesse an den forstlichen Kulturgewächsen anderer Länder und Völker hat, wird solche Pflanzen mit Aufmerksamkeit in ihrer Entwickelung verfolgen; das ist schon Zweck genug, um an solchen verlorenen Posten eine beliebige Zahl von „Anbaufähigen" unterzubringen.

Jedoch haben solche Fremdländer auch einen messbaren Werth; nicht blos erweitert sich unsere Kenntniss über die Holzart, ihr Verhalten gegen unser Klima, sondern, im Falle sie erwächst, werden auch ihre Friichte und Samen Werth haben für wissenschaftliche Sammlungen sowohl als direkt für den Verkauf; ich erinnere z. B. daran, dass die Nordamerikaner den Samen ihrer ureigenen Weymouthskiefer, die sie anf verlassenen Feldgründen anbauen, ausschliesslich aus Europa bezichen. Auch das Holz solcher Exemplare, auch wenn es nicht rerkauft werden kann, ist doch werthyoll für Sammlungen, zu wissenschaftlichen Studien, Experimenten u. s. w.; weiters können solche Exoten zu phänologischen Beobachtungen herangezogen werden, lauter Gesichtspunkte, die den vereinzelten Anbau einer grossen Zahl norlamerikanischer Bamurten sehr wohl rechtfertigen mögen.

Die Zahl der Auserwählten unter den Anbaufähigen rermindert sich sehr beträchtlich rom strenge forstlich-finanziellen Gesichtspunkte.

Holzarten, die auf gutem oder schlechtem Boden zu astreineren, vollholzigeren S'chäften, mit grösseren Dimensionen anfwachsen und somit bessere werthrollere sor timente für den Markt liefern wïrden als es die einheimischen Holzarten vermögen, müssten anbauwürdig sein.

Hierin lassen sich die nordamerikanischen Holzarten nicht mit unseren Kulturbäumen in direkten Vergleich bringen; in Nordamerika 
fussen die lü̈chsten, massigsten Exemplare auf dem vorzüglichsten Boden, den sie sich in mehreren Generationen, selbst in Jahrtausenden sebilde乞 und stetig mit Nährstoffen bereichert haben, auf Boden, der bei uns zum allergı̈ssten Theile ron der Landwirthschaft in Besitz genommen wurde; davon abgesehen, sind vollstündig ausgewachsene 300 bis 600 Jahre und darüber alte Repräsentanten unserer Waldflora zum Tergleich mit der nordamerikanischen nur mehr vereinzelt und dann freistchend rorhanden, wo die Astbildung auf Kosten der Schaftmasse und der Hühe ror sich ging. Wo wir dann noch Urwaldbestiinde besitzen, liegen sie nicht im Optimum der betreffenden Holzart, sondern in den entlegeneren kühleren Bergen; doch fehlen nicht Beweise, dass der ursprüngliche europäische Urwald in Höhen- und Massenentwickelung der einzelnen Individuen dem ostamerikanischen Walde gar nicht, dem westamerikanischen aber ziemlich bedeutend nachstand.

Wenn wir die heutigen Waldungen rergleichen, darf es nicht wundern, dass die nordamerikanischen Urwaldbestände unsere einheimischen in Dimensionen ganz beträchtlich überragen, zu uns in ungrünstigeres Klima, in den geringeren, schon öfters auf Holz genützten Borlen gebracht und in der verhältnissmässig kurzen Umtriebszeit bewirthschaftet, diïften die meisten Nordamerikaner unseren einheimischen Holzarten in Holzmasseproduktion kaum mehr überlegen sein; nur den westamcrikanischen Holzarten scheint eine grössere Lebensenergie überhaupt imnezuwohmen, eine grössere Fühigkeit die nöthige Quantität Stoffe zu massiven Volumina dem Boden und der Luft zu entziehen und damit crsterm rascher zu erschöpfen, wo die gebildeten Holzmassen, wie im Kulturwalde, nicht wieder an den Boden zurückgegeben werden; es ist fraglich, ob solche energische Holzarten auf minder guten Böden bei einer auf Nachhaltigkeit der Nutzung eingerichteten Wirthschaft cin grosser Gewinn sind.

Dass die Riesendimensionen der nordamerikanischen Bäume, wie Jer Pinus ponderosa, Lambertiana, Jeffrey i, der Sequoia, Thuja und Pseudotsuga Douglasii, Chamaecyparis, Lawson iana, ausserordentlich zum Anbau reizen, ist verzeihlich; rom ästhetischon Standpunkte miggen sie alle angebaut werden; anf dem allerbesten tiefgrïndigsten Buden, gegen Sturmwind gesichert, mögen sie vielleicht zu Jimrnsioncon erwachsen, die uns in Staunen versetzen; aber im grossen forstlichen Botriebe davon Nutzen ziehen zu wollen, ist eine Chimäre.

Wichtiger ist die Frage nach bescheideneren Holzarten; im vorausgehenden Kapitel habe ich die Ansicht ausgesprochen, dass die 
anspruchslosesten Holzarten der nordamerikanischen Waldtlora unter den ausgewachsenen Bäumen mit geringen Dimensionen zu suchen sind. Es könnten also hier Bäume in Frage kommen, die etwa 20 bis 25 Meter Hühe in ihren besten Leistungen nicht überschreiten und die schon in der Heimat mit mineralisch geringen, wie sandigen Büden zufrieden sind. Unter den Laubhölzern fallen Fraxinus viridis und Carya poreina auf, dass sie ron ihrem Optimum dem frischen, kräftigen Boden der Flussniederungen - hinweg jene im Norden, diese im Süden in die sanften Mulden der Kiefernwaldungen sich eindrängen und dort zu leidlichen Dimensionen - freilich nach langer Zeit erst - heranwachsen; insbesondere wäre die genannte Hickory, die noch den Vortheil eines werthrollen Holzes - wemn auch viel geringer als auf besserem Boden - bietet, nach dieser Richtung hin zu prïfen.

Auf mineralisch geringwerthigen, sandigen Büden, auf denen unsere Kiefer immer grössere Schwierigkeiten der Wiederbestockung. entgegensetzt und endlich nach langem Kampfe gegen Trockniss Insekten und Pilze zu geringwerthigen Dimensionen emporwächst, auf solchen Böden kann, nach meinem Dafürhalten, keine Lawsonia oder Douglasia, keine Gelb- oder Jeffrey's oder Pechkiefer besseres leisten als dic einheimische Kiefer; erst wo unsere Kiefer ein werthvoller Nutzbaum wird, dürften auch die genamnten exotischen Kiefern zu werthvollen Bäumen aufwachsen. Eher empfehlen sich in solchen Oertlichkeiten Holzarten mit sehr viel leichterem Holzprodukte, wie Pinus Strobus oder die bescheidene Pinus Banksiana, die gegen Frost ebenfalls völlig unempfindlich ist; für warme, steinige Hänge wäre vielleicht neben oder an Stelle der Schwarzkiefer die Stechkiefer, Pin us pungens eine gute Füllholzart, auch wenn sie keine grösseren Dimensionen als die österreichisehe Kiefer erreicht und nur Brennholz liefert.

Nach dem Vorkommen und den Erfahrungen in der Heimat ist die Pechkiefer, Pin us rigid a sehr wohl zum Anban auf den Sandböden der Meeresküste, soweit sie nicht mehr beweglich sind, geeignet; Pinus contorta dürfte hierin nicht nachstehen; im Binnentande hat sich erstere auf geringen Sandbürlen in Europa und in Nordamerika als werthlos erwiesen.

Boden, der geringwerthig nicht aus Mangel an mineralischen Nührstoffen, sondern wegen Ueberschuss an Feuchtigkeit ist, Erlenbruch bis Sumpfboden, beherbergt, wie erwähnt, in Nordamerika noch mehrere, wirthschaftlich sehr wichtige Nutzhölzer, die Thuja 
occi dentalis, Chamaecy paris sphaeroidea, Fraxinus sambucifolia, Taxodium distichum, die östlichen Lärchen, Fichten und Tamnen: auch Pinus Strobus,. Tsuga canadensis verirren sich in solche Standorte, olne aber brauchbare Stämme zu entwickeln. Von diesen beiden letzteren abgesehen, erscheinen die übrigen Holzarten schon zur Erhöhung der Vielseitigkeit der Erträge in solchen bei uns nur einseitig ausgenutzten Standorten prüfungswerth; der Werth dieser Holzarten wird noch erhöht dadurch, dass auch ihr Holz, was Qualitït betrifft, dem der Erlen weit überlegen ist; sollte sich bei einer oder der anderen dieser fremden Holzarten die Hoffnung erfüllen, dass sie bei Fenchtigkeitsmengen oder einem Versumpfungs- und Versäuerungsgrade des Bodens, der die einheimischen Erlen bereits ausschliesst, gedeihen kann, so würde die betreffende Holzart, bei der Hïufigkeit und gegenwärtigen Geringwerthigkeit solcher Standorte, geradezu Nutzpflanze ersten Ranges werden.

Auf den nassen Böden im kühlen Nadelwaldgebiete, auf den Hochmooren (Filzen), in denen sich nur eine kümmerliche Vegetation der Spirke (Pinus montana) erhält, dürften sich Versuche mit der Pin us Murrayana empfehlen, die vielleicht in solchen Oertlichkeiten bessere Dimensionen erreicht als unsere einheimischen, die gemeine Kiefer und die Filzkoppe.

Ebenfals einseitig und mit fast werthlosem Holze sind bei uns recente Flussauen besetzt, wie sie durch Verlandung der Flüsse in Folge ron Correctionsarbeiten gewomnen werden; in Nordamerika vertritt die Stelle der Pappeln, Weiden und Erlen, die bei uns zuerst im neugewonnen Lande erscheinen, die Platane, Plat an us occidentalis, die in dieser Hinsicht in den wïrmsten Gegenden Deutschlands, ihres guten, brennkräftigen Holzes wegen, geprüft zu werden sich lohnen dürfte.

Die Anbauwiirdigkeit einer exotischen Holzart kann weiters begriindet werden, wenn sie Frost und Hitze, besonders Spätfrösten besser widerstehen kann als die einheimischen Arten. In 9 unter 10 Fällen ist das Falliren der einheimischen Holzarten durch Spätfrost rinem lichlgriff' in der Wirthschaft zuzuschreiben; entweder hat man rine empfindliche Holzart auf den unrichtigen Standort gebracht, oder man hat durch eine falsche Hiebsführung den Standort ungünstig verändert, ein Frostloch geschaffen. Es scheint, als wenn es $\%$ bedauern wäre, wrnn unter den Exoten eine Inolyart sich fände, die ohne Rücksicht auf die Bohandlung oder besser Misshandlung democh gediehe; in rxtremen Sinne müsste der Aubau ciner soldhen Holzart zu einer 
Verflachung des forstlichen Gewerbes führen, die ein rorheriges waldbauliches Studium für eine spätere Praxis im Walde unnöthig macht. Zur Wiederbestockung bereits rorhandener frostgeführlicher Standorte, zии Neuauffurstung tiefliegender Oedgründe, werden mehrere Exoten sich eignen, so hat die Pinus Strobus, die Weymouthskiefer, cine Frosthärte bewiesen, die ron keiner einheimischen Holzart übertroffen wird; dass diese Thatsache nichts Ueberraschendes an sich trägt, wurde schon früher erürtert: Pin us monticola dürfte ihr hierin nicht nachstehen und die bis in den hohen Norden Amerika's streichenden Pinus Banksiana und Pinus Murrayana sind sicher so unempfindlich gegen Frost als man nur wünschen kann.

Holzarten sind anbauwürdig, wenn sie den Forderungen unseres Ḱlimas und der Wirthschaft genügen und ein besseres, dauerhafteres, elastischeres, schöneres, schwereres oder auch leichteres, dann aber von besonderer Qualität produziren als unsere einheimischen Holzgewächse. Mustern wir die in den deutschen Waldungen anbaufähigen Baumarten nach dieser Richtung hiv, so ist aus der atlantischen Waldflora unter den zahlreichen Quercus (Eichen) keine, welche unsere deutschen Eichen an Holzgüte, technischer wie physikalischer ïbertrifft: Juglans nigra dagegen liefert ein bekanntermassen werthrolles Holzproduckt; Carya alba, porcina, amara und tomentosa erzeugen ein Holz, das an Giute und Vielseitigkeit der. Verwendung von keiner dentschen Holzart erreicht wird; Acer dasycarpum bildet ein Holz, das leichter, weicher und darum geringer werthig, Acer saccharinum ein Holz, das nicht besser zu sein scheint, als das unserer einheimischen Ahormarten; das Holz von Negundo aceroides (Acer Negundo), sowie dessen Varietät (violaceum), die bei uns neuerdings viel cultivirt wird, ist das geringste in Werth und Gewicht unter allen nordamerikanischen Ahornarten.

Fraxinus americana, pubescens, viridis ïbertreffen in ihrem Hol\%e unsere einheimische Esche nicht; dagegen fällt das Holy der Frax i n us sambucifolia auf, das sich in dünne, lange, tangentale Bänder zerreissen lässt, wodureh es zur Korbflechterei tauglich wird. Betula lenta und lutea zeichnet der Besit\% eines gefübten Kermhol\%es ans, das in Schwere und Brennkraft und auch als Nut\%hol\% die Höl\%er sowohl der europäischen als auch der iibrigen nordamerikanischen Birken ïberragt. Ulmus americana, fulva und racemosia kommen in Holzgüte unseren Ulmen nahe; Gymnocladus can adensis besitzt ein sehr dauerhaftes, dunkles Kernhol\%, ron schmalem Splinte bedeckt; da diese Gattung bei uns fehlt; so kamn sio mit einer deutschen 
Holzart nicht dirckt verglichen werden; Castanea americana verhält sich im Holze wie die bei uns kultivirte Art, ebenso Carpinus americana; die Hölzer der Magnoliaarten, der Ostrya virginica, Tilia americana, der Aesculusarten kennzeichnen keine besonderen Vorzüge. Liriodendron tulip ifera soll ein Holz laben, das für gewisse Zwecke, wie \%. B. Wasserleitungsröhren, Pumpbrumnen ron keiner anderen Laubholzart übertroffen wird; das Holz von Prun us serotina übertrifft in Schünheit der Farbe wohl das der einheimischen Arten; Platanus occidentalis hat ein Holz, das sich im Werth unserer Buche nähert; Sassafras officinale liefert ein sehr dauerhaftes Holz; Celtis occidentalis und Morus rubra bereiten Hölzer wie die bei uns zuweilen gepflanzten Verwandten. Unter den vielen nordamerikinischen Weiden ist bis jetzt keine gefunden worden, die nur cntfernt an den Nutzwerth unserer Kulturweiden heranreichte; freilich sind erstere in dieser Beziehung noch nicht genügend geprüft; die P'spulus-Arten, wie heterophylla, monilifera, tremuloides, balsamifera, grandidentata produciren ein ebenso leichtes und weiches, nur einseitig verwendbares Holz wie die einheimischen Arten.

Die nordmexicanischen Laubhölzer, soweit bei uns ihr Gedeihen wahrscheinlich ist, beherbergen keine in diesem Betreffe hervorragende Art.

Die Eichen der pacifischen Flora, Quereus Garryana und Kelloggii äberragen unsere Eichen im Holzwerthe nicht, und die Eschen-, Ahorn-, Birken- und Erlenarten haỉen den unserigen gegenüber im Holze nichts voraus.

Aus der Reihe der Holzarten, welche der südlichen Hälfte des atlantischen Waldes angehören und damit klimatisch ausserhalb Deutschlands liegen, hat sich Robinia Psevdacaeia als werthvoll unter anderen ligrenschaften auch durch sein Holz erwiesen; es verdient Catalpa speciosa wegen des ausserordentlich dauerhaften, sehr schmalsplintigen Holzes geprift жu werden.

An der Spitze der Narlelhïlzer der atlantischen Region steht bei mos in Dentschland P'inus Strobus, freilich nicht in Folge des Holyes; denn dieses ist sehr leicht, weich, wenig dauerhaft, dagegen für viele Verwendungszwecke, für die wir schwereres Holz nehmen müssen, hervorragend branchbar; P'inus rigida, P'itch-Pine-Pflanze, dire Perhliefer hat trotz ihres Namsons kein Hol\%, das unsere Kiefer in irgand cince Hinsidel ühertrifft; ebenso verhalten sich Pinus resinosa, pungens und Banksiana; die ïbrigen, südlicher wohnenden Kieferm wire I'. australis mol robensis, die alle in das unter dem Namen l'ifrh-Pinchol\% bei uns importirte Produlit liefern, kommen fuir 
unser Klima nicht in Frage. Die Fichten, Picea alba und nigra, die Tannen, Abies Fraseri und balsamea haben unseren Fichten und Taunen gegenüber nichts voraus; ebenso ist die ostamerikanische Lärche im Holze nicht besser als die einheimische Lärche; die Tsuga canadensis kommt in ihrem Holze der Tamne nahe, übertrifft sie aber nicht. Dagegen sind die Hölzer der 'T'huja oceidental is, Chamaceypar is sphaeroidea, Juniperus virginiana und Taxodium distichum als hervorragend werthroll und dauerhaft geschätzt, für welche Holzarten die deutsche Waldflora, ron dem einheimischen Wachholder abgesehen, keine Analoga behufs des Vergleichs besitzt. Die reiche Nadelholzflora des Westens enthält ror allen Pseudotsuga Douglasi i, die in ihrem Holze (Schwere, Dauer, Elasticität) unsere Fichten und Tamnen ïbertrifft, das beste Kiefernholz erreicht und dem Holze der Lärche sich nähert; Pinus ponderosa zeigt trot\% ihres Namens (der Name bezicht sich auf den Vergleich mit dem leichten Holze ron Pinus Strobus, der gegenüber auch unsere Kicfer ponderosa ist, wie auch unsere Kiefer im Vergleiche zu Strobus ebenso Pitsch-Pine ist als Pinus rigida) keine Ueberlegenheit in Holygüte, cbenso wenig wie das Hol\% ron Pinus Murrayana; digegen scheint P. Jeffreyi etwas schwereres und dauchafteres Holz, wegen der intensiveren Verkernung, \%u er\%eugen als die europäische: sehr schweres Hol\% hat Pinus contorta; P. Lambertiana und monticola sind wegen ihrer leichten Hölzer aus demselben Grunde beachtenswerth, wie dic nah rerwandte P. Strobus; bei allen erwähnten, westlichen Kiefern ist aber wohl zu bedenken, dass sie eine ausserordentlich breite Splintschichte besitzen, die rasch ron Pilzen missgefürbt wird, wodurch der Werth eines Stammes sich wesentlich verringert.

Unter den Angehörigen der 'T'mnengattung (Abies) und der Fichtengattung (Picea) ist keine, deren Hol\% cinen höheren Werth besässe, als die einheimische Tame oder Fichte; auch das Holz der T'suga-Gattung übertrifft kaum das der Taune; L iboce d r us de e u r re ns besityt ein Hol\%, das dauerhaft und ron den bei uns producirten Hölzern verschieden ist; gleiches gilt von Chamaecylualis Lawsoniana, nutkacusis, Sequoia gigantea und Thuja gigantea: auch die westamerikanische Eibe theilt mit unserer das voriugliche Hol\%, die Langsamwïchsigkeit und schlechte Form des Schaftes: so vor\%üglich endlich das Hol\% der westlichen Lürche. Larrix oecidentalis, auch sein mag, es diirfte das unserer Lärche aus den besten Gebirgslagen nicht wohl übertreffen. Der westliche Wachholder. Juniperus oceidentalis, steht dem unserigen nahe; dagegen treten die alpinen 
Kíefern der Section Balfouria: P. Balfouriana und aristata durch ihn schweres Holz herror.

Im Urwalde hat man selten Gelegenheit, eine Holzart hinsichtlich ihrer Wilcrstandskiaft gegen Sturmwind zu prüfen, da man solten reine Bestände einer einzigen Art trifft; die Standorte mit seichtem Boden, fester Unterlage und flachwurzelnden Holzarten sind so allseitig. ron grossen Taldmassen eingeschlossen, dass a uch dort der Sturm nur solche uralte Individuen zu Boden wirft, deren Standfestigkeit durch krankhafte Teränderung des Holzkörpers in Folge von Pilzparasiten gelitten hat. Griesebach hat wohl unzuverlässige Reiseberichte für scine \%wecko combinirt, wenn er sagt, dass die häufigen Windfälle in den Oregonfursten, wo verschiedene Millionen ausgewachsener 3-400 jälıriger Baumriesen zusammenstehen, ein Beweis sind für die Kur\%lebigkeit der dortigen Baumarten, verbunden mit geringer Widerstandskiaft gegen Strirungen ron Aussen.

Die Douglasia, diese ist zumeist in den Oregonforsten verbreitot, stcht \%. B. in ihrer Bewurzelung zwischen Kicfer und Tanne; ron iln ist zu erwarten, dass sic eine sturmfeste Holzart sein wird; allein auf seichtgründigem Boden crwächst sie mit so flachem Wurzelwrork wie eine Fichte; dort ist sie in dicser Bezichung nicht besser als die Fichte. Im Allgemeinen kann man sagen, dass alle nordamerikanischen Kiefern, alle Fichten, Tannen, Lärchen, Eichen u. s. w. eine zimmlich gleiche Bewurzelung wie die europäischen Verwandten aufWrisen, so dass der Werth diever Exoten, was Widerstand gegen Wind hetrifft, nach don cinheimischen Verwandten beurtheilt werden mag; die Cupressineen gelten als tiefwurgende Holzarten. Unter den-Laubhïl\%ern ist mir nur eine Holzart bekannt geworden, die in Folge ilues lrichtem. spröden Holzes auffallend leicht rom Winde zerfetyt wirl, es ist diess Acer dasycarpum. Ueber die Widerstandskraft der Exuten gegren Sehnere- und Eisbruch bin ich nicht in Stande einige Anhaltepunlitr goben zu kïmnen; es fehlen ja die gleichartigen, jüngeren Bestände sil gut wir uran\%. Dass die Exoten in unserem Walde mehr noch als die einheinischen Waldbäime den Beschädigungen dureh Thicre anseresetyt sind, habe ich schon erwähnt, die Fähigkeit, eine cmpfindlindse Beschärdignmer, wio theilweiser oder gänzlicher Verlust

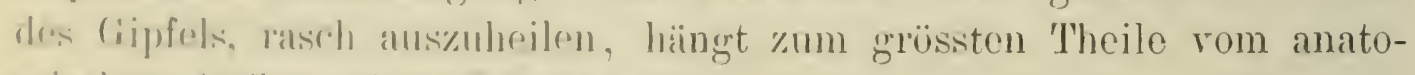
mischen Auflatu cince Pflanze ab)

Broi allan 'Tannen (Abies) sind, wenn die Gipfelknospe im Winter

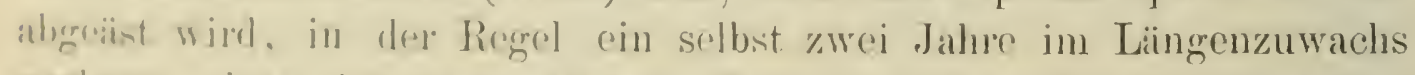

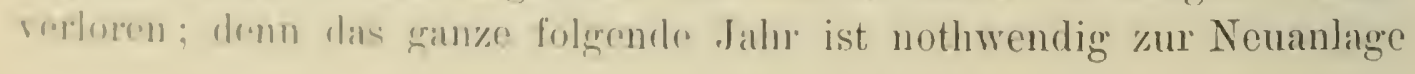


einer Längstriebknospe, da der beschädigte Jahrestrieb entweder bis zur Basis abstirbt, oder keine Seitenknospe trägt, welche sogleich \%u einem neuen Gipfeltriebe auswachsen könnte. Unter den nordamerikanischen Tannen ist keine, die in diesem Punkte einen Vorzug ror unserer Tanne hätte. Auch unsern Kiefern fehlt, wenn die Gipfelmit den benachbarten Quirlknospen zu Grunde gelit, eine Seitenknospe, die sofort die Führung ïbernehmen könnte; die Regel ist, dass ein Seitentrieb sich erhebt und als Gipfeltricb voraneilt; so resultirt bei der Tanne, weniger bei der Kiefer nur zu leicht ein doppelter oder mehrfacher Gipfel. Die nordamerikanische Rothkiefer verhält sich wie unsere Kiefer; dagegen sind die Angehörigen der Section Taeda und Banksia mit Knospen zwischen den Quirlen versehen; Pinus rigida und mitis, auch inops Banksiaua und Murrayana entfalten die der Verwundung zunächst liegende Knospe sofort zu einem neuen Gipfel; sie sind bekannt, insbesonders gilt diess von rigida und mitis, dass sie bis etwa zum zehnten Lebensjahre neu abgeschnitten, zahlreiche Triebe entfalten, von denen einer den übrigen voraneilt; Pinus rigida und mitis überkleiden selbst ältere Stämme und Aeste mit kurzen Trieben aus schlafend gebliebenen Kleinknospen; es dürfte aber auch wenig Kiefern geben, die so sehr einer ausnehmend grossen Heilkraft gegen Verwundungen und Verstümmelungen bedürften, als gerade die rigida.

Die fünfnadeligen Kiefern der Section Strobus verhalten sich wie die Rothkiefern; bis zum fünften Lebensjahre erhebt sich leicht cin Ścitentrieb zum Gipfeltricb, von da an geht die negativ-geotropische Bewegung nur langsam vor sich.

Die Fïhten und insbesonder's die Lärchen haben in der Regel so reichlich Knospen zwischen den Quirlen, dass sie schon im ersten Jahre den Gipfel aus der, der Abbissstelle zunächst liegenden Knospe ersetzen können; bei den Fichten erhebt sich überdiess ein Seitentrieb leicht zum Gipfeltrieb, wodurch zuweilen ein unangenehmes Surplus einer Verheilung, nämlich zwei Gipfel, resultiren; die nordamerikanischen Fichten und Lärchen verhalten sich nicht anders.

Die Douglasia besitzt ebenfalls reichlich Knospen zwischen den Quirlen, ron denen jede die Anlage zu einem Gipfeltriebe in sich trïgt und sich auch sofort hiezu entfaltet, sobald sie durch Entfernung des über ihr liegenden Triebtheiles dazu angeregt wird; in dieser Eigenschaft ist die Douglasia der Tamne weit überlegen und gleicht in Leichtigkeit des Ersatzes des rerloren gegangenen Gipfels durch einen neuen der Lürche. 
Bei den Tsugarten ist der Ersatz des Leittriebes, der durch cin Ueberhängen und durch kräftige Scitensprosse ïberhaupt nicht so ansesesprochen markirt ist, wie bei den rorigen Nadelhölzern, sehr leicht. Chamacynaris Lawsonia, nutkaensis, sphaeroidea, Thuja, Sequoia, Juniperus, Taxodium, Libocedrus ersetzen den rerlorenen Leittriob stets sofort und sehr leicht.

Die Laubhölzer tragen reichlich Seitenknospen, die zu Haupttrieben, sn bald es nöthig wird, auswachsen; selbst solche Laublı̈lzer, die ihre Seitentriebe in Srheinquirlen wie Nadelhölzer aufbauen, tragen zwirchen den Quirlen zahlreiche Knospen, z. B. Cornus macrophylla in Japan, Eriodendron anfractuosum auf Jara, Bombax malabaricum in Indien: solche auffallende Holzarten fehlen der nordamerikanischen und europäischen Waldflora.

Die Tortheile, welehe die nordamerikanischen Holzarten bieten, indem sic weniger den Infectionen durch Pilze ausgesetzt sind, darf man im Allgemeinen nicht hoch anschlagen. Wo alljährlich die Kjefernkulturen durch Schüitte durchłöchert oder gar ummöglich gemacht werden und eine andere Wirthsehaftsmethode nicht Platz greifen kann, da hat sich die fünfnadelige Pinus strobus als werthroll erwiesen, da sie rom der Schuitte der gemeinen Kiefer, soweit sie durch Lophodermium (Hysterium) Pini verursacht wird, verschont bleibt; andere bis jet\%t beobachtete Schüttepilze der Weymouthskiefer, wie Lophodcrmium brachysporum Rostr. und Pestalozzia Hartigii Tubf. haben noch keine merklich schädliche Ausdehnung gewonnen; P. monticola dürfte sich gan\% ebenso wie Strobus in dieser Hinsicht verhalten: hierin haben die zwei- und dreinadeligen Kiefern der unserigen gegeniiber nichts voras: Gelh)- und Pechkiefer leiden augenscheinlich noch mehr als msere Kiefer. Gegen Wurzelparasiten bieten die nordannerikanischen Holzarten liaum Vorzüge; die den Nadelhölzern insbesunders schäidlichen Agaricus melleus und Trametes radiciperda rerschonen die Exoten durchaus nicht; die Weymouthskiefer erliegt denscolhen häuficrore als die cinheimische Kiefer.

(ob gexen Krankleiten des Rindengewebes, hervorgerufen durch Nectria Cronartimn oder Proiza die Exoten sich inmum erweisen werden, i.t nach den ronliegenden Beobachtumgen zweifelhaft. Sicher ist, dass wine Rejhe von Holyerderbern die Exoten, sobald einmal genügend alte Exrmplate rothanden sein werden, ebensu wie die einheimischen

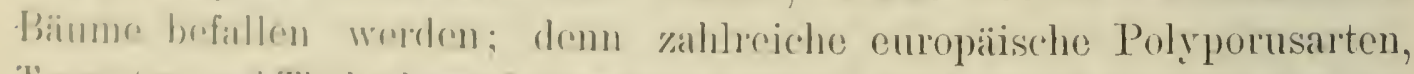
Thanctes und Tholephora finden sich anch im nordamerikanischen Walde; (hensu wird dir Blattkrankheit Rhỵtisma die fremden Ahorne heim- 
suchen, und dass vollends der Keimlingspilz Phytophthora die Saaten der fremden Laub- und Nadelhölzer lichtet und vernichtet, zeigt cin Blick in einen Exoten-Pflanzgarten; Alles in Allem darf in dieser Richtung von den Exoten nicht viel erwartet werden.

Die Weymouthskiefer hat ihre herrorragende Stellung in der Forstkultur nicht zum geringsten Theile der Eigenschaft zu danken, liickig gewordene Kulturen auszufüllen, indem sie rasch ihrer Umgebung nacheilt; besonders in feuchteren, kühleren Standorten macht sich ihr Werth geltend; in wärmeren Lagen mit guten Boden wäre für ähnliche Zwecke vielleicht die Douglasia brauchbar, eine waldbauliche Eigenschaft, die der Anbauwïrdigkeit dieser Holzart ein neues Moment hinzufügt. Die Pechkicfer wurde empfohlen \%ur Erziehung von Waldmäntehn, wozu sie durch ihre Wiederausschlagfühigkeit sich eignen soll; ich glaube, dass derartige Erwartungen sich bei keiner Pinusart erfüllen werden; jene Nadelhölzer, die nach dem Abhiebe Ausschläge wie cin Laubhol\% zeigen, z. B. Sequo ia, Cryptomeria, insbesonders aber Cunninghamia und Ginko gedeihen wohl in wärmeren Tagen Deutschlands (Jahresisotherme ïber 8,50) und wären cher als cine Pinus auf diese Eigenschaft behufs der Nutzbarmachung derselben im forstlichen Betriebe zu prüfen. Ob noch andere Exoten, insbesonder's nordamerikanische, waldbaulich wichtige Eigenschaften besitzen, kann ohne geeignete Versuche liaum festgestellt werden.

Zur Wiederaufforstung cntwaldeter Bergwände, zur Festigung des Geländes in der Hochgebirgsregion, wo zu solchen Zweeken bisher Lärche, Ziurbelkiefer und Krummholzkiefer verwendet wurden, dïrfte es nicht umberechtigt sein, ron Pinus Balfouriana, aristata auch albicaulis und flexilis Vortheile zu erwarten.

Unter den nordamerikanischen Laubhölzern, die bei uns anbaufähig sind, ist nur die Edelkastanie, deren Früchten ein hervorragender Werth zukommt. Da sie augenseheinlich härter gegen Winterkïlte als die europäische Edelkastanie ist, erscheint sie werthroller als diese für den forstlichen Haushalt; die schwarze Wallnuss, die anbaufühigen Hickoryarten haben zwar essbare Frïchte, dagegen ist aber die Schale so hart, dass sie zumeist nur von 'Thieren, besonders Eichhörnchen und Schweinen vertilgt werden. Unter den Nadelhölzern zeichnen sich die Angehörigen der Section Parrya dureh essbare Früchte aus; allein sie gehören der wärmeren Hälfte des Laubwaldes an und müssen erst Versuche darlegen, ob sie bei uns ïberhaupt wachsen; dagegen könnten die heissen, kiesigen Hänge der südalpen und des Appennin zur zweiten Heimat für diese Nusskiefern werden; 
neben Irn Frürhten wäre der Vortheil, den diese zähen, langsamwïlssigen Arten zur Befestignng und Nutzbarmachung des 'Terraines leisten, nicht zu unterschätzen.

Der 'Zuckerahor'n verdient ganz hervorragende Beachtung dureh die beträchtliche Menge werthollen Syrups, den sein Frühlingssaft enthält. Quercus densiflora, Prinos, prinoides und tinctoria sind zwar reich an Tannin, übertreffen aber hierin kaum unsere Eiche. Dagegen ist dic Rinde von Tsuga canadensis und Mertensiana bedeutend gerbstoffi-reicher als jene der europäischnn Nadelhölzer; da die Tsuga's noch wachsen, wo Eiche nicht mehr mit Vortheil auf Gerbstoff genutzt werden kann, erscheinen die genannten Arten werthvoll; die Rinde ler Q uercus tinctoria enthält einen werthvollen gelben Farbstoff; ans Splintwunden der Zuckerkiefer fliesst ein Saft, der nach der Ablunstung eine zuckerreiche, weisse Masse zurücklässt, die als wirksimes Heilmittel gepriesen wird.

Unter den Sträuchem, die den Waldboden bekleiden und werthvolle Vehenprodukte in ilıren Früichten liefern, verdient die nordamerikanische l'reiselbeere, Vace cin ium mac rocarpumh ervorgehoben zu werden, da sir in Standorten - Sphagnum-Sümpfen, Torfmooren — wächst, wo die Holynutyung, wemn überhaupt eine solche möglich ist, zurücktritt.

Die in diesem Kapitel herrorgehobenen Holzarten kennzeichnet irmend cin Tortheil, den sie vor unseren Waldbäumen voraus haben; Woch ist ihre Zahl immer noch zu gross für Versuche im Walde; sic alle anzubauen wäre eine Zersplitterung der Zeit, Arbeit und Geldmittel, die wohl zur Folge hätte, dass schliesslich keine Art cine nennenswerthe Wichtigkeit bei uns erlangen würde.

\section{Anbaupläne und Behandlung der nord- amerikanischen Holzarten als Bäume des deut- schen Waldes.}

'/um Zwerke der Arbeitstheilung nach klimatisch vershiedenen Landschaften und zum \%werke dor Concentrirung der Arbeit innerhalb rince Landschaft habe ich Dentschland in fünf klimatische Zonen yerlegrt. mal für jede cinen Arbeitsplan skizzirt:

a. Unfasst die wärmsten, tiefsten Lagen von Dentschland, die Thäler des lilueins, Untermains, Neckars mit einer mittlesen Jahrestrmperafur iiber $9^{n} \mathrm{C}$. und einer mittleren 'T'emperatur der Haupt-

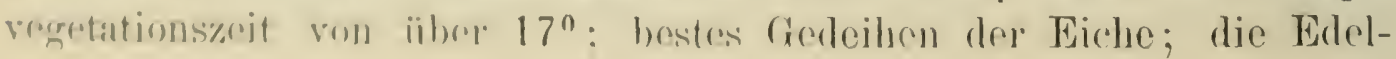


kastanie reift regelmässig ihre Früchte; landwirthschaftlich ist Wein-, Tabak- und Maisbau möglich;

b. umfasst die warmen Lagen mit einer Jahrestemperatur von 8 bis $9^{\circ} \mathrm{C}$. und einer mittleren Temperatur der Hauptvegetationszeit ron 16 bis $17^{\circ}$, bis zu etwa 300 Meter Erhebung über dem Meere; in den Waldungen herrscht die Eiche vor; auf sandigem Boden wird die Eiche durch Kiefern vertreten; Waizenbau überwiegt; auch Hopfenbau;

c. umfasst die Gebiete rom ersten (natülichen) Auftreten der Tanne oder Fichte innerhalb der Laubholzregion bis zum Verschwinden der Stieleiche, somit im Durchschnitt die Lagen zwischen 300 und 600 Meter in Nord- und 700 Meter in Süddentschland, Nordostkiuste: mittlere Jahrestemperatur $6-8^{\circ}$, mittlere Temperatur der Tegetationsmonate 14-16\%. Winterroggen und Gerstenbau;

d. höhere Bergregionen mit Fichten, Tannen und Lärchen bis zum Auftreten der Zürbel- und Krummholzkiefer, von 600 beжw. 700 Meter bis zu etwa 1300 Meter; mittlere Jahrestemperatur von $4-6^{0}$, mittlere Temperatur der Vegetationszeit ron $10-14^{0}$; Sommerroggen, Alpenweiden;

e. Waldgrenzgebiet bis 1600 Meter (Riesengebirge) und etwa 1900 Meter in den Alpen; Jahrestemperatur von $0-4^{0} \mathrm{C}$.; Temperatur der Vegetationszeit $6-10^{\circ} \mathrm{C}$.

\section{Anbauplan fïr a.}

I. An bauklasse:

Juglans nigra,

Carya porcina, alba, tomentosa, Acer saccharinum.

II. Anbauklasse:

Betula lutea und lenta, Juniperus virginiana, Cupressus Lawsoniana, Pseudotsuga Douglasii.
III. Anbauklasse:

Prunus serotina, Catalpa speciosa, Platanus occidentalis, Ulmus americana, Robinia Pseudacacia. Populus balsamifera, monilifera. trichocarpat.

\section{Anbauplan für b.}

I. A nbauklasse:

Acer Saccharinum,

Juglans nigra,

Carya porcina, alba,

Pinus Strobus,

Vaccinium macrocarpum.
II. A nbaluklasse:

Betula lutea und lenta, Fraxinus americana,

Pseudotsuga Douglasii.

Chamaecyparis Lawsoniana. Juniperus virginiana. 
III. A nbauklasse:

Carya porcina,

Fraximus viridis, sambucifolia,

Prumus serotina,

Rubinia Pseudacacia,
Ulmus americana,

Populus monilifera, trichocarpa,

Pinus Banksiana, rigida,

Tsuga canadensis, Mertensiana,

Thuja gigantea, occidentalis,

Picea sitkaensis.

\section{Aubauplan fïr c.}

I. Anbauklasse:

Pinus Strubus,

Vaceinium marecarpum.

11. Anbaulilasse:

Aeer sacellarinum.

Betula lutea und lenta.

Fraxinus americana,

P'scudutsugar Douglasii.
III. Anbauklassc:

Fraxinus sambucifolia, viridis,

Chamaecyparis Lawsoniana, sphaeroidea, nutkaensis,

Thuja gigantea, occidentalis,

Tsuga canadensis,

Pinus Murrayana, rigida, Banksiana.

\section{A ubauplan fï̀ d.}

11. Anbauklasse: Pinus strobus.

Vaccinium macrocarpum.

\section{Anbauplan fïr e.}

III. A n bauklasise: Pinus Murrayana, Balfouriana, aristata, flexilis.

In dire eriste A nbauklasse haben nur solche Holzarten Aufnahme gefunden, deren Aufwachsen zu Nutzbäumen in Deutschland horeits nacherewesen ist und die zugleich einen hervorragenden forstlichen Werth besitzen; letyterer Gesichtspunkt allein entsehied natürlich hrei Varerinium; die Angehörigen dieser Klasse sollen Aufnahme in die uhnodies kleine Sidhar der forstlichen Kulturgewäichse finden und im Grossen angebaut werden.

Mit droll Holzarten der zw citen A nbauklasse sollen grössere Versurhe, etwa alljährlich in geringerer Austehnung auf verschiedenen, inshusmder's den unten genaner angegebenen Standorten angelegt werden, wodureh dew Werth dieser Holzarten als künftig einzu-

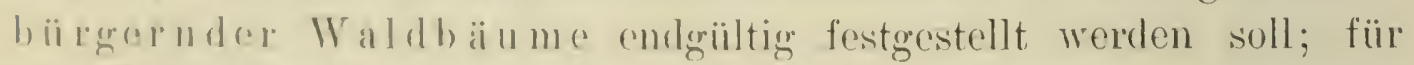
rinr Rrihr. derselben, inshesondere Nadelhölyer, werden noch einige

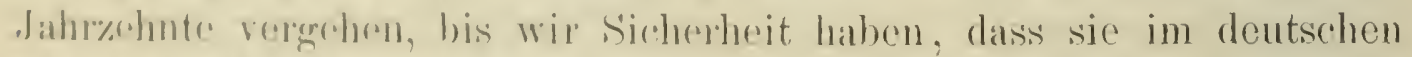
Walde zu Nutzbämmen heranwachsent erst vou da an können einige droselben. wie in coster Linie die Donglasia, in die erste Anbanklasse versitgt werden. 
Die dritte Anbauklasse enthält minder wichtige Holzarten oder solche, die noch nicht näher für die Terhältnisse, für welche sie empfehlenswerth erscheinen, gepröft wurden.

Da die Vorschriften des Tereines der deutschen forstlichen Versuchsanstalten zur Behandlung der nordamerikanischen Holzarten in den ersten Lebensjahren auf die Erfahrungen sich grïnden, die man in Deutschland an den Exoten gesammelt hat, so ist an diesen Normen festzuhalten; als Ergänzung derselben möge das Folgende gelten.

Die Erziehung des Materials geschieht am sichersten in kleinen, sachgemäss angelegten Pflanzgürten mitten im Wralde, worlurch kiinstlicher Schutz gegen Frost und Hitze überflüssig erscheinen; die Pflanzgärten sind wie die in den Wald rerpflanzten Exoten gut gegen Wildfrass zu sichern. Wo Torsichtsmassregeln wie Betheerung, Bekalkung u. a. sich als wirksam an den einheimischen Holzarten erwiesen haben, müge diess auch an den Exoten rorgenommen werden: wo aber die bisherigen Mittel nichts genützt haben, dürfte sich vielleicht ein anderes Verfahren empfehlen, das ich bereits im Jahre 1886 in meinen Reisebriefen aus dem japanischen Walde angegeben habe. Ich glaube. es lat wohl niemand in Deutschland die Wirksamkeit desselben geprüft; die Meisten, die daron Notiz nahmen, haben es wohl für etwas scherzhaftes gehalten; ich kann nicht umhin, hier die Aufmerksamkeit rom Neuen darauf zu lenken. Es werden nämlich in Japan die Pflanzungen der Cryptomeria und Chamaeciparis-Arten gegen das Verbeissen durch Hasen durch Menschenhaare geschützt, indem an alle Pflanzen im Unfange einer Pflanzung in etwa $1 / 2$ Meter Höhe ron Kindern etwas Menschenhaare, wie sie beim Kämmen der Franen sich ergeben, gewickelt werden. Diese Wirrharre haften leicht zwischen den Nadeln der Pflanzen; ebenso könnte an einzeln stehenden Pflanzen leicht der Gipfel wenigstens durch Herumlegen ron etwas Haaren gesichert werden. Diese in der Jägersprache wohl .Terwitterung" genamnte Operation hält die Thiere für einen Winter ron den Pflanzen fern. eine 2 bis 3 malige Wiederholumg bringt wohl die meisten Pflanzen über diese Gefahr hinweg.

In Bezug auf die Erziehung in Pflanzgïrten, sowic der Methode der Auspflanzung und die Oertlichkeiten im Walde gilt als allgremeine Regel: Wo die Gattung der exotischen Holzant in der einheimischen Waldflora vertreten ist, behandle man die fremde Art wie lie einheimische derselben Gattung; die amerikanischen Eichen, Ahorne, Eschen, Ulmen, Birken, Kirschen, Fichten, Tamnen und Lärden lassen sich am sichersten anf diesclhe Wroise cryichen, wie sich diess für die 
rerwandten, cinheimischen Arten bewährt hat; bei der Auspflanzung im Walde gebe man ihnen, wo andere Torschriften nicht bekaunt sind, jene Standorte, die man bei Fehlen der Exoten den betreffenden cinheimischen Verwandten zugetheilt hätte; anch für die weitere Behandlung sind, im Falle nicht Besseres bekannt ist, die Erfahrungen an den inländischen Terwandten zu Grunde zu legen. Die Angehörigen der Sektion Pinaster, Banksia und Taeda lassen sich bei uns am brsten wie die einheimische Kiefer erziehen; ebenso genügen die Erfahrungen, die man mit der Weymouthskiefer gesammelt, zur Auf\%ucht der Kriefern der Sektionen Strobus, Cembra und Balfouria.

Es genïgt somit hier nur für einige in unserer Flora nicht vertretene Gattungen oder für solche Arten, welche ein verschiedenes Verhalten zeigen, einige Bemerkungen ïber Verwendung und Behandlung in Walde hier anzureihen.

Juglans nigra. Seluwarze Wallnuss. Klimatisch kommen dem Optimum der Walhuss in Amerika am nächsten Sïdfrankreich, () ber italien, Südtyrol.

I. Anbauklasse in a; auf dem besten Boden der Flussniederungen in Einzelmischung gepflanzt oder in kleinen Gruppen gesät; rerlangt rolles Licht; seitliche Bedrängung durch andere Laubbäume zur Bekïmpfung der Scitenäste nothwendig; den einheimischen Holzarten gegenïber wohl vorwüchsig.

Il. Anbanklasse in b; Frostgefahr im Frülijahr und Herbst gesteigert; auf dem besten Boden der Flussthäler; in den wärmsten Latgen dre sanften Berghänge, Einzelmischung, soweit vorwüchsig oder Salat wie oben; wo langsamer würhsig, als die einheimischen Laubhïl\%(e); ist as besser den Anbau zu unterlassen.

Carya alba, Weisse Hickory, porcina Sehweinshickory, tomentosa Weichbarige oder Spotthickory. ()ptimum wie bei der Wallnuss. Dagegen sind die Hickory in den ersten 4 bis 5 Jahren langsamwïchsig, so dass sich ein mehrjähriger Vorhau (Siatt) in Lüchordieben empfichlt; anfangs schwache Ueberschirmung mptragend, sind die jungen Pflanzen in solchen Oertlichkeiten gegen Spitfrost gesichert; friihzcitiger Unterbau der so entstehenden Gruppen; Einzelmischung bei der übrigens schwierigen Auspflanzung in Heistern.

I) Se Schweinshickory soll auch auf Kiefernböden I bis III (incl.) Ponitit in den fouchteren Einsenkungen und kleineren frischeren Mulden in der III. Anbanklasse in h versucht werden. 
A cer saccharinum, Zuckerahorn. Das klimatische Optimum dieser Holzart umfasst ron Deutschland die Region a.

I. Anbauklasse für a und b. Einzelmischung oder kleinere Gruppen im Laubwalde; II. Anbauklasse in c, wo die wäimsteen, somnigsten Lagen zu wählen sind; raschwüchsige, Lichtent\%ng vermeidende Holzart.

In $\mathrm{a}, \mathrm{b}$ und $\mathrm{c}$ innerhalb und ausserhalb des Waldes, insbesondere Landstrassen, ist der Zuckerahorn als Schatten- und Zierbaum anzubauen; tiefwurzelnd, daher widerstandsfähig gegen Wind. Für dise Zwecke Erziehung von Heistern in Pflanzgïrten.

Betula lutea Gelbbirke, lenta Hainbirke. Das Optimum dieser Birken füllt mit dem des Z u ckerahorns zusammen.

II. Anbauklasse in a, b, c; in a und b einzeln oder gruppenweise auf Löcherhieben dem Laubwalde beizumengen, auf trockenen, kiesigen oder feuchten Standorten, in welchen unsere einheimischen Laubbaumarten geringen Zuwachs zeigen; in c wären die wärmeren Lagen und ähnliche Standorte wie in a und b zu wählen; beide Birken sind wohl überall in a $b$ und $c$ vorwüchsig; voller Lichtgenus's am besten. (Vide Platane).

Fraxinus americana, Amerikanische Esche, Weissesche. Das Optimum fällt in's mittlere Frankreich, die inneren Thäler Südtyrols, und das mittlere Ungarn.

Diese Esche empfiehlt sich, wo Frostgefahr besteht, also b und a an Oertlichkeiten, wie sie der einheimischen Art zugewiesen werden: Behandlung wie bei der einheimischen Esche.

Fraxinus viridis, Grünesche. Thr Optimum liegt im deutschen Laubwalde.

Aufzucht wie bei unserer Esche; es dürften Versuche dureh Pflanzung anzustellen sein, wie weit sie auf geringerem Sandboden (II. und III. Bonität) zu einem wemn auch niederen, doch in seinem Hol\%e (Kleinnutzholze) werthrollen Baume erwachsen kann; wie bei der Carya porcina wären in b und c die sanften Mulden in den Kiefernbestiunden zı wählen.

Fraxinus sambucifolia, Korb-oder Schwarzesche. Thr Optimum liegt im deutschen La ubwalde.

Aufzucht wie bei unserer Esche; Auspflamzung auf kschenstandorte; ob auch Erlenbruchböden dieser raschw ïchsigen Esche noch zusigen, muss durch Versuche festgestellt werden. 
Castanca americana, Amerikanische Edelkastanie. Optimum im Gebiete der amerikanischen Wallnuss.

Aufzucht wie bei der europäischen Edelkastanie; Anlage von Niederwald oder in Hochwalde zur Holz- und Fruchtgewinnung wie bei der emopäischen Art, jedoch nicht in a sondern in b und vielleicht sngar in den wiamsten Lagen von c; volles Licht am besten.

Prunus serotina, Spätkirsche. Optimum im Gebiete der Wall nuss.

Aufzucht in Pflanzgïrten, leicht auszupflanzen, einzeln oder in klainen Gruppen auf steinigen, mageren Böden in a und den wärmeren Lagen von b; raschwiichsig, volles Licht am besten.

Catalpa speciosa, Westliche Catalpe. Optimum das der Irallnuss, was 'Temperatur betrifft: sie verbreitet sich natürlich nicht in jenes nordamerikanische Laubholzgebiet, das klimatisch dem deutschen Laubwalde am nächsten kommt; durch Anbauversuche ist aber die Anbaufühigkeit in kühleren Gebiete, ähnlich wie für die südlichen (ileditschie und Robinie, in Amerika wenigstens festgestellt worden. Aufzucht in Pflanzgäirten und Auspflanzung mit 1 oder 2 Jahren auf Laubholy-Schirm- oder Löcherschlägen; auch Saat an solchen Oertlichkriten dürfte für diese raschwüchsige Holzart zu versuchen sein; Ëinzolmischung zulässig; seitliche Bedrängung nothwendig; empfindlich regen lirihfrost: erträigt anfangs etwas Ueberschattung; dem Verbrissen dureh Thiere sehr ausgesetzt; nur im Laubwalde von a auf grutem und auch geringerem Borlen.

Platanus vecidentalis. Westliche Platane. Das Optimum liegt als.serhalb Deutschlands in Gebiete der nordamerikanischen II all II 1 ss.

Auspflanzung auf recenten Auen, wie sie durch Flusscorrectionen serwomuen werden: anch solche, die von kurzen Hochwassern alljährlich morh mit rotwas Sind ïberdeckt werden, wïren herauzuzichen; diese Platamo bildet reichliche Wurzelbrut, die zur Anlage neuer Pflanzungen, \% Fischinr'n benutyt werden könnten; wegen Frostgefahr nur für a und die wärmsten Striche von b vielleicht brauchbar; für b und c vienleicht die beiskn Birken verwendbats.

Robinia P'seulacacia, Robinie. Optimum im Gebiete leli amerikanischen Wallnuss.

Fentügend bekannt; soll an ghleichen Oertlichkeiten, wie die Platanre, enre)riuft worlens. 
Ulmus americana, Amerikanische Ulme. Das Optimum liegt im wärmeren, deutschen Laubwalde.

Anzucht wie die europäischen Ulmen; bei dem geringen Werthe dieser Holzart - sie ist nur schellwüchsiger als die einheimischen Arten - empfiehlt sich eine vereinzelte Einsprengung im Laubwalde ron a und den wärmeren Theilen von $b$.

Pinus Strobus, Weymouthskiefer. Optimum in Deutschland in $b$ und c. Aufzucht bekannt; neben der bisherigen Verwendung: Gruppenweise Einmengung auf den sandigen Inseln des Laubwaldes, an Rändern von Sümpfen, schwachen Erhebungen im Erlenbruchboden; Mischwald mit der gemeinen Kiefer, auch Fichte und Tanne; grössere reine Bestände sind zu vermeiden.

I. Anbauklasse in b, e und II. in den wärmeren Lagen von d.

Psendotsuga Douglasii, Douglasia. Das Optimalgebiet dieser werthrollen Holzart umfasst klimatisch die Nordwestküste ron Frankreich, dann Belgien, Holland und Siidengland; die angrenzenden Gebiete wie Irland, Schottland und die unter dem direkten Einflusse der Nordsee und westlichen Ostsee stehenden, deutschen Gebiete kommen dem Optimum nahe. Das Verbreitungsgebiet umfasst klimatisch ganz Deutschland mit Ausnahme der hö̈hsten Bergregionen. Es empfiehlt sich in continentalen Gebieten, ferne rom Optimum, das Verhalten junger Pflanzen zu prüfen, die aus Samen erzogen wurden, der in Mo n tan a gesammelt wurde; sie werden jedenfalls absolut frostunempfindlich (in der Heimat $-35^{\circ}$ zuweilen), dafür aber auch langsamerwüchsig sein; für das dem Optimum zunächst liegende Gebiet, sowie für a und b, vielleicht auch $c$, ist jedoch der Same aus Gegenden westlich rom Cascadengehirge (Washington Terr. und Oregon [Portland]) zu verwenden; die Pflanzen sind sehr raschwuïchsig, aber in Frostlagen empfindlich gegen Spätund Frülffrost, wogegen geeignete Vursichtsmassregehn für die ersten 10 Jahre zu treffen sind; Samen aus Colorado, wie er ron den amerikanischen Händlorn als völlig frosthart für Ostamerika empfohlen wird, ist für uns nicht geeignet; die Pflanzen sind zwar hart, aber auch sehr trïg wüchsig.

Der Douglasiasame liegt in einigen Procenton über; die jungen Pflanzen (unbedeckt, in kleinen I'flanzgiirten im Hochwalde) gedeihen am besten, wenn zweijailhrig verschult und vierjährigg im Wilde verpflinzt; diess hat sich in c bewährt; in h mïgen andere Methoden

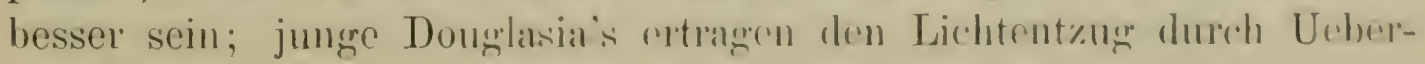


schirmung, gedeihen aber am besten bei freiem Oberlicht; seitlicher Schutz stets gut, bei Frostgefahr nothwendig; enge Pflanzverbände nothwendig zur Erziehung schlanker Stangen und Schäfte; Pflanzungen auf grösseren, kahlen Flächen sind zu vermeiden. Anlage von Gruppen und kleineren reinen Beständen in a an nördlichen und östlichen, in b an allen Expositionen; in c gruppenweise Mischung mit einheimischen Nadelhölzern; auf stabilen Auen gut; auf Auen, die noch der, wenn auch kurzen, Ueberschwemmung unterliegen, nicht brauchbar; auf Kiefernböden I. und II. Bonität bei genügender Frische (besonders an der Küste) und Humusmenge einzeln oder gruppenweise; auf seichtem, kiesigen Boden bei Humusreichthum, im Gebirge, an Bachrändern in engen Thälern vortheilhaft; strenger Boden und solcher mit stagnirendem Wasser ist zu rermeiden; Schutz gegen Wild wünschenswerth.

Es steht zu erwarten, dass die Douglasia, was Holzgüte betrifft, die "Lärche der Ebene und des Tieflandes" wird.

Chamaceyparis Lawsoniana, Lawsonia. Mit dem Klima des Optimums und des Verbreitungsgebietes dieser Holzart in Nordamerika deckt sich in Europa das Klima der Küste von Südwestfrankreich; in Nordamerika betritt der Baum das klimatisch und räumlich nahe liegende Optimalgebiet der Douglasia nicht, wohl aber erwächst letyterer Baum in Gebiete der Lawsonia zu kolossalen Dimensionen. Trotzlem scheint die Lawsonia im grössten Theile des klimatisch so ganz anders gestalteten Deutschland gedeihen zu können; aber nur für die wärmsten Lagen, für a kann ihre Aufzucht in Anbauklasse II riskirt werden; langanhaltende, tiefe Wintertemperaturen b]ciben stets eine grosse Gefahr, gegen die geeignetes Unterbringen ler Pflanzen im Walde, wie sich gezeigt hat, ein theilweise wirksames S'chutzmittel bildet; die Pflanze ist raschwüchsig, frühzcitig guten Samen tragend. Gedeiht am besten bei freiem Oberlichte und Seitenschut\%, crträgrt aber aurch Ueberschirmung; seitliche Bedrängung erwïnscht zum Schutze gregen Wintersonne und zur Erzichung astreinen Matrovials; bei trockenen Lagen sind nördliche, bei frischen auch südliche lxpmsitionen, nach Siiden geöffinete Thäler zu wählen; in b (von dem Kïistengebicte abgesehen) und c wegen gesteigerter Frostogefahr mu' gelogentlicher Anbau (II. Anbauklasse) anzmathen; in der Küsten\%unc ron b und ", aluf Kiefernböden I. und II. Bonität bei guter Humusschichte zusammen mit Douglasia beachtenswerth; auf Boden III. Bonitiit zweifelhaft. In c, in der Bergregion in kleinen Gruppen in den wärustron Strideen dam Nadel-oder Laubwalde beizumengen; 
dabei sind enge Thäler und die Ufer der Bergbäche zu wählen; Schutz gegen Wildverbiss wünschenswerth.

Zur Erziehung des Pflanzmateriales lassen sich auch Stecklinge verwenden, welche nur an schattigen, bodenfrischen Oertlichkeiten zulässig sind; am besten dienen hiezu nach den Erfahrungen in Japan an der nahe verwandten Cham, obtusa, (die bei etwaigem Anbaue genau wie die Lawsonia zu behandeln wäre) $25-30 \mathrm{~cm}$ lange Endtriebe von Seitenzweigen, welche etwas in ihrer Benadelung beschnitten und so abgelängt werden, dass rom zwei Jahre alten Holze noch etwa $3 \mathrm{~cm}$ rerbleiben; die Stecklinge werden in ein durch einen dünnen Stab vorgebildetes Loch $5 \mathrm{~cm}$ tief eingelassen und festgedrückt; an der Jahresgrenze pflegen die neuen Wurzeln zu erscheinen. Besonnung ist stets zu vermeiden; bei mehrtägiger Trockniss ist Bewässerung nöthig. Solche Pflanzen können schon im folgenden Jahre im Walde verwendet werden, wenn nicht die ganze Anlage schon am definitiven Standorte vorgenommen wurde.

Juniperus virginiana, Virginischer Wachholder. Nach dem Klima der Heimat zu urtheilen, fällt zwar ganz Deutschland in das Verbreitungsgebiet des Wachholders, das Optimum liegt aber in Norditalien und Südfrankreich. Es dürften deshalb nur in $a$ und b noch geringe Nutzholzdimensionen $z u$ erwarten sein; in $\mathrm{c}$ wird der virginische Wachholder die Dimensionen des einheimischen kaum mehr übertreffen. Bei der grossen Fähigkeit der Holzart mit den verschiedensten Standorten vorlieb zu nehmen, ist der Anbau zulässig in Eschenstandorten, wie auf steinig-kiesigen Böden, selbst Sandböden bis zu Kiefernböden III. Bonität; doch sollen steinige und sandige Particen nur im luftfeuchten Küsten- oder Gebirgsklima gewählt werden; quelliges 'Terrain, die Nähe der Bäche in der niederen Bergregion sehr passend; die Auspflanzung im Walde hat wohl wegen der raschen Abnalme der anfünglichen Wuchsgeschwindigkeit stets in Gruppen, selbst kleineren, reinen Beständen zu erfolgen; enger Schluss, aber rolle Gipfelfreiheit; vor dem 50. Jahre, wegen breiten Splintes, kaum nutzbar.

Chamaecy aris sphaeroidea, Kugeleypresse. Das Optimum dieser Holzart liegt in gleichen Gebiete mit der Pitch-Pine oder Pechkiefer (vide Pinus rigida); das Verbreitungsgebiet umfasst klimatisch noch die deutsche Nordsecküste.

Aufzucht wie bei der Lawsonia; von dieser Holzart empfehlen sich Versuche in kleineren reinen Bestinden in feuchten Oertlichkeiten ron b und c an der Kü̈ste, welche die gremeine Kiefer nichit mohr 
betritt; in Erlenbruchbüden auch Einzelmischung zulässig, da die Holzart starke Beschattung erträgt. Anfangs langsam, später raschwïchsig.

Chamaecyparis nutkaensis, Nutkacypresse. Das Opti$m u m$ fällt in das $K$ üstengebiet der Ostsee.

Aufzucht wie bei Lawsonia. Es wäre durch Versuche festzustellen, ob vielleicht an der $K$ üste, in $c$, diese Art nicht sicherer und rascherwiichsig ist als die Lawsonia. Weitere Angaben zu machen, bin ich nicht im Stande.

Thuja gigantea, Riesenthuja. Das Optimum deckt sich klimatisch mit dem der Douglasia.

Aufzucht wie bei Lawsonia; Behandlung an der Küste von b und c wie für die Kugeleypresse angegeben; im Binnenlande von b und : in feuchten Oertlichkeiten, Erlen- und Eschenböden, Flussrändern von Bergbïchen in Gruppen zu versuchen; Schatten ertragend; raschwiichsig; enge Pflanzung nothwendig.

Thuja oceidentalis, Gemeiner Lebensbaum. Das Optimum fällt ins Binnenland von De utschland in b. Aufuncht an srhattigen Oertlichkeiten; Verwendung in fenchten Oertlichkeiten, Errenbüilen; bei Anpflanzung auf kahlen Flächen enger Verband und grïsserc Gruppen nothwendig; Versuche sind auf e und d des Binnenlandes aus\%udehnen. Die Holzart erträgt kräftige Beschattung und wäclist langsam; frosthart.

Für ähnliche ungrünstige Standlorte, in denen wegen Uebermass ron Feuchtigknit, wegen Kälte und Vertorfung des Bodens die einheimischen Holzarten ganz felılen oder kümmern, möchte ich

Pinus Murrayana, Murray's-Kiefer, empfehlen. Das Optimum fälut in's Centrum von Deutschland in c. Auf\#urdit wie bei der gemeinen Kiefer; Anlage von reinen Beständen dureh Pflanzung in Hochmooren, wo dic Pinus montana ihr Dasein fristet; in c; und d; völlign frosthart.

Pinus Bäıksiana, Banks' Kiefer. Das Optimum liegt in b, dits Verbreitungsur(t)ict berührt dem Klima nach noch e und tiofore Lagen ron d.

Anf\%urht wie die gremerine Kirfer; Auspflanzung auf die geringwrthigrten, frockmon Sindbüden in b und c, die Küste ansgemommen; välig frosthart. 
P in us pungens, Stechkiefer. Klimatisch liegt das $\mathrm{Op}_{\mathrm{p}}$ timum im Binnenlande von Deutschland in b.

Aufzucht wie bei der gemeinen Kiefer; Versuche auf den geringwerthigsten, kiesig-steinigen, trockenen, heissen Hügelköpfen und Hängen von $a, b$ und $c$.

Pinus rigida, Pechkiefer. Den Klima des Optimums dieser Kiefer dürfte in Europa die nordadriat ische Küste, der Küstenstrich von Venedig bis Pola, bezw. Ancona am nächsten kommen; dem Verbreitungsgebiete im Norden entspricht die Nord- und Ostseeküste b und c. Dort sind Versuche mit der Pechkiefer auf geringem Sandboden rathsam, im Falle unsere einheimische Kiefer nicht wachsen sollte; wo aber diese wächst, wird sie bei uns stets besser sein als Pinus rigida; im Binnenlande nicht zu empfehlen.

Pinus Balfouriana, Balfour's Kiefer, aristata, Fuchsschwanzkiefer und albicalis, weissstämmige Zürbelkiefer, flexilis, Hackenzürbel. Diese aufrecht wachsenden Verteter unscrer Zürbel- und Krummholzkiefer dürften ihre zweite Heimat in Deutschland in d (aristata in c) finden. Sie wachsen langsam, sind frosthart und wären auf ihren Werth zu Wiederbewaldungsund Festigungszwecken im Hochgebirge zu prüfen.

Picea Sitkaensis, Sitkafichte. Ihr Optimum ist die Küste ron Nordwestfrankreich, Südengland, Belgien und Holland; ihr Verbreitungsgebiet streicht an der Ostsee entlang bis tief ins Russische Reich.

Aufzucht in Pflanzgärten und Auspflanzung wie bei der einheimischen Fichte; Versuch an der Küste auf Standorten, von denen die einheimischen Holzarten, insbesonders im Gebiete der Fichte, wegen allzugrosser Bodenfeuchtigkeit zurücktreten.

Tsuga canadensis, die canadische Tsuga und Tsuga Mertensiana, Mertens Tsuga. Die canadische Tsuga bildet reine Bestände von grösserer Ausdehnung in einem Gebiete, das dem Binnenlande ron Deutschland b und c klimatisch am nächsten kommt; die westliche Tsuga, Merten's Tsuga, findet ihr Optimum an denselben Oertlichkeiten wie die Douglasia, geht mit dieser in dem Felsengebirge bis in Klimate, die dem deutschen c und tieferem d entsprechen dürften.

Aufzucht wie bei unserer Tanne; beide schattenertragend; mit freiem Gipfel sehr raschwiichsig; Versuche einzeln oder gruppenweise in Fichten- und Tamnengebiete zur Erzichung werthrolleren Gerbstoff- 
materiales. Beide frosthart; für Mertens Tsuga dürften die Vorsichtsmassregcln, die für die Douglasia empfohlen wurden, anzuwenden sein.

Grösserer Werth als manchen der vorgenannten Holzarten möchte einem kleinen, darniederliegenden Strauche beizulegen sein, dem

Vaccinium macrocarpum, Amerikanische Preiselbeere, Kronsbeere. Diese grossfrüchtige Preiselbeere erstreckt sich in Nordamcrika von der Grenze des Baumwuchses im nördlichen Canada bis ins mittlere Wisconsin, also klimatisch in Deutschland ron e durch d und $c$ bis b. Sie wird in Wisconsin auf ebenen Flächen mit Torfunterlage und sumpfiger Beschaffenheit kultivirt und labei werden die Pflanzungen auf den kalten Mösern so angelegt, dass dieselben zur Nachtzeit, wenn heftiger Frost droht, unter Wasser gesetzt werden können. Es ist mir nicht bekannt, ob in Deutschland in kälteren Lagen Anbanversuche mit der grossfrüchtigen Preiselbeere unternommen wurden, als diess mein Vater, kgl. b. Forstmeister in Grafrath, auf einem ausgedehnten rauhen Moose zwischen Augsburg und München, also etwa 550 Meter über dem Mecre, unternahm.

Schon im Jahre 1882 wurde auf Anregung des grossherzoglich särchsischen Hofgärtners M a urer in Jena eine Fläche von $200 \square$ Meter auf dem Haspelmoore, nachdem dieselbe auf Torf genützt war, mit der Preiselbeere bepflanzt. In dem Berichte, in dem mein Vater die Anpflanzung in grösserer Ausdehmung empfiehlt, heisst es: „die grossfrüichtige Preisselbecre gedieh präichtig, überzog (1883) mit langgestreckten (oft 1,5 Meter langen) I'rieben dicht die ganze Fläche; 1884 (rrgat) sich ein geringer Ertrag; 1885 lieferte diese Fläche bereits 40 Liter, wonach sich der Ertrag pro Hektar auf 2000 Liter stellen wïrdo; nimmt man den Werth unseres gewöhnlichen Preiselbeere aluf dern Markte in München zu 35 is pro Liter als Basis, so gäbe dies einen Eirtrag von 700 Me pro Hektar. Bei dem Umstande, dass dieser kleine Kriechstrauch anf Ländereien gebaut werden kann, welche weder dem Einzcluen noch dem Staate selbst viel nüt\%en - abgetorfte Mösrer - verdient die Kultur der nordamerikanischen Preiselbecre mehr Beachtung, als ihr bisher zugewendet wurde."

Wenn man die grossen fiächen von T'orfmoorböden allenthalben in Deutschland und insbesonders in meiner engsten Heimat, in Oberbayern, sicht, die nach der Abtorfung fast werthlos daliegen, dürfte dis: Kultur der P'reisclbecre, auch wenn später Frnte und Erlös sich betrïchtlich nicdrigre strollen sollten, volkswirthschaftlich und finanziell cin grosser (iowimn sein; dass die grosse Preiselbeere auch bei uns einen Markt wringen wird, darf man annchmen; denn ein ziemlich 
beträchtlicher Theil der alljährlichen Ernte in Wiskonsin wird nach Europa exportirt.

Zur Kulturanlage dürften Stecklinge der Pflanze am besten zu verwenden sein; diese wären in seichte, über dem normalen Wasserstande etwas erhabene Furchen zu legen, wobei der Aushub auf die Südseite zum Schutze gegen die Sonne zu bringen wäre; Standorte, die mehrere Wochen ganz unter Wasser gesetzt werden, sind zu vermeiden.

Zum Schlusse noch einige Worte, um die Abweichungen von dem Arbeitsplane des Vereines der forstlichen Versuchsanstalten zu rechtfertigen:

Pin us rigida steht im Arbeitsplane an erster Stelle; da das unter dem Namen Pitch-Pine zu uns gelangende nordamerikanische Kiefernholz von anderen, südlicheren Kiefern stammt (von Pinus australis und cubensis; ron letzterer in Folge Verwechselung durch die Holzfäller mit ersterer), die bei uns nicht erzogen werden können, das Holz der rigida vielmehr im Werthe unserer Kiefer kaum nahe kommt (Spint $10 \mathrm{~cm}$ breit, astreich); da sie ferner im Binnenlande in Europa wie in Nordamerika sich ungünstiger in Wuchskraft und Wuchsform als unsere Kiefer verhält; da ferner ihre Ausschlagfähigkeit eine Eigenschaft ist, von der im forstlichen Betricbe kaum Gebrauch gemacht werden kann, so habe ich geglaubt, diese Kiefer nur für den Dünensand am Meere empfehlen zu dürfen.

Pinus ponderosa und Jeffreyi haben im forstlichen Betricbe vor unserer Kiefer kaum einen Vorzug; ihre Schönheit und ihre Riesendimensionen, falls letztere sich verwirklichen, werden stets eine hervorragende Zierde unserer Waldungen sein.

Pseudots uga Douglasi i wurde, da ilır Aufwachsen im deutschen Walde zum Nutzbaume noch nicht mit Sicherheit constastirt wurde, der Vorsicht halber in die II. Anbanklasse versetzt.

A eer ealifornieum Torrey und Gray ist nicht ganz korrekt; der Baum heisst Negundo californicum Torrey und Gray. Die rom Arbeitsplane beabsichtigte IIolzart ist eine Varietiit ron Negundo aceroides (Acer Negundo); der wahre Negundo (Acer) californicum ist wohl noch kaum nach Europa gekommen; Professor Meehan in Germantown theilte mir mit, so oft in Deutschland der californische Ahorn verlangt werde, schicke er immer die Varietït violaceum des Acer Negundo - zur Zufriedenheit der Besteller; diese Varietait hat ein so geringwerthiges Hol\% wie die Mutterart selbst. 
Acer saccharinnm habe ich wegen des hohen Werthes dieser Holzart dureh den Syrup, den der Saft enthält, in die erste Anbauklasse rersetzt.

A cer d a s y a rpum wurde wegen seines weichen, leichten Holzes, das geringerwerthiger als das Holz unserer Ahorne ist, nicht empfohlen.

Fraxinus pubescens wird in ihrer Heimat selten über 12 Meter hoch, ihr Holz ist nicht besser als das der einheimischen Esche.

Carya amara steht im Holzwerthe der alba, porcina und tomentosa wesentlich nach; alle drei genannten Arten wurden wegen ihres cminent werthrollen Holzes (Splint und Kern gleich gut!) in die erste Anbauklasse versetzt.

Quercus rubra rerdient wohl kaum eine grössere Beachtung als irgend eine andere nordamerikanische Eiche, da der Vortheil der s.dnellwïchsigkeit durch geringwerthiges Produkt wieder aufgehoben wird.

\title{
XII. Anhang.
}

\section{A natomische Merkmale der Hölzer der nordamerikanischen Coniferen.}

\author{
(Hiezu Tafel IX.)
}

Pseudotsuga: Markstrahlen aus Parenchymzellen mit Tracheiden whe volspringende Verdickungen als Grenzzellen; bei Pinus macrocarpa Intztere mit, bei Pinus Donglasii ohne Spiralverdickung; Längstracheiden mit Spiralen, bei Ps. macrocarpa stets, bei Ps. Donglasii seltener spiralen in ilen letyten Sommerholztracheiden; letzte Tracheiden des summedrolzes mit Hoftïpfeln an den Tangentalwänden; rothbraum grofïrbtes Kermholy; Harzgänge vorhanden.

Tsulfar: Markstralulen aus Parenchymzellen mit glattwandigen 'llarderiden als Grenzyellen; letzte T'racheiden des Sommerholzos mit IJoftïpfoln; Kernhol\% schwach graubraum gefärbt; Harzgänge fehlen.

P’icea: Markstrahlen und letyte Sommerholatracheiden wie T'suga; Kombuly von glejoler fiathe wie Splint; Harzgänge vorhanden.

Jallix: Markstrahlen und Sommerholytracheiden wie Tsuga; Kenmluly rothbraun gefürbt; Harggänge vorhanden.

Ahirs: Markstrahlen durchaus aus Parenchymzellen zusammengeset\%t: Korn- and Splintholz gleichfarbig; Harzgïnge fehlen.

Pinus: Vides Anlaang 2. 
Cupressus, Taxodium, Sequoia, Chamaecyparis, Thuja, Libocedrus, Juniperus: Markstrahlen nur aus Parenchymzellen, Tüpfeln derselben mit dem grösseren Tüpfel der anstossenden Tracheiden einen „Doppeltüpfel“ bildend; mit Tängsparenchym, vorzugsweise im Sommerholz; zahlreiche Hoftüpfel auf den Tangentalwänden des Sommerholzes; Kernholz theils schwach, theils intensiv gefürbt; Holz mit spezifischem Geruche; Harzgänge fehlen; Thuja gigantea zeigt öfters kurze Tracheiden als Grenzzellen der Markstrahlen.

Taxus: Markstrahlen wie Cupressus etc. gebaut; alle Tuängstracheiden mit zahlreichen Spiralen von gleichmässiger Vertheilung innerhalb der Zellen; Kernholz rothbraun gefärbt; Harzgänge fehlen.

Torreya: Markstrahlen wie Cupressus etc. gebaut; Spiralen der Längstracheiden unregelmässig vertheilt, in Gruppen ron 2-4 zusammenliegrend; Kernholz schwach gefärbt; Harzgänge fehlen.

\section{Eintheilung der Kiefern (incl. nicht-amerikanischer) nach nat ürlichen Sectionen.}

(Hiezu Tafel IX.)

Die ursprünglichen Iinné'schen Bezeichnungen Pinus Larix, Pinus A bies sind endlich, älmlich wie Phalaena tortrix dorsana, aus der natuxwissenschaftlichen und auch aus der forstlichen Literatur schon fast ganz rerschwunden; die Trennung der unnatürlichen Linné'schen Gattung Pinus in die auch in dieser Schrift festgehaltenen natürlichen Gattungen Picea, Abies, Larix, Tsuga etc. zwang sich mit der Erweiterumg der Kenntnisse der botanisch so rernachlässigten aber forstlich so eminent wichtigen Coniferen von selbst auf.

Je mehr aber Angehörige der jetzigen Gattung „Pinus", der "Kiefern" bekannt wurden, desto deutlicher zeigte sich, dass auch unter der Gattung Pinus ganz heterogene Formen vereinigt sind; dabei lassen sich nach Anatomie, Biologie und Verbreitung grosse Gruppen erkennen, die wohl nicht als eigene Gattungen, wohl aber als Secti o n en aufgefasst werden können.

Endlicher und seine Nachfolger stellten die Sectionen: Strobus, Cembra, Pinaster, Taeda, Pinca und Pseudostrobus auf; sie legten dabei die Benadelung, Zapfen- und Samenbildung, also wichtige Theile der Anatomic der Pflanzen zu Grunde. G. Engelmann stiess die Endlicher'schen Sectionen um und bildete nur 2 Sectionen: Strobus und Pinaster und zwar auf Grund der Stellung der Harzgänge in den Nadeln, eines einzigen und dabei unwesentlichen Merkmales der Anatomie. Die wichtigen Merkmale benützte Engelmann zur Bildung 
von Unterabtheilungen innerhalb der Sectionen, wodurch sein System nicht vereinfacht, sondern noch complicirter erscheint.

Ich bin wieder zu den natürlichen Sectionen Endlichers'zurückgekehrt, lıabe sie, wie ich glaube, durch Beiziehung der Anatomie des Holzes gefestigt und entsprechend den seit Endlicher (1847) gewonnenen Bereicherungen unserer Kenntnisse auf einstweilen 10 erhöht. Es mag scin, dass die "Sectionen" für botanische Zwecke nicht nothwendig crscheinen; für biologische und forstliche Betrachtungen sind sie jedenfalls fruchtbar.

Pinus, Kernholz hellrothbraun gefärbt, Harzgänge vorhanden.

I. Section Pinaster: zweinadelig, Zapfen von mittlerer Grösse, kegel- bis paraboloidförmig (P. Pinea ausgenommen) aus Quirlknospen; Same ron dem Flügel zangenförmig gefasst; Flügel gross im Verhältniss \%um Samen, let»terer daher flugfähig (ausgenommen P. Pinea); Markstrahlen aus Parenchymzellen und Tracheiden; erstere dünnwandig; 'T'ïpfel der anstossenden Längstracheide gross, schlitzaugenförmig, von der Breite des Lumens der Tracheide; Tracheiden der Markstrahlen mit zackigen Verdickungen; letzte Längstracheiden des Sommerholzes mit spärlichen Hoftïpfeln an den Tangentalwänden; meist auf die nürdlichere oder kïhlere Hälfte des Vorkommens der Kiefern beschräukt; licher dürften folgende Arten zu zählen sein: Pinaster silvestris, Laricio, haleppensis, pyrenaica, Brutia, Pinea, ${ }^{*}$ ) montana, resinosa, densiflora, Thumbergii, sinensis.

II. Section Kh asia: dreinadelig, Zapfen kegelförmig; Same (?); Hol\% ron gleichen anatomischen Bau wie Pinaster; in der südlichen Hälfte heimisch; hicher gehören: Khasia insularis*.

11I. Section Banksia: zweinadelig; Zapfen kegelförmig, klein, meist nicht aus Quirlknospen, sondern aus Knospen am Längstriebe zwischen \%wei Quirlen hervorgehend; **) Same vom Flügel zangenförmig grefasst, aber einc Seite des Samens mehr als die andere vom Flügel bedrekt, Same flugfühig; Markstrahılen des Holzes dünnwandig; 'Tüpfel der korrespondirenden T'racheidenflächo zahlreicher und kleiner als Pinaster; Grenzollen der Markstrahlen Tracheiden mit zackigen Verdickmegen: Letzte Längstracheiden res Sommerbolzes ohne Holztüpfel an drn Tangentalwänden; nördliche und südliche Hälfte heimisch.

*) Die Zutheilung der mit Sternchen versehenen Arten ist zweifelhaft; \%nrreist sind es solche Kicfern, von denen rapfen und Holmproben meiner Sammlung frohlen.

*) Der Tricbtheil (iber dem Kapfen ist wohl als Johannitrieb aufzufassen. 
Hieher gehören : Banksiana, mitis, inops, clausa, glabra, contorta, pungens, tuberculata, Murrayana, muricata, contorta var. Sargentii, Merkusii.

IV. Section Taeda: dreinadelig, Zapfen meist grösser als von Banksia; meist aus Quirlknospen herrorgehend; Same rom Flügel zangenförmig gefasst, flugfähig (ausgenommen Sabiniana); Markstrahlenparenchym bei ostamerikanischen Arten dünn-, bei westamerikanischen dickwandiger; Tüpfelbildung und übriger Bau wie die vorige Section; hieher wären zu zählen: Taeda, australis, cubensis, rigida, serotina, ponderosa, Jeffreyi, Coulteri, insignis, chihuahuana, Engelmanni, Sabiniana, canariensis, patula*, Lawsonii*, Teocote*.

V. Section Pseudostrobus: fünfnadelig, Zapfen mittlere Grösse, kegelig, Same rom Flïgel zangenförmig gehalten, flugfähig (ausgenommen Torreyana); Holz rom anatomischen Baue der Section Banksia auf die südlichere, wïrmere Hälfte beschränkt; hieher dürften zu zählen scin: arizonica, Torreyana, Pseudostrobus, Montezumae, occidentalis, oocarpa, Orizabae*, Wincesteriana*, macrophylla*, leiophylla*, lophosperma*, Lindleyana*, Loudoniana*, apulcensis*, Buonapartea*, Deconiana*, Hartwegii*, filifolia*.

VI. Section Strobus: fünfnadelig, Zapfen lang, hängend, Schuppen dünn, Samenflügel den Samen nur auf einer Seite bedeckend und mit dem Samen fest verwachsen; Same flugfähig; Parenchym der Markstrahlen dünnwandig, bei westamerikanischen Arten etwas dickwandiger; Tüpfel der anstossenden Lüngstracheiden gross, ein bis zwei zusammen, schlitzaugenförmig; Tracheiden der Markstrahlen olme Verdickung, letzte Sommerholztracheiden mit zahlreichen Hoftiipfeln an den Tangentalwänden; nördliche oder kühlere Hälfte. Hieher gehören : Strobus, Lambertiana, monticola, excelsa, Peuce.

VII. Section Cembra: fünfnadelig, Zapfen meist kurz, dickschuppig; Same ohne Flügel, gross; meist im zweiten Jahre keimend; Hol\% wie Section VI; nördliche oder kïltere Hälfte: Cembra, flexilis, reflexa, albicaulis, koraiensis, parviflora, Ayacahuite*.

VIII. Section Parrya: ein-, zwei- und dreinadelig, an der Berührungsfläche weisslich; Zapfen kur\% und dick; Same ohne Flügrel, Bäume III. Grösse der südlichen und wärmeren Hälfte; Holz nach dem Typus von Picea gebaut, nämlich Markstrahlparenchym dickwandig mit zahlreichen kleinen T'üpfoln, Tracheiden der Markstrahlen ohme zackige Verdickungen; zahlreiche Hoftiipfel an den Tangentalwänden der letzten Sommerholztracheiden: Parryana, monophyllil, edulis, usteusperma, Bungeana, Gerardiana, Pinceana*. 
IX. Section Balfouria: fünfnadelig, Zapfen cylindrisch; Same auf ciner Seite mit dem Flügel verwachsen; Same flugfähig; Holz nach dem 'Typus der Scetion Parrya; Bäume II. - III. Grösse der alpinen Region: Balfouria, aristata.

X. Scction Sula: dreinadelig, Zapfen wie Section Taeda, Same mit dem Flügel auf einer Seite rerwachsen; Markstrahlen des Holzes dickwandig mit zahlreichen, grossen Tüpfehn; Tracheiden der Markstrahlen dickwandig, ohne rackig vorspringende Verdickungen; im Summerholze fehlen die Hoftiipfel auf den Tangentalwänden der letzten längstracheiden; anf die sïdliche Hälfte beschränkt: longifolia (nepalensischer Name der Kiefer Sula).

\section{Tabelle zur Bestimmung der wichtigeren Cupressineen (im engeren Sinne) nach Seitenzweigen und Zapfen.*)}

(Hiezu Tafel VI.)

C'llamaccyparis Law soniana: Zapfen (offen) $9: 9 \mathrm{~mm}$, Nadeln (Nadelschuppe) spitz, weich; auf der Unterseite der Seitenzweige, auf der Grenze von zwei Nadeln eine weisse Linie; an Lüngstrieben zwei Nadeln auf gleicher Höhe; Leittricb zart, überhängend.

. Sphacroidea: '/apfen 6:6 mm; Nadelschuppe spitz, am klcinsten ron allen Cham.; Unterseite und Oberseite der '/weige gleich; Leittrich aufrecht.

nutkacnsis: Zapfen 8: $8 \mathrm{~mm}(?)$; Nadehn spitz, kräftig, auf ther Unterseite der Zweige heller als auf der Oberseite; ‘n Lüngstricben drei Naden anf gleicher Höhe; Leittrieb alufrecht.

uhtusa: Zaipfen 10: $10 \mathrm{~mm}$; Nadeln stumpf; auf der Unterseite der Z/weige die Berïhrungskanten von zwei Nadeln reinwoiss; Leittrieb iiberhängend.

pis ifera: T/apfen $7: 7 \mathrm{~mm}$; Nadehn spitz auf der Unterseite der Zweigre jede mit einem weissichen, ovalen Fleeken; Leittrieb) überhäingend.

Thujopsis dulabrata: Zappen 12: $17 \mathrm{~mm}$ (Breite), Schilder des Zilpforls mit grokrimmter Apopleyse; Nadeln gross mit kurzer,

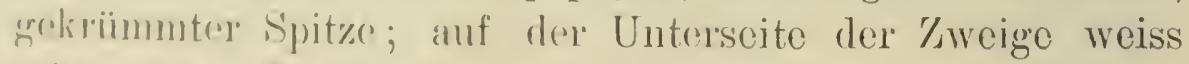
mit griunom Rande. Trittricb aufrechlt.

") Die Vaufen lable ich init Ausnalime der Cham. nutkaensis von wild(rwaljwenden Fxemplaren gepllitckt; an kultivirten Fixemplaren zeigt sich wie bei allen Nadelholmorn cin hetriachtlich grösserer Kapfen. 
Thuja oceidentalis: Zapfen 10:10 nm; Nadeln stumpf, beiderseits am Triebe gleich gefärbt. Nadeln der Längstriebe am Zwcige mit einer glänzenden, erhabenen Oeldrüse; Leittrieb aufrecht.

. gigantea: Zapfon 9:12 mm (Lünge), einzelne Schuppen des Zapfens krïftig, löffelartig; Nadeln stmmpf, auf der Unterseite der Triebe etwas heller; Oeldruise undeutlich, Leittrieb aufrecht.

" japonica: Zapfen 10:10 mm; einzelne Zapfenschuppen sehr dünn, schmal, wenig gewölbt; Nadeln von gigantea nicht zu unterscheiden; Leittrieb aufrecht.

Libocedrus decurrens: Zapfen 2,5 cm lang, an der Basis $1 \mathrm{~cm}$ dick, meist nur aus drei grossen Schuppen bestehend; Same mit grossem Fiügel, oft durch Terwachsung mit dem des benachbarten, verkïmmerten Samens rergrüssert; Nadeln spit\%, stechend; vier Nadeln auf gleicher Höhe stehend; Leittrieb aufrecht.

Biota orientalis: Zapfen $1,5: 1,5 \mathrm{~cm}$ mit hakenförmig gekrümmtem Mittelfortsatz an den Zapfenschuppen; Same ohne Flügel, dem Fichtensamen ähnlich; Nadeln stumpf, an der Rückenseite mit einer Lüngsrinne; an Leittrieben Nadeln spitzer, zwei auf gleicher Höhe; Leittrieb aufrecht.

\section{Tabelle zur Bestimmung der nordamerikanischen Kiefern nach ihren Sämereien*).}

(Hiezu Tafeln VII und VIII. Der Grösse nach georlnet.)

Pinus Torreyana; Flügel liurz, zangenförmig den Samen haltend; Zangen dick und breit; Flügel braun glänzend, undurchsichtig; Same auf einer Seite matt rothbram, etwas ungleichfarbig, andere Seite schwarz, glinzende Fleckchen auf mattem, hellem Grunde; Ansatzstelle der Zange hell, fleckenlos.

"Sabiniana*; Flügel liurz; zangenförmig den Samen haltend; Zangen dick und breit; Same auf einer Seite schwar\%, nach dem Flügcl hin braun und heller, schwach glänzend; die schwar\%e Schichte sich dïnn abblïtternd; darunter liegende Schicht hell ockerfarbig; an den Seiten des Samens zwei erhabene I,eisten. " monophylla*; ohne Flügel; eine Seite dunkle Tüipfel auf hellerem Grunde, andere Scite ganz dunkel.

*) Sämmtliche Sämereien wurden, behufs Anfertigung der Zeichnumg frisch dem Zapfen entnommen; die mit * verschenen habe ich nicht sellsit gesammolt. 
P in us Lambertiana: Flügel gross, sehr dünn, etwas glänzend, undurchsichtig;, gleichmässig chocoladebraun ohne Längsstreifen ; Flïgel an der Samenansatzstelle nicht verdickt, mit einer Seite des Samens fest verwachsen, so dass am Samen Stücke des dümnen Flügels hängen bleiben; eine Seite des Samens (der angewachsene Flügel) schwach glänzend braun mit dunkelm Rande; andere Seite mattgrau mit schwarzen Zackenlinien.

Coulteri; Flügel gross, undurehsichtig; zangenförmig den Samen haltend; an der Ansatzstelle verdickt; Same auf einer Seite matt schwarzbraun mit hellerer Spitze, andere Seite chocoladefarbig braun glänzend wie der Flïgel; Ansatzstelle des Flïgels als heller breiter Saum erkennbar.

Parryana*; Same flügellos, gleichmässig dunkel rothbraun, schwach glänzend, ohne Tüpfel.

Jeffreyi; Flügel gross, hell, an der Spitze etwas dunkler, durchsichtig, den Samen zangenförmig haltend; eine Seite des Samens braun, nach unten hin schwarzbraun, schwach glänzend; andere Seite hellockerfarbig mit schwarzen Flecken; Same schwach gekrümmt.

edulis; Same ohne Flügel, mattbraun oder schwach fleckig; der grössere Same aus Colorado.

a ustralis; Flügel gross, chocoladebraum, glünzend, undurchsichtig, quer wellig, sehr fest den Samen zangenförmig haltend; eine Seite des Samens ockerfarbig, matt, mit cinzelnen kurzen, schwachon Strichen; andere Seite zurḦ̈̈lfte rom Flügel bedeckt mit braunen Streifen auf hellem Grunde: Same mit Längsrippen. leflexa*; Same ohne Flügrel, nine Seite matt chocoladebraun; andere Seite schwach glänzend, mit sehr feinen schwarzen Strichen; Same verschieden gestaltet, an der Spitze schncidig. flexilis*: Same ohme Flïgel, Same beiderseits marmorirt.

albicaulis*; Same ohne Fligel, mattbraun, hell, mit dunkelm Riunde.

ponderosa; Flügel durchsichtig hell, den Samen zangenförmig laltrond; Same ctwas gekrïmmt; cine Seite dınkel mit schwarzen und hraumen lifecken, andere Seite dunkel, matt.

insignis; Fiügol braun, mudurchsichtign, zangenförmig den Samen haltronl; Same matt dunkelgrau mit schwaryen Vertiofungen, diulurch von eubensis unterschieden.

monficolat Flügel sehr dium, glänzend, hell, durchsichtig uwas riithlich, mit ciner Seite des Simmens fest verwachsen; 
Same meist am Oberrande mit Resten des dünnen Flügels, hellockerfarbig mit braunen Flecken, glänzend auf einer (Flügel-) Seite, auf der anderen matt.

Pinus e ubensis; Flügel undurchsichtig, zangenförmig den Samen haltend; eine Seite des Samens mattgrau bis schwarz mit erhabenen, schwarzen Fleckchen, andere Seite ebenso, aber Fleckchen und Striche spärlicher.

" Taeda; Flügel gross, fast undurchsichtig mit dunkler Spitze, zangenförmig den Samen haltend; Samenkorn gekrümmt, eine Seite schwarz mit Lüngsrippen; andere Seite dunkelgrau mit schwarzen, grubigen Vertiefungen, unterer Rand des Samens mit scharfer Kante.

" tub e r culata, Flügel durchsichtig mit braunen Längsstreifen an der Basis, zangenförmig den Samen haltend; eine Seite des Samens mit Längsrippen, gleichmässig dunkel eisengrau, schwach glänzend; andere Seite heller, ohne Rippen mit schwarzen Tupfen; oberer Rand oft ein oder zwei Zähnchen.

" Balfouriana; Flügel crèmefarbig, hell, sehr dünn, durchsichtig, schwach querwellig; Same beiderseits crèmefarbig, schwach glänzend, mit braunen Flecken, Flügel auf einer Seite mit dem Samen fest verwachsen wie monticola.

" p ungens; Flügel durchsichtig, in eine Zange endigend; Same dunkelgrau, matt, mit tiefschwarzen Punkten und Strichen; am oberen Rande mit feinen scharfen, schwarzen Spitzchen. Strobus; Flügel hell, an der Spitze dunkel, durchsichtig, mit einer Seite des Samens rerwachsen; diese Seite des Samens glänzend braun mit kaum duxchscheinenden dunklen Flecken; andere Seite hellbraun, schwach glänzend mit kleinen, schwarzen Flecken und Strichen.

muricata; Flügel an der Basis verdickt, zangenförmig; Same auf einer Seite bleigrau mit einzelnen erhabenen schwaren Tupfen, ohne Längsrippen, andere Seite mit Längsrippen grau und grösseren schwarzen Tupfen. arizonica; Flügel durchsichtig, in eine Zange endigend; Same dunkel ockerfarbig grundirt mit schwarzen 'Tupfen; beiderseits gleich. chihuahuan a; Flügel durehsichtig, hell: Sime wie bei der Fichte in einer löffelartigen Vertiefung des Flïgrels liegend, nicht mit demselben rerwachsen; eine Seite schwach grerippt mit dunkelgrauen lilecken anf hellerem Grunde; gegren die 
Basis hin dunkler; andere Seite hell rothgrau mit dunkeln erhabenen Flecken.

Pinus mitis; Flügel durchsichtig, den Samen zangenförmig laaltend; Same mattgrau mit vielen, schwarzen, etwas glänzenden, erhabenen Wärzchen; Samenrand warzig.

. aristata*; Flügel sehr dünn, hell, durchsichtig, mit dem Samen verwachsen wie monticola; Same beiderseits matt; eine Seite hell-ockerfarbig ohne Flecken, andere Seite mit etwas dunklerem Grunde und braunen Fleckchen.

. Engelmanni; Flügel fast undurchsichtig, den Samen zangenförmig haltend; eine Seite des Samens hellbraun mit schwarzen Punkten; andere Seite etwas heller, glatt ohne Punkte.

" contorta var. Sargentii*; Flügel durchsichtig; Same in einer löffelartigen Vertiefung des Flügels; nur an der Basis die Verticfung einen kleinen Ausschnitt; Same, eine Seite hell-ockerfarbig mit Längsrippen und braunen Flecken; andere Seite soweit rom Flügel bedeckt hell-ockerfarbig mit bramen T'upfen, freie Partic an der Basis des Samens matt braun.

" glabra; Flügel kaum durchsichtig, den Samen zangenförmig haltend; Same hell-ockerfarbig grundirt mit zahlreichen braunen Strichen, andere Seite etwas dunkler.

. serotina; Flügel durchsichtig, zangenförmig endigend, etwas röthlich; Same schwarz, feingrubig; oberer Rand mit einigen Zï̈hnen.

" resinosa; Flügel hell, durchsichtig, den Samen zangenförmig haltend; cine Seite schwach glänzend, gleichmässig olivenbrann, andere Seite matt an der Basis; Ansatzstelle des Flügels dureh einen schwarzen Rand an Samen markirt.

. Banksialia; Sime in einer löffelartigen Ausbuchtung des Flïgels wie bei Chihuahuana; Flïgel durchsichtig; Same dunkelgran mit schwarzen erhabenen Flecken orler Lüngsleisten. (a) a 1 sa; Flügel fast molurchsichtig, den Samen zangenförmig haltend; Same dunkelgrau und matt; Oberfläche rauh; andere Sojte gleichmässig grau, etwas glänzend, mit Längsrippen; oberer Rand mit einem Spitzchen.

in ops; Flügel durchsichtig, ohne braune Lüngsstreifen; Same in ciner liffolutigen Vertiefung des Flügels, welche cine Liingsspalte besitzt; die eine (vom Jingel bedeckte Seite) schwal mit einzelnen branen Gihabonheiten; dic freie Seite bleigran mit Rippen und bramen kumen Spitzchen. 
Pinus contorta; Fliigel fein, durehsichtig, den Samen auf einer Seite bis auf einen Spalt bedeckend; eine Seite des Samens gerippt, gleichmëssig gefürbt, matt chocoladebraun; andere Seite olne Rippen, aber ebenso gefürbt; seltener sind hellere Kürner mit feinen braunen Tüpfeln.

" rigida; Flügel durchsichtig, den Samen zangenförmig festhaltend; Same beiderseits bleigrau mit schwarzen erhabenen Tupfen; einzelne Körner auch mit Längsrippen und dunkelockerfarbig.

" Ml urrayana; Flügel durchsichtig, den Samen wie ein Löffel haltend; der Lüffel mit einer ausgezackten Lüngsspalte; Same schwarz mit Lüngsrippen; oberer Rand mit einem feinen Spitzchen.

(Pinus osteosperma*, die 38. Kiefer der Tereinigten Staaten mit flügellosem Samen, habe ich weder selbst gesammelt, noch auch ron dem Arboretum in Brookline erlangen können.

\section{j. Verzeichniss der an nordamerikanischen Waldbäumen im Spätherbste 1885 und 1887 beobachteten pflanzlichen Parasiten.}

(Hiezu Tafel X.)

\section{a) Phanerogame Parasiten.}

Cuscuta Gronorii auf jungen Liriodendron tulipifera-Pflanzen; Viscum sp.? an Quereus lobata;

Arecuthobium Douglasii Englm. auf Psendotsuga, Douglasii und Larix uccidentalis;

" robustum Englm. an Pinus ponderosa;
$" \quad$ oceidentale Englm. an Pinus ponderosa;
$" \quad$ americanum Nutt an Pinus Murrayana;
" pusillum Peck an Picea nigra und alba;
" Libocedri n. sp. (?) an Libocedrus decurens;

\section{b) Cryptogame Parasiten.}

Puccinidia abietis n. g. et 11 . sp. an Abies concolor;

Gymnosporangrum Libocedri n. sp. (?) an Libocedrus decurrens; IL elampsora salicina*) Lío an Weiden;

*) Die mit * verselenen Pil\%e fand ich anch in . a pan im .Tahre 18s; an Hnl\%gewiiehsen wieler. 


\section{$-434-$}

Chrysomyxa Libocedri n. sp. an Libocedrus decurrens; Roestelia lacerata Sow. an Crataegusarten in Zusammenhang mit Grmmosporangium macrocarpum an Juniperus virginiana. Aecidium sp.? an Fraxinusblättern und Trieben;

" elatinum* Alb. et Schw. (?) an Abies balsamea und Abies concolor.

Aecidium deformans n. sp. an Pinus mitis; Thelephora Perdix* R. Hrtg. an Quercus falcata; Trametes Pini* Fr. an Pinus Strobus, Pinus Murrayana, Picea Sitkaensis, Larix occidentalis, Pseudotsuga Douglasii;

Polyporus igniarius* Fr. an Pyrus und Prunusarten; " sulphureus* Fr. an Quercus und Juglans nigra;

$"$ betulinus* Fr. an Betulaarten;

" applanatus an Acerarten;

" hispidus an Pseudotsuga Douglasii;

" marginatus an Quercusarten;

Daedalia vorax an Libocedrus decurrens;

Agaricus melleus* an Laubholzstöcken;

Exoascus Quercus lobatae n. sp. (?) an Quercus lobata; Sclerotium irritans n. sp. an Chamaecyparis sphaeroidea; Rhytisma acerinum* Fr. an Ahornarten;

"punctiforme* n. sp. an Acer macrophyllum;

$"$ salicinum* Fr. an Weidenarten;

Lophodermium (Hysterium) baculiferum n sp. an Pinus ponderosa, resinosa und Laricio;

$" \quad($ () abietis roncoloris n. sp. an Abies concolor;

" (.) infectans n. sp. an Abies concolor;

Sphacria (Plowrightia) morbosa Schw. an Prunusarten;

Dothidea botulina n. sp. (?) an Birkenarten;

Ceratostoma piliferum* an Splinthol\% gefällter Nadelholzbäume;

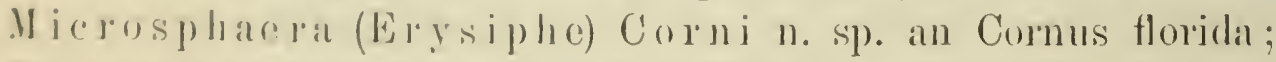

Trichosphatera parasitica R. Hrton an Abies Fraseri;

Nontra roinnabarina* an Ahornarten;

finsialadium spe? an dbies Fraseri;

Hysteriopsis acicola n. gr. et n. sp. an Picea sitkaensis;

(Nahere Beschreilung der Pile und ihrer linwirkung anf die Wirthsfollitryen müge im Texte bei den letzteren nachgesehen werden.) 


\section{Angabe einiger Firmen zum Bezuge von nordamerika. nischen Waldsämereien.}

Jede Art von gewünschten Sämereien, in jeder Menge und mit Garantic der Güte und Provenienz dürften allein von

\section{Robert Douglas \& Sons, Waukegan, Jllinois}

zu erhalten sein. Zur Orientirung über die Preisverhältnisse gebe ich einige Angaben aus der Preisliste pro Frühjahr 1887 wieder:

Pinus Strobus (aus Europa bezogen) per Kilo

Juniperus virginiana . . . . , ,

Thuja occidentalis . . . . . ", ",

Pseudotsuga Douglasii var. glauca ", ", (von Colorado)

Acer saccharinum . . . . . , ,

Betula lenta . . . . . . ", ,

Fraxinus alba (americana) . . . , , ,

Fraxinus viridis . . . . . , ,

Prunus serotina. . . . . ", ,

Catalpa speciosa . . . . . , ,

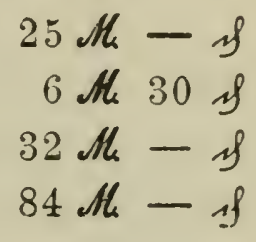

12 M. 60 is

25 Mh - is

12 Nh 60 is

12 Mh 60 is

12 Mh 60 if

33 Ah 60 is

Eine zweite sehr verlässige Firma ist

Thomas Meehan \& Son, Germantown near Philadelphia, Penn.

Unter anderen kann insbesonders Same der Pinus rigida (aus dem nahen Hammonton an der Küuste von New Yersey) von dieser Firma bezogen werden.

Die folgenden Firmen können nur durch Vermittelung der beiden ersten Firmen zur Samenlieferung benütat werden.

A. E. Walker, Florist \& Lardscape-Gardener in Brainerd, Minn. hat sich erboten zur Einsammlung von Pinus resinosa- (Red Pine-) und Pinus Banksiana- (Black- oder Spruce-Pine-) Samen, ron welchen beilen Holzarten von den niedrigen Gruppen und isolirten Bäimen jegliches Quantum Samen erhalten worden kann.

J. R. Coburn, RR. Hotel proprietor, Meacham Oregon (Bloue Mountains) hat sich erboten, von P. Murrayana (Black-P'ine) Simen liefern zu können.

A. E. Pfund Florist, Washingtonstreet Portland, Oregon liefert Samen der Pseudotsugra Doughasii (Rorl fir) rou der Küistenregrion. 
G. B. Hartmann, Dealer in vegetables, fruits and country products, Missoula, Montana; zum Bezuge der harten Form der Pseudotsuga Douglasii (Red fir); bei Missoula ist die Douglasia in zahlreichen niederen Randbäumen und isolirt rorhanden; die Bäume tragen alljährlich reichlich Samen; Firmeninhaber wahrscheinlich weggezogen und Same durch andere Vermittelung ron dorther zu beziehen.

P. Johnson Marshfield, Oregon, hat zugesagt, bei grösseren Bestellungen Samen von Chamaecyparis Lawsoniana (White Cedar) zu liefern.

\section{Corrigenda.}

a. Die Eigenthümlichkeit der nordamerikanischen Florenwerke, alle Länder- und Städtenamen, auch wenn sie in lateinischer Adjektivform gebraucht sind, gross zu schreiben z. B.: Americanus, Pennșyvanicus, Sitkaensis hat mich mehrmals verführt, unbewusst von der bei uns adoptirten Schreibweise americanus etc. abzuweichen; vielleicht wäre es consequenter, da wir ohnediess schon Lambertiana, Banksiana schreiben, der amerikanischen Methode zu folgen.

b. Pinus monticola wurde im Texte zur klimatischen Zone des nördlichen Laubwaldes gezogen; ihrem Optimum nach dürfte sie wohl zu d, der kühlen Region der Fichten und Tannen zu zählen sein.

c. Pinus albicaulis wurde im Texte als zur Section "Balfouria" gehörig bezeichnet; albicaulis, die ich selbst nicht gesehen habe, ist wohl eine Cembra.

d. Der Sectionsname für eine Kieferngruppe, Banksia, ist insoferne nicht recht geeignet, als eine Gattung Banksia bereits unter den Proteaccen existirt; vielleicht wäre „MLurraya" besser.

e. Chamaecyparis nutkaensis, die ich selbst wegen ihrer Soltenheit südlich von V ancouver nicht sah, gehört zur kühlen Region d, nicht zum obersten Rande des Laubwaldes e.

f. Druckfehler :

Seite 20 liemerkung am Fusse lies „Report" statt "Raport".

Scite 40 \%eile 9 und 24 lies "Hickory" statt "Hikory“.

Seite 109) Iennerkung lies "Lowes South States" statt "Cowes".

Sirite $150 \%$ \%rile 15 lies "Water oak" statt nWalter oak".

Seite 19:" Zcile 6 von unten lies "Tafel VI" statt "Tafel VII“.

Seite 235) Zeile 9 lies "T'afel V" statt "Tafel VI".

'Taf. VI lies "Cham. sphaeroidea" statt "Cham. sphaervidea".

'Jaf. VIII lies nMmrilyana var. Sargentii“ statt "contorta var. Sargentii"

"Taf. X lies "Tranches I'inj" statt "Tramentes Pini".

litwaige andere iibersohene Druckfehler wollen durch die weite lintfermung dres Voufassers rom Druckorte antschuldigt werden, welche

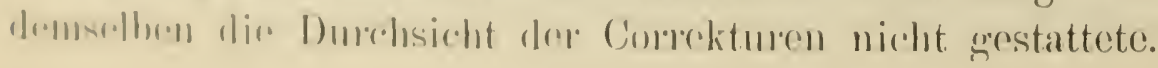




\section{Reg i s ter.}

Seite

A bies amabilis Forb.

- balsamea Mill. (Fig. 6)

220

337

- bracteata Nutt. (Taf. IX)

- concolor Lindl. et Gord.

- Fraseri Lindl.

- grandis Lindl.

- magnifica Murr.

- nobilis Lindl.

- subalpina Engelm. .

Abweichungen rom Arbeitsplane d.

forstl. Versuchsanstalten . 423-424

Acer californicum Diet. . . 166284

- circinatum Pursh (Taf. IV, V) 284

- dasycarpum Ehr. (Taf. III, IV) 165

- glabrum Torr.

285

- grandidentatum Nutt. (Taf. V) . 289

- macroplyyllum Pursh (Tf.IV, V) 283

- Negundo L. (Taf. IV unter Negundo aceroides)

— rubrum L. (Taf. IIJ, IV) . . 165

- saccharinum. Wangh. (Taf. III, IV)

- spicatum Lam.

- striatum Du Roi

Acerineen

Aecidium deformans Mayr an Pinus mitis (Taf. X)

- elatinum? an Picea alba

- - an Abies balsamea und concolor .

- giganteum Mayr an Pinus densi. flora und Pinus Thunbergii .

- spec. an lischen . . . . .

- spec. an Larix americana Michx. Aesculus californical Nutt. . . .

- flava Ait. . . . . . . . 183

- glabra Willd.
Agaricus melleus . . . . . 211 Ahorn :

Achrenblütiger Ahorn . . 166

Eschenahorn, calıfornischer . 284

Eschenahorn, östlicher . 165

Gestreifter Ahorn . . . 166

Grossblätteriger Ahorn . . 283

Rother Ahorn . . . . . 165

Weinahorn . . . . 284

Weisser Ahorn . . . . 165

Zuckerahorn . . . . . 163

Zwergahorn . . . . 285

Akazie . . . . . . . . . . 175

Alder . . . . . . 285286

Black Alder . . . . . 184

Seaside Alder . . . . . 185

Speckled Alder . . . . . 184

Alnus glauca Michx. f. . . . 184

- maritima M[uhl. . . . . . 185

- oblongifolia Torr. (Taf. V). . 286

- rhombifolia Nutt. ('Taf. V) . . 286

- rubra Bong. (Tarf. V). . . . 285

- serrulata . . . . . 184

Amelanchier canadensis Torr. et Gray . . . . . 289

Anatomische Merkinale der Hölzer

der amerikanischen Coniferen 424

Anbau von Acer saccharinum . 415

- - Betula lutea . . . . 415

- Carya alba. . . . . 414

- Castanea americanal . . 416

- Catalpa speciosa . . . 416

- Clamaecyparis Lawsoniana 418

- Chamaecyparis nutkacusis. 420

- Chamaecyparis splhaeroidea 419

- Eraxinus americana . . 415

183 - - Fraxinus sambucifolia . 415 
Anbau von Fraxinus viridis

Seite

_- Juglans nigra

- - Juniperus virginiana.

- Picea Sitkacnsis

- - Pinus Balfouriana.

- - Pinus Banksiana

_ - Pinus Murrayana.

- - Pinus pungens.

- - Pinus rigida .

- - Pinus Strobus

- Platanus occidentalis

- - Prunus serotina

- - Pseudotsuga Douglasii

- Robinia Pseudacacia.

- - Thuja gigantea .

- - Thuja occidentalis

- Tsuga canadensis

- Clmus americana.

- - Vaccinium macrocarpum

Anbaufäh igkeit nordamerikanischer Holzarten in Europa 363-397 Anbauklassen

$411-412$

Anbaupläne mit nordamerikanischen Holzarten in deutschen

Waldungen

$410-424$

Anloaversuche mit Exoten in Amerika $350-363$

Anball würdigkeit der nordamerikanischen IIolzarten . 397

Arbor vitae

Arhotus Menziesii Pursh . . . 286

- xalapensis H. I3. K. (Taf. III, IV)

Arceutholium americanum Nutt. an Pinus MIurrayana

- Donglasii Engelm. an Larix occidentalis

- Douglasii Engelm. an Pscudotsuga Douglasii Carr. (Fig. 10)

306307

- Libocedri n. ST (?) an Libocedrus decurrens

- occidentale Jingeln an P'inus ponderosa

-- pusillum Peck an I'icea albar

- rofustum lingeln. an l'inus ponderesat
414

419

421

421

420

420

421

421

417

416

416

417

116

420

420

421

417

422

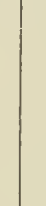

Seite

Arctostaphylos pungrens H. B. K. Ash:

(Taf. V) . . . . . 2:35 266

Black ash . . . . . . 168

Blue ash . . . . . . . 169

Green ash. . . . . . 168

Oregon ash . . . . . 232

Red ash . . . . . . . 169

Water ash . . . . . . . 169

White ash . . . . . . 167

Yellow ash . . . . . 176

Aspe . . . . . . . . . . . 181

Atlantische Waldregion . . . . 13

Audibertia . . . . . . . 266

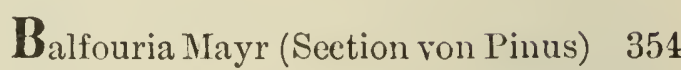

Balsam . . . . . . 181217355

Banksia (Section) . . . . 107

Baumriesen . . . . . . . 36

Bay :

Sweet Bay . . . . . . . 179

Beech :

American Beech . . . . 176

Beerensammeln . . . . . . 59

Berry :

Sugar Berry . . . . . 183

Betula lenta L (Taf. III, IV) . .170

- lutea Michx. f. (Tilf. III, IV) . 170

- nigra L. (Taf. III) . . . . 172

- occidentalis Hook. (Tilf. III, IV) $286^{\circ}$

- papyrifera Marsh.(Fig.7, 'Taff. I') 172

- populifolia $\Lambda$ it. . . . . . . 173

- rubra Michx. (Talf. IV) . . . 172

Big tree . . . . . . . . . 341

Biota orientalis (Tilf. VI)

Birch:

Black birch. . . . . 170286

Canoe-Birch . . . . . . 172

IRed Birch. . . . . 170 172

White Birch . . . . . 173

Yellow birch . . . . . . 170

Birken:

Gelbbirke . . . . . . 170

Hainbirke . . . . . . . 170

Nachenbirke . . . . . . 172

Paplubirke . . . . . . 173 
Birken :

Schwarzbirke

Bitternuss

Scliwarzbirke,

160

Black Jack . . . . . . . . 149

Bodenbeschaffenheit . . . . . 7

Bodenfeuchtigkeit und Acclimatisation $372-373$

Bodengüte, Ansprüclıe der Holzarten hieran.

$373-377$

Brenn- und Kohlholz

43

Brennwerth der Hölzer

Buche, amerikanische

65

Buckeye :

California Buckeyc .

Olino Buckeye

Sweet Buckey

176

288

183

183

Butter nut

152

Butternuss

152

Cajiput

265

Carpinus americana Lam.

177

Carya

152

Carya alba Nutt. (Fig. 6, Taf. III, IV) 158

- amara Nutt. (Taf IV)

160

- aquatica Nutt. (Taf. IV)

162

- myristicaeformis Nutt. ('Taf. IV) 162

- olivaeformis Nutt. (Taf. III, IV')

- porcina Xiutt. (Taf. III, IV ${ }^{\top}$ )

161

159

- sulcata Nutt. (Taf. III, IV

- tomentosa Nutt. (TaIf. III).

Castanea americana liafin.

- pumila Mill.

Castanopsis chrysophylla A. DC. ('Taf. V)

265

Catalpa

181

Catalpa, westliche . . . . 180

Catalpa bignonioides Walt. . . 181

- speciosa Warder

180

Cedar:

Bastard Cedar

Port Orford Cedar.

314

Red Cedar. 194319

White Cedar

193196314321

Celtis occidentalis L. ('Taf. IV')

183

Cembra, Nevada-
Ceratostoma piliferum

Seite

Cereus

434

Cereus giganteus Engelm. . . . 232

Chamaecyparis Lawsoniana Parl.

(Fig. 12, Taf. VI, VIII) . 314-319

- Nutkaensis Spach (Tilf. VI) . 314

- obtusa (Taf. VI)

- pisifera (Taf. VI)

- sphaeroidea Spach (Taf. VI, VIII)

193

Cherry, wild black . . . . . . 178

Chestnut . . . . . . . . 177

Chilopsis saligna D. Don . . 237

Chinquapin . . . . . . 177265

Christusdorn . . . . . . . 176

Chrysomyxa Libocedri Mayr an Libocedrus decurrens (Taf. X) 324

Cicada tredecim . . . . . . . 137

- septendecim . . . . . . 137

Cladastris tinctoria Raf. . . . . 176

Coffectree, Kentucky- . . . . . 176

Configuration der Continente . . 2

Continentale Zone der südlichen Hälfte des winterkahlen Laubwaldes

Continentale Zone des nördlichen Theiles des winterkahlen Laubwaldes

Comus Nuttallii Andıb. . . . . 288

Cottonwood

152287

Black Cottonwood . . 283289

Crataegus . . . . . . . 259

Cucumber tree . . . . . . . 179

Cupressus Goreniana Gord. . 272

— Guadalupensis Wats. . . . . $23 j$

- Lawsonianal Murr. . . . . . 314

- macrocarpa Hort. . . . . . 271

Cuscuta Gronovii an Liriodentron tulipiferi

433

Cypress :

Bald Cypress . . . . . 120

Monterey Cypress . . . 271

Cypresse :

Kugelcypresse . . . . 193

Lawson's Cypresse . . . 314

Monterey Cypresse . . . 271

Nutka Cypresse . . . . . 344 
Cypresse:

Sitki-Cypresse

Sumpf-Cypresse

Diedalea vorax an Libocedrus decurreus

324

Dittelfeige, virginische . . . . $186^{\circ}$

Dauerhaftigkeit der Hölzer . . . 68

Diospyros virginiana $\mathrm{I}_{\text {. . . . . . } 186}$

- texana Scheele . . . . . . 186

Dothidea betulina Mayr (Taf. X) 431

Douglasia . . . . . . . 290-3!17

Douglasia als Nut\%holz . . . . 248

Douglasia, Colorado- . . . . 307

Echinocactus.

266

Edelkastanie :

Amerikanische Edelkastanie 177

'/wergedelkastanic . . . 177

Eibe, pacifische.

344

Eichen des winterkahlen Laubwaldes . . . . . . . 140

Eichen . . . . . . . 261

Chinquapin-Eiche . . . . 145

Bartrams-Eichce . . . . . 150

Blaneiche . . . . . . 261

Durands- Eiche . . . . 145

Firbereiche . . . . . 147

(ial)eleiche. . . . . . . 49

(ierbereiche . . . . . 145

一, callifurnische . . . . 263

Gilanciche. . . . . . 150

Grossfruchteiche . . . . 143

Hartland-Eiche . . . . . 144

korbuciche . . . . . 145

L.denseiche, ("alifornische . 262

-, Floricla. . . . . 101

-, grossfrüchtige . . . . 263

Kellogg's-Eiche . . . . 282

Leicreiche . . . . . 146

Iorbeereichc . . . . . 150

Narleleiche . . . . . . 148

Tirstleiche . . . . . . 141;

Solarlacledeles . . . . 147

Schwarzeiche.

Eichen :

Seite

Schwarzeiche, mexicunische 231

Schwarzeichen . . 140111146

Sicheleiche . . . . . 148

Sumpfeiche . . . . . 150

Sumpfweiseiche . . . . . 144

Wassereiche . . . . 150

Weideneiclıe... . . 151

Weisseichen . . . 140141

Weisseiche, mexicanische . 234

一, westliche . . . . . 281

Veisse Eiche. . . 111145

Eintheilung der Kiefern nach natür-

lichen Sectionen . . . 425-428

Eintheilung der Pracie in drei

Lüngszonen . . . . . 230

Eisenbahnhölzer . . . . . . 38

Elder :

Box Elder . . . . 165284

Elm :

American Elm . . . . . 173

Cedar Elm . . . . . . . 175

Red Elm . . . . . . 174

Rock Elm . . . . . . . 174

Slippery Elm . . . . . 174

White Elm . . . . . 173

Entstehung der Prïric . . . 130

Entwaldung der Gebirge . . 21-23

Erhaltung des Klimi's . . . 52

Erlen . . . . . . . 184

Rotherle, amerikanische . 285

Schwarzerle, anerikanische. 181

See-Lrle . . . . . 185

Weisserle, amerikanische . 184

Erysiplie . . . . . . . 139

Eschen . . . . . . . . 166

Blauesche . . . . . . . 169

Girinesche . . . . . . 168

Korbesche . . . . . . . 168

Oregron-1sche . . . . . 282

Schwarzesche . . . . . 168

Wasseresche . . . . . . 169

Weisse Esche. . . . . 167

lixistenzbedingungen der Wiilder 1

Exoaseus . . . . . . 139

Exoascus? an Quercus lobata

Née . . . . . . 264 
Feinde (thierische und pflanzliche) der Exoten . . . . 378-383

Feuchtigkeitsveränderung der Luft und Accomodation der Pflanzen daran . . . . . 369

Fichte:

Blaufichte . . . . . 352

Engelmanns Fichte . . 352

Schwarzfichte . . . . 218

Siskiyon-Fichte . . . . 355

Sitka-Fichte . . . . . 338

Steckfichte. . . . . 352

Weissfichte . . . . . 219

Fir :

Balsam Fir . . . . . 220

Douglas fir . . . . . 290

Red fir . . . . 290350351

White fir . . . . . . . 334

Firmen zum Bezuge nordanerika-

nischer Waldsämereien a 43j-436

Fliichengrösse d. Wialder Amerika's

$28-31$

Forstliche Bestrebungen in Amerika 90

Foxtailpine . . . . . . 354

Fraxinus alla (Taf. IV).

- americana L. (Tilf. IV unter Fr. alba) . . . . . . 167

- anomila Torr. . . . . . . 289

- oregania Nutt. (Taf. IV) . . 282

- pistaciatefollia (Tat. IV) . . . 236

- platycarpa Michx. (Titf. IV) , 169

- puljescens Lam. ('Titf. IV) . . 169

- quadrangulata Miclix. (Taf. IV) 169

- sambucifoliar (Taf. IV) . . . 168

-- viridis (Taf. IV) . . . . . 168

Frostempfindlichkeit der Holzarten

$367-368$

Früclite der Bäume . . . . . 58

Fusicladium s1)? an Pinus Fratseri 218

Qalleruea xanthomelaena

Gemailssigt-warme Region der nordmexicanischen Waldflora $235-342$

Gemässigt-warme Region des paci-

fischen Waldes . . . 280-345

GeographischeV ertheilung der Kiefern überhaupt . . . . . 197

Gerbstoffgewinnung . . . . 5)

Gleditschia triacanthos L. . . 176

Gleditschie . . . . . 176

Gliederung des winterkahlen Laub. waldes . . . . . . 126

Grossnutzholz . . . . . . 33

Gum, Sweet- . . . . . 182

Gymnocladus canadensis Lam. . 176

Gymnosporangium Libocedrin. sp.?

an Libocedrus decurrens . . 323

- macrosporum an Juniperus virginiana. . . . . . . 195

Halesiat diptera L. . . . . 186

- tetraptera Gmel. . . . . 186

Hamamelis virginica $\mathrm{L}$. . . . . 182

Harzgewiunung . . . . . . . 53

Hazel:

Witch-hazel . . . . . 182

Ifemlock . . . . 195196338356

Heteromeles arbutifolia Roem. . 266

Heyderia . . . . . . 321

Hexenbesen an ancrikan. Kiefern 350

Hexennuss . . . . . . . 182

Hickory . . . . . . . 152

Big Shellbark Hickory . . 161

Blaitterborkige Hickory 。 158

Grossfrüchtige Hickory . 161

Mockernut-Hickory . . . 160

Muskatmusshickory . . . 162

Nutmeg-Hickory . . . 162

Pignut-Itickory . . . . . 159

Schweinsnuss-Hickory . . . 159

Shell-bark-Hickory . . . 158

Spottnuss-Hickory . . . 160

Sumpthickory . . . . 162

Sw:mp-Hickory . . . . 162

Weisse Hickory . . . . 158

IIol\% der Hickorys . . . 153-158

IIolzertrige pro IIektar . . . 37

Hopfenbuche, virginische . . . 177

Hornbaum, amerikanischer . . 177 
Hormbeam :

Hop Hormbeam

Hysteriopsis Mayr .

Hysteriopsis acicola Mayr an Picea Sitkaensis (Taf. X)

\section{$\boldsymbol{J}_{\mathrm{i}: \mathrm{i}}$} Jesup Collection

Juglans

-- cinerea L. (Taf. IV)

152

- nigra L. (Taf. IV)

- rupestris Engelm.

Juniper

Juniperus californica Carr.

- occidentalis Hook.

- pachyphloea Torr.

- Sabiniana (Taf. VIII)

- virginiana L. (Taf. VIII)

Kalfeeplantagen

Kernholz (Farbe)

Kiefer:

Alpine Kiofern

Arizona-Kiefer

balfours Kiefer

Banks Kiefer.

Binnenlandlicferm

fiefer von Chihuahua

Conlter's kiefer.

Cubatiofer

Drelikiefer

Einnatelige Kiefer

fuchs:rluwamzliefer

Gellskiefer

Jeflrey's Kiefer

Monterey-Kicfor

Murray'ts Kiefer

Obispe-kiber .

Parry's Kiefer

lechkiefor

Lothliefor, anerikanische

Sabins Kiefer.

$\therefore$

Sintit Rita-Kiefer

Sterhkiofer

Steinkiefer

Strandkieforn

194

115

333

241

353

109308

327

273

318

$27 \overline{5}$

277

188

211

277

238

192

241

198
Seite

Kiefer:

Südliche Kiefer . . . . 109

Torrey's Kiefer . . . . . 275

Jersey-Kiefer . . . . . . 191

Warzenkiefer . . . . . 274

Weymouthskiefer . . . . 199

Zuckerkiefer . . . . . 324

Kieferngürtel im wintcrkahlen

Laubwalde . . . . . . 123

Kieferngürtel, nördlicher . . . 197

- südlicher . . . . . . 10 j

Kleinnutzholz . . . . . . . . 41

Kohlholz . . . . . . . . . 43

Kühle Region der Nadelwiilder im

pacifischen Walde . . 353-356

Larch _ . . . . . . 221

Larix americana Michx. . . . 221

- Lyallii Parl. . . . . . . . 355

- occidentalis Nutt. . . . . 347

Lïirche :

Lyall's Lerche . . . . . 355

Oestliche Lïrche . . . . 221

Westliche Lïrche • . . 347

Laurel, California . . . . . 265

Lawsonia . . . . . . . . 314

Lebensbaum . . . . . . 196

237 Riesenlebensbaum . . . 319

332 Lecanora subfusca? an Cupresisus macrocarpa . . . . . . 271

Leguminosen . . . . . . . . $17 . j$

Libocedrus decurrens Torr. (Fig 14, Taf. VI, VIII) . . . - $321-324$

Lime tree . . . . . . . 180

Linde, amerikanische . . . . . 180

Lindentree . . . . . . . 180

Lifyuidambar styraciflua L. . . . 182

Liquidamber . . . . . . . 152

Liriodendron tulipifera . . . . 179

Jocust . . . . . . . . 175

Clamy Jocust . . . . . 175

Honcy Locust . . . . . 176

Tophodermium . . . . . . . 210

Lophoderminm abietis concoloris

Mayr an $\Lambda$ bies concolor (Taf. X) 336

_ - an Pinus resinosa . . . 434 
baculiferum Mayr an Pinus Scite ponilerosa Dougl. (Taf. X) .

- infectans Mayr an Abics concolor (Taf. $\mathrm{X}$ )

Lorbeer, californischer

313

336

265

\section{Madroũa}

231286

Mexican. Madroña Magnolia acuminata

\section{4}

- glauca

179

- grandiflora

179

- macrophylla

105

Magnolien

179

Manzanita

179

Maple:

Dwarf maple . . . . . 285

Mountain maple . . . . 166

Red maple . . . . . . 165

Soft maple . . . . . . 165

Striped maple . . . . . 166

Sugar maple . . . . . . 163

Vine maple . . . . . . 284

White maple. . . . . 165

Maserbilılungen . . . . . Ti 139

Maulbeerbaum, amerikanischer . 183

- rother . . . . . . . 183

Meeresströmungen . . . . . . 2

Melampsora an Weiden . . . 139

Mesquit . . . . . . . . 231

Microsphaera Corni Mayr an Cormus florida . . . . . . 434

Mimicri . . . . . . . . . 139

Mistel an Celtis occidcutalis . 183

Möbel- und Wagnerhölzer . . . 40

Morus rubra I. . . . . . . 183

Mullerry, Red- . . . . . . . 183

Myrtle tree . . . . . . . . 215j

Mycelwucherungen, knollige an birken

Nadelwald der gemäissigt kühlen Regrion $216 ;-221$

Nadelwald der gemissiegt kühlen

Region im pacifischen Walde $34.5-353$

Nebenprodukte der Wälder . . 53-59
Nectria cinnabarina an Ahomarten 434

Negundo aceroides Mönch (Tâf. IV) 16.)

- californicum Torr, et Gray . 281

Nicotiana glauca . . . . . . $\cong .56$

Nordatlantische Znne (im encrern Sinne) des winterkalılen Laubwalcles . . . . . . . 131

Nordmexicanische Waldflora 231-242

Nördliche Hälfte des winterkahlen

Laubwaldes . . . . . . . 131

Nyssa capitata Walt. . . . . . 184

- sylvatica Marsls. (T'af. III, IV) 184

- miflora Wangh. . . . . . 184

Oak :

Bartrams oak . . . . 150

Basket oak . . . . . 145

Black oak . . . 117234282

Blue oak . . . . . . 261

Bur-oak . . . . . . . 143

Chesnut oak . . . 145263

Chinquapin-oak . . . . 145

Coastlive-oak . . . . 262

Cow-oak . . . . . . 145

Laurel-oak . . . . . 150

Live-oak . . . . . 101263

Overcup-oak . . . . . 113

Pin-oak . . . . . . 148

Post-oak . . . . . . 114

Red oak . . . . . . 146

Scarlet oak . . . . . . 117

Spanisl oak . . . . . 145

Swamp white oak . . . 141

Tan-bark-oak . . . . . 26:3

Turkey-oak . . . . . 14!

Water oak . . . . . 150)

White oak . . 141231281

Willow oak . . . . . 151

Optimum des Gedeihcus . . . 73

Opuntion . . . . . . . 560

Ostrya virginica I"illd. . . . . 177

Pacifischer Wald . . . . $212-356$

lateitische Waldregion . . . 1:3

Parallele zwischen dem Kilima ile 
nordamerikanischen Wiilder-

Ländern

384

Palmetto

104105

Cabbage Palmetto

104

Dwarf Palmetto .

105

Sabal-Palmetto R. et S. . 104 Pappeln

\section{Balsamipappel}

181

Californ. Pappel .

Balsampappel, pacifisclıe

Zitterpappel, amerikanische

Parasiten (pflanzliche) auf ameri-

kanischen Waldbiumen.

Parrya Mayr (Section von P'imus)

I'asshöle der Gebirge und WValdregionen

P’avia flatva Mönch

- glabra spach.

Pecan

l'ecannuss

Persinnmon

Pestalozizia

Mexican. Persimmon

Picea all)a Jink (Fig. (j) .

Jicea Broweriana Wats.

- Engelmannii Engedn.

- nigra Jink

- pungens Engelm.

- Sitkacnsis C'arr.

Pil\%e als Feincle in winterkahlen

Latubwalde

Pine:

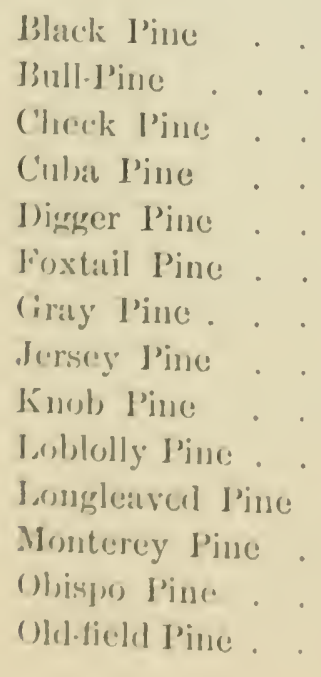

181

287

283

181

433

241

4

183

183

161

161

186

186

210

219

355

352

218

352

338

138

348

327

214

115

277

353

214

191

274

116

109

273

375

116

Pine :

Seite

Pitch Pine . . . . . . 188

Pond Pine . . . . . . . 115

Red Pine . . . . . . 211

Scrub Pine . . . . 116333

Short-leaved Pine . . . . 118

Slash Pine . . . . . . . 115

Southern Pine . . . . . 109

Spruce Pine . . . 116117118

Sugar Pine . . . . . . 324

Table-mountain Pine . . 192

White Pine . 199-211 242348

Yellow Pine . . . . . 308

Pinus albicaulis Engelm. (Taf. VII) 354

- arizonica Engelm. (Taf. VIII) . 239

- aristata Engelm. (Taf. VIII) . 353

- australis Michx. (Taf. VII) . 109

- Balfouriana Murr (Taf. VII) . 354

- Banksiana Lamb. (Taf. VIII) . 214

- cembroides Gordon, non Zucc. 241

- Chihuah uana Engelm.(Taf.VIII) 237

- clausa Vasey (Taf. VIII) . . 116

- contorta Doagl. (Taf. VIII) . 333

- Coulteri D. Don (Tirf. VII) . 332

- culensis Grieseb. (Taf. VII) . 115

- edulis Engelm. (Taf. VII) . . 240

- Elliottii . . . . . . 115

- Engelmannii Carr.(Taf.VI, VIII, auf letat. unter P. macrophylla) 238

- flexilis James (Taf. VII) . . 349

- glabra Walt. (Taf. VIII) . . 117

- inops Ait. (Taf. VIII) . . . . 191

— insignis Dougl. (Taf. VII) . . 273

- Jeffreyi Murr. (Fig. 15 Tiuf. VII)

$$
327-331
$$

- Lambertiana Dougl.(Taf. VII)324-327

- macrophylia Engelm. (Taf. :III) 238

- mitis Michx. (Tiaf. VJII) . . 118

- monophylla Torr. et Frem.

(Taf. VII) . . . . . . . . 241

- monticola Dougl. (Taf. VII) . 331

- muricata D. Don. (Taf. VIII). 275

- Murrayana Balf. (Tal. Vili) 348-350

- Murrayana Balf. var. Sargentii Mayr (Taf. VIII) . . . . . 349

- ostcosperma Engelin. . . . 241

- palustris . . . . . . . 109 
Pinus :

- Parryana Engelm. (Taf. VII)

$242 \quad 277$

- ponderosa Dougl.(Fig. 11,Tf.VII)

$$
308-314
$$

- pungens Michx. f. (Tar. VIII) 192

- reflexa Engelm. (Taf. ViI) . . 242

- resinosir Ait. (Taf. VIII) . . 211

- rigida Mill. (Taf. V1lI) . . . 188

- Sabiniana Dougl. (Fig. 9, Tarf. VII)

277278

- serotina Michx. (Taf. VIII)

- Strobus L. (Taf. VIII)

- Taeda L. (Taf. VII)

- Torreyana Parry (Taf. VII) . 275

- tuberculata Gord. (Taf. VI, VII) 274

- - var. acuta Mayr (Taf. VI) . 275

Piñon . 240241277

P'lanc-tree . . . . . . 177

Planera aquatica Gmel.

Platane:

Californische Platane . . . 285

Mexican. Platane . . . . 236

Westliche Platane . . . . 177

Platanus occidentalis L. . . . . 177

- racemosa Nutt. (Taf. III)

- Wrightii Wats. (Taf. III)

Plowrightia morbosa (Taf. X)

Podosphaera Corni (Taf. X)

Polyporus applanatus an Acerarten

- betulinus Fr. an Birken

- hispidus an Pseudotsuga Douglasii Carr.

- igniarius Fr. an Obstbiilumen.

- marginatus an Buchen

- spec. an Eichen

- sulphureus Fr. an der Eiche und Wallnuss

Populus angustifolia James (Taf. V)

- balsamifera L.

289

181

- Fremontii Wats (Taf. V).

- Fremontii var. Wisliceni Wats. (T:If. III unter Pop. Fremontii)

- monilifera Ait.

- tremuloides Michx. 287

- trichocarpa Torr. et Gray (Taf. V)
Präriale Zone der nördlichen Hälfte des winterkahlen Laubwaldes

135

Prïriale Zone des Südens im winterkahlen Laubwalde.

Prärie $22 \cdot 2-231$

— südliche 225

Prosopis juliflora DC. (Taf. V) 231233 Prunus . . . . . . . 178

- demissa Walp. . . . . . . 288

- emarginatus Walp. . . . . 288

- ilicifolia Walp. (Taf. III) . . 266

- serotina (Taf. IV) . . . . . 178

Pseudostrobus Mayr (Section von Pinus) . . . . . . . . 240

Pseudotsuga Douglasii Carr. (Taf. VI, VIII, IX) . . . 290-307

- Douglasii var. glauca (Taf. VI) 307

- Douglasii var. Inacrocarpa Engelm. . . . . . . 278

- macrocarpa Mayr (Taf. VI, VIII, IX) . . . . . . . 278

Puccinidia Mayr. . . . . . . 337

- abietis Mayr an Abies concolor (Taf. X) . . . . . . 337

Pyrus rivularis Dougl. . . . . 288

- sambucifolia Cham. et Schlecht. 288

Qualitait der Hölzer . . . . . 62

Quercus agrifolia Née (Taf. II, III) 262

— alba L. (Taf. I, II) . . . . 141

- alba $X$ obtusiloba (Taf. I)

- aquatica Walt. ('T:af. I, II) . . 150

- bicolor Willd. (Taf. I, II) . . 144

- Catesbaei Michx. (Taf. I, II) . 14!)

- chrysolepis Liebm. (Taf. II, IlI) 263

- coceinea Wangh. (Taf. I, II) . 147

- densiflora Hook. et Arn. ('Taf. II, V) . . . . . . 263

- densiflorir Hook. et Arn. var. montanla MIayr (Tatf. II) . . . 264

- Donglasii Hook. et Arn.('Taf.II, V') 264

- dumosa Nutt. (Talf. II) . . 266

- Durandii Buckley (Taf. I, II) . 145

- Emoryi Torr. (T:Lf. II, III) . 234

- faleata Michx. ('Taf. I, II) • . 145 
Scitc

Quercus:

- Gambelii Nutt. (Taf. II)

- Garryana Dougl. (Taf. II, V') . 281

- Georgiana Curt. (Taf. II)

- grisea Liebm. (Taf. II, III) . 234

- heterophylla Michx. f. . . . 150

- hypoleuca Engelm. (Taf. II, III) 234

- imbricaria Michx. (Taf. I, II) . 150

- Kellorgii Newby (Taf. II, V) . 282

- laurifolia Michx. (Taf. II) . . 150

- lobata Née (Taf. II, V') . . . 264

- lviata Walt. (Taf. I, II) . . 146

- macrocarpa Michx. (Taf. I, II) 143

- Michauxii Nutt. (Taf. II) . . 145

- nigra L. (Taf. I, II) . . . . 149

- olstusiloba Michx. (T:ıf. I, II) . 144

- oblongifolia Torr. (Taf. II) . . 264

- palustris Du Roi (Taf. I, II) . 148

- Phellos L. (Taf. I, II) . . . 151

- prinoides Willd. (Taf. I, II) . 145

- Prinos L. ('Taf. I, II) . . . . 145

- rubra L. (Taf. I, II) . . . . 146

- rubra v. Texana (Taf. II)

- tinctoria Bartr. (Taf. I, II) . . 147

-- virens Ait. (Taf. II) . . . . 104

- Wisliceni A. I)C. ('Taf. II, III) 262

$\mathbf{R}_{\text {cllwood }}$

267

limennengen u. Fenclitigreit d. Luft 5

Ibhorlodesulron maxinum L. . . 185

lihamnus P'urshiama I)C. . . . 288

lihms-Irten . . . . . . . 266

Rhỵtisma acerinum Fir. an Ahorn

- pmonctiforme Nayr an $\Lambda$ (er marephlyllmu mur Acer (ratalegifolium (T'al'. X)

- sallirinum :

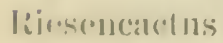

finhinia Prourlatateia L.

- viscrisar Vent.

Ri(l)inic

Drisige Rol,inie

riolung .

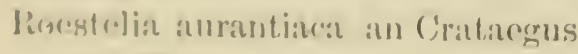
und Pyrus

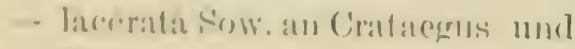
Iyrus
Rosskastanic :

Californ. Rosskastanic . . 288

Gelbe Rosskastanie . . 183

Chio-Rosskastanie . . . 183

Sabal serrulata . . . . . . 105

Sägemühlenindustrie . . . . . 34

Sassafras . . . . . . . 181

Sassafras officinale Nees . . 181

Salix Breweri Bebb. . . . . . 288

- laevigata Bebb. . . . . . . 287

- lasiandra Benth. . . . . . 288

- sessilifolia Nutt. . . . . 288

— Sitkaensis Säns. . . . . 288

Sambucus glauca Nutt. . . . 289

Schottendorn . . . . . . 175

Schütte der Gelbliefer . . . 313

Schusserbaum . . . . . . 176

Sclerotium irritans Mayr an Chamaecyparis sphaeroidea

(Taf. X) . . . . . 434

Sequoia :

Küsten-Sequoia . . . . . 267

Riesen-Sequoia . . . . 341

Sequoia gigantea Decsne (Fig. 16,

Taf. VIII) . . . . . 341-343

-- sempervirens Fndl. (Fig. 7,

'Talf. VIII) . . . . . 267-271

Spaltbarkeit . . . . . . . 70

Sphaeria morbosa Scluw. an Prumus

(Taf. X) . . . . . . . . 139

Spruce:

Black Spruce . . . . 218

Jilue Spruce . . . . . 3.52

White Syruce . . . 219352

'Tideland spruce . . . . . 3338

Strauchuräric . . . . . . 226

Strolse . . . . . . . . . 19!9

liergstrobe . . . . . 331

Zuckerstrobe . . . . . 324

Sultropischer Theil les pacifi-

schen Waldes . . . E(11-279

Sultropischer Wald d. atlantischen

Region. . . . . . 100-122

Subtrop. Zone dor nordannerikan.

13!) Waldflom: . . . . . 231-23\% 
Südlich atlantischer Laubwald im engeren Sinne . . . . 129 Sycanore . . . . . 177236285 „Sylva of North Amerika" . . . 96

Tabelle zur Bestimmung rler Sümereien von Kiefern . 429-433 - - d. wicht. Cupressineen 428-429 Taeda 116 Tanarack . . . . . 221347 Tanne:

Balsamtanne . . . . 220

Balsamtanne, Frasers . . 217

Balsamtanne, westliche . 355

Douglas-Tanne . . . 290

Edeltanne, pacifische . . 350

Küstentanne, grosse . . . 334

Purpurtanne . . . . . 351

Santa Lucia-Timne . . . 337

Schasta Timne . . . . 351

Schierlingstame . . . . 195

Schierlingstanne, westliche . 338

Silbertanne . . . . . . 334

Tanne vou Vancourer . . 334

Taxodium distichum Rich. (Fïg. 3) 120

Taxus brevifolia Nutt. . . . . 344

- - floridana Nutt. . . . . . 197

Telephora Perdix Hrtg an Quercus falcata . . . . . . 139

Theekultur . . . . . . . . 86

Thuja gigantea Nutt. (Fig. 13,

Tilf. VI, VIII, IX) . . $319-321$

- japonica ('I'alf. VI)

- occidentalis L. (Tiuf. VI, VIII) Tlıuja:

Pacifisclie Thuja

Riesen-Thuja .

Thujopsis dolohrata (T:if. VI)

Tilia americana

- - heterophylla

Torreya californica Torr.

- - taxifolia Arn.

Trametes Pini an Larix ocejdentalis

- - an Picea sitkaensis

-_ - an Pinus Minrayana

- - an Pinus Strolus.

273

197

348

340

350

210
Trametes Pini an Pseudotsuga Douglasii (Taf. X) . . . . . . 397

Trametes radiciperda . . . . . 211

Traubenkirsche, spiite . . . . 178

Trichosphaeria parasitica Hrtg. an Pinus Fraseri . . . . . . 218

Trockenheit der Luft und ilır Einfluss auf Frostempfindlichkeit der Pflanzen . . . . 360-361

Tropenwald d, atlant Region 99-100

Tsuga canadensis Carr. (Tarf. VI) 195

- Caroliniana Engelm. (Tarf. VI) 196

- dumosa (Taf. VI)

- Mertensiana Carr (Taf. VI) . 338

- Pattoniana Engelm. (Taf. VI) 356

- Sieboldii (Taf. VI)

Tsuga . . . . . . . . 195

Alpine Tsuga . . . . 356

Westliche Tsuga . . . 338

Tulip tree . . . . . . . . 179

Tulpenbaum . . . . . . . . 179

Tupelo . . . . . . . . 184

Saucrtupclo . . . . . . 181

Sour Tupelo . . . . . . 184

Umbellularia califoinica Nutt. . 265 Ulmen . . . . . . . 173

Amerikanische Ulme . . 173

Dickblitterige Ulme . . . 175

Felsenulme . . . . . 174

Flügelulme . . . . . 174

Kothulme . . . . . 174

Weisse Ulme. . . . . 173

Ulmus alata Michx (Tif. IV) • 17.t

- - americana L. (Tilf. III, IV) 173

- - rassifolia Nutt. (Taf. IV) . 175

- - fulva Michx. (Taf. IV) , 17.

- - racemosa Thomas (T:af. 1V') 17.4

Urbarmachung . . . . . . 49

Verinderung der Walluegetation 80

Vertheilung und physiologische

Rolle d. Hatres im b:ume 111-11s

Viehweide. . . . . . . 44

Viscum sp. an Pinus insignis Dongl. 273

- - ? an Querens lubata Née. 264 
$\begin{array}{ll}\text { Wachholder: } & \text { Seite } \\ \text { Californ. Wachholder . . } & 273 \\ \text { Virginischer Wachholder . } & \mathbf{1 9 4} \\ \text { Westlicher Wachholder . . } & 353 \\ \text { Wiirmemengen an den Grenzen } & \\ \text { der Waldregionen . . . . . } & 7\end{array}$

Wahoo . . . . . . . . 174

Waldbriinde in Amerika . 26-28

- - in den Adirondacks (Fig. 4 und 5) . . . . . . . 124-125

Wallerzengnisse im Allgem. $31-33$

Waldflora der atlant. Region 98-221

Waluflora in Allgemeinen . 7-12

Waldungen Nordamerikas . . . 12

Waldvegetation und Prärie . . . 3

Wallnuss :

Graue Wallnuss . . . . 152

Schwarze Wallnuss . . . 151

Westliche Wallnuss . . . 236

Wallnutt, Black . . . . . . 151

Wasscrstand der Flüsse und Ent-

waldungen . . . . 24-26
Seite

Weiden . . . . . . . 181

Wellingtonia . . . . . . . 341

Winterkahler Laubwald des gemässigt warmen Theiles der atlantischen Region . . 122-215 Wollbaum . . . . . . . . 182

Wolllaus auf Acer dasycarpum . 137

$\mathbf{Y}_{\text {ueca . . . . . . . . } 266}$

Zone der blattabwerfenden Laub-

bẩume i. pacifisch Walle 280-:245

Zuckergewinnung vom Ahorn . 57

Zürbel:

Hackenzürbel . . . . 242

Nevadazürbel . . . . . 348

Weissstïmmige Zürbel . . 354

Zürgelbaum, westlicher.... 183

Zustand des nordamerikanischen

IValdes . . . . . . 18

Zuwachsverhältnisse . . . . . 77 


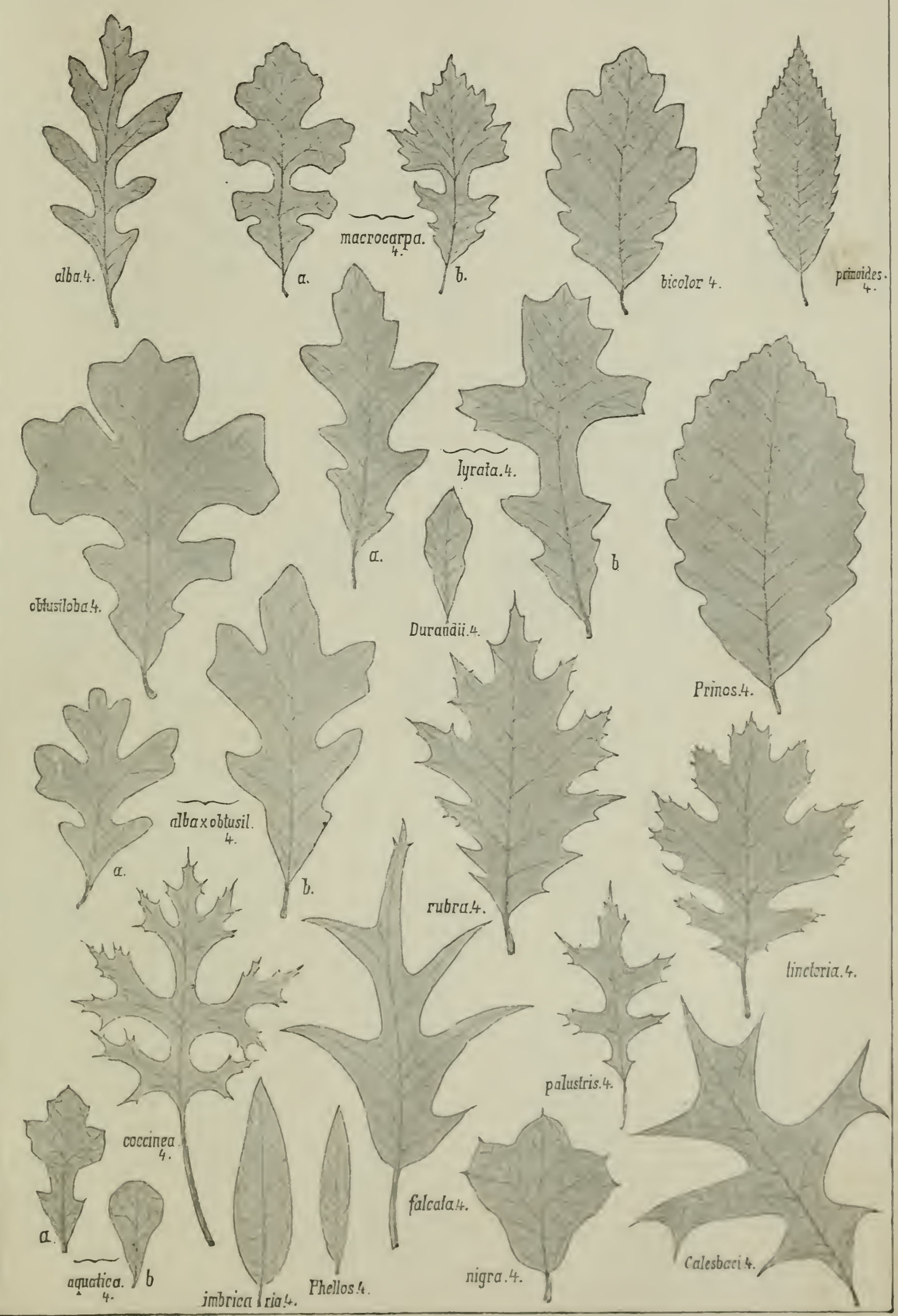





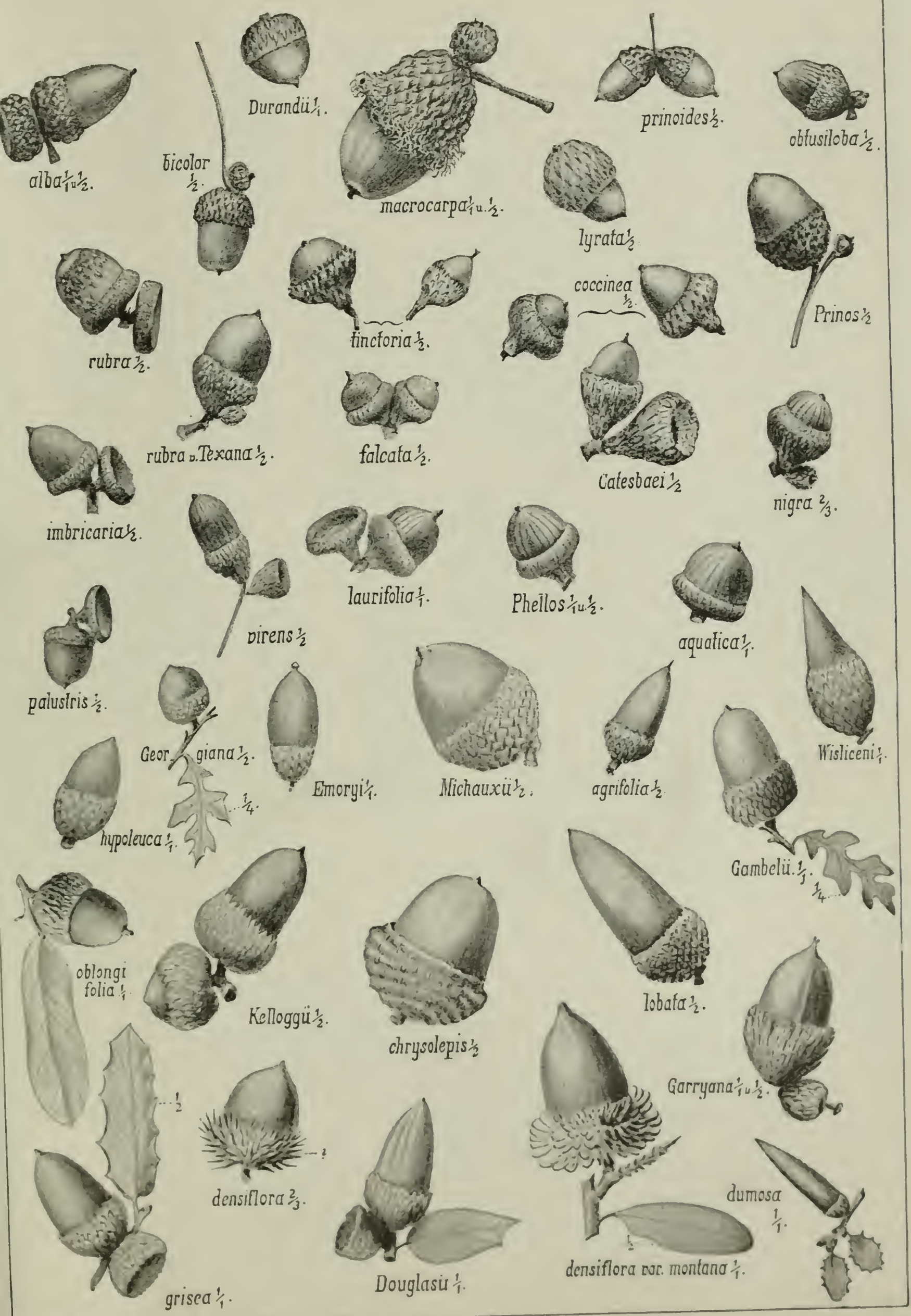



Tafel IIT.

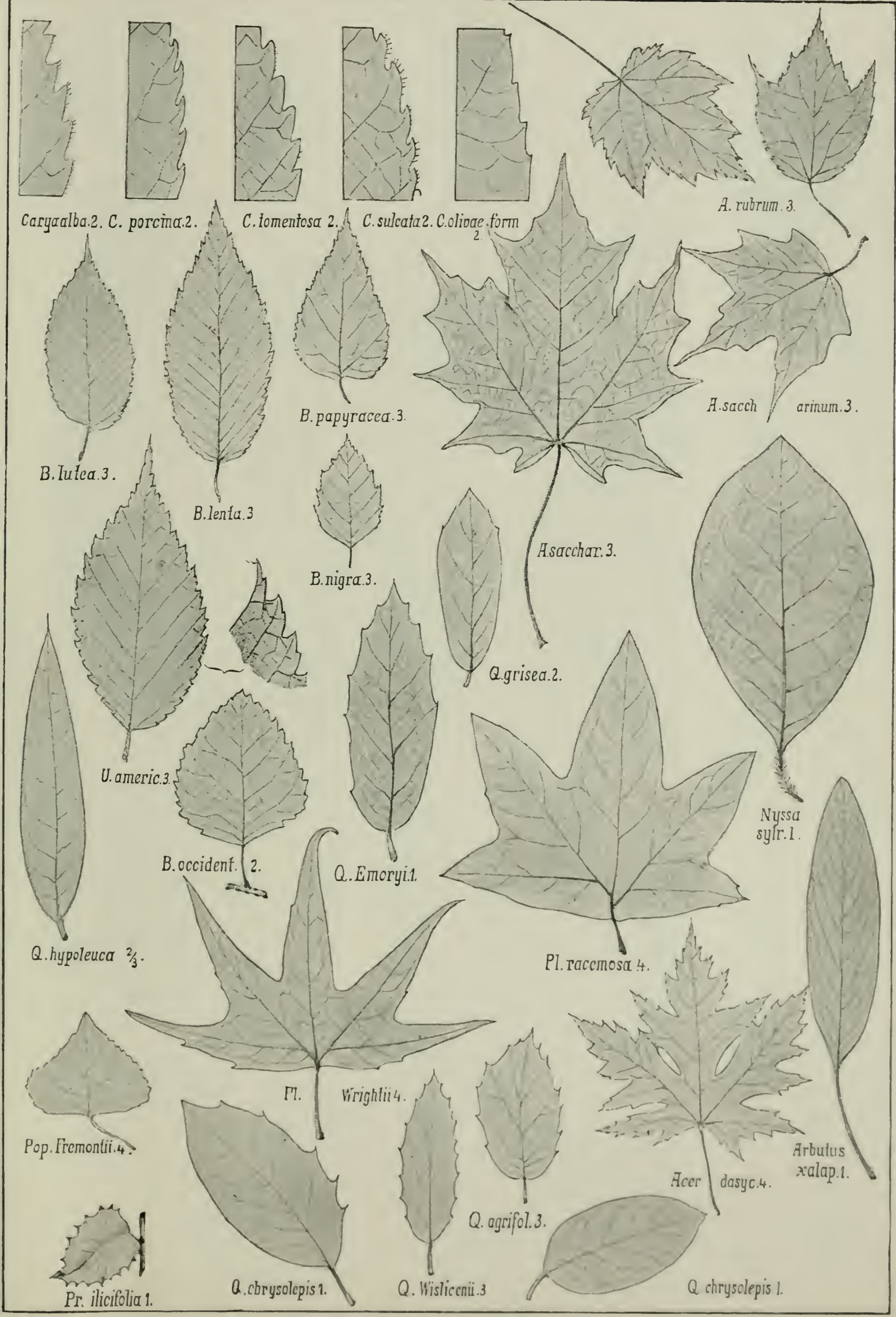





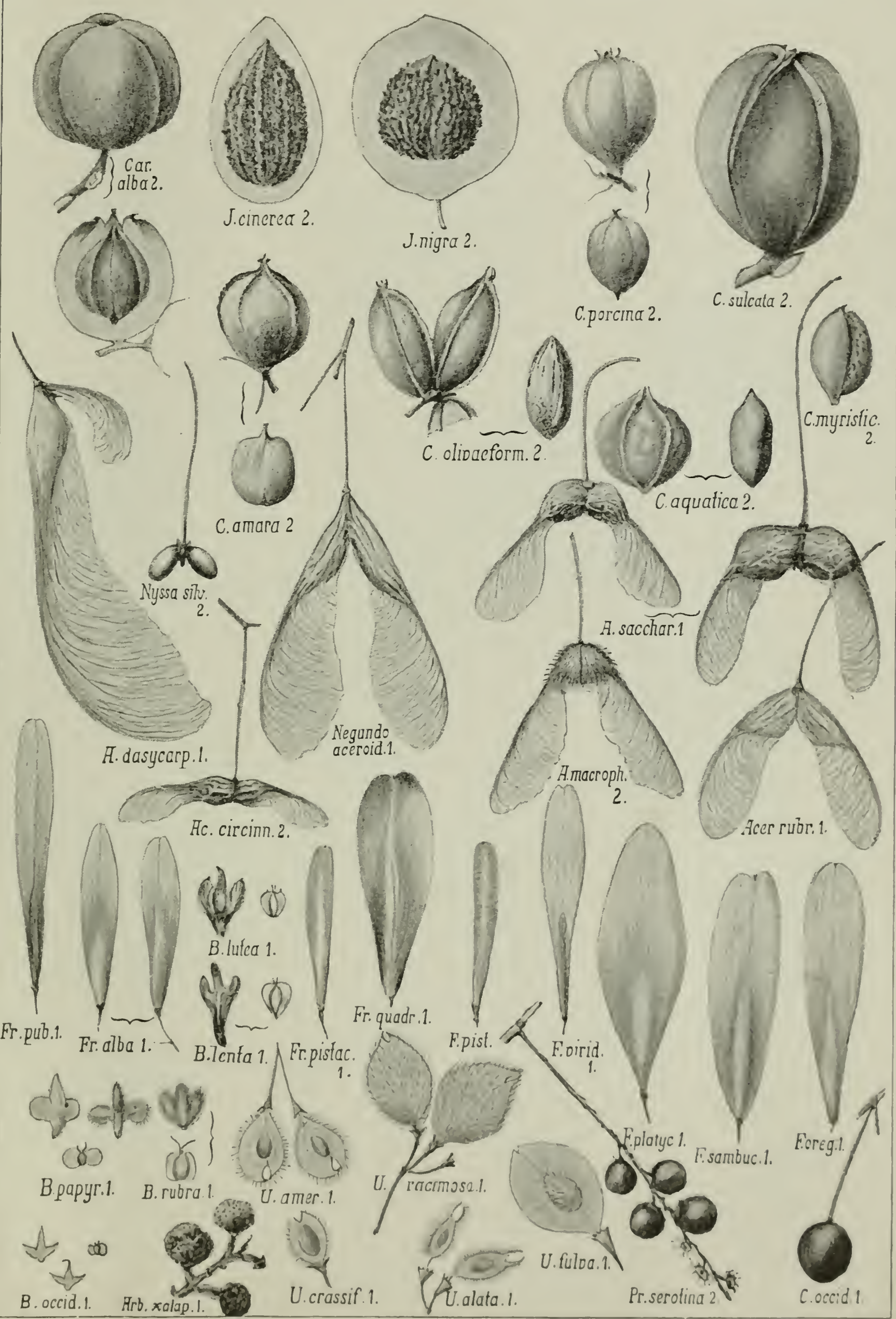




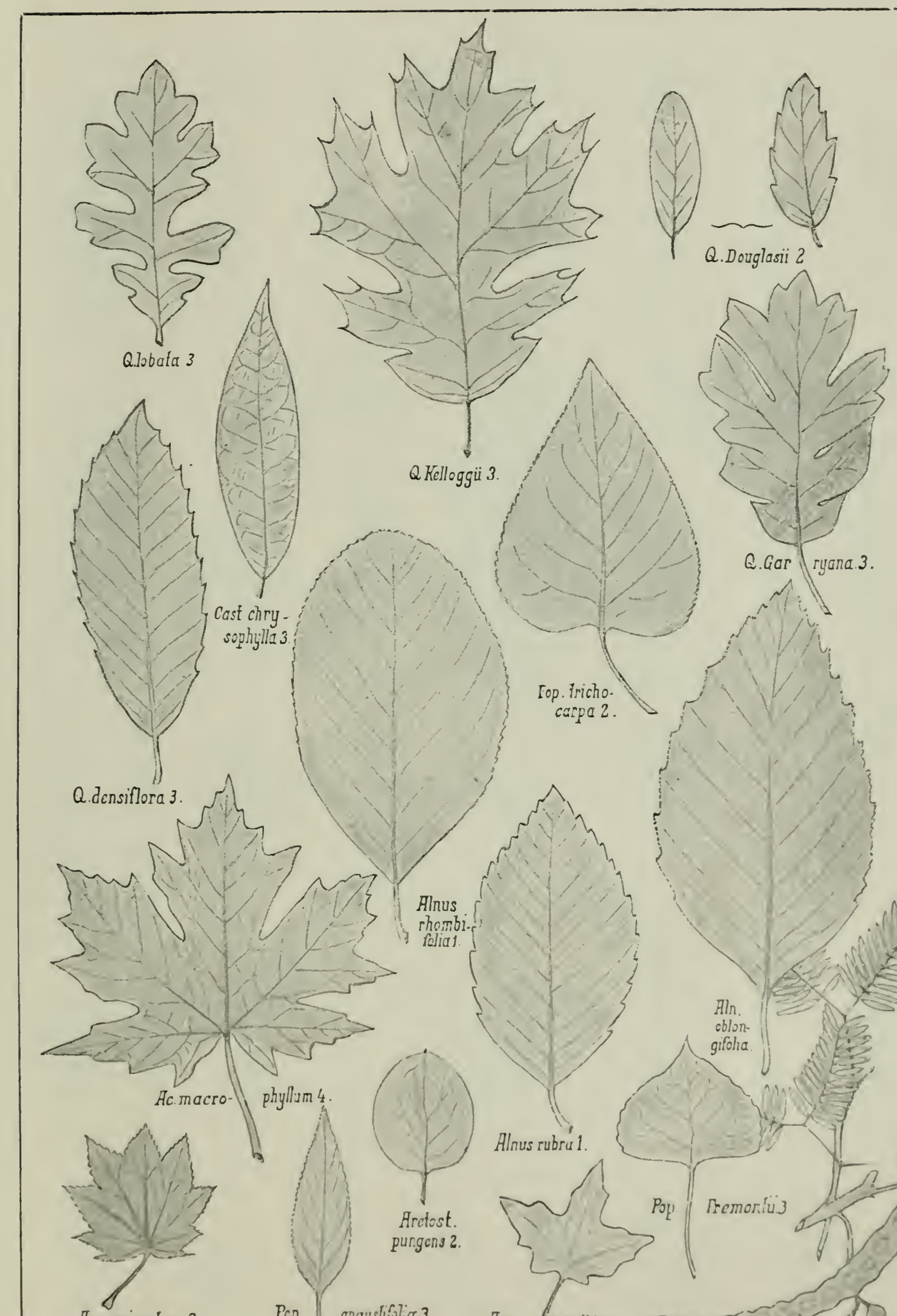

Eop. Fricho carpa 2.

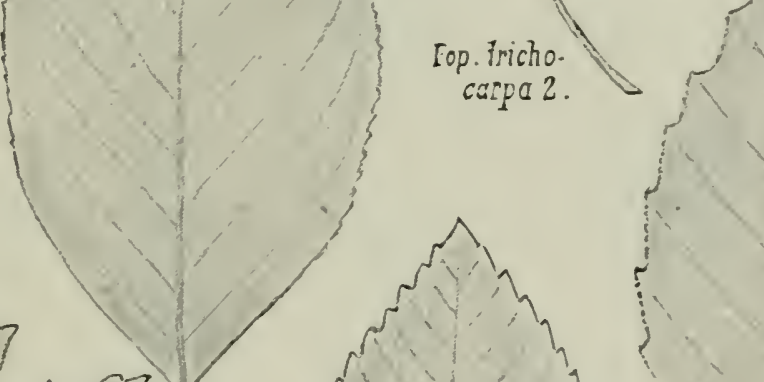

Mc. curcinnalum.3.
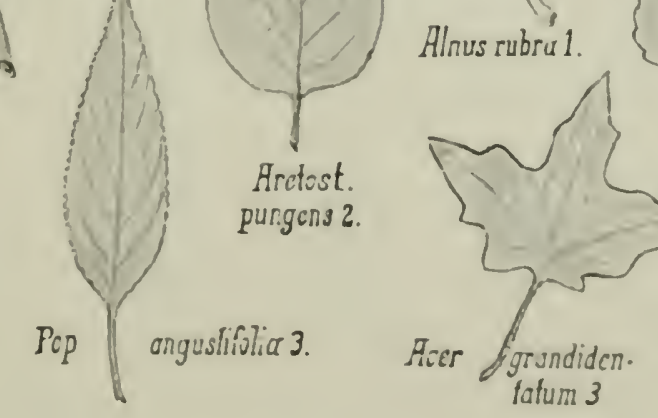

11. Mayr n. 1. N.

Blattformen pacifischer Laubhölzer. 

Tafel VI.

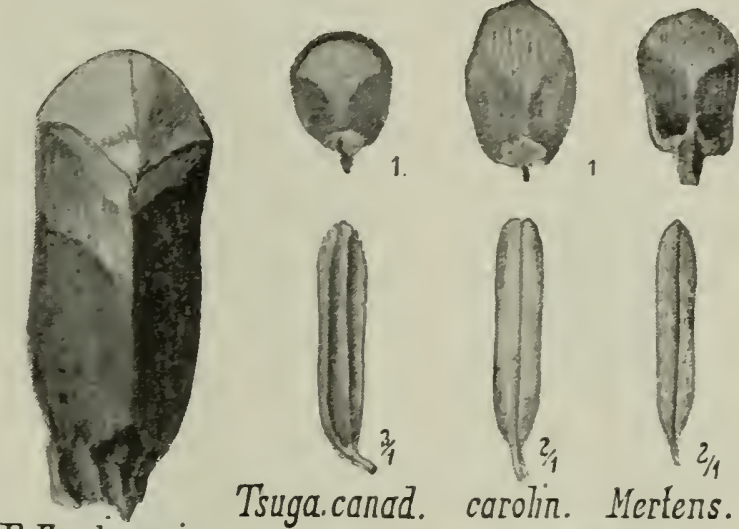

P. Engelmanni.1.

Tsuga.canad. carolin. Merfens.
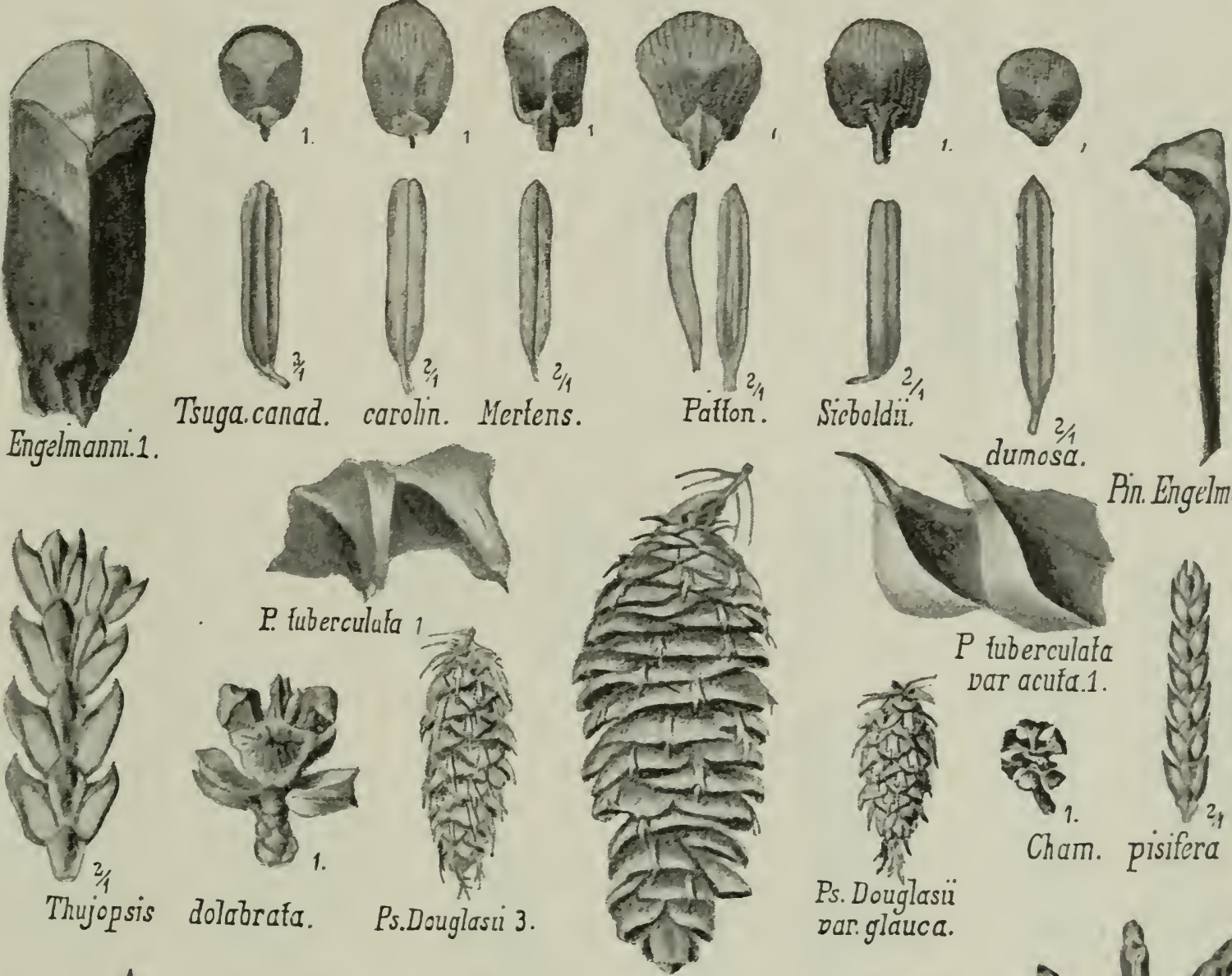

Sicboldii.
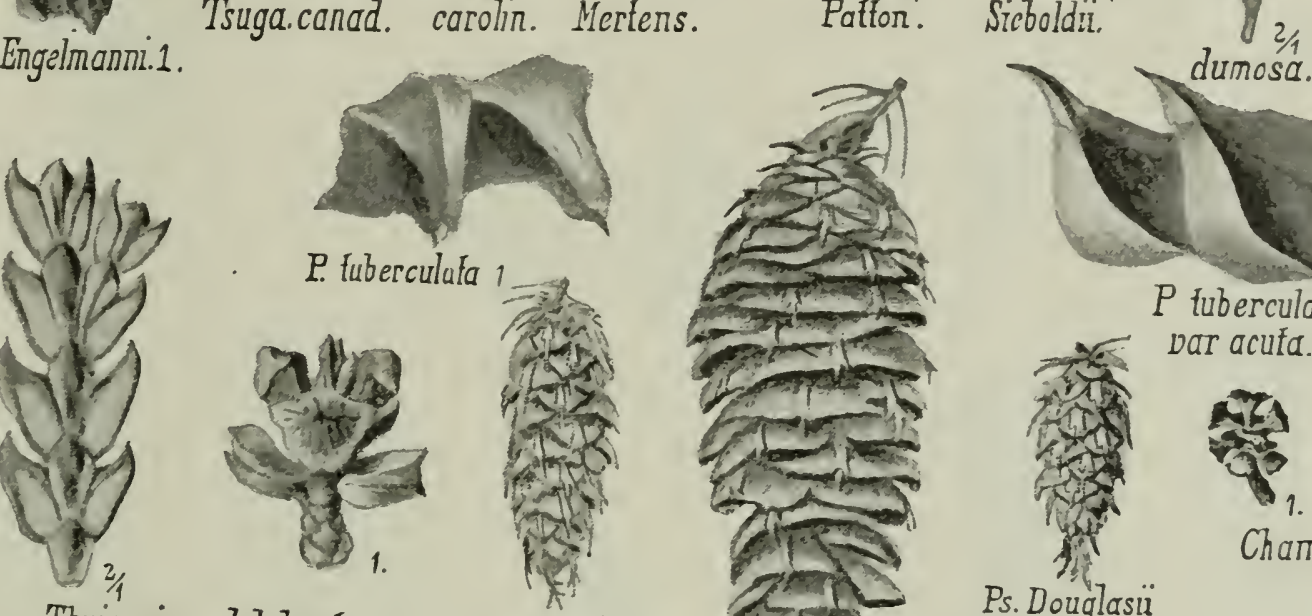

Thujopsis dolabrata. Ps.Douglasil 3.
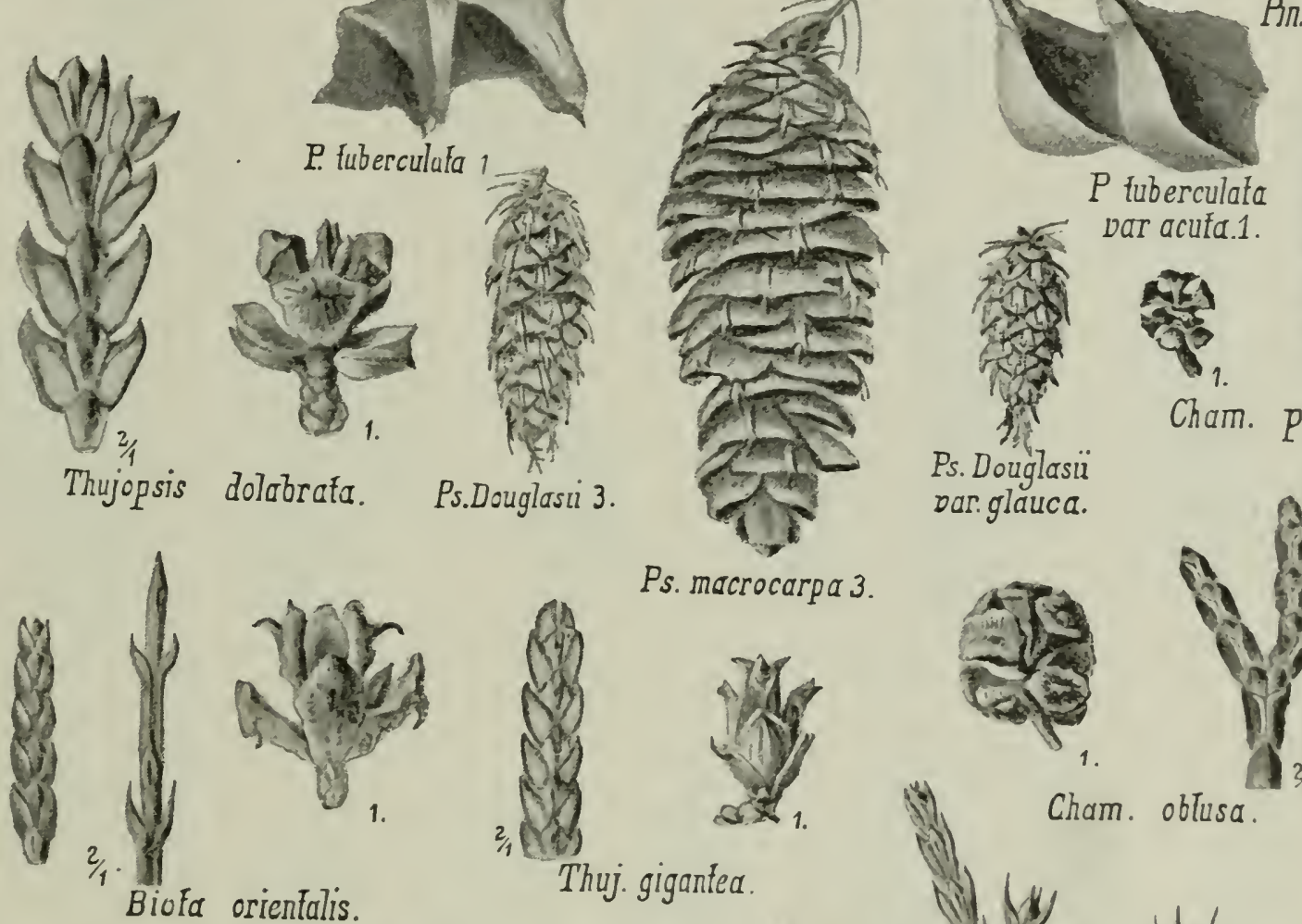

Pin. Engelmanni P fuberculata

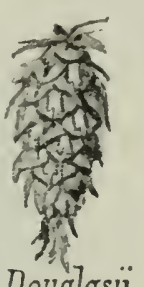
var acufa.1.
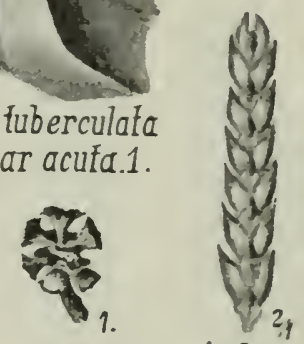

Cham. pisifera

Ps. Douglasï var. glauca.

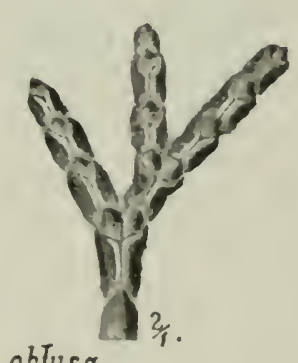

(ii)

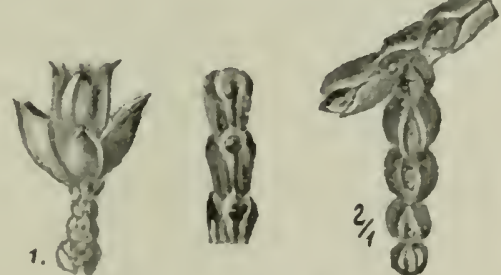

Thuj. occidentalis.

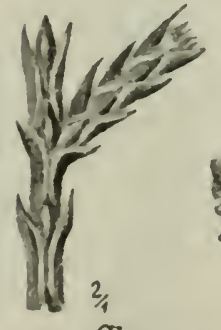

Chamaecyparis Lawsoniana.

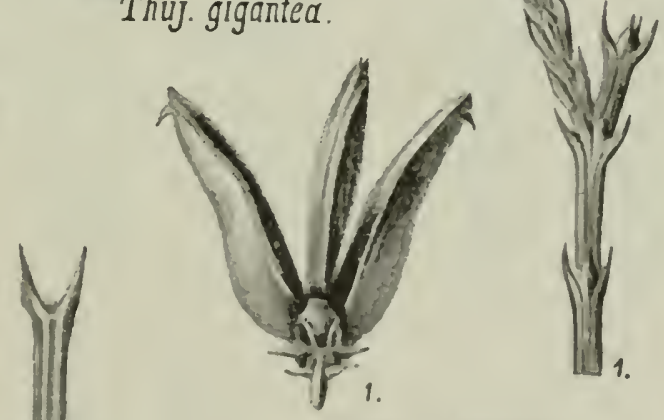

Liboc. decurrens.

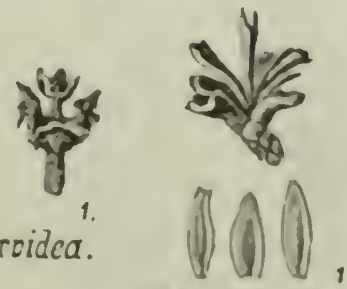

Thuj. japonica.
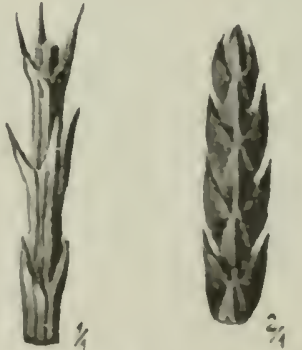

Cham. Nutkaens.
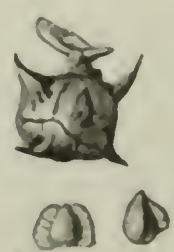

Cham Nutkaens.

ก. Mays n. d. N. gez.

Frucht- und Nadelformen verschiedener Coniferen. 



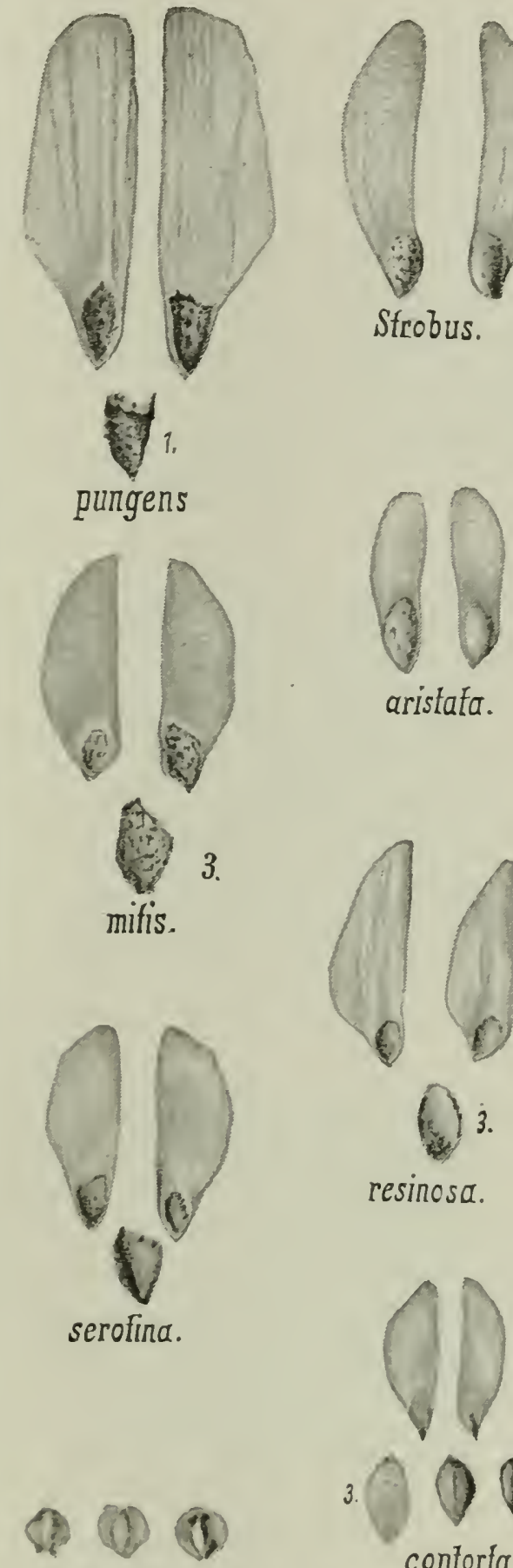

Ch. Lawsoniana.

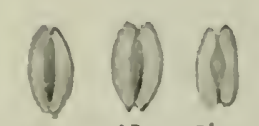

Th. occidenfalis
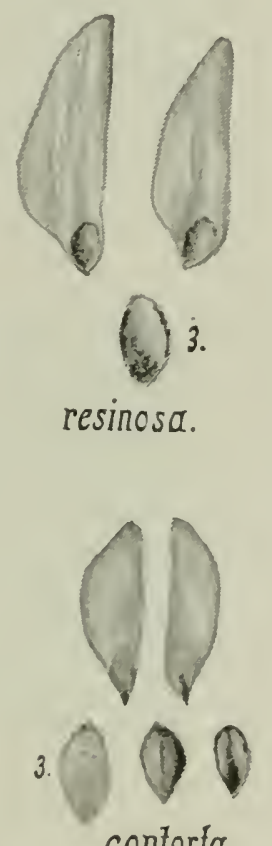

rigida.
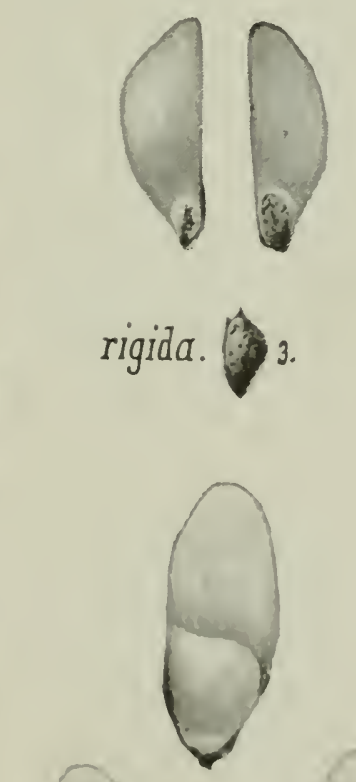

Murrayana.
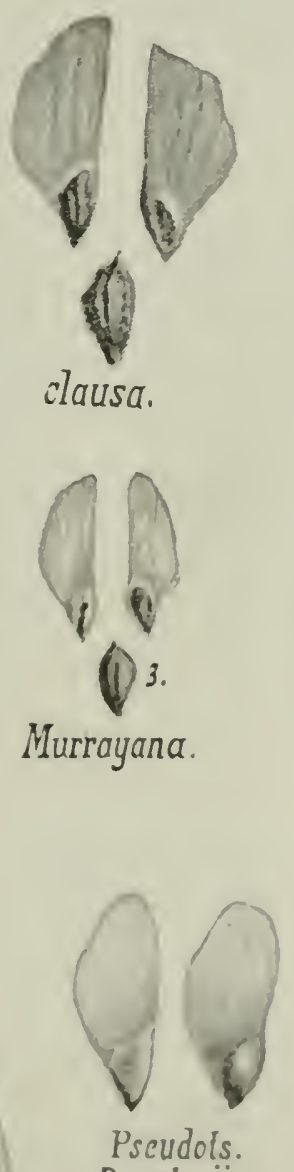
Douglasü.
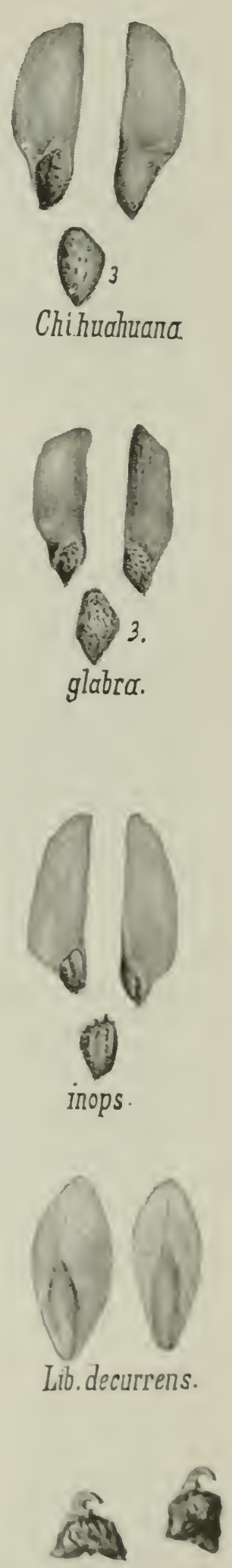

J. Sabiniana.

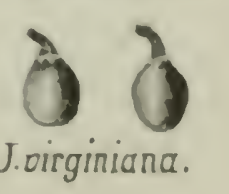

(i) 10 a

Ch. sphacroidea.

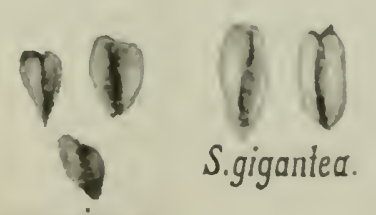

S. semperoirens. 

Tafel IX.

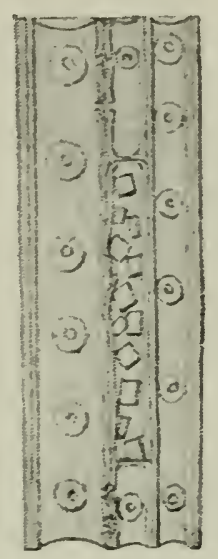

Abies bracieata.

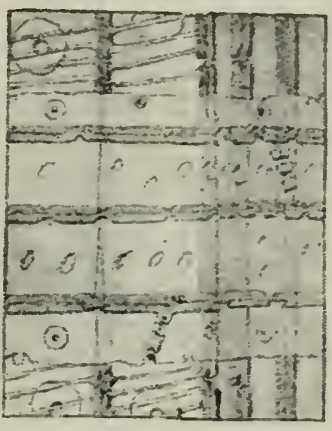

Pseudolsuga Douglasü.

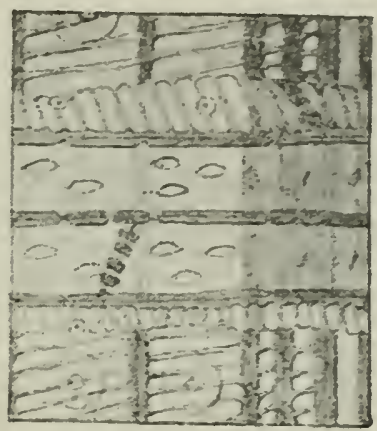

Ps. macrocarpa

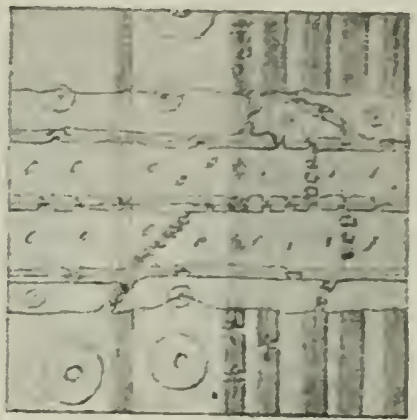

Tsuga chne Haragánge. Picea ${ }_{\text {Larix }}$ mi

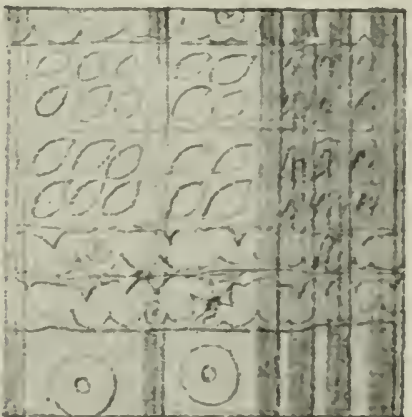

3. Sect. Banksia 2 nadel.

4. " Taeda 3 "

5." Pseudosirobus 5 ".

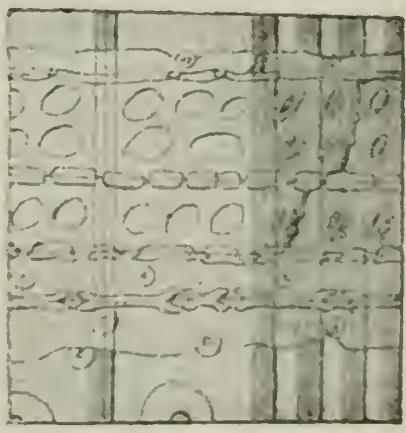

10. Sect. Sula 3 aadel.

6. Sect. Strobus 5 nadel.

7. $n$ Cembra 5 .

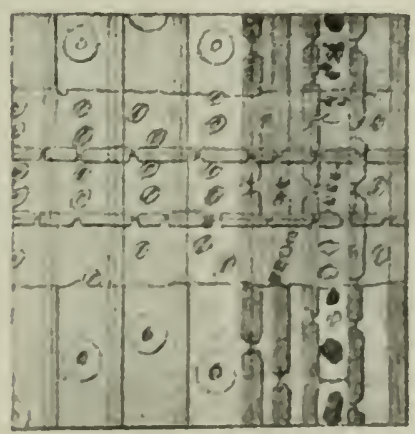

Cupressus, Chamaccyparis. Thuja, Libocedrus, Sequoia, Taxodium, Junipcrus.

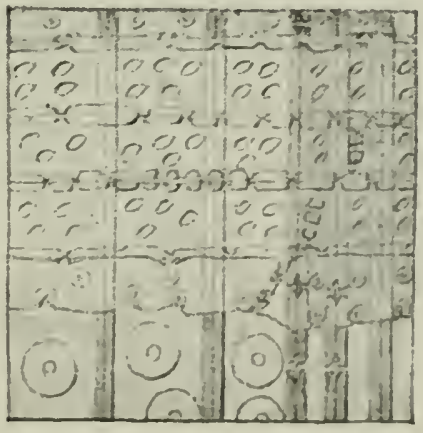

8. Sect Parrya 1.243 nadel. 9 "Balfouria 5 ".

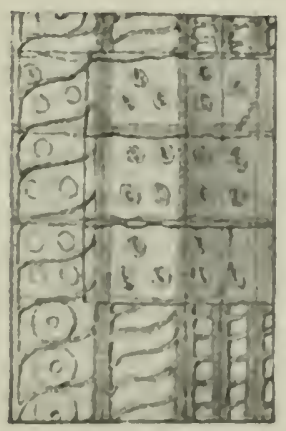

Taxus.

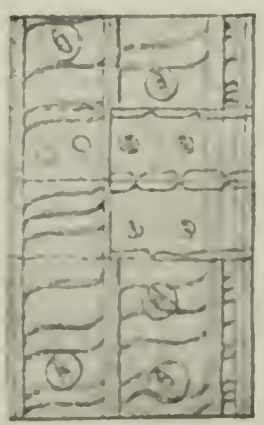

Torreya.

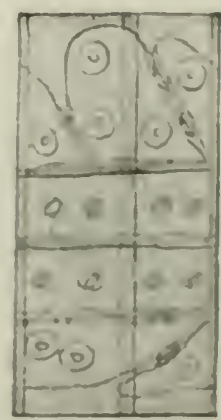

Thuja siganlea.

Anatomische Merkmale des Holzes der nordamerikanischen Nadelbäume, insbesondere der Kiefern nach Sectionen; Vergr. 325. 



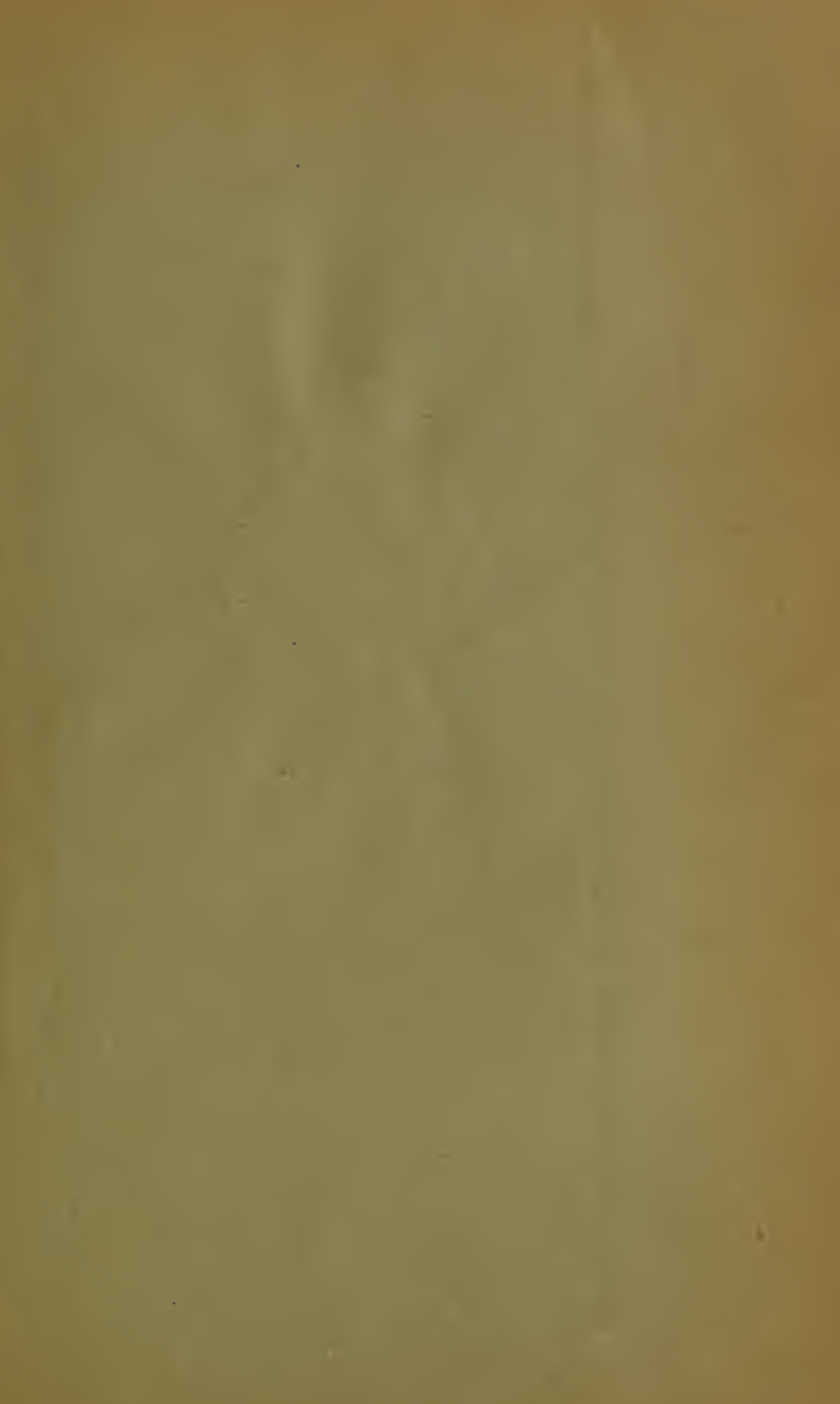




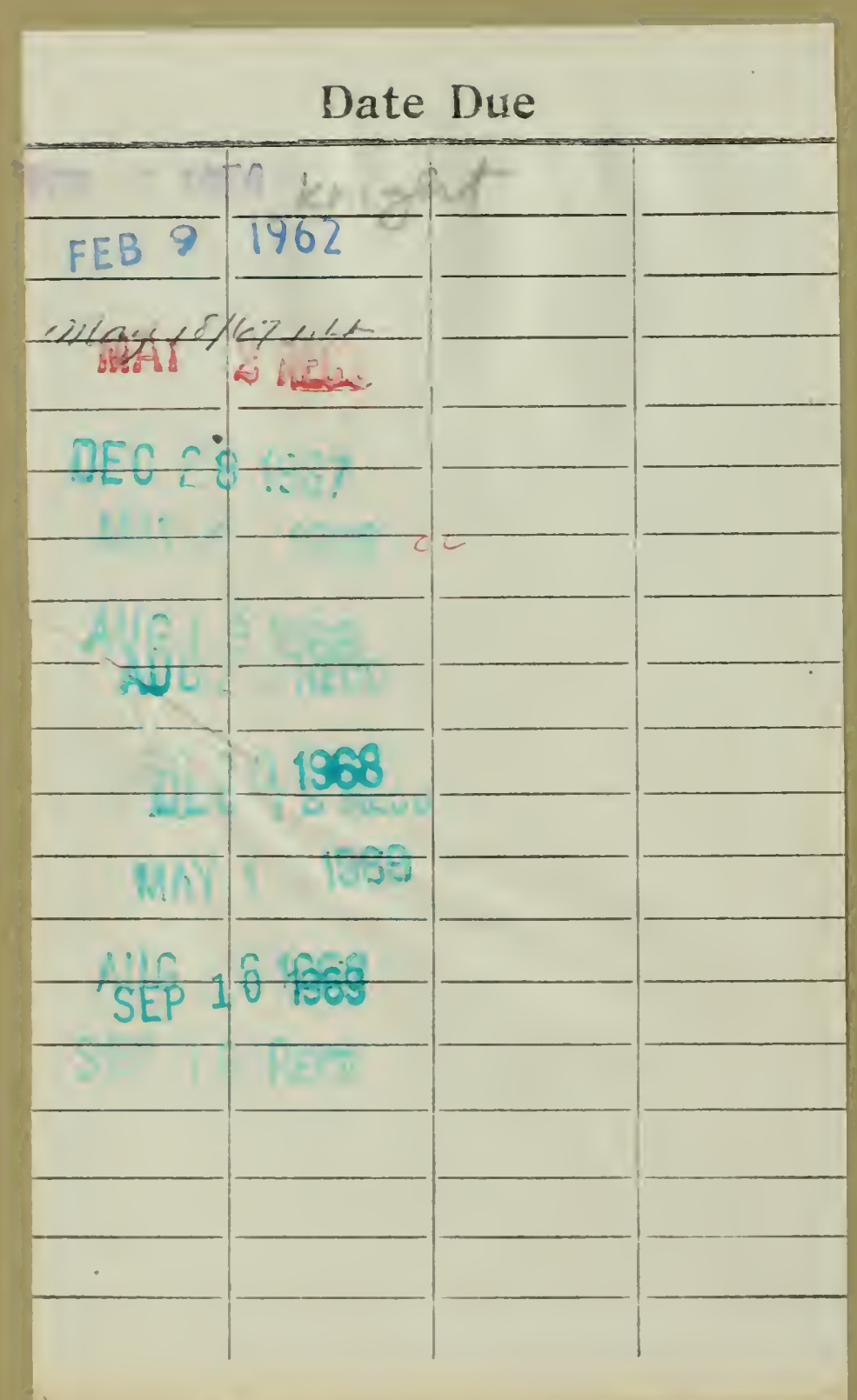




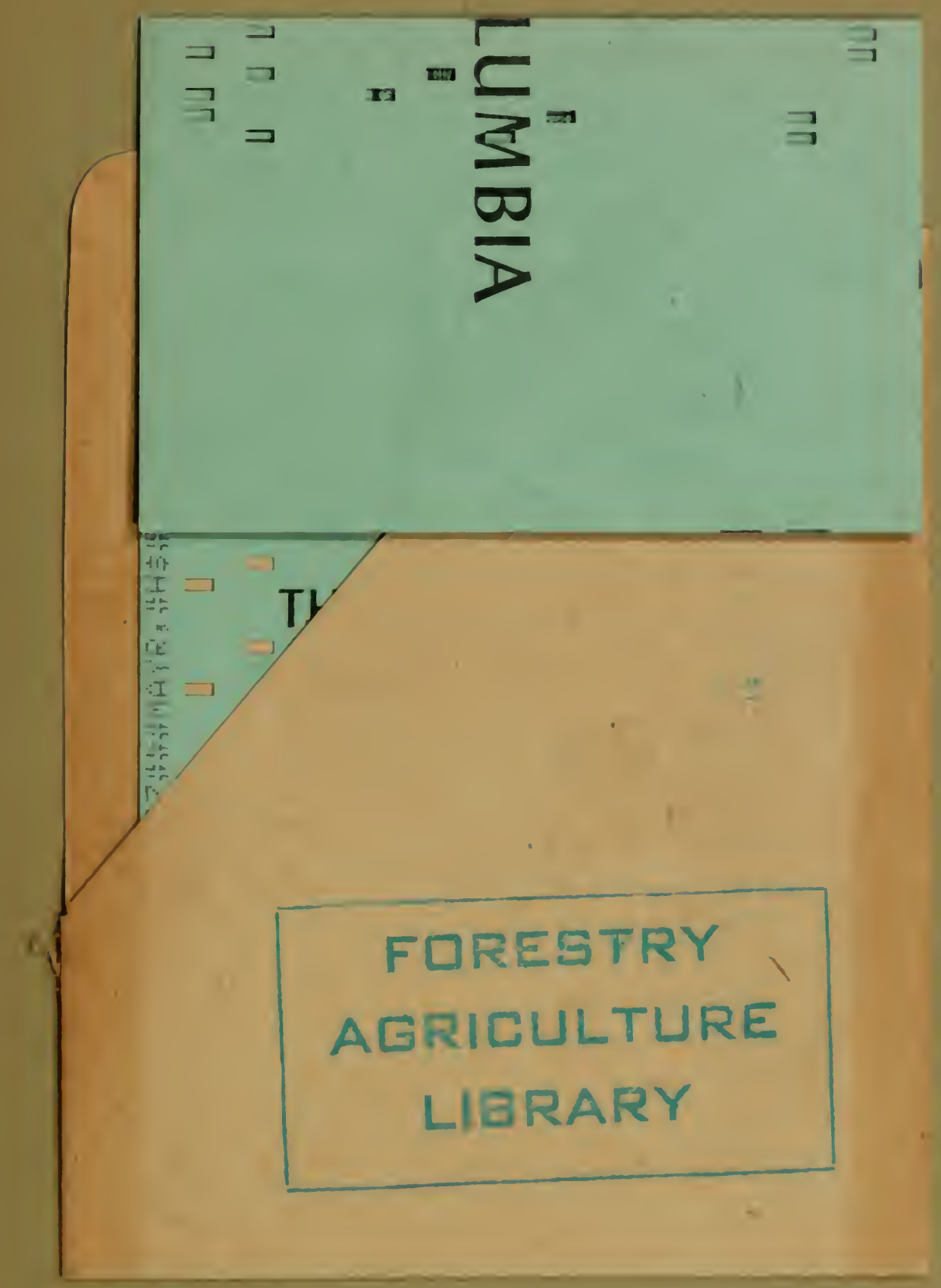


